

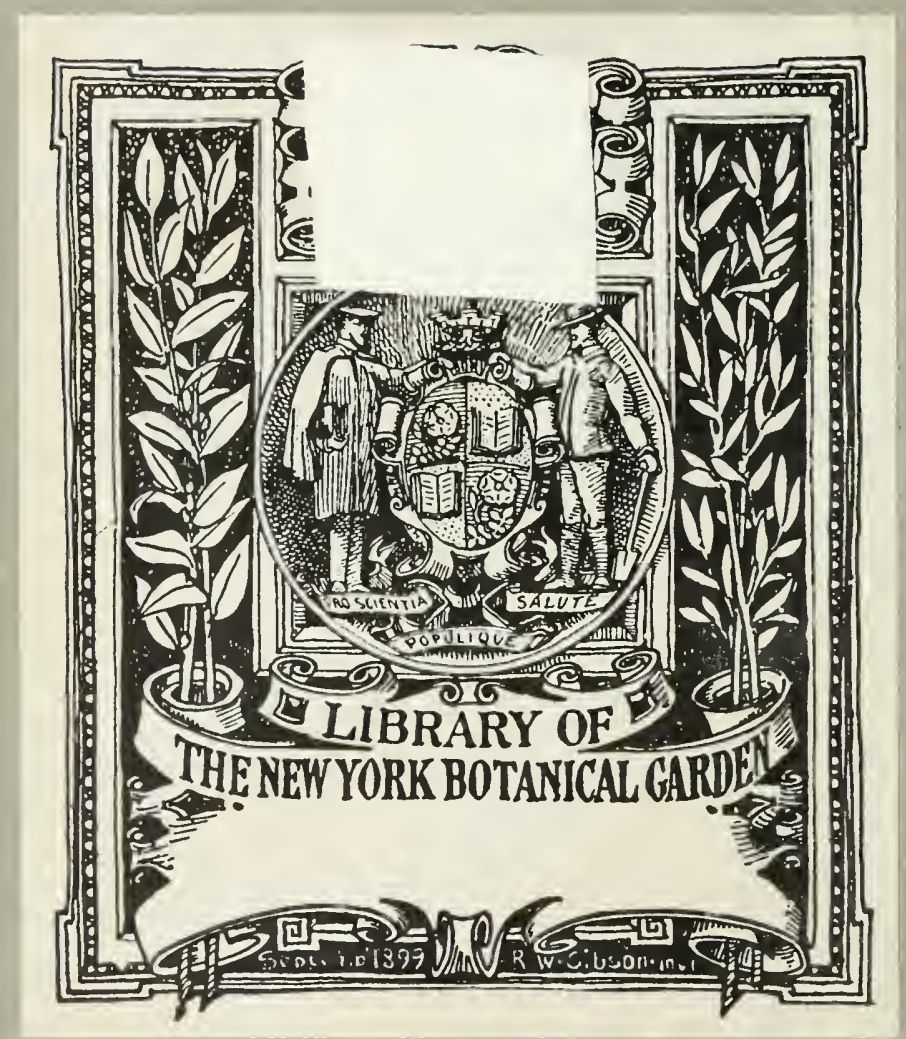








\title{
SYMBOLAE ANTILLANAE
}

SEU

\author{
FUNDAMEN'TA
}

\section{FLORAE INDIAE OCCIDEN'TALIS}

EDIDIT

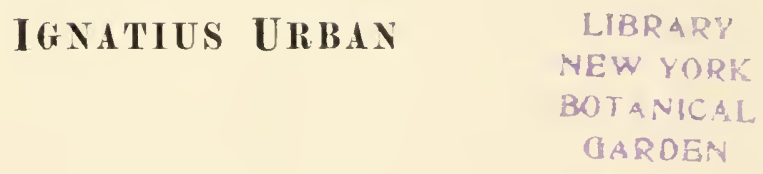

Y O L U II E N III

\section{LIPSIAE}

FRATRES BOR N TRAEGER

$$
1902-1903
$$

PARISISS

PAUL KLINCKSIECK

\section{ICONDIXI}

WILLALS A NORGATE 


$$
\begin{aligned}
& 595 \\
& v .3
\end{aligned}
$$

In lucem prodiere

Fase. I p. $1-160$. . . . . die 1 m. Martii 1902.

" II p. $161-352$. . . . . die 15 m. Angusti 1902.

"III p. $352-546$. . . . . die $1 \mathrm{~m}$. Maji 1903. 


\section{Continet:}

1. Ign. Urban: Bibliographia Indiae occidentalis botanica . 1

II. Ign. Urban: Notae biographicae peregrinatorum Indiae occidentalis botanicorum . . . . . . . . . . . 14

III. C. de Candolle: Piperaceae . . . . . . . . . . . 159

IV. F. Stephani: Hepaticae novae Dussianae II . . . . . 275

V. Ign. Urban: Nova genera et species II . . . . . . 280

VI. V. F. Brotherus: Musci nori Dussiani . . . . . . 421

VII. Ign. Urban: Burmanniaceae . . . . . . . . . 430

VIII. O. Warburg: Ficus L. . . . . . . . . . . 453

IX. O. E. Schulz: Cruciferae . . . . . . . . . . . . 493

X. G. Hieronymus: Selaginellae novae . . . . . . . 524

Index nominum latinorum. . . . . . . . . . 528

Index nominum vernaculorum . . . . . . . . . . 545 



\title{
SYMBOLAE ANTILLANAE
}

SEU

\author{
FUNDAMENTA
}

\section{FLORAE INDIAE OCCIDENTALIS}

EDIDI'T

IGNATIUS URBAN

V O L U II E N III

FASCICULUS I

Continet:

I. Ign. Urban: Bibliographia Indiae occidentalis botanica, p. 1-13

II. Ign. Urban: Notae biographicae peregrinatorum Indiae occidentalis botanicorum, p. $14-158$

III. C. de Candolle: Piperaceae, p. $159-176$

\section{LIPSIAE}

FRATRES BORNTRAEGER 1902

\section{PARISIIS}

PAUL KLINCKSIECK

52, RUE DES ÉCOLES

\section{LONDINI}

WILLLAMS \& NURGATE

14, HENRIETTA STREET, COVENT GARDEN 



\title{
I. Bibliographia Indiae occidentalis botanica.
}

\author{
Continuatio II. \\ Auctore \\ InNATOO URBAN.
}

Alvar. Flor. med.-cub. = Augusto Estriban Alvarez y Ortiz: Importancia y necessidad del estudio de la flora medica-cubana. Habana 1900. So $23 \mathrm{p}$.

Inaugural-Disscrtation zur Erlangmng des Doctor en Farmacia von der Universitït $z$ Habana. Verf. bespricht die über die Flora medica-enbana vorhandenen Arbeiten enbensischer Botanilier, zählt die in Betracht kommenden Familien nach Engier und Prantl Nat. Pflanzenfam. anf und verbreitet sich über einige pharmacentisch wichtige Pflanzen der Insel.

Anders. Cat. Bot. Gard. St. Vinc. = Alexanden Axdersox: Catalogue of plants in His Majesty's Botanical Garden in the island of St. Vincent, September 24, 1806 . [Trans. Soc. Arts, Manuf. and Comm. London. Vol. XXV (1807) p. $187-212$. $8^{0}$.]

Verf. war 1785-1811 Snperintendent des botanischen Gartens zu St. Vincent und führte zahlreiche Nutzpflanzen in denselben ein. In dem Kataloge werden in alphabetischer Ordnung die Commercial and Medicinal, die Esculents, die Medicinal, die in Economy wichtigen Pflanzen, die Vahable woods, Fruits, Exotics curious or ornamental aufgezählt.

Ballet Guadel. = Jules B BLLET: La Guadeloupe. Renseignements sur l'histoire, la flore, la faune, la géologie, la minéralogie, l'agriculture, le commerce, l'industrie, la législation, l'administration. Vol. I. BasseTerre 1890 (sur la couverture 1894). $80527 \mathrm{p}$.

Der Verfasser, ein höherer Beamter auf Guadeloupe, behandelt auf S. $176-527$ die Pflanzenwelt der Insel. Unter Voranstellung der einheimischen Namen werden (S. 176-367) die Bäıme und Sträncher, die Giftpflanzen und Fruchtbäume, die Cnlturpflanzen, Lianen, Küchengewächse, Kräıter, Wasserpflanzen, Zierpflanzen, Nutzhölzer und eine Anzahl eingeführter Nutzpflanzen eingehend botanisch beschrieben und rücksichtlich ilırer Verwendung besprochen. Die den Hölzem beigefügten Angaben über ihre Dichtigkeit, Elasticität, Widerstandsfähigkeit gegen Brnch sind einem Werke des Artillerie-Capitäns Lallemand, die karibischen Namen dem Dictiomaire caraïbe des P. Raymond Breton, die medicinischen Eigenschaften Descourtulz's Flore des Antilles und Gurbourt's Histoire des Drogues simples entnommen.

Urban, Symb. ant. 111. 
S. $368-465$ enthïlt einen Katalog der Phanerogamen von Guadeloupe mit iluren botanischen Namen, Symonymen, karibischen und Vernaeularnamen in der Reilıenfolge der Grisenscu'sehen Flora. Da in demselben die ganze nenere Literatur, insbesondere alle monographisehen Bearbeitungen ron Familien und Gattungen unberïeksichtigt geblieben sind, dagegen melur als ein halbes Hundert Arten in Folge falseher Identificinng Aufnalıme gefundeu hat, welche auf der so eingehend mol planmässig erforschten Insel sieher nieht wachsen, so ist der wissensehaftliche Werth dieser Uebersielit, die ausserdem durch zahlreiche Druck- nnd Schreibfehler entstellt wird, gleieh Null zu eraehten.

Ob der Aufzählung der Moose (S. 469-474) ein grösseres Vertrauen entgegengebraeht werden kam, entzieht sich der Beurtheilung des Referenten.

Von Wichtigkeit ist dagegen der fast durehweg mit genauen Literaturnachweisen rersehene Katalog der Pteridophyten (S. 466-467, 475-521), weleher den Generaleommissär der französisehen Marine H. Mazé zum Verfasser hat. Aus 70 Gattungen werden nicht weniger als 367 Arten nebst zahlreichen Tarietäten namhaft gemacht. Diese grosse Anzahl von Farnen findet seine Erklärung nicht nur in dem Reichthum der Insel selbst, sondern auch in der sorgfältigen, Jahrzehnte lang fortgesetzten Untersuchung derselben auf diese Gewächse hin, besonders durch L'Heriminier, Perrotret, Husnot und Mazé, sowie in der kritisehen, oft stark zersplitternden Bearbeitung durch Fée, Fournier und Mazé selbst. Melnere Arten werden mit der Autorität der beiden zuletzt genannten Autoren als neu aufgeführt, leider ohne Beschreibung.

Das Werk ist weder 1890 noch 1894, sondern erst 1899 in den Buchhandel gekommen.

Eine grössere Anzahl der MazÉ'sehen Farne befindet sich in dem Herbar des Père Duss auf Guadeloupe und im Herbar Krug und Urban.

Boerg. et Pauls. Végét. Ant. dan. = F. Boergesen et Ore Paulsex: La végétation des Antilles danoises, traduit en français par M[le $\mathrm{S}$. Ermisson. [Boxyier's Revue génér. de Botan. Vol. XII (1900) p. $99-107,138-153$ $224-245,289-297,344-354,434-446,480-510$. Tab. $4-14.8^{0}$.]

Französisehe Uebersetzung der bereits in Symb. I p. $14-15$ von Borgesen selbst besprochenen Arbeit.

Borg. Alg. Dan. West-Ind. = F. Borgesex: A contribution to the knowledge of the marine Alga regetation on the coasts of the Danish West-Indian Islands. [Botan. Tidsskr. Kjobenh.. Vol. XXIII (1900) p. $49-57$. Fig. 1-4.]

Verf., weleher sich im Februar und März 1892 und Ende Dec. 1895 bis Anfang Febr. 1896 auf den dänisch-westindischen Inseln Studien halber aufgehalten hatte, theilt Beobachtungen über Algen-Associationen an den Küsten der genannten Inseln, besonders in den Lagunen und Untiefen, mit.

Auf p. 58-60 wird aus obigem Aufsatze ein Auszug in dänischer Sprache angeschlossen.

Buchen. Junc. antill. ef. URB. Symb. I.

Clarke Cyper. antill. of. URв. Symb. II. 
Clute Fern. Jam. - Willard N. Clute: A list of the Fernworts collected in Jamaica. [The Fern Bull. Binghampton, N. Y. Vol. VIII (1900) p. $64-66,89-90$, IX (1901) p. $16-18,43,67.8^{0}$.

Terf. sammelte im Spätwinter 1900 zwei Monate lang in Jamaica besonders Pteridophyten (ca. 250 Arten) und giebt hier eine Aufzählung derselben. Den einzehen Arten werden die Standorte und hier und da auch anderweitige Notizen beigefügt.

Clute Dryopt. Jam. = Wiliard N. Cutre: A new Dryopteris from Jamaica. [The Fern Bull. Binghampton, N. Y. Vol. VIII (1900) p. 67. $8^{\circ}$.]

Beschreibung von Dryopteris Gilberti (ans der Verwandschaft von D. villosa Kze.), welches Verf. März 1900 in Jamaica sammelte.

Davenp. Acrost. lomal. = George E. Davexport: Acrostichum lomarioides Jenman. [Bull. Torr. bot. Club. New York. Vol. XXVI (1899) p. $318-319$.

Verf. bezweifelt die Selbständigkeit der genannten Art gegenüber A. aureum L., soweit die Florida-Pflanze in Betracht kommt, hat aber die Jamaica-Pflanze nicht gesehen.

Dofi. Antill. = Dr. Franz Dofleis: Von den Antillen zum fernen Westen. Jena 1900. 1 vol. 80. 180 p. mit 83 Abbild. im Text.

Verf., Zoologe ron Fach, bereiste in Jahre 1898 die kleinen Antillen, besonders Martinique, sowie das nordamerikanische Festland und giebt von den besuchten Gebieten Schilderungen, die vorher schon in der "Beilage zur Allgemeinen Zeitung" veröffentlicht worden waren. Von den Abbildungen sind einige Vegetationsansichten von Interesse.

Dyer Sugar-cane Dis. = Sir Willay T. Thuseltox Drer: Note on the Sugar-cane Disease of the West Indies. [Ann. of Bot. London. Vol. XIV (1900) p. $609-616.8^{\circ}$.]

Bespricht die beiden in Barbados unter dem Namen "Rind Disease" und "Root Disease" auftretenden Krankheiten des Zuckerrolirs und die sie veranlassenden Pilze.

Fawe. Not. Jan. plants III. = W. FAwceTt: Elementary notes on Jamaica plants. III. [Bull. Botan. Departm. Jamaica. Kingston. Tol. VI (1899) p. $170-171$. Tab. 4. $8^{\circ}$.]

Beschreibung der drei auf Jamaica vorkommenden Nymphaeaceen; vorangeschickt sind die Familien- und Gattungscharaktere. Die Tafel giebt Nelumbium luteum wieder.

Fawe. Jam. Herb. [Bull. Botan. Departm. Jamaica. Kingston. Vol. VI (1899) App. p. 208-210. $8^{0}$.]

Aufzählung der im roraufgehenden Jahre aus Jamaica bekannt gewordenen, für die Wissenschaft, bezw. für die Insel neuen Pflanzenarten.

Franç. Clayt. = E. Frasçais: La claytone de Cuba. [Moniteur. hortic. belge. 1899 p. $190-191$.

Nicht gesehen; nach Botan. Centralbl. vol. LXXX (1899) p. 319. 
Giflord Silvicult. Cul. = J. Gifford: Silvicultural prospects of the island of Cuba. [Forester VI (1900) p. 179-183, illustr.]

Nicht gesehen; nach Bull. Torr. bot. Chub vol. XXVII (1900) p. 656.

Gilb. Ferns Jam. = B. D. Gllblit: Two new ferns from Jamaica. |The Fern Bull. Binghampton, N. Y. Vol. VIII (1900) p. $62-64.8^{0}$.|

Beschreibt Asplenium Chutei und l'olystichum temue, welche von $\mathrm{Mr}$. Cutre, das zweite auch rom Verf., auf Jamaica gesammelt waren.

Grove Diat. West. Ind. = Ebnuxi Grove: Diatoms of St. Vincent, W'estindies. [Brıтt. Journ. of Bot. London. Tol. XXX VII (1899) p. $411-417 . \mathrm{S}^{\circ}$.]

Aufzählung von 200 Brackwasser- und Süsswasscr-Diatomaccen, welche H. H. Surmı an 41 verschiedenen Localitäten auf St. Vincent sammelte. Nene Arten sind nicht darunter.

Die Typen sind im British Huseum (153 mikroskopische Präparate).

Gribonrt Notice $=$ N. J. B. G. Gubourt: Notice sur Frulx Lours L'Herminier, suivie de la nomenclature synonymique créole et botanique des arbres et bois indigènes et exotiques observés ì la Guadeloupe. Paris $1834.8^{\circ} .18 \mathrm{p}$.

Nicht gesehen; nach Pritz. Thes. II ed. p. 131.

Harringt. Flor. Pnerto Ric. = II. W. Harringtox: Fauna and Flora of Puerto Rico [Science II. 10 (1899) p. 286-288].

Nicht gesehen; nach Bull. Torr. bot. Club vol. XXYII (1900) p. 604.

Hart Rep. Bot. Gard. Trinid. $=$ J. H. Hait: Annual report of the Royal botanic gardens Trinidad. Port-of-Spain 1897-1900. Fol.

In dem Capitel „Herbarium“ werden die für die Flora von Trinidad neuen, meistens kurz vorher publicirten Arten namhaft gemacht. In dem Berichte für 1899 wird von G. MasseE anch eine nene Nectria beschrieben.

Hill Forest Porto Rico $=$ R. T. Hill: Notes on the forest conditions of Porto Rico. [Bull. U. S. Departm. Agric., Div. Forestry, XXV (1899) p. $1-48$ tab. $1-8$.]

Nicht gesehen; nach Bull. Torr. bot. Club vol. XXVI (1899) p. 600.

Jean-Lonis Flore d'Haiti = VIctor Duclusé Jeñ-Lous: Dochments pour la Flore indigène d'Haiti. Premier fascicule. Extrait du "Traité de Botanique appliquée à la Flore d'Haiti“. Port-au-Prince 1899. $8^{\circ}$. $\mathrm{V}$ et $28 \mathrm{p}$.

Der Verfasser, ein eingeborener Haitianer (Neger), ist seit längerer Zcit Professor an der Ecole nationale de médecine et de pharmacie zul Port-au-Prince und ausserdem praktischer Arzt. Seine botanischen Studien hat er an der genannten Schule bezw. als Autodidakt gemacht, ohne jemals sein Vaterland verlassen zu haben. Da ihm mit Ausnahme von Grosourdy's Médico botánico criollo und Bocquilion's Etude des plantes des colonies françaises alle botanische Literatur zu fehlen scheint, so hat er sich darauf 
beschränkt, von den beiden abgehandelten Familien der Tauraceen und Cucurbitaceen eine Anzahl Culturpflanzen, hauptsächlich wach den genannten Antoren, zu schildern (Camphora officinalis fand el auf den Höhenzüigen von Furcy etc. wild!?). Am Schlusse der Familien werden einige Arten ron den benachbarten Antillen in veralteter Nomenclatur aufgeführt, ron Haiti nur Cinnamomum montanum (Phoebe montana). Das Werk mag für die dortige medicinische Schule ron einigem Werthe sein, für die Botanik ist es nutzlos; es enthält iiberhaupt nichts von dem, was in dem Titel angekündigt ist.

Jenm. Aspl. Fawc. = Jexux: Asplenium Faucettii Jenm.n. sp. [Gard. Chron. III ser. rol. XXVI (1899) p. 121. $4^{\circ}$ ].

Beschreibung einer neuen auf Jamaica von Wr. HARRis gesammelten Asplenizm - Art.

Jemu. Ferus Brit. Westind. = G. S. Jerux: Ferns of the British West Indies and Guiana. [Bull. Miscell. Inform. Roy. Botan. Gardens Trinidad 1899-1900. Appendix p. 95-133. $8{ }^{\circ}$.

Verf. fährt fort (cf. Symb. I p. 82, II p. 3), die Farne der britischwestindischen Inseln und Guyana's zu beschreiben, und behandelt die Adianteae und Pterideae.

Kiacrsk. Dansk. Saml. = HJıLur Kinkrsiou: Om danske Samlere af restindiske Planter. [Botan. Tidsskr. Kobenh. Tol. XXIII (1900) p. $35-47.8^{\circ}$.]

Auf meine Anregung hin schrieb K. kurze biographische Skizzen von folgenden dänischen Botanikern und Sammleru, welche die Herbarien, besonders das Museum zu Kopenhagen, mit westindischen Pflanzen bereichert liaben: P. E. Benzon, C. C. Berg, F. C. E. Borgesen, H. F. A. Baron von Eggers, C. O. E. Hansex, H. B. Hornbeck, P. E. Isert, H. J. Krebs, H. J. Lissen, F. M. Liebinann, O. V. Paulsen, P. Ravi (aus Norwegen), A. H. Rnse, J. P. B. row Rohr, J. Ryax, J. E. B. Warming, H. West, A. S. Orsted.

0. Kuntze P. Browne $=$ OTто Kuхтz: Ueber neue nomenclatorische Aeusserungen. [Botan. Centralblatt. Cassel. Vol. LXXIX (1899) p. $405-407.80$.

O. Kuntze tritt noch eiumal für die Anerkennung der von P. Browve gegebenen Gattungsnamen ein. Es mag hier nur hervorgehobell werden, dass ich nicht nachgewiesen habe, dass „P. B. wohl formgercchte Diagnosen gab, die aber sonst nicht inmer ordnungsgemäss waren", sondern dass er in seinen ,general characters" Art-Beschreibungen lieferte, die auf die anderen Arten derselben Gattung nicht passen.

Lindau Acauth. antill. ef. UrB. Symb. II.

Mass. Fung. exot. II. = MAsser: Fungi exotici. [Kow Bull. Misc. Inform. Nr. $153-154$ (1899) p. 18t-185.]

Beschreibt zwei neue Pilzarten ron den Bcrmudas. Kew Herbarinm.

Melrill Key West $=$ J. Coswo Menvilu: List of the phanerogams of Key West, South Florida, mostly observed there in March 1872. 
[Memoirs of the Manchester Liter. and Philos. Society III ser. vol. VIII p. $138-154$, seors. impr. London $18 S 4 . S^{\circ}$.]

Dieser in einer schwer zugïnglichen Zeitschrift veröffentlichte Aufsatz ist bisher in der Literatur unbeachtet geblieben. Verf. giel, in der Ninlcitung eine topographische Beschreibung von Key West, constatirt den westindischen Charakter der Flora und zählt 168 Arten nebst einigen Gramineen, Cyperaceen und Farnen nach seinen eigenen Beobachtungen und nach denen ron W. T. F́́aY auf. Er schätzt den Gesammtbestand der Flora anf $200-220$ Arten.

Mez Laur. et Brom. nov. cf. Uris. Symb. II.

Millsp. Plant. Utowan. = Charles F. Mllaspaugil: Plantae Utowanae. [Field Columbian Museum. Chicago. $8^{\circ}$. Publication 43. Vol. II Nr. 1 (March 1900) p. 1-110 et Publication 50. Vol. II Nr. 2 (Aug. 1900) p. $113-124$. c. figur. $8^{\circ}$.]

Unter dem Patronate des Mr. Aluison V. Armour in Chicago machte der Verf. auf der Yacht Utowana ron Ende Dec. 1898 bis März 1899 eine Sammelreise nach Bermuda, Portorico (Jan. 1899: Bay von Cataño, Rio Piedras bis Caguas, Guauica), St. Thomas, Culebras, Sto. Domingo (Umgebung der Hauptstarlt), Jamaica (Port Antonio, Kingston), Cuba (Santiago), Caymans, Isle of Pines, Cozumel, Yucatan und Alacran shoals, um vergleichende Studien zwischen der Flora ron Yucatan, der cr in den letzten Jahren seine Thätigkeit gewidmet hatte, und der Küstcnflora der westindischen Inseln anzustellen. Die Einleitung bringt eincn genauen Bericht über die Reise und die an jedem Orte gesammclte Anzahl von Nummern. In der Aufzählung sind die Pilze von J. B. Eluls und B. M. Everhart, die Pteridophyten von George E. Davenport, die Gramineen ron F. Laurson-Scribner, die Cyperaceen von N. L. Britton, die Amarantaceen von B. Uline, die Nyctaginaceen z. Th. von A. Heinert, die CassiaArten von C. I. Pollard bearbeitet, alles übrige vom Verf. selbst. Zahlreiche neue Arten werden beschrieben und mehrere neue Combinationen von Namen gebildet; sehr vielen Species sind beschreibende Notizen bcigefügt. Die zugehörigen Tafeln harren noch der Veröffentlichung.

In dem zweiten Aufsatze: Rcconsideration of the Cypcraceae werden diese in Anlehnung an Clarke's Monographie der westindischen Arten (Symb. II p. 8-162), aber unter Einziehung von Mariscus und Torulinium noch einmal bearbeitet, begleitet von Beschreibungen der Gattungen und Arten, Bestimmungs-Schlüsseln und guten Frucht-Analysen, bei denen Mrs. Agnes Chase behülflich war.

Die Originalien sind im Field Columbian Museum, Doubletten im Herb. Krug et Unis.

Millsp. Plant. Anamas. = Charles Frederick Millspaugin: Plantae insulae Ananasensis. [Field Columbian Museum. Chicago. $8^{\circ}$. Publication 48. Botanical Series. Vol. I Nr. 6 (Aug. 1900) p. 425 - 439. S $^{\circ}$.]

Aufzählung von 185 Pflanzen der Insel Pinos (an der Sülküste von Cuba gelegen), welche vou José BualN 1850? gesammelt und durch Vermittelung von SaUvalle an Cir. Wright in Cambridge gelangt waren. Es 
werden 4 neue Arten (aus den Gattungen Polygala, Salacia, Sprigelia und Heliotropium) beschricben.

Dic Originalicn im Grar-Herbarium zu Cambridge, Doubletten im Field Columbian Museum zu Chicago, die neuen Arten auch im Herb. KRUG et URB.

* Morris West Ind. Bull. = D. Morris: West Indian Bulletin. The journal of the imperial agricultural Department for the West Indies. Barbados. Vol. I et II Nr. 1, 2 et Extranumber (1899-1901). $8^{0}$.

Im Jahre 1898 beschloss die britische Regierung, zur Hebung der Culturen auf den westindischen Inseln ein neues Department unter der Leitung eines Commissioner of Agriculture und mit dem Sitze in Barbados zu gründen. Diese Stelle wurde Dr. D. Morris, dem Assistant Director ron Kew Gardens, welcher als elemaliger Director des Botanical Department in Jamaica und sachrerständiger Begleiter der Untersuchungs-Commission (vergl. Symb. I p. 87) die grössten Erfahrungen besass, übertragen. Um nun die Landbau betreibende Bevölkerung mit gesunden und wissenschaftlichen Methoden der Bodencultur, der Anzucht und der Bearbeitung der ökonomischen Producte bekanut zu machen, wurde das obige Journal gegründet, welches an alle Interessenten gratis vertheilt wird und ausserdem zı einem sehr mässigen Preise bezogen werden kann. Die erste Nummer erschien am 1. Juli 1899.

Die crfolgreiche Thätigkeit, welche D. Morris bis dahin bereits den englisch-westindischen Colonien gewidmet hatte, wird am besten aus folgender mir freundlichst zur Verfügung gestellten Liste seiner Arbeiten hervorgehen (vgl. auch Symb. I p. 87-88).

D. Monris: A List of Books and Papers, written during the last 18 years, by the Author of the preceding Report, affording further Information on the economic Plants and agricultural Industries of the West Indian Colonies.

Hints and Suggestions for Raising Cinchona Plants from Seeds, and Establishing Cinchona Plantations in Jamaica. Kingston: Government Printing Establishment, 1880.

Annual Report on the Public Gardens and Plantations, Jamaica, for the year 1880,40 p. Kingston: Gorermment Printing Establishment, 1881.

Notes on Liberian Coffee: its History and Cultivation, 14 p. Kingston: Government Printing Establishment, 1881.

Some Objects of Productive Industry. Parts I and II. Coffee and Cinchona, 40 p. Kingston: Institute of Jamaica, 1881.

The Cultivation of Cinchona in Jamaica. Hanłbook of Jamaica. Vol. I, p. 162 -181. Kingston: Gorernment Printing Establishment, 1881.

Suggestions for the Improvement of the Coffee Industry in Jamaica. Extract from Lecture on "Some Objects of Productive Industry." Kingston: Institute of Janaica, 1881.

Anulal Report of the Public Gardens and Plantations, Jamaica, for the ycar 1881, 16 p. Kingston: Government Printing Establishment, 1882.

Cacao: How to Grow, and How to Cure it, 46 1). Jamaica: Government Printing Establishment, 1882. 
The Aplis Blight ou Sugar-eane in Jamaica, with Suggestions for Remedial Heasures, 4 p. Kingston: Government Printing Establislıment, 1882.

The Mungoose on Sugar Estates in the West Indies, 20 p. Kingston: Jamaiea, 1882. (Contains an aeeount of the introduetion of the Mungoose, ITerpestes griseus, as a rat-eateher to Jamaica and Barbados, and the eireumstanees attending its (lisper'sal thronghont the islancls.)

Cinchona Cultivation in Jamaiea. A historieal and deseriptive aeeount of the industry: the eost of eultivation, and the eonditions under whieh the Goverment of Jamaiea offers grants of land for Cinehona. Handbook of Jamaiea, Vol. III, p. 442-461. London: Stanford, 1883.

Annual Report of the Publie Gardens and Plantations, Jamaiea, for the year 1882,24 p. Kingston: Govermment Printing Establishment, 1883.

Planting Enterprise in the West Indies. Proeeedings, Royal Colonial Institute, Vol. XIV (1882-1883) p. 264-315. London: Sampson Low, Marston and Co., 1883.

Cinehona Planting in Jamaiea: a Detailed Statement of Ineome and Expenditure on Cinchona Plantations in Jamaiea. Kingston: Government Printing Establishment, 1883.

The Colony of British Honduras: its Resourees and Prospeets, with partieular Referenee to its Indigenous Plants and Economie Productions, 150 p. London: Stanford, 1883.

Instruetions relative to the Cultivation of the Ramie or China Grass, Gochmeria nivea. Kingston: Government Printing Establishment, 1883.

Annual Report of the Publie Gardens and Plantations, Jamaiea, for the year 1883, 20 p. Kingston: Govermment Printing Establishment, 1884.

Some Objeets of Prodnetive Industry: Part IV, Native and other Fibre Plants, 48 p. Kingston: Institute of Jamaiea, 1884.

Anmul Report of the Publie Gardens and Plantations, Jamaiea for the year 1884, 54 p. Kingston: Government Printing Establishment, 1885.

A Deseriptive List of Forty New Sugar-eanes under experimental Cultivation by the Botanieal Department, Jamaiea. (Reprintel from the Report of the Direetor for the year 1884, p. 31-34.) Kingston: Gorernment Printing Establishment, 1885.

Jamaiea at the World's Exposition (New Orleans). A descriptive eatalogne of the produets of Jamaiea, 30 p. Kingston: Institute of Jamaiea, 1885.

The Oeeurrenee of Droughts: their Causes and the Neans whereby their Effeets might be mitigated, modified, or reliever, 29 p. (A leeture delivererl before the Janniea Soeiety of Agrieulture and Commerce. Kingston: Jamaiea, 1885.)

Annual Report of the Publie Gardens and Plantations, Jamaiea, for the year 1885, 29 p. Kingston: Govermment Printing Establishment, 1886.

Tropieal Fruits. Nature, Tol. XXXIV (1886), p. 316 et seq. London: Maemillan, 1886.

Fruit as a Faetor in Colonial Commeree. Proeeelings, Royal Colonial Institute, Vol. XVIII (1886-1887) p. 123-159. London: Sampson Low, Marston and Co., 1887.

Botanieal Federation in the West Indies. Nature, Vol. XXXV p. $248-250$. London: Macinillan, 1887. 
Report (for the Royal Commission), on the various Fruits and Fruitproducts at the Colonial and Indian Exhibition, 1886, p. $129-146$. Iondon: Clowes \& Son, 1887.

The Dispersion of Seeds and Plants. Nature, Vol. XXXV p. 155 et seq. (Contains reference to the Pimento Industry of Jamaica.) London: Macnillan \& Co., 1887.

Botanical Stations in the West Indies. Kew Bulletin, No. 6, June 1887. London: Eyre \& Spottiswoode, 1887.

Annatto or Roncou; its History, Cultivation, and Preparation. Kew Bulletin, No. 7, July 1887; and Kew Bulletin, No. 9, Septcmber 1887. London: Eyre \& Spottiswoode, 1887.

On the Introduction of eertain West Indian Food-plants to the East Indies. Kew Bulletin, Nr. 8, 1887, August. London: Eyre \& Spottiswoode, 1887.

The Dispersion of Seerls and Plants. Natunc, Vol. XXXVII, p. 446 et seq. (Contains references to the introduetion and distribution of the Guango, Pithecolobimm Saman, and other economie plants to Jamaica.) London: Macmillan \& Co., 1888.

The Vegetable Resources of the West Indies. An address delivered before the London Chamber of Commerce, 27th March 1888. Mr. James Anthony Froude in the chair. London, 1888.

The Colony of the Leeward Islands. A paper read before the Royal Colonial Institute, April 14, 1891. (Deals with the hotanical resources of the Leeward Islands and offers suggestions for the development of local industries.) Proceedings, Royal Colonial Institute, 1890-1891, p. 225-263.

Botanieal Enterprise in the West Indies. (An aeeomnt of a Mission undertaken at the request of the Secretary of State for the Colonies to the West India Islands in $1890-1891$, with partieular reference to their plant productions and the working of the Botanic Stations.) Kew Bulletin, Мay and Jume 1891, p. $103-168$.

Commercial Fibres: A summary of the Cantor Lectures delivered bcfore the Society for the eneouragement of Arts, Manufactures, and Conmerce, March 15, 25, and April 1, 1895; on Fibres, their history and origin, with speeial reference to the Fibre Industries of the West Indies and other of Iler Majesty's Colonial Possessions, 42 p. London, 1895.

The Cultivation of Fruit and Vegetables for an Export Trade in the Bahamas, being the substance of a series of lectures delivered at Nassau, N. P., in 1895-1896. Nassau: Government Printing Office, 1896.

The Sisal Industry of the Bahamas, an account of a white-rope fibre industry established in this and other West Indian Colonies. A paper read before the Society of Arts, March 18, 1896, General Sir Henry Norman, G. C.B., G.C. I. G., C.I.E., in the chair. Jommal of the Society of Arts, March 20, 1896; see also Colonial Reports, Miscellaneous, No. 5, Bahamas, 1896. (The author received the award of the Silver Hedal of the Society of Arts' for this paper.)

The Further Development of Agricultural Industries in Jamaica. A paper read before the Jamaica Agricultural Socicty, April 5, 1897, Sir Henry A. Blake, K. C. II. G., in the chair. Journal of the Jamaica Agrieultural Society, 1897, p. 139-146. Kingston, Jamaica, 1897. 
Palmer Defor. Cub. $=$ W. Palune: Deforested Cuba. [Plant World IV (1891) p. 21-22 tab. 2.]

Nicht gesehen; naeh Bull. 'Torr. bot. Club XXVIII (1901) 1). 318.

Patouill. Champ. Guad, $=$ N. Patoullanid: Champignons de la Guadeloupe, recueillis par le R. P. Duss. [Bull. Soc. mycol. de France. Paris. Vol. XV (1899) p. 191-209, tab. IX, X, vol. XVI (1900) p. $175-188$, tab. VII. $S^{0}$.]

Der so fleissige und erfolgreiche Père Duss hat es nicht bei der Erforschung der Plıanerogamen-Flora der französisch-westindischen Inseln bewenden lassen. Seitdem die Ausbeute an ilm unbekannten oder von der betreffenden Insel noch nicht nachgewiesenen Arten immer geringer wurde, hat er seine Aufmerksamkeit den Kryptogamen geschenkt und scine freie Zeit dem Aufsammeln derselben zunächst auf Guadeloupe, dann aber anch auf grösseren Ferienreisen auf Martinique mit grosser Ausdaner und Sachkenntniss gewidmet. P. besclureibt aus der mykologisehen Ausbeute desselben nicht weniger als 4 neue Gattungen (Cymatella, Dichosporium, Microstelium, Stilbocrea) und 53 neue Arten und fügt zu einigen schon bekannten kritische Bemerkungen hinzu. Die 3 Tafeln geben theils Habitusbilder, theils Analysen. Leider wird nur das Substrat, aber nicht die Insel, von welcher die Arten herstammen, mitgetheilt.

Die Originalien sind im Herb. Duss, Patoulldard und im botan. Museum in Berlin.

Pilger Arthrostyl. cf. URb. Symb. II.

Poit. Flor. Dom. = Prerre Antone Portenu: Florule de SaintDomingue. 1 vol. fol. Msc. (Bibl. Mus. d'hist. nat. Paris).

Nicht gesehen; nach Bureau im Nouv. Arch. du Maséum III sér. vol. IX (1897) p. 26. Porteau hielt sich 1796-1801 auf Haiti auf und brachte ein grosses Herbarium in dem nördliehen Theile der Insel, sowie auf dem benachbarten Eilande La Tortue zusammen; die gesammelten Pflanzen waren mit genauen Besehreibungen und meist auch mit Abbildungen versehen. Hieraus redigirte er nach seiner Rüekkehr 1802-1803 das obige Werk. Da er aber die Aussicht hatte, noeh einmal nach Haiti zurückzukelıren und seine Untersuehungen zu ergänzen und zu erweitern, ein Plan, der wegen der Vertreibung der Franzosen von der Insel nicht zur Ausführung kam, so blieb das Werk unveröffentlicht.

Rocher Jabor. = Dr. G. Rocher: Un nouveau Jaborandi des Antilles françaises. Etude botanique, chimique et pharmacologique du Pilocarpus racemosus. Toulouse 1899. $8^{0} .78$ p. 2 tab.

Verfasser, welcher Professeur de pharmacie et de matière médicale an der Ecole de médecine et de pharmacie zu Clermond-Ferrand ist, hatte aus Guadeloupe Materialien des auf Cuba, Portorico und den kleinen Antillen bis Martinique vorkommenden Pilocarpus racemosus Vahl erhalten und diese einer genauen Untersuchung unterworfen. Er giebt zunächst eine historische Einleitung über die Arbeiten, welche sich mit den verschiedenen, Jaborandi genannten Substanzen beschäftigt haben, eine systematische und anatomische Beschreibung der Pflanze, die Resultate der chemischen Untersuchung ihrer 
Alkaloide und endlich seiner pharmakologischen Studien. Aus letzteren ergiebt sich, dass die Blätter der Antillen-Pflanze dieselben Alkaloide wic $P$. pennatifolius haben und zwar noch mehr Pilocarpin als dieser. Verf. ist der Ansicht, dass man $P$. racemosus an Stelle des brasilianischen Jaborandi's mit Vortheil in der Therapie verwenden kann. Auf den beiden Tafeln wird ein Blatt nebst den anatomischen Details desselben abgebildet.

Ruhl. Eriocaul. antill. ef. URв. Symb. II.

Seguí Flor. med. Cub. = Domrgo Hersando Seguí: Ojeada sobre la Flora médica y tóxica de Cuba. Habana 1900. S .93 p.

Inaugural-Dissertation zur Erlanguug des Doctor en Ciencias von der Universität zu Habana. Verf. bespricht in der Reihenfolge des VAN 'îleghemschen Systems die medicinisch und pharmacentisch wichtigen Pflanzen der Insel Cuba unter Beifügung der einheimischen Namen. Botanisch von Interesse ist die Aufführung der neuen Gattung Torralbasia Kr. et Urb. (ohne Diagnose), gegründet auf Maytemus cuneifolins Griseb. Auf S. 91-92 findet sich auch eine Aufzählung der beuntzten cubensischen Litcratur.

Smith Fung. West Ind. = Axate Lorrais Suitu: On some Fungi from the West Indies. [Journ. Linn. Soc. London. Vol. XXXV (1901) p. $1-19$. tab. $1-3 . \mathrm{S}^{0}$.]

Aufzählung von 161 Pilzen, welche W. R. Eldiotr Juli bis Dec. 1892, März 1894, Oct. 1895 bis März 1896 auf Dominica im Auftrage des British Committee für die Erforschung der Fauna und Flora Westindiens gesammelt hatte; nur je einer ist von Antigua bez. St. Vincent. Es werden eine neuc Gattung (Xyloceras) und 21 neue Arten beschrieben.

Die Originalien sind in British Museum.

Torr. Palm. Cub. = José I. Torralibas: The Palms of Cuba Las Palmas de Cuba. [The Island of Cuba Magazine. Habana. Vol. I (1899) p. 113 - 116. $8^{0}$ c. tabul.]

Fortsetzung der Besprechuug der auf Cuba vorkommenden Palmen (cf. Symb. II p. 5). Aufzähluug der Gattıngen und vom Verf. gezeichnete recht gute Habitusbilder von Yuraguana maritima Kth., Therinax Miraguano Mart., Colpothrinax Wrightii Griseb.

Underw. Botr. Jam. = Lucien M. Underwoon: A new Botrychium from Jamaica. [The Fern Bull. Binghampton, N. Y. Vol. VIII (1900) p. $\left.59-60.8^{0}.\right]$

Beschreibt Botrychinm Jenmoni aus der Ternatum-Gruppe, welches von MIr. Nock und W. N. Clute auf Jamaica gesammelt war.

Das Original im Herb. Underwood.

Urb. Symb. I, II. = Igritrus Urbax: Symbolae antillanae seu Fundamenta Florae Indiae occidentalis. Berolini, Parisiis, Londini. S ${ }^{0}$. Vol. I fasc. III. 1900. p. $385-536$. Vol. II fasc. I. 1900. p. $1-160$, fasc. II. 1900. p. $161-336$.

Zu den Species novae, praesertim portoricenses, welehe den grössten Theil des Il. und III. Fascikels von Band I. einnehmen, giebt der Herausgeber 
noeh ein Supplement (1. 472-481), in welehem ansser anderem noeh 5 nene Arten von Portorieo (eine zugleieh aneh in Hispaniola und St. Thomas rorkommend), 4 rou Haiti, 2 ron Cuba, 1 neue Orehidee ron Jamaiea (diese

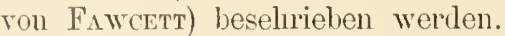

Die sich ansehliessende Bearbeitung der Eriocanlonaceac ist ron dem Monographen der Familie, W. Rouland, ausgeführt. Eine neue Gattung (Syngomanthus) wird auf mehrere, ron Paepalanthus abzutrennende Arten aufgestellt; an neuen Arten finden wir nur zwei, die eine von Sto. Domingo, welche Baron EgGElis als erste Vertreterin der Familie für diese Insel naehwies (die MAYEmorF'sehen dureh Etiquettenverweelıselung wohl irrthümlich lierher gezogenen Speeies stammen wahrseheinlieh aus Guyana), die andere bisher mit einer Mrcuadx'sehen Art aus Nordamerika velweehselte aus Cuba. Von den 16 Arten kommen 14 auf Cuba, 1 auf Hispaniola, 3 auf Trinidad vor; fast alle sind den betreffenden Inselı eigenthümlieh.

Die Juncaceae, von dem bewährten Mollographen F. Buclinvau bearbeitet, besehränken sieh in Westindien nur auf 3 Juncus-Arten, von welehen eine auf Guadeloupe vorkommende neue Art sehr ausfülırlieh besehrieben wird. Der Juncus parviflorus Poir. von Portorieo entpuppte sieh dagegen als die verbreitete Rhynchospora micrantha Valıl.

Die Sabiaceae, von dem Herausgeber bearbeitet, sind in Westindien nur mit 5 Arten vertreten, von welehen 1 eine weite Verbreitung von Portorieo bis Grenada besitzt, 1 Cuba, 1 Haiti, 1 Portorieo, 1 Guadeloupe eigenthümlieh sind; davon werden 3 als nen beschrieben, (eine allerdiugs selıon bei BELLo Ap. aufgefïhrt, aber rïeksichtlieh ihrer Familienzugehörigkeit nieht erkannt). Da Verf. (bereits im Jahre 1895) dieser Familie ein sehr eingelıendes Studium gewidmet hatte, so beselıreibt er hier säımtliehe bisher aus Amerika bekannt gewordenen oler nenen Arten unter Voraussehiekung eines morphologisehen Resumé's, der äusseren, zur leiehteren Frkennung der Familie dienliehen Merkmale, der reformirten Familieneharaktere und der Diagnosen der beiden amerikanischen Gattungen (Ophiocaryum mit 2, Meliosme mit 19 Arten).

Den Sehluss des ersten Bandes bilden die Addenda et Corrigenda, der Index nominum latinorum und der Index nominum rernaeulorum.

Der zweite Band beginnt mit der Fortsetzung der Bibliographia Indiae oecidentalis botaniea, d. lı. mit der Aufzählung und kurzen Bespreehung der seit 1898 veröffentliehten Sehriften und Aufsätze über westindisehe Botanik. Hiermit soll aneh in den folgenden Bänden fortgefahren werden, damit die Interessenten für dies Florengebiet eine leieht zugängliche Uebersieht über die kurz vorher veröffentliehte, sehr zerstrente Literatur erhalten. Dagegen werden Arbeiten über Agrienltur nur noch ansnahmsweise berüeksiehtigt werden.

Die Cyperaceae sind das Resultat eines vieljälnigen Studiums ron C. B. Clarke, bez. ein Auszug aus dessen im Manuseript fertiger Monographie dieser Familie. Aus 26 Gattungen werden 243 fast durehweg bekannte Arten in präeisester Form diagnostieirt und mit einer ausgedehnten Synonymie, sowie der Angabe der Verbreitung rerselıen. Da der Verfasser ein sehr umfangreiehes Material zu seinen Studien benutzt hat, so dürfte dureh seine Arbeit die Verbreitung der Arten dieser Familie in Westindien im Allgemeinen wohl festgelegt sein.

Die in volstehender Abhandlung angewendete Nomenelatur schloss sieh an die Kew Rules an und ging in einigen Punkten noeh über dieselben hinaus. 
Um sie nun aueh denjenigen Botanikern leicht benutzhar zu machen, welche den ältesten Speeiesnamen roranstellen, sah sich der Herausgeber gezwungen, eine Revision der Namen naeh dieser Richtung hin vorzunehmen und leider auch einige neue Combinationen zu selraffen.

Auch die Acanthaceac haben einen Botanilier, G. Lindau, zum Verfasser, weleher sich mit dieser Familie sehon längere Zeit beschäftigt und ausser dem Berhiner Material das mehrerer anderer Museen benutzt hat. Unter den 90 Arten (mit Einschluss der cultivirten) ist auffälliger Woise nur eine Novität. Dagegen werden drei nene Gattungen (Drejerclla, Ancistranthus und Centrilla) aufgestellt. Dem System ist die Sculptur des Pollens zu Grunde gelegt.

Im Ansehluss an seine Monographien beschreibt sodann C. MEz eine neue Lauraeee, rerrollständigt die Beschreibung ron zwei anderen und stellt 6 nene Bromeliaeeen, meist aus Jamaica, auf.

Die Leguminosae novae vel minus cognitae vom Herausgeber enthalten rücksiehtlieh der Mimoseae fast nur die Besehreibungen von neuen Arten, da die elassisehe Bearbeitung von BеnтнAм trotz des jetzt riel umfangreieheren Materials kaum eine Rectification bedurfte. Dagegen war eine kritisehe Aufzällung der westindisehen Caesalpinia-Arten, namentlich aus der Gruppe Guilandina, geboten; leider komnten aler die Arten aus letztgenannter Seetion aus Mangel an vollkommenen Haterialien und bei ihrem ausgeprägten Polymorphismus auch jetzt noeh nieht sämmtlich in befriedigender Weise dargestellt werten. Von Papilionaceae werden zwei neue Gattungen (Hebestigma aus der Verwandtschaft ron Gliricidia und Rhodopis aus der Verwandtsehaft ron Rudolphia) aufgestellt und mehrere andere l'ïcksiehtlich ihrer westindischen Arten monographisch bearbeitet, so Gliricidia (1), Chaetocalyx (3), Pictetia (4), Belaivia (3), Biryn (2), Rudolphia (1), Galactia (mit 27 Arten).

Von den westindisehen Arten der Gramineen-Gattung Arthrostylidium enthält das Fascikel nur einen Theil der Einleitung.

Wain. Lich. nov.= Edv. A. WAmio: Lichenes novi rarioresque. [Hedwigia vol. XXXVIII (1899) Beibl. 6 p. $253-259.8^{0}$.]

Beselmeibt 20 neue Fleehtenarten von Guadeloupe und 1 von Martinique, welehe ron Père Duss in den letzten Jahren daselbst gesammelt wurden.

West Freshw. Alg. II. = W. West and G. S. West: A further contribution to the Freshwater Algae of the West Indies. [Journ. Linn. Soc. London. Vol. XXXIV (1899) p. 279-295. 8\%.]

Die Verfasser zählen 87 Arten von Süsswasseralgen auf, welche ron W. R. Eluotт im Januar und Februar 1896 zum grössten Theile in Dominica gesammelt waren; einige wenige stammen aus St. Vineent. Es fanden sieh darmuter nur eine nene Art und zwei neue Varietäten.

Die Originalien sind im British Museum. 


\title{
II. Notae biograplicae peregrinatorum Indiae occidentalis botanicorum.
}

\author{
Auctore \\ IgNatio URBAN.
}

Einleitung.

Seit dem Beginn meiner historisch-botanischen Studien nahmen die Lebensverhältnisse der botanischen Reisenden, insbesondere Zeit und Ort ihrer sammlerischen Thätigkeit, mein Interesse in hohem Maasse in Anspruch. War es einerseits ein Akt der Gerechtigkeit, ihnen, die aus fernen Ländern unter Gefahren mannigfaltigster Art die wissenschaftlichen Materialien herbeischafften, ein biographisches Denkmal zu setzen, so konnte anderseits die Pflanzengeographie aus der genauen Kenntniss der Reiserouten rüicksichtlich der Verbreitung der einzelnen Arten mancherlei Vortheile ziehen. So entstanden eine Reihe von Biographien tropisch-amerikanischer Sammler, welche ich in ExGLeR's Jahrbüchem veröffentlichte.

Als ich mich im Jahre 1884 entschloss, meine fernere wissenschaftliche Thätigkeit hauptsächlich der Flora Westindiens zu widmen, begann ich auch alsbald für die vorliegende Abhandlung Materialien zusammen zu bringen. Eine Anzahl vortrefflicher Vorarbeiten lag allerdings schon vor:

In erster Linie ist A. Lasìgue: Musée botanique de M. Benjamis Delessert, Paris 1845, zu nennen, welcher eine grosse Anzahl Exposés des Voyages entrepris dans l'intérêt de la Botanique mittheilt, aber weder die Lebensverhältnisse der Reisenden berührt, noch die benutzten Quellen angiebt.

Eine sehr wesentliche Hülfe bot auch G. A. Pritzen: Thesaurus literaturae botanicae, edit. nova, Leipzig 1872, der mit unendlicher Geduld und Sorgfalt aus den verschiedensten Werken, Zeitschriften und wahrscheinlich auch Tagesblättern die Titel von Biographieen oder wenigstens Zeit und Ort der Geburt und des Todes aufführt, allein fast nur von solchen Reisenden, welche auch selbstïndige botanische Werke 
verfassst haben. Diese Biographieen selbst sind aber rücksichtlich der Itinera mit grösster Vorsicht zu benutzen, da von deren Verfassern oft ganz irrige Angaben über die besuchten Inseln gemacht werden.

Catalogue of scientific papers (1800-1883), compiled by the Royal Society of London. 11 vol. $4^{\circ}$. 1867--1896 enthält die Titel der nicht in Buchform erschienenen Werke. Man wird dadurch auch auf nicht botanische Aufsätze aufmerksam gemacht, in welchen sich bisweilen Angaben über die Reisen finden.

Ferner konnten die in verschiedenen Ländern herausgegebenen nationalbiographischen Werke mit Vortheil verwendet werden, z. B.

L. G. Michadd: Biographie universelle, ancienne et moderne. Paris 1811-1862. Vol. I-LXXXV. $8^{\circ}$.

Fraxcis S. Drake: Dictionary of American Biography. Boston 1872. 1 vol. $8^{0}$.

(v. Liliencros): Allgemeine deutsche Biographie. Leipzig 1875 bis 1900. Vol. I-XLV. $8^{\circ}$.

Fraxcisco Calcagno: Diccionario Biográfico Cubano. New York 1878. 1 vol. $8^{\circ}$. 727 p., welches ich der Güte des Herrn Prof. Gonez DE LA M MZA in Habana verdanke.

Leslite Stephex and Sidney Lee: Dictionary of National Biography. London 1885-99. Vol. I-LX. $8^{0}$, unvollendet (bis Whewell).

C. F. BRTcks: Dansk Biografisk Lexikon. Kjøbenhavn 1887-1900. Vol. I-XIV. $8^{0}$, unvollendet (bis Saxtrup).

Endlich besitzen auch einige Länder bereits botanisch-biographische Werke, so z. B.

Miguel Colmeiro: La botánica y los botánicos de la península hispano-lusitana. Estudios bibliográficos y biográficos. Obra premiada por la biblioteca nacional. Madrid $1858.8^{\circ} . \mathrm{X}, 216 \mathrm{p}$.

JaMes BRittex and G. S. Boulger: A biographical index of British and Irish botanists. London 1893. $8^{\circ} .188$ p. and First Supplement. London 1899 p. $193-222$, verbesserter und vermehrter Sonderabdruck aus Britrex's Journ. of Bot. vol. XXVI-XXIX (1888-91) und vol. XXXVI-XXXVII (1898-99).

E. Warnisg: Den Danske botaniske Literatur fra de aeldste Tider til 1880, in Bot. Tidsskr. Kjøbenh. Vol. XII (1880-81) p. $42-131$, $158-247$.

Hjalinar Kraerskou: Om danske Samlere af vestindiske Planter in Bot. Tiddskr. Kjøbenh. vol. XXIII (1900) p. 35 - 47.

Auch schreibt Herr Gymmasiallehrer T. O. B. N. KRok in Stockholm ein ähnliches Werk über schwedische Botaniker, aus welchem er mir durch Herrn Dr. G. O. A. Malare die Westindien betreffenden Partieen freundlichst zur Benutzung überlassen hat. 
Trotz alledem war noch ausserordentlich viel zu thun. Aus Tausenden ron Originaletiquetten wurden in den verflossenen 17 Jahren Angaben über Zeit und Ort der Sammlungen entnommen, theils um dio Itinera zu construiren, theils die Angaben der Biographen zu controlliren und zu verbessern. Da sich alle vorher genannten biographischen Werke mit Ausnahme der dïnischen, cubensischen und nordamerikanischen auf die zur Zeit der Abfassung bereits verstorbenen Botaniker beschränken, so mussten ron zahlreichen noch lebenden Reisenden und Sammlern die nothwendigen Daten beschafft werden, was dieselben auch, von ganz wenigen Ausnahmen abgesehen, mit grosser Bereitwilligkeit thaten. Eine nicht unbedeutende Anzahl bereits Verstorbener hatte ïberhaupt niemals einen biographischen Nachruf erhalten; für mehrere derselben gelang es, einen solchen durch gütiges Entgegenkommen ron Verwandten etc. noch nachzuholen; für viele andere liess sich trotz aller Mühe nur weniges oder auch gar nichts ermitteln. Nach dieser Richtung hin wurde ich besonders unterstützt durch die Herren E. Bureau-Paris, A. Cogndux-Verviers, F. Cundall-Jamaica, U. DammenGrosslichterfelde, Père Duss-Guadeloupe, Baron H. EgGers-Kopenhagen, W. Fawcett -Jamaica, W. Hıreis-Jamaica, F. Heu-Paris, W. B. HeuslexKew, M. Krosfedd-Wien, L. Krug-Grosslichterfelde ( $\uparrow$ ), G. O. A. MaLuEStockholm, E. vox Maltexs - Berlin, Gouez de li MnzA - Habana, D. Morris Barbados, J. Porssox-Paris, L. Wиттuск-Berlin und andere, welche bei den betreffenden Biographieen selbst genannt sind.

Nicht selten finden sich widersprechende oder abweichende Angaben in der Literatur, namentlich über Daten und Inseln. In solchen Fällen bin ich denjenigen Autoren gefolgt, welche sich zuletzt oder am gründlichsten mit der betreffenden Persönlichkeit beschäftigt haben, ohwe mich auf eine längere Discussion einzulassen. Sehr oft habe ich selbst Correcturen rorgenommen und zwar fast ausschliesslich auf Grund von zuverlässigen Herbarzetteln. Dessenungeachtet werden in der Zukunft noch manche Verbesserungen und Ergänzungen beigebracht werden, letztere namentlich aus den Archiven des Muséum d'histoire naturelle zu Paris, in welchen die Correspondenzen der französischen Sammlungsreisenden aufbewahrt werden. Auch ist es sehr wahrscheinlich, dass eine Anzahl Biographieen oder Nachrufe oder sonstiger hergehöriger Notizen übersehen ist, namentlich in gärtnerischen Zeitschriften, weil solche Viten in Sammelwerken ${ }^{1}$ nicht citirt worden sind; zu dieser Befürchtung bin ich um so mehr berechtigt, als mehrere gute Biographicen mir nur durch blossen Zufall bekannt wurden. Ich muss deshalb auch

1) Just's botanischer Jahresbericht z. B. hat urst seit 1892 auf meine Anregung hin die Biographieen berïcksichtigt. 
ron meiner Abhandlung sagen, was Britrex und Boulgkir in der Einleitung zu ihrem Biographical Index schrieben: Such a work must of necessity contain errors both of commission and of omission, and few who consult it can form an adequate opinion of the labour involved in collecting information which, when set down, may appear of the most meagre character.

Alexander, D. W., Sammler für das Herbar des botanischen Gartens zu 'Trinidad, vergl. НART.

Alexander, R. C., ef. Prior.

Anderson, Alexander, (? - 1811), Dr. med., seit 1775 in den Vereinigten Staaten ron Nordamerika, wahrscheinlich als Arzt bei den britischen Truppen, kam als Hospitalarzt nach St. Vincent und war 1785 bis 1811 Superintendent des dortigen botanischen Gartens, den er zu grosser Blüthe brachte. Er starb daselbst kurz nach seinem Rücktritte am S. IX. 1811. A. beabsichtigte eine Flora der Kariben zu schreiben und sammelte deshalb auch auf den Nachbarinseh Martinique, St. Lucia, Barbados, Grenada, Trinidad. 1791 besuchte er Guyana, hauptsächlich um werthvolle Nutzpflanzen für den Garten zu holen.

Coll. Die Guyana-Pflanzen im Herb. Baxks des British Huseum und im Herb. Delessert (ex herb. W. Fonsytur); die westindischen Pflanzen in Kew und im Herb. Delesserer, einiges auch im Herb. des Petersburger bot. Gartens (ex herb. MErTExs). Die von ihm nach lebenden Exemplaren des Gartens zu St. Vincent angefertigten Zeichnungeu sind im Besitz der Linnean Society zu London (Linis. Pin. II ed. Praef.).

Lit. Kew Bull. 1892 p. $94-97$; J. Britren in Dict. Nat. Biogr. I (1885) p. 372 ; Britt. and Boulg. p. 4 ; Urb. Symb. III p. 1.

Aquart, lebte um 1787 auf Martinique, wo er einen grösseren Garten besass, und gab Pflanzen an IsERT ab.

Coll. Museum zu Kopenhagen, auch in Petersburg und im Hofnuseum in Wien.

Auber, Pierre Alexandre, (17S6 - 1843), geb. in Le Havre (Frankreich) im Jahre 1786, kam 1808 als Kriegssekretär mit der französischen Armee nach Spanien, wurde gefangen genommen und studirte in Madrid Medicin und Naturwissenschaften. Darauf wurde er Director des Militärlospitals in Coruña, musste aber in Folge eines Brustleidens einen sechsjährigen Aufenthalt auf den canarischen Inseln nehmen, wo er mit WEBв und Berthelot Excursionen náachte. 1833 ging er nach Cuba, um im Osten der Insel in der Umgebung von Moa eine Kolonie zu gründen. Da diese aber nicht prosperirte, begab er sich nach Habana, wurde mit RAMON DE LA SAGRA bekannt und sammelte für diesen hauptsächlich 
kryptogamische Gewächse und wurde nach dessen Abreise nach Europa Director des botanischen Gartens und Professor der Botanik. Er starb in Habana den 13. IV. 1843.

Coll. Die von C. Montagie für Sagia's Cuba bearbeiteton Kryptogamen sind im Museum zu Paris.

Lit. F. Calcagro: Diccionario biografico Cubano (1878) p. $79-81$.

Aublet, Jean Baptiste Christophe Fusée, (1720-1778), geb. zu Salon in der Provence (Frankreich) den 4. XI. 1720, studirte in Montpellier und Paris Botanik, Pharmacie, Chemie, \%oologic und Mineralogie, an letzterem Orte besonders unter Bervil. De Jussieu, und erhielt den Auftrag, in Isle de France (Mauritius) ein pharmaceutisches Laboratorium einzurichten und einen botanischen Garten zu gründen. Er blieb daselbst $1753-61$ und sandte während dieser Zeit viele Kisten mit Pflanzen, Mineralien und Thieren nach Frankreich. Zu ciner Bearbeitung derselben kam er aber nicht; denn bald nach seiner Rückkehr wurde er als Apothicaire-Botaniste nach Franz. Guyana geschickt, um die Producte dieses Landes kennen zu lernen und Vorschläge zur Hebung der Culturen zu machen. Hier entdeckte or während eines nur zweijährigen Aufenthaltes (1762-64) eine Fülle von neuen Pflanzenformen, die er an Ort und Stelle sorgfältig beschrieb und in einem vicrbändigen Werke: Histoire des Plantes de la Guiane française, Londres et Paris 1775 mit 392 Tafeln, unter der Beihülfe B. de Jussieu's veröffentlichte. Bei seiner Rückreise wurde er ron dem General Grafen D'Estatig, Kommandanten in der Mole St. Nicolas auf Haiti, zum Generaldirector ernamnt und führte in dieser Eigenschaft in der letzten Hälfte des Jahres 1764 zahlreiche Bauten auf. Seine schon in Guyana erschrütterte Gesundheit nöthigte ilın aber, nach Paris zurückzukehren, wo or den 6. V. 1778 starb.

Coll. Herb. Banis im British Museum, Doubletten im Herb. Sirtir in der Linnean Society und (nach Lis. p. 557) bei cinem Grafen Tristax zu Orleans, Pflanzen von Haiti in Montpellier (ex herb. CАмвеss.).

Lit. Aunlet: Guiana vol. I Préface; Biogr. médic. I p. 410 ex Pritz. Thes. II el. p. 10; Du Petit-Thodars in Mich. Biogr. univ. III (1811) p. $14-15$; Las. Mius. Deless. p. $473-74$; Pritz. Thes. II ed. p. $10 ; J_{\text {Acrs. }}$ Guide p. 375.

Badier sammelte Ende des 18. Jahrhunderts auf Guadeloupe. Coll. Herb. de Caxdolue in Genf (ex herb. L'Hérttier).

Baker, Mrs. Barrington, sammelte auf Jamaica Farne, welche von G. S. J Бxwax in seiner Synoptical list bearbeitet wurden.

BALB1s, Giovanni Battista, (1765-1831), Professor der Botanik in Turin, Lehrer und Freund ron BerTero, vertheilte die von diesem 
auf den Antillen und in Neu-Granada gesammelten Pflanzen an die Abonnenten. Da die Etiquetten den Namen von BErTero meistens nicht führen, wohl aber oft den von B.LLis, so wird letzterer mit Unrecht von manchen Autoren als westindischer Sammler citirt.

Bancroft, Edward Nathaniel, (1772-1842), geb. zu London 1772 , studirte zu Cambridge Medicin, besuchte als Militärarzt die WindwardInseln, Portugal und mit Abircroybr's Expedition 1801 Aegypten, prakticirte nach seiner Rückkehr in London und ging in Folge seines geschwïchten Gesundheitszustandes 1811 nach Jamaica, wo er am 18. IX. 1842 als Generalinspector der Armeehospitäler in Kingston starb. Er reröffentlichte auch einige Schriften über Fische und andere Thiere von Jamaica.

Coll. Kew Herbarium.

Lit. C. Creighiton in Dict. Nat. Biogr. III (1885) p. 106 - 7; Britr. and Boulg. p. 10; Cat. Sc. Pap. I. 175.

Barber, Charles Alfred, M. A., Schüler des Christ's College zu Cambridge (England) und Demonstrator der Botanik an der dortigen Universität, wurde 1891 Superintendent des Botanical and Agricultural Department der Leeward-Inseln mit dem Sitze in Antigua und dem Auftrage, die Inseln Dominica, Montserrat und St. Kitts-Neris öfter zu bereisen. Er blieb in dieser Stellung bis März 1S95, wurde dann Professor der Botanik an Indian Civil Engineering College (Forestry Branch) und 1898 Gorernment Botanist zu Madras.

Coll. Kew Herbarium; einiges im Herb. Krug et Urbav.

Lit. Kew Bull. 1891 p. 245, 1898 p. 277 et Add. Ser. I p. 119, 121.

Barham, Henry, (ca. 1650-1726), geb. in England ca. 1650, Wundarzt, ging über Spanien und Madras um 1680 nach Jamaica, wo er im V. 1726 als Surgeon-Major der Kolonialtruppen starb. B. war ein guter Kenner der Fauna und Flora der Insel, sandte Pflanzen und Thiere an SLodxe und führte 1715 Haematoxylon Campechiamum ein.

Coll. Slodve Herbarium in British Museum.

Lit. T. F. Henderson in Dict. Nat. Biogr. III (1885) p. $186-87$; Britr. and Bodlg. p. 11 ; Pritz. Thes. II ed. p. 14 ; Jacks. Guide p. 509; Unв. Symb. I p. 8.

Barkly, Sir Henry, (ca.1815-1898), war der Reihe nach Gourerneur ron British Guiana, Jamaica, wo er besonders Farne sammelte, Victoria, Mauritius und 1,573-77 ron Cape of Good Hope und starb zu South Kensington in London den 21. X. 1898.

Coll. Kew Herbarium.

Lit. Kew Bull. Nr. 144 (1898) p. $335-336$; Cat. Sc. Pap. IX 1. 124. 
Bandin. Nicolas, (ca. 1750-1803), geb. auf der Insel Ré bei La Rochelle an der Westküste Frankreichs ca. 1750 , leiteto als Schiffskapitän die französische Expedition nach den canarischen Inseh, Trinidad, St. Thomas und Portorico 1796-98 (cf. Lestiv) und eine andere nach A ustralien und Timor 1800-1803, welcher Lsschexudut DE LA Tour als Botaniker und Rindé als Gärtner beigegeben waren. Er starb 16. IX. 1803 auf Isle de France (Mauritius). Der Bericht über die letzte Reise wurde von Pérox, einem der Reisebegleiter, unter dem Titel: Voyage aux Terres australes par les frégates le Géographe et le Naturaliste $1807-9.3$ rol. publicirt.

Coll. Herb. Jussieu und Herb. gener. im Museum zu Paris.

Lit. Esmésard in Michaun Biogr. univ. ane. et mod. III (1811) p. 538-39; Lias. Mus. Deless. p. 271, 490; Pritz. Thes. II ed. p.17; Cat. Sc. Pap. I p. 209 ; Uвв. Symb. I p. $94-95$.

Beaupertuis legte 1839 auf Guadeloupe beträchtliche Sammlungen von Phanerogamen und Kryptogamen an.

Coll. Museum zu Paris, einiges im Herb. Krug et Urb.

Beaurois vergl. Palisot de Beauvols.

Bélanger, Charles Paulus, $(1805-1881)$, geb. zu Paris am 29. V. 1805, erhielt von dem franz. Ministerium der Marine und der Kolonien den Auftrag, sich in Begleitung des Vicomte E. Desbassayss ne Richevost zu Lande nach Pondichéry zu begeben und daselbst einen botanischen Garten anzulegen. Man reiste im Jalluar 1825 von Paris ab, kam durch Deutschland, Polen, Südrussland nach dem Kaukasus und Georgien, wo B. seine botanischen Excursionen begann, ron da nach Persien und Ostindien und Ende März 1826 nach Pondichéry. Von hier aus erforschte er einen beträchtlichen Theil der Halbinsel, begab sich 1827 nach Pegu und Java, kehrte 1828 über Mauritius (Isle de France), Réunion (Bourbon), Capland und St. Helena zurück und traf im Juli 1829 mit umfangreichen Sammlungen wieder in Paris ein. Um 1853 wurde er Director des botanischen Gartens zu Saint-Pierre auf Martinique und starb daselbst den 18. XI. 1881.

Coll. Seine Pflanzen von der asiatischen Reise im Herb. Deufessert in Cenf, eine Anzahl niederer Kryptogamen in Berlin. Die MartiniquePflanzen (ca. 12 Centur., darunter manche aus dem dortigen botanischen Garten) im Herb. Delessire, zu Paris, Florenz, Herb. Fraveuenlle, Cossox (hier die Farne), einiges im Herb. Krug et Urban.

Lit. Сн. Bétanger: Voyage aux Indes-orientales. Historique. Paris 1838. $8^{0}$; Las. Mus. Deless. p. $150-153$; Briefl. Mittheilung von Père Duss; Pritz. Thes. II ed. p. 20. 
Bello y Espinosa, Domingo, $(1817-1884)$, geb, in Laguna auf 'Tenerifa (canarische Inseln) im Jahre 1817, studirte auf der dortigen (später aufgehobenen) Universität San Fernando Rechtswissenschaft, promorirte daselbst zum Dr. jur. und ging 1848 nach Portorico, wo el sich in Mayagüez als Adrocat niederliess. Neben seiner Berufsthätigkeit beschäftigte er sich eifrig mit der Naturgeschichte der Insel, besonders mit der Flora des westlichen Theiles, in den späteren Jahren in Gemeinschaft mit dem Consul L. Krutr. 1878 zog er sich in seine Heimatlı zurück und starb, nachdem er als Commissär seiner Provinz 1880 die Fischerei-Ausstellung in Berlin besucht und bei dieser Gelegenheit auch Studien im botanischen Museum gemacht hatte, im Januar 1884 in seiner Vaterstadt. Ausser den Apuntes para la Flora de Puerto-Rico schrieb er auch über die Flora der canarischen Inseln eine populäre Abhandlung: Un jardin canario, welche zuerst in der Revista de Canarias publicirt, dann als besonderes Werk in der Biblioteca de Canarias abgedruckt wurde und auf den Inseln grosse Anerkennung fand.

Coll. Ein Herbarium hat B. nicht angelegt. Die Originalien seiner Arbeit sind im Herb. Krug im botanischen Museum zu Berlin und in den KRuG'schen Icones niedergelegt.

Lit. Francisco M. Pinto in La Ilustración de Canarias. Santa Cruz de Tenerife 15. II. 1884. Año II Nr. XV (mit Porträt); Cat. Sc. Pap. VII p. 132, IX p. 181; Urb. Symb. I p. 9.

Benzon, Peder Eggert, (178s - 1848), geb. als Sohn des Predigers L. J. Bexzox in Vestenskor auf der Insel Laaland (Dänemark) den 27. X. 17S8, bestand 1814 sein pharmaceutisches Examen, liess sich 1817 als Apotheker in Christianssted auf St. Croix nieder, wurde später daselbst Assessor der Pharmacie und kehrte 1848 nach Kopenhagen zurück, wo er kurz nach seiner Ankunft am 24. VII. starb. Er sammelte hauptsächlich auf St. Croix, ausserdem auch auf St. Jan und St. Thomas. Coll. Botan. Huseum in Kopenhagen (meist mit den Herbaretiquetten von Alfred Bexzos).

Lit. Wanx. in Bot. Tidsskr. Kopenh. XII (1880) p. 121; Kraersk. l. c. XXIII (1900) p. 35; Cat. Sc. Pap. I p. 285.

Bertero, Carlo Guiseppe, (1789-1831), geb. zu S. Vittoria in der piemontesischen Provinz Alba (Italien) im Jahre 1789, studirte zunüchst Philosophie in Alba, dann in Turin Medicin und Naturgeschichte, besonders unter BuLBis Botanik und wurde 1811 zum Dr. med. promovirt. Nachdem er in den folgenden Jahren seine medicinischen Studien mit grossem Erfolge fortgesetzt, auf den Eintritt in das Collegio di Мedicina aber verzichtet und nebenbei eifrig in Piemont botanisirt hatte, begab er sich 1816 über Paris als Schiffsarzt nach Westindien. Er hielt 
sich Ende 1816-1818 auf Guadeloupe, 1818 auf st. T'homas, 1818 bis 1819 auf Portorico, 1819-1820 auf Sto. Domingo (Rio Yaqui etc.) und Haiti (Jacmel, Les Cayes, Port-au-Prince etc.), 1820-1821 in Neu-Granada (Sinta Narta und Barrancuilla an unteren Rio Magdalena) auf und kehrte, gezwungen durch die dortige Revolution, 1821 über Janraica nach Europa zurück. Den Lebensunterhalt hatte er sich mit der Ausübung seiner ärztlichen Thätigkeit verdient. Von den zahlreichen Novitäten, die er besonder's auf Hispaniola entdeckte, sind viele bis heute noch nicht wiedergefunden worden. Die Sammlungen, mit Ausnalme derer von Sto. Domingo und Jamaica, waren von B. selbst in einem starken, jetzt in der Bibliothek des botanisehen Gartens zu Turin befindlichen Bande katalogisirt und beschrieben worden. - In Piemont nahm B. seine botanischen Excursionen wieder auf, legte grosse Sammlungen für eine in Aussicht genommene Flora des Landes an, assistirte Moris bei den Vorarbeiten zu seiner Flora Sardoa und brachte in dessen Auftrage mehrere Monate in Sardinien zu. Nach dem Tode seiner Mutter begab er sich auf Anregung von P. de Cavdolue 1S27 nach Chile und erhielt auch hier die Erlaubniss zu prakticiren. Er ging ïber Valparaiso nach Santiago, von dort südwärts nach Raneagua, nördlich nach Aconcagua, hielt sich längere Zeit in Quillota auf, besuchte, durch die Kriegswirren in Chile in seiner Thätigkeit behindert, Anfang 1830 mit A. Caldcleugh auf drei Monate Juan Fernandez und kam mit 300 dort gesammelten Pflanzenarten nach Chile zurück. Am 28. Sept. 1830 segelte er mit dem nordamerikanischen Generalconsul auf den Societätsinseln J. A. Moвrexhout nach Tahiti, legte auch hier umfangreiche und sehr interessante sammlungen an und verliess die Inselgruppe am 9. April 1831 auf einem kleinen Fahrzeuge, welches auf der Falırt nach Valparaiso versclioll.

Coll. B.'s piemontesisches Herbar ist im naturhistorischen Cabinet des R. Istituto tecnico in Turin. - Die Pflanzen von Westindien und Neugranada nahm Prof. Balbis in Empfang und vertheilte sie, nachdem ein grosser Theil von Curt Srrievaen in Halle recht obertlächlich bestimmt worden war, an die Interessenten. Die Hauptsammlung ist im Herbar des botanischen Gartens zu Turin, die zweite erhielt de CAxpolte, andere sind in Berlin (dreifach: direct, ex herb. Kuхтн und im Herb. Kreqg et Urbax ex herb. Sprexgel), Paris, Florenz, München, WÜ̈rzburg, Bologna, herb. Frixquevilue (jetzt Drake del Castillo in Paris). - Die chilenische Ausbeute wurde an Bexs. Delessert in Paris geschickt und auf den Wunsclı der Erben versteigert; sie ging für 1200 Francs in den Besitz des Reisevereins (Unio itineraria) von Steudel, und Hocnstetter in Esslingen über, welche sie an die Herb. Delessert, de Claddolie, Paris, Berlin, Kew, British Huseum, Cossos 
in Paris, Nancy, Leiden, C.rmbssìder (jetzt in Montpellier), Wluxpd in Marburg etc. verkaufte. - Von den Tahiti-Pflanzen ist ein Theil auf unbekannte Weise abhanden gekommen; der Rest ist in Paris, Turin und im Herb. Delesseret in Genf.

Lit. Biblioteca italiana vol. LXXI (Jul. 1833) p. 125-127; Hook. et Arv. in Hook. Bot. Mise. III (1833) p. 303; Ann. des Se. nat. II sér. vol. I (1834) p. 254 ; Poepp. et Endu. Nov. Gen. I (1835) p. II; Gutllexirn in Aun. Sc. nat. II sér. VI (1836) p. 297; L. ColLA: Elogio storico dell' Accademico Dottore Carlo Bertero in Mem. della reale Accademia delle Scienze di Torino ser. II vol. I (1839) p. 123-141; Las. MIus. Deless. (1845) p. $260-263$, 287; E. Burv. in Bull. Soc. bot. de France XXX (1883) p. CXII; P. A. Saccardo La Botanica in Italia (1895) p. 28; F. Johow Estud. sobra la Flora de Juan Fernandez (1896) p. 20-23; die westindische Reiseroute als Correctur der irrthümlichen Angaben CoLLA's nach Herbaretiquetten und nach briefl. Mittheilung des Herrn Prof. C. Mattrodo in Turin aus Bertero's Msc.; Pritz. Thes. II ed. p. 25; Cat. Sc. Pap. I p. 308.

Blain, José, Schwager von F. Sauralle und Freund ron JoH. Guxduchc1, lebte um 1855 auf der Besitzung Retiro im Distrikte Santa Cruz de los Pinos auf Cuba.

Coll. Es existirt ron ihm (a. 1850?) eine Sammlung von der Insel Pinos (an der Südküste von Cuba gelegen), welche von S.uvalue an Cir. WRIGHT weitergegeben wurde und jetzt im GRsY-Herbarium zu Cambridge sich befindet; Doubletten im Field Columbian Museum zu Chicago, die neuen Arten auch im Herb. Krug et URB.

Lit. Mrrlsp. in Field Col. Mus. Bot. I (1900) p. $425-439$ (Aufzälılung der Pflanzen von Pinos); Urs. Symb. III p. $6-7$.

Blauner, Bernhard Friedrich, (? - 1853), ein Schweizer, sammelte 1852-1853 auf Portorico hauptsächlich in der Ungebung der Hauptstadt San Juan, bei Hunncao, wo er die Gastfreundschaft seines Landsmannes S.xpoz-Cunier genoss, und in der Sierra de Luquillo Pflanzen und Thiere, besonders Mollusken, besuchte wiederholt St. Thomas und Vieques und starb am 3. IX. 1853 in Humacao an der Auszehrung.

Coll. (ca. 31/2 Centur.) Herb. de Caxdolle, Bolssier-Barbey in Genf, Meisswer (jetzt in New York).

Lit. R. J. Shutrlewortir: Beiträge zur näheren Kenntuiss der Landund Süsswasser-Mollusken der Insel Portorico in Mittheil. der naturforsch. Gesellsch. Bern 1854 p. 33.

Blodgett, John Loomis, (1809-1853), geb. zu South Amherst in Massachusetts (U. S. A.) im Jahre 1809, erhielt zu Pittsfield sein medicinisches Diplom, lebte anfänglich in Ohio, dann in Mobile (Alabama) und ging darauf als Arzt der Mississippi and Louisiana Colonization Society auf zwei Jahre nach Liberia. Nach seiner Rückkehr liess er sich im December 1838 auf Key West als Arzt und Drogist nieder 
und blicb hier fast bis zu scincm Tode, weleher 1853 zu Amherst elfolgte. B. war einer der ersten Botaniker (ef. CAbanIs), welelier dic im Süden von Florida gelegenen Kícy-Iuseln erforschte; seiue Sammlungen schickte er an Tombey und NutThl, dic verschicdene seiner Entdeckungen in der Fortsetzung von Miculux's Sylva 1842 publicirten. In den letzten Jahren seines Lebens widmetc or sich besonders den Mecresalgen.

Coll. Columbia Univ. zu New York, Gray-Herbarium zu Cambridge, Kow; Algen in Dublin (ex herb. Hurver).

Lit. SARgent Silva I p. 34 .

Boldo, Baitasar Manuel, (? - 1799), Arzt und Botaniker aus Aragonien, wurde im Jahre 1796 an botanischen Garten in Madrid angestellt, un die Nutzbarkeit der dort cultivirten Pflanzen zu untersuchen, und bald darauf der Commission von Guantánamo beigegeben, welche unter der Leitung des Brigadiers Grafen von Moupox y Jaruco die Pläne des projectirten Canals von Güinas auf $\mathrm{Cuba}$ cntwerfon sollte. Er erhielt den Auftrag, der Pflanzenwelt seine besondere Aufmerksamkeit zuzuwenden, sammelte zahlreiche Materialien zu ciner Flora der Inscl und liess die interessantesten Pflanzen von dem der Expedition beigegebenen Zeichner Još́ Guto malen, bis iln ein vorzeitiger Tod in Jalıre 1799 zu Habana dahinraffte.

Coll. Generalherbar des botanischen Gartens zu Madrid, einiges in Herb. Delile in Montpellier.

Lit. Colmerro Botán. Iispano-Lusitana (1858) p. 186-187; F. CALCAgno Dice. biogr. Cubano (1878) p. 120; Urib. Symb. I p. 13-14.

Bonani, Sebastián, sammelte um 1833 in Cuba für Ramon DE LA Stara (vergl. diesen).

Bonpland, A imé Jacques Alexandre (hiess ursprünglich Gousud, von seinem Vater wegen seiner Vorlicbe für Pflanzencultur Bon-plant genannt, welchen Namen er für immer beibehielt), (1773-1858), gcb. zu La Rochelle (Frankreich) den 29. VIII. 1773 als Sohn eines Arztes, studirte auf dessen Wunsch in Paris Medicin, wandte sich aber mit besonderer Vorliebe der Botanik zu, die er im Jardin des Plantes bei Desfontaintes, L. Cl. Ricinard und A. L. Jussieu hörte. Seine Begierde, ferne Länder botanisch zu erforschen, glaubte er am besten als Schiffsarzt befriedigen zu könuen. Nachdem or deshalb seinc Studien auf der Ecole de médecine narale zu Rochefort beendigt hatte, wurde er Hülfschirurg auf dem Schiffe Ajax. Da die französischen Escadres damals aber die Rhede nicht verliessen, so fand cr sich in seinen Hoffnungen getäuscht und nahm den Abschied. In Jahre 1798 lernte er in Paris A. vox Hunizordt kennen und liess sich von diesem bestimmen, ihn auf der Reise im tropischen Amerika zu begleiten (vergl. HuniвoLDT). 
Auf dieser Reise (1799-1804) sammelte er in Gemeinschaft mit letzterem ein Herbar von ca. 6200 Pflanzenarten, die sie an Ort und Stelle untersuchten und grösstentheils mit ausführlichen Beschreibungen versahen. Nur ein verhältnissmässig kleiner Theil der Ausbente wurde in der Monographie der Melastomaceen und in den Plantae aequinoctiales von Нuмвоцдт und B. selbst publicirt; die Durcharbeitung des gesammten Iaterials führte K. S. Kuxtu aus. B. erhielt die Aufsicht über die Gärten von Malmaison und des Schlosses von Navarra, welche er, auf das nachhaltigste von der Kaiserin Josermxe unterstützt, zu hoher Blüthe brachte und in ihrem Bestande auch durch Reisen nach Berlin und Wien ausserordentlich bereicherte. Leider gingen diese prächtigen Schöpfungen, über welche er 1813 ein illustrirtes Werk veröffentlicht hatte, aus Mangel an Fonds einem schnellen Verfalle entgegen, als die Kaiserin im Mai 1814 gestorben war. Dies verleidete B. den Aufenthalt in Frankreich derartig, dass er 1816 nach Südamerika auswanderte. Er verdiente sich anfänglich seinen Lebensunterhalt in Buenos Aires als Arzt, erwarb sich dann ein Landgut zu Santa-Anna in der Prov. Corrientes, wo er hauptsächlich Mate cultivirte, und begann wieder Pflanzen zu sammeln. Ende 1821 aber wurde er von den Dictator von Paraguay Fraxcis, der ihn als Spion betrachtete und auf seine Matecultur eifersüchtig war, gefangen genommen; sein Etablissement wurde vollständig zerstört. Nach fast zehnjähriger Internirung in den Misiones zwischen S. Maria und S. Rosa erhielt er im Febr. 1831 die Freiheit wieder, liess sich in S. Borja in Rio Grande do Sul nieder und betrieb hier die ärztliche Praxis, Landbau und botanische Studien. 1853 siedelte er auf sein altes Gut Santa-Anna in Corrientes über, wo er am 11. V. 1858 starb.

Coll. Hauptsammlung der tropisch-amerikanischen Reise im Museum zu Paris, Doubletten in Berlin (ex Herb. Kuxtn und in Herb. Wildoexow), einiges im Herb. Delessert; die Pflanzen aus dem extratropischen Südamerika in Paris.

Lit. Las. Mus. Deless. p. $452-453$; Bonplandia II (1854) p. $259-263$, IV (1856) p. $1-3$ (mit Porträt); H. Klencke: Alexander von Hunboldt. IIt. Aufl. 1859 p. $245-254$; Ad. Brunel: Biographie d'Aimé Bonpland. III éd. Paris 1871. $8^{\circ} .183$ p. mit Porträt; A. Errnst: Amadeo Bonpland in Soc. cienc. fis. y nat. de Caracas 1869. $8^{0} .17$ p.; Drake Dict. Amer. Biogr. p. 103 ; Henss. Biol. IV p. 122 ; León Bibl. Bot. Mexic. (1895) p. $66-67$, 340 - 343; Pritz. Thes. II ed. p. 35; Jacks. Guide p. 221 ; Cat. Sc. Pap. 1 p. 486 ; Urb. Symb. I p. 67.

Boos, Franz, (1753-1832), geboren zu Frauenalp in Baden den 23. XII. 1753 als Sohn eines Oberhofgärtners in Rastatt, trat 1771 bei der Fürstl. Diftricnstens'schen Verwaltung zu Selowitz in Mähren ein, war 1774-1775 Gartengehülfe beim Fürsten Liecutexsteix zu Eisgrub 
in Mähren und wurde 1776 Gehülfe am k. Hofgarten zu Schömbrum. In Jahre 1783 begleitete er als Gärtner die österreichische Expedition unter F. J. Mänтв in die südösthichen Vereinigten Staaten von Nordamerika, ging mit diesem und Dr. Jon. D.ı. Scнör im Mär\% 1784 nach Providence auf den Bahamas und machte von dort Ausflüge nach mehreren anderen Theilen der Inselgruppe. Am 9. Sept. verliess er die Bahamas, kehrte nach Charleston in Carolina zurück und führte seine Sammlungen (meist lebende Pflanzen) im Mai 1785 nach Wien ïber. Die Ausbeute war so vortrefflich, dass B. rom Kaiser Jostru II. bald darauf den Auftrag zu einer Reise nach Südafrika erhielt; als Gehülfe beim Pflanzensammeln war ihm der Gärtner Georg Scnolt aus Weilbach beigegeben. B. sammelte vom Mai 1786 bis Februar 1787, oft in Begleitung des englischen Reisenden MAssox, im Caplande bis Zwartiland und den Karroo's lebende Pflanzen, Zwiebeh, Samen, Vögel, Insekten und dergl., ging von da, während Scholt durch eine eigenthümliche Verkettung von Umständen bis 1799 in Südafrika zurückgehalten wurde, in April 1787 nach Mauritius (Isle de France) und Réunion (Bourbon) und kam über Capstadt im August 1788 mit einem ungeheuren Transporte von Vegetabilien und Thieren wieder in Schönbrunn an. Nach dem Tode vax der Schoot's 1790 wurde B. Director der Menagerie und des Gartens in Schönbrunn, 1807 Director der k. k. Hofgärten in und bei Wien, trat 1827 in den Ruhestand und starb 23. II. 1832 in Wien.

Coll. Meist lebende Pflanzen in den Schönbrunner Gärten; viele derselben wurden von JAcQUiN beschrieben und illustrirt.

Lit. Jace. Hort. Schoenbr. I p. IV-V, Hominz's Arch. für Geogr. VI (1815) p. 756 - 758; Wurzbacn Biogr. Lexik. II (1857) p. 61-62; Las. Mus. Deless. p. 449, 459-460; Pritz. Thes. II. ed. p. 35 ; M. Kronfeld in Allg. Zeitung, München Juli 1891 Nr. 175 (unter Zngrundelegung eines Msc. in der Bibliothek dos Wiener botan. Gartens: Biogr. Notizen über Franz Boos von seinem Sohne Josepu Boos 1S64) n. v.; M. Kronfeld: Schönbrunn Mse., ans welchem mir der Verf. die betreffende Partie gütigst zur Verfügung stellte; A. Unlauft in Wetrsters: Die botanischen Anstalten Wiens (1894) p. $38-40$.

Borgesen, Frederik Christian Emil, $(* 1866)$, geb. in Kopenhagen den 1. I. 1866, studirte Botanik daselbst und machte von Jan. bis April 1892 und mit O. W. PaUlser von Dec. 1895 bis Febr. 1896 Studienreisen nach St. Thomas, St. Jan und St. Croix. In den Sommern 1895, 1896 und 1898 besuchte er die Faröer-Inseln, um Meeresalgen zu sammeln. B. ist jetzt Bibliothekar am botan. Garten zu Kopenhagen.

Coll. Botan. Museum zu Kopenhagen.

Lit. Knaersk. in Bot. Tidsskr. Kopenh. XXIII (1900) p. 37; Urb. Symb. I p. 14, III p. 2. 
Bosque, Alfredo B. y Reyes, (185S-1895), geb. in Limonar bei Matanzas (Cuba) den 2. VIII. 1858, studirte an der Universität zu Habana, wurde 1887 Doctor der Pharmacie, 1893 Licentiat en Ciencias und darauf Professor der descriptiven Botanik an der Universität, starb aber schon den 23. XII. 1895 zu Habana.

Coll. Herb. Krug et Urbax.

Lit. Briefl. Mittheilung von G. DE LA MLazA; Urb. Symb. I p. 15.

Brace, Lewis Jones Kuight, war auf den Bahamas in dem New Providence Asylum zu Nassau angestellt und sammelte im Auftrage des Gouverneurs H. E. W. Roвnsox und mit Unterstützung der englischen Regierung 1877-1880 die Flora der Insel. 1886 wurde er Assistent am botanischen Garten zu Calcutta und lebt jetzt wieder in Nassau auf den Balıamas.

Coll. Kew Herbarium (525 Nr.).

Lit. Kew Rep. for 1880 p. 30 ; Cat. Sc. Pap. IX 1. 326-327; Uri. Symb. I p. $54-55$.

Bradford, Dr., sammelte $1845-1846$ auf 'Trinidad besonders Urchideen.

Coll. Herb. Kew (ex herb. Hixce).

Lit. Briefl. Mittheilung von Coginiaux.

Bredemeyer, Franz, (1758-1839), begleitete als Gärtner die österreichische Expedition unter F. J. MIALRTER 1783 in die südöstlichen Vereinigten Staaten von Nordamerika und brachte den ersten Transport lebender Pflanzen Jitte 1784 nach Wien. Ende 1784 wurde er mit dem Gärtner Jos. Schüchт zum zweiten Male ausgeschickt, kam über Martinique nach Haiti, suchte hier Maerter auf und sammelte dann 6 Monate lang (Aug. 1785 bis Febr. 1786) in Portorico. Nach Haiti zurückgekeln't wurde er kurz darauf mit Scnücnт nach Venezuela gesandt, von wo beide nach fast zweijähriger Thätigkeit mit reichhaltigen Sammlungen über Curaçao am 12. Sept. 1785 wieder in Wien eintrafen. B. wurde 1793 Hofgïrtner und Aufseher der Obst- und Parkanlagen zu Schönbrunn, 1827 als Nachfolger von Boos Director der k. k. Hofgärten und der Menagerie in Schönbrunn und starb daselbst den 17. V. 1839.

Coll. K. k. Hofmuseum in Wien; Herb. WiLLderow im Botan. Museum zu Berlin.

Lit. JacQ. Hort. Schoenbr. I (1797) p. IV-V; W'rlud. in Nene Schrift. Gesellsch. Naturf. Freunde Berlin III (1801) p. 405; Las. Mus. Deless. 459 - 460; Linden et Planch. Trois. Voy. de M. Linuen [ (1863) p. XXXiX; Pritz. Thes. II ed. p. 39; A. Unzauft in WetTsteln: Dic botamischen Anstalten Wiens (1894) p. 38; Briefl. Mittheilung der Herren Dr. M. Kronfeld und Director A. Uylauft in Wien. 
Breutel, Johann Christian, (1788-1875), geb. in Weissenburg an Sand in Mittelfranken (Deutschland) den 21. I. 1788, erhielt seine Erziehung in Ebersdorf (Reuss), wurde Mitglied der Brüdergemcinde und erlernte die Handschulmacherei. Als Verwalter des äussern Haushaltes der Gemeinde war er 1814-1819 in Guadenfrei (Schlesien), 1819 - 1824 in Neuwied (Rheinprovinz), 1824 - 1832 in Nicsky (Niederschlesien) und als Nitglied der Dircetion 1832-1857 in Berthelsdorf bei Herrnhut thätig. In dieser Stellung machte er zwei grösserc Visitationsreisen, und zwar vom Dec. 1840 bis Juli 1841 nach St. Thomas, St. Croix, St. Jan, St. Kitts und Antigua und 1S53-1854 nach Südafrika. 1853 wurde er Bischof der Brïderkirche, trat 1857 in den Ruhestand und starb 18. II. 1875 in ILerruhut. Dic von B. auf seinen Reisen gesammelten Pflanzen waren hauptsächlich Kryptoganen. Auch besorgte er die Fortsctzung des kryptogamischen Theiles der ron H. G. L. Reichenb.ici herausgegebenen Flora germ. exsicc. von Centuric III an.

Coll. Von den Farnen erhielt G. Kunze (jetzt im Lcipziger Herbar), von den Lebermoosen Goтtscie (jetzt im Berliner Museum) dic erste Doublette; eine grosse Moossammlung (310 Nr.) von B. befindet sich im British Museum. Anderc Sammlungen sind in den städt. naturhist. Museen von Bremen und Lübeck, Bot. Nuseum zu Breslau, im Herb. Hienonvars (jetzt in Berlin) etc.

Lit. Briefl. Mittheilung des Missionsdirectors G. Burkinanot in Berthelsdorf; Reg. Flora XXXII (1849) p. 525; Cat. Sc. Pap. I p. 612; Urb. Symb. [ p. 16.

Broadway, Walter Elias, (* 1863), geb. zu Exbury in Hampshire (England) den 3. V. 1863, war 1884-1888 Gärtner im botanischen Garten zu Kew, 1888-1894 Assistant Superintendent am Garten zu 'Trinidad und ist seit Juli 1894 Curator der botanischen Station zu Grenada.

Coll. Die Grenada-Pflanzen umfassen bis jetzt $1553 \mathrm{Nr}$. Herbarium zu Kew, Ḱrug et Urbas; die 'Trinidad-Pflanzen in erster Linie im Bot. Gard. Herb. zu Trinidad.

Lit. Briefl. Mittheilung ron B.; Unb. Symb. I p. 16-17.

Bromfield, William Arnold, (1801-1851), geb. zu Boldre in the New Forest in der Grafschaft Hampshire (England) im Jahre 1801, studirte an der Universität Glasgow Medicin, widmete sich dann aber dem Studium der Flora von Grossbritannien, besonders von der Insel Wight, von welcher er auch cine Flora verfasste, und machte grössere Reisen: $1826-1830$ durch Mittelcuropa, 1844 nach Westindicn, bcsonders nach Trinidad, wo cr mit Lockset, und Jamaica, wo er mit Macfidpex und Purpie Excursionen machte, 1846-1847 nach Nord- 
amerika von Canada bis New Orleans und St. Louis, 1850 nach Aegypten bis Chartum und Syrien und starb in Damascus den 9. X. 1851 am Typhus.

Coll. Kew Herbarium; sein eigenes Herbar in Ryde auf der Insel Wight.

Lit. Hook. Journ. of Bot. and Kew Gard. Misc. III (1851) p. 373-382; Proc. Linn. Soc. II (1852) p. $182-183 ;$ B. D. J CCKSoN in Dict. Nat. Biogr. VI (1886) p. 398 - 399 ; Britr. and Boulg. p. 23; Pritz. Thes. II ed. p. 41;

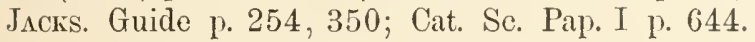

Browne, Patrick (ca. 1720-1790), geb. zu Woodstock in der Grafschaft Mayo in Irland ca. 1720, machte bereits 1737 eine Reise nach Antigua, musste aber wegen Krankheit nach Europa zurückkehren. Er studirte darauf in Paris Naturwissenschaft und besonders Botanik, setzte seine Studien in Leiden fort, wurde hier mit Grovovius bekannt und 1743 zum Doctor Medicinae promovirt. Nachdem or zwei Jahre in London seinen ärztlichen Beruf ausgeübt hatte, ging er nach Westindien, besuchte Barbados, Montserrat, Antigua, St. Christopher (St. Kitts) und liess sich 1746 in Jamaica als Arzt nieder. Alle seine freie Zeit verwendete er auf die naturhistorische Erforschung der Insel, besuchte sümmtliche Theile derselben (vielleicht mit alleiniger Ausnahme von Hanover) und kehrte 1755 mit ca. 1200 an Ort und Stelle beschriebenen Pflanzenarten und zahlreichen Thieren nach England zurück. Schon im folgenden Jahre erschien sein Hauptwerk: The eivil and natural history of Jamaica. Später soll er noch einmal in Westindien, lrauptsächlich in Montserrat und Antigua gewesen sein und reichhaltige Sammlungen angelegt haben, die er an Prof. EDw. Hrut in Dublin abgab; bei der Rückkehr 1781 sei aber seine Bibliothek zu Grunde gegangen. In Irland, wohin er sich später zurüickzog, beschäftigte er sich hauptsächlich mit der dortigen Flora und Fauna, schrieb über die Vögel und Fische der Insel, verfasste einen nicht publicirten Katalog der Pflanzen seiner Heimath und starb den 29. VIII. 1790 in Rushbrook in der Grafschaft Mayo.

Coll. B.'s Pflanzen sind im Lixwé'schen Herbar in der Linnean Society in London, einiges im Herb. Basks im British Museum.

Lit. A. B. Lambert in Trans. Linn. Soc. IV (1798) 1. 31-33; Las. Mus. Deless. p. 488; T. F. Henderson in Dict. Nat. Biogr. VII (1886) p. 53 (ex Walker's Hibernian Mag. 1795 pt. II 1. 195-197); Britт. and Boulg. p. 25; O. Krze. Rev. I (1891) p. XXXIV-XXXV; Pritz. Thes. II ed. 1.44; Jacks. Guide p. 370 ; Ure. Symb. I p. $18-28$, III p. 5.

Brummel, H. ef. Cn. IVright.

Buch, Wilhelm, (* 1862), geb. zu Koenig im Odenwalde in Hessen (Deutschland) den 19. VI. 1862 , studirte 1886-1888 Pharmacio am 
Polytechnikum in Darmstadt, hörte Botanik bei Dır'res und conditionirte nach bestandenem Staatsexamen in Cannes, Florenz und Wieshaden. 1892 ging er nach Haiti und sammelte seit 1s99, anfänglich im Verein

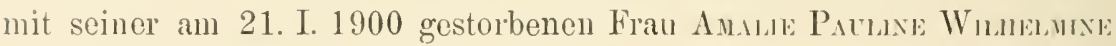
geh. Disek, verw. Baronin ron Liliex.

Coll. Herb. Krute et Urbar (bis jetzt $601 \mathrm{Nr}$.).

Lit. Briefl. Mittheilung ron B.

Buequet, Kapitän der Marine-Infanterie, sammelte um 1877 auf der Insel Marie Galante 66 Arten in 145 Exemplaren.

Coll. Juseum in Paris, einiges im botan. Garten zu St. Petersburg and im Herb. Kríg et Urbas.

Cabanis, Jean Louis, (*1816), geb. zn Berlin den 8. III. 1816, durchforschte in den Jahren 1839-1841 hauptsächlich Süd-Carolina, sammelte aber nur zoologische Gegenstände. Er wurde 1842 Assistent, 1849 Custos am Museum für Naturkunde zu Berlin, verfasste eine Reilie gediegener ornithologischer Arbeiten und lebt seit $1892 \mathrm{im}$ Ruhestande. Die unter seinem Namen gehenden Pflanzen der südöstlichen Vereinigten Staaten, besonders ron Florida und Key West, fand C. auf seiner Reise bei einem Apotheker PAxtsxis auf; sie waren ron einem kurz vorher verstorbenen deutschen Botaniker, lessen Name leider unbekannt geblieben ist, gesammelt und lıätten sclın damals, wenn bearbeitet, die interessanten Beziehungen der Flora ron Süd-Florida zu Westindien nachweisen können.

Coll. Bot. Museum zu Berlin.

Lit. Briefl. Mittheilungen von C. und Prof. MöBrus.

Caley, George, (1770 - 1829), geb. zu Craven in Yorkshire (England) im Jahre 1770, besuchte die Schule zu Manchester und wurde dann Pferdebursche bei seinem Vater. Bei seiner grossen Vorliebe für die Botanik setzte er sich mit Sir Jos. Barks in Verbindung, der ihn nach Australien schickte. In den Jahren 1799-1810 legte er in New Sonth Wales rortreffliche Herbarien und zoologische Sammlungen (diese jetzt im Besitze der Linnean Society in London) an und sandte auch Samen und lebende Pflanzen von dort nach Kew; über Rio de Janeiro kehrte er 1811 nach England zurück. 1816-1822 war er Superintendent des botanischen Gartens in St. Vincent, bis dieser anfgehoben bez. nach Trinidad rerlegt wurde. Er blieb noch bis Mai 1823 auf der Insel und starb den 23. V. 1829 zu Bayswater in England.

Coll. Kew, British Museum, die Pflanzen ron St. Vincent bes. im Herb. Delessert in Genf (ex herb. A. B. Linibert).

Lit. Locnox's Mag. of Nat. Hist. II (1829) p. $310-312$, III (1830) p. $226-229$; Lus. Mus. Deless. p. 278-279; I. Surru in Gard. Chron. 
KXIV (1885) p. 263; Britt. and Botlg. p. 30; Kew Bull. 1891 p. 303, 1892 p. $97-98$, Add. Ser. I (1898) p. 92.

Campbell, Eugène J. F., gehörte bis 1896 dem Botanical Department zu Jamaica an und zwar als Superintendent ron Hope Garrens 1856-18s7, vou Kings House Garden 1887-1890, 1892-1896 und ist jetzt Curator der botanischen station zu British Honduras.

Coll. Vergl. unter FATCETT.

Lit. Briefl. Mittheilung ron W. FAwсEтT.

Catesby, Mark, (1679 oder 1680-1749), geb. zu Sudbury in Suffolk (England) im Jahre 1679 (oder 1680), studirte in London Naturwissenschaft, bereiste $1712-1719$ Virginien und $1722-1726$ mit Unterstützung von Sir Hixs SLoıve und Dr. Sher.rd Carolina, Georgien, Florida und die Bahamas. 1725-1726 hielt er sich auf Providence (Bah.) auf und bestchte ron hier aus Eleutlera, Andros, Abaco und einige andere benachbarte Inseln. Die Abbildungen zu seinen Hauptwerke (1731-1743) hatte er an Ort und Stelle nach frischem Materiale gezeichnet und später selbst auf den Stein ïbeltragen. Er starb zu London den 23. XII. 1749.

Coll. Herb. Sherard in Oxford, Herb. Stodxe im British Mruseum: auch soll sich eine Sammlung im botan. Garten zu Chelsea befunden haben (ex Lis. Mus. Deless. p. 324).

Lit. Las. Mus. Deless. p. 458; Drake's Dict. Amer. Biogr. p. $170-171$; E. Fourvier in Baill. Dict. I p. 655; R. Huxt in Dict. Nat. Biogr. IX (1887) p. 281; Britt. and Boulg. p. 32 ; Sarg. Silva VI 1. 16; Pritz. Thes. II eil. p. 58 ; Jacks. Guide p. 110,362 ; Urb. Symb. I p. $29-30$.

Chapman, Alrin Wentworth, (1S09-1S99), Dr. med., geb. in Southampton, Mass (U. S. A.) den 2S. IX. 1S09, graduirte 1830 zu Amherst, brachte einige Zeit als Lehrer in Georgia und Nord-Carolina zu und absolrirte seine medicinischen Studien in Lonisville, Kentucky. 1835 liess er sich in Florida (anfänglich iu Quincy, dann in Marianua und seit 1847 in Apalachicola) als Arzt nieder und starb an letzterem Orte am 6. IV. 1899, nur wenigen Botanikern persönlich bekannt geworden, un so mehr aber durch seine Flora of the Sonthern United States.

Coll. Cr.'s Originalherbarium, auf welches seine Flor'a sich gründete, erwarb um 1876 das Columbia College zu New York; ein zweites Herbarium, das als Grundlage fül die beiden folgenden Auflagen seiner Flora gerlient hatte, ging sammt der Hauptmasse seiner Bibliothek um 1896 in den Besitz des Biltmore Herbariums in Nord-Carolina über.

Lit. Sarg. Silva VII p. 110 ; W. Trelease: Alvin Wentworth Chapany in The Amer. Natur. XXXIII (1899) p. $613-616$ (mit Bild); Cr. Monr: A. W. Chapmax in Bot. Gazette XXVII (1899) p. $473-478$ (mit Bild); Pritz. Thes. II ed. p. 61; Jacks. Guide p. 361 ; Unв. Symb. I p. $30-31$. 
Chrismar, von, war Salinenverwalter und machte 1849 eine Reise nach St. Thomas, Campêcho, Mexico (bes. Mechoacan) und Nordanlerika.

Coll. Museum zu Berlin.

Clemens, Rev. Thomas, sammelte 1890 - 1891 eine Anzahl Pflanzen auf Tobago.

Coll. Herb. Krug et Urb. (29 Nr.).

Combs, Robert, (1872-1899), geb. in Lyon County in Kansas (Nordamerika) im Jahıre 1872, graduirte an der Kansas Universität in Pharmacie und am Jowa State College in den Wissenschaften und assistirte hier im Department of Botany. Vom Mai 1895 bis April 1896 (nit Ausnalıme der Monate October und November) sammelte er im Districte von Cienfuëgos an der Südküste von Cuba. Nach seiner Rückkehr wurde er Assistent an der Jowa Agricultural Experiment Station und 1898 Field agent of the U. S. Division of Agrostology. Am 11. IV. 1899 starb er in Phoenix in Arizona an der Schwindsucht.

Coll. Hauptsammlung (ca. 71/2 Cent.) in Herbarium des Jowa State College zu Ames, ging Ende 1900 durch Feuer zu Grunde; die übrigen (nach der grösseren oder geringeren Vollständigkeit geordnet) im Gray Herbarium in Cambridge, Bot. Museum zu Berlin, Missouri Bot. Garten in St. Louis, botan. Garten in New York, Kew, Chicago, Kansas Agric. Coll. zu Manhattan.

Lit. The I. S. C. Student. Ames, Jowa, April 18, 1899 vol. XIII no. 7; Urb. Symb. I p. $32-33$.

Commerson, Philibert,(1727-1773), geb. zu Châtillon-les-Dombes im Départ. Aisne (Erankreich) den 18. XI. 1727, studirte 1747-1755 zu Montpellier Medicin und Naturwissenschaften, besonders Botanik, begleitete den Kapitän de Bouganvilue 1767-1769 auf seiner Reise nach Rio de Janeiro, Montevideo, Buenos Aires, Patagonien, den Falklandsinseln, der Magelhaensstrasse, Tahiti, New-Irland, Java, Mauritius (Isle de France). Von hier aus besuchte er 1770 auf vier Monate Madagascar, begab sich im Januar 1771 nach der Insel Réunion (Bourbon), kehrte Ende dieses Jahres nach Mauritius zurück und starb daselbst am 13. III. 1773. Es ist aus den Biographien nicht ersichtlich und auch kaum wahrscheinlich, dass er in Sto. Domingo gewesen ist, obwohl Pflanzen unter seinem Namen von dieser Insel existiren.

Coll. Museum zu Paris. Dupla in Montpellier (ex lerb. CAmbess.), im Ierb. Delessert und zu Lciden. Pflanzen ron Sto. Domingo im Herb. Jussien und im Berliner Museum. 
Lit. Grsene Limn. Praelect. (1792) p. XXIX - XXXVI; Las. Mus. Delessert p. $55-56$; P'. A. GAp: Phimibert Comnerson, Naturaliste Voyageur, Paris $1861.8^{0} .199$ p. (auch Paris $1860.8^{0} .40$ p.); de Lalande: Eloge de Conmersor in Journ. de physique V p. $89-120$, VIII p. $357-363$ (n. v.); Pritz. Thes. II ed. p. 67; Ch. Flahault in Inst. de MIontpellier (1890) p. 37 ; S. P. Oliver in Gard. Chron. III ser. XII (1892) p. $89-90,125-126$, $207-208$.

Cooper. William, sammelte 1859 auf New Providence, Bahamas. Coll. Herbarium des botanischen Gartens zu New York.

Lit. Briefl. Mittheilung von C. F. Millspaugh in Chicago.

Coutance, A., Marine-Apotheker, sammelte vier Jahre (um 1868) auf Martinique und fertigte von allen Pflanzen vortreffliche Abbildungen an. Er lieferte Beiträge zu Husxoт's Glumaceen.

Coll. Ueber den Verbleib seines Herbars ist nichts bekannt.

Lit. Bull. Soc. Linn. de Caen II sér. V p. 251; Jacks. Guide 1. 92, 142, 208, 209, 369; Cat. Sc. Pap. IX p. 591; Urb. Symb. I p. 74.

Cradwick, William, gehört dem Botanical Department zu Jamaica an und war Superintendent von Castleton Gardens 1888 - 89, Hill gardens $1889-91$, Hope gardens $1891-1900$ und ist seit 1900 Travelling Instructor in Agriculture.

Coll. Vergl. unter FAтсетT.

Lit. Briefl. Mittheilung von W. Harris und W. Fawcett.

Crudy, Dr., sammelte vor 1810 auf den Bahamas, St. Thomas und St. Lucia.

Coll. Botan. Museum zu München (mehrere hundert Arten ex herb. Schreber).

Lit. Martius in MIünch. Gelehrt. Anzeig. XXXI (1850) Nr. 89 (ex RADLK. in lit.).

Crueger, Hermann, (1818-1864), geb. in Hamburg den 11. II. 1818, wurde nach dem frühen Tode seiner Mutter bei seinem Oheim, dem Landprediger Fr. Crueger, in Kuhbier in der Priegnitz erzogen, widmete sich dem Apothekerfache, welches er in Lüneburg und Hamburg erlernte, und siedelte 1841 nach Trinidad über, um dort in die Apotheke des Dr. Unici einzutreten. Nebenbei betrieb er Botanik und machte besonders anatomische und pflanzenphysiologische Untersuchungen, die, meist in der Botanischen Zeitung veröffentlicht, ihm unter den Fachgenossen einen sehr geachțten Namen verschafften. Die englische Regierung ernannte ihn nach PurpIE's Tode 1857 zum Gorernment Botanist und Director des botanischen Gartens in Port-of-Spain auf Trinidad, welchen Posten er bis zu seinem Tode bekleidete. Während dieser Zeit widmete er sich mit besonderem Eifer und grossem Erfolge 
der Eirforschung der Pflanzenwelt der Insel, sowohl der Phanerogamen, wie der Kryptogamen, legte ein umfangreiches Herbarium an und machte die Vorarbeiten zu einer Flora, von der sich ein Folioband nebst zahlreichen Zeichnungen in seinem Nachlasse vorfand. Er starb jedoch schon am 28. II. 1864 in San Fernando auf Trinidad bei seinem Freunde Dr. K. Fixich in Folge eines qualvollen Geschwürs an einer Halsarterie. Herbar und Bibliothek gingen in den Besitz des Gouvernements von Trinidad über; ersteres litt aber in der Folgezeit sehr durch Insektenfrass und schlechte Behandlung, bis es von J. H. НАRт 1887 regelrecht montirt wurde.

Coll. Bot. Garten in Trinidad, Kew, Herb. Grisebacu im Bot. Musemm in Göttingen, Herb. Krug et Urbax. - Die grosse Lebermoossammlung im Bot. Museum in Berlin (ex herb. Gortscur).

Lit. Schlechtendal in Botan. Zeitung XXII (1864) p. 119-120; Hart in Ann. Rep. Bot. Gard. Trinidad 1887 p. 11; Pritz. Thes. II ed. p. 72 ; Jacks. Guide p. 376 ; Cat. Sc. Pap. II p. 100, VII p.470; Urr. Symb. I p. 33 - 35.

Cuming, Hugh, (1791-1865), geb. zu West Alvington in Devonshire (England) den 14. II. 1791, hatte schon früluzeitig eine grosse Vorliebe fuil die Naturgeschichte, musste aber das Segelmachen erlernen, kam dabei in Berührung mit Seefahrern und ging mit diesen 1819 nach Valparaiso in Chile. 1826 gab er sein Handwerk auf und widmete sich ganz der zoologischen und botanischen Erforschung des Landes. Mit einer Yacht kreuzte el 12 Monate an den Küsten bis zu den südlichen pacifischen Inseh, um Muscheln und andere Seethiere zu fangen, besuchte Chiloë und bereiste das Innere von Chile von Concepcion bis Coquimbo und die Anden hinauf bis Cumbre. 1831 kehrte er ïber Ecuador, Neu-Granada, Panama und Jamaica zurück. Eine noch ergiebigere Expedition machte er Febr. 1836 bis Nov. 1839 nach den Philippinen (alle Provinzen von Luzon, fermer Corregidor, Mindoro, Panay, Guimarás, Negros, Cebú, Leyte, Samar, Bohol und Mindanao und die islas Visayas). Auf der Rïckreise besuchte er Malacca, Singapore, Sumatra und 1840 auf 12 Tage St. Helena. 130000 Exemplare getrockneter Pflanzen, zahlreiche lebende Orchideen und eine Fülle von Conchylien, Vögeln, Reptilien, Insekten u. s. w. bildeten die Ausbeute. C. starb nach langem asthmatischen Leiden den 10. VIII. 1865 zu London. Seine Conchiliensammlung war eine der grössten der Welt.

Coll. C.'s Pflanzen sind in zahlreichen Museen, besonders die ron den Philippinen, solche ron Jamaica im Wiener Hofmuseum, botan. Garten zu St. Petersburg. - A. DC. Phytogr. p. 405 führt auch Pflanzen von Neuholland und Mexico (aus seinem eigenen Herbar) an; kein Autor erwähnt aber, dass C. dort gewesen sei, auch Hexss. in Biol. IV p. 133 nicht. 
Lit. Las. M[us. Deless. p. 258, 269-270; Athenaeum 1865 II p. 247 bis 248; Gard. Chron. 1865 p. 824 (n. v.); SeEu. Journ. of Bot. III (1865) p. 325 - 326 ; Botan. Zeitg. XXIV (1866) p. 31 - 32; Vidal y Soler Phaner.

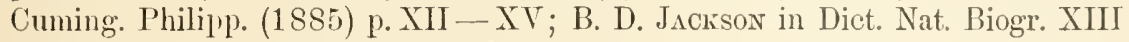
(1888) p. 295 - 296 ; Britt. and Boulg. p. 42 ; Pritz. Thes. II ed. p. 73; Cat. Sc. Pap. II p. $103-104$.

Curtiss, Allan Hiram, (*1845), geb. zu Central Square, Oswego Co., im Staate New York den 9. II. 1845, kam 1862 nach Virginien, begann 1863 bei Alexandria, sowie an den Otter Peaks bei Lynchburg botanisch zu sammeln und mit A. Gray zu correspondiren. Bei seiner Uebersiedelung nach Florida 1875 verkaufte er sein Herbarium an Borssize in Genf. Bald nachher nahm or seine botanische Thätigkeit wieder auf und gab die erste Collection der Southern U. St. Plants heraus (ca. 1500 Species in 7 Jahren). Ausserdem legte er 1878-1879 ein grosses Herbarium für die Universität von Virginien an, präparirte Hölzer für die Philadelphia-Ausstellung, für das Central Park Museum in New York und 1885 für die Ausstellung zu New Orleans sowie für auswärtige Museen. Die so ergebnissreiche Erforschung der Südküste von Florida und der benachbarten Key-Inseln führte er 1880-1881 aus und entdeckte hier zahlreiche Pflanzen als neue Beweise für die Verbreitung der westindischen Flora bis in diese Gegenden. In den folgenden Jalren war er als Herausgeber des Florida Farmer and FruitGrower und Mitherausgeber der Daily Florida Times Union literarisch thätig. Alsdann kehrte er zur Botanik zurück und begann die zweite Ausgabe der Florida-Pflanzen, welche jetzt bis zur sechsten Serie reicht.

Coll. In den meisten öffentlichen und grösseren Privatherbarien Amerikas und Europas.

Lit. Sarg. Silva II p. 50; Briefl. Mittheilung von C.; ?Jacks. Guide p. 366 ; Cat. Sc. Pap. VII p. 473.

Curtiss, Mrs. Floretta A., (*1822), geb. zu Central Square, Oswego Co., im Staate New York den 1. XII. 1822, Mutter des vorigen, hatte seit ihrer Schulzeit ein lebhaftes Interesse für die Botanik und beschäftigte sich in den letzten 20 Jahren sehr eingehend mit der Algen-Flora von Florida. Sie entrleckte verschiedene neue Arten, correspondirte über ilıre Funde mit AGıRDH und präparirte drei Serien von Algen, welche ihr Sohn lierausgab.

Coll. in verschiedenen grösseren Muscen.

Lit. Briefl. Mittheilung von A. H. C.

Dancer, Thomas, (ca. 1750-1811), geb. im nördlichen England ca. 1750, studirte anfänglich Theologie, dann in Edinburgh Medicin, kam 1773 nach Jamaica, begleitete 1779 von hier aus eine Expedition nach Nicaragua, wurde 1781 Arzt an den Bädern zu Bath auf 
J amaica und 1788 Superintendent des Bath Gartens. 1795-1797 hielt er sich seiner angegriffenen Gesundheit wegen in England auf, wurde nach seiner Rückkehr nach Bath Island Botanist, liess sich 1799 als Arzt in Kingston nieder und starb daselbst den 1. VIII. 1811.

Coll. Kew Herbarium und Herb. Delesserert in Genf.

Lit. Gentlem. Magaz. LXXXI. II (1811) p. 390; B. D. JAcks. in Dict. Nat. Biogr. XIV (1888) p. $13-14$; Briтt. and BoulG. p. $44-45$; Journ. Inst. Jam. I (1892) p. 102 - 104 (die Jahreszahleu können unmöglich stimmen), 141 (mit Porträt); Fawc. in Bot. Gaz. XXIV (1897) p. 347-348; Pritz. Thes. II ed. p. 75 ; Jacks. Guide p. 449 ; Urв. Symb. I 1. 35.

Daniell, William Freeman, $(1818-1865)$, Dr. med., geb. in Liverpool (England) im Jahre 1818, war 1841-1853 Militärarzt bei den englischen Truppen in Westafrika. besuchte 1857-1858 die Bahamas, ging 1860 mit der englischen Armee nach China und hielt sich bis 1864 noch einmal in Westindien, besonders Jamaica auf. Er starb den 26. VI. 1865 zu Southampton. Sein Hauptwerk ist: Medical topography and native diseases of the gulf of Guinea. 1 vol $8^{\circ} .1849$.

Coll. British Museum zu London.

Lit. Seemr. Journ. of Bot. III (1865) p. 294; Pharm. Journ. II ser. vol. VII $(1865-1866)$ p. 86 ; Proc. Linn. Soc. $1865-1866$ p. 69 ; B. D. Jacks. in Dict. Nat. Biogr. XIV (1888) p. 35 ; Britr. and Boula. p. 45 ; P'Rirz. Thes. II ed. p. 75 ; Jacks. Guide p. 368 ; Cat. Sc. Pap. II p. 146-147; URE. Symb. I P. 35.

Delessert, Henri, (1815 - 1843), ein Vetter von Benjanis Delessert, sammelte 1838 - 1839 auf Cuba bei Habana und starb daselbst an 1. VII. 1843.

Coll. Herb. Delessert in Genf.

Lit. Las. Mus. Deless. p. 265.

De l'Etang (auch De Létung oder Dhilestaxg geschrieben) sammelte vor 1789 in Haiti.

Coll. Herb. Jussieu und Lamarek in Paris, Herb. de Candomle.

Lit. Layr. Dict. III p. 584; Radlk. Mon. Serj. p. 206.

Descourtilz, Michel Etienne, (1775-1836), geb. zu Boiste bei Pithiviers, Dép. Loiret (Frankreich) den 27. XI. 1775, studirte Medicin, kam im Januar 1799 nach Charleston in Südcarolina, Ende Februar nach Santiago auf Cuba und am 2. April nach Haiti, wo er sich bis 1803 als Arzt und Naturforscher aufhielt. Er bereiste hauptsächlich den nördlichen Theil des Landes von Port-au-Prince bis Cap, verweilte längere Zeit am Flusse Artibonite und legte hier umfangreiche naturhistorische Sammlungen an. Nach Frankreich zurückgekehrt, erhielt er 1814 den medicinischen Doctorgrad, wurde Arzt am Hôtel Dieu zu Beaumont, Präsident der Limné'schen Gesellschaft zu Paris und starb 
1836. Ausser seiner Reisebeschreibung und seiner Flore médicale des Antilles schrieb er über Impotenz und Sterilität, femer einen Guide sanitaire des royageurs aux colonies, über Seekrankheit, gelbes Fieber und Pest, über essbare und giftige Pilze u.s. w.

Coll. Seine Sammlungen wurden von den aufständischen Negem auf Haiti verbrannt, desgleichen ein grosser Theil der Tafeln.

Lit. Briefl. Mittheilung von Prof. F. Hen in Paris; Pritz. Thes. II ed. p. 80 ; Jacks. Guide p. 369 ; Cat. Sc. Pap. II p. 248 ; Urв. Symb. I p. $36-37$.

Desportes, Jean Baptiste René Pouppé, (1704-1748), g'eb. zu Vitré in der Bretagne (Frankreich) den 28. IX. 1704, studirte zu Paris Medicin und wurde ron B. DE Jussieu, dem er auch seine Doctordissertation widmete, in die Botanik eingeführt. Er kam im Jahre 1732 als Arzt nach Cap Français (Haitien) an der Nordküste von Haiti, wurde 1740 Clrefarzt (Médecin du Roi) und Vorsteher des Hospitals daselbst und starb daselbst den 15. II. 1748.

Coll. Herb. Jussieu im Pariser Museum.

Lit. Desp. Hist. malad. de S. Dom. p. 1-14; Moreau de Saint-MÉry Descr. de la partie franç, de l'île Saint-Domingue I edit. Philadelphia (1797) p. 541 ; Pritz. Thes. II ed. p. 81; Urb. Symb. I p. $37-38$.

Despréaux, J. M., (179t-1843), geb. zu Fougères (Frankreich) den 25. XII. 1794, studirte in Paris, trat dann in die Marine ein und kehrte nach dem Sturze N.PoLEox's zum Studium der Medicin zurïck. Im Jahre 1829 begleitete er als Botaniker die wissenschaftiche Expedition unter dem Obersten BoRY de S.nNT-VIxcext nach Morea, sammelte um 1835 auf den canarischen Inseln und begab sich $18+1$ nach Cuba und ron da Anfang 1842 nach Mexico, wo er am 27. XI. 1843 starb.

Coll. Herb. Delessert in Genf.

Lit. Las. Mus. Deless. p. 112-116, 187; Joaquin Garcia Icazmalceta in Museo Mexicano vol. II p. 502 ex León Bibl. Botán.-Mexic. (1895) p. 107 bis 108; Cat. Sc. Pap. II p. 270.

Distin, Dr. Henry, lebte 1810 bis ca. 1840 als Arzt, Sanitätsbeamter und Friedensrichter in Westmoreland auf Jamaica und sammelte besonders $1830-1810$.

Coll. Kew (Herb. Hooker, wo er irrthümlich „Distan" genannt wirl).

Lit. Briefl. Mittheilung von Mr. W. A. Feurtado durch Mr. Frank Cundall in Kingston (Jam.).

Dolley, Charles Sumner, (*1S56), M. D., geb. zu Elyria in Lorraine County, Ohio (U.S. A.) den 16. VI. 1856. Als Professor der Biologie am Swarthmore College 1885-1886 und in gleicher Stellung bis 1892 an der Universität von Pemsylvanien arbeitete er hauptsächlich auf 
dem Gebiete der Zoologie. Während dieser Zeit (um 1887) besuchte er die Bahama-Insel New Providence. Seit 1892 lehrt er die biologischen Wissenschaften, hauptsächlich Botanik, an der Philadelphia High School.

Coll. Herb. der Universität von Pennsylvania.

Lit. Harsmerger: The Botanists of Philadelphia (1899) p. 372 ; Urz. Symb. I p. $39,54--55$.

Don, George, (1798-1856), geb. zu Doo Hillock in Forfarshire (Schottland) den 17. V. 1798, Soln des Superintendenten des botanischen Gartens zu Edinburgh, war 1816-1821 als Obergehülfe am Garten zu Chelsea, besuchte auf der Iphigenie unter Kapitän Subisk als Sammler für die Royal Horticultural Society Brasilien, Westindien (besonders Cuba und Jamaica), Ascension und Sierra Leone (Febr. 1822 bis April 1823). Nach seiner Rückkehr veröffentlichte er monographische Bearbeitungen der Gattungen Allium und Combretum, gab die dritte Auflage von SweEr's Hortus britannicus heraus, setzte Loudox's Encyclopaedia of Plants fort, schrieb A general history of the dichlamydeous plants und starb den 25. II. $1856 \mathrm{zu}$ Bedford Place in Kensington bei London.

Coll. British Museum, Herb. Cambridge (ex herb. Lsxduev), einiges im Herb. Grisebach in Göttingen, die brasilianischen Pflanzen auch im Herb. Mantrus (jetzt in Brüssel). D.'s Privatherbar gehörte MAC NAB in Edinburgh (ex DC. Phyt. p. 408).

Lit. Las. Mus. Deless. p. 376; Proc. Linn. Soc. 1856 p. XXXIX; Cottage Gardener XVI (1856) p. 152 (n. v.); Boulg. in Dict. Nat. Biogr. XV (1888) p. 206 ; Brittr. and Bodlg. p. 50 ; Pritz. Thes. II ed. p. 89; Jacks. Guide p. 116, 407; Cat. Sc. Pap. II p. 314.

Drummond, Thomas, (?-1835), geb. in Schottland, ursprünglich Gärtner in Forfar, interessirte sich schon frühzeitig für Moose und machte sich durch die Exsiccaten-Ausgabe der "Musci scotici“ den Botanikern bekannt. 1825 ging or als Assistent von Dr. J. Richurdsox mit Sir Jomv Frantix's zweiter Land Aretic Expedition nach Nordamerika, kam längs des Ontario- und Winnipeg-Sees bis zum Mackenzie-River und trennte sich 1826 in Cumberland House von den Uebrigen, um die Rocky Mountains zu erforschen. Im Oktober $1827 \mathrm{kam}$ er wieder nach London zurïck und wurde darauf Curator des botanischen Gartens zu Belfast (1828-1829). Im Frühjahr 1831 ging er zum zweiten Mal nach Nordamerika, besuchte die Alleghany Gebirge, kam über St. Louis und New Orleans nach Texas und schiffte sich in Florida nach Cuba ein. Nach kaum einmonatlichem Aufenthalte auf der Insel starb er in Habana im März 1835.

Coll. British Museum, Kew, Edinburgh, Hofmuseum zu Wien, Herb. Delessert in Genf, Fravquevilde (jetzt Drake del Castillo in Paris), 
vis IEtrok in Antwerpen; die Moose ausserdem in Berlin, bei der Akademie zu St. Petersburg, im Herb. DE CAxpolle.

Lit. Ноoк. Bot. Misc. I (1830) p. 178 - 219, Journ. of Bot. I (1834) p. $50-60,183-185$; Froniep's Notizen XXII p. 273, 312 ; Las. Mus. Deless. p. $196-198,204$; B. D. JAcks. in Dict. Nat. Biogr. XVI (1888) p. 41 ; Britt. and Boulg. p. 52 ; Sarg. Silva II p. 25 ; Cat. Sc. Pap. II p. 347.

Duchassaing, Placide D. de Fontbressin, (1818 - 1873), geb, in Moule auf Guadeloupe den 1. XII. 1818 als Sohn eines Grossgrundbesitzer's, kam mit sechs Jahren naclı Paris, wo er im Collège Louis le Grand und in der Ecole de médecine seine Ausbildung erhielt, wurde Dr. med. und Licentiat der Naturwissenschaften und liess sich 1844 in seinem Heimathsorte auf Guadeloupe als Arzt nieder. Neben selı eingehenden zoologischen Studien über Crustaceen, Corallen, Spongien sammelte er sowohl Phanerogamen wie Kryptogamen; ja er gab die Anregung zu der umfasseuden algologischen Erforschung der Insel, welche eine Reihe scharfsichtiger Männer in den folgenden Jahrzehnten ausfülırte (cf. URB. Symb. I p. 106). Er besuchte auch melirere andere Inseln zu Studienzwecken, besonders Désirade und St. Thomas. Nach dem Ausbruche der französischen Revolution 1848 ging D. über Santa Marta nach Panama und griundete eine Maison de santé für Durchreisende und Schiffscapitäne; von hier aus besuchte er auch wiederholt die gegenüberliegende Insel Taboga. Durch Anfeindungen aller Art von da vertrieben, kehrte or 1851 uach Guadeloupe zurück und siedelte später nach St. Thomas ${ }^{1}$ über, wo er bis 1867 als praktischer Arzt thätig war. Die letzten sechs Jahre seines Lebens brachte er in der Heimath seiner Eltern in Périgord in Frankreich zu; hier starb er am 16. IX. 1873. Seit Aufang der fünfziger Jahre luatte er sich ganz der Zoologie zugewendet und reröffentlichte, meist in Gemeinschaft mit Мıпецотт, mehrere wichtige Schriften über Corallen und Spongien; seine letzte Abhandlung ist eine Revue des Zoophytes et des Spongiaires des Antilles, Paris 1870. Auch über die geologischen Verhältnisse von Guadeloupe lat er zwei Aufsätze publicirt.

Coll. Die Hauptsammlung der Phanerogamen von Guadeloupe, Panama und St. Thomas nebst zahlreichen Zeichnungen ging an W. G. Walpkrs in Berlin, der die Bearbeitung derselben begamn, und kam nach dessen Tode durch Kauf in den Besitz Grisebıcu's in Göttingen; eine audere Sammlung erhielt Paris. Das Berliner Museum besitzt fast nur die Guadeloupe-Pflanzen (835 Nr.), sowie eine grosse Sammlung von Algen, Pilzen, Flechten und Moosen von dort. Einiges in Herb. Kew und Krug et Urbax.

1) Die Angaben über die Dauer des letzten Aufenthaltes auf Guadeloupe und St. Thomas stehen bei Duss und SaGot im Widerspruch. 
Lit. Paul Sagot: Notice sur le Docteur Duchassaing in Bull. Soc. bot. France XI (1873) p. 275 - 280; Père Duss: Briefl. Mittheilung; Grisebacir: Novitiae Florae panamensis in Bonplandia VI (1858) p. 3-12; Uns. Symb. I p. 39 et 56 (wo , $1844-48^{\text {" }}$ zu lesen und bei St. Thomas "1850" zu tilgen ist); Cat. Sc. Pap. II p. 358 , VII p. 564.

Duss, Antoine, (*1840), geb. zu Haslé bei Entlibuel im Canton Luzern (Sclıweiz) den 14. VIII. 1840, absolvirte das Gymnasium zu Luzern, braelıte ein Jahr in Freiburg zu, um die französische Sprache zu erlermen, und trat darauf in Paris in die Congrégation du SaintEsprit et du Saint-Coeur de Marie ein. Da er für die Heidenmission zu sehwach war, so schickte man ihn 1865 mach Martinique, wo er zuerst am Collège zu Fort de Franee und seit 1875 zu Saint-Pierre als Professor thätig war. Während er am erstgenannten Orte hauptsäelılieh eonehyliologische Studien getrieben lıatte, wurde er in St. Pierre von dem bekannten Gärtner und Sammler L. Hıнs und dem Direetor des botanischen Gartens Béc.Naer für die Flora der Insel interessirt. In den Jahren 1876-1889 widmete er seine ganze Ferienzeit der Erforschung der Pflanzenwelt, zunäelıst der Phanerogamen und Farne, und maehte zahlreiehe interessante Funde, die von seinen Vorgängern übersehen waren. Auch besuehte er zweimal, $18 S 3$ und 1S55, Dominica und 1885 Sta. Lueia. Im Jahre 1890 wurde er Professor am Collège zu Basse-Terre auf Guadeloupe und untersuchte aueh diese Insel auf das gründlichste und erfolgreiehste, ebenso die kleinen Eilande Désirade, Marie Galante und Saintes, schrieb seine Phanerogamenflora der französisehen Antillen und wandte sich danm fast ausschliesslich den Kryptogamen zu. In den Sommerferien 1899 und 1900 ging er wiederum naeh Martinique, theils um interessantere Phanerogamen in besseren Exemplaren zu beschaffen, theils um die von ihm früher vernaehlässigten Zellenpflanzen dieser Insel einzusammeln.

Coll. Die seit 1882 angelegten Sammlungen mit Ausscliluss von Guadeloupe im Herb. Th. Bernhard, jetzt im Berliner Museum (mit zahlreiehen Verwechselungen der einzelnen Inseln dureh B.). Vollständige Colleetion (4600 Nr.) im Herb. Krug et Urbax. Sandte zahlreiehe Sämereien nach Europa, besonders an Hage if Scumd in Erfurt.

Lit. Briefl. Mittlreilung von D.; Und. Symb. I p. $34-41$, III p. 10, 13.

Dutrône La Couture, Jacques François, sammelte in Haiti 1787. Coll. Museum zu Paris; Dupla in Montpellier (ex herb. Caubess.), einiges in Herb. Krug et Urban.

Lit. Pritz. Thes. I ed. p. 77.

Eggers, Heinriel Franz Alexander Baron von, (*1S44), geb. als Sohn des Polizeidirectors Friedrich BAron v. EgGers in Sehleswig den 
4. XII. 1844, besuchte 1858-1862 das Gymnasium in Odense (Dänemark), studirte darauf in Kopenhagen privatim und trat $186+$ als Officiersaspirant in die dänische Armee ein, in welcher er den Krieg gegen die Deutschen mitmachte. Ende 1864 nahm er Urlaub und liess sich in Laibach in das österreichisch-belgische Corps Kaiserl. mexicanischer Freiwilliger einreihen. Im April 1865 in Vera Cruz angelangt, machte er melırere Expeditionen gegen die mexicanischen Republikaner (Juaristen) mit, wurde Sept. 1865 zum Lieutenant befördert, gerieth aber nach einmonatlicher Belagerung in Oaxaca Oct. 1866 in hiriegsgefangenschaft. Nach seiner Freilassung im April 1867 machte er verschiedene Reisen in südlichen Mexico und kehrte im Nov. d. J. nach Dänemark zurück. Anfang 1868 trat er als Lieutenant wieler in die dänische Armee ein und liess sich $1869 \% u$ den Truppen auf den dänischen Antillen versetzen, wo er 1870 zum Premierlieutenant, 1879 zum Capitän und Compagniechef befördert wurde. Seine Garnison war 1869-1872 St. Croix, $1872-1873$ St. Thomas, $1873-1874$ St. Croix, 1874-1885 St. Tliomas. 1885 trat er mit Pension aus dem Staatsdienst, blieb bis 1887 in St. Thomas und lebt jetzt in Charlottenlund in Dänemark.

E. begann seine für die Kenntniss der Flora der Antillen so erfolgreiche Thätigkeit im Jahre 1870 mit der Erforschung der Insel St. Croix, deren Vegetation er 1876 in seiner St. Croix's Flora (ef. Uri. Symb. I p. 41) schildert und aufzählt. Nach seiner Uebersiedelung nach St. Thomas studirte er auch die Ptlanzenwelt dieser Insel, machte von hier aus Reisen uach Water Island, Vieques und St. Jan und stellte die Resultate seiner Beobachtungen 1879 in seiner Flora of St. Croix and the Virgin Islands (cf. Symb. I p. 42) zusammen. 1880 begann er die Herausgabe der Flora Indiae occidentalis exsiccata. In dieselbe wurden nicht bloss die Pflanzen von St. Thomas aufgenommen, sondern auch diejenigen, welche er auf Dominica $(1880-1883)$, St. Kitts (Dec. 1882), im östl. Portorico (Juni 1881, April, Mai 1883) sammelte und von seinem Diener auf Trinidad (Herbst 1883) sammeln liess. In den Ionaten April bis Juli 1887 machte E. mit Unterstützung der Akadenie ker Wissenschaften in Berlin eine Forschungs- und Sammelreise nach Sto. Domingo, welches von Puerto-Plata aus über Jarabacoa, den Monte Barrero, La Cunbre bis zum Valle nuevo und dem Pico del Valle $(2630 \mathrm{~m}$.) in der Sierra de Cibao erforscht wurde (cf. Symb. p. 45). Auf der Rückreise besuchte er die Umgebung von Cap Haitien in Haiti nnd die südöstliclıste Bahama Turks Island (Grand Turk, 17. Juli 1887), wo die dieser Insel eigenthümlichen Pflanzen wieder aufgefunden wurden. Auf der folgenden Reise untersuchte E. mit Unterstützung des dänischen Karlsbergfonds die Inseln St. Jan und Tortola (Dec. 1887, Jan. 18s8) und ging über St. Thomas, Haiti (Jacmel, 
Port-au-Prince, J'́rémic) nach Jamaica, in dessen östlichem Theile (Guava lidge, Catherines Peak ete.) er Ende Jan. 1888 sammelte. Von la wandte er sich den Bahamas zu, für deren botanische Erforschung die British Association in London eine poknniäre Beilıülfe gewälıt hatte, und besuchte im Monat Februar und in der ersten Hälfte des März 1888 Acklins, Fortune, Long, Hog Island und New Providence. - In den Gebirgen des östlichen Cuba's sanmelte E. vom Febr. bis Mai 1889, besonders am Rio Guaso bei Guantánamo, Arroyo gallego, Rio Seco, La Piedra, El Palenquito, El Jagüey, La Clarita und Sta. Ana, Monteverde (830 m.), La Prenda, Caimanera. - Die Erforschung der kleinen englischen Antillen Tobago, Grenada, St. Vincent, Bequia und Barbados fand rom 20. Oct. 1889 bis 31. Jan. 1890 statt und lieferte für diese mit Ausnahme von St. Vincent noch wenig bekannten Inselı eine rerhïltnissmässig reiche Ausbeute. Diese wie die vorhergehenden Reisen unterstützte der Consul Knug in liberaler Weise durch Vorschïsse und Zahlung eines erhöhten Preises für die erste Nummer. Im Jahre 1891 ging E. über Barbados und Tobago auf Kosten des dänischen Staates nach Venezuela, wo or die Gegend um Caracas besonders bei Sta. Lucia erforsehte. - 1891-1892 hielt er sich in Ecuador auf und untersuchte während sechs Monate das Küstenland um Guayaquil und besonders bei Balao. - 1893 ging er über La Guayra und Curaçao nach Maracaibo in Venezuela, um ein Gutachten über die Asphalt-Lager bei S. Timoteo am Maracaibo-See abzugeben. 1893-1897 war er in Ecuador hauptsächlich in der Prov. Manabi auf der Hacienda El Recreo in der Nähe ron Bahia de Caraquez mit Plantagenwirthschaft beschäftigt und machte in dem botanisch bisher vernachlässigten Küstenlande viele interessante Funde. - 1899 besuchte er noch einmal Trinidad, Tobago und Venezuela, in letzterem Lande besonders die Gegend um Puerto Cabello und Caracas.

Coll. Die nicht numerirten Sammlungen von Phanerogamen und Neeresalgen von St. Croix $(1870-1872,1873-1874)$ wurden dem butanischen Museum in Kopenhagen geschenkt; ein Theil befindet sich auch im Herb. Krou et Urbax. - Die Pflanzen von St. Thomas, Portorico, St. Kitts, Dominica und Trinidad $(1880$ - 1886) sind an fast alle grösseren hotan. Museen und zahlreiche Privatpersonen abgegeben; sie wurden theils von E. selbst versandt (hb. pr.: Nr. 1-1499) und zwar an Kew, die amerik. Museen, theilweise auch an Kopenhagen und Herb. Kring et Urbax, theils von A. TokpfFer in Brandenburg, welcher 11 Centurien mit besonderer Numerirung an die übrigen Museen und PrivatAbonnenten schickte. Die Restbestände der Eagers'schen Ausbeute vertrieb Lanst Berge in Leipzig unter einer dritten Numerirung, während die von C. RExscr in Berlin ausgegebenen Rester des ToEpFrer'schen 
Herbars die ursprüngliche theils ToeprFer'sche, theils Fitids'sche Numerirung beibehielten oder b-Nummern bekamen und ausserdem die 12. Centurie lieferten. Zugleiclı gab E. eine Sammlung Segmenta lignorum Ind. occid. in ca. 350 Arten, sowie Fructus et semina Ind. occid. in ca. 500 Arten heraus. - Die Ausbeute der späteren Reisen wurde von E. selbst vertheilt und hat daher eine übereinstimmende Numerirung; das beste Exemplar derselben nebst allen Unicas befindet sich, soweit Westindien bis 1890 in Betracht kommt, im Herbar Kreg et Urbax, mit Ausnahme derer von St. Jan und Tortola. Die Sto. Domingo-Expedition lieferte die Nr. 1500 - 2861 (und zwar Sto. Domingo 1500-2821, Haiti $2821^{\mathrm{b}}-2845^{\mathrm{b}}$, Turks Island $\left.2846-2861\right)$ und ging an the Herbarien von Kew, Hamburg, Göttingen, Breslau, Leiden, München, de Caxdolle in Genf, Dr. Schrader (jetzt geol. Landesanstalt in Berlin), Prof. Kurtz-Córdoba, J. F. Hammiox-London, Forstinstitut in Petersburg, Dr. Keck (jetzt im Iuseum des botan. Gartens in Wien), Bremen, J. D. Surtu in Baltimore, Prof. P.tucki-Prag, Botan. Garten in New York, Prof. Mez-Halle, Botan. Garten in St. Petersburg, Herb. Deiessert in Genf. - Die Pflanzen ron St. Jan und Tortola (Nr. 3001-3299, $3300^{\mathrm{a}}-3317^{\mathrm{a}}$ ) sind in Kopenhagen und unvollständig im Herb. Klicti et Urbax. - Die Pflanzen von St. Thomas (3416-3420), Haiti (3300 bis $\left.3415^{\text {a }}\right)$, Jamaica $\left(3421-3799^{2}\right)$, Bahamas $(3800-4521)$, Cuba $(4530$ bis 5457), Tobago $\left(5458-5968^{a}\right)$, Grenada $\left.5969-6520\right)$, St. Vincent (6521 - 7027), Bequia (7028 - 7073), Barbados (7074-7383) wurden dagegen wieder durch EgGERs selbst, die Rester durch Rexscu an die meisten der vorhin genannten und einige andere Huseen und Privatpersonen abgegeben, z. B. Budapest, Dresden, Zürich (Botan. Garten), Reichesbach (jetzt im Hofmuseum in Wien), Magres-Berlin, TatkeBerlin (jetzt im Herbar des Prof. Hıussknecht in Weimar). - Die Sammlungen der Venezuela-Reise rom Jahre 1891 sind im Museum ron Kopenhagen, die der übrigen Reisen seit 1890 in den hauptsüchlichsten Museen Europas, z. B. in Kew, Leiden, Berlin; die Alkohol-Materialien von Ecuador im botan. Museum zu Berlin.

Lit. WARM. in Bot. Tidsskr. Kopenh. XII (1880-1881) p. $237-238$ et in Brickd's Dansk biogr. Lex. IV (1890) p. 438-439; Kiakiski. in Bot. Tidsskr. Kopenh. XXIII (1900) p. 37-38; briefl. Jittheilung von E.; Jacks. Guide 1. 404; Cat. Sc. Pap. IX p. 780; Unis. Symb. I p. 41-47, 113, 122.

Ehrenberg, Carl August, (1801-1849), geb. in Delitzsclı in der Prov. Sachsen (Prenssen) den 24. VIII. 1801 als Solnn des dortigen Stadtratlis und Stadtrichters Johisx GotтFried und Bruder des beriulhnten Naturforschers Christia GotTfried, widmete sich dem Kaufmannsstande und war 1827-1828 auf St. 'Thomas, März 1828 bis Juni 1831 in Port-au-Prince auf Haiti, Juli 1831 bis April 1840 in Hexica 
theils in der Hauptstadt selbst, thcils in dem Minenorte Real (Mineral) del Jonte 30 Leguas von ihr entfernt, als Buchhalter thätig. An all diesen Orten legte er umfangreiehe Sammlungen von Thieren und Pflanzeu an; in Mexico studirte er mit besonderer Vorliebe die Caeteen, von denen er zahlleiehe nene Arten beschrieb und in die europäischen Giärten einführte. Nach seiner Rückkehr naeh Berlin trat er in das Geschäft seines Bruders Ferdinaxd ein und starb daselbst an 13. VIII. 1849 an der Cholera.

Coll. Botan. Museum in Berlin und Herbarium des botanisehen Gartens in Halle und zwar von St. Thomas ca. $400 \mathrm{Nr}$, ron Haiti ea. $600 \mathrm{Nr}$, von Mexico ca. $2000 \mathrm{Nr}$.

Lit. León Bibl. Botán.-1lexic. (1895) p. 353-354; Ign. Urban: CarL August Ehrenbera in Engl. Bot. Jalnb. XXIV (1897) Beibl. Nr. 58 p. 3-15; Auszug darans von K. Scummans in Monatsschr. für Kakteenkunde X (1900) p. 138-143; Cat. Sc. Pap. II p. 457-458; Pritz. Thes. II ed. p. 99; Uris. Symb. I p. 151.

Elliott, William R., (*1860), geb, zu London im Jalıre 1860, ging 1881 von Kew Gardens nach Jamaica und von dort nach Grellada, wo er 1886 - 1889 Curator der botanischen Station war und besonders den Farnen sein Interesse zuwandte. Darauf sammelte er in Auftrage des British Committee für die Erforschung der Fauna und Flora Westindicns in erfolgreichster Weise Kryptogamen und zwar 1891 bis 1892 während sechs Monaten in St. Vincent und Anguilla (hier anch Blüthenpflanzen), sodann Juli bis Dee. 1892, März 1894 und Oct. 1895 bis März 1896 in Dominica.

Coll. Die Farne von Grenada in Kew; die Kryptogamen ron St.Vineent und Dominica (über $1000 \mathrm{Nr}$.) besonders im British Museum und in Kew.

Lit. Kew Bull. 1887 Nr. 7 p. 13; D. Molnas in Kew Bull. Add. ser. I (1898) p. 7t; Briefl. Mittheilung von D. Morris; Unb. Symb. I p. 101, 137, $157-158,174,176$, III p. 11, 13.

EIsey, Joseph Ravenskroft, (1834-1857), geb. in England im Jahre 1834, machte als Naturalist und Arzt in Auftrage des englisehen Gouvernements eine 20 -monatliehe, sehr beschwerlichc Forschungsreise nach Austratien und ging im Jahre 1857 von England aus nach Westindien, um für die in Bearbeitung befindliche Grislabacu'sehe Flora zu sammeln. Er kam nach St. Kitts (St. Christopher), starb aber sehon nach seehswöchentliehem Aufentlaalte auf der Insel den 31. XI. 1857.

Coll. Herb. Kew, Grisebach in Göttingen.

Lit. Garden. Chron. 1858 p. 112 ; Britt. and Boulg. p. 56.

Eirust, ${ }^{-A d o l f, ~(1832-1899), ~ g e b . ~ z u ~ P r i m k e n a u ~ i n ~ S c h l e s i e n ~}$ (Deutschland) den 6. X. 1832, wanderte 1861 nach Venezuela aus, wo er sich dem hölıeren Lehrfache widmcte. Lr grï̈ndete 1867 eine 
Sociedad de Ciencias fisicas y naturales de Caracas und legte im Auftrage der Regierung Sammlnngen der Naturproducte von Venezuela an. 1874 wurde er ordentlicher Professor der Naturwissenschaften und der deutschen Sprache an der Central-Universität, zugleich Director des Nationalmuseums und der Universitätsbibliothek in Caracas. Im September 1871 besuchte er die Inselgruppe Los Roques, im Mai 1873 die Insel Margarita und im Januar 1874 die Insel Tortuga, sämmtlich an der Nordküste ron Venezuela gelegen. Er starb zu Caracas den 11. oder 12. VIII. 1899.

Coll. Eine Anzahl Pflanzen im Kew Herbarium; Characeen im Museum zu Berlin. - Land- und Süsswasser-Concliylien im zoolog. Museum zu Berlin.

Lit. Leopoldina XXXVI (1900) p. 47-48; Briefl. Mittheilung des Prof. E. von Martens; Jacks. Guide p. 7, 53, 105, 377, 484; Cat. Sc. Pap. VII p. 623, IX p. 807; Urb. Symb. I p. $48-49$.

Euphrasén, Bengt Anders, (1756-1796), geb. im Kirchspiel Habo, Prov. Westergotland (Schweden) im April 1756, studirte 1784 in Upsala. Im Jahre 1788 machte er mit Unterstützung der Kgl. Akademie der Wissenschaften zu Stockholm eine naturhistorische Reise nach den Antillen und hielt sich rom 8. Febr. bis 16. April auf St. Barthelemy, am 16. und 17. April auf St. Eustache und rom 17. April bis 19. Juni auf St. Christopher (St. Kitts) auf. Nach seiner Rückkehr wurde er stellvertretender Demonstrator der Botanik, starb aber schon den 25. XII. 1796 in Stockholm.

Coll. Seine westindischen Pflanzen wurden im Jahre 1806 an einen Herrn Med.erbora verkauft und gelangten später in den Besitz von P'of. Thunberg, dessen Sammlungen jetzt im Universitätsherbar zu Upsala gesondert aufbewalı't werden. Leider sind mehrere der in seinem Werke aufgezählten Arten bei dem Besitzwechsel des Herbars abhanden gekommen.

Lit. Briefl. Mittheilung des Herrn Gymnasiallehrers T. O. B. N. Kroк durch Vermittelung des Herrn Dr. G. O. J Calsie in Stockholm; Prirz. Thes. II ed. p. 103; Urb. Symb. I p. 49, 176-177.

Fahlberg, Samuel, (1758-1834), geb. in Helsingland (Schweden) den 9. IX. 1758, war 1784 Assistenzarzt am Seraphinen-Krankenlıause in Stochholm, kam als Couvernementsarzt 1785 mach St. Bartheleny, welches kurz vorher in schwedischen Besitz übergegangen war, erhielt 1796 ron der Universität Upsala den Doctor medicinae honoris causa und wurde 1799 zugleich Ingenieur und Feldmesserdirector. Er starh auf St. Eustache den 28. XI. 1834. Ausser auf den genannten Inseln lat er auch auf St. Kitts (St. Christopher), Guadeloupe und Martinique gesammelt.

Coll. Herb. Swartz in Stockholm, Herb. Thunderg in Upsala. 
Lit. Briefl. Jitheilung des Herm Grmmasiallehrers T. O. B. N. Krok (Hurch Vermittelung les Herrn Dr. G. O. MaLme in Stockholm; Cat. Sc. Pap. II P. 545; UnB. Symb. I 1. 50, 176-177.

Faviat, Auguste, (1862-1893), Dr. med., geb. zu La-Chauxde-Fonds im Canton Neuenburg (Schweiz) den 30. IX. 1862, wandte sich nach beendigtem pharmaceutischen Studium der Medicin zı. Śchwindsüchtig geworden siedelte er 1887 nach Madeira ïber und machte von hier aus 1888 eine Reise nach Haiti, wo er in der Umgehung ron Jacmel, Les Cayes, Jérémie, Petit Goave etc. sammelte. Er starb den 13. IX. 1893 in Funchal auf Madeira an der Tuberculose.

Coll. Herb. Boissier-Barber, Krug et Urban (ca. 127 Nr.).

Lit. Briefl. Mittheilung des Hermn R. Buser in Genf.

Fawcett, William, (*1851), geb. zu Arklow, Wicklow Co., in Irland den 13. II. 1851, studirte am Dulwich College in Surrey, am Kings College und an der Universität zu London und wurde $1879 \mathrm{~B}$. Sc. Im August 1880 trat er als Assistent in die botanische Abtheilung des British Museums ein und wurle Ende December 1886 als Nachfolger von D. Mokris zum Director des Departments der Public Gardens and Plantations in Jamaica ernannt; ausserdem ist er Mitglied des Board of Governor des Instituts von Jamaica, des Legislative Council, des Board of Agriculture und seit 1900 Deputy-Chairman der Jamaica Agricultural Society. Bei einem kurzen Besuche der Cayman-Inseln inı Mai $188 S$ legte er eine Sammlung ron 112 Arten an, welche die Grundlage unserer Kenntniss von der Pflanzenwelt dieser Eilande bildet. Im Jahre $189 \pm$ begann er mit Unterstützung der dortigen Regierung eine planmässige Untersuchung der Flora von Jamaica, besonders des östlichen Theiles, die wider Erwarten eine ganze Fülle nener Arten an das Licht brachte, dagegen sehr wenige von den Nachbarinseln bekannte, aber für Jamaica bis dahin noch nicht nacligewiesene und ebenso sehl wenige der alten verschollenen Species. Ihn unterstützten dabei in erster Linie und an elfolgreichsten Whilan HARRIs, ferner Eugexw J. F. Campbeli, Wildian Cradwick, Williaj J. Thompsox, David E. Watt (vergl. diese) und andere.

Coll. Bot. Dep. Herbarium zu Jamaica, Herb. Krug et URbax (n. $5000-8149$ und ca. $130 \mathrm{Nr}$. niedere Kryptogamen), Smithsonian Institution und Department of Agriculture zu Washington, Botan. Garten zu New York, Grux Herbar zu Cambridge (Mass.), Museum zu Kopenhagen, Field Columbian Museum zu Chicago, Herb. Boissier-Baruey zu Genf, eine grössere Anzahl, besonders Kryptogamen, im British Museum, einiges in Kew; die Pflanzen von Cayman nur in Kew.

Lit. Briefl. Mittheilungen von EDM. BAKER rom British Musemm und von F.; UrB. Symb. I p. $50-51,79$, III p. 3. 
Fendler, August, (1813-1883), geb. in Gumbinnen (Ostpreussen) den 10. I. 1813, besuchte einige Jahre das Gymnasium seiner Vaterstadt, wurde Schreiber bei der Stadtverwaltung und kam 1834 auf dic polytechnische Schule in Berlin. 1836 siedelte er nach Nordamerika über, wo cr in mannichfaltigen Stellungen 8 Jahre lang kümmerlich sein Lcben fristete. Von Prof. E. Meyer in Königsberg, dessen Bekanntschaft er 1844 bei einem Besuchc in Deutschland machtc, aufgefordert, sich der botanischen Sammelthätigkeit zu widmen, und von Dr. Exgielmux in St. Louis darin weiter ausgebildet, besuchte er 1846-1847 das damals botanisch noch unbekanntc New Mcxico, 1850 den Isthmus von Panama (bei Chagres), betrieb $1850-1853$ zu Memphis in Tennessee ein Beleuchtungs-Geschäft (Camphene-light) und hielt sich 1854-1858 in der Colonie Tovar in Venezucla auf, wo er eine kleine Besitzung erwarb und neben der Herrichtung vorzüglicher Pflanzensammlungen auch wichtige meteorologische Beobachtungen anstellte. Darauf wurde er Farmer im Stante Missouri, siedeltc 1873 nach Wilmington (Del.) über, schrieb hier sein Werk: "The Mechanism of the Universe" und brachte die letzten Jahre seines Lebens (1877-1883) seiner leidenden Gesundheit wegen auf Trinidad zu, noch eimmal sammelnd, besonders Farne und Bromeliaceen. Er starb hier den 27. XI. 1883.

Coll. Herb. Exfiemaxis (Missouri Bot. Garden), Gray Herbarium in Cambridge, Kew, British Museum, de CArdolde, Borsster-Burber, Demessert in Genf, Froxqueville (jetzt Drake del Castrllo in Paris), Dublin, die aus Nen-Mexico auch in Berlin und Wien (Hofmuseum), die aus Venezuela besonders gut im Herb. Grisebacn in Göttingen, die aus Trinilad in Kew, British Museum, J. D. Sмгтн in Baltimore, Washington, Cambridge (Mass.), College of I'harmacy of the City of New York (ex herb. W. M. Cixbr), die Farne auch im Herb. Delessert in Genf, in St. Petersburg und Edinburgh, die Bromeliaceen in Kew. F. sammelte auch Pilze, Flechten und Moose, besonders in Venezuela.

Lit. A. Gray in Botan. Gaz. IX (1884) p. 111-112 (reimpr. in Gard. Chron. n. s. XXII. 1884 p. 91) et in DANA's Amer. Journ, of Sc. and Arts III ser. XXIX (1885) p. $169-171$ et Scient. Pap. II p. 465-467; W. M. CANby: An autoliography and some reminiscences of the late August Fender in Botan. Gaz. IX (1884) p. 285-290, 301-304, 319-322; Pritz. Thes. II ed. p. 106 ; Jacrs. Guide p. 376 ; Cat. Sc. Pap. II p. 586, VII p. 652 ; Urв. Symb. I p. 41.

Finlay, Kirkman, Dr. med. und praktischer Art in San Fernando auf Trinidad, Tutor von Sir Jos. Hooker und dessen Bruder, sammelte daselbst (ca, 1850-1868), sowie ciniges auf Antigua, Dominica und Grenada (aber nicht auf St. Thomas 1841, wie die Etiquetten einer grossen, wahrscheinlich aus Trinidad stammenden Samm- 
lung im Pariser Museum irthümlich angeben). Er starb auf der Insel. Sein Herbarium ging 1884 in den Besitz des Government ron Trinidarl ïber.

Coll. Bot. Garten zu Trinidad, Kew, einiges im Herb. Kruti et Unв.. und J. D. S.urre in Baltimore.

Lit. J. H. Hart in Ann. Rep. Bot. Gard. Trinidad 1887 p. 11; Cat. Sc. Pap. II p. 613.

Forsström, Johan Erie, (1775-1824), geb. im Kirchspiel Traustrand, Prov. Dalarne (Sehweden) den 16. II. 1775, studirte in Upsala, wurde 1800 Mag. phil. und maehte in demselben Jahre mit G. Wanцамтвкі eine botanisehe Reise nach Lappland und Finmarken. Nachdem er 1801 das Examen chirurgiae bestanden hatte und 1802 zum Prediger geweiht worden war, verwaltete er 1803-1815 das Amt eines Gourernementspredigers und $1805-1812$ zugleich auch das eines Gouvernementsarztes auf St. Barthelemy und besuchte ron hier aus auch andere Inseln, z. B. Saba und Guadeloupe. Im Jahre 1817 wurde er Pfarrer im Kirehspiel Munktrop, Prov. Vestmanland in Sehweden, 1819 Probst und starb daselbst 30. V. 1824.

Coll. Iuseum in Stockholm, theils im Herb. SwaRTz, theils im Generalherbar (ex herb. CAsströм), aber nicht ganz vollständig.

Lit. Briefl. Mittheilung des Herm Gymnasiallehrers T. O. B. N. Kroк dureh Vermittelung des Herrn Dr. G. O. Malaie in Stockholm; Uri. Symb. I p. 177.

Fraser, John, (1750-1811), geb. zu Tomnacloieh in Invernessshire (Schottland) 1750, kam un 1770 nach London, wo er sich in Chelsea als Kleiderhändler niederliess. Dureh den Besuch des dortigen Gartens für die Botanik interessirt, machte er in den Jahren 1780, 1784-1785, 1790, 1791 und 1795 Reisen nach Nordamerika, um neue Pflanzen zu importiren. 1799 ging er im Auftrage des Czaren PAUL nach den südliehen Vereinigten Staaten und ron da 1801 nach Cuba, traf hier mit Hunroldt und Bonpland zusammen und besuchte bei seiner Rückkehr 1802, dureh das Leckwerden des Sehiffes gezwungen, die Bahama-Insel New Providence. Auf seiner letzten Reiso naeh Amerika 1806-1810 hielt er sich 1809 wiederum auf $\mathrm{Cuba}$ auf. Er starb zu Chelsea, wo er in Sloane Square eine Gärtnerei gegründet hatte, den 26. IV. 1811.

Coll. Pflanzen aus den Vereinigten Staaten im Herb. de Candolue und Delessert. Sein eigenes Herbar gehört seit 1849 der Linnean Soeicty in London.

Lit. W. J. Hook. Compan. Bot. Mag. II (1836) p. 300-305 mit Porträt; LAs. IIus. Deless. P. $199-200$; R. Hog in Cottage Gardener VIII p. 250 (n. v.); Fonsstil in Lounon's Arboretum p. 119 (n. v.); G. S. Boulg. in Dict. 
Nat. Biogr. XX (1889) p. $213-214$; Britr. and Boulg. 1. 64; Pritz. Thes. II ed. p. 112 ; Jicks. Guide p. 122, 145.

Fraser, John, Sohn des vorigen, begleitete seinen Vater auf seinen Reisen 1799 nach den südlichen Vereinigten s'taaten, 1801 mach Cuba, 1802 nach der Bahama-Insel New Providence, 1806-1809 nach Nordamerika und ging nach dem Tode desselben 1811-1817 noch einmal nach den Südstaaten. Nach seiner Rückkehr gründete er eine Gärtnerei zu Hermitage in Ramsgate.

Lit. W. J. Hook. Compan. Bot. Mag. II (1836) p. $301-303$; LAs. Mus. Deless. p. 200 - 201; Britt. and Boulg. p. 64.

Fredholm, A., aus Baltimore, begleitete als Botaniker und Sammler die rom biologischen Departement der Johss Horkiss Universität zu Baltimore unter Führung Prof. HuxpHREY's nach Jamaica abgesandte zoologisch-botanische Expedition im Jahre 1897. Er sammelte in der Ungebung ron Port Antonio.

Coll. National-Museum zu Washington.

Lit. Johrs Hopkixs Unir. Circul. vol. XVII (1897) Nr. 132 p.1; Rose in lit.

Friedrichsthal, Emanuel Ritter ron, (1809-1842), geb. zu Brünn in Oesterreich den 12.I.1S09, mährischer Gutsbesitzer, besuchte 1834-1835 Griechenland, 1836 - 1839 mit dem Geologen Au Bour Serbien, Macedonien, die Halbinsel Athos nnd Rumelien und sammelte anf seiner Reise nach Guatemala, Costarica und Nicaragua $18 \pm 1$ auch auf St. Thomas. Schon im folgenden Jahre, am 3. III. 1842, starb er zu Wien.

Coll. Hofmuseum zu Wien, Doubletten in Kew.

Lit. Regensb. Flora XIX (1836) p. 221-222; E. R. Friedrichsthal: Reise in den südlichen Theilen ron Neu-Griechenland. Leipzig 1838; Grises. Spicil. Flor. Rumel. 1 p. VII-_VIII; OnRst. in Hook. Journ. of Bot. and Kew Misc. V (1853) p. 46; Reichardt in Allg. Deutsche Biogr. VIII (1878) p. 68; Hemsl. Biol. IV p. 128; Pritz. Thes. II ed. p. 112 ; Cat. Sc. Pap. II p. 724.

Funck, Nicolas, $(1816$ - 1896), geb. in Luxemburg im Jahre 1816. studirte in Brüssel Architektur und begleitete als Zeichner J. LAxDEx auf dessen ersten beiden Reisen nach dem tropischen Amerika: Dec. 1835 bis März 1837 nach Brasilien (Rio de Janeiro, Espirito Santo, Jinas Geraës und Sĩo Paulo), Dec. 1837 bis Aug. 1840 über Cuba nach Mexico, Yucatan und Guatemala. Auch auf der dritten Lndex'schen Reise war el mit ihm ron Dec. 1841 bis Mai 1842 bei der Erforschung Venezuela's thätig. Während sich Ersterer dann nach Westen wandte, besuchte F. den östlichen Theil: Barcelona, Cumaná, die Halbinseln Araya und Paria, schiffte sich über Caracas nach santaMarta in Neu-Granada ein, um die Sierra Nevada zu besteigen, und 
kelırte ïber Caracas im Dec. 1843 nach Europa zurïck. - 1845 ging F. im Auftrage des Lisplix'schen Etablissements (d'Introduction de plantes nourelles) in Luxemburg in Begleitung von Lous Josepu Scmum nach Guadeloupe, in dessen Gebirgen eine zwar kleine, aber interessante Sammlung angelegt wurde, und von da nach Venezuela, wo sie die Prorinzen Caracas, Carabobo, Barquisimento, Trujillo, Maracaibo, Merida besuchten. Nach einem kurzen Aufenthalte im östlichen Neu-Granada (Chinacota, Pamplona und Baja) kehrte F. über Maracaibo mit reichhaltigen Sammlungen an getrockneten und lebenden Pflanzen nach Europa zurück. Hier erhielt er die Stelle eines Professors der Zoologie am Athenaeum in Luxemburg und 1861 nach Lasdes's Rücktritte die Direction des Jardin royal de Zoologie et d'Horticulture zu Brüssel. 1870-1879 war er Director des zoologischen Gartens in Köln und zog sich dann nach Luxemburg zurück, wo er den 10. VIII. 1896 starb.

Coll. Die getrockneten Pflanzen wurden vor dem Etablissement von J. Lixdex an verschiedene Museen und Private verkauft, z. B. Kew, British Museum, de Candolle, Paris, Oxford, Borssier, Petersburg, Gent, Delessert, Leipzig, Brüssel.

Lit. Las. Mlus. Deless. p. 215-216; Linden et Planchon: Troisième royage de J. Linnen I (1863) p. XLVIII-LVI; León Bibl. Botán.-Mexic. (1895) p. 351; briefl. Mittheilung von Prof. Cogniadx; Cat. Sc. Pap. II p. 740, VII p. 726.

Galeotti, Henri Guillaume, (1814-1858), geb. zu Versailles bei Paris den 8. IX. 1814, trat im September 1835 von Hamburg aus als naturhistorischer Reisender, Geolog und Mineralog unter dem Patronat des Herm Vanderinalex zu Brüssel eine Reise nach Mexico an. Er besuchte Jalapa, las Vigas, Perote, Puebla, die Kette des Iztacciluuatl, Ayotla, Chalco, Pachuco, Real del Monte, wo er mit Eurlesiera zusammentraf, Mextitlan, Zimapan, Guadalajara, Guanajuato, Sierra de Santa Rosa, den Vulkan Popocatepetl, Mechoacan, den Vulkan Jorullo, Umgegend von Mirador, Pic von Orizaba, Oajaca u. s. w. und drang bis zu Hölıen von $3500 \mathrm{~m}$ vor. Auf seiner Rückreise im Jalıre 1840 hielt er sich kurze Zeit auf $\mathrm{Cuba}$ auf. Ausser den Beobachtungen über die physikalische Beschaffenlıeit des Landes, über Geologie und Völkerkunde desselben war es vorzüglich die Botanik, welche er bereicherte. Da die von ihm angelegte Gärtnerei kein Gedeihen latte, so vertraute ihm die königliche Gesellschaft Flora die Direction des botanischen Gartens zu Brüssel an, dessen Eigenthümerin sie damals war. Aber nicht lange bekleidete G. diese ehrenvolle Stellung; denn bereits am 13. III. 1858 erlag er daselbst einem Lungenleiden.

Coll. G. brachte von seiner Reise $7-8000 \mathrm{Nr}$. Pflanzen mit (darunter von Cuba kaum eine Centurie); die vollständigste Sammlung 
in Louvain, ferner in Brüssel, Kew, Paris, Herb. Delessert in Genf, Gent, Lüttich, Petersburg, Wien.

Lit. Las. Mus. Deless. p. 209-211; Levarare Illustr. hortic. V (1858) Misc. p. 27-28; Schlechtend. Bot. Zeit. XVI (1858) p. 119-120; Hesss. Biol. IV p. 125; León Bibl. Botán.-Mexic. (1895) p. 348 - 350; Pritz. Thes. II ed. p. 116 ; Jacks. Guide p. 368 ; Cat. Sc. Pap. II p. $758-759$.

Garber, Abraham Pascal, (1838-1881), geb. zu Columbia in Pennsylvanien (U. S. A.) im Jahre 1838, graduirte am Lafayette College und an der medicinischen Schule der Universität von Pennsylvanien. Er war dann kurze Zeit Arzt in Pittsburg, wurde aber durch seine angegriffene Gesundheit gezwungen, vier Winter im südlichen Florida zuzubringen, wo er mehrere neue Pflanzen entdeckte und zahlreiche westindische Typen besonders auf den Key-Inseln (Key West, Miami etc.) auffand. Im Jahre 1880 machte er auf Anregung von Baron Eggers eine Erholungsreise nach Portorico, wo er besonders in der Umgebung von Yauco sammelte. Schon im folgenden Jahre erlag er der Schwindsucht.

Coll. Gray Herbarium zu Cambridge, Herb. der Acad. Nat. Sc. zu Philadelphia, Herb. CaxBI (jetzt im College of Pharmacy of New York); die Portorico-Pflanzen auch in Kew (142 Nr.), Herb. J. D. Sнiтн in Baltimore und Krug et Urb. (ex herb. EgGers).

Lit. Sarg. Silva I (1890) p. 65-66; Harshberger: Botan. of Philadelphia p. $302-303$.

Gardiner, John, B. S., kam 1885 nach den Bahamas, wurde wissenschaftlicher Rathgeber bei dem Board of Agriculture und erhielt 1886 von dem damaligen Gouverneur H. A. BLAkE den Auftrag, eine Liste der Flora der Colonie zusammenzustellen. Er begnügte sich damit, die Pflanzen auf den verschiedenen ron ihm besuchten Inseln zu bestimmen, sammelte aber nicht.

Lit. Proc. Acad. Nat. Sc. Philad. 1889 p. 349 ; Uns. Symb. I p. $54-55$.

Germain, Diener und Präparator ron Dr. F. L'Herminier auf Guadeloupe, sammelte hauptsächlich in den Jahren 1856-1864 Farne und andere Kryptogamen auf dieser Insel und auf Trinidad. Die Wissenschaft verdankt ihm viele interessante Funde (cf. Fís Foug. et Lyc. Ant.); mehrere Novitäten sind ihm zu Ehren benannt.

Coll. Die Pflanzen gingen durch F. L'Hermixier (cf. diesen) an die Bearbeiter.

Lit. Bull. Soc. Linn. Norm. II sér. IV p. 20; briefl. Jittheilung ron Père Dess.

Gilbert, Benjamin Davis, (* 1835), geb. zu Albany im Staate New York den 21. XI. 1835, graduirte 1857 am Hamilton College zu 
Clinton N. Y., widmete sich in den folgenden 20 Jahren geschäftlicher Thätigkeit, ohne die Botanik ganz \%u vernachlässigen, und war 12 Jahre lang Zcitungs-Redacteur. Um 1889 begann er sich für die Pteridophyten zu interessiren und eiu Farnherbarium zusammen zu bringen. Zu diesem Zwecke sammelte er im Winter 1893 in Martinique und St. Thomas, 1894 in Süd-Californien, Febr. und März 1895 in Jamaica, wo es ihm gelang, zwei Drittel der von dort bekannten Farnarten aufzufinden, und 1898 auf den Bermudas.

Coll. Gilbert Herbarium.

Lit. The Fern Bull. vol. IX (1901) p. 66 (mit Porträt); briefl. Mrittheilung von G.; Urв. Symb. I p. 55, II p. $1-2$, III p. 4.

Gollmer, Julius, (? - 1861), Apotheker, sammelte in St. Thomas und begab sich von da nach Caracas in Venezuela, von wo er während der Jahre 1852 - 1857 umfangreiche zoologische und botanische Collectionen nach Berlin schickte. Er starb 1861.

Coll. Museum zu Berlin (im Ganzen 1396 Nr.).

Lit. E. von Martens: Die Binnenmollusken Venezuela's in Festschr. Gesellsch. Naturf. Freunde Berlin 1873 p. 157.

Gosse, Philip Henry, (1810-1888), F. R. S., geb. zu Worcester (England) den 6. IV. 1810, ging als Kaufmann nach Newfoundland und beschäftigte sich nebenbei mit dem Studium der Insekten. Nach 8-jährigem Aufenthalte daselbst setzte er seine entomologischen Untersuchungen während 3 Jahre im unteren Canada fort, bereiste die Vereinigten Staaten, besonders Alabama, wo er eine Fülle von Zeichnungen von Insekten, besonders der Lepidopteren anfertigte, und kehrte 1839 nach England zurück. Nachdem er die wichtigsten Resultate seiner Untersuchungen unter dem Titel: The Canadian Naturalist (1840) veröffentlicht hatte, brachte er 1844-1845 achtzehn Monate zu Bluefields bei Savanna-la-Mar auf Jamaica zu und sammelte hier auch botanisch. Die Ergebnisse der letzten Reise waren: The Birds of Jamaica, On the Insects of Jamaica und A Naturalist's sojourn in Jamaica. Später beschäftigte er sich hauptsächlich mit dem mikroskopischen Studium der Britischen Rotiferen, nahm einen lervorragenden Antheil an der Einrichtung von öffentlichen und privaten Sammlungen der Seethiere und schrieb auch: Wanderings through the Kew Conservatories 1856. Er starb am 23. VIII. 1888 zu St. Marychurch, Torquay (England).

Coll. Pflanzen von Jamaica im Herb. Boissier-Barbey in Genf.

Lit. Drake Dict. Amer. Biogr. p. 371; Garden. Chron. III ser. vol. IV (1888) p. 250 ; E. TV. Gosse: Life of P. H. Gosse (1. v.); Dict. Nat. Biogr. XXII p. 258; Britt. and Boulg. 1. 70 ; F. Cunnali in Jourll. Inst. Jamaic. II (1895) 1. 185 ; Jucrs. Guide 1. 412 ; Cat. Sc. Pap. II p. 951-953, VII p. $802-803$, X p. 32. 
Greene, Benjamin I)., (1793-1862), geb. zu Boston (U.S. A.) 1793, studirte zuerst Rechtswissenschaft und wurde ddrocat, wandte sich damn der Arzneiwissenschaft zu und vollendete seine medicinischen Studien in Glasgow, Paris und Edinburgh. Da er sich in sehr guten Vermögensverhältnissen befand, so hat er die ärztliche Praxis niemals ausgeübt, sondern sich ganz der Botanik gewidmet, für welche or hauptsächlich durch seinen Freund Sir Wilutıy Hooker in Glasgow begeistert wurde. G. hat selbst nichts ron seinen Entdeckungen und Beobachtungen publicirt, aber eine bedeutende Bibliothek und umfangreiche Herbarien zusammengebracht, die er den Interessenten mit grösster Liberalität zur Verfügung stellte, und die nach seinem am 14. X. 1862 in Boston erfolgten Tode testamentarisch an die Boston Society of Natural History übergingen. Wann er in Cuba war, ist nicht bekannt; sein Biograph erwähnt eine solche Reise überhaupt nicht.

Coll. Kew Herbarium (ex herb. Hooker), Herb. Krug et Urbar, Boston Society of Natural History.

Lit. A. Gray: Benjanin D. Greene in Amer. Journ. of Sc. and Arts II ser. XXXV (1863) p. 449 and Scient. pap. II p. 310 - 311.

Gregg, J., sammelte vor 1786 auf Dominica, Barbados und Tobago.

Coll. Herb. Baxks im British Museum.

Grosourdy, René de, geb. zu Lison, Dép. Calvados in der Normandie (Frankreich), promovirte 1836 in Paris zum Dr. med., wurde alsdann Professeur particulier der Chemie und Naturgeschichte daselbst und reröffentlichte einen Traité de chimie considerée dans ses applications à la médecine, tant théorique que pratique, Paris $1838-1839,2$ vol., sowie: El médico botánico criollo, Paris 1864, 4 vol. Tor dem Jahre 1864 war er in Venezuela und in Portorico und sammelte hier bei Loisa, Cangrejos, Ponce, Coamo, Mayagüez und Aguada, sowie auf der Iusel Vieques (Crab island).

Coll. Museum in Paris (869 Nr. ex Buread in lit.), einiges im Herb. Krug et Urban.

Lit. Briefl. Mittheilung des Iterm Prof. F. IIeñ in Paris; Pritz. Thes. II ed. p. 130; Cat. Sc. Pap. III p. 28 ; Unb. Symb. I p. $63-64$.

Guilding, Rer. Lansdown, (ca. 1797-1831), geb. zu Kingstown auf St. Vincent um 1797, studirte zu Oxford und sammelte auf St. Vincent seit seiner Rückkehr 1817 bis zu seinem wahrscheinlich auf Bermuda am 22. X. 18331 erfolgten Tode. Die an W. J. Hooker gesandten Pflanzen sind sicher nicht sämmtlich von der Insel bez. nicht alle dort einheimisch. Sein Specialstudium bildete die Zoologie.

Coll. Kew Herbarium, Bruchstïcke im Herb. Grisebaci in Göttingen. 
Lit. Britt. and Boulg. p. $74-75$; Kew Bull. 1899 p. $228-229$; Jacks. Guide p. 450 ; Cat. Sc. Pap. III p. $76-77$; Uris. Symb. I p. 64.

Gundlach, Johannes, (1810-1896), geb. zu Marburg in Hessen (Deutschland) den 17. VII. 1810 als Sohn eines Professors der Mathematik und Physik an der dortigen Universität, studirte anfänglich Theologie, dann Zoologie und wurde 1838 in seiner Vaterstadt zum Dr. phil. promovirt. Noch in demselben Jahre schiffte er sich mit dem CacteenMonographen Dr. L. Pfeiffer aus Cassel und dem Gärtner E. Oтто aus Berlin nach Cuba ein und kam Anfangs Januar 1839 in Habana an. Während seine beiden Reisegefährten nach kurzem Aufenthalte die Insel wieder rerliessen, blieb G. daselbst bis zu seinem am 15. III. 1896 erfolgten Tode und widmete wälırend eines Zeitraumes von mehr als 57 Jahren seine ganze Thätigkeit der Erforschung der dortigen Fauna. Seine grosse Bescheidenheit, die Liebenswürdigkeit seines Charakters und seine Bedürfnisslosigkeit ohne Gleichen machten ihn zum populärsten Manne auf Cuba und öffneten ihm die Thüren überall, wo er auf seinen zoologischen Streifzügen hinkam. Da er viele Jahre nit Cr. Wrigrt zusammenreiste, so erwarb er sich auch eine gute Kenntniss der Gewächse, die ihm bei dem Studium der Insekten und deren Futterpflanzen sehr zu Statten kam. Seine zahlreichen Arbeiten sind theils in spanischer Sprache (in Habana und Madrid), theils in deutscher erschienen; von seinen zoolog. Sammlungen haben viele Museen und Privatpersonen, besonders das Museum für Naturkunde zu Berlin erhalten; die grösste Sammlung vermachte er der Akademie der Wissenschaften zu Habana. - Im Jahre 1873 kam G., einer Einladung des Consuls L. Krog folgend, auf 6 Monate und $1875-1876$ auf ein Jahr nach Portorico und durchforschte den ganzen Westen und Nordwesten der Insel von Guanica bis zur Hauptstadt San Juan; auf der zweiten Reise sammelte er auch botanisch.

Coll. Die Pflanzen von Portorico $(1875-1876)$ und $43 \mathrm{Nr}$. von Cuba (1885) im Herb. KRUG et Urbas.

Lit. F. Calcagno Dice. biogr. Cubano (1878) p. 327-328; Dr. Juan Vilaró y Diaz: Biografia del Doctor Juan Gundlacir in La Enciclopedia 26. Febr. 1887 mit Porträt (Sonderabdruck 21 p. $4^{0}$. Habana 1887), übersetzt und mit Zusätzen versehen ron Prof. L. Krug; A. Staul: Fauna de Puerto-Rico p. $20-21,31$; Cat. Sc. Pap. III p. 87, VII p. $868, \mathrm{X}$ p. 89.

Guyon, E., Zoologe, sammelte auf Guadeloupe und Martinique und schenkte eine Collection Pflanzen 1827 an A. von HuмвoLdt.

Coll. Huseum zu Berlin (ex herb. Kunth).

Lit. Cat. Sc. Pap. III p. $97-98$, VII p. $877-878$.

IIahn, Ludwig, (1836-1881), geb. in Güstrow in Grossherzogthum Mecklenburg-Schwerin (Deutschland) den 11. XII. 1836, kam im 
Jahre 1860 als Gärtner an den Jardin des plantes in Paris und ron da 1864 als Obergärtner an den botanischen Garten in St. Pierre auf Martinique. 1865 wurde er der Commission scientifique du Mexique beigegeben. Er durchstreifte Mexico theils im Gefolge der französischen Armee, theils von ihr entfernt unter grossen persönlichen Gefahren und schickte beträchtliche Sammlungen von lebenden und getrockneten Pflanzen sowie Sämereien nach Paris (1865-1866). Nach seiner Rückkehr wurde er von der Direction des Muséum d'histoire naturelle beauftragt, die Flora von Martinique planmässig zu erforschen, eine Aufgabe, die er 1867-1870 mit dem grössten Eifer und Erfolge löste. In dem folgenden Jahrzehnt widmete er sich der Förderung des Gartenbaus und der Obsteultur der Insel, indem er mustergiltige gärtnerische Anlagen schuf, durch zahlreiche Verbindungen mit dem Auslande die besten Sorten importirte, die in seinem Versuchsgarten am Parnass bei St. Pierre kultivirt und durch Pfropfen vermelirt wurden, und auch durch Abfassung eines Manuel du bon jardinier aux Antilles den Interessenten Anweisungen für eine rationellere und erträgnissreichere Cultur ertheilte. Umgekehrt sandte er auch zahlreiche Sämereien und lebende Pflanzen an europäische und nordamerikanische Gärten. Am Zungenkrebs erkrankt, suchte er Heilung durch eine Operation in Paris, starb aber bald nach seiner Rückkehr am 8. II. 1881 in Martinique.

Coll. Hauptsammlung im Museum zu Paris, wo die Pflanzen durch Baillox u. a. ihre provisorische Bestimmung erhielten; die Sammlungen von Martinique (ca. $1732 \mathrm{Nr}$.) in Berlin, bei Borsster-Barber, in Budapest (ex herb. Harvald), British Ifuseum, Brüssel, bei dE CANdolle, Cosson, Delessert in Genf, Fraxquetilue (jetzt Drake del Castillo in Paris), in Frankfurt a. M. (Senckenbergische Gesellsch.), Kew, Lübeck, Lüttich, Petersburg (Bot. Garten), Zürich.

Lit. Reg. Flora 1868 p. 208 (Angebot der Pflanzen ì 30 fres. die Centurie); durch Vermittelung ron Père Duss briefliche Mittheilungen der Wittwe Haнs's, bez. Abschriften von Nekrologen aus den Zeitungen von Martinique; briefl. Nachrichten ron H.'s Freunde J. Potssos in Paris. Die biographische Notiz in der Botan. Zeitung XXXII (187t) p. 335-336 bezieht sich auf einen am 25. [X. 1873 als Mrusiklehrer in Ifexico rerstorbenen ganz andern Ledwig HaHs, welcher 1868 in ILexico WolffiaArten für A. Brads in Berlin sammelte und in Hessa. Biol. IV p. 134 mit dem unsrigen zusammengeworfen worden ist.

Hamilton, William, (?-1856), Med. Dr., sammelte um 1814 auf Haiti, St. Kitts (St. Christopher), Neris (VI. 1814), Antigua, Guadeloupe, Barbados und Tobago und fülnte auch ron der erstgenannten Insel einige neue Pflanzen (Plumieria tuberculata und Theophrasta Jussieui) in die europäischen Gärten ein. Er reröffentlichte 
später zahlreiche chemisch-pharmakologische Aufsätze und starb den 25. V. 1856 zu Plymouth.

Coll. Herbar Desvadx, jetzt im Museum zu Paris; einiges auch im Herb. Turczanivow, jetzt im botanischen Garten zu Charkow.

Lit. Hant. in Trutocr Phil. Mag. XLTV (1814) p. 191; Pharm. Journ. XV (1856) p. 568; Britt. and Bovlg. p. 77; Pritz. Thes. II ed. p. 134; Jicks. Guide p. 368; (at. Scient. Pap. III p. 147-148; Uris. Symb. I p. 64.

Hansen, Carl Olaf Ernst, (* 1865), geb. in Olstykke auf Seeland (Dänemark) den 7. VI. 1865, war 1888-1892 Gehïlfe im botanischen Garten zu Kopenhagen und reiste 1892 nach St. Croix, wo er Inspector des botanischen Versuchsgartens Grange ist. Von hier aus machte er 1897 eine Sammel- und Informationsreise nach dem nördlichen und östlichen Jamaica.

Coll. Bot. Museum in Kopenhagen; Doubletten im Herbar Krug et Urban.

Lit. Kinersk, in Bot. Tidsskr. XXIII (1900) p. 38-40; Ure. Symb. I p. 113 (Bearbeitung der Moose durch C. MüLler).

Harlow, James, Gärtner, wurde um 1670 von Sir Arthur Rownon nach Jamaica geschickt, um lebende Pflanzen zu sammeln und Herbarien anzulegen.

Coll. Oxford, Herb. Sloane im British Museum.

Lit. Slonne Voy. Jam. I. Preface; Jenninan in Britr. Journ. of Bot. XXIV (1886) p. 14; Britt. and Boulg. p. 78; Urb. Symb. I p. 155.

Harris, William, (* 1860), F. L. S., geb. zu Enniskillen in Irland am 15. XI. 1860, kam im Juni 1879 als Gärtner nach Kew, 1881 zum Botanical Department nach Jamaica und verwaltete hier als Superintendent Kings House Gardens and Grounds 1881-1884, Castleton Botanic Gardens 1884-1887, Hope Gardens 1887-1891, Hill Gardens and Cinchona Plantations 1891-1900, Hope Gardens and Hill Gardens seit Dee. 1900 und vertrat den Director in dessen Abwesenheit. Er sammelte, hauptsächlich seit 1894, in den Parishes von St. Andrew (Liguanea Plains, Port Royal und Blue Mountains, Red Hills, Tweedside, Mount Moses etc.), St. Thomas (bei Bath, längs der Küiste etc.), Portland (Lancaster, St. George's District, an der Küste von St. Margaret's Bay bis Manchioneal, an Ufer des Rio Grande etc.), St. Mary (Castleton und Nachbarschaft), St. Ann (Schwallenburgh, Brown's Town, Ramble etc.), St. Catherine (bei Ewarton, auf Holly Mount), Manchester (bei Mandeville und auf den Savannalss bis zum Alligator Pond), St. Elizabeth (Savannah bei Letitz und Cornwall bei Lacoria), Trelawny (längs der Küste), Hanorer (Belvidere), Westmoreland (Shaftston, Bluefields, Grand Vale etc). Seinem unermüdlichen Eifer verdankt die Wissen- 
schaft eine ganze Reihe nener Arten auf dieser von Botanikern schon so oft und so eingehend untersuchten Insel.

Coll. Vergl. unter FAwcetr.

Lit. Briefl. Mittheilung ron H.; Uris. Symb. I p. 112.

Hart, John Hinchley, (* 1847), F. L. S., geb. in England den 10. VII. 1847, besuchte die Grammatik-Schule zu Botesdale in Suffolk, wandte sich dann dem Acker- und Gartenbau sowie botanischen Studien zu und wirkte $1872-1875$ als Landschaftsgärtner in Nora Scotia. 1875 trat er bei dem Botanical Department in Jamaica ein, wurde 1881 Superintendent der Cinchona Plantations und nach dem Fortgange von D. Morris Juli 1886 bis Juni 1887 Acting Director der Public Gardens and Plantations. 1887 wurde er Superintendent des botanischen Gartens in Trinidad und seit 1899 zugleich auch von Tobago. Ausser in Jamaica und Trinidad, hier assistirt von den Obergärtnern IV. E. Broadway (vgl. diesen), W. Lunt (vgl. diesen), von D. W. Alexander, der 1891 auch in Grenada war, BAptiste, F. A. Lodge u. a., sammelte H. in St. Vincent, Greuada, Barbados, Tobago, sowie in Veragua (18S5) und Nicaragua. Auch vertheilte er aus dem repwahlosten und zum Theil verdorbenen Trinidad-Herbar, welches von Locknart, Purde, Crueger, Prestoe, Findar u. a. angelegt war und ron $\mathrm{H}$. wieder in Ordnung gebracht wurde, zahlreiche Doubletten.

Coll. Herb. des Botan. Department in Kingston auf Jamaica (bis Nr. 2025) und des botan. Gartens in Trinidad (bis Nr. 6789), Kew, Krug et Urban, G. S. Jenhan in Denerara, J. D. Sutth in Baltimore.

Lit. Ann. Rep. Bot. Gard. Trinicl. for 1887 p. $10-11$; Briefl. Mittheilung ron H.; Urs. Symb. I p. $15,65-66,98,169$, II p. 2, 3, II p. 4.

Hartweg, Karl Theodor, (1812-1871), geb. zu Karlsruhe in Baden den 18. VI. 1812, stammte aus einer alten Gärtnerfamilie, kam frühzeitig in den Jardin des Plantes zu Paris und ron dort zur Horticultural Society nach London. Im Auftrage der letzteren trat er 1836 eine Reise nach Mexico an, um lebende Pflanzen und Samen zu sammeln und Herbarien auzulegen. Nachdem er ron Tera Cruz ausgehend den Orizaba, San Luis Potosi, Zacatecas, Mechoacan, Mexico und Oaxaca besucht hatte, begab er sich nach Guatemala, Peru, Ecuador und Neu-Granada mod kehrte über Jamaica, wo er im Mai 1843 hauptsächlich in clen Gebirgen nördlich von Port Royal sammelte, mit reichen,Schätzen nach London zurück. Der Erfolg dieser Reise veranlasste die Hortic. Society, iln im Nor. 1845 noch einmal nach Amerika zu schicken. Er durchkreuzte Mexico von Vera Cruz bis Mazatlan, schiffte sich nach Monterey in Californien ein, durchsuchte die weitere Umgebung der Stadt und dehnte seine Excursionen 
nordwärts bis zum oberen Laufe des Sacramento und zu den Sierra foot-hills aus. 1848 kehrte er nach Europa zurück und wurde Hofgä̈rtner zu Schwetzingen in Baden, wo er am 3. II. 1871 starb.

Coll. Hauptsammlung im Kew Herbar, Doubletten in Berlin, im British Museum, bei de Caxpolle, in Herb. Bolssien-Barbey und DiLESSERT in Genf, Florenz, St. Pctersburg, im Hofmuseum zu Wien. HArTwer's eigenes Herbar ist in Lund. - Die Jamaica-Sammlung unfasst kaum 1/2 Cent.

Lit. Las. Mus. Deless. p. 207-209; Lind. et Plancir. Troisième voyage de J. Linnen I (1863) p. LX; Seeur. Journ. of Bot. IX (1871) p. 224 ; Gard. Chron. 1871 p. 313 ; W. H. Brewer Bot. of Calif. II p. 556 ; HeusL. Biol. IV p. 126 - 127; Sarg. Silva II p. 34; León Bibl. Botán.-Mexic. (1895) p. 352-353; Britt. and Boulg. p. 204; Willis L. Jepson: The explorations of Hartwer in America in Erythea V (1897) p. 31-35, 51-56; Benth. Plant. Hartweg. Londini $1839-1857$ 8. IV 393 p.; Pritz. Thes. II ed. p. 136 ; Cat. Sc. Pap. III p. 203; Urb. Symb. I p. 10.

\section{IIaye vergl. Lahaye.}

Heller, A. Arthur, (* 1867), geb. zu Montour County in Pennsylvanien (U.S. A.) den 21. III. 1867, studirte am Franklin and Marshall College in Lancaster (Pa.) und graduirte 1892 zum B. A. In die Botanik fülırte ihn seine spätere Frau cin, welche ilın auch auf mehreren Reisen begleitete. Nachdem er wälırend seiner Studienzeit in den östlichen Vereinigten Staaten erfolgreich botanisirt hatte, so 1890 im westlichen Nord-Carolina (n. 1-215), 1891 ebenda und im südlichen Virginien (n. 216-494), erhielt er 1892 rom U. St. Department ot Agriculture den Auftrag zu einer Expedition in das nördliche Idalı, wo er von April bis September zwischen Lewiston und Hope in Gemeinschaft mit J. H. SandBerg und D. T. MI DovgaL ca. $1000 \mathrm{Nr}$. zusammenbrachte. Im Herbst 1892 besuchte er das südliche Pennsylvanien und Virginien (n. 495-763), 1893 hauptsächlich Virginien (n. 764-1369), 1894 das südliche Texas (n. 1370-1943), 1895 die Hawaii'schen Inseln Oahu und Kauai (n. 1944-2913), 1896 wiederum Idaho (n. 2914-3489), $1897 \mathrm{New}$ Mexico bei Santa Fé (n. 3500 bis 3848), 1898 Washington bei Montesano (n. 3849-4070), Arkansas und Texas (n. 4075--4323). Unter den Auspicien des botanischen Gartens von New York wandte er sich dann der Erforschung von Portorico zu. In den ersten sechs Monaten des Jahres 1899 besuchte cr von Santurce, einer Vorstadt von San Juan, aus die benachbarten Gebiete, machte Excursionen nach Bayamon, Vega-Baja, Arecibo, Caguas, Cayey, Aibonito, Ponce und Fajardo und brachte ein Herbarium von ca. 1400 Blüthenpflanzen und Kryptogamen zusammen. In Januar und Februar 1900 war er auf eigene Kosten in Portorico 
und sammelte besonders bei Mayagüez, ausserdem bei Santurce und in den Luquillos bei Fajardo (n. 4324-4766).

Coll. Die Sammlungen aus den Vereinigten Staaten sind in den meisten nordamerikanischen Herbarien, ausserdem im Herbar BorssierBarbey in Genf $(1891$ - 1894, 1896 - 1898), im botan. Garten zu Edinburgh (desgl.), z. Th. auch in Calcutta (1893, 1894), Kew (1894, 1897), Bot. Garten zu Zürich $(1894,1896,1897)$, bei J. C. Mecvile in Manchester $(1894,1896,1897)$, zu Breslau $(1894,1897,1898)$, St. Petershurg (1894, 1896, 1897, 1898), Paris (1894, 1896), bei Drake dei Castillo $(1896,1897,1898)$, in Leiden (1896 - 1898), bei Prof. Hльssкхеснт in Weimar (1896), im British Museum (1897), Herb. Delessert in Genf(1898). Die rom nördlichen Idaho (1892) in U. S. D. of Agriculture, ron wo die Dupla an andere Museen abgegeben wurden. - Die der Sandwich-Inseln in Washington (U. S. National Herb.), New York (Columbia University). bei T. S. Brandegee in San Diego Cal., in St. Louis (Miss. Bot. Gard.), bei Borssier-Barbey in Genf, zu Cambridge (Gray Herbarium), Edinburgh (Bot. Gart.), Zürich (Bot. Gart.), Calcutta, Philadelphia (Acad. Nat. Sc.), Michigan (Agric. Coll.), bei Addisox Brown in New York, Jamaica Plain (Arnold Arbor.), Montreal (Mc Gill Univers.), Kew, bei J. C. Melvill in Manchester, British Museum, bei Parke, Davis \& Co. in Detroit, Paris, St. Petersburg (Bot. Gart.), bei Drake del Castrllo in Paris, St. Francisco (Calif. Acad. Sc.), Washington (Cathol. Univ.), Minneapolis (Univ.), bei Prof. Haussknecht in Weimar, Leiden, Breslau, Strasburg. - Die von Portorico aus dem Jahre 1899 in Botanischen Garten zu New York. - Die aus dem Jahre 1900 in New York (Bot. Gart.), Washington (U. S. Nat. Herb.), Chicago (Field Col. Mus.), St. Louis (Miss. Bot. Gard.), bei Addison Brows in New York, in Ithaca (Corn. Univ.), Jamaica Plain (Arn. Arbor.), Cambridge (Grar Herb.), Providence (Brown Univ.), Biltmore Herb. in Nord-Carolina, Edinburgh (Bot. Gart.), bei J. C. Melvilu in Manchester, in Leiden, bei Drake del Castillo, in Paris, Breslau, im Herb. Demessert in Genf, Philadelphia (Acad. Nat. Sc.), Herb. Krug et Urbav.

Lit. Harsuberger: The Botanists of Philadelphia (1899) p. 382 - 388; briefl. Mittheilung von $\mathrm{H}$.

Hennecart, Jules, geb. zu Paris den 7. X. 1797, gestorben zu Clisteaux de Combreux bei Tomrnon den 23. XIl. 1888, vergl. Jacqumiont.

Herrick, Francis Hobart, (*1858), geb. zu Woodstock in Vermont (U.S. A.) den 19. XI. 1858, graduirto 1881 am Dartmouth College zuml A. B. und 1888 an der Johns Hopkins University zum Dr. Phil., wurde in demselben Jahre Instructor und Professor der Biologie am Adalbert College der Western Reservo University zu Cleveland in Ohio. Er be- 
suchte im Juni 1886 Abaco, die nördlichste der Bahama-Inseln und mehrere der iln' vorliegenden Key's, als auf einem derselben, Green 'Turtle Key, das Marine-Laboratorium stationirt wurde.

Coll. Herbarien der Yale University und des Adalbert College.

- Lit. Briefl. Mithleilung von H.; Uru. Symb. I 1. 70.

Heuser, 'T. sammelte im April 1869 in Cuba.

Coll. Herb. Kirug et Urbax.

Heward. Robert, (1791-1877), geb. zu Wokingham in Berks (England) 1791, war Clerk am Garten der Horticultural Society zu Kensington und Chiswick und assistirte SABINE bei seinen Crocus - und LisdLeY bei seinen Rosen-Kulturen. 1823-1826 stand er einer Kaffeeplantage in Jamaica vor und brachte in den Bezirken von St. Elizabeth und Manchester eine beträchtliche Anzahl von getrockneten Pflanzen, besonders Farnen zusammen, welch letztere er später selbst bearbeitete. Nach seiner Rückkehr von Westindien war er längere Zeit Mitarbeiter an Londoner Journalen, half bei der Herausgabe der Parlaments-Debatten und war zuletzt beim Colonial Office angestellt. Das letzte Jahr seines Lebens brachte er als Pensionär in Wokingham zu, wo er am 24. X. 1877 starb.

Coll. Herb. Kew, einiges in Herb. Delessert in Genf.

Lit. Las. Mus. Deless. p. 266; 'Trumen's Journ. of Bot. XV (1877) p. 380; Gard. Chron. n. s. VIII (1877) p. 571; BRitt. and Boulg. p. 81; Pritz. Thes. II ed. p. 143 ; Jacks. Guide p. 370 ; Cat. Sc. Pap. III p. 342 ; Urв. Symb. I p. 70.

Hjalmarson, Justus Adalrik, (1823-1876), geb. in Kungself (Schweden) den 9. II. 1823, machte 1847 in Stockholm sein pharmacentisches Examen, conditionirte seit 1850 in St. Thomas und liess sich 1857 als Apotheler in Arceibo auf Portorico nieder, wo er besonders Vögel für das Stockholmer Museum präparirte. Im Jahre 1852 ging er mach Honduras, 1858 mach Puerto-Plata auf Sto. Domingo, um Landschnecken zu sammehn, und auf der Rückreise im Mai desselben Jahres nach Grand Turk (Turks Islands). Während eines 14-tägigen Aufenthaltes daselbst gelang es ihm, die Pflanzen der Insel für die in Bearbeitung befindliche Grisebacu'sche Flora ziemlich vollständig zusammenzubringen. $1867 \mathrm{kam}$ er nach Stockholm, um aus seinen zoologischen Sammlungen eine Auswahl als Grundstock für ein Ifuseum in Portorico zusammenzustellen, welches aber schon am 29. Oct. 1867 durch Erdbeben zu Grunde gerichtet wurde. Er starb den 10. IX. 1876 an Bord eines Dampfers im Atlantischen Ocean.

Coll. Kew Herbarium, Herb. Grisebacn in Göttingen, einiges im Herb. Krür et URBax. 
Lit. Öfvers. Kongl. Tetensk. Akad. Förhandl. Stockholm 1855 p. 343 bis 346,1869 p. 593 (von Prof. Ascnersox mir fremull. iibersetzt); ST.nir. Est. sobre la Flora de Puerto-Rico (1883) p. 11 et Fauna (1883) p. 22; briefl. Mittheilung des Herrn Grmnasiallehrers F. O. B. N. Krok durch Vermittlung des Herm Dr. G. O. Malue in Stockholm; Cat. Sc. Pap. III p. 368.

Higson, Thomas, (1773-1836), Kaufmann zu Kingston in Jamaica, war als Nachfolger von MACFadrex 1828-1832 Island Botanist und Curator des botanischen Gartens zu Bath und starb zu Kingston den 21. XII. 1836 im Alter ron 63 Jahren 10 Monaten.

Coll. Kew Herbarium?

Lit. W. Fawcett in Botan. Gaz. XXIT (1897) p. 348; Abschrift des Leichensteins in der Parish Church von Kingston, mitgetheilt durch F. CuNDall bezw. IV. Fawcett.

Hitchcock, Albert S., (*1865), geb. zu Owasso in Michigan (U. S. A.) den 4. IX. 1865, graduirte am Jowa State Agricultural College 1884 zum B. S. A., 1886 zum MI. S., wurde 1885 daselbst Assistent der Chemie, 1886-1889 Instructor der Chemie an der Iowa State University und 1890 erster Assistent am Missouri Botanical Garden zu St. Louis. Von hier aus machte er rom Nor. 1890 bis Jan. 1891 unter der Leitung des Dr. J. T. RотнRоck eine Sammelreise nach den Bahamas (New Providence, Eleuthera, Cat, Watling's, Crooked, Fortune, Great Inagua), Jamaica (Kingston, Port Morant, Port Antonio, Lucea, Bog Walk, Blue Mountain Peak, Constant Springs) und Grand Cayman. 1892 wurde H. Professor der Botanik am Kansas State Agricultural College, März 1901 Assistant Chief in der Abtheilung für Agrostologie am U. St. Department of Agriculture in W Washington.

Coll. Hauptsammlung im Herbarium des Missouri Botanical Garden zu St. Louis, eine kleine Doubletten-Sammlung im Besitz von H.

Lit. J. E. Hunpurey in New Engl. Magazine 1896 (n. v.); Briefl. Mittheilung von H.; URE. Symb. I p. $70-71$.

Holme, Rev. H. K., sammelte um 1878 in Montserrat.

Coll. Herb. Kew.

Lit. Kew Rep. 1879 p. 41.

Hornbeck. Hans Baltzar (Baltasar), (1800-1870), geb. als Sohn des Consumptionsschreibers und Kassierers C. R. Honsвeck in Kopenhagen den 9. I. 1800, studirte daselbst Medicin und liess sich 1825 als Arzt auf St. Jan nieder. Hier wurde er bald nach seiner Ankunft Districtschirurg und 1827 Landphysikus der dänisch-westindischen Inseln. Er sammelte 'Pflanzen und andere Naturalien hauptsächlich auf St. Jan, ausserdem auch auf St. Thomas, St. Croix und Portorico. Im Jahre 1844 kehrte er nach Kopenhagen zuriick und starb am 2. II. 1870 als Arzt am dortigen Krankenhause (Kopenhavns Sygehjem). 
Coll. Botan. Museum in Kopenhagen.

Lit. Kramers. in Bot. Tidsskr. Kopenh. XXIII (1900) p. 40; Cat. Sc. Pap. III p. 434.

IIoskin sammelte 1811 auf Dominica.

Coll. Herb. Kew, Kreug et Urb. (25 Nr.).

Houstoun, William, $(1695-1733)$, geb. in Schottland im Jahre 1695, studirte seit 1727 unter Bozrmasve in Leiden Medicin und wurde 1729 daselbst zum Dr. med. promovirt. 1729-1733 bereiste er Cuba, Jamaica, Mexico (Vera Cruz) und Campecle und starb den 14. VIII. 1733 auf Jamaica. Seine Pflanzen und Samen sandte el an PliflP Mrler zu Chelsea, welcher eine beträchtliche Anzahl davon in seinem Garden. Diction, publicirte.

Coll. British Mluseum (Herb. Miller, Banks, Slonne), wo auch seine Manuscripte und Zeichnungen aufbewahrt werden, Herb. Lrnné in der Linnean Society, Oxford.

Lit. Gentleman's Magaz. III (1733) p. 662; Pulteney Sketches II p. 231 (n. v.); Rees Cycl. (n. v.); Las. Mus. Deless. p. 450; Heusl. Biol. IV p. 118-119; Boulg. in Diet. Nat. Biogr. XXVII (1891) p.425-426; Britt. and Boulg. p. 87; León Bibl. Botán.-Jexic. (1895) p. $321-322$; Pritz. Thes. II ed. p. 151 ; Jacks. Guide p. 111 ; Urb. Symb. II p. 1.

Hughes, Griffith, war Rector von St. Lucy's Parish auf Barbados und F. R. S. Er publicirte sein Werk: The natural history of Barbados im Jahre 1750.

Coll. Pflanzen sind ron ihm nicht bekannt.

Lit. Boulg. in Dict. Nat. Biogr. XXVIII (1891) p. 175-176; Britr. and Boulg. p.88; Prixz. Thes. II ed. p.152; Jacks. Guide p. 369 ; Urb. Symb. I p. 73.

Humboldt, Friedrich Wilhelm Heinrich Alexander von, (1769 bis 1859), geb. zu Berlin den 14. IX. 1769, verlebte mit seinem Bruder Wilnela seine Jugendzeit in dem nahe gelegenen Schlosse Tegel und wurde von Christian Kunth, dem Onkel des Botanikers, erzogen und von dem bekannten Arzte Dr. E. L. Hew und später von dem jungen K. L. Willdenow in die Botanik eingeführt. 1787 bezog el die Universität Frankfurt a. O., setzte 1788 in Berlin seine Studien privatim fort und ging 1789 nach Göttingen, wo der berühmte Naturforscher Blumenbach lehrte, machte mit Geong Forster im Frühjahr 1790 eine Reise nach den Niederlanden, England und Paris, kam nach Hamburg zur Handelsakademie und 1791 nach Freiberg in Sachsen, um unter dem Geognosten WERxER die bergmännischen Wissenschaften zu studiren. Nachdem er seit 1792 anfänglich als Assessor beim Bergwerksdepartement zu Berlin und bald darauf als Oberbergneister und Generaldirector der Minen in den Fürstenthümern Bayreuth und Anspach thätig gewesen war, zog el sich 1797 in das Privatleben zurück. 1798 begab 
sich H. nach Paris, um sich anf eine grosse Reise in die Tropen vorzubereiten, lernte hier den Botaniker A. Boxplaxi kennen, ging mit diesem nach Madrid und fand bei dem Könige vou Spanien die ausgiebigste Förderung seines Unternehmens. Am 5. Juni 1799 fuhren sie auf der Corvette Pizarro rom Hafen von Coruña ab, besuchten die Canaren, Venezuela bis zum Cassiquiare und Rio Negro und kamen am 19. Dez. 1800 nach Habana auf Cuba. Hier blieben sie fast vier Monate und sammelten besonders in dem Gebiete zwischen der Hauptstadt, Batabano und Trinidad. Die Weiterreise ging nach Cartagena in Neu Granada, auf dem Magdalenenstrome aufwärts nach Ecuador, wo in Quito am 6. Jan. 1802 ein beinahe neummonatlicher Aufenthalt genommen und am 23. Juni der Chimborazo bis zu einer Höhe ron ca. $6000 \mathrm{~m}$. bestiegen wurde, nach Peru und am 23. März 1803 nach Acapulco in Mexico. Nach fast einjährigen Forschungen in diesem Lande schifften sie sich in Veracruz nach Cuba ein, um ihre dort 1801 zurückgelassenen Sammlungen in Empfang zu nehmen und ihre Studien über die Insel zu vervollständigen (März, April 1804), und kamen über Nordamerika am 3. August 1804 wieder in Bordeaux an. ${ }^{1}$ Diese ganz auf H.'s eigene Kosten ausgeführte Reise wurde in ihren allmählich bekannt werdenden ausserordentlichen Resultaten für fast alle Gebiete d'es menschlichen Wissens und Verkehrs von so weltgeschichtlicher Bedeutung, dass man HunвoLd als den zweiten CoLumbus in Europa begrüsste. Nach zweijährigem Aufenthalte in der Heimatlı siedelte er nach Paris iiber, wo er sich 1808 bis 1827 mit der Bearbeitung der Ergebnisse seiner Reise beschäftigte und deren Herausgabe leitete. Die botanische Abtheilung war zuerst von Bonpland selbst (vergl. diesen) in Angriff genommen, der die Monographie der Melastomaceen und die Plantes équinoxiales bearbeitete, dann aber Willdexow und nach dessen Tode (1812) K. S. Kunth übertragen worden; den berühmten Essai sur la géographie des plantes hatte $\mathrm{H}$. bereits 1805 veröffentlicht. Im Jahre 1827 liess sich H. in Berlin nieder und lebte in der nächsten Umgebung des Königs, der ihm bald darauf den Titel Excellenz verlieh. Aber schon 1829 trat er eine neue grosse Reise nach dem Innern des russischen Reiches an, nach dem Ural, Altai

1) Ueber die Betheiligung der beiden Gelehrten an den Sammeln, Präpariren und Untersuehen der Pflanzen sehreibt II, in den Plant. équin. (1805) préface p. VI: „Unis par les liens de l'attaehement le plus tendre, nous avons partagé toutes les souffranees et les dangers de cette entreprise; nous avons herborisé ensemble pendant plus de six ans. Les plantes ont été recueillies par nous deux; et malgré les travaux astronomiques et les recherehes géologiques auxquels je me suis livré, j'en ai dessiné un grand nombre sur les lieux: mais à peine un neuvième a été décrit par moi. C'est M. Bonpland qui, avec le dévouement le plus grand, au milieu des fatigues de ce voyage pénible et souvent aux dépens de son sommeil, a préparé et séché lui seul près de soixante mille échantillons de plantes." 
und dem Kiaspischen Meere, begleitet von dem Mineralogen G. Rose und dem Zoologen und Botaniker C. G. Emmxiserg; die Resultate derselben wurden in den Werken: Reise nach dem Ural etc. und Asie centrale reröffentlicht. Nachdem II. bis 1848 noch melırere Male in halbdiplomatischen Sendungen in Paris geweilt hatte, lebte er von nun an fast ununterbrochen in Berlin und starb daselbst am 6. V. 1859.

Coll. Die Hauptsammlung der amerikanischen Reise (6200 Arten nach Hunzoldt in Plant. équin. préface p. III) befindet sich im Museum zu Paris, Doubletten im Herb. Wrubdexow (hier auch einige Unica) und Kuxtr im Berliner botan. Museum; die Sammlungen der asiatischen Reise in Berlin. Sein eigenes Herbar schenkte H. schon frühzeitig an Kunth; es enthielt aber nichts von seinen Reisen, sondern hauptsächlich Sellow'sche Pflanzen aus Brasilien.

Lit. Las. Mus. Deless. p. 417-418, 452-453; Lindo. et Planch.: Troisième royage de J. Linden I (1863) p. XLII - XLIV; II. Klenche: Alexander von Hunboldt III. Aufl. Leipzig 1859 ; C. F. P. von Martius: Denkrede auf Alexander von Hunboldt in Sitzg. K. Bayer. Akad. d. Wissenschaft. Miünchen 1860. $4^{0} 40 \mathrm{p}$; A Alfred Dove in Allg. Deutsche Biogr. XIII (1881) p. 358 - 383 (mit Literatur); Heusc. Biol. IV p. 121-122; León Bibl. Botán.- - Lexic. (1895) p. 340 -- 343; Pritz. Thes. II ed. p. 152 - 153; Jacks. Guide p. 114, 133, 136, 221, 370, 502; Cat. Sc. Pap. III p. 462-467, VII p. 1035 - $1036, \mathrm{X}$ p. 292; A. Fischer von WaLdheim in Bull. Soc. imp. Natur. de Moscou XLII (1869) II p. 89-102 (Bericht über die botanischen Werke A. vos Hбuвoldt's, russisch). Ueber die Publicationsdaten der einzelnen Lieferungen ron Humbolds's Voyage aux régions équinoxiales vergl. C. D. Sherborin und B. B. Woonward in Britten's Journ. of Bot. XXXIX (1901) p. $202-205$.

Humphrey, James Ellis, (1861-1897), geb. in Weymouth, Mass. (U. S. A.) den 5. VIII. 1861, graduirte daselbst 1877, studirte seit 1882 an der Lawrence scientific School der Harvard Universität zu Cambridge, wurde 1885 B. S. und Assistent von Prof. Goodale. 1887 erhielt er die Stelle eines Instructors of Botany an der Universität von Indiana, 1888 an der State Experiment Station zu Amherst (Mass.) und promovirte 1892 an der Harvard Universität mit einer Nonographie der nordamerikanischen Saprolegniaceen. Im Januar 1893 trat er seine erste Reise nach Jamaica an, um mehrere Nonate in der Umgebung ron Port Antonio die Meeresalgen zu studiren, und ging dann nach Bonn, wo er seine Studien bei Prof. Strasburaer fortsetzte. 1897 wurde er Professor der Botanik an der Johns Hopkins Universität zu Baltimore und fülırte im Sommer desselben Jahres eine zoologisch-botanische Expedition nach Jamaica, wo er am 17. VIII. 1897 in Port Antonio am Fieber starb.

Coll. Sammelte nur Kryptogamen, welche wohl in Baltimore geblieben sind. Dupla der Algen in Phycotheca von Collins, Holden und Sercheld, die Pilze im Berliner Museum. 
Lit. J. S. Kincislet and B. WY. Barton: James Eldis Humphrey in Johns Hopkins Unir. Cirenl. vol. XVII (1897) Nr. 132 p. 17-19; Amer. Natur. XXXI (1897) p. 920-922 mit Porträt, Auszug daraus in Botan. Caz. Chicago vol. XXIV (1897) p. 387 -388; Urb. Symb. II p. 2.

IInsuot. T., machte 1868 eine Reise nach Guadeloupe, Martinique und Marie-Galante und sammelte daselbst vier Monate lang hauptsächlich Glumaceen, Farne, Laub- und Lebermoose, sowie eine Anzahl Pilze und Flechten. Auch stellte er Beobachtungen an über die Häufigkeit und Seltenheit der Arten, ihre Stationen und die Höhe, bis zu welcher sie vorkommen. Er lebt jetzt in Cahan bei Athis, Dép. Orne, und beschäftigt sich besonders mit Woosen und Exsiccaten. Coll. (an sechs Cent.). Die Glumaceen z. B. im British Museum und Kew, die Farue ebenda, sowie in Paris, Brïssel, bei de Caxdolde, die Moose z. B. im British Museun, Kew und bei rerschiedenen Interessenten, die Originalien der Laubmonse im Herb. Schmper (jetzt in Kew), die der Lebermoose im Herb. Gotтsche (jetzt in Berlin), die Flechten und Pilze z. B. im British Nuseum, Paris.

Lit. Pritz. Thes. II ed. p. 153; Jicks. Guide p. 275, 277, 281, 369, 475 ; Cat. Se. Pap. VII p. 1041, I p. 297; Unb. Symb. I p. 74, 141.

Jacquemont. Victor, (1801-1832), geb. zu Paris den 8. VIII. 1801, trat als Voyagenr-naturaliste des Muséum d'histoire naturelle im Jabre 1 s26 eine Sanmelreise nach Nordamerika an und begab sich ron da nach Haiti, wo el vom März bis Mai 1827 hauptsächlich die Umgebung ron Port-au-Prince und Marquissant, St. Marc, Gonaïres, die Rivière froide, Source Barraur, den Col de l'Escalier und die Bords de l'Ester botanisch erforschte. Während der Jahre 18_s - 1832 machte er im Anftrage rles französischen Gouremements eine Reise nach Ostindien. Auf dem Wege dahin besuchte er Teneriffa, Rio de Janeiro, Capland, Réunion und Pondichery. Im Mai 1829 kam er in Calcutta an, ging über den Himalaya nach T'ibet, ron da nach Kashmir und Pendjab und starb den 7. XII. 1832 zu Bombay.

Coll. Museum zu Paris (theils direct, theils im Herb. Jussieu, theils 1889 aus dem Besitze des Herru J. Hexvecurt erhalten), Doubletten in Montpellier (ex lerb. Caubess.), im Berliner Musenm und ca. $150 \mathrm{Nr}$. im Herb. Krog et Urbax.

Lit. Voyage dans l'Jnde par Tictor Jacrevmont vol. I (1841)p. I- III; Las. Mus. Deless. p. $153-155$; Dict. Scienc. nat. I.XI (1845) p. $165-166$; Comte Enouard de Warrex: La vie et les oenvies de Jucquemoxt. Nancy 1852. $8^{0}$ (n. r.); A. de Lacazé in Dinot Nonv. Biogr. génér. vol. XXVI (1858) p. 223 - 226; Pritz. Thes. II ell. p. 153 ; Cat. Sc. Pap. III p. 523.

Jacquin. Nicolaus Joseph Freiherl von, (1727-1817), geh. in Leiden (Holland) den 16. 11. 1727 als Soln eines reichen Tuchfabrikanten, 
besuchte das Gymnasium zu Antwerpen, studirte P'hilosophie auf der Universität Löwen, Medicin zn Leiden und wurde hier von Rosws in die Botanik eingeführt. Darauf erhiclt er eine Assistentenstelle als Wundart in L'aris, wo er zugleich Gelegenheit hatte, Anton Jussieu's botanische Vorlesungen und Bernilird Jussieu's Gartenanlagen zu besuchen. Im Jahre 1752 kam er nach Wien, um seinc wedicinischen Studien zu vollenden. Hier wurde er dem Kaiser Franz I. bekannt, der ihm den Auftrag crtheilte, für den kurz vorher angelegten Garten zu Schönbrunn und die damit verbundenen Menagerien, sowie für das Hof-Naturaliencabinet in Westindien und dem benachbarten südamerikanischen Festlande zu sammeln. Begleitet von dem Gärtner Richard vas der Schot und zwei italienischen Präparatoren, kam er am 28. Juni 1755 in Martinique an und besuchte bis zum Jahre 1759 nach Süden hin St. Vincent, Grenada, Curaçao, Aruba, Venezucla und die Umgebung von Carthagena in Neu-Grenada, nach Norden Guadeloupe, St. Kitts (St. Christoph), St. Eustache, St. Martin, St. Barthelemy, Haiti (1757 bis 1758), Jamaica (1758) und Cuba (1758-1759). Der Erfolg der Reise war, trotzdem J. durch Krankheit auf Haiti lange am Sammeln gehindert und während des französisch-englischen Krieges bci einer Seefahrt gefangen genommen und nach Montserrat und Gonave bei Haiti geschleppt wurde, nach jeder Richtung hin befriedigend: eine Fülle von lebenden Thieren und Pflanzen wurde den Wiener Anstalten von ihm und seinen Begleitern in sieben grossen Transporten zugeführt; umfangreiche Herbarien sowie zahlreiche an Ort und Stelle entworfene Zeichnungen brachte er selbst mit. Nach seiner Rücklehr wurde er Professor der Chemie in Schemnitz, 1768-1797 Professor der Chemie und der Botanik an der Universität in Wien. Seitdem in den Ruhestand getreten und 1806 zum Freiherm ernannt, starb er am 24. X. 1817 in Wien.

Coll. Ueber den Verbleib von J.'s westindischem Herbar ist nichts bekannt. Doubletten im Herb. Banks im British Museum zu London und im Herb. Wildidenow zu Berlin.

Lit. JAcQ. Hort. Schoenbr. I (1797) p. II-III; J. N. Ramann: Rede zur Gedächtnissfeier Nic. Jos. Frexherrin v. Jacquin's, Wien 1818. $4^{0} .28$ p.; Las. Mus. Deless. 1. 488; Sarg. Silva V p. 155; A. Umlauff in R. v. WetrTstrin: Die Botanischen Anstalten Wiens p. 36--37; Pritz. Thes. II ell. p. 154 ; Jacks. Guide p. 13, 110, 112, 139, 144, 263, 270, 369, 416, 417, XXVIII; Unв. Symb. I p. $75-78$.

Jäger, Benedict, sammelte in den Jahren 1825-1827 für den botanischen Garten in St. Petersburg in der Krim, Südrussland, dem Kaukasus und Georgien und 1827-1828 in gleicher Eigenschaft auf Haiti, theils in der Ungebung von Port-au-Prince im Verein mit 
C. Emresberg und den Prinzen F. P. vos Wïrttenberg, theils auf weiteren Excursionen bis nach Miragoane hin. Er blieb bis mindestens 1830 auf der Insel und präparirte aucl Tögel, Insekten, Reptilien etc. für den Verkauf. Seine den Interessenten auf Torausbezahlung angebotenen Pflanzen scheinen nur wenige Abnehmer gefunden zu haben.

Coll. Botan. Garten zu St. Petersburg (359 Arten), beste Doublette im Herb. Krug et Urbas, Oxford.

Lit. Reg. Flora X (1827) I. Beibl. p. $10-12$, XIII (1830) p. 45: Urib. in Engl. Bot. Jahrb. XXIV (1897) Beibl. 58 p. 4 et \$ymb. I p. 79; Maxımowicz briefl. Mittheilung; Pritz. Thes. II ed. p. 154.

Jamain sammelte in Cuba 1863. - Ich weiss nicht, ob derselbe identisch ist mit Alexandre Jayaix, welcher nach Bull. Soc. bot. de France vol. X p. VII an 12. XII. 1863 starb.

Coll. Hofmuseum in Wien (ex herb. Reichenbach fil.).

Jardiu. Edélestan, sammelte 1849-1850 an der Westküste A frika's, 1859 auf den Marquesas-Inseln, 1861 auf Guadeloupe und Martinique und bereiste die Sandwich-Inseln, Californien, die Vereinigten Staten, Terre Neure, Island, die Faroer und Norwegen.

Coll. Herbar des botan. Gartens zu Caen, Bayonne und z. Th. in Paris (die ron Westindien umfassen ca. $3 \frac{1}{2}$ Cent.).

Lit. Briefl. Mittheilung von Père Duss; Pritz. Thes. II ed. p. 155; JAcrs. Guide p. 404; Cat. Sc. Pap. III p. 537, VIII p. 17, X p. 328.

Jenman. George Samuel, früher in Kew, war 1873-1879 Superintendent des botanischen Gartens zu Castleton auf Jamaica und erforschte während dieser Zeit in eingehendster und erfolgreichster Weise die Farnflora der Insel von der Küste bis zu den höclısten Peaks. 1879 wurde er Superintendent des botanischen Gartens und Government Botanist zu Georgetown in British Guyana und machte hier auch grosse Sammlungen von Phanerogamen.

Coll. Die Hauptsammlung der Farne in J.'s Priratherbar, Doubletten in Kew und im British Museum; die Guyana-Pflanzen in Kew.

Lit. D. Morris in Kew Bull. Add. Ser. I (1898) 1. 27; briefl. Mittheilung von J. und Heuslex; Jacks. Guide 1).509; Cat. Sc. Pap. X p. 335; Urв. Symb. I p. $\mathrm{S} 0-82$, II p. 3 , III p. 5 .

Imray. John, (1811-1880), geb. in Schottland den 11. I. 1811, war Arzt auf Dominica und starb daselbst den 22. VIII. 1880. Die Kenntniss der Flora der Insel ist hauptsächlich ilm zu verdanken. Seit 1837 mit der Erforschnng derselben beschäftigt, wurde er oin eifriger Correspondent von sir IV. Hooker und J. LiNDLEF und schickte getrocknete 
und lebende P'flanzen mit ausfiihrlichen Notizen nach Kew, später auch an Grisemacil (bis etwa 1864).

Coll. Kew, Herb. Grisensan in Göttingen, Herb. Kliur et Urisax.

Lit. Journ. of Bot. XVIII (1880) 1. 320; Gart. Chron. n. ser. XIV (1880) p. 361; Bгтtт. and Boulg. p. 90; Cat. Sc. Pap. X p. 306.

Johow, Friedrich Richarl Adalbert, (* 185̃!), geh. zu Chodziesen (jetzt Kohmar) in der Prov. Westpreussen am 5. II. 1859 als Sohn eines Kreisphysikus, studirte 1877-1879 zu Berlin, $1879-1880$ zu Boun Naturwissenschaften, wurde 1880 zum Doctor promovirt und machte im Winter 1882-1883 mit Unterstützung der Kgl. Akademie der Wissenschaften zu Berlin eine Reise nach Trinidad, Dominica und Venezuela. 1884 habilitirte er sich in Bonn als Privatulocent, wanderte aber 1889 nach Clile aus, wo er jetzt Professor am Instituto pedagógico zu Santiago ist. Von hiel aus besuchte er Dec. 1881 bis Febr. 1892, Juli 1892 und Juni 1895 Juan Fernandez und beschrieh in ausgezeichneter Weise die Flora dieser Inseln (Estudios sobre la Flora de las Islas de Juan Fernandez. Santiago de Chile. $4^{0}$. 1896).

Coll. Museumsgegenstände und die wenigen von ihm in Westindien und Venezuela gesammelten Pflanzen im botan. Musemm zu Berlin.

Lit. Inaugural-Dissertation (Untersuchungen ïber die Zellkerne etc.) Bonn 1880, mit Tita; briefl. Mittheilung des Herm Prof. H. Schenck in Darmstadt; JAcrs. Guicle 1. 75, 490; URг. Symb. I p. $82-83$.

Isert, Paul Erdmann, (1757-1789), geb. in Dänemark im Jahre 1757, ging 1783 als Oberarzt nach den dänischen Besitzungen in Guinea, um sich nebenbei naturgeschichtlichen Studien zu widmen, und blieb daselbst bis 1786. Die Rückreise fülırte ilın über Amerika (Columbien) und zwar uach den Inseln St. Croix, St. Thomas, St. Jan, St. Eustache, Guadeloupe und Martinique; namentlich auf der erst- und letztgenannten Insel legte er 1787 grössere botanische Sammlungen an und kehrte in demselben Jahre über St. Croix nach Kopenhagen zurück, wo er schon 1789 starb.

Coll. Botan. Museum in Kopenhagen, Herb. Whudesow in Berlin, Universititsherbar in Leipzig.

Lit. Warm. in Bot. Tidsskr. Kopenh. XII (1880) p. 79; Kinersז. l. c. XXIII (1900) 1) 41; Prtz. Thes. II ed. p. 158; Uri. Symb. I p. 84.

Kendal, Superintendent an Castleton Gardens in Jamaica, sammelte Farne, welche ron G. S. Jenmax in seiner Synoptical list bearbeitet wurden.

Kohaut, Franz, Gärtner aus Neuhaus in Böhmen, begleitete F. W. Subber 1817-1818 auf seiner Reise nach Kreta, Aegypten 
und Palästina, sammelte $1 \$ 19-1821$ in dessen Auftrage auf Martinique und starb 1822 auf cincr Reise an Senegal (vergl. Sinber).

Kíause, E. H. L., (* 1859), geh. zu Stade in Himnover (Deutschland) den 27. VII. 1859, wurde 1881 in Berlin zun Dr. med. promorirt und besuchte als Marinestabsarzt Jan. bis März 1890 Barbados, St. V incent, Dominica, St. Thomas und Haiti (bei Jacmel). Er lebt jetzt als Oberstabsarzt in Saarlouis.

Coll. Herb. Kravse und Klivg et UrbaN (105 Nr.).

Lit. Briefl. Mittheilung ron $\mathrm{K}$.

lírass, Chr., sammelte vor 1838 auf Guadeloupe.

Coll. Herb. de Candolle.

Krebs, Henrik Johannes, (*1821), geb. in Svendborg auf Fünen (Dänemark) den S. VI. 1821 als Soln des Predigers J. K. A. Krikebs, studirte Pharmacie mol ging im Herbst 1843 nach St. Thomas. Von dieser Insel aus machte or verschiedene Reisen nach Nord- und Südamerika, zu den Bermudas und den Bahamas (1866), nach Cuba, Jamaica, Sto. Domingo, Portorico und mehreremals nach s't. Jan und St. Croix. Seit 1853 war er schwedisch-norwegischer Consul auf St. Thomas und zuletzt Präses des Kolonialrathes daselbst. In Jahre 1870 kehrte er nach Dänemark zurück und wohnt jetzt in Kopenhagen. Er veröffentlichte vcrschiedene Aufsätze über Mollusken.

Coll. Botan. Museum in Kopenhagen.

Lit. Warm. in Botan. Tilsskr. Kopenh. XII (1880-1881) p. 188; Ḱnersk. 1. c. XXIII (1900) 1) 41; Cat. Se. Pap. III p. 747, VIII p. 123, X p. 462; URe. Symb. I p. 89.

Kirug, Cart Wilhelm Leopold, (1833-1898), geb. in Berlin den 1. IX. 1833 als Sohn des Rittergutsbesitzers KARL Krou auf Mühlenbeck bei Berlin, besuchte das Joachinsthal'sche Gymmasium, machte das Abiturientenexamen am Gymnasium zum Grauen Kloster und widmete sich damn dem Kaufmannsstande. Noch vor Ablauf der Lehrzeit in Brenen trat er 1857 in das Weltgeschäft von Lameyer \& Co., nachmals Scnulze \& Co. in Mayagüez auf Portorico ein, wurde später alleiniger Inhaber desselben und deutseher sowie englischer Viceconsul. Die Fauna und Flora der Insel verdankt $K$. mehr als allen anderen Reisenden zusammengenommen, sowohl durch seine eigencn Sammlungen (im westlichen 'Theile derselben), als auch durch diejenigen, wchehe Jon. Gusdach 1873 und 1875-1876 und P. Sistexis 1854-1S87 auf seine Kosten zusimmenbrachten. Im'Jahre 1876 nach Berlin zurückgekehrt, widmete cr scine Zeit und Arbeitskraft durch Unterstiitzung von anderen Reisenden, Zusammenbringen und Ordnen der Exsiccaten, durch Ansziehen der gesammten einschlägigen Literatur, Anfertigung eines Ver- 
zeichnisses der Vernacularnamen u. s. w. im Verein mit dem Verfasser fast ununterbrochen den Vorarbeiten einer Flora Indiae occidentalis, bis ihn am 5. IV. 1898 auf seiner Besitzung in Gross-Lichterfelde bei Berlin der Tod aus seiner 'Thitigkeit hiuwegraffte. Der preussische Staat hatte ihm für seine Verdienste um die Wissenschaft den Professortitel veriehen.

Coll. $1554 \mathrm{Nr}$. Portorico-Ptlanzen (mit Einschluss der von GuxdLacu gesammelten) im Herb. Krug et Urbax, desgleichen 340 in Portorico nach der Natur gezeichnete colorirte Tafeln Abbildungen.

Lit. Ian. Urban: Leopold Krug in Ber. deutsch. Botan. Gesellsch. XVI (1898) p. (23) - (37); K. Schumans: Consul Leopold Krug in Verh. Bot. Ver. Brandenb. XXXX (1898) p. CVI-CIX; UnB. Symb. I p. $89-90$.

Kiuntze, Carl Ernst Otto, (*1843), geb. zu Leiprig den 23. VI. 1843, war mit 14 Jahren in der ersten Klasse der dortigen Realschule, lernte das Drogerie-Geschäft und besuchte die Handelsschule. Schon während dieser Zeit durchforschte er die Flora ron Leipzig ziemlich vollständig und beschäftigte sich auch mit den Algen derselben; als Resultat der Studien erschien 1867 die Taschenflora von Leipzig. 1863 bis 1866 conditionirte er als Kaufmann in Berlin, machte grössere Reisen durch Mitteleuropa und Italien und betrieb 1868-1873 in Leipzig eine eigene Fabrik ätherischer Oele. Hierdurch zu Wohlstand gelangt, beschloss er sein weiteres Leben der naturwissenschaftlichen Forschung zu widmen. Zunächst machte er $1874-1876$ eine Reise um die Erde: von Westindien (St. Thomas, Portorico, Saba, Barbados, Trinidad) nacl Venezuela, Neu-Granada, Panama, Costarica, Vereinigte Staaten ron Nordamerika, Japan, China, Anam, Cochinchina, Kambodja, Siam, Java, Singapore, Penang, Birma, Vorderindien, über Aden und Aegypten zurück. Darauf studirte er 1876-1878 in Leipzig und Berlin Naturwissenschaften und wurde im Juni 1878 zu Freiburg in Bad. auf Grund einer Arbeit über Cinchoma zum Dr. phil. promovirt. Nachdem K. in den folgenden Jahren sein Reisewerk "Um die Erde" abgefasst und verschiedene Fragen allgemeinerer Natur behandelt hatte, bearbeitete er in Berlin und Kew die uiber 7700 Nummern umfassende Pflanzenausbeute seiner Weltreise. Die Veröffentlichung hierïber wurde 1891 in Verbindung mit einer nach strengsten Prioritätsregeln vorgenommenen Revision der Gattungsnamen ausgeführt. Zwischendurch waren von ihm verschiedene Monographien (Sargassum, Clematis), die Bearbeitung der Pechuel'schen Pflanzen aus dem Hererolande, sowie der von ihm 1886 im russischen Vorderasien gesammelten Pflanzen erschienen; seine Ausbeute von den Canarischen Insehn 1887-18S8 ist in die Revisio gener. mit aufgenommen. - Die zweite grosse Reise 1891-1892 ging 
nach Südamerika: ron Montevideo nach Argentina, Chile, Boliria, Mattogrosso in Brasilien, Paraguay, Argentina, Uruguay und dem östlichen Brasilien. Auf der dritten Reise, welche durch eine Erkrankung an Emphysem veranlasst wurde, besuchte K. 1894 das Capland, Transvaal, Orange-Freistaat, Natal, Delagoabay, Beira, Mozambik, Dar-es-Salam in Deutsch-Ostafrika und Zanzibal. Die Resultate derselben wurden im III. Theile der Rev. Gen. publicirt. Einen weit über seine Specialstudien hinausgehenden Namen hat sich K. durch die Behandlung der Nomenclaturfrage gemacht.

Coll. Herb. O. Kuxtze in San Remo; Doubletten im Berliner Museum, Kew Herbarium etc., von Westindien im Herb. Krua et Urbax.

Lit. Adolf Miessler: Dr. Otтo Kuntze in Deltsche Rundschau für Geogr. und Statistik XI (1889) p. 572-574 (mit Porträt); O. Koxtze Rev. Gen. I p. $\mathrm{X}-\mathrm{XI}$, III ${ }^{\mathrm{Il}}$ p. $1-4$ (Itinerare), I post p. CLV, III ${ }^{11}$ post 201 (Sehriftenverzeichnis bis 1898); briefl. Mittheilung von O. K.; Pritz. Thes. II el. 1. 172; Jucks. Guide p. 97, 101, 128, 143; Cat. Sc. Pap. VIII p. 137, I p. 478 ; Urв. Symb. I p. 90.

Lahaye (Abbé de la Haye) (? - 1802), lebte gegen Ende des 18. Jahrhunderts als Pfarrer in Dondon, südlich von Cap Haitien, auf Haiti, war ein eifriger Botaniker und sollte die Direction eines 1796 von Porteau in Cap anzulegenden botanischen Gartens übernehmen. Es wurden aber von dem franz. Gouvernement keine weiteren Mittel bewilligt. Als warmer Vertreter der Interessen der Schwarzen in ihrem Unabhängigkeitskampfe gegen die Franzosen kam er nach der Rückkehr der letzteren im Jahre 1802 in den Verdacht, zu seinen Landsleuten zu halten, und wurde deshalb von den Negern ermordet.

Coll. Pflanzen von ihn scheinen im Herb. Jussieu des Pariser Museums zu sein (cf. Juss. Gen. p. 150) .- Nicht zu verwechseln mit ihm ist der Gärtner LaHaıe, welcher Vorgänger von Poiteau als Chef de l'école de botanique im Jardin des plantes zu Paris war und darauf mit $\mathrm{L}_{A_{-}}$ BILLARDIÈE 1791 - 1797 an der Expedition Theil nahm, welche unter dem Kommando von D'Extrecasteaux die Pérouse aufsuchen sollte (ef. Las. Mus. Deless. p. $75-78,267$ ).

Lit. Mackenzie: Notes on Haiti I $(1830)$ p. 183 ; E. Buread in Nouv. Arch. du Muséum III sér. vol. IX p. 15, 16; Urв. Symb. I p. 67.

Lame, A. W., Wundaryt, besuchte (schon vor 184t) die Bermudas, Cuba, Jamaica, St. Thomas, Antigua, Barbados, Grenada und Trinidad. Seine Pflanzen gingen durch Vermittelung W. Browr's in Edinburgh in den Besitz von WV. Hooker über.

Coll. Kew Herbarium.

Lit. Hook. Lond. Journ. Bot. III (1844) p. 226; W. B. Hexsl. Bot. Chall. Exp. (1884) p. 5. 
Lamier, Alejo Helvecio, Naturforscher und Nathematiker, sammelte 1831 Pflanzen und Conchylien für Ranox dE la SAGRA (cf. diesen) auf der Insel Pinos bei Cuba, ron welcher er 1836 auch eine geographische Beschreibung publicirte. Später liess er sich in Cienfuëgos nieder.

Lit. Ranon de la Sagra Cuba X Introd. 1. 29 und XI p. 45 ; CalCagno: Dice. biogr. Cubano (1878) p. 366 ; Cat. Sc. Pap. III p. 844.

La Sagra ef. Sagra.

Lassen, Holger Jorgen, (*1868), geb. in Kopenhagen den 10. VII. 1868, betheiligte sich nach beendigtem Studium 1890 an einer Expedition nach Grönland und begleitete 1891-1892 Warursi (vergl. diesen) nach Westindien und Venezuela.

Coll. Botan. Museum in Kopenhagen.

Lit. Kratersk. in Bot. Tidsskr. Kopenh. XXIII. (1900) p. 42.

Leblond, Jean Baptiste, (1747-1815), geb. zu Toulongeon bei Autun (Frankreich) den 2. XII. 1747, studirte Medicin, machte eine naturhistorische Reise nach dem tropischen Amerika, kan 1767 nach Martinique, besuchte Sta. Lucia und andere Antillen und ging über Trinidad nach Venezuela, Neu-Granada und Peru. Später wurde er von dem französischen Gouvernement nach Guyana geschickt, um Untersuchungen über die Chinapflanzen anzustellen, und blieb daselbst bis 1802, indem er beträchtliche Sammlungen machte. Sein Tod erfolgte den 4. (oder 15.) VIII. 1815 zu Guzy im Dép. Nièvre (Frankreich).

Coll. Museum zu Paris; Herb. Richard (jetzt Drane del Castillo in Paris), Herb. Delessert und de Candolle zu Genf.

Lit. Lenbond: Voyage aux Antilles et à l'Amérique méridionale. Paris 1813. $8^{0}$ (n. v.); Las. Mus. Deless. p. 225 ; F. Denis in Dinot Nouv. Biogr. génér. XXX (1859) p. 99-101; Primz. Thes. II ed. 1. 178; Cat. Sc. Pap. III p. 910.

Ledru, André Pierre, (1761-1825), geb. zu Chantenay bei le Mans, Dép. Sarthe (Frankreich), den 22. I. 1761, Geistlicher von Beruf, begleitete als Botaniker die Expedition des Kápitäus Baudn nach Westindien. Man segelte Ende Sept. 1796 ron Hâre ab, wurde fast sechs Monate auf den canarischen Inseln zurïckgehalten, lief auf acht Tage Trinidad an, ohne viel sammeln zu können, und blieb in St. Thomas rom 29. April bis 16. Juli 1797. Von hier aus machte L. einen zwölftägigen Abstecher nach St. Croix, wo er mit West zusammen botanisirte. Vom 17. Juli 1797 bis 13. April 1798 wurde die nördliche und nordöstliche Partie von Portorico untersucht, welche wie St. Thomas eine reiche Ausbeute an lebenden und getrockneten Pflanzen sowie an Sämereien lieferte. Nach seiner Rückkehr wurde er 
Professeur de législation an der Ecole centrille le la Sarthe in Le Mans, legte hier einen botanischen Garten an und schrieb mehrere lokathistorische, biographische und krunstgeschichtliche Arbeiten. Er starb in Le Mans den 11. VII. 1825.

Coll. Herb. Jussieu und Generalherbar im MIuseun zu Paris (ca. 900 Species in s000 Exemplaren), einiges auch im Herb. Limırck daselbst, Dupla im Museum zu Berlin (ex herb. Kuxтн), Krug et Urвax, Florenz (herb. Wrebi ex herb. Desfoxtatses), Montpellier (ex herb. Cinmess;). Die Vaterländer auf den Etiquetten in Paris sind nicht immer zuverlässig: manche St. Thomas-Pflanzen rïhren zweifellos von Portorico her, auch sind den Sammlungen Pflanzen ron Sto. Domingo beigemengt. Das Privatherbar L.'s im II seum der Stadt Le Mans.

Lit. Las. Jus. Deless. p. $490-491$; Dinot Nour. Biogr. génér. XXX (1859) p. 267 -268; Pritz. Thes. II ed. p. 179 ; Cat. Se. Pap. III p. 923; Urв. Symb. I p. $93-95$.

Lefebre sammelte 1877 auf Guadeloupe Moose.

Coll. Herb. Bescherelle.

Lefroy, Sir John Henry, (1817-1890), geb. zu Ashe in Hampshire (England) am 28. I. 1817, besuchte 1831-1833 die MilitärAkademie zu Woolwich und wurle 1834 Artillerie-Lientenant. 1839 bis 1842 stellte er in Auftrage der onglischen Regiermg in st. Helena, 1842-1844 im englischen Nordamerika magnetische und meteorologische Boobachtungen an, welche durch ihre Genauigkeit und Methodik allgemeine Anerkennung fanden. 1844 begab er sich wiederum nach Toronto, begrïndete das Canadische Institut und war bis 1853 dessen Präsident. Nachdem or in den folgenden Jahren wichtige militärische Stellungen bekleidet und namentlich fiir die Artillerie reorganisatorisch thätig gewesen war, nahm er 1870 als Genorahmajor seinen Abschied. $1871-1877$ war L. Gouverneur und Oberkommandirenter auf den Bermudas und erwarb sich um diese Inseln durch die Erforschung der Geschichte derselben, durch Aufsammeln der einheimischen Flora, Einführung ron Kulturgewächsen, meteorologische und magnetische Beobachtungen und durch Hebung der Wohlfahrt der Beriillierung sehr grosse Verdienste. 1850-1882 war er Gouverneur von Tasmania, zog sich darauf rom öffentlichen Leben zurück und starb am 11. IV. 18:90 zu Lewarne bei Liskeard in Cornwall (England). (Mass.).

Coll. Kew Herbar, einiges auch im Girar-Herbar zu Cambridge

Lit. W. B. Hemsu. Bot. Chall. Exp. (1884) 1).5-6; Sir Jos. D. Hooker in Proc. of the Royal Geogr. Soc. XIII (1\$91) p. 115-122; R. H. Veten in Dict. Nat. Biogr. XXXII (1892) p. 399 -404; Cat. Sc. Pap. IIl p. 930 , X p. 552; Urв. Symb. I p. 95. 
Lehmann, Friedrich Carl, Gärtner von Fach, machte grosse Sammelreisen in Centralamerika mul dem nördlichen Sïdamerika, besuchte im Sept. $1881 \mathrm{~J}$ amaica und lebt jetzt als dentscher Consul in Popayan in Columbien.

Coll. Das Hauptexemplar der älteren Sammlungen wurde an W. Barber in Genf verkauft, das der neueren Sammlungen schenkte er dem botan. Museum zu Berlin, ausserdem im British Museum, Botan. Garten zu St. Petersburg u. s. w.

Leibold, Friedrich Ermst, (1804-1864), geb. in Dorfgarten bei Kiel (Preussen) den 9. XII. 1804, lernte bei Boorn in lilottbeck die Gärtnerei und war dann im Jaxack'schen Garten in Ham bei Hamburg thätig. Von seiner ersten Reise 1835-1838, auf der er den Baron von Lunwig nach dem Caplande begleitete, brachte er reichhaltige Sammlungen heim. Eine zweite Reise unternahm er 1839 nach Cuba und Mexico und eröfinete nach seiner Rückkehr 1844 mit den Ergebnissen dersetben zu Dresden ein „Mexicanisches, Ost- und Westindisches Naturalien- und ethnographisches Cabinet" (cf. Regensb. Flora XXX 1847 p. 360). Nachdem er letzteres veräussert hatte, begab er sich 1847 mit seiner Familie von Neuem nach Amerika und lebte als Farmer in 'lexas, bis er durch den Krieg von dort vertrieben wurde. Er liess sich zunächst in New Orleans nieder und plante eine wissenschaftliche Reise nach Yucatan. Auf dem Wege dorthin starb er in Habana den 21. VII. 1864.

Coll. Universitätsherbar in Leipzig, Kiel, Herb. SchLEchtexdat in Halle, Prag.

Lit. E. OTто in Iamburger Garten- und Blumenzeitung XX (1864) p. 476 -477; D. F. L. von Schlechtendat in Botan. Zeitung XXII (1864) 1. 328; Hexss. Biol. IV p. 129; Cat. Sc. Pap. III p. 939.

L'Epagnier sammelte 1844 in Haiti in der Umgebung von Portau-Prince hauptsiichlich Farne.

Coll. Herb. Denessert in Genf, Herb. Fée im botanischen Garten zu Rio de Janeiro.

Lit. F́́E: Hist. des fougères et lycop. des Antilles.

L'Ilerminier, Félix Louis, (1779-1833), geb. in Paris den 18. V. 1779, liess sich 1798 als Apotheker in Guadeloupe nieder und legte hier botanische, mineralogische und zoologische Sammlungen an. 1815 besuchte er Antigua, St. Barthelemy, St. Eustache, Saba, St. Thomas und die Vereinigten Staaten von Nordamerika; auch in Tobago scheint er gewesen zu sein. Er kehrte 1829 nach Frankreich zuriick und starb den 25. X. 1833 in Paris. 
Coll. Muséum d'list. nat. zu Paris; Herb. Botssıer-Barber in Genf (meist geben die Etiquetten bei deu Pflanzen nicht an, ob Vater oder Sohn der Sammler war).

Lit. Gumbourt: Notice sur F. L. L'Hermner. Paris 1834. S. 18 p. (ex Pritz. Thes. II ed. p. 184); Las. Mns. Deless. P. 491 ; Dinot Nonv. Biogr. génér. XXXI (1860) p. 74 ; Uri. Symb. I p. 95.

L'Herminier, Ferdinand, (1802-1866), geb. in Basse-Terre anf Guadeloupe den 20. VI. 1802 als Sohn des vorigen, studirte in Paris Medicin und starb als selr angeselrener Arzt in Pointe à Pitre auf Guadeloupe den 11. XII. 1866. Wegen seiner Verdienste um die Insel, besonder's bei dem grossen Erdbeben 1843 und der CholeraEpidemie 1866 wurde er zım Ritter bez. Officier der Ehrenlegion ernannt; dio Stadt setzte ilm auf seinem Grabe ein Monument und benannte das naturhistorische Museum der Insel Musće L'Herminier; auf der Spitze des Vulkans Soufrière befindet sich ein Ort, genannt ,Jardin l'Herminier". Die Kenntniss der Flora der Insel, besonder's der kryptogamischen Gewächse (Farne, Laub- und Lebernoose, Flechten, Pilze), wurde durch den Sammelfleiss und den Scharfblick l'H.'s ganz bedeutend gefördert. Vergl. auch Gerusis.

Coll. Muséum d'hist. nat. zu Paris; Herb. Borssner-Bariex in Genf (hier eine grosse Sammlung), Herb. Krutr et Urban (ca. $250 \mathrm{Nr}$.), Wien (Farne und Moose); die rerkäuflichen Farne (von FÉE bearbeitet) in mehreren Museen (Berlin, Botan. Garten zu St. Petersburg, Kew, Herb. de Candolle, Krug et Urbax etc.).

Lit. Fée in Bull. Soe. bot. de France XIV (1867) p. 57-58; briefl. Mitheilung von Père Duss; Cat. Sc. Pap. IT p. 1; Unв. Symb. I p. $12,52$.

Liebnanı. Frederik Michaol, (1813-1856), geb. in Helsingöl (Dänemark) den 10. X. 1813, studirte seit 1832 an der Universitat in Kopenhagen, beschäftigte sich zuerst mit der Flora von Dänemark und der Nachbarländer, besonders mit Algen, machte 1835 eine Reise nach Deutschland, 1836 nach Norwegen, wurde 1837 Docent der Botanik an der Veterinärschule und ging mit Unterstützıng des Königs CHastux V III. nach Mexico, welches er rom Februar 1841 bis Mär 1843 bereiste. Auf der Hinfahrt im Jan. 1841 sammelte er auf St. Croix und Portorico(?), auf der Riickroise hielt er sich April 1843 einige Wochen anf Cuba auf. Mit der Bearbeitung seiner umfangreichen Sammlungen beschäftigt, starb er schon am 29. X. 1856 als ordentlicher Professor und Director des botanischen Gartens in Kopenlagen.

Coll. Bot. Muséum zu Kopenhagen; Doubletten in den Herbarien Kew, Berlin, Leiden, de Caxdolde.

Lit. Las. Mus. Deless. p. 468; Oersten: Notice sur la vie de Luebmann et spécialement sur son voyage au Mexique iu Liemann: Chènes de 
l'Amérique tropicale (1S69) p. VH - X; IIExst. Biol. IV p. 129; Leon Bibl.

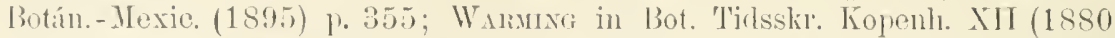

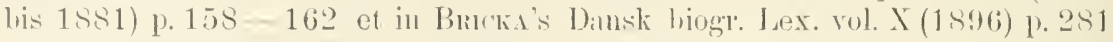
bis 2s3; Kinfisk. in liot. 'lidsskr. XXIII (1900) 1. 12; Jlit\%. Thes. II el. 1. 184; Jacks. Guide 1) 139, 333, 445; ('at. Sc. I'ap. IV 1. 21-23.

Linden. Jean Jules, (1s17-189s), geb. zu laxemburg den 3. II. 1817, machte seine ersten botanischen Excursionen in seiner Heimath und den benachbarten Adennen unter der leitmng F. A. 'Tinant's, des Verfassers der Flora des Grossherzogthums, und erhielt nach Vollendung seiner Studien im Alter ron 18 dahren rom belgischen Gouvernement den Auftrag, eine Forschungs - und Sammelreise in das tropische Amerika zu unternehmen. Als Leichner war ihm Nicolas Funck, als Zoologe August Gunesbrant beigegeben. Sie kamen in Dec. 1835 in Brasilien an, bereisten die Staaten Rio de Janeiro, Espirito Santo, Minas Cieraës und San Panlo und kehrten mit reichen botanischen und zoologischen schätzen im März 1837 nach Belgien zurück. - Auf der zweiten Reise landeten sie im Dec. 1837 in Habana, erforschten drei Monate hindurch die nördlichen und westlichen Partieen von Cuba und gingen im März 1838 mit einer belgischen Gesandtschaft nach Mexico. Hier wurden das Plateau ron Anahuac, die Vulkane Popocatepetl und Iztaccihuatl, dor Cofre de Perote, der Pic von Orizaba und der ganze üstliche Abhang der Cordillere besucht. Von Veracruz schifften sie sich nach Campêche ein und durchkreuzten Yucatan, gingen darauf zur See nach den Staaten Tabasco und Chiapas und drangen bis in das nördliche Guatemala vor. L. kam über Habana und die Vereinigten Staaten in Februar 1841 (seine Begleiter schon im Herbst des vorhergehenden Jahres) nach Belgien zurück. - Die dritte und ergebnissreichste Reise machte L. in Begleitung von Lous Joserh Schum. Sie landeten Ende Dee. 1841 in Guayra in Venezuela, untersuchten diesen Staat sehr eingelıend von Caracas über Cumaná, Merida, die Ufer des Maracaybo-Sees, wendeten sich dann nach Neu-Granada, wo sie die Staaten Soto, Socorro, die Umgebung ron Bogotá, las Bassin des Magdalena, die Prov. Mariquita, den Tolima, die Waldgebiete des Quindiú, Cartago bis zu den Küsten des stillen Oceans erforschten, und kehrten über Honda, Guaduas, Bogotá, die östlichen Provinzen von 'Tunja und 'Tundama, über Merida, Trujillo, Varinas, die Llanos des Orinoco und Carabobo an 17. Aug. 1843 nach Caracas zurïck. In den folgenden IJonaten wurden längere Ausflügre nach Puerto-Cabello und besonders nach Rio Hacho im nördlichsten Neu-Granada gemacht, um die Sierra Nerada de Santa Marta zu erforschen. Anfang März 1844 schiffte sich L. in Rio Hacho nach Jamaica ein, wo er einige Wochen hindurch in den Blue Momntains botanisirte, und begab sich darauf nach 
Santíago de Cuba. Während eines Zeitraumes von sectss Monaten besuchte er im östlichen Theile der Insel die sierra Maestra, die grossen Ebenen des Saltadero und Yatera, die Berge Liban und 'Taurus, die Kieferwälder von Los Hondones und Sagua, die Sierra de Cristal, Sierra Cobre, Nimanima und das Passin des Rio Cauto. Im Oct. 1844 verliess L. Cuba und begab sich über Nordamerika nach Europa, wo er im Febr. 18t5 nach im Ganzen zehnjährigen Reisen in sehr schlechtem Gesundheitszustande eintraf. L. hat auf diesen Reisen nicht allein eine grosse Sammlung getrockneter Pflanzen zusammengebracht, die sehr zahlreiche Novitïten enthielt und an mehrere grössere Iuseen käuflich abgelassen wurde, sondern anch eine Fïlle ron interessanten Arten den emropäisclien Gärten zugeführt, besonders Orchidaceen (cf J. Tinduer: Orchideae Lindenianae. London 1846). Nach seiner Riickkehr errichtete L. cin Etablissement zur Einführung neuer Pflanzen in Luxemburg, übernahm 1852 - 1861 die Direction des Jardin royal de \%oologie et d'Horticulture zu Brüssel, rerlegte zu gleicher Zeit sein Etablissement dahin, kaufte 1870 anch die Gältnerei ron AunRosse Terschaffeut in rent an und rereinigte mit ihr 187:) die Abtheihung für Handelspflanzen, während er Orchideen und nene Einfülırungen in Brüssel weiter knltirirte. Später wurden diese Gïrtmereien unter L. als Direktor in ein Aktienunternehmen, Compagnie continentale, rerwandelt, welche 1887 ihren Wohnsitz wieder in Brüssel nahm und jetzt unter dem Titel Horticulture internationale und unter Lucies Linoex als Direktor ein hohes Ansehen geniesst. L. starb zn Brïssel am 12. I. 1898 als Generalconsul ron Columbien.

Coll. Die getrockneten Pflanzen wurden ron dem Etablissement J. LnNDex an verschiedene Museen und Private rerkauft (vergl. clarüber z. B. Botan. Zeitung T 1847 p. 391, XIV 1856 p. 407), Herb. ne C.xdolle, Delessert, Borssier-Barber in Genf. Graf Franoverille ijetzt Drake del Castillo in Paris), Herb. Wrbis (jetzt in Florenz), Gent, Kew, Leipzig, British Musem in London, Oxford, Paris, Petersburg, Hofmuseum in Wien; von den Restern erhielt das erste Exemplar Briissel, welches augenblicklich die Vertheilung derselhen an andere Museen vornimmt. - Die Cubaptlanzen (a. 1837-1838 unter den ersten Nummern bis etwa 150, a. 1844 ca. Nr. 1692-2213) theilweise auch im Herb. Krog et Urbax: sie wurden von A. Ricunar) (cf. Symb). I. 143), Turezaninow (im Bull. Soc. imp. de Moscou) und ron GriskBACH (cf. Symb. I p. 63), aber nicht vollständig, bearbeitet.

Lit. Las. Mns. Deless. 1). 213-215; Relation du royage scientifique exécuté par M. J. Thxnex in Amm. Sor. d'Agric. et de Bot. de Gand 1846 (n. r.); J. Linneen et J. E. Plancion: Troisième royage de J. Linden dans 
les parties intertropianles de l'Amérique. Plantae Columbianae. 'T'ome I, livaison I (1863) p. XLVIII - IN T; E. Reries: J. Linden und sein Etablissement in Gent in Gartenflora XXIII (1874) p. $196-201$ tab. S01; LEóN Bibl. Botán.- Hexic. (1895) p. 351; A la mémoire de J. Linnen in Ia Semaine horticole. Bruxelles. II (1898) 15 Jan. et 12 Févr. p. 61 - 88; WitTMack: J. Linden in Gartenflora XLVII (1898) p. 171-176 Abh. 53; Gard. Chron. III ser. vol. XV (1894) p. 599-600 und vol. XXIII (1898) p. 40 bis 42 mit Porträt, u. s. w.; Pritz. Thes. II ed. p. 185; Jacks. Guide p. 138, 418, 495; Cat. Sc. Pap. IV p. 28, VIII 1. 233.

Lockart, David, (?-1846), geb. in Cumberland (England), war Gärtner in Kew, begleitete 1816 Kapitän TuckeY als Assistent des Botanikers Christran Surt auf der Congo-Expedition und kehrte, als einziger Ueberlebender von den wissenschaftlichen Mitgliedern der Expedition, iiber Bahia, wo er längere Zeit in Folge der Strapazen krank gelegen hatte, nach England zurück. Im Jahre 1818 wurde er nach Trinidad geschickt und griindete hier unter dem Grouverneur Sir RALPI WOODFond einen botanischen Garten, den er als Superintendent bis zu seinem Tode 1846 verwaltete. Ausser getrockneten Pflanzen schickte er namentlich viele lebende Orchideen ron Trinidad nach Kew; umgekehrt führte er zahlreiche Nutzpflanzen ein, die er zum Theil selbst auf seinen Reisen in Venezuela gesammelt hatte.

Coll. Die Congo-Pflanzen in Kew, die aus Bahia auch im British Museum, die aus Trinidad in Kew.

Lit. Las. Mus. Deless. p. 444; J. Smith in Gard. Chron. XXIV (1885) p. 236; Hart Ann. Rep. Trinid. Bot. Gard. 1887 p. 9 ; Bull. Misc. Inf. Kew 1891 p. 310 - 311 et Add. ser. I p. 55 ; Britt. and Boulg. p. 106 ; Pritz. Thes. II ed. p. 194 ; Cat. Sc. Pap. IV p. 68.

Lodge, F. A., Deputy Conservator im Madras Forest Department, erhielt 1899 von dem Staatssekretär der englischen Kolonien den Auftrag, über den Stand der Forsten in Trinidad zu berichten und Vorschläge über die Frage der Exhaltung derselben zu machen. Er sammelt seitdem für das Herbarium des botanischen Gartens zu Trinidad (cf. HarT).

Lit. Bull. Misc. Inf. Kew 1899 p. 220.

1) Von diesem Werke ist nur die erste Lieferung gedruckt, aber niemals herausgegeben; sie enthält eine Schilderung der ptlanzengeographischen Verhältnisse von Neu-Granada und Venezuela, eine historische Uebersicht über die Forschungsreisen und cine Aufzählung der Plantae Columbianae nebst den Beschreibungen zahlreicher neuer Arten (Ranunculaceae bis Ochnaceae). Um 1874-1875 liess Prof. A. Cogniaux mit Erlaubniss von J. Linden aus den Druckbogen fünf Exemplare herstellen, von welchen eins an J. Linden, eins an den botanischen Garten in Brïssel, eins an E. Marchal in Brüssel, eins an E. Fournisr in Paris und eins an nich gelangte. J. E. Puanchon hat wahrscheinlich nur Correcturbogen besessen. Die dort beschriebenen neuen Arten, welche im Kew Index fehlen, soweit sie nicht sonstwo veröffentlicht sind, müssen als rite publicirt angesehen werden. 
Long, Edward, (1734-1813), geb. zu Tredudwell in Comwall (England) 1734, studirte Rechtswissenschaft, war P'rivatsekretär bei seinem Schwager Sir Hexry Mooke, dem Lientenant Goremor von Jamaica, dann Richter des Viceadmiralitätshofes, 1768 Speaker des House of Assembly. 1769 rerliess er Jamaica, widmete sich literarischen Arbeiten und starb 1813 zu Arundel Park in Sussex.

Lit. Journ. Instit. of Jamaica I (1893) p. 223; Urb. SYrmb. I p. 97.

Lunan, John, lebte um 1814 auf Jamaica. Ueher sein Leben ist nichts bekannt.

Coll. Pflanzen ron ihm sollen sich nach DC. Phyt. p. 430 im Kew Herbarium befinden.

Lit. Pritz. Thes. II ed. p. 198; Jacks. Guide p. 449; Urb. Symb. 1 p. $97-98$.

Lunt, William, (*1871), geb. zu Ashton-U-Lyne bei Manchester (England) den 16. XII. 1871, kam 1892 als Gärtner nach Kew und begleitete in dieser Stellung als botanischer Sammler vom Nor. 1893 bis April 1894 Theodor Bext's Expedition nach Hadramant im südlichen Arabien. Ton Kew wurde er im Sept. 1894 als AssistentSuperintendent nach Trinidad versetzt, wo er für das dortige Herbarium eifrig sammelte und unter anderem die Saccoglottis amaronica wieder auffand, und im Oet. 1898 als Curator der botanischen Station zu St. Kitts-Nevis und Agricultural Superintendent of Sugar Cane Experiments nach St. Kitts.

Coll. Die Hadramaut-Pflanzen in Kew, Doubletten z. B. in Berlin; die Trinidad-Pflanzen im Herb. des botan. Gartens in Trinidad, Kew, Herb. Krug et Urban.

Lit. Kew Bull. 1893 p. 366; briefl. Mittheilung ron L.

Macfadyen. James, $(1800-1850)$, Dr. med., geb. in Glasgow (Schottland) im Jahre 1800, studirte daselbst Medicin und Naturgeschichte, ging auf Sir Wiluna Hooken's Empfehlung 1825 mach Jamaica, um als Island Botanist die Leitung eines zu Bath zu gründenden botanischen Gartens zu ïbernehmen. Da dieser aber aus Mangel an Fonds nicht prosperirte, so legte er nach zwei Jahren sein Ant nieder und widmete sich seinem ärztlichen Berufe in Kingston. Er wurde schliesslich Präsident des Board of Health und ausserdem auch Präsident der Jamaica-Gesellschaft für die Förderung des Ackerbaus und anderer Künste und Wissenschaften. 1850 starb er an der Cholera, mit dem Drucke des zweiten Bandes seiner Flora beschüftigt.

Coll. Kew Herbarium (aber unvollstïndig), einige Bruchstïcke im Herb. Grisebach in Göttingen. 
lit. Proc. Iinn. Soc. II (1851) 1, 135-136; SAmi. Silva II. 73; Journ. of the Instit. of Jamaica 1892 1. 1.11; BRाтt. and liovid. 1. 110; Pritz. 'Thes. II el. p. $199-200$; Jacks. Fuile 1) 137, 370; Cat. Se. Pap. IV 1. 157: Unв. Symb. I p. $98-100$.

Mackenzie. Clarles, hielt sich vom Mai 1826 his August 1827 als englischer Ceneralconsul in Haiti auf.

Coll. Herb. Grisebach in Göttingen.

Lit. Cir. Mackenzie: Notes on Haiti. Lomdon 1830. Il vol.

Macmab. Gilbert, (1815 - 1859), Dr. med., geb. in Edinburgh (Schottland) den 26. XI. 1815 als Solm des superintendenten des rortigen botanischen Gartens Irumau M., studirte daselbst Medicin und betheiligte sich neben seinem Berufe sehr eifrig und erfolgreich an der botanischen Erforschumg ron schottland, der Orkney - und Shetland-Inseln. Im Jahre 1838 ging er nach Jamaica und liess sich als praktischer Arzt anfänglich in St. Ann's, dann in Kingston nieder. Hiel assistirte er MAcFaden sowohl bei seiner umfangreichen Praxis, als auch durch Sammeln und Untersuchung der Pflanzen bei der Ausarbeitung seiner Flora ron Jamaica. Er starb zu St. Ann's am 21. I. 1859.

Coll. Kew, Herbarium der Universitït zu Edinburgh, Oxford, Herb. Grisebach in Göttingen, Krug et Urbax.

Lit. J. H. BALfour: Bingraphical notice of the late Dr. Grlsert M'NAB of Jamaica in Trans. Bot. Soc. Edinburgh. VI (1860) J. 354 - 355; Ввгтt. and Boulg. p. 112.

Iacrae. James, war 1823 Gärtner am botanischen Garten zu st. Vincent, machte 1824-1826 im Auftrage der Horticultural Society zu London eine Sammelreise nach Brasilien (Rio de Janeiro und Santa Catharina), Chile, mach den Galapagos- und Sandwich-Inseln und war 1827 - 1830 Superintendent des botanischen Gartens zu Ceylon.

Coll. Herb. Lindere (jetzt in Cambridge, Orchideen in Kew).

Lit. Las. Mus. Deless. p. 455; Britt. and Boulg. p. 112.

Macrter, Franz Josepl, Professor der Naturgeschichte am Theresianum in Wien, erhielt rom Kaiser Joseru II. von Oesterreich den Auftrag, zur Ergänzung der in Kaiserl. Hofgarten zu Schönbrunn 1780 durch Frost zu Grunde gegangenen tropischen Gewächse, sowie zur Completirung der Menagerie und des Naturaliencabinets eine Expedition nach Amerika zu machen. An derselben nahmen Theil: der Conchylienund Pflanzenmaler Nicolaus von Mold, der Dr. med. Mathias Leorold Stupicz als Botaniker, der Obergärtner in Schönbrunn Fraxz Boos und der Gärtner Franz Bredenexer. Nan kam im Sept. 1783 in Philadelphia an, durchwanderte die östlichen Vereinigten Staaten südwärts bis Florida und schickte Mitte 1784 BREDeneyer mit einem 
Transporte lebender Pflanzen nach Wien zurïck. Wiilurend Stcpicz und MoLl sich bald ron der Expedition lossagten und in den Tereinigten Staaten blieben, gingen MärтеR, Boos und der Anspachische Militärarzt Dr. Johaxy Damid Schöpf im März 1784 nach New Providence auf den Bahamas. M̈̈rтer blieb dort nur zwei Wochen, Schöpf drei Monate, Boos dagegen bis zum 9. Sept. 1784; dieser machte auch Ausflüge nach mehreren anderen Eilanden der Inselgruppe, brachte grosse Sammlungen zusammen und kehrte nach einem mehrmonatlichen Aufenthalte in Carolina im Mai 1785 nach Europa zurück. Zu gleicher Zeit ging Mӥ̈теR nach Haiti, wurde aber ein halbes Jahr lang durch Krankheit am Sammeln gehindert. Hier in Cap français (haitien) suchte ihn Bredeneyer auf, der mit dem Gärtner Joseph Schücnt ron Wien zurückkam, und erhielt den Auftrag, zunächst auf sechs Monate Portorico zu bereisen, darauf im Verein mit Sснӥсnт in Venezuela zu sammeln, ron wo beide im Herbst 1788 mit einer schönen Collection in Wien wieder eintrafen. M. selbst fuhr ron Haiti nach Jamaica und reiste im Jahre 1787 über London zurück.

Coll. K. K. Hofmuseum in Wien; einiges im Herb. Brüssel (ex herb. MoLL). - Bei weitem wichtiger als die Herbarien waren die in die Kaiserl. Gärten ron Schönbrunn importirten lebenden Pflanzen, von welchen JACQUiN zahlreiche Arten hauptsächlich in seinem Hort. Schönbrunn. beschrieb und abbildete.

Lit. Jacǫ. Hort. Schoenbr. I (1797) p. IV; Horsarark's Arch. f. Geogr. VI (1815) p. 756 seq.; J. W. Rideer: Oesterr. Arch. für Gesch. ete. 1832 Nr. 38 (n. r.); Las. Mus. Deless. p. $459-460$; M. Kroxfeld in Wiener Zeitung 1891 n. $210-212$ (n. v.), in Jü̈nchener Allg. Zeitung Juli 1891 Nr. 175 (n. v.), ibid. in Beilage Oct. 1891 Nr. 276: Eine Expedition auf die

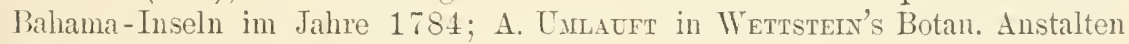
Wiens (1894) p. 38; Pritz. Thes. II ed. p. 200; Urb. Symb. I p. 89.

March, Willian Thomas, (ca. 1795 bis ca. 1872), geb. ca. 1795, lebte in Spanish Town auf Jamaica, zuerst als Adrocat, dann als Clerk of the Supreme Court and Crown und seit cal. 1868 als Island Secretary, d. h. als Leiter der gesammten allgemeinen Verwaltung der Insel unter Aufsicht des Gourerneurs. Er starb um 1872. Seine Liebe zur Botanik zeigte er nicht allein in der Unterhaltung eines prachtvollen Gartens, sondern auch im Aufsammeln von umfangreichen Herbarien (ea. $2000 \mathrm{Nr}$., hauptsächlich in den Jahren 1857-1858). Auch über die Vögel der Insel hat er einige Aufsätze reröffentlicht.

Coll. Kew, Herb!. Girisebacu in Göttingen, Krug et Uribax, Bot. Garten zu St. Petersburg.

Lit. Briefliche Mittheilung von Mr. W. A. Feuntado durch Mr. Fraxk Cundall in Kingston (Jam.); Cat. Sc. Pap. IT p. 227, VIII 1. 323. 
Marie, Edouard Auguste, (1835-18s8), geb. in T'aiti den 12. III. 1835, war zuerst in Neu-Caledonien, über dessen Vügel nnd Mollusken er verschiedene Aufsätze veröffentlichte, dann in Cayenne, kam im Juni 1874 als Sous-commissaire der Marine nach Guadeloupe, wo er sich dem Studium der Hoose widmete, wurde von dort im Aug. 1878 nach Nossi-Bé und später nach Mayotte bei Madagascar versetzt und starb den 11. VI. 1888 in Paris, eben als er sich zur Ruhe gesetzt liatte.

Coll. Moose in Herb. Bescherelde.

Lit. H. Crosse et P. Fischer: Journ. de Conchyliologie XXXVII (1889) p. $94-95$ (Necrologie); briefl. Hittheilung von Père Duss und Prof. E. von Mar'exs; Cat. Sc. Pap. VIII p. 329, X p. 721.

Iartfelt sammelte vor 1791 anf Guadeloupe, Barbados und den benachbarten Inseln für Prof. VaHL.

Coll. Museum zu Kopenhagen.

Lit. VAhl Symb. II (1791) p. 53; Urb. Symb. I p. 173.

Martin, Joseph, wurde im Jardin des plantes zu Paris als Gärtner ausgebildet, ging im Auftrage des französischen Gourernements 1788 naclı Isle de France (Mauritius) und Mahé an der Küste von Malabar und führte 1789 einen T'ransport Nutzpflanzen von Isle de France nach Martinique und Haiti, wo er auch Herbarien anlegte. Später war er Director des Colonialgartens in Französ. Guyana.

Coll. Museum zu Paris, Doubletten in Berlin (ex herb. Kuхтн) und in Florenz (ex herb. Desfontaines).

Lit. Moreau de Satnt-Mŕrix: Descript. de la partie franç. de l'isle de Sainte-Domingue vol. II (1798) p. 368; Las. Mus. Deless. p. 191; Pritz. Thes. II ed. p. 204.

Masson. Francis, (1741-1805 oder 1806), geb. VIII. 1741 zu Aberdeen (Schottland), kam als Gärtner nach Kew, besuchte als erster Sammler dieses Instituts in Auftrage Arrox's 1772-1774 das Capland (zum Theil in Begleitung Thuxpera's), auf einer zweiten Reise 1776 die Azoren, 1777 die Canaren, 1778 Madeira, 1779 Barbados, Grenada, 1780 St. Eustache, Antigua, St. Kitts (St. Christopher), St. Lucia, Nevis, 1781 Jamaica, auf der dritten 1783 Südwesteuropa, auf der vierten $1786-1795$ das Capland, auf der letzten 1797 Nordamerika und starb hier in Montreal XII. 1805 (oder I. 1806). Seine Hauptarbeit behandelt die Stapelien ron Südafrika.

Coll. British Museum (geschenkt ron Arrov), einiges rom Cap im Herb. Dewzssent in Genf. Führte sehr zahllreiche Pflanzen in die englischen Gärten ein.

Lit. Rees' Cyclop. (n. v.); Chnaluers' Biogr. Dict. (n. v.); Las. Mus. Deless. p. $178-179$; J. Surtu in Gard. Chron. n. s. XVI (1881) p. 335; Biztr. in Journ. of Bot. XXII (1884) p. 114-123, 144-148; Mac OWaN 
Ann. Address South Afr. Philos. Soc. $18 S 6$ seors. imp. p. $12-15$; Britt. and Boulg. p. 115 - 116 ; Kew Bull. 1891 p. 295 - 296; B. B. Woowward in Dict. Nat. Biogr. XXXVII (1894) 1. 16; Pritz. Thes. II el. p.208; Jacles. Guide p. 144.

Mattei, Jérôme, (18:1-1894), geb. zu Ajaccio auf Corsica den 26. IV. 1831, wurde Marinearzt, machte als solcher den Krimfeldzug mit und ging 1857 nach Guadeloupe. Hier und auf den klcinen Nachbarinseln war er als Militärarzt thätig, nahı 1869 seinen Abschied und übte die Civilpraxis bis 1887 in Capesterre und bis zu seinem am 21. VII. 1894 erfolgten 'Tode in Basse-Terre aus. Er hatte ein lebhaftes Interesse für Naturgeschichte und sammelte bauptsächlich Algen.

Coll. Herb. Mazé (vergl. diesen).

Lit. Briefl. Mittheilung von M.'s Witwe dureh Père Duss; Urb. Syml. I p. 106 .

Maycock, James Dottin, (?-1837), Dr. med., lebte als Arzt auf Barbados, wo er 1837 starb.

Coll. M. scheint kein Herbar angelegt zu haben.

Lit. Britr. and Boulg. p. 117; Prıtz. Thes. II ed. p. 210; Jacks. Guide p. 369 ; Calt. Sc. Pap. IV p. 305 ; Urb. Symb. I p. 101.

Mayerhoff, Carl Julius, (1805-?), geb. in Neu-Ruppin (Deutschland) den 9. IV. 1805, ging um 1847 als Pflanzer nach Sto. Domingo und sammelte 1856-1859 in der Nähe der Hauptstadt theils für sich, theils für den damals dort residirenden Generalconsul Rob. Scnouburak. Er starb wahrscheinlich auf der Insel.

Coll. Bot. Museum zu Berlin (S68 Nr.) und Herb. Krug et Urbar (210 Nr. rom Gymnasium zu Neu-Ruppin geliauft). - Der ersteren sind irrthümlicher Weise leider eine Anzahl Pflanzen ron Guyana (wahrscheinlich von ScнонвиRGK ges.) beigemengt und zum Theil bereits als von Sto. Domingo stammend in die Literatur übergegangen.

Lit. Briefl. Mittheilung des Herrn Leop. Polwä̈cuen in Berlin durch Vermittelung des Herrn C. Warnstore in Neu-Ruppin.

Maza, Manuel Gomez de la, (*1867), geb. in Habana (Cuba) den 10. V. 1867 , studirte an der dortigen Universität, wurde 1887 auf Grund seiner Arbeit "Flora de Cuba" Doctor en Ciencias Naturales und darauf Licenciat der Medicin. Nachdem er kurze Zeit Assistent an botanischen Garten und am naturlistorischen Museum der Universität gewesen war, wurde er zum Professor der Phytographie und P'flanzengeographie an derselben und zum Director des botanischen Gartens ernannt. Ausserdem übt er die ärztliche Praxis in Habana aus.

Lit. Brief. Mittheilung ron M.; Trus. Symb. I p. 101-105. 
Mazé, Hippolyte Pierre, (1818-1892), geb. in Brest (Frankreich) den 22. XI. 1818, trat 1838 als Sehreiber bei der Marine ein, war 1841-1849 in Französ. Guyana, 1850 auf französ. Besitzungen im grossen Ocean in Garnison und wurde 1851 nach Guadeloupe versetzt, wo er, zeitweilig naeh Martinique und Guyana abkommandirt, his zum Generalcommissar der Marine aufrückte. Ende 1882 nahm er seinen Abschicd und starb in Basse-Terre auf Guadeloupe den 29. I. 1892. M. widmete sich besonders der Erforschung der Algen- und Farnflora der Insel, sowie der benachbarten Eilande Saintes, Marie Galante, Désirade und des weiter nordwestliel gelegenen St. Martin. Auch veröffentlichte er einen Catalogue des Coquilles terrestres et fluviatiles recueillies à la Martinique en 1873 (Journ. de Conch. XXII. 1874 p. $158-173)$ und einen Catalogue révisé des Mollusques terrestres et fluviatiles de la Guadeloupe et de ses dépendances (l. c. vol. XXXI. 1883 p. $5-54)$.

Coll. Ein Phanerogamen-Herbar hat M. nicht linterlassen; seine Farne im Muséc l'Herminier in Pointe-à-Pitre auf Guadeloupe (die Anzahl der Nr. beläuft sich auf ca. 1100) und im Herb. Krug et Urban; scine Algen im British Museum (1509 Exemplare), Herbar Bonxeт in Paris (ex herb. Crounx), Museum zu Berlin (964 Exemplare), Paris, herb. J. Agardh (jetzt im Besitze der Universität Lund).

Lit. Briefl. Mittheilung von Père Duss; Pritz. Thes. II ed. p. 287; Jacrs. Guide p. 370 ; Cat. Se. Pap. X p. 758; Urb. Symb. I p. 105-107.

Melvill, James Cosmo, (*1845), geb. zu Hampstead bei Loudon den 1. VII. 1845, wurde zu Harrow erzogen, publicirte bereits 1864 eine Flora der Umgebung dieses Ortes und studirte am Trinity College zu Cambridge, wo er 1868 zum B. A. und 1871 zum M. A. promovirt wurde. 1871-1872 reiste er in den Tereinigten Staaten, Canada und Westindien und sammelte in Key West 1872 Phanerogamen und Algen. Später wurde er Director einer angesehenen Handelsfirma, welche in Manchester und London ihren Sitz hat. Dessenungeachtet blieb er mit der Wissenschaft in engem Zusammenhange, war 1898-1900 Präsident der Manchester Literary and Philosophical Society und ist Chairman des Committee's des Manchester Museums und Gorernor des Owens College.

Coll. Die Phanerogamen hauptsächlich in IL's eigenem Herbar, dic Algen auch im Herbar $A$ GARDH in Lund.

Lit. Briefl. Mittheilung von M.; Tnms. Journ. of Bot. XIII (1875) p. 258; Pritz. Thes. II ed. 1. 212; Jacks. Guide p. 253; Cat. Sc. Pap. VIII p. 378, X p. 771; Urb. Symb. III p. 5.

Meyer, Louis C., war Schreiber am Kew Herbar gewesen und wurdo dann Superintendent einer Zuckerplantage in Tobago, wo er 
1879 eine kleine Pflanzensanmlung anlegte. Tach ein-bis zwoijährigem Anfenthalte daselbst kehrte er nach Europa zurück, gah in seiner Meimath ein Gartenjournal heraus und ging dann in hollïndischen Diensten naclı Jara.

Coll. Kew Herbarium $(3: 3 \mathrm{Nr}$.).

Lit. Briefl. Mittheilung ron W. B. Hemsler; Tru. Symb. I p. 7, 107.

Miclıaux. André, (1746-1802), geb. auf der Kigl. Domine Satory bei Versailles (Frankreich) den 7. III. 1746, erhielt mur eine mässige Schulbildung, half damm bei der Bewirthschaftung des Gutes und übernahn dasselbe 1763 nach dem 'Tode des Vaters. In Jahre 1777 überliess er die Domäne, welche ihm durch das Hinscheiden seiner Frau rerleidet war, seinem Bruder und widmete sich ganz dem Studium der Botanik, anfünglich bei BERxtro de Jussleu zu T'Tianon, dann zu Paris in Jardin des Plantes. Nachdem el seine botanische Ausbildung durch Reisen und Excursionen in England, den Pyrenäen und Spanien verrollständigt latte, begab er sich mit lem frauzösischen Consul Rousseut 1782 über Syrien nach Persien, durchkreuzte das Land rom indischen bis zum caspischen Ileere und kehrte 1785 mit einem beträchtlichen Herbar und zahheichen Sämereien nach Frankreich zurück. Im September desselben Jahres wurde er ron der französischen Regierung nach den Vereinigten Staaten ron Nordamerika geschickt, um für die Gärten und Forsten Frankreichs Sämereien und junge Pflanzen ron im Freien aushaltenden Gehölzen zu sammeln. In einem Zeitraum rou 11 Jahren bereiste er das ungehenre Gebiet rom atlantischen Ocean bis zum Mississippi und ron Canada bis Florida; in den ersten Monaten 1789 hielt er siclı auf den Bahamas auf, von wo er allein 860 Stück Bäume und Sträucher mitbrachte. Um diese Sammlungen für den Transport vorzubereiten, wurden sie zunächst in besondere Bamschulen bei New Jersey und Charleston ausgepflanzt und darauf bei Gelegenheit nach Frankreich übergeführt (im Ganzen ca. 60000 Stück Bäume und 10 Kisten Sämereien). Im Decenber $1796 \mathrm{kam}$ II. wieder in Paris an, nachdem er einen Theil der mitgebrachten Pflanzen durch Schifíbruch an der holländischen Küste verloren hatte, und beschäftigte sich in den folgenden Jahren theils mit der Cultur der eingeführten Gelı̈lze, von denen el an die Königl. Gärten ron Rambouillet, an Le Moxxer zu Montreuil bei Versailles und andere abgegeben hatte, theils mit der Abfassung seiner Histoire des chènes de l'Amérique. Im Jahre 1800 begleitete Ir. die wissenschaftliche Experlition des Kapitäns BuUdx als Naturforscher nach Australien, rerliess dieselbe jecloch in Mauritius, wo er sechs Monate blieb, und begab sich von dort nach Madagascar. Hier griundete er zu Tamatare einen kleinen botanischen Gaten und starb daselbst 
am 13. XI. 1802 an Fieber. Die ron ihm in Nordamerika gesammelten Pflanzen bearbeitete [. CL. Richard in der Flora boreali-americana 2 rol. 1803.

Coll. Inseum zu Paris (theils eingereiht, theils gesondert), Herb. Richard (jetzt Drake del Castillo in Paris), einiges im Herb. Deensente

Lit. Deleuze: Notice historique sur André Michaux in Ann. du Mfuséun III (1804) p. 191 - 227; S. L. P. Marquis de Cobmines: Notice sur A. Michaux, Paris $1807,8^{\circ}$ (ex Pritz. 'Thes. If ed. p. 216); A. Gray in Hook. Lond. Journ. Bot. I (1842) p. 2-10; Las. Mus. Dcless. p. 60-65; El. Durand: Biogr. Mem. of the Françors André Mrehaux in Amer. Journ. of Science and Arts II ser. XXIV (1857) p. 161 - 165; Didot Nour. Biogr. génér. XXXV (1861) p. 338-339; Abbé Ovide Brunet: Notice sur les plantes de Michnex et sur son voyage en Canada et à la Baie Hudson. 1863 (n. v.); Drake Dict. Amer. Biogr. p. 618 ; C. S. Sarg. Portions of the Journal of AnnrÉ Michaux in Proc. Amer. Plilos. Soc. XXVI (1889) p. 1-145 (n. v.); SARG. Silv. I p. 58; Pritz. Thes. II ed. p. 216; Jacks. Guide p. 141, 360, 508.

Michaux, François André, (1770 - 1855), geb. auf der Kgl. Domäne Satory bei Versailles (Frankreich) den 16. VIII. 1770, einziger Sohn des vorigen, trat mit ihm im Jahre 1785, erst 15 Jahre alt, seine erste Reise nach Nordamerika an und blieb dort bis 1790. Dann studirte er zu Paris Medicin und unterstützte zugleich den Vater nach dessen Rückkehr 1796 bei der Ausarbeitung seiner Histoire des chênes de l'Amérique. 1801-1803 machte er seine zweite Reise nach Nordamerika, um die Forschungen des Vaters fortzusetzen und wie dieser für die Gärten und Forsten Frankreichs geeignete Gehölze zu importiren, und besuchte besonders Kentucky und Tennessee. Auf der dritten Ausreise 1806 wurde das französische Schiff ron einem englischen Kriegsschiffe weggenommen; als letzteres, un Wasser einzunehmen, nach den Bermudas ging, konnte M. während einer Woche (im April) auf der Insel St. Georges botanische Studien machen. Nach seiner Freilassung sammelte er in den folgenden drei Jahren in den Oststaaten von Maine bis Georgia. Nach Frankreich zurückgekehrt, gab er seine Histoire des arbres forestiers de l'Amérique septentrionale $(1810-1813)$ heraus und widmete sich ganz der Cultur und der Vermehrung der von ihm und seinem Vater eingeführten Gehölze. Er starb im Alter von 85 Jahren zu Vauréal bei Pontoise (Frankreich) den 23. X. 1855.

Coll. Museum zu Paris.

Lit. Rapport sur les voyages de Mr. Michaux etc. par Altaire, Bosc, du Petit-'Thouars et Correa de Serra. Paris $1809.8^{0} 11$ p. (ex Pritz. Thes. ed. I p. 193); Lus. Mus. Deless. p. 461 - 462; El. Durand: Biographical Ircmoir of the Françors André Mirmadx in Amer. Journ. of Science and Arts II ser. XXIV (1857) p. 161-177; Didot Nouv. Biogr. génér. XXXV (1861) p. 339; Drake Dict. Amer. Biogr. p. 618; Salig. Silv. XI p. 155; Pritz. Thes. II ed. p. 216 ; Jacks. Guide p. 360,508 ; Cat. Sc. Pap. IV p. 376 ; Urb. Symb. I p. 107. 
Millspaugh, Charles Frederiek, (*1854), geb. zu Ithaca im Staate New York (U. S. A.) den 20. VI. 1854, besuehte die Ithaca Academy, studirte Botanik und Biologie an der Cornell Universität und wurde 1881 rom New York Homoeopathic Medical College zum Dr. med. promovirt. $1881-1887$ war er Arzt zu Binghamton, N. Y., beschäftigte sich aber auch eifrig mit der Flora des oberen Susquehanna-Thals. Ausserdem verfasste er ein zweibändiges reieh illustrirtes Werk: American medieinal Plants. Seit 1894 ist er Curator des Department of Botany an Field Columbian Nuseum (von der Gründung an), seit 1895 zugleich Professor der ökonomischen Botanik an der Unirersität und der medicinischen Botanik am homöopathisch-medicinischen Colleg zu Chicago. Seine erste Reise machte I. 1887-1888 wach Central-Mexico, Yueatan und Cuba (Umgebung ron Habana und Ilatanzas), die zweite Reise nach Yueatan 1894-1895 unter dem Patronate von Mr. Alusox V. Aruour auf der Yacht Iluna, die dritte unter demselben Patronate December 1898 bis März 1899 auf der Yacht Utowana nach Bermuda, Portorico, St. Thomas, Culebras, Sto. Domingo, Jamaiea, Cuba, Caymans, Isle of Pines, Cozumel, Yucatan und Alacran shoals, die letzte November bis December 1900 im Auftrag des Field Musenms nach Jamaica (Port Antonio und Port Morant).

Coll. Hauptsammlung im Field Columbian Inseum in Chicago (Utowana-Expedition ea. Nr. 148 - 1753), Doubletten im Gray Herbarium zu Cambridge und Herb. Kredg et Urbax.

Lit. Briefl. Mittheilmg von MI; Urв. Symb. II p. 4, III p. 6-7.

Mociño. José Mariano, (? - 1819), geb. zu Temascaltepee in Mexico, studirte unter V. Cerrintes in Mexieo und wurde auf den Vorschlag ron Sessé der ron diesem geleiteten Expedition zur Erforschung der Naturprodukte ron Nueva-España $(1795-1804)$ beigegeben. Ausser einem Herbar von ca. 4000 Arten wurde auch eine schöne Sammlnng von colorirten Abbildungen zusammengebracht, welehe Ataxasio Ecueverisi und JuAx CERda nach der Natur gezeichnet hatten. Letztere (1376 Stiick) gelangten nebst verschiedenen Manuscripten durch M., der in Folge ron politischen Misshelligkeiten nach Montpellier geflüchtet war, in die Hand von P. de CArdolle behufs Veröffentliehung und bildeten die Grundlage zur Aufstellung ron 279 Arten und 17 neuen Gattungen. Im Jahre 1817 verlangte If. die Zeichnungen zurück. Um diese der wissenschaftliehen Benutzung zu erhalten, liess DE C_xdulta: sie sümmtlich ron einer grossen Anzahl Damen in Genf eopiren und sandte die Calques jener 279 Arten an die zehn grössten botanischen Museen (Paris, Kew, Berlin, Wien, Leiden, St. Petersburg, Kopenhagen, Briissel, Florenz und Cambridge in Nordamerika). Ueber den 
Terbleib der Originalzeichnungen ist nichts bekannt. II. starb zu Barcelona 1819.

Coll. Tergl. Siesst.

Lit. Flotrens: Eloge hist. de Prrayus de Candolde (1842) p. $22-23$; Las. Mus. Deless. p. $205-206,322$ ohs.; (ouy. Botan. Ponins. Hisj)-Lusit. (1858) p. $49-51,185-186$ et Prim. Not. Veg. Amer. p. $48-49$; DC. Phytogr. p. 434; Hemst. Biol. IV p. $120-121$; Prisz. Thes. Il ed. 1) 220 ; Jacks. Guide p. 367; Cat. Se. Pap. IV 1) 419; León Bibl. Botán.-Nexic. (1895) p. $189-191,323-340$.

MoLt, Karl Marie Ehrenbert Freiherr von, geb. im Dorfe Thalgau im Salzburgischen (Oesterreich) den 21. XII. 1760, Terwaltungsbeamter, Staatsmann und Naturforscher, starb am 1. II. 1838 zu Augsburg als Geheimer Rath und Secretär der mathem.-physik. Klasse der Königl. bayerischen Akademie der Wissenschaften zu Mïnchen, schenkte sein Herbarium von ca. 6000 Arten 1834 an C. F. Ph. vox Martius. Die in demselben enthaltenen Pflanzen von Westindien, welche fälschlich M. als Sammler zugeschrieben werden, stammen von RoHr, Swartz und Mänten (vergl. diese).

Coll. Herb. Martu in Brïssel (hier und in Mart. Nor. Gen. I p. 96 irrthümlich „L. B. de Moll“ genannt).

Lit. Mart. Nov. Gen. I (1824) p. 96; Regensb. Flora XXI (1838) p. 80;

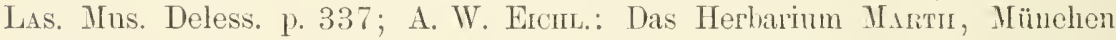
1869 , p. 4, 12; v. Gümber in Allg. Dentseh. Biogr. XXII p. 111-115; Cat. Sc. Pap. IV p. $434-435$, VIII p. 424.

Monteverde. Manuel de, (?-1871), stammite aus Sto. Domingo, kam 1822 nach Puerto-Principe auf Cuba und erwarb sich als Adrocat, Literat, Dichter und Naturforscher eimen Namen. Für Ranox de la SAgra (vergl. diesen) sammelte er Pflanzen; ausserden lieferte er ihm werthvolle Beiträge über die Agricultur der Insel. Er starb im Jahre 1871.

Lit. F. Calcagno Diecionario biografico Cubano (1878) p. 433; Urb. Symb. I p. 142.

Morales, Sebastian Alfredo de, (1823-1900), geb. in Habana (Cuba) im Jahre 1823, homöopathischer Arzt, Dichter und naturwissenschaftlicher Schriftsteller, hielt sich in Folge ron politischen Misshelligkeiten mehrcre Jahre in Ostasien, besonders auf den Philippinen auf und liess sich nach seiner Rückkehr in Matanzas nieder. Hier docirte er am Lycenm Naturgeschichte und $\Lambda$ gricultur und wurde Director der Abtheilung für Wissenschaften. Ton seiner Flora Cubana, deren Manuscript bei einem Schiffbruche 1870 theilweise zu Grunde ging, ist nichts erschienen; er veröffentlichte nur Studien über einzelne Familien und verschiedene Nutzpflanzen, sowie den Anfang einer Flora arboricola de Cuba aplicada. Sein Tod erfolgte 1900. 
Coll. Herb. Kreqg et Urbar (57 Nr. ex a. 1890).

Lit. F. Calcagio Dice. biogr. Cubano (1878) 1. $434 \ldots 435$; hriefl. Mittheilung ron G. DE LA IIAZA; Urb. Symb. I p. 110-111.

Ioritz, Johann Wihelm Karl, (1797-1866), geb. zu KleinSantersleben bei Gross-Rottmerslehen im Kreise Teuhaldensleben, P'rov. Sachsen (Preussen) den 16. XII. 1797 als Solnn des dortigen Schullehrers Hersicm Cimstrax M., welcher 1810 als Cantor und Organist nach Barleben rersetzt wurde. Nach absolvirtem theologischen Studium uahm er 1825 eine Hauslehrerstelle bei Herru row Bredow an, die er bis 1834 bekleidete, und ging darauf nach Westindien. Während des Winter's 1834-1835 sammelte er auf St. Thomas, St. Jan und Februar bis Juni 1835 auf P'ortorico bei Arecibo, San Juan, Caguas, Coamo, Ponce, Guayama und besonders bei Yabucoa. Ton da schiffte el sich im Jumi 1835 nach Venezuela ein, bereiste einen beträchtlichen Theil des nördlich rom Apure und Orinoco gelegenon Landes, besonders die Prorinzen Trujillo und Merida, und kehrte 1837 nach Deutschland zurïck. 1810 begab er sich wioderum nach Tenezuela und liess sich später in der deutschen Colonie 'Torar nieder, wo er Gemüse und Blumen für den Markt ron Guayra züchtete und am 25. VI. 1866 starb. Sein Hauptrerdienst ist das Sammeln von Pflanzen und Thieren in den bereisten Gebieten; ausserdem reröffentlichte el einige Aufsätze über die Entwickelung von Raupen in den Tropen und iiber die Urwälder von Torar etc.

Coll. Sein Privatherbar (cf. Botan. Zeitg. XVIII. 1860 p. 22S) ging in den Besitz dos British Museum ïber. Hauptsammlung im Museum zu Berlin (ca. $1800 \mathrm{Nr}$, davon ca. zwei Cent. aus Westindien), andere in St. Petersburg (Bot. Garten und Kaiserl. Akademie), Hofmuseum in Wien, Unirersitätsherbar in Leipzig, Kiel, bei de CAndolle.

Lit. C. Moritz: Notizen zur Fauna der Insel Puertorico in Wrecis.'s Arch. für Naturgeschichte II. 1 (1836) p. 373-375; Lıs. IIus. Delcss. p. 482 ; Botan. Zeitg. I (1843) p. 406, 647-648, II (18.4) p. $173-175$, $195-197,430-434$, III (1845) p. 688; Lixp, et Plıxch. Troisième royage de J. Limpen I (1863) p. I.X; Selar. Journ. of Bot. IV (1866) p. 304; Regensh. Flora XLX (1867) p. 15; briefl. Mittheilung des Herm Pastor L. W'neroni. zu Gross-Rottmersleben und des Prof. E. vos MLantexs in Berlin; P'ritz. T'hes. II ed. p. 225 ; Cat. Sc. Pap. IV p. 474.

Morris, Daniel, C. M. G., MI. A., Dr. Sc., (*184t), geb. zu Loughor, Glamorgan, in England den 26. V. 1844, erhielt seine Ausbiklung au der Royal School of Mines zu London und an Trinity College zu Dubliu und wurde 1876 durch die goldene Merhaille für Naturwissenschaft ausgezeichnet. 1877-1879 war er Assistant Director der botanischen Gärteu zu Ceylon, December 1879 bis März 1856 Director of P'ublic 
Gardens and Plantations in Jamaica, wo er den Grund zmm Department Herbarimn legte und besonders den Farnen, Gramineen und Orchideen der Insel seine Aufmerksamkeit zuwendete, umd wurde dann Assistant Director von Kow Gardens. In dieser Eigenschaft machte er rom November 1890 bis Februar 1891 eine wesentlich landwirthschaftlichen Zwecken dienende Reise nach Antigua, Dominica, Montserrat, St. Kitts, Nevis, Anguilla, Virgin Islands, St. Lucia, St. Vincent, Grenada, Barbados und Jamaica. Im Jahre 1895 besuchte er die Bahamas. Eine dritte Reise nach den britisch-westindischen Inseln unternahm er 1897 als Mitglied einer Commission, welche sich über den Rückgang der Culturen daselbst und über die Mittel zu ihrer Hebung unterrichten sollte. Folge davon war, dass ein Imperial Department of Agriculture for the West Indies mit dem Sitze in Barbados gegründet und M. 1898 zum Commissioner desselben ernannt wurde. Er hat auch 1882 in British Honduras und 1883 in St. Helena gesammelt.

Coll. Kew Herbarium.

Lit. Briefl. Mitthcilungen von W. B. Heuscer und M.; Fawc. in Bot. Gaz. XXIV (1897) p. 354-355; Morris in Kew Bull. Add. ser. I (1898) P. 144; Cat. Sc. Pap. X p. 855; Une. Symb. I p. 86, 87-88, 111-112, 174, III p. 7-9.

Moseley. Henry Nottidge, (1844-1891), geb. zu Wandsworth in Surrey (England) den 14. XI. 184t, studirte seit 1864 in Oxford, Wien, London und Leipzig Medicin und Natnrwissenschaften, begleitete als Zoologe 1872 die Sonnenfinsterniss-Expedition nach Ceylon nnd 1873 bis 1876 als Naturforscher die Challenger-Expedition. Mit letzterer besuchte er Tenerifa, St. Thomas, Bermuda, die Azoren, Madeira, die Caprerden, St. Paul, Fernando Noronha, Bahia, Tristan da Cunha, Capland, Prinz Edward Island, Crozet Islands, Kerguelen, Heard Island, Australien, New Zealand, Freundschaftsinseln, Matuku, Fiji, Neuen Hebriden, Torres Strasse, Aru, Ke, Banda, Amboina, Ternate, Philippinen, China, Neu-Guinea, Admiralitäts-Insehı, Japan, Sandwich-Inseln, Tahiti, Juan Fernandez, Chile, Magallaensstrasse, Falklands Inseln und Ascension. Im Jahre 1877 machte er eine Reise nach Californien und Oregon und in die Nachbargebiete, wurde 1881 Professor der Anatomie zu Oxford und starb daselbst den 10. XI. 1891.

Coll. Die von ihm auf der Challenger-Expedition gesammelten Pflanzen sind in Kew.

Lit. Moselex: Notes by a Naturalist on the Challenger I ed. (1879); Proc. Limn. Soc. London $1890-1892$ 1) 72 - 73; G. C. Bourne's Memoir mit Porträt in Mosel. Notes by a Naturalist II el. (1892) (n. v.); E. R. Laniester 
in Nature XLV (1891) p. $79-80$; B. B. Woopwari in Dict. Nat. Biogr. XXXIX (1894) p. $176-177$; Britt. and Boulg. l. 210 (in Jouru. of Bot. XXXVI (1S98) p. 443); Cat. Se. Pap. VIII p. 445, X p. 859 - S61; Unis. Symb. I p. 11, 33, 3S, 6s-69, 108, 112, 160.

Munı, William, (181s-18s0), geb. zu Druids Stoke in Gloucestershire (England) in Jahre 1S1S, diente als Officier viele Jahre in Indien, machte den Krimkrieg mit und stand als Oberst in Canada und auf den Bermudas. 1870 - 1876 kommandirte er die englischen 'Truppen in Westindien (Barbados), wurde 1876 Generallientenant, 1878 General und starb den 29. I. $18 S 0$ zu Taunton (England). Als Botaniker hat er sich hauptsächlich durch seine Arbeiten über Gramineen einen angesehenen Namen erworben.

Coll. Kew Herbarium.

Lit. Gard. Chron. n. ser. XIII (1880) p. 169: Bвгтт. Journ. of Bot. XVIII (1880) p. 96; Trans. Bot. Soc. Edinb. XIV (1883) p. 158; BritT. and Boulg. p. 125; H. II. Cuinenter in Dict. Nat. Biogr. XXXIX (1894) p. 313 ; Pritz. Thes. II od. p. 228 ; Jacks. Guide p. 451 ; Cat. Se. Pap. IV p. 545 , VIII p. 471.

Iurray brachte im Jalı'e 1827 in Jamaica eine numerirte Sammlung von ca. sieben Centurien Pflanzen zusammen und sammelte wahrscheinlich auch in Dominica.

Coll. Herb. de Cixdonle in Genf, Museum zu Florenz.

Lit. Radlk. Hou. Paull. p. 135; DC. Prodr. XI p. 564.

Murray, George Robert Milne, (*1858), F. R.S., geb. zu Arbroath in Schottland den 11. XI. 1S58, studirte bei no: BıRY und Giraf zu Soums-Liubicu in Strasburg Botanik und wurde May 1895 als Nachfolger von C.rkruthens Keeper des Botanical Department am British Museum (Natural History). Im Jahre 1886 sammelte er in Grenada als Mitglied der Eclipse Expedition Zellenpflanzen, hauptsächlich Algen. Coll. British Museum.

Lit. Briefl. Mittheilung von II.; Cat. Sc. Pap. X 1. 891 ; UrB. Syml. I p. 114 .

Murray, H. B., sammelte um 1878 auf Sta. Lucia hauptsïchlich Farne.

Coll. Kew Herbarium.

Lit. Kew Rep. 1878 p. 54,1879 p. 41.

IItriay, W. B., Dr., sammelte mm 1871 auf Barbados.

Coll. British Mruseum.

Lit. Journ. of Bot. 1872 p. 178.

Nectoux begleitete einen Transport von Nutzpflanzen ron Cayenne nach Martinique und Haiti, wo er im Januar 1785 als Nachfolger von 
Joctialit de ha Motre Direetor des Colonialgartens (Jardin du roi oder Jardin botanique) in Port-au-Prince wurde. 1789 war er in Jamaica, um einen Anstausch lebender Pflanzen vorzunelımen. N. sammelte in Haiti unter anderem mehrere Seltenheiten, die bisher anf der Insel noch nicht wiecier gefunden worden sind. Man verdankt ihm auch cine Abhandlung: Observations sur la préparation des envois de plantes et arbres des Indes Orientales pour l'Amérique, et leur traitement pendant la traversée (Mém. Soc. d'Agric. Paris 1791 p. $110-123)$. Ob er mit Hurolste N., der vor 1808 eine Reise nach Aegypten machte und über die dortigen Cassia-Arten schrieb, identiseh ist, konnte ich nicht ermittehn.

Coll. Iuseum zu Paris; Dupla in Montpellier (ex herb. Canbess.), einiges im Ilerb. Kreti et Urbax, Herb. zu Florenz (ex lerb. Desfoxtanes).

Lit. Moneau de Sunt-Mímx: Descript. de la partie franç. de l'isle de Sainte-Domingne vol. II (1798) p. 368; ? Pritz. Thes. II ed. p. 231.

Nén, Luis, aus Frankreich gebürtig, beglcitete 1789-1794 Mnuspris auf seiner Reise um die Welt (Südamerika, Mexico, Philippincn, Marianen, Freundscluftsinseln, Südamerika). Die unter seiuem Namen aus Cuba (und Sto. Domingo?) exwähnten Pflanzen des Herb. Pavox sind wahrscheinlich von Skssé und Hocñ̃o gesammelt.

Coll. Herb. des botan. Gartens zu Madrid, die Cuba-Pflanzen im Herb. Bolssura-Barbey zu Genf.

Lit. Las. Mus. Deless. p. 348, 451-452; Colm. Botan. Penins. Hisp.Lusit. (1858) p. 183; Cat. Sc. Pap. IV p. $582-583$.

Nicholls, Henry Alfred Alford, (*1851), C. M. G., geb. zu London den 27. IX. 1851, studirte Arzneiwissenschaft an der Universität Aberdeen und am st. Batholomews' College in London, wurde Dr. med. und ging 1873 nach Dominica, wo er seit 1886 auch sammelte. Von hier aus besuchte el 1890-1891 Barbuda (Aug. 1891), Montserrat, Antigua, St. Vincent und Tobago.

Coll. Kew Herbarium, Knug et Unb.

Lit. Kew Bull. Add. Ser. I (1898) p. 103; briefl. Mittheilung von N.; Cat. Sc. Pap. X p. 921 ; Urb. Symb. I p. 116.

Nicholson, T., Dr. med., lebte un 1831 - 1841 auf Antigua und war ein Correspondent von W. J. Hook Ek.

Coll. Kew Herbarium.

Lit. Britr. and Boulg. p. 127; Urb. Symb. I p. 116.

Nock. W., sammelte $1875-1880$ auf Jamaica Farne, welche von G. S. Juxux in seiner Synoptical list bearbeitet wurden, und ist jetzt Superintendent des botanischen Gartens zu Hakgala auf Ceylon. 
Northrop. Alice Belle geb. Rich, (*1864), geb. in New York City den 6. III. 1864, graduirte am Normal College 1852 und war daselbst 'Tutor in Botany 1885-1889 bis zu ihrer Verheirathung mit J. I. Nokturop. Sie begleitete ihren Gatten 1890 nach den Bahamas nud wird eine Aufzïhlung der dort gesammelten und grösstentheils von ihr selbst bearbeiteten Pflanzen publiciren.

Lit. Briefl. Mittheilung ron Mrs. A. B. N.

Northrop, John Isaiah, (1861-1891), geb. in New York City den 12. X. 1861, graduirte 1884 an der School of Mines des Colnmbia College und wurde, nachdem er cinige Zeit als Chemiker in I'rivatstellung gewesen war, 1888 in New York zum Dr. phil. promovirt. Er wandte sich alsdann der Botanik, Geologie und besonders der Zonlogie zu, docirte die letztere an der genannten Anstalt und wurde 1891 Tutor darin. Bevor er seine Absicht, die zoologischen Studien in Dentschland fortzusetzen, ausführen konnte, verlor er durch in Brand gerathenen Alkohol im Columbia College am 26. VI. 1891 sein Leben. Im Jahre 1890 hatte er mit seiner Frau eine Reise nach den Bahamas gemacht, um daselbst zoologisch und botanisch zu sammchn, sowie geologische Studien anzustellen, und zwei IIonate auf New Providence, vier Monate auf Andros sich aufgehalten.

Coll. Columbia University zu New York, Botan. Mus, zu Berlin (757 Nr.), Kew, Herb. Boissier-Bariber, Gras Herbarium zu Cambridge, Washington (noch nicht abgesandt).

Lit. Artit. Holdicl: A memorial of the late Dr. John I. Norturop in Trans. New York Acad. Sc. XI (1891) 1. 9-12; briefl. Mittheilung ron Mrs. A. B. N.

Nyst, P., vom botanischen Garten zu Brüssel (um 18:6), sammelte auf Guadeloupe und Martinique.

Coll. Numerirte Sammlung von ca. acht Centurien im Herb. des botan. Gartens zu Brüssel.

Lit. Pritz. Thes. II ell. p. 235.

Oersted, Anders Sandöe, (1816 - 1872), geb. als Sohn eines Kaufmanns und Bankdirectors in Pudkoebing auf Langeland (Dïnemark) (len 21. VI. 1816, studirte seit 1835 in Kopenhagen, machte 1842 cine natmrwissenschaftliche Reise in Dänemark, erhielt 1844 den Grad eines Magisters, welcher $185 \pm$ als Doctorgrad anerkannt wurde, und begann im Frühjahr 1845 seine Reise nach Westindien und Centralamerika. Er besuchte St. Thomas, St. Croix, mehrere andere kleine Antillen. \%. B. Grenada, ferner Jamaica, und begab sich im Mai 1846 nach Nicaragua und Costarica, ron wo er im Juli 1848 nach Kopenhagen zurückkehrte. 1851 habilitirte er sich an der Universitiit als Privatdocent, 
wurde 1860 zum Professor ernannt und starb in Kopenhagen am 3. IX. 1872. Die Ergebnisse seiner amerikanischen Reise bezogen sich sowohl anf die Zoologie, besonders die niederen Heeresthiere, als auf die Pflanzenwelt.

Coll. Bot. Nuseum in Kopenhagen, einige Familien anch im Berliner bot. Museum und in kew.

Lit. R. Brown in Trans. Bot. Soe. Edinb. XI $(1872-1873)$ ex Hemsl. Biol. IV p. 130, 328; Kiaersk. in Bot. Tidsskr. XXIII (1900) p. 46-47; Priтz. Thes. II ed. p. 236 ; Cat. Sc. Pap. IV p. $696-697$, VIII p. 537 , X p. $949-950$; Jacis. Guide p. $23,91,102,108,142,146,148,165$, $333,338,367$; Warm. in Bot. Tidsskr. XII $(1880-1881)$ p. $162-171$; Urв. Symb. I p. $118-119$.

Ossa ${ }^{1}$, José Antonio de la, geb. in Habana (Cuba), war seit 1800 literarisch thätig; wurde 1805 Secretär der kgl. patriotischen Gesellschaft und trug in dieser Stellung viel für die Hebung des öffentlichen Unterrichtes bei. Nach der Gründung eines botanischen Gartens in Habana wurde er dessen Director nud hatte diese Stelle bis zum Eintreffen Ranox de la SAgRa's im Jahre 1823 inne. Auch nach dieser Zeit beschäftigte er sich noch eifrig mit Botanik, correspondirte mit DE Cxndolue ïber die gesanmelten Pflanzen und schrieb 1830 eine Flora Habanensis, die aber nicht veröffentlicht wurde.

Coll. Herb. de Candolue in Genf (400 Arten).

Lit. Sagra Cub. X introd. p. 15, 29; Colmeiro Botan. Hisp.-Lusit. (1858) p. 202; F. Calcagno Dicc. biogr. Cubano (1878) p. 479; Pritz. Thes. II ed. p. 238.

0tto, Carl Friedrich Eduard, (1812-1885), geb. zu Schöneberg bei Berlin den 2. I. 1812 als Sohn des Inspectors des botanischen Gartens und Gartendirectors Friedricn Otтo, absolvirte das Realgy mnasium, lernte bei seinem Vater, besuchte die Gärtnerlehranstalt und hörte Vorlesungen an der Universität. Nachdem er sich einige Jahre in England und Frankreich aufgehalten hatte und als Obergehülfe im Berliner botanischen Garten thätig gewesen war, trat er eine Reise nach Cuba, zu welcher der König von Preussen die Mittel bewilligt hatte, in Begleitung des Cacteen-Monographen Dr. Pfeifrer aus Cassel und des Zoologen Gunduacn aus Marburg an. Er verweilte vom Januar bis September 1838 auf der Insel und besuchte die Umgebung von Habana, den District Calajabas (Monte Taburete, Zuckerpflanzung San Roque), den Rio Canimo (Cafetal Fundador und San Juan), Cardenas, Matanzas, sowie Cienfuëgos und Trinidad an der Südküste. Von da ging er über Nordamerika nach Venezuela, sammelte in den Küstengegenden und

1) Ramon de la Sagra schreibt "Osa“. 
den dahinterliegenden Bergketten von Talencia bis Orituco, machte ron Cumaná aus einen Abstecher nach Barrancas und Angostura am Orinoco und kehrte 1841 nach Berlin zurück. Im Jahre $18+4$ w wrde O. Inspector des botanischen Gartens in Hamburg, den er längere Zeit auch selbständig leitete, bis er in Folge von Misshelligkeiten mit dem neuen Director H. G. Reichexbicn Ende 1866 gezwungen wurde, den Absehied einzureichen. Die Zeit bis zu seinem am 11. IX. 1885 in Hamburg erfolgten Tode verbrachte er in dürftigen Verhältnissen, die letzten sieben Jahre in Folge eines Schlaganfalls fast ganz an Erwerbsthätigkeit behindert.

Coll. Botan. Museum in Berlin (Cuba 328 Nr., Venezuela 1567 Nr.); eine kleine Anzahl in Kew und Brüssel (ex herb. MArtuss); auch wurden von R. F. Hoнетаскек in Würtemberg geringere Sammlungen vertrieben (cf. Bot. Zeitung XXIV. 1871 p. 812). - Ausserdem schickte er zahlreiche Sämereien und lebende Pflanzen an den botanischen Garten zu Berlin.

Lit. H. O.: Garteninspector Eduard Otтo in HöLler's Deutsche GärtnerZeitung, Erfurt, VIII (1884) 1). 115-118 mit Porträt; E. Goeze: Garteninspector Edvard Oтто in Hamburger Garten- und Blumenzeitung XLI (1885) 1. $472-477$ mit Bildniss; Cat. Sc. Pap. VIII p. 541; Urb. Symb. I 1. 120.

Oviedo, Gonzalo Fernandez de Oriedo y Valdés (hiess eigentlich Gonzalo Fernandez und nalm die Beinamen nach dem Ursprungsorte seiner Familie aus dem Thale Valdés bei Oriedo in Asturien an), (1478 bis 1557), geb. zu Madrid im VIII. 1478, machte eine Reise nach Italien, wo er längere Zeit im Dienste verschiedener Herzöge zubrachte, ging im April 1514 als Aufseher der Goldschmelzen nach Santa Marta, Darien und Sto. Domingo und kehrte im Juli 1523 von dort zurück. In den folgenden Jahren bis 1856 machte er noch vier Reisen nach Amerika, wurde Regidor von Darien, Gourerneur der Provinz Cartagena und zuletzt Gouverneur der Festungswerke und Regidor von Sto. Domingo, Chronista de Su Magestad de las cosas de las Indias und starb 1557 zu Valladolic.

Coll. Pflanzen sind von ihm nicht bekannt.

Lit. José Aunuon de los Rios: Vidal y escritos de Oviedo in Orieno's Primera parte de la historia natural y general de las Indias ed. Madriel 1851 - 1855, vol. I p.I-CXII; Didot Nonr. Biogr. génér. XXX VIII (1862) p. 1002 -1003; Drake Dict. Amer. Biogr. p. 679; Prirtz. Thes. II ed. p. 238; Uris. Symb. I p. $120-122$.

Oxamendi, Juan Calixto, (1829-18s5), geb. zu Matanzas (Cuba) den 14. X. 1829, besuchte das Colegio zu San Cristóbal, studirte seit 1851 in Frankreich und Madrid, wnde hier 1857 Licentiat der Medicin und promorirte zum Dr. med. in Habana. An letzterem Orte liess er sich 
als praktischer Arzt nieder. Er beschïftigte sich mit der Materia medica, schrieb rerschiedene Artikel ïber Medicinal-Pflanzen Cuba's und starb den 24. VI. 1855 7и Mabana.

Lit. F. Calcagno: Dice. biogr. cubano (1878) p. 480; briefl. Mittheilumg roll G. de la Maza; Urb. Symb. I p. 122.

Pagan, Juan Bianchi, Gutsbesitzer in Añasco auf Portorico, sammelte 1880 - 1884 für den Consul L. Krug.

Coll. Herb. Krifi et UnBax.

Palisot, Ambroise Marie François Joseph P. baron de Beaurois, (1752-1820), geb. zu Arras (Frankreich) den 27. YTI. $1752^{1}$, besuchte das Collège d'Hurcourt zu Paris, war kurze Zeit Mousquetaire, dann seit 1772 Adrocat und wurde nach dem Tode seines Vaters und älteren Bruders durch Erbschaft Generaleimnelmer der Domänen und Forsten im nördlichen Frankreich. Als jener Posten 1777 aufgehoben wurde, beschäftigte el sich unter LestiBotdous in Lille seln eifrig mit Botanik, durehforsehte mit ilm Flandern, Brabant und die Nachbargebiete und trieb mit solchem Eifer mikroskopische Studien, besonders über die Structur und die Geschlechtsverhältnisse der Kryptogamen, dass ihn die Akademie der Wissenschaften zu Paris, wohin er übergesiedelt war, bereits 1781 zu ihrem correspondirenden Mitgliede ernannte und A. I. DL: Jussieu sich mit ihm befreundete. Schon lange von dem Wunsche beseelt, eine Reise quer durch Afrika auszuführen, schloss er sicb 1786 einer von dem Negereapitän Lixdoupes reranlassten Expedition an, welche in Owara am Golfe von Guinea eine Handelsniederlassung griunden wollte. Schon auf dem Wege dahin sammelte er an allen Orten, wo das Schiff anlegte, besonder's in Chamah und Koto an der Goldküste. In den Jahren 1786 - 1787 bereiste er Owara und Benin und schickte seine Sammlungen, wenn siclı Gelegenheit bot, an Jussieu. Weiter in Afrika vorzudringen, war ihm aber nicht möghich, weil sein Schwager und seine europäischen Diener dem Fieber erlegen waren und sich Niemand fand, der ihn begleiten wollte. Ausserdem war er selbst durch wiederholte Fieberanfälle derartig geschwächt, dass sein Freund Lixpolpte ihn an 22. Januar 1788 auf einem mit Negerselaven nach Haiti befirachteten Schiffe zur See befördern musste. Die Hauptmasse seiner Sammlungen, welche in den Händen LixnoLrHE's zurückgeblieben war, ging 1791 zu Grunde, als das Etablissement ron den Engländern geplïndert wurde. Nach einmonatlichem Aufenthalte auf der Insel do Principe und widerwärtiger Seefahrt landete P. an 21. Juni 1788 auf

1) Nach Thíbaut; am 28. X. 1755 nach Cuvier, was unwahrscheinlich ist, weil cr dann nicht 1772 schon Adrocat sein kounte. Teberhaupt ist die THIÉBaut'sche Vita dic gründlichere, auch bibliographisch sehr sorgfältig durchgeführte. 
Haiti und fand bei seinem Onkel, dem Baron de LA Valietrère, Kommandanten der Môle St. Nicolas, Aufnahme und liebevolle Pflege. Er gedachte nun diese Insel zum Gegenstande einer eingehenden botanischen Durchforschung zu machen; allein seine Absicht kam nur theilweise zur Ausführung, weil die bald nachher ausgebrochenen revolutionären Bewegnngen ihn der Politik zuführten und ihn veranlassten, ein Kommando gegen die Neger zu übernehmen. Als die letzteren immer grössere Fortschritte machten, ging P. im October 1791 nach Philadelphia, um im Interesse der Franzosen auf Haiti durch Beschaffung ron Fonds und Lebensmitteln thätig zu sein, bez. die Intervention der Vereinigten Staaten herbeizuführen. Bei seiner Rückkehr 1793 fand er Cap français ron den Negern eingeäschert; dabei waren auch seine Aufzeichnungen von der afrikanischen Reise, sowie seine Haiti-Sammlungen zu Grunde gegangen. Er selbst wurde nacb kurzer Einkerkerung von der Insel verbannt und begab sich nach Nordamerika; das Fahrzeug, auf welchem er sich eingeschifft hatte, wurde aber unterwegs von einem englischen Corsaren ausgeplündert, so dass er ganz ohne Mittel in Philadelphia eintraf. Von Frankreich aber konnte er sich solche nicht beschaffen, da er hier auf die Liste der Emigrirten gesetzt war und die Disposition über sein Vermögen durch Sequestration seiner Güter verloren hatte. Nachdem er eine Zeit lang sein Leben als Sprachlehrer, Musiker und Gehülfe an einem Privatmuseum gefristet hatte, nahm sich der neue französische Gesandte seiner an, so dass es ihm möglich wurde, während dreier Jahre in den Gebieten zwischen dem Hudson, Savannah und Ohio grössere Reisen auszuführen und umfangreiche botanische, zoologische und paläozoologische Sammlungen anzulegen. Aber auch diese gingen zum Theil zu Grunde, da das mit denselben befrachtete Schiff in der Nähe von Halifax scheiterte. Nachdem endlich das Institut de France bei dem Gouvernement seine Rehabilitirung durchgesetzt hatte, gab P. seine weiteren Reisepläne nach den Gegenden jenseits des Mississippi auf und kehrte im August 1798 nach Frankreich zurück. In Paris bearbeitete er aus dem bei Jussiet deponirten Material seine Flore d'Oware et de Benin 180t-1821, seine Insectes recueillis en Afrique et en Amérique 1805-18:1, nahm seine Studien über die Moose und Lycopodiaceen wieder auf, schloss daran Arbeiten über Farne und Palmen, über Blattstellung und über Pflanzenmark und schrieb eine vortreffliche Arbeit über die arä̈ser. Leider sind mehrere seiner Abhandhungen unvollendet bez. unveröffentlicht geblieben. Sein T'od erfolgte zu Paris am 21. I. 1820.

Coll. Herb. Delessert in Genf, Museum zu Paris.

Lit. Arsenne Thiébaut-de-Berneaud: Eloge historique de A. M. F. J. Palisot de Beauvols. Paris $18218^{\circ} 81$ p. mit Porträt (Bibl. Honac.); Cuviere:

Urban, Symb, ant. IU. 
Eloge historique de M. ne Benuvors in Mém. Acad. rles Scienc. de France. IV (1824, lu 1820) p. CCCXVIII-CCCXI,VI; Las. Mus. Deless. p. 70 bis 72; Dирот Nour. Biogr. génér. XXXIX (1862) 1) 86-88; Pritz. 'Thes. II ed. p. 239 ; Jacks. Guide p. 132 , 351; Cat. Sc. Pap. IV p. 743.

Parker, Charles Sandbach, (? - 1868 oder 1869), geb. iu Glasgow (Schottland), studirte unter P. DE CAndolle Botanik, bereiste 1824 Niederländisch und Britisch Guyana und ging ron da mit einem eigenen Schooner wach Westindien (Trinidad, Barbados, St. Vincent, Guadeloupe, St. Croix und Portorico), verlor aber eineu grossen 'Theil seiner Ausbeute durch Schiffbruch zwischen Guadeloupe und Antigua. Er assistirte Roscoe bei seinen Scitamineen und starb 1868 oder 1869.

Coll. Kew Herbarium, Doubletten in Cambridge.

Lit. Regensb. Flora vol. VIII. II (1825) p. 493; DC. Prodr. XII p. 110; Las. Mus. Deless. p. 492 ; Britr. and Boulg. p. 131 ; Cat. Sc. Pap. IV p. 758; Urв. Symb. I p. 108.

Parly, Charles Christopher, (1823-1890), geb. zu Admington in Gloucestershire (England) den 28. VIII. 1823, kam 1832 mit seiner Familie nach Amerika, verlebte die nächsten Jahre auf einer Farm in Washington County, N. Y., erhielt seine Erziehung am Union College in New York und promovirte am Columbia College zum Dr. med. 1846 liess er sich in Davenport (Iowa) nieder und starb daselbst den 20. II. 1890. Nur kurze Zeit als Arzt thätig, widmete er sich bald ganz der botanischen Erforschung des fermen Westens. Fr gehörte als Botaniker unter anderem au: der Mexican Boundary Survey 1849-1852, der Pacific Railway Company 1867, der Commissiou of Inquiry to Santo Domingo 1871 (cf. CH. WrIGHT), der Northwestern Wyoming Expedition 1873; ausserdem machte er zahlreiche Forschungsreisen in das Gebiet zwischen dell Rocky mountains und dem stillen Ocean und nach süuden bis Mexico.

Coll. Sein ausgezeichnetes Herbar ging sammt der Bibliothek 1894 durch Kauf in den Besitz des Iowa Agricultural College zu Ames über und blieb bei dem Brande Ende 1900 glïcklicher Weise verschont. Die Pflanzel von Sto. Domingo in Washington, Cambridge (Mass.), einiges in Kew.

Lit. Hemsu. Biol. IV (1988) p. 131; Prof. J. G. Lemon: The late Dr. Parry in Pacific Rural Press 12. IV. 1890 p. 385 ; C. H. Preston: Biographical Sketch of Dr. C. C. PArry in Proe. Davenp. Acad. Nat. Sc. VI (1893) p. 35-45; Mrs. Parky: List of papers publ. by C. C. Parry ibid. p. 46 - 52; L. H. Pamnel in The J. A. C. Student vol. V Nr. 2 (19. III. 1894); F. H. Knowlton in Biol. Soc. Washingt. XII (1895) p. 497 (n. v.); LeóN Bibl. Botán.-Mexic. (1895) p. 357; Sarg. Silva VII p. 130; Jacks. Guide p. 357, 358; Cat. Sc. Pap. IV p. 767, TIII p. 565, X p. 994; Urв. Symb. I p. 136 . 
Paulsen, Ore Wilhelm, (*1874), geb. in Aarhus (Dänemark) den 22. III. 1874, studirte Botanik auf der Unirersität in Kopenhagen und machte mit F. Borgesex vom December 1895 bis Februar 1896 eine Studienreise nach St. Thomas, St. Jan und St. Croix. Tom März 1898 bis Norember 1899 begleitete er den Premierlieutenant Ordfser auf seiner Pamir-Expedition. P. ist jetzt Assistent am botanischen Museum in Kopenhagen.

Coll. Botan. Museum zu Kopenhagen.

Lit. Kiaersk, in Bot. Tidsskk. Kopenh. XXIII (1900) p. 42; Urb. Symb. I p. 14.

Pavox, José, geb. in Spanien, begleitete Rutz (rergl. diesen) 1778 bis 1788 auf den Reisen in Peru und Chile und überlebte denselben um mehr als 20 Jahre. Die ihm zugeschriebenen Pflanzen ron Cuba, Sto. Domingo, Portorico und Antigua sind wahrscheinlich ron andern spanischen Botanikern gesammelt, ebenso wie die aus Mexico (wohl ron Sessé und Mocrĩo).

Coll. Museum zu Florenz (ex herb. WebB), Herb. Boissier-Barbey zu Genf (über die Entdeckung dieser Sammlnng zu Madrid durch Borssier's Conservator und Reisenden Reuter cf. H. G. Reichexbach in Botan. Zeitg. XXX. 1872 p. 591), Oxford (ex herb. Fielding), British Museum, Kew, Herb. Moricaxd zu Paris, Academie zu Barcelona, einiges im Herb. WILld. zu Berlin.

Lit. Las. Mus. Deless. p. 244-247; Cous. Botan. Penins. Hisp.Lusit. (1858) p. 181; Pritz. Thes. II ed. p. 151, 273; JAcks. Guide p. 377; Cat. Sc. Pap. IV p. 782 , VIII p. 574.

Perrottet, George Samuel, (1793-1870), geb. zu Trully im Kanton Waadt (Schweiz) im Jahre 1793, einer der eifrigsten und erfolgreichsten Reisenden. Von der französischen Regierung beauftragt, nützliche Gewächse nach Bourbon und Cayenne einzuführen, besuchte er 1819-1821 auf der "Rhône" unter Kapitän Philibert Cayenne, die Caprerden, Réunion (Bourbon), Jara, die Philippinen und Madagascar. Im Juni 1824 wurde er rom Marineminister nach Guadeloupe geschickt, um die Nopalpflanze nach Senegambien einzuführen, und brachte 1824-1829 als Director der Culturen am Senegal ein umfangreiches Herbar zusammen, welches die Grundlage zu dem von ihm, Gulltentx und A. Richard herausgegebenen Florae Senegambiae Tentamen bildete. 1834-1839 war er Botaniste-agriculteur des Gourernements ron Pondichery, sammelte die Flora der Ungebung sehr vollständig auf und besuchte 1837 - 1839 die Kïste von Malabar, Bombay und Pounah, sowie bei seiner Rückkehr im Norember 1839 St. Helena. Im Auftrage des französischen Hinisters der Marine und 
der Colonien studirte P. 1839-1840 in Indien und Sïdfrankreich die neuesten und besten Methoden der Seidenraupenzucht und suchte sie in Cayenne (December 1840 bis Februar 1841), Martinique (Februar bis Mai 1841) und Guadeloupe (Mai bis August 1841) einzuführen; ausserdem stellte er Beobachtungen über einen Pilz und ein Insekt an, welche auf letzteren Inseln die Kaffeepflanzungen zerstörten, und veröffentlichte darüber in Gemeinschaft mit Gúkn - Méxwrula ein Mémoire. Im October 1842 schiffte er sich wieder nach Ostindien ein, botanisirte auf der Hinfahrt in Aden, bei Bombay, Calicut, in den Nilagiris und kam im März 1843 in Pondichery an, wo er 1870 als Regierungsbotaniker starb.

Coll. Herb. Delessert und de Caxpolle in Genf, Museum zu Paris, Berlin; von Indien und Senegal auch im Herb. Bolssier in Genf, Drake del Castillo in Paris, Hofmuseum zu Wien; von den Antillen auch im Herb. Krug et Urban, Montpellier (ex herb. Canbess.); kleinere Sammlungen auch anderwärts (cf. Regensb. Flora XXXVIII. 1855 p. 112).

Lit. Notices historiques sur M. M. Sander Perrotretet et Louts Agassiz. Lansanne 1831. $8^{0} 20$ p. (n. v., ex Pritz. Thes. I ed. p. 224); Perrottet: Rapport sur sa mission dans l'Inde, à Bourbon, à la Martinique et à la Guadeloupe in Валот et Poirfé Ann. marit. et colon. Paris XXVII ${ }^{e}$ année $3^{\ominus}$ sér. partie non officielle, tome I (1842) p. 897-972; Las. Mus. Deless. p. 89-94; Dпрот Nouv. Biogr. génér. XXXIX (1862) p. 653 - 654; Рritz. Thes. I ed. p. 105, 199, 246, II ed. p. 131, 244; Jacks. Guide p. 210, 352 ; Cat. Se. Pap. IV p. 835.

Pflug, Dr., sammelte gegen Ende des 18. Jahrhunderts auf St. Croix für Prof. VAHL in Kopenhagen, welcher mehrere nene Arten unter seinen Pflanzen entdeckte, und starb daselbst im jugendlichen Alter (noch vor 1797).

Coll. Herbar VAHL in botan. Museum in Kopenhagen, einiges auch in St. Petersburg.

Lit. VAHL Eclog. I (1797) praef.

Picurda, Louis, (*1848), geb. zu Meslan, Départ. Morbihan (Frankreich), den 18. VII. 1848, erhielt seine Ausbildung zu Langonnet und Paris, studirte Theologie 1869 - 1873 am Seminar auf Martinique und war daselbst als Lehrer bis 1886 thätig, in seinen Mussestunden sich mit Conchyliologie und Entomologie beschäftigend. Am 1. September 1886 wurde er als Professor der Naturgeschichte und der Humanität am Collège St. Martial nach Port-au-Prince auf Haiti geschickt. Hier widmete er sich speciell der Erforschung der Flora und machte in den Ferien Excursionen nach Westen hin bis Jérémie, nach Norden bis Gonaïves und Perrodin, indem er die Berge bis zu $1600 \mathrm{~m}$ Höhe er- 
stieg. In August 1898 kehrte er in Folge seines durch Fieber stark erschütterten Gesundheitszustandes nach Frankreich (Notre Dame de Langonnet) zurück.

Coll. Herb. Krug et Urbax (1667 Nr.).

Lit. Briefl. Mittheilung von P.; UnB. Symb. I p. 113.

Plancllas. José, (1850-1886), geb. zu Coruña (Spanien) im Jahre 1850, studirte an der Universität zu Santiago in Galicien und wurde 1879 Doctor en Ciencias naturales zu Madrid. Später erhielt er den Lehrstuhl für Phytographie und Pflanzengeographie an der Unirersität zu Habana und das Directorat des dortigen botanischen Gartens. Er starb daselbst den 14. III. 1886.

Lit. Briefl. Mittheilung von G. DE LA MAZA.

Plée, Auguste, (1787-1825), geb. zu Paris im Jahre 1787, war Abtheilungschef beim Secretariate des Königlichen Rathes, rerzichtete aber auf dieses Amt, un die kurz rorher gegründete Stelle eines wissenschaftlichen Reisenden am Muséum d'histoire naturelle zu Paris zu übernehmen. Als solcher ging er im Februar 1820 nach II artinique, besuchte Guadeloupe, im Januar 1821. St. Lucia, im Februar 1821 St. Thomas, St. Barthelemy und St. Martin und rerweilte 1822-1823 in Portorico. Von hier aus wandte er sich nach Maracaybo in Veuezuela (1824) und kehrte damn nach Martinique zurück, wo er in Fort-Royal am 17. VIII. 1825 gerade, als er in die Heimath abreisen wollte, starb.

Coll. Die Pflanzen der kleinen Antillen umfassen Nr. 1-765, ausserdem auch Pflanzen aus dem botanischen Garten zu St. Pierre auf Martinique, die von Portorico Nr. 1-1065. Hauptsammlung im Museunı zu Paris, wo auch ein unvollständiges Handherbar aufbewahrt wird; zahlreiche Doubletten im hotan. Museum zu Berlin (ex herb. Кчхтн) und im Herb. Krug et Urbix. - Bei der Etiquettirung scheinen Irrthümer untergelaufen zu sein, da manche seiner sogen. MartiniquePflanzen sicher nicht von hier, sondern ron P'ortorico stammen.

Lit. Las. Mus. Deless. p. 492 ; Didot Nour. Biogr. g’énér. IL (1862) 1. 463-464; Linden et Planchon: Troisième royage de J. Linden I (1863) p. XLVI (mit falschem Geburtsjahre 1800, da er bereits 1811 publicirte); briefl. Mittheilung ron J. Polssox in Paris; Pritz. Thes. II ed. p. 248.

Plumier, Charles, (1646-1704), geb. zu Marseille (Frankreich) den 20. IV. 1646, trat in Jahre 1662 in den Orden der Minimes, studirte zuerst unter" der Leitung des P. Malaxis zu Toulouse Mathematik und wurde darauf zu Rom in Kloster Trinité du Mont von dem Pharmacognosten Père Pmulppe Sergenst sowie ron Fraxz de Oxtruniss und Pago (Srlvius) Boccose in die Botanik eingeführt. Nach 
Frankreich zurückgekehrt machte er grössere botanische Reisen in der Provence und in den Alpen, wurde mit ToukNefort bekannt.und fertigte für eillen neuen Pinax eine grössere Anzahl von Zeichmungen an. In ganz andere Bahnen wurden seine Studien gelenkt, als Surix ihn aut einer Forschungsreise nach den französischen Antillen, die er auf Befehl König Ludwigs XIV. und im Auftrage des früheren Intendanten von Sto. Doningo Mrciel Begux ausführen sollte, wegen seines herrolragenden Zeichentalentes zum Begleiter wählte. Im Jahre 1689 reisten sie ab, besuchten Martinique und Haiti und scheinen sich derartig in ilıre Aufgabe getheilt zu haben, dass Sunux hauptsächlich die Pflanzen für das Herbar präparirte und auf ihre medicinischen Eigenschaften untersuchte, während P. Pflanzen und Thiere zeichnete und sorgfältig beschrieb. Nach achtzehnmonatlichem Aufenthalte kehrten sie zurïck, aus unbekannten Gründen miteinander verfeindet. Surisx erhielt seinen Abschied, P. wurde zum Botaniste du roi ernamnt und bald nachher zum zweiten Male nach Westindien geschickt, wo er gegen sechs Monate blieb. Eine dritte und letzte Reise dahin führte er 1696-1697 aus. In der Zwischenzeit war P. ununterbrochen mit der Abfassung seiner umfangreichen Werke und mit der Herstellung der zugehörigen zahlreichen, sorgfältig ausgeführten Tafeln beschäftigt. Dieselben erstreckten sich nicht bloss auf das Pflanzenreich, sondern umfassten auch das Thierreich, wie: De naturalibus Antillarum $4^{0} 94$ p. und Coelum Americanum seu plantarum piscium volucrumque insulis Antillis et San Dominicana naturalium icones et descriptiones 92 p. u. 160 icones. Ja, er schrieb sogar ein Werk: L'Art de tourner ou de faire en perfection toutes sortes d'ourrages au tour. Lyon 1701. Fol. 80 Taf. Leider konnte nur ein verhältnissmässig kleiner Theil von ihm selbst publicirt werden. Denn schon im Jahre 1704 erhielt er den Auftrag, nach Peru zu reisen und die Chinarinde zu erforschen. In Cadiz in Spanien zog er sich jedoch eine Pleuritis zu, welcher er am 20. XI. 1704 im Alter von 58 Jahren erlag. Das Forschungsfeld P.'s waren die Inseln Martinique (Fort St. Pierre, Fort Royal, Cabesterre, Grande Anse, Grand Cul de Sac, Quartier du Prêcheur, Rivière du Lamentin, Morne Rouge und besonders die Morne de la Calebasse) und Haiti (im südlichen Theile île La Vache, die Umgebung von Léogane, Fond de Baudin, Petit und Grand Goive, See ron Miragoane, der grosse Cul de Sac, die Anses à Pitre, im nördlichen Theile die Rivière froide bis zu deren Quellen, Port de Paix und die gegenüberliegende Insel La Tortue oder Tortuga); dagegen scheint er sich auf den Inseln St. Vincent (Tract. Fil. p. 108, 111, Jacq. Fragm. 54, 55), Guadeloupe (Tract. Fil. 130), St. Christopher oder St. Kitts (Lam. Enc. II p. 497) und St. Thomas (ed. Burm. p. 27) nur sehr kurze Zeit aufgehalten zu haben. 
Coll. P. selbst hat kein Herbar hinterlassen; als Originalien können in Bezug auf die erste Reise die zehn Centurien Pflanzen des Herb. Surıx im Museum zu Paris angesehen werden.

Lit. Plum. Nov. Gen. Praef.; Pludr. ed. Berm. Praef.; Labat Voy. I ed. IV (1722) p. 10, 24, et ed. germ. IV p. 341, 3.16; Sirrexg. Hist. rei herb. II p. 238; J. E. Sumth in Rees Cyclop.; Biogr. unir. anc. et mod. XXXY (1823) p. 93; Biogr. univ. class. III (1829) p. 2404; Las. Ifus. Deless. p. 487-488; Didor Nouv. Biogr. génér. XL (1862) j) 499-501; Pritz. Thes. II ed. p. 249; Jacks. Guide p. 354, 359; Urb. Symb. I p. 123 bis 130 .

Poeppig, Eduard Friedrich, (1798-1868), geb. zu Plauen in Sachsen (Deutschland) den 16. VII. 1798, erhielt seine Gymnasialbildung in Leipzig und auf der Landesschule zu Grimma, studirte 1815-1822 in Leipzig Nedicin und Naturgeschichte und wurde hier 1822 zum Dr. med. promovirt. In demselben Jahre trat er eine grössere Forschung'sund Sammelreise nach Amerika an. 1822-1824 hielt er sich in Cuba auf und botanisirte besonders bei Matanzas, Limonar (Lemonal), auf der Loma de Carerna, bei Sumidero, Cahoba, S. Anna-Cavalleros, S. Elena, am Berge Sabanasso und an den Lagunen von Las Piedras; 1824 bis 1826 besuchte er Pennsylvanien, 1827-1829 Chile, 1829-1832 Peru und den Amazonas und kehrte im October 1832 ron Pará aus nach Europa zurück. Im Jahre 1833 wurde er ausserordentlicher Professor in Leipzig, 1834 Director des zoologischen Museums, 1816 ordentlicher Professor der Zoologie und starb den 4. IX. 1868 auf seiner Villa in Wahren bei Leipzig.

Coll. Die Gesammtausbeute der Reise an getrockneten Pflanzen betrug ca. 17000 Exemplare in ca. 4000 Arten. Die Sammlungen der drei ersten Reisen wurden ron G. Kraze in Leipzig vertheilt; eine der besten besitzt Berlin. Von Peru und dem Amazonas hat das Wiener Hofmuseun 1846 das Hauptexemplar erhalten (P.'s eigenes Herbar, vergl. Botan. Zeitg. IV. 1846 p. 608); Dupla finden sich in Petersburg (Botan. Garten und Akademie), Leipzig, Berlin, bei ne Cavool,k, BolssierBarber, Delessert in Genf, in Kiel, Paris, Halle, Brüssel.

Lit. Dr. Whisturng: Eduard Poeppig in Leipziger Illustr. Zeitung LI (1868) p. 243-245 mit Bildniss; F. Ratzel: Eddaro Poelpig in Mitheil. Ver. für Erdkunde zu Leipzig 1887 p. $3-17$ mit Bildniss und in Allgem. Deutsche Biograph. XXYI (1888) p. 421 - 427; Igr. Urbax: Endard Poeprig in Engl. Bot. Jahrb. XXI Beibl. 53 p. 3-29 mit Bildniss et Symb. I p. 130 bis 131; Pritz. Thes. II ed. p. 250; Jacks. Guide p. $374,377$.

Poiteau, Pierre Antoine, (1766-1854), geb. \%u Ambleny bei Soissons (Frankreich) den 23. III. 1766 von sehr armen Eltern, wurde Gärtuer, erhielt nach wechselrollen Schicksalen $1790 \mathrm{im}$ Jardin des plantes unter Axpré Thocrs Beschäftigung und zwei Jahre später die Aufsicht 
über die Ecole de botanique. Mit eisernem Fleisse ergänzte er hier die Mängel seiner Ausbildung, lernte Latein, Zcichnen und Malen und hörtc dic Vorlesungen des Muscums, das alles neben seiner Berufsthätigkeit in einem Zeitraum von nur drei Jahren. Im April 1796 trat er auf Veranlassung Thoux's von Rochefort aus scine erste Reise nach Haiti an und liess sich im Norden der Insel, in Cap (Haytien) nieder. Da aber die officielle Bestallung als Botaniker von Sciten der französischen Regierung ausblieb, so fand er keine Unterstützung beim franz. Gouvernement der Insel, sondern fristete melrrere Jahre kümmerlich sein Leben theils als Schreiber bei der Marineverwaltung, theils durch Anfertigung von Zeichnungen für die Festungswerke. Er erhielt zwar den Auftrag, in Cap einen botanischen Garten anzulegen, dessen Director der Botaniker Abbé de la Haye werden sollte, empfing aber für dic fünfmonatliche Thätigkeit keinen Pfennig und musste deshalb seine Arbeit einstellen. Erst unter dem Gouverucur General HÉdouvilue und unter seinem Nachfolger, dem Agenten Roune, verbesserte sich seine Stellumg, indem diese ihn für Anlegung von Herbarien regelrecht besoldeten. Als aber letzterer von dem Negergeneral Toussannt Louverture eingekerkert wurde, war P. wieder von allen Mitteh entblösst. Da machte er die Bekanntschaft des Consuls der Vereinigten Staaten, Enwarn Stevexs, eines grossen Pflanzenliebhabers, der sich seiner auf das wärmste annahm. Jetzt erst begann eine planmässige Erforschung des nördlichen Theiles von Haiti. P. sammelte, trocknete und besclirieb die Pflanzen, Turpus, bis dahin Sergeant in dem in Haiti stationirten Bataillon Calvados, zeichnete sie unter Leitung P.'s nicht nur nach ihrem Habitus, sondern auch mit allen analytischen Details. Sie liessen sich sechs Monate lang in Sainte-Suzanne nieder, kehrten auf drei Monate zum Cap zurïck, blieben ein Jahr auf der benachbarten Insel La Tortue bei einem reichen Eigenthümer de Labattue und kamen dann wieder zum Cap, wo sie bis Ende 1800 botanisch thätig waren. STevexs erhielt für seine pecuniären Unterstätzungen von P. die Hälfte der gesammelten Pflanzen und von Turpis die fast 300 Tafeln umfassenden Zeichnungen. Mittlerweile waren die politischen Verhältnisse unter Toussant Lourenture, der sich von der franz. Regierung fast ganz unabhängig gemacht hatte, so ungünstig geworden, dass P. über Philadelphia nach Frankrcich zurückkehrte, wo er gegen Ende des Jahres 1801 mit ca. 1200 Pflanzenarten in 6-7000 Exemplaren, den Beschreibungen derselben, 700 Arten Sämereien und Früchten, sowie zahlreichen Zeichnungen wieder eintraf. - Bald nach seiner Rückkehr unterbreitete P. der Direction des Muséum d'histoire naturelle den Plan zu einer zweiten Expedition nach Haiti. Man ging darauf um so bereitwilliger ein, als der kommandirende General der franz. Armee in Haiti Leclero einen ganz ähnlichen Wunsch an den 
Minister Chaptal gerichtet hatte: es sollten zwei Zoologen, ein Chemiker und Pharmacent, ein Mineraloge, ein Geologe, Nвстосx als Director des botanischen Gartens, Polteau als Botaniker sowie mehrere Gärtner hingeschickt werden. Die Verhandlungen darüber zogen sich bis Anfang 1803 hin; gerade damals aber ging die Insel den Franzosen für immer verloren. - In den folgenden Jahren beschäftigte sich P., meist in Gomeinschaft mit seinem Freunde Turpix, mit der Abfassung mehrerer grösserer reich illustrirter Werke (Traité des arbres fruitiers, Histoire naturelle des oranges, Flore parisienne), leitete die Culturen im botanischen Garten der École de Médecine und wurde 1815 Chef der Pépinières zu Versailles. - Im Jahre 1819 ging P. als Botaniste du roi und Director der Culturen, speciell des Gartens der Épiceries (genannt La Gabrielle) nach Französ. Guyana, wurde aber in seiner Thätigkeit durch administrative Maassregelungen bedeutend eingeschränkt. Dessungeachtet brachte er bei Cayenne, in der Umgebung der Gabrielle und auf einer Expedition an den Ufern der Mana bis zum Jahre 1822, wo er rom Gourerneur zur Aufgabe seiner Stelle gezwungen wurde, ein Herbar ron mehr als 1000 Arten in ca. 12 Exemplaren mit zahlreiclien Zeichmungen und Beschreibungen und eine grosse Sammlung ron Säugetlieren, Tögeln, Reptilien und Mollusken zusammen. Nach rergeblichen Versuchen, eine Anstellung am Jardin des plantes zu erhalten, gelang es P. 1830 endlich, Professor am landwirthschaftlichen Institut zu Fromont zu werden. In dieser Stellung publicirte er noch zahlreiche Werke über Gartenbau, war Redacteur des Bon Jardinier und der Annales de la Société d'horticulture und starb, nachdem er in den letzten Jahren ron einer Pension der letztgenannten Gesellschaft gelebt hatte, den 27. II. 1854 zu Paris.

Coll. Hauptsammlung der Haiti-Pflanzen in Museum zu Paris (auch im Herb. Jussieu); Dupla im Herb. Delessert, de Cindolı.. Herb. Richard (jetzt Drake del Castillo), in der Academy of Natur. Sciences zu Philadelphia, Herb. Krug et Urbax (340 Nr., hier und in Pliiladelphia ex herb. Stevexs), Florenz (ex herb. Webi), Leiden (ex herb. Persoox), Petersburg, Museum zu Neuchâtel, leerb. Whudbexow zu Berlin (unter RudoLpu); über den Verbleib der zugehörigen Zeichnungen und descriptiven Aufnahmen ist nichts bekannt. - Die Hauptsammlung von Guyana im Herb. Richird (jetzt Drake del Castillo) und Herb. Delessiat in Genf, Doubletten in Paris, wo auch die Zeichungen und Manuskriptbeschreibungen sind, St. Petersburg, Kew. - Die Sammlungen sind niemals im Zusammenlange bearbeitet worden.

Lit. Las. Mus. Deless. p. 222, 266-268; J. Decalsxe: Notice sur II. A. Poiteau in Rer. hortic. IV sér. vol. III (1854) P. 115; P. Larousse Grand Dictionn. univ. XII (1874) p. 1275 ; Rousselon in Amm. Soc. d'hortic. de Paris 1854 (n. v.); Sarg. Silva II p. 75; Ev. Bureav: Etude biographique 
sur le Botaniste Pierre-Antorne Poiteau in Nour. Archiv. du Muséum III sér. vol. IX (1897) p. $1-94$ mit Porträt auf S. 3 (ich bin dieser schr sorgfältigen Arbcit gefolgt, welche viele Irrthümer der anderen Biographen anf Grund eines umfangreichen Quellenstudiums richtig stellt); Puirz. Thes. II ed. p. 93, 250, 264; Jacrs. Guide p. 128,421 ; Cat. Sc. Pap. IV p. $969-970$; Urв. Symb. I p. 93, III p. 10.

Ponthieu, de, sammelte vor 1786 in Jamaica, Antigua, Barbuda, Montserrat, Guadeloupe, Grenada und Tobago.

Coll. Herb. Banks im British Museum, Herb. Delessert in Genf (ex herb. Lambert), einiges auch im Herb. SwarTz in Stockholm.

Lit. Las. Mus. Deless. p. 266.

Powell, Henry, (*1864), geb. zu Goodrich, Herefordshire, in England den 13. III. 1864, war Gärtner zu Kew und ist seit 1890 Curator des neuen botanischen Gartens in St. Vincent, wo er hauptsächlich 1891 - 1893 sammelte.

Coll. Kew, einiges im Herb. Kreug et Urbax.

Lit. D. Morris in Kew Bull. Add. Ser. I (1898) p. 93; briefl. Mittheilung durch D. Morris.

Prax. (? - 1858), kam als französischer Vice-Consul 1852 nach Haiti, sammelte besonders 1854 in der Umgebung der Stadt Gonaïves und wahrscheinlich auch auf der gegenüberliegenden Insel gleichen Namens. Er starb daselbst 1858, nachdem er forher Frau und Kind verloren hatte.

Coll. Museum in Paris, einiges im Herb. Krug et Urbax.

Lit. Briefl. Mittheilung von Herrn W. Весн.

Prenleloup, L. A., (? bis ca. 1885), lebte als Apotheker 1853 bis 1869 auf Sto. Doming 6 (wahrscheinlich in der Hauptstadt selbst) und zog sich dann nach Pully bei Lausanne (Schweiz) zurück, wo er um 1885 starb. Sein Herbar (ca. 1054 Nr.) schenkte er testamentarisch der Universität Lausanne.

Coll. Kantonal-Museum (Cabinet de botanique) zu Lausanne, Doubletten im Herb. Krga et Urbax (320 Nr.) und Bolssier-Barbey.

Lit. Briefl. Mittheilung des Prof. J. B. Schnetzler in Lausanne.

Prestoe, Henry, in Kew Gardens ausgebildet, war 1864-1886 als Nachfolger von H. Critger Superintendent des botanischen Gartens in Trinidad, gab im letztgenannten Jahre seine Stellung auf und lebt seitdem als Pensionär in England.

Coll. Kew⿳⺈冂大 Herbarium.

Lit. J. H.' Hart: Ann. Rep. Bot. Gard. Trinill 1887 p. 9; Kew Bull. add. ser. I p. 56; Cat. Sc. Pap. XI p. 63; Unв. Symb. I p. 131. 
Prior, Richard Chandler Alexander, $(* 1809)$, geb. in Corsham bei Bath (England) den 6. III. 1809, wurde in Charterhouse erzogen, in Oxford graduirt, 1840 Fellow of the London College of Physicians, gab aber schon 1841 seine medicinische Praxis auf, um nach Gratz zu übersiedeln und drei Jahre lang Botanik zu studiren. Er sammelte in den Alpen, Croatien und Dalmatien, Italien und Sicilien. Im Jahre $18+6$ begab er sich auf zwei Jahre nach dem Capland, konnte jedoch seine botanischen Ausflüge wegen des Kaffernkrieges nicht über Grabamstown ausdehnen. 1849 ging er nach Canada und den Tereinigten Staaten und ron da im November nach Jamaica, wo er bis August 1850 blieb und die Blue Mountains und den nördlichen Theil der Insel (Moneague) erforschte. Seitdem machte er verschiedene kürzere Reisen nach Italien, Dänemark, Norwegen, Schweden, Frankreich und Deutschland. 1849 fügte er nach den Tode eines nahen Terwandten den Namen "Prior" seinem eigenen (Alexander) hinzu. In den letzten 40 Jahren lebt er theils in London, theils auf seinem Landsitze bei Taunton, mit literarischen Arbeiten beschäftigt (Popular names of British Plants ef. Journ. of Bot. XVIII. 1880 p. 25, Geschichte des Croquet-Spiels, Uebersetzung. ron Ancient Danish Ballads).

Coll. Die Jamaica-Pflanzen in Kew, herb. Grisebach (Göttingen), Krug et Urbax (hier ca. 350 Arten).

Lit. Briefl. Mittheilung ron P.; Pritz. Thes. II ed. p. 253; Jacks. Guide p. 10, 218; Cat. Sc. Pap. I p. 43-44, VI p. 564; Urв. Symb. I p. 57.

Purdie, William, (?-1857), geb. in Schottland, lernte im botanischen Garten in Edinburgh unter W. MA $\mathrm{N}_{A B}$, war darauf in Kew thätig und ging im Auftrage Sir Willia Hooken's Nai 1843 als Sammler von lebenden und Herbarpflanzen nach Jamaica. Während eines einjährigen Aufenthaltes daselbst durchstreifte er die ganze Insel und durchforschte die Flora derselben eingehender als irgend ein anderer Botaniker dieses Jahrhunderts. Von da begab er sich auf Anregung von J. Lisdex, der ihn auf der Rückkehr rom Festlande im April 1814 in Jamaica traf, kurz nachher nach Santa Marta in Neu-Granada, wo er zweimal die Sierra Nevada bestieg und dann die Provinzen Bogotá und das Thal des Rio Magdalena besuchte $(1844-1845)$. Im Jahre 1846 wurde er als Nachfolger von Lockнarт Gorernment's Botanist und Superintendent des botanischen Gartens auf Trinidad. 1851 machte er noch einmal eine Reise in das Innere ron Venezuela und zu Informationszwecken 1854 eine solche nach Portorico, und starb in Trinidad am 10. X. 1857. Einige seiner Pflanzen stammen auch von den Inseln 'T'obago, Guadeloupe und Montserrat.

Coll. Kew Herbarium, Doubletten von Jamaica im Pariser Ifuseum (ex herb. W. Hooker, ohne Angabe des Sammlers), einiges im Herb. Krug 
et Urbax, einige Bruchstiicke im Herb. Grisibucu (Göttingen), Pflanzen ron Trimidad auch in Florenz.

Lit. W. Punne in Hook. Lond. Journ. Bot. III (1844) p. 501-533, IV (1845) p. 14-27, VI (1847) p. 40; SEex. in Bouplandia Y (1857) 1. 364; Linden et Planchon: Troisième voyage de J. Lirnden I (1863) p. LX-LXI; J. H. HART in Ann. Rep. Bot. Gard. Trinidad 1887 p. 9; Britr. and Boulg. p. 139; Kew Bull. Add. ser. I p. 55; Pritz. 'Thes. II ed. p. 254; Cat. Sc. Pap. T p. 43; Unв. Symb. I p. 132.

Pursh (hiess eigentlich Pursch), Friedrich Traugott, (1774 bis 1820), geb. zu Grossenhayn in Sachsen (Deutschland) den 4. II. 1774, beschäftigte sich in Dresden mit Naturwissenschaften, besonders mit Botanik und empfing seine gärtnerische Ausbildung in dem dortigen Königlichen Garten unter Hofgärtner SEldEL. Im Jahre 1799 ging er nach Nordamerika, um in Baltimore die Anlage eines grösseren Gartens zu leiten, erhielt dann die Aufsicht über den damals in grossem Ansehen stehenden Garten ron Wildian Haynutox in Philadelphia (1802 bis 1805) und wurde mit Mühlexberg, Marshale, Bartram, Bartox, Le Coxte und anderen berühmten Botanikern bekannt. Von dem leblaftesten Wunsche beseelt, die Erforschung der nordamerikanischen Flora fortzuführen und MrchaUx-Richard's Flora durch ein vollständigeres Werk zu ersetzen, durchstreifte er 1805-1806 einen grossen Theil der Oststaaten von Maryland bis Carolina und von Pennsylvanien bis New Hampshire. Während er die Materialien für die Publikation vorbereitete, wurde ihm 1807 die Direction des botanischen Gartens in New York, welcher gerade damals aus dem Privatbesitze des Prof. Hosack für den Staat angekauft worden war, übertragen. In Folge eines schweren Fieberanfalls, der seine Kräfte erschöpft liatte, machte or 1810-1811 eine Reise nach Westindien und besuchte Barbados, Martinique, Dominica, Guadeloupe und St. Barthelemy. Nach dreijährigem Aufenthalte in England (1811 - 1814), wo er seine Flora ron Nordamerika nach vergleichenden Studien in den dortigen grossen Herbarien zum Abschlusse brachte und publicirte, begab er sich zur Fortsetzung seiner botanischen Untersuchungen nach Canada und starb am 11. VII. 1820 zu Montreal.

Coll. Sein Herbar ging in den Besitz von A. B. LAnвERT über und wurde nach dessen Tode 1843 im Einzelnen verkauft.

Lit. F. Pursu: Flora Americae septentrionalis vol. I (1814) Preface; Regensb. Flora I (1818) p. 357, III (1820) p. 542, X (1827) p. 192, 491 bis 496 (Nachricht von seinem Bruder CarL August Pursci über das Leben von Friedrici P., worin auch die berichtigende, aber später fast ganz übersehene Mittheilung, dass er nicht in Sibirien, sondern an dem genannten Orte geboren ist), 528; Las. IIus. Deless. p. $460-461$; F. Pursh: Journal of a botanical excursion in the northern parts of the states of Peunsylvania 
and New York, during the year 1807, Philadelphia 1869, edited by 'Thouss P. James (n. v.); F. S. Drake Dict. Amer. Biogi. (1872) y. 746; Salzo. Silva II p. 39; Harshberger Botan. Philad. (1899) p. 113-117; Pritz. 'I'hes. II ed. p. 254-255; Jacks. Guide p. 354, 365, 409, 443.

Ramage, G. A., aus Edinburgh, begleitete H. N. Ridler und den Rev. T. S. Lea im Jahre 1887 auf ihrer Expedition nach Pernambuco (Brasilien) und Fernando Noronha. Im Auftrage des brittischen Committee für die Erforschung der Fauma und Flora Westindiens sammelte er sodann $1888-1889$ in Dominica und Sta. Lucia, kehrte aber im Mai des letztgenannten Jahres in Folge von Kränklichkeit nach England zurück.

Coll. British Museum (hier die Hauptsammlung der brasil. Reise), Kew Herbarium (hier die westindische Sammlung am besten vertreten), die Pflanzen ron Wrestindien auch in Herb. Krug et Urbax (ca. 600 Nr.).

Lit. Ridler in Journ. Linn. Soc. XXVII (1891) p. 1-2; Urb. Symb. I p. $136-137$.

\section{Ramon de la Sagra ef. Sagra.}

Ravn, Peter, (? - 1839), geb. in Dröbak (Norwegen), machte 1816 das chirurgische Examen, ging 1819 nach St. Thomas, wo er 1830 als Garnisonschirurg und $183 \pm$ als Regimentschirurg angestellt wurde, und starb daselbst am 26. IV. 1839. Er sammelte auf St. Thomas, St. Croix, St. Jan und Vieques (Crab Island).

Coll. Bot. Museum zu Kopenhagen, einiges im Herb. de Caxdolle in Genf.

Lit. Krebs Bidr. St. Thom. p. 291; Kiaersk. in Bot. Tidsskr. Kopenlı. XXIII (1900) p. 43.

Rawson, Sir Rawson William, (1812 - 1899), geb. in London den 8. IX. 1S12, bekleidete höhere Stellungen im englischen Colonialdienste und zwar in Mauritius, im Caplande, seit 1864 auf den Bahamas, war bis 1875 Gourerneur der Windward Islands (Barbados) und starb in London den 20. XI. 1899. Sein Hauptinteresse wandte er den Farnen zu; in Verbindung mit Dr. PAPPE publicirte el unter anderem 1858 eine Synopsis Filicum Africae australis.

Coll. British Museum, Kew, Dupla von den Bahamas (a. 1867 bis 1868) und ron Grenada (a. 1870-1872) in Berlin.

Lit. Britten's Journ. of Bot. XXXVIII (1900) p. 63; Bull. Misc. Inf. Kew 1899 p. 221 - 222; Jacks. Guide p. 347; Cat. Sc. Pap. VIII p. 708, XI p. 116; URB. Symb. I p. 38.

Read, James, nordamerikanischer Schiffsofficier, sammelte auf Cuba, Portorico, St. Thomas, St. Croix, Guadeloupe und Curaçao, sowie in China. 
Coll. Acad. of Nat. Scienc. in Philadelphia, die westindischen Pflanzen, deren Ursprung in Bezug auf die einzelnen Insehn nicht immer ganz sicher scheint, auch im Herb. Krugi et Urmss.

Reade, Oswatd A., Pharmacent bei dem Royal Naval Hospital auf den Bermudas, sammelte daselbst un 1880.

Coll. Kew Herbarium.

Lit. Urb. Symb. I p. 134.

Rees, Rev. T. L., sammelte bei Oxford in St. Elizabeth Parish auf Jamaica Farne, welche von G. S. Jexmax in seiner Synoptical list bearbeitet wurden.

Reid, James, Quaker, wurde 1692 auf Kosten des Königs Wilheli von England nach Barbados geschickt und sammelte dort.

Coll. Herb. Slonie im British Museum.

Lit. W. B. Heasslex in Britr. Journ. of Bot. XXI (1883) p. 259 (hier "Read" und "Reede" geschrieben); Britr. and BođLG. p. 141.

Reill. Johannes Justus, (*1835), geb. zu Rauenheim am Main im Grossherzogthum Hessen (Deutschland) den 27. I. 1835, studirte 1853 bis 1855 an der Universität Giessen, war 1858-1860 Lehrer an der Ritter- und Domschule der esthländischen Ritterschaft zu Reral und machte 1860 Reisen in Finnland und Skandinavien. Nachdem er im Winter 1860-1861 seine Studien in Giessen wieder aufgenommen und in Rostock promovirt hatte, lebte er vom Sommer 1861-1863 als Erzieher der Söhne des Gouverneurs Sir Harri Ord auf den Bermudas. 1872 machte R. mit Prof. Freiherrn Kard vos Fritsch eine Studienreise nach den Canarischen Inseln und dem marokkanischen Atlas, 1873 bis 1875 bereiste er im Auftrage der preussischen Regierung Japan. Im April 1876 wurde er Professor der Erdkunde in Marburg, Herbst 1883 in Bonn. Von hier aus besuchte er 1897 Transkaspien, Turkestan und die russischen Culturversuche zu Tschakwa bei Batum. Ausserdem hatte er sich in den Jahren 1872 - 1892 riermal zu Studienzwecken in Spanien aufgehalten.

Coll. Hauptsammlung der Gefässpflanzen von den Bermudas im Herb. Grišbach zu Göttingen, Doubletten (189 Nr.) im Berliner Museum; die Algen von dort im Herb. des botanischen Gartens zu Dublin (ex Herb. Harvey), Doubletten im Berliner Museum und bei Prof. Noll in Bonn. - Die Pflanzen von Japan im Pariser Museum? und in Berlin und St. Petersburg, die emropäischen und marokkanischen in Berlin.

Lit. W. B. Hexsu. Bot. Chall. Exp. (1884) p. 6; briefl. Mittheilung von R.; Cat. Sc. Pap. VIII p. 723, XI p. 133; Urb. Symb. I p. 135.

Reynoso, Alvaro, $(1830-1889)$, geb. in Durán auf Cuba im Jahre 1830, wurde im Colleg zu San Cristóbal erzogen und ging 1847 
nach Paris, 1 m Chemie zu studiren. Hier erhielt er 1854 einen Preis für seine Untersuchungen ïber das Chloroform und promovirte zum Dr. der Wissenschaften. In seine Heimath zurïckgekehrt widmete er sich besonders der Förderung des Landbaus auf der Insel und veröffentlichte verschiedene diesbeziigliche Arbeiten. Sein Hauptwerk: Ensayo sobre el cultivo de la caña de azucar, welches ein Libro de oro der cubanischen Hacendados genannt wurde, erschien 1862 und wurde 1878 in dritter Auflage lerausgegeben. Er starb den 11. VIII. 1889. Grisebach widmete ihm die Gattung Reynosia.

Lit. F. Calcagro Dice. biogr. Cubano (1878) p. 542; Sarg. Silva II p. 19; briefl. Mittheilung von G. DE LA Maza; Cat. Sc. Pap. V p. 181-182, VIII p. 741, XI p. 163; Urb. Symb. I p. 138.

Reynoso, Antonio, lebte um 1833 in Guanimar auf Cuba und sammelte für Rayon dE LA SAgRa (rergl. diesen).

Lit. Urb. Sy̆mb. I p. 143.

Richard, Louis Claude Marie, (1754-1821), geb. zu Auteuil (Frankreich) den 4. IX. 1754 als ältester Sohn des dortigen Hofgärtners Cladde R. und Neffe des Torsteher's des Gartens zu Trianon, rerliess das elterliche Haus, weil er sich nicht nach dem Wunsche seines Vaters dem geistlichen Stande widmen wollte, besuchte das Collège Mazarin zu Paris, studirte dann Mineralogie, Zoologie, vergleichende Anatomie und besonders unter Bershard de Jussieu Botanik und erwarb sich nebenbei nicht nur den Lebensunterhalt, sondern selbst ein kleines Vermögen durch Zeichnen ron Gartenplänen. Im Jahre 1781 wurde er auf den Vorschlag der Akademie der Wissenschaften ron dem König Louss XVI. nach Guyana geschickt, um Nutzpflauzen aus der alten Welt dort einzuführen und auf den französischen Antillen zu verbreiten. Von Cayenne aus machte er 1785 eine Reise nach Brasilien (Pará) und besuchte alsdann vom Februar 1786 bis Norember 1787 die Inseln Martinique, Guadeloupe, Antigua, Barbuda, Anguila, St. Croix, Tortola, St. Jan, St. Thomas, Portorico, Haiti, begab sich darauf wieder nach Guyana und kehrte im Frühjahr 1789 mit reichhaltigen Schätzen aus dem Pflanzen-, Thier- und Mineralreiche und rielen Zeichnungen nach Frankreich zurück. Hier aber standen jetzt andere Männer an der Spitze der Regierung und des Museums, die ron R.'s Mission nichts wissen wollten und sich weigerten, die aus eigenen Mitteln für die Reise gemachten Auslagen zu ersetzen. In Folge dessen verlor er die Lust, seine zahl'reichen Entdeckungen zu publiciren, und musste zum Planzeichnen zurückkehren, um sich den Lebensunterhalt zu verschaffen. Im Jahre 1795 endlich, als Fourcroy die Ecole de Mlédecine gegründet hatte, erhielt er die botanische Professur an derselben, legte 
eimen kleinen botanischen Garten an und bildete eine Reihe Schüler aus. Die wenig zahlreichen, aber hervorragenden Arbeiten, welche von ihm erschienen, standen nach dem Zeugnisse der Zeitgenossen in gar keinem Verhältnisse zu dem, was er auf botanischem und zoologischem Gebiete wirklich erforscht hatte. Nach längerer Krankheit starb er den 7. VI. 1821 zu Paris.

Coll. Sein ausgezeichnetes Herbar ging in den Besitz seines Sohnes, Achille Richard, dem Bearbeiter der Phanerogamen in SagRA's Historia de Cuba, über. Nach des letzteren Tode (1854) wurden die Sammlungen von Vater und Sohn, von denen das Herbarium guyanense-antillanum 2604, das Herb. cubense (Ramon de la Sagra, Lindex etc.) 4464 Arten nebst zahlreichen Doubletten umfasste, 1856 von dem Grafen Albert DE Franqueville in Paris angekauft, welcher sie den Botanikern in liberalster Weise zum Studium überliess. Als dieser gestorben war, kaufte 1891 Drake del Castillo in Paris das Herbar und übergab einen Theil davon dem Pariser Museum. Doubletten sind im Herb. VAHL in Kopenhagen, Herb. Whlddexow in Berlin und im Herb. Cossox in Paris.

Lit. K. S. Kunth: Notice sur Louis-Claude-Marie Richard. Paris 1824. $8^{0} 23$ p. (ex Pritz. Thies. I ed. p. 145); Auszug daraus in Hook. Journ. of Bot. IV (1842) p. $423-433$ (mit Porträt); G. Cuvien: Eloge hist. de M. Richard in liém. du Muséum d'hist. nat. XII (1825) p. 349-366 et in Mém. Acad. Scienc. VII (1827) p. CXCIV - CCXII; Las. Mus. Deless. p. 474; Dict. Scienc. nat. vol. LVI (1845) p. $211-212$; Dıрoт Nouv. Biogr. génér. XLII (1863) p. 184-187; SAGOT in Ann. Sc. nat. VI sér. vol. X (1880) p. 366; die besuchten Inseln gegenïber den irrthümlichen Angaben der Autoren nach Herbaretiquetten; Pritz. Thes. II ed. p. 48, 97, 263; Jacks. Guide p. 8, 36, 129, 354, 508; Cat. Sc. Pap. V p. 187; iuber das Herb. Richard briefl. Mitheilung von Drake del Castillo in Paris und ex Hook. Journ. of Bot. and Kew Misc. VIII (1856) p. 81-82, sowie Botan. Zeitung XIV (1856) p. $151-152$.

Ricksecker, Alfred Edmund, (* 1869), geb. zu West Salem in Illinois (U. S. A.) den 10. XII. 1869 als Sohn des Rev. Jos. J. R. und der folgenden, graduirte 1894 am Oberlin College zum Bach. Art. und wurde daselbst Assistent für Botanik. October 1895 bis September 1896 hielt er sich in St. Croix auf und wurde 1900 zum Professor of Science am Wilton College in Iowa berufen.

Coll. Vollständigste Sammlung im Field Columbian Museum in Chicago, ferner im National Museum in Washington, Miss. Bot. Garden in St. Louis, Gray Herbarium in Cambridge, Universitätsherbar in Minneapolis, Herb. Krug et Urbas (386 Nr.), Bot. Garten in Edinburgh, Oberlin College in Ohio.

Lit. Briefl. Mittheilung von A. E. R. 
Ricksecker. Mrs. Leonora Agnes, (* 1849), geb. zu Nazaretlı in Pennsylvanien (U.S. A.) den 4. I. 1849, besuchte die Moravian Parochial Schools, graduirte am Young Ladies' Seminar zu Beth, Pa., und verheirathete sich 1867 mit dem Rev. Jos. J. Ricksecker. 1893-1897 hielt sie sich in St. Croix auf und sammelte, von ihren beiden Söhmen FraNk und PaUs unterstützt, $1896-1897$.

Coll. Vollständigste Sammlung in Field Columbian ILuseum in Chicago, ferner im botan. Garten zu Edinburgh und im Herb. Krug et Urbax (415 Nr.).

Lit. Briefl. Mittheilung ihres Solnes A. E. R.

Riedlé, Anselme, geb. ca. 1775 zul Yrsée bei Ausbourg (wo?), begleitete als Gärtner des Jardin des plantes mit dem Auftrage, hauptsächlich lebende Pflanzen und Samen zu sammeln, die französische

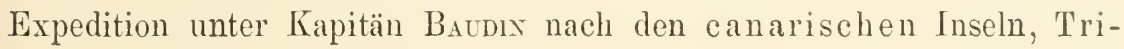
nidad, St. Thomas und Portorico 1796 - 1798 (cf. Lenru) und eine andere unter demselben Kapitän, welcher Leschexault de LA Tour als Botaniker und Guiciexot und Sautier ebenfalls als Gärtner beigegeben waren, nach Australien und Timor 1801-1803.

Coll. Huseum zu Paris, vieles auch im Berliner Museum (ex herb. Kuntu) und Herb. Krotg et Urbax; die Pflanzen von Timor im Ifuseum zu Paris, Doubletten im Herb. Delessert.

Lit. Decaisse in Nouv. Arch. du Mus. dhist. nat. Paris III (1834) p. 335 - 336; Las. Mus. Deless. p. 271, $490-491$; Urb. Symb. I p. $94-95$.

Riise, Albert Heinrich, (1810-1882), geb. zu Aero in Dänemark den 11. IX. 1810, Apotheker, ging als solcher nach St. Thomas, wo er Pflanzen und Conchylien sammelte, kehrte 1870 nach Kopenhagen zurück und starb daselbst den 18. X. 1882.

Coll. Botan. Museum zu Kopenhagen.

Lit. Kuaersi. in Bot. Tidsskr. Kopenh. XXIII (1900) p. $43-44$.

Ritter, Karl, (1s00 - ?), geb. zu Lungwitz bei Dresden im Jahre 1800, machte seine gärtnerischen Studien in Dresden und Leipzig, wurde Hofgärtner in Wien und ging 1820 auf Kosten des Kaisers FraNz I. von Oesterreich nach dem nordwestlichen Haiti, um für die Kaiserlichen Gärten und Hof-Naturalien-Cabinete Sammlungen zu veranstalten. Er hielt sich rom April 1820 bis Ende Februar 1821 auf der Insel auf, hauptsäclılich in der Umgebung von Cap Haitien, zuletzt bei Gonaïres und südwärts bis St. Nare. Nach seiner Rückkehr trat er wieder bei der K. K. Gartenverwaltung als Hofgärtner ein und wurde 1832 Gartendirector beim Grafen Ludwig Szécuéxy in Pressburg. Durch eine rege literarische 'Thätigkeit, sowie durch die Anlage zahlreicher Gärten auf den Gütern der ungarischen Magnaten hat er sehr fördernd auf die kint- 
wickelung des ungarischen Gartenbaus eingewirkt. Ueber Zeit und Ort seines 'lodes ist nichts bekannt.

Coll. Hofmuseum zu Wien, lebende Pflanzen in den Kaiserlichen Gärten zu Schönbrunn.

Lit. Regensb. Flora VII (1824) p. 577-583; C. von Wurzbach Biogr. Lexik. XXVI (1874) p. 185 - 187; briefl. Mittheilung des Herm Dr. M. KroNFeld in Wien; Urb. Symb. I p. $138-139$.

Riroire, Madame, sammelte 1839 auf Martinique.

Coll. Museum zu Paris, einiges im Herb. Kírug et Urban.

Roberts. Mrs. Seed, sammelte zu St. Andrew auf Jamaica Farne welche ron G. S. Jexus in seiner Synoptical list bearbeitet wurden.

Robin, Claude C., Abbé und Geistlicher in Rochambead's Armee während des nordamerikanischen Befreiungskrieges, machte 1802-1806 Reisen im Innern von Louisiana, im westlichen Florida, nach Martinique und Sto. Domingo.

Coll. Ob R. auch in Westindien gesammelt hat, ist mir nicht bekannt.

Las. Mus. Deless. p. 462; F. S. Drake Dict. Amer. Biogr. (1872) p. 774; Pritz. Thes. II ed. p. 256, 265; Jacks. Guide p. 363.

Robinsol, Anthony, (?-1768), Dr. med., stammte aus Sunderland (England), war Arzt in Jamaica und beschäftigte sich eifrig mit der Thier- und Pflanzenwelt der Insel. Er starb 1768. Seine 455 Zeichnungen sind erhalten geblieben und befinden sich in der Bibliothek des Institute of Jamaica; ron seinen Manuscripten ist nur eine Abschrift vorhanden, welche von Lusas benutzt wurde.

Coll. Einiges in Herb. Banks im British Mnseum.

Lit. Britt. and Boulg. p. 144; F. Cundall im Journ. Inst. of Jamaica I (1892) p. 99, (1893) p. 327; T. D. A. CockeriLl in Amer. Naturalist XXVIII (1894) p. $775-780$.

Robinson, H. E. William, Gonverneur der Bahama-Inseln, für deren Culturen er sehr thätig war, sammelte daselbst 1877 und wurde um 1880 Gouverneur von Barbados.

Coll. Kew Herbarium.

Lit. Kew Rep. for 1877 p. 48, 1880 p. 30.

Rohr, Julius Philipp Benjamin von, (ca. 1737-1793), geb. in Dänemark um 1737, war 1757-1791 zuerst Landmesser, später Baurath (Oberconducteur') und ausserdem Oberstlieutenant der Miliz auf St. Croix. Znr Hebung der Baumwollencultur auf den dänischen Inseln machte er seit 1786 Studienreisen nach J amaica, Portorico, St. Tho mas, Montserrat, Guadeloupe, Martinique, Trinidad, Curaçao, Sta. Martha, Carthagena, Cayenne und Surinam und sandte mehrere 
Hundert daselbst gesammelter Pflanzen an Prof. VAHL in Kopenhagen. 1791 nahm er seinen Abschied und rerscholl 1793 mit dem Schiffe auf einer Reise ron Nordamerika nach Guinea.

Coll. Bot. Nuseum in Kopenhagen, einiges in Herb. Banks im British Museum, im Herb. Martius in Brüssel und im Herb. Wmadexow in Berlin (ex herb. Valll).

Lit. Varl Eclog. praef.; Las. Mus. Deless. p. 489; Warm. in Bot. Tidsskr. Kopenh. XII (1880) p. 82; KIAERsk, l. c. XXIII (1900) p. 44; H. von Eggers: hriefl. Mittheilung: Cat. Se. Pap. Y P. 258; Urb. Symb. I p. 140,173 .

Roquefeuille (oder Roquefeuil), Nademoiselle de, schenkte Jussiet 1787-178S Pflanzen ron Haiti (ob selbst gesammelt?).

Coll. Herb. Jussieu in Paris.

Rothrock, Joseph Trimble, (*1839), geb. zu Mc Veytown, Mifflin County, Pennsylranien den 9. IV. 1839, graduirte 1864 an der Lawrence Scientific School der Harvard University und erhielt den medicinischen Doctorgrad 1867 von der Universität Pennsylvanien. 1865 wurde er einer Commission als Botaniker beigegeben, welche in Alaska eine Route für einen Telegraphen durch das Behringsmeer feststellen sollte. $1873-1875$ begleitete er als Arzt und Botaniker Lieutenant WheELER's Exploring Expedition west of the $100^{\text {th }}$ meridian und brachte grosse botanische Sammlungen in Colorado, Arizona, New Mexico und Californien zusammen (ef. Vol. VI der Whatere'schen Reports). Seit 1877 ist er Professor der Botanik an der Unirersität ron Pennsylvanien und hat sein Interesse besonders der Einführung einer rationellen Forstcultur in diesem Staate zugewendet. Ueber seine im Winter 1889 - 1890 nach Westindien unternommene Forschungsreise vergl. HiтCHCOCK.

Coll. Herbar der Academy of Natur. Sciences zu Philadelphia (ex Harshberger p. 29).

Lit. Sarg. Silva VIII p. 92; Harshberger: Botanists of Philadelphia p. 305-313 (mit Porträt); Pritz. Thes. II ed. p. 270; Jacks. Guide p. 357; Cat. Sc. Pap. V p. 303, VIII p. 787, XI p. 228; Unв. Symb. I p. 141.

Rugel, Ferdinand, (1806-1879), geb. zu Weingarten in Baden (Deutschland) den 24. XII. 1806, studirte Pharmacie und wurde Gehülfe in einer Apotheke in Bern, ron wo aus er 1837-1840 botanische Sammelreisen in der'Schweiz, nach Norditalien und Südfrankreich bis zu den Pyrenäen machte. Auf Veranlassung ron R. J. Snutrueworth. welcher damals in Bern lebte, trat er 1840 eine Reise nach den Vereinigten Staaten in Nordamerika an, um Pflanzen und Insekten zu sammeln. Er besuchte Virginia, Carolina, Georgia, Florida, Key West 
(Februar, März 1846) und ging 1849 nach Cuba, wo er hauptsächlich in der Ungebung von Matanzas, an der Punta Brava Bay, am Rio Tumury, Canimar und San Juan, in der Boca de Camarioca, im Thale ron Tomory und in der Punta maya thätig war. Später liess er sich in Knnoxville (Tennessee) als Apotheker und Arzt nieder und bewirthschaftete zuletzt eine Farm in Jefferson County in demselben Staate; hier starb er den 31. XII. 1879.

Coll. Rugel's Herbar ging im Jahre 1881 durch Kauf an IsaAC Martindale und von diesem an das Philadelphia College of Pharmacy über (Harsmberger: Botan. of Philad. p. 326). Die amerik. Pflanzen wurden theils von Shutrleworth, theils rom British Museum, von dem das Herb. Shuttl. 1877 erworben wurde, vertheilt und befinden sich in mehreren Museen, die Cuba-Pflanzen (Nr.1 -400,600-975) im British Museum, Kew, Cambridge (Mass.), Leiden, Krug et Urbax, Petersburg, Grisebach in Göttingen, Columbia College in New York (ex herb. Meissner).

Lit. Regensb. Flora XXI. I (1838) Intell.-bl. p. 29-30, XXIII. II (1840) Intell.-b]. p. 1-2, XXVII (1844) p. 175; Монь in Botan. Zeitg. II (1844) p. $110-111$; Sarg. Silva IX p. 110.

Ruz, Hipólito, (1754-1815), geb. zu Belorado in Alt-Castilien (Spanien) den S. VIII. 1754, Sohn eines Ackerbauers, studirte von 1772 an zu Madrid Naturwissenschaften und besonders Botanik unter C. G. ORTega und A. PaLau und erhielt 1777 ron der spanischen Regierung den Auftrag, in Peru und Chile naturhistorische Sammlungen anzulegen. Mit ihm gingen sein Landsmann José Pavos und der französische Arzt und Botaniker Joseph Donber, letzterer zunächst in der Absicht, Gewächse zu sammeln, welche in Europa acclimatisirt werden könnten. Sie landeten am 8. April 1778 in Callao, durchforschten die Provinz Chancay und schickten ihre Ausbeute an trockenen Pflanzen und Abbildungen nach Spanien. In den folgenden Jahren besuchten sie Huanuco, Chincao, Macora, Cuchero sowie Chile, verloren aber einen grossen Theil der Sammlungen und Manuscripte theils durch den Untergang des Transportschiffes an der portugiesischen Küste (Februar 1786), theils durch Brand in Macora (August 17S5). Dombex hatte Peru mit reichbaltigen Schätzen bereits im April 1784 verlassen und war über Rio de Janeiro zurückgekehrt. Ruz und Pavon suchten die Verluste durch Reisen nach Huanuco, Muña und Pillao nach Kräften zu ersetzen und kamen im September 1788 wieder in Cadiz an. R. starb 1815 in Madrid. Die ihm zugeschriebenen Pflanzen von Portorico sind wahrscheinlich ron Mocĩ̃o und SEssé gesammelt.

Coll. Bot. Garten zu Madrid, British Museum in London, Berliner Museum (ex herb. Lanbert), Nationalherbar zu Washington (ex herb. Berlin, resp. Greifswald), Bot. Garten zu Königssberg. 
Lit. An historical Eulogium on Don Hrpolito Rurz Lopez. Salisbury 1831. So 55 p. (n. v.); Las. Mus. Deless. p. $244-247$; Colar. Bot. Penins. Hisp.-Lusit. (1858) p. 45-46, 179 - 181; Pritz. Thes. II ed. p. 273; JAcks. Guide p. 127, 377; Cat. Sc. Pap. V p. 326.

Ryan, Jolm, Dr. der Medicin, war in der zweiten Hälfte des achtzelınten Jahrhunderts Plantagenbesitzer auf Montserrat und ein Freund ron Rohr. Er sammelte auch auf St. Croix und St. Jan und liess ron seinem Bruder auf Trinidad sammeln. All die vorzüglich präparirten Pflanzen nebst Blüthen und Frïchten in Alkohol, sowie zahlreiche Notizen über Standort etc. übergab er nach seiner Rückkehr Prof. YaHL in Kopenhagen. Er starb im Anfange des neunzehnten Jahrhunderts.

Coll. Bot. Museum in Kopenhagen.

Lit. Vahl Ecl. Praef.; Kraersk. in Bot. Tidsskr. Kopenh. XXIII (1900) p. 44.

Sagra, Ramon de la, (1798-1871), geb. zu Coruña in Galicien (Spanien) im Jahre 1798, erhielt von der spanischen Regierung den Auftrag, die Direction des botanischen Gartens zu Habana zu übernehmen, der, einige Jahre vorher gegründet, bis dahin ron J. A. DE LA Osst verwaltet worden war. Er kam im Jahre 1822 nach Cuba, erhielt zugleich die Professur für Botanik an der Universität und machte sich sehr bald durch seine Abhandlungen über die Reform des botanischen Gartens und Unterrichtes, über die Anwendung der Botanik auf Medicin und Agricultur, über die Nutzptlanzen der Insel, sowie durch die Grïndung der Anales de Ciencias, Agricultura, Comercio y Artes einen geachteten Namen. Un correcte Bestimmungen fuir die ron ihm besprochenen Pflanzen zu erhalten, hatte er sich mit P. DE CANDolus in Genf in Verbindung gesetzt. Schon frühzeitig reifte in ihm der Plan eines gross angelegten Werkes über Cuba, welches die geographischen und klimatischen Verhältnisse, die Bevölkerung; ihre Verwaltung, ihre Sitten, Cultur, den Ackerbau u.s. w. und die gesammte Naturgeschichte der Insel zum Gegenstande haben sollte. Behufs Herbeischaffung der nothwendigen Materialien suchte er damn Correspondenten in allen 'Theilen der Insel zu gewinnen. Für die Erforschung der Flora waren durch Aufsammeln und Trocknen der Pflanzen thätig: J. M. VAlexzuela, der 1833 in der Vuelta Abajo in erfolgreichster Weise sammelte, SEbAstux Bonani, Antonio Reynoso in Guanimar, Maxuel de Mosteriane in PuertoPrincipe, A. H. Lavier auf der Insel Pinos, Pedro Auber, letzterer besonders auf kryptogamischem Gebiete, und andere (rergl. SAGRA Cuba vol. X Introd. p. 28-29). Dass sich ein derartiges Werk in Cuba nicht ansführen liess, lag anf der Hand. S. siedelte deshalh mit seinen Sammlungen im Jahre 1835 nach Paris über und gewann hier für die Be- 
arbeitung der einzehen Abtheilungen unter den französischen Gelehrten herrorragende Kriffte, wiihrend er selbst die allgemeine Einleitung und den Abschnitt ïber Klima und Ackerban schrieb. So entstand die Historia fisica politica y natural de la isla de Cuba. Paris. Folio 1842 bis 1856. S. blieb in Europa, wurde (ieneralconsul von Uruguay, Correspondent des Institut de France und starb im Juni 1871 zu Cortaillod im Kanton Neuchâtel (Śchweiz).

Coll. Aeltere Sammlungen im Herb. de Candolue in Genf, im Herb. Mercier (jetzt in Florenz) und im Herb. Moricand in Paris. Die phanerog. Originalien zn der Historia fisica in Herb. Ricuard, welches nach A. Richard's Tode (1854) in den Besitz des Grafen Franquernlle überging. Dieser vertheilte $1861-1865$ die zahlreichen Doubletten (leider unbestimmt und olme irgend welche Angaben, nur bisweilen mit kleinen Nummerzetteh an den Zweigen) an Paris, Wiener Hofmuseum, Berlin, British Museum, Kew, Herb. Wrвв (jetzt in Forenz), St. Petersburg, Zürich, Herb. de Candolle und Delessert in Genf, Lübeck, Herb. Krug et Urban (125 Nr., ex Herb. Philad.). Tach Fraxgurvalle's Tode kaufte Drake del Castillo in Paris das Herbar Richard und schenkte es später zum Theil dem Pariser Museum. Die Kryptogamen sind im Herb. Moxtagiee (jetzt in Besitze des Muséum d'hist. nat. zu Paris).

Lit. Las. Mus. Deless. 1) 265; Sagra Cuba X Introd. p. 1, $28-29$; Colmeiro Botan. Hisp.-Lusit. (1858) p. 202 - 203; Bot. Zeitg. XXIX (1871) p. 604; F. Calcationo: Dice. Biogr. Cuhano (1878) p.572; Pritz. Thes. II ed. p. 276 ; Jacks. Guide p. $369,370,449$; Cat. Se. Pal. III p. 857 , VI p. 709 , VIII p. $167-168, \mathrm{X}$ p. 518 ; Urв. Symb. I p. 109, 114, 141-147.

Sargent, Charles Sprague, $(* 1841)$, geb. zu Boston in Massachusetts (U. S. A.) den 24. IV. 1841, erhielt seine Ausbildung in Boston an Privatschulen und am Harrard College, von welchem er 1862 graduirt wurde, machte auf Seite der Nordstaten den Secessionskrieg mit und hielt sich dann drei Jahre auf Reisen in Europa auf. 1870 wurde er Professor der Horticultur an Harvard College, später Director des botanischen Gartens der Universitä, 1873 erster Director des Arnold Arboretums zu Jamaica Plain und bald nachher Universitiitsprofessor der Arboricultur. Von seinen zahlreichen Forschungs- und Sammelreisen in den Vereinigten Staaten, aus welchen das gediegene Praclitwerk The Silva of North America, Boston and New York, 11 Bände, gross $4^{0}$ hervorging, seien erwähnt: 1878 zu der Sierra Nevada in Californien, 1879 mit Asa Gray in die südlichen Appalachian-Gebirge, Winter 1880 Südstaaten und Florida, Sommer 1880 nach Colorado und durch die Gebirge der Pacifischen staaten von British Columbien bis zur mexicanischen Grenze vou Arizona in Begleitung von Dr. G. Exglumax, 1883 in die nördlichen Rocky Mountains als Mitglied der Northern Trans- 
continental Survey, 1885 Westindien (Barbados, Martinique, St. Kitts und Jamaica), Texas und Louisiana, April und Norember 1886 Florida Key's, 1887 Florida Key's, Texas und zum nordöstlichen Mexico, 1892 nach Japan, 1893 im Winter nach Arizona und Californien, im Sommer nach Colorado, Siid-Californien und Arizona, 1896 nach den nördlichen Rocky Mountains mit Einschluss des Yellowstone National Park, nach Washington, Oregon, Californien, Arizona und Colorado, 1897 nach Alaska und Californien, 1898 drei Reisen nach den Florida Key's und in die Appalachian-Gebirge, 1900 nach Texas, dem nordöstlichen Mexico und den Golfstaaten, 1901 nach Louisiana, Texas und dem südlichen Arkansas; ausserdem kïrzere Reisen zu den White Mountains von New Hampshire, zu den grossen Seeen und anderen Theilen des Landes.

Coll. Herbar des Arnold-Arboretums.

Lit. Briefl. Mittheilung ron S.; Jacks. Guide p. 360; Unb. Symb. I p. 147 , II p. 5.

Sauvalle, Francisco Adolfo, (1807-1879), geb. zu Charleston in Süd-Carolina (Ver. Staaten) den 1. VII. 1S07, ron französischer Abstammung, erhielt seine Erziehung von seinem siebenten Lebensjahre an in dem Lyceum zu Rouen in der Normandie, nachte darauf grössere Reisen durch Europa und kan 1824 nach Cuba. Durch Uebersetzung medicinischer und naturwissenschaftlicher Artikel, durch Vorschläge, wie die ökonomischen und sanitären Verluältnisse zu rerbessern seien, erwarb er sich nicht geringe Verdienste um die Insel. Seit 1867 Mitglied der Akademie der Wissenschaften zu Habana lebte er auf seinem Landsitze in der Vuelta Abajo bei San Cristóbal an Fusse der Loma del Cuzco und starb am 30. I. 1879. Ausser mit der Botanik beschäftigte er sich auch mit Malacologie.

Coll. Sein Herbar, welches eine der besten Wright'schen Sammlungen enthält, in der Akademie der Wissenschaften zu Habana.

Lit. F. Calcagro Dice. biogr. Cubano (1878) p. 589 ; J. E. Ramos: Elogio del academico de merito Sr. D. Fraxcisco A. Sacralle in Anal. Acad. Cienc. Habana, Rer. cient. XVI (1879) p. 3S-52 und (ex G. dE LA Maza in lit.) in La Enciclopedia. Habana III (1887) p. 377; JAcks. Guide p. 370 ; Cat. Sc. Pap. VIII p. 838; Urb. Symb. I p. $148-150$.

Schack, Baron von, (?-1824), aus Oesterreich gebürtig, lebte längere Zeit auf Trinidad und starb im September 1824 zu Guayra in Venezuela.

Coll. Kew Herbarium (ex lierb. Hooker); er sandte auch lebende Pflanzen an die botanischen Gärten zu Glasgow und Lirerpool und an die Horticnltural Society zu London.

Lit. Regensb. Flora V'III (1825) p. 336; Las. Mus. Deless. p. 492. 
Schimper, Andreas Franz Wilhelm, (1856 -- 1901), geb. zu Strasburg im Elsass (Deutschland) den 12. V. 1856, studirte daselbst 1874 bis 1878, promovirte 1878, habilitirte sich für Botanik in Bonn 1883, wurde 1886 Professor extraord. und erhielt 1899 einen Ruf als ordentlicher Professor nach Basel. Sch. bereiste November 1880 bis December 1881 die üsthichen Vereinigten Staaten von Massachusetts bis Florida, Martinique und Dominica, December 1882 bis September 1883 Trinidad, Dominica (nebst kurzem Aufenthalte auf Grenada, St. Lucia, Barbados) und Venezuela (Prov. Maturin), August 1886 bis Januar 1887 Brasilien (Prov. Rio de Janeiro, Sta. Catharina, Bahia, Pernambuco), August 1889 bis April 1890 Java und Ceylon, und begleitete August 1898 bis Ende April 1899 die deutsche 'Tiefsee-Expedition. Sch.'s Studien auf diesen Reisen erstreckten sich hauptsächlich auf wichtige biologische Fragen. Sein Tod erfolgte am 10. IX. 1901 zu Basel.

Coll. Sch. sammelte meist nur Alkohol-Material, welches in den botanischen Instituten in Bonn und Basel aufbewahrt wird.

Lit. Briefl. Mittheilung Sch.'s; Leopold. XXXVII p. 87; Jacks. Guide p. 107, 493; Cat. Sc. Pap. XI p. $310-311$; Urb. Symb. I p. $150-151$.

Schlim. Louis Joseph, begleitete J. Lxinex auf dessen dritter Reiso December $18+1$ bis October 1844 nach Venezuela, Neu-Granada, Jamaica und Cuba, ging dam im Jahre 1845 mit Nic. Fuxck im Auftrage des LiNDEx'schen Etablissements (d'Introduction pour les plantes nouvelles) in Luxemburg nach Guadeloupe, wo eine nicht unbedentende Sammlung angelegt wurde, und ron da nach Tenezuela. Hier besuchten sie die Provinzen Caracas, Carabobo, Barquisimento, Trujillo, Maracaibo, Merida und wanden sich dann dem östlichen Neu-Granada zu. Nachdem Fuxck bald darauf nach Europa zurïckgekehrt war, verlegte Sch. sein Hauptguartier nach Baja in der Pror. Pamplona, von wo ans er seine Excursionen bis zu den Paramos ron San Turban und Cachiri, in die heissen Regionen von Bucaramanga, Jiron, Floridablanca und bis zu den Uferm des Rio Sube ausdehnte. Leider gingen die Resultate dieser 15 monatlichen Thätigkeit für die Botanik und den Gartenbau durch Schiffbruch an der Mündung des Rio Magdalena verloren. Sch. erforschte dann die Pror. Soto und Oçaña, ging den Rio Magdalena hinab, besuchte die Sierra Nevada de Santa-Marta sowie die Umgebnng von Minca und kehrte im Monat August 1852 nach Europa zurüick.

Coll. Die getrockneten Pflanzen wurden von dem Lindex'schen Etablissement an verschiedene Nuseen verkautt, z. B. Kew, British Museum, Paris, Brüssel, Delessert, Borssier, de Candolle in Genf, WEBB (jetzt in Florenz). 
Lit. Linden et Planchox: Troisième royage de J. Linden I (1863) p. L - LVI.

Schöpf, Johann David, $(1752-1800)$, Dr. med., geb. zu Wunsiedel in Bayern den 8. III. 1752, besuchte das Gymmasium in Hof und die Universität Erlangen, wurde Arzt in Ansbacl und begleitete als solcher 1777 die Ansbacher Truppen, welche von den Engländern im nordamerikanischen Unabhängigkeitskriege angeworben waren, nach Nordamerika. Nach dem Frieden von Versailles 1783 bereiste er die Oststaaten hauptsächlich behufs naturhistorischer Erforschung, ging Ende März 1784 mit Mïrter und Boos auf drei Monate nach den Bahamas (New Prosidence etc.) und kehrte von da im Juni 1784 nach Europa zurïck. Er liess sich in Baireuth als praktischer Arzt nieder und starb in Ansbach den 10. IX. 1800 als Geheimer Hofratl und Präsident der Medicinalcollegien. Die Ergebnisse seiner Reise veröffentlichte Sch. in den Werken: Materia medica americana potissimum regni regetabilis 1787, Beiträge zur mineralogischen Kenntniss des östlichen Theiles von Nordamerika und seiner Gebirge 1787, Reise durch einige der mittleren und siidlichen Vereinigten Nordamerikanischen Staaten, nach Ost-Elorida und den Bahama-Inseln 1788.

Coll. Sammlungen von ihm sind mir nicht bekannt.

Lit. Hermaxy Peters: Johany David Schöpf in Pharmaceut. Rundsehan XIII (1895) p. 151--156; Fred. Hoffuaxy in Pharmacentical Review XVT (1898) p. $296-302$; Pritz. Thes. II ed. p. 286.

Schomburgk, Robert Hermann, (1804-1865), geb. zu Freiburg an der Unstrut (Deutschland) den 5. VI. 1804 als ältester Sohn eines Pfarrers und Bruder des 1891 in Australien verstorbenen Directors des botanischen Gartens in Adelaide Richard Sch., zeigte_schon als Knabe eine grosse Liebe zu der interessanten Pflanzenwelt seiner Heimath, besonders zu den dort zahlreich vertretenen Orchideen, musste aber dem Willen des Taters entsprechend sich dem Kaufmannsstande widmen. Hit einer guten Vorbildung in den Realfächern trat er 14 Jahre alt in Naumburg in die Lehre und kam von da im Jahre 1823 in das Comptoir seines Onkels nach Leipzig. Hier erhielt er Gelegenheit, sich wissenschaftlich mit Botanik zu beschäftigen, die Vorlesungen des Professors Schwigrichex zu hören und die Pflanzen der dortigen grösseren Gärten, besonders des Reicmesbach'schen zu studiren. Das dadurch erwachte Verlangen, die Flora ferner Länder kennen zu lermen, konnte er 182S befriedigen, indem er für das Geschäft seines Onkels eine Anzahl Merinoschafe nach New York iiberfülırte. Kurz nach seiner Ankunft in dieser Stadt erhielt er eine Anstellung als Commis in Richmond in Virginien. Sein Entschluss, die Vereinigten Staaten zum Gegenstande seiner Studien zu machen und dort Sammlungen anzulegen, kam aber nicht zur Aus- 
führung da er bereits im November 1829 nach St. Thomas übersiedelte. Allein seine kaufmännischen Unternehmungen misslangen, sein Eigenthum ging am sylvesterabend 1830 in St. Thomas durch Feuer zu Grunde, während er sich gerade auf einer botanischen Excursion nach St. Jan befand. Diese Verluste bestimnten ihn, allen commerciellen Geschäften zu entsagen und sich nur der Botanik und anderen Naturwissenschaften zu widmen. Er besuchte Portorico, Tortola und Anegada und fertigte ron letzterer unter grossen Gefahren eine ausgezeichnete Karte an, welche die britische Admiralitït 1832 für den Gebrauch der Kgl. Marine reröffentlichte, während die Beschreibung der Insel in den Berichten der geographischen Gesellschaft zu London Aufnahme fand. Durch diese und andere hydrographische Arbeiten in England bekannt geworden, wurde er auf seinen Vorschlag von der geogr. Gesellschaft in London mit der Aufgabe betraut, im Anschluss an Humboldr's Bereisung des Orinoco-Gebietes British Guyana zu erforschen. Auf der ersten Reise 1835 - 1839 ging er von Georgetown aus, entdeckte im oberen Laufe des Berbice Neujahr 1837 die Victoria regia, drang durch die Gebirgsketten des nördlichen Brasiliens bis zum Orinoco nach Esmeralda in Tenezuela vor, ging durch den Cassiquiare, stieg am Rio Branco auf und kehrte durch das Flusssystem des Essequibo nach Demerara zurück. Auf der zweiten Reise $1840-1844$, welche den Zweck verfolgte, die Grenzen von British Guyana anfzunehmen, begleitete ihn ausser einem Marineofficier, einem Maler und Chirurgen sein Bruder, der Gärtner am botanischen Garten zu Berlin Rıcnard Scн. Die Expedition wendete sich zunïchst nach der Mündnng des Orinoco und zum Roraima-febirge; alsdann untersuchte Sich. allein, nur von Indianern begleitet, die Flusssysteme des Cuyuni und des Mazurin Winter 1842 - 1843, vereinigte sich mit den ïbrigen in Pirara, stieg den Rupununi aufwärts und fuhr auf dem Corentyn zurïck. Die Resultate dieser Forschungsreisen auf botanischem, geologischem, physikalischem, geographischem und hydrographischem Gebiete waren so herrorragende, dass die Königin von England Ścu. den Baronettitel verlich. - 1846-1847 hielt sich Scr. elf Ionate lang in Barbados auf, um ein Eisenbahnprojekt für die Insel auszuarbeiten, welches aber nicht zu Stande kam, und Studien zu einer monographischen Arbeit The History of Barbados anzustellen, 1848 - 1857 als britischer Consul in Sto. Domingo, wo er weite Reisen in das Innere z. B. nach dem EnriquilloSee und 1851 zu dem Cibao-Gebirge bis in das Valle de Constanza machte, 1857 - 1864 ats britischer Generalconsul in Bangkok (Siam). Vom tropischen Klima in seiner Gesundheit erschüttert, kehrte er im April 1864 nach Europa zurück und starb am 11. III. 1865 in der Iaison de santé zu Schöneberg bei Berlin. 
Coll. Die Pflanzen der virginischen Inseln gingen an L. Rercuexваси in Leipzig, der sie zu vertreiben hatte, die ron Barbados und Sian sind in Kew und Berlin, die ron Sto. Domingo (ca. $5^{1 / 2}$ Cent.) ebenda und ausserdem auch in Paris, die ron Guyana besonders gut in Kew und im British Museum, Doubletten in Berlin und Paris. Die in anderen Museen befindlichen Guyana-Pflanzen rühren wohl meist von Richard Sch. her, dessen Hauptsammlung in Berlin ist, obwohl auch Pflanzen ron Robert durch Bexthas (ef. Regensb. Flora XXI. 1838 p. 423) verkauft sind.

Lit. Regensb. Flora XII (1829) p. 640, XIII (1830) p. 424; R. HI. Schomburgk: Visit to the ralles of Constanza in The Athenaeum 1852 n. 1291 p. 797-799; Wilhelas Strecker: Reisen der Brüder Schombergk in British Guiana. Frankfurt a. II. 1852. 143 p. S $^{0}$; Peтеru. Mittheil. 1857 p. 322; Autobiographie in Leopoldina I (1859) p. 34-39 (leider von allen Biographen übersehen); Scillechtexd. in Bot. Zeitg. XXIII (1865) p. 131-132; F. Ratzer in Allg. Deutsche Biogr. XXXil (1891) p. $240-243$; Harshberger: Bot. of Philad. p. 190; Pritz. Thes. II ed. p. 286; Jacks. Guide p. 369 ; Cat. Sc. Pap. V p. $520-522$, VIII p. 879 ; Urb. Symb. I p. 152 bis 153 .

Schramm, Alphons, (1823-1S75), geb. zu Weissenburg im Elsass den 1. VIII. 1823, widmete sich dem Steuerfache, war als Beamter in franz. Guyana und Martinique stationirt und kam 1848 als Commis de la douane nach Guadeloupe, wo er allmählich zum Chef de Bureau und Inspectenr sédentaire aufrückte. Er erforschte in erfolgreichster Weise in Terbindung mit IL azé u. a. die Algenflora der Tusel und der benachbarten Eilande Saintes, Marie Galante, Désirade. Ausserdem schrieb er: Crustacées de la Guadeloupe d'après un manuscrit du Dr. Isss Desboxxe I. Brachyures. Basse-Terre 1867, sowie einen Catalogue des Coquilles et des Crustacées de la Guadeloupe enroyés à l'Exposition unirerselle de 1867. II édit. Basse-Terre 1869. 1873 kehrte er nach Frankreich zurück und starb im März 1875 in Nantes an der Lepra.

Coll. Sein Algenherbar ging im Jahre 1S71 bei einer Feuersbrunst zu Pointe-à-Pitre auf Guadeloupe zu Grunde; damit rerbranten auch einige Originalien zu der Algenflora fou Mızé und S'curanss, welche sich nur in diesem befanden.

Lit. Briefl. Nachrichten von Père Duss; Pritz. Thes. II ed. p. 287; Jacks. Guide p. 370 ; Cat. Sc. Pap. V'III p. S85, XI p. 341; Urв. Symb. I p. $105-107$.

Schiicht, Joseph, Gärtner aus Wien, ging mit Bredeneyer auf seiner zweiten Reise 1785 nach IIaiti, 1786-1788 nach Tenezuela (vergl. Bredeyeyer und Mïrter). 
Schumann, Walter, geb. zu Löhne in Westfalen (Preussen), war als Gärtner bei Haage of Sснmidt in Erfurt, 1880-1882 in Tiflis, 1883 in Odessa thätig. 1884 ging er nach Haiti, wo er in der Ungebung von Port-au-Prince sammelte, und von da in demselben Jahre nach Mexico. Hier erhielt er eine Stelle als Obergärtner auf der Hacienda del Jaral in der Nähe der Hauptstadt, durehstreifte das Land von März bis August 1888, um Pflanzen, Tögel, Reptilien und Insekten zu sammein, und wurde dann Besitzer einer Handelsgärtnerei in Mexico selbst. Coll. Die Pflanzen ron Haiti und Jaral verkaufte Prof. Haussкхеснт in Weimar an verschiedene Museen und Private; eine der besten Sammlungen ist in Berlin (ex herb. Bersuardi); die späteren Sammlungen gingen nach England.

Lit. Briefl. Mittheilungen der Herren Lehrer Resnecke und Apotheker A. Lucas in Erfurt und des Herrn Herm. Rothe in Artern.

Schwanecke, Carl, (* 1821), geb. zu Wernigerode (Deutschland) den 4. VII. 1821, erlernte zuerst die Klempnerei, dann die Gärtnerei im Schlossgarten seiner Vaterstadt und trat 1844 als Gehülfe in den damals berühmten Garten des Hofbuchdruckers Decker (Obergärtner Reinecke) in Berlin ein. Im Juli 1846 schloss er sich einer Expedition an, welche ein Herr von Winterfeld, der vorher mehrere Jalıre als Bergdirector in Peru thätig gewesen war, zur Besiedelung der Mosquitoküste zusammengebracht lıatte. Aus Mangel an Geld ging man aber schon in St. Thomas auseinander. Sch. siedelte zunächst nach Vieques, dann nach Portorico über, wo er in der Hacienda des Schweizers Sandoz bei Humacao eine gastfreundliche Aufnahme faud. Von hier aus besuchte er die Gebirge des östlichen Theiles der Insel, besonders die Sierra de Luquillo, nördlich bis nach Fajardo und Rio Blanco, südwestlich bis nach Guayama. Ueber Puerto-Plata auf Sto. Domingo, wo er in Folge Schiffbruchs eine Kiste seiner Pflanzen einbüsste und von October bis Ende December 1849 aufgehalten wurde, traf er, als einziger Ueberlebender der erwähnten Expedition, am 29. Januar 1850 wieder in der Heimath ein. Er conditionirte zunächst im Schlossgarten zu Wernigerode und gründete dann 1852 in Oschersleben eine Handelsgärtnerei, welche sich durch die Cultur der Stiefmütterchen (Pensées) einen Weltruf erworben hat. Dort lebt er im rüstigen Greisenalter noch lieute.

Coll. Phanerogamen im Botan. Museum in Berlin (322 Nr.), einiges in Leipzig und Göttingen, die Kryptogamen, von welchen aber auch an andere Interessenten verkauft wurde, in Berlin; die Gramineen und Farne waren an Воотн in Flottbeck (Holstein) abgegeben.

Lit. Briefl. Mittleilung von Scu.; Gartenflora vol. L (1901) p. 355 lis 358 (Selbstbiographie mit Porträt); Urb. Srrmb. I p. 113, 157, 159. 
Seaforth, Lord Francis, um 1803 Gourerneur ron Barbados, wo er für Dawson Tunxer Algen sammelte. Auch brachte er von dort mehrere Hundert lebende Pflanzen nach England und übergab sie A. B. Lumbert, in dessen Gewächshäusern zu Boyton viele zur Blüthe kamen, die dann getrocknet dem LamberT'schen Herbar einverleibt wurden.

Coll. Herb. Lambert (wo jetzt?).

Lit. D. Don in Lambert's Pinus II ed. App.; Britt. and Boulg. p. 151.

Searing, Dr. Auna H., aus Rochester in New York, sammelte um 1885 auf den Baliama-Inseln.

Coll. Ueber den Verbleib der Sammlung ist mir nichts bekannt.

Iit. Proe. Acad. Nat. Se. Philad. 1889 p. 133.

Segretain, aus Frankreich gebürtig, war Thierarzt des Gouvernements zu Guadeloupe und sammelte daselbst besonders 1852 .

Coll. Museum zu Paris; einiges im Herb. Krug et Urbax.

Lit. Briefl. Mittheilung von Père Duss.

Seitz, Albreclit, (*1865), geb. in Hanau (Preussen) den 14. $\mathrm{r}$. 1865, besuchte die Klingerschule in Frankfurt a. M., musste wegen schwacher Gesundheit das Studium der Chemie aufgeben und wurde Kaufmann. Als solcher lielt er sich mehrere Jahre in Spanien, einige Zeit in Portorico und Venezuela auf und erwarb 1890 eine Pflanzung auf 'Tobago, welche er 1893 mit einer anderen an der King's Bay vertauschte. Allein der Rückgang der Cacao- und Kaffeepreise, die schwierigen Arbeiterverhältnisse und die Unmöglichkeit, durch den Handel mit Rohprodukten (besonders mit Cedernholz) ein gesichertes Auskommen zu finden, zwangen ihn 1896, die Plantage zu verkaufen und nach Hamburg zurückzukehren. Erst im letzten Jahre seines Aufenthaltes auf der Insel trat S. mit dem Verfasser in Verbindung und legte eine vortreffliche Sammlung an.

Coll. Herb. Krug et Urbai (109 Nr.).

Lit. Briefl. Mittheilung von S.

Sessé, Martin, wurde 1788 Director des neugegründeten botanischen Gartens zu Mexico und erhielt ron dem Könige von Spanien Carlos IV. den Auftrag, als Arzt und erster Botaniker eirre wissenschaftliche Expedition zur Erforschung der Naturprodukte von NuevaEspaña zu leiten. Ihm schloss sich J. M. Mock̃̃o (vergl. diesen) an. Schon seit 1789, aber hauptsiichlich ron 1795 - 1804 untersuchten sie die ausgedehnten Gebiete von Nicaragua bis zum Rio Yaqui im nördlichen Mexico und der Halbinsel Californien; ja sie sollen bis zu den Inseln Vancouvers und Charlotte vorgedrungen sein; ausserdem 
sammelten sie in Cuba, l'ortorico und wahrscheinlich auf einigen klemen Antillen. Die Ergebnisse dieser Reisen sowohl an getrockneten Pflanzen wie an bildlichen Aufnahmen waren ganz bedeutend, sind aber leider niemals im Zusammenhange bearbeitet worden. S. starb zu Mexico um 1809 .

Coll. Das Herbar von S. und M. ist seit 1820 im botanischen Garten zu Madrid, eine kleine Anzahl im Herb. Delesslirt in Genf (ex herb. Lambert). Die in den Herbarien von Ruz und Pavox sich vorfindenden Pflanzen von Mexico, Cuba und Portorico sind höchstwahrscheinlich ron S. und M. gesammelt. Ueber die an Ort und Stelle angefertigten Abbildungen vergl. Mociño. - Zahlreiche neue Arten, deren Samen von S. und M. nach Madrid gesandt waren, wurden von $\mathrm{C}_{\mathrm{A} \text { A }}$ NiLles und Lagasca aus dem dortigen botanischen Garten beschrieben.

Lit. Las. Mus. Deless. p. 205-206, 322 obs.; Colm. Botan. Penins. Hisp.-Lusit. (1858) p. $49-51,184-185$ et Prim. Not. Veg. Amer. p. 48 - 49; DC. Phytogr. p. 434; Hemsl. Biol. IV p. 120 - 121; León Bibl. Botán.-Mexic. (1895) p. 323 - 340; Pritz. Thes. II ed. p. 295 ; Jachs. Guide p. 367.

Shakespeare sammelte $1780-1782$ auf Jamaica und führte Culturpflanzen ein.

Coll. Herb. Banks im British Museum.

Lit. Brought. Hort. East. in B. Edw. Hist. IV ed. III p. 367-407.

Sherring, Richard Vowell, F. L. S., sammelte im Auftrage des Committee für die Erforschung der Fauna und Flora Westindiens von October 1890 bis Juni 1891 auf Grenada hauptsächlich Pteridophyten und Orchideen. Lebt als Privatmann in England und macht öfter Reisen zu seinen Besitzungen in Westindien, z. B. nach Jamaica, ron wo er in den Jahren 1880-1887 Herbarien mitbrachte, und nach Trinidad.

Coll. Kew Herbarium und British Museum, Herb. Krug et Urban, J. D. Surth in Baltimore.

Lit. Journ. of Bot. XX (1882) p. 326; briefl. Mittheilung ron W. B. Hemslex; Urb. Symb. I p. 8, 86, 137.

Sicber, Franz Wilhelm, (1789-1844), geb. in Prag (Böhmen) den 30. III. 1789, absolvirte das Gymnasium seiner Vaterstadt, studirte zuerst Architektur, dann das Ingenieurfach und wandte sich darauf den Sprachen, Naturwissenschaften und der Medicin, besonders aber der Botanik zu. Seine Lebensaufgabe bildete das Herbeischaffen und der Vertrieb von Sammlungen hauptsächlich aus dem Pflanzen- und Thierreich. Er selbst bereiste, von kleineren Touren abgesehen, 1811-1812 Italien, 1817-1818 Kreta, Aegypten und Palästina, 1822-1824 Mauritius, Australien (New South Wales) und Capland; ferner schickte er auf seine Kosten als Sammler aus: Franz Kohaut 1819 bis 
1821 nach Martinique, C. Theodor Hilsenberg und W. Bojer 1821 bis 1823 mach Mauritius und II adgascar, F. KoHaur und Jos. Schnid 1822 nach dem Senegal, Franz Wrbsa 1822 nach T'rinidad, CarL Zwyнer 1822 nach dem Capland. Die letzten 14 Jahre seines Lebens brachte er in einer Irremanstalt in Prag zu, wo er den 17. XII. 1844 starb. S. war ein hochbegabter, aber schon früluzeitig an Wahnvorstellungen leidender Mann, der weder mit den Menschen noch mit dem Gelde umzugehen verstand.

Coll. Seine Sammlungen sind in fast allen europäischen und in manchen auswärtigen Herbarien, besonders gut auch in Berlin. Die "Flora Martin." umfasst 400 numerirte Species, dazu ein Supplement von ca. $200 \mathrm{Nr}$. Aussertem befinden sich auch Martinique-Pflanzen in der "Flora mixta“. Die "Flora Trinitatis" enthïlt 382 Arten. S.'s eigenes Herbar ging 1837 in den Besitz des Freiherru vos Reichensach ïber, welcher es 1867 an H. van Heurck in Antwerpen abtrat.

Lit. Leg. Glückselig: Franz Wrihela Sieber. Ein biographischer Denlistein, Wien 1847, 90 p. $8^{0}$ mit Bildniss; A. Martins in H. van Heurck Obs. bot. I (1870) p. 8-9; F. C. Dietrich: Franz Wilimelm Sieber in Jahrb. Königl. botan. Gart. u. Museums zu Berlin I (1881) p. $278-306$; Pritz. Thes. II ed. p. 297; JAcks. Guide p. 313, 350; Cat. Sc. Pap. V p. 684.

Simmonds, Thomas William, (?-1804), geb. zu Dartford? in Kent (England), W undarzt, begleitete den Gouverneur Lord SEaforth im Jahre 1803 nach Barbados, starb aber schon im folgenden Jahre in Trinidad.

Coll. Herb. Lumbert (jetzt?).

Lit. Lus. Mus. Deless. p. 491; Britr. and Boulg. p. 154.

Sintenis, Paul Emst Emil, (* 1847), geb. zu Seidenberg in der Oberlausitz (Preussen) den 4. VI. 1847 als ältester Solm des im Jahre 1865 verstorbenen Kreisplrysikus Dr. Eduard Sintenis, besuchte das Gymmasium zu Görlitz und trat 1863 als Apothekerlehrling ein. Nachdem er in verschiedenen Orten Deutschlands conditionirt hatte, ging er mit seinem Bruder Max 1872 - 1876 nach der Dobrudscha, um Vögel, Säugethiere und nebenbei auch Pflanzen (ca. 1300 Arten) zu sammeln. 1877-1879 studirte er Pharmacie in Breslau und war zugleich Amanuensis bei den Vorlesungen des Prof. Goeppert. Nachdem er wiederum ein halbes Jahr als Apotheker thätig gewesen war, widmete er sich ron nun an ausschliesslich den botanischen Sammelreisen. 1880 ging er mit Unterstützung Dr. KEck's in Begleitung von G. Rigo über Smyrna und Rhodus nach Ċyern (ca. 1200 Arten), assistirte 1881-1882 A. ToepfFer in Brandenburg bei der Leitung des schlesischen 'Tauschvereins, bereiste in dessen Auftrage Herbst 1881 das üsterreichische Litorale, Istrien und Oberitalien und erforschte unter der Aegide 
Prof. Ascherson's 1883 die Troas (ca. 30000 Exemplare). - October 1884 bis Juni 1887 hielt sich S. auf Kosten des Consuls L. Kruta in Portorico auf, um die Insel nach den Anweisungen des Verfassers planmässig zu erforschen. Er sammelte 1884 (vom October an, Nr. 1 bis 525) bei Mayagüez und Maricao, 1885 (Nr. 526 - 3292) bei Cabo-rojo, Bayamon, Fajardo, Cabeza de S. Juan, in der Sierra de Naguabo, Sierra de Luquillo, bestieg am 13. und 14. Juli den Monte Yunque, besuchte Yabucoa, die Sierra de Juncos, Hato grande, Caguas, Aguas buenas, Guayama, Cayey, Aibonito, Barranquitas, Coamo, Juana Diaz, 1886 (Nr. 3293-5815) Coamo, Ponce, Guayanilla, Adjuntas, Yauco, Sabana Grande, San German, Guanica, Utuado, Jayuya, Adjuntas, Pñeuelas, Guayanilla, Ponce, Patillas, Maunabo, Yabucoa, Sierra de Naguabo, Sierra de las Piedras, Rincon, Añasco, Aguada, Aguadilla, 1887 (Nr. 5816 bis 7025) Lares, Pepino, Las Marias, Utuado, Camuy, Hatillo, Arecibo, Manatí, Barceloneta, Ciales, Vega-baja, Morovis, Dorado, Mayagüez und auf der Rückreise im Juni $1887 \mathrm{St}$. Thomas (37 Nr.). - In den folgenden Jahren widmete sich S. wieder rom zeitigen Frühjahr bis zum Spätherbst der Erforschung der Flora des Orients, meist unterstïtzt von dem Gärtnereibesitzer Max Leichtus in Baden-Baden, für den er lebende Pflanzen, besonders Zwiebelgewächse zu sammeln hatte. Er bereiste 1888 Syrien, Mesopotamien bis Mardin in Kurdistan, 1889 türkisch Armenien über Trapezunt bis Khasput, 1890 desgl. bis Egin, 1891 in Gemeinschaft mit J. BorsuüLler die Insel Thasos, die Halbinsel Chalcidice und den thessalischen Olymp, 1892 Paphlagonien über Ineboli bis Tossia, 1894 türkisch Armenien über Trapezunt bis Gümüschkane, 1896 Thessalien, das Pindus- und Pelion-Gebirge, 1900 - 1901 Persien.

Coll. Die Pflanzen aus der Dobrudscha sind am besten in Kew, Petersburg und Berlin vertreten, die von Cypern wurden von Dr. КEсK an zahlreiche Interessenten rertrieben, die Hauptsammlung aus der Troas, von S. selber vertheilt, befindet sich in Berlin. - Die Ausbeute von Portorico wurde unter der Aufsicht des Verfassers in zwei Serien (1885 bis 1890 und $1899-1901)$, von denen die letztere auch die im Jahre 1899 publicirten neuen Arten enthält, in Berlin ausgegeben. Soweit noch keine anderweitige besonders monographische Durcharbeitung der einzelnen Familien stattgefunden hatte, wurden die Bestimmungen im Anschluss an Grisebach's Flora und nach Durchsicht seines Herbars gegeben, besonders bei den Pflanzen der ersten Ausgabe; es sind deshalb hier nicht wenige Correcturen nothwendig. Die Hauptsammlung mit allen Nummern und Standorten ist im Herb. Krug et Urban des Berliner botanischen Museums. Beide Serien erhielten Kew, GRaI-Herb. in Cambridge, Brit. Museum in London, Nat. Museum in Washington, 
P. Sixtenis (dem städt. Museum in Görlitz vermacht), Hofmuseum in Wien, Reichsherbar in Leiden, Herbar der Stadt Genf (Delessert), L. Richter in Budapest, Bot. Garten in St. Petersburg, Bot. Huseum in Hamburg, Bot. Garten in New York, Miss. Bot. Garten in St. Louis, Mus. in München, Paris, Field Col. Mus. zu Chicago, de Candolle, BorssierBarber in Genf, F. Kurtz in Córdoba, Bot. Museum in Breslau, Stockholm (II. Serie direkt, I. Serie ex herb. C. O. Schlxter in Hudiksvall), Bot. Dep. in Jamaica, Bot. Garten in Trinidad, Calcutta, Bot. Garten in Wien, Mus. in Göttingen, Drake del Castillo in Paris, Bot. Mus. der Unirersität in Zürich, H. H. Heller in Lancaster (Pa.), Biltmore Herb. in Nord-Carolina, Budapest (II. Serie direkt, die 1. Serie ex herb. Haxidd), Iowa State College of Agriculture zu Ames, Groningen. Universitätsherbar zu Minneapolis, E. Cossox in Paris, Bot. Garten in Edinburglı, Sydney, Prof. Haussnsecht in Weimar, städt. Museum in Lübeck. Die erste Serie allein erhielten: J. D. Suгтн in Baltimore, städt. Museum in Bremen, Prof. C. Mez-Halle, W. Tatke-Berlin (jetzt im Besitze Prof. Hausskrecht's in Weimar), J. F. Haniltox in London, Dr J. Schrader in Berlin (jetzt in der palaeobotanischen Abtheilung der kgl. geologischen Landesanstalt zu Berlin), Prof. G. Hieroxyaus (jetzt Bot. Museum in Berlin), W. CANBY (jetzt im College of Plarmacy zu New York), Agric. College Ingham Co. in Michigan, Prof. E. Stebler in Chauds de Fonds (Schweiz), Herb. des Polytechnikums in Zürrich, Böhm. Museum in Prag, Acad. of Yat. Sc. zu Philadelphia, Univ.-Herbar zu Lausanne und zwei bis drei andere Herbarien, denen die Sammlungen durch Dr. Keck zugingen. Die Farne allein erlielten Prof. Luerssex in Königsberg, Dr. H. Christ in Basel, die Glumaceen F. Paeske (jetzt im Herb. Göttingen), die Orchideen Prof. KRäxzus in Gross-Lichterfelde, die Melastomaceen Prof. Cogsindx in Verviers, die Lauraceen und Bromeliaceen Prof. C. MEz in Halle, die Cyperaceen O. Boeckeler (jetzt Bot. Museum in Berlin), die Gramineen E. Hackel in St. Pölten, die Araliaceen E. Marchal in Brüssel, die Sapotaceen L. Pierre in Paris, die Sapindaceen L. Radukofer in München, die Nyctaginaceen A. Hennerr, in Wien, die Aquifoliaceen Tн. Loesener in Berlin, die PotamogetonArten A. Bexsetт in Croydon. Die Kryptogamen gingen an Kew, British Museum in London, Städt. Herbar in Genf, Nat. Museum in Washington, Bot. Garten in New York, Mus. in Hamburg, Miss. Bot. Garten in St. Lonis, Bot. Garten in Wien, München, Hofmuseum in Wien, Unir.Herbar in Züriclı, Bot. Garten in St. Petersburg, Stockholm, Groningen, Budapest; die Laubnoose allein an C. MituLter (jetzt im Bot. Museum in Berlin), die Lebermoose an F. Stephani in Leipzig, die Pilze an P. Magers in Berlin und R. G. Bresadola in Trient, die Flechten an Jor. Mëllk:r (jetzt im Herb. Borssier-Barbex), die Characeen an O. Nord- 
stedt in Lund, die Algen an M. Möвms in Frankfurt und F. Hauck (jetzt im Herb. Weber rax Bosse in Ansterdam). - Die Pflanzen der Orientreisen sind in sehr zahlreichen europäischen Museen und Privatherbarien.

Lit. Briefl. Mittheilung von S.; Unb. Symb. I p. 16, 32, 53, 66 bis $67,88,92,108-109,113,114,117,135,159,171-173,291-479$.

Sloane, Sir Hans, (1660-1753), geb. zu Killyleagh in Down Co. (Irland) den 16. IV. 1660 als siebenter Sohn des General-Einnelnmers Alexander S. und seiner Frau Sarah, Tochter des Rev. Dr. Hicks. Mit 16 Jahren bekam er ein Lungenleiden, welches ihn drei Jahre an das Zimmer fesselte und ihn sein ganzes Leben lang sehr vorsichtig, namentlich in Bezug auf geistige Getränke maclite. Er studirte Medicin zu London, Paris und Montpellier, an letzterem Orte aucl Botanik unter Pierre Magiou und Tournefort, und promovirte 1683 zu Orange (Arausio, im Dép. Vaucluse) zum Dr. med. Nachdem er Mitglied des AerzteCollegs zu London geworden war, ging er im Jalıre 1687 als Leibarzt mil dem Herzog von Albenarle, dem neu ernaniten Gourerneur von Jamaica, über Madeira, Barbados, Nevis, St. Christopher, wo jedesmal ein kurzer Aufenthalt Gelegenheit zum Sammeln bot, nach Jamaica. Hier blieb er vou 19. December 1687 bis zum 16. März 1689 und erforschte die Parishes St. Catherine, St. Andrew, St. Mary und St. Ann, besonders die beiden ersten, sehr eingehend. Nach seiner Rückkehr liess sich S. in Bloomsbury Square zu London als praktischer Arzt nieder und gelangte bald zu grossem Ruhm und Anselien. Er wurde 1719 Präsident des Aerzte-Collegs, 1727 als Nachfolger Is. Newtox's Präsident der kgl. Gesellschaft der Wissenschaften, ferner auswärtiges Mitglied der Akademien zu Berlin, Paris, Petersburg, Madrid, Göttingen, Leipzig, königlicher Leibarzt und Generalarzt der englischen Armee, und seit 1716 Baronet. Trotz seiner ausserordentlichen Freigebigkeit brachte ihm seine ärztliche Praxis ein fürstliches Vermögen ein, ron dem er einen grossen Theil auf die Termehrung seiner Bibliothek und seines Museums verwendete. Im Mai 1741 gab er seine ärztliche Praxis auf und zog sich auf seine Besitzung zu Chelsea zurück, wo er am 11. I. 1753 im Alter ron 93 Jahren starb.

Coll. S.'s Sanmlungen gingen laut Testament in den Besitz der englischen Regierung ïber, welche dafür 400000 Mark an seine Erben zu zahlen hatte; sie bildeten den Grundstock zum British Museum und wurden von Chelsea nach Montague House übergefülırt. Die botanischen Collectionen, in welchen sich auch das Herbar Plukenet mit 8000 Pflanzen befindet, werden jetzt nebst der zugehörigen Bibliothek und den Manuskripten in der botanischen Abtheilung des Britislı Museums 
gesondert aufbewahrt. Die Jamaica-Pflanzen nehmen acht grosse Foliobände ein.

Lit. Commentarii de rebus in scientia naturali et medicina gestis, Lipsiae vol. II pars I (1753) p. 367-368, 727-732; Histoire de l'acad. des Scienc. Paris 1753 p. $305-320$; J. D. Micinaelis: Slodner vita in Commentarii Soc. Gotting. tom. IIII ad annum 1754 p. $146-154(503-511)$; Levensbeschryving ran den Heere Haxs Slodise in Uitgezogte Terhandelingen I p. 1 -17 (n. r.); Laseg. Mus. Deless. p. 11, 487; Didot Nouv. Biogr. génér. XLIV (1865) p. 56-58; Britt. and Boulg. p. $155-156$; F. Cuxdall in Journ. Inst. Jan. I (1893) p. 223 (mit Porträt); N. Moone in Dict. Nat. Biogr. LII (1897) p. $379-380$; Pritz. Thes. II ed. p. $298-299$; JAcks. Guide p. 370 ; URB. Symb. I p. $154-157$.

Smith, George Whitfield, (* 1860), geb. zu Barbados den 24. VII. 1860, war 1890 - 1894 Curator der botanischen Station ron Grenada und ist jetzt Travelling Superintendent of the Imperial Department of Agriculture for the West Indies. Im Auftrage des Committee für die Erforschung der Fauna und Flora Westindiens und auf Kosten ron F. Du Caxe Godmax nahm er mit Herb. H. Sumth $1889-1890$ eine g'ründliche Untersuchung der Blüthenpflanzen und Pteridophyten ron St. Vincent (1980 Nr.) und der benachbarten kleinen Inseln (Grenadinen) Bequia (378 Nr.), Cannouan (30 Nr.), Mlustique (163 Nr.) und Union (50 Nr.) ror.

Coll. Die Typen von St. Vincent sind in Kew; die Doubletten gingen an das British Museum, Herb. KRUG et URBAr (sehr reichhaltige Sammlung), Edinburgh, Columbia College in New York, die Farne auch nach Demerara in Brit. Guyana, Cambridge (Mass.), Melbourne. Die Pflanzen von Grenada in Kew, Doubletten im Herb. Krug et Urbax.

Lit. Kew Bull. 1893 Nr. 81 p. 233; Mornis in Kew Bull. Add. ser. I (1898) p. 74; briefl. Mittheilung durch D. Morris; Urb. Symb. I p. 7, 86 bis 87.

Smith, Herbert H., gebürtig aus Nordamerika, ging im Auftrage F. Du Cane Godrax's mit seiner Frau nach St. Tincent, hauptsächlich um auf dem Gebiete der Zoologie zu sammeln. Hier associirte er sich mit H. H. Sumt und führte mit diesem eine planmässige botanische Erforschung dieser Insel und der benachbarten Grenadinen aus (vergl. vorigen).

Lit. Vergl. vorher, Uns. Symb. III p. 4.

Stahl, Dr. Augustin, (* 1842), geb. auf der Insel Curaçao den 21. I. 1842 als Sohn' eines Deutschen und einer Holländerin, besuchte 1853 - 1858 das Gymnasium in Helmstedt in Braunschweig, der Heimath seines V'aters, wurde Apothekerlehrling in Braunschweig und studirte 1861-1864 in Würzburg Nedicin. Nach bestandenem Doctor- 
examen liess er sich im Jamuar 1865 in Portorico als Arzt nieder und lebt seitdem in Bayamon in der Nähe der Hauptstadt San Juan, einige Jahre abgerechnet, die er in Manatí zubrachte. St. widmete sich neben seiner Berufsthätigkeit mit grossem Eifer und Erfolge dem Studium der Naturgeschichte ron Portorico, die er zeitweilig (1874) an dem ersten dort gegründeten Gymnasium docirte, und legte umfangreiche zoologische und ethnologische Sammlungen an. 1883 gab er unter dem Titel: Fauna de Puerto-Rico. Clasificacion sistemática de los animales que corresponden á esta fauna y Catálogo del cabinete zoológico del Doctor A. Stahl einen Catalog leraus, in welchem er 2773 Arten seiner Sammlung (darunter 1837 Portoricenser) aufzählt. 1889 veröffentlichte er eine Schrift über die Urbewohner der Insel: Los Indios Borinqueños (nach OBER: Puerto-Rico p. VII), deren Werkzenge, Idole u. s. w. in seinem naturhistorischen Cabinete in beträchtlicher Anzahl vertreten waren, ferner Arbeiten über die Zuckerrohrkiankheit und medicinische Artikel. Der Botanik hatte sich St. schon in den siebziger Jahren zugewandt und manche interessante Funde an Prof. Grisebach in Göttingen geschickt, der sie aber meist unrichtig bestimmte. Seine numerirte Sammlung fällt in die Jahre 1883-1889 und repräsentirt die Flora der Nordküste von Loiza bis Manatí nebst den angrenzenden Gebirgen des Innern sowie die Gegend nördlich von Ponce (Peñuelas, Adjuntas etc.), welche er 1888 besuchte. Seitdem hat er in Folge ron Kränklichkeit und Ueberhäıfung mit Berufsgeschäften seine botanischen Excursionen eingestellt.

Coll. Herb. Krug et Urbax, sowohl die Bestimmungsexemplare als auch St.'s eigenes Herbar (1144 Nr.), eine kleine Anzahl im botan. Museum in Göttingen (ex herb. Griseb.).

Lit. Briefl. Mittheilung ron St.; Cat. Sc. Pap. XI p.472; Unz. Symb. I p. $158-159$.

Steinheil, Adolph, (1810-1839), geb. zu Strasburg in Elsass im XII. 1810, studirte daselbst sowie in Paris und Montpellier Pharmacie, Chemie und Botanik, war an verschiedenen Orten Frankreichs und 1834 zu Bona in Algier als Pharmaceut und Militärchirurg stationirt und trat 1839 eine Studienreise nach Südamerika an. Nachdem er sich einige Wochen auf Martinique aufgehalten hatte, starb er am 26. V. 1839 auf der Ueberfahrt ron dort nach Caracas. Seine wissenschaftlichen Arbeiten beschäftigten sich hauptsächlich mit morphologischen Fragen; ausserdem begann er in Verbindung mit Barnéoud eine Monographie der Plantaginaceen und von Dianthus.

Coll. Museum zu Paris, einiges von Martinique im Herb. Krua et Urbar, die algerischen Pflanzen auch in Berlin. 
Lit. Regensb. Flora XXII (1839) p. 560; F. M. Barxf́odd: Adolphe Steinheir in Ann. Sc. nat. II sér. rol. XIL (1839) p. 109-118; Pritz. Thes. I ed. p. 198, II el. p. 305 ; Cat. Sc. Pap. T p. $814-815$.

Surian, Joseph Donat, (?- 1691), Arzt, Pharmacognost und Botaniker in Marseille iu letzten Viertel des siebzehnten Jahrhunderts, erhielt von König Ludwa XIV. durch den früheren Intendanten in Westindien, damaligen Intendanten der Galeeren in Marseillo, BEgox, den Auftrag, auf den französischen Antillen seltene und merkwürdige Naturprodukte zu studiren und zu sammeln. Er wählte Charles Plumer, aus dem Orden der Minimes, hauptsächlich wegen seines hervorragenden Zeichentalentes, als Begleiter. Sie reisten $1689 \mathrm{ab}$, besuchten Martinique und Haiti und scheinen sich derartig in ihre Aufgabe getheilt zu luaben, dass SuRIAx hauptsächlich die Pflanzen für das Herbar präparirte und auf ihre medicinischen Eigenschaften untersuchte, während Plumer Pflanzen und Thier . zeichnete und sorgfältig beschrieb. Nach 1S-monatlichem Aufenthalte kehrten sie zurïck, aus unbekannten Gründen mit einander verfeindet. S. erhielt seinen Abschied und starb bereits 1691 zu Marseille, indem er einen Decoct giftiger Kräuter rersehentlich als Purgimittel benutzte.

Cull. Das Herbar Suris enthält in 10 Foliobänden 10 Centurien auf Papier geklebter Pflanzen, war lange in Jussieu's Besitz und wird jetzt im Pariser Museum aufbewahrt; es ist aber nicht sonderlich conservirt. Einige Pflanzen auch im Herb. Jussieu und Valluast ebendort.

Lit. Plumer Genera (1703) p. 37; Labat Voyage I ed. IV (1722) p. 10 seq. und Dentsche Ausg. IV p. 341 folg.; Biogr. unirers. class. III (1829) p. 2955 ; Pritz. Thes. II ed. p. 309 ; Urb. Symb. I p. 124, 130, 160 bis 161 .

Suringar, Willem Frederik Reinier, (1S32-1898), geb. zu Leeuwarden in Holland den 28. XII. 1832 als Sohn eines Buchhändlers, besuchte das Gymnasium seiner Vaterstadt, studirte seit 1850 zuerst Medicin, dann Botanik auf den Unirersitäten Leiden und Utrecht und wurde 1857 zum Doctor promovirt. Noch in demselben Jahre erhielt er die Stellvertretung ron DE VRIESE an der Universitiit Leiden, wurde 1862 dessen Nachfolger und 1871 Director des Reichsherbars daselbst. In diesen Stellungen rerblieb er bis zu seinem am 12. VII. 1898 erfolgten 'Tode. S.'s Arbeiten bezogen sich hauptsächlich auf das Studium der Algen, der Pflanzenteratologie, der Rafflesiaceen, auf die niederländische Flora und die Cactaceen. Ende $188 t$ ging er im Anftrage der niederländischen geographischen Gesellschaft mit einer Reihe anderer Gelehrten nach den niederländisch-westindischen Inseln zu deren wissenschaftlicher Erforschung ab. Man landete an 30. December in Paramaribo (Surinam), besuchte Georgetown, Trinidad und ging ron da nach 
Curaçao. Auf Curaçao verweilten sie den 10.-28. Januar, 11. bis 17. Februar, 27. Februar bis 11. März, 28. - 29. März, auf Aruba den 30. Januar bis 9. Februar, auf Bonaire den 19.-25. Februar, auf St. Eustache den 8. - 21, 29. April, 6.-19. Mai, Saba den 22. bis 28. April, St. Martin den 30. April bis 5. Mai, St. Kitts den 20. bis 22. Mai; rou da fuhren sie üher New York nach Amsterdam zurück.

Coll. Reichsherbar in Leiden, Doubletten im Herb. Krug et Urbay.

Lit. K. Schumann: Willem Frenerik Reinier Surivgar in Monatsschr. für Kakteenkunde VIII (1898) p. 134-137 mit Bildniss und in Terl. Bot. Ver. Brandenbg. XL (1898) p. CXVII-CXVIII; Gard. Clmon. III ser. vol. XXIV (1898) 1. 69; Vuyck: In memoriam Prof. Dr. W. F, R. Suringar in Nederl. Kruidk. Arch. III ser. vol. I (1898) p. I-X; IIUgo de Vries: W. F. R. Suringar in Ber. Deutseh. Bot. Gesellsch. XVII (1899) p. (220) bis (224); Reiseroute nach briefl. Mittheil. von S.; Pritz. Thes. II ed. p. 309 ; Jacks. Guide p. 324, 383, 441, 480, 507; Cat. Sc. Pap. V p. 888, VIII p. 1046, XI p. 531; Urв. Symb. I p. $161-162$.

Swainson sammelte 1830 - 1842 in erfolgreichster Weise auf den Bahamas. Ueber sein Leben ist nichts bekannt. Hit dem Zoologen Willian Swatrsox kann er nicht identisch sein; denu dieser war um 1830 in England thätig und wanderte 1837 nach New-Zealand aus, wo er 1855 starb (cf. Britr. and Boulq. p. 165; Dict. Nat. Biogr. LV p. $192-193$; A. Crïхтнек in Proc. Linn. Soc. London $1899-1900$ p. 14 bis 61 ).

Coll. Kew Herbarium (ex herb. Hooker).

Lit. W. B. Hemsi. briefl. Mittheilung.

Swartz, Olof, (1760-1818), geb. in Norrköping (Schweden) den 21. IX. 1760 als Solm eines Fabrikbesitzers, kam 1778 auf die Unirersität Upsala, studirte zunächst unter Luxx́́ hl. Naturgeschichte, damn Medicin, bereiste 1780 Lulea Lappwark, Finnland und Aland, 1781 Aland, 1782 die Insel Gotland, publicirte unter Linsés Yorsitz 1781 seine Dissertatiou: Jethodus muscorum und machte 1783 sein medicinisches Kandidaten-Examen. Ans 5. August 1783 trat er auf eigene Kosten eine Reise nach Amerika an. Nach fast zweimonatlichem Aufenthalte in Nordamerika landete er am 5. Januar 1784 in der MontegoBay auf $J$ amaica, besuchte von hier aus (wahrscheinlich uur auf kurze Zeit) Cuba und mindestens rom December 1784 bis zum Juni 1785 Haiti, kam dam nach Jamaica zur Fortsetzung seimer Studien zurück und schiffte sich 1786 in Kingston nach Europa ein. Bei seiner Rückkehr verweilte er bis zum Herbst 1787 in London, wo er im Baxk' schen Huseum seine Sammlungen zu bearbeiten begann und Gelegenheit fand, die P. Browas'schen Originalien im Lrsá́schen Herbar und die SLodxe'schen Typen im British Museum zu vergleichen. Während 
seiner Reise, am 14. VI. 17S5, war er bereits zum Dr. med. in absentia promovirt worden. Kaum hatte Sw. die zahlreichen Novitäten in knappster Form als Prodromus einer Flora von Westindien veröffentlicht, als er 1789 zum Intendanten des Kgl. Naturalien-Cabinets auf Drottningholm ernannt wurde. 1791 rertauschte er diese Stelle mit der eines Professors an der soeben gegründeten Bergianischen Gartenschule, welche unter der Aufsicht der Akademie der Wissenschaften zu Stockholm stand, wurde 1807 Intendant des Museums der Akademie, 1811 Sekretär derselben und 1813 Professor der Naturgeschichte bei dem medicinischen Institut. Während dieser Zeit machte Sw. zahlreiche Reisen durch fast alle Provinzen Schwedens, entdeckte viele neue Arten besonders ron Krryptogamen, arbeitete seine Flora Ind. occ. aus und schrieb wichtige Abhandlungen über Pilze, Flechten, Moose, Farne und Orchideen. Sein Tod erfolgte am 19. IX. 1818 zu Stockholm.

Coll. Sein Herbar ging 1819 durch Kauf an die Akademie der Wissenschaften in Stockholm über und wird in der botanischen $\mathrm{Ab}$ theilung des Reichsmuseums aufbewahrt; die westindischen Pflanzen sind leider nicht mehr rollständig rorhanden. Eine grosse Anzahl der letzteren besitzt das British Juseum in London; mehr oder weniger zahlreiche Arten sind im Herb. Willdesow in Berlin, in den Herb. Schreber und Schwägriches in München, VAHL in Kopenhagen, im Herb. der Linnean Society in London, im Prodromus-Herbar von de CAxdolte und im Herb. Martius in Brüssel.

Lit. Swartz Prodr. 1. VI-VIII; Kongl. Vetensk. Acad. Handl. Stockholm 1818 p. 370 - 380; C. A. Agardh: Olof Swartz in Regensb. Flora III (1820) p. $550-558$ und Biographie ïber den Prof. Olof Swartz in Swartz Adn. bot. (1829) p. XXIII - XXIX; C. Sprexg.: Memoria O. Swartzi in Nor. Act. Acad. Nat. Cur. X pars II (1821) p. XXXIV - XLI (abgedruckt in Swartz Adn. bot. p. XII - XXII); Ilagnus af Pontix: Aminnelse-Tal öfrer Herr Olof Swartz. Stockholm 1821. $8^{0}$. 58 p.; Biographie über den Professor Olof Swaltz. Stockholm 1828. So. 32 p. 2 tab. mit Bildniss (n. r.); Joir. Exr. Wirströx: Biographie ïber den Prof. Olof Swartz in SwarTz Adn. bot. (1829) p. XXX - LXXIV mit Bildniss; Hook. Journ. of Bot. II (1840) p. 382 bis 392 (mit Portrït); Sarg. Silva T p. 44; J. Hagex: Olof Swartz, 1760 bis 1818, in Kgl. Norske Vidensk. Selsk. Skr. 1897 (ex Just Bot. Jahresb. XXV 1897. I p. 5); Pritz. Thes. II ed. p. 309-310; Jacks. Guide p. 112, 150, 359, 368; Cat. Sc. Pap. V p. 896-897; Urв. Symb. I p. $162-167$.

Syme, George, (*1St4), geb. in Perthshire (Schottland) am 11. TII. 1S44, erlernte die Gärtnerei in tem Etablissement ron Dıcksos und Tursiblu in Perthi und war 1s79-18st Superintendent bei den botanischeı Gärten zu Jamaica. Hier sammelte er hauptsächlich am IIt. IIoses, bei Castleton, St. Mary, Jones Gap Farne, welche ron G. S. Jexmis in seiner Synoptical list etc. bearbeitet wurden, beschäftigte sich aber 
anch mit dem Studium der Orchideen. Jetzt lebt er in Californien (Petaluma, Sonoma Co.).

Coll. Herb. Kew, Jevmax.

Lit. Briefl. Mittheilung von S. dureh Herm W. Fawcett in Jamaica.

Taylor, Miss Fanny Hope, brachte in den Jahren 1852-1854 in Jamaica eine ausgezeichnete Sammlung von Farnen zusammen, hauptsächlich in den Port Royal Mts., bei Portland, St. David.

Coll. Herb. Kew, herb. Jexuras.

Lit. Jens. in Britt. Journ. of Bot. XXIV (1886) p. 270.

Terrasson sammelte auf Martinique (wann?).

Coll. Museum zu Paris, Montpellier (ex herb. Cambess.).

Thiery, Nicolas Joseph Th. de Menonville, (1739-1780), geb. zu St. Mihiel in der Lorraine (Frankreich) den 18. VI. 1739, studirte Rechtswissenschaft und wurde Adrocat, wandte sich dann aber der Botanik zu und ging nach Haiti, wo er Vorsteher des Colonialgartens in Portau-Prince wurde. Er machte sich hauptsächlich um die Einbürgerung der Cochenille-Zucht auf der Insel verdient und führte 1777 Nopalund andere Nutzpflanzen aus Mexico ein. Nach seiner Rückkehr nach Haiti wurde er Botaniste du roi und starb in Port-au-Prince 1780 Sein Werk: Traité de la culture du nopal wurde erst nach seinem Tode im Jahre 1786 in Cap Français (Haiti) veröffentlicht.

Coll. Museum in Paris, Dupla in Montpellier (ex herb. Caubess.).

Lit. Moreau de Saint-Mériy: Descript. de la partie franç. de l'isle de Sainte-Domingue vol. II (1798) p. 365; Пірот Nonv. Biogr. génér. XLV (1866) p. 200-201; Pritz. Thes. Il ed. p. 315; Leóx Bibl. Botán.-Mlexic. (1895) p. $245-247$.

Thiouville. de, sammelte 1844 auf Guadeloupe hauptsächlich Farne.

Coll. Herb. Fée im botanischen Garten zu Rio de Janeiro.

Lit. FÉE: Hist. des fougères et lycop. des Antilles.

Thompson, William J., gelıört dem Botanical Department zu Jamaica an und war Superintendent ron Castleton Gardens 1889 bis 1890, Kings House Garden 1890 - 1892 und seitlem wieder von Castleton Gardens.

Coll. Vergl, unter FawcerT.

Lit. Briefl. Mittheilung ron W. Harris und W. Fawcett.

Tillson, Arthur G., wurde als Gärtner in Kew ausgebildet, übernahm die 1889 gegründete botanische Station zu Antigua als erster Curator und blieb in dieser Stellung bis Juli 1897.

Coll. Kew Herbarium, einiges im Herb. Krug et Unbax.

Lit. D. Morris in Kew Bull. Add. Ser. I p. 118. 
Torralbas, José I., (*18t2), geb. zu Matanzas (Cuba) den 23. I. 1842 , studirte an der Unirersität zu Habana, wurde $186 \pm$ Licentiat der Medicin und 1890 auf Grund seiner Dissertation: Los Insectos y la seleccion natural de las plantas Doctor en Ciencias naturales. Er ist jetzt Mitglied der Akademie, Professor an der Unirersität und Conservator des botanischen Museums in Habana.

Coll. Herb. Krug et Urban (360 Nr. ex a. 1890-1891).

Lit. Briefl. Mittleilung ron G. DE LA MazA; Urb. Symb. I p. 105, 169, II p. 5 , III p. 11.

Turpin, Pierre Jean François, $(1775-1840)$, geb. zu Vire in der Normandie (Frankreich) den 11. III. 1775, ging im Jahre 1796 mit einer Expedition, welche die französische Regierung zur Wiederherstellung der Ordneng in Haiti ausgerüstet hatte, ron Brest aus als Soldat im Bataillon Calvados nach Cap-Français (jetzt Cap Haitien) und wurde ron Porteau, den er daselbst kennen lernte, in die Botanik eingefülurt. Nach einem kurzen Aufenthalte in Frankreich kehrte er nach Haiti zurück, nahm an der Belagerung ron Jacmel Theil, wurde Zeichner bei dem Chef-Ingenieur Sonel in Port-au-Prince und kam alsdann wieder zum Cap, wo er durch Portesu mit dem nordamerikanischen Consul Edward Sterexs bekannt wurde. Für diesen fertigte er 1799 - 1800 theils in Saint-Suzanne, theils in Cap, theils auf der Insel La Tortue ca. 300 Tafeln Pflanzenabbildungen an. Bald nach Poiteat's Abreise rerliess auch er die Insel und kehrte über Now York und Philadelphia Ende 1802 nach Frankreich zurück. Hier veröffentlichte er eine grössere Reihe ron Arbeiten über Gramineen, Cacteen, Organographie, Physiologie und Pathologie, eine Iconographie régétale (mit Porteau zusammen), eine unrollendet gebliebene colorirte Flore parisienne u. s. w., lieferte ausgezeichnete Abbildungen zu einer Anzahl bedeutender Werke (cf. Pritz. I ed. p. 303) und starb zu Paris am 1. V. 1840 .

Coll. Museum zu Paris, meist unter "Porteau et Turpis" (vergl. Portead), Herb. Lexonulasd jetzt im botan. Garten zu Caen.

Lit. Porteat in Annal. Soc. d'hortic. Paris XXVII p. 90 (n. r.); Regensb. Flora XXIII (1840) p. 543-544; A. Richird: Notice biogr. sur II. Turpis in Turpis Icon. régét. (1841) (n. v.); Las. Mus. Deless. p. 489 bis 490; Dinot Nouv. Biogr. génér. XLV (1866) p. 742 - 743; Pritz. Thes. II ed. p. 93, 250, 325-326; Jacks. Guide 1. 77, 116, 276; Cat. Sc. Pap. VI p. $70-72,761$.

Tussac, F. Richard de, ging um 1786 nach Martinique und ron da nach Haiti, wo er sich 15 Jahre dem Studium der Pflanzenwelt widmete. Er botanisirte in der Ungebung ron Jérémie(?), Port-auPrince, St. Marc, in der Plaine Désolée zwischen Artibonite und Gonaïres, 
Areahaye, St. Suzanne, Port Français und Cap Haitien. Bei der Einäscherung der letztgenannten Stadt am 5. Februar 1802 verbrannten ihm die beinahe 2000 Abbildungen, während er die Manuskripte und die Herbarien rettete. Kurz nachher ging er nach Jamaica, um für die französischen Gärten in Haiti aus dem botanischen Garten zu East lebende Pflanzen zu holen. Er blieb 10 Monate auf der Insel und sammelte in den Blue MIts., St. Mary (St. Georges), St. Andrew (Liguanea), Clarendon, St. Ann, St. Elizabeth und St. James. Von da kehrte er, ohne den eigentlichen Zweck seiner Reise erreicht zu haben, gegen Ende des Jahres 1802 in seine Heimath zurück. - Ueber sein sonstiges Leben ist nichts weiter bekannt.

Coll. Herb. Jussieu (ilım von T. 1807 geschenkt) und Herb. Desvaux in Paris, Museum zu Florenz, Herb. De Candolue, aber überall, wie es scheint, mur wenig.

Lit. Las. IIus. Deless. p. 489; Pritz. Thes. II ed. p. 326 ; Jacks. Guide p. 369 ; Cat. Sc. Pap. VI p. 73; Urb. Symb. I p. $170-171$.

Valenzuela, José Jaria, sammelte hauptsächlich October bis December 1833 in der Tuelta Abajo auf Cuba für Ruxox de la SAgra (vergl. diesen).

Lit. Urв. Symb. I p. 143.

Varanne sammelte um 1851 in Sto. Domingo.

Coll. Juseum zu Paris, etwas im Herb. Krug et Urban.

Waly, Jolm Frederick, (*1848), geb. in London den 26. X. 1848, conditionirte in rerschiedenen grösseren Gärtnereien Englands und in Passy bei Paris, wurde 1873 Obergärtner am botanischen Garten in Trinidad und 1878 am Government botanischen Garten in British Guyana, wo er seit 1900 auch in Botanik unterrichtet. April bis Juni 1895 sammelte er in Barbados ca. 140 Arten. Schrieb 1893 ein Werk über tropische Gärtnerei.

Coll. Kew Herbarium, Krug et Urbas, Washington (Smiths. Inst.), Bot. Garten zu Demerara.

Lit. Briefl. Mittheilung von W.; Unb. Symb. I p. 131.

Walsh, J. J., sammelte um 1889 in St. Martin, St. Eustache, St. Kitts, Dominica, St. Lucia und Grenada.

Coll. Kew Herbarium?

Lit. Une. Symb. I p. 137.

Warming, Johannes Eugenius Bülow, (* 1841), geb. zu Manö (Dänemark) den 3. XI. 1841, begann seine Studien 1859, reiste Februar 1863 nach Brasilien, wo er sich bis 1866 bei dem Paläontologen Dr. P. W. Luxd in Lagoa Santa (Minas Geraës) aufhielt und botanische Unter- 
suchungen anstellte sowie Sammlungen anlegte. Nach seiner Rückkehr nach Kopenhagen wurde er 1868 Magister, 1871 Doctor, 1873 Docent an der Universität daselbst, war 1S82-1886 Lehrer an der Hochschule zu Stockholm und ist seitdem Professor an der Universität und Director des botanischen Gartens in Kopenhagen. 1884 machte er eine Reise nach Grönland, wobei er auch Island berïhrte, 1855 nach Finnmarken, October 1891 bis März 1892 nach Barbados, Trinidad, Venezuela, Portorico (Ponce, Mayagïez, Aguadilla), St. Thomas, St. Croix und St. Jau, 1897 nach den Faroer-Insehn.

Coll. Bot. Juseum in Kopenhagen.

Lit. Warur. in Bot. Tidsskr. XII $(1880$ - 1881) p. 206 - 213; Kiaersh. 1. c. XXIII (1900) p. 44-45; briefl. Mittheilung ron W.; Pritz. Thes. II ed. p. 339 ; Jacks. Guide p. $62,85,90,92,204,333,372,488$; Cat. Sc. Pap. TIII p. 1197 , XI p. $751-752$.

Waters, James, sammelte in Jamaica um 1\$26 - 1S30, wurde, wenn es derselbe ist, 1837 Stipendiary Curate zu St. Elizabeth, 1847 Island Curate ebenda.

Coll. Kew Herbarium.

Lit. Briefl. Mittheilung ron W. B. Hexslex, ron W. A. Feurtado durch Herrn Frank Cundall in Jamaica.

Watt, Darid E., aus Jamaica gebürtig, gehört dem dortigen Botanical Department an und zwar als Gärtner an Hill Gardens.

Coll. Vergl. unter Fawcett.

Lit. Briefl. Mittheilung von W. Harris.

Weinland, Darid Friedrich, (*1829), geb. zu Grabenstetten bei Urach (Württemberg) den 30. VIII. 1829, studirte zu Tübingen 1847 bis 1852 zuerst Philosophie und Theologie, dann Naturwissenschaften, promovirte 1852 mit einer Arbeit über die Generatio spontanea und wurde Assistent an zoologischen Museum zu Berlin für die herpetologische Sammlung. 1855-185s hielt er sich in Cambridge (Mass.) auf und bearbeitete für L. Agassiz's Contrib. Nat. Hist. of the Unit. States die vergleichende Anatomie der Schildkröten und die Entwickelungsgeschichte der Gadoiden. Ton hier aus besuchte er Januar bis Juli 1857 Haiti, um in der Nähe ron Jérémie bei Corail das für den Schiffsverkehr so verhängnissvolle Wachsthum der Korallenpolypen, besonders der Madrepora alcicornis zu studiren; nebenbei machte er auch ethologische Studien und sammelte Echinodermen, Landmollusken und Reptilien, sowie Farne und Meeresalgen. Im October 1858 kehrte W. von Cambridge nach Deutschland zurück, übernahm im folgenden Jahre die wissenschaftliche Direction des zoologischen Gartens und die zoologischen Vorlesungen am Senckenbergischen Stift in Frankfurt a. MI. und begrün- 
dete daselbst die Zeitschrift "Der zoologische Garten". Später liess er sich in Hohenwittlingen auf der Schwäbischen Alb bei Urach nieder md ist hier mit helminthologischen, malakologischen und ornithologischen Studien beschäftigt; auch über die menschlichen und thierischen prähistorischen Bewohner der Höhlen der Alb hat er ein populäres, in vierter Auflage erschienenes Buch verfasst.

Coll. Farne im botan. Museum zu Berlin und im Herb. Krevg et URBan (69 Nr.). p. 773.

Lit. Briefl. Hittheilung von W.; Cat. Sc. Pap. VI p. 304-305, XI

West. Hans, (1758-1811), geb. in Hindsholm auf Fünen (Dänemark) im Jahre 1758 als Solni des dortigen Predigers, studirte in Kopenhagen moderne Sprachen und liess sich 1788 in St. Croix nieder, wo er bis 1800 Rektor der Schulo in Christianssted und später Notarius publicus war. 1802 ging er als Consul nach Holland und starb 1811 in Cassel auf der Rückreise von Frankreich. Er sammelte hauptsächlich auf St. Croix, aber auch auf St. Thomas, Vieques (Crab Istand), Portorico, wo er 1797 mit Ledru Excursionen machte, und in Martinique sowohl Phanerogamen wie Kryptogamen, die er an Prof. VAHL in Kopenhagen schickte.

Coll. Bot. Museum in Kopenhagen, einiges auch im Museum zu Berlin und im Herb. de Caxdolle (ex herb. Puerari).

Lit. Tant Ecl. Praef.; Warm. in Bot. Tidsskr. Kopenh. XII (1880) p. 82 ; Kialnsk. 1. c. XXIII (1900) p. $45-46$; Pritz. Thes. II ed. p. 344; URB. Sy'mb. I p. 173, $174-176$.

Wiles, James, war Gürtner bei R. A. Salisburx, begleitete 1791 bis 1793 den Kapitän Burg auf seiner zweiten Reise nach der Südsee (Otaheiti, Timor etc.), führte 1793 junge Brodfruchtbäume ron dort in die botanischen Gärten zu St. Vincent und zu Liguanea in Jamaica über, die sich auf den Inseln sehr gut einbürgerten, und wurde Vorsteher des letzteren bis ca. 1805 .

Coll. Herb. Delessent in Genf (ex herb. Lambert), Kew?, Herb. Barks im British Museum.

Lit. Bull. Misc. Inf. Kew 1891 p. $300-301,1892$ p. 95 ; Fawc. in Bot. Gaz. XXIV (1897) p. 347; Britr. and Boulg. p. 220.

Wilson, Nathaniel, geb. in Schottland, war 1834 und 1838 Gärtner in Kew und Kensington, ging nach Jamaica, wurde dort 1846 Island Botanist und Vorsteher des Bath Gartens, um welchen er sich durch zahlreiche Einführungen grosse Verdienste erwarb, legte 1860 den Castleton Garten an, nahm 1867 seinen Abschied und starb um 1873. Wahrscheinlich ron Sir W. Hooker beauftragt, für die in Angriff 
genommene Flora of the Brit. West Indies zu sammeln, besuchte er in den Jahren 1857-1858 die verschiedensten Theile der Insel wie St. Andrews, Portland, St. Mary, Mancheoneal, Dolphin Head und sammelte ca. 750 Arten.

Coll. Kew, Brit. Museum, Herb. Gristibacn in Göttingen, Kretr et Urban (hier ca. $250 \mathrm{Nr}$.).

Lit. Bull. Misc. Inf. Kew 1891 p. 321, Add. ser. I (1898) p. 143 bis 144; Fawc. in Bot. Gaz. XXIY (1897) p. 348-349; Cat. Sc. Pap. VI. 388 .

Wilson, Rev. Sherman B., sammelte in Jamaica besonders am Mount Moses 1874 Farne, welche ron G. S. Jexurs in seiner Synoptical list bearbeitet wurden.

Woodford, Sir Ralph, (1784-1828), geb, in England im Jahre 1784, war von 1813-1828 Gouverneur von T'rinidad und starb im Mai $182 S$ auf der See in der Nähe von Haiti.

Coll. Kew Herbarium?

Lit. Briefl. Mittheilung ron J. H. HaRt.

Wrbna, Franz, Gärtner aus Mährisch-Budwitz in Oesterreich, ging im Jahre 1822 nach Trinidad, um für die Exsiccaten Sieber's (vergl. diesen) zu sammeln.

Wright, Charles, (1811-1885), geb. zu Wethersfield in Connectirut (U. S. A.) den 29. X. 1811, besuchte die Schule seines Heimathsdorfes, trat 1831 in das Yale College ein und graduirte daselbst 1835. Nachdem er ein Jahr lang eine Hauslehrerstelle in Natchez (Mississ.) bekleidet hatte, wanderte er in Frühjahr 1837 nach der damals noch unabhängigen Republik Texas aus, wo er 10 Jahre lang theils in Zarvala am Neches-Flusse ais Landmesser, theils in Rutersville in Fayette County und Austin als Lehrer thätig war, nebenbei aber eifrig botanisirte. Während des Krieges mit Mexico 1847-1848 hatte er Gelegenheit, durch Vermittelung seines Freundes Dr. TerTcr, sich einer Freiwilligen-Truppe anzuschliessen und seine Excursionen bis an den Eagle-Pass an der mexikanischen Grenze auszudehnen. Nachdem er seine Sammlungen heimgebracht und auch A. Gray in Cambridge besucht hatte, mit dem er bereits 1844 in Verbindung getreten war, wurde ihm 1849 gestattet, mit einer Abtheilung Regierungstruppen in Texas durch den noch ganz unbekannten Landstrich ron San Antonio nach El Paso am Rio Grande zu ziehen. Die Resultato dieser Reise wurden von A. Gr.y 1852 als "Plantae Wrightianae I" veröffentlicht. Mehr als ein Jahr brachte darauf W. im mittleren Theile ron Texas als Lehrer an einer kleinen Schule zu, bis er im Frühjahr 1851 eine Stellung als Botaniker und Landmesser bei der Expedition fand, die 
unter dem Obersten Gramı die Regulirung der Grenze zwischen Mexico und den Tereinigten Staaten vornehmen sollte. Nachdem er dieselbe von Texas uber New Mexico bis zur Mitte des Territoriums Arizona begleitet hatte, kehrte er im Sommer 1852 ïber St. Louis, wo er Dr. Examlunx die Cacteen ïberlieferte, nach Cambridge zurück. Die auf dieser Reise gemachten Sammlungen bildeten die Grundlage zum II. Theile der "Plantae Wrightianae" (1853) und zusammen mit denen von Dr. Parry, Prof. Therber, Dr. J. M. Bigelow u. a. das Material zur „Botany of the Mexican Boundary Survey" 1859. - In den Jahren 1853 bis 1855 begleitete W. als Botaniker die North Pacific Exploring Expedition unter Kapitän Rrsagold, später unter Commander Johx Rodgers. Man besuchte Simon's Bay in Capland, Sydney, Hongkong, die Boninund Lin-Kiu-Inseln, Japan und die Inseln in der Behringstrasse. Im October $1855 \mathrm{kam}$ man nach St. Francisco zurück, von wo aus W. noch einen mehrwöchentlichen Abstecher nach Nicaragua machte.

Im Herbst 1856 begann W. die Erforschung der Flora von Cuba, welche er bis zum Jahre 1867 mehr förderte, als alle anderen Sammler vor und nach ihm zusammengenommen. Auf der ersten Reise landete er in Santiago und besuchte die Gebirge des Cobre, die Loma del Gato, Nimanima, Saltadero und die Umgebung von Montererde, wo ihm Don Federico Lescallle auf seiner Kaffeepflanzung die ausgiebigste Gastfreundschaft gewährte. Anfang Herbst 1857 kehrte er mit reichhaltigen Sammlungen in seine Heimath zurück. - Ende 1858 ging W. zunächst wieder nach Monteverde und sammelte vom Januar bis Juli 1859 in Gesellschaft des Zoologen Dr. Guxduach ${ }^{1}$ in der näheren und entfernteren Umgebung des Ortes. Während der zweiten Hälfte von 1859 sowie in den beiden folgenden Jahren wurde der ganze Osten der Insel: die Sierra Maestra mit dem Monte Liban und dem Pico del Toro, die Umgebung von Bayamo, wo er bei dem Arzte MAnuel Ykro gastliche Aufnahme fand, die Ufer des Rio Cauto und andererseits Punta de Maysi, Baracoa und Mayari durchforscht. In Winter 1861-1862 wanderte er von Bayamo über Las Tunas, Puerto-Principe, Santo-Espiritu weiter nacli Westen und schlug sein Hauptquartier auf der Zuckerplantage Fermina des Don Snox de Cardexas auf, ron wo aus das sich bis zur Südküste erstreckende Sumpfgebiet, die Cienega de Zapato, unter Führung Guxduach's besucht wurde. Er durchforschte dann die Umgebung von Matanzas und Cardenas, sowie die Tetas de Camarioca und verlegte im Sommer 1862 den Schauplatz seiner Thätigkeit nach dem

1) Es ist bisher von Niemandem darauf hingewiesen, wieviel WriGHT dem Dr. GundaAch zu verdanken hat, der seit 1838 auf der Insel und ïberall bekannt und beliebt, W. auf den grossen Plantagen einführte oder ibm Empfehlungsbriefe an dio Besitzer derselben nitgab. 
westlich ron Habana gelegenen Theile der Insel, in die Vuelta Abajo. Hier fand er auf dem Hato Balestena, einer Viehzüchterei an Südabhange des Gebirges gegenüber Bahia Honda, bei Don Josí Butis, dem Schwager ron SAcralue, gastliche Aufnamme und dehnte seine Excursionen fast bis zum Cap San Antonio, dem südwestlichen Ende der Insel, aus. - Sommer 1864 bis Herbst 1865 hielt er sich wieder in den Tereinigten Staaten, theils in seiner Heimath, theils in Cambridge (Mass.) auf. Auf der letzten Reise durchsuchte er noch eimmal die Tuelta Abajo, ging per Dampfer nach Trinidad (in der Mitte der Südküiste), dessen Umgebung er unter dem Schutze des reichen Don Justo Cautero erforschte, und ron da nach Guantánamo und Santiago, in dasjenige Gebiet, wo er seine Thätigkeit begonnen hatte. Im Juli 1867 rerliess $W$. die Insel und begab sich nach Cambridge, um den GriseBAch'schen Catal. Plant. cubens. auf Grund seiner eigenen Beobachtungen und Untersuchumgen einer Revision zu unterziehen und die zahlreichen neuen Arten demselben einzureihen. So entstand das Werk, welches unter dem Titel "SACralle: Flora Cubana" bekannt ist.

Im Jahre 1871 wurden W., Prof. C. C. PArR und H. Brunuel als Botaniker einer Commission beigegeben, welche in Sto. Domingo Land und Leute behufs Einrerleibung in die Tereinigten Staaten studiren sollte. Man landete am 24. Januar 1871 in der Samana-Bay, durchkreuzte Sto. Domingo nach verschiedenen Richtungen, rerweilte eine Woche in der Hauptstadt von Haiti und kehrte Ende März nach den Vereinigten Staaten zurück. Die botanischen Ergebnisse dieser Expedition waren wegen der ungünstigen Jahreszeit und des eilfertigen Reisens nicht erhebliche.

Den grössten Theil der folgenden Jahre brachte W. in Cambridge zu, wo er im GRır-Herbarium arbeitete, bis ihn die Sorge um seine kranken Geschwister in die Heimath rief. Hier in Wethersfield starb er am 11. VIII. 1885 am Herzschlage. A. GR.1Y sagt ron ilm: W. war ein Mann ron kleiner aber gut gebauter Statur, mehr zähe als kräftig; im böchsten Grade mässig, höchst einfach in seinen Gewolınheiten, stets bescheiden und anspruchslos, aber bestimmt und geradezu in seiner Ausdrucksweise, liebenswürdig, zuverlässig und religiös. Die einzige Triebfeder zu seinen lervorragenden Leistungen war die Neigung und Liebe zur Botanik.

Coll. Die Sammlungen aus Texas etc. und ron der Reise um die Erde scheinen nur wenig verbreitet zu sein. Die beste findet sich jedenfalls im GRIr-Herbarium in Cambridge, eine andere in Kew, aus Texas und New Mexico bei DE Cxrdolue, aus Japan im botan. Garten zu St. Petersburg. - Die rollständigste Sammlung der Phanerogamen und Pteridophyten ron Cuba, welche beinahe $4000 \mathrm{Nr}$. umfasst, ist im 
Gr.s -Herbarium in Cambridge und in der Akademie der Wissenschaften zu Habana (Herb. Suvvalıe), demnächst in Herb. Gassebıcı in Göttingen, dem aber die Ausbente der letzten beiden Jahre fehlt, und im Kew Herbarium. Ansserdem mehr oder weniger vollständig bei Bolssier-Barber in Genf, in Bremen, British Museum, Brüssel (ex lierb. Martius), Budapest (ex herb. Haxtadi), bei de Caxdolle in Genf, Cossox in Paris, Defessert in Genf, Dublin, Kreqg et Urbax in Berlin, Madrid, New York bot. Garten (ex herb. Torrey), New Tork College of Pharmacy (ex herb. W. M. C.nвr), Paris, St. Petersburg, J. D. Surm in Baltimore, Washington, Wien (Hofmuseum ex herb. H. G. Rегснахвасн und botanischer Garten). Moose sind im Gray-Herbar in Cambridge, Berlin (ex herb. C. Müller, bez. ex herb. Gоттsсне), Kew, British Museum, die Flechten (cf. J. Müller in Bot. Zeitung XLII. 1884 p. 14) im Kryptog. Herbar in Cambridge, Paris, British Museum, Herb. Bolssier-Barbey (ex herb. J. Mülder-Ara.), die Pilze im Kryptog. Herbar zu Cambridge, Kew, British Museum, New York bot. Garten (ex herb. J. B. Eluss), die Algen im Kryptog. Herbar in Cambridge. - Die Sto. Domingo-Pflanzen befinden sich im National Museum in Washington, im GrAY-Herbarium zu Cambridge und in Kew (hier nur 57 interessantere Arten).

Lit. A. Gray: Charles Wright in Amer. Journ. Sc. III ser. XXX (1885) p. 247 et XXXI (1886) p. $12-17$ et Scient. Pap. II p. 468-474; Sarg. Silv. I p. 94 ; J. Gundeach briefl. Nittheilungen; Cat. Sc. Pap. VIII p. 1276 ; Urb. Symb. I p. $10-11,15,41,50,59-62,92,96,108$, $113,114,117,134,136,148-150,154,159,160,170,178$.

Wright, William, (1735-1819), Dr. med,, geb. zu Crieff in Perthshire (Schottland) III. 1735, begann 1756 seine Studien auf der Universität Edinburgh, unterbrach dieselben aber 1757, um als Arzt auf einem Walfischfahrer eine Reise nach Grönland zu machen, und wurde nach absolrirtem Examen Schiffsarzt. 1765 begab er sich nach Jamaica, wo er neben der Ausübung seiner medicinischen Praxis in Hampden (Trelawny) seit 1771 auch eifrig sammelte und lebende Pflanzen nach Kew, getrocknete an Sir J. Baxks schickte. 1777-1779 hielt er sich in England und Schottland auf, um seine Studien fortzusetzen. Auf seiner zweiten Reise nach Jamaica 1779 wurde er ron einem spanischen Schiffe gefangen genommen, verlor seinen Hortus siccus und wurde in Spanien internirt. 1782-1785 war er als Generalarzt wiederum in Jamaica und suchte sein Herbarium durch neue Aufsammlungen zu ersetzen, wobei ihn 0. SwarTz unterstützte. $1796-1798$ verweilte el in gleicher Eigenschaft auf Barbados und legte eine grosse Sammlung von Windward-Pflanzen an. Nach seiner Rückkehr liess er sich in Edinburgh nieder, theils mit seiner Praxis, theils mit seinen Sammlungen beschäftigt, und starb daselbst den 19. IX. 1819. 
Coll. Edinburgh, Liverpool, Herb. Basks im British Museum, Kew (ex herb. Fonsyth, welches Brytiny 1835 kaufte), Brïssel (ca. $200 \mathrm{Nr}$. ex herb. Mirtius, ron Rob. Brows bestimmt). Wahrscheinlich stammen einige seiner für Jamaica angegebenen Pflanzen von Barbados.

Lit. Memoir of the late Wiliman Wright, M. D., Edinburgh and London 1828. $8^{\circ} .456$ p. mit Bildniss (n. r.); Naturalist IT (1839) p. 399 (n. v.); Britt. and Boula. p. 187; Journ. of Instit. Jam. II (1895) p. 183; G. S. Boulger in Dict. Nat. Biogr. LXIII (1900) p. 136-137; Pritz. Thes. II ed. p. 351; Cat. Sc. Pap. VI p. 446; Unb. Symb. I p. 59, $178-179$.

Wiirttemberg, Friedrich Paul Wilhelm Herzog ron, (1797 bis 1860), geb. zu Karlsruhe in Schlesien (Deutschland) den 25. VII. 1797, diente zuerst in der preussischen und württembergischen Armee, widmete sich aber dann geographischen und naturwissenschaftlichen Studien. 1822-1824 unternahm er eine Reise nach Nordamerika, besonders zum Mississippi und Missouri, 1829 nach Haiti, wo er August bis October mit C. EHrenberg sammelte, Mexico und den südlichen Staaten der Union, 1839 - 1840 nach dem oberen Nil, 1849 - 1856 nach Nordund Südamerika, 1857 nach Nordamerika, 1858 - 1859 nach Australien, Neu-Seeland, Ceylon und Aegypten. Er starb in Mergentheim (Württemberg) den 25. XI. 1860. Seine Sammlungen erstreckten sich nicht nur auf geographische, ethnographische und antiquarische Gegenstände, sondern auch auf Mineralogie, Geognosie, Botanik und Zoologie.

Coll. Museuns in München.

Lit. Bonplandia VIII (1860) p. 386; Jahreshefte des Vereins f. vaterl. Naturk. in Württemb. XVIII (1862) p. 20-24; P. STÄLIN in Allg. Deutscle Biogr. XXV (1887) p. $243-244$; Cat. Sc. Pap. TI p. 452.

Wullschlägel, Heinrich Rudolf, (1805-1864), geb. in Sarepta (Russland) den 1. II. 1805, erhielt seine Erziehung in Niesky, seine theologische Ausbildung in Gnadenfeld in Schlesien, war 1826-1834 Lehrer in Niesky, Ebersdorf (Reuss) und Herrnluut und leitete $183 \pm$ bis 1843 die Verwaltung des äusseren Haushalts der Brüder-Gemeinde in Neudietendorf (Gotha). 1844-1847 stand er der Mission in Antigua, 1847-1849 in Jamaica (Manchester: Springfield, Fairfield, Chatham), 1849-1855 in Paramaribo in Surinam vor und machte von hier aus im Juni 1855 eine Reise nach der Mosquitoküste zur Einweihung einer neuen Kirche in Bluefields. 1855 trat er in die Direction der Brüdergemeinde in Berthelsdorf bei Herrnliut, wurde 1857 Bischof der Brüderkirche und starb am 29. III. $186 \pm$ in Berthelsdorf.

Coll. Seine westindischen Pflanzen (Nr. 1-760 von Antigua, Nr. $761-1395$ ron Jamaica) im Bot. Museum zu München (Hauptsammlung mit den Original-Etiquetten), Herb. M.ırtus (jetzt Brüissel), Herb. Reichesbach (jetzt im Hofmuseum in Wien), Herb. Grisebicu (jetzt Urban, Symb. ant. III. 
Göttingen), Herb. Krug et Unвıs, Kew (hier sehr wenig). - Die Pflanzen von Surinam sind mit den Original-Etiquetten im Herb. Martius in Brüssel, Doubletten im Herb. Gissebacn. - Die ron der Mosquitoküste im Bot. Museum in Berlin (ex Herb. Görlitz).

Lit. RadLk. Mon. Serj. Ergänz. p.126-127; briefl. Mittheilung des Missionsdirectors G. Burkitardt in Berthelstorf; Uri. Symb. I p. 59.

Wydler, Heinrich, (1800-1883), geb. in Zürich (Schweiz) den 24. IV. 1800, war anfänglich in einer Mfusikalienhandlung, dann in einem Bankgeschäfte thätig, studirte darauf in Zürich und Göttingen Medicin und Naturwissenschaften und unterrichtete einige Jahre an einer Privatschule. Im Frühjahr 1827 trat er auf Anregung P. DE CANDOLLE's und mit Unterstïtzung einiger anderer Botaniker, besonders Delessiert's eine Reise nach Westindien an. Er besuchte auf einen Monat St. Thomas, darauf das östliche Portorico, besonders die Sierra de Luquillo, verlor aber den grössten Theil seiner Ausbeute durch Insekten und Fäulniss und kehrte, nachdem er in Ponce das gelbe Fieber glücklich überstanden hatte, Ende 1827 nach Genf zurück. 1828 bis 1830 war W. Adjunct am botanischen Garten in St. Petersburg, 1830 bis 1834 Conservator des Herb. DE Candolle, erhielt von der Baseler Universität den Dr. med. honoris causa, wurde darauf Lehrer an der Realschule in Bern und schliesslich Professor an der dortigen Universität. Im Jahre 1853 stellte er, durch seine Verheirathung in eine sorgenfreie Lage gekommen, seine Vorlesungen ein, lebte theils in Bern, theils in Strasburg und starb den 6. XII. 1883 zu Gernsbach in Baden. W. liat sich durch seine zahlreichen morphologischen Arbeiten einen sehr geachteten Namen erworben.

- Coll. Vollständigste Sammlung (ca. 425 Nr.) im Herb. de Caxdoul.e, ferner im Herb. Delessert, Berlin, Paris, Florenz, Nancy, Brüssel (ex herb. MLRTius).

Lit. J. SAcus Gesch. d. Botan. (1875) p. 178; Bot. Zeitung XLII (1884) p. $282-287$ (aus einer Antobiographie entnommen); E. Wunschuann in Allg. Dentsche Biogr. XLIV (1898) p. 392 - 393; Pritz. Thes. II ed. p. 352; Jacks. Gnide p. 143 ; Cat. Sc. Pap. VI p. 459-460, VIII p. 1284, XI p. 865; Urb. Symb. I p. 179.

Young, George, Dr. med., Militärarzt in Westindien, sammelte auf Tobago und war der erste Curator des botanischen Gartens in St. Vincent $1765-1774$.

Coll. Herb. Bañs im British Museum.

Lit. Beitr. and Boulg. p. 187. 


\section{Conspectus}

\section{insularum earumque peregrinatorum botanicorum. ${ }^{1}$}

(Peregrinatores uncis circumscripti herbaria non reliquerunt.)

Bermudas.

F. A. Michaux 1806.

A. W. Lane ror $18+4$.

A. F. Kemp ror 1857.

[J. M. Jones ca. 1859.]

J. Rein $1861-1863$.

J. H. Lefroy $1871-1877$.
H. N. Noseley 1873.

O. A. Rearle ca. 1880.

J. F. Kemp 1885.

B. D. Gilbert 1898 (Pterid.).

C. F. Millspaugh 1898.

Key insulae.

J. L. Blodgett 1838-1855.

Ignotus (J. L. Cabanis) vor 1839.

F. Rugel 1846.

A. P. Garber ca. 1870.
J. C. Melvill 1872.

A. H. Curtiss $1880-1881$.

C. S. Sargent 1886, 1887, 1898.

Bahamas.

II. Catesby $1725-1726$.

F. Boos, F. J. Märter u. [J.D.Schöpf] 1784.

A. Michaux 1789.

J. Fraser 1802.

Crudy ror 1810 .

Swainson $1830-1842$.

W. F. Daniell 1857 - 1858 .

J. Hjalmarson 1858.

W. Cooper 1859.

R. W. Rawson $1867-1868$.
H. E. W. Robinson 1877.

L. J. K. Brace $1877-1880$.

A. H. Searing ca. 1885.

F. H. Herrick 1886.

[J. Gardiner 1886 - 1888.]

C. S. Dolley ca. 1887.

H. von Eggers 1887, 1888.

A. S. Hitchcock 1890.

J. I. et A. B. Northrop 1890.

D. Morris 1895 .

Cuba.

[G. F. de Oviedo zw. 1519-1556.] M. Sessé u. J. M. Mociño zwischen

W. Houstoun 1729. $1795-1804$.

N. J. Jacquin $1758-1759$.

?J. Pavon.

O. Swartz 1784.

? L. Née.

1) Nonuulli boc loco enumerati (prasertim veteres) non in Notis biographicis, sed in Bibliographia Symb. vol. I T. 5-1S0 commemorantur. 
B. M. Boldo $1797-1799$.

[A. Parra vor 1799.]

M. E. Descourtilz 1799.

A. von Humboldt und A. Bonpland $1800-1801,1804$.

J. Fraser 1801, 1809.

J. A. de la Ossa ca. $1820-1830$.

G. Don 1822 .

E. Poeppig $1822-1824$.

R. de la Sagra 1822-1835.

F. A. Sauvalle $1824-1879$.

S. Bonani ca. 1833.

Ant. Reynoso ca. 1833.

J. M. Valenzuela 1833.

M. de Monteverde vor 1835.

Th. Drummond 1835.

P. A. Auber 1835 - 1843 (Kryptog.).

J. Linden 1837-1838, 1844.

E. Otto 1838.

H. Delessert $1838-1839$.

[F. W. P. Greenwood ror 1839.]

F. Leibold 1839, 1864.

H. Galeotti 1840.
J. M. Despréaux 1841.

L. M. Liebmann 1843.

A. W. Lane vor 1844.

F. Rugel 1849.

B. D. Greene.

J. Read.

C. Wright $1856-1857,1859$ bis $1864,1865-1867$.

[J. C. Oxamendi ca. $1860-1885$.]

[Alv. Reynoso ca. 1860 - 1889.]

Jamain 1863.

T. Heuser 1869.

[J. Planellas ca. $1880-1886$.]

J. Gundlach 1885.

[G. de la Maza 1887-1901.]

C. F. Millspaugh 1888, 1899.

H. ron Eggers 1889.

A. B. Bosque ca. 1890.

S. A. de Morales ca. 1890.

J. ̇̇. Torralbas ca. $1890-1891$.

[A. Worsley 1894.]

R. Combs 1895-1896.

\section{Pinos.}
A. Lanier 1831.
C. F. Millspaugh 1899 .
J. Blain ca. 1850 .

Cay man.

W. Fawcett 1888 .

C. F. Millspaugh 1899.

A. S. Hitclıcock 1891.

Jamaica.

J. Harlow ca. 1670.

H. Barham $1680-1726$.

H. Sloane 1687-1689.

IV. Houstoun zw. 1729-1733.

P. Browne $1746-1755$.

[E. Long ca. $1755-1769$.]

N. J. Jacquin 1758.

A. Robinson vor 1768 .

W. Wright $1771-1777,1782$ bis 1785.
Th. Dancer $1773-1811$.

Shakespeare $1780-1782$.

F. Masson 1781.

O. Swartz 1784, $1785-1786$.

de Ponthieu vor 1786.

J. von Rohr 1786.

F. J. Märter $1786-1787$.

J. Wiles $1793-1805$.

A. Broughton vor 1800 .

F. R. de Tussac 1802. 
E. N. Bancroft $1811-1842$.

J. Lunan vor 1814 .

C. Bertero 1821.

G. Don 1822.

R. Heward $1823-1826$.

J. Macfadyen $1825-1850$.

J. Waters ca. $1826-1830$.

Murray 1827.

Th. Higson 1828 - 1836 .

H. Distin $1830-1840$.

H. Cuming 1831.

G. Nacnab $1838-1859$.

Th. Hartweg 1843.

W. Purdie $1843-1844$.

H. J. Krebs zwischen $1843-1866$.

A. W. Lane vor 1844.

IV. A. Bromfield 1844.

P. H. Gosse 1844-1845.

A. S. Oersted 1846.

N. Wilson $1846-1858$.

H. R. Wullschlägel $1847-1849$.

R. C. Alexander Prior 1849-1850.

F. H. Taylor $1852-1854$ (Pterid.).

H. Barkly $1853-1856$.

W. T. March bes. $1857-1858$.

W. F. Daniell ca. 1863.

G. S. Jenman $1873-79$ (Pteridoph.).
B. Baker (Pteridoph.).

Kendal (Pteridoph.).

T. L. Rees (Pteridoph.).

S. Roberts (Pteridoph.).

S. B. Wilson 1874 (Pteridoph.).

W. Nock $1875-1880$ (Pteridoph.).

G. Syme $1879-1884$.

D. Morris $1879-1886$.

R. V. Slierring $1880-1887$.

F. C. Lehmann 1881.

J. H. Hart $1881-1887$.

C. S. Sargent 1885.

IV. Fawcett seit 1887.

H. von Eggers 1888.

W. J. Thompson seit 1889 .

D. E. Watt ca. 1890.

A. S. Hitcheock 1890.

E. H. L. Krause 1890.

J. E. Humphrey 1893, 1897 (Krypt.). [A. Worsley 1894.]

W. Cradwick seit 1894.

IV. Harris seit 1894.

E. Campbell 1894-1896.

B. D. Gilbert 1895 (Pteridoph.).

A. Fredholm 1897.

O. Hansen 1897.

C. F. Millspaugh 1899, 1900 .

Tortuga s. Tortue.

[J. B. du Tertre ca. $1650-1656$.]

[C. Plumier zwischen 1689 - 1697.]

P. A. Poitean und P. J. F. Turpin ca. 1799.

Hispaniola.

( $\mathrm{H}=$ Haiti, $\mathrm{D}=$ Sto. Domingo.)

[G. F. de Oviedo zw. 1514-1556.]

[J. de Acosta 1571 - 1587.]

J. D. Surian (H) $1689-1690$.

[C. Plumier (H) 1689-1697.]

[J. B. Labat zwischen $1694-1705$.]

[A. Minguet (H) $1698-1722$.

[L. Feuillée (H) 1705. ]

J.B.R.P. Desportes $(\mathrm{H}) 1732-1748$.
[J. D. Chevalier vor 1752.]

N. J. Jacquin (H) 1757-1758.

F. Aublet (H) 1764.

?Ph. Commerson.

[Nicolson $(\mathrm{H})$ ror 1776. ]

N. J. Thiery de Menonville $(\mathrm{H})$ bis 1780 .

O. Swartz (H) $1784-1785$. 
[A. S. Talverde vor 1785.]

F. J. Märter, F. Bredemeyer und J. Schücht (H) $1.785-1786$.

L. Cl. Richard (H) $1786-1787$.

E. R. de Tussac (H) $1786-1802$. Roquefeuille vor 1787.

J. F. Dutròne 1787.

Nectoux (H) 1788 seq.

Palisot de Beaurois (H) 1788 bis 1791.

De l'Etang (H) vor 1789.

J. Martin (H) 1789 seq.

?L. Née.

P. A. Poitean (H) $1796-1801$.

P. J. F. Turpin (H) 1796-1802.

II. E. Descourtilz (H) $1799-1803$.

?J. Paron.

Lahaye $(\mathrm{H})$ bis 1802.

[C. N. P. Gilber't (H) 1802.]

[C. C. Robin 1802-1806.]

W. Hamilton ca. 1814.

C. Bertero $1819-1820$.

K. Ritter (H) $1820-1821$.

Ch. Mackenzie (H) 1826-1827.

V. Jacquemont (H) 1827.
B. Jäger (H) 1827-1830.

C. Ehrenberg (H) $1828-1831$.

P. Herzog v. Württemberg (H) $18 \geq 9$.

L'Epagnier (H) 184t.

Rob. Schomburgk (D) 184S-1857.

C. Schwanecke (D) 1849.

Varanne (a. 1851.

L. A. Prenleloup (D) 185\%--1869.

Prax (H) 1854.

C. J. Nayerhoff (D) $1856-1859$.

D. Weinland (H) 1857 (Fil., Alg.).

[IT. II. Gabb (D) 1869 - 1871.]

H. Brummel, C. C. Parry, C. Wright (H, D) 1871.

W. Schumann (H) 1884.

L. Picarda (H) $1886-1898$.

H. von Egger's (D) 1887, (H) 1887, 1888.

[J. R. Abad ror 1888.]

A. Favrat (H) 1888.

E. H. L. Krause (H) 1890.

[L. G. Tippenhauer $(\mathrm{H})$ vor 1893.]

C. F. Millspangh (D) 1899.

IV. Buch (H) seit 1899 .

Portorico.

[G. F. de Oviedo zw. $1519-1556$.]

[I. Abbad vor 1782.]

F. Bredemeyer $1785-1786$.

J. von Rohr 1786 .

L. Cl. Richard 1786-1787.

[T. Rodriguez vor 1790.]

II. Sessé und J. MI. Mociño zwischen $1795-1804$.

?J. Pavon.

?H. Ruiz.

H. West 1797.

N. Baudin, A. P. Ledru, A. Riedlé 1797-1798.

C. Bertero 1818- 1819 .

A. Plée $1822-1823$.
C. S. Parker ca. 1825.

H. B. Hornbeck zwischen 1825 und 1844.

H. Wydler 1827.

Rob. Schomburgk ca, 1831.

K. Moritz 1835.

F. M. Liebmann 1841?

H. J. Krebs zwischen 1S43-1866.

C. Schwanecke $1846-1819$.

[D. Bello y Espinosa 1848-1878.]

J. Read.

B. F. Blauner $1852-1853$.

L. Krug 1857-1876.

R. de Grosourdy vor 1864 .

A. Stahl $1865-1889$. 
O. Kuntze 1874.

J. Gundlach $1875-1876$.

A. P. Garber 1880.

J. B. Pagan $1880-1884$.

H. ron Eggers 1881, 1883.
P. Sintenis $188.1-1887$.

E. Warming 189 ?.

[A. Worsley 1894.]

C. F. Millspaugh 1899.

A. A. Heller 1899, 1900.

Antill. minores.

[de Rochefort ror 1658.]

[J. B. Labat 1694-1705.]

Vieques s. Crab island.
[J. B. Labat $z$ wischen $1694-1705$.]
B. F. Blauner $1852-1853$.
H. West ca. 1797.
R. de Grosourdy vor 1864.
P. Rarn zwischen 1819-1839.
H. ron Eggers ror 1887.

\section{Culebra.}

C. F. Millspaugh 1899 .

\section{St. Thomas.}

[C. Plumier zwischen 1689-1697.] E. ron Friedrichsthal 1841.

[J. B. Labat zwischen 1694-1705.] H. J. Krebs 1843-- 1870.

[C. G. A. Oldendorp 1767-1768.] A. IT. Lane vor 1844.

J. von Rohr 1786.

A. S. Oersted $1845-1846$.

L. Cl. Richard $1786-1787$.

P. Duchassaing ca. 1846.

H. West ca. 1795.

von Chrismar 1849.

N. Bautin, A. P. Ledru, A. Riedlé J. Read. 1797.

J. Gollmer ca. 1850.

Crudy vor 1810.

F. L. l'Herminier 1815.

B. F. Blauner $1852-1853$.

P. E. Benzon zwischen 1817-1848.

A. H. Riise bis 1870 .

C. Bertero 1818 .

H. von Eggers $1872-1873,1874$

P. Ravn 1819-1839. bis $1887,1888$.

A. Plée 1821.

H. N. Moseley 1873 (Kirypt.).

[J. B. Ricord-Madianna zw. 1821

O. Kuntze 187 . und 1825.]

P. Sintenis 1887.

H. B. Hornbeck zw. 1825-1844.

E. H. L. Krause 1890.

H. Wydler 1827.

E. Warming 1892.

C. Ehrenberg 1827-1828.

F.C. E. Borgesen 1892, $1895-1896$.

Rob. Schomburgk ca. 18:9-1830.

B. D. Gilbert 1893 (I'terid.).

K. Moritz 1834-1835.

O. W. Paulsen 1895-1896.

Ch. Breutel 1841.

C. F. Millspaugh 1899.

H. ron Eggers 1881. 
St. Jan.

[C. (i. A. Oldendorp 1767-1768.]

J. Ryan ca. 1780.

L. Cl. Richard $1786-1787$.

P. E. Benzon zwischen $1817-1848$.

P. Ravn zwischen 1819-1839.

H. B. Hornbeck $1825-1844$.

Rob. Schomburgk 1830-1831.

K. Moritz $1834-1835$.
Ch. Brentel $18+1$ (haupts. Krypt.). H. J. Krebs zwischen $1843-1870$. II. von Eggers vor 1879, 1887 bis 1888.

E. Warming 1892.

F. C. E. Borgesen 1892, 1895 bis 1896.

O. W. Paulsen $1895-1896$.

\section{Tortola.}
L. Cl. Richard 1786-1787.
H. von Eggers 1887.

Rob. Schomburgk ca. 1831.

Anegada.

Rob. Schomburgk 1831.

St. Croix.

[J. B. du Tertre ca. $1650-1656$.] H. B. Hornbeck zw. 1825-1844.

[J. B. Labat $z$ wischen 1694-1705.] Ch. Breutel 1841 (haupts. Kryptog.).

J. von Rohr 1757-1791. F. M. Liebmann 1841.

[C. G. A. Oldendorp 1767-1768.] H. J. Krebs zwischen 1843-1870.

J. Ryan ca. 1780.

L. Cl. Richard $1786-1787$.

A. S. Oersted $1845-1846$.

P. E. Isert 1787.

H. West $1788-1800$.

Pflug vor 1797.
A. P. Ledru 1797.
P. E. Benzon 1817-1848.
P. Rarn zwischen 1819-1839.
C. S. Parker ca. 1825 .

J. Read.

H. von Egger's $1870-1872,1873$ bis 1874 .

E. Warming 189 ?.

F.C. E. Børgesen 1892, 1895-1896.

O. W. Paulsen $1895-1896$.

A. E. Ricksecker $1895-1896$.

L. A. Ricksecker $1896-1897$.

Anguilla.
L. Cl. Richard $1786-1787$.
W. R. Elliott 1892.
D. Morris 1890 .

St. Martin.
[J. B. du Tertre ca. $1650-1656$.]
H. Mazé ca. $1860-1877$ (Algae).
[J. B. Labat zwischen 1694-1705.]
W. F. R. Suringar 1885.
N. J. Jacquin zw. $1755-1757$.
J. J. Walsh ca. 1889.

A. Plée 1821. 
St. Barthelemy.

[J. B. du Tertre ca. $1650-1656$.] F. Pursh $1810-1811$.

[J. B. Labat zwischen 1694-1705.] F. L. l'Herminier 1815.

N. J. Jacquin zw. 1755-1757.] A. Plée 1821.

S. Fahlberg $1785-1834$.

[J. B. Ricord-Madianna zw. 1821

B. A. Euphrasén 1788. und 1825.]

J. E. Forsström $1803-181$.

Saba.

[J. B. Labat zwischen 1694-1705̃.] F. L. l'Herminier 1815.

J. E. Forsström zwischen 1803 und O. Kuntze 187 . 1815.

W. F. R. Suringar 1885.

St. Eustache.

[J. B. Labat zwischen 169t-1705.] B. A. Euphrasén 1788.

N. J. Jacquin zwischen 1755-1757. F. L. l'Herminier 1815.

F. Masson 1780.

W. F. R. Suringar 1885 .

S. Fahlberg zwischen 1785 - 1834. J. J. Walsh ca. 1889.

St. Kitts s. St. Christopher.

[J. B. du Tertre ca. 1650-1656.] W. Hamilton ca. 1814.

H. Sloane 1687. Ch. Breutel 1841 (haupts. Krypt.).

[C. Plumier zwischen 1689-1697.] J. R. Elsey 1857.

[J. B. Labat zwischen 1694-1705.] H. von Eggers 1882.

P. Browne 1745 . C. S. Sargent 1885 .

N. J. Jacquin zwischen $1755-1757$. W. F. R. Suringar 1885.

F. Masson $1780 . \quad$ J. J. Walsh ca. 1889.

S. Fahlberg zwischen 1785-1834. $\quad$ C. A. Barber ca. 1893.

B. A. Euphrasén 1788.

Nevis.

H. Sloane 1687.

IV. Hamilton 1814.

[W. Smith vor 1745.]

C. A. Barber ca. 1893.

F. Masson 1780.

Barbuda.

de Ponthieu ror 1786.

H. A. A. Nicholls 1891.

L. Cl. Richard 1786-1787.

Antigua.

P. Browne 1745 .

de Ponthieul vor 1786.

F. Masson 1780.

L. Cl. Richard $1786-1787$. 
?J. Paron.

W. Hamilton ca. 1814.

F. L. l'Herminier 1815.

T. Nicholson ca. $1831-1841$.

Ch. Breutel 1841 (haupts. Krypt.).

A. IV. Lane vor 1844.
H. R. Wullschlägel $184 t-1847$.

K. Finlay ca. 1850.

A. G. Tillson $1889-1897$.

H. A. A. Nicholls $1890-1891$.

C. A. Barber $1891-1895$.

Montserrat.

P. Browne 1745.

J. Ryan ca. 1780.

de Ponthieu ror 1786.

J. von Rohr 1786.
H. K. Holme ca. 1878.

H. A. A. Nicholls $1890-1891$.

C. A. Barber ca. 1893.

Guadeloupe.

[J. B. du Tertre ca. $1650-1656$.]

[C. Plumier zwischen 1689-1697.]

[J. B. Labat zwischen 1694-1705.]

N. J. Jacquin zwischen $1755-1757$.

S. Fahlberg zwischen $1785-1834$.

de Ponthieu vor 1786.

J. von Rohr 1786.

L. Cl. Richard 1786-1787.

Martfelt vor 1791.

F. L. l'Herminier' $1798-1829$.

Badier vor 1800 .

J. E. Forsström zw. 1803-1815.

F. Pursh $1810-1811$.

W. Hamilton ca. 1814.

C. Bertero $1816-1818$.

A. Plée 1820.

[J. B. Ricord-Madianna zw. 1821 und 1825.]

G. S. Perrottet 1824, 1841 .

C. S. Parker ca. 1825.

E. Guyon vor 1827.
P. Nyst ca. 1830.

F. l'Herminier ca. $1830-1866$.

Chr. Krauss vor 1838.

Beaupertuis 1839 .

Thiouville 18tt (Pteridoph.).

P. Duchassaing $184 t-1848,1851$ seq.

N. Funck u. L. J. Schlim 1845.

A. Schramm 1848-1873 (Algae).

J. Read.

H. Mazé 1851-1892 (Pteridoph., Algae).

Segretain 1852.

Germain ca. 1856 - 1864 (Krypt.).

J. Nattei 1857-1894 (Algae).

E. Jardin 1861.

'I. Husnot 1868 (Glum., Krypt.).

E. A. Marie 1874-1875 (Musci).

Lefebre 1877 (Musci).

A. Duss seit 1890 .

Désirade.

P. Duchassaing ca. 1846.

A. Schramm ca. $1860-1873$ (Algae).
H. Mazé ca. $1860-1877$ (Algae).

A. Duss 1892.

Marie galante.

[J. B. du Tertre ca. $1650-1656$.]

A. Schramm ca. 1860 - 1873 (Algae). H. P. Jazé ca. 1860 - 1877 (Algae).
T. Husnot 1868 (Glum., Krypt.). Bucquet ca. 1877.

[A. Duss 1895.] 
Les Saintes.

[J. B. du Tertre ca. $1650-1656$.] H. Mazé ca. 1860-1877 (Algae).

[J. B. Labat zwischen 1694-1705.] [A. Duss 1896.]

A. Schramm ca. $1860-1873$ (Algae).

Dominica.

[J. B. Labat zwischen 1694-1705.] [W. Schimper 1881, 1883.]

J. Gregg vor 1786.

F. Johow $1882-1883$.

F. Pursh $1810-1811$.

A. Duss 1883, 1885.

[J. B. Ricord-Madianna zwischen

H. A. A. Nicholls seit 1886 . $1821-1825$.]

J. Imray $1837-1880$.

G. A. Ramage $1888-1889$.

Hoskin 1841.

K. Finlay ca. 1850.

Murray

J. J. Walsh ca. 1889.

W. R. Elliott 1892, 1894, 1895 bis 1896 (Krypt.).

C. A. Barber ca. 1893 .

H. von Eggers 1880-1883.

Martinique.

[J. B. du Tertre ca. 1650-1656.] F. Kohaut (sub Sieber) 1819-1821.

J. D. Surian $1689-1690$.

A. Plée $1820,1825$.

[C. Plumier 1689-1697.]

[J. B. Labat zwischen $1694-1705$.]

[J.B.Ricord-Madianna 1821-1825.]

[L. Feuillée 1703-1704, 1711.]

E. Guyon ror 1827.

P. Nyst ca. 1830.

[Th. de Chanvalon 1751 - 1756.]

Rivoire 1839.

N. J. Jacquin 1755 .

A. Steinheil 1839.

J. B. Leblond 1767.

Terrasson

A. Anderson zw. 1785-1811.

G. S. Perrottet 1841.

S. Fahlberg zwischen $1785-1834$.

C. Bélanger $1853-1881$.

J. von Rohr 1786.

E. Jardin 1861.

F. R. de Tussac 1786 .

L. Hahn 1867-1870.

L. Cl. Richard $1786-1787$.

A. Coutance ca. 1868.

Aquart ca. 1787.

T. Husnot 1868 (Glum., Krypt.).

P. E. Isert 1787 .

A. Duss $1876-1889,1899,1900$,

J. Martin 1789. 1901.

H. West ca. 1795 .

[W. Schimper 1881.]

[C. C. Robin 1802-1806.]

C. S. Sargent 1885.

F. Pursh $1810-1811$.

B. D. Gilbert 1893 (Pterid.).

Santa Lucia.

[J. B. du Tertre ca. $1650-1656$.] J. B. Leblond ca. 1767.

[J. B. Labat zwischen 1694-1705.] F. Masson 1780. 

A. Anderson \%wischen 1785-1811.
A. Duss 1885 .
Crudy vor 1810.
G. A. Ramage $1888-1889$.
A. Plée 1821.
J. J. Walsh ca. 1889.
H. B. Murray ca. 1878 (Pteridoph.).

\section{Barbados.}
[R. Ligon 1647-1650.]
C. S. Parker ca. 1825.
H. Sloane 1687.
[J. D. Maycock vor 1837.]
J. Reid 1692.
A. W. Lane vor 1844 .

[J. B. Labat zwischen 1694-1705.]

Rob. Schomburgk 1846-1847.

P. Browne 1745 .

W. Munro $1870-1876$.

[G. Hughes vor 1750.]

W. B. Murray ca. 1871.

F. Masson 1779.

O. Kuntze 1874.

A. Anderson zwischen 1785-1811.

R. W. Rawson vor 1875 .

J. Gregg vor 1786.

C. S. Sargent 1885.

Martfelt vor 1791.

E. H. I. Krause 1890.

W. Wright $1796-1798$.

H. von Eggers 1890, 1891.

F. Seaforth ca. 1803 .

E. Warming 1891.

T. W. Simmonds $1803-1804$.

J. H. Hart ca. 1895.

F. Pursh $1810-1811$.

J. F. Waby 1895 .

W. Hamilton ca. 1814.

St. Vincent.

[C. Plumier zwischen 1689-1697.] C. S. Parker ca. 1825.

[J. B. Labat zwischen 1694-1705.] H. von Eggers 1889-1890.

N. J. Jacquin zwischen 1755 - 1757. H. H. u. G. W. Smith $1889-1890$.

G. Young $1765-1774$.

E. H. L. Krause 1890.

A. Anderson $1785-1811$.

H. A. A. Nicholls $1890-1891$.

G. Caley $1816-1823$.

W. R. Elliott $1891-1892$ (Krypt.).

L. Guilding $1817-1833$.

H. Powell $1891-1893$.

J. Macrae 1823.

J. H. Hart ca. 1895.

Bequia.

[J. B. Labat zwischen 1694-1705.] H. H. u. G. W. Smith 1890.

H. von Eggers 1890.

Mustique.

H. H. u. G. W. Smith 1890 .

Cannouan.

H. H. u. G. W. Smith 1890 .

Union.

H. H. u. G. W. Smith 1890. 
Grenada.
[J. B. du Tertre ca. $1650-1656$.]
G. Murray 1886 (Algae).
[J. B. Labat zwischen 1694-1705.]
W. R. Elliott $18 \$ 6$ - 1889 (Pterid.).
N. J. Jacquin zwischen $1755-1757$.
H. ron Eggers 1889.
F. Masson 1779 .
J. J. Walsh ca. 1889.
A. Anderson zwischen 1785-1811.
R. V. Sherring $1890-1891$.
de Ponthieu ror 1786.
G. W. Smith $1890-1894$.
A. W. Lane vor 1844.
D. W. Alexander 1891.
A. S. Oersted $1845-1846$.
W. E. Broadway seit 1894.
K. Finlay ca. 1850 .
J. H. Hart ca. 1895.
R. IV. Rawson 1870-1872.

Tobago.

[de Rochefort ror 1665.]

G. Young ca. 1765.

J. Gregg vor 1786.

de Ponthieu vor 1786.

IV. Hamilton ca. 1814.

F. L. l'Herminier'
L. C. Meyer 1879.

H. von Eggers 1889, 1891, 1899.

Th. Clemens $1890-1891$.

H. A. A. Nicholls $1890-1891$.

J. H. Hart ca. 1895.

A. Seitz 1896.

Trinidad.

[G. F. de Oviedo zwischen 1519 bis

\section{6.]}

J. B. Leblond ca. 1767.

Ryan ca. 1780 .

A. Anderson zwischen 1785-1811.

J. ron Rohr 1786.

N. Baudin, A. P. Ledru, A. Riedlé 1797.

R. Woodford $1813-182 \mathrm{~s}$.

D. Lockart 1818-1846.

von Schack ca. 1820.

F. Wrbna (sub Sieber) 1822.

C. S. Parker ca. 1825 .

H. Crueger 1841--1S64.

A. W. Lane vor 1844.

W. A. Bromfield 1844.

Bradford $1845-1846$.
W. Purdie 1846-1857.

K. Finlay ca. $1850-1868$.

Germain ca. 1860 (Krypt..

H. Prestoe $1864-1886$.

O. Kuntze 1874.

A. Fendler $1877-1883$

F. Johow $1882-1883$.

[V. Schimper 1882-1883.]

H. von Egger's 1883, 1899.

R. V. Sherring $1885-1886$ (Pterid.).

J. H. Hart seit 1887.

W. E. Broadway $1888-1894$.

D. W. Alexander 1890 seq.

E. Warming 1891.

Baptiste $1891-1896$.

IV. Lunt 1894-1898.

F. A. Lodge seit 1899 .

Malgarita.

[G. F. de Oviedo zw. 1519-1556.] A. Ernst 1873. 


\section{Tortuga.}

A. Ernst 1874 .

Los Roques.

A. Ernst 1871.

$$
\text { Bonaire. }
$$

W. F. R. Suringar 1885.

$$
\text { Curaçao. }
$$

N. J. Jacquin zwischen $1755-1757$. J. Read

J. von Rohr 1786.

W. F. R. Suringar 1885

F. Bredemeyer 1788.

H. von Eggers 1893.

A ruba.

N. J. Jacquin zwischen $1755-1757$. W. F. R. Suringar 1885. 


\title{
III. Piperaceae.
}

\author{
Exposuit \\ C. ine Cindolle.
}

Claris generum.

Frutices rel arbores . . . . . . . I. Piper Linn.

Herbae.

Antherae 4-loculares. Stigmata 4 . . II. Verhuellia Miq.

Antherae 2-loculares. Stigma unicum simplex rel rarius 2-lobatum

III. Peperomia R. et P.

\section{Piper Linn.}

Piper L. Gen. et Sp. (pro parte); Ruir et Pax. Fl. per. I p. 33; Kunth in II. B. K. Nor. Gen. I p. 46; Bl. Monogr: der oost Ind. Pepers in Terh. d. Bat. Genoots. vol. XI et Enum. Pl. jat. (pro parte); A. Dietr. Spec. I p. 634; Miq. Syst. Pip. p. 305; C. DC. Prodr. XVI, 1 p. 240. - Heckeria, Enckea, Steffensia, Schilleria, Ottonia Kunth in Linnaen XIII. - Coccobryon, Caulobryon KTotrsch Msc. in herb. Berol. - Carpunya Presl Epim. bot. - Schinonephros Griffith Notul. - Potomorphe, Macropiper, Rhyncholepis, Muldera, Cubeba, Callianira, Encliea, Peltobryon, Sphaerostachys, Artanthe, Ottonia, Zippelia et pars Charicae Miq. Syst. Pip. - Macropiper, Heckeria, Piper, Charica, Nematanthera Engl. in Engl.-Prantl Pflanzen-fam. III, I

$$
\text { p. } 6-10 \text {. }
$$

Bractea a flore libera vel rarissime (in speciebus antillanis nunquam) cum flore connata. Flores spicati sessiles rel pedicellati seu simpliciter racemosi, hermaphroditi rel unisexuales. Stamina $1-10$, antheris 4 -locularibus caducis, filamentis persistentibus. Stigmata 2-4. Orulum 2-teguminatum. - Frutices rel arbores. Systema fibrorasculare duplex, id est fasciculis tubum periphericum formantibus et fasciculis intramedullaribus sistens. 


\section{Claris spccierum.}

Scctio Enckea C. DC. Prodr. XVI, 1 p. 240 (emend.). Flores liermaphroditi sessiles rel pedicellati. Bractea a flore distincta. Stamina in flore $5-6$, raro 4. Baccac sat discretae vel subcondensac, ovatae vel raro oblongae. Stigmata $3-5$ in apice baccae sessilia. Spicae oppositifoliac. Flores in antillanis sessiles.

10. Folia penninervia.

Petiolus usque ad limbum vaginans. Limbi subtus villosi

1. P. Hartii C. DC.

Pctiolus basi ima vaginans. Limbi utrinque glabri

2. P. Hohenackeri C. DC.

$2^{0}$. Folia multinervia.

† Limbi orato-elliptici vel elliptici $8-12 \mathrm{~cm}$. Iongi.

Ramuli et limbi puberuli. Bractea hirtella.

3. P. medium Jacq.

Ramuli et limbi glabri. Bractea glabra

4. P. Amalago I.

Himbi oblongo-ovati vel elliptico-lanceolati $6-9 \mathrm{~cm}$. longi.

$\bigcirc$ Limbi utrinque glabri.

Spica folio duplo longior 5. P. Wullschlaegelii C. DC.

Spica folio fere $1 / 3$ brevior

6. P. unguiculatum R. et Pav.

O Limbi subtus pubescentes.

Limbi basi utrinque acuti

7. P. Richardianum C. DC:

Limbi hasi rotundati aut subcordati

8. P. mananthum C. Wright

+ † Limbi 3-lobi . . . . . 9. P. subpanduriforme C. DC.

Sectio Steffensia C. DC. Prodr. XVI, 1 p. 240 (emend.). Flores hermaphroditi sessiles vel pedicellati. Bractea a flore distincta. Stamina in flore 4. Baccae in floribus sessilibus condensae et \pm angulosae vel raro ovatae aut globosae. Spicae oppositifoliae aut (tantum in paucissimis speciebus) axillares.

A. Spicae oppositifoliae.

a. Folia multinervia.

Bacca apice disco in medio stigmatifero coronata

10. $P$. reticulatum $\mathrm{L}$.

Bacca sine disco summo apice stigmatifera

11. P. marginatum Jacq.

b. Folia multiplinervia.

Limbi basi aequilateri, $12-16 \mathrm{~cm}$. longi [mum C. DC.

11. P. marginatum Jacq. $\beta$. fir-

Limbi basi valde inaequilateri usque ad $37 \mathrm{~cm}$. longi

12. P. caracasanum -Bredem.

c. Folia penninervia.

10. Flores pedicellati

13. P. ovatum Vahl 


\title{
SYMBOLAE ANTILLANAE
}

SEU

\author{
FUNDAMENTA
}

\section{FLORAE INDIAE OCCIDENTALIS}

EDIDIT

\section{IGNATIUS URBAN}

\section{0 L U II E N I I I \\ FASCICULUS II}

Continet:

III. C. de Candolle: Piperaceae, p. $161-274$

IV. IT. Stephani: Hepaticae novae Dussianae II, p. 275-279

V. Ign. Urban: Nova genera et species II, p. $280-352$

\section{LIPSIAE}

FRATRES BORN'TRAEGER

\section{2}

\section{PARISIIS}

PAUL, KLINCKSIECK

3, RUE CORNEILLE

\section{LONDINI}

WILLIAMS \& NORRIATE

14, HENRIETTA STREET, COVLAT GARDEN 

$2^{0}$. Flores sessiles.

$\S 1$. Stigmata in floribus ejusdem spicae $3-4$

14. P. splacierocripum C. Wr.

\$2. Stigmata in omnibus florikus 3 .

† Bacea-apice stilifera . . . . 15. I. arale C. DC.

Bacea haud stilifera, id est stigmata in apice baccae sessilia.

Bacca matura tetragona vel subtetragona.

$\times$ Nervus centralis ultra ${ }^{3} / 4$ longitudinis suae nerros subrectos mittens. Limbi basi inaequilateri.

- Limbi basi utrinque acuti aut subacuti.

Limbi utrinque jubeseentes

16. P. rigidum C. DC.

Limbi utrinque glabri 17. P. stamincum. C. DC.

-. Limbi basi saltem uno latere obtusi aut rotundati.

Limbi ntrinque pubescentes, lanceolati

18. P. Suartrianum C. DC.

Limbi tantum subtus pubescentes, ovati rel oratooblongi. . 19. P. tuberculatum Jacq.

Limbi utrinque glabri lanceolato-ovati vel lanceolatooblongi . . 20. P. genimatum Sw.

$\times \times$ Nervus centralis tantum e parte inferiore, seu vix ultra

$1 / 2$ longitudinis suae nervos \pm arcuatos mittens.

* Limbi utroque latere acnti rel subacuti, aequilateri rel subaequilateri.

- Bractea apice peltata rel truncato-peltata, inferne anguste pedicelliformis.

- Limbi adulti utrinque pubescentes

Limbi adulti supra scabri.

Pedunculus petiolo toto multo longior

21. P. subrectinerve C. DC.

Pedimculus petiolo toto fere aequilongus.

Nervi laterales utrinque 6

30. P. hispidum Sw. var. magni-

Nervi laterales utrinque 10 [folium C. DC.

30. P. hispidum Sw. var. pluri-

Limbi adulti supra hand scabri [nere C. DC.

22. P. Seit iii C. DC.

$=$ Limbi tantum subtus pubescentes.

Spica folio $2-3$-plo brevior

23. P. citrifolium Lam.

Spica folio paullo brevior

三 Limbi utrinque glabri

24. P. Ledcbourii C. DC.

25. P. Sehackii C. DC.

- Bractea hand apice peltata, inferne lata

26. P. hebecarpum C. DC.

** Limbi basi \pm inaequilateri et saltem uno latere rotundati aut obtusi.

- Bractea apice peltata, inferne anguste pedicelliformis.

- Limbi utrinque (supra salten ad nervos) pubescentes. 
limbi adulti supra seabri.

$\triangle$ Pedunculus petiolo toto pluries vel sat longior.

Limbi $12-24$ cnl. longi oblongo-elliptici apice acuminati

\section{I'. aduncum $\mathrm{I}$.}

Limbi $12-2 \pm \mathrm{cm}$. longi lanceolato-oblongi 28. P. anyustifolium R. et Pav.

Limbi 9-11 cm. longi elliptico-lanceolati 29. P. confusum C. DC.

$\triangle \triangle$ Pedunculus petiolo toto aequilongus vel paullo Spica limbo fere aequilonga.

Bacca vertice \pm hirsuta

Bacca glabra.

30. P. lispidum Sw.

Limbi oblougo-lanceolati usque ad $15 \mathrm{~cm}$. longi 31. P. Wrightii C. DC.

Limbi oblongo-elliptici $1 \mathrm{~L} / 2 \mathrm{~cm}$. longi

32. P. Harisii C. DC.

Limbi ovato-elliptici $7 \mathrm{~cm}$. longi

33. P. mirrophyllum C. DC.

Spica limbi dimidium aequans

34. P. guaranum C. DC.

Limbi adulti haud supra scabri.

Limbi $22-26 \mathrm{~cm}$. longi

35. P. Uussii C. DC.

Limbi $9 \mathrm{~cm}$. longi 36. P. Fadyeni C. DC.

$=$ Limbi adulti tantum subtus pubescentes.

$\triangle$ Petiolus hasi ima vel fere ima vaginans.

Limbi $19-21 \mathrm{~cm}$. longi.

Petioli pubescontes

37. P. Broadwayi C. DC.

Petioli glabri 38. P. cuspidatum Ham.

|| Limbi usque ad $151 / 2 \mathrm{~cm}$. longi.

Pedunculus petiolo toto fere aequilongus

39. P. jamaicense C. DC.

Pedunculus petiolo toto $2-3$-plo longior

40. P. Murrayamm C. DC.

$\triangle$ Petiolus usque ad limbum raginans.

Bractea pubescens

41. P. mornicola C. DC.

Bractea glabra 42. P. Andersonii C. DC:

- Bractea haud apice peltata.

Petiolus usque ad limbum vaginans

43. P. macrophyllum Kunth.

Petiolus basi ima raginans

44. P. martinicense C. DC.

*** Limbi basi cordulati.

Limbi elliptico-lanceolati 28. P. angustifolium R. et Pav.

Limbi ovati ajice acuminati $\quad[\beta$. Ossamm C. DC.

45. P. Otophyllum C. DC. 
$\bigcirc \bigcirc$ Bacca matura trigona.

- Limbi basi utrinque acuti.

Limbi usque ad $20 \mathrm{~cm}$. longi, suboblique lanceolatoelliptici. . . 46. P. Readii C. J)C.

Limbi usque ad $13 \mathrm{~cm}$. longi, elliptico-lanceolati

47. P. Trinitatis C. DC.

- Limbi basi utrinque rotundati.

Limbi suboblique orato- vel obovato-elliptici apice acuminati . . . 48. P. dilatatum 1. Cl. Rich.

Limbi elliptico-lanceolati apice sat longe acuninati 49. P. tobagoanm C. DC.

... Limbi basi cordati. . 50. P. amitum Kunth.

species incertae sedis.

Limbi elliptici $22 \mathrm{~cm}$. longi, $14 \mathrm{~cm}$. lati

51. P. Eggersii C. DC.

Limbi oblongi $19 \mathrm{~cm}$. longi $5 \mathrm{~cm}$. lati

52. P. angustilimbum C. DC.

B. Spicae axillares

53. P. incurvum Sieb.

Sectio Carpuyar C. DC. Prodr. XVI, 1 p. 326 (emend.). Flores hermaphroditi. Bractea a flore distincta. Stamina 3, quorum 2 lateralia unumque posticum. Baccae sessiles rel (ín unica specie) stipitatae seu inferne in stipitem attemuatae, condensae et \pm angulosae rel (tantum in duabus speciebus) discretae et ellipticae. Spicae oppositifoliae.

$\$ 1$. Bacca stipitata.

Folia 5-nervia. Bacca elliptica. . 54. P. leptostachyum A. Rich.

\$2. Bacca sessilis.

A. Bacca apice stilifera.

Folia 6-plinervia . . . . 55. P. Swartrii C. DC.

B. Bacca haud apice stilifer:ı.

a. Folia pelninervia:

Limbi basi acuti.

Limbi oblongo-elliptici nervis lateralibus yatulo-subadscendentibus . . . . 56. P. aequale Vahl.

Limbi elliptico-lanceolati nervis lateralibus adscendentibus

57. P. conciunum C. DC.

Limbi basi rotumclati vel subrotundati.

Limbi subtus ad nerros pilosi, basi inaequilateri

58. P. Ballisianmm C. DC.

Limbi utrinque glabri, basi aequilateri

59. I. dominicanum C. DC.

b. Folia multiplinervia vel fere multinervia

60. I’. Blattrum spreng.

Sectio Coccobryon C. DC. Prodr. XVT, 1 ]. 336 (1) 1).). Flores hermaphroditi. Bractea a 'flore distincta. Stamina 2 lateralia. Bacca sessilis. Spicae oppositifoliae.

A. Folia penninervia.

Limbi basi inaeqilatera utrinque obtusi, apice attenuato-obtusi

61. P. obtusum C. DC. 
Limbi hasi subaequilatera cordati, apice acmuinati

62. I' artimlatum A. Rich.

B. Folia multiplinervia.

Limbi e hasi sat profunde corrata oblongo-ovati acuminati

63. P. Picardae C. DC.

C. Folia multinervia .

66. P. papantlense C. DC.

Sectio Potomorphe C. DC. Prodr. XVI, 1 p. 331 (p. p.). Flores hermapluroditi. Bractea a flore distincta. Stamina 2 lateralia rel 3 , quorum 2 lateralia et tertium posticum. Baccae sessiles condensae et angulosae. Spicae in apice ramuli axillaris umbellatae vel in axilla solitariae.

Spicae umbellatae, stamina 3.

Folia peltata . . . . . . 64. P. peltatum L.

Folia hand peltata. . . . . . 65. P. umbellatum L.

Sectio Eupiper C. DC. Prodr. XVI, 1 p. 339. Flores unisexuales rel (tantum in $P$. amdrogyno C. DC.) basi spicae hermaphroditi vel in rarissimis speciebus trioicis nunc unisexuales nunc hermaphroditi. Bractea a flore distincta nune libera et centro aut fere centro inserta, nunc rhachi adnata et tantum margine libera. Stamina 2 lateralia vel 3, quorum 2 lateralia et tertium posticum. Bacca (in nostris) sessilis aut stipitata seu inferne in stipitem attenuata.

A. Folia penninervia.

Limbi oblongo-elliptici $81 / 2-14 \mathrm{~cm}$. longi

67. P. retrofractum Vahl.

B. Folia multiplinervia.

a. Bractea rotundata centro sessilis. 6S. P. Betle L.

b. Bractea oblonga vel obovato-oblonga rhachi adnata et margine libera. Limbi elliptici vel ovato-elliptici apice acuminati

Limbi ovato-rotundi apice acuminati

69. P. nigmem L.

70. P. Christyi C. DC.

1. Piper Hartii C. DC. (n. sp.) foliis modice petiolatis, subovatoellipticis, basi aequilatera utrinque rotundatis, apice breviter acuminatis acumine obtuso, supra glabris, subtus dense villosis, nervo centrali alte ultra medium suum nerros patulo-adscendentes utrinque 6 - 7 mittente, petiolo usque ad limbum vaginante pedunculoque per anthesin quam petiolus breviore dense villosis; bractea cucullata inferne lata et utrinque hirsuta, vertice inflexo superne adspectu tridentato glabroque et inferne carnose subproducto hirsutoque; antheris ovato-rotundis.

Ramuli villosi, spiciferi circiter $2 \frac{1}{2} \mathrm{~mm}$. crassi, in sicco pallide fulvescentes, collenclymate hand libriformi in fasciculos discretos disposito, fasciculis intramedullaribus 1 -seriatis numerosis, canali vacuo nullo. Limbi in sicco subcoriacei opaci, superiores usque ad $14 \mathrm{~cm}$. longi et ad $7 \mathrm{~cm}$. lati; petioli circiter $12 \mathrm{~mm}$. longi. Pedunculi circiter $8 \mathrm{~mm}$. longi; spicae per anthesin circiter $3 \mathrm{~cm}$. longae et $3 \mathrm{~mm}$. latae; rhachis glabra. Flores 
densi. Stamina 6, ad basin ovarii rhachi inserta, antheris caducis filamenta aequantibus. Stigmata 3 sessilia linearia.

Hab. in Trinidad: Broadway et Hart 11. 5574, 5662, 6012.

2. Piper Hohenackeri C. DC. foliis brevissime petiolatis, oblongoellipticis, basi aequilatera attenuatis et acutis, apice acuminatis acumine acuto, utrinque glabris, nerro centrali fere tota longitudine sua nervos tenues circiter 12 patulo-adscendentes nerrulis validioribus saepe intermixtos unumque infimum adscendentem ntrinque mittente, petiolo basi ima vaginante pedunculoque petiolum fere duplo superante glabris; spica quam folium pluries breviore recta cylindrica apice mucronulata, bracteae glabrae latae rertice cucullato calceoliformi; bacca glabra oboratosubquadrangula.

Piper Hohenacheri C. DC. Prodr. XVI, 1 (1869) 1). 243.

Ramuli juniores altero latere hirtelli dein glabri, spiciferi $1^{1}$, $\mathrm{mm}$. crassi, in $3 \mathrm{~mm}$. crassis collenchymate continuo libriformi, fasciculis intramedullaribus 1 -seriatis circ. 12 , canali racuo nullo. Limbi in sieco membranacei, minute pellueido-punctulati nitiduli, $16 \mathrm{~cm}$. longi, ad $6 \mathrm{~cm}$. lati; petioli $3 \mathrm{~mm}$. longi. Pedunculi $6 \mathrm{~mm}$. longi; spicae fere maturae $3 \mathrm{~cm}$. longae et $3 \mathrm{~mm}$. crassae: bractea coriacea baccam subamplectens. Stamina 6 basi ima baccae alnata. Stigmata $3-4$ sessilia brevia.

Hab. in insulis Caribaeis (ex h. Sprexger sub $I$. aeqnali L. in h. Berol., an rere ex ins. Caribaeis?, specimen baccis immaturis rertice rhomboideis). - In silvis Guianae batavae prope urbem Paramaribo: Kappler ed. Hohenacker n. 1668 (in h. Boiss.).

3. Piper medium Jacy. foliis modice petiolatis, superioribus ovato-ellipticis ellipticisve, basi aequilatera rotundatis vel basi ima acutis, apice longiuscule acuminatis acumine obtusiusculo mucronulatoque, supra glabris, subtus ad nerros puberulis, petiolo basi ima vaginante pedunculoque petiolum adultum aequante aut paullo superante puberulis; spicis densifloris, maturis quam folia paullo brevioribus, bracteae ovario proximae obovatae dorso villosulae vertice inflexo nudo; staminibus 4 -6; bacca glabra ovata.

Piper medium Jacq. Ic. var. I (1781) p. 2 t. 8 et Coll. I p. 141; Lam. Ill. p. 80; Tahl Enmm. I p. 330; Willd. Sp. I p. G0 et herb. n. GS1!; C. DC. Prodr. XVI, 1 p. 246 (excl. syn. I'. discolor Sw.).

Piper reticulatum Tell. Fl. Flum. I (1827) t. 61.

Piper ceanothifolium Kunth! in H. B. K. Nor. Gien. I (1815) p. 26 et Syn. I p. 111; C. DC. l. c. p. 247; Sum. Fl. Cub. n. 2232 p. 144; Duss! Fl. jhan. p. 177.

Piper orthostachyum Kunth in Limnaea XIII (1839) 1. 602; C. DC. l. c. p. 247.

Piper Tigerianum C.DC!. Prodr. l.c. (1869) 1.250 (qmoarl e Cuba). 
? Piper sammeides ITam. Pe. (1825) p. 3; C. DC. Prode: p. 375.

Piper Sieberi Kew liull.! 1893, p. 272, - uon C: DC.

Euchen plontoginea Kimth! in Limuea XIII (1839) p. 599; Miq..! Syst. p. 356 et in Limmaca XX p. 133.

Encken cennothifolia Kimuth! in Limnen XIII (1839) p. 597; Miq.! Syst. p. 337 et in Limnoea XX p. 133 et in Mart. Flor. Bras. $I T, 1$ p. 28 t. 2 fig. 2.

Encken orthostachyo Kimth! in Limaea XIII (1839) p. 601; Wiq.! Syst. p. 360, in Limmen XX p. 133, in Mart. Flor. Bras. l. c. Enclea Sieberi Griseb.! Flor. (1859) p. 170 (p. p.) et Cat. pl. Cub. p. 65 .

Higuillo de limon Port. ex Krrng et Sint., Quene de lézard Guad., Malimbé $v$. Queue de rat Mart. ex Dnss.

Frutex 4-8-pedalis, ramulis junioribus puberulis, spiciferis fere $1 / 1{ }_{2} \mathrm{~mm}$. crassis laevibus, collenchymate hand libriformi in fasciculos discretos disposito, fasciculis intramedullaribus 1 -seriatis sat numerosis, canali vacuo nullo. Folia inferiora basi cordata, superiora ut in diagnosi; limbi in sicco membranacei, creberrime et minute pellucido-punctati, reticulatonerrulosi, usque ad $11 \mathrm{~cm}$. longi et $5-6 \mathrm{~cm}$. lati; petioli superiores circ. $1 \mathrm{~cm}$. longi. Spicae florentes fere $6 \mathrm{~cm}$. longae et $1 \frac{1}{2}-2 \mathrm{~mm}$. crassae; rhachis hirtella. Stamina rlachi inserta, antheris reniformibus, filamenta aequantibus. Ovarium oblongum, summo apice stigmata 3 reflexa gerens. Bacca sessilis, apice stigmatibus crassiusculis oratis brevibusque coronata, fere $1 \frac{1}{2} \mathrm{~mm}$. longa.

Hab. in Cuba: Wright 11. 3678, Rugel n. 305 (in h. Griseb.), in silvis ad La Piedra $500 \mathrm{~m}$. alt.: Eggers n. 4760; Jamaica: Sloane (in herb. cum icone ined. n. 79), Murray n. 626 (in h. DC. et Kew), prope Toms River 160 m. alt.: Thompson n. 8049; Haiti: Poiteau, prope Gronaïves ad Ennery: W. Buch n. 113, Fonds des nègres secus viam ab Aquin ad Hiragoane, Corail ad viam d'Icaya: Picarda n. 960, 1342; Sto. Domingo prope Puerto-Plata juxta flumen Nameyes alt. $50 \mathrm{~m}$., in silva juxta flumen Bajabonico: Eggers n. 1626, 1703; Portorico prope Maricao circa habitationes, prope Cabo-Rojo in Monte Grande, prope Fajardo in silvis montanis, prope Hato-Grande in monte Gregorio, in silvis ad rivulum superiorem prope Cayey, prope Yabucoa in silva primaeva ad Jácana: Sintenis n. $296,296^{\mathrm{b}}, 955,1683^{\mathrm{b}}, 2365,2477,5266$, prope Mayagïez: Krug n. 978, Bañadero: Eggers, ad Cabo-Rojo: Heller: n. 4420; St. Thomas in silvis St. Peter, 300 m. alt.: Eggers ed. Toepff. n. 375 ; St. Jan 200 m.: Eggers n. 3091; St. Croix ad Bassin, Crequis: Ricksecker n. 189, 356; Guadeloupe: Bertero, Read, L'Herminier, Ravin de Basse-Terre, Trois Rivièrcs: Duss n. 2564 ${ }^{\mathrm{b}} ; 2564^{\mathrm{c}}$; Martinique: Hahn n. 264, in silvis regionis mediae vulgaris: Duss n. 1332; St. Vincent: H. H. et G. W. Smith n. 1922; ? Barbados in fruticetis: Eggers n. 7340; 
- praeterea in Mexico, silris Mirador alt. 1000 m., prope Oaxaca Galeotti n. 6018, 6014 (fid. Martens et Gal. Bull. Ac. Brux. X n. 2 p. 22), in silvis umbrosis pr. Colipa: Liebmann n. ‘2; Guatemala: Friedrichstahl n. 1815, 1644, Primavera, Depart. Sololá, alt. 760 pp.: Donnell Smith n. 775; Honduras San Pedro Sula, Depart. Santa Bárbara: 1. Smith: n.5461; Costarica Baie de Salinas, haies du Turalba, prope Sto. Domingo de Golfo Dulce: Pittięr n. 2924, 4111. 'Tunduz n. 9927; Sora Granata ad Bordones et Cumana: Humboldt in h. Willd. 11.688; Brasilia: Salzmann n. 623, Pohl n. 5020, Hartius n. 120s. Riedel n. 123, 688, in silvis Bahia: Martius, Rio de Janeiro: Gaudichaud n. 81, 84, Restinga de Gavea: Schwacke n. 1601, ald Corenvado: Lanosdorff 11. S4, S5. 98, Schwacke n. 4784, pror. Rio Negro ad Rio Parahiba: Martius; Paraguay in nemoribus prope Guarapi, in silvis Santa Barbara: Balansa n. 4536, 2628, ad Assumption: Norong n.692, Balansa n. 2320; Argentina in silvis Coloniae Resistentia, Norte pror. Corrientes: Spegazzini n. 11, Puerta de Tucuman: Lorentz et Hieronymus n. 960.

4. Piper Imalago Linn. foliis modice petiolatis, o basi inat aequilatera et acuta ovatis vel ovato-ellipticis, apice longiuseule acuminatis acumine acuto mucronulatoque, utrinque glabris, 5-7-nerviis, petiolo basi ima vaginante pedunculoque petiolum paullo superante glabris; spica limbum aequante rel eo paullo breviore densiflora glabra, bracteae ovario proximae obovato-subrotundae glabrae vertice inflexo; staminibus 5-6; bacca ovata glabra.

Piper Amalogo Limn. Sp. I ed. I (1753) p. 29, II ed. p. 11 (quood sym. Sloone); West Fl. St. Croix p. 268; Hill Dict. XXVI p. 17 fig. 17, 4; Sworts! Obs. p. 19 (h. Filld. ". Gs4); Vahl En. I p. 32s; Willd.! Sp. I p. 160 (excl. syn. Pluk.); C. DC. Prodr. XVI, 1 p. 248.

? Piper discolor Sw. Prodr. (1788) p. 15 et Flor. I p. 52.

Piper plantonginemm Lam. Ill. I (1791) p. 80.

Enclien Sieberi Miq. Syst. (1843) p. 358; Griseb.' Fl. It. Ind. p. 170 (p. p.) et I'eg. íar. p. 48.

Piper Sieberi C. DC. Prodr. XII, 1 (1869) p. 248 (excl. pl. Ring.).

Piper longmm arborem altins Sloane Cat. (1696) p. It et Hist. I p. 134 t. 87 fig. 1 et h. Sl. l. c.

Piper frutescens diffusmm ramis flexilibns genicnlatis etc. P. Browne Jam. (1756) p. 121.

Sommms foliis lanceolato-oiatis Limn. Hort. Cliff. p. 140 (excl. sym. Plum.).

Poivre ò épis läches Descomrt. Fl. méd. VI (182S) t. $12 \overline{7}$.

Frutex ramulis glabris, spiciferis in sicco $1 \frac{1}{2} \mathrm{~mm}$. crassis, collenchymate haud libriformi in fasciculos discretos disposito fasciculis intra- 
medullaribus 1 -scriatis canali racuo nullo. Limbi in siceo membranacei, subpellucidi, creberrime pellucido-punctati, $9-12 \mathrm{~cm}$. longi et $4-6 \mathrm{~cm}$. lati; petioli superiores adulti usque ad $1 \mathrm{~cm}$. longi. Peduneuli circiter $1 \frac{1}{2} \mathrm{~cm}$. longi; rhachis glabra. Stamina rhachi inserta, antheris reniformibus. Bacca vix $1 \frac{1}{2} \mathrm{~mm}$. longa, stigmatilus ovatis crassiusculis et brevibus coronata.

Hab. in Jamaica: P. Browne, swartz (in h. DC. et in h. Willd. n. 68t), Sloane, Distin, Alexander (in h. Kew), Millspaugh n. 1943; Ind. occ. rerisimiliter e Ste. Croix: West (in h. DC.); Dominica: Imray n. 351 (in h. Griseb. sub Enclea Sieberi); Martinique: Duss n. 12; St. Vincent in ralle prope Sandy Bay alt. $66-100$ m.: H. H. et G. W. Smith n. 219; Trinidad: Sieber n. 224.

5. Piper Wullschlaegelii C. DC. foliis breviter petiolatis subovato-lanceolatis, basi aequilatera vel parum inaequilatera acutis, apice attenuato-acuminatis acumine acuto, utrinque glabris, 5 -nerviis, petiolo basi vaginante pedunculoque petiolum paullo superante glabris; spica folium fere duplo superante densiflora, rhachi pubescente, bractea ovario proxima orato-subrotunda intus et dorso pubescente; ovario glabro.

Piper Wullschlaegelii C. DC. Prodr. XVI, 1 (1869) p. 249.

Enckea Amalago a. Griseb.! Fl. W. Ind. (1859) p. 169.

Frutex ramulis glabris, spiciferis per anthesin $1 / 2 \mathrm{~mm}$. crassis, in vetustioribus $2 \mathrm{~mm}$. crassis, collenchymate haud libriformi in fasciculos discretos disposito, fasciculis intramedullaribus 1 -seriatis $4-5$. Limbi in siceo rigidi opaci et minute pellucido-punctulati, $6 \mathrm{~cm}$. longi, $2 \mathrm{~cm}$. lati; petioli $4 \mathrm{~mm}$. longi. Stamina $5-6$ rhachi inserta. Baccae immaturae oblongo-ovatae subremotae. Stigmata 3 sessilia brevia et obtusa.

Hab. in Jamaica: Wullschlaegel (in lu. Monac.), prope St. Thomas i. E.: Wilson n. 637 (in h. Griseb.).

6. Piper unguiculatum Ruiz et Pav. foliis superioribus breviter petiolatis, oblongo-ovatis, basi rotundatis, ima basi leviter inaequilatera utrinque minute calloso-subauriculatis, superne attenuato-acuminatis, apice obtusiusculo et mucronulato, utrinque glabris, 5 -nerviis, petiolo basi ima vaginante pedunculoque petiolum superante glabris; spica quam folium fere $1 / 3$ breviore densiflora, rhachi puberula, bractea ovario proxima rotundata subcucullata basi extus hirtella intus glabra; staminibus 4-6; ovario ovato glabro; baccis sublaxis ovatis glabris vel rarissime puberulis.

Piper unguiculatum R. et Pav.! Fl. Per. I (1798) p. 34 t. 57 fig.b; Vahl En. I p. 331; C. DC. Prodr. IVI, 1 p. 249.

Piper terminale Kunth! in H. B. K. Nov. Gen. I (1815) p. 57.

Piper celtidifolium Ham. Prodr. (1825) p. 2; Desf. Cat. hort. Par. ed. 3 p. 414 . 
Piper dubinu A. Dietr. Sp. I (1831) p. 694.

Piper glancesccus Jacq. Ecl. (1S11) t. 76.

Piper pyrifolinm Opin! in Reliq. Hacnk, I (1830) p. 158.

Pipce Berteroamum C. DC. Prodr. l. c. (1869) p. 249.

Piper discolor Schlecht. in Limnuea $V$ (1830) p. 74 , - non Sw.

Piper Schlechtendalii Steud. Sourencl. II ed. II (18.1) 1. 343.

Encliea muguiculata K'mth! in Limuea XIII (1839) p. 592 ; Miq.! Syst. p. 352 .

Enckea glancescens Kunth in Limnaea XIII (1839) p. 5.94; Miq. Syst. p. 354 et in Hook. Lont. Journ. IV p. 4.4.

Euclica discolor Kunth! in Limaea l. c. p. 595; Wiq. Syst. p. 361.

Encliea Amalago a. Griseb.! Flor. (1859) p. 169 (excl. syu. Sloane).

Frutex usque ad $5 \mathrm{~m}$. altus, ramulis glabris, spiciferis circiter $1 \mathrm{~mm}$. crassis, collenchymate hand libriformi in fasciculos discretos disposito, fasciculis intramedullaribus 1 -seriatis 7 sat crassis. Limbi in sicco rigido-membranacei, subpellncidi et pellucido-punctulati, $6-9 \mathrm{~cm}$. longi, $2 \frac{1}{2}-4 \mathrm{~cm}$. lati, in ramulis sterilibus basi cordulati; petioli superiores circiter $5 \mathrm{~mm}$. longi. Pedunculi adulti usque ad $1 \frac{1}{2} \mathrm{~cm}$. longi. Stamina rhachi inserta, antheris ovatis filamenta paullo superantibus. Stigmata, 3 sessilia hrevissima et obtusa. Bacca cum stigmatibus hand reflexis $1 \frac{1}{2} \mathrm{~mm}$. longa.

Hab. in Jamaica: Bertero (in h. DC. et h. Berol.), Wilson n. 178 et Alexander (in h. Griseb.), ad Hope Tavern $200 \mathrm{~m}$. alt., in Yallahs Valley alt. 830 m.: W. Harris n. 6505, 6590, Blue Mount.: O. Hansen; Grand Cayman ad Spot Bay: Millspaugh n. 1299. - praeterea in Mexico, Columbia, Guyana, Peruria (vide: C. DC. Prodr. l. c., Hemsl. Biol. centr. am. III p. 59).

7. Piper Richardianum C. DC. foliis breviter petiolatis, ellipticolanceolatis, basi aequilatera subacutis, apice acuminatis acumine acuto, supra glabris, subtus praesertim ad nerros puberulis, 5-nerviis, petiolo basi ima vaginante pedunculoque petiolum duplo superante breviter hirtellis; spicis quam folia adulta paullo brevioribus, rhachi dense et pallicle hirtella, bractea orario proxima subrotundato-cucullata margine et basi dorso hirsuta; orario glabro; stigmatibus reflexis.

Piper Richardiamm C. DC. Prodr. XVI, 1 (1869) p. 249; Sauv. Fl. Cul. и. 2234 p. 1.t.

Enclea Amalago var. hirtella Griseb.! F\%. IT. Ind. (1859) p. 169.

Frutex humilis, ranulis hirtellis, spiciferis in siceo $1 \mathrm{~mm}$. crassis, in $1 \frac{1}{2} \mathrm{~mm}$. crassis collenchymate haud libriformi in fasciculos discretos disposito, fasciculis intramedullaribus 1 -seriatis 4 , canali vacuo nullo. Limbi in sieco membranacei subopaci, creberrime pellucido-punctulati, ad $8 \mathrm{~cm}$. longi et ad $4 \mathrm{~cm}$. lati; petioli fere $6 \mathrm{~mm}$. longi. Stamina 6 rhachi inserta, antheris reniformibus. Stigmata $3-4$ sessilia brevia et obtusa.

Hab. in Cuba: Wright n. 514; J amaica: March n. 1403.(h. Griseb.). 
8. Piper mananthum C. Wright, foliis breviter petiolatis, ovatolanceolatis, basi oblique truncato-rotundatis vel subcordatis, apice attemuato-acnminatis acumine mucronulato, supra glabris, subtus praecipue ad nervos puberulis, 5-nerviis, petiolo hasi raginante pedunculoquo petiolum multo superante puberulis; spica florente sat laxiflora, quam limbus paullo breriore, rhachi dense hirtella, bractea obovato-rotunda extus basi hirtella intus glabra; ovario glabro; stigmatibus reflexis.

Piper mananthum C. Wright in Sanv. Cub. (1871) n. 2235 p. 144.

Frutex divaricato-ramosus ramulis pubemlis, spiciferis in sicco fere $1 \mathrm{~mm}$. crassis, in $1 \frac{1}{2} \mathrm{~mm}$. crassis collenchymate hand libriformi in fasciculos discretos disposito, fasciculis intramedullaribus 1 -seriatis 3 . Limbi in siceo membranacei, minutissime pellncido-punctulati, ad $81 / 2 \mathrm{~cm}$. longi et ad $3 \frac{1}{2}$ cm. lati; petioli circiter $3 \mathrm{~mm}$. Iongi. Pedunculi per anthesin $12 \mathrm{~mm}$. longi. Stamina $4-5$, plerumque 4, rhachi inserta, antheris reniformibus. Stigmata 3 sessilia brevia et obtusa.

Hab. in Cuba prope Matanzas v. in Zarabanda: Wright s. n.

Obs. Species P. Kunthii C. DC. proxima.

9. Piper subpanduriforue C. DC. foliis breviter petiolatis, e basi obtusa inferme obovatis, superne inaequaliter trilobis, lobis lateralibus brevissimis obtusis, centrali longe lineari-acuminato acumine acuto, vel junioribus e basi ovata subito lineari acuminatis, omnibus utrinque glabris, 5-nerviis, petiolo basi ima vaginante pedunculoque petiolum paullo superante glabris; spica florente quam folium paullo breviore subdensiflora, rhachi dense puberula, bractea ovario proxima rotundata et subcucullata intus et basi extus dense puberula.

Enckea subpantmiformis Miq. in Limnaea XXVI (1853) p. 217.

Encliea Amalago nar. varifolia Griseb.! F7or. (1859) p. 169.

Piper panduratum C. DC. Prodr. IVI, 1 (1869) p. 250.

Frutex ramulis glabris in sicco nigrescentibus, spiciferis fere $1 / 2 \mathrm{~mm}$. crassis, in $1 \frac{1}{2} \mathrm{~mm}$. crassis collenchymate haud libriformi in fascieulos discretos disposito, fascicnlis intramedullaribus 1 -seriatis circiter 7 sat crassis. Limbi in sicco rigiduli opaci, minute pellucido-punctulati, $71 / 2 \mathrm{~cm}$. longi, sub lobis $1 \mathrm{~cm}$. lati, lobo centrali in medio $6 \mathrm{~mm}$. lato; petioli $5 \mathrm{~mm}$. longi. Stam ina $4-6$, rhachi inserta, antheris reniformibus filamenta superantibus. Ovarium ovatum glabrum. Stigmata 3 sessilia, brevia et obtusa.

Hab. in Jamaica: Wullschlaegel (in h. Monac., Berol., Griseb.).

Obs. Species quoad foliorum evolutionem P. tricuspe C. DC. (Artanthe tricuspis Miq.) in Seem. Bot. Herald p. 200 t. 42 a cl. Hiquelio descriptum ac figuratum referens, verisimiliter, ut illud, alius speciei (forsan $P$. unguiculati R. et Pav.) varietas.

10. Piper reticulatum L. foliis breviter petiolatis, superioribus e basi aequilatera cordata rotundatave late ovatis, apice acuminatis acumine acuto, utrinque glabris, 7-9-nerviis, petiolo basi ima raginante pedun- 
culoque petiolum paullo superante glabris; spica quam folium breviore densiflora apice acuminata, rhachi hirtella glandulosaque, bracteae parvae oblongo-spathulatae dorso hirtellae vertice minuto inflexo glabro triangulari-lunulato; bacea oborato-subquadrangula, superne relutina et in apice disco glabro orbiculari in medio stigmatifero coronata.

Piper reticulatmm Linn. Spec. I cd. I (1753) p. 29, II ed. p 11 (excl. syn. Piso et Maregr.); Hill Dict. TXIT p. 1S; Lam. Ill. t. So; Sw. Obs. p. 19?; Willd. Sp. I p. 162; Tahl En. I p. 330; C. DC. Prodi. IVI, 1 p. 295 (quoarl icon. Plum.).

Piper Duchassaingii C. DC. Proll. XII, 1 (1569) p. 251.

Piper smilacifolimm C. DC. l. c. p. 245 (quood sp. Antill.); Driss! Fl. phan. p. 175; - non H. B. K.! (h. Willd. n. 691 f. 1).

Encken reticulata Miq. Syst. (1843) 1). 365.

Enclien smilacifolia Griseb.! Fl. W. Irnd. (1859) p. 169 (excl. syn. Willd.) et Veg. Kar. p. 48.

Sommus botryitis major Plum. Descr. Pl. Am. (1693) p. 57 t. 75.

Frutex $3-4$-perlalis, ramulis glabris, longitudinaliter striolatis, spiciferis per anthesin in sicco $1 \mathrm{~mm}$. crassis, in $3 \mathrm{~mm}$. crassis collenchymate hand libriformi fasciculis intramedullarilus 1 -seriatis canali vacuo nullo. Limbi in sicco rigidi, subopaci, pellucido-punctulati, ad $27 \mathrm{~cm}$. longi et ad $16 \mathrm{~cm}$. lati, nervnlis primariis transverse parallelis; petioli $1 \frac{1}{2} \mathrm{~cm}$. longi. Spicae bacciferae in sicco flaridae ad $12 \mathrm{~cm}$. longae et cum baccis ar $5 \mathrm{~mm}$. crassae, apice acuminatae. Stamina 4 basi ima baccae adnata, antheris subglobosis parvis. Bacca \& $\mathrm{mm}$. longa et $1 \frac{1}{2} \mathrm{~mm}$. crassa, disco coriaceomembranaceo fere $1 \mathrm{~mm}$. diametro et in medio stigmata sessilia $3-5$, plerumque 3 , brevia et obtusa gerente.

Hab. in St. Eustache: Suringar; Guadeloupe: Duchassaing, West, Bertero, sparsim in ripis fluminis Galion, ad Houelmont ria ad Batterie: Duss n. 2834, 3411; Martinique: Duss n. 502, Piton de la Case Narire: Hahn n. 1112; St. Vincent: Anderson (in h. Kew); Trinidad: Purdie n. 524, Schack.

11. Piper marginatum Jacq. foliis longe petiolatis e basi aequilatera et cordata orato-rotundis, apice acuminatis acumine acuto, utrinque glabris, margine ciliolatis, $9-11$-nerviis vel nervis 3 centralibus paullo supra basin solutis, petiolo usque ad limbum vaginante pedunculoque quam petiolus dimidio vel plus breviore glabris; spica submatura limbum fere aequante funiformi apice mucromulata, bracteae pelta triangulari margine pedicelloque angusto hirsutis; bacea glabra.

Piper marginatum Jacq. Ic. rar. II (1786) p. 2 t.215, Collect. It p.128; C. DC. Prodr. X TI, 1 p. 245; Same. Fl. Cub. 1. 2231 p. 111.

Piper decumanum Anbl. Grian. I (1775) p. 21? (excl. syn. Maregr.); Willd. Sp. I p. 162; Tahl En. I p. 331 (excl. syn.); Kunth! in H. B. K. Nov. Gen. I p. 57 et Syn. I p. 112. 
Piper reticulatum Su: Obs. (1791) p. 19; - non Limn.

Piper candatum I'ahl Ecl. I (1796) p. 3 et Eutum. I p. 335.

Piper alare Ham. Irode. (1825) p. 3.

Schilloriu caudata Kmuth! in Limuaca XIII (1839) p.716; Griseb.! F7. W'. Ind. p. 170, rat. pl. Cub. p. 65.

Schilleria marginata Kunth! l.c. p. 718.

Artanthe candata Miq.! Syst. (1843) p. 380, in Hook. Lond. Journ. Bot. IV p. 433 et in Mart. Flor. Bras. IT. I p. 32.

Saumme frutescens fol. pluntog. etc. Plum. Descr. (1693) t. 76 . Anizillo Doming. ex Bert.; Higuillo oleroso Port. ex Sint.

Frutex ad 5-metralis. Ramuli glabri, spiciferi fere $2 \mathrm{~mm}$. crassi, collenchymate haud libriformi in fasciculos discretos in sectione transversali elongatos disposito, fasciculis intramedullaribus 2 -seriatis, canali vacuo nullo. Limbi in sicco firmule membranacei pellucido-punctulati $12-16 \mathrm{~cm}$. longi latique, nervulis transverse subparallelis; petioli usque ad $4 \mathrm{~cm}$. longi. Spicae submaturae fere $3 \mathrm{~mm}$. crassae. Stamina 4 ad basin baccae inserta, antheris rotundatis quam filamenta brevioribus. Bacca subtetragona. Stigmata 3 , sessilia linearia.

Hab. in Haiti prope Pétionville: Picarda n. 437b; Sto. Domingo prope Puerto-Plata ad ripan rivuli circa La Rosa alt. $100 \mathrm{~m}$.: Eggers n. 2481; Trinidad: Lockart (in h. Kew). - praeterea in Panama: Seemann n. 114, Sutton Hayes n. 741, ad Bahia Honda et communis circa Panama: Seemann n. 901, 902 (fid. Miq. in Seem. Bot. Herald p. 198); Surinam: Kegel n. 85 et n. 135 (fide Miq. in Linn. XXII p. 76); Guiana gallica prope Karouany: Sagot n. 533, ad Cayenne: h. Desv. (in h. Mus. Par.); Venezuela: Fendler n. 1142 (in h. DC.) et Moritz n. 1801 (h. Brit. Mus.), ad Caracas: Humboldt (in h. WVilld. n. 697); Ins. Salutis: herb. Lenormand; Brasilia, prope Santarem et Pará: Spruce n. 1 (in h. DC.), 3658, 733 (in h. Francav.), prope Pernambuco: Gardner n. 1828 (in h. Kew); Peruvia ad Chincao: fide Miq.

Var. $\beta$. anisatum C. DC. foliis supra ad nervos, subtus ad nervos et ad nervulos puberulis, spicis aromaticis.

Piper anisatum Kunth! in H. B. K. Nov. Gen. I (1815) p. 58; Opiz in Reliq. Haenk. I p. 161.

Piper narginatum B. catalpaefolium C. DC. Prode. IVI. I (1869) p. 246 (p. p.).

Artanthe catalpaefolia Miq. Syst. (1843) p. 382 (p.p.).

Hab. in Venezuela in ripa fluminis Orinoci prope Hato del Capuchino: Humboldt et Bonpland n. 1056 (in herb. Willd. n. 698).

Var. $\gamma$. catalpifolium C. DC. foliis supra appresse pilosis, subtus and nerros nervulosque pubescentibus.

Piper catalpacfolium. Kunth! l.c. (1815) p. 5 S. 
Artanthe catalpaefolia Miq. Syst. (1843) p. 382 (p.p.).

Piper marginatum $\beta$. catalpaefotim C. D)C. l. c. (p. p.).

Hab. in Trinidad: Hart n. 600s; - praeterea in Nora Granata in locis umbrosis pror. Cumana inter Cumanacoa et San Fernando, alt. 100 hexap.: Humboldt et Bonpland n. 375 (in herb. Willd. 1. 699).

Var. $\delta$. firmum C. DC. foliis glabris, basi et apice ut in specie, sed magis oratis ac multiplinerriis, nempe nervis 3 centralibus usque ad $1 \mathrm{~cm}$. supra basin solutis, spicis aromaticis.

Piper marginatum et a. firmum C. DC. l. c. (1869) p. 246.

Hab. in Cuba: Wright n. 2267 (in h. DC.), n. 2287? (fide Sauv. l. c.); Haiti: Poiteau, in Morne de l'Hôpital, ad Corail in via Icaja alt. circ. 1200 m., ad Pérodin alt. 1200 m.: Picarda n. 1060, 1344, 1629; Sto. Domingo: Bertero (in h. DC. et Berol.), prope Puerto-Plata ad Arroyo del Caballo circa Isabel de la Torre alt. $100 \mathrm{~m}$, in silva montis Isabel alt. $370 \mathrm{~m}$., prope Puerto-Plata in rupibus inter frutices litorales, in silvis juxta flumen Bajabonico, prope Batey ad ripam fluminis Yasica: Eggers n. 1558, 1573, 1673, 1705, 262s; Portorico, prope Bayamon in silvis montanis ad Pueblo-riejo, prope Aguadilla in silvis montanis ad Victoria, prope Manatí in fruticetis ad ripam fluminis: Sintenis n. 981, 5791, 6682, prope Quebradillas: Gundlach n. 986, prope Bayamon in umbrosis: Stahl 1). 277.

12. Piper caracasanum Bredem.?, foliis longiuscule petiolatis, oblongo-ellipticis, basi valde inaequilatera semi-cordatis, utrinque rotundatis lobo longiore petiolum velante, apice breviter acuminatis acumine obtusiusculo, supra glabris, subtus praesertim ad nerros nerrulosque puberulis, nervo centrali subtus prominente paullo ultra $1 / 2$ longitudinis suae nerros alternos utrinque 6 mittente, quorum inferiores 2 a basi soluti diraricantes superioresque 4 adscendentes, petiolo dorso puberulo usque ad limbi latus longius raginante.

Verisimillime Piper caracasamum Bredem.! (in h. Trilld. 21. 679); Link .Jahrb. I, 3 (1820) p. 61; Opis in Reliq. Haenk. I p. 155; C. DC. Prodr. XVI, 1 p. 306.

Steffensia? caracasana Kunth in Linnaea XIII (1S39) p. 664. Artanthe caracasana Miq.! Syst. (1S43) p. 398.

Arbor $3,3 \mathrm{~m}$. alta. Ramuli dense puberuli, in sicco fuscescentes, fere $5 \mathrm{~mm}$. crassi, collenchymate haud libriformi in fasciculos discretos disposito, fasciculis intramedullaribus 1 -seriatis, canali racno centrali. Limbi in sicco membranacei, minute pellucido-punctulati, fere $37 \mathrm{~cm}$. longi et $21 \mathrm{~cm}$. lati; petioli infra limbum $5 \mathrm{~cm}$. inter limbi latera $1 \mathrm{~cm}$. longi.

Hab. in Tobago in silris montanis juxta flumen Cremorne: Eggers n. 5860; - patria typi est Tenezuela. 
13. Piper ovatum Vahl, foliis brevissime petiolatis, ovato-ellipticis, basi ina brevissime inaequilatera cordulatis, apice acuminatis acumine acuto, utrinque glabris, nervo centrali e tota longitudine sua nervos patulos subrectos tenues ntrinque circiter 12 mittente, petiolo basi ima vaginante pedunculoque petiolum aequante glabris; spica baccifera quam folium 1/2 breviore, rhachi glabra parce fusco-punctulata, bractea parva spathulata apice inflexo-galeata, post anthesin a flore remota; flore pedicellato pedicello glabro; ovario ovato, apice in stilum brevem attenuato, stigmatibus minutis; bacea matura pedicello paullo longiore, elliptico-ovata, glabra, apice mucronulata.

Piper ocatum. Tahl! Eclog. (1796) p. 3 t.1, Emum. I p. $325 ;$ C. DC. Prods. ITI, 1 p. 253.

Ottomia Trahlii Kunth! in Limmaea XIII (1839) p. 585; Miq. Syst. p. 542; Griseb.! Fl. W. Ind. p. 172.

Frutex ramulis glabris, longitudinaliter leviter striolatis, spiciferis vix $2 \mathrm{~mm}$. crassis, collenchymate zona interua libriformi in fasciculos discretos disposito, fasciculis intramedullaribus 1 -seriatis 6 , canali vacuo nullo. Limbi in sicco membranacei, subpellucidi, indistincte pellucido-punctulati, circiter $14 \mathrm{~cm}$. longi et $6^{1 / 2} \mathrm{~cm}$. lati; petioli circiter $7 \mathrm{~mm}$. longi. Stamina 4. Bacca fere $1 \frac{1}{2} \mathrm{~mm}$. longa.

Hab. in Trinidad: Ryan (in herb. Vahl, herb. Willd. n. 651, herb. DC.), Fendler 11. 669 et Purdie (in h. Kew), in nemoribus ad Arima, Maraccas: ex Griseb. 1. c., in Tucker's Valley: Herb. Trin. 11. 5713.

14. Piper sphaerocarpum C. Wr. foliis parvis, brevissime petiolatis, ellipticis, basi ima aequilatera acutis rel acutiusculis, apice acutiusculis obtusisve utrinque glabris, nervo centrali e basi vel paullo supra basin nervos adscendentes utrinque 1 - 2 sub medio limbi per anastomoses evanidos et tota longitudine sua nervulos patulo-subadscendentes alternos circiter 12 mittente, petiolo basi vaginante pedunculoque petiolum pluries superante minute puberulis; spica folii dimidium fere aequante, bractea adulta cucullato-obovata dorso et margine puberula; ovario rotundato, stigmatibus brevibus obtusis; bacca globosa glabra.

Piper sphaerocarpum C. Wr. in Sauv. Cub. (1871) n. 2246 p. 145.

Ottonia sphaerocarpa Griseb.! Pl. Wr. (1860) p. 176 et Cat. p. 65. Piper sphaerostachyum C. DC. Prodr. XVI. I (1869) p. 326.

Frutex $2-5$-pedalis, ramis patentissimis glabris, ramulis junioribus minute puberulis, dein glabris, spiciferis tenuibus in sicco $1 / 5 \mathrm{~mm}$. crassis, in $1 \frac{1}{2} \mathrm{~mm}$. crassis collenchymate haud libriformi inaequaliter continuo, fasciculis intramedullaribus 1 -seriatis 5, canali vacuo nullo. Limbi in sicco membranacei glaucescentes, subpellucidi et crebro pellucido-punctulati, superiores circiter $6 \mathrm{~cm}$. longi et $27 \mathrm{~mm}$. lati, inferiores ad $7 \frac{1}{2} \mathrm{~cm}$. longi et ad $4 \mathrm{~cm}$. lati; petioli superiores fere $2 \mathrm{~mm}$. longi. Pedunculi circiter 12 um. longi; spicae bacciferae $2 \frac{1}{2} \mathrm{~cm}$. longae; rhachis minute puberula. 
Stamina 4, rhachi inserta, antheris rotunlato-ovatis, filamenta fere aequantibus, cadncis. Baccae fere ${ }^{1 / 2}$ mm. diametro, in sicco brunneac. Stigmata $3-4$, plerumque 4. - Planta odoren Myricacearum referens.

Hab. in Cuba: Wright 11. 271, 273, prope villam Jonte Terde dictam: Wright n. 495, in Nonte Libanon: Linden n. 1828.

Var. $\beta$. tenuifolium C. DC. 1. c. limbis tenuiorilus, superioribus ad $7 \mathrm{~cm}$. longis et ad $32 \mathrm{~nm}$. latis.

Ottonia sphaerocarpa iar. articuluta Griseb.! Cat. (1866) p. 65. Hab. in Cuba orientali prope Mata: Wright 11. 2272.

15. Piper ovale C. DC. foliis modice petiolatis, ovato-ellipticis, basi subaequilatera obtusis, apice acuminatis, utrinque glabris, nervis subtus prominulis centrali usque ad $1 / 2$ longitudinis suae nervos altermos adscendentes utrinque 6 mittente, petiolo usque ad $2 / 3$ longitudinis raginante glabro, pedunculo fere aequilongo, apicem rersus aureo-puberulo; spica cylindrica densitlora quam folium dimidio breviore, bracteae cucullatae dorso aureo-hirsutae vertice inflexo peltan simulante margine et postice longius aureo-hirsuto; bacca globosa glabra, stilo persistente mucronata.

Piper ovale C. DC. in Seem. Joum. of Bot. IV (1866) p. 166 et Prodr. III, 1 p. $261=$ ? P. exserens (Hiq.) C. $D C$.

Ramuli glabri, spiciferi $2 \mathrm{~mm}$. crassi, collenchymate continuo zona interna libriformi, fasciculis intramedullaribus 1 -seriatis, canali vacuo nullo. Limbi in sicco firmo-membranacei, minute pellucido-punctulati, 17 cur. longi, $9 \mathrm{~cm}$. lati; petioli $15 \mathrm{~mm}$. longi. Spica submatura, $9 \mathrm{~cm}$. longa, cum baccis fere $5 \mathrm{~mm}$. crassa; rhachis hirsuta. Stanina 4 basi baccae adnata. Stilus bacca brevior; stigmata 3 linearia recurva.

Hab. in Trinidad: Fendler n. 668 (in herb. Kew); - praeterea in Venezuela prope Tovar: Fendler n. 2398 (in h. DC.); Nova Granata in prov. Barbacoas: Triana n. 19.

16. Piper rigidum C. DC. foliis breviter petiolatis, anguste oblongis, basi sat inaequilatera utrinque acutiusculis, apice attenuatoacutis, supra ad nervum centralem, subtus ubique dense et breriter subcinereo-pubescentibus, nervo centrali tota longitudine sua nervos tenues subadscendentes utrinque $9-10$ nervulosque mittente, petiolo usque ad limbi latus brevius vaginante pedunculoque petiolum totum fere duplo superante; spica post antlıesin limbi dimidium fere aequante, rhachi hirtella, bracteae apice truncato-peltatae pelta lunulata margine pedicelloque lato subcinero-luirsutis; bacca glabra.

Piper rigidum C: DC. Prodr. XVI, 1 (1S69) 1). 264.

Piper Swartrianum Sauc. Fl. Cub. (1871) n. 2235 p. 141 (p.p.). Artanthe Suartriana Griseb. Cat. (1S66) p. 65. 
Ramuli dense subcinereo-pubescentes, spiciferi fere $1 \mathrm{~mm}$. crassi, collenchymate haud libriformi in fasciculos discretos disposito, fasciculis intramedullaribus 1 -seriatis 6 , canali racuo $n u l l o$. Limbi in sicco subcoriacei opaci, subtus subcinerascentes, circiter $9 \frac{1}{2} \mathrm{~cm}$. longi et $22 \mathrm{~mm}$. lati; petiolus infra limbum $4 \mathrm{~mm}$. et inter limbi latera $7 \mathrm{~mm}$. longus. Spica fere matura cum baccis $1 \frac{1}{2} \mathrm{~mm}$. crassa. Stamina 4 , basi ima baccae adnata. Bacca subtetragona angulis rotundatis. Stigmata 2 sessilia, brevia et obtusa.

Hab. in Cuba: Wright n. 2270 et uon 2271 (in h. DC.), n. 2269 (in h. Kew).

Var. p. Terdeanum C. DC. (11. var.) limbis basi utrinque obtusis, junioribus ut in specie, adultis utrinque glabris cinerascentibus et coriaceis, fere $11 \mathrm{~cm}$. longis et $3 \mathrm{~cm}$. latis.

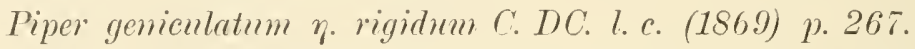

Piper Suartianum Sanv. Fl. Cub. (18r1) n. 2238 p. 144 (p. p.).

Hab. in Cuba orientali prope villam Monte Verde dictam: Wright n. 1418 .

17. Piper stamineum C. DC. foliis breviter petiolatis, lanceolatooblongis, basi inaequilatera utrinque acutis acutiusculisve, apice attenuatis obtusiusculisque. junioribus subtus minutissime puberulis, adultis utrinque glabris, nervo centrali fere tota longitudine sua nervos tenuissimos subpatulos utrinque 8-10 mittente, petiolo usque ad limbi latus brevius vaginante pedunculoque petiolum paullo superante glabris; spica matura quam limbus paullo breviore, apice mucromulata, bracteae pelta lunulata margine pallide hirsuta, pedicello denso hirsuto; bacca glabra, tetragona.

Artanthe staminea Miq.! in Hook. Lond. Jomm. IV (1845) p. 461; Walp. Aun. III p. 349.

Artanthe geniculata Griseb.! Cat. pl. Cmb. (1866) p. 65, - non Miq. Piper genicnlatm e. stamineum C. DC. Prodr. XVI (1869) p. 267. Piper geniculatm Samv. Fl. Cub. (1871) n. 2240 p. 144 (p.p.). Piper Swartiamm Sanx. Fl. Cnb. (1871) n. 2238 p. 144 (p. p.).

Rami vetustiores teretiusculi, valde crassi, cortice laevi albicante; ramuli glabri, teretes, lenticellosi, tenuiter striolati, spiciferi fere $1 \mathrm{~mm}$. crassi collenchymate haud libriformi in fasciculos discretos disposito, fasciculis intramedullaribus 1 -seriatis, canali vacuo nullo. Limbi in sicco subcoriacei, opaci, cinerascentes, fere $9 \mathrm{~cm}$. longi et $2 \frac{1}{2} \mathrm{~cm}$. lati; petioli infra limbum $2 \mathrm{~mm}$, inter limbi latera $5 \mathrm{~mm}$. longi. Spica submatura fere $1 \mathrm{~mm}$. crassa; rhachis glabra. Stamina 4 antheris ovato-rotundis exscrtis. Bacca secundum rhachin $1 / 4 \mathrm{~mm}$. longa, transverse $1 / 2 \mathrm{~mm}$. lata. Stigmata 3 sessilia linearia.

Hab. in Cuba orientali prope villam Monte Verde dictam: Wright n. 1417 (in h. DC.), 2271 (in h. Griseb. et Berol.), ad Rio Jipiro alt. $150 \mathrm{~m}$. (arbor $3 \mathrm{~m}$. alt., floribus albis): Eggers n. 5397; Jamaica in montibus ad Manchester: Purdie. 
Var. $\beta$. longifolium C. DC. (n. var.) limbis ad $15 \mathrm{~cm}$. longis et $2 \frac{1}{2}$ cul. latis, in sicco haud cinerascentibus, rigidis opacis, ramulis lenticellis parce conspersis.

Hab. in Cuba: Wright s. n. (in h. Berol.).

1S. Piper Swartzianum C. DC. foliis brevissime petiolatis, lanceolatis, basi valde inaequilatera utrinque obtusis, apice acuminatis sub)nucronulatisque, supra glabris, subtus sat dense et brevissime hirtellis, nervo centrali subtus prouinulo tota longitudine sua nerros $10-12$ tenues patulo-subadscendentes nervulosque utrinque mittente, pctiolo nsque ad limbi latus brevius raginante pedunculoque petiolnm totum aequante brevissime hirtellis; spica matura folium aequante, bracteao pelta triangulari nargine pedicelloque flavide hirsntis; hacca glabra tetragona.

Piper Suartianum C. DC. Prodr. XVI, 1 (1S69) p. 265 (exclus. syn. Griseb.).

Artanthe Suartriana Miq. Syst. (1814) p. 490.

Ramuli lenticellis conspersi, juniores puberuli, cito glabri et in sicco pallidi, spiciferi $1^{1 / 2} \mathrm{~mm}$. crassi, $3 \mathrm{~mm}$. crassi collenchymate sparse libriformi in fasciculos discretos disposito, peridermio sat crasso, fasciculis intramedullaribus 1 -seriatis 10 , canali vacno nullo. Limbi in sicco coriacei, opaci, ad $14^{1 / 2} \mathrm{~cm}$. longi et $4 \mathrm{~cm}$. lati; petioli infra limbum $2 \mathrm{~mm}$., inter limbi latera $7 \mathrm{~mm}$. longi. Spica matura $4 \mathrm{~mm}$. crassa. Stamina 4 rhachi inserta. Baccae densae secus rhachin, $1^{1 / 2} \mathrm{~mm}$. longae, transverse $1 \mathrm{~mm}$. Stigmata 3.

Hab. in Haiti: Poiteau (in li. Deless., Berol.); Portorico prope Peñuelas: Stahl n. 1000, prope Utuado ad Cayuco in silva primaeva montis Cerro Hueco: Sintenis n. 6570.

19. Piper tuberculatum Jacq. foliis petiolatis, oblique oratis vel orato-oblongis oblongisve, basi valde inaequilatera utrinque rotundatis, apice subacuminatis acntis, supra glabris, subtns ad nerros nerrulosque puberulis, nervo centrali subtus prominulo tota longitudiue sua nervos subpatulos subprominulos ntrinque $S-10$ ramulis validis intermixtos mittente, petiolo nsque ad limbi latus brevius raginante pedunculoque petiolum fere aequante puberulis; spica folium aequante vel superante, bracteae pelta triangulari subrhomboidalive margine pedicelloque cucullato hirsutis; bacca glabra.

Piper tuberculatum Jacq. Ic. rar. II (17S6) p. 2 t. 210, Collect. Ir p. 7; Tahl En. I p. 323; Kunth! in H. B. K. Nor: Gen. I p. 53 ct Syn. I p. 109; C. DC. Prodr. ITI, 1 p. 265; Saue. Fl. Cub. n. 2239 p. 144; Duss! Fl. phan. p. 176; O. Kitse. Rier. II p. 565.

Piper macroumum Kunth in H. B. K. Noc. Gen. I (1815) p. 5\%. Piper mutans Opia in Reliq. Hacnti. I (1830) p. 156 t. 28 fig. ? Steffensia tuberculata Kunth in Limnaere XIII (1839) p. 61.1. 
Artanthe tuberenlata Miq.!' Syst. (1841) p. 197 et in Mook. Lomel. Journ. IT p. 464 et in Limaea $\mathrm{XX}$ p. 163 et in Mart. Flor. Bras. II, 1 p. 54; Griseb. F7. W. Ind. 1\% 171.

Artanthe decurens Miq.! Syst. (1S44) p. 402.

Arbor circiter 16 -pedalis. Ramuli juniores puberuli, dein glabri, leviter striolati, laeves vel lenticellis verruculoso-tuberculati, spiciferi fere $1^{1 / 4} \mathrm{~mm}$. crassi; collenchymate haud libriformi in fasciculos discretos disposito, fasciculis intramedullaribus 1 -seriatis, canali vacuo nullo. Limbi in sicco membranacei, parcissime pellucido-punctulati, $7-14 \mathrm{~cm}$. longi, $4-6 \mathrm{~cm}$. lati; petioli infra limbum usque ad $7 \mathrm{~mm}$. et inter limbi latera ad $15 \mathrm{~mm}$. longi. Spica matura usque ad $4 \mathrm{~mm}$. crassa. Stamina 4 , ima baccae basi adnata, antheris reniformibus, quam filamenta paullo brevioribus. Baccae subtetragonac, inferne lateraliter subcompressae, apice rotundato-truncatae, secundum rhachin hand elongatae. Stigmata 3 sessilia brevia.

Hab. in Cuba prope Habana: Ossa (in l.. DC.); Jamaica: Bertero; Guadeloupe, in lort. Mazé ubi verisim. introductum: Duss n. 2831; Tobago prope Frenchfield in silvis interioribus juxta flumen Bacolet: Eggers n. 5558, 5692; Trinidad: Sieber n. 17, Lockhart et Schack (in h. Kew), O. Ktze. 1. c., herb. Trinid. n. 1308, 2235, 2236, 3520, 6009; praeterea per Americam intertropicam dispersa (rid. C. DC. Prodr. XVI, 1 p. 265, Bull. h. Boiss. V p. 698, VI p. 482, ser. 2 v. I p. 355 , Donn. Smith En. Part II et IV, Engler Bot. Jahrb. X p. 287, Dur. et Pitt. Primit. II p. 236).

20. Piper geniculatum Sw. foliis breviter petiolatis, lanceolatoovatis rel lanceolato-oblongis, basi valde inaequilatera utrinque obtusis vel latere longiore rotundatis rel utrinque rotundatis, apice acuminatis acumine obtusiusculo vel acuto, utrinque glabris, nervo centrali subtus prominulo fëre tota longitudine sua nervos subtus subprominulos adscendentim subpatulos nervulis validis intermixtos utrinque $\mathrm{S}-12$ mittente, petiolo usque ad limbi latus brevius vaginante pedunculoque petiolum totum subaequante glabris; spica matura quam folium breviore obtusa, bracteae pelta lunulata margine hirsuta pedicello lato; bacca glabra lateraliter compressa.

Piper geniculatum Sw.! Prodr: (17SS) p. 15, Fl. Ind. oce. I p. 57 et Ic. ined. t. 51 (ex U.b.); Tahl Eu. I p. 322; Willd.! Spec. I p. 163;

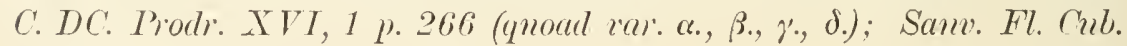
и. 2210 p. 114 (p.p.).

Piper macrophyllme Sur.! Prodi: (1788) p. 15, Fl. I p. 54; Tahl En. I p. 322; Willd. l. c.

Piper verucosum Su.! Prodr. (17SS) p. 15, Fl. I p. 56; Tahl l. c.; Willd.! l. c. (excl. syn. Sloane); A. Rich. in Sagra Cub. XI p. 227. Piper nitidum Sw.! Prodr. (1788) l.c., Fl. p. 58 et Ic. ined. t. 52 (ex Lrb.); Tuhl En. p. 31t (quoul sym. Sur); Willd. l. c. et herb. n. 633!' 
Piper nodulosum Link Enmu. I (1821) p. 36.

Piper lapathifolium C. DC. l. c. p. 323 (quond sp. Purlie).

Steffensia geniculata Kmuth! in Limmen IIII (1839) 1. G12.

Steffensia Luschnathiana I'muth! l. c. (1839) 1.616.

Steffensin xylopioides Kimth! l. c. (1839) p. 610.

Artanthe geniculate Miq.! Syst. (1844) 1.4.93, in Hook. Lond. .Journ. Bot. IV p. 463, in Nederl. Kimidk. I p. 222, in Limnaea X. p. 163, iu Mart. Flor. Bias. IV, 1 p. 53 t. 18 fig. 2.

Aitanthe Lnschuathiana Miq.! Syst. (18t4) p. 494, in Hook. Lond. Jonin. Bot. l. c. p. 463, in Limmaen 1. c. p. 163, in Mart. Flor. Bras. l. c. p. 53 t. 19 fig. 2.

Artanthe xylopioilles Miq.! Syst. (1841) 1. 492, Ill. p.78 t. 86, ill Mart. Fl. Bias. l. c. t. 18 fig. 2.

Artanthe xestophylla Miq.! Syst. (1811) 1). 491, in Hook. Lond. Jouru. l. c. p. 462 .

Artanthe verncosa Griseb.! Fl. W. Ind. (1859) 1. 171, Cat. pl. Cub. p. 65 .

Aitanthe macrophylla Griseb.! l. c. p. 171.

Piper longum arborenm fol. latiss. Sloane Cat. (1696) p. 45 et Ilist. I p. 135 tab. 88 fig. 1 et Coll. ic. in Bit. Mus. n. 84 (cum planta).

Frutex ant arbor $15-20$-pedalis, ramis ramulisque glabris longitudinaliter et leviter striolatis ac saepe albido-verucosis, nodis valde tumidis, ramulis spiciferis ad $3 \mathrm{~mm}$. crassis collenchymate haud libriformi in fasciculos discretos disposito, fasciculis intramedullaribus 1 -seriatis multis. Limbi in sicco firmi aut subcoriacei, opaci, epunctulati rel indistincte pellucido-punctulati, usque ad $25 \mathrm{~cm}$. longi et ad $12 \mathrm{~cm}$. lati; petioli infra limbum 2-6 mm., inter limbi latera $1-2 \mathrm{~cm}$. longi.

Variat ut sequitur:

a. limbis lanceolato-ovatis, basi utrinque sat rotundatis, apice breviter $\nabla$. brevissime acuminatis acumine obtusiusculo, usque ad $18 \mathrm{~cm}$. longis et $8-9 \mathrm{~cm}$. latis, in sicco firmis aut subcoriaceis, ramulis laevibus.

Piper macrophyllum et I. geniculatmm Sw. l.c.

Piper geniculatmu var, $\alpha, \gamma$ C. DC. l. c. (quoad spec. Sw.).

Piper longum arborem foliis latissimis Sloane l.c.

Hab. in Jamaica: Swartz (in h. DC. et Willd. n. 633 [juren.], 637), Wilson n. 664, Macfadyen, Purdie (in h. Kew cum ramulis primum atro-rubentibus dein albicantibus), Alexander (in h. Griseb.), ad St. Georges $660 \mathrm{~m}$ : alt.: W. Harris 11. 5569.

b. limbis lanceolato-ellipticis, basi utrinque sat late rotundatis latere longiore subauriculiformi, apice breviter et brevissime acuminatis acumine acutiusculo, usque ad $28 \mathrm{~cm}$. longis et ad $12 \mathrm{~cm}$. latis, in sicco coriaceis, ramulis lenticellis pallidis conspersis. 
Piper vervecosum Su.! l.c.

Piper yemiculatmu C. DC: rar. \& (quoar sp. Sw.).

Artanthe Lessertiana Mir. Syst. p. 105 (quoad sp. Willd.).

Hab. in Jamaica: Swartz (in h. Wilh. n. 638), Wullschlaegel (in h. Griseb. et lr. Krug et Urb.); - Brasilia prope San Gabriel da Cachoeira ad Rio Negro: Spruce 11. 2132.

c. limbis (nondum adultis) oblongo-lanceolatis, basi utrinque obtusis, apice acuminatis acumine acuto.

Piper geniculatm C. DC. l. c. (p.p.).

Hab. in Cuba: Wright n. 2269 (in h. DC.), in parte orientali prope Mata: Wright sine num. (in h. Griseb.).

d. limbis oblongo-lanceolatis, utrinque subacutis aut acutis, apice sat longe acuminatis acumine acuto, in sicco membranaceis, $14-20 \mathrm{~cm}$. longis, $4 \frac{1}{2}-5 \mathrm{~cm}$. latis, ramulis laeribus.

Piper genienlatum C. DC. et var. a (p.p.) l.c.

Artanthe genientata Miq. in Mart. Fl. Bras. l. c. t. 18.

Artanthe xylopioides Miq. 7. c. t. 18 fig. 2, Ill. t. 86.

Artanthe Lnschnathiana Miq. l. c. t. 19.

Hab. in Guiana anglica, Surinam, Tenezuela, Brasilia (vide C. DC. et Miq. 11. c.).

e. limbis lanceolato-oratis, utringue obtusis, apice sat longe acuminatis acumine acuto, in sicco firmis, $17 \mathrm{~cm}$. longis 7 cull latis, petiolo infra limbum vix $3 \mathrm{~mm}$. longo.

Piper geniculatmm var. ß. C. DC. l. c.

Hab. in Brasilia: Martius 11. 1205.

f. limbis basi utrinque acutis, apice acuminatis acumine acuto, usque ad $17 \mathrm{~cm}$. longis et ad $4 \mathrm{~cm}$. latis, ramulis primum atro-rubentibus, dein albicantibus.

Hab. in Trinidad: Schack, Lockhart (in h. Kew).

21. Piper subrectinerve C. DC. (u. sp.), foliis brevissime petiolatis, lanceolatis, basi leviter inaequilatera utrinque acutis, apice acute et sat longe acuminatis, supra scabridis, subtus praesertin ad nervos nervulosque adpresse pilosis, nervo centrali ad $1 / 2$ longitudinis suae nervos adscendentes subrectos utrinque $6-7$ mittente, petiolo basi ima raginante adpresse piloso; pedunculo subglabro petiolum totum multo superante, spica matura limbi dimidium paullo superante, bracteae pelta triangulari margine pedicelloque angusto et rhachi hirsutis; bacca hilsuta.

Frutex 8-10-pedalis. Ramuli juniores adpresse pilosi, dein glabrati, spiciferi $2 \mathrm{~mm}$. crassi collenchymate in faseiculos discretos zona in- 
terna libriformes disposito, lasciculis intranedullaribus 1 -seriatis canalibus vacuis nullis. Limbi in sicco membranacei, creberrime pellucido-punctulati, ad 18 cm. longi et ad $4^{1}$. cm. lati, juniores supra pilosi, dein pilis delapsis scabridi; petioli infra limbum usque ad $5 \mathrm{~mm}$. et inter limbi latera ad $4 \mathrm{~mm}$. longi. Pedunculi $2^{\prime}{ }_{2} \mathrm{~cm}$. longi; spicae maturae fere $12 \% \mathrm{~cm}$. longae et $3 \frac{1}{2} \mathrm{~mm}$. crassae. Stamina 4, rhachi inserta, antheris suluglobosis quam filamenta adulta pluries brevioribus. Orarium hirsutum. Bacca tetragona. Stigmata 3 sessilia linearia.

Hab. in St. Vincent in silva montis Soufriere: Eggers 11. 6924, in montibus St. Andrews: Eggers 11. 6736.

22. Piper Scitzii C. DC. (n. sp.) foliis brevissime petiolatis, oblongo-lanceolatis, basi leviter inaequilatera utrinque subacutis, apice longe acuminatis acumine acutissimo, utrinque laand dense appresse pilosulis, nervo centrali usque ad $1 / 3-1 / 2$ longitudinis suae nerros adscendentes alternos utrinque 4 mittente, petiolo basi ima vaginante pedumeuloque petiolum paullo superante appresse et parce pilosulis; spica florente quam folii limbus fere triplo breviore, apice obtusa, bracteae pelta triangulari margine pedicelloque augusto dense hirsutis; ovario glabro.

Frutex $6-9$ ped. altus. Ramuli juniores adprosse pilosuli, spiciferi fere $2 \mathrm{~mm}$. crassi, collenchrmate in fasciculos discretos libriformes disposito, fasciculis intramedullaribus 1 -seriatis, canali vacuo nullo. Limbi in siceo membranacei, minute pellucido-punctulati, ad $19 \mathrm{~cm}$. longi et ad $6 \frac{1}{2} \mathrm{~cm}$. lati; petioli ad limbi latus longius rix $5 \mathrm{~mm}$, inter limbi latera $5 \mathrm{~mm}$. longi. Pedunculi fere $8 \mathrm{~mm}$. longi; spicas in rivo erectae ut candelae et albescentes, in sicco flarescentes et florentes $2 \mathrm{~mm}$. crassae. Antherae subglobosae quam filamenta multo breviores. Stigmata 3 sessilia linearia. Bacca ignota.

Hab. in Tobago ad Kings Bay, 60 m. alt. in silvis: Seitz n. 48.

29. Piper citrifolium Lam. foliis brevissime petiolatis, elliptico- r. subovato-lanceolatis, basi leviter inaequilatera obtusis vel subacutis apice Jonge et suboblique acuminatis acumine acuto, supra glabris nitidulis, subtus praesertim ad nervos nervulosque hirtellis, nervis subtus prominulis, centrali paullo ultra $1 / 2$ longitudinis suae nerros alternos adscendentes utrinque 4-5 mittente, petiolo fere usque ad 1/2 longitudinis vaginante hirsuto; pedunculo quam petiolus breviore adulto glabro, spica quam folium adultum $3-4$-plo breviore mucronata, bracteate coriaceae rertice triangulari-Iunulato maryine pedicelloque sat late inter baccas producto, extus rubiginoso-hirsutis; bacea subtetragona, vertice rotundato rubiginoso-pubescente.

Piper eitrifolimm Iam. III. I (1791) p. SO (tesite Desfont. in h. Willd. и. 63t); C. Dr: Prodr. XTI, 1 1. 270.

Piper rugosum Vahl Ein. I (1SOL) 1). 31s. 
Jiper Jacquemontionmm Kumth! in Limaco XIII (1539) 1).63I. I'iper IIyllerinnmm C. DC. Prods: XVI, 1 (1S69) 1. 280. Steffensio Jarenemontiana Kunth! in Limmea XIIJ (1839) p. 631. Artanthe Jocquemontiomn Miq.! Syst. (18t4) p. 463.

Artanthe trichostachya Miq. Syst. (1811) 1. 188. Artanthe Wydlleriana Miq.! Syst. (1814) 1. 487. Artanthe ingosn Giriseb. H7. W. Ind. (1S.59) p. 171 (non Miq.). Jaboramdi sp. quarta arborescens Piso Hist. nat. med. ed. 1658 p. $216 \mathrm{cmm}$ iconc.

Frutex, ramnlis hirtellis et minnte verruculosis, spiciferis fere $2^{1 / 2} \mathrm{~mm}$. crassis, collenchymate zona interna libriformi in fasciculos discretos transverse elongatos disposito vel subcontinuo, fasciculis intramedullaribus 1 -seriatis, canali vacuo mullo. Limbi in siceo rigiduli, minute pellucido-punctulati, $12-21 \mathrm{~cm}$. longi, $5-7 \frac{1}{2} \mathrm{~cm}$. lati; petioli circiter $5 \mathrm{~mm}$. longi. Spicae rectae, maturae $4-5 \mathrm{~cm}$. longae et fere $4 \mathrm{~mm}$. 'rassae. Stamina 4 , basi ima baccae adnata, antheris ovato-rotundis. Bacca subtetragona vertice rotundata. Stigmata 3 sessilia, oblonga, apice obtusa.

Hab. in Haiti: Jacquemont, Poiteau (in h. Berol.), h. Willd. n. 634 (ded. Desf.), Fontaine de Marquisant prope Port-au-Prince in umbrosis: Jacquemont (in herb. Kew), prope Corail alt. circ. $1200 \mathrm{~m}$., prope Jérémie ad viam Bordes: Picarda n. 81, 1345, 1346; Sto. Domingo prope Samaná in praeruptis silvarum solo argillaceo alt. $50 \mathrm{~m}$., prope PuertoPlata in declivibus silvaticis montis Isabel de la Torre alt. $150 \mathrm{~m}$., prope Jarabacoa ad La Hagua alt. 600 11., ad ripam fluminis Mameyes alt. 150 m.: Eggers 17. 1501, 1564, 2080, 2539; Portorico: Blauner (in h. DC.), Bertero (in h. Berol.), Wydler n. 321 (in h. Deless.), prope Jayagüez alt. 10 ped.: Heller n. 4440, prope Cabo-Rojo in Monte Grande et ad rivulos, prope Fajardo in silvis montanis, in Sierra de Luquillo in regione media montis Jimenes locis humidis, prope Hato-Grande juxta rivulum in Monte Gregorio, inter Yabucoa et Maunabo ad La Pandura in saxis graniticis, prope Aguadilla in silvis montanis ad Victoria: Sintenis n. $462^{\mathrm{e}}, 873^{\mathrm{c}}, 955^{\mathrm{b}}, 1683$, 2.626, 5060, 5787, in Cerro de la Pandura in silvis $500 \mathrm{~m}$., Sierra de Luquillo ad Bañadero in silvis et fruticetis altis: Egger's ed. Toepff. n. 473, 972, ıb. pr. n. 1163 (in h. Kew, cum limbis basi aequilateris acutis aut subacutis); - praeterea Ruatan ins. Bay of Honduras: G. F. Gaumer (in h. Kew); Mexico: Liebmann n. 151 (in h. Cand.); Guyana anglica: Schomburgk n. 1185 (in h. Boiss.).

\section{Piper Ledebourii C. DC. Prodr. XVI, 1 (1869) p. 281.}

Hab. in Brasilia (C. DC. 1. c.).

Var. $\beta$. jamaicense C. DC. (n. var.), foliis breviter petiolatis, oblongo-ellipticis, basi leviter inaequilatera utrinque acutis, apice acumi- 
uatis acumine obtusiusculo, supra glabris, subtus at nerros nerrulosque appresse et parce pilosulis, nervis subtus prominulis, centrali fere usque ad $1 / 2$ longitudinis suae nervos alternos adscendentes utrinque 5 mittente, petiolo basi ima raginante pedunculoque quam petiolus totus breviore glabris; spica quam folii limbus paullo breviore apice mucronulata, bracteae pelta lunulata margine pedicelloque angusto dense et pallide hirtellis; ovario glabro.

\section{Piper Ledebourii C. DC. in Eugl. Jnhrl. X (1889) 1. 28 .}

Frutex 2 m. altus. Ramuli glabri laeves, spiciferi fere $2 \mathrm{~mm}$. crassi collenclymate zona interna libriformi in fasciculos discretos disposito, fascicnlis intramedullaribus 1 -seriatis canali racno centrali. Limbi in viro obsemre virides, in sicco rigidi, opaci, parce pellncido-pmuctulati, circiter usque ad $13 \mathrm{~cm}$. longi et $5 \mathrm{~cm}$. lati: petioli infra limbum $5 \mathrm{~mm}$., inter limbi latera fere $3 \mathrm{~mm}$. longi. Pedunculi $5 \mathrm{~mm}$. longi; spicae maturae fere $2 \mathrm{~mm}$. crassae. Stamina 4, basi ima ovarii adnata, antheris rotundatis, quam filamenta fere duplo brevioribus. Stigmata sessilia 3 linearia.

Hab. in Jamaica in montibus supra Kingston alt. $150 \mathrm{~m}$.: Lehmann 1 . 979 .

25. Piper Schackii C. DC. foliis 'modice petiolatis, basi aequilateris, inferioribus late ovatis, basi lato-rotundatis, apice oblique acuminatis acumine acuto, superioribus ellipticis, basi subacutis, apice acuminatis acumine acuto, omnibus utrinque glabris, nervo centrali subtus prominulo fere usque ad $1 / 2$ longitudinis suae nervos alternos patuloadscendentes utrinque $3-4$ nervulosque validos mittente, petiolo basi ima raginante pedunculoque quam petiolus duplo breviore, glabris; spica subflorente limbi dimidium vix aequante haud mucronata, bracteae pelta triangulari-lunulata margine ciliolata; ovario basi villosulo.

Piper Schackii C. DC. Prodr. TVI, 1 (1869) p. 288.

Altanthe Schackii Miq.! in Hook. Lond. Joum. IV (1815) p. t18.

Lrtruthe cornscans Griseb. Fl. W. Ind. (1559) p. 171, - nou Miq.

Ramuli glabri. Limbi in siceo membranacei pellucido-punctulati, superiores $17 \mathrm{~cm}$. longi et fere $8 \mathrm{~cm}$. lati; petioli superiores fere $15 \mathrm{~mm}$. longi. Spica subflorens fere $1 \frac{1}{2} \mathrm{~mm}$. crassa. Stamina 4 .

Hab. in Trinidad: Schack (in h. Kew).

26. Piper hebecarpun C. DC. (n. sp.) foliis brevissime petiolatis, oblongo-lanceolotis, hasi leviter inaequilatera utrinque acutis vel altero latere obtusis, apice longe acuminatis, supra glabris, subtus ad nervos nervulosque hirsutis, nervo centrali nerros adscendentes fere usque ad $1 / 2$ longitudinis suae utrinque 5 - 6 mittente, petiolo hirsuto basi ima vaginante; pedunculo subglabro petiolum multo superante, spica submatura limbi dimidium fere aequante, ipice obtusa, bracteae vertice mitriformi carnoso et glabro, pedicello brevi dense hirsuto; bacea lirtella. 
Piper citrifolimm Duss! F7. phan. (1897) 1\%.178, - non Lam.

Ramuli juniores hirtelli, spiciferi circitcr 2 mm. crassi, collenchymate in fasciculos discretos zona interna libriformes disposito, fasciculis intramedullaribus 1 -seriatis. Limbi in siceo membranacei creberrime pellucidopunctulati, circiter $15 \mathrm{~cm}$. longi et $4 \mathrm{~cm}$. lati; petioli $5 \mathrm{~mm}$., pelunculi $15 \mathrm{~mm}$. longi. Spicae submaturae fere $2 \mathrm{~mm}$. crassae; rlachis glabra. Stamina 4, rhachi ad basin baceae inserta, antheris globosis, quam filamenta multo brevioribus et exsertis. Bacea sultetragona. Stigmata 3 sessilia.

Hab. in Martinique in silvis humidis: Duss n. 18, 1334.

27. Piper aduncum Linn. foliis breviter petiolatis, oblongoellipticis, basi plus minusre inaequilatera utrinque rotundatis cordulatisve vel latere minore acutis majore rotundatis, apice sat longe acumiuatis acumine acuto, supra scabris, subtus praesertim ad nervos appresse pilosis et saepe ciliolatis, nerro centrali subtus prominente fere usque ad $1 / 2$ longitudinis suae nervos adscendentes alteruos utrinque $6-7$ subtus prominulos mittente, petiolo basi ima vaginante utriuque hirtello; pedunculo puberulo adulto petiolum totum duplo et plus superante, spica matura quam folii limbus paullo breviore, mucronata plus minus uncinata, bracteae pelta triangulari pedicelloque angusto fusce vel flavide hirsutis; bacca glabra.

Piper aduncum L.! Sp. I ed. I (1753) p. 29 et II ed. p. 41; Hill Dict. p. 18 t. 18 f. 2; Jacq.! icon. rar. II t. 210; Aubl. Hist. I p. 21; Willd. Sp. I p. 163; Tahl En. I p. 319; Opir in Reliq. Haenli. I p. 154: I'ell. Fl. flum. t. 60; C. DC. Piodr. XTI, 1 p. 285.

Piper scabrum Lam. Ill. (1791) p. SO.

Piper celtidifolium Irmth! in H. B. K. Nov. Gen. I (1815) p. 50 et Synops. I p. 106 (h. Willd. n. 664).

Steffensia adunea Kunth! in Linnaea IIII (1839) p. 633.

Steffensia celtidifolia Kmuth! in Limaea l. c. (1839) p. 635.

Lrtanthe adunca Miq.! Comm. phyt. (183S) p. 19 t. 1 f. 1, Syst. 1. 119, in Mart. Flor. Bras. IV, 1 p. 46 t. $1 \pm$ fig. 2, in Nederl. Truidl. I p. 222; Griseb.! Fl. W. Ind. p. 171.

Irtanthe celtidifolia Miq.! Syst. (1811) p. 152.

Artanthe Velloriana Miq.! in. Limnaea XX (1847) p. 155, in Mart. Hilor. Bras. l. c. p. 44, in Hook. Lond. Jomru. Bot. IT p. 456.

Samrums arbor. fr. adunco Plum. Descr. (1693) p. 59 t. 77.

Piper longum fol. nerv. Sloane Cat. (1696) p. 44 et Hist. I p. 135 t. 87 f. 2.

Poivrier à fruit crochu Descont. Fl. Ant. III p. 355 t. 230 ; Higuillo oloroso Portor. ex Krry.

Frutex ramosus. Ramuli nodosi juniores lirsuti, postea glabri et subscalıri, spiciferi fere $2 \mathrm{~mm}$. crassi, collenchymate zona interna libriformi 
in fasciculos discretos disposito, fasciculis intramedullaribus 1 -seriatis, canali vacuo nullo. Limbi in sicco rigido-membranacei, pellucido-punctulati, juniores supra appresse pilosuli, dein pilorum hasibus persistentibus scabri, $17-20 \mathrm{~cm}$. longi, $7-8 \mathrm{~cm}$. lati; petioli infra limbum $2^{1 / 2} \mathrm{~mm}$., inter limbi latera $2 \mathrm{~mm}$. longi. Spica matura fere $2 \mathrm{~mm}$. crassa. mucrone $1 \mathrm{~mm}$. longo pubernlo. Stamina 4, basi ima baccae adnata, antheris parris snbglobosis. Bacca tetragona. Stigmata 3 sessilia linearia cito decidua.

Hab. in Cuba ad El Sigual in silvestribus (arbor $4 \mathrm{~m}$. alt.): Eggers n. 4654; Jamaica: Swartz et Murray n. 367, 603, 60t (in l.. DC.), ad Hope 200 m. alt.: E. Campbell n. 6431, prope Port Morant: Hitchc. Bah. p. 123; Haiti: Picarda n. 970, Jacquin in lı. Willd. n. 663; Sto. Domingo: Mayerloff n. 340, prope Samaná in fruticetis et silvis: Eggers n. 1503; Portorico: Wydler n. 261 et Bertero (in li. DC.), O. Ktz. (Rer. II p. 564), prope Mayagiez: Krug n. 981, Heller n. 4357 (hb. Deless.), in silvis Cerro de la Pandura $600 \mathrm{~m}$. alt. prope Jaunabo: Eggers ed. Toepff. 11. 472, hb. propr. n. 669, prope Mayagüez in humidis umbrosis ad Boquillas versus, prope Lares in fruticetis circa carernam Pajita: Sintenis n. 118, 6026; Grenada in montibus (parra arbor): W. E. Broadway 11. 572, in silvis montis Feliz, alt. $530 \mathrm{~m}$. (arbor 16 ped. alt.): Eggers n. 6086; Barbados: ex Mayc. Fl. p. 39; Trinidad: Lockhart, Crueger (in h. Kew), Sieber n. 259 (in l. DC.): - praeterea late per Americam intertropicalem dispersa (vid. C. DC. Prodr. XVI, 1 p. 285, Bull. hrb. Boiss. V p. 698 , VI p. 483 , in Dur. et Pitt. Primit. I p. 108, II p. 237, in Donn. Sm. En. part II p. 65, IV p. 131).

Form. b. ramulis junioribus villosis et limbis subtus ubique adpresse hirsutis, P. angustifolium $\beta$. Ossanum referens, tantum villositate breviore ab eo discrepans.

Hab. in Tobago in silva montana juxta Hope River, alt. $200 \mathrm{~m}$., (arbor 16'alta): Eggers 11. 5610; T'rinidad: Fendler 11. 666 (in l. Kew), ad Belmonte: Herb. Trinidad in. 5552.

2S. Piper angustifolium R. et Par.! Fl. Per. I p. 39 t. $57 \mathrm{f}$. a var. $\beta$. Ossanum C. DC. foliis brevissime petiolatis, elliptico-lanceolatis, basi inaequilatera utrinque rotundatis et cordulatis latere longiore subauriculiformi, apice sat longe acuminatis acumine acuto, supra scabris, subtus appresse villosis, nerro centrali subtus prominente fere usque ad $1 / 2$ longitudinis suae nerros adscendentes alternos subtus prominulos utrinque 7 mittente, petiolo basi ima vaginante pedunculoque petiolum totum fere duplo superante rillosis; spica quan folii limbus laud multo breviore, apice mucronulata, bracteae pelta triangulari margine pedicelloque angusto villosis; bacea juniore liirtella dein glabra.

Piper angustifolium $\beta$. Ossanum C. IVC. Prodr. XVI, 1 p. $2 S 6$.

Piper angustifolium a. cordulatum forma I C. DC. l. c. 
I"iper angustifolimm same. 1\%. (Yub. (1871) 11. 2213 p. 145.

? Jijer linguaefolimm Ham. Prodr. (1525) 1. 3; 1. Dielr. Sp. I 1. $636 ;$ C. DC. l. e. p. 375.

? Piper Inncifolimm Ham. Prodr. (1S25) 1. 3; C.DCY. l. c.

? Artanthe linguaefolia Miq. Syst. (1844) p. 533.

? Artanthe lancenta Miq. l. c. p. 526 .

Platanillo de monte Cub. ex Egg.

Frutex ramulis dense villosis, spiciferis fere $3 \mathrm{~mm}$. crassis, collenchymate zona interna libriformi in fasciculos discretos disposito, fasciculis intramedullaribus 1 -seriatis canali vacuo nullo. Limbi in siceo rigidi pellucido-punctulati, juniores supra appresse pilosi, dein pilorun basibus persistentibus verruculoso-scabri, adulti usque ad $16 \mathrm{~cm}$. longi et $6 \mathrm{~cm}$. lati; petioli infra limbum $3 \mathrm{~mm}$, inter limbi latera $2 \mathrm{~mm}$. longi. Spicae plus minus uncinatac, fere matmae $2 \mathrm{~mm}$. crassac. Stamina 4 , basi ima baccae adnata, antheris parvis reniformibus. Bacca subtetragona. Stigmata 3 sessilia linearia.

Hab. in Cuba: Ossa 1. 288, Sagra (in h. DC.), Wright n. 3676 (in h. Kr. et Urb.), prope La Piedra $500 \mathrm{~m}$. alt. in sylvestribus: Eggers n. 4760, prope Matanzas: Kugel n. 214; ?Sto. Domingo: Ham. l. c.

29. Piper confusum C. DC. foliis breviter petiolatis, ellipticolanceolatis, basi inaequilatera utrinque rotundatis, apice acuminatis acumine acuto, supra scabris saepe bullatis et verruculis albidis obsitis aetate laevigatis, subtus ad nervos nervulosque pilosis, centrali nervo subtus prominente, fere usque ar $1 / 2$ longitudinis suae nervos subadscendentes alternos subtus prominulos utrinque 5 mittente, petiolo basi vaginante pedunculoque petiolum totum 2-3-plo superante hirsutis; spica quam folii limbus paullo breviore mucronulata, bracteae pelta triangulari-lunulata margine hirsuta, pedicello angusto subglabro; bacca glabra.

Piper confusum C. DC. in Seem. Jomm. IV (1S66) p. 211 et Prods. IVI, 1 p. 270 ; Same. Fl. Cub. n. 2241 p. 145.

Artanthe admea Griscb.! Pl. Wr. (1860) p. 176 et Cat. p. 65.

Ramuli dense hirsuti, spiciferi fere $2 \mathrm{~mm}$. crassi collenchymate subcontinuo libriformi, fasciculis intramedullaribus 1 . seriatis canali vacuo nullo. Limbi in sicco rigidi opaci pellucido-punctulati $9-12 \mathrm{~cm}$. longi $4 \frac{1}{2}-5 \mathrm{~cm}$. lati; petioli infra limbum vix ad $3 \mathrm{~mm}$., inter limbi bases $5 \mathrm{~mm}$. longi. Spicae fere maturae $7 \frac{1}{2} \mathrm{~cm}$. longae, $2 \mathrm{~mm}$. crassae. Stamina $t$, basi ima baccae aduata, antheris ovatis parvis, quam filamenta fere triplo brevioribus. Stigmata sessilia 3 linearia.

Hab. in Cuba orientali prope Nonte Verde: Wright n. 494, 773.

Var. $\beta$. prendanum C. DC. (n. var.) ramulis et foliis brevius et parcius hirsutis, limbis latere breviore acutis aut subacutis, petiolis infra limbum fore $8 \mathrm{~mm}$. longis. Frutex $2 \mathrm{~m}$, altus.

Hab. in Cuba ad La Prenda alt. 800 m.: Eggers 11. 5255. 
30. Piper hispirlum Sw. foliis breriter petiolatis, elliptico-lanceolatis, basi modice inaequilatera rotundatis vel obtusis, apice longiuscule verruculoso-scabris, subtus ad nervos et nervulos appresse hirtellis, nerFo centrali subtus prominulo fere usque ad $1 / 2$ longitudinis suae nervos adscendentes subtus subprominulos leviter arcuatos utrinque $5-6$ alternos mittente, petiolo basi ima raginante pedunculoque petiolum totum aequante vel paullo superante hirsutis; spica matura quam folium breviore apice mucronulata, bracteae apice peltatae pelta triangularilumulata margine hirsuta; bacca apice plus minus pubescente.

Piper hispidum Su.! Prodr. (1788) p. 15 et Ic. ined. t. 53 (extib.).

Piper hirsutmm Su:! F7. Ind. oce. I (1797) p. 60; Tahl Enmm. I p. 323; Willd. S1. I p. 163; C. DC. Prodr. XVI, 1 p. 276; Duss Fl. phan. p. 176.

Piper scabrum Su. F\%. I (1797) p. 59 et Ic. imed. t.54 (cx Uib.).

Piper bullatum Vahl En. I (1801) p. 313 (excl. syn. Lam.).

Piper hirsutum ;. jamaicense C. DC. (1869) l.c.

Steffensia hirsuta Kmuth! in Limmea XIII (1539) p. 611.

Steffensia scabra Kunth! 1. c. (1839) p. 640.

Artanthe hirsuta Miq.! Syst. (1S14) p. 116 et in Hooli. Lond. Jomrn. IV p. 156 .

Artanthe scabra Miq.! Syst. (181t) p. 147 et in Hook. Lond. Jomm. l. c.; Griseb.! Fl. W. Ind. p. 171.

Artanthe aspera Miq.! in Hook. Lond. Jomm. IV (1845) p. 456. Artanthe Olfersiana Miq.! in Limnaea $\mathrm{XX}$ (1847) p. 156 et in Mart. Flor. Bras. IV p. 16.

Anisete Doming. ex Egg.; Higuillo oloroso Port. ex Krng; Iatico Martin. ex Plée.

Frutex 6-10 m. altus ramosus. Ramuli hirsuti et postea rerruculoso-scabri, spiciferi fere $1 \frac{1}{2} \mathrm{~mm}$. crassi, collenchymate zona interna libriformi in fasciculos discretos disposito, fisciculis intramedullaribus 1 -seriatis, canali vacuo nullo. Limbi in siceo membranacei, crebre pellicido-punctulati, $12-19 \mathrm{~cm}$. longi, $6-11 \mathrm{~cm}$. lati, juniores supra adpresse pilosuli, dein pilorum basibus persistentibus verrucoso-scabris; petioli infra limbun $5-10 \mathrm{~mm}$., inter limbi latera $2-5 \mathrm{~mm}$. longi. Spicae maturae $10-11 \mathrm{~cm}$. longae et ad $4 \mathrm{~mm}$. crassae. Stamina 4 , basi ima baccae adnata, antheris parris reniformibus. Stigmata 3 sessilia.

Hab. in Cuba: Ossa (in h. DC.), prope Bayamesa 500 m, alt.: Eggers 11. 4689; Jamaica: Swartz (in h. DC. et in h. Willd. n. 666), Jarch n. 1902, 1390 (in h. Griseb. sub . Irt. scabra) et n. 1379 (in h. Kew), ad Port Antonio: Millspaugh n. 892, ad Norwich: Millspaugh n. 1871; Haiti: Picarda n. 141, prope Port-au-Prince ad Bizothon: Eggers n.3315, prope Fessard ad ripas Rivière Froide: Picarda n. 1425; Sto. Domingo, prope Puerto-Plata in convalli fluminis Mameyes alt. $150 \mathrm{~m}$., in monte 
Isabel de la Torre alt. $250-7.45 \mathrm{~m}$., prope Jarabacoa ad La Hagua alt. 600 m.: Eggers n. 1746, 2538, 2744, 2803, 3090; Portorico: Bertero, prope Mayagiiez: Heller n. 4439, Krug 11. 982, prope Cabo-Rojo ad rirulos, in Sierra de Luquillo in monte Jimenes, prope Hato-Grande in Monte Gregorio, prope Adjuntas ad Vuelta de los Tajones, prope Yabucoa ad Sta. Helena in La Pandura, prope Pepino in declivibus umbrosis ad Lneas: Sintenis 11. 873, 1399, 2622, 4510, 5020, 5876, 7016, in Cerro de la Pandura alt. $600 \mathrm{~m}$. in silvis, in Plaja de Humacao in palude Poyal: Eggers ed. Toepff. n. 474, 970; Guadeloupe, Basse-T'erre, Gourbeyre etc. alt. $70-600$ m.: Duss 11. 2568 (fid. Duss Fl. p. 177); Martinique in montibus $300-1000 \mathrm{~m}$. altis: Duss sine n. et 11.2113 (in Fl. p. 177), Pitons du Capot: Plée; St. Vincent in vallibus silvaticis et locis apertis prope rivulos alt. $170-500 \mathrm{~m}$. commune: H. H. et G. W. Smith n. 48, 1325; Tobago in convalli fluminis Great Dog River in silvis: Eggers n. 5762. - praeterea late per Americam intertropicam dispersa (Vid. C. DC. Prodr. XVI, 1 p. 276, Bull. l. Boiss. VI p. 483, ser. 2, I p. 355, Donn. Smith En. part II, IV, V, Dur. et Pitt. Primit. I p. 106 , II p. 236).

Tar. $\beta$. magnifolimm C. DC. limbis basi utrinque acutis, ad $20 \mathrm{~cm}$. longis et ad $9 \mathrm{~cm}$. latis, nervis lateralibus utrinque 6 .

Piper hirsutum var. $\gamma$ magnifolimm C. I)C. Prodr. XVI. I (1869) p. 276 (specim. Berter. exclud.) p. 276.

Piper hirsutum Sauv. Fl. Cub. (1S71) n. 2242 p. 145.

Hab. in Cuba orientali: Wright n. $\underline{493}$, prope Monte Verde alt. 800 m.: Eggers n. 5098; Jamaica: Alexander (in h. Griseb.); Martinique ad Troisième pont: Hahn n. 263.

Var. $\gamma$ plurinerve C. DC. (n. var.) limbis adultis basi utrinque vel saltem altero latere acutis, ad $21 \mathrm{~cm}$. longis et ad $101 / 2 \mathrm{~cm}$. latis, nervis lateralibus utrinque 8 .

Hab. in St. Vincent, in silva montis St. Andrews: Eggers n. 6806, locis humidis ad rivulos in silvis alt. $0-330 \mathrm{~m}$., commune (petiolis ac nervi centralis basi rubris): H. H. et G. W. Smith n. 33.

Var. $\delta$. albescens C. DC. (n. var.) ramulis junioribus dense hirtellis, dein glabratis et albescentibus, lenticellis concoloribus dense asperatis, limbis basi latere longiore rotundatis aut subrotundatis, circiter $10 \mathrm{~cm}$. longis et $4 \frac{1}{2} \mathrm{~cm}$. latis, in sicco pallidis.

Hab. in Portorico, prope Maricao in silvis montis Montoso: Sintenis $11.873^{\mathrm{b}}$.

Obs. I. Varietatem Tondurii C. DC. (in Dur. et Pitt. Primit. I p. 106) sat referens. 
Obs. II. Ill. O. Suart: nomen sum: Pijpe lirsutum (Prodr. a. 1788) "ad evitandam confusionem nominis trivialis cum $P$. hispridulo" sto (i. e. nunc Peperomia hispidula A. Dietr.) in P. hirsutum (Flor. a. 1797) mutavit, quod legibus nomenclaturae hodiernis non respondet.

31. Piper Wrightii C. DC. (n. sp.), folis breviter petiolatis, oblongo-lanceolatis, basi inaequilatera latere longiore rotundatis, breviore obtusis rel subacutis, apice acuminatis acumine acuto, supra appresse pilosis, dein scabris, subtus dense et molliter appresse hirsutis, nerro centrali usque ad $1 / 2$ longitudinis suae nervos adscendentes utrinque 6 - 7 mittente, quorum inferiores oppositi, petiolo basi ima raginante pedunculoque petiolum totum paullo superante hirsutis; spica limbi dimidium superante matura apice obtusa, bracteae pelta triangulari margine pedicelloque angusto dense villosis; bacea subtetragona, adulta glabra, glandulis conspersa.

Piper mollicomum C. DC. Prodr. XVI, 1 (1869) p. 316 (quoad specimen Wrightii); Sauc. Fl. Cub. n. 2245 p. 145.

Ramuli dense hirsuti, spiciferi fere $1 \frac{1}{2} 17 \mathrm{~m}$. crassi, collenclyymate subcontinuo zona interna libriformi, fasciculis intramedullaribus 1 -seriatis, canali racuo nullo. Limbi in sice firmulo-membranacei creberrime pellucido-punctulati circiter usque ad $15 \mathrm{~cm}$. longi et $4^{1 / 2} \mathrm{~cm}$. lati; petioli sub limbo fere $5 \mathrm{~mm}$., inter limbi latera 3 mm. longi. Pedunculi adulti fere $15 \mathrm{~mm}$. longi; spicae maturae fere $8 \mathrm{~cm}$. longae et vix ad $3 \mathrm{~mm}$. crassae. Stamina 4, basi ima baceae adnata, antheris subrotundis parvis, quan filamenta multo brevioribus. Stignata 3 sessilia linearia. Ovarium et bacca junior parce pilosa.

Hab. in Cuba orientali: Wright n. 1687 (in h. DC. et Griseb.).

32. Piper Harrisii C. DC. (n. sp.) foliis breviter petiolatis, oblongoellipticis, basi inaequilatera latere longiore rotundatis subrotundatisre, apice acute acuminatis, supra junioribus rillosis et adultis scabris, subtus adultis praesertim ad nerros villosis, nerro centrali fere usque ad $1 / 2$ longitudinis suae nerros adscendentes alternos utrinque 5 mittente, petiolo villoso basi ima vaginante; pedunculo petioli totius dimidium paullo superante parce villoso, spica subflorente quam folii limbus fere triplo breviore, apice mucronulata, bracteae pelta lunulata margine hirtella.

Ramuli villosi, pilis sat longis, spiciferi circiter 2 mm. crassi, collenchymate continuo zona interna libriformi, fasciculis intramednllaribus 1 -seriatis numerosis, canali racuo nullo. Limbi in sicco firumli opaci pellucido-punctulati subtusque fusco-punctulati, $11^{1 / 2} \mathrm{~cm}$. longi fere 47 mm. lati; petioli infra limbum et inter limbi latera fere $6 \mathrm{~mm}$. longi. Spicae subflorentes $3 \mathrm{~mm}$. crassae. Stamina 4. Stigmata 3. Bacea ignoti.

Hab. in Jamaica: Wilson n. 468 (in h. Griseh.), in Blue mountains: W. Harris 11. 5174. 
33. Pipel microphyllum C. DC. (n. sp.), foliis modice petiolatis, orato-ellipticis, basi brevissime inaequilatera latere longiore subrotundatis, breviore subacutis vel obtusis, apice acuminatis, acumine juniore acuto dein obtusiusculo, supra scabris, subtus praesertim ad nervos appresse hirsutis, nervo centrali fere usque ad $1 / 2$ longitudinis suae nervos utrinque 4 alternos mittento quorum inferiores patulo-adscendentes superiores adscendentes, petiolo basi ima vaginante parce hirtello; pedunculo petiolum paullo superante praesertim superne parce hirtello, spica folii limbum aequante apice mucronata, bracteae pelta triangulari margine pedicellique dorso hirsutis; ovario glabro.

Ramuli juniores parce pilosuli cito glabrati et laeves, spiciferi $1 \mathrm{~nm}$. crassi, collenchymate zona interna libriformi in fasciculos discretos disposito, canali vacuo nullo. Limbi in sicco firmo-membranacei, pellucido-punctulati, juniores supra appresse pilosuli, dein pilorum basibus persistentibus scabri, circiter $7 \mathrm{~cm}$. longi, $3 \mathrm{~cm}$. lati; petioli infra limbum $3 \mathrm{~mm}$, inter limbi latera $1 \frac{1}{2} 111 \mathrm{~m}$. longi. S picae florentes $2 \mathrm{~mm}$. classae; rliachis glabra. Stamina 4, basi ima baccae adnata, antheris parvis subglobosis. Bacca verisimillime haud trigona. Stigmata sessilia 3 linearia. Spicae mucro puberulus, $2 \mathrm{~mm}$. longus.

Hab. in Jamaica in Blue mountains: W. Harris n. 5172.

Obs. Species $P$. sepicolce C. DC. proxima, ramulis ac foliis multo minus pubescentibus spicisque mucronatis ab eo discrepans.

34. Piper guavaumu C. DC. (n. sp.), foliis breviter petiolatis, oblongo-lanceolatis, basi modice inaequilatera latere longiore subrotundatis, breviore subacutis obtusisve, apice longiuscule et oblique acuminatis acumine acuto, supra scabris, subtus ad nervos nervulosque appresse hirsutis, nervo centrali usque ad $1 / 2$ longitudinis suae nervos utrinque 5-6 inferiores subadscendentes superiores adscendentes alternos mittente, petiolo basi ima raginante pedunculoque petiolum totum aequante hirtellis; spica submatura folii dimidium aequante apice mucronata, bracteae pelta triangulari margine pedicellique dorso dense hirtellis; bacca apice minute velutina.

Ramuli juniores hirtelli, dein glabrati et scabridi ac pallidi, spiciferi $2 \mathrm{~mm}$. crassi, nodis tumidis, collenchymate subcontinuo zona interna libriformi, fasciculis intramedullaribus 1 -seriatis, canali vacuo nullo. Limbi in sicco firmo-membranacei, parce pellucido-punctulati, usque ad $17 \mathrm{~cm}$. longi ct $6 \mathrm{~cm}$. lati; petioli infra limbum vix $5 \mathrm{~mm}$. et inter limbi latera $4 \mathrm{~mm}$. longi. Spica submatura circiter $2 \mathrm{~mm}$. crassa, merone vix $2 \mathrm{~mm}$. longo lense hirtello. Stamina 4, antheris subreniformibus parvis. Bacea subtetragona. Stigmata 3 sessilia linearia.

Hab. in Jamaica in Guava Ridge alt. 660 m.: Eggers n. 3744.

35. Piper Dussii C. DC. (n. sp.), foliis breviter petiolatis, ellipticis, basi inaequilatera utrinque rotundatis, apice acuminatis, supra 
junioribus parce pilosis, subtus ad nervos nervulosque adpresse pilosis, nervo centrali usque ad $1 / 3-1 / 2$ longitudinis suae nervos adscendentes alternos utrinque 8 mittente, petiolo hirsuto basi ima raginante; pedunculo parce piloso, adulto petiolum totum fere aequante, spica subflorente quam limbus fere triplo breviore apice mucronulata, bracteae pelta lunulata margine perlicelloque angusto hirsutis.

Piper reticulatum Duss! F7. phan. (1897) p. 175, - non L.

Queue de rat Guad. ex Duss.

Frutex 5-10 p. altus. Ramnli juniores dense villosi, dein glabrescentes, spiciferi circiter $3 \mathrm{~mm}$. crassi, collenchymate continuo sat crasso zona interna libriformi, fasciculis intramednllaribus 1 -seriatis numerosis, canali vacuo nullo. Limbi in sicco membranacei, pellucido-punctulati, usque ad $26 \frac{1}{2} \mathrm{~cm}$. longi et ad $12 \frac{1}{2} \mathrm{~cm}$. lati; petioli infra limbum $5 \mathrm{~mm}$., inter limbi latera fere $10 \mathrm{~mm}$. longi. Spicae subflorentes fere usque ad $3 \mathrm{~mm}$. crassae. Stamina 4, antheris sulgglobosis. Orarium glabrum. Bacea verisimillime subtetragona. Stigmata 3 sessilia linearia.

Hab. in Guadeloupe in nemoribus Bains jaunes et Matuba alt. $400-1000 \mathrm{~m} .$, ubi frequens: Duss n. 2835.

Var. $\beta$. scabridum C. DC. foliis adultis supra scabridis.

Queue de lezard s. Malimbe Mart. ex Duss.

Frutex 3-8-pedalis. Spica matura limbi dimidium fere aequans et $3 \mathrm{~mm}$. crassa.

Hab. in Martinique in nemoribus usque ad alt. $230 \mathrm{~m}$. commune: Duss n. 1337 .

36. Piper Fadyeni C. DC. foliis brerissime petiolatis, oblique oblongo-ovato-ellipticis, basi subaequilatera vel inaequilatera rotundatis, apice breriter acuminatis acumine acuto, utrinque molliter pubescentibus, nerris subtus prominulis, centrali nerros alternos adscendentes utrinque 5 mittente, petiolo fusce villoso; pedunculo petiolum multo superante glabro, spica quam folium paullo breviore, bracteae pelta triangulari vel lunulata margine hirtella; bacca lateraliter compressa, rertice glanduloso pubescente.

Piper Fadyeni C. DC: Prodr. XTI, 1 (1869) p. 284.

Artanthe scabra var. foliis minoribus Miq. in h. Kew.

Ramuli fusce remote villosi. Limbi in sicco membranacei, minute pellucido-punctati, $9 \mathrm{~cm}$. longi, $4 \mathrm{~cm}$. lati; petioli $2-3 \mathrm{~mm}$. longi. spicae florentes $7 \mathrm{~cm}$. longae, $3 \mathrm{~mm}$. crassae.

Hab. in Jamaica: Macfadyen n. 82 (in h. Kew.).

V 37. Piper Broadwayi C. DC. (n. sp.) foliis breviter petiolatis, oblongo-ellipticis, basi inaequilatera adultis utrinque rotundatis, apice acuminatis acumine acuto, supra glabris, subtus ad nervos sat dense pilosis, nervo centrali fere usque ad $1 / 2$ longitudinis suae nervos adscen- 
dentes alteruos utrinque 6 mittente, petiolo dorso appresse piloso, basi ima raginante; pedunculo glabro petiolum totum fere aequante, spica subflorente folii dimidium subaequante apice mucronulata, bracteae pelta triangulari margine hirsuta.

Ramuli glabri laeves, spiciferi fere $2 \mathrm{~mm}$. crassi nodis junioribus pilosis, collenchymate haud libriformi in fasciculos discretos disposito, fasciculis intramedullaribus 1 -scriatis, canali vacuo nullo. Limbi in sicco membranacei, pellucido-punctulati, usque ad $22^{1 / 2} \mathrm{~cm}$. longi et ad $10 \mathrm{~cm}$. lati, juniores in latere breviore acuti; petioli adulti infra limbum usque ad $10 \mathrm{~mm}$., inter limbi latera $5-7 \mathrm{~mm}$. longi. Pedunciili usque ad $20 \mathrm{~mm}$. longi; spicae maturae $4 \mathrm{~mm}$. crassae. Stamina 4 , ima basi baccac inserta, antheris rotundatis parvis, filamenta fere aequantibus. Bacca tetragona glabra. Stigmata 3 sessilia.

Hab. in Guadeloupe: Krauss n. 1818 (in h. Cand.); Dominica: Ramage; Grenada in Grand Etang in nemoribus montanis: Broadway n. 1480 .

Obs. Species P. Anurayano C. DC. affinis, foliis majorihus ac nervis lateralibus numerosioribus et magis adscendentibus discrepans.

38. Piper cuspidatum Ham. foliis breviter petiolatis, ellipticoovatis, adultis basi inaequilatera latere longiore rotundatis breviore obtusis, apice longiuscule et suboblique acuminatis acumine acuto, supra glabris, subtus fuseo-punctulatis et ad nervos appresse hirtellis, centrali nervo fere usque ad $1 / 2$ longitudinis suae nervos alternos adscendentes utrinque 5 mittente, petiolo basi ima raginante pedunculoque quam petiolus totus paullo breviore glabris; spica adulta limbi dimidium fere aequante, bracteae pelta triangulari margine puberula; bacea glabra.

Piper cuspidatum Ham.! Prodr. (1825) p. 3; A. Dietr. Sp. I p. 648; C. DC. Prodr. XVI, 1 p. 375 (excluso syn. Miq.).

Ramuli glabri laeves, spiciferi circiter $2 \mathrm{~mm}$. crassi collenchymate zona interna libriformi in fasciculos discretos disposito fasciculis intramedullaribus 1 -seriatis, canali racuo nullo. Limbi in sicco membranacei, pellucido-punctulati, adulti $19^{1} / 2 \mathrm{~cm}$. longi et $9^{3} / 4 \mathrm{~cm}$. lati; petioli adulti infra limbum fere $7 \mathrm{~mm}$. et inter limbi latera $5 \mathrm{~mm}$. longi. Spicae haud apice mucronatae, maturae $2 \mathrm{~mm}$. crassae. Stamina 4, ima basi baccae inserta, antheris parvis rotundatis, filamenta fere aequantibus. Baccae tetragonac. Stigmata 3 sessilia.

Hab. in montibus Hispaniolae: Herb. Desvaux (nune in Mus. Par.).

39. Piper jamaicense C. DC. foliis breviter petiolatis, ellipticooblongis, basi inaequilatera latere longiore rotundatis breviore acuto aut rotundatis, apice acuminatis acumine acuto et mucronulato, supra glabris, subtus ad nervos parce et appresse hirtellis, nervis subtus prominulis, centrali usque ad $1 / 2$ longitudinis suae nervos alternos adscendentes utrinque $4-5$ mittente, petiolo basi ima vaginante appresse lirtello; 
pedunculo glabro petiolum totum fere aequante, spica quam limbus fere dimidio breviore apice mucronulata, bracteae pelta lunulata margine pedicellorue angusto hirtellis; bacca glabra.

Artanthe jamaicensis Griseb.! Fl. II. Ind. (1559) p. 170.

Piper geniculatum a. jamaicense C. DC. Prodr. TYT, 1 (1869) 1. $26 \pi$.

Ramuli glabri laeres, spicifcri fere $2 \mathrm{~mm}$. crassi collenchrmatc continuo zona interna libriformi fasciculis intramedullaribus 1 -seriatis. Limbi in sicco membranacei, subopaci pellucido-punctulati, circiter $13 \mathrm{~cm}$. longi et $5 \mathrm{~cm}$. lati; petioli infra limbum ad $4 \mathrm{~mm}$. et inter limbi latera ad $5 \mathrm{~mm}$. longi. Spica submatura $2 \mathrm{~mm}$. crassa. Stamina 4 , basi luaccae adnata, antheris rotundato-reniformibus quam filamenta paullo brevioribus. Bacca tetragona. Stigmata 3 sessilia linearia.

Hab. in Jamaica: Alexander (in l. Griseb. et Krug et Urb.), ad Castleton Hill alt. $330 \mathrm{~m}$. (parva arbor 12-pedalis): IV. J. Thompson 1. 8027 .

Forma magnifolia. limbis ad $15 \frac{1}{2} \mathrm{~cm}$. longis et ad $6 \mathrm{~cm}$. latis. Artanthe jamaicensis Griseb.! l.c. (p.p.).

Hab. in Jamaica: Alexander (in h. Kew).

Forma ovalifolia, limbis ovatis, basi inaequilatera utrinque rotundatis, apice acuminatis acumine acuto, usque ad $11 \mathrm{~cm}$. longis et $5 \frac{1}{2} \mathrm{~cm}$. latis.

Artanthe jamaicensis Griseb.! l.c. (p.p.).

Hab. in Jamaica: Alexander (in ll. Griseb.).

40. Piper Murlayanum C. DC. foliis brevissime petiolatis, elliptico-oblongis, basi inaequilatera latere longiore rotundatis breviore rotundatis vel obtusis, apice acuminatis acumine acuto mucronulatoque, supra glabris, subtus ad nerros parce appresse hirtellis, nervis subtus prominulis centrali rix usque ad $1 / 2$ longitudinis suae nerros alternos subadscendentes utrinque 5 mittente, petiolo basi ima raginante appresse liitello; pedunculo glabro, petiolum totum 2-3-plo superante, spica folii dimidium superante apice mucromulata, bracteae pelta lunulata margine pallide hirtella; bacca glabra.

Piper Murrayanum C. DC. Prodr. XT1, 1 (1869) p. 280.

Ramuli glabri laeres, spiciferi fere $2 \mathrm{~mm}$. crassi collcnchymate continuo zona interna libriformi fasciculis intramedullaribus 1 -scriatis. Limbi in sicco membranacei, subopaci, pellucido-pmetulati, circiter $13 \mathrm{~cm}$. longi et $5 \% \mathrm{~cm}$. lati; petioli infra limbum fere $1 \mathrm{~mm}$, inter limbi latera rix $3 \mathrm{~mm}$. longi. Spica submatura $2 \mathrm{~mm}$. crassa. Stamilla 4 , rluachi ad baccae basin insertis, antheris rotundatis, quam filamenta brevioribus. Bacca tetragona. Stigmata 3 sessilia.

Hab. in Jamaica: Murray n. 497 (in h. DC.). 
41. Piper mornicola C. DC. (11. sp.), foliis breviter petiolatis, oblongo-ellipticis, basi leviter inaequilatera utrinque rotundatis, apice acuminatis acmmine acuto, supra glabris, subtus ad nervos nervulosque appresse pilosulis, nervo centrali vix usque ad $1 / 2$ longitudinis suae nervos arlscendentes utrinque 5 mittente, quorm supremi alterni, petiolo usque ad limbum vaginante dorso appresse pilosulo; pedunculo quam petiolus multo breviore, spica jurenili quam folii limbus fere triplo breviore, apice nucromulata, bracteae pelta rotundato-lunulata, margine hilsuta.

Arbor 2,6 m. alta. Ramuli glabri, spicoiferi circiter 1 mm. crassi, in $2 \mathrm{~mm}$. crassis collenchymate continuo libriformi fasciculis intrancdullaribus 1 -seriatis cauali racuo centrali. Limbi in sicco membranacei, croberlime pellucido-punctulati, usque ad $14 \mathrm{~cm}$. longi et circiter $4^{1 / 2} \mathrm{~cm}$. lati; petioli infra limbum circiter $8 \mathrm{~mm}$. et inter limbi latera $2 \mathrm{~mm}$. longi. Pedunculus adhuc jurenilis vix $2 \mathrm{~mm}$. longus; spica in specimine juvenilis $2 \mathrm{~mm}$. crassa. Stamina 4. Ovarium ignotum.

Hab. in Tobago, in silva primaeva montis Morne d'Or alt. $500 \mathrm{~m}$.: Eggers n. 5843 .

Var. $\beta$. lomgifolium C. DC. (n. var.) limbis usque ad $15^{1 / 2} \mathrm{~cm}$. longis et fere $5 \mathrm{~cm}$. latis, basi latere breviore acutis, longiore obtusis. Arbor lumilis foliis tenuibus.

Hab. in 'Tobago, in convalli fluminis superioris Great dog river: Eggers n. 5789.

42. Piper Audersonii C. DC. (n. sp.), foliis modice petiolatis, oblongo-ellipticis, basi subaequilatera altero latere rotundatis altero subacutis, apice acuminatis acumine acuto, supra glabris, subtus ad nelvos puberulis, nervo centrali ad $1 / 2$ longitudinis suae nerros adscendentes utrinque 4-5 sursumque nervulos aliquot validos mittente, petiolo ultra medium vaginante dorso puberulo; pedunculo petiolum aequante subglabro, spica eylindrica apice obtusa quan limbus pluries breviore, bracteae apice truncato-peltatae pelta angusta triangulari glabra pedicello acquilato glabro; bacca glabra.

Ramuli glabri, in sicco atro-rubescentes, spiciferi $1 \frac{1}{2} \mathrm{~mm}$. crassi, collenchymate libriformi in fasciculos discretos disposito, fasciculis intramedullaribus 1 -seriatis, canalibus racuis unllis. Limbi in sicco firmi, ad $13^{1} / 2 \mathrm{~cm}$. longi, ad $5 \% \mathrm{~cm}$. lati; petioli $12 \mathrm{~mm}$. longi. Spica matura $24 \mathrm{~mm}$. longa, 4 mu. crassa. Stamina 4 .

Hab. in Sta. Lucia: Anderson (in h. Forsytl, nunc Kew et Krug et Urb.).

Obs. Species quoad folia et spicas $P$. citrifolium Lam. sat referens.

43. Piper macroplıylum Kunth, foliis modice petiolatis, elliptico-oblongis, basi subinaeruilatera utrinque rotundatis cordulatisre rel 
subattenuato-obtusis, apice acmminatis acumine acuto, supra glabris, subtus ad nerros appresse pilosulis, nerro centrali subtus promiuulo usque ad $1 / 2$ longitudinis suae nervos alteruos subadscendentes subtus prominulos utrinque 5 mittente, petiolo usque ad limbum vagimante pedunculoque petiolum subaequante glabris: spica cylindrica mucronata, matura quam folii limbus pluries breviore, bracteae subcucullatae inferne dorso hirsutae apice truncatae rertice triangulari; bacea glabra.

Piper macrophyllum Kunth! in II. I3. K. Tor. Cen. I (1S15) 1. 46 (cxclus. sym. Sucuts et T'ahl) et Sym. I p. 10.3; C. DC: Prodr. XTI, 1 p. 2 \% 2.

Schilleria macrophylla Kumth! in Limmaen XIII (1839) p. 715.

Artanthe macrophylla Miq.! Syst. (1S+4) 1). 42.3 et in Hook. Lomrl. Joum. Bot. IV 1. 452.

Frutex 10-pedalis. Ramuli glabri laeves, spiciferi $2 \mathrm{~mm}$. crassi, collenchymate haud rel sparse libriformi in fascicnlos discretos disposito, fasciculis intramedullaribus 1 -seriatis, canali vacuo centrali haud continno. Limli in sicco membranacei, minnte pellncido-punctulati, $17-24 \mathrm{~cm}$. longi, S-12 cm. lati; petioli fere $1 \frac{1}{2} \mathrm{~cm}$. longi. Spica matura $4-5 \mathrm{~cm}$. longa et $5 \mathrm{~mm}$. crassa, mucrone fere $2 \mathrm{~mm}$. longo. Stamina 4, ima basi ovarii adnata, antheris subreniformibus, quam filamenta multo brevioribus. Stigmata 3 sessilia linearia.

Hab. in Sto. Domingo prope Puerto-Plata in sylvis montis Isabel de la Torre 370 m.: Fggers 11. 1571; Portorico: Wydler n. 260, prope Maricao in silvis montis Montoso, prope Cabo-Rojo in Monte Grande, in Sierra de Luquillo in regione media montis Jimenes, prope Juncos in monte Florida, prope Adjuntas in silva prim. ad Las Cruces et ad Anrlubo, prope Yabucoa in silva prim. ad Guayarota et ad Jácana, prope Las Marias in silvis montanis ad Tabonuco: Sintenis 11.462, 462 b, 1666 , $1666^{b}, 4476^{\mathrm{b}}, 4693,5165,5267,5989$, in Sierra de Luquillo ad Bañadero $660-800 \mathrm{~m}$. alt., in fruticetis et in silvis altis umbrosis: Eggers ed. 'Toepff. n. 971, hb. propr. n. 1164; Guadeloupe, in magna saranna prope stagnum Volcanard prope Gourbeyre: Duss n. 2568, 3596; II Irtinique: Isert (in h. Willd. n.640), Fouché (in h. Boiss.); St. Vincent: Guilding (in h. Kew), in silvis humidis montosis alt. $160-600 \mathrm{~m} .:$ H. H. et G. IV. Smith 11.30, in montibus St. Andrews: Eggers 12.6797, in monte Soufrière: Eggers 11. 6925; Trinidad, in silvis ad Ciparia: Bot. Card. Herb. n. 2618; - praterea in Mexico ad Miralores: Linden 11. 120; Tenezuela in convalli Caripensi: Humboldt et Bompland in hb. Willd. n. 610; Peruvia: "Nathews 11. $1145^{\text {bis. }}$

44. Piper martinicense C. DC. foliis brevissine petiolatis, lanceolato-oblongis, basi leviter inaeruilatera rotundatis, apice longiuscule acuminatis, supra gylabris, subtus ad nerros nervulosque appresse hip- 
tellis, nervo centrali fere usque ad $1 / 2$ longitudinis suae nervos alternos adscendentes utrinque 5 mittente, petiolo basi ima raginante pedunculoque petiolum superante hirsutis; spica limbi dimidium parum superante, bracteae rertice mitriformi carnoso glabro vel parce hirtello; bacea glabra.

Piper martinicense C. DC. in Briquel Ann. Jard. bol. Genive II (1S9S) p. 259.

Ramuli retrorsum hirtclli, punetulis asperis muniti, in sieeo atrorubeseentes, spiciferi fere $1 \frac{1}{2} \mathrm{~mm}$. erassi, eollenclymate fere eontinuo zona interna libriformi, fascienlis intramedullaribus 1 -seriatis. Limbi in sieco membranacei, crebre pellueido-punetulati, $12-17 \mathrm{em}$. longi, 4-6 eni. lati; petioli infra limbum $1-2 \mathrm{~mm}$. inter limbi latera vix $2 \mathrm{~mm}$. longi (nec $1 / 2-1 \mathrm{em}$. longi ut in (lescrip. prim.). Spicae submaturae eireiter $2^{1 / 2} \mathrm{~mm}$. erassae, in sieeo rubeseentes, apiee aeuminatae haud nucronatac, submaturae eirciter $2 \frac{1}{2} \mathrm{~mm}$. erassae. Stamina 4 , basi ima baecac adnata, antheris rotundato reniformibus, quam filamenta multo brevioribus. Baeea tetragona. Stigmata 3 sessilia minuta.

Hab. in Martinique, in silva Calebasse: Hahn n. 1143 (in h. Cand.).

Tar. $\beta$. Montis-pilati C. DC. (n. var.) foliis lanceolato-ellipticis, basi magis inaequilatera rotundatis, petiolis infra limbum ad $5 \mathrm{~mm}$. inter limbi latera ad $4 \mathrm{~mm}$. longis, collenchymate zona interna libriformi in fasciculos discretos disposito.

Hab. in Martinique in Montagne Pelée: Mahn n. 267 (ibid.), in nemore campi Colson, alt. $400-780 \mathrm{~m}$., copiosum (frutex $1-1,80 \mathrm{~m}$. altus, rectus mediocriter ramosus): Duss n. 4472.

45. Piper Otophyllum C. DC. (n. sp.), foliis brevissime petiolatis, ovatis, basi inaequilatera cordulatis, latere longiore auriculato petiolum velante, breviore rotundato, apice acuminatis, utrinque praesertim ad nervos nervulosque sat longe, villosis, adultis supra bullulatis ac seabris, nerro centrali fere usque ad $1 / 2$ longitudinis suae nerros utrinque $5-6$ mittente quorum inferi arcuatim patuli et superiores adscendentes, petiolo dense villoso; pedunculo petiolum totum paullo superante glabro, spica submatura quam folii limbus fere $1 / 3$ breriore apice mucronulata, bracteae pelta triangulari margine dense hirsuta antice acuta, pedicello angusto hirsuto; bacea apice puberula.

Ramuli densc villosi, spiciferi fere $2 \mathrm{~mm}$. erassi eollenehymate continuo zona interna libriformi, faseiculis intramedullaribus 1 -seriatis, eanali vacno centrali. Limbi in sieeo mombranacci, erebre pellncido-punetati ad $15 \mathrm{~cm}$. longi et ad $8 \frac{1}{2} \mathrm{~cm}$. lati; potioli infra limbum vix, inter limbi latera vix $2 \mathrm{~mm}$. longi. Pedunculi fere $1 \mathrm{~cm}$. longi; spica submatura $9 \frac{1}{2} \mathrm{~cm}$. longa, basi $3 \mathrm{~mm}$. erassa. Stamina 4, antheris subglobosis, quam filamenta rhachi ad basin baccae inserta multo brevioribus. Baeea subtetragona. Stigmata sessilia 3 brevissima.

Hal), in Jamaica, Blue Nountains: W. Harris n. 5108. 
46. Piper Readii C. DC. (n. sp.), foliis breviter petiolatis, suboblipue lanceolato-ellipticis, basi inaequilatera utringue acutis subacutisve, apice sat longe acuminatis, supra glabris, subtus ad nervos haud dense pilosis, nervo centrali ultra $1 / 3$ longitudinis suae nerros alternos adseendentes utrinque $5-6$ mittente, petiolo dorso piloso, paullo ultra basin vaginante; peduneulo glabro quam petiolus paullo breviore, spica matura limbi dimidium fere aequante apice subaeuta, bracteae pelta triangulari margine pedicelloque angusto hirsutis; bacca apice hirtella.

Ramuli juniores puberuli, dein glabri, spiciferi $2^{1 / 2} \mathrm{~mm}$. crassi, collenchymate continuo zona interna libriformi, fasciculis intramedullaribus 1 -seriatis, canali vacuo nullo. Limbi in siceo membranacei, minutissime pellncidopunctati, usque ad $20 \mathrm{~cm}$. longi et ad $9 \mathrm{~cm}$. lati; petioli infra limbum $1 \mathrm{~cm}$. inter limbi latera $5 \mathrm{~mm}$. longi. Spicae maturae fere usque ad $3 \mathrm{~mm}$. crassae. Bacea obpyramidato-trigona. Stigmata 3 sessilia.

Hab. in Guadeloupe: Read.

47. Piper Trinitatis C. DC. (n. sp.), foliis breviter petiolatis, elliptico-lanceolatis, basi modice inaequilatera utrinque acutis, apice sat longe acuminatis aeumine acuto, utrinque et subtus praesertim ad nerros nervulosque appresse pilosis, nervo centrali fere usque ad $1 / 2$ longitudinis suae nervos adscendentes alternos ntrinque 5-6 mittente, petiolo appresse piloso paullo ultra basin raginante; spica matura limbi dimidium paullo superante apice obtusa, braeteae pelta triangulari margine hirsuta pedicello angusto rhachique hirsutis; bacca glabra.

Ramuli juniores parce pilosi, dein glabri, nodis rix tumidis, internodiis usque ad $4 \mathrm{~cm}$. longis, spiciferi fere $2 \mathrm{~mm}$. crassi collenchymate suhcontinuo zona interna libriformi, fasciculis intramedullaribus 1 -seriatis canali vacuo nullo. Limbi in sicco membranacei, minute et inconspicue pellucidopunctulati, usque ad $13 \mathrm{~cm}$. longi et circiter $4 \frac{1}{2} \mathrm{~cm}$. lati; petioli infra limbum $5 \mathrm{~mm}$., inter limbi latera $3 \mathrm{~mm}$. longi. Spicae rigide adscendentes. Stamina 4, basi baceae inserta, antheris rotundatis quam filamenta brevioribus. Bacea obpyramidato-trigona. Stigmata 3 sessilia linearia.

Hab. in Trinidad: Bot. Gard. Herb. n. 6010.

Obs. Species $P$. tobayoano C. DC. proxima, limbis basi utrinque acutis et pedunculis spicisque longioribus ac adscendentibus ab co discrepans.

48. P'iper dilatatum L. Cl. Rich. foliis breviter petiolatis, suboblique ovato-ellipticis vel obovato-elliptieis, basi inaeruilatera vel subaequilatera utrinque rotundatis rel obtusis, apice acuminatis acumine aeuto mucronulatoque, utrinque praesertim ad nervos pilis sparsissimis longiuseulis et sensim deeiduis obsitis, nervis subtus prominulis centrali usque ad $1 / 2$ longitudinis suae nerros alternos subadscendentes utrinque $5-7$, plerumque 6 mittente, petiolo basi vaginante utrinque lirtello; peduneulo glabro vel puberulo petiolum totum subaequante rel eo bre- 
riore, spica quam folium 2-3-plo breviore obtusa, bracteae pelta triangulari margine pedicelloque angusto villusis; bacea glabra.

Piper dilatatum L.Cl. Rich.! in Aet. Soc. Hist. nat. Por. (1792) 2. 105; Tahl Enum. I p. 320; West Fl. St. Croix 1. 265; C. DC: Prodr. TVI, 1 p. 314; Duss! Fl. phan. 1. 179.

Piper vernucostm Willd. Sp. I (179S) p.163 (quoad syn. Sloume). Piper corylifolimm Kumlh! in Limaen TIII (1839) 1. 699.

Schilleria ulmifolia Kumlh! l. c. 1). 698 .

Schilleria corylifolia Kunth l. c. 1. 699.

Artanthe ulmifolia Miq.' Syst. (1S41) 1. +72 et in Hook. Lond. Joum. Bot. $I \mathrm{~T}^{\mathrm{T}}$ 1. $45 \mathrm{~T}$.

Artanthe corylifolia Miq.! Syst. (1844) p. 474 et in Mart. Filor. Bras. $I \mathrm{~T}, 1$ p. 49.

Artanthe Bredemeycri Griscb.! Fl. W. Ind. (1S59) p. 170.

Malimbi inc. Martin. ex Duss.

Frutex $8-10$-pedalis, ramulis junioribus pilis raris obsitis dein glabris, spiciferis fere $3 \mathrm{~mm}$. crassis, collenchymate zona interna sparsim (spec. Krauss) libriformi rel zona interna tota libriformi (spec. EGg.) in fasciculos discretos disposito vel subcontinuo fasciculis intramedullaribus 1 -seriatis. Limbi in siceo membranacei, minute pellucido-punctati, $16-25 \mathrm{~cm}$. longi, 6-12 cm. lati; petioli infra limbum $5-15 \mathrm{~mm}$. inter limbi latera $3 \mathrm{~mm}$. longi. Spicae maturae $2^{1 / 2} \mathrm{~mm}$. vrassae. Stamina 4, basi ima baccae atnata, antheris rotundis quam filamenta multo brevioribus. Bacca obpyramidato-trigona. Stigmata 3 sessilia.

Hab. in St. Croix ad Crequis: A. E. Ricksecker n. 421; Saba: Suringar; St. Eustache: Suringar; Antigua: Wullschlaegel n. 534 (in h. Griseb., sub Art. Bredemeyeri), Nicholson (in l. Kew); Guadeloupe: Bertero, Perrottet, Krauss (in h. DC.), Ducliassaing (in h. Griseb. sub Art. Biedcmeycri), secus rivulos et locis humidis in nentore Bains jaunes: Duss 11. 2569; Dominica: Imray n. 134 (in h. Griseb. sub Art. Bredemeycri), Goodwill Valley, Wallhouse: Eggers hb. pr. n. 55, 57; Martinique: Sieber n. 7 (in h. Berol. sub nom. P. aurilum), Duss n. 1337b, in Calebasse: Hahn n. 266 (in h. Cand.), sparsim in nemoribus fontis Absalon: Duss n. 4473; Grenada: Broadway n. 34 et 140 (sp. cult.), in silva interiore montis Feliz alt. $400 \mathrm{~m}$., inter Goyave et Grand Pauvre: Eggers n. 6015, 6325; Barbados, in nemoribus: Lane (in h. Kew); Trinidad: Sieber n. 18; - practerea in Mexico ad Colipa: Liebmann n. 16 (in h. Cand.), in valli Cordora: Bourgeau n. 13 (ibid.); Costarica, Panama, Colombia, Venezuela, Brasilia (Vid. C. DC. Prodr. l. c. et in Dur. et Pitt. Primit. fasc. I p. 120).

Var. $\beta$. Vincentianum C. DC. (n. var.) limbis magis ellipticis, $16-17 \mathrm{~cm}$. longis, ad $7 \frac{1}{2} \mathrm{~cm}$. latis, basi inaequilatera utrinque rotundatis vel altero latere subacutis, spica limbi dimidium vix aequante. 
Piper confusum Liew Bull.! 1893 1). 272.

Iiper dilatatum Kere Isull. l. e.

Ramuli juniores hand dense pilosi, collenchymate subcontinno zona interna libriformi.

Hab. in St. Eustache ad Quill: Suringar; St. Tineent, copiose prope mare et usque ad $500 \mathrm{~m}$. alt. locis apricis siccis: H. H. et G. IT. Suith n. 916, prope Liberty Lodge alt. $200 \mathrm{~m}$.: Fgger's n. 6529, in fruticetis haud rara: Krause n. 59; Becquia in wooded rarines $260 \mathrm{~m}$. alt.: Smitlı B n. 245.

49. Piper tobagoanum C. DC. (n. sp.), foliis breviter petiolatis, elliptico-lanceolatis, basi modice inaequilatera utrinque rotundatis, apice sat longe acuminatis acumine acuto, utrinque et subtus praesertim ad nervos nerrulosque appresse pilosis, nervo centrali fere usque ad 1/2 longitudinis suae nervos adscendentes alternos utrinque 5 mittente, petiolo appresse piloso basi ima raginante; pedunculo adulto subglabro, petiolum totum fere aequante, spiea matura limbi dimidium subaequante apice obtusa, bracteae pelta triangulari margine pedieelloque angusto lirisutis; baeca glabra.

Jumbee Candlebush Tobag. ex Egg.

Arbor 8-10-pedalis. Internodia brevia, superiora usque ad $2 \mathrm{~cm}$. longa nodis sat tumidis. Ramuli juniores appresse et haud dense pilosi, dein glabri, spieiferi fere $1 \mathrm{~mm}$. crassi, collenehynate subcontinno zona interna libriformi, fasciculis intramednllaribus 1 -seriatis, canali centrali vacuo. Limbi in sieco membranacei, minnte pellucido-punctulati, usque ad $17^{1}{ }_{2} \mathrm{~cm}$. longi et ad $7 \mathrm{~cm}$. lati; petioli infra limbum $3 \mathrm{~mm}$., inter limbi latera $4 \mathrm{~mm}$. longi. Spicae maturae $6 \mathrm{~cm}$. longac, vix $3 \mathrm{~mm}$. crassae, in sicen horizontales; rhachis parce hirsuta. Stamina basi baccae inserta, antheris rotundatis, quam filamenta brevioribus. Bacca obpyranidato-trigona flavide glandulosa. Stigmata 3 sessilia.

Hab, in Tobago, in eonvalli fluminis Baeolet ad Calder Hall: Egger's 11. 5673, juxta Great dog river in convalli superiore: Egger's n. 5753 .

Obs. Species I. leploctudo C. DC. (in Dur. et Pitt. Primit. II 1. 249) proxima, fere tantum pilis longioribus diserepans.

Var. $\beta$. Lumilion C. DC. (n. var.) limbis usque ad $20 \mathrm{~cm}$. longis et fere ad $7 \mathrm{~cm}$. latis.

Planta $1^{1}$ z ped. alta, ramulorum structura ut in specic.

Hab, in Tobago, in collibus ad Rymnymade, alt. $100 \mathrm{~m}$., fluminibus Great Courland et Craig Hill confluentibus: Eggger's 11. 5934.

50. Piper auritum Kuntlı, foliis modice petiolatis, orato-ellipticis, basi ralde inaequilatera cordatis, apice attenuatis of acutis, supra dense puberulis subtus molliter pubeseentibus, nerris subtus prominulis, 
centrali supra basin fere usque ad $1 / 2$ longitudinis suao vel paullo ultra nerros adscendentes alternos utrinque 2-3 et $1-2$ c basi divaricantes mittente, petiolo usque ad limbi latus brevius raginante pedunculoque margine hirsutis; bacca trigona glabra.

Piper auritum Kunth! in H. I. K. Noe. Gen. I (1S15) p. 54, Synops. I p. 109; Mart. et Gal. in Bull. Ae. Brux. I p. 21; C. DC. Prodr. IVI, 1 p. 320.

Schillevia aurita Kunth! in Limnuea XIII (1S39) p. 713. Artanthe amrita Miq.! Syst. (1844) p. 400.

Artanthe Scemamniana Miq.! Bot. Her. (1852-57) p. 199 t. 39.

Ramuli glabri, spiciferi usque ad $4 \mathrm{~mm}$. crassi, collenchymate haud libriformi in fasciculos discretos disposito, fasciculis intramedullaribus $2-3$ seriatis. Limbi in sicco membranacei, pellucido-punctulati, circiter $16 \mathrm{~cm}$. longi et $9 \mathrm{~cm}$. lati; petioli infra limbum circiter $2^{1 / 2}$ cn. et inter limbi latcra $5 \mathrm{~mm}$. longi. Spicae maturae $4 \mathrm{~mm}$. crassae, ebullitione aromaticae. Stamina rhachi inserta 4 vel apice spicae 3 aut 2 , antheris rotundatis. Stigmata 3 sessilia linearia.

Hab. in ?St. Thomas: Friedrichsthal (in h. Lenorm. et Kew); praeterea in Mexico, America centrali, Columbia (vid. C. DC. l. c. et in Bull. herb. Boiss. T p. 701, in Domm. Smith Enum. II, 65, IV p. 131, V p. 73, in Dur. et Pitt. Primit. I p. 218, II p. 257.

Obs. Verisimiliter a el. Friedrichstunal non in St. Thomas, sed in America centrali collectum et labello quoad patriam erroneo praeditum.

51. Piper Eggersii C. DC. (n. sp.), foliis modice petiolatis, late ellipticis, basi inaequilatera latere longiore rotundatis breviore acutis, apice acuminatis acumine acuto, utrinque parce et longiuscule pilosis, nervo centrali fere usque ad $1 / 3$ longitudinis suae nervos adscendentes alternos utrinque $5-6$ mittentc, petiolo parce piloso basi ima raginantc; pedunculo parce piloso petiolum usque ad limbi latus longius aequante, spica sub anthesi quam folii limbus fere triplo breviore apice mucronulata, bracteae pelta triangulari margine pedicelloque-et rhachi hirsutis; ovario parce hirtello.

Frutex 8-pedalis. Ramuli parce pilosi, spiciferi $2 \mathrm{~mm}$. crassi collenchymate subcontinuo zona interna libriformi, fasciculis intramedullaribus 1 -seriatis, canali racuo nullo vel centrali obsoleto. Limbi in sicco tenuiter membranacei, minute pellucido-punctati, $22 \mathrm{~cm}$. longi et usque ad $14 \mathrm{~cm}$. lati; petioli infra limbum fere $1 \mathrm{~cm}$. inter limbi latera fere $1 / 2 \mathrm{~cm}$. longi. Spica sub anthesi $2 \mathrm{~mm}$. crassa. Stamina 4, rlachi inserta. Orarium sessile, superne in stilum eo brevius et glabrum contractum. Stigmata 3 linearia. Bacea stilifera.

Hab. in Barbados in silvis Turner's Hall Wood rara: Eggers n. 7157 .

Obs. Species forma limborum $P$. dilatatum Rich. sat referens, ab eo limbis majoribus, ramulorum structura et ovario stilifero ac hirtello discrepans. 
52. Piper angustilimbun C. DC. (n. sp.), foliis breviter petiolatis, oblongis, basi modice inaequilatera rotundatis, apice longe acuminatis acumine acuto, ntrinque praesertim ad nerros appresse et haud dense pilosis, nerro centrali fere usque ad $1 / 2$ longitudinis suae nervos adscendentes tenues utrinque 4 mittente, petiolo basi ima vaginante pedunculoque petioli totius dimidium fere aequante appresse pilosis; spica sub anthesi quam limbus pluries breviore et tenui, bracteae pelta triangulari margine pedicelloque angusto hirsutis.

Frutex. Ramuli tenues parce, sed sub nodis densius, appresse pilosi, cito glabrati, spiciferi vix $1 \mathrm{~mm}$. crassi collenchymate subeontinuo libriformi, fasciculis intramedullaribus 1 -seriatis canali vacuo nullo. Limbi in siceo tenuiter membranacei, minutissime pellucido-punctati, usqne ad $19 \mathrm{~cm}$. longi et ad $5 \mathrm{~cm}$. lati; petioli infra limbum $5 \mathrm{~mm}$, inter limbi latera vix $4 \mathrm{~mm}$. longi. Spica sub anthesi $1 \frac{1}{2} \mathrm{~mm}$. crassa, apice brevissime mucronulata. Stamina 4. Stigmata 3 .

Hab. in Tobago, in monte Morne d'Or, alt. 500 m.: Eggers n. 5870.

53. Piper incurvum Sieber, foliis modice petiolatis, ovatis, basi aequilatera rotundato-cordatis rel rotundatis truncatisve, apice obtusiuscule acuminatis, utrinque glabris, novemnerviis, nervo centrali usque ad $1 / 4$ longitudinis suae nerros utrinque 2 e basi et 2 supra basin alternos mittente, petiolo ultra limbi basin vaginante; spicis solitariis pedunculatis, quam limbi paullo brevioribus, rhachi villosula, bractea triangulari-obovata minuta sessili, extus inferne et intus hirsuta; baccis basi rhachi immersis et cum ea coalitis.

Piper ineurum Sicber! Mse. apud Selult. Mant. I (1822) 1. 238; C.DC. Prodr. XIT, 1 p. 294; Duss! Fl. placun. p. 177.

Piper guadeloupense C. DC. in Briquet Am. Jard. bot. Genève II (189S) p. 264.

Artanthe Martivicae Mir. Syst. Pip. (1844) p. 413 (teste Lrb.). Enckea reticulata Griseb.! T'eg. Kar. (1557) p. 48.

Scandens vel repens. Ramuli glabri, in sicco pallide fuscescentes, collenclyymate libriformi in fasciculos transrerse elongatos disposito, fasciculis intranedullaribus 2 -seriatis, eorum exterioribus paucis interioribus rero numerosis crassisque. Limbi in sicco firmi, opaci supra fuscescentes, subtus pallidiores et crebre fusco-punctulati, $9^{1 / 2} \mathrm{~cm}$. longi, circiter $8 \mathrm{~cm}$. lati; petioli circiter $4 \frac{1}{2} \mathrm{~cm}$. longi. Spicae maturae circiter $5 \mathrm{~mm}$. classae, fasciculis intramedullaribus destitutae. Stamina 4 minnta. Stilns nullus. Stigmata 4 .

Hab. in ?St. Croix ex West; Guadeloupe: L'Herminier, Duss n. 2565 ; Dominica ad Laudat alt. 600 m.: Eggers ed. 'Toepff. n. 661, hb. pr. n. 1006, Ramage; Martinique: Sieber 11. 254, Plée n. 702 (mus. Paris), in Forêt Bouillon: Hahn n. 1303 (in h. Cand. et Berol.), in montibus haud rara: Duss 1.9, 1333, in nemoribus interioribus ad fontem 
Absalon ubi cupiosum: Duss n. 4477; St. Vincent: H.H. et G. W. Smith n. 1923 (in h. Kew); - Guiana in silvis: Richard (in lı. Francav.).

54. Piper leptostachyum A. Rich. foliis brevissime petiolatis, elliptico-lanceolatis, basi aequilatera acutis, apice attenuato-acutis, supra glabris, subtus ad nervos minute puberulis, 5 -nerviis, nervis 3 centralibus validioribus subtus prominulis usque ad apicem ductis aliis tenuissimis, petiolo hasi ima raginante pedunculoque petiolum pluries superante minute puberulis; spica matura folium aequante laxiflora, rhachi puberula, bractea subrotundata coneava extus minute puberula; ovario oblongo, apice in stilum tetragonum producto; bacca ellipsoidea, apice in stilum brevem, basi in stipitem bacea multo breviorem attenuata.

Piper leptostachyum A. Rich.! in La Sagra C'ub. XI (1S50) p. 228; Sam: Fl. Cul. n. 2230 p. $14 t$.

Piper Lindeniamm C. DC. in Seem. Jomm. IV (1866) p. 218.

Piper cubense C. DC: Prodr: XVI, 1 (1S69) p. 336.

Encliea Amalago Griseb.! Cal. pl. Cub. (1S66) p). 65 (quoad Wright 11.513).

Ollonia punclata Griseb.! Cat. pl. Cul. (1866) p. 65.

Frutex $2 \mathrm{~m}$. altus. Ramuli puberuli, spiciferi vix $1 \mathrm{~mm}$. crassi, collenchymate haud libriformi in fasciculos discretos disposito, fasciculis intramedullaribus 1 -seriatis 8 , canali vacuo mullo. Limbi in sicco firmomembranacei, opaci, parce pellucido-punctulati, circiter $6 \mathrm{~cm}$. longi, $2 \frac{1}{2} \mathrm{~cm}$. lati; petioli fere $3 \mathrm{~mm}$. longi. Pedunculi usque ad $2 \mathrm{~cm}$. longi, in vivo purpurei; spicae rhachis vix $1 / 2 \mathrm{~mm}$. crassa. Flores in vivo albi. Stamina 3, rhachi inserta, filamentis adultis antheras cllipticas fere aequantibus. Stigmata 3 brevissima. Bacca matura cum stipite et stilo $5 \mathrm{~mm}$. longa et $2 \mathrm{~mm}$. in medio crassa glabra. Stigmata 3 brevissima ovata.

Hab. in Cuba orientali: Wright n. 513, 2272, ad La Prenda 800 m. alt.: Eggers 11. 5339, prope Santiago in Pinal de Hondones: Linden n. 1777 (fructiferum in h. DC.).

55. Piper Swartzii C. DC. foliis modice petiolatis, ellipticis, basi leviter inaequilatera acutis, apice acuminatis acumine obtusiusculo, utrinque glabris, 6-plinerviis, nerro centrali paullo supra basin nerrum ntrinque adscendentem opposite mittente, lateralibus externis tenuissimis e hasi solutis, petiolo basi ima vaginante pedunculoque petiolum adultum totum paullo superante minute puberulis; spica florente quam folii limbus sat breviore, bractea obovato-rotunda subcucullata glabra; orario oblongo glabro, superne in stilum aequilatum et aequilongum desinente; bacca sessili, elliptica, glabra, apice stilo mucronata.

Enclien Surtarii Griseb.! Fl. WT. Tnd. (1859) p. 169.

Piper psendoblatlarmm C. DC: in Limaen XXXITI (1871-73) p. 362 . 
Frutex S-perlalis. Ramuli juniores minute puberuli den glabri, spiciferi $1 \mathrm{~mm}$. crassi, collenclymate laud lilniformi in fasciculos discretos disposito, fasciculis intramedullaribus 1 -seriatis, canali racuo nullo. Limbi in sicco firmo-membranacei opaci pellucido-punctulati, usque arl $7^{1 / 2} \mathrm{~cm}$. longi et ad $5 \% \mathrm{~cm}$. lati; petioli infra limbum $6 \mathrm{~mm}$. et inter limbi litera usque ad $4 \mathrm{~mm}$. longi. Rluachis dense et minute puberula vix $1 \mathrm{~mm}$. crassa. Stamina 3, quorum unum posticum, antheris rotundatis, quam filamenta multo longioribus. Bacca matura cum stilo 3 mm. longa.

Hab. in Jamaica: Wilson n. 637 (in h. Criseb.), Narch n. 1393 (in l. Kew), in Blue mountains: W. Harris n. 5175 , below Tinegar Hill alt. $1200 \mathrm{~m}$. : TV. Harris n. 7417 (spec. fructiferum).

56. Piper aequale Talı, foliis breviter petiolatis, oblungo-ellipticis, basi subaequilatera acutis acutiusculisve, apice longinscule acuminatis acumine obtuso, utrinque glabris, nervis subtus vix prominulis, centrali usque ad $3 / 4$ longitudinis suae nervos subalternos patulo-subadscendentes tenues utrinque $6-7$ nervulis ralidis intermixtos mittente, petiolo basi ima raginante perunculoque petiolum fere aequante glabris: spica cylindriea obtusa. matura yuam folii limbus fere triplo breviore. bracteae glabrae apice truncato-peltatae pelta triangulari; bacca suboborato-trigona glabra.

Piper aequale Tahl Eelog. (1796) p. 4 t. 3 et Emmm. I 1\%. 315: (. 1)C. Prodr. XVI, 1 p. 310, in Engl. Juhrb. X p. 289; Hnss! Fl. phan. p. 178 .

? Piper pmetatum R. et I'ar. Flor. per. I (179S) p.36 t.62 fig.a; ?Opir in Reliq. Haenli. I p. 151.

Piper Martiamm C. I) C. l.c. (1869) p. 291 (quoad syn. Griseb.). Artanthe aequalis Miq. Syst. (1814) p. 511 et IIl. p. 79 t. SS; Giriseb.! Fl. II. Ind. p. 172.

Artonthe Mortiano Griseb. Fl. IV. Ind. (1859) p. 172 (erctus. syn. Schackii Miq.).

Malimbé Martin. ex I)uss.

Frutex erectus, 6 - $\mathrm{S}$-pedalis. Ramuli glabri, in sicco palliıli, nodis tumidis, collenchymate continuo libriformi, fasciculis intramclullaribus 1 -seriatis, canali racuo centrali. Limbi in sicco rigiduli, subpellucidi, minute pellucido-punctulati, usque ad $16 \mathrm{~cm}$. longi et ad $7 \mathrm{~cm}$. lati; petioli $8-17 \mathrm{~mm}$. longi. Spica matura fere $6 \mathrm{~cm}$. longa et $3 \mathrm{~mm}$. crassa. Stamiua 3 , basi ima baccae adnata. Stigmata 3 sessilia linearia.

Hab. in Haiti ad Pétionville: Picarda n. 437, 438; Montserrat: Ryan (in h. Tahl,. h. Willd. n. 649); Guadeloupe: Funck et Sehlin n. 29, l'Herminier (in l. Cand.), in silvis T'rois Rivières ubi frequens: Duss n. 2564; Dominica: Imray n. 225; Martinique: Hahn sin. num. (in h. Cand.), Duss n. 17, $1355^{\mathrm{b}}$, in vial La 'lrace prope Deux-choux ubi sat copiosum (frutex $0,8-1,5 \mathrm{~m}$. altus): Duss n. 4474; Sta. Lucia: 
Cruly (in h. Monac.), Anderson (in h. Kew); St. Vincent in silvis montium St. Andrews $730 \mathrm{~m}$. alt.: Eggers $\mathrm{n} .6765$; Tobago in convalli fluminis superioris Great dog river (arbuscula), in silva primaeva Montis Morne d'Or $500 \mathrm{~m}$. alt. (arhor 3,3 m. alta): Eggers 11.5779 , 5851, in silva Dog river: Eggger's n. 5762 (in h. (rött.); T'rinidad: Sieber n. 192 (in h. Berol.), Fendler n. 663; - praeterea in Nova Gramata: Lehmann n. 838; Brasilia: Riedel n. 287 (in h. Petrop.), Pohl n. 5035 (in l. Vindob.).

Var. $\beta$. ovalifolium C. DC. Prodr. XVI, 1 (1869) p. 511, foliis ovato-ellipticis, apice acuminatis acumine acuto, basi aequilatera rotundatis.

Hab. in Trinidad: Sieber n. 192 (in h. DC.).

Var. $\gamma$. Dussii C. DC. (n. var.), perennis repens et scandens ramis descendentibus.

Hab. in Guadeloupe, in nemoribus humidis ad Camp Jacob: Duss n. 2565.

Var. $\delta$. lasiocarpum C. DC. (n. var.), orario et bacea matura parce hirtellis.

Hiper aequale Kew Bull.! 1593 p. 270.

Frutex. Limbi $13 \mathrm{~cm}$. longi et ad $5 \mathrm{~cm}$. lati.

Hab. in Martinique in silvis humidis $400-700 \mathrm{~m}$. alt.: Duss n. 19, Bélanger n. 251; St. Vincent, rarum in silvis supra $330 \mathrm{~m}$. alt.: H. $\overline{\mathrm{H}}$. et G. W. Smith n. 1326,193 (in h. Kew).

57. Piper concinum C. DC., foliis breviter petiolatis, ellipticolanceolatis, basi aequalatera aut subinaequilatera acutis, apice longiuscule acuminatis acumine acuto, utrinque glabris, nervis subtus vix prominulis, centrali usque ad $3 / 4$ longitudinis suae nervos suboppositos adscendentes utrinque $3-4$ nervulosque validos mittente, nervis infimis fere e basi ortis, petiolo basi ima vaginante pedunculoque quam petiolus paullo breviore glabris; spica florente filiformi quam folium duplo breviore, bracteae apice truncato-peltatae pelta triangulari glabra, pedicello dorso basi hirtello.

Piper concinnum C. DC. Prodr. XVI, 1 (1869) p. 328.

Artanthe concinna Miq.! in Limnaea XY (1S47) p. 151 et in Iart. Flor. Bras. IV, 1 p. 43 t. 13 f. 2.

Ramuli glabri tenues, spiciferi $1 \frac{1}{2}$ mm. crassi, collenchymate continuo libriformi, fasciculis intramedullaribus paucis 1 -seriatis. Limbi in sicco rigiduli, subopaci, minutissime pellucido-punctulati, $9 \mathrm{~cm}$. longi, $3 \frac{1}{2} \mathrm{~cm}$. lati; petioli $1 \mathrm{~cm}$. longi. Spica florens fere $1 \mathrm{~mm}$. crassa.

Hab. in Brasiliae umbrosis silvis: Pohl n. 5032 (in h. Vindob.).

Var. $\beta$. trinitense C. DC. (n. var.), limbis oblongo-lanceolatis, usque ad $12 \mathrm{~cm}$. longis et fere ad $4^{1 / 2} \mathrm{~cm}$. latis, in sicco membranaceis, 
potiolis et pedunculis fere aequilongis fere $7 \mathrm{~mm}$. longis, spica florente Jimbi dimidium aequante vix $1 \frac{1}{2} \mathrm{~mm}$. crasso apice obtuso.

Artanthe xylosteoides Griseb.! Fl. W. Ind. (1859) p. 172; r. Dr:

Prodi. l. c. p. 293 (quoad sp. Trin.), - non Miq.

Hab. in Trinidad: Crueger (h. Griseb.), Bot. Gard. Herb. n. 1557.

5S. Piper Balbisianum C. DC. (n. sp.), foliis brevissime petiolatis, suborato-ellipticis, basi modice inaequilatera utrinque rotundatis, apice acuminatis acumine acuto, supra glabris, subtus ad nervos nerrulosque adpresse et haud dense pilosis, nervo centrali fere ad $1 / 2$ longitudinis suae nerros adscendentes utrinque 5-6 alternos mittente, petiolo haud dense appresse piloso, basi vaginante; pedunculo glabro quam petioli totius dimidium paullo breviore, spica quam limbus fere triplo breviore, bracteae pelta triangulari margine pedicelloque angusto hirsutis; bacca glabra.

Ramuli glabri subglabrive, spiciferi $3 \mathrm{~mm}$. crassi collenchymate haud libriforni in fasciculos distinctos disposito, fasciculis intramedullaribus 1 -seriatis, canali vacuo nullo. Limbi in sicco membranacci, minute pellucidopunctulati, usque ad $15^{1 / 2} \mathrm{~cm}$. longi et ad $8 \mathrm{~cm}$. lati; petioli infra limbum usque ad $7 \mathrm{~mm}$., inter limbi latera $3 \mathrm{~mm}$. longi. Spica matura $4^{1 / 2} \mathrm{~cm}$. longa, vix $3 \mathrm{~mm}$. crassa apice obtusa; rlachis glabra. Stamina 3 quorum unum posticum, hasi baceae inserta, antheris ovatis, quam filancenta paullo brevioribus. Bacca obpyramidato-trigona, glabra, in sicco nigra. Stigmata 3 sessilia linearia.

Hab. in Guadeloupe: Bertero (in herb. Krug et Urb. ex herb. Sprengel sub P. cornifolium).

$\checkmark \quad$ 59. Piper dominicanmm C. DC. (n. sp.), foliis breviter petiolatis, suborato-ellipticis, basi aequilatera rotundatis subrotundatisve, apice longiuscule acuminatis acumine obtusiusculo, utrinque glabris, nerro centrali fere ad $2 / 3$ longitudinis suae nervos subadscendentes utrinque 5-6 nerrulosque ralirlos mittente, petiolo basi raginante pedunculoque fere aequilongo glabris; spica submatura quam limbus fere triplo breviore, apice subacuta, bracteae pelta triangulari margine ciliolata, pedicello sat angusto in sicco membranaceo margine ciliato, rhachi glabra; bacea glabra.

Ramuli glabri, spiciferi $2 \mathrm{~mm}$. crassi, collenclymate in fasciculos discretos disposito libriformi, fasciculis intramedullaribus 1 -scriatis, canali vacuo centrali. Limbi in sicco membranacei minutissime pellucido-punctulati circiter $21 \mathrm{~cm}$. longi ct usque ad $11 \mathrm{~cm}$. lati; petioli ferc 12 mm. longi. Spica submatura vix $3 \mathrm{~mm}$. crassa in sicco rufescens; bracteae pelta magria $2 \mathrm{~mm}$. lata. Stamina 3, rhachi ad baccac basin inserta. Bacca obpyramidato-trigona. Stigmata 3 sessilia brerissima.

Hab. in Dominica: Duss n. 19.

Obs. Species a $P$. aepuedi Tahl forma ac magnitudine limbortum et ramulorum structura discrepans. 
60. Piper blattarum spreng. foliis breviter petiolatis, ellipticis, basi aequilatera acutis, apice acuminatis acumine obtuso, utrinque glabris, 5 -plinerviis vel fere 5-nerviis, nervis subtus prominulis, centralibus 3 plus minus alte et fere usque ad $1 / 3$ longitndinis supra basin rel interdum fere e basi solutis, petiolo basi vaginante pelunculorue petiolum 2-3-plo superante glabris; spica filiformi, matura folium superante, rlachi puberula, bractea minuta a bacea matura sat remota, apice truncato-peltata, pelta triangulari puberula, pedicello subeucullato; bacca globosa glabra.

Piper blattarm Spreng.! in Nene Emtdect. II (1821) p. 100; C. DC. Prods: X IT, 1 p. 329.

Peperomia blottommm A. Dietr. Sp. I (1831) p. 150.

Encliea blattarmm Kunth! in Limuara XIII (1839) p. 600; Miq.! Syst. 1). 364 .

Higuillo oloroso Portor, ex Sirt., Eggers.

Frutex $3-4 \mathrm{~m}$. altus, dichotome ramosus, nodis tnmidis, internodiis $2-6$ cm. longis, ramulis junioribus minutissime puberulis cito glabris, spiciferis circiter $1 \mathrm{~mm}$. crassis, collenchymate haud libriformi in fasciculos discretos transverse elongatos disposito, fasciculis intramedullaribus 1 -seriatis, canali vacto nullo. Limbi in sicco firmo-membranacei, creberrime pellucidopunctati, fuscescentes, $6 \frac{1}{2}-9 \mathrm{~cm}$. longi, $2 \frac{1}{2}-3^{1 / 2} \mathrm{~cm}$. lati; petioli $7-10 \mathrm{~mm}$. longi. Pedunculi ad $2 \mathrm{~cm}$. longi; spica alba (ex Sint.), matura circiter $12 \mathrm{~cm}$. longa, $1 \frac{1}{2} \mathrm{~mm}$. crassa. Stamina 3 , rhacli inserta, per anthesin inaequilonga, filamentis adultis antheras multo superantibus et exsertis prope basin articulatis tarde caducis. Bacea aurantiaca (ex Sisc.) fere $2 \mathrm{~mm}$. diametro. Stigmata 3 sessilia brevia obtusa, quorum unum plerumque anticum.

Hab. in Portorico: Bertero n. 482, Wydler 11. 407, prope Maricao in silvis montis Montoso, in Sierra de Luquillo in regione media montis Jimenes in silvis, prope Adjuntas ad margines silrae primaerae ar Guilarte, in Sierra de Naguabo ad margines silvae primaevae ad Los Ranchones, in Sierra de Lares ad Guajataca: Sintenis n. 217, 1663, 4618, 5362, 6255, in Sierra de Luquillo alt. $660-1000 \mathrm{~m}$. in silvis altis ad orillam amnium inter saxa: Egger's ed. 'Toepff. n. 969, hb. pr. 1171,1280 .

Var, $\beta$. magnifolium C. DC. Prodr. XVI, 1 (1569) p. 329 foliis majoribus et firmioribus, limbis $11 \mathrm{~cm}$. longis et fere $\overline{5} \mathrm{~cm}$. latis.

Hab. in Portorico: Bertero (in lı. Berol.), Eggers n. 1171 (in h. Kew).

()bs. Planta blattis infesta ex Bertero in schedulis, ideoque nomen specificum.

61. Pipel obtusum C. DC. foliis molice petiolatis, oblongoellipticis, basi inaequilatera utrinque obtusis, apice subattenuato-obtusis, 
supra glabris, subtus al nervum centralem minutissine puberulis dein glabris, nerro centrali subtus prominulo, paullo supra basiu nerros adscendentes oppositos utrinque 2 et altius nerrulos validos subadscendentes alternos mittente, petiolo usque ad limbi latus longius raginante pedunculoque petiolum totum fere aequante minute puberulis; spica matura folii limbum aequante, apice mucronulata, bracteae pelta triangulari margine pedicelloque angusto hirsutis; bacca glabra.

Piper obtusum (: DC: Prodr. XVI, 1 (1869) 1). 325.

Artanthe geniculata Griseb.! Cat. pl. C'ub. (1866) 1).65.

Ramuli minute puheruli, spiciferi fere $1 \mathrm{~mm}$. crassi, collenchymate hand libriformi in fasciculos discretos disposito peridermate subepidermidali sat crasso, fasciculis intramedullaribus 1 -seriatis, canali vacuo centrali. Limbi in sicco rigidulo-membranacei, pellucido-punctati, circiter usque $11 \mathrm{~cm}$. longi et $4^{1} \mathrm{~cm}$. lati; petioli infra limbum $5 \mathrm{~mm}$, inter limli latera vix $3 \mathrm{~mm}$. longi. Spica matura $2 \mathrm{~mm}$. crassa; rhachis glabra. Stamina 2, antice laterali rhachi ad basin baccae inserta, antheris rotundatis, filamenta fere aequantibus. Bacca tetragona, ad rhachin elongata. Stigmata 3 sessilia brevia.

Hab. in Cuba: Wright n. 2271 (in h. DC. et h. Kew).

62. Piper articulatum A. Rich. foliis breviter petiolatis, oblongooratis, basi subaequilatera cordatis, apice acuminatis, utrinque glabris, nerro centrali nerros patulo-adscendentes utrinque 4 mittente, quorum

- infimi non procul a basi soluti, petiolo usque ad limbum raginante pedumculoque petiolo aequilongo glabris; spica matura folium subsuperante, bracteae apice truncato-peltatae pelta lunulata margine hirsuta; hacca sessili subtetragona glabra.

Piper articulatum A. Rich.! in Sagra Cub. XI (1850) p. 227; Sanu. Fl. Cub. n. 2251 p. 145; C. DC. in Briquet Ann. Surd. bot. Genive $I I$ P. 26 .

Piper Sagranum C: DC: Prodr. XVI, 1 (1869) 1) 292.

Piper Sagraeanum Sanv. Fl. Cub. (18-1) n. $22+4$ p. 145.

Enckea articulata Griseb. Cat. pl. Cub. (1866) p. 6.5.

Ramuli glabri, collenchymate haud libriformi in fasciculos discretos disposito, fasciculis intramedullaribus 1 -seriatis, canali vacno centrali. Limbi in sicco firmulo-membranacei, minute pellueido-punctulati, usyue ad $12 \mathrm{~cm}$. longi et $6 \mathrm{~cm}$. lati; petioli all $12 \mathrm{~mm}$. longi. Spiea matura circiter $2 \mathrm{~mm}$. crassa. Stamina 2 lateralia, rhachi ad imam baceae basin inserta, filamentis: hrevissimis antheris rotundato-reniformibus. Stigmata 3 sessilia ovata brevia.

Hab. in Cuba: h. Rich. (in h. Francar. ubi $P$. articulatum dictum), Wright sine n. et R. de la Sagra (in h. Krug et Urb. et Kew), Wright n. 3677 (in h. Kew), n. 3675 (fid. Saur. l. c. sub P. Sagroeuno).

$\checkmark$ 63. Piper Picardae C. DC. (n. sp.), folis breviter petiolatis, e basi sat profunde cordata et aequilatera oblongo-ovatis, apice acuminatis, supra praesertim ad nerros puberulis, subtus tomentosis, 11-pli- 
nerviis, nervo centrali fere usque ad $1 / 3$ longitudinis suae nervos 2 adscendentes alternos oppositosve mittente, petiolo tomentoso ultra medium raginante; pedunculo tomentello petiolum fere aequante, spica matura folii limbum aeguante, apice mucronulata, rhachi glabra, bractene pelta lunulata margine pedicelloque angusto hirsutis; bacca glabra.

Ramuli tomentosi, spiciferi $1^{1}{ }_{2} \mathrm{~mm}$. crassi, collenchymatc haud liluriformi in fascirulos discretos disposito, fasciculis intramedullaribus 1 -seriatis, canali vacuo centrali. Limbi in sicco fulvescentes, firmule membranacci, opraci, pcllucido-punctulati, fere $11 \mathrm{~cm}$. longi et $5 \mathrm{~cm}$. lati; petioli circiter $16 \mathrm{~mm}$. longi. Spica matura $2 \mathrm{~mm}$. crassa. Stamina 2 lateralia, antheris reniformibus, quam filamenta brevioribus. Bacca tetragona. Stigmata 3 sessilia.

Hab. in Haiti, in planitie ad Payan alt. $800 \mathrm{~m}$., prope Jérémie: Picarda n. 156, 1343.

Forma b. limbis in sicco tenuioribus, usque ad $16^{1 / 2} \mathrm{~cm}$. longis et ad $9 \mathrm{~cm}$. latis petiolisque usque ad $5 \mathrm{~cm}$. longis.

Hab. in Haiti prope Corail alt. 1200 m.: Picarda n. 1344 .

64. Piper peltatum L. foliis longe petiolatis, adultis fere usque ad $1 / 4$ supra basin peltatis, rotundato-ovatis basi repando-cordatis cordatisve, apice protracto-acutis, adultis utrinque glabris, nervis subtus prominulis, centrali usque ad $1 / 3-1 / 4$ longitudinis a petiolo nervos alternos oppositosve adscendentes utrinque 2 et e basi nervos magis arcuatos utrinque $5-6$ mittente, petiolo usque ad $1 / 3$ longitudinis suae vaginante glabro; spicis pedunculo communi axillari glabro quam petiolus 3-4-plo breviore, $6-10$ umbellatis breviter pedunculatis densifloris, maturis quam petioli fere triplo brevioribus, bracteae inferne stipitiformis et glabrae apice peltatae pelta triangulari-lunulata, margine hirsuta; bacca apice glandulis conspersa.

Piper peltatum L.! spec. I ed. I (1753) 1. 30, II ed. I p. 42; Hill Dict. XXYI p. 19 t. 19 f. 4; Anbl. Hist. Guian. I p. 21; Lam. Ill. p. 81; Sunati Obs. p. 21; Willd. Sp. I p. 166; Tahl Eumu. I 1. 336; C. Dr: Prode. XVI, 1 p. 331; Samu. Fl. Cub. 11. 22.18 p. 145; Duss! Fl. Phan. p. 175; Kew Bull. 1893 p. 272.

Piper prumosmm Willd. Herb. "1. 705!; Kmuth in II. B. K. Nor. Gell. I (1815) p. 59.

Piper speciosmm Willd. Herb. n. ro4!, Kmuth l. c.

Piper scutatum Willd. Herh. 11. 703!

Heckeria peltata Kminth! in Limmea XIII (1839) p. 565.

Heclierin scutato Kunth! I. c.

Heekeria speciosa Kunth! l. $c$.

Peperomia penimose Kmuth Synops. I (1822) p. 12.; A. Diets: I p. 142 . 
Peperomia speciosa Krmth Sym. I (1822) p. 124; A. Dietr. Sp. I p. 142; Opio in Reliq. Haenk. rol. I p. 161.

Peperomia peltata A. Diete. Spec. I (1831) p. 142.

Peperomia scutata A. Nietr. l. c. p. 143.

Potomorphe peltata Miq.! Comm. phyt. (1838) p.37, Syst. p. 203, in Limaen X.T p. 229, in Mart. Flor. Bres. IV, 1 p. 26; Griseb.! Fl. W. Iud. p. 169 et Cat. pl. Cub. p. 64.

Potomorphe scutata Miq.! Comm. phyt. (1838) p.37, Syst. p.206, in Mart. Fl. Bras. IV, 1 p. 37.

Potomorphe speciosa Miq. Comm. phyt. (1838) p. 34, Syst. p. 205.

Saumus arborescens folies amplis rotundis umbil. Plum. Deser. plant. Am. (1693) p. 56 t. 74.

Poivrier en bouclier Descourtilz Fl. Ant. IV p. 14 t. 236; Basquiña cerrada Port. ex Krug; Corkwood Sab. ex Suring.; Bois anisette Mart. ex Duss.

Frutex 3-4-pedalis. Caules glabri, nodis parum tumidis, collenchymate haud libriformi in fasciculos discretos disposito, fasciculis intramedullaribus 2 -seriatis, canali vacuo centrali. Limbi in sicco membranacei, subopaci, crebre pellucido-punctati, $20-32 \mathrm{~cm}$. longi latique; petioli circiter $20 \mathrm{~cm}$. longi. Pedunculi communes teretes, $4-7$ cm. longi, ad $1^{1} / 2 \mathrm{~mm}$. crassi; spicae maturae $7-8 \mathrm{~cm}$. longae, fere $2 \frac{1}{2} \mathrm{~mm}$. crassae. Stamina 2 , basi ima baccae adnata, antheris reniformibus, quam filamenta brevioribus. Stigmata 3 minuta sessilia filiformia. Bacca obpyramidatotrigona, fere $1 / 2 \mathrm{~mm}$. longa.

Hab. in Cuba orientali: Wright n. $496,496^{\text {b }}$ (fide Sauv. l. c.); Jamaica: March (in h. Griseb.); Haiti prope Mariani: Picarda n. 497, in Norne Château ad Jérémie: Eggers n. 3396, ad Cap Haitien ad rivulum ultra Marchegal: Eggers n. $2845^{\circ}$; Sto. Doming o: Mayerhoff n. 339, prope Puerto-Plata in umbrosis silvarum juxta flumen Mameyes, ad rivulum circa La Rosa alt. 100 m.: Eggers n. 1623, 2482; Portorico, in silvis montis Montoso prope Maricao, prope Mayagüez: Sintenis n. 119, $119^{\text {b }}$, prope Mayagüez: Heller n. 4451, Krug n. 975; St. Croix ad Big Fountain: A. E. Ricksecker n. 446; Saba, in monte: Suringar; Nartinique: Jardin n. 344 (in h. Lenorm.), Hahn n. 255 (in h. Brit. Mus.), 1644 (in hr. Griseb.), locis humidis in Morne supra Boulevard St. Pierre: Duss n. 1340, 4037; St. Vincent: Guilding (in h. Kew), prope Calvary in montibus St. Andrews: Eggers n. 6793, commune in omnium rallium silvis: H. H. et G. W. Smith n. 190; Barbados prope St. Joseph's Church in fossis ad viam:-Eggers n. 7305; Grenada, prope Belvedere in montibus alt. 500-600 m.: Eggers n. 6123; Tobago, locis humidis in Kings Bay alt. circ. 33 m.: Seitz n. 68, in convalli fluminis Bacolet ad Cradley versus in humidis: Eggers n. 5719; Trinidad, in horto bot.: Herb. Trin. n. 5531; - praeterea in America centrali, Colımbia, Venezuela, Urban, Symb. ant. III. 
Guiana, Ecuador, Peruvia, Brasilia (vide C. DC. Prodr. l. c., in Bull. h. Boiss. V p. 702 , VI p. 494 , in Dur. et Pitt. Primit. I p. 126 , II, 3 p. 277, Domn. Smith Enum. II p. 66, V p. 65).

Var. ßr. hirtellum C. DC. (n. var.) ramulis pedunculis petiolis limbisque al nervos utrinque dense breviter lirtellis, amentis $4-5$ pedunculo communi umbellatis.

Hab. in Cuba, in silvestribus umbrosis ad El Aji $200 \mathrm{~m}$. alt.: Eggers n. 4664; Haiti in parte septentrionali locis umbrosis humidis prope Dondon: W. Buch n. 452.

65. Piper umbellatum L. foliis longe petiolatis, rotundato-reniformibus, basi profunde cordatis, apice attenuato-acutis, supra subtusque ad nervos breviter hirtellis, nervis subtus prominulis, centrali fere usque ad $1 / 6$ longitudinis nerros 1 - 2 alternos vel suboppositos adscendentes et 5-6 e basi ipsa divaricantes mittente, petiolo fere usque ad $1 / 2$ longitudinis raginante dorso striatim hirtello vel hirsuto; spicis pedunculo communi quam petiolus pluries breviore et juniore striatim hirtello 4-7-umbellatis breviter pedunculatis, maturis quam petioli fere duplo brevioribus, densifloris, apice obtusis, bracteae inferne stipitiformis et adultae glabrae apice peltatae pelta triangulari-lunulata margine hirsuta; bacca apice glandulis conspersa.

Piper umbellatum L. Sp. I ed. I (1753) p. 30, II ed. p. 43; Hill Dict. XXVI p. 20 t. 20 f. 2; Aubl. Hist. Guian. I p. 22; Jacq. Ic. var. t. 216; Lam. Ill. p. 81; Vahl Enum. I p. 336; Suavtz Obs. p. 21; Willd. Sp. I p. 167 et Herb. n. 700!; Kumth in H. B. K. Nov. Gen. I p. 59; Opis in Reliq. IIaent. I p. 161; Vell. Fl. fum. t. 54; A. Rich. in La Sagra Cub. XI p. 227; C. DC. Prodr. XVI, 1 p. 332 ; Sauv. Fl. Cub. n. 2219 p. 145.

Piper peltatum R. et Pav. Fl. per. I (1798) p. 38 t. 59 f. a.

Piper latifolimm Lam. Ill. (1791) p. 81.

Piper sidacfolium Link et Otto Ic. pl. sel. (1820) p. 15 t. 6!

Piper subpeltatum var. $\beta$. sidaefolium C. DC. Prodr. (1869) p. 334.

Peperomia umbellata Kunth Synops. I (1S22) p. 124; A. Dietr. Sp. I p. 142.

Peperomia sidaefolia A. Dietr. I (1831) p. 141 (exchs. sym. Roem. et Schult.).

Heckevia umbellata Kunth! in Limnaea XIII (1839) p. 569.

IIeckeria sidaefolia Kunth! in Limaea XIII (1839) p. 569; O. Tt:e. Rev. II p. 564 .

Potomorphe umbellata Miq.! Comm. phyt. (1838) p. 36, Syst. 1.208, in Limnaca XX p. 629, in Mart. Flor. Bras. IV, 1 p. 26; Griseb.! Flor. W. Ind. p. 169, Cat. pl. Cub. p. 64. 
Potomorphe sidaefolia Miq.! Syst. (1843) p. 209, in Limmaca XI p. 129, in Mart. Flor. Bras. IV, 1 p. 25, in Hook. Lond. Journ. Bot. IV p. 431.

Sanrurns arborescens folis amplis cordatis non umbilicatis Plum. Descr. plant. Amer. (1693) p. 55 t. 73.

Poivrier à Ombelles Descourtil: Fl. Ant. I (1821) p. 177 t. 37; Basquiña Port. ex Krng et Sinteris.

Frutex circiter $2 \mathrm{~m}$. altus, ramulis striatim hirsutis, spiciferis fere $5 \mathrm{~mm}$. crassis, collenchymate zona interna et laterali libriformi in fasciculos discretos disposito, fasciculis intramedullaribus 1 -seriatis, canali vacuo centrali. Limbi in sicco membranacei, subpellucidi, minute et crebre pellucido-punctati, adulti $17-18 \mathrm{~cm}$. longi, $22-23 \mathrm{~cm}$. lati; petioli adulti circiter 20 cm. lougi. Pedunculi communes (prophyllo fertili) in eadem axilla saepe binati ad $15 \mathrm{~mm}$. longi, pedunculi ipsi $7 \mathrm{~mm}$. longi; spicae maturae fere $3 \mathrm{~mm}$. crassae. Stamina 2 rhachi ad basiı ovarii inserta, antlieris rotundatis quam filamenta brevioribus. Bacca obpyramidato-trigona. Stigmata 3 sessilia linearia.

Hab. in Cuba: Alambique, Wright 496 (in h. Monac.), prope Yumury: Rugel n. 382; Jamaica: Swartz l. c., Murray n. 28 (in h. DC.), in planitie prope Kingston: Hansen, inter Moore Park et Portland: Harris 11. 6631, ad Norwich: C. F. Nillspaugh n. 1870; Haiti: Picarda n. 106, Poiteau (in h. DC. et h. Berol.); Sto. Domingo ad Jarabacoa alt. 550 m.: Eggers 11. 2010 (in h. Goett.), prope Jarabucoa ad ripam rivuli Yerba buena alt. $500 \mathrm{~m}$. , in silvis montis Isabel de la torre alt. $300 \mathrm{~m}$.: Eggers n. 2070, 2795; Portorico: Bertero (in h. DC.), prope Jlaricao in fluminis convalli, prope Cayey in silva ad Planaje locis humidis, prope Utuado in scopulosis ad Los Angeles et in silvula Coff. arab. ad Roncador: Sintenis n. 466, 2316, 6224, 6264, 6497, prope Mayagüez: Krug. n. 974, prope Rio de Mameyes alt. $500 \mathrm{~m}$. in locis humidis: Eggers ed. Toepff. n.882; - praeterea MIexico, Panama, Venezuela, Colombia, Guiana gallica, Brasilia (vide C. DC. Prodr. 1. c. et in Bull. h. Boiss. V p. 702).

\section{Species exoticae in Antillis cultae.}

66. Piper papantlense C. DC., foliis modice petiolatis, basi aequilateris, apice acuminatis acumine acuto, inferioribus ovatis, basi rotundatis cordatisve, supremis ovato-lanceolatis, basi acutis, omnibus utrinque glabris, 5-7-nerviis, nervis subtus prominulis, petiolo usque ad $1 / 3-1 / 2$ longitudinis vaginante pedunculoque aequilongo glabris; spica matura folium aequante vel superante, bracteae apice truncato-peltatae pelta triangulari margine minute ciliolata, rhachi hirtella; bacca obovatosubtetragona glabra. 
Piper papantlense C. DC. Prodr. IVI, 1 (1S69) p. 398, in Dur. et Pitt. Primit. I p. 277.

Piper diandrum C. DC. in Limaca XXXVII (1871-73) p. 364.

Ramuli glabri, spiciferi circiter $1 \frac{1}{2} \mathrm{~mm}$. crassi, collenchymate continuo haud libriformi zona cellularum sclerosarum contimua circumdato, fasciculis intramedullaribus 1 -seriatis. Limbi in sicco firmo-membranacci, minute pellucido-punctulati vel epunctulati, superiores circiter $11 \mathrm{~cm}$. longi et $5 \mathrm{~cm}$. lati; petioli $15-25 \mathrm{~mm}$. longi. Spicae maturae usque ad $25 \mathrm{~cm}$. longae et $4 \mathrm{~mm}$. crassae. Stamina 2, rhachi inserta, antheris reniformibus quam filamenta brevioribus. Bacca sessilis. Stigmata 4 sessilia linearia.

Hab, in Dominica cultum, unde ab Imray ad hort. Kew. missum; patria est Mexico in silvis Papantla: Fischer n. 74 (in h. Petrop.) et America centralis (vide C. DC. in Linn., Dur. et Pitt. I. c., Donn. Smith Enum. part 4 p. 182).

67. Piper retrofractum Vahl, foliis breviter petiolatis, oblongoellipticis, basi subaequilatera vel inaequilatera subacutis obtusisve vel rotundatis, apice attenuato-acuminatis, utrinque glabris, nervis subtus prominulis, centrali usque ad $2 / 3$ longitudinis suae nervos alternos adscendentes utrinque 3 nervulosque, ralidos aliquot mittente, petiolo basi ima raginante pedunculoque petiolum totum aequante vel paullo superante glabris; stirpis masc. spica florente quam folii limbus breviore, bractea rotundata centro sessili glabra et coriacea, staminibus $2-3$ plerumque 2 , antheris subsessilibus, oblongis et subtetragonis; stirpis fem. foliis plerumque majoribus, spica quam limbus multo breviore, bractea ut in mare, ovario rhachi immerso ac inferne cum ea concreto, baccis subglobosis coalitis, stigmatibus 3 .

Piper retrofractum Vohl! Enmm. I (1801) p. 314.

Piper longmm Rmmph. Amb. V (1747) p. 333 t. 116 f. 1 (prava).

? Phamacum longum valgare Rumph. l.'c. p. 42 t. 26 f. 1.

? Piper Amalago Rheede Mal. T'II (168S) p. 31 t. 16 (longitudine amentorm diversmm).

Piper. Amalago L. Sp. I ed. (1753) p. 29 et II ed. p. 41 (exchnsis syn. Sloame, Ilukenet et Rheede?).

? Piper melaminis Hill Dict. XXVI (1775) t. 16 fig. 3.

Piper longmm Piso Mont. arom. (1658) p. $182 \mathrm{cmm}$ icone.

Piper maritimum Bl. in h. Lngd. bat.

Piper longmm Bl.! in Terh. der bot. Genoots. XI (1826) p. 197 t. 19, Emm. pl. jai: 1 p. 70.

Piper callosum Opiz in Msc. (Haente $2.73 !$ in h. Mart.).

Piper officinarum C. DC. Prodr. X IT, 1 (1869) p. 356.

Piper Choba Hook. in Flor. Brit. Ind. V (1890) p. 84.

Chavica officimanm Miq.! Syst. (1843) p. 236 , Illustr. p. 39 t. 34. 
Charica maritima Miq.! Syst. (1813) p. 26.), Iltustr. p. 40 t. 35.

Chavica Labillurdieiri Miq. Syst. (1813) p. 263.

Chacica? retrofracta Miq.! Syst. (1813) \%. 275.

Frutex scandens, ramulis glabris, spiciferis femineis al $2 \mathrm{~mm}$. crassis, masculis tenuioribus, collenchymate hand libriformi in fasciculos discretos disposito, cellulis sclerosis inter liberos fasciculos periphericos, fasciculis intramedullaribus 1 -seriatis, canali racuo centrali. Limbi in sicco firmomembranacei, minute pellucido-punctulati, $\delta^{1}{ }_{2}-16 \mathrm{~cm}$. longi, $3^{1 / 2}-6^{1 / 2} \mathrm{~cm}$. lati; petioli infra limbum $5-10 \mathrm{~mm}$., inter limbi latera usque ad $5 \mathrm{~mm}$. longi. Pedunculi fem. fere $15 \mathrm{~mm}$. longi; spicae masc. florentes fere $5 \mathrm{~cm}$. longae et $3 \mathrm{~mm}$. crassae, fem. mat. ad $10 \mathrm{~mm}$. crassae; rhachis glabra. Bracteae fere $1^{1}, 2 \mathrm{~mm}$. diametro. Antherae subtetragonae, rimis lateralibus dehiscentes, connectiro ultra loculos haud producto. Stigmata brevia ovata.

Cultum in St. Tlon mas, ubi rerisimiliter ex insula Trinitatis allata et ad habitationes et in hortis haud frequens, ad arbores scandens: Eggers hb. pr. n. 551, ed. Toepff. n. S\$1; in Timor, Celebes, Phillipinis, Sumatra, Jara indigenum ac in China et India cultum (vide: C. DC. 1. c. sub $P$. officinarmm).

68. Piper Betle L. foliis modice rel longe petiolatis, rotundatooratis vel superioribus oratis, omnibus apice acuminatis, acumine acuto, basi subinaequilatera rel inaequilatera, inferioribus cordatis, superioribus rotundatis, utrinque glabris, 5-9-plinerriis plerumque 7 -plinerriis, nerris subtus prominulis, centrali fere usque ad $1 / 3-1 / 4$ longitudinis suae nerros adscendentes utrinque $1-2$ mittente, caeteris nerris e basi solutis, petiolo usque ad $1 / 3-1 / 4$ longitudinis vaginante glabro; pedunculo glabro in mare petiolum aequante, in femina eum superante; stirpis masc. spica adulta folii limbum aequante, bractea rotundata vel oborata centro sessili, rhachi livtella, staminibus 2 filamentis brevibus latis; stirpis fem. spica quam folium pluries breviore, bractea ut in mare, ovario rhachi immerso et inferne cum eo coalito apice tomentoso, stigmatibus $4-5$ lanceolatis breribus; baccis coalitis.

Piper Betle L.' Spec. I cd. I (1753) 1). 28 et II ed. p. 10 et Flor. Zeyl. p. 27; Herb. Burm. III p. 32 et IT f. 9; Hill Dict. IX II p. 16 t. 16 fig. 2; Lam. Illnstr. p. 79; Tahl Enmm. I p. 32S; Trilld. Sp. I 1. 159; Roxb. Fl. Ind. I p. 160; Lond. Fneyel. 11. 50 ; P. 28; Bl. in Verh. der bat. Genoots. XI p. 206; (Y. DC. Prodr. XITI, 1 p. 359; Ilook. Fl. Birit. Ind. Ir p. 85.

Piper malamiris L. Sp. I ed. (1553) p. 29, II ed. p. 11 (quoad syn. Rumph.): Fahl Emmm. I p. 327; Lam. Ill. p. 79?

Chavica Betle Miq.! Syst. (181.3) 1. 22S, in Limmea IX p. 130, Flor. Ind. bat. I pars 2 p. 139, smmatian p. 412.

Charica amriculata Miq.! S!yst. (1S43) p. 269. 
Artanthe hexayyna Wiq.! Syst. (1S14) 1..112.

Sirit folium Rumph. Amb. I (1747) 1.336 t. 116 fig. 2..

Beelle Codi Rheede Mal. T'II (16SS) p. 29 t. 15.

Frutex scandens ramulis glabris, spiciferis circiter $21 / 2 \mathrm{~mm}$. crassis, collenchymate continuo ant subcontinuo sparse libriformi, cellulis brmneis in parenchymate corticali ac in medulla numerosis, fasciculis intramedullaribus 1 -seriatis. Limbi in siceo firmo-membranacei, quam minutissime pellucido-punctulati, $10-13 \mathrm{~cm}$. longi, $4^{1} / 2-9 \mathrm{~cm}$. lati; petioli $1 \frac{1}{2}-2 \frac{1}{2} \mathrm{~cm}$. longi. Spicae masc. fere $2 \mathrm{~mm}$. crassae; stamina lateraliter compressa; antherae breves, apice rimis dehiscentes, connectivo nltra loculos hand prodncto. Filamenta quam antherae paullo breviores aequilata. Spicae fom. maturae fere ad $5 \mathrm{~cm}$. longae et ad $1 \mathrm{~cm}$. crassae.

Hab. in Guadeloupe: Duss n. 2833 (fide Duss 1. c.), Bertero (h. DC.); Martinique ubi cultum: Duss n. 1339; St. Vincent, in silvis ad St. Andrews $330 \mathrm{~m}$. alt., ad arbores scandens et a ramulis pendens: H. H. et G. W. Smith n. 1641; Trinidad: Sieber n. 382 (in h. DC.), ad Port of Spain: h. Trin. n. 5223; in Nova Guinea, Philippinis, Borneo, Java, Sumatra, Tonkin, Hongkong indigenum ac cultum. In India orientali cultum (vide C. DC. I. c. et in Ann. Jard. bot. Genève II p. 272, Schum.-Lauterb. Flora d. d. Schutzgeb. p. 260).

69. Piper nigrum $\mathrm{L}$. foliis modice petiolatis, inferioribus rotundato-oratis, basi aequilatera rotundatis vel leviter cordatis trumeatisve, superioribus ovato-ellipticis ellipticisve plerumque inaequilateris, basi subaequilatera obtusis acutiusculisve, omnibus apice acuminatis acumine acuto, utrinque glabris 7 -pli-9-plinerviis, nervis adscendentibus subtus prominulis, 3 centralibus fere ad $1 / 6-1 / 7$ longitudinis supra basin solutis alternis vel subalternis, caeteris e basi solutis, petiolo usque ad $1 / 2-2 / 3$ longitudinis vaginante peduneuloque subaequilongo glabris; spica hermaphrodita vel unisexuali, matura sublaxiflora folium aequante pendula, rhachi hirtella, bractea oblonga glabra margine libera, basi obtusa apice rotundata; staminibus 2 ; stigmatibus $3-5$; baccis liberis globosis in sicco nigris.

Piper nigrum L.! Spec. I ed. (1753) p. 28 et II ed. p. 40 et Filor. Zeyl.n.26; h. Burm. III f. 21 et 44 et IV f. 21; Vahl Enum. I p. 329; Hill Dict. XYVI p. 26 t. 26 fig.1; Loud. Encycl. n. 505 p. 28; Willd. Sp. I p. 159; Mart. Syst. mat. med. p. 99; Spach Hist. phan. t. 125; Klotrsch in Hayne draneigew. XIV t. 6; Hassk. Pl. Jav. rar: p. 19.4; Bl. in Verh. d. bat. Genoots. XI p. 191, Enum. Pl. Jav. I p. 69; Miq..' Syst. p. 308, Illustr. p. 50 t.50, in Hook. Lond. Jourm. bot. IV p.438; Schnitrl. Icon. t. 81 fig. 1-5; C. DC. Prodr. XVI, 1 p. 363; Hook. Flor. brit. Ind. Y p. 90; Duss! Ft. Phan. p. 179; Kew Bull.! 1893 p. 272.

Piper fallax Vahl! Enum. I (1804) p. 335. 
Piper spurium Link Emmm. Horti Berol. (1S21) p. 37 (fid. Roem. et Schult.).

? Piper colomum Presl Bot. Bemerli (1S+4) p. 112.

Piper rotmdum nigrmu Pluk. Alm. (1696) p. 297 t. 437 fig. 1; Ioris. Hist. p. 602 t. 15 fig. 1.

Malago Cod Rheede Mal. VII (1688) p. 23 t. 12.

Poivrier aromatique Descount. Flor. Ant. VI (1828) p. 182 t. 424 .

Frutex scandens, dioicus rel monoicus et tum stirpe hermaphrodita sterili trioicus, ramulis glabris, spiciferis usque ad $3 \mathrm{~mm}$. crassis, collenchymate continno libriformi, fasciculis intramedullaribns 1 -seriatis, canalibus racuis inter fascicnlos periphericos et intramedullares unoque centrali. Limbi in sicco juniores membranacei et minute pellucido-punctulati, adulti coriacei opaci, usque ad $13 \mathrm{~cm}$. longi et ad $9 \mathrm{~cm}$. lati; petioli $2-3 \mathrm{~cm}$. longi. Filamenta crassa brevia; antherae quam filamenta multo breviores, rotundato-reniformes, connectivo nltra loculos hand producto. Stigmata lanceolata reflexa decidua.

Cultum in Antillis ex Descourt. l. c.; Guadeloupe: Bertero, Basse terre: Duss n. 2832 (fid. Duss); Martinique: Duss n. 1338; St. Vincent in silvis leeward side alt. $500 \mathrm{~m}$. ad arbores, rarissimum: H. H. et G. W. Smith n. 1324; - Brasilia ubi cultum: h. DC.; indigenum ac cultum in insulis Sundaicis, Tonkin, Ceylon, India orientali (vide: C. DC. Prodr. l. c. et in Ann. Jard. bot. Genève II p. 274, in Schum.Lauterb. Flor. d. d. Schutzgeb. p. 261).

70. Piper Christyi C. DC. (n. sp.), foliis modice petiolatis, oratorotundis, basi aequilatera rotundatis, apice acute acuminatis, utrinque glabris, 7-plinerriis, nervis tenuibus 3 centralibus paullo supra basin solutis, petiolo basi ima raginante pedunculoque aequilongo glabris; spicis masc. florentibus folia superantibus filiformibus glabris, bractea adulta obovato-oblonga, rhachi alnata, margine libera, apice rotundata, basi attenuata; staminibus 4 , interdum 5 quorum unum centrale.

Ramuli glabri, nodis vix tumidis, spiciferi $1 \mathrm{~mm}$. crassi collenchymate haud libriformi in fascicnlos discretos disposito, fasciculis intramedullaribus 1 -seriatis. Limbi in sicco firmo-nembranacei, inconspicue pellucidopunctulati, usque ad $71 / 2 \mathrm{~cm}$. longi et ad $6 \frac{1}{2} \mathrm{~cm}$. lati, nervis centralibus fere $7 \mathrm{~mm}$. supra basin solutis; petioli superiores fere $1 \frac{1 / 2}{2} \mathrm{~cm}$. longi. Spicae masc. florentes fere $13 \mathrm{~cm}$. longae, vix $2 \mathrm{~mm}$. crassac; bracteae $2 \mathrm{~mm}$. longae. Antherac ovato-rotundae, filamenta superantcs, connectivo ultra loculos haud producto.

In horto 'l'rinidad culta, ubi a T. Christy et Co. Londini missum: Herb. hort. Trin. n. 5009, 5663. mulosis.

Obs. Numero 5663 adsunt inflorescentiae monstrosae cum spicis ra- 


\section{Verhuellia Miq.}

T'erhuellia Miq. Syst. Pip. p. 17 (pro parte) et Ill. Pip. p. 5 t. 1 fig. .1; C. DC. in Lém. Soc. Phys. XVIII t. 1 fig. 5 -s et Prodr. YYI, 1 p. 391 (pro parte); Benth. et Hook. Gen. III p. 131; Schmits in Filora 1872 p. 422 t.6, 7; Engl. in Engl.- Prantl Pfl.-fam. III, 1 p. 10. Mildea Ciriseb. Cat. pl. Cub. p. 63.

Bractea hypopeltata a flore libera. Flores spicati hermaphroditi. Stamina 2 lateralia, antheris 4 -locularibus maturitate 4-valvatis. Stigmata 4. Ovulum 1-teguminatum. - Herbulae repentes. Caulis fasciculo fibrovasculari unico centrali et structura concentrica nunitus. Folia ad nodos radicantes rosulata inaequalia, adspectu verticillata vero alterna. Pedunculi spiciferi e centro rosularum surgentes.

\section{Clavis specierum.}

Limbi adulti reniformes. Bracteae pelta rotundato-elliptica

71. V. Imuria C. DC.

Limbi adulti rotundato-reniformes. Bracteae pelta obovata

72. V. pellucida Schmitz

Limbi adulti orbiculato-cordulati. Bractene pelta orbicularis

73. V. hydrocotylifolia C. Wright

71. Verhuellia lumaria C. DC. foliis in rosula 3-6 longe petiolatis, adultis late reniformibus, basi cordulatis, apice rotundatis, supra sparse pilosulis, subtus glabris subglabrisve, tenuissime 5-nerriis, petiolo pedunculoque petiolum evolutum fere aequante glabris; spica filiformi laxiflora, folii limbum fere triplo superante, bractea rotundato-elliptica, glandulis conspersa, paullo infra medium peltata brevissime pedicellata; filamentis brevibus, antheras longitudine vix aequantibus, antheris transverse oblongis, loculis connectivo valde segregatis; orario epidermidis cellulis productis hispidulo, ovato, inferne breviter attenuato, superne breviter subcylindrico; stigmatibus linearibus recurvis.

Peperomia hnaria Ham.! Prodr. Fl. Ind. Occ. (1825) p. 2; C. DC. Prodr. XVI, 1 p. 467.

Verhuellia elegans Liq. Syst. (1843) p. 48 et Illustr. l. c.; C. DC. Mém. Soc. phys. l. c. (errore typ. sub V. reniformis) et Prodr. l. c. (excl. syn. A. Dietr.); Schmitz l. c.

Piper reniforme Willd. Herb. n. 742!, ed. Limk Jahrb. I. III (1820) p. 64 (non Poir.).

Peperomia reniformis A. Dietr. Spec. I (1831) p. 162.

Peperomia serpens Griseb. Flor. (1859) p. 164 (excl. syu. Su.).

Peperomia Innaris A. Dietr. Spec. I (1831) p. 167.

Verhuellia sp. incert. Niq. Syst. (1843) p. 49. 
Caulis glaber, in sicco fere $1 / 2 \mathrm{~mm}$. crassus membranaceus. Limbi in sicco tenuiter membranacei, pellucidi, usque ad $1 \mathrm{~cm}$. longi et $1 \frac{1}{\mathrm{~g}} \mathrm{~cm}$. lati; petioli membranacei usque ad $4 \mathrm{~cm}$. longi.

Hab. in Haiti: Poiteau (in h. Francar. et h. Willd. n. 742), Hamilton (in h. MLus. Par.).

72. Verhuellia pellucida Schmitz, foliis in rosulis 4-5, adultis longe petiolatis, rotundato-subreniformibus, basi subtruncata in petiolum breviter contractis, apice rotundatis, supra sparse pilosulis, subtus glabris subglabrisve, tenuissime 3-5-nerviis, petiolo pedunculoque petiolum evolutum paullo superante glabris; spica filiformi laxiflora, submatura folii limbum paullo superante, bractea obovata infra medium peltata et breviter pedicellata; filamentis brerissimisl, antheris transverse oblongis, loculis connectivo lato valde segegratis; ovario epidermidis cellulis productis hispidulo, inferne breviter attenuato, superne breviter cylindrico; stigmatibus linearibus recurris; bacca subglobosa epidermidis cellulis productis hispidula.

Verhuellia pellucida Schmits in Flora 1872 p. 122 t. 8 fig. $31-43$.

Verhuellia elegans C. DC. Prodr. XII, 1 (1869) p. 391 (quoad spec. Wrightii); Sauv. Fl. Cub. n. 2252 p. 145.

Mildea elegans Griseb. Cat. pl. Cub. (1866) p. 63.

Herbula gregarie repens, caulibus filiformibus glabris in sicco fere $1 / 4 \mathrm{~mm}$. crassis. Limbi in sicco tenuiter membranacei, pellucidi, maximi usque ad $10 \mathrm{~mm}$. longi et $13 \mathrm{~mm}$. lati; petioli usque ad $21 / 2 \mathrm{~cm}$. longi, membranacei.

Hab. in Cuba occidentali: Wright n. 2264.

73. Verhuellia hydrocotylifolia C. Wright, foliis in rosulis $3-5$, longiuscule petiolatis, orbiculato-cordatis vel subreniformi-cordatis, supra sparse pilosulis, subtus glabris, tenuissime $3-5$-nerviis, petiolo pedunculoque petiolum evolutum fere duplo superante giabris; spica filiformi, folii limbum paullo superante, bractea orbiculari, centro peltata et pedicellata; filamentis antheras longitudine superantibus, antheris transverse oblongis, loculis connectivo lato valde segregatis; orario sub apice nudo contracto, inferne orato, epidermidis cellulis productis hispidulo; stigmatibus linearibus recurvis.

Terhuellia hydrocotylifolia C. Wright in Sauv. Cub. (1871) 11. 2253 p. 145; Schmits in Flora 1872 p. 403 et 422 t. 7 fig. $1-36$.

Mildea hydrocotylifolia Griseb.! Cat. pl. Cub. (1866) p. 63.

Verhuellia cordifolia C. DC. Prodr. X TI, 1 (1S69) p. 391.

Herbula gregarie repens, caulibus tenuissime filiformibus, in sicco fere ${ }^{1 / 4} \mathrm{~mm}$. crassis. Limbi in sicco tenuiter membranacei, pellucidi, maximi $4 \mathrm{~mm}$. longi et fere $7 \mathrm{~mm}$. lati; petioli usque ad $9 \mathrm{~mm}$. longi membranacei. Hab. in Cuba occidontali, in rupibus montis Toro: Wright n. 2266. 
III. Peperomia Ruiz et Pav.

I'iper L. (ie'n. et Sp. (pro parte). - I'eperomia Ruis et I'au. Prodr. Fl. per: (179t) p. S t. 2, Fl. per. I p. 29; Kunth in II. B. K. Nov. Gen. I p. 60; A. Dietr. Sp. I p. 1H1; Miq. Syst. Itip. p. 63; Giriseb. Fi. W. Ind. p. 164; C. DC. Prodr. XIT, 1 p. 392; Hensch. Etud. Pep. in Nor. Act. reg. Soc. Upsal. ser. 3 vol. VIII; Benth. et Hook. Gen. III p. 132; Engl. in Eugl.-Prantl Pflamsen-fam. III, 1 p.10; H. Dahlstedt Stndien ïber süd-u. central-amerik. Peperomien in Kongl. Svenska Vetensliaps-Alad. Handl. Band XXXIII no. 2 (1900).

Bractea a flore libera vel rarissime (tantum in duabus speciebus) cum flore concreta. Flores hermaphroditi spicati, saepissime post anthesin rhachis processu conico in sicco plerumque inconspicuo suffulti. Stam in a 2 lateralia, antheris 2 -locularibus, maturitate 2 -valvatis. Stigma unicum parvum rotundatum vel raro 2-lobatum-partitum, lobis brevissimis. Ovulum 1-teguminatum. - Herbae. Systema fibrovasculare fasciculis discretis in caulis sectione transversali numerosis et sparsis aut paucis et tum circa medullam centralem. dispositis formatum.

Obs. Folium multinervium dico, quando nervi omnes e basi limbi discedunt; multiplinervium, quando partim e basi limbi partim supra e nervo centrali abeunt; penninervium, quando nervi laterales omnes supra basin limbi e nervo centrali abeunt.

\section{Clavis specierum.}

A. Bractea a flore distincta et hypopeltata.

a. Folia alterna (cf. n. 77).

$1^{0}$. Ovarium apice stiliferum.

Bacca inferne in stipitem attenuata 74 . P. hispidula A. Dietr.

$2^{0}$. Orarium stilo destitutum.

† Ovarium summo apice vel paullo infra apicem et oblique stigmatiferum.

Bacca inferne in stipitem attenuata.

Limbi ovati $1 \frac{1}{2} \mathrm{~cm}$. longi 75. P. tenella A. Dietr.

Limbi orbiculares $3 \mathrm{~mm}$. diametm

76. P. emarginella C. DC.

$\bigcirc \bigcirc$ Bacca hand inferne in stipitem attenuata seu sessilis.

$\times$ Folia parva, id est limbis longitudine $2 \mathrm{~cm}$. haud superantibus.

- Limbi lanceolati ovative.

Folia utrinque pubescentia, limbis lanceolatis

77. P. Eggersii C. DC.

Folia tantum supra pubescentia, limbis ovalibus nsque ellipticis 78. P. portoricensis Urb.

Folia utrinque glabra, limbis ovatis

79. P. vincentiana C. DC. 
-. Limbi e basi acuta oborati.

Caulis pubescens.

Limbi usque ad $13 \mathrm{~mm}$. longi, utrinque pilosi

80. P. Cogniauxii Urb.

Limbi usque ad $15 \mathrm{~mm}$. longi, utrinque longe pilosi

Caulis glaber.

81. P. spathophylla Dahlst.

Limbi obcordati usque ad $16 \mathrm{~mm}$. longi

32. P. cordifolia A. Dietr.

-.. Limbi rotundati.

Limbi usque ad $8 \mathrm{~mm}$. longi, utrinque setulosi

83. P. rotundifolia Kunth

Limbi usque ad $12 \mathrm{~mm}$. longi, utrinque glabri

84. P. subrotundifolia C. DC.

$\times \times$ Folia modica, id est limbis $2-9$ cm. longis.

- Folia utrinque pubescentia.

- Stigma paullo sub apice ovarii oblique insertum rel inconspicuum.

Bractea glabra.

$\triangle$ Limbi utrinque longiuscule pilosi.

Limbi basi rotundati ant obtusi.

Limbi $2^{1 / 2}-3 \mathrm{~cm}$. longi. Spicae axillares terminalesque . . 85. P. subvillosa V. H. et Müll.

Limbi usque ad $6 \mathrm{~cm}$. longi. Spicae terminales aut apice ramulorum oppositifoliae

86. P. Dussii C. DC.

Limbi basi acuti.

Limbi usque ad $4^{1 / 2} \mathrm{~cm}$. longi. Spicae oppositifoliae . 87. P. Casimiri V.H. et Mïll.

$\triangle \triangle$ Limbi utrinque puberuli.

Limbi $2-3 \mathrm{~cm}$. longi. Spicae terminales

88. P. yabucoana Urb. et C.DC.

Limbi $3 \frac{1}{2}-5 \mathrm{~cm}$. longi. Spicae axillares

89. P. hirtella Miq.

Bractea ciliata . . . 90. P. hirta C. DC.

= Stigma summo apice orarii insertum.

Limbi lanceolati usque ad $5 \mathrm{~cm}$. longi. Spicae apice ramulorum oppositifoliae . 91. P. dissitiflora C. DC.

Limbi orato-lanceolati usque ad $6 \mathrm{~cm}$. longi. Spicae oppositifoliae . . . 92. P. Hahnii C. DC.

- Folia tantum subtus pubescentia.

Limbi laud nigro-punctulati . 93. P. Antillarum C. DC.

Limbi nigro-punctulati.

Limbi rhombeo-lanceolati, $4-4^{1 / 2} \mathrm{~cm}$. longi

Limbi lanceolati, usque ad $3 \frac{1}{2} \mathrm{~cm}$. longi

94. P. Belangeri C. DC.

95. P. Smithiana C. DC.

-.. Folia utrinque glabra.

Ramuli altero latere duplici serie pilorum e petiolo decurrente muniti

96. P. glabella A. Dietr. 
Ramuli omnino glabri.

$\triangle$ Limbi $2-3^{1 / 2} \mathrm{~cm}$. longi.

$\uparrow$ Spicae limbis subaequilongac

97. I. trumcigandens C. DC.

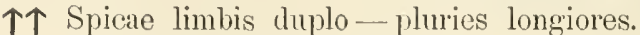

Petioli $2-5 \mathrm{~mm}$. longi.

Limbi nigropunctati

98. P. myrtifolia A. Dietr.

Limbi haud nigropunctati

99. P. Hamiltoniana Miq.

Petioli $12-25 \mathrm{~mm}$. longi

100. P. petiolaris C. DC.

$\triangle \triangle$ Limbi $4^{1} \frac{1}{2}-9 \mathrm{~cm}$. longi.

$\uparrow$ Limbi muitinervii.

$\downarrow$ Caulis haud alatus.

Spicae foliis aequilongae vel paullo longiores.

Limbi ovati 11 -nervii

101. P. Vanhearckii C. DC.

Limbi elliptico-lanceolati 7-nervii

102. P. Rupertiana C. DC.

Spicae foliis $2-3-p l o$ longiores.

Limbi elliptico-lanceolati apice obtusiusculi, 5 -nervii

103. P. guadeloupensis C. DC.

Limbi lanceolati utrinque acuti, 5 -nervii

104. P. Sintenisii C. DC.

Limbi ovato-elliptici apice acuti, 5 -nervii

105. P. Broadwayi C. DC.

Limbi anguste lancenlati, 5-nervii

106. P. diaphanoides Dahlst.

$\downarrow \downarrow$ Caulis alatus

107. P. alata R. et Pav.

$\uparrow \uparrow$ Limbi multiplinervii.

* Limbi basi acuti,

Limbi lanceolati, nigropunctati

108. P. acuminata (L.) C. DC.

Limbi e basi acuta oblongi, apice acuminati, haud nigropunctati

109. P. Harrisii C. DC.

** Limbi basi cordati.

Limbi utrinque glabri

110. P. pellucida Kunth

$\times \times \times$ Folia magna, id est limbis usque ad $17 \mathrm{~cm}$. longis.

Spicae axi communi racemose confertae

111. P. pernambucensis Miq.

+ Orarium superne antice oblique complanatum et \pm scutatim auctum, apice distincte acuminatum et infra apicem antice stigmatiferum.

Folia distincte peltata.

Folia supra glabra, subtus pubescentia

112. P. maculosa W. Hook. 
Folia utrinque glabra.

113. P. hermandicefolia Miq.

Folia haud peltata vel tantum basi ima vix peltata.

$\times$ Limbi multinervii.

- Folia utrinque pubescentia.

Limbi rotundati $3^{1 / 2}-4^{1 / 2} \mathrm{~cm}$. longi

114. P. urocarpa Fisch. et Mey.

Limbi rotundati circiter $11 / 2 \mathrm{~cm}$. longi

115. P. scandens R. et Pav.

- Folia utrinque glabra.

Limbi e basi cuneata obovati

116. P. cuneata Miq.

Limbi ovato-lanceolati 117. P. cuspidata Dahlst.

$\times>$ Limbi multiplinervii.

Limbi ovati vel oblongo-ovati basi rotundati, $8 \mathrm{~cm}$. longi

118. P. distachya A. Dietr.

Limbi late ovati basi cordati, $12 \mathrm{~cm}$. longi

119. P. Wrightiana C. DC.

$\times>>$ Limbi penninervii.

- Limbi elliptico- vel oblongo-lanceolati.

Spicae foliis fere aequilongae

Spicae foliis multo longiores.

120. P. talinifolia Kunth

Pedunculus petiolo fere aequilongus

121. P. nematostachya Link.

Pedunculus petiolo fere duplo longior

122. P. myriocarpa Miq.

- Limbi obovati vel oblongo-obovati.

- Folia clistincte petiolata vel limbis inferne in petiolum decurrentibus.

Petioli $1 \frac{1}{2}-3 \mathrm{~cm}$. longi.

Spicae limbis longiores

Spicae limbis aequilongae

123. P. obtusifolia A. Dietr.

124. P. alpina A. Dietr.

= Folia sessilia.

Folia inferne attenuata, ambitu rubro-marginata

125. P. clusiifolia Hook.

Folia inferne attenuata haud ambitu rubro-marginata

Folia basi amplexicaulia 126. P. cuneifolia A. Dietr.

127. P. amplexicanlis A. Dietr.

b. Folia opposita rel terna, quaterna, quina.

† Folia parra, id est limbis usque ad $1 \frac{1}{2} \mathrm{~cm}$. longis.

Limbi clare longiores quam latiores.

$\times$ Rhachis spicae glabra.

- Folia utrinque glabra vel tantum minute puberula.

* Ovarium superne in stilum summo apice stigmatiferum productum.

Folia terna. Limbi elliptico-obovati

128. P. Grisebachii C. DC. 
* Ovarium summo apice stigmatiferum.

Folia quaterna. Limbi clliptici oborati

129. $P$. quadrifolia Kunth

*** Ovarium paullo infra apicem oblique stigmatiferum.

Folia terna - quaterna, petiolata.

Limbi elliptici apice obtusi. Pedunculi usque ad 3 mm. longi 130. P. papillosula Dahlst.

Limbi elliptici apice subacuti. Pedunculi $4 \mathrm{~mm}$. longi . . 131. P. discolor C. DC.

Folia quaterna - quina, sessilia.

Limbi oblongo-spathulati

132. P. galioides Kunth

- Folia tantum supra pubescentia.

Limbi lineari-oblongi . 133. P. fliformis A. Dietr.

-.. Folia tantum subtus pubescentia.

Limbi oblongo-elliptici 134. P. verticillata Miq.

$\times \times$ Rhachis spicae hirtella.

Limbi rhombeo-elliptici ellipticive

135. P. reflexa A. Dietr.

Limbi vix longiores quam latiores.

Folia opposita. Limbi utrinque puberuli

136. P. circinnata Link.

Folia opposita. Limbi subtus ad nervum centralem longe pilosi

137. P. fimbriata Miq.

† Folia modica, id est limbis $2-5 \mathrm{~cm}$. longis.

Folia omnia opposita aut summa terna.

$\times$ Folia utrinque glabra.

Limbi rhombeo-elliptici utrinque acuti

138. P. quadrangulai is A. Dietr.

$\times \times$ Folia utrinque pubescentia.

Spicae foliis fere aequilongae

139. P. ciliata Kunth

Spicae foliis multo longiores

140. P. Langsdorffiii Miq.

Folia ommia terna-quaterna.

$\times$ Ovarium superne in stilum apice stigmatiferum productum.

Pedunculi usque ad $3 \frac{1}{2} \mathrm{~cm}$. longi, hirtelli

141. P. trifolia A. Dietr.

Pedunculi usque ad $6 \mathrm{~mm}$. longi, glabri

142. P. Balbisii Dahlst.

$\times>$ Orarium sine stilo, at ipsum summo apice stigmatiferum.

Limbi lanceolati . . 143. P. rhombea R. et Pav.

$\times>\times$ Ovarium paullo infira apicem oblique stigmatiferum.

- Folia utrinque glabra.

Limbi obovati apice emarginati, 3 -nervii

144. P. obovata C. DC.

Limbi oblongi acuminati acumine obtuso, 3 -nervii

145. P. stellata A. Dietr.

Limbi subrlombeo-elliptici, 7 -nervii

146. P. dominicana C. DC. 
- Folia utrinque pubescentia.

Limbi e basi cuneata obovato-subrhombei

147. P. polystachya A. Dietr.

Folia magna, id est limbis $6-9 \mathrm{~cm}$. longis.

- Ovarium superne in stilum latum apice stigmatiferum productum.

Folia opposita aut ralius terna. Limbi oblongo-lanceolati

148. P. septemnervis $\mathrm{R}$. et Pav.

- Ovarium sine stilo, at ipsum summo apice stigmatiferum.

Folia terna oppositare. Limbi lanceolati 5-nervii

149. P. pseudopereskiifolia C. DC.

Folia terna-quina. Limbi lanceolato-elliptici 3 -nerrii

150. P. perestiifolia Kunth

B. Bacca haud hypopeltata et cum flore concreta.

Limbi basi acuti

Limbi basi rotundati .

151. P. Herminieri C. DC.

152. P. bracteiflora C. DC.

74. Peperomia hispidnla A. Dietr. foliis petiolatis, subrotundis, basi emarginatis obtusisve, tenuissime 5 -nerriis, supra sparse pilosulis, subtus glabris et minute punctulatis, petiolo glabro; pedunculo oppositifolio petiolum multo superante, basi pilosulo, spica folii limbum fere triplo superante, filiformi glabra laxiflora, bractea orbiculari centro subsessili; ovario stiloque aequilongo glabris; bacca elliptica hispidula, inferne in stipitem attenuata, apice stilo mucronata.

Peperomia hispidula A. Dietr. Sp. I (1831) p. 165; Griseb. Fl. II. Ind. p. 165; C. DC. Prodr. IVI, 1 p. 397 (quoad sp. Griseb., exclus. aliis spec.); Hemsl. Biol. Centr. Am. III p. 60; Sodiro Mon. Pip. p. 81 .

Piper hispidulum Su. Prodr. (1788) p. 15 et Flor. Ind. Oce. I p. 63 et Icon. tab. 4.

Peperomia hispidula a. Suartziana Dahlst. Stud. (1900) p. 13.

Acrocarpidium hispidulum Miq. Syst. (1843) p. 54.

Herbula inferne repens, ramulis erectis, in sicco fere $1 / 2 \mathrm{~mm}$. crassis, usque ad $6 \mathrm{~cm}$. longis, ad nodos pilosulis. Limbi in sicco tenuiter membranacei, $6-10 \mathrm{~mm}$. longi, $7-12 \mathrm{~mm}$. lati; petioli $3-4 \mathrm{~mm}$. longi. A ntherae subglobosae; filamenta antheris per anthesin longiora (in sp. Harrisir). Bacca fere $1 \frac{1}{2}$ mm. longa. Stigma in apice stili parrum glabrum.

Hab. in Jamaica, in nemorosis humidis montium altissimorum Blue Mountains: Swartz (in h. Mus. bot. Stockl., fide Dahlst. l. c.), in Blue Mountains Peak $2470 \mathrm{~m}$. alt., ad Newliaven Gap alt. $1870 \mathrm{~m}$. solo humido, Morse's Gap alt. 1600 m.: W. Harris 1..6728, 7548, 7970; praeterea in Costarica, Columbia, Venezuela, Ecuador, Brasilia, Argentina (vide: C. DC. 1. c. et in Bull. h. Boiss. V p. 704, VI p.509, Griseb. Symb. p. 91, Sodiro 1. c.), Paraguay: Balansa n. 2306.

Obs. Species in insula Martinique non reperta est, ut cl. Dahlstedt 1. c. p. 14 ex herb. Willd. n. 731 indicat: plagula species duas continet, 
quarum altera Pep. mummularifolia H. B. K., a cl. Isert in Martinique collecta, altera (exemplaria 2 inferiora) Pep. hispidula A. Dietr. verisimiliter a cl. Swartz Willdenowio donata, sed chm priole confusa (Urb. in lit.).

75. Peperomia tenella A. Dietr. foliis brevissime petiolatis, ovatis, apice attenuato obtusis et summo apice saepe enarginulatis, margine ciliatis et supra marginem versus parce pilosulis dein glabris, subtus glabris, conspicue 3-nerviis cum nervulo marginali ab apice breviter decurrente, caeterum eveniis, petiolo pedunculoque terminali petiolum multo superante glabris; spica folii limbum fere dimidio superante, bractea orbiculari centro subsessili; ovario emerso elliptico, basi attenuato, superne in stilum brevem carnosum desinente, stignate globoso, puberulo; bacca obovata, inferne in stipitem longum attenuạta, apice stilo breviter mucronata, stipite tenui baccam fere aequante.

Peperomia tenella A. Dietr. Sp. I (1831) p. 153; Griseb.! Fl. W. Ind. p. 165 et Pl. Wr. I p. 175 et Cat. pl. Cub. p. 63; C. DC. Prodr. XII, 1 p. 396; Sauv. Fl. Cub. n. 2254 p. 145; Duss! Fl. phan. p. 170; Dahlst.! Stud. p. 21.

Piper tenellum Sw. Prodr. (1788) p. 16 et Flor. Ind. Occ. I p. 65 et Icon. ined. tab. 31 (ex Urb. in lit.); Vahl Enum. I p. 345; Willd. Sp. I p. 163.

\section{Acrocarpidium tenellum Miq. Syst. (1843) p. 53.}

Herba caule simplici, $10-12 \mathrm{~cm}$. alto, pilosiusculo, basi decumbente, in sicco fere $3 / 4 \mathrm{~mm}$. crasso. Limbi in sicco rigidulo-membranacei membranaceive pellucido-punctulati, circiter $15 \mathrm{~mm}$. longi et $6 \mathrm{~mm}$. lati; petioli vix $2 \mathrm{~mm}$. longi. Pedunculi fere $1 \mathrm{~cm}$. longi; spicae rhachis $1 / 2 \mathrm{~mm}$. crassa. Filamenta antheras fere aequantia; antherae rotundato-ellipticae. Bacca propria fere $1 \mathrm{~mm}$. longa.

Hab. in Cuba orientali: Wright n. 523 (in h. DC.); Jamaica inter muscos collium editiorum: Bertero n.2659 (ex herb. Sprengel in h. Krug et Urb.), supra truncos praecipue putridos, inter muscos, dependens, in montibus frigidis: Swartz (in h. Stock.), W. Wilson n. 466 (in h. Griseb. fide Dahist. l. c.), Catherines Peak 1330 m. alt.: Eggers n. 3652; Guadeloupe ubi interdum epiphytica in arbusculis montis sulphurigeris: Richard (in h. Francar.), inter muscos ad arbores in silvis humidis ad viam a Matouba ad Savannam Ananas alt. 890-950 m.: Duss n. 3248.

Var. $\beta$. glabra C. DC., limbis utrinque glabris, summo apice ciliolatis, oblongo-ovatis, $8-12 \mathrm{~mm}$. longis, internodiis quam in specie brevioribus ad $5 \mathrm{~mm}$. longis.

Peperomia tenella $\beta$. glabra C. DC. Prodr. XVI, 1 (1869) p. 396; Dahlst. $l . c$.

Hab. in Cuba orientali: Wright n. 523 (in h. Krug et Ulb.); praeterea Venezuela prope Tovar: Fendler n. 1818, Brasilia ad Mantiqueira (fide Dahlst. l. c.). 
76. Peperomia emarginella C. DC., foliis minutis petiolatis, subreniformi-rotundatis, apice emarginulatis, utrinque margineque remote pilosulis, 3-nerriis, petiolis pedunculisque terminalibus petiolos paullo superantibus glabris; spicis limbos fere duplo superantibus subdensifloris, bractea orbiculari centro subsessili; ovario rotundato, summo apice stigma globosum et puberulum gerente; bacca oblonga, inferne in stipitem brevem attenuata.

Peperomia emarginella C. DC. Prodr. XII, 1 (1869) p. 437; Henschen Et. p. 23; Duss! Fl. phan. p. 170; Dahlst.! Stud. p. 22.

Piper emarginellum Swo. edid. Wikstr. Guad. (1827) p. 56 (teste Dahlst.).

Acrocarpidium exile Miq. Syst. (1843) p. 56.

Peperomia exilis Griseb.! Fl.W. Ind. (1859) p. 164 et Pl. Wr. p. 175 et Cat. p. 63; C. DC. Prodr. XVI, 1 p. 397; Saus. Fl. Cub. n. 2255 p. 145; Kew Bull.! 1893 p. 272.

Peperomia minima C. DC. l.c. p. 399.

Herbula caespitosa, caulibus repentibus, ramosissimis, glabris, in sicco $1 / 4 \mathrm{~mm}$. crassis. Folia alterna; limbi in sicco membranacei, juniores obovati, adulti subreniformi-rotundati, fere $4 \mathrm{~mm}$. longi et $6 \mathrm{~mm}$. lati; petioli ad $3 \mathrm{~mm}$. longi. Bacea $1 \frac{1}{2} \mathrm{~mm}$. longa subarcuata.

Hab. in Cuba: Wright n. 519; Jamaica: Wilson n. 626 (in h. Griseb. fide Dahlst. l. c.); India occidentali, veris. Haiti: Poiteau? (in b. Deless.); Portorico ad arbores sylvae primaerae, prope Bañadero in Sierra de Luquillo alt. $1000 \mathrm{~m}$. in silris umbrosis: Eggers ed. Toepff. n. 876, Sierra de Las Piedras ad Los Rabanos, prope Maricao in convalli fluminis superioris, prope Jayuya juxta flumen circa San Patricio, prope Peñuelas ad Las Cruces, Sierra de Luquillo in regione media montis Jimenes, Sierra de Naguabo in monte Piedra Belleta: Sintenis n. $469^{\text {b }}, 1247^{\text {b }}, 1579,4462,4644,5419$; Guadeloupe in silris densis umbrosis ad arbores, alt. 370-700 m.: Duss n. 2829; Martinique: Duss n. 1268, in nemore fontis Absalon ubi copiosa ad truncos viros rel mortuos: Duss n. 4475; St. Vincent in Upper Richmond Valley, 660 m. alt. ad truncos putridos silvae juxta flumen: H. H. et G. W. Smith n. 1647; Trinidad prope Chaguanas (spec. fructiferum): Bot. Gard. Herb. n. 1428.

77. Peperomia Eggersii C. DC. foliis parvis, breriter petiolatis, lanceolatis, basi acutis, apice acutiuscule acuminatis, utrinque villosulis, 3 -nerviis nerruloque marginali ab apice ultra medium decurrente, petiolo appresse villosulo; "pedunculis axillaribus terminalibusque petiolos superiores fere aequantibus glabrisque, spicis folia parum superantibus densifloris, bractea orbiculari centro subsessili glandulis conspersa; orario emerso glandulis consperso, paullo sub apice obtuso, stigma glabrum minutum oblique gerente.

Urban, Symb. ant. III. 
Peperomia Eggersii C. DC. in Briquet Ann. Jard. bot. Genève II (1898) p. 282.

Herba arboricola, in sicco flavicans, caulibus villosulis, e basi ad nodos radicante erectis, fere $20 \mathrm{~cm}$. longis et $2 \mathrm{~mm}$. crassis, superne breriter ramulosis. Folia media opposita v. alterna, suprema in apice ramulorum opposita vel ternata; limbi usque ad $18 \mathrm{~mm}$. longi et $11 \mathrm{~mm}$. lati, in sicco rigiduli, praeter nervulum marginalem fere enervulosi et epunctulati; petioli inferiores fere $5 \mathrm{~mm}$., superiores vix $4 \mathrm{~mm}$. longi. Pedunculi saepe basi squama fulti. Filamenta antheras subrotundas aequantia.

Hab. in Sto. Domingo, in arboribus silvae umbrosae prope Valle nuevo, alt. $1900 \mathrm{~m}$. : Eggers 11. 2165.

78. Peperomia portoricensis Urb. foliis parvis petiolatis, superioribus obovato-ellipticis ellipticisve, basi acutis, apice obtusis, utrinque parce pilosulis, margine apicem versus ciliolatis, dein supra glabris, 5 -nerviis nervis tenuibus, petiolo hirtello; spicis terminalibus solitariis pedunculatis, ipsis folia multo superantibus, filiformibus subdensifloris, bractea rotundata centro subsessili; bacca ovato-globosa, verruculosa, apice oblique mucronulata.

Peperomia portoricensis Urb.! Symb. ant. I (1899) p. 292; Dahlst.! Stud. p. 106 t. 4 fig. 2.

Yerba de Guavá Portor. ex Sint.

Caules repentes, juniores dense et adpresse hirtelli, usque ad $1 \mathrm{~mm}$. crassi, ramulos spicigeros crectos breves dense adpresse hirtellos emittentes. Limbi inferiores rotundati rel obovato-rotundati et saepe apice leviter emarginulati, superiores ut supra usque ad $16 \mathrm{~mm}$. longi et ad $8 \mathrm{~mm}$. lati, in siceo fusco-maculati; petioli fere $2 \mathrm{~mm}$. longi. Pedunculi $5 \mathrm{~mm}$. longi; rhachis glabra. Ovarium emersum obovatum, infra apicem oblique stigmatiferum. Stigma parvum glabrum. Filamenta brevissima; antherae ellipticae. Rhachis sub bacca natura in processum conicum brevem producta. Bacea sine pseudocupula.

Hab. in Portorico, ad arbores in silvis primaeris prope Aybonito ad Barrio del Pasto, prope Adjuntas ad Las Cruces, inter Adjuntas et Guayanilla in monte Ahocardo, prope Utuado ad Mameyes, prope Marica in monte Alegrillo: Sintenis 11. 465, 2886, 4302, 4695, 6542.

79. Peperomia vincentiana Miq. foliis parvis brevissime petiolatis, ellipticis, basi subattenuatis, apice obtusis, utrinque tenerrime puberulis dein glabris, uninerviis rel inconspicue 3 -nerviis, petiolo tenerrime puberulo; pedunculis terminalibus, petiolos paullo superantibus, subglabris, spicis maturis folia superantibus remotifloris, bractea orbiculari centro breviter pedicellata.

Peperomia vincentiana Miq.! in Hook. Lond. Joum. IV (1845) p. 415; C. DC. Prodr. XIT, 1 p. 405; Dahlst.! Stud. p. 152. 
Peperomia demissa Dahlst.! Stud. (1900) p. 149 (quoad spec. Eggersii?).

Herbula repens, caule filiformi vage ramoso glabro, ramulis erectis tenerrime puberulis. Limbi in sicco membranaceo-rigiduli, $5-10 \mathrm{~mm}$. longi, $4-7 \mathrm{~mm}$. lati; petioli $2 \mathrm{~mm}$. longi. Pedunculi $3-5 \mathrm{~mm}$. longi; spicae $3-5 \mathrm{~cm}$. longae.

Hab. in St. Vincent: Guilding (hb. Kew), in summo monte St. Andrews alt. $830 \mathrm{~m}$. ad saxa et truncos arborum: H. H. et G. W. Smith n. 921; Grenada in nemoribus montanis gregaria: Broadway n. 624, in monte Morne au Camp alt. 830 m. repens: Eggers n. 6198?

80. Peperomia Cogniauxii Urb. foliis modice petiolatis, oboratis rel ellipticis, basi acutis, apice rotundatis subtruncatis vel obsolete emarginatis, utrinque appresse et haud dense breviter pilosis, 3-nerviis, nervis lateralibus inconspicuis, petiolis appresse breviter pilosis; pedunculis terminalibus petiolos fere duplo superantibus, appresse breviter pilosis, spicis folia fere triplo superantibus, tenuiter filiformibus, bractea orbiculari centro subsessili; ovario subimpresso stigmate punctiformi oblique inserto; bacca semiimmersa ovato-globosa, glandulis conspersa, apice oblique subacutata.

Peperomia Cognianxii Urb.! in Symb. Ant. I (1899) p. 292; Dahlst.! Stud. p. 104 t. 4 fig. 3.

Herba arboricola, caulibus vix $1 / 2 \mathrm{~mm}$. crassis, aliis elongatis decumbentibus et radicantibus, aliis adscendentibus $4-6 \mathrm{~cm}$. longis, illis pilos articulatos, patentes longiusculos, his plerumque simplicibus pilos sursum curvatos gerentibus. Limbi in sicco membranacei, plus minusve pellucidopunctulati, $5-12 \mathrm{~mm}$. longi, $3-5 \mathrm{~mm}$. lati; petioli fere $1 \mathrm{~mm}$. longi. Spicae vix $1 / 2 \mathrm{~mm}$. crassae. Baccae brunneae vix $1 / 2 \mathrm{~mm}$. longae. Rhachis sub bacea ut videtur delapsa in processum conicum producta.

Hab. in Portorico prope Barranquitas in truncis retustis silvae primaevae montis Torrecillo, alt. 1130 m., Oct. fruct.: Sintenis n. 1963.

81. Peperomia spathophylla Dahlst. foliis petiolatis, e basi cuneata obovatis, petiolisque utrinque sat longe et dense pilosis, $3-5$ nerriis nervuloque marginali ab apice decurrente; pedunculis terminalibus, parce pilosis, petiolos paullo superantibus, spicis sublaxifloris, limbos fere duplo superantibus, bractea orbiculari fere centro breviter pedicellata; ovario emerso obovato, sub apice obtuso oblique stigmatifero; stigmate parro glabro.

Peperomia spathophylla Dahlst.! Stud. (1900) p. 105 t. 4 fig. 1.

Peperomia metapalcoensis C. DC. Prodr. XVI, 1 p. 416 (quoad spec. Wrightii); Saur. Fl. Cub. n. 2262 p. 146.

Peperomia Miqueliana Griseb.! Cat.pl. Cub. (1866) p. 63 (nomen tantum, excl. syn., non C. DC. 1866). 
Herba e nodis radicans, ramulis sat dense et longe pilosis in sicco $1 \mathrm{~mm}$. crassis. Limbi in sicco membranacei, usque ad $15 \mathrm{~mm}$. longi et ad $1 \mathrm{~cm}$. lati; petioli $5 \mathrm{~mm}$. longi. Spicae florentes $1 \mathrm{~mm}$. crassae. Filamenta antheris breviora; antherae ellipticae.

Hab. in Cuba prope Baracoa: Wright n. 2262.

Var. $\beta$. monteverdensis C. DC. (n. var.), limbis multo majoribus $4 \mathrm{~cm}$. longis et $3 \mathrm{~cm}$. latis.

Hab. in Cuba prope Monteverde: Eggers n. 5127 (in h. Kew).

Obs. Verisimiliter species.

82. Peperonia cordifolia A. Dietr. foliis longiuscule petiolatis, e basi attenuata obovatis, apice emarginatis seu obcordatis, supra puberulis, tenuiter 3-nerviis nervuloque marginali ab apice breviter decurrente, petiolo pedunculoque terminali petiolum fere aequante glabris; spica submatura folii limbum pluries superante laxiflora, bractea orbiculari centro subsessili; ovario emerso obovato, sub. apice stigma glabrum gerente.

Peperomia cordifolia A. Dietr. Sp. I (1831) p. 154: Griseb.! Fl. W. Ind. p. 164; C. DC. Prodr. XVI, 1 p. 421; Dahlst.! Stud. p. 103. Piper cordifolium Sw.! Prodr. (1788) p. 16 et Flor. Ind. Occ. I p. 71 et Icon. ined. tab. 30 (ex Urb.); Vahl Emum. I p. 345; Willd.! Sp. I p. 165.

Peperomia spatulata Ham.! Prodr. (1825) p. 2.

Acrocarpidium cordifolium Miq. Syst. (1843) p. 56 et in Ilook: Lond. Joum. IV p. 411 et in Limaea XX p. 118.

Herba repens aut scandens, caule filiformi $1 / 2 \mathrm{~mm}$. crasso, juniore puberulo dein glabro. Limbi in sicco membranacei pellucidi remote venulosi, usque ad $16 \mathrm{~mm}$. longi et ad $8 \mathrm{~mm}$. lati; petioli $5-8 \mathrm{~mm}$. longi.

Hab. in Jamaica: Swartz (in h. Willd. n. 730), Wilson (in h. Kew), Bertero n. 2637, herb. Desvaux (in h. Mus. Par.), prope Fairfield in saxis et arboribus repens, rarior: Wullschlaegel n. 1372 (in h. Monac. et h. Griseb., sec. Dahlst. 1. c.).

83. Peperomia rotundifolia Kunth, foliis petiolatis, ovato-orbicularibus orbicularibusve, utrinque tenuiter hand dense setulosis margineque ciliatis, 3-nerviis; spicis terminalibus breviter pedunculatis, limbos adultos fere duplo superantibus, pedunculo petiolum subaequante, bractea orbiculari centro subsessili; ovario impresso obtuso; stigmate minuto glabro.

Peperomia ratundifolia Kunth! in H. B. K. Nov. Gen. I (1815) p. 65 (herb. Willd. n. 732); Griseb.! Fl. W. Ind. p. 164; Hensehen Et. p. 46; Duss! Fl. phan. p. 170; Dahlst.! Stud. p. 99. 
Piper rotundifolium Linn. Spec. I ed. I (1753) p. 30, II ed. p. 42 et h. pr.; Anbl. Hist. Guian. I p. 21; Spreng. Syst. I p. 118.

Piper nummularifolium Sw. Prodr. (1788) p. 16 et Obs. p. 20 et Fl. Ind. Occ. I p. 72; Vahl En. I p. 348; Willd.! Sp. I p. 166; Spreng. Syst. I p. 118.

Peperomia nummularifolia Kunth! l.c. (1815) p. 66 (herb. Willd. n. 733), Pl. aeq. t. 2 p. 54 et Synops. I p. 118; Griseb. Flor. p. 164, Pl. Wr. I p. 175 et Cat. p. 63; C. DC. Prodr. XVI, 1 p. 420; Duss! Fl. phan. p. 170; Sodiro Mon. Pip. p. 108.

Acrocarpidium mummularifolium Miq.! Syst. (1S43) p. 52 et in Hook. Lond. Journ. Bot. IV p. 411.

Saururus repens fol. orbic. Plum. Descr. pl. Am. (1693) p. 52 t. 69.

Piper Inngum minimum herbaceum scandens Sloane Cat. (1696) et Hist. p. 137 et in coll. ic. orig. t. 90.

Yerba de medio real Port. ex Sint., Petit mouron Guad., Gironflé $v$. Mouron Mart. ex Duss.

Herbula in ramis arborum repens, e nodis radicans, caulibus filiformibus valde debilibus, in sicco vix $1 / 2 \mathrm{~mm}$. crassis, jumioribus puberulis. Limbi in sicco tenuiter membranacei, pellucidi, subtus saepe parce nigropunctulati, $6-10 \mathrm{~mm}$. longi, $5-9 \mathrm{~mm}$. lati; petioli adulti circiter $3 \mathrm{~mm}$. longi. Spicae florentes fere $1 \mathrm{~mm}$. crassae; rhachis glabra; bractea extus nigro-punctulata. Filamenta brevia; antherae ellipticae. Ovarium paullo sub apice stigmatiferum. Bacca subglobosa, rhachis processu conico sat longo tarde stipitata.

Hab. in Cuba: Sagra, Santos (in h. DC.), in parte orientali: Wright n. 518, 520 (ibid.), prope villam Honte Verde dictam: Wright n. 521 (ibid.); Jamaica ex Griseb. (l. c.); Haiti: Poiteau; Portorico ad ąrbores in Sierra de Luquillo in regione media montis Jimenes, prope Cayey in silvis ad Pedro Avila, prope Adjuntas juxta flumen ad La Galsa, prope Utuado ad Salto arriba, prope Yabucoa ad Quebrada Grande, prope Barceloneta in scopulosis calcareis silvarum ad Florida, prope Maricao in valli fluminis, in Sierra de Naguabo in monte Piedra Belleta: Sintenis n. 469, 1247, 1669, 2352, 4200 b 4577, 5158, 6733, prope Bayamon in silvis: Stahl n: 98, 614; Guadeloupe: Bertero, locis humidis umbrosis alt. $400-1000 \mathrm{~m}$. haud frequens inter Trois Rivières et Matouba: Duss n. 2828; Dominica: Nicholls n. 45; Martinique: Duss n. 20, ad arbores vetustas locis humidis, copiosa in nemoribus Camp Almae, in arboribus repens: Duss n. 1269, 4471; Antigua: Wullschlaegel; St. Vircent ad ripam rivuli Petit Bordel ad arbores repens: Eggers n. 6893, in Wallilabou valley in silvis humidis ad arbores: H. H. et G. W. Smith n. 257; Grenada in monte Feliz alt. 400 m., vulgaris ad arbores gregaria: Eggers n. 5978, 6009 ${ }^{\text {}}$; Trinidad: Sieber n. 16; praeterea Mexico: Liebmann n. 82 ; America centralis, 
Colombia, Venezuela, Guiana, Brasilia (vide C. DC. Prodr. 1. c. et in Bull. h. Boiss. V p. 708 , VI p. 507, ser. 2 I p. 359, in Donn. Smith En. part 4 p. 136, Sodiro l. c.).

Var. $\beta$. pilosior C. DC. caule densius et longius pubescente.

Peperomia mummularifolia $\beta$. pubescens C. DC. Prodr. XVI, 1 (1869) p. 421 et in Dur. et Pitt. Primit. I p. 133.

Acrocarpidium nummularifolium forma pilosior Miq. in Linnaea XVIII (1844) p. 710.

Yerba linda Port. ex Egg.

Hab. in Sto. Domingo in silva summi montis Isabel de la Torre $770 \mathrm{~m}$. alt. inter muscos ad arbores, prope cavernam Cupey ad arborum truncos repens in silva juxta flumen Camú, alt. 150 m.: Eggers n. 1592, 2707; Portorico in arboribus ad orillam fluminis Mameyes: Eggers ed. Toepff. n. 877, prope Barranquitas ad arbores silvae prim. in monte Torrecilla alt. $1130 \mathrm{~m}$.: Sintenis n. 2024; Martinique ad Lamentin: Hahn n. 732; Grenada: Broadway n. 51; - praeterea in Mexico prope Jalapa ex Miq. (l. c.); Costa Rica prope Carillo: Pittier n. 566 . in Andibus Quitensibus: Jameson n. 244, 340 (in h. DC.).

Var. $\gamma$. ovata Dahlst. (n. var.), limbis ellipticis, basi acutis, apice obtusis, utrinque puberulis, usque ad $11 \mathrm{~mm}$. longis et $7 \mathrm{~mm}$. latis.

Peperomia rotundifolia L. forma ovata Dahlst.! Msc. in h. Frug et Urb.

Hab. in Tobago in silva prim. montis Morne d'Or, alt. $500 \mathrm{~m}$. ad arbores repens: Eggers n. 5819.

84. Peperomia subrotundifolia C. DC. glabra, foliis modice petiolatis, subreniformi-rotundatis, inferioribus e basi subcordata ovatis. omnibus 3-nerviis, reticulato-nervulosis nervuloque marginali ambitu currente; pedunculis terminalibus rarius axillaribus, petiolos aequantibus, spicis folia pluries superantibus filiformibus subdensifloris, bractea orbiculari centro subsessili; ovario impresso obovato; stigmate puberulo.

Peperomia subrotundifolia C. DC. in Seem. Joum. of Bot. IV (1866) p. 136 et Prodr. XVI, 1 p. 423; Sauv. Fl. Culb.u. 2266 p. 146. Peperomia serpens Griseb.! Cat. (1S66) p. 63, - non Loudon.

Herba basi radicans, caulibus simplicibus cum spicis terminalibus circitcr $22 \mathrm{~cm}$. longis et $1 \mathrm{~mm}$. crassis. Limbi in sicoo membranacei tenues pellucidi, $12 \mathrm{~mm}$. longi et ad $16 \mathrm{~mm}$. lati; petioli fere $1 \mathrm{~cm}$. longi. Spicae florentes circiter $8 \mathrm{~cm}$. longae, $3 / 4 \mathrm{~mm}$. crassae. Orarium paullo sub apice oblique stigmatiferum. Rhachis sub bacca matura, in specimine delapsa. in processum producta.

Hab. in Cuba: Wright n. 2263 (in h. DC. et Krug et Urb.). 
85. Peperomia subvillosa van Heurck et Müll. Arg. foliis modice petiolatis, ovatis, basi rotundato-obtusis, apice breviter et obtuse protracto-acuminatis, utrinque laxe rilloso-pubescentibus, supra fuscosubtus nigro-punctulatis, 5-nerviis, petiolo pedunculoque aequilongo patentim pilosis; spicis axillaribus terminalibusque densifloris, folia subaequantibus, bractea orbiculari obsolete acuminulata subexcentrice peltata; ovario rhachi impresso cylindrico-ellipsoideo apice obtuso.

Peperomia subvillosa van Heurck et Miill. Arg. in Heurck Obs. Bot. fasc. I (1876) p. 113 .

$\mathrm{Caules}$ procumbentes, irregulariter ramosi, ramis adscendentibus, superne patentim hirsutis, ramulis spiciferis fere $1 \mathrm{~mm}$. crassis. Limbi in sicco membranacei, $2^{1 / 2}-3 \mathrm{~cm}$. longi, $1 \frac{1}{2}-2 \mathrm{~cm}$. lati; petioli $4-7 \mathrm{~mm}$. longi. Spicae $2 \mathrm{~cm}$. longae et $2 \mathrm{~mm}$. crassae. Orarium paullo sub apice stigma minutum gerens.

Hab. in Martinique: Sieber (in h. van Heurck et specimen sterile in h. Cand.), in montibus altis: Duss n. 15 .

86. Peperomia Dussii C. DC. (n. sp.), foliis breviter petiolatis, oratis, basi obtusis rotundatisve, apice acuminatis acumine obtusiusculo, utrinque cum petiolis appresse setoso-pilosis et subtus fusco-punctulatis, 5 -nerviis; spicis apice ramulorum oppositifoliis terminalibusque, breviter pedunculatis, ipsis florentibus quam limbi brerioribus sublaxifloris, bractea orbiculari centro subsessili; ovario emerso oborato apice obliquo, stigmate inconspicuo.

Herba inferne e nodis radicans. Ramuli in sicco subcoriacei, fere $3 \mathrm{~mm}$. crassi, sat longe setoso-pilosi. Folia caulina inferiora limbis oratorotundatis, apice breviter acuminatis, usque ad $3 \mathrm{~cm}$. longis et $21 / 2 \mathrm{~cm}$. latis, superiora limbis ut in diagnosi, in sicco membranaceis usque ad $6 \mathrm{~cm}$. longis et ad $3 \frac{1}{2} \mathrm{~cm}$. latis; petioli pedunculique fere $6 \mathrm{~mm}$. longi. Spicae florentes circiter $2 \frac{1}{2} \mathrm{~cm}$. longae et $2 \mathrm{~mm}$. crassae.

Hab. in Martinique, in silvis humidis montium: Duss n. 14 (pro majore parte).

87. Peperomia Casimiri van Heurck et Müll. Arg. foliis modice petiolatis, lanceolatis, utrinque acutis, supra subtusque appresse pilosis ciliatisque, 5-nerviis, petiolis pedunculisque fere aequilongis et oppositifoliis appresse pilosis; spicis florentibus limbos fere aequantibus subdensifloris, bractea orbiculari centro subsessili; orario emerso ellipsoideo, apice oblique deplanato; stigmate inconspicuo.

Peperomia Casimiri van Heurcli et Mïll. Arg.! in Heurcli Obs. Bot. fasc. I (1876) p. 661.

Herba basi procumbens, inferne longe radicans et superne e nodis radices filiformes emittens. Ramuli appresse et sat longe pilosi, spiciferi $1 \mathrm{~mm}$. crassi. Limbi in sicco membranacei, fere usque ad $4 \frac{1}{2} \mathrm{~cm}$. longi 
et ad $2 \frac{1}{2} \mathrm{~cm}$. lati; petioli usque ad $1 \mathrm{~cm}$. longi. Spicae florentes $1^{1 / 4} \mathrm{~mm}$. crassae.

Hab. in Martinique in silvis humidis montium: Duss n. 14 (pro minima parte); Trinidad: Sieber (in h. van Heurck et in h. Cand.).

88. Peperomia yabucoana Urb. et C. DC. foliis longe petiolatis, inferioribus $1-2$ suborbicularibus, caeteris ovatis vel breviter ovatis, basi rotundatis, apice obtusissimis vel obtusis, utrinque puberulis et margine ciliolatis, 5-nerviis nervuloque marginali superne ab apice decurrente; spicis terminalibus longiuscule pedunculatis, quam limbi fere duplo longioribus, pedunculis petiolos superantibus minute pilosis, bractea rotundata centro peltata; bacca basi rhachi impressa, ovata, apice subacuta, glabra.

Peperomia velutina Urb.! Symb. Ant. I (1899) p. 293, - non Linden et André Ill. hort. 1872 t. 89 (nomen propterea mutandum).

Herba caulibus basi decumbente radicantibus adscendentibus, $10-18 \mathrm{~cm}$. longis, inferne $2-2 \frac{1}{2} \mathrm{~mm}$. crassis, simplicibus vel ramosis, inferne parce, ad apicem dense et breviter patenti-pilosis. Limbi in sicco membranacei epunctulati, inferiores $1-2 \mathrm{~cm}$. diametro, caeteri $2-3 \mathrm{~cm}$. longi, $1 \frac{1}{2}-2 \mathrm{~cm}$. lati. Spicae florentes circiter $5 \frac{1}{2} \mathrm{~cm}$. longae et $1 \mathrm{~mm}$. crassae; rhachis glabra. Bacca sessilis et sine pseudocupula, fere apice stigma glabrum minutum oblique gerens.

Hab. in Portorico prope Yabucoa in saxis ad Sta. Helena, m. Sept. fruct.: Sintenis n. 5127.

89. Peperomia hirtella Miq. foliis breviter petiolatis, ovatis vel ellipticis, basi obtusis acutisve, apice acuminatis acumine acuto, utrinque appresse puberulis, $3-5$-nerviis, petiolis adpresse pilosulis; spicis axillaribus quam limbi plerumque brevioribus, pedunculatis subdensifloris, pedunculis petiolos paullo superantibus, bractea suborbiculata subsessili; orario elliptico summo apice stigmatifero.

Peperomia hirtella Miq.! in Hook. Lond. Journ. IV (1845) p. 414; Griseb.! Fl. W. Ind. p. 165; C. DC. Prodr. XVI, 1 p. 416.

Herba pedalis inferne crebre radicans decumbens, ramulis erectis appresse hirtellis, spiciferis fere 2 nım. crassis. Limbi in sicco membranacei, subtus glanduloso-punctulati, $3 \frac{1}{2}-5 \mathrm{~cm}$. longi et ad $3 \mathrm{~cm}$. lati; petioli $2-8 \mathrm{~mm}$. longi.

Hab. in Dominica: Imray n. 244 (in h. Kew).

90. Peperomia hirta C. DC. foliis longiuscule petiolatis, rhombeooboratis, basi cuneato-acutis, apice obtusiusculis obtusisve, utrinque appresse et dense pubescentibus et ciliatis, 5-7-nerviis, petiolo pedunculoque petiolum superante dense hirsutis; spicis axillaribus terminalibusque, sat longe pedunculatis densifloris, folia multo superantibus, rhachi hirtella, bractea rotundata dense ciliata centro brevissime pedicellata; orario emerso obovato. 
Peperomia hirta C. DC. Prodr. XVI, 1 (1869) p. 412; Sauv. Fl. Cub. n. 2258 p. 145.

Peperomia hirtella Griseb.! Pl. Wr. I (1860) p. 175 et Cat. pl. Cub. p. 64, - non Miq.

Herba erecta, caule hirsuto ramuloso, ramulis in sicco circiter $2 \mathrm{~mm}$. crassis. Limbi in sicco membranacei, subpellucidi et pellucido-punctulati, ad $5 \mathrm{~cm}$. longi et ad $22 \mathrm{~mm}$. lati; petioli ad $3 \mathrm{~cm}$. longi. Pedunculi ad $3 \frac{1}{2} \mathrm{~cm}$. longi; spicae florentes circiter $10 \mathrm{~cm}$. longae et in sicco $2 \mathrm{~mm}$. crassae. Antherae rotundato-ellipticae, filamentis $1 / 4 \mathrm{~mm}$. longis paullo brevioribus. Ovarium apice oblique stigmatiferum. Stigma carnosum et hirtellum.

Hab. in Cuba orientali: Wright n. 511,512 (in h. DC. et in h. Berol.). - In cl. M. Michelin caldariis e terra mexicana nuper orta.

91. Peperomia dissitiflora C. DC. foliis breviter petiolatis, lanceolatis, basi ima subacutis, apice acuminatis, utrinque appresse pilosis et ciliatisque et nigro-punctulatis, 5-nerviis nerruloque marginali ab apice ultra medium decurrente, petiolis pedunculisque apice ramulorum oppositifoliis et petiolos superantibus appresse hirsutis; spicis florentibus folia superiora vix superantibus; floribus evolutis dissitis; ovario oblongo, summo apice stigmatifero, bractea rotundata; bacca globosa puberula apice mucronulata.

Peperomia dissitiflora C. DC. in Briquet Amn. Jard. bot. Genère II (1898) p. 279.

Herba repens ant scandens?, caule ad $3 \mathrm{~mm}$. crasso, ramulis hirtellis rigidis. Limbi in sicco membranacei, $4-5 \mathrm{~cm}$. longi et ad $17 \mathrm{~mm}$. lati; petioli $6 \mathrm{~mm}$. longi; nervi 3 medii in sicco distincti, quorum laterales supra limbi medium eranescunt, externi inconspicui. Pedunculi $4-5 \mathrm{~mm}$. longi; spicae maturae fere $1 \frac{1 / 2}{\mathrm{~mm}}$. crassae. Bacca matura rhachi processu conico stipitata. Stigma orbiculare papillosnlum.

Hab. in Dominica: G. A. Ramage (in h. Kew); Martinique, in silva Forêt de la Trinité dicta: Hahn n. 649 (in h. Cand.), locis umbrosis humidis Camp Colson rara in truncis arborum: Duss n. 4476; Sta. Lucia in silva (cum caule et petiolis rubris): Ramage (in lı. Kew).

92. Peperomia Hahnii C. DC. foliis modice petiolatis, oratolanceolatis, basi obtusis, apice acutis, utrinque appresse setoso-pubescentibus, 5-nerviis, petiolo pedunculoque oppositifolio vel terminali et petiolum aequante appresse setoso-pubescentibus; spicis post anthesin limbos fere aequantibus sublaxifloris, bractea orbiculari centro subsessili; orario emerso elliptico, summo apice stigmatifero.

Peperomia Hahnii C. DC. in Linnaea XXXVII (Jul. 1872) p. 368 .

Herba arboricola, inferne e nodis radicans, ramulis suberectis parce setuloso-pubescentibus, spiciferis anguste alatis fere $1 \mathrm{~mm}$. crassis. Limbi 
in sicco tenuiter membranacei, subpellucidi epunctulati, $5-6 \mathrm{~cm}$. longi, $23-30 \mathrm{~mm}$. lati; petioli circiter $12 \mathrm{~mm}$. longi. Spicae post anthesin $1 \mathrm{~mm}$. crassae. Stigma papillosulum.

Hab. in Martinique ad Cocoyer supra arbores: Hahn 12.257 (in h. Cand.).

93. Peperomia Antillarum C. DC., ramulis apice altero latere pilosulis; foliis petiolatis, inferioribus e basi cuneata obovatis, apice rotundatis, superioribus elliptico-lanceolatis, apice acutis subacutisve, omnibus 5-nerviis, supra glabris, subtus sat dense pilosis, petiolis pedunculisque terminalibus petiolos paullo superantibus glabris; spicis folia multo superantibus, bractea orbiculari centro pedicellata; ovario emerso obovato, sub apice stigmatifero.

Peperomia Antillarum C. DC. Prodr. XVI, 1 (1869) p. 447 (em.); Sauv. Fl. Cub. n. 2278 p. 146; Dahlst.! Stud. p. 124.

Peperomia obtusifolia var. cuneata Griseb.! Pl. Wr. (1860) p. 175 et Cat. p. 64.

Peperomia gnadaloupensis $\beta$. pubescens C. DC. Prodr. XVI, 1 (1869) p. 416; Sauv. Fl. Cub. n. 2261 p. 145 (p. p.).

Peperomia dendrophila f. parvifolia foliis obtusiusculis Griseb.' Pl. Wright. (1860) p. 175 et Cat. p. 64.

Herba ramulis erectis, in sicco $2 \mathrm{~mm}$. crassis. Limbi in sicco firmomembranacei, opaci, inferiores usque ad $5 \frac{1}{2} \mathrm{~cm}$. longi et ad $2 \mathrm{~cm}$. lati superiores ad $3 \frac{1}{2} \mathrm{~cm}$. longi et ad $1 \frac{1}{12} \mathrm{~cm}$. lati; petioli inferiores ad $\mathrm{S} \mathrm{mm}$., superiores ad $3 \mathrm{~mm}$. longi. Spicae florentes circiter $11 \mathrm{~cm}$. longae et $1 \mathrm{~mm}$. crassae; rhachis glabra. Stigma parrum minute pilosulum; ovarium emersum obovatum.

Hab. in Cuba orientali prope villam Monte Verde dictam: Wright n. 511 (in h. Boiss. et Griseb., non 511 in h. DC.), n. 1688 (in h. DC. et Griseb.).

94. Peperomia Belangeri C. DC. foliis modice petiolatis, lanceolato-ellipticis, basi acutis, apice acuminatis acumine obtusiusculo, utrinque crebre nigro-punctulatis, supra glabris, subtus appresse pilosis ciliatis, 7 -nerviis, nervis exterioribus tenuissimis nervulo marginali ab apice decurrente, petiolo pedunculoque terminali vel axillari appresse pilosis; spica folii limbum fere aequante vel paullo superante, bractea orbiculari centro subsessili; ovario emerso oborato apice oblique depresso. stigmate proprio destituto.

Peperomia Belangeri C. DC. Prodr. XVI, 1 (1869) p. 411.

Herba basi procumbens, caule appresse piloso, in sicco circiter $2 \mathrm{~mm}$. crasso. Limbi in sicco membranacei, subpellucidi, $4-4^{1} / 2 \mathrm{~cm}$. longi et $2-2 \% \mathrm{~cm}$. lati; petioli $1 \mathrm{~cm}$. longi.

Hab. in Martinique: Bélanger n. 137 (in h. Boiss.). 
95. Peperomia Smithiana C. DC. (n. sp.), foliis breviter petiolatis, lanceolatis, basi acutis, apice longiuscule acuminatis, supra glabris, subtus haud dense pilosulis et nigropunctulatis 5-nerriis nerruloque marginali ab apice decurrente, petiolo pedunculoque axillari petiolum paullo superante glabris; spicis florentibus quam limbi paullo brevioribus; ovario emerso obovato, summo apice stigmatifero.

Herba ut videtur erecta, caule glabro, in sicco fere $1 \mathrm{~mm}$. crasso. Limbi in sicco membranacei, usque ad $3^{1 / 2} \mathrm{~cm}$. longi et ad $13 \mathrm{~mm}$. lati. Rhachis glabra glandulis conspersa. Stigma puberulum.

Hab. in St. Vincent, in Morne Garon alt. $830 \mathrm{~m}$.: H. H. et G. W. Snith n. $1645^{b}$.

96. Peperomia glabella A. Dietr. ramulis altero latere ciliatis; foliis petiolatis, subobovato-ellipticis rel elliptico-rhombeis, basi subcuneatis, apice breviter acuminatis obtusiusculis acutisve, utrinque glabris et crebre nigro-punctatis, 5 -plinerviis nervis lateralibus tenuibus paullo supra basin solutis, aut 5 -nerriis, petiolo supra ciliato externe glabro: spicis filiformibus densifloris breviter pedunculatis, folia $2-3$-plo superantibus, axillaribus solitariis aut subpaniculatim confertis et squamis fultis, bractea rotundata centro subsessili; ovario emerso, sub apice oblique stigmatifero; bacca ovata laevi, apice breviter oblique acutata.

Peperomia glabella A. Dietr. Sp. I (1831) p. 156; Miq. Syst. p. 97: Griseb. Flor. p. 165 (p. p.) et Cat. p. 64; C. DC. Prodr. XTI, 1 p. 417; Dahlst.! Stud. p. 121 (excl. var. $\gamma)$.

Piper glabellum Sw.! Prodr. (1788) p. 16 et Fl. Ind. Occ. I p. 68: Vahl En. I p. 345; Willd. Sp. I p. 165.

Piper scandens Sw. Prodr. (1788) p. 16.

Peperomia brachyphylla A. Dietr. Sp. I (1831) p. 157; Niq. l.c. p. 99; Waura Bot. Erg. p. 132 t. 82.

Peperomia caulibarbis Miq.! Syst. (1843) p.98; C. DC. l. c. p. 409.

Peperomia lineatipila Rich.! in La Sagra Cub. XI (1850) p. 229.

Peperomia trinervis $\beta$. brachyphylla C. DC. l. c. (1S69) p. 41;.

Herba epiphyta al saxicola, ramis e nodis radicantibus, altero latere serie duplici pilorum e petiolis decurrente instructis, in sicco $2-3 \mathrm{~mm}$. crassis. Limbi in sicco firmo-membranacei aut subcoriacei, usque ad $4 \mathrm{~cm}$. longi et ad $2 \frac{1}{2} \mathrm{~cm}$. lati; petioli $5-7 \mathrm{~mm}$. longi. Pedunculi circiter $1 \mathrm{~cm}$. longi glabri; spicae adultae $9-12 \mathrm{~cm}$. longae, in sicco $1 \mathrm{~mm}$. crassae; rhachis glabra. Bacca sessilis sine pseudocupula.

Hab. in Cuba: Sagra (in h. Francav. sub P. lineatipila Rich.), Wright n. 506 (in h. Stockh. f. Dahlst. l. c.), prope Monteverde alt. $800 \mathrm{~m}$. in arboribus repens: Eggerss n. 5124, prov. Sta. Clara prope Cieneguita: Combs n. 693; Jamaica in lapidosis montosis: Swartz (in h. DC.), in montibus prope Kingston: O. Hansen, in Ilount Dakin alt. $330 \mathrm{~m}$. 
growing on trees hanging in festons: W. Harris n. 5685, prope Browns Town 400 m.: Harris n. 7173; Portorico in sylvis primaevis ad arbores: Schwanecke, prope Maricao in convalli fluminis superioris, prope CaboRojo in saxosis ad Bella Vista, in Sierra de Luquillo in regione media montis Jimenes, Sierra de Yabucoa in monte Cerro-Gordo, prope Cayey juxta flumen Plata, Sierra de Juncos in monte Guvuy, prope Adjuntas ad Saltillo, Las Cruces, in monte Cienega, prope Utuado ad Cayuco et ad Mameyes: Sintenis n. 464, 611, 1249, 1667, 2801, 2802, 2807, 4084, 4203, 4288 b 4303, 6413, 6540, prope Mayagüez: Krug n. 977, prope Yauco: Garber n. 62, St. Thomas ad Signalhill alt. 460 m.: Eggers ed. Toepff. n. 266; St. Eustache ad Quill: Suringar; Saba: Suringar; Grenada: R. V. Sherring (in h. Kew); Barbados ad rupes: Eggers n. 7359 ; - praeterea Guyana, Brasilia (vide C. DC., Dahlst. l. c.).

Var. $\beta$. Jimenesana forma b. limbis lanceolatis usque ad $5^{1 / 2} \mathrm{~cm}$. longis.

Peperomia caulibarbis $\beta$. Jimenesana C.DC. in Dur. et Pitt. Primit. II (1899) p. 284 (quoad sp. Donnell Smithii).

Hab. in Jamaica ad Bog Walk: W. Fawcett n. 8133; Sto. Domingo prope Angostura ad rupes calcareas repens: Eggers n. 1834; Trinidad in hort. botanico: Broadway n. 5478; - praeterea Costarica ad Jimenes (C. DC. l. c.).

Var. $\gamma$. brachyphylla C. DC. limbis elliptico-ovatis apicem versus ciliolatis usque ad $4 \mathrm{~cm}$. longis et ad $2 \mathrm{~cm}$. latis.

Piper brachyphyllum Spreng. Syst. I (1825) p. 116.

Peperomia brachyphylla Miq. Syst. (1843) p. 99; Wawra Bot. Erg. p. 182 t. 132 fig. 1.

Peperomia trinervis $\beta$. brachyphylla C. DC. Prodr. XVI, 1 (1869) p. 417 .

? Peperomia glabella forma parvifolia O. Ktrne. Rev. II (1891) p. 564 .

Hab. in Cuba orientali prope villam Monte Verde dictam: Wright n. 506; Haiti: Poiteau; Sto. Domingo in monte Loma Isabel de la Torre, alt. $790 \mathrm{~m}$. in arboribus scandens: Eggers n. 2773; - praeterea Colombia, Brasilia (vide C. DC. in Bull. Herb. Boiss. V p. 706, $2^{\text {me }}$ ser. VI p. 357, Engl. Jahrb. XXIX p. 26; Wawra, O. Ktze. l. c.

Var. $\delta$. Eustatiana C. DC. (n. var.), limbis lanceolatis utrinque acutis usque ad $6 \frac{1}{2} \mathrm{~cm}$. longis et ad $27 \mathrm{~mm}$. latis in sicco tenuiter membranaceis et pallidis 5 -nerviis, petiolis usque ad $1 \mathrm{~cm}$. longis.

Hab. in St. Eustache ad Quill: Suringar. 
97. Peperomia truncigandens C. DC. (n. sp.), foliis longiuscule petiolatis, superioribus e basi acuta ellipticis, apice longiuscule acuminatis acumine obtuso, utrinque glabris, 3-5-nerviis, petiolis minute puberulis; pedunculis axillaribus et terminalibus glabris petiolos, spicis ipsis limbos subaequantibus, bractea orbiculari centro breriter pedicellata; bacca emersa, ovato-globosa, apice oblique apiculata.

Herba ramulis minute puberulis, ad $2 \mathrm{~mm}$. crassis. Limbi in sicco membranacei, inferiores e basi cuneata obovati fere $1 \mathrm{~cm}$. longi, superiores ad $22 \mathrm{~mm}$. longi et ad $12 \mathrm{~mm}$. lati; petioli fere ad $1 \mathrm{~cm}$. longi. Spicae bacciferae vix $1 \mathrm{~mm}$. crassae; rhachis glabra. Ovarium emersum, sub apice obtuso stigmatiferum. Stigma parvum glabrum. Bacca sine pseudocupula.

Hab. in Guadeloupe, Pied de la Grande Découverte, ad truncos vetustos cum muscis repens: Duss n. $3616^{\text {b }}$.

98. Peperomia myrtifolia A. Dietr. glabra, foliis breviter petiolatis, rhombeo-oblongis, basi acutis, apice obtusis, nigro-punctatis, 3 -nerviis et fere enervulosis nervuloque marginali ab apice ultra medium decurrente; pedunculo petiolum aequante, spicis axillaribus terminalibusque filiformibus densifloris, folia pluries superantibus, bractea orbiculari nigro-punctulata centro subsessili; ovario emerso obovato, stigmate punctiformi.

Peperomia myrtifolia A. Dietr. Sp. I (1831) p. 147; C. DC. Prodr. XVI, 1 p. 438 et in Linncea XXXVII p. 387; Dahlst.! Stud. p. 124 (quoad sp. Pfug); - non P. myrtifolia Miq. Syst. (1843) p. 92.

Piper myrtifolium Vahl Enum. I (1804) p. 341.

Caulis pedalis simplex glaber coriaceus. Limbi in sicco firmulomembranacei, opaci, $33 \mathrm{~mm}$. longi, $15 \mathrm{~mm}$. lati; petioli fere $4 \mathrm{~mm}$. longi. Ovarium oblique stigmatiferum.

Hab. in St. Croix: Pflug (in h. Vahl musei Haun.).

99. Peperomia Hamiltoniama Miq. glabra, foliis breriter petiolatis, ellipticis, basi acutis, in petiolum decurrentibus, apice subattenuatis obtusiusculis, 5-nerviis, nerris exterioribus tenuibus; spicis terminalibus solitariis, folia fere duplo superantibus, densifloris filiformibus, breviter pedunculatis, pedunculis petiolos paullo superantibus, bractea rotundata centro subsessili; ovario subacuminato, stigmate minuto.

Peperomia Hamiltoniana Miq.! in Hook. Lond. Journ. of Bot. $\mathrm{IT}^{\text {r }}$ (1866) p. 417; C. DC. Prodr. X TI, 1 p. 422.

Herba nedalis dichotome ramulosa. Limbi subopaci, inferiores rhombeo-elliptici vel subobovato-rhombei, superiores ut in diagnosi $3 \frac{1}{2} \mathrm{~cm}$. longi et $17 \mathrm{~mm}$. lati; petioli $3 \mathrm{~mm}$., pedunculi $5-7 \mathrm{~mm}$. longi. Spicae floreutes $6-7 \mathrm{~cm}$. longae.

Hab. in Jamaica: Jac Fadyen n. 108 (in l. Kew); - praeterea in Colombia (vide C. DC. in Bull. h. Boiss. $\mathrm{Y}$ p. 706). 
Tar. $\beta$. emarginulata C. DC. (n. var.) limbis plerisque apice leviter emarginulatis, spicis terminalibus axillaribusque folia fere triplo superantibus.

Limbi in sicco membranacei, subpellucidi, superiores circiter $3 \mathrm{~cm}$. longi et $14 \mathrm{~mm}$. lati. Spicae fere $2 \frac{1}{2} \mathrm{~mm}$. crassae. Bacca sessilis subglobosa, apice oblique mucronulata, glandulis conspersa, sine pseudocupula.

Hab. in St. Croix, in rupibus ad Créquis: A. E. Ricksecker n. 422.

100. Peperomia petiolaris C. DC. glabra, foliis inferioribus longe, superioribus modice petiolatis, inferioribus e basi cuneata obovatis, superioribus subovato-rhombeis, basi acutis, apice acutiusculis obtusiusculisve, $\bar{\jmath}$-nerviis, nervis exterioribus tenuibus; pedunculis quam petioli inferiores brevioribus, spicis axillaribus terminalibusve filiformibus, folia pluries superantibus, adultis laxifloris, bractea rotundata centro subsessili; ovario obovato; bacca ovato-acutiuscula.

Peperomia petiolaris C. DC. in Seem. Journ. of Bot. IV (1866) p. 138 et Prodr. XVI, 1 p. 414 (excl. spec. Hoffm.) et Mém. Soc. phys. XXVII tab. 8; Dahlst.! Stud. p. 43.

Peperomia pellucida Griseb. Cat. (1866) p. 63, - non Kth.

Herba erecta, inferne radicans, ramulis spiciferis $1 \mathrm{~mm}$. crassis. Limbi in sicco membranacei, pellucido-punctati, inferiores usque ad $2 \frac{1}{2} \mathrm{~cm}$. longi et $2 \mathrm{~cm}$. lati, superiores circiter $2 \mathrm{~cm}$. longi et $1 \mathrm{~cm}$. lati; petioli inferiores usque ad $2^{1 / 2} \mathrm{~cm}$. longi. Spicae post anthesin circiter $11 \mathrm{~cm}$. longae, $1 / 2 \mathrm{~mm}$. crassae. Bacca rlachis processu breviter stipitata.

Hab. in Cuba: Wright n. 2261; - praeterea in Paraguay meridiem versus ab urbe: G. O. Malme (in h. Stockh. sec. Dahlst. l. c.).

101. Peperomia Vanhenrekii C. DC. foliis breviter petiolatis, oratis, basi inferioribus rotundatis, superioribus obtusis, apice breviter acuminatis acumine acuto vel obtusiusculo, adultis utrinque glabris, 11 -nerviis, nervis tenuissimis nerruloque marginali ab apice ultra medium decurrente, petiolo pedunculoque aequilongo glabris; spicis axillaribus, limbos aequantibus densifloris, bractea orbiculari, centro subsessili; ovario emerso, glandulis consperso, apice subacuto, antice oblique stigmatifero; stigmate punctiformi.

Peperomia Tanheurcki C. DC. in Tan Heurck et Mïll. Arg. Obs. Bot. fasc. I (1876) p. 116.

Caulis in specimine simplex glaber $2 \mathrm{~mm}$. crassus. Limbi in sicco membranacei, subpellucidi, crebre pellucido-punctulati, circiter $4 \frac{1}{2} \mathrm{~cm}$. longi et $3 \frac{1}{2} \mathrm{~cm}$. lati; petioli $5 \mathrm{~mm}$. longi. Spicae florentes fere $1 \frac{1}{2} \mathrm{~mm}$. crassae.

Hab. in Martinique: Sieber (in l. V. Heurck et l. Cand.).

102. Peperomia Rupertiana C. DC. glabra, foliis breviter petiolatis, superioribus ellipticis vel elliptico-lanceolatis, basi acutis subacutisve, apice breviter attenuatis acntis obtusiusculisve, inconspicue 
nigro-punctulatis, 7 -nerriis; pedunculo petiolum paullo superante, spicis axillaribus terminalibusque densifloris filiformibus, limbos paullo superantibus, bractea rotundata centro peltata; orario impresso oblongoobovato.

Peperomia Rupertiana C. DC. Prodr. XVI, 1 (1869) p. 413; Dahlst.! Stud. p. 124.

Peperomia acuminata Miq. in Hook. Loud. Joum. IV (1845) p. 416; Griseb. Flor. W. Ind. p. 165 (p. p.); Dahlst.! Stud. p. 123 (p. p.), - non R. et Pav.

Caulis fere tetragonus, glaber, superne circiter $2 \frac{1}{2} \mathrm{~mm}$. crassus. Folia alterna, vel terminalia opposita; limbi membranacei subpellucidi, circiter $5 \mathrm{~cm}$. longi et $3 \mathrm{~cm}$. lati; petioli $7 \mathrm{~mm}$. longi. Spicae florentes $6-10 \mathrm{~cm}$. longae et $2 \mathrm{~mm}$. crassae. Stigma minutum.

Hab. in Antigua: Wullschlaegel n. 537; Dominica super Princip. Rupert caput: hb. Kew, Jardin (in h. Lenorm.); Martinique, sparsa in nemoribus: Duss n. $4 \underline{98}$ ?, locis saxosis de la Plaine (Trois Ilets): Duss 1. 4479 ; Barbados in Forster Hall rood in rupibus calcareis: Eggers n. 7202 , ad Bathoteba under the cliffs: Waby n. 81 .

103. Peperomia guadaloupensis C. DC. glabra, foliis breviter petiolatis, elliptico-lanceolatis, basi acutis, apice obtusiusculis et praesertim subtus nigro-punctatis, 5-nerviis; spicis axillaribus terminalibusque subdensifloris pedunculatis, folia fere triplo pedunculisque petiolos fere duplo superantibus; bractea orbiculari centro subsessili; orario emerso orato; bacca ovato-globosa, glandulis conspersa, apice oblique mucronulata.

Peperomia guadaloupensis C. DC. in Seem. Joum. of Bot. $\mathrm{IV}^{\mathrm{T}}$ (1866) p. 139 et Prodr. XVI, 1 p. 416 (emend. et excluso spec. Fraser ac varietate pubescens).

Piper acuminatum West! Fl. St. Croix (1793) p. 268 (non L.).

Peperomia acuminata Griseb.! Fl. W. Ind. (1859) p. 165 (p. p.), et Pl. Wr. p. 175 et Cat. pl. Cub. p. 63, - non R. et Pav.

Peperomia cubana C. DC. Prodr. XVI, 1 (1869) p. 413 (exclus. sp. Richard); Sauv. Fl. Cub. n. 2259 p. 145.

Peperomia myrtifolia Dahlst.! Stud. p. 12.4 (excl. sp. Pfug).

Herba ramulosa, ramulis in sicco $2 \frac{1}{2} \mathrm{~mm}$. crassis. Limbi in sicco membranacei, pellucido-punctulati, usque ad $4 \frac{1}{2} \mathrm{~cm}$. longi et ad $2 \mathrm{~cm}$. lati; petioli vix ad $5 \mathrm{~mm}$. longi. Spicae fructiferae fere usque ad $11 \mathrm{~cm}$. longae et ad $2 \mathrm{~mm}$. crassae. Orarium sub apice oblique stigmatiferum. Stigma puberulum. Bacca globosa sine pseudocupula et apice oblique mucronulata.

Hab. in Cuba orientali: Wright n. 504; Jamaica: Wilson n. 467 (in h. Götting.); St. Croix ad Springard: West (in h. DC.); Guadeloupe: Jardin (in h. Lenorm. et h. DC.); - praeterea Guatemala (vide C. DC. in Donn. Smith Enum. part IV p. 134). 
104. Peperomia Sintenisii C. DC. (n. sp.), foliis breviter petiolatis, superioribus lanceolatis, basi cuneatis, superne attenuatis, apice acutis et parce ciliolatis, caeterum petiolisque utrinque glabris, 5-nerviis; pedunculis axillaribus terminalibusque, petiolos duplo superantibus, spicis glabris subdensifloris, folia fere triplo superantibus, bractea subellipticorotunda, centro breviter pedicellata; bacea emersa elliptica, glandulis conspersa, apice brevissime oblique acutata.

\section{Peperomia acuminata Dahlst.! Stud. (1900) p. 123 (p.p.).}

Herba e basi radicante erecta, caulibus glabris, in siceo circiter $3 \mathrm{~mm}$. crassis. Limbi in sicco membranacei, opaci fuscescentes, inconspicue pellucido-punctulati et laaud nigro-punctulati, inferiores e basi cuneata obovati, fere $3 \mathrm{~cm}$. longi et $2 \frac{1}{2} \mathrm{~cm}$. lati, superiores usque ad $4 \frac{1}{2} \mathrm{~cm}$. longi et circiter $2 \mathrm{~cm}$. lati; petioli fere $5 \mathrm{~mm}$. longi. Spicae florentes in sicco $1 \frac{1}{2} \mathrm{~mm}$. crassae; rlachis glabra maturitate sub bacca in processum conicum brevem producta. Antherae parvae subglobosae. Stigma parvum puberulum, paullo sub apice baccae insertum. Bacca sine pseudocupula.

Hab. in Portorico prope Maricao in silvis ad montem Alegrillo, prope Cayey in silva ad Pedro Avila: Sintenis n. 463, 2800.

105. Peperomia Broadwayi C. DC. (n. sp.) glabra, foliis modice petiolatis, orato-ellipticis, utrinque acutis, 5 -nerviis nervuloque marginali ab apice decurrente; pedunculis axillaribus petiolos aequantibus, spicis folia duplo et plus superantibus, subdensifloris, bractea orbiculari, centro pedicellata, glandulis conspersa; bacca globosa glandulis conspersa, apice oblique et obtuse apiculata.

Herba ut videtur erecta, caule ramuloso, in viro rubro, ramulis sicco fere $3 \mathrm{~mm}$. crassis. Limbi in sicco firmulo-membranacei, crebre pellucidopunctati, inferiores usque ad $5 \frac{1}{2} \mathrm{~cm}$. longi et ad $3 \mathrm{~cm}$. lati, superiores circiter $4^{1 / 2} \mathrm{~cm}$. longi et $22 \mathrm{~mm}$. lati; petioli $6 \mathrm{~mm}$. longi. Spicae in siceo $3 \mathrm{~mm}$. crassae. Filamenta brevissima; antherae ovatae. Ovarium obovatum paullo sub apice oblique stigmatiferum. Stigma globosum papillosulum. Bacea cum apiculo fere $1 \mathrm{~mm}$. longa, sine pseudocupula.

Hab. in Martinique circa Camp de l'Alma rarissima: Duss n. 1262; Grenada, on banks in the lower mountain districts: Broadway 11. 647.

106. Peperomia diaphanoides Dahlst. Stud. (1900) p. 112 t. 4 fig. 3 .

Hab. in Brasilia.

Var. $\beta$. vincentensis Dahlst. foliis breviter petiolatis, anguste lanceolatis, basi acutis apice longiuscule acuminatis, apice parce ciliolatis, caeterum utrinque glabris, 5 -nerviis, petiolis pedunculisque terminalibus petiolos fere aequantibus glabris; spicis maturis limbos fere aequantibus sublaxifloris, bractea orbiculari centro subsessili; bacca rhachi subimpressa, ovato-globosa, glandulis conspersa, apice oblique apiculata. 
Peperomia diaphanoides var. vincentensis Dahlst.! Stud. (1900) p. 114 t. 10 fig. 4.

Peperomia nemorosa Kew Bull.! 1893 p. 272, - non C. DC.

Herba basi radicans, ramulis glabris erectis cum spicis terminalibus fere $9 \mathrm{~cm}$. longis in sicco vix $3 / 4 \mathrm{~mm}$. crassis. Limbi in sicen membranacei, pellucidi, minute pellucido-punctati, superiores usque ad $4 \frac{1}{2} \mathrm{~cm}$. longi et ad $13 \mathrm{~mm}$. lati, inferiores elliptici multo breviores et latiores; petioli vix $3 \mathrm{~mm}$. longi. Spicae maturae vix $1 \frac{1}{2} \mathrm{~mm}$. crassae. Ovarium sub apice oblique stigmatiferum. Stigma minutum glabrum. Bacca sine pseudocupula.

Hab. in St. Vincent in Morne Gavon, alt. $830 \mathrm{~m}$., ad saxa et arbores: H. H. et G. W. Smith n. 1645 .

Obs. Species P. drusophilae C. DC. (in Linnaea XXXVII p. 372) proxima, limbis longins acuminatis et spicis haud dense bacciferis ab ea discrepans.

107. Peperomia alata R. et Pav. foliis breviter petiolatis, oblongoellipticis, basi acutis in petiolum decurrentibus, apice sat longe et suboblique acuminatis acumine acuto apice excepto ciliolato, utrinque glabris, $3-5$-nerviis nervuloque marginali ab apice decurrente, petiolo pedunculoque axillari vel terminali petiolum aequante glabris; spicis densifloris, maturis folia paullo superantibus, bractea orbiculari centro subsessili; ovario semiimmerso; bacca glandulis conspersa, globosa, apice oblique vix mucronulata.

Peperomia alata R. et Pav.! Fl. per. I (179S) p. 31 t. 48 fig. b; Ham. Prodr. p. 2; A. Dietr. Sp. I p. 149; Miq.! Syst. p. 87; C. DC. Prodr. XVI, 1 p. 418 (excl. sp. Andrieux n. 97); Henschen Et. p. 40 t. 4 fig. 5; Dahlst.! Stud. p. 109.

\section{Piper alatum Vahl En. I (1804) p. 342.}

Peperomia dendrophita Griseb.! Fl. W. Ind. (1859) p.165 et Cat. pl. Cub. p. 6t (excl.n. 168S), Sauv. Fl. Cub. n. 2264 p. 146.

Peperomia cubana C. DC. Prodr. XVI, 1 (1869) p. 413 (quoad sp. Rich.).

Herba circiter $25 \mathrm{~cm}$. alta, basi radicans, caule glabro, anguste alato, in sicco circiter $3 \mathrm{~mm}$. crasso. Limbi in sicco membranacei, pellucidopunctulati, superiores $6-10 \mathrm{~cm}$. longi, $3-4 \mathrm{~cm}$. lati; petioli $5-10 \mathrm{~mm}$. longi. Filamenta antheris minutis subrotundis paullo longiora. Ovarium sub apice stigma minutum glabrum gerens. Rhachis tarde sub bacca caduca in processum conicum sat longum producta. Bacca sine pseudocupula, fere $1 / 2 \mathrm{~mm}$. longa (in spec. Wrightii 11.500 ).

Hab. in Cuba orientali: Wright n. 500,503 (in h. DC.), prope El Palenquito in arboribus $600 \mathrm{~m}$. alt., in Loma del Jagüey alt. $700 \mathrm{~m}$. in rupestribus scandens: Eggers n. 4861, 4948; Jamaica ex Griseb.; Haiti: Poiteau, Picarda n.667; Sto. Domingo, in silva summi montis Isabel de la Torre ad arbores alt. $770-790$ m.: Eggers 11. 1598, 2768; 
Portorico, in silvis primaevis prope Barranquitas in monte Torrecilla alt. 1130 m., in Sierra de Naguabo in saxis montis Piedra Belleta, prope Adjuntas ad Las Crnces, in monte Cienega ad La Lucia versus et ad Bajaha, prope Utuado ad Iameyes: Sintenis u. 1246, 1961, 4200, 4202. 4300, 5340, 6541, 6971; St. Croix: Richard (in h. Franquer.); Grenada, in convalli fluminis Concord Valley: Eggers n. 6505; - praeterea in Venezuela, Colombia, Ecuador, Peruvia, Brasilia (vide C. DC. 1. c. et in Bull. h. Boiss. V p. 706, Sodiro in Monogr. Pip. p. 99.

Var. $\beta$. pterocaulis C. DC. foliis brevius petiolatis, latioribus brevioribusque.

Peperomia alata ß. pterocoulis C.DC. Prodr. XVI, 1 (1869) p. 418.

Peperomia pterocaulis Miq.! Syst. (1843) p. 86 et in Mart. Flor. Bros. IV, 1 p. 11.

Peperomia alata Hensehen Etud. Pep. (1873) p. 40.

Peperomia Telloriona Miq.! Syst. (1843) p. S8, in Limnaea XX p. 122 et in Mart. Flor. Bras. $I T, 1$ p. 11.

Hab. in Haiti: Poiteau (in h. Deless.); - praeterea in Brasilia (non Trinitate ut in Prodr. dixi) culta: hb. Fischer (in h. DC. et Petrop.): in monte Corcovado: Martius (in h. Monac.), prope Rio de Janeiro in Serra dos Orgãos: Schwacke n. 4404 (in h. Cand.).

Tar. $\gamma$ - angustifolia C. DC. foliis angustioribus magis acuminatis. bacca subglobosa apice oblique mucronulata (in spec. Wrightii n. 505).

Peperomio alata $\%$ angnstifolia C. DC. Prodr. XVI, 1 (1869) p. 418.

Peperomia dendrophilo Griseb.! Pl. Wr. I (1860) p. 175 et Cat. p. 64 (pro parte).

Hab. in Cuba orientali: Wright n. 505 (in h. DC. et Griseb.), prope villam Nonte Verde dictam: Wright n. 503 p. p. (in h. DC.).

108. Peperomia acuminata C. DC. glabra, foliis petiolatis, lanceolatis rel subrhombeo-lanceolatis vel elliptico-lanceolatis, basi aequilata vel subinaequilata acutis, apice acuminatis, utrinque creberrime nigro-punctulatis, 5-plinerriis enerrulosis, nerris inconspicuis, lateralibus paullo supra basin rel fere e basi solutis; spicis-axillaribus terminalibusque, filiformibus, adultis folia pluries superantibus dense nigropunctulatis, pedunculo petiolum subaequante, bractea rotundata centro subsessili; orario rhachi subimpresso ovato, summo apice acutiusculo et infra apicem stigma parrum puberulum gerente; bacca ovato-globosa laeri, apice oblique rostelląta.

Piper aemminatm Linn. Spec. I ed. I (1753) p. 30 et II ed. p. 42; Willd. Sp. I p. 164; Sx. Obs. p. 20; Anbl. Guian. I p. 21: Vahl En. p. 342 (excl. syn. R. et Par.); Maye. Fl. Barb. p. 40. 
Peperomia nigropunctata Miq.! Syst. (1843) p. 188 et in Hook. Lond. Journ. Bot. IV p. 429; C. DC. Prodr. XVI, 1 p. 409 (p. p.).

Peperomia glabella Griseb.! Fl. W. Ind. (1859) p. 165.

Peperomia melanostigma $\gamma$.glabrior C. DC. Prodr. XVI, 1 (1869) p. 409.

Peperomia nemorosa C. DC. l.c. p. 415 (quoad spec. antill. et h. Willd. и. 721).

Peperomia melanostigma Sauv. Fl. Cub. (1871) n. 2256 p. 145.

Peperomia glabella var. nigropunctata Duss! F7. phan. (1897) p. 172; Dahlst. Stud. p. 122.

Peperomia acuminata (L.) Dahlst.! Stud. (1900) p. 123 (p. p.).

Saururus alius humilis Plum. Descr. Plunt. amer. (1693) p. 54 t.71.

Mouron v. Mouron grand feuille Guad. et Martin. ex Duss.

Herba epiphyta ramosa, inferne e nodis radicans, ramis sat longis in siceo fere $2 \mathrm{~mm}$. crassis. Limbi in sicco membranacei subopaci, $5-8 \mathrm{~cm}$. longi, $21 / 2-4 \frac{1}{2} \mathrm{~cm}$. lati; petioli $1-1 \frac{1}{2} \mathrm{~cm}$. longi. Amenta ad $14 \mathrm{~cm}$. longa et $1 \mathrm{~mm}$. crassa; rhachis dense nigro-punctulata. Antherae parrae rotundatae; filamenta brevissima.

Hab. in Cuba: Sagra (in h. Francav. sub P. mucronata Rich.), Wright n. 503 p. p. (in h. DC.), n. 504; Jamaica: Swartz (in h. Monac.); Saba: Suringar; St. Martin: Suringar; Antiguà: Wullschlaegel n. 537; Guadeloupe: Krauss (in h. DC.), L'Herminier (in h. Cand.), ad arbores regionis mediae vulgaris e gr. in Camp Jacob: Duss n. 2567, 2567 b; Martinique: Sieber n. 67, ad arbores et ad terram locis umbrosis, saepe ut diaphoretica et febrifuga adhibita: Duss n. 13, 499, 500, ad arbores: Hahn n. 649 (hb. Krug et Urb., non hb. Cand.); St. Vincent in silvis montosis ad arbores: H. H. et G. W. Smith n. 1321?; - praeterea in Columbia (vide C. DC. in Bull. h. Boiss. $T$ p. 706); Guiana (vide C. DC. et Dahlst. l. c.).

109. Peperomia Harrisii C. DC. (n. sp.) glabra, foliis brevissime petiolatis, e basi acuta anguste oblongis, apice acuminatis, 7 -plinerriis, nervis tenuibus, lateralibus utrinque 2 e basi, tertio fere $1 \mathrm{~cm}$. supra basin solutis; spicis quam folia fere duplo longioribus filiformibus densifloris brevissime pedunculatis, bractea subelliptico-rotunda, centro brevissime pedicellata; orario emerso superne in scutulum elliptico-rotundum apice obtusum fere medio stigmatiferum producto; bacca globosa, glandulis minimis conspersa, apice scutulum obtusum oblique gerente.

Herba arboricola, ramis usque $1 \mathrm{~m}$. longe peudentibus gracilibus, in sicco $1 \mathrm{~mm}$. crassis, internodiis circiter $3 \frac{1}{2} \mathrm{~cm}$. longis. Limbi in sicco tenuissime membranacei, circiter $57 \mathrm{~mm}$. longi et $16 \mathrm{~mm}$. lati, reticulatonervulosi, pellucido-punctulati; petioli vix $3 \mathrm{~mm}$. longi. Pedunculi fere $6 \mathrm{~mm}$. longi; spicae submaturae $11 \mathrm{~cm}$. longae et cireiter $1 \mathrm{~mm}$. crassae. Filamenta antheras aequantia. Bacca sine pseudocupula. 
Hab. in Jamaica ad Belvidere alt. $166 \mathrm{~m}$. ad ripas fluminis: WT. Harris 11. 7630 .

110. Peperomia pellucida Kunth, glabra, foliis modice petiolatis, deltoideo-cordatis, apice acuminatis acumine obtusiusculo, 7-nerviis, nervis tenuibus, petiolo basi amplexicauli; pedunculo oppositifolio petiolum fere aequante, spica laxiflora filiformi quam folium fere duplo longiore, bractea rotundata centro subsessili; ovario summo apice stigmatifero; bacca sessili globosa, apice mucronulata, longitudinaliter rugulosa, rugis minute verruculosis.

Peperomia pellucida Kunth! in H. B. K. Nov. Gen. I (1815) p. 64 et Synops. I p. 117 et Plant. aeq. II p. 53; A. Dietr. Sp. I p. 164; Iiq.! Syst. p. 79, in Hook. Lond. Joum. Bot. IV p. 413, in Linnaea XX p. 120; C. DC. Prodr. XVI, 1 p. 402; Duss! Fl. phan. p. 171; Dahlst.! Stud. p. 16 t. 1 fig. 1.

Piper pellucidum L.! Sp. I ed. I (1753) p. 30 et II ed. p. 42 et herb. L.; Hill Dict. XXVI p. 18 t. 18 fig. 3; Aubl. Guian. I p. 21; Lam. Ill. p. 82; T'ahl En. I p. 346; Willd. Sp. I p. 163; Spreng. Syst. I p. 117.

Piper concinnum Haw. Succ. Rev. p. 198 (evolutione haud anmua ut videtur tantum discrepans).

Peperomia concinna A. Dietr. Sp. I (1831) p. 164; C. DC. Prodr. IVI, 1 p. 439.

Saururus minor procumbens Plum. Descr. Pl. Amer. (1693) p. 54 tab. 72 .

Pipe: foliis cordatis caule procumbente L. Hort. Cliff. (1737) p. 6 t. 4 .

Poivier à feuilles transparentes Descourt. Fl. Ant. III t. 226 p. 340 .

Coclaria Port. ex Sint., Cochléaria Guad., Herbe à coureze Tartin. ex Duss.

Herba annua (fid. Duss 1. c.), pedalis vel semipedalis vel minor e radice fibrosa erecta ramosa, ramis in sicco firmo-membranaceis subpellucidis. Limbi in sicco tenuiter membranacei, pellucidi, usque ad $21 / 2 \mathrm{~cm}$. longi et ad $2 \mathrm{~cm}$. lati; petioli $1 \frac{1}{2} \mathrm{~cm}$. longi. Rami plerumque post 3 internodia pedunculis oppositifoliis terminati. Spicae in sicco membranaceae, circiter $3 / 4 \mathrm{~mm}$. crassae. Filamenta brevissima; antherae rotundatae. Bacca circiter $1 / 2 \mathrm{~mm}$. longa sine pseudo-cupula, stigmate carnosulo puberulo.

Hab. in Jamaica, ad Hope alt. $233 \mathrm{~m}$. locis umbrosis humidis: W. Harris 11. 6951, in Titclifield peninsula: Millspaugh n. 1S96; Haiti e Martinique introducta: Picarda n. 1219; Portorico prope Fajardo et Naguabo in hortis culta: Sintenis n. 1716 , 5483; St. Thomas in silvis inter saxa ad Signalhill alt. 400 m.: Eggers ed. Toepff. n. 267; St. Croix 
ad Catherine's Rest et ad Bassin: A. E. Ricksecker n. 120, J. J. Ricksecker 1. 122; Guadeloupe in Basse-terre locis hunidis alt. $10-800 \mathrm{~m}$. frequens: Duss n. 2571; Martinique locis humidis et umbrosis vulgaris: Duss n. 1265; St. Vincent ad rupes prope Calvary: Eggers n. 6791, in silris aliisque locis umbrosis et humidis ad arbores, saxa ac etiam ad muros et fossas: H. H. et G. W. Smith n. $594 ;$ Barbados in Newcastle wood ad rupes: Eggers n. 7259; Grenada in horto botanico: Broadway n. 1168, in monte Feliz terrestris alt. 400 m.: Eggers n. 5980; Tobago: Eggers n. 5734; Trinidad: Sieber n. 207 (in h. DC.), in horto botanico: Bot. Gard. Herb. n. 2236; praeterea in Costarica, Columbia, Venezuela, Mexico, Guiana anglica, batava, gallica, Ecuador, Peruria, Brasilia, Africa tropica occidentali (vide C. DC. Prodr. l. c. et Bull. h. Boiss. V p. 705 , VI p. 516, ser. 2 t. I p. 358 , in Dur. et Pitt. Primit. I p. 226, II p.285, in Donn. Smith Enum. part II p. 67, part IV p.136, part $V$ p. 80 ; Dahlst. St. p. 17).

111. Peperomia pernambucensis Miq. foliis modice petiolatis, lato ellipticis, basi attenuatis et in petiolum decurrentibus, apice breviter attenuatis acutis, utrinque glabris, nervo centrali subtus prominulo nervos adscendentes tenuissimos utrinque $7-8$ mittente; spicis in axillis foliorum rhachi communi cymose et plerumque alternatim confertis, squamis minutis caducis fultis, breviter pedunculatis, bractea orbiculari centro peltata; ovario emerso obovato fusco-punctato; stigmate minuto inconspicuo; bacca subrotunda minima.

Peperomia pernambucensis Miq.! in Hook. Lond. Journ. IV (1845) p. 420, in Mart. Flor. Bras. IV, 1 p. 13; Griseb. Fl. W. Ind. p. 167; C. DC. Prodr. XVI, 1 p. 405.

Herba arboricola, caule glabro radicante. Li mbi $17 \mathrm{~cm}$. longi, $71 / 2 \mathrm{~cm}$. lati; petioli usque ad $3 \frac{1}{2} \mathrm{~cm}$. longi. Inflorescentiae rhachis infra spicas $2 \mathrm{~cm}$., caeterum $4 \frac{1}{2} \mathrm{~cm}$. longa; pedunculi $4 \mathrm{~mm}$. longi; spicae maturae $6-7 \mathrm{~cm}$. longae.

Hab. in Trinidad, ubi rara: ex Griseb. (l. c.); - praeterea prope Pernambuco in silva super magnae arboris truncum: Gardner n. 1157 (in h. Kew).

112. Peperomia maculosa W. Hook. foliis magnis longe petiolatis, oblongo-rel elliptico-ovatis, basi rotundatis aut subretusis, paullo supra basin peltatis, apice breviter et acute cuspidatis, adultis supra tantum inferne et margine subtus ubique pubescentibus, nervo centrali fere usque ad $1 / 4$ longitudinis suae nervos tenuiores adscendentes utrinque 3 mittente, quorum inferiores utrinque 2 a petiolo soluti, petiolo pubescente; spicis apice caulis plerumque binatis (uno terminali altero squama oblongo-acuminata fulto), pedunculatis, folia superantibus densi- 
floris, pedunculo quam petiolus fere quadruplo breviore pubescente, bractea suborato-rotunda paullo infra centrum subsessili; bacca verruculosa ovata, apice processu fere aequilongo curvato angusto rostrata.

Peperomia maculosa Hook. Exot. Fl. (1825) t. 92; A. Dietr. Sp. I (1831) p. 63 (excl. syn. R. et Pav.); C. DC. Prodr. XVI. I p. 431 (p. p.); Dahlst. Stud. p. 71 (excl. syn. R. et Pav.).

Piper maculosum L. Sp. I ed. I (1753) p. 30 et II ed. p. 42; Lam. Ill. p. 81; Vahl En. I p. 344 (excl. syn. R. et Pav.); Willd. Sp. I p. 166; Spreng. Syst. I p. 118; Haw. Pl. succ. p. 4.

Peperomia monsterifolia Griseb.! Cat. pl. Cub. (1866) p. 64.

Peperomia septuplinervia C. DC. Prodr. XVI, 1 (1869) p. 431; Sauv. Fl. Cub. n. 2270 p. 146.

Saururus hederaceus, caulibus maculosis, major Plum. Descr. Pl. Amer. (1693) p. 60 t. 66.

Poivrier tacheté Descourt. Fl. Ant. VI (1828) t. 417.

Caulis haud dense hirtellus, pilis fere $1 \mathrm{~mm}$. longis, inferne e nodis radicans, in sicco superne $4-5 \mathrm{~mm}$. crassus succulentus. Limbi in sicco rigidi opaci, ad $16 \mathrm{~cm}$. longi et ad $8 \mathrm{~cm}$. lati, nervis albidis; petioli circiter $10 \mathrm{~cm}$. longi rel inferiores longiores ad $15 \mathrm{~cm}$. longi. Pedunculi circiter $3 \mathrm{~cm}$. longi; spicae ad $25 \mathrm{~cm}$. longae et inferne in sicco ad $6 \mathrm{~mm}$. crassae; rhachis glabra. Antherae minutae valvis ellipticis. Bacca rhachis processu lato et brevissimo pedicellata.

Hab. in Cuba. Wright n. 2260 (in h. DC. et Griseb.); Jamaica in silvis saxosis ad Abbey Green alt. 1260 m.: W. Harris n. 6430; Haiti prope Barotin ad Petite Rivière 1300 m. alt.: Picarda n. 1601; Portorico in sylvis primaevis prope Adjuntas ad Las Cruces et in montibus Galsa et Cerrote: Sintenis n. 4125, 4348, 4458.

Obs. Species pubescentia (a cl. Haworth jam notata) limborumque forma magis oblonga a $P$. variegata R. et Pav. discrepans.

113. Peperomia hernandifolia A. Dietr. foliis longe petiolatis, ad $1 / 3-1 / 4$ longitudinis a basi peltatis, ovatis vel lato-ovatis, basi rotundatis, apice abrupte acuminatis acumine acuto, adultis supra glabris, subtus praesertim ad nervum centralem minute puberulis, 7-9-nerviis, nervo centrali subtus subprominente ralido, lateralibus tenuibus inconspicuis, petiolo dense minute et subretrorsum puberulo; spicis apice ramuli axillaris squama fultis solitariis longe pedunculatis densifloris, maturis quam limbi fere duplo brevioribus, pedunculo quam petiolus fere triplo breviore, dense et minute puberulo, bractea rotundata centro peltata; bacca emersa ovata glabra sat longe rostrata, rostro tenui.

Peperomia hernandifolia A. Dietr. Sp. I (1831) p. 157; Miq. Syst. p. 72 et in Hook. Lond. Journ. Bot. IV p. 42S; Griseb. Pl. Wr. I p. 175 et Cat. pl. Cub. p. 64; C. DC. Prodr. XVI, 1 p. 436; Duss! Fl. phan. p. 172; Dahlst.! Stud. p. 71. 
Piper hernandifolium Vahl En.I (1804) p.344; Spreng. Syst.I p.11S. Peperomia Ponthieni Miq.! Syst. (1843) p. 186; C. DC. l.c. p.432; Sauv. Fl. Cub. n. 2273 p. 146.

In arboribus repens, e nodis racticans, caule minute puberulo, in sicco inferue fere $3 \mathrm{~mm}$. crasso. Limbi in vivo carnosi nitidi obscure virides, in sicco subcoriacei pellucido-punctulati fuscescentes, usque ad $8 \mathrm{~cm}$. longi et usque ad $6 \mathrm{~cm}$. lati; petioli "sauguinei", adulti circiter $9 \mathrm{~cm}$. longi. Spicae maturae fere $2 \mathrm{~mm}$. crassae. Filamenta brevissima; antherae ellipticae. Bacca sessilis sine pseudocupnla.

Hab. in Cuba: Ossa (in h. DC.), in parte orientali prope villam Monte Verde dictam: Wright n. 497 (in h. DC.), n. 647 (fide Sauv.), ad La Clarita alt. $800 \mathrm{~m}$. in arboribus: Eggers n. 5199; Portorico in silvis primaevis Sierra de Luquillo ultra planitiem montis Jimenes ad arbores, prope Adjuntas ad Las Cruces et in monte Guaraguao ad arbores: Sintenis n. 1395, 4199, 4349; Saba in monte: Suringar; Guadeloupe ad arbores silvarum locis humidis et umbrosis Chemin des Bains-Jaunes à la Savane à Mulet, Matouba, alt. $600-1000$ m.: Duss n. 2570; Do minica: Nicholls n. 5, in silvis ad lagunam calidam: Eggers ed. Toepff. n. 766, prope Laudat: Eggers hb. pr. n. 43; Martinique ubi rara: Duss n. 1264, in via La Trace inter Deux-choux et Calvaire du Gros Morne: Duss n. 4478; St. Vincent: Guilding (in h. Hook.), in monte St. Andrews alt. $660-800$ m. haud rara: H. H. et G. W. Smith n. 920; Grenada in silva summi montis Morne au Camp alt. $830 \mathrm{~m}$. ad arhores repens: Eggers n. 6197; India occ.: Ponthieu (in h. Deless.); praeterea in Costa Rica, ad truncos in silvis prope La Palma, alt. 4459 m.: Pittier n. 12539 ; Venezuela: Moritz n. 342.

114. Peperomia urocarpa Fisch. et Mey. foliis longe petiolatis, ovato rotundis, basi rotundatis vel leviter cordatis, apice breviter attenuatis acutis acutiusculisve, utrinque appresse pilosulis, 7 -nerviis, nerris subtus subprominulis, petiolo appresse pilosulo subtereti supra canaliculato; spica ramulum axillarem terminante pedunculata, pedunculo appresse pilosulo squama lineari fulto, spica ipsa limbo paullo breviore densiflora, bractea parva rotundata centro subsessili; ovario subimmerso; bacca cylindraceoellipsoidea, inferne papillosa, patentissima et longe rostrata, rostro baccan aequante subfiliformi.

Peperomia urocarpa Fisch. et Mey. Ind. Sem. hort. Petrop. IV (1837) p. 42; C. DC. Prodr. XVI. 1 p. 433; Dahlst. Stud. p. 81.

Acrocarpidium urocarpum Miq. Syst. (1843) p. 60.

? Piper rotundifolium Hill Dict. XXVI (1775) p. 19 t. 19 fig. 2. p. 118 .

Acrocarpidium majus Liq.! Syst. (1843) p.60 et in Linnaea XX

Peperomia major C. DC. Prodr. XVI, 1 (1869) p. 432; Henschen Et. p. 49 t. 8 fig. 3; Dahlst.! Stud. p. 77 t. 2 fig. 22. 
Peperomia hederacea Miq.! in Mart. Fl. Bras. IV, 1 (1S52) p. 20.

Peperomia ionophylla Griseb. Pl. Wr. I (1860) p.175 et Cat. p. 64; C. DC. Prodr. l. c. p. 436; Sauv. Fl. Cub. u. 2276 p. 146.

Peperomia pseudomajor C. DC. in Briquet Ann. Jard. bot. Genève II (1898) p. 281.

Herba repens aut scandens, ramulis inferne e nodis radicantibus, in sicco circiter $2 \mathrm{~mm}$. crassis, appresse pilosulis. Limbi in sicco membranacei vel rigidi, pellucido-punctulati, majores $3 \frac{1}{2}-4^{1} / 2 \mathrm{~cm}$. longi, $3-4 \mathrm{~cm}$. lati; petioli usque ad $4 \mathrm{~cm}$. longi. Ramulus spiciferus usque ad $3 \mathrm{~cm}$. longus. Bracteae diametro $1 / 4 \mathrm{~mm}$. An therae ellipticae subsessiles. Bacca matura rhachis processu brevissime stipitata.

Hab. in Cuba orientali prope villam Monte Verde: Wright n. 516 , 625 (in h. Griseb. fide Dahlst. l. c.), in Loma del Jagüey alt. $700 \mathrm{ml}$.: Eggers n. 4946 (sp. fruct.); Sto. Domingo ad truncos arborum repens in monte Isabel de la Torre alt. 300 m.: Eggers n. 2817; Portorico ad arbores silvae primaevae prope Aybonito ad Barrio del Pasto, prope Adjuntas in monte Cienega et ad Las Cruces, in Sierra de Lares ad Guajataca, prope Utuado ad liameyes: Sintenis n. 2887, 4204, 4261, $6122,6540^{\text {b}}$; Saba in montibus: Suringar; Guadeloupe, locis humidissimis inter Charret et Le Galion: Duss n. 3700; - praeterea in Venezuela, Columbia, Ecuador, Brasilia (vide Miq., C. DC., Henschen, Dahlst., 1l. c.; C. DC. in Bull. h. Boiss. V p. 710 , VI p. $510,2^{\text {me }}$ ser. p. 359; Sodiro Monogr. Pip. p. 118).

115. Peperomia scandens R. et Pav. foliis longiuscule petiolatis, ovato-rotundatis vel subreniformibus, basi truncatis vel repando-subcordatis, apice brevissime attenuatis et obtusiusculis, 5-7-nerviis, supra ubique et subtus praesertim ad nervos appresse puberulis, petiolo puberulo; spicis ranulos oppositifolios aut axillares un isquamosos terminantibus filifornibus dellsifloris, limbos aequantibus vel paullo superantibus, bractea rotundata centro subsessili; bacca emersa ovato-cylindrica laeri, apice processu filiformi munita.

Peperomia scandens R. et Pav.! Fl. per: I (179S) p. 32 t. 51 fig.b; C. DC. Prodr. IVI, 1 p. 434; Sauv. Fl. Chb. n. 2275 p. 146.

?Piper serpens Sw. Prodr. (17SS) p. 16 et Flor. I p. 69; Willd. Sp. I p. 165; Tahl Enmm. I p. 347; Spreng. Syst. I p. 118 (ef. Dahlst. Stud. p. 79).

Piper seandens Vahl En. I (1501) p. 346.

Piper bractatm Thomp. in Trans. Soc. Lim. IX (1S08) t. 5 p. 203 t. 21 fig. 2.

Peperomia repens Kunth! in H. B. K. Nov. Gen. I (1815) p. 65 ; A. Dietr. Sp. I p. 159; Griseb.! Fl. W. Ind. p. 165 et Cat. p. 64; Dahlst.' Stud. p. 79. 
Piper repens Poir. Enc. Suppl. IV (1816) p. 467; h. Willd. n. 72 S. Piper herbaceum Roem. et Sch. Syst. I (1817) p. 503.

Peperomia reniformis Hook. Exot. Fl. (1825) tab. 164.

Piper Guildingiamum Spr. Syst. cur. post. (1827) p. 20.

Peperomia pnticaris Opiz Reliq. Haenk. I (1830) p. 262.

Peperomia Myosums A. Dietr. Syst. I (1831) p. 162.

Acrocarpidium repens Miq. Syst. (1843) p. 57 et Ill. p. 10 t. 3 fig. 6 et in Limaea XX p. 118 et in Nederl. Kmidl. I p. 220.

Acrocarpidium pulicare Miq. Syst. (1843) p. 57.

Acrocarpidium scandens Miq. l. c. p. 59.

Acrocarpidium Gnildingiamm Miq. in Hook. Lond. Journ. Bot. IT (1845) p. 412.

Verhuellia serpens Niq. Syst.(1843) p.49; C.DC.Prodr. XVI,1 p.392.

Vinagre Portor. ex Eggers.

Herba scandens rel repens, caule filiformi puberulo, in sicco $1 \mathrm{~mm}$. crasso. Limbi in sicco membranacei, subpellucidi, fere epunctulati, parce nervulosi, circiter $1 \frac{1}{2} \mathrm{~cm}$. longi et usque ad $18 \mathrm{~mm}$. lati; petioli $1 \frac{1}{2}-2^{1} / 2 \mathrm{~cm}$. longi et inferiores interdum longiores. Pedunculi fere $1 \mathrm{~cm}$. longi; rhachis glabra. Antherae minutae rotundae.

Hab. in Cuba orientali prope villam Monte Verde dictam: Wright n. 517, prope Arroyo de Pedro alt. 600 m.: Eggers n. 5282; Jamaica in Golden Valley prope St. Thomas alt. $200 \mathrm{~m}$.: W. Harris n. 5455, ad Brandon Hill road alt. $230 \mathrm{~m}$.: W. J. Thompson n. $\$ 100$, in montibus humidis: O. Hansen; Haiti: Poiteau (hb. Willd. 1. 727), ad Etang Ray: Picarda n. 951; Sto. Domingo: Bertero (ex h. Sprengel in h. Berol.), inter Batey et Jamao ad arbores vetustas silvarum repens, alt. $100 \mathrm{~m}$.: Eggers n. 2603; Portorico ad truncos et in rupibus: Bertero, prope Quebradillas: Gundlach n. 1492, prope Bayamon 500 m. alt.: Stahl n. 691, 880, La Sarana prope oppidum Luquillo locis umbrosis repens: Eggers ed. Toepff. n. 1053, hb. pr. n. 1229, in Sierra de Naguabo in monte Piedra Belleta, prope Adjuntas in silvula Coff. arab. ad Buenarista, prope Utuado in silvula Coff. arab. ad Pellejas et ad Cayuco, prope Yabucoa ad La Pandura et circa Sta. Helena, prope Barceloneta in calcareis silvarum ad Florida: Sintenis n. 1248, 4578, 4579, 5100, 512S, 6596, 6732, Sierra de Luquillo: Blauner n. 204 (in h. DC.); St. Vincent, copiose in rupestribus et ad arbores ad orientem montis Morme Soufrière alt. $660 \mathrm{~m}$. ex Thomp. (l. c.), in silvis montanis ad arbores et saxa haud frequens alt. $330-660$ m.: H. H. et G. W. Smith n. 1323; Grenada in monte Feliz ad arbores silvarum scandens, $400 \mathrm{~m}$. alt.: Eggers n. 5977; - praeterea in Columbia, Peru, Guiana, Brasilia.

116. Peperomia enneata Miq. foliis modice petiolatis, e basi cuneata oboratis rel spathulatis, apice obtusis raro retusis, utrinque 
glabris rel apicem versus pilosulis, 7-nerviis, centrali nervo valido, lateralibus aegre discernendis, petiolo glabro; spicis apice ramulorum terminalium v. axillarium solitariis pedunculatis, pedunculo squama fulto, bractea orbiculari centro pedicellata; bacca apice in processum filiformem acuminata.

Peperomia cuneata Miq. in Hook. Lond. Jonm. bot. IV (1845) p. 429; C. DC. Prodr. XVI, 1 p. 433.

Herba carnosa, basi radicans, superne erecta. Limbi carnosi, utrinque glandulis fuscis crebris elevato-punctati, $4-7 \mathrm{~cm}$. longi, $1 \frac{1}{2}-2 \frac{1}{2}$ paullo infra apicem lati; petioli $2 \mathrm{~cm}$. longi. $\mathrm{Spicae} 7-8 \mathrm{~cm}$. longae (ex Miq.).

Hab. in St. Vincent: Guilding (fide Miq. l. c.).

Forma $\beta$. foliis minoribus, limbis in sicco distincte pellucidopunctatis, $4-5 \mathrm{~cm}$. longis, $2,8-4 \mathrm{~cm}$. latis, petiolis $8-10 \mathrm{~mm}$. longis; bacca cylindrica.

Peperomia obtusifolia var. cuneata Duss! Fl. phan. p. 173.

Peperomia obtusifolia $\beta$. cuneata Dahlst.! Stud. (1900) p. 65 (p. p.).

Hab. in Martinique in regione inferiore ad arbores et saxa locis humidis: Duss n. 10, 1266, in monte Calebasse in arboribus: Hahn n. 250 (in h. Cand.).

117. Peperomia cuspidata Dahlst. foliis longiuscule petiolatis, orato-lanceolatis, basi rotundatis, apice longiuscule vel longe acuminatis acumine acuto, utrinque glabris, apicem versus minute ciliolatis, 7 -nerviis, nervis 3 mediis inter se valde approximatis et quasi parallelis, lateralibus utrinque 2 arcuatim adscendentibus, petiolo pedunculoque quam petiolus fere duplo breviore glabris; spicis ramulo axillari 2-3-jugatis tenuibus, squamulis fultis, quam limbi multo brevioribus, bractea rotundata minuta centro subsessili; bacca angusta fusiformi, apice longe rostrata.

Peperomia cuspidata Dahlst.! Stud. (1900) p. it t. 2 fig. 17.

Peperomia distachya f. foliis longins acuminatis Griseb.! Pl. Wright. (1860) p. 175 , Cat. p. 64.

Peperomia producta San. Cub. (1871) n. 2269 p. 146 (p.p.).

Caulis ut videtur erectus, glaber, e nodis radicans, in sicco fere $21 / 2 \mathrm{~mm}$. crassus; internodia fere $2 \frac{1}{2} \mathrm{~cm}$. longa. Limbi in sicco membranacei, opaci, usque ad $5 \mathrm{~cm}$. longi et ad $2 \mathrm{~cm}$. lati; petioli $2 \mathrm{~cm}$. longi. Ramuli spicigeri usque ad spicam inferiorem fere $12 \mathrm{~mm}$. longi. Pedunculi 7-s mm. longi. Bacca apice scutellum obliquum fere medio stigmatiferum gerens, scutello apice in processum subcylindricum baccam fere aequantem protracto, angusta fusiformis cum processu usque ad $11 / 2$ mm. longa.

Hab. in Cuba orientali: Wright n. 502 (in h. Grise's. et Krug et Urb.). 


\section{$112-x+0 \%$}

Piperaceae.

118. Peperomia distachya A. Dietr. foliis longe petiolatis, ovatis rel oblongo-ovatis, inferioribus basi cordulatis, superioribus basi ima brevissime peltatis rotundatis rel tantum obtusis, omnibus apice longiuscule acuminatis acumine acuto, junioribus subtus parce pilosulis, dein utrinque glabris, apicem versus ciliolatis, nervo centrali usque ad 1/2 longitudinis suae nervos $1-2$ mittente, caeteris nervis e basi ortis, petiolo glabro rel apicem versus ciliolato; spicis in apice ramuli axillaris binatis pedunculatis, pedunculis quam foliorum limbi paullo brerioribus, spicis ipsis filiformibus densiflorisque, bractea orbiculari centro subsessili; ovario leviter immerso; bacca patente oblonga, apice processu ea paullo breviore angusto rostrata.

Peperomia distachya A. Dietr. Sp. I (1831) p. 156; Miq. Syst. p. 184 (quoad sp. antill.); C.DC. Prodr. XVI, 1 p. 428 (quoad sp. Poit.); Griseb. Pl. Wr. I p. 175 et Cat. pl. Cub. p. 64 (p. p.).

Piper distachyon L. I ed. I (1753) p. 30, II ed. p. 42; Sw. Obs. p. 21; Willd. Sp. I p. 166; Vahl Enmm. I p. 344; Lam. Ill. p. S1; Spreng. Syst. I p. 118.

Peperomia producta Griseb.! Fl. W. Ind. (1859) p. 166 et Pl. Wr. p. 175 et Cat. pl. Cub. p. 64; C. DC. Prodr. l. c. p. 430; Sam. Fl. Cub. n. 2269 p. 146 (p. max. parte); Dahlst.! Stud. p. 72.

Saururus hederaceus cauliculis maculosis minor Plum. Descr. Pl. 1m. (169:3) p. 51 t. 67 (cum limbis majoribus ad $11 \mathrm{~cm}$. longis et ad $6 \mathrm{~cm}$. latis).

Herba scandens aut repens, caule glabro vel parce pilosulo (in sp. Wright. n. 501), e nodis radicante, in sicco $2-3 \mathrm{~mm}$. crasso. Limbi in sicco membranacei, pellucidi sutpellucidive, parce renulosi, circiter $8 \mathrm{~cm}$. longi et $4 \frac{1}{2} \mathrm{~cm}$. lati; petioli ad $4^{1 / 2} \mathrm{~cm}$. Ramuli spiciferi fere $4 \mathrm{~cm}$. longi. Pedunculi squamis oblongis apice acutis cito deciduis fulti, fere $12 \mathrm{~mm}$. longi. Antherae ellipticae subsessiles. Orarium superne in scutulum oblique productum; scutulo angusto in medio stigmatifero. Stigma carnosum puberulum. Bacca cum processu $1 \frac{1}{2} \mathrm{~mm}$. longa.

Hab. in Cuba orientali: Wright n. 501 , prope villam Monte Verde dictam: Wright n. 508, 1419, 1420, in Loma del Jagüey alt. $700 \mathrm{~m}$.: Eggers n. 4944 (in h. Götting.), 4945 (in h. Krug et Urb.); Jamaica: Swartz (ex Griseb. 1. c.), prope St. Georges $660 \mathrm{~m}$. alt. in arborum truncis: W. Harris n. 5635; Haiti: Swartz l. c., Poiteau (ex h. Philad. in h. Krug et Urb.); Sto. Domingo in Loma Isabel de la Torre alt. $790 \mathrm{~m}$. in arboribus repens: Eggers n. 2772; Portorico in silvis primaevis ad arbores repens, prope Maricao in convalli fluminis superioris, Sierra de Luquillo in monte Jimenes, prope Adjuntas ad Las Cruces et in monte Galsa et in monte Cerrote et in monte Andubo, prope Yabucoa in monte Sombrero: Sintenis n. 470, 1393, 4201, 4343, 4350, 4476, 4796, 5129, 
in Sierra de Luquillo ad Bañadero alt. 800 m.: Eggers ed. Toepff. n. 1054, hb. pr. n. 1237.

Var. $\beta$. cubensis C. DC. limbis superioribus basi cordatis, basi haud peltatis, circiter $5 \frac{1}{2} \mathrm{~cm}$. longis et $3-3 \frac{1}{2} \mathrm{~cm}$. latis, spicis apice ramuli axillaris binatis rel in apice caulis $3-4$ approximatis, maturis quam foliorum limbi sat brevioribus, pedunculis circiter $7 \mathrm{~mm}$. longis.

Peperomia cubensis C. DC. in Seem. Joum. of Bot. IV (1S66) p. 142 et Prodr. XVI, 1 (1869) p.433; Sauv. Irl. Cub. n. 2274 p. 146 : Dahlst.! Stud. p. 76.

Peperomia distachya Griseb. Pl. Wr. I (1860) p. 175 et Cat. p. 64.

Hab. in Cuba orientali: Wright n. 499, in Loma del Jagüey alt. $700 \mathrm{~m}$. in rupestribus: Eggers n. 4944.

119. Peperomia Wrightiana C. DC. foliis longe petiolatis, superioribus e basi cordata rel obtusa late ovatis, apice longiuscule acuminatis acumine acuto, utrinque glabris ciliolatis, 7-pli-9-nerviis, nervo centrali utrinque nervum unum paullo supra basin mittente, aliis nervis e basi solutis, omnibus subtus prominulis, petiolo glabro; spicis apice ramulorum axillarium solitariis pedunculatis, ipsis florentibus folii limbo fere dimidio brevioribus, pedunculis quam petioli et spicae pluries brevioribus, bractea orbiculari centro breviter pedicellata; ovario emerso, superne oblique complanato et apice acuminato, sub acumine antice stigmatifero.

Peperomia Wrightiana C. DC. Prodr. XVI, 1 p. 431; Sauv. Fl. Cub. n. 2271 p. 146; Dalelst. Stud. p. 77.

Peperomia distachya forma folio majori pedunculo brevi Griseb.' Cat. pl. Cub. (1866) p. 64.

Herba scandens?, caule e nodis radicans, in sicco fere $2 \mathrm{~mm}$. crasso. Limbi in sicco firmulo-membranacei, subpellucidi et pellucido-punctati, circiter $12 \mathrm{~cm}$. longi et usque ad $8 \mathrm{~cm}$. lati; petioli $10-12 \mathrm{~cm}$. longi. Ramulus spicifer sub spica squimas 2 alternas e basi lata oblongo-acuminatas glabras fere $1 \frac{1}{2} \mathrm{~cm}$. longas gerens. Pedunculus sub antliesi fere $1 \mathrm{~cm}$. longus; spica florens fere $6 \mathrm{~cm}$. longa, $1 \frac{1}{2} \mathrm{~mm}$. crassa.

Hab. in Cuba orientali: Wright n. 498 (in h. DC. et Griseb.).

120. Peperomia talinifolia Kuntl, glabra, foliis brevissime petiolatis, oblongo-lanceolatis, basi cuneatis, apice attenuatis acutiusculisque, nervo centrali fere tota longitudine sua nervos patulo-subadscendentes utrinque 6 mittente; spicis axillaribus terminalibusque, solitariis rel geminatis, folia fere aequantibus densifloris, pedunculis petiolos multo superantibus.

Peperomia talinifolia Kunth in H. B. K. Nov. Gen. I (1815) p. 62 t. 8 et Synops. I p. 116; Miq. Syst. p. 193; Griseb. Fl. Wr. Ind. p. 167; C. DC. Prodr. XVI, 1 p. 406; Dahlst. Stud. p. 48. 
Caulis $46 \mathrm{~cm}$. altus erectus, simplex vel ramosus, carnosus. Folia alterna; limbi usque ad $4 \mathrm{~cm}$. longi et ad $48 \mathrm{~mm}$. lati; petioli basi tumidi, vix $5 \mathrm{~mm}$. longi. Ramuli spicigeri inferne aphylli, superne sub spicis folia minora gerentes. Pedunculi usque ad $2 \mathrm{~cm}$. longi (ex Kunru l. c.); bracteae orbiculares, tota superficie postica fere adnatae. Ovarium immersum oblique ovatum acuminatum, facie externa impressa paullo supra medium stigmatifera (ex MıQ. l. c.).

Hab. in Trinidad ex Griseb. (1. c.); - praeterea in Nova Granata ex Kunth (l. c.).

121. Peperomia nematostachya Link, foliis breviter petiolatis, elliptico-lanceolatis, basi obtusis vel rotundatis, apice acuminatis acumine acuto, supra glabris, subtus pilis longis sparse hirtellis apicem versus ciliolatis, nervo centrali usque ad $1 / 4$ longitudinis suae nervos suboppositos utrinque 2 mittente, petiolo glabro; spicis binatis breviter pedunculatis densifloris filiformibus, folia fere triplo superantibus, bractea rotundata glandulosa centro subsessili; ovario semiimmerso, apice scutato, scuto glanduloso oblongo-elliptico; bacca patente cylindrica, apice oblique rostellata.

Peperomia nematostachya Link Jahrb. I, 3 (1820) p. 63; A. Dietr. Sp. I p. 156; Miq. Syst. p. 183; C.DC. Prodr. XVI, 1 p. 430; Dahlst. Stud. p. 87 .

Peperomia Parkeriana Miq. in Hook. Lond. Journ. Bot. IV (1845) p. 425 (p. p.) et C. DC. Prodr. XVI, 1 p. 475 (p. p., fide Dahlst. l. c.).

Peperomia distachya Miq. Syst. (1843) p. 184 (quoad sp. Guianensia) et Ill. t. 23; C. DC. Prodr. XVI, 1 p. 428 (quoad spec. Brasil. et Guian.); Dahlst. Stud. p. 89 (p. p.).

Caulis basi lignosus ramosus glabriusculus, sursum hirtellus, ad arborum truncos repens. Limbi in sicco rigidulo-membranacei $5-7 \mathrm{~cm}$. longi, $1-2^{1 / 2} \mathrm{~cm}$. lati, supra minute stellato-puberuli (fide MIQ. 1. c.); petioli $2-8 \mathrm{~mm}$. longi. Pedunculi $1 / 2-1 \mathrm{~cm}$. longi.

Hab. in 'Trinidad: Crueger (in h. Krug et Urb.)?; - praeterea in Guiana, Peruvia, Brasilia (vide: Miq., C. DC., Dahlst. ]. c.).

122. Peperomia myrocarpa Miq. foliis longiuscule petiolatis, elliptico-lanceolatis summisque lanceolatis, basi acutis, apice acuminatis acumine acuto, utrinque glabris, petiolo ciliato dein glabro; spica terminali, folia fere triplo superante, densiflora, pedunculo glabro petiolum fere duplo superante, bractea rotundata centro breviter pedicellata; ovario ovato, apice oblique rostrato, sub rostro scutato stigmatifero; bacca patente ovato-cylindrica, apice oblique acutata.

Peperomia myriocarpa Miq.! Syst. (1843) p. 185 et in Mart. Flor. Bras. IT, 1 p. 22 t. 1 fig. 5; C. DC. Prodr. XVI, 1 p. 426; Dahlst. Stud. p. 86 t. 2 fig. 28 (bacca). 
Herba scandens aut repens e nodis radicans. Caulis glaber, basi sublignosus. Limbi in sicco subcoriacei, pellucido-punctati, circiter $6 \frac{1}{2} \mathrm{~cm}$. longi et $2 \frac{1}{2} \mathrm{~cm}$. lati; petioli $1 \frac{1}{2} \mathrm{~cm}$. longi. Pedunculi fere $4 \mathrm{~cm}$. longi; spica matura inferne cum baccis fere $3 \mathrm{~mm}$. crassa.

Hab. in Trinidad ad Irais: Coll. ignotus (veris. Crïger) n. 361 (ficle Dahlst. 1. c.); — praeterea in Guiana, Brasilia (vide Miq., C. DC., Dahlst. 1. c.).

Obs. Cl. DAHLSTEDT verisimiliter eandem plantam Trinitensem (P. macrostachya herbarii Griseb.) sub $P$. nematostachya Lk. et $P$. myriocarpa Miq. enumeravit. "Irais" non est collector, sed locus natalis (URB.).

123. Peperomia obtusifolia A. Dietr., glabra, foliis carnosis, e basi in petiolum decurrente obovatis vel oblongo- seu spathulato-obovatis vel obovato-rotundatis, apice breviter subattenuatis rotundatis vel obtusis emarginulatisve, nervo centrali usque ad $1 / 2$ longitudinis suae vel ultra nervos adscendentes utrinque $3-5$ inconspicuos mittente; spicis pedunculatis terminalibus solitariis vel saepius binatis aut in apice ramulorum $3-4$ paniculatis, folia \pm superantibus densifloris, bractea rotundata centro breviter pedicellata; ovario immerso; bacca ovato-cylindrica rel ovato-globosa, apice \pm longe rostrata.

Peperomia obtusifolia i. Dietr. Sp. I (1S31) p. 151 (excl. syn. Jacq. t. 212); Miq. Syst. p. 194 et in Mart. Fl. Bras. IV, 1 p. 21 (excl. syn. Plmm. et Jacq.); Griseb. Fl. W. Ind. p. 166 (excl. icon. Jacq. 212); C. IUC. Prodr. XVI, 1 p.429 (excl. syn. Jacq., Tahl et rar. B); Dahlst.' Stud. p. 61; Duss! Fl. phan. p. 173; Saux. Fl. Cub. n. 2268 p. 146.

Piper obtusifolium L.! Sp. I ed. I (1753) p. 30 et II ed. p. 43 et h. pr.; Aubl. Pl. Gmian. I p. 22; Trew-Ehret t. 96; Haworth Pl. Succ. p. 7; Tohl En. I p. 329 (excl. syn. Jacq.); Spreng. Syst. I p. 118 (excl. syn. Jacq.); Ait. Hort. Kew. ed. 2 p. 71.

Piper magnoliaefolium Jacq. Coll. III (1789) p. 210 et Ic. rar. II t. 213; Willd. En. p. 47; Tahl l. c. p. 338; Ait. l. c.; Spreng. l. c. p. 115 .

Piper humile Poir. in Lam. Enc. T (1801) p. 473.

Piper Milleri R. et Sch. Syst. I (1817) p. 337.

Piper tithymaloides Trahl! En. I (1804) 1. 340.

Peperomia emarginata R. et Pav. Fl. per. I (179S) p. 30 t. 49 fig. a.

Peperomia hemionitidifolia Ham.! Prodr. (1825) p. 2; Miq. l. c. p. 75 ; C. UC. l. c. p. 467 .

Peperomia magnoliaefolia A. Dietr. l. c. (1831) p.153; C. DC. l. c. p. 427 et in Bull. h. Boiss. T p. 709, TI p. 718 et in Dur. et Pitt. Primit. I p. 133, II p. 288; Samv. Fl. Cub. n. 2267 p. 116; Sodivo Mon. Pip. p. 115; Dahlst.! Stud. p. 5s; Duss! Fl. phan. p. 173. 
Peperomia tithymaloides A. Dietr. Sp. I (1831) p. 152; Niq. Syst. p. 192; C. DC. Prodr. l. c. p. 439.

Peperomia subrotunda A. Dietr. l.c. (1831) p. 154.

Peperomia pseudoamplexicaulis C. DC. Prodr. l. c. (1869) p. 432; Stur. Fl. Cub. n. 2272 p. 146.

Saururus humilis folio carnoso subrotundo Plum. Descr. Pl. Amer. (1693) p. 53 t. 70.

Piper longum humilius fructu e summitate caulis producto Sloane Cat. (1696) p. 45 et Hist. p. 136 et herb. in herb. mus. brit. II fol. Ss cum planta.

Poivrier à feuilles obtuses Desc. Fl. Ant. V (1827) t. 313.

$\mathrm{Caulis}$ perennis succulentus erectus vel adscendens, basi e nodis radicans, simplex vel ramosus, ramis in sicco coriaceis $3-6 \mathrm{~mm}$. crassis. Limbi in sicco coriacei, subopaci, pellucido-punctulati, $5-12 \mathrm{~cm}$. longi. $3^{1 / 2}-5 \mathrm{~cm}$. lati; petioli \pm distincti $1^{1 / 2}-3 \mathrm{~cm}$. longi. Pedunculi eroluti petiolos \pm superantes, $2-5 \mathrm{~cm}$. longi, squamis fulti. Spicae maturae $6-14 \mathrm{~cm}$. longae, in sicco usque ad $4 \mathrm{~mm}$. longae. Antherae ellipticae: filamenta immersa. Ovarium superne in scutulum apice rostratum productum, in medio scutuli stigmatiferum.

Variat ut sequitur:

A. Bacca orato-cylindrica rel cylindrica. Pedunculus spica 2-3-plo brevior.

Var. $1^{0}$. Limbi adulti longitudine $5 \mathrm{~cm}$. superantes, plerumque $8-15 \mathrm{~cm}$. longi.

Hab. in Cuba orientali: Wright n. 1689 (in h. DC. et Krug et Urb.): Jamaica ad Morse's Gap 1630 m. alt.: Harris n. \$104; Haiti in montibus prope Miragoane ad Icard, prope Pérodin: Picarda n. 295, 1622; Sto. Domingo prope Jarabacoa ad arbores silvarum circa La Hagua $600 \mathrm{~m}$., in Loma Isabel de la Torre alt. 790 m.: Eggers n. 2082, 2769 : Portorico in silvis primaevis ad arbores et saxa, prope Aybonito ad Barrio del Pasto, prope Adjuntas ad Las Cruces, ad Yagua rersus et in monte Cienega et in monte Guaraguao et in monte Cerrote, prope Jayuya juxta flumen circa San Patricio: Sintenis n. 2971, 4185, 4334, 4394. 4456 , 4686; St. Thomas, Signalhill in silva umbrosa ad saxa: Eggers ed. Toepff. n. 370; St. Eustache: Suringar; Guadeloupe ad Houelmont: Duss n. 2572; Martinique: Duss n. 1267; St. Vincent, in silvis montis St. Andrews ad saxa gregaria: Eggers n. 6669; Grenada prope Tendôme ad rupes repens: Eggers n. 6412; - praeterea Florida Mexico, Costarica (Pitt. n.1269), Guatemala, Nicaragua, Columbia, Surinam, Ecuador, Peruvia, Brasilia (vide: Dahlst. l. c. sub P. obtusifolia et variet.). 
Tar. $2^{0}$. Limbi adulti usque ad $4 \mathrm{~cm}$. longi, oborato-spathulati apice emarginulati.

Peperomia magnoliaefolia $\gamma$. parvifolia C. DC. Prodr. XVI, 1 (1S69) p. 427.

Hab. in Cuba: Ossa (in h. DC.), Wright n. 510 (in h. Krug et Urb.); Haiti: Picarda n. 554, prope Corail: Picarda n. 1449.

B. Bacca ovato-globosa vel elliptica. Pedunculus spica pluries brevior. Tar. $1^{0}$. Limbi adulti $6-13 \mathrm{~cm}$. longi.

Hab. in Cuba: Wright n. 510 (in h. Stock. fide Dahlst.), in parte orientali prope villam Monte Verde dictam: Wright n. 509 (in h. DC.); Jamaica: March n. 1388, Sloane (in h. Mus. brit.); Haiti: Poiteau (in h. Deless.); Sto. Domingo: Mayerhoff; Portorico in silvis primaevis ad arbores et rupes prope Maricao in monte Montoso, prope Yabucoa ad Piedra Azul, prope Ciales in declivibus umbrosis: Sintenis n. 467, 5470, 6782, prope Utuado locis humidis: Gundlach n. 985; St. Croix: West (in h. DC.); Guadeloupe: Perrottet (in h. Deless.); Antigua: ? Poitean (in h. Deless.); Trinidad: Sieber n. 349, 365 (in h. DC.); praeterea Mexico, Costarica, Venezuela, Surinam, Brasilia (vide Dahlst. 1. c. sub P. magnoliaefolia et variet.).

Var. $2^{0}$. Limbi adulti usque ad $3 \mathrm{~cm}$. longi, apice emarginulati.

Peperomia magnoliaefolia $\delta$. microphylla Dahlst. l. c. p. 61.

Hab. in Cuba orientali: Wright n. 510 (in h. Griseb. et Krug et Urb.); Portorico, Sierra de Luquillo in rupibus summi montis Yunque: Sintenis 11. 1745 .

C. Specimina propter spicas nimis jureniles incertae formae.

Hab. in Cuba prope Montererde alt. 800 m.: Eggers n. 5126; Haiti: Poiteau, in alpibus dictis Le grand fond de Port-au-Prince alt. $1000 \mathrm{~m}$. ad fontes aquarum: B. Jaeger, prope Pérodin, Corail: Picarda n. 1449, 1619; Sto. Dom ingo ad arbores silvarum summi montis Isabel de la Torre alt. $770 \mathrm{~m}$. , in monte Barrero inter saxa alt. $1200 \mathrm{~m}$. , ad rupes repens juxta flumen Mameyes alt. 150 m.: Eggers n. 1593, 2029, 2543; Portorico prope Bayamon in silvis umbrosis: A. Stahl n. 92, prope Lares in silvis montanis ad Callejones, prope Utuado in silva primaera ad Paso palma: Sintenis n. 5938, 6371; Dominica: G. A. Ramage; Martinique: II ${ }^{\text {me }}$ Rivoire, ad arbores regionis inferioris: Duss n. 11; St. Vincent in silvis ad arbores pendens alt. $330-660 \mathrm{~m}$. alt.: H. H. et G. W. Smith n. 1322, 1642; Grenada in montibus: IV. E. Broadway 11.1412 . 
124. Peperomia alpina A. Dietr. foliis longe petiolatis, e basi cuneata oboratis, apice subattenuato-obtusiusculis, junioribus rersus basin minute puberulis, centrali nerro usque ad $1 / 3$ longitudinis suae nerros versus margines adscendentes utrinque 3 mittente, petiolo glabro angusto basi dilatato; spicis ramulos axillares inferne bracteolas steriles alternas 2-3 gerentes terminantibus, pedunculatis densifloris filiformibus, limbos fere aequantibus, pedunculis glabris petiolos fere aequantibus, bractea orbiculari centro subsessili; ovario immerso, apice longe triangulari-rostrato; stigmate punctiformi puberulo infra rostrum inserto.

Pepcromia alpina A. Dietr. Sp. I (1831) p. 185; Miq.! Syst. p.188; Griseb. Fl. W. Ind. p. 16 7 (exchus. spec. cub.); C. DC. Prode. XVI, 1 p. 429 (exches. spec. cul.); Dahlst. Stud. p. 58.

Piper alpinum Sw.! Prodr. (1788) p. 15 et Fl. Ind. occ. I p. 62; Vahl Earm. I p. 340; Willd. Sp. I p. 163; Spreng. Syst. I p. 115.

$\mathrm{Caulis}$ usque ad $50 \mathrm{~cm}$. longus suberectus glaber, basi radicans. Limbi rigidi opaci, majores $5^{1 / 2}-6^{1 / 2} \mathrm{~cm}$. longi, $3^{1 / 2}-4 \mathrm{~cm}$. lati; petioli $2-4 \mathrm{~cm}$. longi, in siceo ob margines convergentes adspectu subteretes.

Hab. in Jamaica summis in alpibus: Swartz (in h. Willd. n. 716), in middle mountains: Wiles (in 1. Deless.).

Obs. P. alpina Kew Bull. 1893 n. 83 p. 272 e St. Vincent (Smith n. 1643) non luue spectat, sed verisimiliter speciem novam ob fructus deficientes non describendam sistit.

125. Peperomia clusiifolia Hook. glabra, foliis sessilibus, oblongo-obovatis, inferne attenuatis, basi subauriculatis, apice emarginatis, anbitu rubro-marginatis, nervo centrali ultra $1 / 2$ longitudinis suae nervos adscendentes tenues utrinque 4 mittente; spicis pedunculatis terminalibus solitariis vel geminatis, folia superantibus densifloris, bractea rotundata rel subquadrangulari centro peltata; baccis oratis, processu brevi et lato terminatis.

Peperomia chusiifolia Hook. Bot. Mag. (1829) t. 2943; Dahlst.! Stud. p. 62.

Piper chusiifolium Jacq. Coll. III (1789) p. 209 et Icon. rar. II t. 212.

Piper obtusifolizm Lam. IIl. (1791) p. 81; Tahl En. I p. 339 (excl. syn. Plum. et L.).

? Piper magnoliaefolizm Ilaw. Pl. succ. (1812) p. 6 .

Piper marginatum Hawo. Suppl. (1819) p. 3.

Peperomia obtusifolic A. Dietr. Sp. I (1831) p. 154 (quoad syn. Jacq. t. 212); Miq. Syst. p. 194 (p. p. et excl. syn. Plum.).

Peperomia amplexicaulis f. grandifolia Miq. in Hook. Lond. Joum. Bot. IV (1845) p. 430. 
Peperomin obtusifolio p. clnsiifolia C. DC. Prodr. XVI, 1 (1869) p. 429 (excluso syu. Griseb.).

Peperomia amplexicanlis P. longifolia C.DC.1.c.p.425 (fide Dahlst. Stud. p. 62).

Caulis inferne radicans, rugosus ruber ramosus. Folia usque ad $12 \mathrm{~cm}$. longa et ard $4 \frac{1}{2} \mathrm{~cm}$. lata, margine recurvata, carnoso-coriacea. Pcdunculi $2-3 \mathrm{~cm}$. longi.

Hab. in Jamaica: Wullschlaegel n. 1371 (in h. monac. et in h. Griseb. fid. Dahlst. l. c.), ad Banana river alt. $400 \mathrm{~m}$. in rupestribus: Eggers n. 3449. - In caldariis culta ex Antillis (Hook. l. c.).

126. Peperomia euneifolia A. Dietr. glabra, foliis sessilibus, oblongo-spathulatis, inferne attenuatis, apice obtusis et leviter emarginulatis coriaceis, nervo centrali ultra $1 / 2$ longitudinis suae nervos adscendentes utrinque $3-4$ inconspicuos mittente; spicis apice caulis $2-3$ jugatis pedunculatis, bractea orbiculari glandulis flavis conspersa centro subsessili; ovario basi immerso glandulis flavis consperso, scutulo subulato fere in medio stigmatifero; bacea ovata, rostro ea dimidio breviore apice obtusiusculo.

Peperomia cmeifolia A. Dietr. Sp. I (1831) p. 146; Miq. Syst. p. 194; Dahlst.! Stud. p. 63.

Piper cuncifolimm Jacq. Coll. IV (1790) p. 127 et Icon. var. II p. 214; Vahl Enmm. I p. 340; Willd. Enmm. I p. 47; Link Enmm. I p. 38; Roem. et Schmlt. Syst. I p. 115.

Peperomia talinifolia Link in Jahrb. I, 3 (1820) p. 64.

Piper amplexifolimm Link Enmm. I (1821) 1).39; Rocm. el Schult. Syst. Mant. I p. 243.

Peperomia amplexifolia A. Dietr. Sp. I (1831) p. 145; Miq. Syst. p. 197; C. DC. Prodr. IVI, 1 p. 426.

Caules in sicco coriacei, ad $7 \mathrm{~mm}$. crassi. Folia in siceo coriacea pellucido-punctulata, usque ad $14 \mathrm{~cm}$. longa ct ad $5 \mathrm{~cm}$. lata. Pedunculi usque ad $2 \mathrm{~cm}$. longi; spicae in siceo flavac, florentes et partim bacciferae circiter $9 \frac{1}{2} \mathrm{~cm}$. longae.

Hab. in Jamaica, in rupestribus ad Guava Ridge alt. $660 \mathrm{~m}$. : Eggers n. 3731 (in h. Krug et Urb.), 3705 (in h. Haun. fid. Dahlst. l. c.), ad Flamstead alt. 1000 m. in rupibus: Eggers n. 3513 (sine spica); Trinidad: O. Ktze.

127. Peperomia amplexicaulis A. Dietr. glabra, foliis sessilibus, lanceolato - spathulatis, basi ima amplexicaulibus, apice contracto-obtusiusculis, coriaceis, nervo centrali usque ad $2 / 3$ longitudinis suae nervos utrinque $3-4$ adscendentes mittente; spicis in apice caulis solitariis rel'geminatis squamis fultis, densifloris, folia subsuperantibus, peduncu- 
latis, bractea rotundata centro subsessili; bacca obovato-cylindrica, apice oblique rostrata, rostro baccae quintam vel sextam partem aequante.

Pepromia amplexicanlis A.Dietr. Sp. I (1S31) p.144; Miq.! Syst. p. 196; Griseb.! Fl.W. Ind. p. 166 (cxcl. var. a et $\beta$ ); C. DC. Prodr. TTI, 1 p. 425; Dahlst.! Stud. p. 63.

Piper amplexicaule Su.! Prodr. (1788) p. 16 et Fl. Ind. occ. I p. 17 et Icon. incel. tab. 56 (ex Urb. in lit.); Willd. Sp. I p. 165; Vahl Enum. I p. 33S; Roem. et Sch. Syst. I p. 316; Spreng. Syst. I p. 115.

Peperomia amplexicaulis $\beta$. longifolia C. DC. l.c.

? Pcperomia simplex Ham. Prodr. (1825) p. 2.

Caulis erectus, fere simplex, pedalis, subangulosus rigidus, in sicco $3-4 \mathrm{~mm}$. crassus. Folia $6-11 \mathrm{~cm}$. longa, $2-3^{1 / 2} \mathrm{~cm}$. lata. Pedunculi $15-20 \mathrm{~mm}$. longi.

Hab. in Jamaica: Swartz (in h. Stockh., in h. Willd. n. 712), March (in h. Krug et Urb. ex h. Griseb.), ad Money Corner alt. $260 \mathrm{~m}$.: W. J. Thompson n. 8067.

128. Peperomia Grisebachii C. DC. glabra, foliis ternis, breviter petiolatis, elliptico-obovatis, basi ima acutis, apice rotundatis et laevissime emarginulatis, 3-nerviis, nervis inconspicuis; spicis terminalibus solitariis, folia pluries superantibus, filiformibus sublaxifloris, pedunculis folia fere aequantibus, bractea orbiculata centro subsessili; antheris minimis subsessilibus; ovario emerso, superne in stilum oblongum summo apice stigmatiferum producto.

Peperomia Grisebachii C. DC. in Linnaea XXXVII (1871-73) p. 382; Dahlst. Stud. p. 167 t. 3 fig. 14, t. 4 fig. 3.

Peperomia obversa Griseb.! Pl. Wr. (1860) p. 176 et Cat. pl. Cub. p. 64 et Flor. W. Ind. p. 168 (quoad spec. cub.); C. DC. Prodr. XVT, 1 p. 455; Sauv. Fl. Cub. n. 2282 p. 147; - non A. Dietr.

Peperomia Swartiana Griseb.! Flor. (1859) p.167 (quoad specim. portor.).

Peperomia tenerrima Schlecht. f. robustior Dahlst.! Stud. (1900) p. 185.

Herba caule repente e nodis radicante, ramulis amentiferis densifloris cum spicis circiter $8 \mathrm{~cm}$. longis et fere $2 \mathrm{~mm}$. crassis. Limbi in sicco rigiduli, subpellucidi, pellucido-punctulati, enervulosi, $1 \mathrm{~cm}$. longi, $8 \mathrm{~mm}$. lati; petioli $2 \mathrm{~mm}$. longi. Spicae florentes in sicco $2 \mathrm{~mm}$. crassae, circiter $5 \frac{1}{2} \mathrm{~cm}$. longae. Stilus glandulis pellucidis faretus. Stigma carnosum glabrum. Bacca ovata basi pseudocupularis (fide DaнLst. ic. cit.).

Hab. in Cuba: Wright n. 515; ?Portorico orient. 830 m. alt.: Schwanecke, in Sierra de Naguabo in silva montis Piedra Pelada (spec. sterile): Sintenis n. 5420 . 
129. Peperomia quadrifolia Kunth, glabra, foliis quaternis, brevissime petiolatis, e basi cuneata obovatis, apice emarginatis, subcoriaceis, inconspicue 3 -nerviis; spicis terminalibus solitariis densifloris longiuscule pedunculatis, ipsis folia 2-3-plo superantibus, bractea orbiculata centro breviter pedicellata; ovario subimmerso orato superne attenuato et summo apice stigmatifero; bacca oblongo-ovata emersa, basi pseudocupulari, apice mucronata.

Peperomia quadrifolia Kunth in H. B. K. Nov. Gen. I (1815) p. 69 (hb. Willd. n. 754!); Miq.! Syst. p. 159; Griseb. Fl. W. Ind. p. 168; C. DC. Prodr. XVI, 1 p. 454 (excl. syn. IJook. fl. exot.); Hensch. Et. p. 33 t. 4 fig. 6 (bacca); Dahlst.! Stud. p. 185 t. 3 fig. 17.

Piper quadrifolium L. Sp. II ed. I (1762) p. 43; Aubl. Hist. Guian. I p. 21; Swartz Obs. p. 22.

Peperomia alpina Mart. et Gal. in Bull. Brux. X, 2 (1843) p.19, - non A. Dietr.

Piper foliis quaternis Plum. Am. ed. Burm. (1760) p. 238 t. 242 fig. 3 .

Herba inferne e nodis radicans, ramulis erectis $10-12 \mathrm{~cm}$. longis sulcatis, $1 \frac{1}{2} \mathrm{~mm}$. crassis. Limbi in sicco subpellucidi rigidi, ad $1 \frac{1}{2} \mathrm{~cm}$. longi et ad $7 \mathrm{~mm}$. lati; petioli ad $2 \mathrm{~mm}$. longi. Pedunculi fere $2 \mathrm{~cm}$. longi.

Hab. in Jamaica: Macfadyen, prope Clydesdale: W. Harris n.7097, prope Cinchona: Fawcett n. 8162; Sto. Domingo prope Jarabacoa ad truncos arborum juxta flumen Yaqui alt. 550 m.: Eggers 11. 2004; Portorico prope Yauco: Garber n. 113, prope Maricao in convalli fluminis superioris ad silvarum arbores, prope Adjuntas ad arbores vetustas in silvula Coff. arab. ad Junco: Sintenis n. 468, 4697: - praeterea Mexico, Guatemala, Venezuela, Ecuador, Peruria (vide C. DC. 1. c. et in Donn. Sm. Enum. part IV p. 136, in Bull. h. Boiss. VI p. 521$)$.

130. Peperomia papillosa Dahlst. foliis ternis - quaternis, petiolatis, ellipticis, basi acutis, apice obtusis, inconspicue 5-nerviis, utrinque (praesertim in foliis jurenilibus) minutissime papilloso-puberulis; spicis terminalibus longe pedunculatis, pedunculos aequantibus, folia pluries superantibus, densifloris filiformibns, bractea rotundata centro pedicellata; bacca rhachis processu pedicellata, ovata, sub apice contracta et oblique stigmatifera.

Peperomia papillosa Dahlst.! Stud. (1900) p. 170.

Herba repens, e nodis rádicans, ramulis minutissime papilloso-puberulis, spiciferis cum spica circiter $8 \mathrm{~cm}$. longis, $1 \mathrm{~mm}$. crassis. Limbi in sicco membranacei, subpellucidi, $1 \frac{1 / 2}{2} \mathrm{~cm}$. longi, $1 \mathrm{~cm}$. lati; petioli ad $3 \mathrm{~mm}$. longi. Pedunculi ad $3 \mathrm{~cm}$. longi.

Hab. in Cuba in Loma del Jagüiey, $700 \mathrm{~m}$. alt. in arboribus mortuis repens: Eggers n. 5289 (in h. Krug et Urb., non 5829 ut in Dahilst. l. c.). 
131. Peperomia discolor C. DC. foliis ternis, petiolatis, ellipticis, basi et apice subacutis, supra glabris, subtus ad nervos minute velutino-puberulis, 3 -nerviis et reticulato-nervulosis; spicis filiformibus tenuibus sublaxifloris pedunculatis, pedunculis petiolos aequantibus.

\section{- Peperomia discolor C. DC. Prodr. XVI, 1 (1869) p. 463.}

Herbula. Caulis basi radicans, $5-6 \mathrm{~cm}$. altus, teres tenuis glaber. Limbi in sicco rigidulo-membranacei subopaci, $15 \mathrm{~mm}$. longi, 7-8 $\mathrm{mm}$. lati; petioli et pedunculi $4 \mathrm{~mm}$. longi.

Hab. in Jamaica: Macfadyen (in h. Kew).

132. Peperomia galioides Kunth, foliis quaternis - quinis, sessilibus, inferioribus obovatis, superioribus oblongo-spathulatis vel oblongis, apice obtusis, junioribus utrinque minute puberulis, dein glabris, inconspicue 3 -nerviis nervuloque marginali ab apice decurrente; spicis axillaribus terminalibusque, folia pluries superantibus, filiformibus sublaxifloris breviter pedunculatis, bractea rotundata centro peltata; ovario impresso ovato, apice oblique apiculato, apiculo obtuso in medio stigmatifero; bacca ovata apice oblique apiculata.

Peperomia galioides Kunth in H. B. K. Nor. Gen. I (1815) p. 71 (herb. Willd. n.762!); Humb. Pl. Aeq. II p.58; Kunth Syn. I p. 123; Miq.! Syst. p.156 ct Ill. p.22 t.20 et in Mart. Flor. Bras. IV, 1 p. 15 t. 2 fig. 2; Griseb.! Fl.W. Ind. p. 167; C. DC. Prodr. XII, 1 p. 463; Ienschen Et. p. 36 t. 4 fig. 3; Sodiro Mon. Pip. p. 143; Dahlst.! Stud. p. 126.

Piper galioides R. et Sch. Syst. I (1817) p. 335.

Pepromia suaveolens Ham. Prodr. (1825) p. 2; C. DC. l. c. p. 466.

Piper suacolens Cat. Hort. Par. ex Ham.

Herba erecta vel basi decumbens, simplex vel ramosa, caule et ramulis teretiusculis minutissime puberulis, spiciferis in sicco circiter $1 \mathrm{~mm}$. crassis. Limbi in sicco membranacei, subpellucidi et pellucido-punctulati, superiores $15-20 \mathrm{~mm}$. longi, circiter $5 \mathrm{~mm}$. lati. Pedunculi circiter $1 \mathrm{~cm}$. longi; spicae usque ad $8 \mathrm{~cm}$. longae et $1 \mathrm{~mm}$. crassae. Bacea sine psendocupula, glutinoso-rerruculosa, rhachis processu brevi.

Hab. in ? Cuba ex Hamilton (l. c.); Jamaica: March, prope Portland Gap alt. 1800 m.: W. Harris n. 5498; Haiti in montibus Furcy alt. 1515 m.: Picarda n. 1513; - praeterea late per Americam intertropicalem dispersa (V. auct. cit. et C. DC. in Dur. et Pitt. Primit. I p. 234, II p. 294, in Bull. l. Boiss. ser. 2. I p. 360).

133. Peperomia filiformis A. Dietr. foliis oppositis et apice ramulorum ternis-quaternis, petiolatis, lineari-oblongis, basi acutis, apice obtusis, supra et praesertim ad apicem pilosulis, subtus glabris, 3-nerviis, nervis lateralibus inconspicuis, nervulo marginali ab apice brevissime decurrente; spicis terminalibus pedunculatis filiformibus folia fere duplo 
superantibus subdensifloris, pedunculis glabris, adultis folia paullo superantibus, bractea orbiculari centro subsessili; ovario emerso oborato, sub apice obtuso, oblique stigmatifero; bacca subglobosa, glandulis asperulata, oblique et obtuse apiculata.

Peperomia filiformis A. Dietr. (non R. et Pav.) Sp. I (1831) p. 177; Dahlst. Stud. p. 125 (excl. syn. P. linearis C. DC.).

Piper filiforme Sw. Prodr. (1788) p. 16 et Icon. t. 5 et Fl. Ind. occ. I p. 73; Vahl En. I p. 351; Willd. Sp. I p. 169.

Peperomia Swartziana Miq. Syst. (1843) p. 155; Griseb. Fl. W. Ind. p. 167 (excl. patria Portor.); C. DC. Prodr. XVI, 1 p. 466.

Herba repens, caule filiformi glabro, in sicco $1 / 2 \mathrm{~mm}$. crasso, ramulis spiciferis cum spicis usque ad $3 \frac{1}{2} \mathrm{~cm}$. longis. Limbi in sicco membranacei, pellucidi et minute pellucido-punctulati, $8-9 \mathrm{~mm}$. longi, $21 / 2-3 \mathrm{~mm}$. lati; petioli usque ad $4 \mathrm{~mm}$. longi. Pedunculi ad $10 \mathrm{~mm}$. longi; rhachis glabra, tarde sub bacca in processum conicum sat longum producta. Stigma glabrum papillosum. Bacca $1 \frac{1}{4} \mathrm{~mm}$. longa sine pseudocupula.

Hab. in Jamaica: Swartz (in h. Mus. brit.), in Green Hill Wood ad truncos putridos alt. 1160 m., ad Morse's Gap alt. 1630 m.: W. Harris n. 7781,7969 .

Obs. Species P. lineari C. DC. 1. c. p. 463 proxima, ab ea foliis plerisque oppositis et spicis paullo brevioribus discrepans.

134. Peperomia verticillata A. Dietr. foliis ternis-quinis, brevissime petiolatis, oblongo-ellipticis vel suboborato-oblongis, basi subacutis, apice breviter acuminatis acumine obtuso obtusiusculove, utrinque cum petiolis dense et minute puberulis, carnosis, inconspicue 3-nerviis; spicis terminalibus axillaribusque, filiformibus densifloris, folia pluries superantibus, pedunculis quam folia paullo brevioribus puberulis, bractea orbiculata centro pedicellata; ovario emerso obovato, apice oblique apiculato, infra apicem stigma puberulum gerente.

Peperomia verticillata A. Dietr. Sp. I (1831) p. 179; Miq. Syst. p. 166; Griseb.! Fl. W. Ind. p. 167 et Cat. pl. Cub. p. 64; Dahlst.! Stud. p. 128 .

Piper verticillatum L.! Syst. ed. X (1759) p. 856 et Sp. ed. II p. 43 et h. Linn.; Hill Dict. XIVI p. 20 t. 20 fig. 5?; Lam. Ill. p. 83; Willd. Sp. I p. 168; Vahl En. I p. 353.

Piper pulchellum Ait. Hort. Kevv. ed. I (1789) p.50, ed. II p.72; Vahl l. c. p. 352 .

Piper rubellum Haw. Succ. (1819) p. 3; Spreng. Syst. Cur. post. p. 20 .

Peperomia rubella Hook. Exot. Fl. (1823) t. 5s; A. Dietr. Sp. I p. 178 ; C. DC. l. c. p. 461 . 
Peperomia pulchella A. Dietr. l.c. (1831) p.177; Miq. Syst. p.165; Griseb. l. c.; C. DC. Prodr. XVI, 1 p. 462; Sunv. Fl. Cul. n. 2283 p. 147.

Saurums n.8 erectus minor fol. orb. vert. P. Browne Jam. (1756) p. 204.

$\mathrm{H}$ e rba ad $20 \mathrm{~cm}$. alta, succulenta, verticillatim ramulosa, ramulis $1 \mathrm{~mm}$. crassis pube minuta pilis longioribus intermixta restitis, caulibus sterilibus longe hirsutis. Limbi ramulorum fertilium $15-20 \mathrm{~mm}$. longi, 8-10 mm. lati, caulium sterilium limbi rotundati vel elliptici quam fertilium multo minores; petioli $1 \mathrm{~mm}$. longi. Spicae florentes usque ad $6 \mathrm{~cm}$. longae; rhachis glabra. Filamenta antheris rotundis paullo longiora.

Hab. in Cuba: Wright n. 2265; Jamaica: Swartz (in h. Stockh. f. Dahlst.), ? March n. 1884, ad Banana River alt. 400 m., ad Hope River alt. 400 m.: Eggers n. $3449^{\mathrm{b}}, 3471$; - praeterea in Mexico, ins. Sandwich (vid. C. DC. l. c.).

135. Peperomia reflexa A. Dietr. foliis ternis-quaternis, brevissime petiolatis, rhombeo-ellipticis ellipticisve vel raro ovatis, basi acutis vel raro obtusis, apice obtusis et raro retusis, utrinque glabris vel subtus parce pilosulis, obsolete 3 -nerviis, petiolo hirtello; spicis terminalibus sat longe pedunculatis pedunculos fere aequantibus vel superantibus, folia 2-8-plo superantibus, pedunculo glabro vel hirtello, rhachi dense hirtella, bractea orbiculari centro longe pedicellata pedicello cum flore rhachi profunde immerso; ovario ovato acuto, summo apice stigma capitellatum et puberulum gerente; bacca ovato-cylindrica subpatente, basi pseudo-cupulifera cum filamentis rhachis processu pedicellata.

Peperomia reflexa A. Dietr. Sp. I (1S31) p. 180; Miq.! Syst. p. 169 et in Mart. Flor. Bras. IT, 1 p. 17 et in Hook. Lond. Journ. Bot. IV p. 426; Wight Icon. t. 1933 fig. 1; Miq. Flor. Ind. bat. I, 2 p. 436; Griseb.! Fl. W. Ind. p. 168; C. DC. Prodr. XYI, 1 p. 451 (excl. specim. Macnab.); Henschen Et. p. 26; Sodiro Mon. Pip. p. 133; Sauv. Fl. Cub. n. 2281 p. 147; Dahlst.! Stud. p. 174.

Piper reflexnm L. fil. Suppl. (1781) p. 91; Lam. Ill. p. 83; Thunb. Flor. Cap. p. 443; Vahl Enum. I p. 353; Sw. Obs. p. 23.

Piper tetraphyllum Forst. Prodr. (1786) n.25; Willd. Sp. I p. 168.

Piper pusillum Bl. in Verh. Bat. Genoots. XI (1826) p. 382 fig. 37.

Piper aemulum Endl. Prodr. Fl. Norf. (1833) p. 36; Baner Ill. Norf. ined. t. 127 (teste Endl. l. c.).

Peperomia "tetraphylla Hook. et A'n. in Beech. Bot. (1S41) p. 97.

Herba spithamea inferne e nodis radicans, di-trichotome ramulosa, ramulis in sicco circiter $1 \frac{1}{2} \mathrm{~mm}$. crassis sulcatis hirtellis glabrisre. Limbi in siceo rigidi vel subcoriacei, subtus impresso-punctati, 8-15 mm. longi, $5-9 \mathrm{~mm}$. lati; petioli $1-3 \mathrm{~mm}$. longi. 
Species quoad foliorum formam, consistentian et pubescentiam leviter, quoad spicarum longitudinem sat variabilis. Late per orbem terrarum in regionibus intertropicalibus ac Africa et Australia australibus dispersa (vide: auct. cit. l. c. ac C. DC. in Doun. Snith Enum. part II p. 67, part IV p. $137, \mathrm{~V}$ p. 76 , in Dur. et Pitt. Primit. I p. 234, II p. 294, in Bull. h. Boiss. III p. 521, ser. 2 I p. 359, in Engl. Jahrb. XXIX Beibl. 65 p. 27, in O. Ktze. Rev. III, Dic. p. 272; Benth. Fl. austr. VI p. 206; M. Bailey Synops. p. 419; Hook. Fl. Brit. Ind. V p. 99 ; Trim. Fl. Ceyl. III p. 432; Dr. d. Cast. Fl. Pol. p. 166; B. Balf. Socot. p. 260).

Var. $\beta$. enervulosa C. DC. Prodr. l. c. (1869) p. 452 , foliis ellipticis utrinque subattenuatis vel potius elliptico-rhombeis subcoriaceis enervulosis plerumque $15 \mathrm{~mm}$. longis, adultis utrinque hirtellis.

Peperomia reflexa, forma americana Miq. Syst. (1S43) p. 173; Dahlst.! Stud. p. 175.

Hab. in Cuba: Linden n. 794 (teste Griseb. Cat. p. 64); Jallaica ad Abbey green in rupibus alt. 1260 m.: W. Harris n. 6515; Haiti inter Furcy et Payan: Picarda 11. 292; Sto. Domingo in Pico del Valle ad rupes alt. 2630 m.: Eggers n. 2167.

Var. $\gamma$. valantoides C. DC. l. c., foliis ut in praecedente sed minoribus, 9 mm. longis.

Piper quadrifolium Vell. Fl. flum. I (1827) t. 62.

Peperomia valantoides Miq. Syst. (1843) p. 174 ct in Linnaea XX p. 126 t. 1 fig. 3 ct in Mart. Fl. Bras. 1 V, 1 p. 17 t. 2 fig. 5.

Hab. in Jamaica: March n. 1367 (in h. Krug et Urb.); - praeterea in Nova Hollandia, Brasilia (vid. Miq. et C. DC. 1. c.), in caldariis culta.

136. Peperomia circimmata Link, foliis oppositis, brevissime petiolatis, orbicularibus, utrinque tenuiter puberulis; spicis terminalibus folia pluries superantibus filiformibus densifloris pedunculatis, pedunculis puberulis basi 2 -bracteolatis, bractea rotuudata centro subsessili; ovario emerso, summo apice stigmatifero.

Peperomia circinata Link Jahrb. I, 3 (1S20) p. 64 fidc R. ct Sch. Mant. I p. 245; Miq. in Linnaea XX p. 127 et in Mart. Hil. Bras. IV, 1 p. 21; C. DC. Prodr. XVI, 1 p. 444 (cxcl. syn. Griseb. et Sl.); Sauv. Fl. Cub. n. 2277 p. 146; Dahlst. Stud. p. 155.

Piper circinatum Schult. Mant. I (1822) p. 245.

Acrocarpidium rotundifolium Miq. Syst. (1843) p. 62.

Peperomia circularis Henschen Et. (1S73) p. 24 t. 1 fig. 5 (cum pedunculis brevioribus quam in specim. antill.). 
Peperomia cyclophylla Hemsl. Biol. cent. am. III (1882) p. 59 (p. p.).

Herba caule filiformi longissime repente puberulo, pilis mollibus sensim deciduis. Limbi in sicco rigiduli, diametro circiter $6 \mathrm{~mm}$; petioli $1 \mathrm{~mm}$. longi. Spicae florentes circiter $2 \mathrm{~cm}$. longae.

Hab. in Haiti: Poiteau (in h. Deless., h. DC., h. Kr. et Urb., h. Willd. n. 741 sub Piper circulare); - praeterea in Guiana batava prope Paramaribo; Brasilia: Sieber (in h. Willd. n. 740), Pohl (lı. Vindob.), in vicinitate Obidos: Spruce (iı h. DC.), in truncis arborum prov. Minas Geraës ad oppidum Jacotinga prope Caldas: Henschen (l. c.); Paraguay ex Dahlst.

137. Peperomia fimbriata Miq. foliis oppositis - ternis, breviter petiolatis, rotundis vel elliptico-rotundis, supra glabris, subtus ad nervum centralem longe ot molliter pilosis ciliatis, 3 -nerviis, petiolo piloso; spicis terminalibus densifloris folia pluries superantibus pedunculatis, pedunculis petiolos pluries superantibus pilosis, bractea orbiculari centro breviter pedicellata; ovario immerso ovato, apice in stilum contracto; stilo summo apice stigmatifero; bacca subemersa globosa apice rostellata.

Peperomia fimbriata Miq.! Syst. (1813) p. 178; C. DC. Prodr. IVI, 1 p. 449; Dahlst. Stud. p. 161.

Erecta, caule circiter $22 \mathrm{~cm}$. alto, in sicco tetragono, molliter sparse et longc piloso. L i m bi in sicco coriacei, minute pellucido-punctulati, $10-12 \mathrm{~mm}$. longi; petioli circiter $2 \mathrm{~mm}$. longi. Pedunculi fere $20 \mathrm{~mm}$. longi, spica circiter 7 cm. longa.

Hab. in Sta. Lucia: Anderson (in lı. Deless.).

Var. p. pilosior Miq. in Mart. Fl. Bras. p. 20 t. 2 fig. 111.

Hab. in Brasilia (vide Miq. I. c.; C. DC. l. c. et in Bull. h. Boiss. ser. 2 I p. 360 ).

138. Peperomia quadrangulalis A. Dietr. glabra, foliis brevissime petiolatis, rhombeo-ellipticis, utrinque acutis, 3 -nerviis; spicis apice ramuli axillaris binatis pedunculatis, pedunculis petiolos multo, spicis folia fere duplo superantibus.

Peperomia quadrangularis A. Dietr. Sp. I (1831) p. 169; Miq. Syst. p. 135; Griseb.! Fl. IV. Ind. p. 168 (excl. syn. Mart.); C. DC. Prodr. IVI, 1 p. 446.

Piper quadrangulare Thomps. in Trans. Soe. Limn. IX (1S0S) p. 202 t. 21 fig. b.

Peperomia angulata Dahlst.! Stud. (1900) p. 156 (quoad specim. Cruegerii).

Caulis spitlamcus simplex vel parce ranosus, c nodis radicans tetragonus. Folia opposita; limbi $21 \mathrm{~mm}$. longi et $19 \mathrm{~mm}$. lati; petioli circiter $3 \mathrm{~mm}$. longi. 
Hab. in Trinidad: Crueger (in h. Krug et Urb. ex h. Griseb.), in trunco arboris vetustae, via inter St. Joseph et Caroni flunı.: ex Thompson (l. c.).

139. Peperomia ciliata Kuntl, foliis oppositis, summis ternis, petiolatis, elliptico-oblongis, utrinque acutis, supra et subtus praesertim ad nervos pubescentibus ciliolatis, 5-nerviis nervuloque marginali ab apice decurrente, petiolis pedunculisque axillaribus aequilongis hirtellis, spicis folia fere aequantibus filiformibus laxifloris, bractea subrotunda centro subsessili; ovario emerso, apice stigmatifero.

Peperomia ciliata Kmnth! in H. B. K. Nor. Gen. I (1815). p. 68; Miq. Syst. p. 119; Griseb. Fl. W. Ind. p. 168; C. DC. Prodr. XVI, 1 p. 441; Socliro Mon. Pip. p. 125.

Piper ciliatmm Roem. et Schlt. Syst. I (1817) p. 333.

Peperomia quitensis Miq.! in Hook. Lond. Joum. Bot. IV (1845) p. 426 .

Herha basi radicans, caule erecto hirtello, circiter $25 \mathrm{~cm}$. alto et in sicco $2 \mathrm{~mm}$. crasso. Limbi in sicco membranacei subpellncidi et pellucidopunctulati, circiter $3-5 \mathrm{~cm}$. longi, $2-2 \frac{1}{2} \mathrm{~cm}$. lati; petioli vix $2 \mathrm{~mm}$. longi. Filamenta brevia; antherae globosae. Stigma discoilco-papillosulum.

Hab. in Portorico prope Yauco: A. P. Garber n. 38 (in h. Kew); Antigua et Trinidad: ex Griseb. (l. c.); - praeterea in convalli juxta coenobium Caripense ad arborum truncos alt. 430 hexap.: Humboldt (in h. Willd. n. 744); Peruvia: Pavon (in h. Boiss.); Quito: Hartweg n. 1395 (in li. Francav.).

140. Peperomia Langsslorffii Miq. foliis modice petiolatis, supremis alternis, caeteris oppositis vel raro ternis, obovato- vel ellipticorhomboideis, basi fere cuneatis, apice parum attenuatis obtusiusculis aut acutis, utrinque appresse pilosis margineque ciliatis, 3 -nerviis, petiolo dense piloso; pedunculis plerumque terminalibus petiolos superiores paullo superantibus, spicis folia multo superantibus laxifloris filiformibus, bractea adulta rotundata centro breviter pedicellata; ovario emerso ovato, sub apice oblique stigmatifero, stigmate globoso papillosulo.

Pepreromia Langsdorffii Miq.! Syst. (1813) p. 110 et in Limnaea XX p. 124 et in Mart. Fl. Bras. IV, 1 p. 13; C. DC. Prods. XVI, 1 p. 443.

Micropiper Langsdorffii Miq.! Comm. phyt. (1838-40) p. 52 t.s fig. 5 .

Peperomia humilis A. Dietr. Sp. I (1831) p. 168.

Peperomia blanda var. Langsdorffii Henschen Et. (1873) p. 39. Piper humile Tahl Enmm. I (180t) p. 349.

Peperomia Langsdorffii Miq. var. dissimilis (Kth:) Dahlst.! Stud. (1900) p. 131. 
Suffruticulus rix pedalis succulentus basi radicans, ramis erectis simplicibus rel pauci-ramosis teretibus dense pilosis, iu sicco inferne circiter $4 \mathrm{~mm}$. crassis. Limbi in sicco membranacei, pellucido-punctulati, usque ad $5 \mathrm{~cm}$. longi et ad $24 \mathrm{~mm}$. lati; petioli inferiores usque ad $1 \frac{1}{2} \mathrm{~cm}$., superiores fere $1 \mathrm{~cm}$. longi. Spicae submaturae $10 \rightarrow 12 \mathrm{~cm}$. longae et in sicco $1 \mathrm{~mm}$. crassae, rhachis sub bacca (in specimine delapsa) in processum conicum producta.

Hab. in ?Haiti in Morne de l'Hôpital ad rupes, alt. $800 \mathrm{~m}$. (specim. sterile): Picarda n. 1045; Sto. Domingo: Bertero n. 419; Portorico, prope Salinas de Cabo-Rojo in silvis montis Juliana, prope Coamo ad saxa in flumine ad Farajones: Sintenis 11. 546, 3120; St. 'Thomas al Jumbee Gut ad saxa in silva umbrosa: Eggers ed. Toepff. n. 179; St.Jan ad Rogiers 330 m. alt.: Eggers 11. 3263 (h. Haun. ex Dahlst.); St. Croix: Eggers, West (h. Haun. ex Dahlst.), hb. Hornemann (in h. r. Heurck et h. Cand.); Tortola ad Sage Mountain alt. $260 \mathrm{~m}$. in rupestribus: Eggers n. 3187 (in l. Haun. f. Dahlst. l. c.); Antigua ad Cedarlill: Wullschlaegel n. $538,541^{\text {b }}$ (h. Monac. ex Dahlst.).

141. Peperomia trifolia A. Dietr. foliis ternis, brevissime petiolatis, ellipticis, basi acutis, apice obtusis et leviter emarginulatis, supra glabris, subtus praesertim ad nerros pilosis et margine ciliatis, inconspicue 3 -nerviis nervuloque marginali ab apice decurrente; spicis terminalibus longiuscule pedunculatis filiformibus densifloris, florentibus folia fere dimidio superantibus, pedunculis hirtellis, bractea orbiculari centro breviter pedicellata; orario emerso superne in stilum oblongum summo apice stigmatiferum pruducto; bacca oblongo-orata laevi apice stilo mucronata.

Peperomiu trifolia A. Dietr. Sp. I (1831) p. 173; Miq. Syst. p. 118; Griseb.! Fl. W. Ind. p. 168; C. DC. XII, 1 p. 462 ; Dahlst.! Stud. p. 162 t. 3 f. 7 (exclus. syn. P. obversa A. Dietr.).

Piper trifolium L. Sp. I ed. I (1753) p. 30 et II ed. p. 43; Hill Dict. XIVI t. 20 f.3; Aubl. Pl. Guian. I p. 22; Lam. Ill. p. S3; Tahl En. I p. 351; Willd. Sp. I p. 167.

Peperomia ovalifolia Hool. Exot. fl. II (1825) t. 165; A. Dietr. l. c.; Miq. Syst. p. 154 et in Hool. Lond. Jomrn. IV p. 424; C. DC. Prodr. l.c. p. 450.

Peperomia trifolia forma pilosior Dahlst. l.c. (1900) p. 163.

Saururus hederaceus triphyllus Plum. Descr. Pl. Am. (1693) p. 52 t. 68 .

Grand moiron Guad., Mouron Mart. ex Duss.

Herba scandens, e nodis radicans, ramulis adpresse hirtellis, in siceo $1 \frac{1}{2} \mathrm{~mm}$. crassis. Folia inferiora opposita; limbi in siceo membranacei subpellucidi, usque ad $2 \mathrm{~cm}$. longi et ad $1 \mathrm{~cm}$. lati; petioli fere 3 num. longi. Pedunculi usque ad $3 \frac{1}{2} \mathrm{~cm}$. longi. Antherae ellipticae, filamenta supe- 
rantes. Stilus glandulis pellucidis globosis farctus; stigma carnosum glabrum. Bacca sussilis sine pseudocupula.

Hab. in Guadeloupe: Richard (in h. Francav.), Duchassaing, Krauss, Bertero (in h. DC.), ad arbores in nemoribus humidis Grand Étang (Capesterre): Duss n. 2566 ${ }^{\text {b }}$, 3617; Dominica: Imray n. 334 (in h. Kew); Martinique: Steinheil n. 170, Hahn 11. 260, ad arbores vetustas locis humidis: Duss n. 1263; St. Vincent in silva montana St. Andrews ad arbores, in praeruptis ad ripam fluminis Lodge, in silvis montis Soufrière: Eggers n. 6673, 6830 ${ }^{\mathrm{b}}, 6934$, in silvis humidis ad arbores frequens: H. H. et G. W. Smith n. 995 et $871,871^{\text {a }}$ (fide Kew Bull. 1893 p. 273), prope Kingstown ad arbores vetustas: E. H. L. Krause 1. 50; 'Trinidad: Sieber n. 299; — praeterea in Guiana ex Aublet (Pl. Gui. I p. 22); Brasilia: Glaziou n. $\$ 952$.

142. Peperomia Balbisii Dahlst. foliis ternis, breviter petiolatis, ellipticis, basi acutis, apice obtusis et leviter emarginulatis, supra glabris, subtus parce pilosulis, margine apicem versus ciliolatis, inconspicue 3-nerviis nervuloque marginali ab apice decurrente; spicis terminalibus breviter pedunculatis, filiformibus densifloris, florentibus folia fere dimidio superantibus, pedunculis glabris, bractea orbiculata centro breviter pedicellata; bacca oblongo-orata laevi, apice stilo recto mucronata.

Peperomia Balbisii Dahlst.! in Duss Flor. pham. Ant. frame. (1897) p. 174 et Stud. (1900) p. 164 t. 9 fig. 2.

Piper obouatum Balb.! Msc. ed. Dahlst. l. c.

Peperomia trifolia C. DC. Prodr. XVI, 1 (1S69) p. 462 (quoad sp. Berteroan.).

\section{Mouron rouge incol. Gruad. ex Drss.}

Herba scandens, e nodis radicans, ramulis adpresse hirtellis, in sicco $1 \frac{1}{2} \mathrm{~mm}$. crassis. Folia inferiora opposita; limbi in siceo membranacei, subpellucidi, usque ad $17 \mathrm{~mm}$. longi et ad $9 \mathrm{~mm}$. lati; petioli superiores $1 \frac{1}{2} \mathrm{~mm}$. longi. Pedunculi usque ad $6 \mathrm{~mm}$. longi; rhachis glabra. Ovarium emersum oblongum, superne in stilum oblongum summo apice stigmatiferum productum. Antherae ellipticae, filamenta sua superantes. Stilus glandulis pellucilis globosis farctus; stigma carnosum glabrum. Bacca sessilis et sine pseudocupula.

Hab. in Guadeloupe: Bertero n. S57, in Camp Jacob vulgaris ad arbores et truncos vetustos scaudens, $400-1000 \mathrm{~m}$. alt.: Duss n. 2566 , lrois Rivières in silvis humidis rara, $580-1000 \mathrm{~m}$. alt.: Duss 11. 2836.

143. Peperomia rhombea R. et Pav. erecta, omnino glabra vel ramulis junioribus puberulis; foliis ternis - quaternis, breviter petiolatis, lanceolatis, basi acutis, apice attenuato-obtusiusculis, $3-5$-nerviis, nervis Jateralibus inconspicuis eentrali nervo paullo validiore; spicis 
terminalibus axillaribusque, folia fere duplo superantibus, sublaxifloris, longiuscule pedunculatis, pedunculis petiolos multo superantibus, bractea orbiculari centro sat longe pedicellata; ovario impresso oblongoovato glandulis consperso summo apice stigmatifero; bacca ovata.

Peperomia rhombea R. et Pav. Fl. per. I (1798) p. 31 t. 46 fig.b; A. Dietr. Sp. I p. 180; C. DC. Prodr. XVI, 1 p. 465; Henschen Etudes p. 31; Dahlst.! Stud. p. 188 t. 111 fig. 33.

Piper rhombeum Vahl Ennm. I (1804) p. 353.

Peperomia Myrtillus Miq. Syst. (1843) p. 154 et in Hook. Lond. Journ. IV p. 425; Griseb.! Fl. W. Ind. p. 168 et Cat. p. 64; C. DC. Prodr. l. c. p. 449; Sauv. Fl. Cub. n. 2280 p. 147.

? Peperomia reflexa forma peruviana Miq. Syst. (1843) p. 174.

Herba succulenta. Canles e radice fasciculato-fibrosa multi, dichotome ramulosi, in sicco circiter $1 \mathrm{~mm}$. crassi. Limbi in sicco rigido-membranacei, snbpellucidi, $1 \frac{1}{2}-3 \mathrm{~cm}$. longi et $7-10 \mathrm{~mm}$. lati; petioli vix ad $4 \mathrm{~mm}$. longi. Pedunculi ad $2 \mathrm{~cm}$. longi; spicae maturae $1 \frac{1}{2} \mathrm{~mm}$. crassae; bracteae pedicellns immersus. Stigma papillosulum. Bacca basi psendocupularis.

Hab. in Cuba: Wright n. 522, in silva montis Libanon: Linden n. 1794; Jamaica: Wiles (in h. Deless.), ad Norse's Gap: W. Harris n. 7968: Sto. Domingo prope Jarabacoa ad truncos arborum juxta flumen Yaqui alt. 550 m.: Eggers n. 2005; Portorico ad arbores retustas prope Adjuntas ad Juncos et in monte Galsa, prope Lares ad rupes in silra primaera ad Mirasol: Sintenis 1. 4191, 4774, 6140; - praeterea in Costarica (vide: C. DC. in Dur. et Pitt. Primit. I p. 136, in Donn. Smith Enum. part IT p. 135); Tenezuela (vide: C. DC. Prodr. XVI, 1 p. 449); Peruvia (ex R. et Pav. l. c.).

144. Peperomia obovata C. DC. foliis ternis, breviter petiolatis, obovatis, basi acutis, apice emarginatis, utrinque glabris, 3 -nerviis enervulosis nervis ipsis inconspicuis, petiolo juniore puberulo; spicis terminalibus solitariis, folia pluries superantibus, densifloris, pedunculis petiolos duplo superantibus, bractea suborbiculari centro subsessili; bacca ovato-acuta, basi immersa, apice oblique stigmatifera.

Piper oboratum Vahl! Eclog. I (1796) p. 5.

Piper obrersum Vahl! Emum. I (1804) 1. 354; Roem. et Schult. Syst. I p. 331; Spreng. Syst. I p. 121.

Peperomia obversa A. Dietr. Sp. I (1831) p. 173; Griseb. Flor. W. Ind. p. 168 (quoad spec. e Montserrat); C. DC. in Limnaea vol. XXXVII p. 388 (non C. DC. Prodr. XVI, 1 p. 455 nec Griseb. Cat. pl. Cul. p. 64).

Peperomia trifolia Dahlst. Sturl. p. 162 (quoad sper. Rymmi). 
Caulis ramosus, ramis diffusis e nodis radicantibus, ramulis junioribus hirtellis. Limbi in siceo firmuli, subpellncidi, fere $2 \mathrm{~cm}$. longi; petioli $3 \mathrm{~mm}$. longi. Rlachis glabra. Bacca apice subscutatim oblique truncata et basi scutuli stigmatifera, stigmate in sicco minuto.

Hab. in Montserrat: Ryan (in lı. Haun. ex lı. Valıl).

145. Peperomia stellata A. Dietr. folis petiolatis, ternis - quinis, oblongis, acuminatis acumine obtuso, 3 -nerviis, glabris; spicis terminalibus axillaribusque filiformibus laxifloris, bractea ovata; ovario ovato, apice oblique stigmatifero; stigmate villoso; bacca sessili oblonga.

Peperomia stellata A. Dietr. Syst. I (1S31) p. 175; Miq. Syst. p. 153; Griseb.! Fl. W. Ind. p. 167; C. DC. Prodr. XVI, 1 p. 452?

Piper stellatum Sw. Prodr. (17S8) p. 16 et Flor. Ind. oce. I p. 74; Willd. Sp. I p. 168; Vahl En. I p. 355; Jucq. Coll. III p. 212 ct Icon. rar. II p. 2 t. 217; Roem. et Sch. Syst. I p. 332.

Peperomia rhomboides Dahlst.! Stud. (1900) p. 190, - non $P$. rhomboidea Hook. ct Arn.

Caulis teres pubescens, interdum ferrugineus, ramis oppositis (ex DieTr. 1. c.). Limbi subtus ad lentem villosuli (JACQ. Coll. l. c.), $2-2 \frac{1}{2} \mathrm{~cm}$. longi, 8- $10 \mathrm{~mm}$. lati; petioli fere $5 \mathrm{~mm}$. longi. Spicae folia fere duplo superantes; pedunculi fere $10 \mathrm{~mm}$. longi (JAcQ. Icon. rar. tab. 217 ubi verisimillime ovarii apex pro stigmatis lobo superiore habetur).

Hab. in Jamaica: March (in l. Krug et Urb. ex h. Griseb. fragment. ster.), in silvis umbrosis alpium ex Swartz (l. c.), - in caldariis Schoenbr. culta (Jacq. 1. c.).

Var. $\beta$. Narchii C. DC. (n. var.), foliis subtus praesertim ad nervos dense puberulis, spica terminali.

Herba caule simplici dense hirtello, cum spica circiter $22 \mathrm{~cm}$. alto ct in sicco $2 \mathrm{~mm}$. crasso. Limbi superiores apice obtusiusculi (adhuc juveniles?), fere $1 \mathrm{~cm}$. longi et $5 \mathrm{~mm}$. lati, alii inferiores? apice acuti usque ad $3 \mathrm{~cm}$. longi et ad $11 \mathrm{~mm}$. lati; petioli $2 \mathrm{~mm}$. longi. Pedunculus $6 \mathrm{~mm}$. longus; spica $3 \% \mathrm{~cm}$. longa, $1 \mathrm{~mm}$. crassa. Stigma orbiculare carnosum glabrum.

Hab. in Jamaica: March (in h. Krug et Urban ex h. Griseb.), ad Morse's Gap in rupibus inter muscos: Fawcett n. $\$ 164$.

146. Peperomia dominicana C. DC. glabra, foliis ternis vel apice ramulorum oppositis, breviter petiolatis, subrhombeo-ellipticis, apice attenuato-obtusiusculis, coriaceis, 7 -nerviis; spicis terminalibus solitariis pedunculatis filiformibus densifloris, folia fere duplo superantibus, bractea rotundata centro subsessili; ovario emerso, apice oblique acutato, stigmate inconspicuo.

Peperomia dominicana C. DC. in Seem. Joum. of Bot. IV (1866) p. 146 et Prodr. XVI, 1 p. 458. 
Ramuli coriacei glabri, in siceo usque ad $5 \mathrm{~mm}$. crassi. Limbi $3^{1} / 2 \ldots 4^{1 / 2} \mathrm{~cm}$. longi, fere $2 \mathrm{~cm}$. lati; petioli $5 \mathrm{~mm}$. longi. Pedunculi ad. $2 \mathrm{~cm}$. longi.

Hab. in Sto. Domingo: L. Cl. Richard (in h. Francar. et Deless.).

147. Peperomia polystachya Hook. foliis ternis, rarius quaternis aut oppositis, petiolatis, e basi cuneata obovato-subrhombeis rlombeisve, apice breviter subattenuatis obtusiusculisque, utrinque sparse pilosis ciliolatis, 3-nerviis et reticulato-nervulosis; spicis longiuscule pedunculatis axillaribus terminalibusque subdensifloris, folia duplo superantibus, pedunculis hirtellis, bractea rotundata centro brevissime pedicellata; ovario emerso, apice oblique stigmatifero.

Peperomia polystachya Hooker Exot. Fl. (1823) t. 23; A. Dietr. Sp. I p. 173; Miq. in Mart. Flor. Bras. IT, 1 p. 1 t. 1.; Dahlst. Stud. p. 133; C. DC. Prodr. XII, 1 p. 161 (excl. syn. Micr. Blumei Miq.). Piper obtusifolium Jacq. Icon. rat. I (1781) p. 2 t. 9; Lam. Ill. p. 82, - non Lim.

Piper polystachyon Ait. Hort. Kew. ed. I (1789) p. 49, ed. II p. 72; Vahl Enum. I p. 354; Willd. Sp. I p. 167 et herb. n. 748! (specim. cult.); Loud. Encycl. p. 29 n. 537.

Herba erecta, caule pubescente. Limbi in sicco membranacei $3-4 \mathrm{~cm}$. longi, ad $2 \mathrm{~cm}$. lati; petioli ad $5 \mathrm{~mm}$. longi. Pedunculi ad $2 \mathrm{~cm}$. longi, spica in sicco $1 \mathrm{~mm}$. crassa.

Hab. in Antillis: L. Cl. Richard (in h. Francav.); Jamaica ex Hook. (l. c.); St. Croix ex Hook. (l. c.); - praeterea Brasilia, verisimiliter spontanea et in hortis culta ex Miq. (in Mart. Flor. Bras. l. c.), ad Petropolin super arborum truncos: Wawra et Maly (fide Wawra Bot. Ergeb. p. 131); Argentina (vide Dahlst. l. c.).

148. Peperomia septemnervis R. et Pav., glabra, foliis oppositis rarius ternis, breviter petiolatis, oblongo-lanceolatis, basi attenuatocuneatis, apice longiuscule acuminatis acumine acuto, 5-7-nerviis; spicis axillaribus terminalibusque densifloris, folia fere duplo superantibus, pedunculatis, pedunculis petiolos duplo superantibus, bractea subelliptico-rotunda centro pedicellata, pedicello cum flore immerso; ovario ovato, apice breviter stilifero, stilo lato summo apice stigmatifero; bacca elliptica laevi, apice in stilum ea breviorem contracta.

Peperomia septemneris R. et Par. Fl. Per. I (1798) p. 31 t. 47 fig.c.; A. Dietr. Sp. I p. 171; Miq. Syst. p. 152; Grised.! Fl. W. Ind. p. 168; C. DC. Prodr. XVI, 1 p. 441; Dahlst.! Stud. p. 191 t. 111 fig. 36 (bacca?).

Piper septemnerve Vahl Emum. I (180.1) p. 349. 
Herba pedalis. Radix fasciculatn-fibrosa. Canles plurimi, nodis purpurascentibus (fid. Pav. l. c.), in siceo circiter $2 \mathrm{~mm}$. crassi. Timbi in siceo rigidi, opaci, pellucilo-punctulati, circiter $\mathrm{S} \mathrm{cm}$. longi et $2-2 \frac{1}{2} \mathrm{~cm}$. lati; petioli $5-7 \mathrm{~mm}$. longi. Spicae in sieco $1 \frac{1}{2} \mathrm{~mm}$. crassae. Bacea sine psendo-cmpula. Rhach is sub bacca in specimine delapsa in processum $3 / 4 \mathrm{~mm}$. longum producta.

Hab. in Jamaica: March, ad John Crow Peak alt. 2000 m.: W. Harris n. 7966; Haiti prope Payan alt. 800 m.: Picarda n. 286; praeterea in Peruvia ad Pozuzo: ex R. et Pav. (l. c.).

149. Peperomia psendo-pereskifolia C. DC. glabra, foliis ter$n$ is oppositisve, petiolatis, lanceolatis, basi in petiolum cuneatis, apice sat longe acuminatis acumine acuto, 5-nerviis nervis subinconspicuis; spicis axillaribus terminalibusque, folia subduplo superantibus, densifloris, pedunculis petiolos superantibus, bractea rotundata centro pedicellata, pedicello cum flore profunde immerso; ovario ovato sub apice contracto et summo apice stigma capitellatum puberulum gerente; bacca globosa, apice stignate mucronulata, basi rhachis processu elongato pedicellata.

Peperomia psendo-peresticuefolia C. DC. Prodr. XVI, 1 (1869) p. 418; Saur. Fl. Cub. 11. 2279 p. 146; Wahlst.! Stud. p. 191 t. 111 fig. 37 (bacea).

Peperomia alpina Griseb.! Cat. Pl. Wr. (1860) p. 176 et Cat. p. 64, - non Dietr.

Herba cpiphyta?, ramulis divaricantibus, spiciferis cum spicis fere ad $25 \mathrm{~cm}$. longis, in siceo coriaceis tetragonis, $1 \mathrm{~mm}$. crassis. Limbi in sicco subopaci, pellucido-punctulati, pallide virescentes rigidi, ad $9 \mathrm{~cm}$. longi ct ad $3 \mathrm{~cm}$. lati; jetioli circiter $5 \mathrm{~mm}$. longi. Pedunculi $2-3 \mathrm{~cm}$. longi; spicae maturae ad $12 \mathrm{~cm}$. longae. Antherac parvae cllipticae. Bacca sine pseudocupula, sed in sicco tamen inferne pallidior.

Hab. in Cuba orientali prope villam Monte Verde dictam: Wright n. 507 (in lı. DC., Boiss., Berol.), in Loma del Jagïey alt. 600 m.: Eggers n. 5157.

150. Peperomia pereskiifolia Kuntl, glabra, foliis ternis - quinis, brerissime petiolatis, coriaceis, lanceolato-ellipticis, basi in petiolum decurrentibus, apice obtusis acutiusculisve, 3 -nerviis nervis subtus prominentibus; spicis terminalibus longiuscule pedunculatis subdensifloris, folia multo superantibus, bractea oblongo-elliptica, apice obtusa acutiusculave, centro subsessili; ovario semiimmerso oblongo-elliptico, summo apice stigma capitellatum penicillato-liirsutum gerente.

Teperomia peresliaefolia Kunth! in H. B. K. Nov. Gen. I p. 6s, Synops. I p. 120; Miq. Syst. p. 150, in Mart. Flor. Bras. IV, 1 p. 15; C. DC. Prodi: XVI, 1 p. 453; Uohlst.! Stud. p. 196 t. 111 fig. 34 (bacca). 
Peperomia mbricaulis A. Dietr. Sp. I (1831) p. 182, Wiq. Syst. p. 149, in Mart. Flor. Bras. l. c. p. 14.

Piper pereskiaefolium Jacq. Coll. IV (1790) p. 126, Icon. rer. II tab. 219; Tahl Enum. I p. 352; Willd. Sp. I p. 167 et herb. 746 !

Piper rubricaule Tees Hor. ber. p. 48 tab. S; Link Enum. I p. 39.

Caules $1-2$-pedales, basi lignescentes, parce et dichotome ramusi, in sicco circiter $2 \mathrm{~mm}$. crassi et sulcati. Limbi ad $6 \mathrm{~cm}$. longi et ad $2 \frac{1}{2} \mathrm{~cm}$. lati, in sicco ad lentem impresso-punctati. Pedunculi fere $4 \mathrm{~cm}$. longi; spicae florentes circiter $12 \mathrm{~cm}$. longae et $1 \mathrm{~mm}$. crassae.

Olim culta in horto Halensi (ex h. Spreng., cum patria Jamaica sine dubio errore addita); patria est Nicaragua (ex Dalılst.), Venezuela, Peruvia orient., Brasilia.

151. Peperomia ILerminicri C. DC. foliis modice petiolatis, oblongo-oratis, basi ima acutis, apice acuminatis acumine acuto, utrinque appresse hirtellis et nigropunctulatis, 5-nerviis; perlunculis oppositifoliis, petiolos paullo superantibus, spicis quam limbi superiores paullo longioribus, floribus adultis cum bracteis rhachi tumefacta breviter stipitatis, bractea laud peltata ovato-acuta; ovario oblongo, apice obtuso, stigmate inconspicuo; bacca globosa glanduloso-hirtella.

Peperomia Herminieri C: DC: in Mém. Soc. Phys. Genève XXVII. 2 (1882) p. 306 tab. 14.

Herba truncos muscosos scandens, ramulis junioribus hirtellis ad $3 \mathrm{~mm}$. crassis. Limbi in sicco membranacei $4 \mathrm{~cm}$. et usque ad $6 \frac{1}{2} \mathrm{~cm}$. longi et ad $3 \frac{1}{2} \mathrm{~cm}$. lati; petioli ad $12 \mathrm{~mm}$., plerumque $6-8 \mathrm{~mm}$. longi. Spicae circiter $4 \mathrm{~cm}$. longae et inter flores circiter $1 \mathrm{~mm}$. crassae.

Hab. in Guadeloupe: L'Herminier (in h. Boiss.); Dominica, in silvis ad Laudat: Eggers hb. pr. n. 1031.

Var. $\beta$. stigmatifera C. DC. (n. var.) ovario summo apice stigma bilobum lobis rotundatis hirsutis gerente.

a. foliis ut in specie.

Hab. in Guadeloupe, locis humidis in regione superiore ad arbores, alt. $800-1000 \mathrm{~m}$;, in via Bains Jaunes à la Savane à mule haud frequens: Duss n. 2567?

b. forma limbis minoribus ad $3 \frac{1}{2} \mathrm{~cm}$. longis.

Hab. in Martinique, in silvis Plateau militairo (Case Pilote), ad radices arborum aut in terra, rara: Duss n. 4038.

152. Peperomia loracteiflora C. DC. foliis breviter petiolatis, inferioribus ovatis rel rotundato-ovatis, superioribus oblongo-ovatis, basi rotundatis aut obtusis, apice breviter acumiuatis acumine obtusiusculo, onnibus petiolisque utrinque appresse hirsutis et nigro-punctatis, 5-nerviis; pedunculis apice ramulorum oppositifoliis appresse hirsutis, spicis

Urban, Symb. ant. 111 . 
quam limbi dimidio et ultra longioribus, floribus adultis cum bractea rhachi producta stipitatis, bractea haud peltata ovato-rotundata; ovario obovato-subgloboso, stignate nullo; bacca globosa puberula.

Peperomia bracteiflora C. DC. in Mém. Soc. Phys. Genève XXVII. 2 (1882) p. 307 tab. 15; Duss! Fl. phan. p. 173.

Repens aut scandens?, caule ad $3 \mathrm{~mm}$. crasso glabro, ramulis rigidis in juventute pilosulis. Limbi in sicco membranacei, inferiores $3 \frac{1}{2} \mathrm{~cm}$. lati, superiores usque ad $4 \mathrm{~cm}$. longi et ad $2^{1 /} / 2 \mathrm{~cm}$. lati; petioli usque ad $5 \mathrm{~mm}$. longi. Spicae maturae circiter $6 \mathrm{~cm}$. longae et inter flores ad $2 \mathrm{~mm}$. crassae.

Hab. in Martinique, in Forêt du Cocoyer: Hahn n. 647 (in h. Cand. et Berol.), in silvis densis humidis regionis mediae ex. gr. Calebasse, Lorrain, Champfleur: Duss n. 496, 497.

Var. $\beta$. stigmatifera C. DC. (n. var.), ovario summo apice stigma minutum glabrum gerente, limbis circiter $2 \mathrm{~cm}$. longis et $12 \mathrm{~mm}$. latis. Hab. in Martinique, in montibus altis: Duss n. 16.

Genus excludendum.

Symbryon Griseb. Cat.pl. Cub. (1866) p. 64; C. DC. Prodr. XVI, 1 p. 471; Benth. et Hook. Gen. III p. 133; Engl. ct Prantl Pflanzenfam. III, 1 p. 11.

Propter florum ac ramulorum structuram genus e Piperaceis exchudendum. 


\title{
IV. Hepaticae novae I)ussianae II.
}

\author{
Descripsit \\ Franciscus Stephanl. \\ (ef. Symb. II p. 467-472.)
}

$\checkmark$ Riccia subplana Steph. (n. sp.). Monoica, mediocris, glaucovirens. Frons ad $12 \mathrm{~mm}$. longa, crassa, quadruplo latiol quam alta, ob furcas parum sulutas obcuneata, furcis apice late truncatis, profunde bilobis acuteque sulcatis: alis convexis, explanatis rel decurvis, supra terram expansis vel terrae appressis. Costa lata, strato antico triplo humilior, postice partum convexa, saepe subplana, utrinque in alas attenuata, frondis pagina postica itaque optime applanata. Squamae posticae parvae, sub margine occultae, tenerrimae, purpureae. Sporae magnae $(90 \mu)$ laxe reticulatim lamellatae, foreolis $12-42 \mu$, angulis trabeculatim papillatis. Ostiola mascula brevia, valida.

Hab. in Martinique in Morne Rouge (Pointe Fine): Duss n. 579 (ex parte).

Riccia (Ricciella) Dussiana Stepl. (n. sp.). Monoica, minor, pallide virens. Frons ad $7 \mathrm{~mm}$. longa, repetito-furcata, crassa, triplo hatior quam alta, antice canaliculata, sub apice acnte sulcata, obtusa, alis convexis explanatis, marginem versus parum attenuatis, ipso margine abrupte acuto. Costa valida, strato antico aequialta, postice cuneatim producta, aetate rotundata, utrinque in alas attenuata. Squamae posticae tenerrimae, hyalinae, sub margine occultae. Stratum anticum laxe cavernosum, cavernis sub 24 in frondis diametro. Sporae $70 \mu$ latae alatae, reticulatim lamellatae, foveolis ad $9 \mu$ lamellis validis obtusis. Ostiola mascula longe producta, hyalina.

Hab. in Martinique in Fonds St. Denis ad terram, Aug. 1901: Duss п. 577.

Metzgeria Iussiaua Steph. (n. sp.). Sterilis, pallida, regulariter furcatim ramosa, corticola vel muscicola. Frons ad $2 \mathrm{~cm}$. longa, omnino plana (semper?), apice rotundata, alis ntrinque nudis margine ipso 
tantum setulosis, setulis remotiusculis, simplicibus, strictis, recte patentibus. Costa tenuis, dorso et rentre cellulis corticalibus biseriatis tecta, postice setulis sparsis brevibus hirta. Cellulae alarum $27 \times 36 \mu$, ad costam ipsam majores, marginem versus parum minores. Reliqua desunt.

Hab. in Martinique, in silvis du plateau Chou (près des DeuxChoux), m. Sept. 1901: Duss n. 597.

Jumcermannia Dnssiama Stepli. (n. sp.). Dioica, mediocris, pallide bruneola, rigida, dense intricatim caespitosa. Caulis ad $12 \mathrm{~mm}$. longus, simplex, validus, fuscus et rigidus, ralicellis longis fuscirlulo-rubescentibus arete repens. Folia caulina parum imbricata, concava, curvatim patula, marginibus anguste incurvis, in plano oblique rotundata, postice breviter inserta longeque radicellosa, antice oblique decurrentia. Cellulae apicales $27 \mu$, basales $36 \times 54 \mu$ trigonis magnis hyalinis, cuticula aspera. Ampligastria caulina nulla. Folia floralia 2, perianthio altissime accreta marginibus solum liberis erecto-patulis. Perianthia ambitu elliptica vel clavata, ore angustato crenulato tertio supero plicato libero et vix exserto, ceterum foliis suis omnino accreto; folia basalia subfloralia libera, caulinis simillima majora. Amphigastrium florale late ligulatum erectnm, marginibus recurvis canaliculatim foliis suis coalitum. Androecia mediana; bracteae 6 -jngae foliis minores et parvae, confertae basi saccatim ampliatae, integerrimae, marginibus late recurvis apertae.

Hab. in Martinique inter Ajoupa et Bouillon solo humido: Duss n. 344, in Morne Rouge prope cavernam Notre Dame de Lourdes ad terram, Aug. 1901: Duss n. 569.

V Plagiochila amplexicaulis Steph. (n. sp.). Dioica, mediocris, rigidissima, brunea, in rupibus laxe caespitosa. Caulis ad $4 \mathrm{~cm}$. longus, strictus fuscus et tenax, simplex vel pauciramosus, ramis plus minus divergentibus. Folia caulina 2,5 mun. longa, imbricata, decurvohomomalla, in plano late ovato-triangularia, brevissima basi inserta, margine antico substricto nudo, postico e basi valde areuata (iu plano caulem late superante) substricto, 12 -dentato, dentibus magnis validis, basalibus majoribus longe attenuatis, apice angustissimo emarginato-bidentulo. Cellulae apicales $18 \mu$ trigonis magnis, basales $27 \times 36 \mu$ trigonis maximis. Folia floralia bijuga, canlinis multo majora, similia, intima grosse dentata, dentibus numerosis superne minoribus, basi postica valde irregularibus, saepe maximis hamatisque. Perianthia matura semiexserta, late pyriformia, ore parum angustato truncato, grosse spinoso, spinis validis porrectis remotiusculis, irregularibus; ala lata, perianthio duplo brevior, crispata paucispinosa. 
Androecia in planta multo graciliore terminalia, nutantia, ex apice geniculatim innovata, bracteis 10 - jugis, confertis, superne porrectis, integerrimis acutis.

Hab. in Martinique in Montagne Pelée ad arbores et saxa, Sept. 1901: Duss n. 684 .

Plagiochila Dussiana Steph. (n. sp.). Dioica mediocris, gracillima, rigidissima et fragilis, rufo-brunea, corticola. Caulis ad $4 \mathrm{~cm}$. longus, tenuis, fuscus et durus, pauciramosus. Folia $2 \mathrm{~mm}$. longa, remota, subrecte patula vel squarrose recurva, vix decurrentia, in plano oblongo-linearia, triplo longiora quam lata (basi parum angustata) integerrima apice inciso bifida, sinu subrecto obtuso vel acuto, laciniis parum divergentibus, lanceolatis. Cellulae apicales $27 \mu$, trigonis maximis, saepe confluentibus, basales $27 \times 45 \mu$ parietibus maxime trabeculatim incrassatis. Androecia mediana, longe spicata, bracteis laxe insertis, ad 14-jugis, ex inflata basi angustatis, apice oblique porrectis inciso-bispinosis.

Hab. in Martinique in Montagne Pelée ad arbores inter muscos, Sept. 1901: Duss 11. 602.

Isotachis tenax Steph. (n. sp.). Sterilis, pusilla, rigidissima, rufa, dense depresso-caespitosa, corticola. Caulis ad $10 \mathrm{~mm}$. longus, pinnatim multiramosus, fuseus et durus, validus. Folia caulina parva, vix $0,5 \mathrm{~mm}$. longa, imbricata vel contigua, subrecte patula, conduplicatim concava, brevi basi inserta, in plano quadrato-rotundata, ad medium biloba, lobis late triangulatis divergentibus, sinu recto obtuso, margine antico nudo, postico inferne 1-2-dentato, dentibus ralidis pungentibus. Cellulae apicales $18 \mu$, medianae $18 \times 27 \mu$, basales $18 \times 36 \mu$, parietibus maxime aequaliterque incrassatis. Amphigastria imbricata, appressa, utrinque dente maximo armata, apice ad medium bifida, interdum trilobata, lobis semiovatis divergentibus, inaequalibus, acutis vel obtusis vel longe acuminatis. Reliqua desunt.

Hab. in Guadeloupe in Horne d'Echelle ad arbores, Jun. 1901: Duss n. 550 .

Obs. Distinctissima species, statura minore et cellulis maxime incrassatis facile distinguenda.

$\checkmark$ Odontolejeunea subbifida Steph. (n. sp.) Sterilis, magna, flaccida, brunea, corticola. Caulis ad $4 \mathrm{~cm}$. longus, arete repens, tenuis, fuscus, durus, irregulariter pinnatus, pinnis confertis subrecte patulis, brevibus longisque mixtis. Folia caulina adulta ad 1,5 mm. longa (ramulina minora) recte patula, concava, falcato-ovata, acuta vel obtusa, integerrima vel sub apice paucidenticulata, antice caulem longe tegentia 
nusquam superantia longeque soluta, insertio folii itaque brevissina. Cellulae apice $18 \mu$, medio $36 \mu$, regulariter hexagonae, basi $36 \times 54 \mu$ trigonis nullis. Ocella 2 , in ipsa basi seriata, $45 \times 90 \mu$. Lobulus magnus, angustus, folio cluplo brevior, e lata basi sensin attenuatus, apice oblique truncatus, carina parum curvata, levi sinu in folii marginem excurrente. Amphigastria caulina caule quintuplo latiora, reniformia, profunde sinuatim inserta, apice brevissime biloba, sinu parro lunato, lobis obtusis rel rotundatis.

Hab. in Guadeloupe in Plateau des Rivières in cortice arboris: Duss n. 513; Martinique in silvis Deux Choux, Sept. 1901: Duss n. 674 .

Pycnolejeunia Dussiana Steph. (n. sp.). Dioica, minor, flaccida, pallide virens, corticola. Caulis ad 3 cm. longus, parum breviterque pinnatus, pinnis subrecte patulis, parvifoliis. Folia caulina vix $3 \mathrm{~mm}$. longa, imbricata, plano-disticha, recte patula, integerrima, basi antica ampliata et caulem parum superantia, falcato-ovata i. e. margine postico substricto, antico arcuato, apice rotundato. Cellulae apicales $18 \mu$, regulariter hexagonae, trigonis parris, basales $27 \times 36 \mu$ trig. majusculis acutis. Lobulus folii parvus folio quintuplo brevior, recte patens, oblongus, apice angustiore oblique truncato, carina papulosa arcuata, sinu subrecto obtuso in folii marginem abeunte. Amphigastria caulina appressa, caule triplo latiora, sinuatim inserta, ambitu subrotunda, ad medium incisobiloba, lobis late orato-triangulatis margine distincte angulatim repandis, obtusiusculis. Flores $Q$ in pimis terminales, uno latere immovati. Folia floralia caulinis longiora, oblongo-ligulata vel ovato-oblonga, obtusa vel acuta, margine grosse repanda, Jobulo longe accreto, basi valde angustato, spathulato. Amphigastrium flor. foliis suis fere aequimagnum late ovatum, lobulis utrinque breviter coalitum, ad $1 / 3$ inciso-bifidum, sinu lato acuto, lobis late triangulatis superne abrupte acuminatis subsetaceis.

Hab. in Guadeloupe in Matouba (Rivière Rouge) in cortice arboris, Nov. 1901: Duss n. 699.

Taxilejeunea Urbani Steph. (n. sp.). Monoica, parva sed grandifolia, tenera et pallide virens, corticola. Caulis vix $10 \mathrm{~mm}$. longus, varie ramosus, arcte repens, pro planta validus (in planta melius evoluta forsan multo magis elongatus). Folia adulta imbricata, juniora contigua vel remotiuscula, vix $1 \mathrm{~mm}$. longa, recte patula, plano-disticlia, margine cellulis prominulis crenata, lata basi inserta, leviter asymmetrica, margine antico quam posticus magis areuato. Cellulae apicales $18 \mu$, medio $27 \times 45 \mu$, basi $36 \times 45 \mu$ trigonis nullis. Lobulus subnullus ad plicam exiguam reductus. Amphigastria caule triplo latiora, sinuatim inserta, subrotunda vel parum latiora quam longa, plano-appressa, 
sinu recto acuto vix ad medium biloba, lobis late triangulatis obtusiusculis. Flores $q$ in ramulis parvis lateralibus terminales, uno latere innovati, innovationibus repetito-floriferis. Folia floralia caulinis multo minora, obovata rel semiovata, obtusa integerrima vel repanda, lobulo parvo lanceolato ad medium soluto. Amphigastrium florale foliis suis brevius, orato-rotundatum, apice exciso-bidentulum. Perianthia matura parum exserta, parva, obconica, longe rostrata, rostro conico angustato, superne 5-plicata, plicis haud decurrentibus, in acie cellulis inflato-proninulis cristulatis. Androecia minima, in caule lateralia, bracteis $2-3$, parvis cucullatis, laevibus.

Hab. in Martinique in Montagne Pelée ad saxa, Sept. 1901: Duss n. 615 . 


\section{Nova genera et species II.}

Exposuit

IGNATIUS URBAN.

Tinantia caribaea Urb. (n. sp.) foliis ovatis, obovato-ellipticis usque oblongis, basi sensim v. subsensim in petiolum angustatis, supra breviter, subtus brerissime pilosis; sepalis ad basin dense, superne longius et parcius pilosis; petalis pallidissime libacinis; filamentis 3 longioribus inferioribus nudis, 3 brevioribus superioribus ad et supra medium barbatis, antheris subdissimilibus; ovarii loculis 2-ovulatis.

Descriptio e planta viva: Annua usque $1,5 \mathrm{~m}$. alta. Caulis crectus succulentus, ad nodos inferos radices purpurascentes numerosas deorsum emittens, ad basin usque $1,5 \mathrm{~cm}$. crassus, supra nodos nsque $3 \mathrm{~cm}$. incrassatus, teres viridis, posterius ramosus, glaber v. hinc illinc parcissime et tenuiter pilosus. Foliorum vaginac latere laminae opposito $5-8 \mathrm{~mm}$. longae et hoc loco breviter pubescentes, nervis plus minus purpurascentibus, margine supero obliquo ciliato-pilosae; petiolus $1-1,5 \mathrm{~cm}$. longus, ca. $0,7 \mathrm{~cm}$. latus, plus minus marginatus; limbus ovatus, obovato-ellipticus usque oblongus, basi sensim v. subsensim angustatus, apice manifeste acnminatus, $10-18 \mathrm{~cm}$. longus, $4-6 \mathrm{~cm}$. latus, plerumque 9 -nervis, nervis supra impressis, subtus prominentibus, supra pilis brevibus patentibus basi subincrassatis, margine et subtus pilis brevissimis praesertim ad nervos obsitus. Inflorescentia in caule ramisque revera terminalis, basi peduncnli ima interdum gemmis $2-3$ ex axillis foliorum summorum ortis, nune in cymas paucifloras evolutis comitatus; pedunculus $3-10 \mathrm{~cm}$. longus, pilis basi incrassatis longis et brevibus tenuibus patentibus obsitus, apice cymose 3-(2-)furcatus; prophylla primaria ramis perpaullo sursum adnata semiquadrangularia, caetera suborbicularia $\mathrm{v}$. ovata $1,5-2 \mathrm{~mm}$. longa membranacea hyalina, margine parce pilosa, caeterum glabra; rami postremo usque $30 \mathrm{~mm}$. longi, apice initio revoluti, sensim dense 5-20-flori; pedicelli 4-7 mm. longi, plus quam $1 \mathrm{~mm}$. crassi, breviter et dense hirtclli, pilis longioribus paucis intermixtis. Alabastrum oratum obtusum, $7 \mathrm{~mm}$. longum, $4-4,5 \mathrm{~mm}$. crassum. Flores lateraliter deorsum spectantes. Sepala in aestivatione vix imbricata, libera viridia ovato-oblonga, $6-7 \mathrm{~mm}$. longa, $3-3,5 \mathrm{~mm}$. lata, extrinsecus supra basin pilis brevibus densis simplicibus, superne pilis longioribus apice glanduliferis subparcis obsita, chartacea, dor'so sub apice incrassata, in fructu parum aucta erecta. Petala in aestivatione 
imbricata, exterius inferum, basi ima inter sese vix connata, suborbicularia concava, superiora $7-8 \mathrm{~mm}$. longa, inferum paullo brevius, membranacea, cito collabentia. Stamina basi petalis parum adnata, inaequalia; filamenta 3 ante et juxta petalum extimum posita sub anthesi infera $6 \mathrm{~mm}$. longa, plane nuda, post anthesin subspiraliter contracta; antherae ovales utrinque leviter emarginatae, dorso medio affixae, riolaceae 1,2 mm. longae, connectivo anguste oblongo loculo unico subaequilato, loculis introrsum dehiscentibus; filamenta 3 ante et inter petala superiora posita paullo breviora, ad et supra meilium apice excepto pilis moniliformibus longiusculis flaris ornata; antherae ovali-orbiculares, flavae, $1 \mathrm{~mm}$. longae; loculis paullo magis lunato-curvatis, caeterum ut antea; pollinis granula in utraque anthera subconformia oralia usque ellipsoidea, minutissime granulata, $55-56 \mu$ longa, $22-30 \mu$ diametro. Stylus 2,5 mm. longus, ad apicem sursum curvatus et attenuatus, glaber; stigma minutum disciforme. Ovarium ovatum, obtusissime trigonum glabrum, stylo aequilongum, 3-loculare; ovula in quoque loculo 2 supraposita, angulo interiori longitrorsum affixa. Capsula a calyce paullo superata, ovalis $\mathrm{r}$. breviter ovalis, $5-7 \mathrm{~mm}$. longa, $4-5 \mathrm{~mm}$. crassa, glabra. Semina in quoque loculo 2 v. 1 , subsemiglobosa rugulosa $2-2,5 \mathrm{~mm}$. lata, latere altero sulcata, altero subplano apiculata.

Hab. in Guadeloupe prope Basse-Terre locis humidis, TroisPonts, antea rara, nunc frequens: Duss n. 3ł17, 4523 ; Martinique rarissima: Duss. - Culta anno 1901 e seminibus Dussianis in lorto botan. berolinensi.

Obs. Affinis T. Sprucei C. B. Clarke, quae foliis subtus glabris, sepalis glabris ant vix puberulis, inflorescentiis apice 1 -, raro 2 -radiatis, prophyllis ovatis, filamentis omnibus barbatis, antheris omnibus rotundatis differt. Longius distat T. erecto (Jacq.) Schlecht. prophyllis oblongis, sepalis et petalis majolibus, hisce caeruleis v. purpurascentibus, capsula oblonga 9 mm. longa, loculis $3-5$-spermis.

Rajania Sintenisii Uline (n. sp.) glaberrima, foliis ovato-oblongis, acuminatissimis, basi profunde cordatis, 7-9-nervibus; floribus masculis in glomerulis $3-5$-floris dispositis.

Folia rigide membranacea, $7 \mathrm{~cm}$. longa, $3,5 \mathrm{~cm}$. lata, petiolo duplo longiola. Spicae in axillis per $2-3$-nas fasciculatae; glomeruli approximati. Perianthium 1,5 mm. latum. Planta feminea ignota.

Hab. in Portorico prope Mayagïez in fruticetis montis Mesa: Sintenis n. 109.

(ULLNE)

Iristolochia stenophylla Urb. (n. sp.) fruticosa volubilis, ramis hornotinis, petiolis, pedicellis brevissime pilosulis; pseudostipulis reniformibus, $3-5 \mathrm{~mm}$. longis; foliis $5-10 \mathrm{~mm}$. longe petiolatis, lanceolato-linearibus, $e^{0}$ basi breviter cordata sensim angustatis, lobis 2 basalibus rotundatis, apice acutis r. obtusis, $8-4 \mathrm{~cm}$. Iongis, $1,5-0,8 \mathrm{~cm}$. latis, integris, e basi 3-nervibus, supra glabris, subtus minutissime pilosulis; pedicellis $1,5-2 \mathrm{~cm}$. longis, solitariis; calyce extrinsecus brerissime pilosulo subrecto, usque ad labium $10 \mathrm{~mm}$. longo, utriculo orali, 
tubo infundibuliformi, sub angulo recto in labium $15 \mathrm{~mm}$. longum tubo non intrusum producto.

Caules retustiores elevatim obtusanguli, glabrescentes, 1,5-1 mm. crassi, hornotini ad apicem pube articulata perbrevi erispula patente vestiti, mox glabrescentes. Pseudostipulac ar axillas nunc olviac, nune deficientes. Folia petiolo prehensili. postremo coriacea, supra nitidula, subtus placa, nervis 2 latcralibus e basi prodemutibus secus uargincm nsque ad medium productis, supra basin ipsam ramulum brevem extrinsecus emittentibus, omnibus utrinque prominentibus et dense reticulato-anastomosantibus. Calyx striatus, ante anthesin ipsam labello brevior; urceolus $4,5 \mathrm{~mm}$. longus, 3 mm. crassus; tubus perpaullo oblique inscrtus, inferme 1,5 mm., superne $3 \mathrm{~mm}$. crassus; labium unicum, non caudatum, apice obtusissimum, plicatum lanceolato-lineare, supra basin $3 \mathrm{~mm}$. latum. Stamina 6. Ovarium linearielongatum, brevissime pubescens.

Hab. in Haiti in Anse à Veau, m. Jul. flor.: Picarda n. 1281.

Obs. Habitu affinis A. bilabiatae L. (Plum. ed. Burm. tab. 32 fig. 1, Herb. Willd. n. 17056), quae foliis duplo latioribus, ovato-oblongis v. oblongo-lanceolatis, labio erecto extrinsecus plicato et in tubum calycinum supcrum intruso differt. A. lincarifolia $\mathrm{Wr}_{\mathrm{r}}$. (e Cuba) pseudostipulis multo majoribus, foliis angustioribus, et praesertim tubo calycino utriculo valde oblique inserto, subcylindracco, labio pluries angustiore erecto recedit.

Lonchocarpus neurophyllus Urb. (n. sp.) foliis 5-9-foliolatis, foliolis $1,5-2 \mathrm{~mm}$. longe petiolulatis, obovatis, ovatis usque ellipticis, apice rotundatis v. obtusissimis, interdum emarginatis, basi rotundatis, obtusis v. acutatis, $2-5 \mathrm{~cm}$. longis, $1-2,2 \mathrm{~cm}$. latis, nervo medio et lateralibus supra impressis, subtus valde prominentibus et reticulatoanastomosantibus, margine integris, coriaceis rigidis, supra punctulatoscabriusculis, subtus breviter et dense pubescentibus; inflorescentiis brevissime pedunculatis densi- et multifloris; pedicellis genuinis $1,5-2 \mathrm{~mm}$. longis, apice prophylla minuta gerentibus; calyce brevissime et late undulato-5-dentato, $2 \mathrm{~mm}$. Iongo; corolla violacea, vexillo late orbiculari, supra unguem brevissimum non auriculato, $6 \mathrm{~mm}$. longo, alis carinam aequantibus.

\section{Biajama St. Doming. ex Bertero.}

Frutex $2-3,3$ m. altus. Rami vetustiores teretes, hornotini superne subangulati, breviter et dense pubescentes. Stipulae vix conspicuae, $0,5-0,8 \mathrm{~mm}$. longae, breviter lanceolatae. Folia petiolis $1,5-2 \mathrm{~cm}$. longis, basi subincrassatis, subteretibus v. a latere paullo compressis, supra canaliculatis; foliola exstipellata, opposita, supra viridi-glancescentia nitida, subtus pallidiora opaca, nervis utroque latere $6-10$, sub angulo ca. $50^{\circ}$ abeuntibus, subrectis, reticulo supra vix conspicuo, subtus inter pubem prominente. Inflorescentiae 3-8 mm. longe pedunculatae, multiflorae, folio breviores, $4-7 \mathrm{~cm}$. longac, rhachi brevitcr pubescente; bracteae lanceolatae, $0,7-1 \mathrm{~mm}$. longae; pedunculi speciales $0,8-1,5 \mathrm{~mm}$. longi, plermmquc 2-flori; prophylla ea. 0,5 $\mathrm{mm}$. longa, ovata, sub calyce ipso inserta. Calyx suboblique cupuliformis, apice $3,5 \mathrm{~mm}$. diametro, minute et adpresse pilo- 
sulus, dentibus valde depressis, antico paullo manifestiore. Vexillum intus supra basin, ut ridetur, flavidum, explanatum $8 \mathrm{~mm}$. latum, apice satis excisum, basi subito in unguiculum $0,6 \mathrm{~mm}$. longum contractım; alae liberae obovato-oblongae, apice rotundatae, superne $2 \mathrm{~mm}$. latae, limbo unguiculum 6 -plo superante; carinae petala in parte $2 / 5$ superiore connata, apice iterum libera, intus subrecta, dorso arcuata, apice obtusa, limbo unguiculum duplo superante. Stamen rexillare basi ipsa liberum, caeterum cum aliis connatum, omnia in parte $1 / 4-1 / 5$ superiore libera, inferne recta, ad partem liberam incurva; antherae oratae uniformes. Orarium lineare brevissime et adpresse dense pilosum, ea. 8-ovulatum; stylus $2 \frac{1}{2}$-plo brevior incurrus; stigma capitellatum.

Hab. in Haiti inter La Coupe et Pintade in solo calcareo sicco, 150 m. alt., m. Sept. flor.: Buch n. 405; Sto. Domingo: Bertero n. 524 (sterilis).

Lonchocarpus Ehrenberegii Urb. (n. sp.) foliis 7-11-foliolatis, foliolis $1-3,5 \mathrm{~mm}$. longe petiolatis, elliptico-oblongis usque oblongolanceolatis, rarius inferioribus ovalibus, utrinque aequaliter v. inferne magis et saepius cuneatim angustatis, apice obtusis r. acutis, $2-5 \mathrm{~cm}$. longis, $1-1,5 \mathrm{~cm}$. latis, nerro medio supra plus minus impresso, lateralibus prominulis $r$. in sulco levi prominulis, subtus valde prominentibus et reticulato-anastomosantibus, margine integris rarius undulatocrenulatis, coriaceis rigidis, supra tenuiter punctulatis, non v. vix scabriusculis, subtus minuta et adpresse pilosulis; inflorescentiis breviter pedunculatis, sublaxi- et multifloris; pedicellis genuinis $1-2 \mathrm{~mm}$. longis, apice prophylla minuta gerentibus; calyce brevissime v. obsolete undulato- 5 -dentato, $2 \mathrm{~mm}$. longo; corolla rubra v. dilute rubra, vexillo late orbiculari, supra unguem brevissimum non auriculato, $6-6,5 \mathrm{~mm}$. longo, alis carinam superantibus; legumine lineari, $4-7 \mathrm{~cm}$. longo, $0,6-0,8 \mathrm{~cm}$. lato, minute et adpresse pilosulo.

\section{Bois Caiman Hait. ex. Jaeger.}

Frutex $3-5$ m. altus (ex JAEG.). Rami vetustiores teretes, lenticellis parvis rotundis obsiti, hornotini superne obtusanguli, ninute adpresseque obsolete pilosuli. Stipulae $0,8 \mathrm{~mm}$. longae, triangulares. Folia petiolis $1-2 \mathrm{~cm}$. longis, hasi parum incrassatis, a latere paullo conrpressis, supra canaliculatis; foliola exstipellata, in ramis sterilibus usque 25, opposita, supra glanca v. brunescentia nitida, snbtus pallidiora opaca, nervis ntroque latere $6-10$, sub angulo $40-50^{\circ}$ abeuntibus, subrectis. Inflorescentiae $3-8 \mathrm{~mm}$. longe pedunculatae, multiflorae, folio breviores, postremo usque $7 \mathrm{~cm}$. longae, rlachi brevissime et dense pilosa; bracteae oratae r. ovato-lanceolatae; $0,5-0,7 \mathrm{~mm}$. longac; pedunculi speciales $1-2,5 \mathrm{~mm}$. longi, plermmque 2 -flori; proplyylla anguste ovata, ca. 0,4 mm. longa, sub calyce inserta. Calyx suboblique cupuliformis, apice $3 \mathrm{~mm}$. diametro, minute et adpresse pilosulus, dentibus valde depressis, antico vix prodnctiore. Yexillum intus surra basin ut videtur obscurius coloratum, explanatum $7 \mathrm{~mm}$. latum, apice emarginatum, basi subito in unguiculum $0,8 \mathrm{~mm}$. longum 
contractum; alae libcrac oblongae apice rotundatae, superne $1,7 \mathrm{~mm}$. latac, limbo unguiculum 6 -plo supcrante; carinac petala in parte $2 / 5$ supcriore connata, dorso areuata, intus uinus curvata, apice obtusa, limbo unguiculum 2\% - 3-plo superante. Stamen vexillare basi excepta cum caeteris connatum, omnia in parte $1 / 3 \ldots 1 / 4$ superiore libera, inferne recta, ad partem libcram inculva; antherae subovatae uniformes. Ovarium lineare brevissime r. obsolete adpresse pilosum, ca. 8-ovulatum; stylus duplo brevior subrectangulari-incurvus; stigma capitellatum. Legumcn $2-3 \mathrm{~mm}$. longe stipitatum planum rectum v. leviter arcuatum, coriaceum, sutura altera duplo latiore, vix v. tenuiter reticulato-renosum, supra seminm $5-8$ positionem non rugosum. Semina reniformia, ad umbilicum emarginata, obscure brumea, $4,5-5 \mathrm{~mm}$. longa, $3-3,5 \mathrm{~mm}$. lata.

Hab. in Haiti m. Aug., Sept. flor.: C. Ehrenberg n. 26, Picarda n. 348, in sylvis prope Port-au-Prince, m. Aug. flor.: Jaeger n. 201, prope Pétionville m. Febr. flor:: Picarda n. 968.

Obs. Praecedenti arcte affuis, sed notis indicatis valde constantibus diversus.

Genus Savia Willd. (sensu strictiore species antillanas tantun complectens) in sectiones sequentes bene dividi potest:

Eusavia Urb. Cocci verisimiliter monospermi. Semina ovali-globulosa, transversim subteretia. Cotyledones subrotundae planae, basi cordatae, radicula perbrevi 4-6-plo longiores, albidae v. pallide virides. - Huc S. sessiliflora (Sw.) Willd. e Cuba, Jamaica, Hispaniola, Portorico, St. Thomas, St. Croix.

Hoterosavia Urb. Cocci dispermi. Semina a dorso ovata, ventre longitrorsum acutata, transversim subtrigona. Cotyledones oratae, basi cordatae, concavae, altera margine recurva, radicula duplo longiores. Huc S. erythroxyloides Griseb., S. chusiifolia Griseb., S. laurifolia Griseb., omnes ex insula Cuba.

\section{$\checkmark$ Chacnotheea Urb.}

(n. gen. Euphorbiacearum.)

Flores dioici apetali, masculi: Sepala 5, in aestivatione valde imbricata, orbicularia concava membranacea, subaequalia, sub authesi plus minus reflexa. Discus extrastaminalis fundum calycis vestiens, margine a sepalis solutus crenulatus, glaber. Stamina 5 sepalis opposita; filamenta basi inter sese coalita; antherae juniores reniformi-suborbiculares, dorso supra basin affixae, extrinsecus longitudinaliter birimosae et delriscentes, loculis parallelis contiguis apice confluentibus, defloratae ob valvas reflexas a latere visae obcordatae; pollinis granula (aquae immersa) ovalia laevia tririmosa. Ovarii rudimentum columnare lineare triangulare, basi cum filamentis coalitum; styli 3 liberi subulati patenti-recurvati saepius inaequales, dentibus minoribus interjectis. 
Flores feminei: Sepala et discus ut in mare. Ovarium 3-loculare, loculis 2 -orulatis; styli 3 perbreves liberi bifidi patentes v. reflexi, lobis linearibus, apice subincrassatis et papillosis. Capsula in coceos 2-valves desiliens, columnam linearem triangulam relinquens, exocarpio nervis elevatis anastomosantibus dense pereurso, endocarpio soluto indurato. Semina in quoque loculo verisimiliter solitaria, breviter ovata convexa ecarunculata, exarillata, dorso supra basin chalazam excavatam praebentia, apice intus subhamato-producta, testa stratiformi- impresso-reticulata, endospermio carnoso crasso. Cotyledones breviter ovatae planae tenues, in radiculam dimidio breviorem curvatan contractae nee cordatae. - Arbores v. frutices glabrae, ramis teretibus. Stipulae parvae, basi biauriculatae. Folia distiche alterna integerrima rigidule membranacea, e basi 3-5-nervia, caeterum pennivenia. Flores e pulvinaribus bracteolas numerosas emittentibus plures glomerati v. fasciculati, pedicellis pilis articulatis restitis, flor. femin. longioribus.

Species 2 arete affines antillanae.

Obs. Genus ex affuitate Securinegae, quae disci glandulis flor. masc. 5, loculis antherarum modice hiantibus, coccis dispermis, seminibus toto coelo diversis, ad ventrem acutatis, testa laevi, chalaza ventrali, cotyledonibus carnosis. Longius distat Sacia (sensu strictiore) petalis obviis, antheris solemniter introrsis, loculis longitudinaliter modice hiantibus, apice discretis, ovario flor. masc. ninutissimo, stylis 3 liberis lamelliformibus, seminis chalaza ventre obvia non concava, testa laevi nitida, embryonis radicula breriore, cotyledonibus basi cordatis, stipulis basi non auriculatis, foliis exacte penniveniis.

1. Chaenotheca neopeltandra Urb. foliis exacte oratis basi rotundatis v. subtruncatis; floribus masculis pluribus glomeratis subsessilibus.

Phyllanthus neopeltandrus Griseb.! in Nachr. Kgl. Ges. Götting. 1865 p. 167 et Cat. p. 16; Miill. Arg. in DC. Prodr. XT. II p. 335; Sauv. Cub. u. 1957 p. 126.

Diasperus neopeltandrus O. Ktre. Rev. II (1S91) p. 600.

Hab. in Cuba in litore umbroso prope Iatanzas: Rugel n. 281.

2. Chaenotheca domingensis Urb. (n. sp.) foliis oratis r. ovalibus, rarius obovatis v. ellipticis, basi obtusis v. acutatis, apice obtusis v. rotundatis, $2-3 \mathrm{~cm}$. longis, 1,2-2 cm. latis, menbranaceis v. postremo subchartaceis, margine planis v. subrecurvis, nervis lateralibus supra tenuiter proninulis, subtus tennissimis v. obsoletis; pedicellis masculis 1 -paucis 2-3 nm. longis, brevissime pubescentibus.

Arbor $6,6 \mathrm{~m}$. alta. Rami vetustiores teretes cinerei; ramuli distichi. Stipulae ovato-triangulares $v$. triangulari-lanceolatae, basi obsolete biauriculatae, apice obtusiusculae v. obtusae, $0,7-1 \mathrm{~mm}$. longae. Folia petiolis 3-4 mm. longis, nervis lateralibus 2 v. sub-4 e basi prodeuntibus et 
margini subparallelis fere usque ad medium productis, caeteris utroque latere $3-4$ sub angulo ca. $60^{\circ}$ abeuntibus, in statu juniore subtus dense reticulato-conjunctis, adulta supra subopaca glanco-viridia, subtus glaucescentia. Sepala membranacea $1,5 \mathrm{~mm}$. longa, margine minute et brevissime ciliata, caeterum glabra, 3-nervia, subanthesi patenti-reflexa, alba. Filamenta superne sensim angustata, 1,3 mm. longa, suberecta; antherae juniores reniformi-suborbiculares. Styli columna vix $1 \mathrm{~mm}$. longa, ramis 3 inaequalibus. Flores feminei ignoti.

Hab. in Sto. Domingo in sylvis ad Llano Rafael, solo calcareo, $200-300 \mathrm{~m}$. alt, et in fruticetis ad Palmarejo, m. Majo flor.: Eggers n. $1904^{\text {b }}, 1905$ (p. p.), 1906 (p. p.).

Obs. In aliis herbariis sub Eggers n. 1905 et 1906 habitu sinilis Savia sessiliflora W. conservatur.

Phyllanthus pachystylus Urb. (n. sp.) ramulis glabris compressis; stipulis lanceolatis subulato-acuminatis, $2 \mathrm{~mm}$. longis; foliis $3-4 \mathrm{~mm}$. longe petiolatis, ellipticis usque lanceolatis, ad basin sensim angustatis, apice obtusiusculis r. obtusis, $3,5-5 \mathrm{~cm}$. longis, $1-2 \mathrm{~cm}$. latis, coriaceis, margine revolutis, supra in sicco olivaceis, subtus glaucis; fasciculis 3-6-floris, inferioribus ex axillis euphyllorum minorum, superioribus ex axillis squamarum prodeuntibus, in racemum elongatum collectis; pedicellis flor. masc. $10-12 \mathrm{~mm}$. longis; sepalis obovatis $\nabla$. obovato-ellipticis, $2 \mathrm{~mm}$. longis; disci glandulis 6 suborbicularibus subplanis, crenulatis et areolatis; staminibus 3 plane in columnam coalitis; pedicellis flor. fem. $2-4 \mathrm{~mm}$. longis; sepalis obovato- v. spathulatooblongis, $3 \mathrm{~mm}$. longis; disco breviter cupuliformi, margine crenulato, basin orarii cingente; stylis in colmmnam ovario fere duplo longiorem counatis, apice liberis reflexis et breviter bifidis.

Phyllanthus mutans Griseb.! Cat. (1866) p. 15 (p. p.); Sauv. Cub. n. 1960 p. 126 , - non Su.

Rami purpureo-nigrescentes, lenticellis parcis oblongis obsessi. Stipulae bruneae, basi nou productae. Folia nervo medio supra impresso, lateralibus $5-6$ sub angulo $50-60^{\circ}$ abeuntibus, supra subimpressis, subtus temuiter prominulis, non anastomosantibus. Racemus usque $10 \mathrm{~cm}$. longus; bracteae inferiores euphylloideae, oblongo-lanceolatue usque anguste lanceolatae $1,5-1 \mathrm{~cm}$. Iongae, superiores squamiformes lineares r. spathulatolineares, ca. $2 \mathrm{~mm}$. longae. Flores masculi in eodem fasciculo plerumque femineis intermixti, pedicellis pluries longioribus duplo tenuioribus insignes, serius evoluti (ideoque proterogyni); pedicelli apice ipso incrassati. Sepala in aestivatione valde imbricata, subcoriacea, apice obtusissima v. rotundata. Antherae arcte sessiles, triangulares, lateraliter deliscentes, connectivis crassiusculis supra antheras in gibberem prominentem connatis. Flores feminei in quoque fasciculo 2-4; pedicelli apice solemniter turkinato-incrassati. Sepala coriacea margine tenuiora. Ovarium sphaeroideum. Styli rami lineares; columna crassiuscula.

Hab. in Cuba: Wright n. 1947. 
Obs. Ph. nutans Sw. affinis (e Jamaica) ramulis teretibus, foliis oratis tenuioribus, nervis lateralibus supra prominulis, floribus omnibus longe pedicellatis, sepalis flor. fem. oboratis, Ph. Grisebachianus Müll. Arg. (e Cuba) nervis lateralibus supra prominulis, pedicellis $1-2$ ex axillis euphyllorum, femineis ca. $1 \mathrm{~cm}$. longis, masculis brevioribus, sepalis femineis obovatis differunt.

Phyllanthus barbadensis Urb. (n. sp.) monoicus, ramis teretibus, floriferis tenuiter et breviter $\nabla$. brevissime pilosis; stipulis lanceolatis $\mathrm{r}$. lanceolato-linearibus, vix $1 \mathrm{~mm}$. longis; foliis $1,5-2 \mathrm{~mm}$. longe petiolatis, ovatis $\mathrm{v}$. anguste oratis, basi rotundatis $\mathrm{v}$. acutatis, apice obtusis v. obtusissimis v. obsolete et obtuse acuminatis, $2,5-6 \mathrm{~cm}$. longis, ad ramulos inferioribus minoribus saepius oboratis et apice emarginatis, omnibus postremo chartaceis, supra in sicco nigrescentibus, subtus olivaceis; floribus ad apicem ramulorum ex axillis bractearum $2-7$, in racemum terminalem $\mathrm{v}$. panniculam collectis et praeterea linc illinc ad axillas euphyllorum fasciculatis, pedicellis $7-12 \mathrm{~mm}$. longis; sepalis 6 ovatis, masc. $1 \mathrm{~mm}$., fem. 1,5 mm. longis, disco flor. masc. e glandulis 6 crassis breviter oboratis, apice concavis, flor. fem. breviter cupuliformi, basin ovarii cingente, margine crenulato; stylis inferne in columnam connatis, superne liberis reflexis bifidis; capsulis depressis trigonis, longitrorsum 3-sulcatis.

Frutex 0,4-1 m. altus. Rami retustiores castanei, cortice saepius rimoso, lenticellis rotundatis obsiti; ramuli distiche dispositi, pube patente, interdum unilaterali (latere folio antecedenti opposito), posterius eranescente. Stipulae bruneae. Folia petiolis supra brevissime pilosis, nerro medio supra inferne subimpresso, superne tenuiter prominulo, lateralibus pinnatim dispositis, 7-10, sub angulo ca. $60^{\circ}$ abeuntibus, supra in sicco nigrescentia, subtus pallidiora brunea r. olivacea glabra, margine plana. Florum fasciculi basi squamas minutas gerentes, inaequaliter evoluti; pedicelli vix $0,2 \mathrm{~mm}$. crassi, glabri. Flores masculi in fasciculis inferioribus axillaribus tantum observati. Sepala in aestivatione imbricata, membranaceochartacea, glabra. Stamina 3 plane in columnam connata, antherarum loculis dorso appositis, subquadratis, lateraliter longitrorsum sulcatis. Flores feminei racemum terminalem formantes et praeterea quoque in fascicnlis axillaribus obvii: Sepala paullo majora crassiora. Ovarium globosum. Stylorum colmmna ovario duplo brevior, ramuli lineares. Capsulae $3-4 \mathrm{~mm}$. longae, $6 \mathrm{~mm}$. diametro.

Hab. in Barbados in Forster's Hall wood haud infrequens, 11. Jan. flor:: Eggers n. $7121^{b}, 7123^{b}, 7130,7209^{b}$, ad Jack in the box sully et sub Hackleton's cliff: Waby n. 15.

Obs. Ex affinitate $P h$. nutans Sw. (e Jamaica), qui stipulis $2-3$-plo majoribus, foliis $3-5 \mathrm{~mm}$. longe petiolatis, non nigricantibus, crassioribus, sepalis $3-4 \mathrm{~mm}$. longis, fructibus globulosis vix longitrorsum sulcatis etc. recedit.

Phyllanthus acacioides Urb. (n. sp.) ramis plus minus bruneofurfuraceis, ad apicem papilloso-scaberulis, ramulis ultimis glabris $r$. 
subglabris, ob folia decurrentia subangulatis; stipulis ramorum triangularibus v. orbiculari-triangularibus, cuspidato-acuminatis, ramulorum lineari-subulatis, $1-0,4 \mathrm{~mm}$. longis; foliis brevissime, sed manifeste $(0,5-0,3 \mathrm{~mm}$. longe) petiolatis, oblongo-linearibus, apice obtusis $\mathrm{v}$. acutiuseulis, inferne subaequilateris obliquis sensim angustatis, $1-0,5 \mathrm{~cm}$. longis, 2,5-1,5 mm. latis, subtus albidis, rigide membranaceis; floribus masculis ad axillas solitariis $\mathrm{v}$. binis, $3-5 \mathrm{~mm}$. longe pedicellatis; glandulis crassis contiguis; staminibus in columnam coalitis, antheris 5; floribus femineis ad axillas solitariis, usque $1 \mathrm{~mm}$. longe petiolatis; sepalis ovato-orbicularibus, ovario aequilongis; glandulis minutis; stylis arcte reflexis, calyci adpressis, apice bifilis.

Arbor $4 \mathrm{~m}$. alta. Rami teretes, pube brunea irregulariter ramulosa, foliis cum stipulis conformibus, sed plerumque minoribus v. angustioribus distiche obsiti; ramuli ultimi pro quoque ramo usque 40, tenues, supra subsulcati, $10-6 \mathrm{~cm}$. longi. Folia in quoque ramulo $35-45$, nervo medio et utraque parte $3-4$ lateralibus subtus tenuiter v. tenuissime prominulis, supra obsoletis, margine plana v. subplana. Flores ex axillis foliorum superiorum prodeuntes, masculi: Pedicelli filiformes, $0,1 \mathrm{~mm}$. crassi, ad apicem sensim incrassati. Sepala 5 obovata v. orbiculari-obovata, ca. $1 \mathrm{~mm}$. longa, chartacea, margine tenuiora, 1 -nervia. Disci glandulae albescentes, semionbiculares, ca. $0,3 \mathrm{~mm}$. latae, obsolete stipitatae. Stamiuum columma fere $0,5 \mathrm{~mm}$. longa; anthcrae 2 exteriores, 3 interiores, didymae, loculis horizontaliter dehiscentibus. Flores feminei masculis parciores iisque intermixti v. profundius inserti. Pedicelli crassiores. Sepala 5, $0,7 \mathrm{~mm}$. longa, ovario arcte adpressa eique acquilonga, subeoriacea. Disci glandulae minutac disjunctae. Ovarium ovato-orbiculare. Styli libcri, $0,5 \mathrm{~mm}$. lati, ca. $1,5 \mathrm{~mm}$. longi.

Hab. in Tobago in sylvis montis Morne d'or, $500 \mathrm{~m}$. alt., m. Nov. flor.: Eggers n. 5840.

Obs. Affinis Ph. mimosoides Sw. (e St. Bartheleny, Antigua, Guadeloupe, Dominica, Truidad) stipulis ad ramos penultimos triangulari-lanceolatis v. lanccolatis, foliis sessilibus, subtus pallidis sed nou albescentibus, basi plerumque valde inacquilatera obtusiuseulis r. obtusis, glandulis flor. mase. minoribus, antheris 3 , sepalis flor. fem. ovato-ellipticis usque oblongis, ovarium duplo superantibus, stylis divergentibus, sed non reflexis, gracilioribus recedit.

Phyllanthus Buchii Urb. (n. sp.) verisimiliter dioicus, fruticulosus, ramis vetustioribus teretibus, lornotinis plus minus angulatostriatis, folia $25-50$ gerentibus; stipulis lanceolatis v. e basi latiore lanceolatis setaceo-acuminatis integris; foliis vix $0,5 \mathrm{~mm}$. longe petiolatis distichis, ovalibus usque elliptico-oblongis, basi rotundatis v. obsolete cordatis, apice rotundatis r. cujusvis ramuli inferioribus brevissime apiculatis, $0,3-0,9 \mathrm{~cm}$. longis, $0,17-0,3 \mathrm{~cm}$. latis; floribus masculis ad axillas $1-3$, femineis solitariis, ca. $1 \mathrm{~mm}$. longe pedicellatis; 
sepalis 6 liberis, masculis $0,8 \mathrm{~mm}$., femineis $1,3 \mathrm{~mm}$. longis; staminibus 3 ; seminibus dorso et lateribus tenuissime v. obsolete striatis.

Fruticulus $0,6-1,3 \mathrm{~m}$. altus. Rami vetustiores lignosi, denudati, brmescentes, apice abortientes, floriferi plures virides glabri, $7-13 \mathrm{~cm}$. longi, supra basin $0,4-0,5 \mathrm{~mm}$. crassi, fere usque ad basin foliosi, basi v. supra basin squamis nonmullis bruneis obsiti. Stipulae ca. $1 \mathrm{~mm}$. longae subscariosae, pallidae, superne saepius brunescentes. Folia internodiis aequilonga usque 3-plo longiora, postremo coriacea, crassiuscule marginata, nervo medio parum, lateralibus $3-5$ plerumque non conspicnis. Flores masculi $0,8-1 \mathrm{~mm}$. longe pedicellati. Sepala ovalia v. subobovata, 1 -nervia, apice rotundata pallida integra membranacea; squamae 6 cum sepalis alternantes peltato-suborbiculares $5-6$-lobae (v. e glandulis $6-8$ connatae). Stamina usque supra medium connata; antherae reniformes, basi in emarginatura arcte affixae, loculis divergentibus breviter orbicularibus sublateraliter longitrorsum dehiscentibus, postremo apice confluentibus. Flores feminei $1-1,2 \mathrm{~mm}$. longe pedicellati. Sepala ovalia, ovata v. obovata, crassiora, ad marginem membranacea; glandulae in cupulam profunde 6 -fidam coalitae, lobis subquadratis. Styli 3 horizontales, ad medium bifidi, ramis divaricatis linearibus a pice postremo recurvis. Ovarium breviter globulosum glabrum. Capsula depressa sphaeroidea, 1,5 mm. longa, 2,5 mm. diametro, 3-locularis. Semina $1 \mathrm{~mm}$. longa, striis dorsalibus ca. 9 minutissime et densissime transversim conjunctis, lateralibus ca. 6, omnibus subserpentinis, flava $v$. flavo-brunea.

Hab. in Haiti prope Ennery in montibus calcareis siccis, $400 \mathrm{~m}$. alt., m. April. flor:: Buch n. 251.

Obs. Affinis Ph. junceo Müll. Arg. $=P h$. squamato C. Wr. (e Cuba: Wright n. 1937), qui caulibus pedalibus, ramis vetustioribus elevatim striatis, novellis $10-20$-phyllis, foliis obovatis r. oblongo-obovatis, margine incrassato recurvis, nervo medio subtus bene prominente, floribus masculis ad axillas numerosioribus, staminibus 2 usque ad apicem coalitis discrepat. Pl. polycladus Urb. (e Portorico et Guadeloupe) praeter alias notas distributione sexuum (floribus in axillis inferioribus masculis, in superioribus femineis) statim dignoscendus est.

$\checkmark$ Phyllanthus bahamensis Urb. (n. sp.) arbor, ramis hornotinis papilloso-scaberulis; stipulis triangulari-lanceolatis $1,5-2 \mathrm{~mm}$. longis acutis, ferrugineis, margine palliclioribus v. albescentibus; foliis $2-3 \mathrm{~mm}$. longe petiolatis, obovato-ellipticis usque lanceolatis, basi obtusiusculis v. acutatis, apice rotundatis, obtusis v. brevissime et obtuse acuminatis, 2,5-5 cm. longis, $1-2 \mathrm{~cm}$. latis, membranaceis v. postremo chartaceis; floribus (masculis tantum notis) ad ramulos breves paucifoliatos ex axillis squamarum (i. e. inter stipulas) et euphyllorum 1-4, pedicellis 2-3 mm. longis subrigidis; sepalis exterioribus ovatis, interioribus orbicularibus, 1,5 mm. longis, chartaceis, margine membranaceis; disco extrastaninali plano, margine brevissime libero et undulato-crenato; antheris orbiculari-ovatis, $0,6 \mathrm{~mm}$. longis.

Urban, Symb, ant. III. 
Arbor 6,6 m. alta (cx EcG.). Rami vetustiores obscurc brmnei, lenticellis crebris obsiti, teretes, hornotini plus minus angulati, distiche dispositi. Stipulae basi biamiculatac, apice acutac r. acuminatae. Folia nerro medio supra prominulo, lateralibus utroque latere $6-10$ tenuibus supra prominulis, obsolete anastomosantibus, margine plana v. angustissine recurva, supra nitidula, subtus pallicliora opaca. Sepala 4 , in aestivatione imbricata, cxteriora interdum acuminata. Stamina 4; filamenta $0,8 \mathrm{~mm}$. longa.

Hab. in ins. Balıam. New Providence in Blue Hills, m. Febr., Mart. flor:: Egger's 11. 4241, 4464, Andros in Red Bays m. April. flor:: Northop) 11. 488.

Obs. Arcte affinis $P \%$. scandens Miill. Arg. canlibus scandentibus, foliis $3-5 \mathrm{~mm}$. longe petiolatis, usque $7 \mathrm{~cm}$. longis, $3 \mathrm{~cm}$. latis, nervis subtus multo magis prominentibus, pedicellis in glomerulis masculis pluribus $v$. numerosis $5-7 \mathrm{~mm}$. longis, antheris anguste oratis recedit.

Phyllanthus isolepis Urb. (n. sp.) ramulis penultimis convexis, supra canaliculatis; stipulis lanceolato- linearibus subulatis $1,5-3 \mathrm{~mm}$. longis; phyllocladiis distichis, lanceolatis v. anguste lanceolatis, utrinque subaequaliter v. raro inferne magis angustatis, $5-8 \mathrm{~cm}$. longis, $1-1,5 \mathrm{~cm}$. latis, usque ad v. paullo infra medium florigeris, crenaturis utroque latere $10-16$ plurifloris; floribus masculis $1,5-2,5 \mathrm{~mm}$. longe pedicellatis, sepalis $0,6-0,7 \mathrm{~mm}$. longis, filamentis apice liberis; floribus femineis $0,5-1,5 \mathrm{~mm}$. pedicollatis, urceolo hypogyno ad squamas 6 minutas suborbiculares liberas reductis, stylis inferne connatis, capsulis globulosis, apice subacutis, longitrorsum vix v. leviter 3 -sulcatis.

Rami retustiores teretes bruneo-grisei r. griseo-albescentes, cicatricibus ramulorm penultimorum decidnorum non r. vix prominulis, apice squamis densis (i. e. foliis singulis ad squamas reductis eorunque stipulis binis conformibus) lanceolato-acuminatis $3 \ldots 4 \mathrm{~mm}$. longis bruneis crasse coriaceis induratisque comosi; rami penultimi spiraliter dispositi, $15-20 \mathrm{~cm}$. longi, supra basin magis, ad apicen sensim minus convexi, sub phyllocladiis interdum folia minuta squamiformia gerentes. Phyllocladia margine infero integra, supero dense crenata, coriacen, apicc obtusiuscula, raro obtusa v. rotundata, nerris sublongitrorsis tenuissimis. Flores masculi in quoque glomerulo $1-5$. Sepala breviter obovata v. subrhombea, membranacea. Disci glandulae 6 breviter orbiculares, obsolete stipitatae. Stamina usque au nedium v. panllo ultra inter sese connata; antherarum locnli apice contigui, inferne dirergentes, dorso sibi appositi, lateraliter longitrorsum sulcati. Flores feminei: Sepala ut in mare. Disci glandulae 6 liberae minutae, ad basin ovarii sitac, masculis conformes suborbiculares. Ovarium subglobosum. Styli supra basin r. usque ad medium coaliti, superne recurvi, apice in lacinias $3-5$ anguste lineares divisi. Capsulae ca. 2,5 mm. diametro, basi truncatac r. obsolete excavatac, apice acutiusculae, bruneac sublaeves, transversim suborbiculares.

Hab. in Jamaica prope Ferry Pen $50 \mathrm{~m}$. alt., m. Jun. fl. et fr.: E. Campbell n. 6280. 
Obs. Ph. angustifolius Sw. et speciosus Jacq. habitu similes pedicellis longioribus, urceolo hypogyno integro v. 6-lobo, stylis subliberis, capsulis trigonis depressis et praeterea squamis ramos penultimos suffulcientibus solitariis, basi valde dilatatis, $I \%$. latifolius Sw. foliis latioribus, pedicellis 5 - $8 \mathrm{~mm}$. longis, floribus multo majoribus, urceolo hypogyno integro ovarium dimidium restientc et praeterea squamis 3 ramos penultimos suffulcientibus oratis obtusis recedunt.

Croton microstachyus Desr. monoicus, foliis $10-3 \mathrm{~mm}$. longe petiolatis, basi eglandulosis, ovatis, basi subobliqua et plus minus inaequilatera anguste cordatis, apice obtusissimis v. rotundatis, nunc obsolete emarginatis, 3,5-2 cm. longis, 2,5-1 cm. latis, e basi $5-3-$ nervibus, caeterum pinnatinervibus, nervis supra leviter impressis, margine minute et crebro dentatis, supra pilis stellaribus breviter et crassiuscule stipitatis dense obsessa, subtus pube eadem flavida v. flaroalbida tomentosulis; inflorescentiis $2-3,5 \mathrm{~cm}$. longis, inferne v. ad basin femineis, caeterum masculis; pedicellis florum masc. $1-1,5 \mathrm{~mm}$. longis, alabastris sphaeroideis $2,5 \mathrm{~mm}$. diametro, staminibus ca. 15 ; pedicellis flor. fem. $2-3 \mathrm{~mm}$. longis, sepalis ovatis r. rhombeo-oratis r. anguste ovatis, margine non recurvis; stylis e basi bipartitis, ramis supra basin iterum bipartitis, filiformibus; capsulis globulosis, vix 4 mm. diametro; seminibus ovatis, $2,7 \mathrm{~mm}$. longis.

\section{Croton microstachyus Desv.! in Ham. Prodr. (1825) p. 56.}

Frutex. Rami retustiores glabrati teretes bruneo-cinerei, lornotini pilis breviter stipitatis stellaribus flavidis tomentosuli. Stipula e $3-5 \mathrm{~mm}$. longae filiformes pubescentes, satis longe persistentes. Folia petiolis subteretibus, nervis lateralibus (praeter basales) $2-5$, sub angulo $45^{0}-60^{\circ}$ abeuntibus, supra plus minus obsolete reticulato-anastomosantibus, subtus modice prominentibus, chartaceo-coriacca, supra mollia in sicco olivacea, radiis pilorum inferiortim quam superiorum ca. dimidio longioribus. Inflores centiae in apice ramorum terminales solitariae 15-30-florae; pedunculus subnullus v. usque ad $1 \mathrm{~cm}$. longus; rhachis tomentosa, superne densiflora; bracteae filiformes $2-3 \mathrm{~mm}$. longae, inferiores florem femineum solitarium, superiores flores masculos $1-3$ in axilla gerentes. Flores masculi (juniores): Sepala 5 in aestiratione valvata, oblonga v. ovato-oblonga, chartacea, dorso tomentosula, $2-2,3 \mathrm{~mm}$. longa. Petala oblongo-spathulata, sepalis aequilonga v. vix longiora, margine infero et intus superne longiuscule albido-pubescentia, dorso breviter et adpresse sericeo-pilosa. Disci glandulae semiorbiculares satis amplac. Filamenta usque ad apicem dense pubescentia; antherae in alabastris inflexae, juniores ovatae. Flores feminei: Sepala brevissime et obtuse acuminata, florifera $2 \mathrm{~mm}$., fructifera $3 \mathrm{~mm}$. longa, integra coriacea, intus supra basin glabra, caeterum utrinque dense tomentoso-pubescentia. Petala nulla. Discus amplus calycis fundum vestiens eique adnatus, margine 5-crenatus. Ovarium sphaeroideum, flavido-tomentosum. Stylorum rami apice excepto dense et breviter pubcscentes, patentes, apice incurvi, ca. $2 \mathrm{~mm}$. longi. Capsulae tomentosulae; cocci columellam filiformem, apice incrassatam relinquentes. Semina laevia. 
Hab. in Hispaniola: Hamilton (in herb. Desvaux, numc in museo Paris.).

Obs. I. Affinis C. sidifolio Lam., qui foliis margine integris subintegrisve, supra pilis brevissimis obsitis, basi rotundatis v. vix cordatis, floribus brevius pedicellatis, scpalis femin. longioribus, filancntis ad basin tantum pubescentibus recelit.

Obs. II. Nomen „microstachyus" parum idoneum, quia racemi magnitudine mediocri gaudent.

Obs. III. E caeteris Crotonis spcciebus a cl. Hamuton (Prodr. p. 55-56) descriptis $C$.guadeloupensis Desv.! est $C$. astroites Ait., C. bahamensis Desv.! est C.lucidus L. - C. microcarpus Desv. (ex Hispaniola) et C. angustifolius Desv. (ex Hispaniola) in Herb. Desvaux (nune in museo Paris.) desiderantur ideoque ob descriptionem nimis brevem oblivioni tradendi sunt.

Croton waltherioiles Urb. (n. sp.), monoicus, foliis $7-311 m$. longe petiolatis, basi limbi glandulam unicam parvam gerentibus v. eglandulosis, ovatis, breviter v. anguste ovatis, basi rotundatis v. subtruncatis, saepius subcordatis, apice rotundatis, obtusis v. breviter apiculatis, $2,5-1,5 \mathrm{~cm}$. longis, $1,5-0,8 \mathrm{~cm}$. latis, e basi 5 -nervibus, nervis supra leviter impressis, margine crenatis v. irregulariter crenulatis, utrinque pilis stellatis brevibus dense obtectis; inflorescentiis $1,5-2 \mathrm{~cm}$. longis; floribus $1-3$ inferioribus femineis, caeteris v. omnibus masculis; pedicellis flor. masc. $3-3,5 \mathrm{~mm}$. longis, alabastris sphaeroideis, $2 \mathrm{~mm}$. diametro, staminibus ca. 16 ; pedicellis flor. fem. $1-2 \mathrm{~mm}$. longis, sepalis suborbicularibus, valvatis, margine recurvis; stylis usque v. fere usque ad basin bipartitis, ramis saepius iterum bifidis filiformibus.

Frutex 1,30-2 m. altus. Rami vetustiores teretes glabrescentes cinerei, hornotini plus minus compressi, pilis stellatis flavidis $\mathrm{v}$. fulvis brevibus tomentosuli. Stipulac lineari-subulatae, $3 \mathrm{~mm}$. longae. Folia petiolis subteretibus, glandulis basalibus, si adsunt, sessilibus, nervis lateralibus praeter basales utroque latere $1-2$ sub angulo $20-35^{\circ}$ abeuntibus, non anastomosantibus, chartacea, radiis pilorum paginae inferioris quam superioris paullo longioribus. Inflorescentiae in apice ramorum terminales, 7-15-florae; pedunculus submullus r. usque 1 cm. longus; rhachis tomentosa; bracteae $1-1,5 \mathrm{~mm}$. longae, filiformes, deciduae, in axillis flores solitarios gerentes. Flores flavi, masculi: Sepala 5 in aestivatione valvata, ovata obtusinscula, vix $2 \mathrm{~mm}$. longa, membranacco-chartacea. Petala elliptico-oblonga, sepala smperantia, 2,5 $\mathrm{mm}$. longa, $0,8 \mathrm{~mm}$. lata, apice rotundata, intus pubescentia, margine infero barbata, membranacea. Disci glandulae satis amplae, snbquadrato-orbiculares, sublibcrae. Fila men ta $2-2,5 \mathrm{~mm}$. longa, ad basin pubescentia; antherac in alabastro inflexae, orbiculari-subquadratae, lateraliter intus dehiscentes. Flores feminei: Sepala suborbicularia, sub anthesi $2,5 \mathrm{~mm}$. diametro, brevissime v. obsolete apienlata, integra subcoriacea, extrinsecus pilis stellatis, intus pilis simplicibus vestita, posterius nt videtur panllo accrescentia. Petala (v. staminodia?) nulla v. hine illine ad squamcllas minutas pilosas reducta. Discus amplus basin calycis vestiens, margine libero sublobatus. Ovarium breviter globnlosum, dense flavido-pubescens. Stylorum lobi incurrati, breviter pilosi. 
Hab. in Haiti prope Gonaïves ad Ennery, m. April. flor:: Bucl n. 143 .

Obs. Habitu affinis C. betulinus Vahl (in Antillis, praesertim majoribus late divulgata) pube albida, foliis brevius petiolatis, grosse crenatis, e basi trinerviis, floribus masculis ca. $1 \mathrm{~mm}$. longe pedicellatis, staminibus $9-11$, calycis feminei laciniis oborato-ellipticis, saepius 1-2-lobatis, styli ramis linearibus breviusculis omnino recedit.

Croton polytomus Urb. (n. sp.) monoicus, foliis $10-5 \mathrm{~mm}$. longe petiolatis, basi limbi glandulas 2 breviter stipitatas parvas saepe difficile conspicuas gerentibus, ovatis v. ovato-orbicularibus, basi anguste cordatis, apice brevissime acuminatis, obtusis v. rotundatis, $3-1,5 \mathrm{~cm}$. longis, 2-1,5 cm. latis, e basi 3 -nervibus, nervis supra impressis, margine integris, supra pilis brevibus crassiuseulis tenuiter ramulosis dense vestitis, subtus pilis stellaribus pallide flavido-tomentosis; inflorescentiis $1-2 \mathrm{~cm}$. longis e basi densi- et multifloris; floribus infimis 1 - parcis femineis, caeteris masculis; pedicellis flor. masc. ca. $1 \mathrm{~mm}$. longis, alabastris sphaeroideis, $1,5 \mathrm{~mm}$. diametro, staminibus $14-16$; pedicellis flor. fem. $0,5-0,8 \mathrm{~mm}$. longis, sepalis triangulari-lanceolatis; stylis fere usque ad basin in ramos filiformes longiusculos divisis; capsulis globulosis, leviter longitrorsum 3 -suleatis; seminibus ovalibus convexis, $3 \mathrm{~mm}$. longis, sublaevibus.

Rami teretes, pilis brevibus dense multiramulosis, apice ramulos 1 - paucos longiores emittentibus fulro-tomentosi, apice subumbellatim ca. 5 -ramulosi. Stipulae non observatae. Folia petiolis teretibus, nervis lateralibus utroque latere $3-4$, sub angulo $50-60^{\circ}$ abeuntibus, simplicibus, bifurcis v. infimis parce ramulosis, non anastomosantibus, subtus crassiuscule prominentibus, crassiuscule coriacea, supra in siceo brunescentia scabriuscula. Inflorescentiae in apice ramorum inter ramulos umbellatim dispositos terminales sessiles; pedunculus nullus; rhachis sub floribus densissime aggregatis occulta tomentosula; bracteae ca. $1 \mathrm{~mm}$. longae triangulares, infimae flores fem. solitarios, caeterae flor. masc. $3-5$ gerentes. Flores albidi, masculi: Sepala 5 in aestiratione valvata, ovata acuta $1-1,3 \mathrm{~mm}$. longa, chartacea, dorso tomentosula. Petala rectangulari-elliptica, sepala superantia, $1,5 \mathrm{~mm}$. longa, $0,7 \mathrm{~mm}$. lata, inferne ad marginem et intus pubescentia, apice parcissime pilosula, caeterum glabra, membranaceo-chartacea. Disci glandulae 5 parvae, transversim subovales, inferne adnatae. Filamenta $1,5 \mathrm{~mm}$. longa, ad basin pnbcscentia; antherae in alabastris inflcxae, ovato-subquadratae, intus dehiscentes. Flores feminei non rite visi: Sepala in fructu $1,5 \mathrm{~mm}$. longa crasse coriacea rigida integra, extrinsecus pilis stellatis obsita, intus glabra. Discus annularis crenulatus. Styli $3 \mathrm{~mm}$. longi, infernc pilosuli, apice uncati. Capsulac ca. 4-5 mm. diametro, dorso tomentosulae, exocarpio facile solubili; valvae columnam $4 \mathrm{~mm}$. longam, linearem, apice brevitcr et obtuse 3 -lobam relinquentcs. Semina $1,8 \mathrm{~mm}$. lata.

Hab. in Haiti prope Cadets, $1200 \mathrm{~m}$. alt., m. Jan. flor.: Picarda n. 1092 . 
Obs. Ex affinitate C. lencophlebii Griseb., qui foliis ovato-oblongis, superne sensim angustatis, subtus pilos eximie ramulosos densissimos gerentibus, inflorescentiis laxifloris, inferme flores plures femineos praebentibus etc. plane discrepat.

Croton litoralis Urb. (n. sp.) monoicus, foliis $3-1,5 \mathrm{~mm}$. longe petiolatis, basi eglandulosis, anguste v. elliptico-obovatis, basi obtusis, apice rotundatis $v$. subtruncatis, $1,5-0,7 \mathrm{~cm}$. longis, $0,7-0,4 \mathrm{~cm}$. latis, penninervibus, nervis supra subimpressis, unargine integris subintegrisve, supra pilis valde abbreviatim stellaribus adspersis, subtus pilis stellaribus brevibus adpressis sordide $\mathrm{r}$. cinereo- albido-tonentosulis, plus minus concavis; inflorescentiis $1,5-2,5 \mathrm{~cm}$. longis, fere a basi laxiuscule floriferis, plerumque bisexualibus, floribus $2-5$ infimis femineis, caeteris r. omnibus masculis; pedicellis flor. masc. $0,5-1 \mathrm{~mm}$. longis; alabastris splaaeroideis, $1 \mathrm{~mm}$. diametro; staminibus ca. 15; perlicellis flor. fem. $1-1,5 \mathrm{~mm}$. longis, sepalis lineari-lanceolatis; stylis e basi in lobos 2 lineares bipartitis; capsulis globulosis, $4 \mathrm{~mm}$. longis, longitrorsum 3 -sulcatis; seminibus ovali-ellipticis, fere $3 \mathrm{~mm}$. longis, laevibus.

Frutex $1 \mathrm{~m}$. altus, ramosus. Rami vetustiores teretes, residuis pubis tomentosuli v. (lemum glabrati, apice sub racemis vetustis bifurcati, hornotini angulati $v$. subcompressi, squamulis v. pilis adpresse et brevissime multiradiatis flavido-tomentosuli v. quasi incrustati, superne dichotome ramosi. Stipulae nullae. Folia petiolis subteretibus, supra obsolete v. vix sulcatis, nervis lateralibus utroque latere $3-5$ supra subimpressis, subtus prominulis, sub angulo $40-50^{\circ}$ abeuntibus, ad marginem supra interdum obsolete dichotomis et conjunctis, rigide coriacea, supra pallide viridia, subtus sordide v. albido-cinerea. Inflorescentiae terminales, non v. usque $0,3 \mathrm{~cm}$. longe pedunculatae; rhachis tomentosula angulata; bracteae subabortivae calliformes, inferiores flores fem. solitarios, superiores flores masc. $2-3$ in axilla gerentes. Flores masculi: Sepala 5 in aestivatione valvata, ovata r. anguste ovata, ca. $1 \mathrm{~mm}$. longa, 0,5-0,6 mm. lata, obtusa, chartacea, dorso pilis stellaribus abbreviatis tomentosula. Petala oborato-spathulata, sepala paullo superantia, $1,3 \mathrm{~mm}$. longa, margine infero barbati, caeterum glabra, membranacea. Disci glandulae reniformes subliberae. Filamenta $1 \mathrm{~mm}$. longa, basi villosula; antherae in alabastro inflexae, subquadrato-rotundatae, margine intus dehiscentes. Flores feminei: Sepala $1 \mathrm{~mm}$. longa, obtusa, posterius non accrescentia, dorso tomentosa. Disci glandulae 5 subcontiguae annuliformi-dispositae. Petalorum (v. staminum) rudimenta minutissima glanduliformia v. obsoleta. Ovarium globulosum flavido-tomentosum. Styli $1,5 \mathrm{~mm}$. longi, dorso inferne tomentosi, lobis apice involutis. Capsulae pilis abbreviatim stellulatis tomentosulae; valvae columnam linearem apice incrassato breviter trifurcam relinquentes. Semina 1,4 mm. lata, utrinque convexa, olivacea nigro-punctata, caruncula satis ampla biloba.

Hab. in Cuba in litoralibus prope La Caimanera, m. Majo fl. et fr.: Eggers n. 5388 .

Var. $\beta$. Rugrolianus Urb. foliis oblongis v. lineari-oblongis, 0,5$0,3 \mathrm{~cm}$. latis, nervis lateralibus nullis v. obsoletis, subtus flavido-tomen- 
tosulis, longitrorsum plicatis; inflorescentiis brevioribus $0,5-1,5 \mathrm{~cm}$. longis; floribus masculis subsessilibus; capsulis breviter ovali-globosis; seminibus bruneis.

Croton rosmarimifolius var. Griseb. Cat. (1S66) p. 17.

Hab. in Cuba: Rugel n. 160.

Obs. Ex affinitate (sed non areta) C. discoloris Willd,; ad C. rosmarinifolium Griseb. nullas habet rationes.

$\checkmark$ Croton martinicensis Urb. (n. sp.) dioicus, foliis $25-5 \mathrm{~mm}$. longe petiolatis, basi glandulas $2-4$ breviter stipitatas parvas gerentibus, ovato-oblongis $\mathrm{v}$. ovato-lanceolatis, basi rotundatis r. obsolete emarginatis, apice obtusis r. obtusiusculis et mucronulatis, $6-4 \mathrm{~cm}$. longis, $2,5-1,5 \mathrm{~cm}$. latis, ramulorum saepius ovatis v. ovalibus usque ad $2,5 \mathrm{~cm}$. longitudine decrescentibus, nerris pinnatis supra impressis, margine integris, supra glabris minute punctulatis, subtus pube densa stellari flaridoalbescente brevi tomentosulis; inflorescentiis masculis $8 \mathrm{~cm}$. et ultra longis, longe pedunculatis, valde laxifloris; pedicellis $3 \mathrm{~mm}$. longis; alabastris sphaeroideis, basi perpaullo in pedicellum protractis, obtuse 5 angulatis, $2 \mathrm{~mm}$. diametro; sepalis anguste ovatis v. oratis, $2,5-3 \mathrm{~mm}$. longis; staminibus ca. 21.

Rami inferne teretes, superne angulato-striati, lepidibus parvis stellatim et breviter multiradiatis adpressis flavidis ommino incrustati, alternatim ramosi. Stipulae nullae. Folia petiolis sulterctibus, supra plus minus sulcatis, nervis lateralibus utroque latere $10-12$ sub angulo $60-70^{0}$ abeuntibus, infimis fere e basi prodcuntibus paullo magis arduis, omnibus ante marginem dichotomis et supra saepius coujunctis, supra in sicco olivaceo-brunescentia, subtus flavido-cinerasccntia. Inflorescentia terminalis $5 \mathrm{~cm}$. longe pedunculata; rhachis angulata, pilis stellaribus abbreviatis dense obtecta; bracteac lanceolato-lineares v. lineares, 1,5-2 $\mathrm{mm}$. longae, 2 -- 3 florae. Flores masculi: Scpala 5 in aestivationc ralvata, apice brevissime et obtuse acuminata, chartaceo-coriacea, dorso pilis stellarilus dense obsita. Pctala lanceolata, acuminata, acumine incurvo obtusiusculo, ad basin magis angustata, 2,7 mm. longa, $0,8 \mathrm{~mm}$. lata, sepalis sulaequilonga, margine infero barbata, caeterum glabra, chartacea. Disci glandulae 5 semiorbiculares. Filamenta basi ima albido-pubescentia, 1,5 mm. longa; antherae in alabastro inflexae, ovatac, intus dehiscentes. Flores feminei et fructus ignoti.

Hab. in Martinique: Duss n. 492.

Obs. Affinis $C$. discolor $\mathrm{W}$. foliis $5-15 \mathrm{~mm}$. longe petiolatis, basi obtusis, superne non F. minus angustatis, floribus masculis densioribus, brevius pedicellatis, alabastris non angulatis, staminibus minus numerosis differt.

Croton Priorianus Urb. (n. sp).) monoicus; foliis alternis r. arl apicem ramulorum oppositis $\mathrm{r}$. ternatim rerticillatis, $15-4 \mathrm{~mm}$. longe petiolatis, sub limbo r. ad ejus basin glandulas 2 v. plures breviter v. brevissime stipitatas gerentibus, anguste lanceolatis v. oblongo-linearibus, 
basi rotundatis v. subcordatis, superne v. e parte inferiore sensim angustatis, apice obtusis v. rotundatis et brevissime apiculatis, $6-2,5 \mathrm{~cm}$. longis, $1,5-0,7 \mathrm{~cm}$. latis, nervo medio supra valde, lateralibus leviter impressis, margine integris, supra pilis stellatis valde abbreviatis scabriusculis, subtus pilis stellatis brevibus flaridu- v. albescenti-tomentosis; inflorescentiis bisexualibus, $4-6 \mathrm{~cm}$. longis; pedicellis flor. masc. ca. $1 \mathrm{~mm}$. longis; alabastris globosis $1,5 \mathrm{~mm}$. diametro; staminibus ca. 16 ; flor. fem. subsessilibus; stylis usque ad basin bifidis; capsulis globulosis.

\section{Croton Cascarilla a. Griseb.! Flor. (1859) p. 38, - non Limn.}

Rami vetustiores teretes glabrescentes, hornotini pilis stellatis dense flavido-tomentelli, superne plus minus angulati. Stipulae non observatae. Folia petiolis subteretibus, glandulis basalibus usque $0,5 \mathrm{~mm}$. longe stipitatis parvis, nervis lateralibus $9-15$, sub angulo $60-70^{\circ}$ abeuntibus, supra ante marginem interdum bifurcatis et conjunctis, subtus non anastomosantibus, chartaceo-coriacea v. subcoriacea, supra in sicco olivacea v. brunescentia. Inflorescentiae terminales; pedunculus $1-2 \mathrm{~cm}$. longus, rhachis angulata tomentosula; bracteae parvae triangulares, inferne flores femineos solitarios, superne flores masculos $1-3$ inaequaliter evolutos gerentes. Flores masculi: Sepala 5 ovata obtusiuscula vix $1,5 \mathrm{~mm}$. longa crassiuscule chartacea. Petala obovato-lanceolata, margine infero pilis longiusculis tenuibus crispulis barbata, sepala paullo superantia, chartacea. Disci glandulae transversim oblongae, medio emarginatae. Filamenta basi pubescentia, basi ima connata, caeterum libera glabra, $1,5-2 \mathrm{~mm}$. longa; antherae in alabastro inflexae, subquadratae v. ovatae, lateraliter sed paullo intus dehiscentes. Flores feminei: Sepala coriacea lanceolata, 2 mm. longa, extrinsecus tomentosula. Petala (r. staminodia?) minutissima glanduliformia, discum vix superantia. Disci glandulae 5 transversim rectangulari-ellipticae. Ovarium breviter globulosum tomentosum. Styli lobi latiuscule lineares. Capsulae (non plane maturae) 4,5 mm. diametro.

Hab. in Jamaica: Alexander (Prior), March n. 1653.

Obs. Ex affinitate C. Jaegeriani Müll. Arg. (e Haiti).

Croton angustatus Urb. (n. sp.) dioicus, foliis alternis v. sub inflorescentiis verticillatis, $11-3 \mathrm{~mm}$. longe petiolatis, subtus ad basin glandulas 2 minutas breviter stipitatas v. plerumque obsoletas gerentibus, linearibus v. rarius oblongo-linearibus, basi rotundatis v. subcordatis, apice rotundatis $\nabla$. obtusis nunc obsolete apiculatis, $2,5-5 \mathrm{~cm}$. longis, $0,3-0,9 \mathrm{~cm}$. latis, nervo medio supra solemniter impressis, lateralibus crebris subhorizontalibus, leviter sulcatis, supra pilis plerumque simplicibus brevissimis inferne incrassatis scabridis, subtus pilis stellaribus pallide flavis v. rufescentibus tomentosis, integris; inflorescentiis femineis (tantum visis) paucifloris, usque $3,5 \mathrm{~cm}$. longis, pedicellis $1-2 \mathrm{~mm}$. longis; sepalis ovatis $\nabla$. anguste ovatis, $1,5 \mathrm{~mm}$. longis; stylis supra basin v. in $1 / 4$ alt. bifidis, lobis linearibus integris; capsulis depresse globosis, mediocriter longitrorsum 3 -sulcatis. 
Frutex $0,6-1,3 \mathrm{~m}$. altus. Rami vetustiores terctes glabrati grisei, alternatim ramosi et sub inflorescentiis (delapsis) $2-5$-tomi, hornotini pilis v. squamulis abbreviatim multiradiatis flavidis v. rufis dense v. densissime adspersi. Stipulae non observatae. Folia petiolis subtcretibus, glandulis basalibus difficile conspicuis, nervis lateralibus utroque latere $10-25$, sub angulo $70-80^{\circ}$ abeuntibus, ante marginem plus minus manifeste bifurcis et conjunctis, supra olivacea v. nigrescentia, subtus pallide flavida v. rufescentia, chartaceo-coriacea. Inflorescentiae (femineae) in apice ramorum et ramulorum terminales, $2-12$-florae; pedunculus subnullus r. usqu $1 \mathrm{~cm}$. longus; rhachis pube ramorum; bracteae triangulares v. triangulari-lanceolatae, interdum 3 -lobae, vix $1 \mathrm{~mm}$. longae; pedicelli crassiusculi, sub calyce subito crassiores. Sepala 5 obtusiuscula v. brevissime et obtuse acumiuata, extrinsecus tomentosa, coriacea, alba, sub fructu non ampliata. Petala (r. staminodia?) cum sepalis alterna minuta glanduliformia, discum vix superantia. Discus annularis, plus minus crenulatus, margine liber. Ovarium brevitcr sphaeroideum, flavido-tomentoso-villosum. Styli inferne pilis stellaribus parvis obsiti, $2-3 \mathrm{~mm}$. longi, ramis convexis leviter sulcatis, apicc incurvis $v$. involutis. Capsulae $3,5 \mathrm{~mm}$. longae, $4 \mathrm{~mm}$. crassae, squamulis abbreviatim multiradiatis rufescentibus sublaxe obsitae, exocarpio viridi. Scmina juniora obovata.

Hab. in Haiti prope Gonaïves in Morne Bonpère $600 \mathrm{ml}$. alt., m. Jun. fl. et fr.: Buch 11. 711; Sto. Doningo ad Rio Yaqui prope Angostura in rupibus calcareis, 220 nı. alt., nı. Majo flor.: Eggers n. 1824.

Obs. Hinc ad C. linearem Jacq., illine ad C. viminalem Griseb. aceedens.

Croton Picardae Urb. (n. sp.) virisimiliter dioicus, foliis alternis, 7-3 $\mathrm{mm}$. longe petiolatis, sub limbo glandulas $2 \mathrm{v}$. plures filiformistipitatas gerentibus, anguste lanceolato-linearibus v. sublinearibus, basi obtusis v. rotundatis, superne sensim angustatis, apice acutiusculis $\mathrm{r}$. obtusiusculis, $7-3 \mathrm{~cm}$. longis, $0,7-0,3 \mathrm{cml}$. latis, nervo medio et crebris lateralibus supra arcte impressis, margine integris, supra pilis brevissimis 1 -pauciradiatis, basi incrassatis scabriusculis, subtus pilis pluriradiatis tomentosis pallide flavis; inflorescentiis masculis multifloris, $3-5 \mathrm{~cm}$., pedicellis $1-1,5 \mathrm{~mm}$. longis; alabastris sphaeroideis $2 \mathrm{~mm}$. diametro, pilis stellatis plus minus parce indutis; staminibus ca. 16: inflorescentiis femineis abbreviatis v. usque $3 \mathrm{cn}$. longis, $1-10$-floris, pedicellis subnullis; stylis usque ad basin bifidis; capsulis depresse globosis, profunde lougitrorsum 3 -sulcatis; seminibus rotundato-oratis, $2-2,3 \mathrm{~mm}$. longis, convexis, praesertim intus dense impresso-punctatis.

Rami teretes, pilis tubcreuliformibus brevissime multiradiatis sordide albidis v. sordide brunescentibus ad apicem dense, inferius laxius obscssi, demum glabrescentes et virides. Stipulae non observatae. Folia petiolis subteretibus, glandulis basalibus usque $0,8 \mathrm{~mm}$. longe stipitatis parvis, nervis lateralibus $15-25$, sub angulo $60-70^{\circ}$ abeuntibus, ante marginem saepe bifurcis non anastomosantibus, chartaceo-coriacea, supra olivacea r. brunescentia, radiis pilorum inferiorum inaequilougis brevibus v. plerisque brevissimis. Inflorescentiae masculae ad apicem ramorum ramulorumque 
solitariae; pedmnculus ca. 1 em. longus, rhachis pilis abbreviatim multiradiatis dense obsessa, angulata v. eompressa; bracteae in axilla flores $1-3$ inaepualiter evolutos gerentes, parvae triangulares. Sepala 5 elliptica obtusinseula $2 \mathrm{~mm}$. longa, membranaceo-chartacea, margine glabra. Petala elliptico-spathulata, margine infero pilis tenuibus longinsculis erispulis barlata, sepalis subaequilonga, ut videtur purpurascentia, membranacea. Filamenta basi ima subconnata et pubescentia, caeterum libera glabra, 1,5-2,5 min. longa; antherae in alabastro inflexae ovatae, lateraliter, sed paullo intus dehiscentes. Flores feminei: Sepala eoriacea lanceolata 1,5 $\mathrm{mm}$. longa, extrinsecus tomentosula. Petala (v. staminodia?) minuta filiformia, sepalis 5-plo breviora. Diseus fundo calycis adnatus, margine erenulatus. Ovariu m breviter globosum tomentosum. Styli lobi lineares incurvati. Capsulae $3 \mathrm{~mm}$. longae, $4-4,5 \mathrm{~mm}$. diametro, parce stellato-pilosae, apice subemarginatae. Semina $1,8-2 \mathrm{~mm}$. lata, vix $1 \mathrm{~mm}$. crassa, intus non carinata.

Hab. in Haiti prope Payan: Picarda n. 177, 369 ${ }^{b}$.

Obs. Ex affinitate C. linearis Jaeq., a quo praeter alias notas fructibus seminibusque discrepat.

Croton megaladenus $U_{r} b$. (n. sp.) monoicus, foliis $35-6 \mathrm{~mm}$. longe petiolatis, basi subtus glandulis binis amplis brunescentibus sessilibus solemniter ornatis, anguste r. lineari-lanceolatis, basi rotundatis r. subcordatis, longe infra medium usque ad apicem sensim angustatis, apice acutis, $9-3,5 \mathrm{~cm}$. longis, $1,8-0,6 \mathrm{~cm}$. latis, margine integris, saepius undulatis, penninervibus, nervo medio supra sulcatoimpresso, lateralibus numerosis supra prominulis $r$ ' in sulco levi prominulis, supra glabris $r$. pilis minutis simplicibus v. parce raro multiradiatis obsitis, subtus pilis stellaribus griseo-tomentosulis; inflorescentiis $4-8 \mathrm{~cm}$. longis, breviter pedunculatis, multifloris, inferne $\mathrm{r}$. ad basin femineis, superne masculis; floribus masculis e quaque bractea $3-7$, pedicellis $1,5-4 \mathrm{~mm}$. longis, alabastris sphaeroideis v. globulosis, $1,5 \mathrm{~mm}$. diametro, staminibus $15-20$; pedicellis flor. fem. solitariis submullis v. usque $1 \mathrm{~mm}$. longis, sepalis lanceolatis r. lineari-lanceolatis; stylis supra basin v. in $2 / 5$ alt. bipartitis; capsulis globulosis $3,5-4 \mathrm{~mm}$. diametro, longitrorsum 3 -suleatis; seminibus obovatis $2-2,3 \mathrm{~mm}$. longis, utrinque subimpresse punctatis.

Croton Cascarilla Lim. Spec. II ed. II (1763) p. 1424 (quoad syn. Plum.); Mïll. Arg. in DC. Prodr. XV. II p. 616 (item).

Croton cascarilloides Geisel. Crot. Monogr. (1807) p. \& (quoad syn. Plum.).

Ricinoides nelacagni folio Plmm. Cat. (1703) p. 20 et Plant. amer. ed. Burm. p. 236 tab. 240 fig. 1!

Thé du pays Hait. ex Jacquem.

Suffrutex $1,6-2,6 \mathrm{~m}$. altus r. arbor usque 7 -metralis ralde ramosa. Rami vetustiores teretes non striati, pilorum residuis scabriusculi, apice 
sub racemis delapsis bifurcati, llomotini terctes $r$. superne angulati, pilis v. squamulis breviter multiradiatis flaridis v. pallide flavidis vix prominulis densissime obtecti v. tomentosuli. Stipulae minutissimae glanduliformes v. nullae. Folia petiolis subteretibus, supra obsolete r. levitcr sulcatis, nervis lateralibus utrorue latere $12-20$ subtus prominentibus, sub angulo $45-60^{\circ}$ abeuntibus $\mathrm{r}$. infimis 2 magis arduis, non ramosis, ante marginem interdum olsoletc coujunctis, margine plana, subcoriacea r. chartaceo-coriacea, supra in sicco viridia v. olivacea, sapore camphorae et aetheris (ex JAcQuem.). Inflorescentiae terminales, 0,5-1 cm. longe pedunculatae; rhachis angulata squamuloso-tomentosula; bracteae flor. masc. parvae semilunares v. hreviter triangulares, saepius glandulis stipitatis comitatae, flor. fem. calliformes v. valde abbreriatae. Flores albi (ex Buch, Prc.), masculi: Sepala 5 in aestivatione valvata, ovata obtusa v. obtusiuscula, $1,5 \mathrm{~mm}$. longa, $0,8 \mathrm{~mm}$. lata, chartacea, dorso flavo- v. pallide flavo-tomentosula. Petala oblonga, sepala paullo superantia, 1,8-2 $\mathrm{mm}$. longa, ca. $0,5 \mathrm{~mm}$. lata, margine infero pilis longiusculis barbata, apice parce pubescentia, caeterum glabra, membranacea. Disci glandulae liberae crassiusculae subdidymae. Filamenta $1,5-2 \mathrm{~mm}$. longa, basi villosula; antherae in alabastro inflexae, breviter rectangulari-ovales, intus dehiscentes. Flores feminei: Sepala $1-1,3 \mathrm{~mm}$. longa obtusiuscula, posterius non accrescentia, dorso tomentosa. Discus annuliformis 5 -crenatus v. 5 -partitus breris a calyce subliber. Petala (v. staminodia?) parva, sed bene conspicua, apicc glanduloso-incrassata. Orarium sphaeroidem flavido-tomentosum. Styli 1,3-1,8 mm. longi, dorso infero plus minus tomentosi, lobis linearibus apice involutis. Capsulae pilis stellaribus tomentosae; valvae columnam linearem apice incrassato breviter tri- v. sub-sex-furcatam relinquentes. Semina $1,5 \mathrm{~mm}$. lata, utrinque convexa, brunea, caruncula biloba.

Hab. in Haiti prope Gonaïres m. Dec., Mart. flor:: Jacquemont, Picarda n. 1560, Prax, prope Haté Roché: Buch n. 180, prope André: Buch n. 200.

Olss. I. Ex affinitate C. Sagracani Mïll. Alg. (e Cuba).

Obs. II. C. Cascarilla Bemn.! (Bahamas ins. Providence leg. Daniell, cf. ctiam Daniell in Pharmac. Journ. IV $1862-63$ p. 226 tab. fig. 1), cujus folium e inuseo britanico examinavi, forma hujus folii cum specie antecedente bene convenit sed planc differt pube stellari subtus flava, nervis latcralibus minus numerosis, impressis et in sulco non prominulis et praesertim glandulis basalibus pluries minoribus parvis recedit.

Croton brachytrichus Urb. (n. sp.) dioicus (?), ramis superne lepidibus brevissime et radiatim multiramulosis adpressis indutis; foliis $6-3 \mathrm{~mm}$. longe petiolatis, basi glandulis plerumque 2 tenuibus breviter stipitatis obsitis, oratis usque lineari-lanceolatis, basi rotundatis $r$. obtusissimis, apice obtusis $\nabla$. acutis, saepius brerissime apiculatis, $1,5-3,5 \mathrm{~cm}$. longís, $0,6-1 \mathrm{~cm}$. latis, margine plano integris, nervis supra impressis, lateralibus $10-18$ sublorizontalibus, supra punctulatis cacterum glabris, subtus pilis stellaribus flavo-griseis deusissine obtectis; inflorescentiis (femineis tantum visis) $1-2,5 \mathrm{~cm}$. longis, pedunculatis, paucifloris; pedicellis flor. fem. $1-1,5 \mathrm{~mm}$. Iongis, sepalis 
anguste v. lineari-lanceolatis; stylis fere usque arl basin in lobos 2 lineares partitis; capsulis globulosis, fere $4 \mathrm{~mm}$. longis, mediocriter longitrorsum 3-sulcatis; seminibus ovalibus, $3 \mathrm{~mm}$. longis sublacvibus nitidis.

Rami retustiores teretes glabrescentes griseo-brunei valde ramosi; ramuli hornotini angulati, pube lepidota sordide flava. Stipulae minutae glanduliformes v. nullae. Folia petiolis angulatis supra sulcatis, nervo medio supra profunde sulcato-impresso, subtus valde prominente, nervis lateralibus sub angulo $70-80^{\circ}$ abeuntibus, supra impressis, ad margincm dichotomis et saepius conjunctis, chartacea v. chartaceo-coriacea, supra in sicco olivacea v. brunescentia, subtus pilis stellaribus breviter multiradiatis adpressis dense vestita, apice ipso subcucullato-plicata. Inflorescentiae terminales, $1-2 \mathrm{~cm}$. longe pedunculatae, femineae $2-5$-florae; rhachis angulata, pube ramorum; bracteae lanceolato-lineares, 0,7-1 mm. longae. Flores feminei: Sepala 5 in aestivatione valvata, $2 \mathrm{~mm}$. longa, $0,5-0,6 \mathrm{~mm}$. lata, obtusa, extrinsecus pilis brevibus adpressis lcpidiformibus induta, intus glabra, subcoriacea, postcrius non v. vix accrescentia. Petala (v. staminodia?) bene evoluta, sepalis subaequilonga, linearia r. lineari-subulata, margine pubescentia. Disci glandulae 5 subsemiorbiculares, inferne calycis fundo adnatae. Ovarium sphaeroideum trigonum flavido-tomentosum. Styli $1,5 \mathrm{~mm}$. longi, dorso infero brevissime pubescentes, apice involuti, crassiusculi, intus sulcati. Capsulae dorso pilis stellaribus parcis obsitae, in sicco nigrescentes; valvae columnam triangulam ad margines breviter pilosam, superne sensim crassiorem relinquentes. Semina $1,5 \mathrm{~mm}$. lata, utrinque convexa, obsolete v. vix impresso-punctata, nitidissima, cinerascentia, caruncula latiuscula biloba, raphe basi saepe apiculato-producta.

Hab. in Haiti prope Port-au-Prince: Picarda n. 1299.

Obs. Affinis C. origanifolius Lam. pube ramorum et foliorum subtus manifeste radiata, foliis latioribus, supra stellato-pilosis, nervis multo minus numerosis (utrinque 5-7), inflorescentiis plurifloris bisexualibus, seminibus brevioribus, manifestius punctatis recedit.

Croton Poitaei Urb. (n. sp.) monoicus, foliis $20-5 \mathrm{~mm}$. longe petiolatis, subtus ad basin v. sub basi glandulas 2 parras v. minutas subsessiles v. sessiles, nunc obsoletas gerentibus, lanceolatis v. lincarilanceolatis, basi obtusiusculis, superne sensim angustatis, apice obtuso in apiculum brevem contractis, $3,5-1,5 \mathrm{~cm}$. longis, $1-0,5 \mathrm{~cm}$. latis, sed plerisque longitrorsum plicatis, margine integris, nervo medio supra subimpresso, lateralibus supra non conspicuis, subtus prominentibus pinnatis, supra pilis stcllaribus adpressis dense obsitis, subtus eadem pube, sed densiore flavida r. forruginea tomentosulis; inflorescentiis $2-3 \mathrm{~cm}$. longis, $3-7 \mathrm{~mm}$. longe pedunculatis, floribus inferioribus 2-6 femineis, caeteris masculis; pedicellis flor. masc. in quaque bractea $3-5$, ca. $1,5 \mathrm{~mm}$. longis, alabastris sphaeroideis, ca. $1 \mathrm{~mm}$. diametro; staminibus ca. 16 ; flor. fem. usque $1 \mathrm{~mm}$. longe pedicellatis, sepalis lanceolatis; stylis bipartitis; capsulis globulosis, $3,5 \mathrm{~mm}$. diametro, 
longitrorsum 3-sulcatis; seminibus obovatis $2 \mathrm{~mm}$. longis, impressopunctatis.

Rami teretes, vetustiores longitrorsum rimosi, ranulis erectis, hornotini squamulis r. pilis stellaribus breviter et multiradiatis adpressis fuscis v. ferrugineis tomentosi. Stipulae nou observatae. Folia petiolis subteretibus supra vix sulcatis, nervis lateralibus utroque latere $4-6$, sub angulo $45-55^{\circ}$ abeuntibus, saepius bifurcis et ante marginem conjunctis, infimis 2 supra basin e nervo medio abeuntibus magis arduis (angulo $20-30^{\circ}$ ) et longioribus, subcoriacea rigida. Inflorescentiae in apice ramorum et ramulorum terminales; rhachis angulata tomentosa; bracteae breves triangulares, inferiores flores femin. solitarios, superiores flores masc. $3-5$ gerentes. Flores masculi: Sepala 5 in aestivatione valvata, subanguste ovata, obtusa, chartacea, dorso tomentosa. Petala oblongo-spathulata, margine ad basin barbata, apice parce pilosa, caeterum glabra. Filamenta basi villosa; antherae juniores breviter rectangulares, margine intus rimosae. Flores feminei: Sepala $1 \mathrm{~mm}$. longa, oltusiuscula, posterius non accrescentia, dorso tomentosa. Staminodia cum sepalis alterna brevia lineari-lanceolata. Discus annulatus 5 -crenatus. Ovarium globulosum tomentosum. Styli fere $2 \mathrm{~mm}$. longi inferne tomentosuli, lobis anguste linearibus, apice involutis. Capsulae pilis abbreriatim stellaribus flavidis tomentosulae. Semina dorso magis, intus minus convexa, caruncula biloba.

Hab. in Haiti prope Fort-de-Paix: Poiteau.

Obs. Affinitas apud C. stenoplyyllum Griseb. (Wright n. 1669).

$\checkmark$ Croton suloglaber Urb. (n. sp.) monoicus, foliis $30-8 \mathrm{~mm}$. longe petiolatis, sub limbo ipso glandulas 2 subsessiles gerentibus, ovatis, basi rotundatis, apice acuminatis, $7-5 \mathrm{~cm}$. longis, $4,5-3 \mathrm{~cm}$. latis, e basi 3 - v. sub-5-nervibus, caeterum solemniter penninervibus, nargine toto inaequaliter serratis $v$. crenatis, utrinque subglabris, mesubranaceis; inflorescentiis $2-3 \mathrm{~cm}$. longis, fere e basi floriferis; floribus infimis 1-2 femineis, caeteris masculis; pedicellis flor. masc. ca. $1,5 \mathrm{~mm}$. longis, alabastris sphaeroideis, $1,5 \mathrm{~mm}$. diametro, stamini'us 11 ; pedicellis fructuum $1,5 \mathrm{~mm}$. longis, sepalis spatluulato-linearibus; stylis usque ad basin in ramos filiformes, superne paullo dilatatos dirisis; capsulis globulosis, modice longitrorsum sulcatis.

Rami teretes, non v. vix striati virides, pilis stellaribus parcis $\mathrm{r}$. parcissimis tuberculiformi-incrassatis flavidis obsiti. Stipulae filiformisetaceae 5-7 mm. longae, posterius deciduae. Folia petiolis supra anguste sulcatis, nervis lateralibus sub angulo $40-50^{\circ}$ abeuntibus, supra prominulis, vix v. non ramosis, juniora pilis parcis $\mathrm{v}$. parcissimis stellaribus, posterius ad puncta reductis obsita, supra in sicco olivaceo-brunescentia, subtus pallide viridia. Inflorescentiae in apice ramorum terminales, vix r. usque ad $0,5 \mathrm{~cm}$. longe pedunculatae, flor. fem. a masculis spatio $4-6 \mathrm{~mm}$. longo disjunctis; rhachis pilis stellaribus parcis obsita; bracteae filiformisubulatae, fem. $3-4 \mathrm{~mm}$., masc. ca. 1,5 mm. longae, basi utrinque stipulas $2-3$ glanduliformes gerentes, omnes uniflorae. Flores masculi $10-15$ in ruoque racemo. Sepala 5 in aestivatione valvata, orato-elliptica, apice 
rotundata et brevissime pubescentia, vix $1 \mathrm{~mm}$. longa, chartacea, dorso parce stellato-pilosa. l'etala elliptica, sepala parum supcrantia, 1,3 $\mathrm{mm}$. longa, 0,5 mm. lata, margine infero pilis longiusculis barbata, intus plus minus pubescentia, apice parce pilosula, membranacea. Disci glandulae 5 mediocres ovatae, inferme fundo calycis adnatae. Filamcinta usque $1,8 \mathrm{~mm}$. longa, basi ipsa pubescentia; antherae in alabastro inflexae, rotundato-reniformes, intus dehiscentes. Flores feminei non rite visi: Sepala plus minus inaequilonga, in fructu $3-4 \mathrm{~mm}$. longa, superne $1 \mathrm{~mm}$. lata, integra subcoriacea, extrinsecus pilis parcis stellatis obsita, intus glabra. Staminodia 5 cum sepalis alterna $0,5 \mathrm{~mm}$. longa, antheris minutis cassis anguste oratis. Disci glandulae rectangulares basi sepalorum adnatae. Styli 2,5 mm. longi serpentini glabri. Capsulae pilis stellaribus parcis obsitae.

Hab. in Martinique locis siccis saxosis prope Case-Pilote, Ste. Luce: Duss.

Obs. Arcte affinis C. Guildingii Griseb.

$\checkmark$ Icidoton (?) microphyllus Urb. (n. sp.) dioicus?, ramis minute puberulis; foliis spiraliter dispositis, sessilibus usque $0,7 \mathrm{~mm}$. longe petiolatis, ovalibus, ellipticis v. obovatis, basi et apice rotundatis v. obtusis, $0,3-1 \mathrm{~cm}$. longis, $0,2-0,4 \mathrm{~cm}$. latis, margine integris, setis parcis obsitis; floribus masculis (tantum cognitis) in ramis abbreviatis spiniformibus 1 - 3 racemosis; sepalis 3 ovalibus apice obtusis $4 \mathrm{~mm}$. longis; antheris apice brevissime barbatis.

Verisimiliter fruticosa. Rami teretes cinerascentes, superne brevissime et minute patenti-pilosi, internodiis $0,3-0,7 \mathrm{~cm}$. longis. Stipulae liberae lanceolatae $1-1,5 \mathrm{~mm}$. longae. Folia pennivenia, nervis supra non v. vix conspicuis, subtus utrinque $2-3$ prominulis, supra in sicco bruneo-nigrescentia, parce et brevissime pilosa v. subglabra, setis unicellularibus ,valde urentilus" ad marginem versus adjectis, subtus multo pallidiora, ad nervos brevissime pilosa v. glabrescentia, margine plana v. anguste recurva. Rami floriferi masculi $0,2-1 \mathrm{~cm}$. longi, inferne plerumque euphyllis nonnullis obsiti, superne ex axillis bractearum triangulari-lanceolataram et apice ipso flores gerentes; pedicelli $3 \mathrm{~mm}$. longi. Alabastra ovata, extrinsecus parce setosa et setulis brevissimis dense obsita. Sepala , alba“", in aestivatione valvata et arcte cohaercntia, expansa plus minus reflexa concava, $2 \mathrm{~mm}$. lata, coriacea, dorso obtuse 3-4-costata. Petala nulla. Stamina toro subplano carnoso dense insidentia, ca. 36, libera erecta, pluriseriata, exteriora pauca multo breviora, cactera omnia subaequilonga fere $3 \mathrm{~mm}$. longa; antherae extrorsae, ovatae v. breviter rectangulares, apice emarginato brevissime barbatae, loculis connectivo paullo discretis, parallelis oblongo-linearibus longitrorsum rimosis. Ovarii rudimentum nullum.

Hab. in Haiti prope Corail ad margines viarum prope castellum, m. Dec. flor.: Picarda n. 1361.

Obs. Flores feminei nondum cogniti demonstrabunt, an planta re vera ad Acidoton pertineat, an genus novum constituat. Spccies altera jamaicensis, A. urens Sw., foliis distichis $3-6 \mathrm{~mm}$. longe petiolatis, $6-12$ cr. longis prominenti-reticulato-venosis, sepalis $3-5$ acuminatis omnino diversa est. 
Tetrorehidium rubrivenium Poepp. et Endl. Nor. Gen. III (1845) p. 23 tab. 227!; Baill. Etud. Euph.439; Miill. Arg. in DC. Prodr. XV 2 p. 1133 et in Mart. Flor. Bras. XI. II p. 512 tab. 72 fig. II!; Pax in Engl.-Prantl Nat. Pflansenfam. IIT, 5 p. $91 \mathrm{Fig.} 57 \mathrm{C}-\mathrm{G}$.

Arbor trunco gracili, $12 \mathrm{~m}$. alta (ex Swrtu). Rami hornotini glabri. Folia novella pilis parcis flavescentilus obsita, mox glabrata, obovato-oblongal, inferne sensim angustata, apice obtuse acuminata, ca. $20 \mathrm{~cm}$. longa, $7--8 \mathrm{~cm}$. lata, margine remote dentata, membranacea, venis primariis utrinque ca. 7, secundariis tenuissimis parun $\mathrm{v}$. vix conspicuis. Inflorescentiae masculae interrupte spicatae $r$. subpanniculatae. Sepala membranacea triangularia pubescentia. Ovarii rudimentum lineare antheras aequans. Flores feminei non obvii.

Hab. in St. Vincent in sylvis montanis humidis supra Upper Richmond valley ad centrum insulae versus rarum, alt. $800 \mathrm{~m}$., m. Aug. flor.: H. H. et G. W. Smith s. n., - praeterea in America continentali tropica.

Obs. Genus ex Antillis nondum cógnitum erat, in Flora of St. Vincent and adjacent islands (Kew Bull. 1893 No. 81) omissum.

$\checkmark$ Sebastiania hexaptera Urb. (n. sp.) dioica, ramis glabris inermibus; foliis oppositis v. suboppositis, $4-2 \mathrm{~mm}$. longe petiolatis, ovatoellipticis usque elliptico-oblongis, basi obtusis v. acutis, apice acuminatis, $5-10 \mathrm{~cm}$. longis, $1,5-4,5 \mathrm{~cm}$. latis, margine minute v. obsolete crenulatis, crenulis $1-2$ infimis glanduliformibus; spicis masculis gracilibus densifloris, bracteis 1 -floris, margine 2 -glandulosis, sepalis 3 in alabastro apertis distinctis, staminibus 3 liberis; spicis femineis typice 3 -floris, sed flore infimo tantum evoluto, stylis 3 recurvis integris; capsulis $5 \mathrm{~mm}$. longis, dorso alis 6 inferne parum, superne usque $1,5 \mathrm{~mm}$. late prominentibus costatis.

Excaecaria spec. Duss! Flor. Aut. frane. (1897) p. 40.

Frutex 1,3-4 m. altus pulcherrimus rectus, femineus minor quam mas (ex Duss). Rami teretes, tenuiter striati, non raro dichotomi, internodiis $2-10 \mathrm{~cm}$. longis, juniores superne angulati. Stipulae breviter triangulares $\mathrm{v}$. suborbiculares obtusae $0,5-1 \mathrm{~mm}$. longac, glandulosoincrassatae, ramo arcte adpressae. Folia petiolis eglantlulosis supra sulcatis, pennivcnia, nervo medio supra prominente, lateralibus $7-11$ sul angulo $70-80^{\circ}$ abeuntilus, utrinque praesertim subtus prominulis et anastomosantibus, margine plana, chartacea v. subcoriacea, utrinque nitidula, subtus pallidiora. Spicae masculae tcrminales et axillares, simplices $\mathrm{r}$. raro basi ramum unicum gerentes, a basi multiflorae, $3-10 \mathrm{~cm}$. longae, rhachi recta glabra; bracteae triangulares breviter acuminatae, ca. $1 \mathrm{~mm}$. longae et latae, margine utroque ad basin glandula ovali $v$. suborbiculari 0,3-0,4 mm. longa ornatae, inferne incrassatae, spiraliter dispositae; flores sessiles. Sepala libera, ovata, margine obsolete ciliata, apice incurva, ca. $1 \mathrm{~mm}$. longa, posticum paullo brevins. Stamina cum sepalis alterna; filancnta divaricata, basi ima sibi accumbentia, $0,7 \mathrm{~mm}$. longa; antherae 
basifixae, reniformes, loculis superne contiguis, infernc paullo divergentibus, breviter ovalibus, rima ampla lateraliter fere ab apice usque infra medium dehiscentibus, non conflucntibus. Ovarii rudimentum nullum. Spicae femineae terminales et axillares (anne semper terminales ramuloque axillari saepe supcratae?) valde abbreviatae ca. $5 \mathrm{~mm}$. longae, initio ca. 3 -florae, sed flore infimo tantum evoluto, caeteris in alabastris minutis abortivis, rhachiqne supra florem evolutum delapsa 1 -florae; bracteac ovatae acutac ca. 1,3 $\mathrm{mm}$. longae, glandulis crassiuscule ct brevissime stipitatis, antice ambitu anguste oblongis concaviusculis et squamellis breviter linearibus bruneis 1 -parcis obsitis $0,8 \mathrm{~mm}$. latis, extrinsecus juxta glandulam stipulis (v. si vis, prophyllis) lanceolato-linearibus munitae; flores sessiles. Sepala basi vix connata, orbiculari-ovata, brevissime acuminata vix $1 \mathrm{~mm}$. longa, in commissura lobnlo triangulari v. lanceolato aucta, crassiuscula, margine obsolete ciliata, apice incurva. Styli basi obsolete connati, dein recurri et ovario accumbentes, apice iterum hamato-incurvi, longitudine ovarium superantes, a latere compressi et longitrorsum sulcati. Ovarium ipsum globulosum, sed cortis 6 crassis superne alato-prominentibus notatum. Capsula verisimiliter globosa, alis 6 apice triangulari-productis superata, laevis 3 -locularis; cocci usque ad basin 2 -partiti, columcllam apice 3 -furcatam relinquentes. Semina subovata, transversim subteretia, basi truncata, ventre iinea longitudinali subimpressa notata, chalaza basilari, apice caruncula scutelliformi parva flavescente coronata, $3,5 \mathrm{~mm}$. longa, inferne 2,5 $\mathrm{mm}$. crassa, laevia vix nitidula brunescentia. Embryo non plane maturus cotyledonibus ovatis.

Hab. in Guadeloupe in sylvis Sofaya (à 5 kilomet. du bourg de Sta. Rose), m. Sept. flor.: Duss n. 3239; Martinique in sylvis saxosis Grande Rivière, 380 m. alt.: Duss n. 890 .

Obs. I. E sectione Sarothrostachys, sed nulli alii speciei arctius affinis.

Obs. II. Quoad rationem morphologicam ranorum et inflorescentiarum plantae vivac cxaminandae erunt.

Sebastiania Pieardae Urb. (n. sp.) monoica, ramis unilateraliter brevissime patenti-pilosis, in spinas excurrentibus; foliis alternis ca. $1 \mathrm{~mm}$. longe petiolatis, oratis usque elliptico-oblongis, basi obtusis v. rotundatis, apice obtuso leviter emarginatis, $1,7-0,8 \mathrm{~cm}$. longis, $1--0,4 \mathrm{~cm}$. latis, margine supero crenatis $v$. crenulatis v. serrulatis v. subintegris, infero utrinque glandula plerumque solitaria nunc deficiente obsessis, caeterum eglandulosis; spicis tenuibus, floribus $1-2$ infimis femineis, caeteris v. omnibus masculis; bracteis 1 -floris, basi $1-2$-glandulosis; calycis segmentis 3 in alabastro apertis distinctis; filamentis usque ad medium in columnam connatis; stylis 3 basi brevissime connatis, recurvis integris; capsulis $4-4,5 \mathrm{~mm}$. longis, dorso parcissime et minute tuberculatis.

Frutex valde ramosus. Rami virides teretes, in sicco plicatostriatuli, pube latere infrafoliari obria minuta praediti, apice sieut ramuli supremi in spinas desinentes ideoque 2-3- v. ope pseudodichotomiac 4 -8-spinosi. Stipulae triangulares vix $1 \mathrm{~mm}$. longae deciduae. Folia 
petiolis eglandulosis, pennincrvia, nerro medio supra subimpresso, lateralibus supra inconspicuis, subtus utrinque $2-3$ tenuibus arcuatis v. obsoletis, crenis antice minute nigrescenti-ajpiculatis, glandulis marginis inferioris utrinque $0-2$ parvis nigrescentibus medio concaviusculis sessilibus, margine plana r. recurra; coriacea rigida, supra viridi-olivacea nitida, subtus pallidiora. Spicae terminales rel axillares, pleraeque autem ad basin dichotomiac spinarum juxta basin folii (delapsi) obriae, $5-10 \mathrm{~mm}$. longae, $8-12$ florae, nunc ad florem unicum femineum reductae; rhachis glabra subtortuosa; bracteac minutae triangulares v. truncatae vix $0,4 \mathrm{~mm}$. longae, superiores utrinque, infimae latere altcro tantum glandula crassa semilunari $0,6 \longrightarrow 0,8 \mathrm{~mm}$. lata ca. $0,5 \mathrm{~mm}$. longa instructae. Flores arcte sessiles; masculi: Sepala 3 in aestivatione valvata, membranacea, antica oratolanceolata, fere $1 \mathrm{~mm}$. longa, posticum brevius subtriangulare, omnia margine ciliata. Stamina 3 cum sepalis alterna; filamenta $0,8 \mathrm{~mm}$. longa erecta; antherae basifixae reniformes, loculis ovatis apice contignis, inferne divergentibus, ab apice oblique usque supra medium lateraliter, sed perpaullo magis intus, rima dehiscentibus, apice subconfluentibus. Orarii rudimentum nullum. Flores feminei: Sepala 3 basi vix r. brevissime coalita, 0,5-1 mm. longa, basi v. ad commissuram hine illinc lobulum minutum gerentia. Styli basi ca. 0,2-0,3 $\mathrm{mm}$. longe connati, crassiuscule lineares, crassiores quam latiores, inferne horizontales, dein recurvi et ovario subaccumbentes eique longitudine aequales, $0,8 \mathrm{~mm}$. longi. Ov a ri u m globulosum v. spliaeroideum, obtuse trigonum glabrum 3 -loculare; ovula in quoque loculo solitaria, sub apice affixa, orata. Capsula globulosa olivacea 3-cocea; cocci columellam subtrialatam relinquentes usque ad basin 2 -partiti. Semina ovata, $3 \mathrm{~mm}$. longa, $2 \mathrm{~mm}$. lata, basi truncata r. concaviuscula medio obsolete apiculata, ventre linea subimpressa notata, chalaza basilari, apice caruncula seutelliformi parva flavida coronata, olivaceo-brunescentia, laevia nitida. Embryo?

Hab. in Haiti prope Port-au-Prince in Plateau du Morne de l'Hôpital ca. $1050 \mathrm{~m}$. alt., m. Jul. fl., Nov. fl. et fruct.: Picarda n. 842.

Olus. Nulli alii arctius affinis et aegre sectioni ulli subjungenda nisi Adenoygne (sensu Benthamiano).

Sapimm hippomane G. F. W. Mey. petiolis $2,5-0,7, \mathrm{~cm}$. longis, sub apice glandulas binas $1-2 \mathrm{~mm}$. longas lineari-cylindraceas gerentibus, foliis obovatis, anguste ovatis v. plerumque ovalibus v. ellipticis, basi rotundata v. obtusissima brevissime in petiolum productis, apice (plerumque abrupte) brevissime acuminatis, acumine cucullato-inflexo, $7-15 \mathrm{~cm}$. longis, $3,5-7 \mathrm{~cm}$. latis, margine subintegris v. leviter crenulatis, saepius glandulas pro latere $1-3$ manifestas vario loco e margine prodeuntes praebentibus, nervis sub angulo $70-80^{\circ}$ e medio abeuntibus ad marginem rersus subarcuatis; inflorescentiis terminalibus plerumque masculis, interdum $1-2$ lateralibus adjectis, in parte tertia v. dimidia inferiore femineis, $7-12 \mathrm{~cm}$. v. ultra longis, folia superantibus, glandulis bractearum valde abbreviatarum ovalibus v. suborbicularibus planis; sepalis masculis 2 pallide pupurascentibus, vix usque ad medium 
coalitis, femineis 3 liberis (initio rerisimiliter basi coalitis) triangularibus, orarii basin circumdantibus; ovario globuloso apice rotundato; stylis 3 basi coalitis, horizontaliter divaricatis et apice revolutis, explanatis fere $3 \mathrm{~mm}$. longis, 0,8 mm. latis; capsulis sessilibus, spluaeroideis, 7-8 mm. longis, dorso (normaliter) laevibus, coccis 3 (raro 4) columellam linearem triangulam apice trifidam relinquentibus; seminibus oborato-orbicularibus, $5-5,5 \mathrm{~mm}$. longis, convexis, sub membrana extima cinnabarina decidua tuberculatis; cotyledonibus breviter ovatis, basi subcordatis, radicula parum longioribus.

Sapinm hippomane G. F. W. Mey. Prim. Esseq. (1818) p. 275 (excl. syn. Phum.); Miq. in Limnaea XYI (1848) p. 475 et Stirp. sur. p. 97 tab. 29!

Hippomane glandulosa Limn. Spec. I ed. II (1753) p. 1191 (p. p., qnoad syn. Pluki.).

Hippomane biglandnlosa Limn. Spec. II ed. II (1763) p. 1131 (p. p., quoad syn. Plnk.).

Sapium ancuparium Willd. Spec. IV, I (1805) p. 572 (1) p.); Mayc. Burb. p. 369.

Stillingia hippomane Buill. Etud. Fuphorl. (1858) \%. 513.

Sapinm ancuparim p. hippomane Griseb. Flor. (1859) 1. 49 (p. p.).

Sapium biglandulosum a. Meyeriamm Müll. Arg.! in Linnuea XXXII (1S63) p. 116.

Sapinm suberosm Mïll. Ary.! in Limnaea XXXIV (1865) 17. 217; Hemsl.! in Hook. Icon. XTY'II tab. 2681!

Excaecaria snberosa Mäll. Arg.! in DC! Prodr. $\mathrm{XT}^{\top}, 2$ (1866) p. 1202.

Excaecaria biglandulosa a. hippomane ILüll. Arg.! in DC. Prodr. XV, 2 (1866) p. 1204 (p.p.?).

Sapinm glandulosum Morong in Ann. New Tork Acad. Sc. VII (1893) p. 227 (p.p., excl. patriu).

? Lanrifolia venerata, folio leviter serrato oblongo obtuso sloane Cat. (1696) p. 136 et Hist. I p. 39.

Tithymalus arbor americana, mali medicae foliis amplioribus Pluk. Alm. (1691) p. 369 tab. 229 fig. 8!

Poison-tree Hngh. Barb. (1750) p. 144 (p.p.).

Milk tree Barbad. ex Egg.

Hab. in Barbados: Rob. Schomburgk n. 8 (non 709, qui numerus mutuationi inservivit), in Forster's Hall Wood in silvis (frutex $1,3 \mathrm{~m}$. v. arbor $6-20 \mathrm{~m}$. alta), m. Jan. fl. et fr.: Eggers n. 7237, 7238; praeterea in Surinam: Hostmann n. 314. 
Obs. I. Specimina laudata bene congruunt, excepto Schomburgkiano fructifero, quod certe pustulis depressis suberosis in foliis fructibusque obviis subdeformatum est, ut cl. Heusuer jam opinabatur.

Obs. II. Cl. E. H. L. Kradse in insula Barbarlos prope St. Andrews in Turners hall-wood specimen Sapii sterile foliis usque pedalibus usque $9 \mathrm{~cm}$. latis elliptico-oblongis, apice in acumen angustum planum eglandulosum contractis, margine toto dentibus sublinearibus apice nigrescentibus argute serrulatis, dentibus perparcis glanduloso-incrassatis hinc inde interjectis, membranaceis, nerris lateralibus sub angulo ca. $60^{\circ}$ abeuntibus, magis arcuatis m. Jan. 1890 legit, quod rerisimiliter ad nostram speciem pertinet. Arbor gracilis mediocris, poison tree nominata, succum lacteum copiosum profert, si cortex leviter vulneratur.

Obs. III. Arcte accedit S. nucuparium Hemsl. in Hook. Ic. XXVII tab. 2650 (vix Jacq.).

Sapium laurocerasus Desf. petiolis $4-1 \mathrm{~cm}$. longis, apice sub lamina glandulas binas parum prominentes $v$. usque $1 \mathrm{~mm}$. longas gerentibus, foliis breviter ovalibus usque elliptico-oblongis, basi obtusissima v. rotundata vix in petiolum productis, raro acutis, apice in acumen brerissimum r. obsoletum subplanum contractis, $6-22$ cm. longis, $2,5-8 \mathrm{~cm}$. latis, margine obsolete $\nabla$. minute aequaliter serrulatis $\nabla$. crenulatis, crenis antice in apiculos nigrescentes excurrentibus, nervis numerosis rectis subhorizontalibus (angulo $80-90^{\circ}$ ); inflorescentiis unisexualibus (dioecis?), axillaribus v. in ramulis brevibus 1 -paucifoliatis terminalibus, foliis 2 -pluries brevioribus, masculis $2,5-6 \mathrm{~cm}$. longis, glandulis bractearum suborbicularibus $\nabla$. ovali-orbicularibus, saepius concaviusculis, sepalis 2 usque supra medium coalitis; spicis femineis $1,5-3 \mathrm{~cm}$. longis, $1-5$-floris, glandulis bractearum rotundis cupuliformi-concaris, sepalis ovato-triangularibus, initio supra basin coalitis, denum liberis, ovario ovato v. anguste ovato, plus minus acuminato, stylis 3 recurvatis, apice revolutis ca. $2 \mathrm{~mm}$. longis; $0,3 \mathrm{~mm}$. latis; capsulis solemniter usque $4 \mathrm{~mm}$. longe stipitatis, sphaeroideis, $8-10 \mathrm{~mm}$. longis, dorso laevibus, coccis 3 columellam linearem triangulam relinquentibus; seminibus ovalibus v. anguste ovalibus, transversim subteretibus, dorso subcarinatis, sub membrana extima plus minus tuberculatis, $5-7 \mathrm{~mm}$. longis; cotyledonibus ovatis v. rotundato-oratis, basi cordatis, radicula duplo v. fere duplo longioribus.

Sapium laurocerasus Desf. Cat. plant. hort. Par. III ed. (1829) 1). 411 .

Stillingia lanrocerasus Baill. Etud. (1858) p. 513 tab. 6 fig. 1 - 9!

Sapinu lanrocerasns a. gemnimun Niül. Arg.! in Linnaen IXXII (1863) p. 116.

Excoecuia lanirocerasns a. genuina Mïll. Arg.! in DC!. Prodr. IV, II (1S66) p. 1202; Baill. Hist. T p. 134 fig. 210, 211!

Sapium ancupacinu Bello Ap. II (1883) p. 111, - nou eJucq. 
'Tabeiba $\%$ Hincha-huevos Port. ex Sint., Manzanillo I'ort. ex Lyg. et Sint., Lechesillo ex Bello.

Frutex r. arbor usigue $15 \mathrm{~m}$. alta. Flores virides. Capsulae virides brunescentes (ex SiNT.).

Hab. in Portorico in sylvis primaeris prope Bayamon, in Sierra de Luquillo in regione media montis Jimenes et ad El Fronton $900 \mathrm{~m}$. alt., Sierra de Naguabo in monte Piedra Pellada, Sierra de Juncos in monte Guvuy, Sierra de Yabucoa in Cerro Gordo, prope Cayey in fruticetis ad rivulum Campita, prope Adjuntas in monte Guilarte, prope Hatillo in montibus saxosis ad Guayanes, fl. Febr., Mart., Majo, Jun., Aug., Sept., fr. April., Jun., Oct.: Bertero, Eggers hb. pr. n. 1213, ed. Toepff. n. 977, Schwanecke, Sintenis n. 1659, 2574, 2675, 2786, 4554, 5392, 6260, Stahl n. 399, 964. - Olim cult. in horto Berol. (fortasse ex horto Paris. e seminibus Ledruanis).

Obs. I. Inter specimina numerosa mascula florifera spicam unicam (Eggers 11. 977) inveni, quae ad basin florem femineum solitarium praebuit.

Obs. II. Exemplar a cl. Sintenis in statu sterili sub nomine vernaculo "Quemadora" et sub n. 6597 prope Utuado in sylvis ad Cayuco lectum nervis secundariis sub angulo $80-70^{\circ}$ e medio abeuntibus, ad marginem versus arcuatis, lamina breviter acuminata, margine manifestius crenulata gaudet. An status jurenilis (arbuscula $3 \mathrm{~m}$. alta)?

Obs. III. Sapium jamaicerse Sw. Adnot. bot. (1829) p. 62 (herb. Willd. n. 17944) e Jamaica $=$ Excaecaria laurocerasus $\gamma$. laurifolia Müll. Arg. (p. p.) omnino diversum est foliorum nervis lateralibus sub angulo ca. $70^{\circ}$ abeuntibus, spica terminali mascula decidua, latcralibus priori approximatis inferne femineis, glandulis ad bracteas omnibus planis v. subconvexis, sepalis femineis in $2 / 3$ alt. coalitis, lobis 3 late triangularibus, ovario globuloso apice rotundato arcte sessili, seminibus (ex Sw.) orbiculatis; caetera mihi ignota. - Verisimiliter hue spectant specimina e Sto. Domingo: Nayerhoff; Eggers n. 1736 (haec in fructu tantum) = Excaecaria laurocerasus $\beta$. elliptica Min̈ll. Arg. p. P., sed vix cubensia, quanquam habitu bene conveniunt: Wright 11. 578, Eggers n. 4909 , Combs n. $160=$ Stillingia laurifolia A. Rich. in Sagra Cub. tab. $69 !=$ Sapium laurifolium Griseb. p. p. = Excaccaria laurocerasus $\beta$. elliptica Müll. Arg. p. p. et $\gamma$. laurifolia Müll. Arg. p. p. ob calycem femineum urceolatum, apice 3 -dentatum, posterius unilatcraliter ruptum. Quam ad quaestionem solvendam materies melior e Jamaica et Hispaniola necessaria est. Omnia haec specimina ab aliis antillanis speciebus bracteis praesertim femineis bene evolutis ovarium usque supra medium v. usque ad apicem obtegentibus, in statu juniore solemniter imbricatis floresyue omnino includentibus discrepant.

Sapium caribaeum Urb. petiolis $3-1 \mathrm{~cm}$. longis, apice sub lamina glandulas binas $0,3-1 \mathrm{~mm}$. longas convexas v. breviter cylindraceas gerentibus, foliis ovalibus usque elliptico-oblongis, basi obtusa vix $\mathrm{v}$. brevissime in petiolum productis, apice breviter $\mathrm{v}$. brevissime acuminatis, acumine obtuso plano subplanove, $7-14 \mathrm{~cm}$. longis, $3-6 \mathrm{~cm}$. latis, margine integris v. obsoletissime ef minute crenulatis, fere semper 
glandulas pro latere $1-2$ manifestas vario loco e margine prodeuntes praebentibus, nervis sub angulo $70-S 0^{\circ}$ e medio abeuntibus, ante marginem arcuatis; inflorescentiis terminalibus bisexualibus, in $1 / 3-1 / 4$ inferiore femineis, caeterum masculis, $10-25 \mathrm{~cm}$. longis, folia usque 3 -plo superantibus, glandulis bractearum valde abbreviatarum breviter ovalibus usque suborbicularibus planis v. subplanis; sepalis purpurascentibus, masculis 2 usque supra medium coalitis, femineis membranaceis in urceolum apice 2-dentatum connatis; ovario globuloso, apice rotundato, stylis 2, raro 3 patentibus, apice revolutis, ca. $1 \mathrm{~mm}$. longis, 0,2 $\mathrm{mm}$. latis; capsulis $0,5-1 \mathrm{~mm}$. longe stipitatis, didymis, 5-6 mm. longis, dorso laevibus, coccis plerumque 2 columellam obovato-oblongam planam, cujus crura nıarginalia membranam deciduam circumdant, relinquentibus; seminibus orbicularibus convexis sub membrana extima cinnabarina decidua obsolete tuberculatis, $3,5 \mathrm{~mm}$. diametro; cotyledonibus orbiculatis basi subcordatis, radicula duplo longioribus.

Hippomane glandmlosa Lim. Spec. I ed. II (1753) p. 1191 (p.p., qnoad synon. Plmm.).

Hippomane biglandulosa Lim. Spec. II ed. II (1763) p. 1431 (p.p.).

Sapinm ancuparimm Maré in Bull. Soc. bot. de France IXX (1883) p. 101; Rolfe! in Kew Bull. Ni. 81 p. 276; Dnss! Flor. Ant. fram: p. 37, - non Jacq.

Sapinm glandmlosmm Morong in Ann. New Yorli Acad. Se. VII (1893) p. 227 (p.p., excl. patria).

Sopimm spec. Hemsl.! in Hool. Icon. XXVII (1901) ad tab. 2680 p. 2.

Manranilla lanni foliis oblongis Plum. Gen. (1703) p. 50 et ed. Bmrm. p. 164 tab. 171 fig. 2! (folics more Plmmeriano manifestins renatis, sed caeternm bona, sine dubio e Martiniqne).

Bois de soie Gmud. ex Duss, La-gli Domm. ex Ram., Boisla-glu r. glutier Mart. ex Dnss, La gluie St. Lnc. ex Ram.

Arbor mediocris v. elata, glabra. Rami teretes, in sicco plus minus plicato-striati, juniores angulati, dense foliosi. Stipulae ovatae v. ovatotriangulares, 1,5-2 mm. longae. Folia petiolis subteretibus, supra angurtissime sulcatis, nerro medio supra non v. vix impresso, lateralibus 9 - 13 crassioribus cum tenuioribus intermixtis, supra prominulis, praesertim subtus temuiter anastomosantibus, adulta coriacea, margine plana. Spicae inferne 2-4 mm. crassae; bracteae breviter v. brevissime triangulares $\mathrm{r}$. superiores semilunares, $0,3-0,5 \mathrm{~mm}$. longae, glandulis $1,2-2 \mathrm{~mm}$. longis, margine ipso saepius paullo incurvis, infimis (sub floribus femineis) deciduis. Flores masculi supra quanque bracteam $9-11$, basi bracteolis minutis fimbriato-laceris circumdati. Calyx $1-1,3 \mathrm{~mm}$. longus. Filamenta $1,3-1,5 \mathrm{~mm}$. longa, inter sese sublibera; antherae reniformes, vix $0,5 \mathrm{~mm}$. longae, lateraliter suboblique dehiscentes. Flores feminei supra quamque bracteam solitarii. Calyx 1,7-1,8 mm. longus, supra ovarium constrictum 
et in tubum perbrevem hidentatum productus, initio purpurascens, postremo stramineus, satis longe persistens. Styli basi breviter connati, expansi 1,5 mm. longi, 0,2-0,3 $\mathrm{mm}$. crassi. Capsulac purpurascentes. Semina non plane matura.

Hab. in Guadeloupe in regione inferiore et media usque ad $1000 \mathrm{~m}$. alt., e. gr. in sylvis Bains jaunes, Trois Rivières, m. Sept. Nov. flor:: Duss 11. 2932; Dominica in sylvis ad Laiou (viscid milky juice used as bird-lime), m. Jun. flor.: Ramage; Martinique frequens: Duss, Hahn n. 882, 1844, Hohenack. Arzn. u. Handelspfl. n. 752; Sta. Lucia ad Belair, m. Majo flor.: Ramage; St. Vincent: Smith n. 1265.

Obs. I. Planta a cl. Ducirassaing in Guadeloupe lecta (Excaccaria biglandulosa rar. aucuparia Müll. Arg.) herbarii berolinensis sterilis fortasse statum jurenilem sistit et foliis oblongis v. oblongo-lanceolatis, anguste et longius acuminatis, $20-25 \mathrm{~cm}$. longis, $5-6 \mathrm{~cm}$. latis, membranaceis gaudet (cf. Hemsl. in Hook. Ic. XXVII tab. 2650).

Obs. II. Species nostra sine dubio S. Jenmani Hemsl. in Hook. Icon. plant. XXVII (1900) tab. 2649, quod ovario uniloculari gaudet, arcte affinis est.

Obs. III. S. aucuparium Jacq. (prope Cartagenam lectum) longe distat foliis oblongo-lanceolatis, superne sensim angustatis, apice crasso subcartilagineo inflexo, horizontaliter venosis, margine manifeste serrulatis, pluriglandulosis, stylis 3.

Sapium leucogynum C. Wright ap. Griseb. in Nachr. Ges. Götting. 1865 p. 176 et Cat. p. 19.

Sapium lencospermum Griseb.! l. c. p. 177 et Cat. p. 19.

Excaecaria lencogyna Mïll. Arg. in DC. Prodr. XV. 2 (1866) p. 1208; Sam. Cub. n. 2055 p. 132; Na:a Periant. p. 50.

Excaecaria lcucosperma Müll. Arg. l. c. p. 1209; Sauv. u. 2054 l.c.; Mãa l.c.

Hab. in Cuba occidentali: Wright n. 2000, $2000 \mathrm{~A}$.

Obs. S. leucospermum Griseb. a typo, ut cl. MüLler jam opinatus est, specifice non diversum est; nam membrana seminum immaturorum in aliis quorque Sapii speciebus albida v. pallide flava est et nonnisi postremo in statu maturo erubescit.

Sapium adenodon Griseb. Pl. Wright. I (1860) p. 160 ct Cat. p. 19 .

Excaecaria eglandulosa Mïll. Arg. in DC. Prodr. IV. 2 (1S66) p.1209 (excl. syn. Richard et variet.); Sant. ('ub. 11.2056 p. 132 (excl. syn. Rich.); Mana Periant. p. 50 (ut antea).

Bonania adenodon Benth. in Benth. et Hook. Gen. III (18S0) p. 335; Ind. Kew. I p. 321.

Hab. in Cuba orient. in praeruptis prope Monteverde, m. Ang. flor:: Wright n. 1428, in sylvestribus prope El Palanquito $600 \mathrm{~m}$. alt.: Eggers n. 4843 (sterile). 
Obs. I. Quanquam seminum structura nondum cognita est, non dubito quin liaec species ad genus Sapii pertineat. Bractcae biglandulosae, flores plerumque 3 suffulcientes, calyx breviter bilobus, raro inaequaliter trilobus, filamenta sublibera, antherarum loculis confluentibus.

Obs. II. Planta Richardiana: Stillingia eglandulosa A. Riclı.! in Sagra's Cuba XI (1850) p. 202 e deseriptione et specimine Sagraeano originario ad Excaccariam Sagraei Jüll. Arg. (excl. syn. Exe. myrcifolia Griseb.) spectat.

Bonania microphylla Urb. (n. sp.) monoica, ramis glabris; foliis ca. $0,5 \mathrm{~mm}$. longe petiolatis, subsessilibus, ovatis $v$. suborbicularibus, basi subtruncatis $\nabla$. obsolete cordatis, apice rotundatis saepius subemarginatis, $0,4-0,9 \mathrm{~cm}$. longis, $0,3-0,7 \mathrm{~cm}$. latis, plicato-incurvis, margine minute et parce crenulatis v. subintegris, subtus juxta marginem basalem saepius glandula parra nigra impressa notatis, crasse coriaceis rigidissimis; spicis masculis brevibus, triadibus florum $10-15$, bracteis 3 -floris, margine non glandulosis; calyce urceolato, margine obsolete lobato; filamentis 3 connatis; capsulis solitariis $4 \mathrm{~mm}$. longis, coccis usque ad basin 2 -partitis.

Frutex $1 \mathrm{~m}$. altus. Rami vetustiores bruneo-nigrescentes, cortice fisso r. desiliente, teretes, ramulis et tuberculis (i. e. basi petiolorum delapsorum et gemmis non erolutis) distiche obsessi, internodiis $0,3-0,8 \mathrm{~cm}$. longis, hornotini plicato-angulati. Stipulae triangulares r. suborbiculares, acutae $\mathrm{v}$. obtusae, ca. $1 \mathrm{~mm}$. longae, ramis arete adpressae, incrassatae, initio purpureo-brunescentes, margine hine illine denticellatae, persistentes. Folia disticha alterna, petiolis solemniter articulatis praedita, pennivenia, nervo medio supra non r. vix conspicuo, subtus crassiusculo sub folii apice in apiculum perbrevem brunescentem excurrente, lateralibus numerosis $(10-12)$ densis crassiusculis utrinque prominulis parallelis, margine ipso plana, nitida, flavo-riridia. Spicae masculae ad apicem ramulorum axillares simplices (juniores ca. $0,6 \mathrm{~cm}$. longae), rhachi crassiuscula glabra; bracteae spiraliter dispositae, pentagono-triangulares, breviter acuminatae, margine supero erosulo-denticellatae, ferrugineae, inferne coriaceae, margine membranaceae. Calycis lobi 3 perbreves antice subtruncati. Antherae oratae, loculis parallelis lateraliter sulcatis. Ovarii rudimentum nullum. Capsulae ad axillas r. ad apicem ramorum solitariae subsessiles sphaeroideae, basi subcmarginatae, dorso laeres, 3 -loculares; cocci usque ad basin 2 -partiti, columellam inferne linearem, superne valde ampliatam et trialatam relinquentes. Semina ovato-globulosa. basi subtruncata, ventre linea longitudinali notata, clialaza basilari, caruncula nulla, $2,5 \mathrm{~mm}$. longa, $2 \mathrm{~mm}$. crassa, testa subcrustacea; endospermium crassum carnosum. Embryonis cotyledones orbiculares, basi cordatae, planac, radiculam longitudine aequantes.

Hab. in Cuba prope La Caimanera, m. Majo fl. et fr.: Eggers n. 5455 .

Obs. I. Arete affinis B. cubana A. Rich. in Sagra Cub. XI p. 201 (B. culiensis 1. c. in icone tab. 68) differt foliis $2 \mathrm{~mm}$. longe petiolatis, ovalibus usque elliptico-oblongis, $1-2,5 \mathrm{~cm}$. longis, manifestius cremulatis, planis v. subplanis, capsulis majoribus. Hace quoque speries (i. e. typus generis) capsula 3-loculari, coceis usque ad basin 2-partitis gaudet. 
Obs. II. Sapium crythrospermum (Griseb.) Mïll. Arg. non est Bonanine spec. nt Benthay in Benth. et Hook. Gen. III 1).335 voluit, sed ex structura scminum sine ulla dubitatione verum Srpium glandulis binis basi laminae, non petiolo sub lamina insertis praebet.

\section{Gymmanthes allicans Urb.}

Excoecaria albicans Griseb.! in Nachr. Ges. Wiss. Gött. 1865 1). 179 et Cat. 1). 20; Mara Periant. p. 50 (76) (cum in. albicans et ierulosa).

Sebastiania Grisebachiana Mäll. Arg. in DC. Prodr. XV. 2 (1S66) p. 1183 (cum iar. albicans et virens Miill. Ary.).

Sebastiania albicans C. Wr. in Sauv. Cub. (1870) n. 2019 p. 132. Excoecaria vemulosa C. Wr. Msc. ap. Miill. Arg. l. c.

Inflorescentiae ad axilas plerumque plures, masculac v. ad basin flores $1-3$ femineos gerentes. Flores masculi: Bracteae basales, eglandulosae, 1-florae. Pedicelli brevissimi. Sepala omnino nulla. Stamina 5 - 12; antherae extrorsae, obsolete apiculatae. Flores feminei: Pedicelli sub anthesi $2-3 \mathrm{~mm}$., fructiferi usque $2 \mathrm{~cm}$. longi. Sepala 3. Styli satis alte in columnam coaliti. Orula ex apice loculi pendula. Capsula non stipitata, calyci incumbens. Semina subpentagona, chalaza in luasi ipsa emarginata sita. Embryo non plane maturus verticalis; radicula supera cotyledonibus ellipticis ultra duplo brevior.

Hab. in Cuba: Wright n. 2003, 2004.

Gymmanthes recurva Urb. (n. sp.) certe monoica, ramis glabris; foliis $1,5-2 \mathrm{~mm}$. longe petiolatis, anguste obovatis usque elliptico-oblongis, inferne sensim angustatis, basi ipsa obtusiuscula in petiolum contractis, apice rotundatis, $2,5-3,5 \mathrm{~cm}$. Iongis, $0,8-1,5 \mathrm{~cm}$. latis, margine integris, recurvis v. revolutis, subtus in facie utrinque glandulis 1 - 2 impressis (nunc deficientibus) inferne notatis, crasse coriaceis; spicis masculis $0,3-0,6 \mathrm{~cm}$. longis, $8-15$-floris, bracteis 1 -floris, margino non glandulosis; floribus masculis supra bracteam brevissime podicollatis; sepalis $1-2$ anticis tantum evolutis, liberis; filamentis $4-3$ valde abbreviatis; capsulis junioribus solitariis.

Bonania spec. Benth. in Benth. et Hook. Gen. plant. III (1S80) p. 335 .

$\mathrm{R}$ am i vetustiores cinerascentes teretes plicatuli, internodiis $0,5-1,5 \mathrm{~cm}$. longis, hornotini pallide brunei striati v. angulati. Stipulae brevissime triangulares v. subsemiorbiculares, ca. 0,3 mm. longae. Folia pennivenia, nervo medio supra vix v. parum impresso, lateralibus $4-6$ sub angulo ca. $45^{\circ}$ abeuntibus utrinque prominentibus v. supra postremo obsoletioribus, reticulato-anastomosantibus, margine tenuiore minute et parce glandulosopl tata, supra in sicco olivacea, subtus brunescentia. Spicae masculae termir...s et axillares, rhachi, crassiuscula glabra; bracteae spiraliter dispositae, lätivenle triangulares obtusissimae iutegrae coriaceae, $0,6-0,7 \mathrm{~mm}$. longae, ca. $1 \mathrm{~mm}$. latae; pedicelli $0,4-0,6 \mathrm{~mm}$. longi. Sepala suborbicu- 
laria ca. 0,5 mm. longa membranacea, margine denticellata. Antherae subsessiles, subquadrato-orbiculares vix $0,5 \mathrm{~mm}$. longae, loculis lateraliter, sed paullo magis extrorsm longitudinaliter dehiscentibus, contiguis parallelis. Ovarii rudimentum nullum. Flores feminei in axillis solitarii, an e basi spicae caeterum masculae delapsae orti?; pedicelli basi squamellis circumdati, 10-15 mm. longi, ad apicem incrassati, recurvi. Sepala 3 subsemiorbicularia $\mathrm{r}$. lunata, $0,4 \mathrm{~mm}$. Jonga, $0,8 \mathrm{~mm}$. lata, posticum paullo minus, margine denticellata, coriacea. Orarium (longe defloratum) globosum, supra calycem sessile. Styli 3, fere liberi, divaricati, ovario subaccumbentes, ca. 1,5 $\mathrm{mm}$. longi.

Hab. in Cuba: Wright 11. 3705.

Obs. Gymmanthis species, certe non Bonaniae.

\section{Krusiodendron Urb.}

(nov. gen. Rhamnacearum.)

Flores hermaphroditi. Calyx fere ad basin 5-, raro 4- v. 6partitus, tubo perbrevi subplano, lobis triangulari- v. anguste ovatis acutis, intus superne carinam elevatam obtusam crassiusculam crenulatam gerentibus. Petala 0 . Stamina numero sepalorum iisque breviora, sub disci crenaturis ad calycis simus inserta, in aestivatione suberecta, filamentis subulatis, antheris ovatis v. ovato-orbicularibus, obtusis, intus lateraliter dehiscentibus. Discus latiuscule annularis carnosus, margine libero 5-crenatus, basin ovarii cingens. Ovarium breviter conicum in stylum attenuatum, pseudobiloculare carinis 2 parietalibus intus fere usque ad parietem oppositum productis sibique accumbentibus sed inter sese liberis; ovula 2 suborbicularia v. breviter ovata, micropyle infera extera; styli 2 inferne $\nabla$. usque ad apicem connati, ramis si adsunt patentibus apice parum incrassato stignatosis. Drupa ovata v. ovoidea $r$. ovali-globosa, basi tubo calycis circumscisso parvo suffulta, carne parca, putamine tenui osseo, 1-, rarissime 2-locularis. Seminis testa endocarpio arcte adhaerens; albumen omnino nullum. Embryo nudus, subglobosus v. breviter oralis r. breviter ovatus, bruneus; cotyledones subsemiglobosae, crasse carnosae, non oleosae; radicula inter basin cotyledonum plane v. fere tota retracta iisque 4-5plo brevior. - Frutex r. arbor antillana, inermis, ramis junioribus minnte v, minutissime pilosulis. Folia in ramis inferiora saepius alterna, superiora plerumque opposita $\mathrm{v}$. subopposita, penninervia, ovata r. ovalia, obtusa v. obtuse subacuminata, apice saepius emarginata, eoriacea v. subcoriacea, integerrima, persistentia. Stipulae minutae, in axillis foliorum approximatae, sel inter sese liberae, e basi latiore subulatae. Inflorescentiae axillares hreviter pedunculatae r. subsessiles, cymose umbelliformes pauciflorae. Flores viridi-flavi. 
Obs. I. Rhammes differt calycis tubo campanulato v. unceolato, ovario 2-4-loculari, drupa 2-4-pyrena, albumine carnoso, cotyledonibus planis, Zi:yphus sepalis intus usque al basin 1-nervibus, drupa 2 -3-loculari, foliis distichis e basi $3-5$-nervibus, stipulis plerumque in spinas mutatis, Ceanothus sepalis membranaceis, petalis obviis, drupa 3 -cocca, albumine carnoso, Sentia petalis obriis, fructu 2-4-1yreno, seminibus compressis, cotyledonibus plano-convexis, Condalia calycis tubo late obconico v. hemisphaerico, ovario 2 -loculari v. carina altera tantum evoluta et intus inter ovula producta 1-loculari, albumine carnoso, cotyledonibus planis, ramis spinescentibus; Rhamidium longe distat calycis tubo hemisphaerico v. subturbinito, petalis obviis, ovario mucilaginoso, biloculari v. (in specimine Malme 1028) carina parietali altera tantum evoluta et producta 1-loculari, bacca exsucca, endocarpio membranaceo, semine compresso oleoso, stipulis intrapetiolaribus inter sese connatis, Sarcomphalus, cui cl. WEberbauer in Engl.Prantl Pfl.-Fam. ILI. 5 p. 405 plantam nostram associare vult, petalis obviis, antheris distincte extrorsum dehiscentibus, drupa 2-3-loculari, seminibus valde compressis, endospermio obvio, cotyledonibus planis tennibus, omnia, yuantum scio, genera antecedentia testa embryoni adhaerente.

Obs. II. Fructus maturi in herbariis rarissime inveniuntur; descriptio seminis nostra e speciminibus jamaicensibus (Harris 5797).

\section{Lirusiodendron fierrenu Urb.}

Rhammus fervens Tahl in West St. Croix (1793) 1. 276 (nomen tantum) et Symb. 111 (179.1) 1. 11 tab.5S!; R. et Sch. Syst. 1 1 p. 2S3; Spreng.! Syst. I p. 767.

Zi:yphus cmarginatus Su. Flor. III (1S06) p. 1954; Wikstr. St. Bathel. 1). 420.

Ceanothus ferreus I?. DC. Prode: II (1S25) 1). 30; Schlecht.! iu Limnaea $I T^{\top}$ p. SS.

Sentia ferven Brongu. in Anu. Se. nat. I sér. I (1S27) p. 363; riviseb.! Kar. p. 33.

Coudalia ferrea Griscb.! Flor: (1559) p. 100; Walp. Amu. VII 1. 58S; A. Gray in Bot. Ga: $1 \mathrm{~T}$ 1). 20S; Eyg.! St. Croix p. 110 et St. Croix and Tirg. Isl. 1). 40; Stahl! Estud. IV p. 11; Chapm. Flor. South. Stat. II ed. Suppl. p. 612 et III ed. p. 76; Trelease iu Trans. St. Lonis Acad. V p. 362; liew Bull.! u. S1 p. 24.3; Duss! Flor. Aut. fiane. 1. 92.

Rhammidimm ferrenm Sarg. Gard. and For. IV (1891) p. 16 ex Sury. Silua 11 (1S92) 1). 29 tab. 5S!; Tielcase in Gray et Riob. Syun. Flor. 1. 1 \%. 104.

Sucomphahs? fercens Webcrb. edid. Trelease I. $c$.

Black Iron wood Florid. ex Trel.; Palo de hierro Sto. Doming. cx Egg., Port. ex Stahl; Espejuelo Port. cx. Gmall.; Hdden-wood St. Thome ex Egy.; Petit bois-de-fer $r$. Bois de fer blanc Guad. cl Hart. ex louss. 
Hab. in Florida austr.: Cabanis, in Key ins. e. gr. in Upper Netacombe Key in sylris solo corallino, m. Jun. flor.: Curtiss n. 462; Baham. ins. Andros in Fresh Creek, m. Jun. fl.: Northrop n. 611; Jamaica ad Content Road $330 \mathrm{~m}$. alt., ad Westphalia $1160 \mathrm{~m}$. alt., in Blue Mts. ad 'Tweedside, Jun., Jul. fruct.: Harris n. 5030, 5723, 5797; Haiti prope Jérémie in Plaine in ripa paludis, m. Jan. fl.: Picarda n. 1328; Sto. Domingo: Mayerhoff, prope Santiago ad Cuesta de piedra in sylvis $300 \mathrm{~m}$. alt. (arbor $13 \mathrm{~m}$. alta), ad Llano Rafael in sylvis $300 \mathrm{~m}$. alt., ad Lopez $350 \mathrm{~m}$. alt., m. Majo, Jun. fl.: Eggers n. 1925, 1925 $1925^{\mathrm{c}}$; Portorico prope Bayamon in sylvis litoralibus, prope Luquillo in fruticetis ad Masi, prope Fajardo in fruticetis litoralibus et in monte IIula, prope Peñelas in montibus calcareis ad Talla boa poniente, prope Guanica in sylra inter La Rosa et Barinas arl mare versus, prope Quebradillas, prope Vega-baja in fruticetis litoralibus, m. Majo flor.: Gundlach n. 1440 , Sintenis n. $1643,1841^{\text {b }}, 3874,4824,700$ 2, Stahl n. 77 , 461 ; 586; St. Thomas: Ehrenberg, Oersted (hb. Haun.), ad Flaghill $100 \mathrm{~m}$. alt. in sylvis et fruticetis, m. Majo fl.: Eggers ed. Toepff. n. 334; St. Croix ex Vahl; St. Barthelemy ex Swartz; Guadeloupe: Bertero, Perrottet, locis siccis saxosis parum frequens, m. April., Majo fl.: Duss n. 3256; Dominica ex Griseb.; IIartinique in collibns calcareis satis frequens: Duss 11. 166, 1S2; St. Vincent: Smith 11. 1845. $\checkmark$

Reynosia Northropiana Urb. (n. sp.) ramis hornotinis minute patenti-pilosulis; foliis $3-4 \mathrm{~mm}$. longe petiolatis, ovali-ellipticis usque elliptico-oblongis, basi obtusis, apice rotundatis $\mathrm{r}$. subtruncatis et plus minus emarginatis, $3-4,5 \mathrm{~cm}$. longis, 1,2-1,8 cm. latis, nervo medio supra solemniter impresso, apice in emarginaturam brevissime v. vix producto non spinoso, lateralibus utroque latere $8-10$ parum prominulis et dense reticulato-anastomosantibus, margine plano depresse v. obsolete crenulatis, coriaceis; inflorescentiis $3-6 \mathrm{~mm}$. longe pedunculatis, cymose umbelliformibus, pedicellis $2-3 \mathrm{~mm}$. longis; calyce $2,5 \mathrm{~mm}$. longo, tubo semigloboso; petalis superne semiorbicularibus, apice emarginatis, inferne late triangularibus vix unguiculatis, $0,8 \mathrm{~mm}$. longis.

Rami vetustiores teretes brunei v. cinerascentes glabri, lenticellosi, hornotini tenuiter striati, pulverulento-pilosuli. Stipulae intrapetiolares inter sese connatae, nunc apice bifidae, triangulari-lanceolatie r. anguste lanceolatae, vix 2 mm. longae. Folia opposita decussata, petiolis teretibus sulura sulcatis, nẹrvis lateralibus sub angulo ca. $70^{\circ}$ abemtilus, subtus cum reticnlo applanatis, erenis valde depressis inaerpuilongis, nunç olusoletis, dorso inter crenas saepius nigro-pumctata, supra nitida in sicco brunescentia, subtus multo pallidiora. Inflorescentiae ad axillas solitariae, pedunculo compressinsculo striato, initio dichotomae, flore terminali ut videtur saepins deficiente, ramis perbrevibus fasciculato-cincinusis, 4-10-florae; prophyllia primaria lineari-subulata, 1,5-2 mm. longa, sequentia breviora. Alabastra 
breviter globosa aeutinsenla. Calyeis lobi 5 ovato-triangulares acuti, tubum longitudine aepuantes v. vix superantes, erecti, intus superne erasse carinati, apice inerassati. Petala post filamenta paullo sub simubus ealycis inserta, marginibus panllo incurvis, explanata vix latiora quam longiora, sepalis multo breviora, inferne usque ad basin late et sensim angustata. Stamina margini disci inserta, sepalis breviora; filamenta 0,7 mm. longa; antherae globoso-ovatae, $0,5 \mathrm{~mm}$. longae, dorso in $2 / 5$ alt. affixae, lateraliter dehiscentes. Discus calycis tubum fere usque ad lobos investiens. Ovarium liberum, globulosmm, in stylum attenuatum, spurie 2-loculare, carina altera e pariete intus prodennte paene ad parietem contrarium exereseente et hoc loco paullo incrassata, altera non evoluta; ovula in quoque loculo solitaria. Stylus vix $0,4 \mathrm{~mm}$. longus; stigma peltatum obsolete v. vix lisuleatum.

Hab. in insula Baham. Andros ad Rod Bays, m. April. flor.: J. I. et A. R. Northrop 11. 510 .

Obs. Ex affinitate R. reticulatae (Griseb.) Uıb.

Sarcomphalus crenatus $\mathrm{Urb}$. (n. sp.) spinis ad ramos retustos raris, ramis glabris subglabrisve; foliis $5-8 \mathrm{~mm}$. longe petiolatis, oratis v. ovalibus, basi parum v. obsolete cordatis saepius paullo in petiolum productis, apice obtusissimis v. rotundatis, $5-7 \mathrm{em}$. longis, $3-5 \mathrm{~cm}$. latis, margine toto crenatis, chartaceis v. coriaceis, nervis 2 longitrorsis e basi ima prodeuntibus et usque ad apicem arcuato-productis, nervulis transversim anastomosantibus subtus tenuiter prominulis; pedunculis parce v. vix pilosulis; calyce tomentosulo, lobis ovato-triangularibus tubum subaequantibus; petalis rotundatis unguiculo duplo longiore suffultis; stylis 3 usque supra medium connatis; ovario 3-loculari; drupa $16-18 \mathrm{~mm}$. diametro.

Arbor $6-13 \mathrm{~m}$. alta. Rami vetustiores teretes cincrascentes, hornotini lineis e petiolorum margine prodeuntibus plus minus angulati; spinae hinc illinc ad ramos vetustiores juxta foliorum axillam altero v. ntroque laterc obviae, reetae, $3-4 \mathrm{~mm}$. longae. Stipulae e basi latiore lineares obtusinsenlae, 1,2-1,5 mm. longae, pilosulae, enarcidae et decidnae. Folia petiolis supra sulcatis, limbo basi saepius in petiolum triangulari-prodncto, nervis 3 primariis supra subimpressis, subtus erassiusculc prominentibus, inter sesc subhorizontaliter anastomosanti-conjunetis, lateralibus ad marginem nervos secundarios 5-6 arcuatos emittentibus, crenis nume manifestis, nunc obsoletis, antice callosis v. apiculatis, juniora ad nervos brevissime pilosula, adulta glabra, margine plana. Inflorescentiae ad axillas foliorum juxta gemmam non evolutam latere altero v. utroque abeuntes et praeterea terminales, pedunculis $0,6-1,2 \mathrm{~cm}$. longis, parcissime ct brevissime pilosulis v. subglabris, bis ter eymose divisae, dein in monochasia abemntes r. initio semel trifurcatae; frophylla lineari-lanceolata pallicla emareida deciclua, 2-1 mun. longa; pedicelli primarii usque $4 \mathrm{~mm}$. longi, sequentes breviores, brevissime tomentosulo-pubescentes. Flores viriduli. Calycis tubus breviter turbinatns; loli in aostivatione valvati, intus superne carinati, 2 mm. longi. Petala vix $2 \mathrm{~mm}$. longa, limbo ca. $0,7 \mathrm{~mm}$. lato concaro, intus 
inferne carinato, unguiculo ad basin sensim attenuato. Discus tubum calycis investiens 10 -crenatus. Filamenta sepalis paullo breviora; antherae initio inflexae, dein erectae, extrorsae, in $3 / 4$ alt. affixac, suborbiculares, apice perpaullo emarginatae, loculis inferne patentibus. Styli 1,3 $\mathrm{mm}$. longi, quoad liberi aequicrassi, patentes, apice stigmatosi. Orarium basi disco immersum, subliberum, breviter globosum, apice subtruncato brerissime pilosulum, 3-loculare, orulis suborbicularibus. Drupa scutello calycino ca. $5 \mathrm{~mm}$. diametro suffulta, epicarpio tenui nitido, carne ca. $4 \mathrm{~mm}$. crassa, endocarpio orali obtuse apiculato ca. $13 \mathrm{~mm}$. longo, $9 \mathrm{~mm}$. diametro, osseo, obsolete triangulari 3-loculari. Semina obovata, $6 \mathrm{~mm}$. longa, $4 \mathrm{~mm}$. lata, planiuscula laevia nitida, pallide brunea, basi nigrescente subemarginata; testa chartaceo-coriacea fragilis; endospermium tenue. Embryo fere magnitudine seminis, flavo-viridis planus; cotyledones orbiculari-ovales tenues accumbentes, basi emarginatae; radicula $4 \frac{1}{2}$-plo brevior teres in sinum cotyledonum semiretracta.

Hab. in Haiti: Picarda n. 52, 550, prope Gonaïres loco sicco calcareo ad Dubédon, 200 m. alt., m. April. fl.: Buch n. 592.

Anm. Del morphologische Aufbau ist folgender. In der Achsel der Blätter befindet sich gewöhmlich je eine unentwickelte Laubknospe, neben der links und rechts bald je ein Doru, bald auf der einen Seite ein Dorn, auf der anderen ein Laubspross, oder auch nichts steht. Mutterblätter für diese Sprosse, welche wohl als unterste Seitenprodulte jener Laubknospen anzuselien sind, konnte ich nicht wahrnehmen; sie stehen gerade über den Nebenblättern. In der oberen Partie der Zweige treten nun an deren Stelle die Blüthenstände auf, bald nur an der einen Seite der Blattachsel, bald an beiden. An der Spitze der Zweige findet man gewöhnlich drei Inflorescenzen, zwei neben der Achsel des oft abgefallenen Laubblattes und eine terminale.

Obs. Orario et fructu 3-loculari sicut eadem embryonis structura gaudet etiam S. reticulatus (Vahl) Urb.

Cissus Picardae Urb. ramis pilis brevissimis patentibus dense obsitis, floriferis ecirhosis; foliis $1-3 \mathrm{~nm}$. longe petiolatis, simplicibus, oblongis v. oblongo-lanceolatis usque linearibus, basi rotundatis v. obsolete cordatis, apice rotundatis, obtusis v. acutis, $2-7 \mathrm{~cm}$. longis. $0,5-1,2 \mathrm{~cm}$. latis, margine dentatis, dentibus inferioribus angustis et lnargini magis adpressis, superioribus latioribus apiculatis, nerro medio supra elevatim prominente, utrinque brerissime et dense pilosis, in sicco obscure brunescentibus; inflorescentiis oppositifoliis, $1-2 \mathrm{~cm}$. longis, $3-5$-floris, pedicellis $4-6 \mathrm{~mm}$. longis; calyce non lobato; corolla non constricta, petalis $2,3 \mathrm{~mm}$. longis.

Rami retustiores subcompressi, punctis nigrescentibus tuberculati, floriferi subteretes striati $r$. angulato-striati; cirrhi qui suppetunt simplices, apice disciformi-dilatati. Stipulae oblongae v. breviter oblongo-lanceolatae, $3-1,5 \mathrm{~mm}$. longae. Folia nervis lateralibus sulra non v. vix conspicuis, 
subus prominulis, subcoriacea, subtus paullo pallidiora. Peduneuli supra medium florem solifarium bracteolae oppositum nunc leficientem et apice ipso eymulan 3-4-floram gerentes; prophylla parva ovato-triangularia acuta; pelicelli obsolete pilosuli. Flores lemaphroditi, purpurascentes subpruinati. Alabastra ovata apice rotundata. Calycis tubus vix $0,4 \mathrm{~mm}$. altus integer. Petala 4 in ealyptram eohaerentia, demum interdum soluta, ovata, margine incurva, apiee lineari deorsum verso, eoriacea. Filamenta $1 \mathrm{~mm}$. longa, inferne erassiora; antherae ovatae, eonneetivo praesertim inferne valde incrassato et basi ultra loenlos paullo produeto. Discus crasse earnosus, integer, extrinsecus 4 -suleatus, eupularis, inferne ovario adhaerens. Stylus 1,2 mm. longus, crassinseulus, inferne sensim inerassatus; stigma punetiforme. Baceae anguste et suboblique obovatae, apice obtusae v. obtusiusenlae, 5-6 $\mathrm{mm}$. longae, $3,5-4 \mathrm{~mm}$. latae. Semina immatura.

Hab. in Haiti ad Petite Rivière de l'Artibonite in Plateau de la Crête à Pierrot, 111. Jul. fl. et fruct.: Picarda 11. 1641.

Obs. Ex affinitate C. sicyoidis L.

Cissus macilenta Urb. ramis glaberrinis cirrhiferis; foliis $3,5-$ $0,5 \mathrm{~cm}$. longe petiolatis, 3 -foliolatis, foliolis iuferioribus obovato-oblongis usque lanceolato-linearibus, apice obtusis $\mathrm{v}$. acutis, inferne sensim et longe angustatis, $4-2 \mathrm{~cm}$. longis, $1-0,3 \mathrm{~cm}$. latis, margine dentibus parcis subulatis patulis obsitis, superioribus v. fere omnibus linearibus usque $5 \mathrm{~cm}$. longis, $3-1 \mathrm{~mm}$. latis, integris subintegrisve, glaberri$\mathrm{mis}$, in siceo viridibus $\mathrm{v}$. obscure viridibus; inflorescentiis oppositifoliis $7-10$ cm. longis, composito-umbellatis, multifloris, pedicellis $5-7$, raro usque $15 \mathrm{~mm}$. longis; floribus rubris; calyce obsolete 5-lobulato; corolla non constricta; petalis vix $2 \mathrm{~mm}$. longis; baccis $3 \mathrm{~nm}$. longis.

Cissus acida L. enr. P. macilenta J. E. Planch.! in DC. Monoyr.

\section{T. II (18S7) p. 535.}

Prostrata v. seandeus. Rami vetustiores subalato-angulati, einerascentes, minute nigro-punctati, lornotini elevatim multistriati, virides; eirrli simpliees apice non dilatati. Stipulae triangulini-laneeolate v. lanceolatac, 2,5-1,5 mm. longae. Foliola latiora membranacea, nervo metlio et lateralibus supra farum prominulis, angustiora subcoriacea, margine saepius reeurva v. revoluta. Peduneuli $3,5-5 \mathrm{em}$. longi, angulato-striati; nubellae primariae $4-5$-radiatne, radiis simplieibus v. semel eymosis, apice nmbellatim 12-20-floris; prophylla triangularia perexigua. Flores hermaphroditi. Alabastra breviter ovato-eylindracea. Calyeis tubus $0,5 \mathrm{~mm}$. longus, dentibus late triangularibus perbrevibus. Petala 4 in ealyptram eohaerentia, demum interdum soluta, ovata, margine ineurva. apiee triangulari deorsum verso, subcoriaeea. Filamenta $1 \mathrm{~mm}$. longa, apice attenuata; antherae ovatae, eonnectivo inferne inerassato, ultra loeulos basi parum producto. Discus erasse carnosus integer, extrinsecus profunde 4 -sulcatus, suleis aliis 4 levioribus alternantibus, leviter eupularis, inferıe ovario atlaerens. Stylus ea. $1 \mathrm{~mm}$. longus, erassinseulus, inferne parum et sensim inerassatus; stigma pumetiforme. Baeeae breviter et suboblique obovatae, apice rotundatae, $2,5 \mathrm{~mm}$. crassae. 
Hab. prope Haiti in insula Gonaïves in montibus Oreille batarde dictis: Prax, in Haiti prope Gonaïres ad Jitora maris, m. Majo flor.: Buch n. 51 (foliolis angustis), in montibus Cahos in saxosis calcareis siccis, $100 \mathrm{~m}$. alt., m. Jul. flor.: Buch n. 475 (foliolis latioribus).

Obs. Optime diversa a Cisso acida L., quae forma folioloruu, floribus albis $r$. flavis majoribus, baccis $5-7 \mathrm{~mm}$. longis discrepat.

\section{Teobuchiat Urb.}

\section{(nor. gen. Bombacacearum.)}

Calyx campanulatus, apice truncatus v. breviter 3-lobus. Stamina 15, quorum perpauca sterilia, ad basin in columnam apice cornua 5 integra erecta crassa emittentem connata, caeterum libera; antherae biloculares, loculis more intestinorum anfractuosis. Orarium superum, columna centrali saepius fissa imperfecte 5-loculare; ovula in quoque loculo crebra, pleraque horizontalia. Stylus apice ut videtur simplex. Fructus... - Arbor. Folia digitata, foliolis 7 crenatis. Pedunculus... Flores speciosi magni. Petala oblonga alba.

Obs. Ceiba Gärtn. (Eriodendron DC.) staminibus semper 5 (etiam in sectione Campylanthera antheris aeque bilocularibus) differt; longius distat Chorisia H. B. K. staninibus plane in tubum coalitis, antherarum loculis parallelis, dentibus tubi staminei 5 bifidis, ovario semiinfero.

\section{$\checkmark$ Neobnchia Paulinae Urb. (n. sp.).}

Arbor pulcherrima $10-13 \mathrm{~m}$. alta. Rami teretes glabri. Folia petiolis subteretibus in siceo rubro-brunescentibus $15-7 \mathrm{~cm}$. longis praedita, digitatim 7 -foliolata; foliola $2,5-6 \mathrm{~cm}$. longc petiolulata, ovata, ovalia г. obovata, hasi plerumque paullulum in petiolum producta, apice rotundata $v$. brevissime acuminata, 5-11 cm. longa, $4-5 \mathrm{~cm}$. lata, margine basi excepta leviter r. manifestius crenata, nervo medio supra subplano, lateralibus $8-10$ utrinque prominulis et tenuiter reticulato-anastomosantibus, chartaceo-coriacea, margine plana, glabra. Pedicelli $20-40 \mathrm{~mm}$. longi, $2-2,5 \mathrm{~mm}$. crassi. Calyx prima jurentute plane clausus, alabastrum petalorum obtegens; tubus campanulatus $15-20 \mathrm{~mm}$. longus, praesertim inferne crasse carnosus, extrinsecus glaber, intus brerissime et dense flavosericeus; loli si adsunt depresse triangulares, $3-4 \mathrm{~mm}$. longi. Petala in aestivatione contorta, oblonga v. anguste oblonga, inferne sensim angustata, apice ohtusa, $11-16 \mathrm{~cm}$. longa, $2,8-3,3 \mathrm{~cm}$. lata, inferne chartacea, stuperne membranacea, dorso tomentosula, intus minutissime pilosa, sul,obliqua inaequilatera, latere altero quam altermm duplo latiore, erectopatentia. Stamina ad hasin in columnam $12 \mathrm{~mm}$. longam, superne pubescentem connata; cornua columnae e basi arcuata erecta dorso pubescentia latiuscule linearia carnosa obtusa 6-7 mm. louga, luasin filamentorum circumdantia; filamenta supra columnam libera, fertilia $8-10 \mathrm{~cm}$. longa, sterilia breviora, glabra; antherae $5-7 \mathrm{~mm}$. longae; loculi inter sese sulliheri; pollinis granula aquae immersa globulosa 4 -porosa. Orarium ovatum, $5 \mathrm{~mm}$. longum, supra loculos oblongo-productum glabrum; ovula apice 
applanata et concaviuscula, subturbinata. Stylus in columna staminali dense patenti-pubescens, caeterum glaher, ca. $12 \mathrm{~cm}$. longus, apice (non bene viso) stigmatosms.

Hab. in Haiti in silvis apricis calcareis prope Dubedon, $200 \mathrm{~m}$. alt., m. Julio flor:: Buclı n. 652, prope St. Marc m. Jul. Hor.: Picarda 11. 1607 .

Olis. Planta in lonorem cl. Bucmu, investigatoris florae haitiensis felicissini, ejusque beatac uxoris atque itincrum primariorum comitis, dominae Amaliae Paulinae Wilmelminae e gente Dieck dicata est.

Banara Vanderbiltii Urb. (n. sp.) ramis hornotinis dense pubescentibus; stipulis filiformibus; foliis $4-7 \mathrm{~mm}$. longe petiolatis, elliptico-oblongis usque lanceolatis, basi rotundatis r. obtusis, apice acutis v. subsensim et acute acuminatis, $12-4 \mathrm{~cm}$. longis, $5-1,3 \mathrm{~cm}$. latis, margine sinuato-dentatis v. crenatis, initio utrinque pubescentibus, nervis lateralibus 2 basalibus margini parallelis iisque valde approximatis usque in $1 / 3-1 / 2$ alt. productis; floribus in apice ranulormm solitariis, flavis, 3-meris, pedicellis $15-20 \mathrm{~mm}$. longis; sepalis ac petalis subconformibus utrinque tomentosulis, $5-8 \mathrm{~mm}$. longis.

Frutcx 3,3 11. altus. Rami retustiores teretes, laeves glabri, hornotini pilis sordide v. flavido-allis patentilus villosuli, lasi squamas 2 obovatas gerentes. Stipulac $3-4,5 \mathrm{~mm}$. Iongae pubescentes, hinc illine glandulis parcis marginc obsitae, satis longe persistentes. Folia petiolis quam rami densius pulescentilıs eglandulosis, dentibus parvis sulutus glandulosis, ncrvis lateralibus ntroque latere $3-5$, superioribus arcuato-adscendentilus, sulitus plurilıs tenuiorilus mims curvatis interjectis et anastomosantibus, pulve molli supra sparsa, josterius evanescentc, sulitus densiore et villosula, chartacea, in sicco nigrescentia. Flores ramos laterales abbreviatos plerunque 1-2-phyllos terminantes; pedicelli basi articulati, medio ca. 0,6 $\mathrm{mm}$. crassi, ad apicem paullo incrassati, breviter et dense pubescentes. Sepala 3 triangulari- v. sulrhombeo-lanceolata, plus minus manifeste et olitusinscule acuminata, $5-7$ 1mm. longa, $3-4 \mathrm{~mm}$. lata, pubc sordide albida lnevi tomcntosula, sulcoriacea, margine integra, patentia. Pctala 3 ovata ol,usa v. olitusiuscula, $6-8 \mathrm{~mm}$. longa, $3,5-5 \mathrm{~mm}$. lata, margine denticulis parcis minutis glanduliformibus obsito plerumque recurva, luce permeante nervis plurilus anastomosantilus percursa, consistcntia atque pube selıalorum. Stamina numcrosa sulperigyna pluriseriata; filamenta usque $811 m$. longa filiformia glabra; antherae rotundatae v. subquadrato-rectangulares, $0,4-$ 0,6 mm. longae, supra hasin affixae, longitrorsum dehiscentes. Ovarium ovato-globosum glabrum, placentis 4 parictalibus sub anthesi vix proninentilus, posterius excrescentilus, ovulis numerosis ovato-oblongis, in stylum attenuatum. Stylus $6,5-7 \mathrm{~mm}$. longus, crassiusculus, in $2 / 3-3 / 4$ alt. saepius geniculato-sulıcurvatus; stigmata 4 minuta sessilia.

Hab. in Portorico ad margines sylvarum prope Cataño, n. Majo fl.: Heller n. 1370 (C. Vanderbilt Exploration Fund).

Obs. Inflorescentiis $\mathbf{1}$-floris insignis et mulli alii speciei arete affinis. 
Casearia ollorata Macf. inermis, ramis hornotinis brevissime $\mathrm{v}$. minute pilosulis; stipulis lanceolatis $v$. lineari-lanceolatis acutis v. breviter subulatis $1-1,5 \mathrm{~mm}$. longis; foliis $4-6 \mathrm{mn}$. longe petiolatis, anguste oratis, obovatis v. subrhombeis, basi acuta parum v. manifeste il petiolum angustatis, apice vix v. mediocriter acuminatis, acumine obtusissimo, interdum leviter emarginato, $3,5-8,5 \mathrm{~cm}$. longis, $2-3,5 \mathrm{~cm}$. latis, margine plus minus manifeste crenulatis, crassiuscule chartaceis; floribus in axillis foliorum (saepius delapsolum) $4-10(-15)$ fasciculatis, pedicellis $4-5 \mathrm{~mm}$. longis supra v. sub medio articulatis; sepalis $4-5 \mathrm{~mm}$. longis, basi $0,6-0,8 \mathrm{~mm}$. longe connatis, elliptico-oblongis, apice obtusis; staminibus 8 cum staminodiis supra basin calycis abeuntibus et cum is in $1 / 3$ alt. in tubum connatis, staminodiis latiuscule linearibus dense pubescentibus; ovario ovato, sensim in stylum dimidio longior'em attenuato.

Casearia odorata Macf. Flor. Jam. I (1837) p. 215 (ex descript. optima), - non Teijsm. et Binn. (1855).

Casearia ramiflora iar. spinosa Griseb.! Flor. (1859) p. 24 (p. p.).

Frutex $2-3,3 \mathrm{~m}$. altus. Rami saepius horizontaliter divaricati teretes parce striati, brunei v. grisei, lenticellis parvis ol,tecti, hornotini pube hrevissima patula $v$. suberecta obsiti. Stipulae satis persistentes pallidae pilosulae. Folia in ramis floriferis disticha, petiolis gracilibus, 0,5 $\mathrm{mm}$. crassis, supra leviter v. vix sulcatis pilosulis, nervo medio supra inferne parum, superne magis prominente, lateralibus utroque latere $6-7$ utrinque prominentibus et reticulato-anastomosantibus, crenis depressis antice mucronulum deciduum gerentibus, margine plana, pellucido-punctata, lineolis parcis v. parcissimis intermixtis, praesertim supra nitida, subtus ad nervos minute v. obsolete pilosula. Pedicelli ca. $0,2 \mathrm{~mm}$. crassi, sub articulatione dense et brevissime, superne parcius v. parcissime pilosuli; bracteae oratae v. suborbiculares $1-1,5 \mathrm{~mm}$. longae; prophylla nulla. Sepala viridi-alba (ex МAcF.), dorso minute et parce adpresseque pilosula, tubo breviter semigloboso, in aestivatione quincuncialiter imbricata, sub anthesi erecta v. patentia, crassiuscule cliartacea, lineolis et sub apice punctis flavidis notata. Stamina 8 subhypogyna, tubo ca. $1 \mathrm{~mm}$. longo; filamenta quoad libera $1,5-2 \mathrm{~mm}$. longa glabra; antherae anguste ovatae in $1 / 3$ alt. affixae, vix $0,5 \mathrm{~mm}$. longae, apice ad dorsum glanduloso-incrassatae. Staminodia quoad libera $1 \mathrm{~mm}$. longa densissime pubescentia. Ovarium breviter et suberecto-pilosum; placentae 3; orula numerosa placentis ca. 4-seriatim affixa. Stylus $1,5 \mathrm{~mm}$. longus inferue sensim incrassatus glaber; stigma fere 3 -plo crassius, vertice concaviusculum.

Hab. in Iamaica: Alexander, Purdie, Swartz (hb. Holm.), in Yallah's Valley 500 m. alt. m. Jun. flor., in Green Valley m. Oct. flor., ad Cascade Rock m. Sept. fl.: Harris n. 5744, 6595, 8155 , in savannahs vulgaris ad St. Thomas in the Vale, in Port Royal mountains, m. Aug., Sept. flor.: ex Macf. 
Ohs. C. guianensis Urb. (Iroucana guianensis AubI., C. ramiflora Vahl) stipulis 2-4 $\mathrm{mm}$. longis, foliis majorilus, sub anthesi jurenililus, pedicollis supra hasin articulatis, sepalis in $1 / 4-1 / 3$ alt. coalitis, C. spinosa Willd (herh, n. 8344!) ramis spinescentihus, patenti-pilosis et notis antecedentis. recedunt.

Casearia (Pitumba) bahamensis Urb. (n. sp.) inermis, ramis glaberrimis; stipulis valde deciduis; foliis $6-8 \mathrm{~mm}$. longe petiolatis, ovatis usque ellipticis, basi rotundatis r. obsolete cordatis, apice obtusissimis v. breviter et obtuse acuminatis, $3,5-1,5 \mathrm{~cm}$. longis, $2,2-1 \mathrm{~cm}$. latis, margine depresse crenulatis v. subintegris, maturis rigide coriaceis; inflorescentiis axillaribus et ad ramos abbreviatos pseudoterminalibus, corymbose 1 -4-floris, pedicellis $6-8 \mathrm{~mm}$. longis, supra basin articulatis; calyce $5 \mathrm{~mm}$. longo, in $1 / 5$ alt. gamosepalo, lobis obovatis v. anguste oboratis, apice rotundatis; staminibus $8 \mathrm{ex}$ ore tubi calycini abeuntibus; staminodiis cum staminibus insertis iisque alternantibus, clavatis pilosulis; ovario breviter ovato, stylo subaequilongo, stigmate capitato; fructu depresse globuloso costato, $3-5 \mathrm{~mm}$. longo, $4-6 \mathrm{~mm}$. crasso.

Fruticosa. Rami vetustiores teretes grisei, hornotini plus minus angulati, basi ima squamulis nonnullis circumdati. Folia disticha, petiolis gracilibus $0,3-0,5 \mathrm{~mm}$. crassis, supra angustissime sulcatis, nerro medio supra subplano, lateralibus $5-6$ utrinque prominulis et densissime reticulato-conjunctis, crenis parum prominulis, margine plana, minute pellucidopunctata non lineolata, adulta nitida. Pedunculus $2-3 \mathrm{~mm}$. longus; bracteae triangulares vix $0,3 \mathrm{~mm}$. Iongae deciduae; pedicelli ca. $1 \mathrm{~mm}$. supra basin articulati. Calyx extrinsecus minute, intus brevissime et dense pilosus: tubus breviter campanulato-turbinatus; lobi in aestivatione quincuncialiter valde imbricati, sub anthesi erecti v. patentes, chartacei, obscure punctati. Stamina et staminodia perigyna, supra insertionem inter sese lrevissime in annulum connata; filamenta vix $2,5 \mathrm{~mm}$. longa, parce pilosula; antherae dorso supra hasin affixae, ovatae, 0,5 $\mathrm{mm}$. longae, intus longitrorsum dehiscentes, dorso sul, apice minute nigro-punctatae. Staminodia vix $1,5 \mathrm{~mm}$. longa, inferne linearia, superne clavata, hreviter pilosa. Orarium superne hreviter et parcissime pilosum, caeterum glabrum; placentae 3 ; ovula numerosa pluriseriatim affixa, ascendentia. Stylus 1,5 mm. longus, inferne paullo crassior et parcissime tcnuiterque pilosus; stigma fere 3 -plo crassius, vertice concaviusculum. Fructus exocarpium carnosum, endocarpium subcrustaceum, oltuse costatum. Semina $1-5$, arillo flavido margine irregulariter inciso circumdata, si solitarium sphaeroideum, $2-3 \mathrm{~mm}$. latum, caeterum angulata, hrunea, depresse vesiculoso-granulata; endosperminm copiosum crasse carnosum. Cotyledones suborbiculari-cordatae planae, radicula brevi ohtusa 21/2-plo longiores.

Hab. in insula Balıam. Andros prope Nicols Town, m. Mart. flor., m. April. fruct.: Northrop n. 384.

Obs. Planta nomine Thiorliae serratae in collectione Northropiana determinata ad hane speciem (cf. Urb. in Engl. Jalıb. XV p. 295) omnino nullas praebet relationes. 
Passiflora anadenia Urb. (n. sp.) ramis hornotinis minute et parce adpresseque pilosulis; stipulis lineari-subulatis r. lineari-acuminatis, $5-6 \mathrm{~mm}$. longis, persistentibus: foliis petiolos $5-2 \mathrm{~mm}$. longos eglandulosos gerentibus, fere usque ad basin bipartitis, non ocellatis, $3-v$. sub5 -nervibus, parte integra $4-8 \mathrm{~mm}$. longa, lobis linearibus $6,5-3 \mathrm{~cm}$. longis, $5-2 \mathrm{nmm}$. latis, patentibus, apice obtusis apiculatis, supra brevissime patenti-pilosis, subtus glabris, chartaceo-coriaceis, lobo intermedio minuto reflexo; pedunculis ad axillas euphyllorum $1-2$, longitudine 8-12 mm., $2 \mathrm{~mm}$. sub calyce articulatis, sub medio usque ad basin bracteas 3 lineari-subulatas alternas gerentibus; sepalis lanceolatis $10-11 \mathrm{~mm}$. longis, inferne $2,5 \mathrm{~mm}$. latis; petalis dimidio brevioribus membranaceis $7-8 \mathrm{~mm}$. longis, $2,5 \mathrm{~mm}$. latis; corona exteriore e filis aequicrassis sepala fere aequantibus composita, intus magis inferne serie aliorum brevi aucta, intermedia breviter tubulosa dentata; ovario glabro.

Caules 1,5-1 mm. crassi, angulato-striati. Cirrhi simplices. Stipulae rubescentes erectae, $0,5-0,7 \mathrm{~mm}$. latae. Folia petiolis supra sulcatis, minute pilosulis, basi obtusa, nerris 3 supra tenuiter, subtus crasse prominentibus, praesertim supra dense reticulato-anastomosantibus, margine anguste revoluta, rigida, in sicco olivaceo-brunescentia. Pedunculi 1-flori; bracteae $2-3 \mathrm{~mm}$. longae. Alabastra obovata. Floris tubus $1,5 \mathrm{~mm}$. longus, $5 \mathrm{~mm}$. diametro. Sepala chartacea obtusissima, nervis 3 paullo crassioribus et aliis tenuioribus inter sese anastomosantibus notata, dorso glabra. Petala colore verisimiliter pallida, nervis parcis anastomosantibus percursa. Corona fancialis (exterior) sepalis perpaullo brevior, filis filiformibus aequicrassis $8-9 \mathrm{~mm}$. longis, 1 -nervibus, 1 -seriatis; praeterea adsunt inter exteriorem et intermediam fila brevia vix supra $1 \mathrm{~mm}$. longa, apice subclavato-incrassata; intermedia breviter tubulosa plicatula, usque ad medium in dentes triangulares incisa, $1,5 \mathrm{~mm}$. longa; basilaris calliformis parum prominens. Gynandrophorum $5 \mathrm{~mm}$. longum, sepalis duplo brevius. Filamenta quoad libera sub ovario ipso abeuntia $3,5 \mathrm{~mm}$. longa, recurva; antherae fere $3 \mathrm{~mm}$. longae, oblongo-lineares. Ovarium globosum. Fructus globosus, $1 \mathrm{~cm}$. (v. ultra?) diametro.

Hab. in Haiti prope Pétionville, m. Nor. fl.: Picarda n. 1174.

Passiflora bicrura Urb. (n. sp.) ramis hornotinis breviter et parce patulo-pilosis; stipulis lineari-subulatis, $4-4,5 \mathrm{~mm}$. longis, persistentibus; foliis petiolos $10-5 \mathrm{~mm}$. longos eglandulosos gerentibus, ambitu abrupte ovalibus, non ocellatis, $3-$ v. sub- 5 -nervibus, $5-7 \mathrm{~cm}$. longis, $3 \div 5 \mathrm{~cm}$. latis, usque infra medium bicruribus, parte integra $2-3 \mathrm{~cm}$. longa, lobis lanceolatis v. anguste lanceolatis, $3-4 \mathrm{~cm}$. longis, medio $8-15 \mathrm{~mm}$. latis, patulo-erectis, obtusis et brevissime apiculatis v. acutis, sinu basali rotundato, supra glabris, subtus brevissime pilosis, chartaceis, lobo intermedio deficiente; floribus ad ramos aphyllos breves paribus $3-5$ stipularum obsitos obviis, pedunculis ad nodos $1-2$, longitudine $2,5-3 \mathrm{~cm} ., 5 \mathrm{~mm}$. sub calyce articulatis, supra basin bracteas lineari- 
subulatas alternas gerentibus; sepalis ovato-lanceolatis $9 \mathrm{~mm}$. longis, inferne $4-4,5 \mathrm{~mm}$. latis; petalis vix brevioribus membranaceis $7,5 \mathrm{~mm}$. longis, 4,5 mun. latis; corona exteriore e filis aequilatis quam sepala paullo brevioribus composita, intus magis inferne serie aliorun brevi ancta, intermedia breviter tubulosa dentata; ovario glabro.

Caules 1,5-1 mm. crassi, plus minus compressi, cleratim v. angulato-striati. Cirrli implices. Stipula e purpurascentes, plerumque erectac, $0.3-0,4 \mathrm{~mm}$. latae. Folia petiolis supra sulcatis breviter patentipilosis, basi obtusa v. rotundata, nervis 3 supra in sulco prominulis, subtus manifeste prominentibus, ramosis (lateralibus etiam c basi extrinsecus), supra nou, subtus tenuiter v. obsolete anastomosantibus, margine angustissime revoluta, in sicco olivacea v. brunescentia. Pedunculi 1-flori; bracteae $1-2 \mathrm{~mm}$. longae. Alabastra breviter ovata. Flores albi; tubus $1,5 \mathrm{~mm}$. longus, $8 \mathrm{~mm}$. diametro. Sepala chartacea, apice obtusa, nervis 3 anastomosantibus percursa, dorso glabra. Petala apice rotundata, nerro solitario ramoso notata. Corona faucialis (exterior) filis lincaribus usque $7 \mathrm{~mm}$. longis 1 -nervibus 1 -seriatis scabrinsculis; praetcrea adsunt inter exteriorem et intermediam fila brevia cum exterioribus alterna vix $2 \mathrm{~mm}$. longa, ad apicem vix crassiora, scabriuscula; intermedia breviter tubulosa multiplicata, usque ad medium in dentes late triangulares incisa, $2 \mathrm{~mm}$. longa; basilaris carnosa vix 0,5 mm. prominens papillosa. Gynandrophorum (an plane evolutum?) $3,5 \mathrm{~mm}$. longum. Filamenta sub ovario ipso abeuntia, recurva; antherae orales $2 \mathrm{~mm}$. longae. Orarium oboratum; styli reflexi, stigmatibus depresse semiglobosis.

Hab. in Haiti ad sepes in Morne Fourmi, 1000 m. alt.: Buch n. 693.

Obs. Praecedenti affinis et cum ea habitu similis P. bilobatae Juss. (ex eadem insula), quae lobis foliorum rotundatis $\mathrm{v}$. emarginatis, floribus duplo v. ultra minoribus apetalis differt. - Speciem aliam (non floriferam) foliis bilobatis, sed subtus ocellatis cl. Bertero ex insula Jamaica reportavit, quae fortasse veram P. nom malem L. (a cl. Grisebach et Masters ad P. perfoliatam L. sub titulo synonymi landatam) sistit. Omnes hae species a formis P. suberosae L. bicruribus petiolis eglandulosis statim dignoscendae sunt.

Passiflora luciensis Urb. (n. sp.) ramis glabris subglabrisve; stipulis lineari-subulatis, setaceo-productis $5-6 \mathrm{~mm}$. longis persistentibus; foliis petiolos $1,5-2,5 \mathrm{~cm}$. longos eglandulosos gerentibus, ambitu ovalibus $\mathrm{v}$. anguste ovalibus solemniter bilobis, lobis ovato-oblongis apice rotundatis erectis parte integra $2-21 / 2$-plo brevioribus, sinu basi rotundato disjunctis, totis $8-10 \mathrm{~cm}$. longis, $4-6 \mathrm{~cm}$. latis, membranaceis, 3-nervibus, subtus ocellatis, utrinque glabris; pedunculis ad axillas euphyllorum solitariis, $3-3,5 \mathrm{~cm}$. longis, $4 \mathrm{~mm}$. sub calyce articulatis, ad medium bracteas subulatas gerentibus; sepalis oblongo-lanceolatis $15 \mathrm{~mm}$. longis, inferne $5 \mathrm{~mm}$. latis; petalis fere duplo brevioribus, membranaceis, $8 \mathrm{~mm}$. longis, $4 \mathrm{~mm}$. supra basin latis; corona exteriore e filis superne ligulatis quam sepala 3 -plo brevioribus composita, intermedia dorso basi fila setacea gerente, ipsa tubulosa plicata; ovario pubescente. 
Caules trianguli elevatim striati, juxta nodos minute et crispule pilosuli, caeterum glabri. Cirrhi simplices elongati. Stipulae recurratae. Folia petiolis minute v. obsolete pilosulis, nervis supra tenuiter prominulis, intermedio in aristam brevem excurrente, omnibus reticulato-anastomosantibus, glandulis inter nerrum medium et laterales 5-7, quarum 2 basales ovales r. oblongae, caeterae orbiculares, non pellucidis uniseriatis, supra parum nitentia, subtus vix pallidiora. Pedunculi 1-flori, minute r. obsolete pilosuli; bracteae 3 saepius subrerticillatae $1,5-2 \mathrm{~mm}$. longae. Floris tubus brevis $7 \mathrm{~mm}$. diametro cupuliformis. Sepala viridia chartacea obtusa, nervis 3 paullo crassioribus et $5-6$ paullo tenuioribus notata, dorso minute $\mathbf{r}$. obsolete pilosula. Petala colore rerisimiliter pallida, nerris parcis anastomosantibus percursa. Corona faucialis (exterior) sepalis 3-plo brevior, filis linearibus, in $1 / 3$ superiore liguliformibus et plus minus trigonis, $5 \mathrm{~mm}$. longis, superne $0,8 \mathrm{~mm}$. latis, 1 -nervibus, 1 -seriatis, cum filis profundius (dorso coronae intermediae) insertis setaceis apice paullo et irregulariter dilatatis $\mathrm{v}$. Ilentatis, paullo brevioribus, vix $5 \mathrm{~mm}$. longis subalternantibus; intermedia tubulosa multiplicata, margine supero brerissime irregulariter lacero-fimbriata $3 \mathrm{~mm}$. longa; basilaris crassa carnosa annularis integra plicatula $0,8 \mathrm{~mm}$. Ionga. Gynandrophorum $8 \mathrm{~mm}$. Iongum, sepalis fere duplo brevius. Filamenta quoad libera sub orario ipso abeuntia, $4 \mathrm{~mm}$. longa, recurva; antherae $4 \mathrm{~mm}$. longae oblongo-lineares. Orarium ovoideum breviter pilosum. Styli $6 \mathrm{~mm}$. longi, basi deflexi, dein ascendentes, ad apicem dilatati; stigma breviter obreniforme. Fructus globosus, $1 \mathrm{~cm}$. (v. ultra?) diametro.

Hab. in Sta. Lucia ad Barrabara, m. Aug.-Oct. flor.: Duss 1. 442,881 .

Obs. Arcte affinis $P$. rotundifolice L., quae foliorum forma, floribus ad axillas plerumque geminis, bracteis 2 sub articulatione, tertia profundius insertis recedit. Descriptio coronarum, quam cl. Mastens in Flor. Bras. XIII, I p. 588 huic speciei attribuit, accurata non est, saltem quoad specimina caribaea (typica ill. Plumerm et etiam Limsaei).

Pasciflora orbiculata Car. ramis hornotinis ad apicen parce et minute pilosulis, mox glabrescentibus; stipulis lineari-subulatis $2,5-4 \mathrm{~mm}$. longis persistentibus plus minus reflexis $\nabla$. sublorizontali-arcuatis; foliis petiolos $3-1 \mathrm{~cm}$. longos eglandulosos gerentibus, suborbicularibus v. semioralibus, basi subtruncatis r. leviter et late cordatis, antice breviter 3 -lobis, lobo intermedio semilunari, quam limbus $4-5$-plo breviore, quam laterales plerumque longiore et duplo latiore interdum emarginato, aduitis $5-7 \mathrm{~cm}$. longis, $6-7 \mathrm{~cm}$. latis, cluartaceis $r$. subcoriaceis, 3-nerribus, subtus ocellatis et obsolete pilosulis 5 . subglabris, supra glabris; pedunculis ad axillas euphyllorum geminis, $3,5-5 \mathrm{~cm}$. longis, in $2 / 3-5 / 6$ alt. articulatis et hoc loco bracteas gerentibus; floribus in alabastro lineari-oblongis, rubris v. rubro-violaceis; sepalis linearioblongis, $3-3,5 \mathrm{~cm}$. longis, medio $6-7 \mathrm{~mm}$. latis; petalis fere duplo brevioribus, tenuiter membranaceis, $1,5-1,8 \mathrm{~cm}$. longis, $2-3,5 \mathrm{~mm}$. 
latis; corona exteriore cylindrica margine superiore truncata nunc crenulata, non filamentosa, interiore $5 \mathrm{~mm}$. longa inflexa.

Pessiflora orbiculata Caran. Dissert. I (1790) p. 456 tab. 286!'; Spreng. Syst. III p. 43.

Inrncuia orbiculata Pers. Syn. II (1807) 1). 222; DC: Prodr. III p. 333.

Passiflora mumenia M. Mast. in Traus. Liun. Soc. X.YVII (1871) p. 634 et in Mart. Flor. Bras. XIII, I (1872) p. 557 (p.p.), - non Linn.

Caules scandentes plus minus compressi sulcato-striati glabrescentes. Cirrlıi simplices. Folia petiolis minute pilosulis, nervis supra tenuiter, subtus magis prominentibus, dense reticulato-anastomosantibus, glandulis impressis basalibus nullis, inter nervum medium et laterales uniseriatis pellucidis 2-4-nis, supra parum nitida, subtus opaca. Pedunculi 1-flori; bracteae ad r. plerumque perpaullo sub articulatione pedicelli ternae lineares verticillatae v. subalternae, $2-3 \mathrm{~mm}$. longae. Floris tubus $5-6 \mathrm{~mm}$. longus, $7 \mathrm{~mm}$. crassus, 10 -sulcatus, intus cavernas 10 praebens, apice paullo constrictus. Sepala ad basin et superne paullo angustata, apice obtusa, nervis 3 crassioribus et $8-10$ tenuioribus percursa, crassiuscule chartacea. Petala tenuia, coronae aequilonga v. paullo breviora, eique in sicco adhaerentia, linearia $\mathrm{v}$. oblongo-linearia, nervis $5-7$ percursa. Corona exterior ex sicco ad apicem flava, caeterum rubra, $1,8-2 \mathrm{~cm}$. longa, cylindrica $6 \mathrm{~mm}$. crassa, nervis creberrimis; interior ex apice tubi floris abiens, fere usque ad ejus basin inflexa, $5 \mathrm{~mm}$. longa, membranacea, multiplicata, antice truncata et irregulariter incisa v. scissa, efilamentosa enervis; basilaris nulla. Gynandrophorum sepalis aequilongum, $3,5-4 \mathrm{~cm}$. longum, vix $1 \mathrm{~mm}$. crassum. Staminum tubus gynophoro $2-3 \mathrm{~mm}$. brevior; filamenta $6-7 \mathrm{~mm}$. longa; antherae oblongo-lineares, $6 \mathrm{~mm}$. longae. Ovarium ovale glabrum; styli $7 \mathrm{~mm}$. longi, apice clavato-globosi, unilateraliter stigmatosi. Fructus globulosi v. ovali-globulosi, flavi (ex PIc.).

Hab. in Haiti in sylvis umbrosis montis Le Grand Fond: Jaeger n. 173, in Horne Tranchant 400-1800 m. alt., m. Jul., Aug. flor.: Christ n. $1753,1753^{\mathrm{b}}$, Picarda n. 772.

Obs. I. Descriptio et icon ill. Cavanillesii cum nostris plantis bene quadrant praeter bracteas crassiusculas elongatas et corollam deficientem. Sed non dubito, quin cl. autor ulteriorem tenuem brerem coronae in sicco adhaerentem pallidam ideoque difficile conspicuam negligentia praeterierit. Bracteas autem in P. murucuia (tab. 287) revera setaceas et alternas eodem modo auxit et verticillatim dispositas praebuit.

Obs. II. P. murucuia L. (ex eadem insula) foliis transversim oblongatis divaricato-bilobis, lobo intermedio non evoluto $\mathrm{v}$. lateralibus breviore, $0,5-$ $1,5 \mathrm{~cm}$. longe petiolatis, pedicellis $1,5-2 \mathrm{~cm}$. longis, ad $\mathrm{v}$. sub medio bracteatis, corona exteriore usque ad apicem rubra, interiore brevissima parum prominente, staminum tubo usque ad ovarium producto bene diversa est.

Passiflora cubensis Urb. (n. sp.) ramis hornotinis superne minute et parce pilosulis; stipulis lineari-subulatis $2-3 \mathrm{~mm}$. longis persistentibus, plus minus reflexis v. horizontaliter sitis; foliis petiolos $10-5 \mathrm{~mm}$. 
longos eglandulosos gerentibus, ambitu obtriangularibus 5 . semiovalibus, ad basin cuneatis r. obtusis, antice plus minus bilobis, lobis parte integra $1 \frac{1}{2}-5$-plo brevioribus semiorbicularibus usque oratis, antice rotundatis v. truncatis, nune emarginatis, raro acutis, sinu basi rotundato $r$. saepius lato et truncato, raro lobulo intermedio minimo interjecto, adultis $3-5 \mathrm{~cm}$. longis et superne latis, chartaceis $\mathrm{v}$. subcoriaceis, sub-5-nerribus, subtus ocellatis, junioribus subtus minute pilosulis, $\operatorname{mox}$ glabrescentibus; pedunculis ad axillas euphyllorum solitariis 1,5 $2 \mathrm{~cm}$. longis, in $3 / 5-2 / 3$ alt. articulatis, bracteas 3 subulato-setaceas alternas sub medio $\mathrm{r}$. ad basin versus gerentibus; floribus in alabastris cylindraceo-oblongis; sepalis et petalis pallide sanguineis, illis linearioblongis $2-2,5 \mathrm{~cm}$. longis, medio $6 \mathrm{~mm}$. latis; petalis $1 / 4-1 / 3$ brevioribus membranaceis $1,7-2 \mathrm{~cm}$. longis, $4-5 \mathrm{~mm}$. latis; corona exteriore e filis 1 -seriatis lineari-subulatis corolla pluries brevioribus composita, interiore breviter tubulosa, ca. $2 \mathrm{~mm}$. longa erecta; ovario glabro.

Passiflora coriacea A. Rich. in Sagra Cuba X (1845) p. 288 et Ess. Fl. Cub. p. 599, - non Juss.

Passiflora oblongata Griseb.! Pl. Wr. I (1S60) p. 189 et Cat. p. 113; Sanv. Cub. n. 896 (906) p. 56; Mast. in Trans. Linn. Soc. IXVII p. 634 et in Mart. Flor. Bras. XIII. I p. 557 (p. p.), non $S w$.

Passiflora Murucuja Griseb.! Cat. (1866) p. 114, - non Linn.

Caules scandentes, 3-v. 4 -anguli, elevatim striati. Cirrhi simplices. Folia petiolis minute pilosulis r. glabratis, supra sulcatis, nerris supra tenuiter, subtus multo magis prominentibus, dense reticulato-anastomosantibus, glandulis impressis basalibus nullis, inter nerrum medium et laterales uniseriatis subpellucidis 2-7-nis, supra nitida, subtus subopaca. Pedunculi 1 -flori; bracteae $2-3 \mathrm{~mm}$. longae. Floris tubus $5-6 \mathrm{~mm}$. longus, $7-9 \mathrm{~mm}$. crassus, basi concarus, non impresso-sulcatus nec cavernas intus praebens. Sepala subaequilata v. ad medium paullo latiora, apice olitusiuscula v. obtusa, nervis 3 crassioribus et $10-12$ tenuioribus, superne reticulato-anastomosantibus percursa, crassiuscule chartacea. Petala oblongolinearia, supra medium latiora, nervis $9-11$ superne evanescentibus $r$. anastomosantilus percursa. Coronae exterioris (faucialis) fila plane libera 4-6.mm. longa, e liasi 1-3-nervia, superne sensin angustata, glabra; interior e tubo corollae ad ejus medium abiens plana enervis margine supero irregulariter dentata. Gynandrophorum sepalis sulheruilongum, 2,2 $2,5 \mathrm{~cm}$. longum, fere $1,5 \mathrm{~mm}$. crassum. Staminum tulus usque ad r. fere ad ovarium productus; filamenta $5 \mathrm{~mm}$. longa; antherae sul, medio affixae oblongae, basi subemarginatae, $4,5-5 \mathrm{~mm}$. longae. Orarium ovale; strli $4 \mathrm{~mm}$. longi, stigmatibus orbiculari-reniformibus. Baccae hreviter oratae, (au plane maturae?) $12 \mathrm{~mm}$. longae, $10 \mathrm{~mm}$. crassae. Semina anguste ovata, $3 \mathrm{~mm}$. longa, $1,5 \mathrm{~mm}$. lata, lineis $6-7$ crasse prominentibus tuherculatis transversim percursa. 
Hab. in Cuba: Wright n. 198a 1615 (quem non vidi), prope Habana: Don, prope Guanabacoa m. April. flor. supra frutices scandens: Otto n. 191, prope Cienfuegos ad Calicita m. Sept. flor. et fruct.: Combs n. 318 .

Obs. I. P. coriacca Juss. petiolis biglandulosis, foliis peltatis, transrersim ellipticis, pedicellis geminis, petalis deficientibus, $P$. oblonyata Sw. petiolis $2,5-3,5 \mathrm{~cm}$. longis, foliis pluries majoribus, ambitu ovalibus, floribus in racemum terminalem collectis, pedicellis geminis sub medio articulatis, bracteas ad $\mathrm{v}$. sub articulatione gerentibus, tubo floris cylindraceoelongato, $15-17 \mathrm{~mm}$. longo, corona exteriore e filis ca. $2 \mathrm{~mm}$. longis aequilatis composita, interiore memlranacea e tubo $6 \mathrm{~mm}$. supra ejus basin ahemute ca. $6 \mathrm{~mm}$. longa deflexa, $P$. murucuia L. foliorum lobis magis divaricatis, floris tubo cavitates 10 praelente, corona exteriore tubulosa efilamentosa, stylis longioribus toto coelo diversae sunt. Nagis accedit ad $P$. cutream L., quae praeter foliorum formam floribus purpureis basi non intrusis, coronae exterioris filis rix $3 \mathrm{~mm}$. longis aequicrassis, interiore perhrevi vix $0,5 \mathrm{~mm}$. longa, stylis $8-10 \mathrm{~mm}$. longis, stigmate pluries minore discrepat.

Olss. II. Sub Wright n. $198^{a}$ forma alia insignis distributa est, quae ad axin primarium folia elliptica $v$. oblonga superne obsolete triloba v. subintegra, ad secundarium folia semiovalia v. semielliptica, basi rotundata, antice brevissime biloba $v$. triloba offert, sed floris characteribus a $P$. cubensi non recedit.

Passiflora dasyatenia Urb. (n. sp.) ramis hornotinis pilis brevibus crispulis dense vestitis; stipulis lineari-subulatis, $5-7 \mathrm{~mm}$. longis, valde deciduis; petiolis $4-1,5 \mathrm{~cm}$. longis, in $1 / 4-2 / 5$ altitudinis glandulas binas contiguas sessiles puberulas gerentibus, foliis ovatis v. ovatoellipticis, basi et apice rotundatis, non lobatis, $7-10 \mathrm{~cm}$. longis, $4-5 \mathrm{~cm}$. latis, margine dentatis, coriaceis, supra subglabris, subtus brevissime et crispule pilosis, nervis 2 basalibus usque ad medium productis, omnibus dense reticulato-anastomosantibus, reticulo supra impresso, subtus bene prominente; pedunculo fructifero $4 \mathrm{~cm}$. longo, in $4 / 5$ alt. cicatrices 3 verticillatas bractearum delapsarum gerentibus; floribus ignotis; fructibus ovato-globosis, brevissime pilosis, $32 \mathrm{~mm}$. longis, $28 \mathrm{~mm}$. crassis.

Scandens. Rami teretes striati, flavido-brunescentes, annotini glabrescentes, pube simplici ad apicem tomentosula, flavo-grisea, mox lignescentes. Cirrhi simplices. Stipulae arcuato-incurvae brevissime pubescentes. Folia petiolis subteretibus, supra sulcatis, brevissime pilosulis, nervo medio supra tenuiter prominulo parce $\mathrm{v}$. obsolete pilosulo, lateralibus utroque latere $4-6$ sub angulo $40-45^{\circ}$ abeuntibus, glandulis ocellatis nullis, dentibus saepius inaequalibus obtusis, supra brunescentia, parum nitentia, subtus pallidiora. Pedunculi ad axillas solitarii (an semper?), 1 -flori, fruetiferi usque $1,5 \mathrm{~mm}$. crassi. Gynophorum $12 \mathrm{~mm}$. longum. Semina orata compressa, $5 \mathrm{~mm}$. longa, $3 \mathrm{~mm}$. lata, plicis parum prominentibus. Cotyledones breviter ovales planae, radiculam 3 -plo superantes.

Hab. in Cuba, inter frutices scandens prope El Aji, m. Febr. fruct.: Eggers n. 4670. 
Obs. Ob flores deficientes dubiae affinitatis, habitu ad P. serratifoliam L. et malacophyllam Mast. accedens.

Cuplıea urens Ḱoelne (n. sp.). Fruticulus humilis; caules ramique pro parte ascendentes pro parte erecti, $10-38 \mathrm{~cm}$. longi, graciles, teretes, ima basi tantum ramulosi, hirtello-strigosi ac \pm setulosi, setulis (ex W. Buch) urentibus. Folia decussata, internodiis circ. aequilonga, petiolis brevissimis $v$. ad $1,5 \mathrm{~mm}$. longis insidentia, $7-12 \mathrm{~mm}$. longa, $4-9 \mathrm{~mm}$. lata $\mathrm{r}$. floralia interdum $4 \mathrm{~mm}$. tantum aequantia, late coldato-ovata v. - deltoidea, acutiuscula, supra scabriuscula, subtus strigosa, demum rigidula: nervi utrinsecus circ. 4. Racemi simplices, foliati; pedicelli interpetiolares, $3-5 \mathrm{~mm}$. longi, apice bracteolati, brevissine hirtelli parceque glandulosi. Calyx $6-6,5 \mathrm{~mm}$. longus, bresissime calcaratus, rectus, inde a medio dilatatus (sed fructifer ubique aequalis), brevissime glanduloso-lispidulus; lobi aequales, violacei; appendices brevissimae. Petala riolacea, dimidio calyce vix longiora, subrotundata, ventralia 4 dorsalibus duobus vix angustiora ac vix longiora. Stamina paullo supra tubi $1 / 2$ inserta, tubum longe non aequantia, glaberrima. Ovarium glaberrinum; stylus eodem subbrevior, demum lobos vix aequans; discus semierectus, crassiusculus; ovula 5--6. Semina 2 mm. longa, paliida, angustissime subalbicanti-marginata.

Hab. in Haiti ad Marmelade prope Gonaïres, in declivibus siccis calcareis, $400 \mathrm{~m}$. alt.: Buch n. 447.

(E. Koенуе.)

Gaultheria domingensis Urb. (n. sp.) ramis hornotinis pilis longiusculis bruneis restitis; foliis $2-3 \mathrm{~mm}$. longe petiolatis, oratis, basi rotundatis v. leviter cordatis, apice brevissime et acute acuminatis, $1,5-3 \mathrm{~cm}$. longis, $1-2 \mathrm{~cm}$. latis, margine plus minus recurvo integris subintegrisve, utrinque et margine pilis setuliformibus bruneis adspersis; inflorescentiis terminalibus et saepius ex axillis foliorum summorum lateralibus, pedicellis $4-8 \mathrm{~mm}$. longis; calycis lobis orato- v. triangulari-lanceolatis, $5-6 \mathrm{~mm}$. longis, in statu fructifero vix accrescentibus: corolla calycem parum v. vix superante, $6-7 \mathrm{~mm}$. longa, pilis brevibus erectis v. subelectis vestita, lobis ovatis r. breviter ovatis, ca. $1 \mathrm{~mm}$. longis; antheris longitudinaliter dehiscentibus.

Fruticulus $5-30 \mathrm{~cm}$. longus, repens et inferne radiculas emittens. Rami retuštiores teretes, brunei, pube longe persistente, hornotini inferne squamas plus mimus numerosas, densas v. remotiusculas, ellipticas v. oblongas $2-7 \mathrm{~mm}$. longas striatas coriaceas margine ciliatas gerentibus, pilis densis setiformibns patulis v. suberectis. Folia apice saepe glandulosoincrassata, nervo medio supra impresso, latcralibus ntroque latere $2-3$ arcuatis, supra non, subtus plus minus manifeste reticulato-anastomosantibus, postremo crasse coriacea rigida, supra nitida olivacea, subtus brunescentia. Inflorcscentiae racemosae r. corymbosae, pauci- r. pluriflorae, pubescentes; bracteae et prophylla orata usque lanceolata, dorso glabra, 
squamis canlinis similia. Calyx basi coalitus, in statu fructifero, ut videtur, basi carnosus; lobi inferne quiucuncialiter imbricati, plus minus acuminati, dorso glabri, margine ad basin parce $\mathrm{v}$. vix setulosi, caeterum tenuitcr ciliati, coriacci, lnce pcrmeante lense nerrosi. Corolla rosea (ex EgG.), rubra (ex Plcarna), urceolata, inferne $4 \mathrm{~mm}$. dianctro, intus brevissime et parce pilosa; dentes tubo $6-7$-plo breviores, dorso supcro et margine glabri, in aestivatione parmm imbricati. Stamina 10, inclusa; filamenta basi imac corollae arnata, basi et apice excepto tenuiter pilosa, supcrne sensim angustata, 4 et $5 \mathrm{~mm}$. longa; antherae ovatae, dorso sub medio affixae, apice cornulus 4 brevibus ornatae, basi nudae v. cornu solitario brevi instructae, rima longitudinali ab apice ad basin dehiscentes; pollinis granula in tetradibus cohaerentia, laevia. Discus annularis basi orarii adnatus, margine libero obtuse 10 -dentatus. Orarium semiglobosum, apice pilis erectis brevibus v. brevissimis obsitum, 5-loculare. Stylus $4 \mathrm{~mm}$. longus aequicrassus glaber v. inferne breviter et patenti-pilosus; stigma parvum, postremo saepius obsolete 5 -lobum. Capsula calyce persistente incrassato circumdata et superata, depresse globulosa, apice intrusa, ca. $4 \mathrm{~mm}$. diametro, loculicide dehiscens, pericarpio tenui; placentae e columna crassa brevi centrali abeuntes, sursum curvatae, crassae. Semina numerosa, breviter v. triangulari-ovata, $0,3-0,4 \mathrm{~mm}$. longa, nitida, brunea.

Hab. in Haiti in montibus Furcy, m. April., Aug. flor.: Christ n. 1675, Picarda n. 269, 1039; Sto. Domingo in Valle nuevo inter saxa, 2270 m. alt., m. Majo fl. et fruct.: Eggers n. 2198.

Obs. Altera species domingensis G. coccinea Urb. (nec H. B. K.) = Brossaea coccinea Linn. Spec. I ed. (1753) p. 1190, condita in Plum. Gen. p. 5 tab. 17, ef. ctiam Plum. ed. Burm. tab. 64 fig. 2, recedit ex iconibus citatis et descriptione a cl. Layarck Enc. I p. 470 e manuscriptis Plumierianis hausta habitu (frıtex $3-4$-pedalis), foliis leviter dentatis glabris, floribus scarlatinis, 6 lineas longis, corolla apice integra v. ex icone leviter crenulata, calyce fructifero accrescente, capsula pluries majore. — Tertia species antillana G. cordifolia (Sw.) Raeusch. (nec H. B. K.) e Guadeloupe!, Martinique!, Trinidad (ex Griseb.) foliis apice obtusis (latiuscule glanduloso-apiculatis), margine manifeste denticulatis, calyce fructifero basi non carnoso, corolla extrinsecus glabra, lobis tubo ca. 4-plo brevioribus, antheris angustioribus differt. Cum G. anastomosans H. B. K.:, quacum cl. Grisebach infeliciter conjunxit, species ulterior omnino nullam habet affinitatem.

Irdisia coriacea Sw. Prodr. (1788) p. 48, Flor. I p. 470 et 1. Eualalupensis Duchass. (nec Duchass. et Walp. ut el. Mez scripsit) Hsc. ap. Griseb. Karib. (1857) p. 89. - Cl. Mez in Symb. ant. II (1901) p. 398 et Pflanzenr. Myrsin. (1902) p. 80 nomen ulterius sub titulo synonymi ad speciem Swartzianam duxit, sed ex mea sententia omnino immerito. Ill. SwARTz speciei suae inter alios characteres attribuit sequentes: Folia avenia enervia; flores purpureo-coccinei; antherae cuspidatae apice loculis perforatis, et ex descriptione msc. sicut ex icone inedita tab. 64 optime cum illa congruente: petala lanceolata acuta; antherae sublineares, filamentis 3 -plo longiores, apice 2 -perforatae; 
stylus stamina superans. A. guadalupensis autem foliis eximie renosis, petalis albis $r$. flaro-viridibus $r$. flarescentibus r. aurantiacis (ex Duss, Sintexis et aliis) et interdum apicem versus nomnumuam purpurascentibus (sec. Mez), oratis apice obtusissimis r. rotundatis, antheris ovatis г. breviter ovatis, late et longitrorsum usque ad basin deliscentibus, filamentis subaequilongis, stylis quam stamina sub anthesi brevioribus gaudet ideoque omnino non eadem species esse potest ac 1 . coriacea Sw. Planta Swartziana (rerisimiliter e Jamaica r. Hispaniola) aretissime affinis est, ut ill. Swartz ipse adnotarit, $A$. timifolice Sw. (Icon. ined. tab. 63), a qua nomnisi foliis aveniis paullo angustioribus rigidis et sepalis subrotundis discrepat, et praesertim A. Harrisianae Mez, quae foliis supra renosis tantum (an etiam in statu rivo?) differt. Si ill. Swartz posterius sub nomine A. coriaceae specimina A. guadalupensis Duchass. (e Dominica) distribuit et in herbario suo conservavit, id quod non solum phytographis, sed etiam monographis saepius occurrit, loc errore diagnosis A. coriaceae sicut icon originaria e rivo delineata supprimi non potest. Propterea planta insulae Portorico et Antillis minoribus propria nomen 1. guadalupensis Duchass. conservare debet, dum A. coriacea Sw. adhuc in dubio haeret rel rerisimilius eum A. Harisiana Iez coincidit.

Bisgoeppertia Prenleloupii Urb. (n. sp.) caulibus filiformibus; foliis lanceolatis v. lineari-lanceolatis, basi in petiolum $1-1,5 \mathrm{~mm}$. longum angustatis eumque marginantibus, ad apicem acuminatis, $8-12 \mathrm{~mm}$. longis, 2-3 mm. latis; racemis terminalibus elongatis laxifloris, ramis inferioribus cincinnose 3 - 2 -floris, caeteris ommibus 1 -floris, prophyllis a calyce $0,5-1 \mathrm{~mm}$. longe remotis; sepalis anguste lanceolato-linearibus, longe subulato-acuminatis $6-7 \mathrm{~mm}$. longis; tubo corollae brevi, intus superne pilosulo, lobis eum verisimiliter vix superantibus, lanceolatis acutis $3 \mathrm{~mm}$. longis; stigmate anguste cylindrico, stylo reliquo subaequilongo.

Caules ca. $0,5 \mathrm{~mm}$. crassi, superne volubiles, lineis 4 e marginilus petiolorum decurrentibus elevatis tenuibus notati, glabri, internodiis folia paullo superantibus usque duplo brevioribus, in inflorescentia elongatis usque $10 \mathrm{~cm}$. longis. Folia nervo medio supra non r. vix conspicuo, subtus prominulo, lateralibus uullis, chartacea, margine plana, superiora ramos inflorescentiae suffulcientia sensim angustiora, summa linearia. Inflorescentia usque pedalis; bracteae lineares acuminatae. $6-3 \mathrm{~mm}$. longae; pedicelli in ramis unifloris $6-4$ mu. longi; prophylla lineari-subulata. Sepala intus concaviuscula, dorso carinata, supra basin $0,7-0,8 \mathrm{~mm}$. lata, dein sensim acuminata. Corolla non rite visa, verisimiliter calycem non superans; lobi nervo merlio ramosulo. Stamina tubo corollino ad faucem inserta; filamenta antheris 3 -plo breviora glabra; antherae 1,2 min. longae sublineares obtuse et obsolete apiculatae, sub $1 / 3$ alt. affixae. Stylus $2,5 \mathrm{~mm}$. longus, postremo 
inferne toltuosus; stigna vix $1,5 \mathrm{~mm}$. longum, 0,2 mm. crassum, $\mathrm{cx}$ apice styli descendens et ejus partcn superiorem more calyptrae tubulosac arcte circumdans, apicc obtusissimum. Capsula apice corolla soluta marcescente breviter coronata, subanguste ovalis, 5 11m. longa, 2,5 mm. crassa, valvarum marginibus placentiferis valde intrusis subbilocularis. Semina crebra, ovata, subrotundata r. triangularia, irregulariter et dense reticulata, marginibus reticuli tuberculato-prominentibus, brunco-nigrescentia.

Hab. in Sto. Domingo, m. Mart. fruct. et in alabastris: Prenleloup n. 335 .

Obs. Ex affinitate B. gracilis O. Kitze. (e Cuba), quae foliis linearibus $1-2 \mathrm{~cm}$. longis, $0,7-1,5 \mathrm{~mm}$. latis, floribus in apice caulium et ramorum $3-7$ subcapitnlatis, calyce $4 \mathrm{~mm}$. longo discrepat.

Anmerkung. Gegenüber der früheren zutreffenden Beschreibung von Benthan und Hooker (Gen. II p. 808), sowie Batlion (Hist. X p. 132) liaben Kловцаuch (Bot. Centralbl. LX 1994 p. 356) Grisebach's Angaben folgend und Gilgr (Nat. Pflanzenfam. IV. 2 p. 70) auf Krobladch's A utorität hin von der Narbe eine unrichtige Darstellung geliefert. Sowohl bei dem Typus (B. volubitis O. Ktze.) wie bei unserer Art ist die Narbe linealisch walzenförmig und steigt von der Griffelspitze, wo sie befestigt ist, als ein ringsum geschlossener Cylinder, der obersten Griffelpartie eng anliegend, herab und ist auf der ganzen Aussenwand desselben papillös; die Spitze ist sehr stumpf ganzrandig, fast gestutzt.

$\checkmark \quad$ Lisianthus laxiflorus Urb. (n. sp.) foliis $5-1,5 \mathrm{~mm}$. longe petiolatis, elliptico-lanceolatis usque lanceolatis, superne magis quam inferne angustatis, basi acuta $\mathrm{v}$. obtusa paullo in petiolum protractis, antice subsensim et longe acuminatis, $12-4 \mathrm{~cm}$. longis, $4-1 \mathrm{~cm}$. latis; inflorescentiis laxe corymbosis paucifloris, pedicellis 2,5-0,7 cm. longis; calyce 10-12 mm. longo, lobis lanceolato-linearibus, subulato-acuminatis, dorso obsolete carinatis; corolla $32-40 \mathrm{~mm}$. longa, tubo in $1 / 2$ inferiore cylindraceo, dein infundibuliformi, lobis tubo rix dimidio brevioribus, oblongo-lanceolatis acuminatis; filamentis corolla brerioribus.

Leianthus longifolius var. gracilis Bello Ap. I (1881) p. 299; Krug Ic. tab. 65!, - non Griseb.

Lisianthus gracilis Perk.! in Engl. Bot. Jahrb. XXXI (1902) p. 493, - non Griseb.

Campanilla Port. (ex Sint.).

Annua $r$. perennans. Radix valde ramosa. Caules $40-70 \mathrm{~cm}$. alti, plus minus glaucescentes, glabri, ramosi; rami teretes, lineis 4 e margine petiolorum decurrentibus eleratis notati. Folia nervo medio supra subplano r. impresso, lateralibus utrinque $2-3$ tenuiter prominulis arcuatis, ante marginem longitrorsum versis ct conjunctis, tenuissime reticulatoanastomosantibus, membranacea r. subchartacea, margine plana. Inflores- 
centiae axillares, $5-15 \mathrm{~cm}$. longe pedunculatae, $2-8$-florae, initio plerumque trichotomae, dein cincinnosae; bracteae inferiores euphylloideae, sed pluries minores, lanceolato-acuminatae, caeterae lanceolato-lineares r. lineares, $2-1 \mathrm{~cm}$. longae; rhachides elevatim diaphano-4-carinatae. Calycis tubus vix $2 \mathrm{~mm}$. longus et crassus; lobi erecti virides, membranaceo-marginati, interiores paullo angustiores, nerro medio prominente obsolete carinati. Corolla flava; tubus inferne vix $2 \mathrm{~mm}$., sub apice $5 \mathrm{~mm}$. crassus, $19-23 \mathrm{~mm}$. longus; lohi $13-17 \mathrm{~mm}$. longi, inferne $4 \mathrm{~mm}$. lati. Filamenta medio tubi corollini affixa et loc loco incrassata, lobis parte tertia r. dimidia breviora; antherae exsertae, dorso medio affixae, subanguste ovales, obsolete et obtuse apiculatae, 2,5 mu. longae. Orarium lineari-oblongum. Stylus $20-24 \mathrm{~mm}$. longus, filiformis; stigma cum antheris in eaden altitudinc situm $\mathrm{v}$. eas paullo superans, peltato-subcapitatum, vertice transversim subsulcatum, marginibus recurvis Capsula corolla marcescente longe coronata, lineari-oblonga, $10-15 \mathrm{~mm}$. longa, 2-3 $\mathrm{mm}$. crassa, placentis intrusis subbilocularis. Semina breviter orata, triangularia r. subrotunda, subcompressa r. angulata, $0,3-0,4 \mathrm{~mm}$. diametro, subforeolato-tuberculata brunea.

Hab. in Portorico in sylris primaeris, ad margines sylrarum et in declivibus prope Humacao, Peñuelas in monte Las Cruces, inter Adjuntas et Guayanilla ad Vira Cristo, prope Yauco, Maricao in monte Alegrillo, Mayagiiez, Lares ad Buenos Aires, Utuado ad Isabon et Santa Isabel, m. Dec. - Jun. Hlor.: Garber n. 64, Heller n. 4474, Schwanecke, Sintenis n. 202, 4386, 4650, 6077, 6189, 6424.

Obs. L. longifolius Linn. (e Jamaica et Sto. Domingo) floribus confertioribus, pedicellis (supra prophylla suprema) $1-5 \mathrm{~mm}$. longis, sepalis dorso alato-carinalis, corolla $40-50 \mathrm{~mm}$. longa, capsula elliptica v. ellipticooblonga recedit. - Lisiantlus gracilis Griseb. sicut Leianthus longifolius var. gracilis Griseb.! (= Lisianthus glandulosus A. Rich.!) a nostra planta omnino dirersi sunt, quam ob rem nomen Perkinsianum rejiciendum est.

Lisianthus domingensis Urb. (n. sp.) foliis $10-3 \mathrm{~mm}$. longe petiolatis, ellipticis $v$. anguste ovatis, basi cuneatim in petiolum protractis, apice acuminatis, $7-2 \mathrm{~cm}$. longis, $3-1 \mathrm{~cm}$. latis; inflorescentiis laxe et paucifloris; calyce $7 \mathrm{~mm}$. longo, vix in $1 / 4$ alt. coalito, lobis lineari-lanceolatis acuminatis, duobus angustioribus dorso obtuse carinatis; corolla $28 \mathrm{~mm}$. longa, tubo in parte $2 / 5$ inferiore cylindraceo, dein infundibuliformi, lobis tubo duplo brevioribus lanceolato-linearibus acuminatis.

Frutex $0,30-0,60 \mathrm{~m}$. altus glaber. Rami teretes, lineis 4 e margine petiolorum decurrentibus parum elevatis notati. Folia nerro medio supra subplano, lateralibus utrinque $1-2$ arcuatis, tenuiter v. obsolete reticulato-anastomosantibus, membranacea r. chartacea, margine plana r. subplana. Inflorescentiae axillares $5-8 \mathrm{~cm}$. longe pedunculatae, subcorymbosae, $1-5$-florae; bracteae inferiores euphylloideae sed minores, superiores v. omnes lineares $8-3 \mathrm{~mm}$. longae; rhachicles diaphano-angulatae; pedicelli supra bracteae supremae insertionem $15-5 \mathrm{~mm}$. longi. Calyx inferne vix 
$1,5 \mathrm{~mm}$. crassus; lobi erecti virides membranaceo-marginati. Corolla flava; tubus inferne $1,5 \mathrm{~mm}$., sub apice $3 \mathrm{~mm}$. crassus; lobi $10 \mathrm{~mm}$. longi, $3 \mathrm{~mm}$. lati. Filamenta tubo corollino in $2 / 5$ alt. inserta, dorso supra insertionem calloso-inerassata; antlierae e tubo corollae paullo exsertae, ovales, dorso sub medio affixae, fere $2 \mathrm{~mm}$. longae. Orarium latiuscule lineare, superne obsolete attenuatum. Stylus $16 \mathrm{~mm}$. longus; stigma cum antheris in eadem altitudine situm, crassum obsolete bilobum. Capsula corolla marcescente circumdata et superata, oblonga, 11-12 $\mathrm{mm}$. longa, ca. $3 \mathrm{~mm}$. crassa, bivalvis. Semina breviter ovata, subquadrangularia r. rotundata, saepius subcompressa, ca. 0,3 mm. longa, solemniter subfoveolato-tuberculata, brunea.

Hab. in Haiti prope Gonaïves in Morme Fourmi, $1000 \mathrm{~m}$. alt., in fruticetis apricis, m. Jur. fl. et fr.: Buch n. 761.

Obs. Affinis L. glandulosus A. Rich.! (e Cuba) foliis angustioribus ovato-oblongis $\mathrm{r}$. lanceolatis, corollae tubo in parte $3 / 4$ inferiore cylindraceo, dein ampliato, lobis anguste ovatis tubo 4-jolo brevioribus, staninibus multo altius insertis recedit. - Longius distat L. silenifolius Urb. (Leianthus silenifolius Griseb. e Cuba quem cla. Perkiss in Engl. Jalırb. XXXI p. 492 immerito cum praecedente conjunxit) ramis et rhachide inflorescentiae non striatis, foliis basi latiuscula sessilibus, pedicellis $2-3 \mathrm{~mm}$. longis, calyce $5 \mathrm{~mm}$. longo, lobis ovato-lanceolatis, corollae lobis anguste ovatis thibo ad basin tantum cylindraceo 5 -plo brevioribus, staminibus tubo in $1 / 3$ alt. insertis.

\section{Cluelouanthus frigidus Urb.}

Lisianthus frigidus Sw. Prodr. (17SS) p. 40 et Flor. I p. 352; Spreng. Syst. I p. 587; Hool. Icom. II t. 195; Griseb.! in DC. Prodr. IX p. 78 et Kar. p. 94 et Flor. p. 424; Kew Bull.! n. 81 p. 263; Duss! Flor. p. 402 .

Lisianthus acuminatus Desr. in Lam. Encycl. III (1789) p. 660. Lisianthus grandiflorns Wilistr. Guad. (1828) p. 61; Griseb. Kar. p. 91, - non Aubl.

Helia frigida O. Ktze. Rev. II (1S91) p. 428.

Lis-montagne $v$. Gueule-de-loup-montagne Guad. ex Inss.

Hab. in Guadeloupe in montibus insulae maxime elevatis, e. gr. Sarane à Mulets, Soufrière, Savane aux Ananas, Grande-Découverte etc. inter sphagna, muscos et lycopodia, $1000-1440 \mathrm{~m}$. alt., fere totum per annum florens: Beaupertuis, Bertero, Duss n. 2306, l'Herminier; Dominica in regione muscosa montis Soufrière: ex Swartz et Griseb.; St. Tincent in fruticetis apricis ad Soufrière $600 \mathrm{~m}$. alt. et ultra, m. Jan. fl. et fr.: Eggers n. 6904, Smith n. 18.

Obs. Pollinis granula certissime in tetradibus disposita, prominentiis breviter linearibus notata, plantam generi Chelonanthi attribuunt, sed capsulae orales usque ellipticae erectae a diagnosi generica abhorrent. Filanenta sub apice valde incurva; placentae fructus involutae.

Plumieria Mar(hii Urb. (n. sp.) glaberrima, petiolis $40-80 \mathrm{~mm}$. longis, margine eglandulosis, foliis ellipticis, basi rotundatis, apice 
obtusissimis et breviter mucronatis, $30 \mathrm{~cm}$. longis, $10 \mathrm{~cm}$. latis, in sicco chartaceis, nervo medio supra praesertim superne impresso, lateralibus utroque latere 25-30 (tenuioribus non v. raro intermixtis) sub angulo $70-80^{\circ}$ abeuntibus et ante marginem ipsum conjunctis, utrinque prominulis, supra et subtus in siceo subaequaliter bruneis nitidis, ad basin plicatis, caeterum planis; pedunculis $10-15 \mathrm{~cm}$. longis compressis, prophyllis parvis, pedicellis saepe subcurratis, $10 \mathrm{~mm}$. longis; calycis lobis obovatis, $3 \mathrm{~mm}$. longis; corolla $3,8 \mathrm{~cm}$. longa, lobis obovatis, tubum duplo superantibus, $12-15 \mathrm{~mm}$. latis.

Plumieria Tenorii Griseb.! Flor. (1861) p. 411, - non Gasparr.

Truncess et rami ignoti. Folia petiolis medio $4 \mathrm{~mm}$. latis, nervis lateralibus subrectis, utrinque tenuissime reticulato-anastomosantibus. Inflorescentia subcapitato-contracta, multiflora; bracteae et prophylla ovata usque semiorbicularia, $3,5-2 \mathrm{~mm}$. Ionga, decidua. Calycis lobi dorso medio crassi, ad marginem attenuati, apice saepius obtuse apiculati, 1,5$2 \mathrm{~mm}$. lati. Corollae tubus $12 \mathrm{~mm}$. longus, medio $2 \mathrm{~mm}$. crassus, ad apicem vix ampliatus, glaber, intus breviter pubescens; lobi ca. $23 \mathrm{~mm}$. longi, margine glabri. Stamina tubo corollino $2 \mathrm{~mm}$. supra basin inserta; antherae subsessiles, $2 \mathrm{~mm}$. longae, lineares, superne attenuatae, acutae, dorso supra basin affixae. Styli $2 \mathrm{~mm}$. Iongi, basi et apice liberi, caeterum cylindraceo - incrassati.

Hab. in Jamaica: March n. 1820.

Obs. I. P. Tenorii Gasp. e lescriptione Candolleana foliis oborato-oblongis, basi attenuatis, margine revolutis recedit.

Obs. II. P. bicolor Seem., quam el. Grisebach synonymam laudat, a nostra specie diversa est.

Obs. III. Arcte accedit specimen a cl. Wuldschlatger sub n. 1361 in Jamaica prope Fairfield collectum et a cl. Grisebach infeliciter sub $P$. obtusa enumeratum, quod foliis basi acutis $\mathrm{v}$. in petiolum protractis (15$20 \mathrm{~cm}$. longis, $6,5-8 \mathrm{~cm}$. latis), nervis sub angulo $65-70^{\circ}$ abeuntibus differt. Flores in herb. Gotting. et Monac. deficiunt.

Plumieria stenopetala Urb. (n. sp.), cicatricibus foliorum delapsorum ipsis non v. vix prominulis, sed interdum ad ramos elevatim decurrentibus; petiolis $20-8 \mathrm{~mm}$. longis, margine eglandulosis, foliis elliptico-oblongis usque oblongo-spathulatis, inferne plerumque magis angustatis, basi ipsa plerumque acutatis, apice rotundatis r. brevissime acuminatis, apiculo reflexo, saepius longitrorsum plicatis, $13-5 \mathrm{~cm}$. longis, 4-2 cm. latis, chartaceis v. crassiuscule chartaceis, nervo medio supra anguste canaliculato-impresso, lateralibus utroque latere $20-25$ sub angulo ca. $60^{\circ}$ abeuntibus et usque ad marginem productis, supra glabris, subtus juxta nervum medium et ad basin nervorum lateralium breviter pubescentibus; inflorescentiis $3-7 \mathrm{~cm}$. longe pedunculatis, prophyllis parris, pedicellis $5-8 \mathrm{~mm}$. longis; calycis lobis interioribus suborbicularibus, exterioribus transversim ovali-rectangularibus, rix supra 
$1111 \mathrm{~m}$. longis; corolla alba, $48-50 \mathrm{~mm}$. longa, lobis lanceolatis $\mathrm{v}$. lineari-lanceolatis, tubum duplo superautibus, $4-5 \mathrm{~mm}$. latis.

Ir rangipani $\iota$. Frangipanier Hait.

Arbor 6-8 m. alta (ex Pic.), folia m. Jan. dejicit (ex Ehrenb.). Rami annotini teretes r. foliis decurrentibus plus minus obtusanguli, hornotini hrevissime et minute patenti-puberuli. Folia petiolis $1,3-1,5 \mathrm{~mm}$. latis, supra sulcatis et in sulco brevissime pilosis, basi intus crassiuscule biglandulosis, nervis lateralibus subrectis, ante marginem ipsum conjunctis, brevioribus non raro intermixtis, supra olsolete prominulis r. subimpressis, subtus bene prominentibus, tenuissime reticulato-anastomosantibus, margine plana v. anguste recurva, in sicco brunescentia. Inflorescentiae pedunculo $2-3 \mathrm{~mm}$. crasso, brevissime patenti-pilosulo, terete v. angulato, subcapitato-cymosae, postremo e cincinnis breviter thyrsoideae; prophylla depresse triangularia v. semilunata, $0,5-1 \mathrm{~mm}$. longa, $3-4 \mathrm{~mm}$. lata, decidua. Calycis lobi crasse coriacei, apjice subtruncato brevissime et latiuscule apiculati, 1,2-2 mm. lati. Corollae tubus $12 \mathrm{~mm}$. longus, medio $1,5 \mathrm{~mm}$. crassus, ad apicem vix ampliatus glaber, intus pubescens; lobi $35-38 \mathrm{~mm}$. longi, apice obtusi, margine basali altero breviter pubescentes. Stamina tubo corollino $2 \mathrm{~mm}$. supra basin inserta; filamenta perbrevia; antherae lanceolato-lineares acutae, $2 \mathrm{~mm}$. longae, dorso supra basin affixae. Styli 2,5 $\mathrm{mm}$. longi, basi et apice stigmatifero liberi, caeterum connati et cylindraceo-incrassati.

Hab. in Haiti in Plaine prope St. Marc, m. Jul. flor.: Picarda n. 1608, in saxosis calcareis siccis prope Gouaïves 100 m. alt., m. Mart. flor: Buch n. 346 , in collibus Plaine: C. Elırenberg n. 367.

Plumieria Paulinae Urb. (n. sp.) cicatricibus foliorum delapsorum ipsis vix prominulis, sed crasse et elevatim ad ramos decurrentibus; petiolis 15-20 mm. longis, margine eglandulosis, foliis ellipticis v. oblongis, basi ipsa acutatis, apice obtusissimis v. rotundatis, interdum brevissime acuminatis, $9-12 \mathrm{~cm}$. longis, $4-5 \mathrm{~cm}$. latis, chartaceis, nervo unedio supra anguste impresso, lateralibus ntroque latere $24-28$ sub angulo ca. $60^{\circ}$ abeuntibus et usque ad marginem productis, supra glabris vix nitentibus, subtus praesertim ad nervos breviter pubescentibus; inflorescentiis pedunculatis, multifloris, prophyllis parvis, pedicellis $4-5 \mathrm{~mm}$. longis; calycis lobis interioribus late orbicularibus, exterioribus transversinı rectangularibus, $1 \mathrm{~mm}$. lougis; corolla alba, $50-55 \mathrm{~mm}$. longa, lobis obovato-oblongis, tubum duplo v. ultra superantibus, nsque $12 \mathrm{~mm}$. latis.

\section{Frangipani IIait.}

Rami annotini foliis breriter decurrentibus crasse angulati, hornotini glabri. Folia petiolis medio $1,5-2 \mathrm{~mm}$. latis, brevissime et dense patentipilosis, supra leviter sulcatis, basi intus pluriglandulosis, nervis lateralibus subrectis, ante marginem ipsum conjunctis, brevioribus hinc inde intermixtis, supra subimpressis, subtus tenuiter prominentibus, tenuissime reticulatoanastomosantibus, margine plana $\nabla$. angustissime recurva, in sicco brunes- 
centia. Inflorescentia pedunculo inferme $3 \mathrm{~mm}$. crasso, brevissime patentipiloso, quadrangulo, subcapitato-panniculata; bracteae et prophylla semiorbicularia r. semilunata, $1-0,5 \mathrm{~mm}$. longa, $3-4 \mathrm{~mm}$. lata, decidua. Calycis lobi coriacei, apice truncato biemarginati, $1,5-2 \mathrm{~mm}$. lati. Corollae tubus $16 \mathrm{~mm}$. longus, medio $2 \mathrm{~mm}$. crassus, ad apicem vix ampliatus, extrinsecus glaber v. subglaber, intus pubescens; lobi usque $38 \mathrm{~mm}$. longi, margine altero et intus ad basin breviter et dense pubescentes. Stamina tubo corollino $2,5 \mathrm{~mm}$. supra basin inserta; filamenta subnulla; antherae oblongo-lineares $2 \mathrm{~mm}$. longae. Styli fere $2,5 \mathrm{~mm}$. longi, a $2 / 5$ alt. usque ar stigmata cylindraceo-incrassati v. quasi tubo cylindraceo circumdati.

Hab. in Haiti in territorio Plaine dicto in saxosis calcareis siccis, 100 m. alt., m. Martio flor.: Buch n. 348 .

Obs. In lonorem beatae Amaliae Paulinae Wilhelminae e gente Dieck, uxoris cl. Buchi ejusque in itineribus botanicis comitis, quae die $21 \mathrm{~m}$. Jan. 1900 diem obiit supremum.

Plumieria biglandulosa Urb. (n. sp.) petiolis $15-20 \mathrm{~mm}$. longis, in $1 / 3$ alt. glandulas binas lineares $1-2 \mathrm{~mm}$. longas gerentibus, foliis elliptico-lanceolatis, utrinque subaequaliter $v$. ad basin paullo magis angustatis, basi acutis, apice obtusiusculis 5 . brevissime acuminatis, 15-17 cm. longis, $5-6 \mathrm{~cm}$. latis, in sicco chartaceis, nerro medio supra impresso, lateralibus utroque latere ca. 40 (tenuioribus et brevioribus saepius interjectis) sub angulo $55-60^{\circ}$ abeuntibus et usque ad marginem productis, supra rix prominulis, utrinque glabris; prophyllis parvis; pedicellis $5-10 \mathrm{~mm}$. longis; calycis lobis breviter et late orbicularibus, vix $2 \mathrm{~mm}$. longis; corolla alba, $5,5-6 \mathrm{~cm}$. longa, lobis oboratis v. anguste obovatis, tubnm duplo superantibus, $15-$ $20 \mathrm{~mm}$. latis.

\section{Frangipani inc. Hait.}

Rami mihi non visi. Folia petiolis medio ca. $4 \mathrm{~mm}$. latis, glandulis eorum inferne sensim incrassatis, nervis lateralibus ante marginem ipsum conjunctis, interpositis ca. in medio lateris utriusque evanescentibus, ommibus dense et oblique, supra obsoletius, subtus manifeste anastomosantibus, margine plana, in sicco nigrescentia et fragilia. Inflorescentia verisimiliter $1,5-2,5 \mathrm{~cm}$. tantum longe pedunculata, subcapitato-cymosa, breviter patentipilosa; prophylla semiovalia usque lunata, $2,5-1,5 \mathrm{~mm}$. longa, decidua. Calycis lobi coriacei, apice subtruncato bis emarginati, $2-2,5 \mathrm{~mm}$. lati. Corollae tubus $18-20 \mathrm{~mm}$. longus, $3 \mathrm{~mm}$. crassus, ad apicem paullo ampliatus, extrinsecus parce et breviter pilosus, intus pilis erectis brevibus plus minus obsitus; lobi $35-40 \mathrm{~mm}$. longi, margine altero breriter ciliati. Stamina tubo corollino $2 \mathrm{~mm}$. supra basin inserta; filamenta perbrevia, $0,5 \mathrm{~mm}$. longa; antherae lineari-lanceolatae, dorso supra basin insertae, $2,5 \mathrm{~mm}$. longae. Styli $2,5 \mathrm{~mm}$. longi, basi et apice stigmatifero liberi. caeterum connati et incrassati (quasi tubo duplo crassiore circumdati).

Hab. in Haiti in collibus prope Gonaives: Buch n. 217.

Obs. Habitu affinis $P$. mexicanae Lodd. 
Plumieria gibbosa Urb. (n. sp.) ramis superne cicatricibus foliorum delapsorum valde hippocrepiformi-prominentibus dense aggregatis obsitis; petiolis $30-15 \mathrm{~mm}$. longis, margine eglandulosis, foliis anguste oblongis, ad basin paullo magis angustatis, basi ipsa obtusis, apice rotundatis, $15-10 \mathrm{~cm}$. longis, $3,5-2 \mathrm{~cm}$. latis, crassiuscule chartaceis, nervo medio supra anguste impresso, lateralibus utroque latere $27-32$ sub angulo $75-85^{0}$ abeuntibus et fere usque ad marginem productis, utrinque praeter pubem parcam brevem subtus ad nervos laterales obriam glabris nitidis; pedunculis ca. $10 \mathrm{~cm}$. longis, prophyllis parvis; pedicellis 7-10 mm. longis; calycis lobis semiorbicularibus v. transversim ovalibus, $1 \mathrm{~mm}$. longis; corolla $3,8-4 \mathrm{~cm}$. longa, lobis obovato-ellipticis, tubum plus quam duplo superantibus, $10 \mathrm{~mm}$. latis.

Frangipani épineux Hait.

A rhor 5-6 m. alta. Rami annotini cicatrices forma hippocrepidis dorso interdum bituberculato valde (usque $4 \mathrm{~mm}$.), ad latera sensim minus prominentes crebros gerentes, hornotini glabri. Folia petiolis medio $1-1,5 \mathrm{~mm}$. latis, supra anguste et profunde sulcatis, parce breviter et tenuiter pilosis, basi intus pluriglandulosis, nervis lateralibus subrectis, ante marginem conjunctis, brevioribus interpositis parcis, supra tenuissime, subtus magis prominentibus et tenuissime reticulato-anastomosantibus, margine plana v. anguste recurva, in sicco bruneo-nigrescentia. Inflorescentia pedunculo inferne ca. $6 \mathrm{~mm}$. lato glabro, compresso (an semper?), breviter panniculata, ramis in cymas excurrentibus breviter puberulis, multiflora; bracteae et prophylla semiorbicularia v. semilunata, $1-0,5 \mathrm{~mm}$. longa, $2-3 \mathrm{~mm}$. lata, decidua. Calycis lobi crasse coriacei, apice truncati, $1,2-1,7 \mathrm{~mm}$. lati. Corollae tubus $12 \mathrm{~mm}$. longus, medio $1,3 \mathrm{~mm}$. crassus, ad apicem vix ampliatus, extrinsecus glaber, intus pubescens; lobi ca. $25 \mathrm{~mm}$. longi, margine infero altero pilosi, caeterum glabri. Stamina tubo corollino vix $2 \mathrm{~mm}$. supra basin inserta; filamenta vix $1 \mathrm{~mm}$. longa; antherae subiineares $1,5 \mathrm{~mm}$. longae, dorso supra basin insertae. Styli $2 \mathrm{~mm}$. longi, basi et apice stigmatoso liberi, caeterum cylindraceo-incrassati.

Hab. in Haiti in Savane brûlée ad Petite Rivière de l'Artibonite, m. April. flor.: Picarda n. 1600.

Plumieria domingensis Urb. (n. sp.) ramis superne cicatricibus foliorum delapsorum valde hippocrepiformi-prominentibus dense aggregatis obsitis; petiolis $25-30 \mathrm{~mm}$. longis, margine eglandulosis, foliis obovatis v. obovato-oblongis, basi obtusis r. acutatis, apice rotundatis v. subtruncatis, nunc emarginatis, $10-13 \mathrm{~cm}$. longis, $5-6 \mathrm{~cm}$. latis, coriaceis, nervo medio supra subimpresso, lateralibus utroque latere $30-35$ sub angulo $75-80^{\circ}$ abeuntibus et fere usque ad marginem productis, supra glabris, subtus griseo-tomentosulis; pedunculis $16-$ $18 \mathrm{~cm}$. longis, prophyllis parvis, pedicellis $5-8 \mathrm{~mm}$. longis; calycis lobis semiorbicularibus, vix $1,5 \mathrm{~mm}$. longis; corolla alba, $3,5-3,8 \mathrm{~cm}$. longa, lobis anguste obovatis $\mathrm{v}$. obovato-ellipticis, tubum dimidio r. fere duplo superantibus, $9-12 \mathrm{~mm}$. latis. 
Frutex $2 \mathrm{~m}$. altus (ex EGG.). Rami annotini cicatrices forma hippocrepidis v. potius nidi hirundinis dorso valde (usque $5 \mathrm{~mm}$.), ad latera sensim minus prominentes crebros gerentes, glabrescentes, hornotini dense et breviter griseo-pubescentes. Folia petiolis medio 2,5-4 $\mathrm{mm}$. latis tomentosulo-pubescentibus, basi intus pluriglandulosis, nervis lateralibus ante marginem conjunctis, brevioribus interpositis nullis v. subnullis, supra tenuibus, tenuissime reticulato-anastomosantibus et postremo plicatulis, margine plana v. late recurva, supra nitida, in sicco brunescentia. Inflorescentia pedunculo inferne ca. $5 \mathrm{~mm}$. crasso, breviter et tenuiter pubescente, dense capitatocymosa, multiflora; prophylla semilunaria, 1,5-1 mm. longa, 2-3 mm. lata. Calycis lobi crasse coriacei, apice subtruncati, $2-3 \mathrm{~mm}$. lati. Corollae tubus $10-14 \mathrm{~mm}$. longus, $2-2,5 \mathrm{~mm}$. crassus, ad apicem rix ampliatus, extrinsecus glaber, intus pilis brevibus erectis dense instructus; lobi $20-27 \mathrm{~mm}$. longi, margine parce pilosi v. glabri. Stamina tubo corollino $2 \mathrm{~mm}$. supra basin inserta; filamenta vix $1 \mathrm{~mm}$. longa; antherae lineari-lanceolatae $2 \mathrm{~mm}$. longae, dorso supra basin insertae. Styli $2 \mathrm{~mm}$. longi, basi et apice stigmatoso liberi, caeterum connati et incrassati.

Hab. in Haiti: Poiteau; Sto. Domingo prope Puerto-Grande ad Susua in rupibus calcareis ad maris litora, m. Junio flor.: Eggers n. 2593 .

Obs. Affinis $P$. sericifoliae $\mathrm{Wr}^{\mathrm{r}}$. (e Cuba), quae foliis brevius petiolatis oblongis, pedunculo duplo breviore, corollis $50 \mathrm{~mm}$. longis, lokis ellipticooblongis $7-8 \mathrm{~mm}$. latis recedit.

\section{$\checkmark$ Jacquemontia verticillata Urb.}

Ipomoer verticillata Linm. Syst. I ed. II (1759) p. 924; Elmgr. in Limn. Amoen. V p. 394.

Convolvulus verticillatus Limn. Spec. II ed. I (1762) p. 220; Lun. Jam. I p. 88; R. et Sch. Syst. IV p. 276 (non H. B. K., qui est J. nodiflora).

Convolvulus parviflorus Desr. in Lam. Enc. III (1789) p. 556 (non Trahl 1791, nec Salisb. 1796).

Convolvulus polycarpus H. B. K.! Tor. Gen. III (1818) p. 98; R. et Sch. Syst. IV p. 301; Kth. Syn. II p. 214.

Convolvulus micranthus R. et Sch. Syst. IT (1819) p. 276; Choisy in DC. Prodr. IX p. 414; A. Rich. in Sagra Cuba XI p. 133; Griseb.! Flor. p.474 et Pl. Wr. II p. 527 et Cat. p. 207; Meissn. in Mart. Flor. Bras. VII p. 311; Sauv. Cub. n. 1675 p. 108; Ma乞a Periant. p. 272; Kev Bull. n. 81 p. 265 (non Willd. 1825).

Comrolvulus Plumerii Spreng. Syst. I (1825) p. 602.

Ipomoea polycarpa G. Don Gen. Syst. IV (1S38) p. 270.

.Jacquemontia micrautha G. Don Gen. Syst. IV (1838) p. 283.

Quamoclit purpurea solanifolia minor Plum. Msc. vol. II tab.62 (ex Burm. et Desrouss.).

Conrolvulus minor scandens, flor. plur. alaribus P. Br. Jam. (1756) p. 153 n. 6. 
Ipomoea foliis cordato-oblongis simosis, flor. vertic. Plmm. ed. Bmm. (1756) p. 83 tab. 94 f. 2 !

Hab. in Baham. Andros in Conch Sound m. Mart. fr.: Northrop n. 424; Cuba: La Sagra, Valenzuela, prope Habana ad Regla: Humboldt et Bonpland n. 1278 (in herb. Willd. n. 3657), prope Castillo de Jagua 11. Sept. fl. et fr.: Combs n. 548; Jamaica: March n. 1167; Haiti: Ehrenberg, Nectoux, Poiteau, prope Jérémie in montibus m. Jan. fl. et fr.: Picarda 11. 1390; Sto. Domingo: Bertero; St. Vincent: Guilding ex Griseb.; Trinidad: ex Griseb.

Var. $\beta$. stenophylla Urb. foliis lanceolato-linearibus v. sublinearibus, supra basin $2-5 \mathrm{~mm}$. latis; sepalis anguste r. filiformi-acuminatis.

Comrolulus micranthus Griseb. Pl. Wr. II p.527 et Cot. p.207; Sam. l.c.; Mara l. c. (p. p.).

Hab. in Cuba: Wright n. 455, 1654.

Jacquemontia jamaicensis Hall. f. valde variabilis, quoad folia saepius in eodem specimine; foliis $1-15 \mathrm{~mm}$. longe petiolatis, linearibus, oblongis, ellipticis, ovato-oblongis, ovato-lanceolatis, ovatis r. obovatis, apice acutis $\mathrm{v}$. plerumque obtusis et breviter mucronatis $r$. emarginatis, basi sensim in petiolum angustatis v. obtusis v. rotundatis $\mathrm{v}$. truncatis, $2-25 \mathrm{~mm}$. latis; inflorescentiis pauci- v. unultifloris; corolla $10-15 \mathrm{~mm}$. longa in $2 / 5$ alt. coalita alba, interdum roseo-colorata, sed sepalis exterioribus interiora semper obsolete v. manifeste superantibus 2,8-3,3 mm. longis obtusis $\mathrm{v}$. acutatis; valvis $5-6 \mathrm{~mm}$. longis.

Jacquemontia jamaicensis Hall.f. edid. Solereder Syst. Anat.(1899) p. 641 .

Convolvulus jamaiccnsis Jacq. Obs. III (1768) p 6; Choisy in DC. Prodr. IX p. 414; Griseb.! Flor. p. 474 et Cat. p. 207; Saur. Cub. n. 1676 p. 10s; Egg.! St. Croix p. 132 et St. Croix and Virg. Isl. p. 73; Gard., Br. et Doll. Bah. p. 393; Hitche. Bah. p.110; Millsp. in Field Col. Mns. Bot. II p. S8.

Convolvnlus rnderorins H. B. K.! Nov. Gen. III (1818) p. 96; Spreng. Syst. I p. 609; Choisy in DC. Prodr. IX p. 414; A. Rich. in Sagra Chb. XI p. 131.

Convolvmlus frondosus Willd.! Msc. ed. R. et Sch. Syst. IV (1819) p. 303; Spreng. Syst. I p. 610; hb. Willd. n. 3662!

Ipomoca ruderaria G. Don Gen. Syst. IV (1S38) p. 267.

Convolvulns jamaicensis $\beta$. major A. Rich. in Sogra Cuba XI (1850) p. 134; Walp. Am. Y p. 534.

Conrolvulus haranensis Griseb.! Pl. Wr. (1S62) p. 527 (var. corolla majori) et Cat. p. 207; Sonu. Cub. n. 1678 p. 108; Chapm. Flor. 
S. U. St. II ed. p. 640 et III ed. p. 329; A. Gray Syn. Flor. II. 1 p. 435, - non Jacq.

Convolvulus Garberi Chapm. in Bot. Gar. III (187s) p. 11.

Jacquemontia raderaria IIall. f.! in Engl. Bot. Jahtrb. XVI (1893) p. 543.

Linum scandens flore dilnte purpareo Sloane Cat. (1696) p. 89 et Hist. I p. 206 tab. 130 f. I!

Hab. in Florida austr. locis arenosis ex Cliapm. et Gray; in Bahia Honda Key: Curtiss n. 2171*; Baham. New Providence ad Killarney 111. Iart. fl.: Eggers n. 4367, ad Nassau 11. Jan. fl.: Northrop n. 135, Eleuthera et Cat Island ex Hitchc., Hog Island: Egger's n. 4057, Crooked Island ex Hitchc., Fortune Island: Eggers n. 3853 (foliis obovatis), 3822 (fol. linearibus), Acklins Island: Eggers n. 3904; Cuba: Sagra, Wright n. 1653, prope Habana: ex herb. Humb., ad Castillo de Jagua: Combs n. 557, prope Matanzas: Rugel n. 155 (p. p.); Jamaica: Hansen, March n. 1168; Haiti: Poiteau, ad Habitation Prince ne. Dec. fl. et fr.: Picarda 11. 1551 (p. p.), in Morne des Platons $400-500$ m. alt.: Picarda 11. 1181; Sto. Domingo: Mayerhoff; Cayman ex Millsp.; Portorico in Cabeza de San Juan, prope Bayamon in fruticetis litoralibus, prope Guantea in rupibus litoralibus ad Punta de los pescadores, in Monte El Maniel (form. foliis obovatis r. anguste oratis crassiuscule coriaceis, inflor. 1-3floris), in fruticetis litoralibus ad Salinas, in monte Puerco, prope Salinas de Cabo-rojo in litoralibus, m. Febr. fl. et fr., prope Mayagüez: Krug n. 780 , Schwanecke, Sintenis 11. 588 b $2481^{\mathrm{b}}, 3355,3452,3453,3454^{\mathrm{b}}$, Stahl n. 792; St. Thomas in fruticetis ad Northside Bay, m. Dec.Febr. fl.: Eggers ed. Toepff. n. 139; Water Island ex Egg.; St. Croix ex Egg., - praeterea Yucatan ex Millsp.

\section{Jacquemontia serpyllifolia Urb.}

Convolvulus serpyllifolius H. B. K.! Nov. Gen. III (181S) p. 95; Kunth Syn. II p. 212.

Ipomoea serpyllifolia. G. Don Gen. Syst. IV (1838) p. 267; Choisy in DC. Prodr. IX p. 351; A. Rich. in Sagra Cub. XI p. 130; Griseb. Cat. p. 206; Saut. Cub. n. 1672 p. 108; Maia Periant. p. 271.

Convoludus Valenzuelanus A. Rich. in Sagra Cul). XI (1850) p.134; Walp. Ann. V p.533; Griseb.! Cat. p. 207; Sanr. Cul. u. 1675 p. 108; Mara Periant. p. 272.

Hab. in Cuba: Wright 11.3101, prope Habana ad Regla: Humboldt et Bonpland n. 4509, ad Guanabacoa in campis siccis, m. Oet., Dec. fl.: Morales 11. 43, Torralbas 11. 121, in Vuelta Abajo: Valenzuela.

Obs. I. Rami recti v. volubiles, interdum in eodem specimine.

Obs. II. Ill. Kinnth l. c. Concolvulo polycarpo suo patriam "prope Regla et Omitlan Hexicanorum", C. serpyllifolio "loca temperata prope Moran et 
Regla alt. 1250 hex. Nova Hispania" adscripsit, sed sine ulla dubitatione errore calami infelici. Nam prior in herb. Willd. sub n. $3657 \mathrm{cum}$ schedula originaria "Havana, Regla n. $1278 \mathrm{leg}$. Humboldt" et in herbario generali a manu Kunthiana ipsa fere eodem modo (Bonpl. msc. n. 1278) inscriptus asservatur. Ulteriori in herb. gen. cl. Kunti ipse „Insula Cubae Regla. Ex herb. Humboldt n. 4509" adnotavit. Regla est non solum urbs mexicana, sed etiam urhs parva prope Habana in Cuba; quomodo Omitlan (sine dubio mexicanum) et Moran in textum Kunthianum irrepserint, nescio. Quia hae species a nemine in continente iterum repertae sunt (cf. Hemsl. Biol. II p. 393,397$)$, J. serpyllifolia et verticillata in flore mexicana delendae sunt.

Jacquenontia havanensis Urb. caulibus rectis, brevissime pulverulento-pilosis; foliis $1,5--5 \mathrm{~mm}$. longe petiolatis, anguste ovatis, ovato-oblongis $\mathrm{v}$. oblongis, basi obtusis, apice rotundatis v. subtruncatis, non r. vix apiculatis, $5-15 \mathrm{~mm}$. longis, $3-6 \mathrm{~mm}$. latis, rigidis coriaceis, margine recurvis; inflorescentiis semper 1 -floris, prophyllis minutis r. obsoletis, pedunculis (cum pedicellis) $6-9 \mathrm{~mm}$. longis; sepalis exterioribus 2 obovatis v. suborbicularibus, apice rotuncatis ca. $1,5 \mathrm{~mm}$. longis, interioribus late orbicularibus brevissime v. obsolete apiculatis, $2 \mathrm{~mm}$. longis, exteriora manifeste superantibus; corolla $10 \mathrm{~mm}$. longa, lobis tubum longitudine aequantibus, oratis obtusis, margine lato membranaceo; staminibus tubo $1,5 \mathrm{~mm}$. supra ejus basin affixis inferne papillosis; stigmatum lobis (e statu juniore) ovatis; capsulis $3 \mathrm{~mm}$. longis; seminibus ovatis anguste marginatis.

Convolvulus havanensis Jacq. Obs. II (1767) p. 25 tab. 45 f. 3 ! et Amer. pict. tab. 264 f. 97; R. et Sch. Syst. IV p. 282; Spreng. Syst. I p. 606, - non autor. recent.

Ipomoca havanensis Chois. in DC. Prodr. IX (1845) p. 368; A. Rich. in Sagra Cuba XI p. 132.

Hab. in Cuba prope Havana ex Jacq., prope Matanzas: Rugel n. 155 (p. p.).

Obs. Omnia cum descriptione Jacquiniana bene congruunt petalis exceptis, cujus margines latos membranaceos ill. autor praetervidit; corollae lobi genuini sunt ut in icone lanceolato-lineares acuti. - J. serpyllifolia Urb. praesertim foliis duplo et ultra minoribus, petiolis duplo tenuioribus, sepalis exterioribus acuminatis, interiora longitudine aequantibus 5 . paullo superantibus, corolla $6-7 \mathrm{~mm}$. longa in $1 / 3$ alt. gamopetala recedit.

Operculina leptoptera Urb. (n. sp.) ramis ca. 1 mm. late membranaceo-alatis, brevissime et parce adpresseque pilosulis; foliis $3-0,8 \mathrm{~cm}$. longe petiolatis, ambitu triangulari-ovatis, basi profunde cordatis, superne sensim angustatis, acutis v. obtusiusculis, apice breviter aristatis, majoribus ca. $8 \mathrm{~cm}$. longis, supra basin $5-6 \mathrm{~cm}$. latis, margine integris subintegrisve, utrinque minute et parce pilosulis, subtus praesertim ad nervos; inflorescentiis $5-8$-floris, bracteis lanceolato-oblongis v. ob- 
longis, breviter acuminatis, $17-10 \mathrm{~mm}$. Iongis, pedicellis $3-3,5 \mathrm{~cm}$. longis; sepalis flavo-viridibus, $17-22 \mathrm{~mm}$. longis, extrinsecus molliter tomentosulis; corolla violacea, $50-55 \mathrm{~mm}$. longa, calycem triplo superante.

Rami rolubiles, ipsi angulato-subteretes, sed alis e petiolorum margine decurrentibus 3 obsiti, herbacei, quoad suppetunt $2-2,5 \mathrm{~mm}$. crassi. Folia petiolis breriter patenti-pilosis, sinu basali fere $1 \mathrm{~cm}$. profundo, lobis basalibus rotundatis, nervis utroque latere $7-8$, infimis 3 valde approximatis, caeteris sub angulo ca. $50^{\circ}$ abeuntibus paullo arcuatis, omnibus utrinque prominulis tenuissime transversim anastomosanti-conjunctis, membranacea, utrinque obsctre viridia. Inflorescentiae pedunculis $3,5-5 \mathrm{~cm}$. longis breviter patenti-pilosis, ex sicco purpureo-brunescentibus, vix alatis, corymbosae, in monochasia abeuntes; bracteae pallidae, dorso brevissime patenti pilosae, explanatae $6-7 \mathrm{~mm}$. latae, membranaceae; pedicelli superne paullo et sensim incrassati, sub apice $2 \mathrm{~mm}$. crassi. Sepala ovata, $12-14 \mathrm{~mm}$. lata, apice obtuso r. rotundato breviter mucronata, exteriora $20-22 \mathrm{~mm}$., interiora $17-18 \mathrm{~mm}$. longa, haec magis membranacea et dorso glabra, illa brevissime et medio dorso longius pubescentia, omnia nervis permultis, sed extrinsecus non conspicuis percursa. Corolla usque $9 \mathrm{~mm}$. supra basin anguste campanulata et hoc loco in statu compresso $7 \mathrm{~mm}$. lata, dein subito et valde dilatata, glabra. Stamina tubo corollae $8 \mathrm{~mm}$. longe adnata, quoad libera ca. $10 \mathrm{~mm}$. longa, glabra, sensim angustata; antherae ca. $4 \mathrm{~mm}$. longae, demum contortae, paullo supra basin affixae; pollinis granula laevia, plicis 3 munita. Gynophorum ca. $1 \mathrm{~mm}$. longum, margine superiore in discum brevem annularem abiens. Ovarium globosum glabrum, 2 -loculare, ovulis in quoque loculo 2 ovatis, apice subito in stylum contractum; stylus $18 \mathrm{~mm}$. longus, superne sensim attenuatus; stigma bilobum, lobis patentibus.

Hab. in Martinique, Hauteurs des Trois Islets: Duss n. 426.

Obs. Affinis O. triquetrae (Vahl) Hallier f. (e St. Croix et St. Thomas), quae ramis angustius (ca. $0,5 \mathrm{~mm}$. late) alatis foliisque densius et molliter pubescentibus, inflorescentiis $1-2$-floris (v. ex VAHL $3-5$-floris), pedicellis $1,2-2 \mathrm{~cm}$. longis, calyce postremo roseo et praesertim corolla alba. sepala dimidio v. $2 / 3$ superante $28-32 \mathrm{~mm}$. longa recedit. Longius distant O. ventricosa (Choisy) Peter (e St. Barthelemy, Antigua, Guadeloupe, Martinique), a cl. HALLIER in Engl. Jahrb. XVIII p. 120 infeliciter cum praecedente conjuncta, ramis non alatis, foliis cordiformibus acıminatis, sepalis $30-40 \mathrm{~mm}$. longis, corollis albis $70-95 \mathrm{~mm}$. longis, fructu(?) et $O$. alata Urb. (Comolvilus alatus Ham. 1825, Ipomoea altissima Mart. 1845, Operculina altissima Meissn. 1869, I. pterodes Choisy 1845, O. pterodes Meissn.! e Cuba: Wright n. 3083 p. p., St. Vincent?: Smith n. 1159, Grenada: Eggers n. 6495, Tobago: Eggers n. 5471, Trinidad: Hart n. 2172, Venezuela, Guiana, Brasilia) sepalis glabris, bruneo-rubris aequilongis $r$. interioribus perpaullo longioribus $22-25 \mathrm{~mm}$. longis, corolla lıtea a basi late campanulata, calycem duplo superante.

\section{Opereulina macrocarpa Urb.}

Convolvulus macrocarpus Linn. Syst. X ed. II (1759) p. 923 et Spec. II ed. I p. 222. 
Convolvulus operculatus Gomer in Mem. Acad. Lisb. III (1812) 1Kem. Corresp. 27 ex Ind. Kew. I p. 604.

Ipomoea operculata Mart.! in Spix und Martius Reise in Bras. II (182S) p. 547; Choisy in DC. Prodr. IX p. 361; Griseb.! Kar. p. 100.

Operculina conrolvulus Silva Manso Enum. Subst. Bras. (1S36) p. 12, 49 ex Ind. Kew. II p. 352; Meissn.! in Mart. Flor. Bras. VII p. 211 (cum synon.) tab. 74; Hall. f. in Jahrb. Haml. Anst. XVI Beiheft 3 p. 39.

Convolvulus polyphyllos, flore et fructu purpureis maximis Plum. Cat. (1703) p. 1.

Convolvulus foliis pedato-palmatis Plum. ed. Burm. (1756) p.SO tab. 91 f. 1 !

Hab. in Guadeloupe in sepibus, m. Dec., Jan. fl.: Duchassaing, - praeterea Brasilia.

Obs. Species Linnaeana in Plum. l. c. condita nostram plantam cum icone Plumieriana optime congruentem sine ulla dubitatione praebet. Icon in Flora Bras. recedit foliis solemniter digitatis nec pedatis, et descriptio corollam albam offert. An formae diversae, an color corollae a cl. Plumier erronee "purpureus" indicatus?

Ipomoea tomentosi Urb. (non Choisy 1838).

Convolvulus tomentosus Linn. Spec. I ed. I (1753) p. 156 et II ed. I p. 222; Lun. Jam. I p. 90; Roem. et Sch. Syst. IT p. 264; Spreng. Syst. I p. 594.

Convolvulus jamaicensis Spreng. Syst. I (1825) p. 595, - non Jacq.

Ipomoea jamaicensis Don Gen. Syst. IV (1837) p. 278 (diagnosis e cl. Spreng. mutuata); Choisy in DC. Prodr. IX p. 384 (item); Griseb.! Flor, p. 473 (excl. var. $\beta$ ).

Pharbitis tomentosa Choisy in DC. Prodr. IX (1545) p. 342; Hall. f. in Engl. Jahrl. XVIII p. 137.

Convolvulus jamaicensis trilobatus foliis tomentosa lanugine densiori et levissima Pluk. Alm. (1696) p. 115 tab. 167 f. 4!

Convolvulus folio lanato in tres lacinias diviso Sloane Cat. (1696) p. 55 et Hist. I p. 154 tab. 98 f. 2 !

Convolvulus scandens, foliis trilobis quandoque cordatis P. Br. Jam. (1756) p. 152.

Hab. in Jamaica: Bertero, March, - praeterea in Panama (ex Hall. f. l. c.).

Obs. I. Cl. Bertero labello speciminis berolinensis suo inscripsit: „Convolvulus tomentosus L. e Jamaica var. glabritie et tomento". Hoc specimen foliis supra brevissime, subtus breviter et adpresse pubescentibus, pedunculis brevissime pubescentibus, sepalis margine brevissime, dorso obsolete 
pilosulis gaudet. Cl. Sprexger pro suo Conv. jamaicensi sine dubio exemplar quoad pedunculos calycemque glabrius Berteroanum ante oculos labuit.

Obs. II. I. acuminata (Vahl) R. et Sch. late divulgata a specie praecedente foliis glabris r. minus pubescentibus, plerumque integris, sepalis saepius distantibus, corollae tubo magis ampliato et extrinsecus ninus intense colorato vix specifice differt.

$\checkmark$

Ipomoea flaro-purpurea Urb. annua $S-15 \mathrm{~cm}$. alta glabra; foliis pedatim $3-5$-partitis; sepalis orato-oblongis subulato-acuminatis, dorso parce pilosis; corolla flava, tubo inferne intus purpureo.

Ipomoea punctata C: Wright in Sanu. Cub. (1870) n. 1632 p.105, - non Macf. (1831) nec C. Wright (1866).

Hab. in Cuba prope Trinidad en las sabanas del potrero Manatí y en Casilda m. Mart. fl.: Wright n. 3645 , ibidem in savannis solo arenoso, m. Mart. flor.: E. Otto n. 143.

Obs. Si I. punctata Macf. in Hook. Bot. Misc. II (1831) p. 116 (e Jamaica) cum specie vetustiore (fortasse ex affinitate $I$. acuminatae $\mathrm{R}$ et Sch.) congruit, nomen Wrightianum ei speciei, quae a cl. Grisebach in Cat. cub. 1866 p. 202 sub $I$. digitata L. var. enumerata est et quae non solum ab I. digituta L., sed etiam ab I. panniculata (L.) R. Br. habitu simili specifice differt, conserranclum est, quanquam diagnosis Grisebachiana nimis brevis est.

Ipomoea rubra Millsp. in Field Col. Mns. Bot. II (1900) p. 86 . - Convolvulus mber Vahl Eclog. II (1798) p. 12. - Ipomoea setifera Poir.! in Lam. Enc. VI (1804) p. 17. - Portorico, Guadeloupe, Martinique, St. Vincent, Amer. cent. tropica, Senegambia.

Tar. $\beta$. albo-flavida Urb. floribus pallide flavidis.

Ipomoea ciliolata Stahl! Est. VI (1888) p. 153, - non Pers.

Hab. in Portorico prope Bayamon passim, sed parum frequens, m. Dec. flor.: Stahl n. 791.

Var. $\gamma$ palustris Urb. foliis multo angustioribus, inflorescentiis 1 -floris, bracteis ovatis $6 \mathrm{~mm}$. longis, calycis costis alato-prominentibus crenulatis, corolla quam in typo duplo minore $2,5-3 \mathrm{~cm}$. longa.

Hab. in Portorico prope Bayamon in pratis paludosis ad Palo seco, m. April. flor.: Sintenis n. 962.

$\checkmark$ Iponoea Walpersiana Duchassaing Msc. (n. sp.) glabra; ramis plus minus $3-4$-angularibus; foliis $t-9 \mathrm{~cm}$. longe petiolatis, inferioribus triangularibus basi subtruncatis $7-9 \mathrm{~cm}$. latis, $6-8 \mathrm{~cm}$. longis, acuminatis, superioribus anguste ovatis $v$. orato-triangularibus, plerumque fere a basi sensim angustatis r. subacuminatis, basi late cordatis, lobis patentibus, $3,5-5 \mathrm{~cm}$. latis, $5-7 \mathrm{~cm}$. longis, margine integris; inflorescentiis $3-15 \mathrm{~cm}$. longe pedunculatis, corymbose pluri- r. multifloris, bracteis omnibus hypsophylloideis, pedicellis $15-20 \mathrm{~mm}$. longis; 
sepalis glabris, valde inaequilongis, exterioribus $4-6 \mathrm{~mm}$., interioribus $7,5-8 \mathrm{~mm}$. longis, omnibus apice rotundatis; corolla colore?, $50 \mathrm{~mm}$. longa, infundibuliformi-cylindracea, tubo in statu compresso supra medium $8 \mathrm{~mm}$. lato, limbo ut videtur integro.

Rami plus minus $3-4$-angulares, multistriati, fructiferi usque $3,5 \mathrm{~mm}$., floriferi 1,5-2 mm. crassi. Folia petiolis supra anguste sulcatis, nervis secundariis ntroque latere $6-9$, infimis $3-4$ ad basin abeuntibus, caeteris sub angulo $40-45^{\circ}$ e medio prodeuntibus, omnibus supra prominulis, subtus manifeste reticulato-anastomosantibus, chartacea v. crassiuscule chartacea. Inflorescentiae pedunculo inferne v. ad basin terete, superne plus minus compresso, $1,5-3,5 \mathrm{~mm}$. lato, breviter racemosae, ramis 1 -paucifloris; bracteae et prophylla orata $\mathrm{v}$. anguste ovata $1,5-1 \mathrm{~mm}$. longa; pedicelli angulati, medio ca. $0,8 \mathrm{~mm}$. crassi. Flos unicus tantum obvius, imperfecte examinatus. Sepalım extimum orbiculare, $4 \mathrm{~mm}$. longum et latum, dorso sub apice obsolete apiculatum, anguste marginatum, sequens late ovatum $5,5-6 \mathrm{~mm}$. longum, 4,5 $\mathrm{mm}$. latum, intermedium suborbiculare inaequilaterum $7 \mathrm{~mm}$. longum, $6,5 \mathrm{~mm}$. latum, intima suborbicularia $7,5-8 \mathrm{~mm}$. longa, margine latiuscule membranaceo-attenuata, omnia luce permeante nervis numerosis ramosis et anastomosantibus, extrinsecus paullo conspicuis percursa. Corollae radii mesopetali lineari-lanceolati. Filamenta plane inclusa, longiora usque ad basin corollae $18 \mathrm{~mm}$., breviora $13 \mathrm{~mm}$. longa; antherae latiuscule lineares, superne attennatae et recurvae, $3,5 \mathrm{~mm}$. longae, in $1 / 5$ alt. affixae. Discus annularis brevis. Stylus ca. $16 \mathrm{~mm}$. longus glaber; stigma didymum. Ovarium ovato-globulosum, in stylum attenuatum, 2 -loculare, orulis in quoque loculo 2 ovato-oblongis. Capsula globulosa 10-12 mm. diametro, 4-valvis; valvae ovato-ellipticae ca. $15 \mathrm{~mm}$. longae, $7-8 \mathrm{~mm}$. latae. Semina ambitu suborbicularia, $5 \mathrm{~mm}$. longa, bruneo-nigrescentia, dorso et ventre brevissime velutina, margine basi excepta pilis usque $5 \mathrm{~mm}$. longis albidis patentibus restita.

Hab. in Guadeloupe: Duchassaing.

$\checkmark$ Ipomoea trinitensis Urb. (n. sp.) ramis teretibus, supra et sub foliorum axillis parce patenti-pilosis, caeterum glabris subglabrisve; foliis $4,5-6 \mathrm{~cm}$. longe petiolatis, ovatis, basi profunde cordato-sinuatis, apice acuminatis, $7,5-10 \mathrm{~cm}$. longis, $4-6 \mathrm{~cm}$. latis, margine integris v. supra medium dente $v$. crena solitaria notatis, utrinque dense et molliter pubescentibus; inflorescentiis $4-10 \mathrm{~cm}$. longe pedunculatis, corymbose pluriv. multifloris, bractea infima saepius magna euplyylloidea, caeteris parvis hypsophylloideis, pedicellis primariis $7-12 \mathrm{~mm}$. longis; sepalis glabris, valde inaequilongis, exterioribus $5-7 \mathrm{~mm}$., interioribus $10 \mathrm{~mm}$. longis, omnibus apice obtusis v. rotundatis; corolla colore?, $50-60 \mathrm{~mm}$. longa, infundibuliformi-cylindracea, tubo in statu compresso supra medium $10-12 \mathrm{~mm}$. lato, limbo ut videtur integro.

Rami teretes multistriati, quoad suppetunt $2-2,5 \mathrm{~mm}$. crassi, pube ubi adest tenui brevi. Folia petiolis supra sulcatis, praesertim superne breviter et patenti-pilosis, lobis 2 basalibus rotundatis modice patentibus ca. $1,5 \mathrm{~cm}$. longis, nervis supra prominulis, lateralibns utroque latere $8-10$, 
superioribus sub angulo $45-50^{\circ}$ abeuntibus, non anastomosantibus, pube supra brevi adpressa, subtus densiore sordide alba velutina, chartacea. Inflorescentiae pedunculo inferne subterete usque $2,5 \mathrm{~mm}$. crasso glabro, ad apicem plus minus compresso, parce piloso, subumbellato-racemosae, ramis cincinnose 1 - paucifloris; bracteae lanceolatae, propliylla ovato-lanceolata v. lanceolata $3-1,5 \mathrm{~mm}$. longa; pedicelli medio ca. $1 \mathrm{~mm}$. crassi. Sepala 2 exteriora ovata obtusa $5-7 \mathrm{~mm}$. louga, $4-5 \mathrm{~mm}$. lata, margine angusto tenuiora, intermedium oblique ovatum $8,5 \mathrm{~mm}$. longum, interiora breviter ovalia, apice rotundata, $10 \mathrm{~mm}$. longa, $7 \mathrm{~mm}$. lata, margine late attenuata, omnia luce permeante nervis numerosis ramosis et anastomosantibus, extrinsecus conspicuis percursa. Corollae tubus e basi ca. $7 \mathrm{~mm}$. longa infundibuliformi subcylindraceus; limbi radii mesopetali lineari-lanceolati, nervis praeter marginales crassiores tenuibus ca. 5 percursi. Stamina tubo corollino ca. $5 \mathrm{~mm}$. longe adnata, quoad libera $12-15 \mathrm{~mm}$. longa; antherae lineares, superne angustatae, $5 \mathrm{~mm}$. longae, obsolete apiculatae, in 1/5 alt. affixae. Discus anmulatus brevis. Stylus ca. $20 \mathrm{~mm}$. longus glaber; stigma didymum, lobis adnatis ovato-globulosis crassis. Ovarium breviter ovatum in stylum attenuatum, orulis oblongis.

Hab. in Trinidad: Bot. Gard. Herb. n. 2945.

Obs. Antecedenti proxime affinis.

Ipomoea rubrocincta Urb. (n. sp.) glabra, foliis $25-8 \mathrm{~mm}$. longe petiolatis, $3-1,5 \mathrm{~cm}$. longis, fere usque ad basin palmati-partitis, parte integra $2-8 \mathrm{~mm}$. longa, lobis $7-5$, oblongis usque anguste lanceolatis, apice obtusis v. subtruncatis et emarginatis, intermedio $7-4 \mathrm{~mm}$. lato, lateralibus sensim brevioribus, angustioribus et paullo altius connatis; inflorescentiis $2-5 \mathrm{~cm}$. longe pedunculatis, $2-6$-floris, pedicellis primariis $5-6 \mathrm{~mm}$. longis; sepalo extimo (1) breviter ovato $2, \overline{5}-$ $3 \mathrm{~mm}$. longo, sequente (2) ovato $3,5 \mathrm{~mm}$. longo, interioribus ovalibus fere $4 \mathrm{~mm}$. longis, omnibus apice rotundatis, dorso non carinatis; corolla rubra $35-42 \mathrm{~mm}$. longa, e basi angusta usque in $1 / 4$ alt. sensim dilatata, hoc loco paullo ventricosa, (compressa) $10 \mathrm{~mm}$. diametro, dein cylindracea sub fauce $9 \mathrm{~mm}$. diametro, limbo integro.

Rami volubiles, quoad suppetunt virides herbacei, usque $2 \mathrm{~mm}$. crassi, lineis elevatis e margine petioli decurrentibus striati v. inferne angulato-striati. Folia petiolis supra canaliculatis, sed marginibus sibi accumbentibus, primo usque ad $2-4 \mathrm{~mm}$. supra basin tripartita, lobo intermedio oblongo, lateralibus usque ad $3-8 \mathrm{~mm}$. supra basin iterum $2-3$-partitis, lobis extrinsecus sensim decrescentibus, omnibus chartaceis r. subcoriaceis, rigidiusculis, margine paullo calloso-incrassato undulatis ideoqne specie crenulatis sed revera integris, nerris e basi $5-7$ in lobos abcuntibus, supra anguste, subtus crassiuscule et late prominentibus, lateralibus in lobo intermedio sub angulo ca. $70^{\circ}$ abeuntibus, ante marginem arcuato-conjunctis. Inflorescentiae semel, raro bis cymose divisae, dein v. ab initio cincinnosae; prophylla $1,5-1 \mathrm{~mm}$. longa oblongo-lanceolata decidua. Sepala parum inaequalia, viridia, margine purpureo-cincta, interiora saltem ad basin, coriacea, margine tenuiora, omnia luce permeante nervis valde numerosis contiguis parallelis percursa, nervo medio dorso non 
prominente. Corollae tubus basi $2,5 \mathrm{~mm}$. diametro, dein sensim ampliatus, superue cylindraceus, dein in limbum patentem integrum expansus; limbi radii mesopetali anguste lanceolati, nervis nonnullis anastomosantibus percursi; areae commissurales tenuiores, nervis e radio mesopetalo oblique prodeuntibus numerosis tenuibus notatae. Stamina tubo cornllino $3-3,5 \mathrm{~mm}$. supra ejus basin affixa, e tubo exserta; filamenta $22-25 \mathrm{~mm}$. longa, ad basin $4-6 \mathrm{~mm}$. longe dense pubescentia, caeterum glabra, ad apicem attenuata; antherae lanceolato-lineares $3,5 \mathrm{~mm}$. longae, in $1 / 4$ alt. affixae, inferne bicrures. Discus breviter cupuliformis, $0,5 \mathrm{~mm}$. altus, integer carnosus. Stylus 22-26 mm. longus, tenuiter filiformis glaber; stigma didymum, lobis subglobosis sibi adhaerentibus, irregulariter multisulcatis; ovarium anguste ovatum, apice non incrassato in stylum subito contractum, 2-loculare; ovula in quoque loculo 2.

Hab. in Haiti solo calcareo sicco, $150 \mathrm{~m}$. alt., in saltu montium inter La Coupe et Pintade, m. Sept. flor.: Buch n. 482.

Obs. Foliis simillima I. microdactylae Griseb. (e Cuba), quae inflorescentiis breviter v. brevissime $(0,5-2 \mathrm{~cm}$. longe) pedunculatis, margine sepalorum late membranaceo albido, tubo corollae cylindraceo, superne (in statu compresso) $5 \mathrm{~mm}$. lato, limbo 5 -fido, staminibus $6 \mathrm{~mm}$. supra basin corollae abeuntibus, ad basin glabris, antheris latioribus et brevioribus, ovario in stylum pluries crassiorem sensim attenuato abunde differt. - I. digitata L. (Plum. ed. Burm. tab. 92 f. 1) foliorum Iobis in altitudine subaequali abeuntibus, pedicellis pluries longioribus, corollae coccineae tubo infundibuliformi, limbo breviter 5 -lobo diversa est.

Ipomoea viridiflora Urb. (n. sp.) ramis junioribus minute et brevissime pilosulis; foliis $2-1,5 \mathrm{~cm}$. longe petiolatis, pedatis, ab initio 3 -foliolatis, foliolo intermedio $3-5 \mathrm{~mm}$. longe petiolulato, oborato $\mathrm{v}$. anguste obovato, apice rotundato et emarginato, inferne sensim $r$. cuneatim angustato, $3-4 \mathrm{~cm}$. longo, $1,5-2,5 \mathrm{~cm}$. lato, lateralibus $2-3 \mathrm{~mm}$. longe petiolulatis, usque ad basin v. fere usque ad basin bisectis, lobo inferiore iterum lobulum gerente; inflorescentiis $1-2 \mathrm{~cm}$. longe pedunculatis, 1 - paucifloris, pedicellis primariis ca. $1 \mathrm{~cm}$. longis; sepalis aequilongis $6 \mathrm{~mm}$. longis, exterioribus obovato-orbicularibus, apice rotundatis, interioribus valde concavis late orbicularibus apice emarginatis, omnibus dorso laeribus; corolla viridi (ex EHrexberg); capsula (juniore) globulosa, calycem non superante.

Rami volubiles rubro-brunei teretes striati, quoad suppetunt $2 \mathrm{~mm}$. crassi. Folia petiolis ob margines sibi arcte accumbentes angustissime suicatis, nervis in foliolo intermedio utroque latere $5-7$ sub angulo ca. $50^{\circ}$ abeuntibus, utrinque prominulis, subtus praesertim ad nervos obsolete pilosula, membranacea v. chartacea, margine angustissime recurvo et flexuoso saepius specie crenulata. Inflorescentiae 1 -florae v. cincinnose pauciflorae; prophylla decidua; pedicelli brevissime pilosuli angulati apice obconico-incrassati. Sepala viridia, exteriora $4 \mathrm{~mm}$. lata, coriacea margine tenuiora, interiora $5-5,5 \mathrm{~mm}$. lata, margine late membranaceo-attenuata, luce permeante ca. 7-nervia. Discus breviter cupuliformis. Orarium 
globosum, apice rotundato calloso in stylum contractum, biloculare; orula in quoque loculo 2 anguste ovata. Semina (immatura) obovata, dorso et intus subglabra, margine loinge villosa.

\section{Hab. in Haiti: C. Ehrenberg n. 345.}

Obs. Fortasse affinis I. pedatae Poit.! (ex Haiti), quae foliolis apice obtusis v. breviter acuminatis, pedunculis $12-14 \mathrm{~cm}$. longis, sepalis $9 \mathrm{~mm}$. longis, (an etiam corolla?), capsulis junioribus ovatis v. ellipticis recedit, et quae a cl. Haltuer f. in Engl. Jahrb. XVI p. 557 immerito cum I. carolina L. toto coelo diversa conjuncta est.

Ipomoca nematoloba Urb. (n. sp.) glabra, foliis $9-3 \mathrm{~mm}$. longe petiolatis, digitatis, foliolis 5 filiformibus, usque $35 \mathrm{~mm}$. longis, ca. $0,5 \mathrm{~mm}$. crassis, primo intuitu subteretibus, sed re vera plicato-incurvatis $\mathrm{r}$. inrolutis, apice obtusissimis, nunc obsolete mucronulatis; inflorescentiis plerumque 3 -floris, $1-3 \mathrm{~mm}$. longe pedunculatis, ob folia materna cito decidua in racemum plus minus elongatum collectis, pedicellis $3-5 \mathrm{~mm}$. longis; sepalis exterioribus semiovalibus $3 \mathrm{~mm}$. longis, 2,7-3 mm. latis, interioribus ovalibus, $3,5 \mathrm{~mm}$. Iongis, vix $2,5 \mathrm{~mm}$. latis, omnibus apice rotundatis, dorso non carinatis; corolla albido-virescente, $18 \mathrm{~mm}$. longa, tubo infundibuliformi, Iobis ei aequilongis latiuscule ovalibus $7-7,5 \mathrm{~mm}$. latis.

Rami rolubiles, cito lignescentes, $1-1,5 \mathrm{~mm}$. crassi, teretes, vetustiores brunescentes, plus minus plicato-striatuli, hornotini flavo-virides. Folia petiolis supra anguste sulcatis, post delapsum basin ipsam gibberosoprominentem relinquentibus; foliola in apice petioli circumcirca inserta, postica (minora) basi saepius citius decidua, omnia a basi ad apicem subaequilata, explanata $1-1,5 \mathrm{~mm}$. lata, nervis non conspicuis. Flores in cincinnos $1-4$ floros racemuliformes dispositi; prophylla lanceolata, $1-2 \mathrm{~mm}$. longa. Sepala extrinsecus risa subaequalia et subaequilonga, obscure viridia, coriacea, exteriora margine tenuiora, interiora ad marginem magis attenuata, omnia nervis pluribus subparallelis percursa et punctis nonnullis subpellucidis notata, nervo medio dorso non v. vix prominente. Corollae tubus $8-9 \mathrm{~mm}$. lougus, ad medium ca. $3 \mathrm{~mm}$., sub apice $4 \mathrm{~mm}$. crassus, utrinque glaher; lobi $9-10 \mathrm{~mm}$. longi, apice subemarginati, area intermedia crassiore lineari-lanceolata, nervis pluribus inaequicrassis percursa et punctis subpellucidis inter nervos longitrorsum seriatis notata, areis lateralibus paullo angustioribus, subito tenuiter membranaceis nervulis ramulosis e margine areae intermediae prodeuntibus oblique percursis. Stamina ad medium tubi corollini affixa, exserta; filamenta $9 \mathrm{~mm}$. longa, a basi ad apicem sensim attenuata, usque ad r. usque supra medium dense papillosa, papillis inferioribus elongatis piliformibus, praesertim e margine prodeuntibus, superioribus sensim decrescentibus, lobis corollae parte tertia breviora; antherae anguste oblongae, $3 \mathrm{~mm}$. longae, dorso sub medio affixae, inferne bicrures. Discus breviter cupuliformis $0,5 \mathrm{~mm}$. altus, integer carnosus. Stylus $15 \mathrm{~mm}$. longus filiformis, longe persistens glaber; stigma didymum, lobis subglobosis superne patentibus; ovarium ovatum, ad styli insertionem paullo incrassatum, 2 -loculare; ovula in quoque loculo 2, oblongo-linearia. Fructus junior oboratus, supra basin attenuatus, 
flavido-apiculatus, apiculo breviter et late conico demum (capsula dehiscente) leciduo. Semina juniora margine pilis deorsum versis obsita.

Hab. in Haiti prope Gonaïves in collibus siccis fruticeto obsitis ad montem Bienac, m. Jan. flor.: Buch 11. 587.

Obs. E sectione Eriospermi, sed nulli alii speciei arctius affinis.

Ipomoea lenconcura Urb. (n. sp.) glabra, foliis $30-5 \mathrm{~mm}$. longe petiolatis, digitatis, foliolis 7, raro 5 r. 6, elliptico-oblongis usque oblongo-lanceolatis, inferne sensim petioluliformi-angustatis, apice plerumque acuminatis, rarius obtusis, $30-5 \mathrm{~mm}$. longis, $10-1 \mathrm{~mm}$. latis, nervis subtus bene prominentibus albidis; inflorescentiis $7-2 \mathrm{~mm}$. longe pedunculatis, 10-1-floris; ob folia materna saepius decidua v. diminuta in racemum elongatum collectis, pedicellis primariis $12-7 \mathrm{~mm}$. longis; sepalis inaequilongis, exterioribus ovatis r. breviter ovatis, ca. $3,5 \mathrm{~mm}$. longis, interioribus anguste ovatis v. obovatis $5 \mathrm{~mm}$. longis, omnibus apice rotundatis v. interioribus subemarginatis; corolla sanguinea, $35-45 \mathrm{~mm}$. longa, subcylindracea v. medio paullo inflata, tubo in statu compresso usque $5 \mathrm{~mm}$. lato, limbo integro; capsulis oblongis $15 \mathrm{~mm}$. longis, superne $6-7 \mathrm{~mm}$. latis, calycem 4-plo superantibus.

Rami retustiores lignescentes teretes plus miuus plicato-striati, saepius dense et elevatim punctati, cinerascentes, homotini teretes $r$. obsolete angulati, interdum dense et minute punctulati. Folia petiolis supra basin deciduis, reliquiis eorum postremo valde incrassatis, magnitudine in eodem ramo valde variabilia; foliola petiolulis nullis v. usque $3 \mathrm{~mm}$. longis, valde inaequilonga, ad basin valde decrescentia, basalia obtusiora, nervis utroque latere $6-8$ sub angulo ca. $60^{\circ}$ abenntibus, non anastomosantibus, subtus paullo calloso-incrassatis, subtus pallidiora densissime punctulata, chartacea, margine plana integra. Inflorescentiae plerumque semel cymose divisae, dein in cincinnos abeuntes; prophylla decidua; pedicelli medio vix $0,4 \mathrm{~mm}$. crassi, superne sensim et paullo incrassati. Sepala viridia r. pallide rubrotincta, basi paullo inter sesc coalita, iutus minute et dense punctata, coriacea, exteriora margine vix, interiora latius attenuata, luce permeante plurinervosa, nervo inedio dorso saepius prominente. Corolla in limbum patentem expansa; limbi radii mesopetali liueari-lanceolati, nervis crassioribus 3 et parcis tenuioribus anastomosantibus percursi, ut videtur minus colorati; areae commissurales tenuiores, nervis e margine radii mesopetali oblique abeuntibus numerosis tenuibus notatae. Stamina tubo corollino $4-5,5 \mathrm{~mm}$. supra ejus basin affixa; filamenta $17-20 \mathrm{~mm}$. longa, ad basin 2,5-3 mm. longe pubescentia, caeterum glabra; antherae lineares $4 \mathrm{~mm}$. longae, in $1 / 4$ alt. affixae. Discus annulatus carnosus obsolete crenulatus. Stylus ca. $25 \mathrm{~mm}$. longus, inferne crassiusculus, dein filiformis, glaber; stigma didymum, lobis globulosis sibi adlacrentibus; ovarium ovatum, in stylum paullo contractum, 2-loculare, ornlis in quoque loculo 2 lineari-oblongis. Capsulac a basi arl apicem paullo ampliatae, longitrorsum tenuiter multistriatae, 4-valves. Semina anguste oblonga, $5 \mathrm{~mm}$. longa, 1,3 $\mathrm{mm}$. lata, ventre et dorso minute pilosula, apice et margine pilis usque $12 \mathrm{~mm}$. longis flavido-albis rectis, circumcirca expansis dense restita. 
Hab. in Haiti, m. Jan. fl.: Ehrenberg n. 134, Picarda n. 16, 73, prope Gonaïves in jugo montium ad La Coupe, locis siccis, m. Dec. flor: Buch n. 5 .

Obs. I. Affinis I. eriosperma Urb. (Comolrulus criospermus Desr.!, Exogonium criospermum Choisy! ex Hispaniola) foliolis 7-9, lanceolatolinearibus, omnibus apice rotundatis v. subtruncatis, nervis lateralibus nullis v. obsoletis, sepalis aequilongis $3,5 \mathrm{~mm}$. longis, capsulis (ex Desr.) ovoideis calycem duplo superantibus discrepat.

Obs. II. I. eriosperma Bertero! ap. Spreng. Syst. I (1825) p. 598, Choisy in DC. Prodlr. IX p. 388 (e Guadeloupe), quam cl. Sprenget l. c. cum Comolvulo bahiensi pelunculis brevissime pilosulis, sepalis inaequalibus multo minoribus diverso (hb. Willd. n. 3753) confudit quamrue cl. HaLlier f. in Engl. Bot. Jahrb. XVI (1893) p. 558 cum dubio ad I. batatoidem Chois. duxit, est lusus angustifolius $I$. repandae Jacq. Vidi folinm et fruetus a cl. Mattinolo ex herbario Taurinensi benevole missa: inflorescentia, calyx, capsulae omnino conveniunt; folia sunt quam pleraque $I$. repandae exemplaria multo angustiora, sublanceolata, e basi latiore ca. $12 \mathrm{~mm}$. lata paullo cordata subsensim longe acuminata, supra basin obsolete biloba fere eorlem modo, quem specimina Sintenisiana n. 289 in Portorico prope Maricao lecta praeter typum normalen praebent.

Ipomoca Furcyensis Urb. (n. sp.) foliolis 7, lanceolatis, raro elliptico-oblongis, inferne valde sensim et longe in petiolulos breves angustatis, superne longiuscule acuminatis, apice ipso obtuso, membranaceis $v$. chartaceis; pedunculis $6-3 \mathrm{~cm}$. longis, $1-1,3 \mathrm{~mm}$. crassis, pedicellis primariis $1-1,5 \mathrm{~cm}$. longis; sepalis rubro-coloratis, subaequilongis, elliptico-oblongis usque orato-ellipticis $10 \mathrm{~mm}$. longis; corolla ex sicco purpurea, tubo subcylindraceo. supra medium perpaullo ampliato, in statu compresso $7-9 \mathrm{~mm}$. lato, sub limbo iterum perpaullo constricto; staminibus longiuscule exsertis, $40-45 \mathrm{~mm}$. longis; orario breviter orato; capsula juniore ovato-elliptica, e calyce vix excedente.

Rami volubiles, teretes, elevatim striati, hine illine granulati v. tuberculati, glabri, qroad suppetunt, $2 \mathrm{~mm}$. crassi. Folia petiolis $1-3 \mathrm{~cm}$., petiolulis $1-4 \mathrm{~mm}$. longis; foliola $2-5 \mathrm{~cm}$. longa, $0,5-1 \mathrm{~cm}$. lata, nervo medio supra anguste prominente, lateralibus utroque latere $6-9$ sub angulo ca. $60^{\circ}$ abeuntibus tenuiter prominulis, non anastomosantibus, glabra, margine flexuoso specie undulato-cremulata. Inflorescentiae $1-v$. cymose 3-5-florae; prophylla decidua. Sepala subcoriacea, exteriora ellipticooblonga, obtusiuscula v. obtusa, $3,5--4,5 \mathrm{~mm}$. lata, interiora ovato-elliptica, apice rotundata, $5-5,5 \mathrm{~mm}$. lata, margine tenuiora, omnia nervis pluribus extrinsecus non vo vix manifestis percursa, dorso laevia glabra. Corolla $5-6 \mathrm{~cm}$. longa; tubus basi $3,5 \mathrm{~mm}$., sub limbo in statu compresso $7 \mathrm{~mm}$. latus; limbi radii mesopetali ut videtur paullo pallidiores, anguste lanceolati. Stamina tubo corollino $7 \mathrm{~mm}$. longe adnata, basi $4 \mathrm{~mm}$. longe dense pubescentia; antherae lineares, $4,5 \mathrm{~mm}$. longae, dorso in $1 / 4$ alt. affixae. Discus breviter cupuliformis, crasse carnosus, margine obsolete undulatus. Orarium 2-loculare, ovulis in quoque loculo 2 anguste et oblique oratis, dorso 
obsolete papillosis, in stỵlum sensim angustatum; stigma didymum, lobis subglobosis connatis tuberculatis. Capsula (junior) $10 \mathrm{~mm}$. longa, $6 \mathrm{~mm}$. crassa, acuminata.

Hab. in Haiti in montibus Furcy, $1515 \mathrm{~m}$. alt., m. Nov. flor.: Picarda n. 1501.

Obs. Affinis I. heptaphylla Griseb., quae verisimiliter vera I. carolina L. est, quod jam cl. Halmer f. enuntiavit, foliolis superne minus angustatis, obtusis $1-2 \mathrm{~cm}$. latis, nervis magis horizontalibus, sepalis viridibus inaequilongis, interioribus $7 \mathrm{~mm}$. longis, corolla $4 \mathrm{~cm}$. longa, tubo supra calycem sensim ampliato, infundibuliformi recedit.

Ipomoea macrorrhiza R. et Scl. foliolis 7, rarissime in eadem planta 8 v. 6 v. 5, elliptico-oblongis usque anguste lanceolatis, ad basin valde sensim petioluliforni-angustatis, apice ommibus acuminatis, membranaceis $\nabla$. chartaceis; pedunculis $6-1 \mathrm{~cm}$. longis, $1-1,5 \mathrm{~mm}$. crassis, pedicellis primariis $1-1,5 \mathrm{~cm}$. longis; sepalis interioribus $9-10 \mathrm{~mm}$. longis; corolla rubra v. scarlatina v. violacea, tubo supra calycem subito campaniformi-dilatato, ad medium (in statu compresso) usque $20 \mathrm{~mm}$. lato; staminibus inclusis $\mathrm{r}$. apice antherarum rix exsertis, $15-25 \mathrm{~mm}$. longis; orario ovato usque oblongo; capsula juniore elliptica v. ellipticooblonga, 2-21/2-plo longiore quam latiore, calycem superante.

Ipomoen macrorhi:os Roem. et Schult. Syst. IV (1819) p. 211; Choisy! in DC. Prodr. IX p. 388.

Convolvulus macrorhizos Lim. Syst. I ed. (1759) p. 923 et Spec. II ed. I p. 223; Desrouss. in Lam. Enc. III p. 567.

Batatas macrorhinos G. Don Gen. Syst. IV (1837) p. 261.

Convolvulus coccineus heptaphyllos, radice crassissima Plum. Cat. (1703) p. 1 et ed. Burm. p. 79 tab. 90 fig. 1! (excl. syn. Sl., Br. et Pluk.).

Hab. in Haiti: Picarda n. 704, Poiteau, prope Corail m. Dec. flor.: Picarda n. 138s, prope Gonaïves ad Bassin, solo calcareo aprico $200-500 \mathrm{~mm}$. alt., arbores ascendens, m. Nov. flor.: Buch n. 560 ; Sto. Domingo: Mayerhoff.

Obs. I. Plantae descriptae sine ulla dubitatione, quod icon Plumieriana sicut diagnosis Desrousseauxiana e manuscriptis Plunierianis (vol. II t. 58) hausta demonstrant, typum Limaeanum sistunt.

Obs. II. Utrum I. heptaphyllam Griseb. (e Cuba), I. Furcyensem, macrorrhizam, Horsfalliae, Grisebachii, ternatam pro speciebus propriis, an pro subspeciebus habere praeferas, minoris momenti est. Certe membra seriem terminantia inter sese valde discrepant et fere omnia ejusdem speciei exemplaria (in eadem insula) valde congruunt.

Iponoea IIorsfalliae W. Hook. foliolis 5, rarius 7, obovatis usque lanceolatis, inferne usque ad v. fere ad insertionem angustatis, petiolulos nullos v. perbreves relinquentibus, apice obsolete $v$. manifeste acuminatis, membranaceis v. subchartaceis; pedunculis $12-4 \mathrm{~cm}$. longis, $1,5-2 \mathrm{~mm}$. 


\section{SYMBOLAE ANTILLANAE}

SEU

\section{FUNDAMENTA}

\section{FLORAE INDIAE OCCIDENTALIS}

EDIDIT

\section{IGNATIUS URBAN}

\section{0 L U II E N I I I \\ FASCICULUS III}

Continet:

V. Ign. Urban: Nova genera et species II, p. $353-420$

VI. V. F. Brotherus: IIusci novi Dussiani, p. 421-429

VII. Ign. Urban: Burmanniaceae, p. $430-452$

VIII. O. Warburg: Ficus L., p. $453-492$

IX. O. E. Schulz: Cruciferae, p. $493-523$

X. G. Hieronymus: Selaginellae novae, p. 524-527

Index nominum latinorum, p. 528

Index nominum rernaculorum, p. 545

\section{LIPSIAE}

FRATRES BORNTRAEGER

1903

\section{PARISIIS}

PAUT, KTINCKSIECK

3, RUE CORNEILLE

\section{LONDINI}

WILLLAMS \& NORGIATE 14, HEXRIETTA STREET, COVENT GARDEN 

crassis; pedicellis primariis $1,5-2,5 \mathrm{~cm}$. longis; sepalis rubescentibus, interioribus $10-12 \mathrm{~mm}$. longis; corolla obscure rosea r. pallide purpurea, tubo supra calycem subsensim dilatato, vix rentricoso, cylindraceo-infundibuliformi, ad medium (in statu compresso) usque $18 \mathrm{~mm}$. lato; staninibus bene exsertis, $30-45 \mathrm{~mm}$. longis; ovario orato; capsula breviter ovali, parum longiore quam crassiore subquadrangulari, apice rotundato in stylum contracta, calycem non v. vix superante.

Ipomoea Horsfallicie W. Hook. in. Bot. Mag. LXI (1834) tab. 3315; Paxt. Mag. III. tab. ud p. 50!; Knnow\% and Weste. Flor. Cab. I p. 61 tab. 29!; Haund Bot. I tab. 31 (ex Pritr. Ic.); Egg. St. Croix and Virg. Isl. p. 73 .

Ipomoea pendula Clooisy in DC. Prodr. IX (1845) p. 387 (quoad syn. Hooli.); Duss! Flor. p. 440, - non R. Br.

Batatilla Port. ex Sint., Liane rouge à tonnelles Mart. et Guad. ex Duss.

Hab. in Portorico prope Coamo in sylvis ad Farajones, inter Peñuelas et Adjuntas $800 \mathrm{~m}$. alt., prope Adjuntas in sylvis primaevis montis Cienega, inter Adjuntas et Guayanilla in sylvis montis Ahorcado, prope Guanica ad Montalba, prope Maricao in sylvis montanis, m. Jun., Jul., Nov., Dec. fl., Febr. fr.: Sintenis n. 450, 3109, 4404, 4655, LXII, Stahl n. 1041, - culta in ins. Virgin. ex Egg., Guadeloupe: Duss n. 3086, Martinique: Duss 11. 1882.

Obs. Ill. Hooker 1. e dixit: "The seeds were received by Charles Honsfalu. Esq. eitlee from Africa or from the East Indies", sed mullibi haee species spontanea collecta est, nisi in Portorico, quod affinitate areta cum I. Grisebachii et macrorrhiza confirmatur. - Planta culta foliola non semper 5, ut in ommibus descriptionibus legitur, sed etiam 7 procreat, quod specimina Dussiana (sicut spontanea Sintenisiana) demonstrant.

$\sqrt{ }$

Ipomoea Griscbachii Urb. (n. sp.) foliolis 5, raro in eodem ramo 3, obovatis usque oblongo-lanceolatis, inferne sensim v. cuneatim angustatis, manifeste petiolulatis, apice brevissime r. manifeste et abrupte acuminatis, subcoriaceis v. coriaceis; peduneulis $12-1 \mathrm{~cm}$. longis, $1,5-2 \mathrm{~mm}$. crassis, pedicellis primariis $2,5-3,5 \mathrm{~cm}$. longis: sepalis ut videtur viridibus v. apice et margine tinctis, interioribus $10-12 \mathrm{~mm}$. longis; corolla extrinsecus pallide rosea, areis limbi commissuralibus obscure roseis, tubo late infundibuliformi supra calycem subsensim dilatato v. paullo ventricoso; staminibus inclusis, $15-18 \mathrm{~mm}$. longis; ovario globuloso v. ovato-globuloso; capsula subglobosa, calycem non v. vix superante.

? Ipomoea pulchella W. Hook. in Bot. Mag. LXXIII (1S17) 1).4305!, - non Roth.

Urbau, Symb. ant. 111 . 
Ipomoea macromhina Griseb.! Flor. (1861) p. 471 (p.p.); Mast. in Gard. Chrom. new ser. XXIII p. 566 (p.p.), - non R. el Sch.

? Ipomoea Horsfalliae Mast. in Gard. Chrom. new ser. XXIII (1855) p. 566 (quoad specim. Mart.).

Rami alte volubiles, teretes, obsolete plicato-striatuli, glabri v. breviter pilosi, quoad suppetunt, usquc $5 \mathrm{~mm}$. crassi. Folia petiolis $3-8 \mathrm{~cm}$., petiolulis $2-5 \mathrm{~mm}$. longis; foliola $6-12 \mathrm{~cm}$. longa, $2,5-5,5 \mathrm{~cm}$. lata, nervo medio in sulco levi valde anguste prominente, lateralibus utroque latere $5-8$ sub angulo ea. $60^{\circ}$ abeuntibus, tenuiter prominulis, non anastomosantibus nec pellucidis, parce v. parcissime setuloso-pilosa, subtus brevius, v. glabra, margine subcalloso integra. Inflorescentiae pluriflorae, semel more trichasii, deinde r. ab initio cymose divisae r. cincinnose cvolutac; prophylla decidua. Sepala coriacca, inaequalia, extcriora breviter ovata r. ovalia, apice obtusa $v$. rotundata, $6-8 \mathrm{~mm}$. longa, $5-7 \mathrm{~mm}$. lata, interiora oborata, concava usque $9 \mathrm{~mm}$. lata, apice rotundata r. obtusissima, margine tenuiora, omnia nervis pluribus extrinsecus non manifestis percursa, dorso laevia glabra. Corolla $6-6,5 \mathrm{~cm}$. longa; tubus basi ca. $4 \mathrm{~mm}$. crassus, ad medium (in statu compresso) $15-19 \mathrm{~mm}$. latus; limbi radii mesopetali anguste lanceolati, nervis primariis 5 et pluribus tenuioribus anastomosantibus; areae commissurales radios $10 \mathrm{~mm}$. longe superantes, valde amplae, medio leviter emarginatae, late semiorbiculares temues, nervis e radii mesopetali margine prodeuntibus numerosis percursae. Stamina tubo corollino $7 \mathrm{~mm}$. longe adnata, basi $4 \mathrm{~mm}$. longe pilis simplicibus densissime pubescentia; antherae lineares, superne attemuatae, in 1/5 alt. affixae, $5 \mathrm{~mm}$. longae. Discus brevissime cupuliformis, crasse carnosus, margine undulatus. Ovarium 2-loculare, ovulis in quoque loculo 2, a dorso anguste ovatis, margine brevissime pilosis, in stylum subcontractum; stigma didymum, lobis connatis subglobosis tuberculatis. Capsula $8-9 \mathrm{~mm}$. diamctro; valvae ellipticae $12-13 \mathrm{~mm}$. longae, $6-7 \mathrm{~mm}$. latae. Semina (non plane matura) ovata v. latiuscule ovata, $6 \mathrm{~mm}$. longa, $3-4 \mathrm{~mm}$. lata, margine dense pilifera, pilis $10-12 \mathrm{~mm}$. longis.

Hab. in Jamaica: Hart n. 994, in Yallahs Valley 560 m. alt., m. Sept. flor.: Harris n. 6839, prope Moneague in Guy's Hill: Alexander.

Obs. I. In herb. Grisebachiano duae plautae aliae a cl. March collectae sub nomine I. macrorrhizae asservantur, altera speciei descriptae similior sed foliis chartaceis, floribus majoribus usque ad $8 \mathrm{~cm}$. longis ut videtur pallidioribus, altera foliolis saepius $3-4$ pilosis, longius (usque $7 \mathrm{~mm}$. longe) petiolulatis, corollae tubo ut videtur obscurius rubro, limbo pallidiore. Sed quia fragmenta tantum inter sese mixta praebent, nil certi dici potest.

Obs. II. Planta a cl. Wullschlaegel in Jamaica prope Fairfield (sub n. 926) lecta differt ramis elevatim striatis v. angulatis, foliolis $4-5$, sepalis interioribus $14-15 \mathrm{~mm}$. longis obscure coloratis differt, sed ob corollan deficientem non describenda (mus. Monac.).

Ipomoea ternata Jacq. foliolis 3, rarissime in eodem ramo 4, ovatis, late ovatis, subrhombeis, obovatis v. anguste ovalibus, basi rotundatis usque acutatis, manifeste, brevissime v. vix petiolulatis, apice nunc breviter, nunc longiuscule acuminatis, coriaceis $\mathrm{v}$. crasse coriaceis; pedun- 
culis $6-2 \mathrm{~cm}$. longis, $2-2,5 \mathrm{~mm}$. crassis, perlicellis primariis $4-6 \mathrm{~cm}$. longis; sepalis interioribus $16-18 \mathrm{~mm}$. longis; corolla alba, tubo supra calycem dilatato ventricoso v. subinfundibuliformi, medio $20 \mathrm{~mm}$. diametro: staminibus exsertis ca. $40 \mathrm{~mm}$. longis; orario ovato; capsula ignota.

Ipomoea ternata Jacq. Hort. Schocnbr. I (1797) p. 16 tab. 37!; Poir. in Lam. Enc. Suppl. It p. 631; Choisy in 1)C. Prodr. IX p.361. Comrolvulus ternatus Spreng. Syst. I (1825) p. 590.

Batatas ternata G. Don Gen. Syst. IV (1837) p. 262.

Ipomoea macrorrhina forma Griscb. Flor. (1861) p. 471 (p. p.). - non R. et Sch.

Ipomoea Thomsoniana Mast. in Gard. Chron. new ser. IXI (188.3) p. 818 cum icone in pag. 817, XXIII p. 567.

Ipomoea macrorhina var. ternata Mast. I. c. n. s. XXIII (1885) p. $56 \pi$.

Ipomoea macrorkiza var. Thomsoniana Mast. 1. c. p. $5 \dot{6} \overline{7}$.

Ipomoca Horsfallice alba Hort. ex Mast. l. c. X.I p. 818.

Hab. in Jamaica prope Old England $1160 \mathrm{~m}$. alt., supra arbores humiles volubilis, m. Sept. fl., prope Cinchona 1660 m. alt., m. Sept. flor:: Harris n. $6598,7410$.

Obs. I. Inflorescentiae in speciminibus spontaneis 3-(v. pluri?) florae, in cultis (junioribus) ad florem in cyma terminalem unicum reductae.

Obs. II. Huic affine est spceimen a cl. WuLlschlägeL sub 11.925 in Jamaica prope Bethabara lectum (in arbores altissimas scandens) ramis et petiolis tuberculatis, foliis trifoliatis, foliolis $15-20 \mathrm{~mm}$. longe petiolulatis, chartaceis, sepalis interioribus $12-13 \mathrm{~mm}$. longis, corollis deficientibus (mus. Monac. et Götting.).

Ipomoea limeolata Urb. (n. sp.) glaberrima, ramis bruneis nitidis; foliis $3-5 \mathrm{~cm}$. longe petiolatis digitatis, foliolis 3 manifeste $(4-7 \mathrm{~mm}$. longe) petiolulatis, obovato-ellipticis usque elliptico-oblongis, basi acutis v. in petiolulos angustatis, apice breviter cuspidato-acuminatis, $5-8 \mathrm{~cm}$. longis, $2-4 \mathrm{~cm}$. latis, subcoriaceis, nervis lateralibus ntroque latere 10 - 12 sicut tertiariis arcte lineolato-anastomosantibus subpellucidis; inflorescentiis paucifloris, perdicellis primariis $2,5-3 \mathrm{~cm}$. longis; sepalis subinaequilongis, $S-10 \mathrm{~mm}$. longis, apice obtusissimis r. rotundatis, dorso laevibus glabris: corolla verisimiliter rubra.

Ipomoea macrorrhina forma Griseb.! Flor. (1861) p. 471 (1). p.), - mon R. et Sch.

Rami lignescentes teretes $r$. subterctes striati, circumeirea sicut folia et inflorescentiae in sicco brunei, lacres. Foliola semper 3 , nerro melio supra infcrne subimpresso, superne vix prominulo, lateralibus sub angulo ca. $60^{0}$ abeuntibus, supra parum prominulis, subtus manifostioribus olsscrrioribus, tenuioribus crebris serpentinis et anastomosantibus internuxtis, ante marginem ipsum coujunctis, omnibus bene subpcllucidis, margine plano 
integra v. subundulata, supra nitidula, subtus paullo pallidiora. Inflorescentiae pedunculo $3-4 \mathrm{~cm}$. longo, $1-1,5$ mun. crasso, $2-3$-florac, ramis alternis; prophylla decidua; pedicelli superne angulati. Sepala in sieco brunea coriacea, extimum ovatum $8 \mathrm{~mm}$. longum, $6 \mathrm{mmm}$. latum, sccundum $9 \mathrm{~mm}$. longum, 6,5 $\mathrm{mm}$. latum, interiora explanata suborbicularia $10 \mathrm{~mm}$. longa, margine lato tenuiora, luce permeante densissime multinerrosa. Corolla in alabastro tantum visa, calyce certe plurics longior. Stamina basi ipsa villosula, caeterum glabra; antherae lineares, superne angustatac, dorso sul) medio affixae, 5,5 mm. longae. Discus carnosus, basin ovarii cingens. Ovarium ovatum glabrum, in stylum sensim attenuatum, 2 -loculare, ovulis in quoque loculo 2 elliptico-oblongis. Stylus $33 \mathrm{~mm}$. longus glaber filiformis, stigmate bigloboso.

Hab, in Jamaica: Wilson n. 1126 (aut 1155).

Obs. Ab I. macrorrliza et ternata omnino diversa praesertim structura foliolorum.

Ipomoea Buchii Urb. (n. sp.) ramis junioribus minute patentipilosulis, pilis parcis brevibus patentibus intermixtis; foliis $5-1,5 \mathrm{~cm}$. longe petiolatis, ambitu pentagonis, basi late et leviter cordatis, $3,5-5 \mathrm{~cm}$. longis, 4-6 cm. latis, 3-partitis, parte integra $10-3 \mathrm{~mm}$. longa, lobo intermedio late ovali-elliptico v. elliptico-oblongo, apice obtuso, lobis lateralibus leviter v. usque ad medium bilobulatis; inflorescentiis 1 -floris, pedunculo $12-6 \mathrm{~mm}$., pedicello $6-8 \mathrm{~mm}$. longo; sepalis 2 exterioribus ovalibus 4,5 mm. longis, apice rotundatis, interioribus obovato-orbicularibus $6 \mathrm{~mm}$. longis, apice subtruncatis, omnibus dorso non carinatis; corolla alba (ex Buch) 40 - $45 \mathrm{~mm}$. longa, e basi sensim usque $20 \mathrm{~mm}$. ampliata, lobis limbi quoad liberis (inter radios mesopetalos productis) semiorbicularibus ca. $8 \mathrm{~mm}$. longis.

Rami volubiles, quoad suppetunt pallide rubescentes duri $1 \mathrm{~mm}$. crassi, plus minus trianguli striati, internodiis $2,5-6 \mathrm{~cm}$. longis. Folia petiolis supra anguste sulcatis, limbo in sinum basalem perpaullo producto, lobis apice breviter filiformi-mucronatis, apicali et basalibus apice obtusis, intermediis apice rotundatis et saepius paullo emarginatis, nervis e basi 5 supra vix prominulis, lateralibus lobi intermedii sub angulo $55-60^{\circ}$ abeuntibus, supra obsolete anastomosantibus, tenuissimis, membranacea, utrinque (subtus praesertim ad nervos) parce et brevissime pilosa, margine scabriuscula plana. Pedunculi breviter pubescentes; prophylla lineari-lanceolata v. lineari-subulata, 2,5-3 mm. longa, ca. $0,7 \mathrm{~mm}$. lata, decidua; pedicelli ad apicen sensim incrassati. Sepala inaequalia, pallide viridia, exteriora subplana $3,5 \mathrm{~mm}$. lata, anguste hyalino-marginata, intermedium oblique obovatoorbiculare, interiora valde concava, explanata $5,5 \mathrm{~mm}$. lata, late marginata, omnia coriacea, luce permeante obsolete multincrvosa glaberrima. Corollac tubus basi $3 \mathrm{~mm}$. diametro, dein sensim ampliatus; limbi radii mesopetali late lanceolati, ca. $14 \mathrm{~mm}$. longi, basi $6 \mathrm{~mm}$. lati, nervis 3 anastomosantilus percursi. Stamina tubo corollae $7 \mathrm{~mm}$. supra basin affixa inclusa; filamenta $12-14 \mathrm{~mm}$. longa, basi $2 \mathrm{~mm}$. longe dense pubescentia, caeterum glabra; antherae oblongo-lineares, 3,5 mm. longae, supra $1 / 4$ alt. affixae. 
Discus annularis carnosus integer, 0,4 mm. altus. Stylus ca. $25 \mathrm{~mm}$. longus filiformis glaber; stigma ut videtur aurantiacum transversim orale multisulcatum. Orarium breviter turbinatum apiculo conico coronatum 2 loculare; ovula in quoque loculo 2.

Hab. in Haiti in montibus umbrosis ad la Petite Coupe, $250 \mathrm{~m}$. alt., m. Oct. flor.: Buch n. 817 .

Obs. Species a cl. inventore indefesso nuperrime missa ante I. viridifloram Urb. p. 348 inserenda est.

Cordia elliptica Sw.! Prodr. (1788) p. 47 et Flor. I p. 461 quoad plantam jamaicensem a nemine iterum in liac insula collectam valde affinis est C. reticulatae Vahl Ecl. III (1807) p. 5 ex insulis caribaeis, a qua solummodo differt foliis oblongis, $8-11 \mathrm{~cm}$. longis, $3-4 \mathrm{~cm}$. latis (basi obtusa brevissime in petiolum angustatis), inflorescentiis brevissime pilosis (nec tomentosis), alabastris uninus dense tomentosulis, ita ut species Vahliana nonnisi formam Swartzianae latifoliam praebeat. Cordia elliptica Sw. quoad plantam dominicanam in herb. Holmiensi deficientem sine dubio C. reticulatam Vahl ipsam sistit. - Cordia elliptica Griseb. quoad saltem exemplar Alexandri! toto coelo diversa et sub nomine C. Farvettii a nobis descripta est (cf. Symb. I p. 391).

Cordia nitida Vahl var. angustata Urb. (u. var.) foliis oblanceolatis usque lanceolato-linearibus, $4-8 \mathrm{~cm}$. longis, $1-2 \mathrm{~cm}$. latis; floribus ad apicem cymarum brevissine pedicellatis v. subsessilibus, post delapsum vix pedicellum relinquentibus. - Arbor $10 \mathrm{~m}$. alta, floribus albidis.

Hab. in Sto. Domingo prope Santiago ad Gurabo, $250 \mathrm{~m}$. alt., m. Majo fl. et fr.: Eggers n. 1957, ad Lopez 350 m. alt., m. Jun. fl. et fr.: Eggers n. 2381.

Cordia haitiensis Urb. (n. sp.) ramis pilis brevibus albidis sursum curvatis v. adpressis strigosis obsessis; foliis $2-3 \mathrm{~mm}$. longe petiolatis, anguste v. lineari-lanceolatis, inferne magis angustatis, sed basi ipsa in petiolum subcontractis, apice obtusis v. obtusissinis, 3,5-2 cnı. longis, $0,7-0,4 \mathrm{~cm}$. latis, superne v. ad apicem crenulatis, chartaceo-coriaceis, supra pilis brevissinis basi bulboso-inflatis scabris, nervis supra inpressis; inflorescentiis in dichotomiis et ad ramos rannlosque terminalibus, $0,5-2 \mathrm{~cm}$. longe pedunculatis, capitatis, globosis r. ovatis, $10-20$ floris; calyce in alabastro obovato-globoso, lobis conniventibus, tubo sub anthesi $2 \mathrm{~mm}$. longo campanulato, albido-piloso, lobis ovato-triangularibus, brevissime apiculatis, tubo dimidio brevioribus; corollae flavae tubo obovato, e calyce vix exserto 3 num. longo, lobis breviter ovatis, tubo $2 \frac{1}{2}$-plo brevioribus; filamentis tubo corollino in $2 / 3$ alt. affixis, antheris inclusis. 
Frutex $1,3-2 \mathrm{~m}$. altus. Rami teretes in sicco tenuiter plicati brunei glabrescentes, hornotini teretes pilis basi incrassatis. Folia petiolis delapsis basi gibberem relinquentibus, nervis lateralibus utrinque $5-7$ sub angulo $30-35^{\circ}$ abcuntibus supra impressis, subtus plus minus reticulatoconjunctis, margine supero angustissime, infero latius recurva v. revoluta, pilis supra densissimis valde abbreviatis, subtus praescrtim ad nervos brevibus restita, in sicco brunescentia. Capitula $6-7 \mathrm{~mm}$. diametro; flores sessiles. Calyx cxtrinsecus breviter et subadpresse albido-pilosus, superne $2 \mathrm{~mm}$. crassus, non striatus, sed luce permeante 10 -nervis, chartaceus; lobi $1 \mathrm{~mm}$. longi. Corolla extrinsecus glabra, intus ad et sub medio pubescens, inferne chartacea, superne membranacea; lobi crispulo-plicati, apice rotundati. Filamenta quoad libera glabra brevissima; antherac subquadratae, $0,4 \mathrm{~mm}$. longae, dorso supra medium affixae. Ovarium ovato-acuminatum; ovula ovato-oblonga r. oblonga, supra basin affixa. Stylus $2 \mathrm{~mm}$. longus, in $2 / 3$ alt. 4 -fidus; stigmata obovata.

Hab. in Haiti locis siccis prope Plaisance, $250 \mathrm{~m}$., m. Majo flor.: Buch n. 355.

Obs. Affinis C. angustifolia R. et Sch. pube ramorum pulverulenta, inflorescentiis latcralibus et in dichotomiis terminalibus, longins pedunculatis, spicatis, corollis calycem duplo et ultra superantibus albis recedit.

Cordia cxarata Urb. ramis junioribus pilis albidis suberectis v. erecto-patentibus pubescentibus v. villosulis; foliis $1,5-3 \mathrm{~mm}$. longe petiolatis, obovatis, ovalibus v. ovali-ellipticis, basi obtusis, apice rotundatis, $2-1 \mathrm{~cm}$. longis, $1-0,5 \mathrm{~cm}$. latis, margine irregulariter crenatis, coriaceis, supra pilis albidis dense obsessis, postremo scabridis; inflorescentiis terminalibus et lateralibus, capitatis v. postremo breviter spicatis, subsessilibus usque $8 \mathrm{~mm}$. longe pedunculatis; calyce in alabastro ovali, lobis conniventibus, tubo sub anthesi $2-2,5 \mathrm{~mm}$. longo obovato, breviter piloso, lobis triangularibus obsolete et obtuse apiculatis, tubo $2-21 / 2$-plo brevioribus; corollae tubo subcylindraceo, e calyce exserto, $5 \mathrm{~mm}$. longo, lobis ut videtur ovatis, tubo 3-plo brevioribus; filamentis fauci corollae insertis, antheris paullo exsertis; drupa oblique ovata $3-3,5 \mathrm{~mm}$. longa.

Cordia villosa Spreng.! Syst. I (1825) p. 651; DC. Prodr. IX p. 500, - non Spreng. Neue Entdeck. III (1S22) p. 31.

$\mathrm{Rami}$ vetustiores brumei $\mathrm{r}$. nigrescentes teretes, in sicco plicatuli scabriusculi v. glabrati, hornotini pallidiores teretes r. subteretes, pilis noduloso-scabriclis, crassitie rami brevioribus. Folia petiolis basi v. supra basin deciduis, nervis lateralibus utrinque $4-5 \mathrm{sub}$ angulo ca. $60^{\circ}$ abeuntibus rectis, sicut medio arcte impressis (quasi exaratis) vix v. parum ramosis, pube supra initio molliore, postremo rigidiore brevitcr pubescentia, margine ad crenas plus minus recurva, viridia v. brunea, subtus pallidiora. Capitula 5 - 15 -flora, $5-7 \mathrm{~mm}$. diametro, postremo usque $12 \mathrm{~mm}$. longa; flores sessiles. Calyx superne $2,5 \mathrm{~mm}$. crassus, non striatus, sed luce permeante 10 -nervis, chartaceus; lobi 0,8 mm. longi. Corolla extrinsecus glabra, 
intus ad stamina adnata pilis longiusculis obsessa membranacea; lobi imperfecte visi. Filamenta quoad libera $1 \mathrm{~mm}$. longa glabra; antherae oralirectangulares $0,8 \mathrm{~mm}$. longae, medio affixae. Ovarium anguste ovatun, stylo fere duplo brevius; ovula supra basin affixa, oblonga. Stylus vix $2,5 \mathrm{~mm}$. longus, in $\% / 4$ alt. partitus; stigmata brevia oblonga. D l'upa calyce persistente plus minus circumdata, inferne $2 \mathrm{~mm}$. diametro, tubercnlata.

Hab. in Haiti prope Gonaïres in Morne: Prax; Sto. Domingo: Bertero.

Obs. E sectionis Myxae Endl. serie Spicaeforminm, sed ad Dasycephalas accedit.

Corria calcicola Urb. (n. sp.) ramis breviter et adpresse setulosis; foliis 4-6 mm. longe petiolatis, elliptico-oblongis v. oblongo-lanceolatis, inferne magis angustatis, ad basin plerumque cuneatis, apice acutis v. obtusis, $4-6 \mathrm{~cm}$. longis, $2-2,5 \mathrm{~cm}$. latis, margine supero plus minus manifeste dentatis, subcoriaceis, supra scabridis; inflorescentiis capitatis, sessilibus v. usque $5 \mathrm{~mm}$. longe pedunculatis, ad apicem ramorum 2-5-natim in glomerulum collectis; calyce in alabastro oborato, lobis conniventibus, tubo sub anthesi $4 \mathrm{~mm}$. longo orato, lobis e basi triangulari linearibus, saepe inaequilongis, tubo paullo longioribus v. brevioribus, crassiusculis, adpresse pilosis; corollae tubo cylindraceo, e calyce exserto, $6 \mathrm{~mm}$. longo, lobis obovatis, tubum dimidium paullo superantibus; filamentis tubo corollino fere in $3 / 5$ alt. affixis, antheris subexsertis; drupa suboblique ovata, $5 \mathrm{~mm}$. longa, abortu 1 -loculari.

Frutex 2,5-3,5 m. altus. Rami vetustiores brunei v. nigrescentes teretes, hornotini paliidiores, obtuse subangulati, pilis basi non bulbosis, rigidis albidis scabridi. Folia nervis lateralibus utrinque $5-7$ sub angulo ca. $60^{\circ}$ abeuntibus rix arcuatis, sicut medio supra impressis, subtus reticulato-conjunctis, margine anguste recurvata v. revoluta, supra pilis brevibus adpressis basi vix incrassatis dense obtecta, subtus pilis paullo longioribus tenuioribus adpressis vagiversis pubescentia, in sicco obscure viridia, subtus pallidiora. Capitula specialia 5-10 nm. diametro, $10-20$-flora; flores sessiles. Calyx extrinsecus breviter strigoso-pilosus, 2,5 mm. liametro, non striatus, coriaceus; lobi supra basin subteretes, apice obtusi. Corolla alba, utrinque glabra, membranacea; lobi apice rotundati r. subtruncati, hinc illine crenati. Filamenta glabra; antherae clliptico-rectangulares, $1 \mathrm{~mm}$. longae, sub medio affixae. Ovarium ovato-oblongum, stylo fere 3 -plo brevius, 4-loculare; ovula lateraliter fere in $1 / 3$ alt. affixa, ohlonga acuminata. Stylus $5 \mathrm{~mm}$. longus, in $2 / 3$ alt. in ramos subacqnales divisus; stigmata 4 oblonga planiuscula. Drupa calyce persistente ampliato circumdata tubumque paullo superans, nitida in sicco olivacea.

Hab. in Haiti prope Gonaïves ad Ennery, 500 m. alt., solo calcareo sicco, m. Sept. flor.: Buch n. 485.

Obs. E sectionis Myxae Endl. serie Dasycephalarum. 
Cordia Picardac Urb. (n. sp.) ramis pilis bruneis plus minus patulis dense pubescentibus; foliis $10-6 \mathrm{~mm}$. longe petiolatis, breviter v. rotundato-ovatis, basi subtruncatis, non r. vix in petiolum protractis, apice rotundatis, $3-5,5 \mathrm{~cm}$. longis, $2,5-4,5 \mathrm{~cm}$. latis, margine basi excepta crenatis, initio chartaceis, postremo coriaceis, supra scabridis; inflorescentiis terminalibus solemniter capitatis, $1-5 \mathrm{~cm}$. longe pedunculatis; calyce in alabastro obovato, lobis conniventibus, tubo sub anthesi $6,5-7 \mathrm{~mm}$. longo, e basi cylindracea glabra turbinato, patentirufo-pubescente, lobis inferne triangularibus, superne breviter linearibus, tubo fere 3-plo brevioribus crassiusculis patenti-pilosis; corollae tubo infundibuliformi, e calyce exserto, $8 \mathrm{~mm}$. longo, lobis rotundatis, tubo duplo brevioribus; filamentis tubo corollino in $2 / 3$ alt. affixis, antheris subexsertis; drupa (juniore) breviter ovali, $4 \mathrm{~mm}$. longa, abortu uniloculari.

Rami retustiores teretes, in sicco plicatulo-striati, scabridi, brunei, hornotini obtusanguli, bruneo-nigrescentes, pube simplice inaequilonga, sed crassitie rami breviore. Folia petiolis infra medium articulatis, parte inferiore persistente et plus minus liamata, nervis lateralibus $4-5$ sub angulo $45-55^{\circ}$ abeuntibus parum arcuatis, sicut medio supra impressis, utrinque reticulato-conjunctis, supra pilis brevibus pallide bruneis obsita, postremo multo rigidiora, supra bullato-areolata et basibus pilorum inflatis cinereis notata, subtus pilis bruneis postremo pallescentibus brevilus pubescentia, margine anguste recurva, supra nigro-brunescentia, subtus pallidiora. Capitula 1,2-1, $8 \mathrm{~cm}$. diametro, 20-30-flora; flores arcte sessiles. Calyx supra basin 1,5 mm., sub lobis $4 \mathrm{~mm}$. diametro, non striatus, sed luce permeante 10 -nervis, chartaceus; lobi vix $3 \mathrm{~mm}$. longi, superne subteretes obtusi. Corolla alba, extrinsecus glabra, intus sub medio ad filamenta adnata pilis longiusculis obsita, membranacea; lobi apice rotundati emarginati. Filamenta quoad libera glabra: antherae ovali-rectangulares, 0,7 $\mathrm{mm}$. longae, in $2 / 5$ alt. affixae. Ovarium ovato-oblongum, stylo vix duplo brevius; ovula juxta basin affixa, oblonga acuminata. Stylus $4 \mathrm{~mm}$. lougus, in $2 / 3$ alt. bifidus; stigmata 4 oblongo-linearia. Drupa calyce persistente ampliato plane inclusa, $3 \mathrm{~mm}$. diametro nitida, in sicco nigrescens.

Hab. in Haiti prope Port-au-Prince in montibus Furcy, locis humidis, m. April. flor.: Picarda n. 1000.

Obs. Sectionis Myxae Endl. seriei Dasycephalarum adscribenda et habitu C. calocephalae Cham. (e Brasilia) affinis.

Cordia asperrima P. DC. ramis setulis brevibus albidis sursum curvatis obsessis; foliis $7-10 \mathrm{~mm}$. longe petiolatis, ovatis v. subanguste ovatis, basi rotundatis $v$. in petiolum protractis, apice obtusis $v$. acutis, $6-3$ cm. longis, 3,5--2 cm. latis, margine basi excepta irregulariter lentatis, chartaceo-coriaceis r. demum coriaceis rigidis, supra setulis brevibus basi bulbosis scabris, postremo areolatis; inflorescentiis re rera terminalibus, inferioribus specie extraaxillaribus pedunculo ad ramum 
dichotomiarum alterum saepius sursum adnato $8-1 \mathrm{~cm}$. longo, solemniter capitatis ca. 20 -floris; calyce in alabastro obovato, lobis basi conniventibus, superne divaricatis, tubo sub anthesi $3,5-4 \mathrm{~mm}$. longo, obovato-cylindraceo, ad basin glabro, caeterum breriter et plus minus adpresse strigoso-piloso, lobis inferne o rato-triangularibus, superne linearibus subteretibus, tubum subaequantibus reflexis; corollae tubo cylindraceo superne sensim ampliato, e calyce paullo exserto $5 \mathrm{~mm}$. longo, apice truncato undulato, lobis nullis; filamentis tubo corollino ad medium insertis, antheris ad os sitis; drupa oblique ovato-globosa, $3,5-4 \mathrm{~mm}$. longa, abortu uniloculari.

Cordia asperrima P. DC. Prodr. IX (1845) p. 498.

Hab. in Jamaica: Bertero n. 2749, ad Farm Pen 66 m. alt., m. Aug. fruct.: Campbell n. 5857, inter Stony Hill et Old Road, $330 \mathrm{~m}$. alt., m. Jul. fl. et fruct.: Harris n. 5915 (floribus albis, drupis scarlatinis).

Obs. I. Flores (imperfecte obvii) fortasse heterostyli sunt: styli breviores ramis stigmatosis multo brevioribus latioribus anguste oblongis, longiores ramis longioribus linearibus apice clavatis gaudent.

Obs. II. Species jamaicensis sine ulla dubitatione praesertim ob inflorescentias corollamque a C. lima diversa.

Cordia lima Roem. et Schult. ramis setulis brevibus albidis $r$. cinereis sursum curvatis et pilis brevissimis tenuibus restitis; foliis $5-7 \mathrm{~mm}$. longe petiolatis, oratis $\mathrm{v}$. anguste ovatis, basi paullo in petiolum protractis, apice obtusis $\mathrm{v}$, acutis, $5-2 \mathrm{~cm}$. longis, $3-1,5 \mathrm{~cm}$. latis, margine basi excepta crenatis $v$. crenulatis, coriaceis, demum rigidis, supra setulis brevissimis basi bulbosis scaberrimis, postremo plus minus areolato-bullatis; inflorescentiis rarissime hine illine terminalibus, plerisque axillaribus sessilibus v. usque $10 \mathrm{~mm}$. longe pedunculatis capitatis 3-8-floris; calyce in alabastro breviter ovali, lobis conniventibus, tubo sub anthesi $3-4 \mathrm{~mm}$. longo obovato-globoso, breviter et subparce setuloso, lobis triangularibus brevissime $r$. breviter et obtuse lineari-productis; corollae tubo cylindraceo-infundibuliformi, e calyce exserto, 5-6 mm. longo, lobis ovatis tubo duplo brevioribus; filamentis sub fauce corollae insertis, antheris ad os sitis; drupa ovato-globosa $\mathrm{r}$. globulosa 2,5-3,5 mm. longa, abortu uniloculari.

Cordia lima Roem. et Schult. Syst. IV (1819) p.465.

Varonia lima Desv. Jouru. I (1S08) p. 278 (e.x P. I)C.).

Cordia radula Spreny.! Syst. I (1825) p. 65\%.

Lithocardium limum O. Kitse. Rer. II (1891) p. 976.

Varronia scaberrima Bert.! Mse. ap. Spreny.! l. c.

Hab. in Sto. Domingo: Bertero (ex herb. Spreng.); Haiti: Poiteau, prope Gonaires in Horne Bellance, $1000 \mathrm{~m}$. alt., m. Jul. flor:: Buch 
n. 645 (frutex squarrosus, 1,3-2 11. altus, floribus albis); Portorico prope Marica in monte Alegrillo: Sintenis n. 338.

Obs. Specimen portoricense cum domingensibus benc congruit praeter calyces specie fructiferos multo majores $5-6 \mathrm{~mm}$. crassos (nec $3-4 \mathrm{~mm}$.); calyces autem excmplaris portoricensis non fructus includunt, sed corollam minutam basi organis glanduliformibus ea. 7 ovalibus $2,5 \mathrm{~mm}$. longis racuis circumdatam v. suffultam praebent quod rerisimiliter ictu inscctorum deformatum est. In floribus fructibusque perfectis iterum cum descriptione supra e speciminibus Hispaniolae data comparandum.

Tar. $\beta$. subinflata Urb. foliis basi subtruncatis, non v. vix in petiolum protractis; calyce brevissime et pateuti-pubescente tenuiore, globuloso-subinflato, lobis longius lineari-productis.

Cordia radula P. DC.! Prodr. IX (1845) p. 498, - non Spreng. Varronia scaberrima Bert.! Msc. ap. DC. l.c.

Hab. in Sto. Domingo: Bertero (herb. Berol. et Cand.).

Cordia areolata Urb. (n. sp.) ramis pilis brevibus basi incrassatis patulis $\nabla$. sursum curvatis initio griseis dein plus minus brunescentibus dense obsitis; foliis $12-5 \mathrm{~mm}$. longe petiolatis, ovatis, basi rotundatis, non v. parum in petiolum protractis, apice acutiusculis, $6-2,5 \mathrm{~cm}$. longis, 4,5-1,5 cm. latis, margine basi excepta dentatis, coriaceis rigidis, supra areolato-bullatis, utrinque scaberrimis; inflorescentiis in ramis foliatis terminalibus, capitatis, sessilibus v. usque 5 mm. louge pedunculatis; calyce in alabastro globulose, lobis conniventibus, tubo sub anthesi $4,5 \mathrm{~mm}$. Jongo, breviter turbinato, subparce patenti-piloso, lobis e basi triangulari linearibus, tubo duplo brevioribus $v$. subaequilongis subteretibus patenti-pilosis; corollae tubo late infundibuliformi, e calyce exserto, $8 \mathrm{~mm}$. longo, lobis ambitu subrotundatis, tubo $2-21 / 2$-plo brevioribus; filamentis tubo corollino paullo infra medium affixis, antheris inclusis; drupa oblique ovata, 5 mm. longa, abortu uniloculari.

Frutex 2,6 m. altus. Rami divaricati, vetustiores teretes in sicco plicatuli brunei scabridi, hornotini pilis inaequilongis et inaequicrassis simplicibus minute scabriusculis restiti, interdum (ope formicarum?) norlosoincrassati. Folia pctiolis infra medium articulatis, parte inferiore persistente et plus minus hamata, nervis lateralibus $3-5$ sub angulo $45-60^{\circ}$ abeuntibus vix v. parum areuatis, sicut medio profunde impressis utrinque reticulato-anastomosantilus, areolis reticuli supra bullato-prominentibus, pilis supra brerissimis basi bulboso-inflatis; subtus tenuioribus praesertim ad nervos obviis, dentibus saepe inaequimagnis margine recurvis, supra brunescentia nitida, subtus viridia. Capitula $1-1,5 \mathrm{~cm}$. diametro, $10-20$ flora; flores sessiles. Calyx supra basin $2 \mathrm{~mm}$., sub lobis $5 \mathrm{~mm}$. diametro, non striatus, sed luce permeante 10 -nervis, chartacens, sub lobis sub anthesi quoque panllo constrictus; lobi $3-5 \mathrm{~mm}$. longi obtusi. Corolla alba, extrinsecus glabra, intus sub medio ad filamenta adnata pilis longinsculis obsita, membranacea; lobi apice plus minus emarginati, margine crenati. Fila- 
menta quoad libera glabra, $2 \mathrm{~mm}$. longa; antherae ovales, 1,3 $\mathrm{mm}$. longae, sub medio affixae. Ovarium ovatum acuminatum, stylo 4 -plo brevius; ovula supra basin affixa, oblonga obtusa. Stylus $8 \mathrm{~mm}$. longus, in $2 / 3$ alt. bifidus; stigmata 4 linearia ad apicem paullo dilatata. Drupa calyce persistente fere inclusa, $3-3,5 \mathrm{~mm}$. diametro, inferne plus minus tuberculata, rubra.

Hab. in Sto. Domingo prope Jarabacoa, $600 \mathrm{~m}$. alt., m. Majo fl. et fr.: Eggers n. 2002.

Obs. Habitu affinis C.limae R. et Sch., sed capitulis terminalibus multifloris, corolla majore etc. statim dignoscenda.

Cordia serrata Gürke in Engl.-Prantl Nat. Pflanzenfam. IV. 3 (1893) p. 83.

Tournefortia serrata Limn. Spec. I ed. I (1753) p. 140 ct II ed. I p. 201 (cum var. B.), - mon Cordia serrata Jiss. (1806) nec Roxb. (1814).

Varronia mirabiloides Jacq. Enmm. (1760) p. 14 ct Sclect. p. 41 tab. 33!; Sw. Prodr. p. 48 et Flor. I p. 465; Desn. Journ. I p. 273 (ex DC.).

Varronia bullata Linn. Spec. II ed. I (1762) p. 276 (quoad sym. Jacq.); Jacq. Select. pict. p. 25 tab. 43 et Ausg. Geu:. II t. 55!, - non Linn. Amoen. V p. 394.

Varronia geniculata Pers. Syn. I (1805) p. 167.

Cordiopsis mirabiloides Desv. Journ. I (1808) p. 273 (ex DC:).

Cordia chamaedrifolia Rees Cycl. XXXVI (1817) n. 2 (ex A. DC. l. c.).

Cordia mirabiloides Rocm. et Sch. Syst. IV (1819) p.465; Spreng.! Syst. I p. 654 .

Cordia strigosa Spreng.! Nene Ental. III (1822) p. 30 et Syst. I p. 649 .

Cordia mirabiliflora A. DC. Prodr. IX (1845) p. 499.

Cordia mirabiliflora var. chamaedrifolia A. DC. l. c.

Cordia bullata Griseb.! Cat. (1866) p. 209; Sam. Cub. 11. 1707 p. 110, - non R. et Sch.

Lithocurdium scrratnum O. Ktre. Rev. II (1891) p. 976.

Cordiopsis mirabitiflora P. DC. Msc. ex A. DC. l.c.

Calabura alba Pluk. Alm. (1696) p. 75 tab. 152 fig. 4!

Pittonia arborescens chamaedrifolia major et minor Plum. Gcm. (1703) p. 5 et ed. Burm. p. 224 tab. 228 fig. 1 et 2!

Dent de Chien blanc Hait. ex Sw., Bombon capitaine Hait. ex Pic. $v$. Bombon chat Hait. cx Jaey.

Frutex subscandens $v$. debilis $1,3-3,3 \mathrm{~m}$. altus (ex EgG. et Bucul) r. arbor usque $8 \mathrm{~m}$. alta, rariat ramis lornotinis pilis brevibus parcis $\mathrm{r}$. crebrioribus v. densis adpressis, patulis v. horizontaliter patentibus, tenuioribus 
saepins intermixtis vestitis, foliis ovatis, ovato-oblongis usque oblongolaneeolatis, $2,5-7 \mathrm{~cm}$. longis, $1-4 \mathrm{~cm}$. latis, membranaceis usque coriaceis, cymis initio capituliformibus, posterius laxioribus v. laxifloris, in cincinnos excurrentibus, calycis lobis plus minus longe subulato- v. filiforni-productis, interdum triangulari-muticis; pube tubi plerumque alba, interdum ferruginea, corolla alba magnitudine varia, tali modo, ut varietates condendae non sint. - Flores solemniter heterostyli aut interdum homoeostyli sunt. - Cotyledones supra terram elatae late semiorbiculares crenatae $2 \mathrm{~cm}$. longae, $1,5 \mathrm{~cm}$. latae.

Hab. in Cuba: Wright n. 3116; Haiti: Jacquemont, Jäger n. 180, Mackenzie, Picarda n. 283, 995, ad Cap Français: C. Ehrenberg, ad Petite Rivière de Bayonnais et prope Marchand, m. Majo, Jul. fl.: Buch n. 64, 186, prope Port-au-Prince: Schumann n. 307, ad rivière Bizothon m. Jan. fl. et fr.: Eggers n. 3351, ad Petit Goave: Favrat n. 110; Sto. Domingo: Bertero n. 627, 860, Mayerhoff n. 45, Schomburgk n. 84, inter Santiago et Lopez ad vias, 230 m. alt., m. Majo flor.: Egger's n. 1835, in sylvis ad Palmar: Eggers n. 1835 , ad La Ceybita 300 m. alt., m. Jun. flor.: Egger's n. 1835, ad El Castillo in rupibus calcareis $250 \mathrm{~m}$. alt.: Eggers n. $1835^{\mathrm{c}}$.

Aegiphila Swartziana Urb. (n. sp.) ramis hornotinis pilis brevibus patentibus obsitis; foliis $4-5 \mathrm{~mm}$. longe petiolatis, ovalibus v. anguste ovalibus, basi rotundatis, apice mediocriter acuminatis, $6-7 \mathrm{~cm}$. longis, $3-4 \mathrm{~cm}$. latis, supra glabris, subtus ad nervum medium breviter pilosis, subtus non v. obsolete impresso-punctatis; inflorescentiis axillaribus $1-3 \mathrm{~mm}$. longe pedunculatis, laxe racemosis v. subpanniculatis, 3-9-floris, breviter patenti-pilosis, pedicellis (inter .prophylla et calycem) $3-6 \mathrm{~mm}$. longis, superne sensim incrassatis; calyce turbinato, supra ovarium plus minus manifeste constricto, breviter patentipiloso, $4 \mathrm{~mm}$. longo, margine dentibus 4 triangularibus apiculatis tubo ca. 5 -plo brevioribus instructo; corolla $18 \mathrm{~mm}$. longa glaberrima, lobis oblongo-linearibus, tubo duplo brevioribus.

Rami sub nodis obtuse tetragoni, eaeterum subteretes, griseo-flavidi, pube brevi laxa. Folia petiolis breviter patenti-pilosis, nervo medio supra plano latiusculo parcissime pilosulo, lateralibus utroque latere $7-8$ sul, angulo $50-60^{\circ}$ abeuntibus, utrinque prominulis, parce $\mathrm{v}$. vix anastomosantibus, margine integra, utrinque nitida, in sicco nigrescentia, chartacea, subtus supra basin orbiculis nonnullis nigris glandulosis notata. Inflorescentiae usque $3 \mathrm{~cm}$. longae, pube articulata, sel non secernente laxa; bracteae lineares, $2-3 \mathrm{~mm}$. longae; prophylla bracteis conformia, sed minora; pedicelli inferne ca. $0,3 \mathrm{~mm}$., sub calyce $0,6-0,7 \mathrm{~mm}$. crassi. Calyx chartaeeo-coriacens, lobis saepius lineari-apiculatis. Corolla coriacea; tubus $12 \mathrm{~mm}$. longus, e parte inferiore anguste cyliniluacea $0,8 \mathrm{~mm}$. crassa supra medium sensim incrassatus, sub apice $1,8 \mathrm{~mm}$. crassus; lobi $6 \mathrm{~mm}$. longi, $2 \mathrm{~mm}$. lati, apice obtuso plus minus cucullati. Stamina tubo corollice 2,5 110 . sub ore inserta; filamenta quoad libera $1 \mathrm{~mm}$. longal antherae in 
$1 / 5$ alt. affixae, sublineares, fere $2 \mathrm{~mm}$. longae, apice ex ore corollae parum prominentes. Stylus plane inclusus, $6 \mathrm{~mm}$. longus, a medio bificlus.

Hab. in Jamaica: Swartz (mus. Holm., Ae. trifidae intermixta).

Obs. Ae trifida Sw.! ramis glabris, foliorum nervis lateralibus parcioribus, inflorescentiis terminalibus et lateralibus, hisce longius (usque $2 \mathrm{~cm}$. longe) pedunculatis et plerumque 3 -floris, obsolete $\mathrm{r}$. brevissime et adpresse pilosulis, pedicellis $1-3 \mathrm{~mm}$. longis, calyce minute subparce et adpresse pilostilo, anguste turbinato $6 \mathrm{~mm}$. longo, manifestius dentato diversa est, sed foliorum forma et magnitudine sicut corolla cum nostra bene convenit.

Aegiphila plicata Urb. (n. sp.) ramis hornotinis ad apicem brevissime parce et adpresse pilosis, mox glabrescentibus; foliis $2-3 \mathrm{~mm}$. longe petiolatis, ovatis $\nabla$. anguste ovatis, basi rotundatis v. subcordatis, apice acuminatis, $5-7,5 \mathrm{~cm}$. longis, $3-4 \mathrm{~cm}$. latis, utrinque glabris, subtus densissime et minute glanduloso-impressis; inflorescentiis axillaribus et terminalibus sessilibus r. usque $3 \mathrm{~mm}$. longe pedunculatis, subcapitatim plerumque 3 -floris, breviter et adpresse pilosis, pedicellis nullis v. usque $1 \mathrm{~mm}$. longis; calyce turbinato, supra ovarium non r. vix constricto, 3 nım. longo, brevissime et parce adpresse pilosulo, margine apiculis 4 brerissimis $\mathrm{v}$. obsoletis notato; corolla $18 \mathrm{~mm}$. longa, glaberrima, lobis oblongo-linearibus, tubo dimidio brevioribus.

Raın i obtusissime v. obsolete tetragoni, vetustiores sordide flavescentes, hornotini in sicco nigrescentes. Folia petiolis subglabris, nervo medio supra prominulo, lateralibus utroque latere $6-8$ sub angulo ca. $60^{\circ}$ abeuntibus, supra prominulis et minus, subtus magis anastomosantibus, margine integra, ntrinque nitida, in sicco nigrescentia, subtus pallidiora, coriacea, pleraque longitrorsum plicata, subtus inferne praesertim ad basin versus orbiculis glandulosis pluribus v. multis nigris notata. Inflorescentiae $3-7 \mathrm{~mm}$. longae, pube (sub lente valida) articulata non secernente; bracteae lineares, superne angustiores, ca. $1 \mathrm{~mm}$. longae; prophylla bracteis conformia iisque valde approximata, sed multo minora; pedicelli si adsunt, $0,4-0,5 \mathrm{~mm}$. crassi. Calyx subcoriaceus, margine undulato-4-denticulatus. Corolla coriacea; tubus $12 \mathrm{~mm}$. longus, e parte inferiore anguste cylindracea $0,8 \mathrm{~mm}$. crassa supra medium sensim incrassatus, sub apice $2 \mathrm{~mm}$. crassus; lobi $8 \mathrm{~mm}$. longi, $2 \mathrm{~mm}$. lati, apice obtusi v. rotundati, nume subeucullati. Stamina tubo corollae $3 \mathrm{~mm}$. sul, ore inserta; filamenta quoad libera $1 \mathrm{~mm}$. longa; antherae in $1 / 4$ alt. affixae, oblongae, 1,2 $\mathrm{mm}$. longae, apice ex ore corollae non prominentes. Stylus plane inclusus, $10 \mathrm{~mm}$. longus, in $2 / 3$ alt. bifidus.

\section{Hab. in Jamaica: Bertero n. 2105.}

Obs. Ex affinitate Ae. trifidae Sw., quae foliis $5-10 \mathrm{~mm}$. longe petiolatis, basi obtusissimis v. rotundatis, nervis lateralibus parcioribus, chartaceis, subtus obsolete v. non glanduloso-impressis, orbiculis subtus ad basin parcis, inflorescentiis solemniter pedunculatis, pedicellis evolutis, calyce elongato-turbinato, $6 \mathrm{~mm}$. longo, lohis manifestis discrepat.

Aegiphila unillor'a Urb. (n. sp.) ramis hornotinis pilis mediocribus patulis adspersis; foliis 5-6 mun. longe petiolatis, anguste ovatis 
usque ellipticis, basi rotundatis r. obtusis, apice acuminatis, $6-8,5 \mathrm{~cm}$. longis, 2,5-3,5 cm. latis, supra glabris, subtus ad nervos breviter et parce pilosis, subtus minute v. obsolete glanduloso-impressis; floribus in ramulis abbreviatis terminalibus $\mathrm{v}$. ex axillis foliorum solitariis, pedicellis (supra prophylla) $3-4 \mathrm{~mm}$. longis; calyce oblongo, $7 \mathrm{~mm}$. longo, pilis plus minus patulis sordide et pallide flavis villosulo, lobis ovatis v. anguste ovatis breviter acuminatis tubo $21 / 2$-plo brevioribus; corolla flava, $18 \mathrm{~mm}$. longa glaberrima, tubo e calyce parum exserto, lobis linearibus tubo subaequilongis.

Frutcx irregulariter ramosus. Rami vetustiores subteretes, pallide et sordide flavi, lenticellis permultis suborbicularibus obsiti, hornotini obtuse tetragoni, pube laxa. Folia petiolis patenti-pilosis, nervo medio supra subimpresso, sed in sulco iterum anguste prominulo, lateralibus utroqne latere $4-5$, intermediis sub angulo ca. $50^{\circ}$ abenntibus arcuatis, basalibus 2 magis arduis, margini infero parallelis, omnibus supra non v. parun prominulis, supra non v. vix, subtus manifeste anastomosantibus, margine integra, utrinque nitidula, supra in sicco bruncscentia, subtus olivacea, crassiuscule chartacea v. chartaceo-coriacea, subtus praesertim ad basin versus orbiculis nonnullis brunescentibus glandulosis notata. Pedunculi perbreves, $1-2 \mathrm{~mm}$. longi; prophylla lineari-subulata, $1,5-2,5 \mathrm{~mm}$. longa; pedicelli inferne $0,5 \mathrm{~mm}$., sub calyce $1 \mathrm{~mm}$. crassi. Flores verisimiliter heterostyli. Calyx crasse coriaceus, pube manifeste articulata, lobis ca. $2 \mathrm{~mm}$. longis. Corolla crasse coriacea; tubus $9-10 \mathrm{~mm}$. longus, inferne anguste cylindraceus, $1 \mathrm{~mm}$. crassus, ad apicem sensim incrassatus, $2 \mathrm{~mm}$. crassus; lobi $8-9 \mathrm{~mm}$. longi, $1-1,5 \mathrm{~mm}$. lati, apice obtusi, subcarnosi. Stamina tubo corollae $3,5 \mathrm{~mm}$. sub ore inserta; filamenta quoad libera vix $0,3 \mathrm{~mm}$. longa; antherae dorso in $1 / 6$ alt. affixae, oblongo-lineares, $0,8 \mathrm{~mm}$. longae, plane inclusae. Stylus $14 \mathrm{~mm}$. longus, in $3 / 5$ alt. bifidus, ramis exsertis. Fructus calyce ovato v. breviter ovato, $8-9 \mathrm{~mm}$. longo, $7-8 \mathrm{~mm}$. crasso, patenti-piloso in vivo smaragdino, in sicco nigrescente fere usque ad apicem inclusus, subanguste ovatus, $8 \mathrm{~mm}$. lougus, $5 \mathrm{~mm}$. crassus, apice obtusus, 4-locularis.

Hab. in Jamaica in Silver Hill Woodland, 1171 m. alt., m. Jan. fl. et fr.: W. Harris n. 5533 .

Obs. I. Ae. foetida Sw.! ramis dense pubescentibus, foliis $2-3 \mathrm{~mm}$. longe petiolatis, basi subcordatis, inflorescentiis plurifloris, calyce $3 \mathrm{~mm}$. longo, densissime villoso, margine subintegro, corollae tubo calycem pluries superante, lobis tubo duplo et ultra brevioribus, fructu a calyce vix semiincluso, Ae. trifida Sw.! ramis glabris, inflorescentiis plurifloris, calyce minute adpresseque pilosulo, dentibus tubo 4 -plo brevioribus, corollae albidae tubo calycem ferc duplo superante, lobis tubo duplo et ultra brevioribus differunt.

Obs. II. In speciebus tribus antecedentibus verisimiliter, paene certe in ultima, flores heterostyli sunt; sed specimina semper statum unicum praebuerunt.

Aegiphila nerrosa Urb. (n. sp.) ramis hornotinis pilis brevissimis articulatis patulis v. sursum curvatis densissime obtectis; foliis $3-5 \mathrm{~mm}$. longe petiolatis, ellipticis, basi obtusissimis v. rotundatis, apice breviter 
acuminatis, medio $\mathrm{r}$. paullo supra medium latissimis, $7-12 \mathrm{~cm}$. longis, $3-5$ cm. latis, supra pilis brevissimis basi inflatis scabriusculis v. subglabris, subtus praesertim ad nervos brevissime pilosis et minute glanduloso-impressis, reticulo nervorum subtus valde prominente; inflorescentiis terminalibus et interdum qnoque ex axillis foliorum summorum axillaribus panniculam densam usque $4 \mathrm{~cm}$. longam formantibus; pedicellis 2 - $5 \mathrm{~mm}$. longis; calyce inferne subcylindraceo, dein late turbinato v. subcampanulato, breviter v. brevissime adpresse piloso, $3,5-4 \mathrm{~mm}$. longo, apice 4-lobo, lobis semiorbicularibus antice rotundatis, tubo ca. 3 -plo brevioribus; corolla (evoluta non visa) glaberrima, tubo calycem triplo (v. ultra?) superante.

\section{Aegiphila elata Sw.! Prodr. (17SS) p. 31 et Flor. I p. 254 (p.p.).}

Rami vetustiores subteretes brunescentes, hornotini teretes $r$. inferne obtuse quadranguli, pube pallide v. sordide flava, longe persistente. Folia petiolis brevissime et dense pubescentibus, nervo medio supra solemniter prominente, lateralibus utroque latere $6-8$, sub angulo $50-60^{\circ}$ abeuntibus arcuatis, supra teuniter, subtus crassiuscule prominentibus, utrinque dense reticulato-anastomosantibus, reticulo subtus multo magis prominente, margine integra, utrinque nitida, supra in sicco obscure viridia, subtus pallidiora, chartacea v. chartaceo-coriacea, orbiculis glandulosis subtus ad basin mullis. Pedunculi nunc breves, nunc usque $6 \mathrm{~cm}$. longi, brevissime tomentosulo-pilosi; bracteae lanceolatae usque lineares, supra saepe orbiculis inaequimagnis (glandulosis?) prominulis notatae; prophylla $3-1 \mathrm{~mm}$. longa filiformia; pedicelli inferne ca. $0,3 \mathrm{~mm}$., sub calyce 0,7-0,8 mm. crassi. Calyx chartaceo-coriaceus, lobis antice non $r$. vix apiculatis, fructifer semiglobosus v. semiovalis, $5-6 \mathrm{~mm}$. longus, $6-8 \mathrm{~mm}$. diametro, in sicco brunescens.

Hab. in Jamaica: Swartz (mus. Holm.); Haiti circa Payan, $800 \mathrm{~m}$. alt.: Picarda n. 171, prope Pétionville circa Fessard ad pedem Morne de l'Hôpital: Picarda n. 1418.

Obs. Ae. elata Sw.! (p. p., Griseb.! Flor. p. 500, e Jamaica, Cuha, Hispaniola) bene discrepat foliis longius petiolatis, majoribus, ad basin rersus latissimis, subtus glabris subglabrisve, nervis tertii ordinis subtus multo minus prominulis, inflorescentiis lateralibus et terminalibus, amplioribus et multo laxioribus, pedicellis $4-8 \mathrm{~mm}$. longis (an etiam corolla genitalibusque?).

$\checkmark$ Clerodendron Picardae Urb. (n. sp.) ramis junioribus hrerissime patenti-pilosis et tuberculis plus minus prominentibus obsessis; foliis ad apicem ramorum confertis, alternis v. oppositis, $7-3 \mathrm{~mm}$. longe petiolatis, obovato-oblongis usque oblongo-lanceolatis, in $2 / 3-4 / 5$ long. latissimis, inferne sensim et longe angustatis, basi ipsa obtusiuscula v. obtusa in petiolum contractis, apice breviter $v$. mediocriter acuminatis, $5-15 \mathrm{~cm}$. longis, $1,5-4 \mathrm{~cm}$. latis, margine integris $\mathrm{v}$. ad basin imam utroyue margine dentes $1-3$ spinescentes gerentibus; inflorescentiis 
axillaribus paucifloris et terminalibus multifloris panniculatis, ramis panniculae alternis, pedicellis $3-4 \mathrm{~mm}$. longis; calyce breviter campanulato, $3-4$ num. longo, late et brevissime v. breviter 5 -dentato; corollae tubo infundibuliformi, $16-18 \mathrm{~mm}$. longo, densissime et brevissime patenti-piloso, lobis ovatis $v$. breritel ovatis.

Frutex $0,3-1,3 \mathrm{~m}$. altus, nunc parce nunc crebro ramosus (ex Picarda). Rami retustiores teretes brunescentes, pilis simplicilus longe persistentibus, tuberculis mammiformibus v. breviter conicis usque $0,5 \mathrm{~mm}$. longis pilosulis; ramuli enjusve anni inferne denudati r. squamis parcis linearibus ca. $3 \mathrm{~mm}$. longis, plerumque alternis obsiti, apice comam foliorum gerentes. Folia nervo medio supra prominente, lateralibus utroque latere $8-11$, superioribus sub angulo $45-50^{\circ}$ abeuntibus, infimis magis arduis, supra tenuiter prominulis v. subimpressis, subtus tenuissime reticulato-allastomosantibus, membranaceo-chartacea v. chartacea, supra setulis brevissimis basi incrassatis parcis v. parcissimis scabriuscula, subtus brevissime patenti-pilosa et glandulis minutissimis luteis adspersa, supra in sicco obscure viridia, subtus pallidiora. Inflorescentiae terminales, pedunculo $2-5 \mathrm{~cm}$. longo adjecto $8-14 \mathrm{~cm}$. longae, $3-5 \mathrm{~cm}$. diametro, brevissime et dense pubescentes; bracteae lineari-subulatie, 6-1 $\mathrm{mm}$. longae; rami erecto-patentes, plerique alterni, cymose $3-5$-flori. Calyx brevissime pilosus et glandulis minutis adspersus; lobi late v. latissime triangulares, tubo 3-5-plo breviores. Corollae tubus ad basin cylindraceus, $2 \mathrm{~mm}$. crassus, dein sensim usque $6 \mathrm{~mm}$. ampliatus, pilis simplicibus et articulatis dense indutus et glandulis crebris minutis adspersus, intus glaber v. superne minute pilosulus; lobi obtusi, $4-6 \mathrm{~mm}$. longi, $3,5-4 \mathrm{~mm}$. lati, reflexi. Stamina $5--6 \mathrm{~mm}$. supra basin corollae inserta, tubum ejus ca. $10 \mathrm{~mm}$. superantia; filamenta glabra; antherac oblongae obtusae $2,5 \mathrm{~mm}$. longae, dorso medio affixac. Stylus $30 \mathrm{~mm}$. longus subglaber; stigmata linearisubulata, 1,3 mm. longa. Ovarium semiglobosum. Fructus junior subglobosus glaber.

Hab. in Haiti prope Payan ad habitationem Icard, m. Jan. fl., in montibus Furey 1515 m. alt., m. Aug. flor.: Picarda n. 172, 621.

Obs. Ex affinitate aretissima Cl. Sagraei Schaner (e Cuba).

Salvia lorachyphylla Urb. (n. sp.) fruticosa, ramis retustioribus subteretibus, hornotinis obtuse quadrangulis, breviter et dense patentipilosis; foliis $5-10 \mathrm{~mm}$. longe petiolatis, breviter rlombeis lisque obovato-spathulatis, basi cuneatis, apice obtusis v. rotundatis, $3-1,5 \mathrm{~cm}$. longis, 2,5-1 cm. latis, margine superiore crenatis, nervis supra impressis, supra dense et breviter patenti-pilosis, subtus praesertim ad nervos brevissime pilosulis, in sicco brunescenti-viridibus, rigide coriaceis; inflorescentiis terminalibus $3-5 \mathrm{~cm}$. longis sublaxifloris, bracteis infimis euplylloideis, caeteris ovatis acuminatis integris, persistentibus, pedicellis $5-1,5 \mathrm{~mm}$. longis; calyce $5-6 \mathrm{~mm}$. longo, lobis 3 inaequilatis, postico orbiculari-ovato, anticis dimidio latiore, omnibus subaequilongis; corollae caeruleae calycem $1 \frac{1}{2}$-plo superantis tubo inferne 
cylindraceo, supra medium antice subito ventricoso-dilatato et hoc loco subgeniculato, labio superiorc subrecto, inferiore paullo longiore 3-lobo patente.

Frutex 0,6-1,3 m. altus. Rami in sicco brunei, quoad suppetunt $1,5-3 \mathrm{~mm}$. crassi, internodiis $2,5-4 \mathrm{~cm}$. longis, pilis parce r. rix articulatis valde inaequilongis albidis. Folia nervis lateralibus $2-4$ supra obsoletius, subtus manifestius anastomosantibus et crassiusculis, subtus densissime glandulose impresso-punctata. Inflorescentiae rerticillastri demum usque $3-5 \mathrm{~mm}$. longe inter sese remoti, $2-6$-flori; bracteae $5-2,5 \mathrm{~mm}$. longae, ca. $2 \mathrm{~mm}$. latae, cxtrinsecus pilosae. Calyx turbinato-tubulosus, extrinsecus breviter patenti-pilosus, glandulis flavis intermixtis, intus inferne glaber, superne minutissime puberulus, 9 -nervis; labium posterius integrum orbiculari-ovatum, tubo duplo brevius, anterius paullo minus profunde lifidum, lobis breviter ovato-triangularibus breviter acuminatis, tubo $21 / 2$-plo brevioribus. Corolla subrecta, $15 \mathrm{~mm}$. longa, ad labia pracsertim ad superius breviter pubescens, caeterum glabra, intus glabra; tubus inferne vix supra $1 \mathrm{~mm}$., supra medium fere $3 \mathrm{~mm}$. crassus, intus exannulatus; labium superius (explanatum) ovale, tuho dimidio brevius, apice subintegrum, concarum, inferius paullo longius, lobo intermedio dilatato, $7 \mathrm{~mm}$. lato, ambitı vix semiorbiculari, apice emarginato, lateralibus perparvis $1,5 \mathrm{~mm}$. latis semiorbicularibus integris. Stam in a fauci corollae affixa, labium superius aequantia; filamenta $2 \mathrm{~mm}$. longa, supra insertionem antherae fere $1 \mathrm{~mm}$. producta aequilata, apice subemarginata; connectivum $8 \mathrm{~mm}$. longum, cruribus subaequilongis, inferioribus inter sese agglutinatis fere duplo latioribus canaliculatis subrectis, sub insertione lateraliter triangnlari-productis, loculo carentibus, superioribus antheriferis; antherae anguste oblongae, 1,5 mm. longae, in $2 / 5$ alt. affixae. Staminodia non observata. Discus postice subabortivus, autice squamam carnosam rectangulari-ovatam ovaria superantem sistens. Stylus cum stigmatibus $15 \mathrm{~mm}$. longus, antheras vix superans, ad apicem pilis articulatis patentibus obsitus, caeterum glaber; stigma bifidum, ramo antico duplo breviore et fere duplo latiore rix currato, postico plus minus revoluto. Ovaria clliptica.

Hab. in Haiti prope Marmeladc in montibus siccis $500 \mathrm{~m}$. alt., m. Sept. flor.: Buch n. 449.

Obs. Species in sectionem Calosphace \$ 3 Brachyanthae F. Scorodoniae apnd Bentham (in DC. Prodr. XII p. 315) inserenda, sed nulli alii aretius affinis.

Salvia Buchii Ulb. (n. sp.) fruticosa, ramis obtuse quadrangulis, pilis minutissimis albidis pulverulentis; foliis $15-3 \mathrm{~mm}$. longe petiolatis, subobliquc ovatis usque oblongo-lanceolatis, basi plus minus cuncatis, apice obtusis usque longiuscule acuminatis, $5-10 \mathrm{~cm}$. longis, $2-3 \mathrm{~cm}$. latis, "margine basi cxcepta dense serrato-crenulatis, nervis supra tenuiter prominulis, supra minutissime et obsolete pilosulis, subtus pube pulverulenta albescente densissime obtectis mollibus, chartaceis $r$. chartace-membranaccis; inflorescentiis terminalibus, pedunculatis, dense spiciformibus, ca. $10 \mathrm{~cm}$. longis, bracteis suborbicularibus ovatis r. sub- 
quadratis, apice filiformi-productis, deciduis, pedicellis subnullis usque $2 \mathrm{~mm}$. longis; calyce $8-9 \mathrm{~mm}$. longo, lilacino-villosulo, posterius pallescente, lobis 3 inaequilatis, postico ovato, anticis fere duplo angustioribus perpaullo brevioribus; corollae albae calycem parum superantis tubo inferne subcylindraceo, superne sensim dilatato, subarcuato, labio superiore subrecto, inferiore paullo longiore 3-lobo patulo.

Frutex 1,3-2 m. altus. Rami hornotini in sicco pallide viridiolivacei $2-3 \mathrm{~mm}$. crassi, internodiis $8-2 \mathrm{~cm}$. longis, pube panciarticulata. Folia nervis lateralibus $3-6$, supra non v. obsolete anastomosantibus, subtus dense et tenuiter v. obsoletc reticnlatis, supra obscure viridia, subtus albido-viridia, uinnte et dense glanduloso-punctata, utrinque plana. Inflorescentiae verticillastri sub anthesi $4-7 \mathrm{~mm}$. distantes, sed internodiis vix conspicuis continuae, in quaque bractea 5-7-florae; bracteae cum acumine $9-12 \mathrm{~mm}$. longae, $4-6 \mathrm{~mm}$. latae, apice subtruncato subito in acumen limbo sulsaequilongum contractae, parallelinerves, intıs sulglabrae, dorso brevissime jubescentes, margine breviter lilacino-villosulae, memlranaceae. Calyx anguste turbinato-tubulosus, extrinsecus villosulus, glandulis aegre conspicuis intermixtis, 9 -costatus; labium posterius integrum, tubo fere duplo brevius, anterius perpaullo minus profunde bifidum, lobis apice obsolete et obtuse acuminatis, tubo duplo brevioribus. Corolla subarcuata $10-11 \mathrm{~mm}$. longa, ad apicem patenti-pilosa, caeterum glabra, intus glabra; tubus inferne vix supra $1 \mathrm{~mm}$., superne $2 \mathrm{~mm}$. crassus, intns exannulatus; labium superius (explanatum) subquadratum, apice plus minus bilobum, tulı 6-7-plo brevius, concavinsculum, inferius paullo longius, lobo intermedio dilatato $3,5 \mathrm{~mm}$. lato, ambitu semiorbiculari, margine crenulato, apice emarginato, lateralibus $1-1,3 \mathrm{~mm}$. latis, obovatis $\mathrm{v}$. suborbicularibus. Stamina sub fauce inserta, labium supcrius aequantia; filamenta $1,5 \mathrm{~mm}$. longa, supra insertionem non producta, superne angustata; connectivum $5 \mathrm{~mm}$. longum, dorso glandulis obsolete stipitatis obsitum, cruribus superioribus paullo brevioribus, inferioribus inter sese connatis, sensim dilatatis, concavis subrectis, sub medio latere exteriore saepins denticulo obsitis, loculo carentibus, superioribus antheriferis; antherae elliptico-oblongae, $1 \mathrm{~mm}$. longae, in $2 / 5$ alt. affixae. Staminodia quam filamenta perpaullo profundius inserta, $0,5 \mathrm{~mm}$. longa, superue dilatata v. antlieram mimutam (assam deformatam gerentia. Discus postice perbrevis, antice squamam subcarnosam olovatam ovaria fere duplo supcrantem sistens. Stylus cum stigmatibus $9-10 \mathrm{~mm}$. longus glaber; stigma bilobum, lobo antico ovatooblongo subrecurvo, postico minuto dentiformi. Ovaria ovalia.

Hab. in Haiti prope Gonaïves in Morne Bellance in fruticetis humidis, $800 \mathrm{~m}$. alt., m. Jul. flor.: Buch n. 658 .

Obs. Affinis S. eviocalyx Bertero (e Jamaica) inflorescentiis abbreviatis, verticillastris pancifloris, bracteis lanceolato-linearibus, calyce $7 \mathrm{~mm}$. longo campanulato, dentibus obtusis, corolla calycem duplo superante, stylo superne fatenti-piloso, stigmate postice evoluto quam anticum longiore plane diversia est.

Cestrum inclusum Urb. (n. sp.) ramis superne, foliis subtus, pedicellis, calyce extrinsecus pilis laminiformibus lanceolatis $v$. linearibus 
margine fimbriato-laceris plus minus floccoso-indutis; foliis $15-5 \mathrm{~mm}$. longe petiolatis, oralibus usque oblongo-lanceolatis, basi obtusis v. acutiusculis, apice brevissime $\mathrm{v}$. obsolete et obtuse acuminatis, $8-15 \mathrm{~cm}$. longis, $2,5-5,5 \mathrm{~cm}$. latis; inflorescentiis axillaribus brevissime pedunculatis v. sessilibus $2-3$-floris, pedicellis $5-12 \mathrm{~mm}$. longis; calyce cylindraceo, $11-13 \mathrm{~mm}$. longo, lobis 3 , raro $4-5$, tubo $6-7$-plo brevioribus; corollae tubo e calyce breviter prominente, inferne anguste cylindraceo, in $3 / 5$ alt. usque ad os anguste turbinato; fructu oblongo exsucco, a calyce plane incluso.

Frutex 2,5 m. altus, ramis dependentibus (ex EGG.). Ramuli vetustiores teretes cinerascentes glabrati, hornotini subangulati, pube flavo-grisea. Folia nerro medio supra impresso, sed in sulco iterum plus minus prominente, lateralibus $7-10$ sub angulo ca. $70^{\circ}$ abcuntibus ad marginem arcuatis, supra prominulis et tenuissine reticulato-anastomosantibus, supra glabra nitida, subtus paullo pallidiora, demum subglabrescentia, margine anguste recurva. Pedunculus nullus v. usque $5 \mathrm{~mm}$. longus; bracteae calliformes (v. deciduae?). Calyx cylindraceus, superne parum ampliatus, $2-2,5 \mathrm{~mm}$. crassus, fructifcr anguste oblongus et plus minus manifeste 10 -nervis; lobi triangulares obtusiusculi ca. 1,5 mm. longi. Corollae tubus $16 \mathrm{~mm}$. longus, inferne $1 \mathrm{~mm}$., sub apice $3 \mathrm{~mm}$. crassus, extrinsecus glaber, intus ad filamenta adnata brevissime albido-pilosulus; lobi 5 reflexi, $7 \mathrm{~mm}$. longi, tubo plus quam duplo breviores, ovato-v. oblongo-lanceolati, obtusiusculi, nunc obsolete apiculati, $3 \mathrm{~mm}$. lati, extrinsecus tomentosuli, margine involuti. Stamina 5 (raro 4), quoad libera $5 \mathrm{~mm}$. longa glabra, ad insertionem intus squamulosa; antherae breviter ovatae, dorso sub medio affixae, os tubi corollini attingentes. Discus cupuliformis, chartaceus, margine erosulus. Ovarium ovatum glabrum; ovula medio dissepimenti longitrorsum affixa. Stylus $15 \mathrm{~mm}$. longus, inferne glaber, superne brevissime scabriusculus; stigma stylo ca. 3-plo crassius, crasse peltatum. Fructus a calyce $3 \mathrm{~mm}$. longe superatus, $9 \mathrm{~mm}$. longus, $3 \mathrm{~mm}$. crassus, glaber sublaevis; pericarpium coriaceum exsuccum. Semina in quoque fructu $10-13$, pleraque oblonga angulata, $3 \mathrm{~mm}$. longa, $1 \mathrm{~mm}$. lata, suprema et infima breviora et latiora, omnia bruneo-nigrescentia, obsolete rugulosa; endospermium amplum carnosum. Embryo subrectus; cotyledones ovali-orbiculares compressae, radicula parte tertia breviores.

Hab. in Haiti: Nectoux; Sto. Domingo in sylvis Sierra de Palo Quemado $810 \mathrm{~m}$. alt., m. Majo fruct.: Eggers 11. $1871^{\mathrm{b}}$.

Obs. Nulli alii arctius affine, inter omnes Indiae occidentalis species et alias quas vidi, fructu a calyce superato et obtecto, insiguis et sectionem novan: Psendocestrum sistens.

Brunfelsia Fawcettii Urb. (n. sp.) ramis foliisque glabris; foliis 6-10 mm. longe petiolatis, elliptico-oblongis v. oblongo-lanceolatis, inferne subsensim angustatis, basi ima acutis $v$. obtusiusculis, antice solemniter et satis longe acuminatis, apice ipso acuto v. acutiusculo, $11-7 \mathrm{~cm}$. longis, $4-2 \mathrm{~cm}$. latis, $2 \frac{1}{2}-3$-plo longioribus quam latioribus, planis; floribus in apice ramorum et praeterea ramulorum valde 
abbreviatorum ex axillis foliorum superiorum prodeuntium, squamis pubescentibus tantum ornatorum solitariis, pedicellis sub anthesi $11-18 \mathrm{~mm}$. longis glabris; calyce anguste campanulato 9-11 mm. longo, lobis tubo glabro $3-5$-plo brevioribus margine brevissime ciliatis; corollae tubo $10-11 \mathrm{~cm}$. longo glabro, calycem ca. 10 - plo superante, lobis cum limbo $3-3^{1} / 2$ - plo longiore.

Rami teretes flavo-l,runei, cortice laxe accumbente, hine illinc fisso, internodiis inferiorilus usque $1,5 \mathrm{~cm}$. longis, superioribus sensim minoribus v. minimis. Folia superiora conferta, petiolis profunde canaliculatis, nigrescentibus, plcrumque laevibus, nervo medio supra anguste et valde impresso, lateralibus utroque latere $7-10$, sub angulo $55-60^{\circ}$ aleuntibus, utrinque prominulis et reticulato-anastomosantibus, ante marginem dupliciter conjunctis, marginc ipso diaphano plano v. vix recurvo, utrinque praesertim supra nitentia, subtus multo pallidiora. Pedicelli ramulis $3-5 \mathrm{~mm}$. longis sfuamas plures oblongas usque lineares $2-4 \mathrm{~mm}$. longas brevissime flavidopubesccntes gerentibus insidentes, sub anthesi vix 1,5 mm. crassi. Calycis tubus in statu compresso superne $6-7 \mathrm{~mm}$. latus; lobi semiorbiculares $\mathrm{r}$. breviter ovati, $1,5-2,5 \mathrm{~mm}$. longi. Corollae tubus subrectus, medio in statu compresso $3 \mathrm{~mm}$. latus, ad basin paullo attenuatus, apicc subito in limbum explanatus; limbus $50-55 \mathrm{~mm}$. diametro, subtus glaber, supra ad basin brevissime pilosulus, lobis rotundatis ca. $20 \mathrm{~mm}$. longis, verisimiliter in vivo crassiusculis, margine crispis. Staminum longiorum filamenta ca. $18 \mathrm{~mm}$. sub ore tubi corollini affixa, quoad libera $18 \mathrm{~mm}$. longa, breviorum $4 \mathrm{~mm}$. profundius affixa, $17 \mathrm{~mm}$. longa; antherae priorum ad os sitae, posteriorum inclusae, hreviter ct late reniformes, aequales, loculis confluentibus. Stylus glaber; stigma bilobum, lobis obtuse triangularibus. Ovarium ovatum glabrum.

Cult. in Jamaica in prov. Manchester in Brokenhurst, verisimiliter in hac insula indigena, m. April. flor.: Fawcett n. 8140.

Obs. Affinis B. undulata Sw.! petiolis brevibus, foliis non acuminatis, in $2 / 3-4 / 5$ long. latissimis, pedicellis sub anthesi $5-7 \mathrm{~mm}$. longis, calyce $7 \mathrm{~mm}$. longo, tubo corollac breviore, brevissime articulato-piloso discrepat.

Brunfelsia maliformis Urb. (n. sp.) ramis hornotinis ad apicem brevissime pilosulis, mox glabratis; foliis $5-9 \mathrm{~mm}$. longe petiolatis, elliptico-oblongis v. lanceolatis, inferne in petiolum angustatis, acutis, ad apicem plus minus sensim acuminatis, apice ipso obtusiusculo r. obtuso, ad medium latissinis, $10-5 \mathrm{~cm}$. longis, $3,5-2 \mathrm{~cm}$. latis, $21 / 2-31 / 2$-plo longioribus quam latioribus, planis, glabris; floribus in apice ramortum $1-3$ et praeterea interdum ex axillis foliorum superior'um, pedicellis sub anthesi $10-15 \mathrm{~mm}$. longis; calyce anguste campanulato-tubuloso $9-11 \mathrm{~mm}$. longo, lobis tubo $4-5$-plo brevioribus, sed interdum uno alterove profundius soluto; corollae tubo $5-7 \mathrm{~cm}$. longo, sicut pedicellis et calyce glaberrimo, calycem $6-7$-plo superante, lubis cum limbo $3-4$-plo longiore; fructu $4-5 \mathrm{~cm}$. diametro, pericarpio (in siceo) $7-8 \mathrm{~mm}$. rrasiso; seminibus $4-6 \mathrm{~mm}$. longis, $3 \mathrm{~mm}$. latis. 
Frutex 2,6-3 11 . altus $v$. arhor $6,6 \mathrm{~m}$. alta. Rami teretes, cortice laxe accumbente fisso et lesiliente obtecti, internoliis variis. Folia sub tloribus conferta, petiolis profunde canaliculatis, glabris r. parce pilosulis postremo quoque laevibus nec furfuraceis, nervo medio supra auguste sulcatoimpresso, lateralibus utroque latere $6-9$ sul, angulo $70-80^{\circ}$ abeuntibus, utrinque tenuiter prominulis et subtus parum r. obsolete, supra manifestius anastomosantibus, ante margincm conjunctis, margine angustissime recurra, utrinque nitida, subtus paullo pallidiora. Pedicelli basi squamis nonnullis linearibus $1-2 \mathrm{~mm}$. longis valde deciduis circumdati et hoc loco minute pilosuli, caeterum glabri, sub antlesi medio ca. $1 \mathrm{~mm}$. crassi. Calycis tubus in statu compresso superne $5-6 \mathrm{~mm}$. latus, glaberrimus; lobi semiorbiculares usque ovati, $1,5-3 \mathrm{~mm}$. longi. Corolla pallide flara; tubus vix arcuatus, supra medium in statu compresso ca. $4 \mathrm{~mm}$. latus, inferne sensim subattenuatus, apice subito in limbum abiens, intus ad faucem brevissime puberulus; limbus $30-40 \mathrm{~mm}$. diametro, lolis breviter rhombeis $\mathrm{v}$. semiorbicularibus $1-1,5 \mathrm{~cm}$. longis. Staminum longiorum filamenta ca. $15 \mathrm{~mm}$. sub ore tubi corollae unilateraliter affixa, quoad lihera $13 \mathrm{~mm}$. louga, hreviou $4 \mathrm{~mm}$. profundius affixa, sed caeterum eadem longitudine libera; antherae inchusae reniformes ca. $3 \mathrm{~mm}$. latae, loculis confluentibus. Stylus glaher; stigma inter antlieras situm bilobum. Ovarium ovatum glabrum. Fructus calyce usque ad hasin bipartito suffultus sphaeroideus sublaeris, bisulcatus, ut videtur non deliscens, endocarpio pergamaceo flavo, mesocarpio carnoso consistentia fere medullae. Semina ill pulpa immersa ca. S0 - 100 , oblique ovata, latere altero recto, altero curvato, ad ventrem versus magis compressa; testa brunea granulata; endospermium copiosum. Embryo curvatus; cotyledones subanguste ovatae, radicula parum v. dimidio breviores.

Hab. in Jamaica ad Westphalia Road, $1000-1260$ m. alt., prope Charlottenburgh, ad Robertsfield $660 \mathrm{~m}$. alt., m. April. flor., m. Aug., Sept. fruct.: Harris n. 5646, 6809, 6813, 739s, W. Jekyll 1. 8125 . Olim culta in hort. Calcutt.

$\checkmark$ Brunfelsia Iarrisii Urb. (n. sp.) ramis foliisque glabris; foliis 4--8 mm. longe petiolatis, lanceolatis v. oblongo-lanceolatis, utrinque subaequaliter v. ad basin paullo magis angustatis, basi sensim in petiolum productis, antice sensim $v$. subsensim acuminatis, apice ipso concaviusculo et obtusiusculo, $9-6 \mathrm{~cm}$. longis, $2,8-1,6 \mathrm{~cm}$. latis, $3-4$ plo longioribus quam latioribus, planis; floribus in apice ramorum terminalibus solitariis, pedicellis sub anthesi $5-8 \mathrm{~mm}$., fructiferis usque $18 \mathrm{~mm}$. longis; calyce anguste campanulato-tubuloso $15-17 \mathrm{~mm}$. longo, lobis tubo 4-6-plo brevioribus; corollae tubo $8-10 \mathrm{~cm}$. longo, sicut pedicello calyceque brevissime articulato-piloso, calycem 4-6plo superante, lobis cum limbo $2-3$-plo longiore; fructu $3 \mathrm{~cm}$. diametro, pericarpio (in sicco) $1,8 \mathrm{~mm}$. crasso; seminibus $7 \mathrm{~mm}$. longis, $5 \mathrm{~mm}$. latis.

Rami teretes, pallide brunei, cortice laxe accumbente, fisso et desiliente obtecti, internodiis brevibus, $1-7 \mathrm{~mm}$. longis. Folia cujusvis rami 
inferiora magis distantia, supcriora conferta, petiolis profunde canaliculatis, postremo furfuraceis, nervo medio supra anguste impresso, latcralibus utroque latere $9-12$, sub angulo $70-80^{\circ}$ abeuntibus, supra temiter, subtus paullo magis prominulis et anastomosantibus, ante marginem conjunctis, margine ipso diaphano angustissime recurvo, utrinque nitida, subtus pallidiora. Pedicelli basi squamis nomnullis linearibus $\mathrm{v}$. lanceolato-lincaribus breviter pubescentibus $3-5 \mathrm{~mm}$. longis circumdati, sub anthesi vix $1,5 \mathrm{~mm}$. crassi. Calycis tubus in statu compresso superne $7 \mathrm{~mm}$. latus, pube brevissima articulata dense obtectus; lobi semiorbiculares usque ovati, $2-4 \mathrm{~mm}$. longi. Corollae tubus parum arcuatus, medio in statu compresso $4-5 \mathrm{~mm}$. latus, inferne vix v. paullo angustior, apice subito in limbum abiens; limbus amplus $50-70 \mathrm{~mm}$. diametro, utrinquc, intus ad basin puberulus, lobis subquadrato-rotundatis, $1,5-2,5 \mathrm{~cm}$. longis. Staminum longiorum filamenta ca. $25 \mathrm{~mm}$. sub ore tubi corollini unilateraliter affixa, quoad libcra $15 \mathrm{~mm}$. longa, breviorum $7 \mathrm{~mm}$. profundius affixa, sel caeterum eadem longitudine libera; antherae inclusae reniformes ca. $3 \mathrm{~mm}$. latae, inferiores paullo angustiores, loculis confluentibus. Stylus glaber; stigma cum antheris fil. long. in eadcm altit. situm, bilobum. Ovarium breviter ovatoconicum glabrum. Fructus calyce usque ad basin bipartito suffultus, glolulosus sublaevis, ut videtur bivalvis, endocarpio osseo flavo, mesocarpio medulloso-crustaceo. Semina in pulpa immersa, ratione parca (ca. 15) suboblique orata compressa; testa brunea, anguste reticulata; enclospermium copiosum. Embryo curvatus; cotyledones breviter orbiculares, radicula $21 / 2$ - plo breviores.

Hab. in Jamaica: Hart n. 891 (florifera), prope Portland Gap m. Nov. fruct.: W. Harris 11.7472.

Obs. I. B. undulata Sw.! (e Jamaica) = B. jamaicensis Griseb.! Flor. p. 432 (p. p.) foliis $3-6 \mathrm{~mm}$. longe petiolatis, oblanceolatis v. obovatolanccolatis, $10-15 \mathrm{~cm}$. longis, floribus $2-3$ terminalibus, calyce $8 \mathrm{~mm}$. longo, tubo corollae calycem $10-14$-plo superante, fructu? differt. Descriptio Benthamiana (in DC. Prodr. X p. 200) a Swartziana satis recedit et vix ad eandem speciem attinet.

Obs. II. Brunfelsiae species in Jamaica difficillimae botanicis hujus insulac iterum atque iterum commendandae sunt. Necessaria sunt notae de florum colore, de colore et dehiscentia fructuum, et fructus maturi ex eadem arbore, e qua flores sumti erant.

Tecoma acrophylla Urb. (11. sp.) ramis hornotinis et jnflorescentiis pilos densissimos patentes articulatos, apice hypocrateriformi- v. breviter turbinato-dilatatos et ad marginem faciei radiatim in ramulos breves irregulariter abeuntes gerentibus; foliis trifoliatis, foliolis lateralibus basi obsolete et oblique cordata subsessilibus, terminali basi obtusa ca. $7 \mathrm{~mm}$. longe petiolulato, omnibus obovatis, apice rotundatis r. subtruncatis, $13-14 \mathrm{~cm}$. longis, $7-8,5 \mathrm{~cm}$. latis, supra scabriusculis, subtus crasse nervosis, crasse coriaceis rigidis; inflorescentia apice ramorum umbelliformi, ramis bis ter cymose dirisis, prophyllis linearibus patentibus; calyce $12-15 \mathrm{~mm}$. longo; corolla bruneo-rubra $5-5,5 \mathrm{~cm}$. longa. 
Arbor $3-5 \mathrm{~m}$. alta, trunco satis gracili, apice coma foliorum florumque ornata (ex Bccr). Rami teretes plicato-striati, pube brunea brevi. Foliola petiolis?, nervo medio impresso, lateralibus utroque latere $8-9$ sul, angulo $45-55^{\circ}$ abeuntibus, supra impressis $r$. in sulco paullo prominulis, subtus crasse prominentibus et dense reticulato-anastomosantibus, margine anguste recurro integra, supra modice et breviter pubescentia, subtus ad ncrvos primarios et secundarios pilis articulatis apice dilatatis, inter nervos pilis simplicibus brevibus patentibus albidis et praeterea lepidibus bruneis orbicularibus breviter stipitatis v. subsessilibus dense obtecta, secus nerros plicata, in sicco brunescentia, subtus paullo pallidiora. Inflorescentiac radii in apice ramorum gemmam non evolutam inter sese gerentes, $3-5 \mathrm{~cm}$. longi; bracteae et prophylla conformia, $8-12 \mathrm{~mm}$. longa, $0,5-0,7 \mathrm{~mm}$. lata, arcuato-patentia; pedicelli genuini $6-1 \mathrm{~mm}$. longi. Calyx initio plane clausus, sub anthesi brevitcr subcylindraceus, (in sicco compressus) $6 \mathrm{~mm}$. diametro, in ca. $1 / 3$ superiore bilabiatus, lobis inaequilongis integris obtuse acuminatis r. superiore bilobulato, extrinsecus pilis apice lypocrateriformi-dilatatis dense pubescens, in sicco nigrescens. Corolla glabra; tubus supra basin cylindraceus, $4 \mathrm{~mm}$. crassus, supra calycem subincurvus et sensim ampliatus usque $10 \mathrm{~mm}$. crassus, intus ad filamentorum insertionem pilis articulatis pubescens, caeterum glaber; lobi oblique et breviter orbiculares, tnbo 3-plo breviores. Stamina $10 \mathrm{~mm}$. supra basin corollae affixa ct hoc loco pubescentia, caeterum glabra; filamenta longiora $20 \mathrm{~mm}$., breviora $15 \mathrm{~mm}$. longa; antlerarum loculi divaricato-patentes, fere $4 \mathrm{~mm}$. longi, anguste oblongi; staminodium $4 \mathrm{~mm}$. longum. Discus basin ovarii cingens crassissimus. Ovarium oblongo-lineare, fere a basi sensim in stylum ca. $25 \mathrm{~mm}$. longum angustatum; stigmata anguste obovata obtusa, $3,5 \mathrm{~mm}$. longa, $2 \mathrm{~mm}$. lata, foliacca; orula numerosa obovato-orbicularia.

Hab. in Haiti prope Bilboro in montibus, $600 \mathrm{~m}$. alt., m. Majo flor.: Buch n. 349.

Tecoma Buchii Urb. (n. sp.) ramis hornotinis et inflorescentiis pilos densos patentes articulatos, apice hypocrateriformi- r. scutelliformidilatatos et margine faciei denticulatos (si mavis, lepides stipitatas) et praterea lepides creberrimas parvas sessiles gerentibus; foliis $10-6 \mathrm{~mm}$. longe petiolatis, $3-5$-foliolatis, foliolis lateralibus sessilibus, terminali $2-4 \mathrm{~mm}$. longe petiolulato, omnibus obovato-oblongis v. oblongo-ellipticis, basi obtusis, apice brevissime acuminatis $\mathrm{v}$. lateralibus obtusis, $5-2 \mathrm{~cm}$. longis, $2-1 \mathrm{~cm}$. latis, supra densissime et minute lepidotis et vix v. parum scabriusculis, subtus manifestius lepidotis et crasse nervosis, crasse coriaceis rigidis; inflorescentiis apice ramorum brevissime corymbosis, semel bis cymose divisis, prophyllis brevibus linearibus; calyce $11-13 \mathrm{~mm}$. longo; corolla pallide violacea, t,5 cm. longa; capsula lineari, $6 \mathrm{~cm}$. longa, $6 \mathrm{~mm}$. lata.

Frutex 1,3-2,6 m. altus (ex Bucri). Rami retustiores subteretes glabri cinerascentes, hornotini sub foliis plus minus compressi, pube brevi et brevissima decidua, sed lepidibus longe persistentibus. Folia opposita, petiolo convexiusculo non sulcato, subtus valde convexo, densissime lepidoto, 
petiolulis supra anguste sulcatis; foliola nervo medio et latcralibus supra impressis, lisce utroque latere $6-10$, sub angulo ca. $60^{\circ}$ abeuntibus, snbtns crasse prominentibus et reticulato-anastomosantibus, margine plano v. vix recurvo integra, lepidibus plerisque sessilibus, parcioribus praescrtim subtus plns minus stipitatis, in sicco brunescentia v. glancescentia, supra nitidula. Inflorescentiae in apice ramorum inter sese gemmam non erolutam gerentes, $1-2 \mathrm{~cm}$. (praeter flores) longae; prophylla $2-3 \mathrm{~mm}$. longa, 0,6-0,8 mm. lata; pedicelli $4-7 \mathrm{~mm}$. longi. Calyx initio plane clausus, sub anthesi breviter eylindraceus, (in sicco compressus) 5 nim. diametro, in $1 / 3-1 / 4$ superiore bilabiatus, lobis inaequilongis, superiore v. utroque bilobulato, apice rotundatis et saepius brevissime apiculatis, extrinsecus lepidibus stipitatis et sessilibus dense pubescens, in sicco nigrescens. Corolla cxtrinsecus pilis parcis articulatis apice dilatatis obsita; tubus inferne eylindraceus ca. $4 \mathrm{~mm}$. crassus, superne sensim infundibuliformi-dilatatus, sub apice ca. $1 \mathrm{~cm}$. diametro, subrectus, intus ad basin glaber, supra filamentorum insertionem antice brcviter, superne longius pubescens, postice glaber; lobi oblique semiorbiculares, tubo 4-5-plo breviores. Stamina $7 \mathrm{~mm}$. supra basin corollae affixa et loc loco pubescentia, caeterum glabra; filamenta longiora $15 \mathrm{~mm}$., breviora $12 \mathrm{~mm}$. longa; antherarum loculi divaricato-patentes $2,5 \mathrm{~mm}$. longi, anguste oblongi, connectivo subsemigloboso superati; staminodium $4 \mathrm{~mm}$. longum lineare. Discus basin ovarii cingens crassissimus. Ovarium lineare lepidotum, in stylum ca. $13 \mathrm{~mm}$. longum sensim angustatum; stigmata suborbicularia, apice rotundata, 1,5 mm. longa et lata, foliacea; ovula numerosa obovata. Capsula subcurvata, obtusiuscule et breviter acuminata, striata brunescens, lineis paucis elevatis striata, lcpidilus sessilibus et brevissime stipitatis scabrida. Scmina ipsa orbicularia v. hreviter ovalia brunca, cum alis albidis membranaceis, $11-13 \mathrm{~mm}$. longa, $3-4 \mathrm{~mm}$. lata.

Hab. in Haiti in montibus siccis calcareis Morne La Pierre non procul a mari, $200 \mathrm{~m}$. alt, m. Majo fl. et fr.: Buch 1.612.

Obs. Habitu affinis T. lepidophyllae Griseb., quae pule tantum lepidota, petiolis supra sulcatis longioribus, foliolis minus crassis, costis tenuioribus, medio longius petiolulato, inferne sensim angustato, inflorescentiis 1 -floris, capsulis multo longiorilus longe acnminatis differt.

\section{Picardaca Urb.}

(n. gen. Rubiacearum).

Flores 5-meri. Calycis tubus turbinatus subcompressus; limbus perbrevis integer. Corolla coriacea; tubus subinfundibularis, intus ad medium villosus, cacterum glaber; lobi in aestivatione valvati, carnosuli, intus ad marginem brevissime villosuli, caeterum glabri, tubo duplo breviores, suberecti. Stamina tubo corollae medio inserta; filamenta crassa lineari-attenuata, basi ima vix villosula, caeterum glabra; antherae dorso affixae, oblongae, e tubo exsertae, rimis longitudinalibus anticis dehiscentes. Discus carnosus, concavus, margine elevato basin styli laxe annulari-cingente, integer. Ovarium 2 -loculare; stylus 
crassiuscule filiformis, ramis 2 oblongo-linearibus obtusis inter sese connatis ad margines liberos paullo divergentes intus stigmatosis; placentae septo affixae crassiusculae, bilamellatae; ovula numerosissima multiseriata. Capsula... Semina... - Frutex haitiensis, glaber, ramis teretibus. Stipulae interpetiolares breves squamiformes triangulares integrae coriaceae, longe persistentes. Folia mediocriter petiolata, mediocria chartacea ovali-elliptica, basi cuneata, nervosa, minutissime pellucido-punctata. Racemi pauciflori pedunculati. Flores majusculi brunei.

Obs. Ex affinitate Condamineae DC. et Rustine Klotzsch, quarum prior calycis limbo lobato $v$. dentato circumscisse deciduo, corollae fance rillosa, ramulis compressis, stipulis magnis elongatis 2 -partitis chartaceis, cymis trichotome corymbosis, ulterior antheris basifixis, poro v. rimula terminali dehiscentibus, stipulis amplis elongatis deciduis discrepat.

\section{Picardaca haitiensis Urb. (n. sp.).}

Rami tcretes cinerco-hrunescentes non striati, sed in sicco plus minus plicatuli. Stipulae inter petiolos obviae, intra petiolos non v. par'um raginanti-cohaerentes, breviter triangulares brevissimc acuminatac, $1,5-2 \mathrm{~mm}$. longae. Folia petiolis $4-\mathrm{S} \mathrm{mm}$. longis, supra subplanis, ratione tenuibus, ovali-elliptica, utrinque aeqnaliter angustata v. paullo supra merlium latissima, infernc sensim angustata, apice obtusa, $6-3 \mathrm{~cm}$. longa, $3-4 \mathrm{~cm}$. lata, nervo medio supra (basi excepta) prominente, lateralibus utroı pue latere $6-8$, sub angulo $50-60^{\circ}$ abeuntibus subarcuatis, supra tenuiter, subtus magis prominentibus et utrinque reticulato-anastomosantibus, margine plana, utrinque nitida, supra in siceo nigrescentia, subtus brunea. Inflorescentiae terminales, pedunculo vix $2 \mathrm{~cm}$. longo, ipsae $2-4 \mathrm{~cm}$. longae; bracteae infimae interdum euphylloideae, cacterae v. omnes squamiformes, lanceolatac $3-1 \mathrm{~mm}$. Iongae; pedicelli $2,3-1 \mathrm{~cm}$. longi, lenticellosi, superne bracteolas minutas gerentes. Calycis tubus turbinatus $6-7 \mathrm{~mm}$. longus, sub limbo $4 \mathrm{~mm}$. crassus, in sicco plicato-rugosus; limbus $1-1,5 \mathrm{~mm}$. longus. Corolla $25 \mathrm{~mm}$. longa; tubus inferne $5 \mathrm{~mm}$. crassus, cylindraceus, a medio usque $9 \mathrm{~mm}$. ampliatus, intus ad et infia staminum insertionem $4 \mathrm{~mm}$. longe pilis pallide bruneis simplicibus densissime et longiuscule villosus; lobi ovati aṕice acutati, dorso minute scabriusculi. Filamenta fere a basi sensim attenuata, $11 \mathrm{~mm}$. longa; antlierae rectae, dorso in 2/; alt. affixac, defloratac elliptico-oblongae $6 \mathrm{~mm}$. longae. Discus margine elevato integer undulatus. Stylus $18 \mathrm{~mm}$. longus, eleratim pluristriatus subaequicrassus, $0,8 \mathrm{~mm}$. crassus; rami connati $4 \mathrm{~mm}$. longi, 1,5 mm. lati, intus stigmatosi. Ovarium pariete carnoso instructum; septum crassum; placentarun lamellac breves, ovula latere cxteriore ad parietem et septum verso gerentes; ovula obovata minuta. Capsula junior anguste turbinata.

Hab. in Haiti prope Pétionville, 500-600 m. alt., m. Aug. 1893 flor.: Picarda n. 1129.

Rondeletia Cluistii Urb. (n. sp.) ramis junioribus pilis brevibus adpressis albidis sericeis dense vestitis; foliis binatim oppositis, $S-12 \mathrm{~mm}$. 
longe petiolatis, ovali-ellipticis v. elliptico-oblongis, utrinque subaequaliter v. antice magis angustatis, basi plerumque acutis, raro obtusis, apice acutis, $5-9 \mathrm{~cm}$. longis, $2-4 \mathrm{~cm}$. latis, $2 \frac{1}{2}-3$-plo longioribus quam latioribus, margine angustissime recurvatis, subtus breviter et parcissime, ad nerrum medium paullo magis pilosis, supra glabris, coriaceis; inflorescentiis axillaribus panniculatis subpaucifloris, floribus omnibus $1-2 \mathrm{~mm}$. longe pedicellatis; calycis lobis triangulari-lanceolatis, tubo semiovali paullo brevioribus; corollae tubo cylindraceo, ad apicem vix v. parum ampliore, extrinsecus pilis brevissimis albidis dense obsito, $6 \mathrm{~mm}$. longo, lobis suborbicularibus, tubo 3-4-plo brevioribus; antheris inclusis, $1,7 \mathrm{~mm}$. longis, filamentis perbrevibus.

Frutex $3-4 \mathrm{~m}$. altus (ex Christ). Rami vetustiores teretes glabrescentes cinereo-brinescentes, epidermide longitrorsum multirimosa, juniores clevatim striati. Stipulae triangulares vix v. breviter acuminatae, $4-5 \mathrm{~mm}$. longae, intus villosulae, dorso sericeae. Folia nervo medio supra subplano, subtus crasse prominente, lateralibus utroque latere $6-8$ supra non, subtus tenuiter prominulis et tenuissime reticulato-anastomosantibus, pilis subtus adpressis, supra in sicco bruneo-nigrescentia, subtus viridi-olivacea. Inflorescentiae $1,5-2 \mathrm{~cm}$. longae, albido-sericeae; bracteae lanceolatac 2,5-1,5 mm. longae; prophylla 0,7-1 mm. longa. Flores 5-meri. Caly cis tubus tomentosus; lobi $0,7-1 \mathrm{~mm}$. longi, parce et brevissime pilosi. Corollae tubus inferne $1 \mathrm{~mm}$., superne usque $1,5 \mathrm{~mm}$. crassus, pube reflexa adpressa, intus glaber; lobi apice rotundati, intus albido-tomentosuli, extrinsecus brevissime pilosi. Filamenta tubo medio inserta; antherae in $1 / 3$ alt. affixae, oblongo-lineares. Stylus (an in flor. dolichostylis?) tubo corollae aequilongus, $6 \mathrm{~mm}$. longus, supra basin pilosulus, lobis parte integra 5 -plo brevioribus, $0,8 \mathrm{~mm}$. longis ovatis, carnosis.

Hab. in Haiti ad Fessard, m. Majo flor.: Christ n. 1711.

Obs. Ex affinitate R. impressac $\mathrm{Kr}$. et Urb. et R. microcalycis $\mathrm{Kr}$. et Urb., quarum prior pube patente, foliis ternatim verticillatis acuminatis, nervis lateralibus supra impressis, subtus crassius prominentibus, inflorescentiis longioribus, corollae tubo tenuiore, lobis obovatis, posterior pube brevissime pulverulenta, foliis duplo longius petiolatis, nervis supra impressis, calycis lobis minutis, corollae tubo breviore et tenuiore, crispule pilosulo discrepat.

Exostema acuminatum Urb. (n. sp.) ramis junioribus glaberrimis; stipulis e basi depresse triangulari filiformi-acuminatis; foliis $2-3 \mathrm{~mm}$. longe petiolatis, lanceolatis v. ovato-lanceolatis, basi rotundatis non v. vix in petiolum protractis, a medio v. magis a basi longe et subsensim acuminatis, apice acutis, $4-6 \mathrm{~cm}$. longis, $1-2 \mathrm{~cm}$. latis; inflorescentiis axillaribus, 1 - raro 2 -floris, pedunculis $10-15 \mathrm{~mm}$., pedicellis $3-4 \mathrm{~mm}$. longis; floribus 5 -meris; calyce toto $5 \mathrm{~mm}$. longo, tubo oblongo v. elliptico-oblongo quam limbus 5-dentatus 2-4-plo longiore; corolla $60-70 \mathrm{~mm}$. longa, $20-25 \mathrm{~mm}$. longe in tubum vix $1,5 \mathrm{~mm}$. crassum coalita, lobis linearibus tubo duplo et ultra longioribus, $1-1,5 \mathrm{~mm}$. latis; staminibus basi ina corollae adhaerentibus et inter 
sese eonnatis; ovulis in quoque loculo ca. 20 ; capsula (non plane matura) elliptico-oblonga, $15 \mathrm{~mm}$. longa, $5 \mathrm{~mm}$. lata.

Exostemma salicifolium Griscb. Cat. (1866) p. 125 (quoad plantam domingonsom).

Frutex $2 \mathrm{~m}$. altus v. saepius arbor $3-7 \mathrm{~m}$. alta, glaherrima. Rami teretes, vetustiores subsuberosi, flavo- r. albido-grisei, cortice longitrorsum fisso, lenticellis parvis rotundatis notato, hornotini in siceo bruneo-nigrescentes, internodiis $1,3-3 \mathrm{em}$. longis. Stipulae interpetiolares, $1-2,5 \mathrm{~mm}$. longae, e basi latiore plus minus lineari-produetae. Folia nervo medio supra prominente, lateralibus arcuatis supra prominulis, subtus obsolete v. vix anastomosantibus, ehartacea v. submembranacea, margine angustissime recurva, supra nitida, in sicco bruneseentia. Peduneuli perpaullo supra axillas foliorum inserti, tenues, vix $0,3 \mathrm{~mm}$. crassi; prophylla laneeolatolinearia, ca. $1 \mathrm{~mm}$. longa. Calycis tubus basi acutatus; limbus cupuliformis, dentibus plus minus manifestis triangularibus. Corolla alba odorifera; tubus linearis, intus superne glaber, inferne brevissime et dense pilosus; lobi in aestivatione imbrieati, patentes recurvati. Filamenta $4-5 \mathrm{em}$. longa, quoad tubo corollino inclusa apice excepto breviter patenti-pilosa; antherae basi affixae, lineares, $12-15 \mathrm{~mm}$. longae, $0,5 \mathrm{~mm}$. latae. Discus obsoletus. Stylus $5,5-6,5 \mathrm{~cm}$. longus, glaber, inforne eompressus; stigma ovato-oblongum, obtusangulum, $1,5 \mathrm{~mm}$. longum. Ovarium eonvexum, 2 -loculare; ovula placentae crassiusculae elliptieae medio dorso longitrorsum sed angustissime parieti adnatae 4 -seriatim (i. e. biseriatim in faeie media, $1+1$-seriatim ad angulos) affixa, ovata $v$. breviter ovata eompressa pendula.

Hab. in Haiti prope Gonaïves in sylvis aprieis ad Dubedon, 200 m. alt., m. Jun. flor.: Buch n. 753; Sto. Domingo prope capitalem, m. Aug., Sept.: Rob. Sehomburgk n. 42, 85, prope Santiago in sylvis ad Llano Rafael (sine flore et fruct.): Eggers n. 1798.

Obs. Affine E. salicifolium Griseb. (e Cuba) ramis bifariam minute pilosulis, foliis lanceolatis, utrinque subaequaliter v. ad basin paullo magis angustatis subcuneatis, apice obtusis, $2,5-4 \mathrm{~cm}$. longis, $0,8-1,2 \mathrm{~cm}$. latis, corollae tubo (ex Griseb.) lokis aequilongo, eapsula $7-8 \mathrm{~mm}$. lata, ellipsoidea diversum est.

Erithalis revoluta Urb. (n. sp.) stipulis inter petiolos breviter triangularibus, intra petiolos brevissime v. breviter vaginanti-conjunetis; foliis 4-7 mm. longe petiolatis, obovato-oblongis usque oblongo-laneeolatis, inferne valde sensim in petiolos angustatis, apiee acutis v. breviter aeuminatis, $3--5 \mathrm{em}$. longis, $1-2 \mathrm{em}$. latis, margine plus mimus revolutis; inflorescentiis paucifloris, foliis subaequilongis; ealycis limbo supra ovarium $1 \mathrm{~mm}$. longe cupuliformi-produeto; corolla $4 \mathrm{~mm}$. longa; drupis obovatis $3,5-4 \mathrm{~mm}$. longis, $5-6$-locularibus.

Frutex $3-4 \mathrm{~m}$. altus glaber. Rami vetustiores teretes plieato-striati grisei v. brunescentes, hornotini plus minus quadranguli, apice resinam exsudantes, internodiis $1-0,3 \mathrm{~cm}$. longis. Stipulae $1,5-2 \mathrm{~mm}$. longae, saepius brevissime apieulatae, posterius nigreseentes. Folia ad apicem ramorum conferta, petiolis limbo deeurrente anguste marginatis, nervo medio 
supra inferue prominente, ar apicem evanescente, lateralibus nullis v. raro uno alterove subtus teunissime prominulo, crasse coriacea rigida, in sicco viriclia, subtus paullo pallicliora. Inflorescentiae axillares $7-15$-florae, corymbosae; pelunculus $1-3 \mathrm{~cm}$. longus compressiusculus; bracteae triangulares, plus minus longe acmminatae. Calycis tubus turbinatus; limbus aequilongus r. paullo lougior; dentes 5 late triangulares, limbo 3-plo breviores. Corolla vix in $1 / 10$ alt. gamopetalia; loli 5 lanceolato-lineares obtusi, intus carinati, ca. $1 \mathrm{~mm}$. lati. Filamenta basi corollae inserta pilosula; antherae oblongo-lineares obtusae $1,5 \mathrm{~mm}$. longae. Drupac calycis cupula coronatae, $2-2,5 \mathrm{~mm}$. crassae, merliocriter costatae.

Hab. in Portorico in sylvis litoralibus ad Caño gordo, m. Febr. detlor.: Sintenis n. 3796.

Obs. E. parviflora Griseb. (e Cuba) differt fuliis longins petiolatis, apice obtusis, planis, calycis limbo 3-plo breviore, drupis ovali-globosis profunde sulcato-costatis.

Chione coriacea Urb. glabra, foliis $6-10 \mathrm{~mm}$. longe petiolatis, anguste ovalibus, obovato-ellipticis r. oblongis, ad basin sensim in petiolum angustatis, apice rotundatis v. obtusis, raro subacutatis, $6-10 \mathrm{~cm}$. longis, $2-4,5 \mathrm{~cm}$. latis, nervis lateralibus sub angulo ca. $70^{\circ}$ abeuntibus, utroque latere $10-12$, subtus vix v. parum et obsolete anastomosantibus; inflorescentiis minute pilosulis, pedicellis $1-2 \mathrm{~mm}$. longis; alabastris maturis $1,5 \mathrm{~mm}$. diametro, corolla $6 \mathrm{~mm}$. longa, initio cylindracea, postremo subcampanulata, lobis semiorbicularibus, tubo ca. 5 -plo brevioribus; stylo postremo apice breriter bifido, lobis stigmatosis breviter triangularibus obtusis; drupis ovato-ellipticis, vix $5 \mathrm{~mm}$. longis.

Psychotria coriacea Spreny.! Syst. I (1825) 1). 742 (excl. patr. Amer.-austr.), - non Poir.

Psyehotria exserta DC. Prodr. IV (1830) p. 517.

Linio St. Doming. ex Mayerh.

Frutex 1,3 m. altus (ex EGG.). Rami vetustiores teretes non striati cinerascentes, hornotini subteretes v. plus minus compressi, internodiis valle inaeruilongis $0,5-8 \mathrm{~cm}$. longis. Stipulae $6-7 \mathrm{~mm}$. longae, inferne in vaginam connatae, superne bilobae, lobis interpetiolaribus triangularibus $\mathrm{v}$. triangulari-ovatis, obtusis v. apiculatis, clartace-membranaceae, in sicco brumescentes, intus inferne squamulis linearibus ca. $1,5 \mathrm{~mm}$. longis dense obsitae, posterius sursum erectae et deciduae. Folia petiolis supra sulcatis, nervo medio supra plano v. parum impresso, subtus crasse prominente, lateralibus subtus tenuiter prominentibus subrectis, margine angustissime recurva, supra valde uitida in sicco viridi-brunescentia, subtus olivacea. Inflorescentiae $2,5-7 \mathrm{~cm}$. longe pedunculatae, panniculatae v. subcorymbosae ter quater trichotomae, ramulo intermedio caeteris aequali v. paullo provectiore; bracteae minutae ramulis plus minus sursum adnatae, $1,5-0,5 \mathrm{~mm}$. lougac. Calycis limbus cupuliformis $0,5-0,8 \mathrm{~mm}$. longus; dentes late triangulares v. obsoleti, limbo panllo usque 4-plo breviores. Alabastra subcylindraceooblonga. Corolla alba (ex EGG.), initio antheseos cylindracea, dein superue reutricoso-inflata usque $4 \mathrm{~mm}$. crassa, glabra; lobi 5 erecti ca. $1 \mathrm{~mm}$. longi. 
Filamenta tubo corollae in $1 / 3$ alt. inserta; antherae lineares, dorso medio affixae, 2,3 mm. longae, connectivo producto brevissime apiculatae, postrcmo exsertae. Discus ammularis carnosus. Stylus $7 \mathrm{~mm}$. longus, lobis initio arcte accumbentibus, postremo patentibus et recurvis. Ovarium breviter' oboratum, minute pilosulum, 2-loculare; orula in quoque loculo solitaria, ab apice pendula. Irupae (non plane maturae) obsolete costatae, ca. $2 \mathrm{~mm}$. crassae.

Hab. in Sto. Domingo: Bertero n. 1031, Mayerhoff, prope Limon ad La Cumbre, 670 m. alt., m. Jun. flor.: Eggers n. 2438.

Scolosanthus densiflorus Urb. (n. sp.) ramis junioribus minutissime scabriusculo-pilosulis, apice in spinas 3 -furcatas floriferas excurrentibus, cacterum incrmibus, internodiis $2-4 \mathrm{~cm}$. longis; foliis $2-5 \mathrm{~mm}$. longe petiolatis, ovatis r. breviter ovatis, nune subrhombeis, basi paullo in petiolum productis, apice obtusis r. obtusissimis, $1,5-2,5 \mathrm{~cm}$. longis, $1-1,7 \mathrm{~cm}$. latis; floribus solummodo ad spinas obviis in capitula 5- 12 flora collectis, pedicellis nullis; calyce toto $2 \mathrm{~mm}$., corolla 4,5 $\mathrm{mm}$. longa; ovario glabro.

Frutex $2-3,3 \mathrm{~m}$. altus. Rami retustiores brmescentes, tenuiter striati, juniores plus minus compressi, sicut ramuli cx axilla foliorum supremolum abeuntes in spinas transformati ileoque furcam 3 -ramosam sistentes. Spinac terminales rectae, laterales interdum subrecurvae, omnes in eadem furca subaequilongae, $1,3-2 \mathrm{~cm}$. longae, ad v. supra medium squannulas 2 oppositas floriferas gerentes, squamulis $1-2$ paucifloris sub apice saepius additis. Stipulae intrapetiolares triangulares acuminatae $1-2 \mathrm{~mm}$. longae. Folia nervo medio supra impresso, lateralibus $2-3$ supra non v. vix conspicuis, subtus tenuissime prominentibus arcuatis non anastomosantibus, supra valele nitentia, in siceo brunescentia, subtus multo pallidiora. FJores flavi, 4-meri. Calycis tubus cylintraceo-ellipticus subteres; lobi supra basin r. inferne connati, tubo $3-4$-plo breviores, quoad liberi semiorhiculares, margine obsolete ciliati. Alabastra clavata. Petala in $3 / 5$ alt. in tubum anguste turbinatum, intus glabrum connata; lobi in aestivatione anguste imbricati, ovati obtusi, sub anthesi reflexi. Stamina corollae basi ima adhaerentia; filamenta basi inter sese ca. $0,7 \mathrm{~mm}$. Ionge coalita, apice et basi excepta parce pubescentia, $4 \mathrm{~mm}$. longa; antherae exsertae, oblongae, apice obtusae, $1,5 \mathrm{~mm}$. longae, loculis ad basin attenuatis, infra insertionem saepe inaerualiter productis. Stylus $5 \mathrm{~mm}$. longus, glaber, inferne filiformis, in $1 / 3$ alt. suprema duplo latior subruadrangulus purpurascens, apice truncatus brevissime bilobus stigmatosus. Ovarium liloculare, sectione transversa fasciculis 8 vasorum nigrescentibus notatum; orula in quoque loculo solitaria, ab apice loculi pendula, linearia.

Hab. in Haiti prope Gonaïves in Morne Bonpère, 600 m. alt., m. Junio flor.: Buch n. 728.

Obs. I. Se. grandifolius Kr. et U1h, habitu affinis, spinis lateralibus, stipulis truncatis, foliis majoribus, floribus pedicellatis, forma alabastri, corolla majore intus pubescente, staminibus altius comnatis, antheris lincarihus ete. plane diversus. 
Obs. II. Scolosanthus Srograeanus Millsp.! in Field Colnmb. Mns. Bot. Ser. II. 1 (1900) 1. 102 (ex insula Culebras) est Anthacanthus acicularis Nees (Acanthacea).

Psychotria dolichocarpa Urb. (n. sp.) ramis lornotinis pilis articulatis longiusculis patentibus rufis dense hirsutis; stipulis initio vaginam integram $10-12 \mathrm{~mm}$. longam formantibus, posterius in partes 2 late oratas fissis, mox deciduis; foliis $4-7 \mathrm{~mm}$. longe petiolatis, ovaliellipticis r. ellipticis, inferne sensim in petiolum angustatis, apice anguste acuminatis, $7-10 \mathrm{~cm}$. longis, $2,5-4$ cm. latis, nervis supra solemniter impressis, chartaceo-coriaceis, supra ad nervos breviter pubescentibus, subtus praesertim ad nervos ferrugineo-barbatis, margine planis; inflorescentiis terminalibus sessilibus $2-3$-radiatis, radiis iterum trichotomis, dein cymulas trifloras gerentibus, breviter et dense patenti-liirsutis; floribus omnibus sessilibus v. in cyma lateralibus usque $2 \mathrm{~mm}$. longe pedicellatis; calyce supra ovarium cupuliformi-producto, lobis inaequalibus ovatis usque lanceolatis; corolla ...; baccis (junioribus) anguste oblongis, longitrorsum sulcatis, $8-10 \mathrm{~nm}$. longis, $2,5 \mathrm{~mm}$. crassis, breviter patenti-hirsutis.

Frutex metralis. Rami retustiores teretes non striati glabrati grisei, hornotini pube multiarticulata postremo non pallescente obtecti, internodiis 2-8 cm. longis. Stipulae gemmam anguste ovato-acuminatam massa alba resinosa obtectam includentes, rufae et rufo-pubescentes, postremo submembranaceae, mnltinerves, (an inter petiolos bifidac?). Folia medio latissima, nervis lateralibus utroque latere $10-12$ sub angulo $50-60^{\circ}$ abeuntibus, all marginem arcuatis, non ramosis, supra manifestius et impresse, subtus plus minns obsolete reticulato-anastomosantibus, supra in sicco olivaceo-nigrescentia glahrescentia, subtus pallidiora, pube persistente articulata rufescentc inter nervos brevi, ad nervos longiore patente vestita. Inflorescentiae usque $4 \mathrm{~cm}$. longae, pube densa rufa; bracteae deciduac. Calycis limbus breviter tubulosus ca. $1,5 \mathrm{~mm}$. longus; lobi limbo aequilongi v. paullo longiores recurvati utrinque pilosi. Discus crasse carnosus breviter cylindraceus fere $1 \mathrm{~mm}$. longus. Fructus 10 -sulcati, ad basin magis attenuati, postremo glabrescentes.

Hab. in Jamaica in Holly Mount prope Ewarton, 830 m. alt, m. Aug. deflor.: Harris n. 6455 .

Obs. Fortasse affinis Ps. hirsutae Sw. (e Jamaica), quae foliis duplo longius petiolatis ad basin minus sensim angustatis, subtus plumbeis, nervis $6-8$, inflorescentiis longe pedunculatis panniculatis, calyce subglabro, limbo cum dentibus vix $1 \mathrm{~mm}$. longo omnino discrepat.

Psychotria stenocarpa Urb. (n. sp.) ramis hornotinis pilis simplicibus brevibus patentibus densissimis initio rufis, sed mox albescentibus restitis; stipulis initio raginam integram $8-10 \mathrm{~mm}$. longam formantibus, quae posterius supra petiolum alterum unilateraliter et profunde finditul, mox deciduis; foliis $5-3 \mathrm{~mm}$. longe petiolatis, oborato-ellip- 
ticis usque oblongis, inferne sensim et longe angustatis, basi ipsa obtusis v. acutis, apice obtusis $\mathrm{v}$. brevissime et obtuse acuminatis, $3,5-2 \mathrm{~cm}$. longis, $1,5-0,8 \mathrm{~cm}$. latis, nervis supra impressis, coriaceis, utrinque breviter, subtus praesertim ad nervos patenti-pilosis, margine plus minus late revolutis; inflorescentiis terminalibus sessilibus breviter denseque patenti-pilosis, cymosis; floribus in angulis cymae subsessilibus, ultimis specie usque $4 \mathrm{~mm}$. longe pedicellatis; calyce supra ovarium campanulato-producto, lobis anguste ovatis; corolla $9 \mathrm{~mm}$. longa, subcurrata, lobis anguste oratis tubo $4-5$-plo brevioribus; baccis (junioribus) anguste oblongis, longitrorsum sulcatis.

Verisimiliter fruticosa. Rami vetustiores teretes, non striati, demum glabrescentes grisei, ramnlosi, ramnlis patentibus arcuatis, internodiis $1-2 \mathrm{~cm}$. longis. Stipulae initio gemmam omnino includentes, posterius unilateraliter fissae, a latere fisso explanatae subrectangulares, apice truncatae et emarginatae, membranaceae, inter petiolos nervis binis (raro ternis) supra verticem pcrpanllo productis percursae, bruneae, brevissime patenti-pilosae, internodio accrescente sursum provectae et postremo deciduae. Folia in vernatione utrinque arcte revoluta, in $2 / 3-3 / 4$ alt. latissima, nervis lateralibus $4-6$ sub angulo $40-45^{\circ}$ abeuntibus non ramosis nec anastomosantibus, supra in sicco nigrescentia, brcvissime et sparse pilosa, subtus brunea, ad nervos breviter et dense albido-pubescentia, inter nerros brevissime pilosa. Inflorescentiae $1,5-3 \mathrm{~cm}$. longae, a basi $2-4$-tomac, dein v. postremo cymosae; rami dense patenti-pilosi; bracteae inferiores ovato-lanceolatae, $2-2,5 \mathrm{~mm}$. longae, margine obsolete et parce denticulatae; prophylla subulata $1-1,5 \mathrm{~mm}$. longa. Flores verisimiliter heterostyli. Calycis limbus integer $2 \mathrm{~mm}$. longus, albide patenti-pilosus; lobi limbo ca. duplo breviores recurvati. Corollae tubus inferne cylindraceus, superne sensim usque fere duplo ampliatus, extrinsecus brevissime patenti-pilosus, intus superne dense pubescens; lobi apice sublineari hamato-inflexo cucullati, chartacei. Filamenta in flor. brachystylis tubo corollae in $3 / 4-4 / 5$ alt. affixa, $1 \mathrm{~mm}$. longa glabra; antherae oblongo-lineares, $1,3 \mathrm{~mm}$. longae, dorso in $1 / 3$ alt. affixae. Discus crasse carnosus breviter subturbinatus, $0,8 \mathrm{~mm}$. longus. Orarinm patenti-pilosum; ovula oblonga basifixa. Stylus $4 \mathrm{~mm}$. longus, ramis linearibus inter sese conglutinatis (v. coalitis?). Fructus (junior) anguste olslongus, $6 \mathrm{~mm}$. longus, $2 \mathrm{~nm}$. crassus, breviter patcnti-pilosus.

Hab. in Sto. Domingo: Rob. Schomburgk 11. 19.

Obs. Nulli alii ex India occidentali speciei, nisi praecedenti, subaffinis.

Psychotria cyclophylla Urb. (n. sp.) ramis hornotinis minute patenti-pilosis; stipulis initio vaginam integram $6-7 \mathrm{~mm}$. longam formantibus, quae, posterius supra petiolum alterum unilateraliter et profunde finditur, mox deciduis; foliis $4-7 \mathrm{~mm}$. longe petiolatis, orbicularibus $v$. breviter obovato-orbicularibus, basi rotundata perpaullo in petiolum productis, apice rotundato vix $\mathrm{v}$. brevissime et latiuscule acuminatis, 2,5-4 cm. longis, $2-3,5 \mathrm{~cm}$. latis, nervo medio supra subplano, crasse coriaceis, utrinque glabris; inflorescentiis terminalibus 
breviter pedunculatis glabris trichotomis, dein cymose evolutis; floribus in angulis cymae sessilibus, ultimis specie usque $2 \mathrm{~mm}$. longe pedicellatis; calyce supra ovarium cupuliformi-producto, lobis brevissime et late triangularibus; corolla $7 \mathrm{~mm}$. longa, recta, lobis tubo duplo brevioribus, anguste ovatis r. ovato-oblongis; baceis (junioribus) breviter ovatis sulcato- costatis.

Rami retustiores teretes vix plicato-striati, epidermide creberrime scissa, pallide brunci, juniores compressi v. plus minus quadranguli, internodiis 1-2 cm. longis. Stipulae initio gemmam includentes, posterius unilateraliter fissae, a latere fisso explanatae breviter ovatae, apiee subtruncatae, membranaceae, inter petiolos nerris binis erassiusculis pereursae, bruneae, minute pilosulae, internodio accrescente sursum provectae et deciduae. Folia medio v. plerumque supra medium latissima, nervo merlin subtus crassiuscule prominente, lateralibus utroque latere $4-5$ sub angulo $50-60^{\circ}$ abeuntibus, supra parum conspieuis, non prominentibus, subtus tenniter prominulis non anastomosantibus, supra in siceo pallide olivacea, subtus obscuriora, margine angustissime recurva, subtus domatiis glabris sul,glalurisve instructa. Inflorescentiae ea. $3 \mathrm{~cm}$. longae; pedunculus $5-8 \mathrm{~mm}$. longus; braeteae late triangulares v. semiorbieulares, $0,5-1 \mathrm{~mm}$. Iongae; rani iterum trichotomi, dein bis eymose divisi. Flores verisimiliter heterostyli, Calyx supra orarium $1,5 \mathrm{~mm}$. longe cupuliformi-productus, subearnosus; dentes limbo $3-4-$ plo breviores depresse triangulares. Corollae tubus infundibuliformis, fere a basi sensim usque duplo ampliatus minutissime scabriusculus, intus ad staminum insertionem breviter pubescens; lobi inaequales carnosuli, apice cneullato-inflexo. Filamenta in flore dolichost. tubo corollae in $2 / 3$ alt. inserta, brevissima; antlerae inchusae oblongae, in $1 / 4$ alt. affixae, vix $1,5 \mathrm{~nm}$. longae. Diseus erasse carnosus globulosus. Ovarium glabrum. Stylus exsertus glaber $6 \mathrm{~mm}$. longus; stigmata oblongolinearia brevia. Baccae ealycis cupula coronatae. - Flores et biecae in sicen nigrescentia, coeta aquam rubro tingunt.

Hab. in Haiti: Poiteau.

Obs. Ex affinitate Ps. coronatae Griseb. et rerolutae DC.

Psychotria mornicola Urb. (n. sp.) ramis hornotinis minute patenti-pilosulis; stipulis initio raginam integram formantibus, posterius in partes 2 interpetiolares oblongas obtusas $4 \mathrm{~mm}$. longas plus minus profunde fissis, mox deciduis; foliis $2-4 \mathrm{~mm}$. longe petiolatis, obovatis usque oblongis, inferne valde sensim in petiolum angustatis, apice rotundato $r$. obtuso saepius subacutatis, $2-3 \mathrm{~cm}$. longis, $0,7-1,3 \mathrm{~cm}$. latis, nervo medio supra superne vix, inferne magis impresso, coriaceis, supra glabris, subtus ad nervum minute pilosulis; inflorescentiis terminalibus breviter pedunculatis subglabris trichotomis, dein cymose evolutis; floribus in angulis cymae sessilibus, ultimis specie usque $2 \mathrm{~mm}$. longe pedicellatis; calyce supra ovarium cupuliformi-producto, lobis brevissime et late triangularibus; corolla $7 \mathrm{~mm}$. longa, subcurvata, lobis anguste oblongis, tubo duplo brevioribus; baccis (jnnioribus) oralibus suleatocostatis. 
Frutex $2-3,3 \mathrm{~m}$. altus. Rami vetustiores teretes plicato-striati cinerascentes, valde ramosi, juniores compressi r. plus minus quadranguli, internodiis $0,8-2,5 \mathrm{~cm}$. longis. Stipulae initio gemmam omnino includentes, posterius supra petiolos plus minus profunde fissae, tenuiter membranaceae, sed inter petiolos nerris 2 crassiusculis percursae, bruneae, minute pilosulae, internodio accrescente sursum provectac et deciduae. Folia in $2 / 3-3 / 4$ alt. latissima, nervo medio subtus crasse prominente, lateralibus utroque latere $3-4$ sub angulo $45-50^{\circ}$ abeuntibus, supra rix conspicuis, subtus tenuiter prominulis non anastomosantibus, supra obscure, subtus laete viridia, margine plana r. angustissime recurva, domatiis parris. Inflorescentiae $2-3 \mathrm{~cm}$. longae; pedunculus $8-10 \mathrm{~mm}$. longus; bracteae late triangulares $0,5-0,8 \mathrm{~mm}$. longae; rami bis ter cymose divisi. Flores rerisimiliter heterostyli. Calyx supra orarium fere $1 \mathrm{~mm}$. longe cupuliformiproductus; dentes limbo 4-5-plo breviores depressi. Corollae albae tubus subcylindraceus, superne parum ampliatus, minutissime pilosulus, intus sub staminum insertione villosus; lobi carnosuli, apiculo inflexo. Filamenta in flore dolichost. tubo corollae in $3 / 4$ alt. inserta, subnulla; antherae inclusae, oblongo-lineares, in $1 / 5$ alt. affixae. Discus crasse carnosus, breviter cylindricus. Ovarin m glabrum. Stylus exsertus glaber, 6,5 mm. longus; stigmata sublinearia, stylo ca. 8-plo breviora. Baccae calycis cupula coronatae.

Hab. in Haiti in MIorne Bellance, $800 \mathrm{~m}$. alt., m. Jul. flor.: Buch n. 656 .

Ols. Ex affinitate Ps, coronatue Griseb. et rerolutae DC.

$\checkmark$ Psychotria Buchii Urb. (n. sp.) ramis hornotinis glaberrimis; stipulis intra petiolos plus minus raginanti-conjunctis, superne ab initio liberis triangularibus $\mathrm{v}$. triangulari-acuminatis, $2-3 \mathrm{~mm}$. longis, mox deciduis; foliis $2-4 \mathrm{~mm}$. longe petiolatis, lanceolatis usque ellipticis $\mathrm{r}$. obovatis, ad basin sensim r. subsensim in petiolum angustatis, acutis v. obtusis, apice acutis 5 . acutatis, nunc rotundatis et apiculatis, paullo supra medium latissimis $3-5 \mathrm{~cm}$. longis, $1-2,5 \mathrm{~cm}$. latis, nervo medio supra subplano r. praesertim inferue parum impresso, coriaceis, utrinque glabris: inflorescentiis terminalibus mediocriter pedunculatis $\mathrm{v}$. raro sessilibus, glabris trichotomis, dein cymosis; floribus in cymula omnibus sessilibus r. subsessilibus, triades formantibus, 4-11eris; calyce supra ovarium cupuliformi-producto, lobis brevissimis late triangularibus; corolla $11-14 \mathrm{~mm}$. longa, lobis tubo fere $2 \frac{1}{2}$-plo brevioribus, orato-oblongis r. oblongis; baccis breviter ovoideis, $4-5 \mathrm{~mm}$. longis, laevibus r. sublaevibus; seminibus dorso profunde 3 - rarius $1-2$ sulcatis.

Frutex $0,3-1 \mathrm{~m}$. v. arbor $3-5 \mathrm{~m}$. alta. Rami vetustiores teretes plicato-striati grisci, hornotini suluquadranguli v. compressiusculi, intcrnodiis $2-3 \mathrm{~cm}$. longis $\mathrm{v}$ ad ramulos brevioribus. Stipulae initio gemmam compressam includentes, sed ab initio plus minns profunde liberae, crassiuscule chartaceae r. subcoriaceae, extrinsecus minntissime pilosulae, intus juxta commissuras adpresse et dense pilosae, medio glabrae, apice obtusissimae

Urban, Symb. ant. III. 
usque acuminatae, bruneac, medio dorso saepius carinatae. Folia vernatione alterum paullo recurvum, alterum paullo concavum, nervo medio supra plano v. subimpresso, lateralibus utroque laterc $5-7$, sub angulo $65-75^{\circ} \mathrm{ab}-$ euntibus, supra subimpressis v. vix conspicuis, subtus prominulis, vix in pressis v. obsoletis, non anastomosantibus, margine plerumque recurva, supra glaucescenti-viridia nitidula, subtus in sicco olivacea opaca non domatiata. Inflorescentiae $1-3 \mathrm{~cm}$. longae glaberrimae; pelunculus $1,5-4 \mathrm{~cm}$. longus compressus, raro nullus; bractcae triangulares acuminatae v. subulatoacuminatac, longe persistentes; rami primarii iterum trichotomi, dein $\nabla$. ab initio cymosi. Flores verisimiliter heterostyli. Calyx supra ovarium $1-1,5 \mathrm{~mm}$. longe cupuliformi-productus subcanosus; dentes 4 raro sub-5, limbo 2-4-plo breviores. Corolla alba (ex Bचch); tulus cylindracens v. superne infundibuliformis, extrinsecus glaber, intus inferne v. supra basin glaber, caeterum brevissime pubescens; lobi crasse coriacei v. carnosuli, apice inflexo cucullati. Filamenta in flor. brachyst. ca. 1,5 mm. sub ore corollae affixa, antheris aequilonga v. duplo breviora, in sicco nigrescentia; antherae ex ore exsertae $\mathrm{v}$. subexsertae, lineares apice obsolete apiculatae, dorso in $1 / 4$ alt. affixae, $2 \mathrm{~mm}$. longae. Discus crasse carnosus subsemiglobosus. Ovarium minutissime et obsolete scabriusculum. Stylus inclusus $6,5-9 \mathrm{~mm}$. longus, glaber, in $1 / 3$ superiore bilobus, stigmata linearia $v$. oblongo-linearia. Baccae breviter ovales v. ovali-globosae, calycis cupula coronatae, $4-5 \mathrm{~mm}$. longac, $3-3,5 \mathrm{~mm}$. crassae. Semina ventre levitcr bisulcata.

Hab. in Haiti prope Labrande in declivibus siccis calcareis $350 \mathrm{~m}$. alt., m. April. flor.: Buch n. 595, in Morne Bellance in fruticetis, $800 \mathrm{~m}$. alt., m. Jul. fl. et fr.: Buch n. 684, prope Marmelade in montibus siccis calcareis, $500 \mathrm{~m}$. alt, m. Jul. fl. et fr.: Buch 11. 416 (forma angustifolia foliis lanceolatis v. anguste lanceolatis), prope Cadets $1200 \mathrm{~m}$. alt., m. Jan. fl. et fr.: Picarda n. 1088, 1095.

Obs. Habitu simillima Ps. revolutae DC., coronatae Griseb. et affinibus, sed toto coelo diversa stipulis perbrevibus ab initio bipartitis, floribus omnibus sessilibus 4 -meris ratione longis, fructibus non costato-sulcatis, seminibus dorso $1-3$ - (nec 5-) sulcatis.

Psychotria brevistipula Urb. (n. sp.) ramis hornotinis minutissime patenti-pilosulis; stipulis intra petiolos alte vaginanti-conjunctis, superne ab initio liberis, ultra vaginam parum usque semiorbiculariproductis, totis $1,5 \mathrm{~mm}$. longis, deciduis; foliis $4-2 \mathrm{~mm}$. longe petiolatis, ellipticis usque oblongo-lanceolatis, inferne sensim in petiolum angustatis, apice obtusis v. obtusissimis, medio v. paullo supra medium latissimis, $3,5-2 \mathrm{~cm}$. longis, $1,5-0,8 \mathrm{~cm}$. latis, nervo medio per totam longitudinem supra anguste impresso, subcoriaceis r. coriaceis, utrinque glabris; inflorescentiis terminalibus, breviter pedunculatis, minute pilosulis, semel bis trichotomis, dein cymosis; flore in cyma terminali subsessili, lateralibus usque $1 \mathrm{~mm}$. longe pedicellatis, 5-meris; calyce supra ovarium brevissime cupuliformi-producto, lobis minutis late triangularibus; corolla $5 \mathrm{~mm}$. longa, lobis tubo vix duplo brevioribus, ovato- 
oblongis r. oblongis; baccis (junioribus) globulosis, ut videtur sulcatocostatis.

Frutex. Rami patentes v. divaricato-patentes teretes in siceo plus minus plicato-striati, bruneo-nigrescentes, graciles quoad suppetunt vix $1,5 \mathrm{~mm}$. crassi, hornotini plus minus compressi, internodiis postremo $1-2 \mathrm{~cm}$. longis. Stipulae initio gemmam compressam includentes, sed ab initio superne liberae subcoriacene, extrinsecus minutissime pilosulae, intus juxta commissuras adpresse pilosae, apice obtusissimac v. rotundatae, bruneae, posterins sursum erectae et deciduae. Folia vernatione subplana, nerro medio subtus crassiuscule prominente, lateralibus utroque latere $4-6$ sub angulo ca. $70^{\circ}$ abeuntibus, supra non conspicuis, subtus tenuiter prominulis non anastomosantibus, margine recurva, supra in sicco olivacea nitida, subtus glaucescentia, non domatiata. Inflorescentiae $1-1,5 \mathrm{~cm}$. longae; pedunculus ca. $1 \mathrm{~cm}$. longus compressus; bracteae primariae ex ovato satis longe acuminatae, ca. $1,5 \mathrm{~mm}$. longae, superiores breviores. Flores veris. heterostyli. Calyx supra ovarimm ca. $0,25 \mathrm{~mm}$. longe productus; dentes parum prominentes $\mathrm{v}$. late triangulares. Corolla alba; tubus superne paullo ampliatus, latiusculus, extrinsecus minute pilosulus, intus supra medium pubescens; lobi chartace-coriacei, apice non cucullati. Stamina... Discus depressus carnosus. Ovarium brevissime pilosum. Stylus in flor. brachystylis $2 \mathrm{~mm}$. longus; stigmata obovato-oblonga, parte integra 5 -plo breviora.

Hab. in Cuba ad Nimanima, m. Aug. flor.: Linden n. 2206.

Obs. Ex affinitate Ps. eveniae C. Wr. et Ps. subalatae C. Wr., quarum prior ramis hornotinis et inflorescentiis glabris, illis triplo crassioribus, foliis subtus pilosulis, nervo medio subtus duplo crassiore, inflorescentiis robustioribus, fructibus junioribus ovalibus differt, posterior longius distat ramis hornotinis bicarinatis, foliis hrevissime petiolatis, nervo medio supra inferne parum impresso, caeterum plano, inflorescentia sub-5-flora, fructibus anguste ovalibus.

Diodia rigidla Cham. et Schlecht. var. angustissima Urb. (n. var.) caulibus $0,5-0,8 \mathrm{~mm}$. crassis glabris; setis stipularibus $1-2 \mathrm{~mm}$. longis; foliis angustissime linearibus $0,5-0,8 \mathrm{~mm}$. latis; corolla $12 \mathrm{~mm}$. longa.

Hab. in Sto. Domingo ad Loma Mata Clara, $600 \mathrm{~m}$. alt., inter gramina pineti m. Jun. flor.: Eggers 11.2340 , in Valle nuevo $2270 \mathrm{~m}$. alt. inter gramina: Eggers 11. 2287.

Mitracarpus frigidus K. Schum.! in Mart. Flor. Bras. FI. o; (1888) p. 81. (1818) p. 531.

Spermacoce frigida Willd.! herb. ed. Roem. et Schult. Syst. III $\checkmark$ Var. portoricensis Ur.b. (n. var.) $50 \mathrm{~cm}$. altus erectus, inferne sublignescens, ramosus, ramis glabris brunescentibus r. badiis, ad axillas foliorum plerumque ramulos breves $v$. abbreriatos dense foliosos gerentibus; vagina stipulari glabra, setis $3-5$ subglabris $v$. parce brevissimeque ciliatis, longioribus $4-5 \mathrm{~mm}$. longis; foliis sublinearibus, ad basin vix v. parum, ad apicem valde sensim angustatis acutis, $3-6 \mathrm{~cm}$. longis, $1,5-3 \mathrm{~mm}$. latis, margine plano $\mathrm{r}$. recurvato et subtus ad nerrum 
medium scabris, caeterum glabris; inflorescentiis capitatis terminalibus et praterea saepe $1-4$ lateralibus, sub anthesi $13-18 \mathrm{~mm}$. diannetro; sepalis lateralibus sub anthesi $2-3 \mathrm{~mm}$. longis lanceolato-linearibus valde plicatis acutis, margine breviter ciliatis, caeterum glabris; corolla $5 \mathrm{~mm}$. longa, lobis tubo $2-2 \frac{1}{2}$-plo brevioribus, ovatis v. triangulariovatis; orario glabro; seminibus $0,9 \mathrm{~mm}$. longis, pallide brumeis.

\section{Borreria podocephala Stahl! Est. I (1887) p. 89, - non DC.}

Rami qui suppetunt inferne usque 4,5 $\mathrm{mm}$. crassi, vetustiores subteretes, in parte juniore striis 4 elevatis, e margine foliorum decurrentibus per paria approximatis notati, in area angustiore plani, in latiore convexi, internodiis $3-10 \mathrm{~cm}$. longis. Stipularum vaginae in parte regetativa semiorales, $3-4 \mathrm{~mm}$. longae, sub capitulis nou conspicuae; setae applanatae, lineari-subulatae, pallide purpureae v. albescentes. Folia sessilia, nervo medio supra superme non conspicuo, inferne angustissime impresso, subtus parum prominente albescente, lateralibus nullis v. solitariis obsoletis longitrorsis, erecto-patentia. Capitula sphaeroidea. Flores sessiles v. usque $1 \mathrm{~mm}$. longe pedicellati. Calyx dense bruneo-lineolatus; sepala lateralia crassiuscula, mediana e basi latiore subulata, dimidio v. duplo breviora, sed caeterum lateralibus conformia, omnia basi brevissime v. breviter connata. Corollae albae tubus subcylindraceus, extrinsecus glaber, intus in $1 / 3$ alt. parce pilosulus; lobi apice inflexi. Filamenta ad corollae os inserta, perlirevia, antheris duplo breviora; antherae oblongo-lineares albidae. Stylus $4-4,5 \mathrm{~mm}$. longus, in $1 / 5$ superiore bifidus. Capsula calyce fere 3 -plo longiore superata, rotundo-quadrangularis, 1,2 mm. longa, medio circumscissa, dissepimento e cupula inferiore paullo prominente. Semina breviter ovalia, ventre medio concava, caeterum cruce obliqua sulcata, dorso obsolete reticulata.

Hab. in Portorico in arenosis prope Bayamon, m. Jan., Jun. fl.: Stahl n. 231, 519, prope Manatí in pratis ad Coto, m. Apr. fl.: Sintenis n. 6740 , loco non adnotato: Heller n. 21.

Obs. Typus Willdenowianus (Herb. n. 2623 e Silla de Caracas) ramis pubescentibus, foliis lanceolatis v. oblongis, $\mathrm{S}-15 \mathrm{~mm}$. latis, supra brevissime pilosis, subtus breviter pubescentibus, nervis lateralibus utroque latere $2-3$ arcuatis, antheris pallide violaceis, seminibus ovali-ellipticis nigrescentibus differt.

Mitracarpus Christii Urb. (n. sp.) perennis?, caulibus erectis, in sicco brunescentibus, plerumque simplicibus, glabris; vagina stipulari inferne glabra, superne v. apice sericea, setis $3-5$, inferne breviter sericeopilosis, longioribus $3 \mathrm{~mm}$. longis; foliis linearibus, ad basin angustatis, superne sensim acuminatis, apice acutis r. acutissimis, $1,5-3 \mathrm{~cm}$. longis, $1-2,5$ mm. latis, margine recurvo v. revoluto integris, glabemimis; inflorescentiis capitatis terminalibus et usque 6 lateralibus, postremo $5-7 \mathrm{~mm}$. diametro; sepalis lateralibus sub anthesi $1,5-2 \mathrm{~mm}$. longis, linearjbus v. lineari-lanceolatis, margine infero ciliatis, caeterum glabris; corolla 2-3 mm. longa, lobis triangulari-ovatis, tubo duplo brevioribus, glabra; ovario breviter piloso; seminibus $0,9 \mathrm{~mm}$. longis, bruneis. 
Caules, qui suppetunt, $25-35 \mathrm{em}$. longi, inferne ea. $1 \mathrm{~mm}$. crassi, plus minus quadranguli, angulis elevatis, faciebus inacquilatis, latioribus magis convexis, brunescentes, glaberrimi v. sub vaginis pilos perpareos breves gerentes, internodiis inferioribus $4-7 \mathrm{~cm}$. Iongis, supremis brevioribus. Stipularum vaginae sub eapitulis oboratae, $2,5-3 \mathrm{~mm}$. longae et supernc latae; satae linearisubulatae, bruneo-albeseentes. Folia sessilia, nervo medio supra anguste impresso, subtus erassiusenle prominente, lateralibus utroque latere 1 - 2 sublongitrorsis $\mathrm{r}$. nullis, supra in sicco obscure viridia, subtus pallidiora, horizontaliter patentia v. subreeurva. Capitula postremo semiglobosa. Flores subsessiles v. usque $2 \mathrm{~mm}$. longe pedicellati. Sepala lateralia riridia subcarnosa superne angustata, plerumque acuta, mediana paullo usque triplo breviora lanceolatosuhulata membranaeea hyalina ciliata, omnia basi plus minus connata. Colollae tubus subcylindraceus v. superne paullo ampliatus, intus sub medio puberulus; lobi apiculo inflexo. Filamenta sub corollae ore ipso inserta, perhrevia; antherae ovatae plus minus cyaneae. Stylus $2,5-3 \mathrm{~mm}$. longus, in $1 / 3 \ldots 1 / 4$ superiore hifidus. Capsula calyce aequilongo coronata, ehartaeea fragilis ambitu subquadrata, $1,5 \mathrm{~mm}$. longa et paullo angustior, supra $1 / 3$ alt. ciremmseissa, parte inferiore glabra, superiore breviter pilosa, dissepimento e cupula inferiore suhoblique seeta prominente. Scmina ovalia v. breviter ovalia, ventre medio reetangulari-emarginata, cacterum cruee obliqua sulcato-impressa, dorso minute reticulata.

Hab. in Haiti in montibus Furcy, $1500 \mathrm{~m}$. alt., m. Jul. florere incipit, n. Dec. fruct.: Christ n. $1696,1759$.

Mitracarpus polycladus Urb. (n. sp.), annuus, caule erecto, a basi bis ter multiramoso, ramis glabris in siceo viridi-albescentibus; vagina stipulari glabra v. parce et brevissime pilosa, setis $3-\overline{5}$ glabris v. inferne parce et brevissime pilosis, longioribus $2.5-3 \mathrm{~mm}$. longis; foliis lineari-lanceolatis usque sublinearibus, utrinque sed superne magis angustatis, apice mucronatis, $3.5-1,5 \mathrm{~cm}$. longis, $5-2 \mathrm{~mm}$. latis, margine plano v. recurvato superne scabris, caeterum glabris; inflorescentiis capitatis terminalibus, laterali unica hinc illinc adjecta, postremo $7-12 \mathrm{~mm}$. diametro; sepalis lateralibus sub anthesi 2,5-3 mm. longis, lineari-lanceolatis plus minus acuminatis, margine brevissime ciliatis, caeterum glabris; corolla 5 mm. Jonga, lobis ovatis, tubo fere 3 - plo brevioribus, glabra; ovario superne parcissime et brevissime patenti-piloso; seminibus $1,2-1,3 \mathrm{~mm}$. longis, nigrescentibus.

Radix palaris usque pedalis, superne $5 \mathrm{~mm}$. crassa, parce ramosa brunea. Caulis, qui suppetit, $25 \mathrm{em}$. longus, basi $5 \mathrm{~mm}$. erassus, iterum atque iterum lamosus; rami plus minus quadranguli, angnlis elevatis, faeiebus inaequilatis, latioribus magis convexis, internodiis $2-5 \mathrm{~cm}$. longis. Stipularnm vaginae sub capitnlis initio semiglobosae, 1,5-2 $\mathrm{mm}$. longae, posterius magis explanatae; setac lineari-subulatae albescentes. Folia sessilia, nervo medio supra non v. vix eonspicuo, subtus prominente, lateralibus utroque latere solitariis longitrorsis r. nullis, supra viridia, sulitus pallidiora et saepius albido-lineolata, plus minus horizontaliter patentia. Capitula postremo subglobosa. Flores sessiles v. subsessiles. Sepala lateralia pallide riridia erassiuscula, mediana pallidiora v. hyalina, paullo v. duplo breviora 
lanceolato-r. lineari-acuninata, ciliata, omnia hasi rix r. brevissime connata. Corollae tubus inferne cylindraceus, superne paullo ampliatus, intus in $1 / 3$ alt. pubescens; lobi apiculo inflexo, lineolis albidis instructi. Filamenta ad corollae os inserta, manifesta, antheris duplo breviora; antherne ublongae albilae. Stylus (an in flor. brachystylis?) $3 \mathrm{~mm}$. longus, in 1/:' superiore bifidus. Capsula calyce aequilongo r. paullo longiore superata. ambitu breviter oralis, 1,5 mm. longa et paullo angustior, glabra r. subglabra, sub medio circumscissa, dissepimento e eupula inferiore triangulariprominente. Semina rectangulari-ovalia, rentre medio concara, caeterum cruce obliqua sulcata, dorso minute reticulato-impressa.

Hab. in Portorico prope Guanica in rupibus litoralibus ad Caño gordo inter frutices, m. Febr. fl. et fr.: Sintenis n. 3750 .

Vernomia boringuensis Urb. (n. sp.) ramis inferne subglabris, superne praesertim in parte florifera unilateraliter pilis sursum curvatis v. patulis plus minus obsitis, hornotinis sterilibus arl apicem circumcirca et densissine albido-pubescentibus; foliis $4-1,5 \mathrm{~mm}$. longe petiolatis, ovatis usque oblongo-lanceolatis, basi rotundatis v. raro obsolete cordatis, superne sensim acuminatis, $2,5-6 \mathrm{~cm}$. longis, $1-2 \mathrm{~cm}$. latis, margine integris subintegrisve, membranaceo-chartaceis usque chartaceocoriaceis, penninervibus, supra parce r. parcissime et brevissime pilosis, subtus breviter r. mediocriter sericeo-r. substrigoso-pilosis, utrinque r. subtus tantum glanduloso-impressis; inflorescentiis laxe cymosis et cincinnosis, bracteis (prophyllis) forma et magnitudine caulinorum, superne tantum decrescentibus; capitulis 18 - 20 -floris, involucro $7-8 \mathrm{~mm}$. longo, squamis 6-7-seriatis, omnibus superne sensim angustatis et apice acutissime acuminatis, dorso supero saepe rubescente minutissime pilosulis; pappo biseriali, setis interioribus squamellas exteriores lineares 4-plo superantibus, ad apicen obsolete r. parum incrassatis, pallide bruneis; corollis albidis $\mathrm{r}$. albo-carneis $\mathrm{r}$. albo-roseis, $9 \mathrm{~mm}$. longis; achaeniis $1,5-1,8 \mathrm{~mm}$. longis, leviter 10 -costatis, pilis suberectis dense sericeis.

Fruticulus r. frutex $0,5-3 \mathrm{~m}$. altus. Rami teretes elevatim multistriati, posterius brunescentes glabrescentes, pube simplice plus minus currula griseo-albida, internodiis variis $1-7 \mathrm{~cm}$. longis. Folia alterna, petiolis breviter pubescentibus, supra sulcatis, nervis supra tenuiter prominentibus, lateralibus utroque latere $4-7$, sub angulo $35-45^{\circ}$ abeuntibus, arcuatis ante marginem conjunctis, infimis plerumque minus arduis, parce $r$. non anastomosantibus, supra initio plana, postremo secus nervos impressa, margine plano v. plerumque anguste revoluto integra r. denticulos parros obtusos glanduloso-incrassatos gerentia, juniora tenuissima pellucido-punctata. adulta plus minus glaucescentia nitida, subtus pallidiora, pube albida r. sordide albida, subtus densiore et longiore r. parca et brevi. Inflorescentiae in apice ranorum et ramulorum terminales, in panniculam amplam collectae; bis usque quater cymose divisae, lein cincinnosae, axibus cincinni plerumque flexuosis; prophylla sub capitulo euphyllis aeqnalia. Capitula sessilia $r$. brevissime (usque $1 \mathrm{~mm}$.) pedunculata, turbinata, $9-10 \mathrm{~mm}$. longa, medio $5-6 \mathrm{~mm}$. crassa; involucri squamae $45-60$, infimae lineari-subulatae, ab 
$1,5 \mathrm{~mm}$. sensim accrescentes, summae lineares acumiuatae usque $7 \mathrm{~mm}$. longae, $0,7-1 \mathrm{~mm}$. latae, ommes cartilagineae, dorso infero plerumque parce et longiuscule pilosae, sordicle v. viridi-stramineae ad apicem saepe rubescentes, nervo medio parum v. non prominente. Receptaculum convexum glabrum. Pappi squamae exteriores ca. 20 inaequales planae, margine obsolete v. manifeste denticulatae, setae interiores $24-36,5,5 \mathrm{~mm}$. longae spinuligerae. Corollae inferne anguste cylindraceae, a medio in limbum usque ad basin 5 -sectum dilatatae; lobi lineares acuminati. Stamina ad basin limbi corollae inserta; antherae fere $2,5 \mathrm{~mm}$. longae, basi bidentatae, apice in ligulam anguste lanceolatam loculis $3-4$-plo breviorem productae. Styli in parte $1 / 5$ superiore bicrures, ramis scabriusculis apice attenuatis. Achaeuia pallide brumescentia, oblongo-linearia, pilis albidis.

Hab. in Portorico in Sierra de Juncos in gramiuosis apricis montis Guvuy, prope Utuado ad margines sylrarum ad Paso Palma, prope Lares in fruticetis ad Jobo et ad margines sylrarum ad Anon, prope Maricao ad margines sylvarum, prope Mayagüez $160 \mathrm{~m}$. alt., m. Nor. - Mart. fl. et fr.: Heller n. 4391, Sintenis n. 388, 2659, 5ั854, $6079,6362$.

Var. $\beta$. Stahlii Urb. foliis non impresso-punctatis: achaeniis glabris subglabrisve, vix $1 \mathrm{~mm}$. superantibus.

Vernonia arborescens Su: var. Lessingiana Stahl! Est. V (1887) p. 103 (p.p.), - non Giriseb.

Hab. in Portorico prope Bavamon, 500 m. alt.: Stahl n. 23S, 667, prope Aybonito in declivibus m. Nov. fl.: Sintenis n. 2862.

Obs. I. Ex affinitate V. Berteroanae DC.

Obs. II. Baccharis myrsinites Griseb.! Flor. (1861) p. 366 est Ternonia acuminata Less.: specimen Yacnabianum typum, Purdieanum varietatem sistit quoad e statu valde juvenili dijudicari potest. - Tera B. myrsinites (Lam.) Pers. Hispaniolam inlrabitat, ex affinitate areta $B$. halimifoliae L.

Eupatorium bahamense $\mathrm{Urb}_{\mathrm{r}}$. (n. sp.) ramis hornotinis pilis brevissimis plus minus sursum curratis dense restitis; foliis $12-5 \mathrm{~mm}$. longe petiolatis, anguste ovatis, ovato-oblongis v. oblongis, basi anguste cuneatin in petiolum protractis, infra medium latissimis, superne sensim angustatis, apice rotundatis r. obtusis, $6-2 \mathrm{~cm}$. longis, $2-0,6 \mathrm{~cm}$. latis, margine anguste recurvo $v$. revoluto integris, rarissine linc illine parce v. crebrius denticulatis, penninerribus, sed pari nervorum supra basin cuneatam magis arduo r. sublongitrorso, cliartaceis r. chartaceo-coriaceis, utrinque glabris v. subtus minute pilosulis; inflorescentiis corymbosis; capitulis usque $6 \mathrm{~mm}$. longe pedunculatis $\mathrm{v}$. plerumque in apice ramorum 2-3-1atim sessilibus r. subsessilibus, 6-12-floris; involucri squamis solemniter inbricatis, $5-6$-seriatis, dorso 3 -nervibus, apice plus minus incurro rotundatis r. intimis obtusis; corollis $4-4,5 \mathrm{~mm}$. longis, lobis tubo $5-6$-plo brerioribus; orario $3,5 \mathrm{~mm}$. longo, ad costas minute scabrido. 
Eupatorium integrifolium Gard., Brace et Doll. Bah. (18S9) p. 387, - non Bert.

Frutex 1,3 m. altus. Ram i vetustiores tenuiter striati, bruneo-cinerascentes glabri, homotini pube articulata grisea olstecti, internodiis $3-1 \mathrm{~cm}$. longis. Folia opposita, petiolis supra sulcatis minute pubescentibus, nervo medio supra prominulo, latcralibus 2 supra partem cuneatam sub angulo $30-45^{\circ}$ abeuntibus, usque ad medium productis, caeteris utroque latere $1-3$ minus arduis brevioribus et tenuioribus, non v. obsolete anastomosantibus, supra nitidula, minute pellucido-punetata, subtus glandulis creberrimis impressis notata. Inflorescentiae terminales, satis densac, $2-5 \mathrm{~cm}$. longae et diametro; bracteae euphylloideae, sensim decrescentes, oblongae usque lanceolatae, supremae lineares squamiformes $3-1,5 \mathrm{~mm}$. longae; rami patentes v. erecto-patentes, inferne nudi, apicc ramulosi, ramulis glomerulos $2-3$ ceplalos gerentibus. Capitula cylindracea $8-9 \mathrm{~mm}$. longa, 2,5 $\mathrm{mm}$. diametro; squamae ca. 21 , exteriores ovato-oblongae v. oblongae $2-4 \mathrm{~mm}$. longae, intermediae anguste lanceolato-lineares, $1,5-1,3 \mathrm{~mm}$. latae, interiores sublineares $7-8 \mathrm{~mm}$. longae, ca. $1 \mathrm{~mm}$. latae, omnes superne paullo magis angustatae, cartilagineae, apice inflexo herbaceae et parcissime pilosulae, caeterum glabrae, margine hinc illinc minute lacero-dentatae, stramineae, apice ct nervis brunescentibus; receptaculum lineari-cylindraceum, 1,5 mm. longum. Pappi setae $34-38$ uniseriatae, fere $4 \mathrm{~mm}$. longae, nonnullis minoribus, spinuligerae, aequicrassae, albidae. Corollae albae (ex EGG.), inferne cylindraceae, superne sensim usque dimidio ampliatae, glandulis parcissimis adspcrae; lobi anguste triangulares. Stamina corollae in $1 / 3$ alt. affixa; antherae $1,7 \mathrm{~mm}$. longae, basi obtusae, apice in ligulam ovatam loculis 5 -plo breviorem productae. Discus valde evolutus, $0,5 \mathrm{~mm}$. longus. Styli a medio bifidi, ramis aequicrassis apice obtusis. Ovarium inferne attenuatum, 3-4-costatum.

Hab. in ins. Baham. New Providence in Blue hills, m. Mart. flor:: Eggers n. 4424, Andros prope Nicols Town, m. Mart. flor.: Northrop 12. 359 .

Obs. Ex affinitate E. comyzoidis Vahl, quod foliis dentatis r. incisodentatis acuminatis, inflorescentiae ramis divaricatis, capitulis omnibus pedunculatis, squamis apice non incurvis etc. differt.

Eupatorium mononeurum Urb. (n. sp.) ramis hornotinis parce et minute pilosis $\mathrm{v}$. subglabris; foliis $25-40 \mathrm{~mm}$. longe petiolatis, ovatis, sed ad basin late cuneatim productis, basi ima acutatis, apice longe acuminatis, ca. $15 \mathrm{~cm}$. longis, $7-8 \mathrm{~cm}$. latis, margine basi excepta inaequaliter r. subduplicato-dentatis v. serratis, subpenninervibus, membranaceis $\mathrm{v}$. membranaceo-chartaceis, utrinque glabris subglabrisve; inflorescentiis amplis panniculatis, ramis longe nudis ad apicem panniculam specialem gerentibus; capitulis $7-2 \mathrm{~mm}$. longe pedunculatis, 21 -floris; involucri squamis $6-7$-seriatis, solemniter imbricatis, 1 -nervibus, apice rotundatis, oblongis usque linearibus; corollis $4 \mathrm{~mm}$. longis, lobis tubo 5-6-plo brevioribus; achaeniis $3 \mathrm{~mm}$. longis, parce et brevissime pilosis, acute 5 -costatis. 
Verisimiliter fruticosum. Rami teretes, inaequaliter multistriati brunescentes, pube sursum curvata, internodiis $1,5-4 \mathrm{~cm}$. longis. Folia oplosita, petiolis supra canaliculatis, minute ct parce pilosulis, nerro medio supra subplano v. inferne parım impresso brevissime pulverulento-pilosulo, lateralibus utroque latere $4-6$, inferioribus magis approximatis et minus arduis, superioribus sub augulo $45-30^{\circ}$ abeuntibus, omnibus supra prominulis, extrinsecus ramosis et tenuiter reticulato-anastomosantibus et minute v. obsolete pilosulis, supra densissime elevatim punctata, subtus glandulis creberlimis immersis minutis praedita. Inflorescentiae terminales, laxae, subglabrae, usque $15 \mathrm{~cm}$. longae, usque $20 \mathrm{~cm}$. latae; bracteae inferiores euphylloideae sel multo minores, superiores squamiformes lineares $v$. anguste oblongae, $2-0,7 \mathrm{~mm}$. longae; rami primarii divaricati, secundarii patentes racemose v. subcorymbose $5-10$-cephaii. Cap itula subcylindracea $8-9 \mathrm{~mm}$. longa, 2,5 mm. crassa; involucri squamae $44-48$, extcriores (infimae) anguste ovatae v. ovato-oblongac $0,7 \mathrm{~mm}$. longae et longiores, intermediae oblongae v. oblongo-lineares, 1 - v. obsolete 3 -nerves, summae (intimae) lineares, $5-6 \mathrm{~mm}$. longae, $1-0,5 \mathrm{~mm}$. latae, 1 -nerres, cartilagineae, stramineae, margine supero brevissime ciliatae, valde debiles; axis inter squamas obconico-cylindraceus, $1,8 \mathrm{~mm}$. longus. Pappi setae $35-37$ uniseriatae subaequilongae, $3,5 \mathrm{~mm}$. longae, minute spinulosae, aequicrassae, albae. Corollae a basi sensim usque duplo ampliatae, glandulis parcis obsitac; lobi triangulares. Stamina corollac in 1/4 alt. inserta; antherae inclusae, 1,5 mm. longae, basi obtusae, apice in ligulam breviter oratam loculis ca. 5 -plo breriorem excurrentes. Discus ralde evolutus obconicus, $0,6 \mathrm{~mm}$. longus. Strli in $1 / 3$ superiore bicrures; lobi subaequicrassi obtusi. Achacnia ad basin valde attenuata, griseo-nigrescentia.

Hab. in Dominica in Morne Gombo, m. Dec. fl., Mart. fruct.: Eggers hb. propr. n. 71, 1451.

Obs. Species squamis involucri valde deciduis fere semper 1 -nervibus insignis; ex affinitate E. trigonocarpi Griseb.

Eupatorium medullosum Urb. (n. sp.) ramis homotinis pubescentibus; foliis $3-4 \mathrm{~mm}$. longe petiolatis, ovatis $r$. anguste ovatis, basi rotundatis $r$. latissime cuneatis et obtusis, apice obtusis, $3,5-5 \mathrm{~cm}$. longis, 2-3,5 cm. latis, margine (basi excepta) dentatis, penninervibus, sed nervis sursum curratis et sublongitrorsis, chartaceo-coriaceis v. coriaceis; inflorescentiis corymbosis, pleio- v. polycephalis; capitulis $0-9 \mathrm{~mm}$. longe pedunculatis, ca. 25 -floris; involucri squamis $6-7$ seriatis, solemniter imbricatis, apice obtusis $\mathrm{v}$. rotundatis; corollis $3,5 \mathrm{~mm}$. longis, lobis tubo toto 6 -plo brevioribus; ovario $3-3.5 \mathrm{~mm}$. longo, ad apicem brevissime et parce piloso, caeterum glabro.

Fruticulus $0,6-1 \mathrm{~m}$. altus. Rami crassiusculi v. crassi, hornotini 3-4 mm., annotini usque $8 \mathrm{~mm}$. crassi, teretes, plus minus striati, valde medullosi, in sicco hrumei, pilis articulatis sordide albidis v. brunescentibus dense induti, postrcmo glabrescentes. Folia opposita, petiolis late sulcatis, ncrvo medio supra prominulo $r$. in sulco prominulo, lateralibus utroque latere $3-5$, infimis ad $v$. paullo supra basin prodeuntibus usque ad medium productis, caeteris e nervo medio sub angulo $30-40^{\circ}$ abeuntibus 
arcuatis, utrinque reticulato-anastomosantibus, dentibus aequalibus v. subinieyualibus, supra glahria in siceo nigrescentia, subtus ad nervos plus minus pare pilosa, inter nervos glandulis densissimis impressis nigris obsita. I nflorescentiae terminales, $2-3 \mathrm{~cm}$. longae, $3-5 \mathrm{~cm}$. latae; bracteae euphylloideae, sed minores, caterae squaniformes, lineares r. ovatae; rami plus minus villosuli; pednuculi speciales angulati v. compressi. Capitula 8-9 $\mathrm{mm}$. Longa, $3-3,5 \mathrm{~mm}$. crassa; involueri squamae ca. 45 , exteriores (infinae) semiovales $1-1,5 \mathrm{~mm}$. longae, sequentes orliculares $v$. ovales $1,5-2 \mathrm{~mm}$. longae, summae (intimae) ellipticae usque oblongolineares, $4-5 \mathrm{~mm}$. longae, $1,5-0,8 \mathrm{~mm}$. latae, ommes antice rotundatae v. obtusae, dorso quoad non obtectae $7-3$-nerves, cartilagineae, bruneae, arl marginem pallidae et plus minus fiml,riato-ciliatae; axis inter squamas $2 \mathrm{~mm}$. longus, cylindraceus. Pappi setae $42-54$, uniseriatae, subinaequilongae, sul anthesi 2,5 mm. longae, obsolete et adpresse spinuligerae. Corollae inferne anguste cylindraceae, supra medium sensim sed parum ampliatae, laeves; lobi anguste triangulari-ovati. Stamina corollae in $1 / 3$ alt. inserta; antherae inclusae, $1 \mathrm{~mm}$. longae, basi obtusae, apice in ligulam ovatam loculis $4-5$-plo breviorem excurrentes. Styli in $3 / 7-4 / 7$ superiore bipartiti; lobi subclavato-lineares obtusi. Ovarium lineare inferne valde attemuatum.

Hab. in Martinique, verisimiliter smmmis in montibus: Duss 11. $295^{\text {b et } c \text {. }}$

Duae formae occurrunt:

$\alpha$. foliis planis, capitulis $5-9 \mathrm{~mm}$. longe pedunculatis cylindraceis $\left(295^{\mathrm{b}}\right)$,

$\beta$. foliis plus minus bullatis, capitulis $0-5 \mathrm{~mm}$. longe pedunculatis ellipticis $\left(295^{\mathrm{c}}\right)$.

Obs. Ex affinitate E. trigonocarpi Griseb.

Eupatorium Jaererianum Urb. (n. sp.) ramis hornotinis pilis brevissimis sursum curvatis obsitis, nonnullis brevibus patentibus intermixtis; foliis saepius alternis, $12-5 \mathrm{~mm}$. longe petiolatis, oratis, inferioribus basi late cordatis, sed perpanllo in petiolum protractis, superioribus basi truncatis r. obtusis, omnibus apice subsensim acuminatis, $5,5-3 \mathrm{~cm}$. longis, $3,5-1,5 \mathrm{~cm}$. latis, margine inaequaliter r. subduplicato-crenatis, e basi trinervibus, membranaceo-chartaceis, ntrinque brevissime pilosis; inflorescentiis panniculato- r. subcorymbosis; capitulis $6-1 \mathrm{~mm}$. longe pedunculatis, 25-30-floris; involueri squamis sub3 -seriatis, linearibus, infimis et intimis acuminatis, caeteris obtusis, dorso minute et subparce pilosulis, totis r. superne plus minns 1nbro-coluratis; corollis fere $5 \mathrm{~mm}$. longis, lubis tubo 5 -plo brevioribus; achaeniis in eodem capitulo inaequilongis, $4-5 \mathrm{~mm}$. longis, parce et brevissime pilosis.

Verisimiliter fruticosum. Ram i vetustiores teretes multistriati glabri pallide brunei, hornotini pube articulata sordicle alba v. In'unescente obsiti, intemodiis $1-4$ cm. longis. Folia opposita r. saepins alterna, hine inde 
ternatim in verticillum collecta, petiolis supra leviter sulcatis, brevissime pubescentibus, nervo medio supra inferne non, supcruc parum prominente, lateralibus 2 infimis e basi ipsa usque in $2 / 3$ alt. productis, cxtrinsecus ramosis, caeteris utroque latere $2-3$ sub angulo $40-45^{\circ}$ abeuntibus, brevioribus intermixtis, ommibus supra non v. obsolete, subtus manifeste reticulato-anastomosantihus, margine plana, pube supra manifestiore, subtus glandulis subparcis minutis luteis adspersa, supra in sicco nigrescentia, subtus olivacea. Inflorescentiae terminales, $5-7 \mathrm{~cm}$. longae, $4-10 \mathrm{~cm}$. diametro; bracteae inferiores euphylloideae, sensim v. subito decrescentes, superiores lineares $4-1,5 \mathrm{~mm}$. longae; rami saepius alterni, plus minus patentes, inferne nudi, apice glomerulum capitulorum gerentes. Capitula campanulato-turbinata, postremo usque $10 \mathrm{~mm}$. longa, melio ca. $5 \mathrm{~mm}$. diametro; involucri squamae $19-22$. infimae $3-5 \mathrm{~mm}$. longae linearisubulatae, caeterae ca. $8 \mathrm{~mm}$. longae, $1-0,8 \mathrm{~mm}$. latae lineares 3 -nerves, margine integrae v. subintegrac, chartaceae, margine tenuiores, dorso glandulis adspersae, intimae inferne angustatae. Pappi setac $30-34$ subaequilongae, $4 \mathrm{~mm}$. longae, ad apicem obsolete incrassatae, minutc spinulosae, sordide albidae. Corollae inferne lineari-cylindraceae, a $3 / 5$ alt. sensim in limbum duplo crassiorem ampliatae, glandulis subparcis adspersae; lobi triangulari-lanceolati. Stamina corollac medio affixa; antherae inciusae $1,6 \mathrm{~mm}$. longae, basi obtusae, apice in ligulam triangularem obtusam loculis 6 -plo brevioren productae. Stylus supra medium bicruris, lobis saepe inaequilongis, ad apicem dilatatis obtusis, in sicco nigrescentibus. Acliaenia 5 -nervia ad basin valde attenuata.

Hab. in Haiti in montibus Le grand fond dictis prope Port-auPrince usque $1000 \mathrm{~m}$. alt., m. Dec. flor: Jaeger n. 47.

Ots. Ex affinitate $E$. ageratifolii DC., quod foliis semper oppositis, basi truncatis, involucro fere duplo breviore facile distingucndum est.

Eupatorium Hartii Urb. (n. sp.) ramis hornotinis pilis brevibus patulis crispulis dense vestitis; foliis $9-5 \mathrm{~mm}$. louge petiolatis, anguste oratis v. ovato-oblongis, basi rotundata subito in petiolum protractis eumque marginibus revolutis marginantibus, a parte $1_{3}^{\prime}$ inferiore ad apicem obtusiusculum r. obtusum sensium angustatis, $3,5-2 \mathrm{~cm}$. longis, $1,7-1$ cm. latis, margine depresse crenatis, penninervibus, sed pari luervorum supra basin tertio areuato-longitrorso usque $3 / 5-2 / 3$ folii longitudinis producto, clartaceo-coriaceis, utrinque praesertiul subtus ad nerros brevissime puberulis, caeterum glabris; inflorescentiis panniculatis; capitulis $4-1 \mathrm{~mm}$. Ionge pedunculatis, $14-16$-floris, involucri squamis biseriatis, latiuscule v. oblongo-linearibus, apice obtusis v. rotundatis, superne plus minus rubro-violaceo-coloratis, dorso obsolete et parce pilosulis; corollis 4,5 $\mathrm{mm}$. longis, lobis tubo 4-plo brevioribus; orario $3,5 \mathrm{~mm}$. longo, brevissime piloso.

Terisim. fruticosum. Ram i vetustiores teretes multistriati glabrescentes, in sicco brunei, hornotini pube articulata brunescente dense vestiti. Folia opposita, petiolis supra sulcatis, superne limbo revoluto, ad basin sensin evanescente marginatis, subtus brevissime pubescentibus, nervo medio supra 
vix v. parum prominulo, lateralibus utroyne latere $4-5$, quormm 2 infimi sub angulo $70-80^{\circ}$ abeunt, sequens praccedenti saepius valde approximatus $3-4 \mathrm{~mm}$. supra basin sub $30-40^{\circ}$, caeteri minus ardui, tenuiorilus et lrevioribus intermixtis, omnibus supra non r. obsolete, subtus tenuiter anastomosantibus, crenis truncatis antice obsolete v. non ap,iculatis, hasi integra recurva, caeterum subplana, subtus minute et dense impresso-punctata, supra in siceo brunescentia vix v. non nitidula, obscure, subtus griseo-viridia. Inflorescentiac terminales, pube ramorum, $3-6 \mathrm{~cm}$. longae ct diametro; bracteae inferiores euphylloideae sensim rlecrescentes, superiores lanceolatolineares v. lineares, $5-2 \mathrm{~mm}$. longae; rami plus minus patentes, inferne nudi, superne glomerulos capitulorum gerentes. Capitula campanulata, postremo $8 \mathrm{~mm}$. longa, medio ca. $5 \mathrm{~mm}$. diametro; involucri squamae $14-17$, infimae lincari-subulatae $3-4 \mathrm{~mm}$. longae, intermediae oblongo- v. lanceolato-lincares ca. $1,5 \mathrm{~mm}$. latae, luce permeante obsolete $5-3$-nerves, intimae lineares, $5,5-6 \mathrm{~mm}$. longac, ca. $1 \mathrm{~mm}$. latae, inferne plus minus angustatae, ommes praeter infimas apice saepe crispulae v. recurvae, subcoriaceae, margine tenuiores, dorso glandulis minutis adspersae. Pappi setae $28-30$, inaequilongae, longiores $2,5 \mathrm{~mm}$. longae, aequicrassae, minute spinuligerae, albidae. Corollae tubus supra basin cylindraceus, ab $1 / 3$ alt. subsensim in limbum 3-plo crassiorem campanulato-cylindraceum dilatatus, glandulis perparcis adspersus; loli anguste triangulares, margine incrassati. Stamina tubo corollae in $1 / 3$ alt. affixa; antherae apice parum exsertae, $1,3 \mathrm{~mm}$. longae, basi obtusae, apiee in ligulam breviter ovatam, loculis 4-plo breviorem productae. Stylus in $3 / 5$ alt. bifidus, ramis superne aequilatis, apice obtusis. Achaenia (immatura) 5-costata, ad basin valde attenuata.

Hab. in Jamaica: Hart 11. 657, in Blue Mountains Peak, m. Febr. flor.: Harris s. n. (Herb. bot. Dep. Jam.).

()bs. Petiolis lamina decurrente revoluta subalatis facile recognoscendum. Affine E. tristi DC. et E. ageratifolio DC., quorum prius ramis hirsuto-velutinis, petiolis semipollicaribus, foliis late ovatis, $1 \frac{1}{2}$ poll. latis, supra scabridis, subtus velutino-hirsutis, eapitulis 25 -floris, involneri squamis linearibus acutis, non coloratis, posterius petiolis $1-2 \mathrm{~cm}$. longis, foliis basi subtruncatis vix in petiolum productis, duplo et ultra majoribus tenuioribus, capitulis ca. 10 -floris, involucri squamis multo angustioribus viridibus differunt.

V Eupatorium triradiatum Urb. (n. sp.) ramis hornotinis densissime villosulis; foliis $\tilde{5}-3 \mathrm{~mm}$. longe petiolatis, ovatis, basi rotundatis v. obsolete cordatis, apice obtusis v. obtusissimis, $5,5-3,5 \mathrm{~cm}$. longis, $4-2 \mathrm{~cm}$. latis, margine usque ad basin dentatis v. crenatis, supra basin $5-7$-nervibus, chartaceis, supra setulis brevibus scabridis, subtus brevissime et adpresse pubescentibus; inflorescentiis triradiatis, radiis apice glomerulum capitulorum $5-8$ gerentibus; capitulis $0,5-2 \mathrm{~mm}$. longe pedunculatis, $12-21$-floris, inrolucri squamis sub-2-seriatis, apice obtusis v. acutatis, linearibus; corollis $2-2,5 \mathrm{~mm}$. longis, lobis tubo toto 5-6-plo brevioribus; achaeniis $1,5-2 \mathrm{~mm}$. longis, 5 -costatis, parce et brevissime pilosis. 
Terisimiliter fruticosum. Rami teretes, vetustiores glabrescentes l.runcscentes leviter striati, hormotini puhe villosa articulata sordide flaro-albida v. pallide brunescente plus minus patente vestiti, internodiis $4--8 \mathrm{~cm}$. longis. Folia opposita, petiolis breviter villosulis, nervo medio supra parum v. vix prominulo, lateralibus infimis $2-4$ divaricatis margini basali subparallelis, sequentibus duobus $2-3 \mathrm{~mm}$. supra basin abeuntibus arcuatim longitrorsis, ca. usque in $2 / 3$ alt. folii productis, caeteris superioribus lateralibus parcis sub angulo $60-70^{\circ}$ abeuntibus, omnibus tenuiter reticulato-anastomosantibus, dentibus v. crenis saepe inaequalibus, pube supra plus minus patente, subtus sordide albida brevissima, subtus glandulis minutis luteis adspersa, minutissime pellucido-punctata. Inflorescentiae terminales breviter villosulac, $2-2,5 \mathrm{~cm}$. longae, $3-5 \mathrm{~cm}$. latae; bracteae infimae euphylloideae, sed diminutae, caeterae lanceolatae r. lineares $4-1,5 \mathrm{~mm}$. longae; rami 2 laterales $1-2 \mathrm{~cm}$. longi, intermedius brevior. Capitula $5 \mathrm{~mm}$. longa, medio $2.5 \mathrm{~mm}$. crassa; involucri squamae $10 \ldots 18$ lineares, interiores $3 \mathrm{~mm}$. longae, $0,5-0,8 \mathrm{~mm}$. latae, chartaceae, margine integrae, dorso quoad non obtectae villosulae et glandulis adspersae, pleraeque intermediae luce permeante 3-nerves, intimae et extimae 1 -nerres; receptaculum subplanum. Pappi setae $30-34$, subinaequilongae, longiores vix supra $2 \mathrm{~mm}$. longae, spinulosae, subaequicrassae. Corollae in $2 / 5$ alt. inferiore cylindraceae, dein subsubito usque duplo dilatatae, limbo cylindraceo-campanulato, dorso glandulis parcis obsitae; lobi triangulares recurri. Stamina corollae sub ejus medio affixa; antherae inclusae, $0,8 \mathrm{~mm}$. lougae, basi obtusae, apice in ligulas satis amplas semiorales loculis $3-4$-plo breviores excurrentes. Styli in $2 / 3$ alt. bicrures. Achaenia cinereo-nigrescentia, inferne attenuata.

Hab. in Haiti in montibus Cadets $1200 \mathrm{~m}$. alt., m. Januario fl. et fr.: Picarda n. 1097.

Duae formae in partibus regetativis plane congruentes sub eodem numero occurrunt:

$\alpha$. capitulis squamas involucri $14-18$ gerentibus, $17-21$-floris, achaeniis $2 \mathrm{~mm}$. longis, inferme magis attenuatis,

$\beta$. capitulis squamas involucri $10-12$ gerentibus, ca. 12-floris, achaeniis $1,5 \mathrm{~mm}$. longis.

Obs. Ex affinitate arcta E. villosi.

Eupatorium Poeppigii Spreng. Syst. III (1826) p. 415; DC. Prodr. I p. 183; A. Rich. in Sagra Cuba II p. 43.

Eupatorium cubense P. DC. Prodr. V (1836) p. 172: A. Rich. in Sagra Cuba II p. 41; Griseb.! Cat. p. 147; Saur. Cub. n. 1197 1. $7 \%$, non Pers.

Eupatorium deltoideum Poepp.! Exs. ap. Spreng. l.c., - non Jacq.

Hab. in Cuba e. gr. prope Habana, Matanzas, Guanabacoa: Morales n. 14, Poeppig;, Sagra, Torralbas n. 196, 204, 217, ? Tright n.2S0S (foliis paullo recedens).

Eupatorium maestrense Urb. (n.sp.) ramis hornotinis pilis articulatis bruneo-nigrescentibus brevibus dense pubescentibus; foliis $7-4 \mathrm{~mm}$ 
longe petiolatis, oratis, inferne paullo v. rix productis, basi ipsa obtusiusculis v. obtusis, superne sensim acuminatis, apice acutis, $6-3 \mathrm{~cm}$. longis, 3,5-1,6 cm. latis, margine depresse crenatis, foliis ad ramulos floriferos orato-oblongis, $3-1,5 \mathrm{~cm}$. longis, $1,5-1 \mathrm{~cm}$. latis, obsolete v. vix crenatis, omnibus chartaceis, nervis 2 lateralibus $5-7 \mathrm{~mm}$. supra basin abeuntibus sublongitrorsis, supra nitidis breviter et parce pilosis, subtus opacis, ad nervos brevissime pilosis, caeterum glandulis luteis creberrimis adspersis; inflorescentiis in ramis ramulisque terminalibus, solemniter panniculatis; capitulis $0,5-2 \mathrm{~mm}$. longe pedunculatis, $10-14$ floris; involucri squamis sub-2-seriatis; corollis $2,7 \mathrm{~mm}$. longis, lobis tubo 5 -plo brevioribus; achaeniis $1,7 \mathrm{~mm}$. longis, glabris.

Eupatorium cubense A. Rich. in Sagra Cub. XI (1850) p. 41 (p. p.), - non DC.

Frutex. Rami teretes multistriati obscure brunei, pube plus minus crispula patente longe persistente, internodiis $5-2.5 \mathrm{~cm}$. longis. Folia opposita, petiolis breriter et dense pubescentibus, supra sulcatis, nervis lateralibus brevibus supra basin et sub longitrorsis plerumque additis, superioribus sub angulo 50-600 abeuntibus, omnibus utrinque, supra minus et temuius, reticulato-anastomosantibus, crenis antice obtuse apiculatis, supra in siceo bruneo-nigrescentia, subtus olivacea, margine plana. Inflorescentiae $5-10 \mathrm{~cm}$. longae, $7-10 \mathrm{~cm}$. diametro, valde laxae; bracteae inferiores euphylloideae, sensim decrescentes, superiores et in ramis anguste lineares $2,5-1 \mathrm{~mm}$. longae; rami horizontales ad apicem ramulosi et capitula dense aggregata gerentes. Involucrum 2,5-3 min. longum; squamae $9-11$, minoribus $2-3$ extrinsecus sitis inclusis, anguste lanceolato-lineares v. sublineares, obtusiusculae r. obtusae, dorso vix, margine brevissime pilosae, glandulis flavis crebris adspersae, margine non membranaccae, nedio subcarinatae, ad apicem obscure purpurascentes. Pappi setae $27-31$ uniseriatae, ad apicem subincrassatae, manifeste spinuligerae, vix $2,5 \mathrm{~mm}$. longae. Corollae tubus inferne lineari-cylindraceus, in $2 / 5$ superiore subcampanulatus, glandulis adspersus; lobi triangulares. Stamina tubo corollae nedio inserta; antherae $0,9 \mathrm{~mm}$. longae, basi obtusae, apice in ligulam loculis 5 -plo breviorem semiovalem productae. Stylus a medio bifidus; rami superne sensim dilatati, apice subtruncati. Achaenia inferne sensim et ralde angustata, 5-costata, glandulis adspersa.

Hab. in Cuba prope Santiago in Sierra Maestra regione temperata, m. Jul. flor. et fr.: Linden n. 2004.

Obs. E. cubense DC. pube ramorum perbrevi sordide alba, foliis basi subtruncatis, e hasi ipsa trinerribus, subtus brerissime tomentosulis, inflorescentiis corymbosis etc. toto coelo diversum est.

Eupatorium semicrenatum Urb. (n. sp.) ramis hornotinis pilis brevissimis creberrimis sursum curvatis obtectis: folis omnibus alternis, $6-10 \mathrm{~mm}$. longe petiolatis, anguste triangularibus v. ovato-triangularibus, basi subtruncata vix v. levissime et latissime cordatis, fere a basi sensim angustatis, apice acutis, $5-8 \mathrm{~cm}$. longis, $2,5-4 \mathrm{~cm}$. latis, mar- 
gine infero grosse crenatis, supero integris v. subintegris, e basi trinervibus, membranaceis, supra pilis minutis subparcis scabriusculis, subtus minute, ad nervos manifestius pilosis, densissime subpellucido-punctatis, ramealibus $2-3 \mathrm{~mm}$. longe petiolatis orato-lanceolatis, $2.5-1,5 \mathrm{~cm}$. longis, $1,5-0.8 \mathrm{~cm}$. latis, basi paullo in petiolum productis. margine integris subintegrisve; inflorescentiis panniculatis; capitulis laxis $10-5 \mathrm{~mm}$. longe tenuiter pedunculatis, 16-17-floris; involucri squamis sub-2seriatis, linearibus acutis r. plerumque obtusiusculis, dorso minute pilosulis viridibus; corollis $3 \mathrm{~mm}$. longis, lobis tubo fere 6 -plo brerioribus; achaeniis vix $3 \mathrm{~mm}$. longis, parce et brevissime pilosis, $5-7$-costatis.

Verisimiliter fruticosum. Rami retustiores teretes multistriati postremo glabrescentes cinerascentes, pube articulata sordide albida, internodiis $2-3,5 \mathrm{~cm}$. longis. Folia petiolis leviter sulcatis, breviter pubescentibus, nervo medio supra prominulo, 2 lateralibus basalibus usque supra medium productis parmm curvatis, caeteris ntroque latere $3--4$ snb angulo $60-70^{\circ}$ abeuntibus, omnibus supra tenuissimis, subtns tenuibus et laxe reticulato-anastomosantibus, margine plana, pube ope lentis tantum conspicua, subtus densissime glandulis impressis punctata, viridia, subtus panllo pallicliora. Inflorescentiae terminales et laterales, pule ramorum, ca. $7 \mathrm{~cm}$. longae, $5-7 \mathrm{~cm}$. latae; bracteae inferiores euphyllis ramulorum similes, sensim decrescentes, superiores lanceolato-lineares $\mathrm{r}$. lineares, axibus sursum adnatae $4-2 \mathrm{~mm}$. longae; rami omnes alterni patentes $\mathrm{r}$. subrecurvi, superiores monocephali. Capitula campanulata, postremo $6 \mathrm{~mm}$. longa, medio vix $4 \mathrm{~mm}$. crassa; inrolucri squamae $13-15$, exteriores lanceolato-lineares, $2,5-3,5 \mathrm{~mm}$. longae, 3 -nerres, intimae lineares $4 \mathrm{~mm}$. longae 2-1-nerves, omnes superne angustatae, dor'so minute pilosulae et glandulis adspersae chartaceae. Pappi setae $37-40$ uniseriatae, subaequilongae vix $3 \mathrm{~mm}$. longae, minute spinuligerae sordide albidae, ad apicem parum v. vix incrassatae. Corollae fere a basi sensin nsque dimidio ampliatae, glandulis parcis obsitae; lobi triangulares. Stamina corollae in $2 / 5$ alt. affixa; antherae vix $1 \mathrm{~mm}$. longae, basi subtruncatae, apice in ligulas semiorbiculares loculis 7-9-plo breviores productae. Stylus in $1 / 2$ superiore bifidus, ramis superne sensim incrassatis, apice obtusissimis numc obsolete emarginatis. Achaenia inferne paullo attenuata.

Hab. in Haiti: Poiteau.

Obs. Foliis omnibus alternis facile recognoscendum.

Eupatorium Gundlachii Urb. (n. sp.) ramis hornotinis pilis brevibus densissimis patentibus crassiusculis rigidis scabridis; foliis $3-4 \mathrm{~mm}$. longe petiolatis, ovatis r. anguste ovatis, basi rotundatis r. subtruncatis, superne subsenşim angustatis, apice obtusiusculis r. obtusis, $1,5-3 \mathrm{~cm}$. longis, $1-1.5 \mathrm{~cm}$. latis, margine basi excepta crenatis, e basi $3-\mathrm{v}$. sub5 -nervibus, subtus dense et eleratim reticulatis areolis concaris, subcoriaceis non impresso-punctatis, supra setulis brevissimis scabridis, subtus pube densa et brevissima cinereis; inflorescentiis parvis subcorymbosis densis; capitulis 5-1 mm. longe pedunculatis, ca. 17-floris; 
involucri squamis sub-2-seriatis, exterioribus obtusiusculis brevissime pilosis, interioribus longioribus acuminatis, omnibus plus minus linearibus; corollis $3,5 \mathrm{~mm}$. longis, lobis tubo fere 6 -plo brevioribus; achaeniis 3,3 mm. longis, brevissime patenti-pilosis, $7-8$-costatis.

Eupatorium cynanchifolium Griseb.! Pl. Wr. II (1862) p. 512 et Cat. p. 117 (excl. syn.); Saux. (ub. n. 1198 p. 77 (1) p.), - non P. DC.

Terisimiliter fruticosum. Rami teretes, plus minus manifeste striati, pallide brunescentes, pilis paucicellularibus, inferne crassiusculis, superne acuminatis, internodiis $2-2,5 \mathrm{~cm}$. longis. Folia opposita, petiolis supra subplanis, nervo medio supra tenuiter promincnte, lateralibus 2 basalibus longitrorsis fere usque ad apicem productis, caeteris $1-3$ parum manifestis sub angulo $45-50^{\circ}$ abeuntibus, omnibus supra prominulis et plus minus obsolete et subimpresse reticulato-anastomosantibus, reticulo subtus solemniter prominente flaro-albescente, glandnlis luteis minutis in reticulo obviis, sed parum conspicuis. Inflorescentiae terminales densae, pube ramorum, ca. $2 \mathrm{~cm}$. longae, $3 \mathrm{~cm}$. diametro; bracteae inferiores euphylloideae, superiores anguste lineares, 2,5-1 mm. longae; rami patentes. Capitula campanulata, $7 \mathrm{~mm}$. longa, ca. $4 \mathrm{~mm}$. crassa; involucri squamae ca. 12, exteriores lanceolato-lineares $1,5-3 \mathrm{~mm}$. longae, intcriores sublineares, superne acutatae r. acuminatae, inferne plus minus angustatae, omnes specie 3-1-nerves, sed luce permeantc plerumque 5-nerves, chartaceae virides brevissime pilosae. Pappi setae $22-24$ uniseriatae, inaequilongae, longiores 2,3 $\mathrm{mm}$. longae, manifestc spinulosae, aequicrassae pallide stramineae. Corollae albae, fere a basi sensim usque duplo ampliatae, glandulis parcis obsitae; lobi triangulares. Stamina corollae in $2 / 5$ ejus alt. inserta; antherae inclusae, vix supra $1 \mathrm{~mm}$. Iongae, basi obtusae, apice in ligulas triangulari-ovatas loculis 5-plo breviores productae. Discus brevis annulatus, $0,2 \mathrm{~mm}$. altus. Stylus in $1 / 2$ superiore bifidus, lobis superne sensim incrassatis, apice obtusissimis. Achaenia inferne sensim attenuata, brunescentia.

Hab. in Cuba in praeruptis: Wright n. 1632.

Obs. E. cymanchifolium DC.! toto coelo differt ramis apice pulverulento-relutinis, foliis subcordatis, subintegris, supra tenuissime pulverulentopilosis, capitulis $10-12$-floris, corollis $2 \mathrm{~mm}$. longis, achaeniis vix $2 \mathrm{~mm}$. longis ct revera arctissime ad E. cubense DC. accedit.

Eupatorium polystictum Urb. (n. sp.) ramis hornotinis pilis brevibus densissimis plus minus sursum curvatis crassiusculis bruneis scabridis; foliis $4 \mathrm{~mm}$. longe petiolatis ovatis, anguste ovatis v. ellipticis, basi rotundatis, apice obtusiusculis v. obtusis, $2-3 \mathrm{~cm}$. longis, $1-1,5 \mathrm{~cm}$. latis, margine remote dentatis $v$. superioribus subintegris, paullo supra basin 3 -nervibus, areolis reticuli subtus planis, rigide coriaceis, utrinque glabris et tenuiter impresso-punctatis; inflorescentiis panniculatis laxiusculis; capitulis $6-3 \mathrm{~mm}$. longe pedunculatis, $10-11$-floris; involucri squamis sub-2-seriatis, linearibus acutis, dorso brevissime pilosis; corollis vix supra $3 \mathrm{~mm}$. Longis, lobis tubo $4-5$-plo brevioribus; ovario subglabro, sed glandulis crassiusculis adsperso. 
Eupatorimm cynanchifolium iar. Griseb.! Cat. (1866) 1\%. 147.

Empatorim cynanchifolimm Same. (ub. n. 1198 p. Ti (p. p.), -

non $D C$.

Terisimiliter fruticosum. Rami teretes, sub pube obsolete r. vix striati, brumescentes, pilis pancicellularibus inferme crassis, superne acuminatis, intcrnodiis 1,5-2 cm. longis. Folia opposita, petiolis supra sulcatis, nervo malio supra prominente, lateralibus hasalibus 4 v. sub-6, quorum 2 interiores crassiores et longiores usque in $2 / 3$ alt. producti, caeteris utroque latere $1-3$ sub angulo ca. $60^{\circ}$ abeuntibus, omnilus supra tenuiter promimulis, suhtus hene prominentibus et reticulato-anastomosantibus, dentibus apice subtus glandulosis, supra nitidnla pallide olivacea, subtus olivaceobrunescentia, utrinque subtus densissime glanduloso-impresso-punctata ct praesertim subtus glandulis lnteis minutis adspersa. Inflorescentiae terminales, pritie ramorum, ca. $5 \mathrm{~cm}$. longae, $4 \mathrm{~cm}$. diametro; hracteae inferiores euphylloideae, sed subito pluries minores, superne sensim decrescenter, superiores lanceolato-lineares r. lineari subulatae, $3-1,5 \mathrm{~mm}$. longae; rami patentes. Capitula anguste subcampanulata, fere $7 \mathrm{~mm}$. longa, $3,5 \mathrm{~mm}$. crassa; involucri squamae ca. 12, extcriores lanceolatac v. lanceolato-lineares $1,5-3 \mathrm{~mm}$. longae, interiores lineares, apice acutatae, rarins obtusiusculae, inferne saepius jaullo angustatae, 4 nim. longae, 1 -nerves v. luce permeante nume 3-nerves, chartaceo-coriaceae, medio lruneae, margine pallidae, dorso glandulis crebris crassiusculis adspersae. Pappi setae $34-41$ uniscriatae, subaequilongae, $3 \mathrm{~mm}$. longae, acquicrassae, manifeste spinulosae. Corollae fere a basi sensim sed parum (usque dimidio) ampliatae, glandulis subparcis adspersae; lobi triangulares $\mathrm{v}$. ovato-triangulares. Stamina corollae in 1/3 alt. affixa; antherae inelusae $1,3 \mathrm{~mm}$. longae, basi obtusae, apice in ligulam breviter oratan obtusam, loculis fere 5-plo breviorem productae. Stylus a medio bificlus, lobis superne sensim dilatatis, apice obtusis. Orarium sul, anthesi $2 \mathrm{~mm}$. longum.

Hab. in Cuba: Wright n. 2809.

Obs. A praecedentc optime dirersum.

$\checkmark$ Eupatorium illitum Urb. (n. sp.) glabrum, ramis hornotinis succo exsudato nitido bruneo illitis: foliis $10-7 \mathrm{~mm}$. longe petiolatis, ovatoellipticis v. ellipticis, basi obtusis, superne paullo magis angustatis, apice obtusiusculis, $6-9 \mathrm{~cm}$. Longis, $2,5-3 \mathrm{~cm}$. latis, margine (basi excepta) serratis, exacte peminerribus, coriaceis: inflorescentiis corymbosis polycephalis; capitulis $7-12 \mathrm{~mm}$. longe pedunculatis, $14-16$-floris; involucri squamis subbiseriatis apice obtusis v. subtruncatis; corollis $4 \mathrm{~mm}$. longis, lobis tubo toto 5 -plo brevioribus; achaeniis 2,5 1mm. longis, glandulis arlspersis, caeterum glabris.

Frutcr $2-3 \mathrm{~m}$. altus. Rami teretes plicato-striati, in siceo nigrescentes, internodiis $1-2 \mathrm{~cm}$. longis. Folia opposita, petiolis supra sulcatis, nervo merlio supra solemniter impresso, lateralibus utroque laterc $S-9$ sub angulo $50-60^{\circ}$ abeuntibus subarcuatis, supra promimulis r. in sulco leri prominulis, subtus hene prominentibus, utrinque dense et anguste reticulatoanastomosantibus, dentibus parvis r. mediocribus saepius inacqualibus, supra 
illita nigreseentia, subtus brunea, utrinque punetulata nitida. Inflorescentiac terminales, $3-5 \mathrm{~cm}$. longae, $4-6 \mathrm{~cm}$. latae; bracteae inferiores emplyylloideae, obovato-ellipticae v. ellipticae, petiolatae, $0,5-1 \mathrm{~cm}$. longae, integrae, cacterae lanceolato-lineares v. lineares; rami succo exsiccato illiti niticli; perlunculi speciales nudi v. bracteolis $1-3$ obsessi, ca. $0,5 \mathrm{~mm}$. crassi. Capitula $6 \mathrm{~mm}$. longa; involueri squamae $12-14$, exteriores $1-2,5 \mathrm{~mm}$. longae, lineares superne paullo angustatae, apice ol,tusae, interiores $4 \mathrm{~mm}$. longae, $0,7-1 \mathrm{~mm}$. latae apice obtusissimae r. subtruncatae, margine brevissime plus minus fimbriato-denticellatae, $3-1$-nerves, dorso glandulis minutis adspersae. Receptaculum parvum glabrum. Pappi setae $23-26$, uniseriatae, subinaequilongae, usque $3 \mathrm{~mm}$. longae, spinuligerae. Corollae in $1 / 3$ infer. anguste cylindraceac, dein sensim usque duplo ampliatae, inferne glandulis parcis obsitae; lohi ovati v. triangulariovati. Stamin a corollae in $2 / \mathrm{s}$ alt. inserta; antherae inclusae, 1,3 mm. longae, basi obtusae, apice in ligulas ovatas obtusas loculis 6 -plo breviores excurrentes. Styli in $3 / 7-1 / 2$ superiore bipartiti; lobi subclarato-lineares obtusi. Achaenia 5 -costata nigrescentia.

Hab. in IIaiti in montibus Furcy ad Tête bois de pin, $1800 \mathrm{~m}$. alt., m. Nor. flor. et fruct.: Picarda n. 1495.

Eupatorium dictyoneurum Urb. (n.sp.) glabrum, foliis $10-6 \mathrm{~mm}$. longe petiolatis, oblongo-lanceolatis usque lanceolato-linearibus, basi obtusis v. rotundatis, superne sensim angustatis et longe acuminatis, $9-6 \mathrm{~cm}$. longis, $2,5-1 \mathrm{~cm}$. latis, margine remotiuscule v. remote denticulatis v. dentatis, exacte penuinervibus, utrinque densissime reticulatis, subcoriaceis; inflorescentiis corymbosis, densissime polyceplatis; capitulis $1-3 \mathrm{~mm}$. longe pedunculatis, 4-5-floris; involucri squamis 1 -seriatis linearibus 5-6, quarum unica exterior minor est, apice obtusis v. rotundatis; pappo inferne plus minus violascente; corollis $1-5$ num. longis, lobis tubo toto 4 -plo brevioribus; acliaeniis vix $2,5 \mathrm{~mm}$. longis, elevatim 5-costatis, parce et brevissime pilosis.

Verisimiliter fruticosum. Rami teretes striati bruneseentes, line illine resina r. succo exsiecato illiti, internodiis $1-3 \mathrm{~cm}$. longis. Folia opposita, petiolis subteretibus supra sulcatis, nervo medio supra sulcato-impresso, lateralibus utroque latere $9-12$, sub angulo $40-60^{\circ}$ abeuntibus, inferiolibus magis, superioribus minus arduis, supra tenuiter, subtus crassiuseule froninentibus, utrinque densissime reticulato-anastomosantibus, dentibus patulis, subtus pallidiora glandulis minutissimis luteis non impressis adspersa, utrinque glabra. Inflorescentiae terminales, $3-5 \mathrm{~cm}$. longae, $5-8 \mathrm{~cm}$. diametro; bracteae infimae euphylloideae, caeterae lineares $10-1 \mathrm{nun}$. longae, parce et brevissime pilosulae; rami glabri v. superne parcissime et brevissime pilosuli. Capitula $6,5-7 \mathrm{~mm}$. longa, 1,5-2 mm. crassa, cylindracea; involncri squamae $3-4 \mathrm{~mm}$. longae, $0,6-0,8 \mathrm{~mm}$. latae, chartaceae, antice obsolete denticellatae, dorso glabrae v. parcissime pilosae, sed glandulis flavis adspersae, nervis $3-5$ extrinsecus parum v. non conspicuis, interdum violascentes; receptaculum planum. Pappi setae 25-28, inaequilongae, longiores $3 \mathrm{~mm}$. longae, manifeste patenti-spinulosae, subaequicrassae, ad apicem paullo attenuatae. Corollae in $1 / 3$ inferiore anguste cylindraceae, dein sulj- 
sensim triplo ampliatae, limbo eampanulato-cylindraceo, dorso glandulis flavis adspersae; lobi anguste ovato-triangulares v. ovato-lanceolati. Stamina corollae in $2 / 5-3 / 7$ alt. affixa; antherac inclusae, ca. $1,3 \mathrm{~mm}$. longae, basi obtusae, apice in ligulas ovatas loculis $4-5$-plo breviores excurrentes. Styli fere usque ad medium bierures; lobi superne paullo incrassati obtusi. Achaenia bruneo-nigresecntia, inferne valde attemuata.

Hab. in Haiti in montibus Le grand fond dictis prope Port-auPrince, usque $1000 \mathrm{~m}$. alt., m. Dec. fl. et fr.: Jaeger 11. 46, in Morne de l'Hôpital, $800 \mathrm{~m}$. alt., m. Januar. fl.: Picarda n. 1207.

Obs. Inrolueri squamis $5-6$ et floribus $4-5$ in eapitulo obviis ad Milaniam accedit.

Erigeron domingensis Urb. (n. sp.) caule $5-15 \mathrm{~cm}$. alto, pilis parcis v. crebrioribus patentibus obsito, simplice r. ramum solitarium emittente; foliis basalibus $5-20 \mathrm{~mm}$. longe petiolatis, obovato-oblongis $r$. lanceolatis, inferne longe in petiolum angustatis, apice rotundatis $r$. obtusis nunc brerissime acuminatis $\mathrm{r}$. apiculatis, $5-10 \mathrm{~mm}$. longis, $2-3,5 \mathrm{~mm}$. latis, margine integris v. dentibus $2-4$ munitis, glabris v. pilosis, caulinis $4-8$, brevius petiolatis et angustioribus, lanceolatis v. lineari-lanceolatis, $1-2$-dentatis; capitulis in apice caulis ramique solitariis, involucro lemisplaerico, 2 -seriato, 4-5 nm. longo, squamis dorso parce et brevissime pilosis, superne plerumque purpurascentibus, exterioribus obtusiusculis, interioribus acutatis; floribus radialibus fem. ex siceo violaceis $30-60$, disci herm. $20-32$.

Planta verisimiliter annua, radices numerosas crasse filiformes emittens. Caulis erectus r. ascendenti-crectus, inferne $0,3-0,8 \mathrm{~mm}$. crassus, obtusangulus, pilis articulatis. Folia utrinque pilosa r. glabra, caulina superne decrescentia et laxiora, superiora linearia acuta integra. Capitula $7 \mathrm{~mm}$. longa, $6-7 \mathrm{~mm}$. diametro; involueri squamae exteriores $2-3 \mathrm{~mm}$. longae, interiores dimidio v. duplo longiores $0,7-0,8 \mathrm{~mm}$. latae, herluaceae, margine membranaceo pallidiores. Pappi setae aequales, sub anthesi $2,5 \mathrm{~mm}$. longae, pallide rufescentes, flor. fem. $23-25$, flor. herm. 25-28. Corollae radii femineae 2 -seriatac, $5 \mathrm{~mm}$. longae, omnes bene ligulatae; tubus superne pilis parcis pluricellularibus suberectis obsitus; limbus tubo $2 \frac{1}{2}$-plo longior, 4 -nervis, apice 3 -dentatus, $0,8 \mathrm{~mm}$. latus. Corollae disci hermaphroditae $3 \mathrm{~mm}$. longae; tubus in 1/3 alt. linearis, tcin sensim ampliatus, ad commissuras punctis v. lineolis aurantiacis notatus; lobi 5 anguste ovati, tubo 4-plo et ultra breviores. Antlerae $1 \mathrm{~mm}$. longae, basi obtusissimae, apice in ligulas angustas loculis fere 5 -plo breriores productae. Achaenia (immatura) pilis brevihus suberectis obsita, oblonga, 1,5 mm. longa.

Hab. in.Sto. Domingo in Valle Nuero ad ripam rivuli in graminosis lunidis et inter saxa, m. Majo florif.: Eggers 11. 2217, 2271.

Ous. E sectione Euerigeron, labitu E. stenophylli Eaton utahensis.

Erigeron polycladus Urb. (n. sp.) perennis, stolones ramosos emittens et caespitem formans; caulibus florigeris erectis $v$. ascendentibus, $4-8 \mathrm{~cm}$. longis, glaberrimis simplicibus; foliis rosularum basalium 
$5-7 \mathrm{~mm}$. longe petiolatis, obovatis r. oblongo-spathulatis, inferne sensim et longe in petiolum angustatis eumque usque ad basin late marginantibus, apice obtusinsculis v. obtusis, nune brevissime apiculatis, 7 - $12 \mathrm{~mm}$. longis, $3-4 \mathrm{~mm}$. latis, caulinis brevius petiolatis v. sessilibus, lanccolatis usque lincaribus; capitulis in apice caulium solitariis, involucro hemisphaerico sub-3-seriato, 4-4,5 mm. longo, squamis glabris, obscure viridibus, plus minus albido-marginatis, linearibus ad apicem angustatis, plerisque obtusiusculis v. obtusis; floribus albis (ex Duss), radialibus fem. ca. 60 , disci hern. ca. 20 ; achacniis $1,5 \mathrm{~mm}$. longis, margine parcissime et brevissime pilosis.

Erigeron jamaicensis Duss! Flor. des Ant. franc. (1897) p. 359, - non Limn.

Petite margarite Martin. ex Duss.

Stolones $0,7-1,5 \mathrm{~mm}$. crassi. Caules florigeri foliis subdecurrentibus angulati. Folia rosulae nervo medio supra plano, lateralibus 2 e basi prorleuntibus longitrorsis margini parallelis, caeteris obsoletis, marginc plana, in siceo viridia, caulina superne decrescentia, summa linearia acuta. Capitnla $5 \mathrm{~mm}$. longa; involucri squamae exteriores $2-2,5 \mathrm{~mm}$. longae, vix ₹. anguste albido-marginatae, interiores $4 \mathrm{~mm}$. longac, ca. $0,6 \mathrm{~mm}$. latae, 1 -nerves, nervis interrupte flavido-incrassatis. Pa pi setae acquales $2,5 \mathrm{~mm}$. longae, pallide rufescentes, flor. fem. $21-23$, fl. herm. 23-29. Corollae radii femineae 2 -seriatae, fere $3 \mathrm{~mm}$. longae, pilis parcissimis erectis obsitae; limbus tubo aequilongus v. parum longior, sub-3-nervis sublinearis obsolete bicrenatus $\mathrm{v}$. integer, $0,25 \mathrm{~mm}$. latus. Corollae disci $2,5 \mathrm{~mm}$. longac; tubus in parte $1 / 3$ inferiore anguste cylindraccus, dein usque dimidio ampliatus, ad commissuras striis 5 luteis notatus; lobi 5 triangulari-lanceolati $\mathrm{r}$. anguste ovati, tubo 6-plo breviores. Stamina corollae in $1 / 3$ alt. affixa; antherae $0,7 \mathrm{~mm}$. longae, basi obtusae, apice in ligulas lineari-subulatas, loculis 3 -plo breviores excurrentes. Stylus in $1 / 5$ superiorc bifidus, ramis parum exsertis linearibus, ad apicem attenuatis. Achaenia linearia, ad basin attenuata, pallidc brunea, 2-3-costata.

Hab. in Martinique nonnisi in litoralibus.autour des magasins du Macouba, m. Sept. flor.: Duss n. 969, 4672.

Obs. E. jamaicensis L. est planta annua caulc usque pedali, foliis plnries majoribus repando-dentatis pilosulis.

Erigeron arameosus Urb. (n. sp.) caulibus e caudice pluribus $8-15 \mathrm{~cm}$. altis, arachnoideo-floccosis; foliis sessilibus v. si vis late et usque $5 \mathrm{~mm}$. longe petiolatis, ambitu oblongis v. ellipticis, $0,8-1,5 \mathrm{~cm}$. longis, $0,2-0,5 \mathrm{~cm}$. latis, profunde pinnatipartitis, lobis utroque latere $3-5$, lanceolatis v. lineari-lanceolatis, obtusis, floceoso-pubescentibus; eapitulis ad apicem caulium spicatim dispositis, involucro hemisphaerico, subbiseriato, 4-4,5 mm. longo, scuamis dorso crispulc pubescentibus, pallide viridibus, apice acutatis; floribus fem. 45-58, herm. 5-6.

Planta annua r. perennans? Radix palaris $2-2,5 \mathrm{~cm}$. longa, ramos plures usque $15 \mathrm{~cm}$. longos subhorizontales emittens. Caules e basi arcuata 
lignescente erecti, plerumque simplices, satis dense foliosi, inferne $1-1,5 \mathrm{~mm}$. crassi, pube e pilis inferne crassioribus articulatis, superne valde attenuatis sordide albis composita. Folia petiolis lamina decurrente alatis basi paullo dilatatis, parte media integra $0,6-1,2 \mathrm{~mm}$. lata, lobis $1,5-2,5 \mathrm{~mm}$. longis, $0,6-1 \mathrm{~mm}$. latis crassiusculis, margine recurvatis fragilibus. Capitula fere $5 \mathrm{~mm}$. longa et diametro; involucri squamae exteriores ca. $2 \mathrm{~mm}$. longae, interiores dimidio r. dullo longiores pallide marginatae, margine superiore lacero-pilosae, 0,7--1 mm. latae. Pappi setae aequales, postremo fere $3 \mathrm{~mm}$. longae, sordide albidae, flor. fem. $16-19$, flor. herm. 24-25. Corollae fem. pluriseriatae, subaequales filiformes, 2,5 $\mathrm{mm}$. longae, pappo aequilongae, $0,1 \mathrm{~mm}$. crassae, subglabrae $r$. superne parcissime et brevissime pilosae; limbus tubo $6-8$-plo brevior, at vix v. dimidio latior, apice raro integer, plerumque inaequaliter 2 -dentatus, stigmatibus subaequilongus $\mathrm{v}$. paullo longior, enervis. Corollae herm. $3 \mathrm{~mm}$. longae; tubus crassiuscule filiformis, $0,3 \mathrm{~mm}$. crassus, superne parcissime pilosus, subito in limbum diplo breriorem et duplo crassiorem campanulatum dilatatus; lobi lanceolati, limbo integro aequilongi. Stamina corollae mediae (sub limbo) inserta; antherae totae $0,7 \mathrm{~mm}$. longae, basi obtusissimae, apice in ligulas lineares loculis dimidio hreviores profluctae. Stigmata linearia acutata. Achaenia elliptico-oblonga, applanata, pilis parcis brevissimis erectis obsita, vix $1,5 \mathrm{~mm}$. longa, $0,6 \mathrm{~mm}$. lata.

Hab. in Sto. Domingo in Valle nuevo inter gramina, $2270 \mathrm{~m}$. alt., m. Majo tlor. et fruct.: Eggers n. 2200.

Obs. E sectione Cacnotus, nulli alii speciei antillanae affinis; accedit ad andinas e. gr. E. niveus Sch. Bip.

Gundlachia domingensis A. Gray. Capitulum 5-8-florum, floribus radii femineis et disci hermaplroditis plerumque numero aequalibus $3+3$ v. $4+4$, interdum 4 (v. 3 ) femineis et 2 v. 3 masculis. Limbus fl. herm. in $1 / 5-1 / 3$ alt. connatus, raro usque ad basin 5-partitus, tubo subaequilongus v. usque dimidio longior. Styli rami fl. herm. intus plani, margine stigmatoso obsoleto v. manifesto, appendice anguste triangulari v. lineari-lanceolata dimidio v. duplo breviore superati. - Quoad liabitum, folia, ramificationem, inflorescentiam valde variabilis:

Var. $\alpha$. genuina Urb. ramis apice ramulos plures stricte erectos iterum ramulosos corymbose dispositos emittentibus, capitulis ad ramulos superne subspicatis, breviter $\mathrm{r}$. brevissime pedunculatis; foliis linearibus utrinque subaequaliter angustatis, caulinis $3-4 \mathrm{~mm}$. latis.

Solidago domingensis Spreng.! Syst. III (1826) p. 539; P.DC. Prodr: V p. $3 \dot{4}$.

Hab. in Sto. Domingo: Bertero.

$\checkmark \quad$ Var. $\beta$. Lintleniana $U_{r} b$. ramis apice inflorescentiam plus minus panniculatam gerentibus; foliis linearibus v. lanceolato-linearibus, utrinque subaequaliter v. inferne paullo magis angustatis, $3-7 \mathrm{~mm}$. latis. 
Solidngo Lindeniana 1. Riech. in Sagra Conba X7 (7850) p. 40.

Bacheris plarmicifolia Griseb.! I'. Wr. (1862) p.513, - non DC:

Solidago domingensis Griseb.! Cal. (1866) p. 150; Sauv. Cub. n. 1233 p. 79.

Gmullachia domingensis A. Gray Bol. Conlr. in Proc. Amer. Acad. IVI (18S0) 1. 100; O. Iloffm. in Engl.-Irantl Nat. I'fl.-fam. IV. 5 (1890) p. 166.

Hab. in Cuba: Wright n. 1314, prope Santiago: Linden n. 2142 (ex A. Rich.); Sto. Domingo: Mayerhoff n. 246.

Var. $\gamma$. corymbosa Urb. inflorescentiis in apice ramorum corymbosis; foliis lincari-lanceolatis usque oblongo-lanceolatis, apice obtusis et brevissime apiculatis $v$. plerumque rotundatis, nunc emarginatis, inferno multo magis v. longe angustatis, $0,7-2 \mathrm{~cm}$. latis.

Baccharis dioica Griseb.! Kar. (1857) p. 85 et Flor. p. 366 (p. p., nompe qnoard plantas foliis oblanceolatis); Duss! Flor. Ant. frane. p.361, - non Vahl.

Solidago domingensis Hitche. Bah. (1893) p. 97.

Sereno Port. ex Gundl.; Bois Guillaume Désir. ex Duss.

Hab. in ins. Baham. Cat Island ex Hitche, Fortune Island m. Febr. fl.: Eggers n. 3825 (frutex metralis viscosus), Long Cay: Brace n. 456 (lıb. Kew. ox Rolfe in lit.), Inagua ex Hitchc., Turks Island Grand Turk, m. Jul. flor., satis frequens: Eggers n. 2859; Sto. Domingo: Rob. Schomburgk n. 167\%, Maycrhoff; Portorico prope Canuy in litoralibus: Gundlach n. 1468, prope Quebradillas in litoralibus: Gundlach n. 1428; Barbuda: Nicholls; Désirade: Desbonnes, ibidem dans la ravine Cybèle, ubi frequens, alt. 25 - 35 m.: Duss n. 2810 (frutex $1-8$-pedalis v. usque 4 -metralis, inferne rectus, dein volubilis).

Obs. I. Baccharis dioica Vahl! Symb. III p. 98 t. 74 (B. Vahliii DC.), quacum cl. Grisebacu nostrae plantae varietatem $\gamma$ ' infeliciter conjunxit, eadem paene distributione geographica gaudet: Bahan. New Providence in Foxhill: Eggers 11. 4250, Northrop 11. 68 (hb. Kew. ex Rolfe in lit.), Eleuthera ex Hitchc., Hog Island: Eggers 11. 4063, Inagua ex Hitchc, Jamaica: hb. Kew collectore ignoto (ex Rolfe in lit.), Haiti: Poiteau, Sto. Domingo: Bertero n. 666, Mayerhoff, prope Puerto-Plata in rupibus litoralibus: Eggers n. 2723, St. Croix: Real, Richard, J.J.Ricksecker n.372, II ontserrat ex hb. Vahl in hb. Willd. n. 15560.

Obs. II. Specimina a el. PUimie et MacNab in Jamaica collecta et a cl. Griseb. sub B. dioica laudata in herb. Kewensi desunt, ut nesciam, an ad Gundlachiam, anne ad Baccharis pertineant.

\section{Baccharis cotinifolia L'rb.}

Eupatorinm cotinifolimm Willd.! Phylogr. (1794) p. 11 lab. 7 fig. 1! et Spec. III p. 1769; Spreng. Syst. III p. 416; DC. Prodr. V p. 182 . 
Baccharis speciosa P. DC. Prodr. V (1836) p. 399; Griseb.! Kar. p. 85 et Flor. p. 366; Kew Bull.! n. 81 p. 259; Duss! Flor. Ant. frane. p. 360 .

Eupatorium Braunii Polakousliy! in Limnaea YLI (1877) p. 576; Hemsl. Biol. II p. 93.

Bois Guillaume Mart. cx Duss.

Frutex $1-2,3 \mathrm{~m}$. (v. in Costarica usque $5 \mathrm{~m}$.) altus, ramis fastigiatis numerosis rigidis, ornamenti causa colendus.

Hab. in Guadeloupe in regione superiore 600-900 m. alt. parum frequens e. gri. in Sarane à Mulets, Savane aux Ananas, Grande Découverte à Matouba locis apricis, m. Aug. usque Jan. fl.: Duss n. 2512, 2952; Dominica: Duss, in montibus ad Lake Roseau ca. 1000 m. alt. rara: Eggers hb. pr. n. 76, ed. 'Toepff. n. 611; Martinique in Pitons de l'Alma, route de I'Alma aux Deux-Choux, Hauteur du Fond Layette (Case Pilote) $400 \mathrm{~m}$. alt.: Duss n. 204, 935, 4073, Isert in hb. Willd. n. 15147 , Sieber n. 197; Sta. Tucia: Duss; St. Vincent in cacumine Soufrière satis frequens, m. Tov. flor.: Eggers n. 6913, Smith n. 1226; - praeterea in Costarica prope Angostura: Polakowsky n. 508.

Pluchea Eagersii Urb. (n. sp.) caule pilis brevibus crispulis adsperso; foliis arete sessilibus, ovato-oblongis r. oblongo-lanceolatis, basi manifeste cordata subsemiamplexicaulibus, inferne aequilatis v. supra basin latissimis, apice obtusis r. acutatis, $6-4 \mathrm{~cm}$. longis, $2,8-1,5 \mathrm{~cm}$. latis, margine glanduloso-crenulatis, utrinque brevissime pilosis; inflorescentia terminali subcorymbosa, 10 - 20-cepluala, $5-8$ cm. diametro, capitulis $7-8 \mathrm{~mm}$. longis, involucri squamis non coloratis, interioribus breviter setaceo-acuminatis; floribus ex sicco sordide flaridis; orario breviter piloso.

Frutcx crectus strictus non ramosus (ex EGG.). Caulis teres elevatim multistriatus, purpureo-brunescens, pube articulata brunca. Folia nerro medio supra tenuiter prominente, lateralibus utroque laterc $7-10$, infimis 3 valde approximatis et subliorizontalibus, caeteris sub angulo $50-60^{\circ}$ abeuntibus, supra tenuius, subtus magis prominentibus et reticulato-anastomosantibus, chartacea rigidiuscula, pilis brevissinis, ad costam subtus paullo longioribus, bruneis crassiusculis, glandulis pallide flavis intermixtis. Inflorescentia chracteata v. ramis infimis apice euphylla minora gerentibus. Capitula semioralia; involucri squamae imbricatac ca. 3-seriatae, infimac ovato-acuminatae v. ovato-lanceolatae, superiores lanceolato-lineares v. lineares, usque 5,5 mm. longae, omues extrinsecus brevissime pubescentes, uninerves, dorso medio 'brunescentes, margine flavidae; receptaculum convexiusculum. Flores feminci in ambitu numerosi pluriseriati; pappi setae $16-19$ aequicrassae spinulosae sordide albido-flavae. Corollae filiformes $4 \mathrm{~mm}$. longae, apice pauciglanduloso brevissime trilobae, lobis lanceolatis obtusiusculis. Flores hermaplroditi in centro ca. 19; pappi setae 28-30. Corollae $5,5 \mathrm{~mm}$. longae, infcrne lineares, a medio sensim usque duplo ampliatae; 
lobi lineari-lanceolati, dorso glandulifcri, limbo dimidio v. duplo breviores. Stamina $u$ bo in $1 / 3$ alt. affixa; antherae vix supra $2 \mathrm{~mm}$. longac, apice in ligulas laneeolatas loculis $3-p l o$ breviores excurrentes. Stylus breviter bilobus.

Hab. in Sto. Domingo in Savana de Cupey prope Loma Isabel de la torre $360 \mathrm{~m}$. alt., in graminosis, m. Jun. flor.: Eggers n. 2681.

Obs. Pl. bifious I)C., lubitu simillima, differt foliis inferne plus miuus angustatis, basi sessili truncatis nec corlatis, nervis lateralibus magis ardnis r. sublongitrorsis, involucri bractcis plus minus coloratis, floribus roseis.

Sachsia bahamensis Urb. (n. sp.) foliis basalibus obovatis v. oborato-oblongis, $2,5-4 \mathrm{~cm}$. longis, $1-2 \mathrm{~cm}$. latis, margine dentatis, caulinis $2-5$ valde remotis lanceolato-linearibus v. linearibus v. summis ovatis $1-0,3 \mathrm{~cm}$. longis, denticulatis v. integris; inflorescentia $6-9$ cephala, involucro $7 \mathrm{~mm}$. longo, squamis exterioribus dorso toto et intermediis dorso supero medio glandulis subsessilibus obsessis, intimis dorso nudis linearibus acutis $\mathrm{v}$. breviter acuminatis, $0,7-1 \mathrm{~mm}$. latis; flor. fem. 3S-39, lierm. $9-10$.

Planta percnnans? Radix primaria abbreriata, radiculas plures funiformes plus minus elongatas emittens. Caulis $15-45 \mathrm{~cm}$. longus, inferne $1-1,5 \mathrm{~mm}$. crassus, striatus, purpurascons, praesertim superne scabriusculus, basi ima inter foliorum rosulam villosus. Folia basalia rosulata, 2-10 $\mathrm{mm}$. longe petiolata, ad basin plus minus louge in petiolum angustata eumque marginantia, apicc rotundata, nervo medio supra prominulo, lateralibus utroque laterc $4-6$, basalibus cxceptis sub angulo $65-80^{\circ}$ abeuntibus, jlus minus manifeste anastomosantibus, chartacea r. subeoriacea, supra brevissime $r$. abbreviatim pilosa, subtus glandulis minutis lutcis adspersa. Inflorescentiae laxc subeorymbosae, ramis $1-3$-cephalis, glandulis parvis brevissime stipitatis v. subsessilibus dense obsessis et seabridis, pube alia nulla; braetcae triangulares brevitcr acuminatae, nomnullac steriles; pedunculi speciales (supra bracteam summam) $5-12 \mathrm{~mm}$. longi, $0,4-0,5 \mathrm{~mm}$. crassi. Capituta cylindraceo-campanulata, postremo $9 \mathrm{~mm}$. longa, medio $4-5 \mathrm{~mm}$. crassa; involneri squamae ca. 6-scriatae, infimae $1-1,5 \mathrm{~mm}$. longae, eaetcrae sensim longiores imbricatae, unincrres, ad apicem eiliatofimbriatae, margine albidac, caeterum virides v. plus minus rubescentcs, post fructum delapsum reflexae. Receptaculum subconvexum, restigiis florum obsolete tuberenlatum. Pappi setae postremo $4 \mathrm{~mm}$. longac, minute spinulosae, flavo-albidac, in flor. fem. 23-25, in herni. 28-32. Corollac fem. pluriscriatae, filiformes $4,5-5 \mathrm{~mm}$. longae, $0,2 \mathrm{~mm}$. erassae, lobis 3 v. 4, perbrevibus tubo $10-15$-plo brevioribus lanceolato-linearibus erectis, unico interdum profundius soluto, styli lobis 2 (v. 3) filiformibus superatae. Corollae her'm. $5-5,5 \mathrm{~mm}$. longae, inferne lineares $0,3-0,35 \mathrm{~mm}$. crassac, $\mathrm{ab} 3 / 5-2 / 3$ alt. sensim et paullo crascores, lobis 5 oratis obtusiusculis tubo toto $9-10-p l o$ brevioribus, dorso glandulis parcis obsitis. Filamenta corollae mediae inserta; antherae fere $2 \mathrm{~mm}$. longae, apice in ligulam obtusissimam loculis duplo breviorem productae, basi sctaceo-caudatae. Styli lobi filiformes obtusi, parum exserti. Achaenia fere omnia ut videtur benc evoluta, latiuscule linearia, basi et apiec parum attenuata, 1,7 mm. louga, 
subcompressa, striis $8-10$ subinaequicrassis costata, pilis brevibus suberectis obsita, flavo-brumea.

Hab. in Baham. Andros ad Red Bays, m. April. flor. et fr.: Northrop n. 479, New Providence in Blue Hills, m. Mart. flor. et fr.: Egggers n. 4446.

Obs. Habitu simillina S. divaricatae Griseb. et polycephalae Griseb., quae involucri squamis duplo angustioribus, longe acuminatis statim dignoscendae sunt.

Gnaphalium portoricense Urb. (n. sp.) annuum, usque $2 \mathrm{~m}$. altum, ramis tomento arachnoideo albido plus minus dense obtectis; foliis basi plus minus auriculiformi-dilatata sessilibus et subsemiamplexicaulibus sed non $\nabla$. rix decurrentibus, linearibus r. lineari-lanceolatis, inferne parum v. vix angustatis, ad apicem sensim acuminatis et acutissimis, inferioribus $9-12 \mathrm{~cm}$. longis, $1,2-1,7 \mathrm{~cm}$. latis, superioribus (ad ramos floriferos) $8-4 \mathrm{~cm}$. longis $0,8-0,3 \mathrm{~cm}$. latis, subtus incanotomentosis, supra obscure viridibus et pilis valde abbreviatis adspersis nec araneosis; inflorescentiis terminalibus corymbosis; involucri squamis ca. 3-seriatis, basi araneosis, caeterum glaberrimis albidis nitidis, interioribus obtusis r. obsolete brevissimeve acutatis, apice fere semper integris; floribus femineis ca. 45, hermaphroditis ca. 8.

Gmaphalium domingense Bello 1p. I (1881) p. 286; Stahl Est. I p. 148; Krug Icon. tab. 279!, - non Lam.

Botoncillo Portor, ex Sint.

Radix annua palaris ramosa. Ca $\mathrm{C}$ is erectus; rami internorlis 2-0,5 cm. longis, sub inflorescentia $2-3 \mathrm{~mm}$. crassi. Folia nervo medio parum prominulo, lateralibus in foliis inferioribus utroque latere $1-3$ sub angulo $10-20^{\circ}$ abeuntibus sublongitrorsis, non ramosis, subtus non conspicuis, in superioribus nullis, ob marginem hine illine recurvum undulatocrenata, supra pilis perbrevibus patulis articulatis scabriuscula, subtus pilis tenuibus elongatis simplicibus dense albido-tomentosa, chartacea r. crassiuscule chartacea. Inflorescentiae $10-25 \mathrm{~cm}$. diametro; bracteae inferiores eupliylloideae sensim decrescentes, supremae 5-2 mm. longae; rami apice glomerulos capitulorum gerentes. Capitula sessilia v. subsessilia, campanulata, $6 \mathrm{~mm}$. longa; involucri squamae inferiores anguste ovatae r. ovatolanceolatae, superne sensim angustatac acutiusculae, $3-4 \mathrm{~mm}$. longae, interiores lineares $4-5 \mathrm{~mm}$. longae, omnes superne enerves albilae v. e pallide stramineo albidate. Pappi setae corollis perpanllo longiores, valde deciduae, supra basin minute patenti-, eaeterum obsolete adpresse spimulosae albae. Corollae femin. filiformes, superne sensim attennatae, vix $3,5 \mathrm{~mm}$. longae, inferne $0,2 \mathrm{~mm}$., superne $0,1 \mathrm{~mm}$. crassae, dentibus brevibus linearibus, stigmatibus exsertis revolutis. Corollae lo $\mathrm{rm}$. anguste cylindraceae subaequicrassae, $3,5 \mathrm{~mm}$. longae, $0,3 \mathrm{~mm}$. crassae; lobi lanceolati crispuli tubo ca. S-plo breviores. Stamina corollae in ejus $1 / 3$ alt. affixa; antherae vix $1,5 \mathrm{~mm}$. longae, basi setaceo-productae, apice in ligulas anguste lanceoLatas loculis 3 -plo breviores productae. Stylus in $1 / 1$ superiore bifidus. Achaenia elliptico-oblonga brunea glabra, $0,5 \mathrm{~mm}$. longa, $0,4 \mathrm{~mm}$. lata. 
Hab. in Portorico in deelivibus umbrosis ad Eneas, prope Utuado in unontibus seopulosis ad Los Angeles, prope Peñuelas in deelivibus montis Jagua, prope Maricao in monte Montoso, m. Jan. flor.: Sintenis 11. $205,205^{\text {b }}, 4590,5836,5919$.

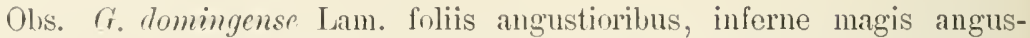
tatis, supra pilis simplicibus elongatis plus minus araclnoideo-tomentosis, involucri squamis obtusioribus, colore magis stramineis diserepat; an re vera specifice diversa sit, monographo hujus generis diffcillimi perito eruendum est.

Guaphalium Egarerii Urb. (n. sp.) perennans, ea. $25 \mathrm{~cm}$. altum, tomento pallide albo-flavido; foliis basi lata r. subauriculata sessilibus, semiamplexicaulibus, ad marginem ca. $2 \mathrm{~mm}$. decurrentibus, ellipticolaneeolatis v. laneeolato-linearibus, inferne magis sensim angustatis, apiee aeutatis, intermediis $1,5-2 \mathrm{em}$. longis, $0,3-0,6 \mathrm{~cm}$. latis; inflorescentiis in apiee ramorum terminalibus, laterali unica in specimine nostro adjecta, 2,5-4 em. longe peduneulatis, eapitatis; involueri squamis biv. sub-3-seriatis, interioribus inferne araneosis et sub pube brunescentibus, superne glaberrimis tlavis nitidis, apice breviter inciso $2-4$ apieulatis; floribus femineis ea. 30 , hermaphroditis $3-5$.

Radix verisimiliter perennans, lignescens, palaris ramosa. Caulis inferne ramosus, foliis emarcidis griseo-nigrescentibus praeditus; rami floriferi $1-1,5 \mathrm{~mm}$. crassi, simplices, densissime araneoso-tomentosi. Folia internodiis duplo r. pluries longiora, nervis non conspicuis, ob marginem linc illine recurvum specie undulato-crenata, utrinque subaequaliter pallide flavido-araneoso-tomentosa, summum fere a basi sensim angustatum. Inflorescentiae globulosae v. breviter cylindraceae $1-2 \mathrm{~cm}$. longae, $1,2-1,5 \mathrm{~cm}$. crassae. Capitula campanulata, $4 \mathrm{~mm}$. longa; involucri scuamae exteriores lanceolatae $\mathrm{v}$. anguste lanceolatae, ca. $3 \mathrm{~mm}$. longae, apice integrae v. obsolete incisae, interiores numerosiores et longiores, laneeolato-lineares $\mathrm{v}$. lineares, $3,5-4 \mathrm{~mm}$. longae, $1,3-0,8 \mathrm{~mm}$. latae. Pappi setae corollis aequilongae, valde deciduae, ad basin patenti-, caeterum adpresse spinulosae, vix supra $3 \mathrm{~mm}$. longae, albae. Corollae femin. filiformes, superne paullo attenuatae, $3 \mathrm{~mm}$. longae, inferne $0,15 \mathrm{~mm}$., superne $0,1 \mathrm{~mm}$. crassae, dentibus minutis, stigmatibus vix $\mathrm{r}$. breviter exsertis. Corollae herm. anguste cylindraceae, aequicrassae v. ad apicem obsolete ampliatae, $3 \mathrm{~mm}$. longae, $0,3 \mathrm{~mm}$. crassae; loli anguste triangulares, tubo ca. 10-plo breviores. Stamina corollae in ejus $1 / 1$ alt. affixa; antlierae vix $1,5 \mathrm{~mm}$. longae, lasi setaceo-productae, apice in ligulas lanceolatas loculis fere 4 -plo breviores excurrentes. A chaenia $0,7 \mathrm{~mm}$. longa, fere $0,3 \mathrm{~mm}$. crassa, elliptico-oblonga, brunea glabra.

Hab. in Sto. Domingo in Valle nuevo, alt. 2270 m., m. Majo flor.: Eggers n. 2231, 2263.

Obs. Affine $G$. luteo-albo L., quod involucri squamis obtusissimis v. subtruncatis, floribus fem. multo tenuioribus et brevioribus, herm. dimidio brevioribus etc. differt. 
Wedelia Iongipes Urb. (n. sp.) canle petioloque pilis patentibus obsitis; foliis $2-5 \mathrm{~cm}$. . summis $1 \mathrm{~cm}$. longe petiolatis, ovatis, basi plus minus truncata vix v. manifeste in petiolum produetis, apice obtusiusculis r. obtusis, $3,5-7 \mathrm{~cm}$. longis, $2-5 \mathrm{~cm}$. latis, margine toto inaequaliter et grosse dentatis v. crenatis, supra pilis brevibus albidis basi bulboso-inflatis scabridis, subtus ad nervos breviter, inter nerros brevissime pilosis; pedunculo in apice caulis solitario, $3-4 \mathrm{~cm}$. longo, monocephalo; involucro $6-7 \mathrm{~mm}$. longo, squamis oblongis; floribus fem. ca. 5 , limbo $9 \mathrm{~mm}$. longo, herm. ca. 30 .

Planta annua ca, $35 \mathrm{~cm}$. longa. Radix palaris, parum ramosa. Caulis erectus obtusangulus, ca. $1,5 \mathrm{~mm}$. crassus, pilis praesertim al apicem internodiorum et ad internodium summum obviis patentilus v. sulkleflexis setuliformihus albidis articulatis, interuodiis $5-14 \mathrm{~cm}$. longis. Folia petiolis coucaviusculis in sulco hrevissime puliescentibus, al marginem parce setulosis, nervo medio supra prominulo, lateralibus 2 inferioribus $5-10 \mathrm{~mm}$. supra basin sub angulo $40-50^{\circ}$ aheuntibus usque ad medium v. ultra productis, caeteris utroque latere 2-4, omuibus subtus hene prominentibus et reticulato-anastomosantibus, reticulo supra tenuiter impresso, chartacea, supra in sicco hruneo-nigrescentia, subtus multo pallidiora. P'edunculus dense pateuti-pilosus; capitula $12-14 \mathrm{~mm}$. louga; involucri sınamae ca. 7, afice olitusae v. rotundatac, usque $3 \mathrm{~mm}$. latac, dorso breviter pilosae, intus superne breviter sctulosae; paleae oblongo-lanccolatae, supernc acutatae et margine breviter ciliatae, dor'so medio parce et brevissime pilosac, $4-4,5 \mathrm{~mm}$. longae. Pappi setae v. squamulac valde abbreviatae albidac, basi in annulum hrevem connatae. Corollae f cm. $11 \mathrm{~mm}$. longae, limbo tubum 5 -plo superante, oblongo, apice emarginato, $4 \mathrm{~mm}$. lato, ca. 13 -nervi, dorso glandulis minutis sulsessilibus adsperso, supra basin parce piloso. Corollae lı er m. 5,5 mm. longae, in $2 / 5$ alt. in limbum subcylindraceum fere 3 -plo crassiorem subito dilatatae, lolis triangulari-ovatis obtusis limbo fere 4 -plo brevioribus, dorso brevissime scabridae, cacterum glabrae. Antherae fcre $2 \mathrm{~mm}$. Iongae, apice in ligulas triangulari-ovatas loculis 4-plo lreviores contractae, loculis basi brevissime et obtusiuscule productis. Styli rami acutati brevissime pilosi. Ovarium praeter pilos parcissimos ad apicem obvios glahrum, sub anthesi $2,5 \mathrm{~mm}$. longum, lincare, ut videtur senuper trigonum.

Hab. in Haiti: Picarla n. 564. noscenta.

Ols. A speciebus aliis antillanis petiolis elongatis statim dig-

Melanthera Bu(hii Urb. (n. sp.) ramis et pedunculis pilis brevibus horizontaliter patentibus dense obsitis; foliis (superioribus) $1,5-0,5 \mathrm{~cm}$. longe petiolatis, ex ovato lanceolatis, basi plus minus triangulari-productis, supra basin usque ad apicem sensim et longe acuminatis, $7-3 \mathrm{~cm}$. longis, supra basin $3-1 \mathrm{~cm}$. latis, margine inaequaliter et dense dentatis, supra scabridis; inflorescentiis semel bis cymose divisis, pedunculo speciali primario $6-8 \mathrm{~cm}$. longo; pappi setis $10-12$; corollis $5 \mathrm{~mm}$. longis; achaeniis glabris $2-2,3 \mathrm{~mm}$. longis. 
Planta $0,60-1,30 \mathrm{~m}$. alta. Rami elevatim angulato-striati, striis stramineis $r$ albescentibus, pilis supra l,asin articulatis, caeterum simplicibus minute scabriuseulis. Folia basi paullo in petiolos decurrentia, nervis lateralibus 2 supua basin e medio prodeuntibus usque al $\mathrm{v}$. fere ad medium produetis, cacteris sub angulo $40-55^{\circ}$ abeuntibus, supra non v. vix conspicuis, subtus bene prominentibus ef reticulato-anastomosantibus, supra pilis hrevibus et brevissimis adspersa, subtus praesertim ad nerros breviter pilosa. Inflorescentia $3-7$-ceplala valde laxa; propliylla inferiora eupliylloidea, superiora saepius alterna, anguste lanceolata, 1,5-0,5 cm. longa; peduneuli speciales $1-0,7 \mathrm{~mm}$. crassi. Capitula sub antlıesi $0,8-1 \mathrm{em}$. diametro; involueri squamae sulbiseriatae adpressae anguste ovatae obtusae r. breviter et obtuse acuminatae $3-4 \mathrm{~mm}$. longae, lense et breviter strigoso-pilosae, virides; receptaculum semiglobosum; paleae rhombeo-ovatae usque oblongolanceolatae acutae $\mathrm{r}$. breviter acuminatae, dense et parallele striatae, margine supero brevissime ciliatae, dorso brevissime piloso-scabridae. Pappi setae ovario subaequilongae, postremo $1,5-2 \mathrm{~mm}$. longae rigidae pallide stramineae. Corollae albae (ex $\mathrm{Buch})$, in parte $1 / 5-1 / 4$ inferiore anguste cylindraeeae, dein subito ultra duplum dilatatae cylindraceae, superne minute scabriusculae; lobi anguste ovati v. ovato-elliptici, obtusiuseuli, tul,o $4-5$ plo breviores. Stamina tubo in $1 / 5-1 / 4$ alt. inserta; antherae nigrae, ipsae $2 \mathrm{~mm}$. longae, basi loculis brevissime productis, apice in ligulam triangulari-oblongam fere 4-plo breviorem excurrentes. Styli in $2 / 3$ alt. bifidi, ramis subulato-aenminatis, e corolla parum prominulis. Aeliaenia brunea aureo-tincta, anguste obovata, sub apice truncato ipso constricta, dimidio crassiora quam latiora, subcompresso-tetragona, marginalia latere exteriore subplaula, interiore convexa.

Hab. in Haiti in regione calcarea sicca ad Bilboro, $700 \mathrm{~m}$. alt, m. Majo flor.: Buch n. 364 .

Obs. M. angustifolia A. Ricl. (e Cuba: Wright n. 3607) differt caulibus pilos brevissimos adpressos gerentibus, petiolis $5-3 \mathrm{~mm}$. longis, foliis oblongo-linearibus, superne latissimis $6-10 \mathrm{~mm}$. latis, inferne sensim angustatis, apice breviter acuminatis, inflorescentiis $1-2$-eephalis, pappi setis 1 - perpaucis, corollae lobis ovatis, ligulis antherarum fere duplo brevioribus lreviter ovatis.

Chacnocephalus rupestris Urb. (n. sp.) ramis hornotinis breviter et dense patenti-pilosis; foliis $12-5 \mathrm{~mm}$. longe petiolatis, rhomboideis, ellipticis, oblongis usque lanceolatis, inferne sensim et longe v. satis longe angustatis, apice obtusiuseulis v. acutis v. breviter acuminatis, $15-7 \mathrm{em}$. longis, $6,5-2,5 \mathrm{~cm}$. latis, manifeste v. obsolete dentieulatis, supra scabris, subtus brevissime et adpresse pilosis; inflorescentiis corymbosis polycephalis, pedunculis $12-2 \mathrm{~mm}$. longis; capitulis 6 - 10 -floris, postremo 5-6 mm. diametro, involucri squamis erectis adpressis; floribus postremo quoque ereetis; corollis $4 \mathrm{~mm}$. longis, lobis limbo paullo brevioribus; achaeniis ipsis obovato-oblongis v. oblongis, $4-5 \mathrm{~mm}$. longis, breviter et adpresse setuloso-pilosis, alis 2-3-plo angustioribus, nunc in eodem capitulo deficientibus. 
Frutex 2-4 m. altus, ilregulariter crescens. Rami teretes plus minus striati, pallide brunescentes, pube articulata inaequilonga recta $\mathrm{r}$. plus minus curvata, internodiis $2-1 \mathrm{~cm}$. longis. Folia alterna, limho sensim in petiolum producto eumque paullo marginante v. subito contracto et obtusiusculo, semper supra medium latissima, nervo medio supra prominulo, lateralibus utroque latere $8-11$ sub angulo $50-60^{\circ}$ aheuntibus, supra non, subtus tenuiter reticulato-anastomosantibus, supra ad nervos breviter v. brevissime pilosa, inter nervos setulis brevissimis basi inflatis scabrida, subtus praesertim ad nerros pilosa, dentibus obtusis calloso-incrassatis, membranaceo-chartacea r. cliartacea. Inflorescentiae 5-20 cm. diametro; rami primarii ex axillis euphyllorum sensim decrescentium abeuntes, corymbos speciales gerentes; lracteae superiores lineares; pedicelli breviter patentipilosi. Capitula turbinata; involucri squamae genuinae (exteriores) $3-5$ suborbiculares v. breviter rlomheo-ovatae r. oratae $1-2,5 \mathrm{~mm}$. longae, caeterae flores amplectentes (paleae) duplo et ultra longiores $4-6 \mathrm{~mm}$. longae, complicatae, obovatae r. spathulatae, apice rotundatae r. subtruncatae, dor'so supero breviter pubescentes. Pappi setae 2 lineari-sululatae, intus sulcatae, parce et brevissime pilosae, plus minus inaequales, antica usque duplo latiore et plerumque paullo breviore, stramineae. Corollae leviter v. obsolete incurvae, in parte $1 / 5-1 / 4$ inferiore cylindraceae, parce pilosae, dein subsubito in limbum 3 -plo crassiorem subcylindraceum glabrum dilatatae; lobi erecti lanceolato-lineares, in alt. subinaequilonga liberi. Stamina corollae sub dilatatione adnata; filamenta sub loculis calloso-incrassata; antherae fere $2 \mathrm{~mm}$. longae, basi in dentes breves inter sese connatos productae, apice in ligulas lanceolatas loculis 3-plo breviores excurrentes. Discus bene evolutus crassiusculus. Styli in $1 / 3$ superiore bifidi, ramis recurvatis, ad apicem acutiusculum brevissime papilloso-pilosis. Achaenia cum alis $2-3 \mathrm{~mm}$. lata, aristis dimidio v. fere duplo longiora, ipsa brunescentia $r$. cinereo-brunescentia, postreuno basi pilorum incrassata granılata, alis flavis v. flavo-bruneis, ca. $0,7 \mathrm{~mm}$. latis.

Hab. in Jamaica, praesertim ad rupes secus fluviorum ripas, $m$. Jan. fl. et fr., e. gr. ad Hope river $500 \mathrm{~m}$. alt., ad Bridge Hill $500 \mathrm{~m}$. alt., ad New Castle Road 400- $500 \mathrm{~m}$. alt., infra Mavis Bank $630 \mathrm{~m}$. alt., in Mount Mansfield $300 \mathrm{~m}$. alt., inter Falls River et Stoneleigh 900 m. alt.: Eggers 11. 3571, Harris 11. 7793, 7795, 7797, 7809-7811, 7813.

Obs. Altera hujus generis species janaicensis, Ch. petrobioides Griseb., est frutex $7 \mathrm{~m}$. altus, ramis minute et parce puberulis, foliis breviter petiolatis v. subsessililus, capitulis $12-16$-floris, involucri squamis linearibus reflexis $4-5 \mathrm{~mm}$. longis, corollis $5 \mathrm{~mm}$. longis, lobis limbo duplo brevioribus, dentilus antherarum basalibus liberis, achaeniis (ex Griser.) angustissime alatis.

Senecio lncens Urb. ramis lignescentibus, tortuosis, verisimiliter volubilibus tomentosis; foliis $5-3 \mathrm{~mm}$. longe petiolatis, orato-ellipticis v. anguste oratis, basi rotundatis r. obtusis, apice obtusis r. acutis, $6-3 \mathrm{~cm}$. longis, $2,5-1,5 \mathrm{~cm}$. latis, $2-3$-plo longioribus quam latioribus, margine plano r. recurro denticulis parcis parrisque jncrassatis 
mammilliformibus patentibus obsitis v. superioribus integerrimis, supra initio araneosis, cito glabrescentibus lucidis, subtus persistenter araneosotomentosis, punctis grossis plus minus pellucidis notabilibus; inflorescentiis terminalibus et lateralibus glomeratis $10-25$-cephalis tomentosis, pedunculis specialibus nullis v. usque $2 \mathrm{~mm}$. longis, involucri squamis exterioribus 1 -- 3 minoribus, interioribus 8 liberis extrinsecus tomentosis, 3,5-4 mm. longis; capitulis heterogamis, $10-12$-floris; floribus 2-4 ligulatis femineis, caeteris hermaphroditis; achaeniis (junioribus) glabris, 10 -striatis.

Conyza lucens Poir. in Lam. Enc. Suppl. II (1811) p. 3.11; Spreng. Syst. III p. 508; DC. Prodr. V p. 389.

Conya domingensis Willd.! Herb. n. 15621 ed. Spreng. Syst. III (1826) p. 508 .

\section{Senecio conyioides I. DC.! Prodr. VI (1837) p. 412.}

Rami teretes, tomento floccoso-araneoso allido v. flavescente densissime obtecti. Folia nervo melio supra inferne subimpresso, superne prominentc, lateralibus $6-8$ sub angulo $60-80^{0}$ aheuntibus, supra tenuiter prominentibus et reticulato-anastomosantibus, subtus parum v. vix ramosis, subcoriacea, supra punctis grossis resiculiformibus notata, in sicco brunea, subtus incano- $\mathrm{r}$. postremo flavescenti-tomentosa. Inflorescentiae in apice ramorum plures plus minus congestae et in ramulis brevibus pancifoliatis $v$. aphyllis plerumque 2; bracteae lineares r. lineari-subulatac; glomeruli subglobosi. Capitula obovato-turbinata, $6 \mathrm{~mm}$. longa, superne $3-3,5 \mathrm{~mm}$. crassa; involucri squamae exteriores $1-2 \mathrm{~mm}$. longae lanceolato-linearcs $\mathrm{v}$. lineares acuminatae, interiores subbiseriatac lineares $\mathrm{v}$. intimae angustc lanceolatae, superne angustatae, sed apice obtusiusculae et brevissime ciliatae; receptaculum parum convexum. Pappi setae in fl. fem. $78-80$, in herm. $92-100$, aequicrassae spinnlosae, ca. $3 \mathrm{~mm}$. longae, albae. Corollac feur. $4 \mathrm{~mm}$. longac; limbus ovalis recurvatus tubo acqulongus, apice minute 3 -crenatus, 4 -nervis; styli rami recurvi apice subtruncati. Corollae herm. 4-4,3 mm. longae, inferne lineari-tubulosae, supra medium subcampanulatae; lobi ovato-triangulares, tubo toto 4-plo breviores, dorso apice valde calloso-incrassati. Stamina corollae mediae inserta; antherae vix $1,5 \mathrm{~mm}$. longae, basi brevissime et obtusiuscule apiculatae, apice in ligulas lanceolatas loculis 3-plo breviores excurrentes. Styli in $1 / 4$ superiore bifidi, ramis apice subtruncatis et papillosis.

Hab. in Haiti: Nectoux.

Obs. Aster frutescens, staechadis citrinae folio Plum. Cat. (1703) p. 10 et ed. Burm. p. 30 tab. 42 fig. 1! est Senecio Picardae Krr. et Urb. Symb. I p. 469 (foliis in icone Plumieriana paullo magis sinuato-dentatis).

Inastraluhia Picardac Urb. (n. sp.) ramis hornotinis tomento pallide et sordide flavo obtectis; foliis $6-10 \mathrm{~mm}$. longe petiolatis, anguste oratis $v$. anguste obovatis usque elliptico-oblongis, basi rotundata subito in petiolos contractis, apice rotundatis r. obtusis, $6-3 \mathrm{~cm}$. longis, 
2,5-1 cm. latis, margine integerrimis; capitulis multifloris, ambitu campanulatis, medio fere $2 \mathrm{~cm}$. crassis, involucro sub-10-seriali, usque $3 \mathrm{~cm}$. longo, solemuiter imbricato, squamis dorso tomentosis, infimis (exterioribus) brevissimis, caeteris sensim longioribus, interioribus longissimis flores (sine antheris) longitudine aequantibus, omnibus erectis; corollis $22-23 \mathrm{~mm}$. longis, usque supra $1 / 3$ alt. gamopetalis; achaeniis densissime villosis, $5 \mathrm{~mm}$. longis.

Frutcx $1,5-2 \mathrm{~m}$. altus, ramosus. Rami vetustiores teretcs glabrescentes, hrunei, cortice saepius longitudinaliter fisso, hornotini tomento densissimo c pilis sigmoideis $\mathrm{r}$. varie curvatis hrevissimis non v. vix prominentibus contexto obtecti. Folia petiolis supra planiusculis caeterum teretihns tomentosis insidentia, nervo medio supra impresso, lateralibus utroque latere $7-10$ sub angulo $65-80^{\circ}$ abeuntibus supra leriter v. vix impressis ct densissime tenuiterque anastomosantibus, subtus prominentibus obsolete $\mathrm{v}$. non anastomosantibus, crasse coriacea, margine plana, supra initio densissime tomentosula, sed cito glabrescentia, subtus tomento persistente sordide et pallide flavo more ramorum hornotinorum obtecta. Capitula in apice ramorum solitaria sulsessilia v. sessilia, sub antlıesi sine antheris ca. $3 \mathrm{~cm}$. longa, medio fere $2 \mathrm{~cm}$. crassa; involucri squamac infimae hreviter ovatae $\mathrm{r}$. ovatae, $1,5-2 \mathrm{~mm}$. longae, cacterae lincari-lanceolatae $\mathrm{v}$. lineares, sensim acuminatae subpungentes, $2-1,8 \mathrm{~mm}$. latae. Pappi setae $37-45$ biseriatae crassiusculae spinulosac, $17-18 \mathrm{~mm}$. longac, flaridae. Corollae totac in sicco bruneae; tubus $8-9$ mm. longus linearis $0,7 \mathrm{~mm}$. crassus, in $4 / 5$ alt. subsubito dimidio ampliatıs, $1,2 \mathrm{~mm}$. crassus; lobi anguste lineares, apice revoluti, $12-13 \mathrm{~mm}$. longi. Filamenta tulo ad ejus dilatationem inserta, $13 \mathrm{~mm}$. longa; antlierae totac $13 \mathrm{~mm}$. longae, exscrtae, basi in caudas lineari-subulatas papilligeras $3 \mathrm{~mm}$. longas productae, apice in ligulas quoad liberas lineares acuminatas ferc $2 \mathrm{~mm}$. longas excurrentes. Stylus $33-36 \mathrm{~mm}$. longus, lobis perbrevibus, $0,8 \mathrm{~mm}$. longis ercetis obtusis, ex antheris parum cxsertis. Achaenia pilis suberectis albidis nitilis villosa.

Hab. in Haiti prope Cadets, $1200 \mathrm{~m}$. alt., m. Jan. flor.: Picarda n. 1073.

Obs. Affinis A. ilicifolin Don (e Cuba) differt foliis sinuato-lobatis, lobis pungentibus, involucri squamis ca. 7-seriatis, fere duplo latioribus, corollae tubo ad apicem paullo et sensim dilatato, lobis in sicco pallidis, antlueris $15 \mathrm{~mm}$. longis, lasi $5 \mathrm{~mm}$. longe caudatis.

Anastraphia bahamensis Urb. (n. sp.) ramis hornotinis tomento albido obtectis; foliis $5-2 \mathrm{~mm}$. longe petiolatis, obovatis r. obovatooblongis, inferne sensim $r$. subsensim angustatis, apice rotundatis $\mathrm{r}$. subtruncatis, $2,5-1 \mathrm{~cm}$. longis, $1,5-0,5 \mathrm{~cm}$. latis, margine supero $\mathrm{r}$. antico spinoso-denticulatis, nervis lateralibus sub angulo ca. $45^{\circ}$ abeuntibus; capitulis ramulos breves terminantibus ideoque saepius in racemum collectis, 8-9-floris, ambitu oblongo-turbinatis, medio $6-7 \mathrm{~mm}$. latis, involucro ca. 6 -seriato $1,8-2 \mathrm{~cm}$. longo, solemniter imbricato, squamis (infimis exceptis) dor'so glabris r. margine parce arachnoideis, infimis 
(exterioribus) brevissimis, caeteris longioribus, interioribus longissimis flores (sine antheris) longitudine aequantibus, onnibus acuminatis semper erectis; colollis $14 \mathrm{~mm}$. longis, in $1 / 5$ alt. coalitis; achaeniis pilis suberectis laxis r. glandulis tantum obsitis, $3 \mathrm{~mm}$. longis.

Anastraphia pancifloscula Hitche. Bah. in Miss. Bot. Gard. Rep. IT (1893) p. 102 (1. p.) tab. 12!; Northe. Flor. of New Provid. p. 72; - non C. Iright Mse. (c Sto. Domingo).

Frutex 1,3 m. altus, valde ramosus. Rami retustiores teretes glabrescentes striati brunei, cortice demum longitudinaliter fisso, hornotini tomento densissimo e pilis varie curvatis brevissimis non prominentibus contexto obtecti. Folia petiolis supra planiusculis, dorso convexis tomentosis insidentia, secus nervum nedium vix v. non prominulum subsulcata, ncrvis lateralibus utroque latere $3-4$ supra non impressis, densissime tenuiterque anastomosantibus, subtus prominentibus et plus nimus manifeste anastomosantibus, crasse coriacea, margine recurva, dentilus spinoso-pungentibus plerumque $3-5$, supra practer marginem al, initio glabra nitida, subtus tomento persistente sordide flavido-albido obtecta. Capitula in apice ramulorum dense $\mathrm{v}$. densissime foliatorum sessilia, sub anthesi (sine antheris) $1,8-2 \mathrm{cnt}$. longa; medio $0,6-0,7 \mathrm{~cm}$. crassa; involucri squamae infimae triangulares v. ovato-lanceolatae, $2-3 \mathrm{mu}$. longae, saepius tomentosulae, caeterae lanceolatae usque lineares glabrae $v$. subglabrae, sensim acuminatae, $2-1 \mathrm{~mm}$. latae. Receptacul $\mathrm{mm}$ intra bracteas $2 \mathrm{~mm}$. longum, apice convexiusculum. Pappi setae $34-39$ subbiseriatae crassinsculae spinulosae, $14 \mathrm{~mm}$. longae, stramineae v. leviter brumescentes. Corollae in sicco ad basin bruneae, caeterum pallidae; tubus 2,5-3 mu. longus cylindraceus ad apicem paullo crassior, medio $0,6-0,7 \mathrm{~mm}$. crassus; lobi angustissime lineares, stricte erecti, apice incrassato obtusi, $10,5-11,5 \mathrm{~mm}$. longi. Filamenta in ore tubi inserta, usque $11 \mathrm{~mm}$. longa; antherae totae $8,5-9 \mathrm{~mm}$. longae, plus minus exsertae, hasi in caudas lineari-subulatas glabras $2 \mathrm{~mm}$. longas productae, aprice in ligulas quoad liberas lineari-acuminatas ca. $1 \mathrm{~mm}$. longas excurrentes. Stylus purpurascens (ex EGG.) postremo 18 mm. longus, lobis perbrevibus $0,5 \mathrm{~mm}$. longis erectis obtusis, ex antheris plus minus exsertis. Achaenia sukglabra v. pilosa.

Hab. in ins. Baham. Andros Island, m. Jun. flor.: Northrop n. 639, in Fortune Island, m. Febr. flor.: Eggers n. 3866.

Anastraphia Northropiana Greenman in Combs Cuba in Trans. Ac. Sc. St. Lonis VII (1S97) p. 435 (p. p., nempe quoad plant. bale.; Northr. l. c.; foliis $\mathrm{S}-4 \mathrm{~mm}$. longe petiolatis, $3-1,5 \mathrm{~cm}$. longis, basi rotundata $v$. obtusa in petiolum contractis, margine fere semper integris raro hinc illine spinuloso-dentatis, supra initio tomentosis, nervis lateralibus utroque latere $4-6$ sub angulo ca. $70^{\circ}$ abeuntibus, involucro ca. $12 \mathrm{~mm}$. longo quam flores multo breviore, squamis superioribus recurvatis $\mathrm{r}$. revolutis plus minus arachnoideis, capitulis ca. 13 -floris, pappi setis $11 \mathrm{~mm}$. longis, corollis $10-11 \mathrm{~mm}$. longis, in $1 / 4$ alt. v. paullo ultra gamopetalis optime differt. 
Auastraphicu pancifloscula Hitche. Bah. (1893) p. 102 (p.p., nou tab. 12, nec C. Wrigltt).

Hab. in ins. Baham. New Providence, m. Mart. flor:: Eggers n. 4473 (arbor $4 \mathrm{~m}$. alta), Andros in Fresh Creek m. Jun. flor.: Northrop n. 640 .

Var. $\beta$. Combsii Urb. foliis plerisque repando-dentatis $\mathrm{r}$. spinuloso-dentatis, integerrimis intermixtis, nervis supra manifeste impressis, involucro $9 \mathrm{~mm}$. longo, squamis paucioribus, capitulis ca. 9 -floris, corollis in $1 / 5$ alt. tantum coalitis.

Anastraphica Noctheopiana Greenman l. c. (p. p.) tab. XXXVI!

Hab. in Cuba prope Calicita in rupibus litoralibus, m. Aug. flor.: Combs 11. 521 .

Anastraphia oligantha Urb. (n. sp.) ramis hornotinis tomento flarido-albo obtectis; foliis $4-2 \mathrm{~mm}$. longe petiolatis, oboratis r. obovato-oblongis, inferne parum v. sensim angustatis, apice reflexo plerumque truncatis, $1,7-1 \mathrm{~cm}$. longis, $1-0,6 \mathrm{~cm}$. latis, margine basi excepta parce spinoso-dentatis, nervis lateralibus subtus non, supra parum conspicuis, sub angulo ca. $45^{\circ}$ abeuntibus; capitulis ramulos breves terminantibus $4-5$-floris, ambitu anguste oblongis, medio ca. $4 \mathrm{~mm}$. crassis; involucro ca. 6 -seriato, $2,5 \mathrm{~cm}$. longo, solemniter imbricato, squamis praesertim inferioribus apice tomentosulis, ad basin obtectum sericeis, caeterum glabris, infimis (exterioribus) brevissimis, caeteris gradatim longioribus, interioribus longissimis $20-22 \mathrm{~mm}$. longis, superne angustatis, sed apice obtusiusculis, semper erectis; corollis...; achaeniis dense sericeis, 5 mm. longis.

Auastraphia paucifloscula C. Wiight! Msc. in herb.; Hitche. Bah. (1S93) p. 102 (nomen, sed non descr. nec tab.).

Mclichrysum arboresceus, ilicis cocciglandiferae folio Plum. Cat. (1703) 1. 9 ct edid. Bucm. p. 114 tab. 123 f. 2!

Rami hornotini tomento densissimo e pilis varie eurvatis brevissimis non prominentibus eontexto obteeti. Folia petiolis supra leviter v. vix sulcatis, dorso eonvexis tomentosulis insidentia, nervo medio supra plus mimns impresso, lateralibns utroque latere $4-6$ supra leviter impressis, densissime retienlato-anastomosantibns, reticulo interdmm obsoleto, subtus non v. vix eonspienis, crasse coriacea, sinuato-dentata, dentibus utroque latere $3-4$ triangularibus hreviter spinulosis, inter dentes arcte reeurva, supra initio levitor tomentosula, dein glabreseentia, nitida, subtns tomento persistente albido-flavo densissimo obteeta. Capitula in apiee ramulorum sessilia; involncri squamae infimae ovatae obtusae, $1,5-2,5 \mathrm{~mm}$. longae, intermediae ovato-laneeolatae v. lanceolato-lineares, intimae lineares, $2,5-2 \mathrm{~mm}$. latae, extrinsecus supra basin breviter et tenuiter sericeae. Receptaculum inter bracteas vix $2 \mathrm{~mm}$. longum, apiee planum. Pappi setae $66 \ldots-70$ hiseriatae, $14 \mathrm{~mm}$. longae, inter sese inaequierassac, manifeste spinulosae, stra- 
mineae. Corollae juniores (tantum visae) in sieeo pallidae; tubns perbrevis, obsenlior; lobi anguste lineares apiee incrassato oltnsi. Antherae juniores $9 \mathrm{~mm}$. longae, apice in ligulas plus minus connatas lineari-subulatas loculis aequilongas apiee inerassatas exeurrentes. Stylus purpuraseens. A ehaenia superne $1,5 \mathrm{~mm}$. lata, dorso conrexa, intus earinata, pilis allidis ereetis sericea.

Hab. in Sto. Domingo: Wright, Parry et Brummel.

Obs. A plantis bahamensibus optime diversa. - Nomen Wrightianum ob confusionem a el. Нiтcнсоск faetam mutandum elat.

Chaptalia membranacea Urb. (n. sp.) foliis $5-1 \mathrm{~cm}$. longe petiolatis, ellipticis r. elliptico-oblongis, basi subito v. subsubito in petiolum protractis, apice brerissime acutatis $v$. obsolete acuminatis, margine toto minute r. manifestius retrorsum denticulatis, $4-7 \mathrm{~cm}$. longis, $1,5-2,5 \mathrm{~cm}$. latis, tenuiter membranaceis, supra glabris v. subglabris, subtus arachnoideo-tomentosulis; pedunculis ca. $15 \mathrm{~cm}$. longis; capitulo multifloro, involucro $10 \mathrm{~mm}$. longo sub-3-seriato, squamis inferioribus lineari-subulatis nigrescentibus, interioribus linearibus breviter et obtusiuscule acuminatis, inferne viridibus, superne purpurascentibus; achaeniis ipsis $2-2,3 \mathrm{~mm}$. longis, parce et brevissime pilosis, rostro aequilongis v. in flor. hermaphroditis duplo brevioribus.

Rhizoma perenne eylindracenm ea. $5 \mathrm{~mm}$. erassum, radieulas numerosas crassiusenle filiformes emittens. Folia rosulata, petiolis in eadem planta valde inaequilongis dense tomentosis, ntrinque subaequaliter angustata, nervis lateralibus utroque latere $3-5$ supra tenuissime prominentibus, dentibus breviter subulato-apiculatis, tomento e pilis longis tenuissimis contexto, supra in sieco viridia, subtus pallide r. flavido-cinerea. Pedunculus fere $1 \mathrm{~mm}$. erassus, leviter, ad apicem densius arachnoideo-floceosus. Capitulum solitarium, $12 \mathrm{~mm}$. longum, medio ca. $6 \mathrm{~mm}$. erassum; involucri squamae infimae $2-3 \mathrm{~mm}$. longae, intermediae perpareae, intimae $12-15$, medio fere $1 \mathrm{~mm}$. latae, inferne paree araehnoideae, superne glabrae membranaeeae. Pappi setae $38-44$, v. in floribus hermaphroditis usque 52 , pallide bruneseentes, $4-5 \mathrm{~mm}$. longae. Corollae marginales $6 \mathrm{~mm}$. longae, limbo purpuraseente laneeolato-lineari $0,3 \mathrm{~mm}$. lato, apiee minute $2-3$-crenato, tubum longitudine aequante, caeterae femineac pleraeque steriles, $5-2 \mathrm{~mm}$. longae, limbo perbrevi, stylo hreviore, hermaphroditae regulares fertiles pallidae $5 \mathrm{~mm}$. longae, inferne lineares, a merlio sensim ampliatae, lobis laneeolatis aequalibus tubo toto ca. 7 -plo brevioribus. Filamenta corollae mediae inserta; antherae $1,8 \mathrm{~mm}$. longae, apice in ligulas subtruncatas, basi in eandas antheris duplo breviores piliformes produetae. Styli semper bifidi, lobis flor. hermaphroditorum brevioribus. Achaenia pallide brunescentia, angulis albidis.

Hab. in Sto. Domingo prope Puerto-Plata in saxis montis Loma Isabel de la torre inter muscos humidos, $670 \mathrm{~m}$. alt., m. April. flor.: Eggers n. 1582.

Chaptalia Eggersii Urb. (n. sp.) foliis 2-1 cm. longe petiolatis, ovalibus, ellipticis r. obovato-ellipticis, ad basin in petiolum angtis- 
tatis, apice obtusis $\mathrm{v}$. rotundatis, margine integris, $1-2,5 \mathrm{~cm}$. longis, 0,5-1 cm. latis, subcoriaceis, supra glabris v. parce arachnoideis, subtus pallide flavido-tomentosis; pedunculis $7-15 \mathrm{~cm}$. longis; capitulo multifloro, involucro $10-11 \mathrm{~mm}$. longo, ca. 5 -seriato, squamis linearibus sensim acuminatis, inferne viridibus plus minus araneosis, superne obscure rinoso-purpurascentibus; achaeniis (immaturis) glaberrimis, breviter (an postremo quoque?) rostratis.

Perennis? Radiees plures cylindraceo-lineares elongatae. Folia msnlata, petiolis in eadem planta inaeruilongis, plus minus arachnoideotomentosis, nervo medio supra prominente, lateralibus utroque latere $5-6$ supra parum r. vix, subtus non conspicuis, supra nitida in sieco brunescentia, subtus tomento e pilis longis simplicibus temuibus contexto obtecta. Pedunculus ca. $1 \mathrm{~mm}$. crassus arachnoideo-floccosus, ad apieem dense et pallide flavo-tomentosus. Capitulum solitarium, $10-12 \mathrm{~mm}$. longum, medio $6-7 \mathrm{~mm}$. crassnm; iuvolncri squamae infimae $2-3 \mathrm{~mm}$. longae, dorso albido-tomentosae, caeterae sensim longiores imbricatae $1-1,3 \mathrm{~mm}$. latae, superne glabrae membranaceae. Pappi setae flor. rad. ca. 65, flor. eaet. femin. ca. 50, flor. herm. ca. 100 , sordide et pallide flavae, $6 \mathrm{~mm}$. longae. Corollae marginales $8 \mathrm{~mm}$. longae, limbo pallido nunc apiee subpurpuraseente lanceolato-lineari, $0,6-0,8 \mathrm{~mm}$. lato, apice minute $2-3$ crenato, 3-4-nervi, tubum paullo superante, caeterae femineae 4,5-3 min. longae, limbo brevi v. perbrevi stylo breviore, hermaphluroditae (non plane evolutae) $6-7 \mathrm{~mm}$. longae, inferne (rglindraceo-lineares, a medio perpanllo et ralde sensim ampliatae, lolis lineari-lanceolatis, in altitndine inaequali inter sese coalitis. Filamenta eorollae mediae inserta; antherne $2 \mathrm{~mm}$. longae, apice in ligulas subtruneatas breves, hasi in caudas antheris dimidio breviores setaceas productae. Styli semper bifidi, lolis flor. hermaphroditorum brevioribus.

Hab. in Sto. Domingo in graminosis juxta rirulum in Valle nuero, $2270 \mathrm{~m}$. alt., m. Majo flor.: Eggers 11.2220.

Obs. Caeterne speeies ex India oceir. ad Chaptaliam redneendae sunt:

Ch. dentata Cass. in Dicl. Sc. Nal. XXVT (1S23) p. 104. -- Tussilago denlala Lim. Spee. II ed. II (1763) p. 1213. - Thessilago albicans Su.! Filor. III (1S06) p. 1348, herb. Wille. n. 15711. - Leria albicans P. DC. in Am. Mhs. Paris XIX (1S12) p. 68. - Chaplalia relbicans Norller. Flor. of New Provid. (1902) p. 73. - I'lum. exl. Burm. lub. 10 fig. 2 e Baham. ins. Andros, Cuba, Janaica, Hispaniola, Portorico. - Variat aehaeniis scabridis v. laevibus, brevins v. perlonge rostratis.

Ch. media Urb. - Leria media Griseb.! Pl. Wrigh. (1862) p. 515 e Cuba: Egger's n. 4986, Wright 11. 332.

Ch. nutans Hemsl. Biol. Cent: Amer. II (18S1) p. 255. - Thessilago mulaus Linn. Syst. ed. X. II (1759) p. 1214. - Leria metuns P. DC. in Am. Mus. Par. XIX (1812) p. 68. - Phum. ed. Bum. lab. 11 fig. 1 e Jamaica (ex Griseb.), Hispaniola, Portorico, St. Thomas, St. Jan, St. Croix, Antigua (ex Griseb.), Gnadeloupe, Dominica (ex Griseh.), Martinique, St. Vineent, Barbados, Grenada, Tobago, Trinidad (ex Griseh.), Amer. trop. cont. 

IIright.

('h. obovata C. Wright in Same. Cub. (1S70) n. 1329 \%. S3 e Cuba:

('h. pumila Urb. - Tussilayo pumila Su..' Prodr. (17S5) 1\%. 113 et Ic. ined. tab. 17! et herb. Willd. n. 15712. - Leria memila P. DC. in Ann. Mus. Paris XIX (1S12) p. 68 e Jamaica: Swat\% (mus. Ber.), ad Bryan's Hill, m. Jan. fl.: Harris (Bot. Dep. Herb. Jam.).

Ch. stenocephala Urb. - Leria stenocephala Criseb. Cat. (1866) p. 158 e Cuba. 


\title{
VI. Musci novi Dussiani.
}

\author{
Descripsit \\ V. F. Brotнerus.
}

1. Dicranella Intinicar Broth. (n. sp.). Dioica; gracilis, caespitosa, caespitibus laxis, late extensis, lutescenti-viridibus, laand nitidis. Caulis ad $5 \mathrm{~mm}$. usque altus, erectus, parce radiculosus, densiuscule foliosus, simplex. Folia sicca erecta, humida suberecta, indistincte subsccunda, canaliculato-concava, inferiora minora, ovato-lanceolata, supcriora majora, e basi ovata lanceolato-ligulata, obtusa, usque ad 2,2 mm. longa, marginibus paulum revolutis, summo apice obtuse denticulato, nervo crasso, basi ca. $0,075 \mathrm{~mm}$. lato, infra summum apicem eranido, ccllulis rectangularibus, minutis, basilaribus multo longioribus et laxioribus. Bracteae perichactii foliis subsimiles. Seta vix $1,5 \mathrm{~cm}$. alta, tenuis, sicca flexuosula, humida strictiuscula, lutescenti-rubra. Theca crecta, symmetrica, ovali-oblonga, ca. 1,2 mm. longa, brevicollis, brunnea, laevis. Annulus latus. Peristomium simplex, dentibus infra orificium oriundis, conniventibus, rubris, apice lutescentibus, ca. $0,32 \mathrm{~mm}$. longis et ca. $0,045 \mathrm{~mm}$. latis, ultra medium bifidis, cruribus inaequalibus, basi dense trabeculatis et striatis, ubique dense papillosis. Operculum e basi conica longe et oblique rostratum. Spori 0,012-0,015 mm., ochracei, minutissime punctulati. Caetera ignota.

Hab. in Martinique ad viam inter Calvaire et Deux-Cloux, ad terram: Duss n. 52 (in Herb. Berol.).

Obs. Species $D$. stenocarpae Besch. valde affinis, sed statura multo minore foliisque ipso acumine dentibus obtusis fraeditis dignoscenda. Forsan potius ut varietas D. stenocarpae consideranda.

2. Fissidens (Pachyfissidcus) rochensis Broth. (n. sp.). Dioicus; gracilis, caespitosus, caespitibus rigidis, densis, atroviridibus, hand nitidis. Caulis ad $1,5 \mathrm{~cm}$. usque altus, erectus, infima basi fusco-radiculosus, e basi jam dense foliosus, simplex. Folia rigida, multijuga, sicca et lumida stricta, erecto-patentia, anguste lanceolato-linearia, acutiuscula, 1,1-1,3 mm. longa et ca. $0,25 \mathrm{~mm}$. lata, summo apice 
indistincte denticulata, limbata, limbo lutescente, latiusculo, infra summum apicem evanido, lamina vera intus histratosa, lamina apicali longior, lamina dorsalis inferne augusta, ad basin nervi enata, nervo crassiusculo, infra summum apicem evanido, cellulis minutis, incrassatis, lumine angulato, laevissimis. Cactera ignota.

Hab. in Guadeloupe, in rivulo Roche, alt. $680 \mathrm{~m}$. ad saxa: Duss n. 116 (in Herb. Berol.).

Ols. Species minuta, foliis limbatis valde peculiaris.

3. Syrrhopodon (Eusyrrhopodon) Dussii Broth. (n.sp.). Dioicus; gracilis, caespitosus, caespitibus laxiusculis, humilibus, mollibus, pallide fuscescenti-viridibus, nitore destitutis. Caulis erectus, vix ultra $5111 \mathrm{~m}$. altus, fusco-radiculosus, dense foliosus, simplex vel furcatus. Folia sicca suberecta, vix flexuosula, hunida erecto-patentia, e basi angusta, ca. 1,8 mm. longa in laminam usque ad 1,3 num. longam, angustissime setaceam, obtusam sensim attenuata, limbata, limbo angusto, hyalino, integro, summo apice tantum denticulato, nervo dorso scabro, summo apice spiculoso, cum apice evanido, cellulis partis laninalis niuutissimis, densissime verrucosis, cancellinae laxis, breviter rectangularibus, inanibus. Caetera ignota.

Hab. in Martinique, Morne-Rouge: Duss 11. 83 (in Herb. Berol.) nec non ad foutem Absalon: Duss n. 16, ad truncos arborum.

Obs. Species S. scabro Mitt. et S. Schucaneckeano C. Müll. affinis, sed foliis multo longiorilus oculo nudo jam disgnoscenda.

4. Syrrhopodon (Calymperopsis) martinicensis Broth. (n. sp.). Dioicus; robustus, caespitosus, caespitibus laxis, rigidis, viridibus, nitidiusculis. Caulis ad $2,5 \mathrm{~cm}$. usque altus, erectus, fusco-radiculosus, deuse foliosus, foliis supremis in rosulam confertis, superne ramosus, ramis fastigiatis. Folia sicca adpressa, apicalia interdum spiraliter contortula, humida patentia, profunde carinato-concava, o basi brevi, vix latiore late ligulata, abrupte breviter acuminata, acuta, 3,5-4 mm. longa et ca. 0,95 mul. lata, marginibus incurvis, integerrimis, summo apice indistincte crenulatis, elimbata, nervo albicante, siccitate dorso nitido, laevi, cum apice evanido, cellulis partis laminalis minutis, subrotundis, minutissime papillosis, cancellinae breviter scalariformis breviter rectangularibus, laxis, inauibus, basilaribus ad marginem angustis, 6-7-seriatis. Caetera ignota.

Hab. in Martinique, Morne-Rouge ad truncos arborum: Duss n. 372 p. p. (in Herb. Berol.) et prope St. Denis ad terram: Duss n. 306 (in Herb. Berol.).

Obs. Species S. subrlisciformi Dus. habitu simillima, sed foliis elimbatis prima fronte dignoscenda. 
5. Calymperes (IIyophilina) guadalupense Broth. (n. sp.). Dioicum ; robustiusculum, caespitosum, caespitibus rgidiusculis, laxis, viridibus. Caulis usque ad 2,5 cm. altus, erectus vel adscendens, fuscoradiculosus, dense foliosns, superne ramosus vel simplex. Folia sicca flexuosula, marginibus involutis, humida patentia, canaliculato-concava, e basi vaginante, superne haud dilatata subito elongate lanceolato-subulata, obtusa, parte vaginali ca. $1,5 \mathrm{~mm}$. longa et ca. $0,7 \mathrm{~mm}$. lata, parte laminali ca. $4 \mathrm{~mm}$. longa, marginibus erectis, apice minute serrulatis, nervo infra summum apicem evanido, dorso laevi, cellulis minutis, subrotundis, pellucidis, laevibus, cancellinae rectangularis vagina brevioris breviter rectangularibus, internis majoribus 4 -seriatis, externis minoribus 10 -seriatis, teniolae in parte vaginali intramarginalis, in parte laminali marginalis, usque ad apicem productae angustissimis, lutescentibus, ad ventrem 6 -serialibus, basilaribus et ventralibus 1 -seriatis. Caetera ignota.

Hab. in Guadeloupe, Morne Hirondelle, ad truncos arborum: Duss n. 241 (in Herb. Berol.).

Obs. Species distinctissima, statura elata foliorumque forma et structura faciliter dignoscenda.

6. Splachnobryum clatum Broth. (n. sp.). Dioicum; gracile, caespitosum, caespitibus densis, altis, mollibus, viridibus, haud nitidis. Caulis usque ad $3 \mathrm{~cm}$. altus, erectus, flexuosulus, parce radiculosus, laxiuscule foliosus, parce ramosus. Folia sicca erecta, vix flexuosula, humida erecto-patentia elongate oblonga, breviter acuminata, obtusa, $1,3-1,7 \mathrm{~mm}$. Ionga et $0,38-0,48 \mathrm{~mm}$. Iata, marginibus erectis, superne minute et obtuse serrulatis, nervo crassiusculo, infra summum apicem evanido, cellulis laxis, superioribus subrhombeis, inferioribus longioribus subrectangularibus, omnibus laevissimis. Caetera ignota.

Hab. in Martinique, Morne Paillasse, ad rupes: Duss 11. 20 (in Herb. Berol.); Guadeloupe ad Saint-Louis, alt. $680 \mathrm{~m}$., ad rupes: Duss n. 127 (in Herb. Berol.).

Obs. Species a congenerilus caespitibus altissimis jam dignoscenda.

7. Barlunla (Eubarbula) hymenostylioides Broth. (n. sp.). Dioica; gracilis, caespitosa, caespitibus mollibus, densis, inferne ferrugineis, superne laete viridibus. Caulis usque ad $1,5 \mathrm{~cm}$. altus, erectus, parce radiculosus, dense foliosus, superne ramosus, ramis fastigiatis. Folia sicca flexuosula, humida erecto-patentia, carinato-concara, e basi semiamplexicauli, decurrente sensim angustata, acutiuscula, $1,3-1,4 \mathrm{~mm}$. longa, basi ca. $0,3 \mathrm{~mm}$. lata, marginibus paulum revolutis, summo apice parce denticulatis, nervo basi $0,05-0,06 \mathrm{~mm}$. lato, rufescente, cum apice rel paulum infra apicem evanido, dorso laovi, cellulis subquadratis, 
basilaribus breviter reetangnlaribus, omnibus valde pellucidis, lacrissimis. Caetera ignota.

Hab. in Nartinique prope Saint-Picre et in Fonds Saint-Denis, ad terram: Duss n. 299 (in Herb. Berol.).

Obs. Species B. subulifoliae Sull. et B. ferrinere; C. Mïll. valde affunis, ab hac foliis denticulatis, ab illa foliis multo brevius acuminatis dignoscenda.

8. Hyophila mollis Brotlı. (n. sp.). Dioica; gracilis, caespitosa, caespitibus mollibus, densis, late extensis, fuciliter dilabentibus, viridissimis. Caulis $5-7 \mathrm{~mm}$. altus, erectus, parce radiculosus, dense foliosus, superne ramosus, ramis fastigiatis. Folia sicca adpressa, apiealia contorta, humida suberecta, carinato-coneava, e basi breviter spathulata late ovalia, rotundato-obtusa, usque ad 1,1 $\mathrm{mm}$. longa, superne usque ad $0,6 \mathrm{~mm}$. lata, marginibus erectis, integerrimis, nervo crassiusculo, sat longe infra apicem evanido, dorso laevi, collulis rotundato-hexagonis, $0,007-0,010 \mathrm{~mm}$., minutissime papillosis, basilaribus multo majoribus, breviter rectangularibus, lyyalinis, laevibus. Caetera ignota.

Hab. in Guadeloupe in Camp-Jacob, ad terram: Duss n. 223 (in Herb. Berol.).

Obs. Species tenella, foliis e hasi breviter spathulata late ovalilus, rotundato-obtusis, nervo sat longe infra apicem evanido faciliter lignoscenda.

9. Iyophila guadalupensis Broth. (n. sp.). Dioica; gracilis, caespitosa, caespitibus mollibus, densis, late extensis, faciliter dilabentibns, viridissimis. Caulis vix ultra $5 \mathrm{~mm}$. altus, ereetus, parce radiculosus, dense foliosus, simplex. Folia sicca incurvo-erecta, haud contorta, bumicla patula, carinato-concava, spatlulato-ligulata, obtusiuscula, mucronata, usque ad $1,8 \mathrm{~mm}$. longa et $0,47 \mathrm{~mm}$. lata, marginibus erectis, integerrimis, nervo crasso, viridi, in mucronem excurrente, dorso laevi, eellulis rotundato-hexagonis, inferne quadratis, $0,007-0,010 \mathrm{~mm}$., minute papillosis, basilaribus multo majoribus, breviter rectangularibus, hyalinis, laevibus. Caetera ignota.

Hab. in Guadeloupe in Camp-Jaeob, ad tertam: Duss n. 218 (in Herb. Berol.). sissima.

Obs. Species praecedenti labitu simillima, sed foliorum forma diver-

10. Macromitrium (Leiostoma) Mussii Broth. (n. sp.). Pseudautoicum; robustiuseulum, caespitosum, caespitibus densis, fuscescentibus, superne viridibus, nitidiuseulis. Caulis repens, fnsco-radiculosus, ramis erectis rel adscendentibus, $5-10 \mathrm{~mm}$. altis, dense foliosis, simplicibus. Folia ramea sicea arcte adpressa, apice eurvatula, lrumida ereeto-patentia, carinato-concava, lanceolata, breviter acuminata, acuta, $3 \mathrm{~mm}$. vel paulum ultra longa, basi ea. $0,57 \mathrm{~mm}$. lata, marginibus 
erectis rel uno latere basi parce revolutis, summo apice minute crenulatis, nervo rufescente, cum apiee evanido, cellulis reetangularibus, paulum inerassatis, basilaribus elongatis, incrassatis, lumine lineari, omnibus laevissimis. Bracteae perichaetii foliis similes, longius acuminatae, cellulis superioribus longioribus et angustioribus. Seta usque ad 1,5 em. alta, sicea dextrorsum torta, flexuosula, rubra, laevissima. Theea ereeta, oblongo-cylindriea, ca. $2 \mathrm{~mm}$. longa, fuscescens, laevis. Peristomium simplex, dentibus brevissimis, truneatis, albidis, valde papillosis. Spori $0,025-0,030 \mathrm{~mm}$., virides, papillosi. Operculum aciculare. Calyptra glabra. - Planta mascula minutissima, in foliis superioribus radieans.

Hab. in Martinique in Montagne Pelée, ad terram: Duss n. 351 (in Herb. Berol.).

Obs. Species ob folia hasi haul papillosa, sed apice crenulata inter Lciostomas peculiaris, cum nulla alia commutanda.

11. Philonotis evanescens Broth. (n. sp.). Dioica; gracilis, caespitosa, caespitibus mollibus, densiusculis, glauco-viridibus, haud nitidis. Caulis ad $1 \mathrm{~cm}$. usque altus, erectus, inferme fusco-radiculosus, densiuseule foliosus, simplex, obtusus. Folia sicea adpressa, haud subsecunda, humida suberecta, carinato-concava, laneeolata, obtusa, apiealia acutiuscula, $0,57-0,75 \mathrm{~mm}$. longa et $0,20-0,26 \mathrm{~mm}$. lata, marginibus lenissime revolutis, geminatim serrulatis, nervo temui, infra apicem evanido, dorso serrulato, cellulis ubique laxe et breviter rectangularibus, hyalinis, laevibus. Caetera ignota.

Hab. in Guadeloupe in Gourbeyre, ad murum fontem cingentem: Duss n. ’3S (in Herb. Berol.).

Var. $\beta$. acutifolia Broth. (n. var). Caulis superne fasciculatim ramosus. Folia acuta.

Hab. in Guadeloupe in Plateau des Rivières: Duss n. 248 (in Herb. Berol.).

Obs. Species $P h$. gracillimae Angstr. foliorum structura value affinis, scl statura robustiore foliisque densius confertis jam dignoscenda.

12. Philonotis subsphaericarpa Broth. (n. sp.). Dioiea; tenclla, eaespitosa, caespitibus mollibus, pallide viridibus, lraud nitidis. Caulis vix $5 \mathrm{~mm}$. altus, ereetus, dense rufo-radiculosus, apice ramosus, ramis $3-5$, vix ultra 3 mm. longis, curvatis, densifoliis, obtusis. Folia sicca adpressa, haud subsecunda, humida subereeta, earinato-concava, c basi lineeolata anguste acuminata, acuta, usque ad $1,2 \mathrm{~mm}$. longa et $0,28 \mathrm{~mm}$. lata, marginibus revolutis, geminatim serrulatis, norvo crassiusculo, cum apice evanido, cellulis supremis angustis, dein laxioribus, rectangularibus, papillosis. Braeteae periehaetii longius et angustius aemminatae, 
tenerrime areolatis, marginibus crectis, subintegris. Seta vix $2 \mathrm{~cm}$. alta, flexuosula, tenuis, rubra. Theca minuta, suberecta, subglobosa, sicca horizontalis, plicata, fusco-rubra. Peristomium normale. Caetera ignota.

Hab. in Martinique in Bois de la Calebasse ad viam inter Ajoupa et Bouillon, ad terram: Duss n. 39 (in Herb. Berol.).

Obs. Species Ph. sphacricarpae (Sw.) Schwaegr. affinis, sed ramis brevissinis, seta breviore et theca minore dignoscenda.

13. Daltonia Dussii Broth. (n. sp.). Synoica; robusta, caespitosa, caespitibus parvis, laxiusculis, mollibus, lutescenti-viridibus, nitidiusculis. Caulis ad $1,5 \mathrm{~cm}$. usque altus, erectus, fusco-radiculosus, dense fuliosus, subsimplex. Folia sicca flexuosulo-adpressa, humida erecto-patentia, indistincte carinato-concava, e basi elliptica lanceolatoligulata, breviter cuspidata, ca. $3 \mathrm{~mm}$. longa et ca. $0,76 \mathrm{~mm}$. lata, limbata, limbo lutescente, basi latissimo, e seriebus cellularum elongatarum, angustarum usque ad 10 composito, superne sensim angustiore, integerrimo, usque ad apicem producto ibidemque a $1-2$ seriebus cellularum formato, nervo longe infra apicem evanido, cellulis supremis subrhombeis, lumine ovali vel elliptico, dein sensim longioribus, basilaribus elongate rhomboideis, infimis brevibus, laxis, pulcherrime fusco-aureis, omnibus laevissimis. Bracteae pericliaetii minutae, obtusissimae, apiculatae, vix limbatae, enerves, integrae. Seta $7-8 \mathrm{~mm}$. longa, strictiuscula, tenuis, rubra, superne grosse papillosa. Theca erecta vel suberecta, ovalis, crassicollis, fusca, laevis. Peristomium duplex. Exostomii dentes reflexi, lanceolato-subulati, ca. $0,45 \mathrm{~mm}$. longi et ca. $0,075 \mathrm{~mm}$. lati, dense lamellati, lamellis valde rugulosis, densissime papillosis, luteis. Processus ca. $0,20 \mathrm{~mm}$. longi, lineares, obtusi, valde papillosi, lutei. Spori $0,020-0,022 \mathrm{~mm}$., virides, minutissime papillosi. Operculum e basi convexa breviter aciculare. Calyptra operculum obtegens, elegantissime fimbriata, apice fuscidula, glabra.

Hab. in Martinique, inter Ajoupa et Bouillon ad ramulos arborum rarissima: Duss n. 345 (in Herb. Berol.).

OL.s. Speeies D. brasiliensi Mitt. affinis, sed braeteis perichaetii obtusissimis, apieulatis jam dignoseenda.

14. Lepidopilum (Tetrastichium) calomicron Broth. (n. sp.). Autoicum; gracillimum, foliis arborum adnatum, viridissimum, nitidum. Canlis elongatus, repens, valde complanatus, cum foliis ad $2,8 \mathrm{~mm}$. usque latus, hic illic faseiculatim fusco-radiculosus, dense foliosus, vage ramosus, ramis brevibus, obtusis. Folia tetrasticha, lateralia, subborizontalia, planiuscula, oblonga, subito breviter acuminata, acuta, ca. $1,25 \mathrm{~mm}$. longa et ca. $0,53 \mathrm{~mm}$. lata, marginibus erectis, superne serru- 
latis, enervia, cellulis elongatis, angustissimis, dorsalia minora, erectiora, ovata, breviter acuminata, serrulata. Bracteae perichaetii minutae, erectae, ovato-lanceolatae, parce serrulatae. Seta $8 \mathrm{~mm}$. alta, strictiuscula, tenuissima, rubra, superne papillosa. Theca minuta, cermua, oblonga, fuscidula. Peristomium duplex. Exostomii dentes linearilanceolati, obtusi, ca. $0,28 \mathrm{~mm}$. longi et ca. $0,05 \mathrm{~mm}$. Jati, dense articulati, minute papillosi, pallide carnosuli. Processus concolores, dentium longitudinis, carinati, angustissime perforati, papillosi. Spori $0,017-0,020 \mathrm{~mm}$., virides, laeves. Operculum e basi alte convexa breviter conico-rostratum. Calyptra (junior) anguste conica, basi fimbriata, glabra.

Hab. in Martinique in Morne Rouge, ad folia arborum: Duss 11. 352 (in Herb. Berol.).

Obs. Species elegantissima, statura pergracili a congeneribus jan dignoscenda.

15. Lepidopilum (Eulepidopilum) integrifolium Broth. (n. sp.). Dioicum; robustiusculum, caespitosum, caespitibus mollibus, densis, viridissimis, nitidiusculis. Caulis ad $3 \mathrm{~cm}$. usque altus, erectus, basi fusco-radiculosus, paulum complanatus, dense foliosus, vage ramosus, ramis erectis, obtusis. Folia sicca vix contracta, faciliter emollita, lateralia erecto-patentia, concaviuscula, paulum asymmetrica, oblongolanceolata, breviter acuminata, acuta, ca. $3 \mathrm{~mm}$. longa et ca. $0,95 \mathrm{~mm}$. lata, marginibus usque ad apicem revolutis, integerrimis, elimbata, nervis binis, tenuibus, paulum divergentibus, ultra medium folii productis, cellulis elongatis, utrinque acutis, pellucidis, laevissimis, media minora, orato-acuminata. Bracteae perichaetii minutae, erectae, lanceolatae, integerrimae, enerves. Seta usque ad $7 \mathrm{~mm}$. alta, strictiuscula, crassiuscula, rubra, summo apice tantum mammillosa. Theca erecta, oblonga, fuscidula.. Spori $0,015-0,020 \mathrm{~mm}$., virides, laeves. Opercu$1 \mathrm{~m}$ e basi conica breviter rostratum. Calyptra fuscidula, nuda, apice lamellis prominulis scaberula.

Hab. in Guadeloupe in Bois des Bains-Jaunes, ad truncos arborum rarior: Duss n. 222 (in Herb. Berol.); Morne Grame-Verte: Duss n. $460^{\text {a }}$ (in Herb. Berol.); Martinique in Morne-Rouge, ad truncos arborum: Duss n. 372 ex p. (in Herb. Berol.).

Obs. Species foliis integerrimis jam dignoscenda.

$\checkmark$ 16. IIookeria (Euhookcria) Antillarum Broth. (n. sp.). Autoica; laxe caespitosa, caespitibus mollibus depressis, pallide viridibus, vernicoso-nitidiusculis. Caulis repens, per totam longitudinem hic illic fasciculatim fusco-radiculosus, pimnatim ramosus, ramis usque ad $5 \mathrm{~mm}$. longis, complanatis, cum foliis ca. 2,2 mm. latis, patulis densiusculo foliosis, obtusis. Folia tenera, hyalina, lateralia subhorizontalia, 
asymmetrica, oblonga, in acumen subpiliforme contracta, limbata, limbo ex unica serie cellularum composito, ad summum apicem producto, marginibus crectis, superne minute serrulatis, nervis binis, tonuibus, ultra medium productis, dorso parce denticulatis, collulis ubique laxis, supcrioribus rotundato-liexagonis, $0,025-0,030 \mathrm{~mm}$., basilaribus longioribus, media minora, erectiora, clliptica, brevius acuminata. Bracteae perichaetii minutae, c basi late orata sensim piliformi-attenuatae, integrac; seta ca. $12 \mathrm{~mm}$. alta, e basi geniculata erceta, tenuis, rubra, laevissima. Theca horizontalis, ovalis, atro-purpurea. Peristomium normale. Spori $0,010-0,012 \mathrm{~mm}$., olivacei, lacves. Operculum longe aciculare. Calyptra albida, glabra.

Hab. in Martinique ad viam inter Gros-Morne et les Deux Choux ad limga putrida: Duss n. 68 (in Herb. Berol.).

Ous. Species pulchella, tenella, caule pinnatim ramoso, ramis brevibus, foliis subpiliformi-acuminatis, superne serrulatis faeiliter dignoscenda, cum II. rariante Sull. comparanda.

17. Ilookeria (Euhoolicria) suloshareosa Broth. (n. sp.). Dioica; robustiuscula, caespitosa, caespitibus mollibus, laxiusculis, pallide viridibus, haud nitidis. Caulis elongatus, repens, parce radiculosus, ramosus, ramis 'patulis, complanatis, cum foliis ca. $4 \mathrm{~mm}$. latis, latiuscule foliosis, brevioribus, simplicibus vel longioribus, parce ramulosis, obtusis. Folia tenera, hyalina, lateralia subhorizontalia, asymmetrica, oblonga, in apiculum angustum subito contracta, limbata, limbo ex unica serie collularum composito, ad summum apicem producto, marginibus erectis, superne minute serrulatis, nervis binis, tenuibus, infra apicem evanidis, dorso laevibus, cellulis ubique laxis, superioribus subrotundohexagonis, ca. $0,050 \mathrm{~mm}$., basilaribus longioribus. Bracteae perichaetii multo minores, e basi lata sensim lanceolato-subulatae. Seta $2 \mathrm{~cm}$. vel paulum ultra alta, erecta, flexuosula, rubra, lacvissima. Theca liorizontalis, ovalis, sordide fusca. Operculum rostratum, rostro recto, subulato, longitudine thecam aequante. Calyptra ignota.

Hab. in Martinique in Mornc-houge ad latera canalis: Duss n. 285 (in Herb. Berol.).

Obs. Species II. glareosue Broth. affinis, sed foliis laxius insertis, haul homomallis, oblongis nee orato-oblongis dignoscenta.

18. Hookeria (Euhookeria) demsifolia Broth. (n. sp.). Dioica; gracilis, caespitosa, caespitibus mollibus, parvis, densiusculis, depressis, pallide lutescenti-vel fuscescenti-viridibus, haud nitidis. Caulis elongatus, repens, hic illic fusco-radiculosus, dense ramosus, ramis erectopatentibus rol patentibus, complanatis, cum foliis $2 \mathrm{~mm}$. vel paulum ultra latis, dense foliosis, brevioribus, simplicibus vel longioribus, parce 
ramulosis, obtusis. Folia erecto-patentia, tenera, hyalina, lateralia anguste orato-oblonga, breviter acnminata, acuta, limbata, limbo ex unica serie cellularum composito, ad summum apicem prodncto, marginibus erectis, superne minute serrulatis, nervis binis, tenuibus, infra apicem evanidis, dorso laevibus, cellulis superioribus rotundato-hexagonis, usque ad $0,050 \mathrm{~mm}$., basilaribus longioribus. Caetera ignota.

Hab. in Martinique ad Nacouba in rupibus: Duss n. 274 (in Herb. Berol.), in Calebasse ad ligna putrida: Duss n. 9 (in Herb. Berol.). Obs. Species foliis dense confertis oculo nudo jam dignoscenda.

19. Hookeria (Euhookeria) limbatula Broth. (n. sp.). Dioica; gracilis, caespitosa, caespitibus mollibus, parvis, densiusculis, depressis, fuscescenti-viridibus, haud nitidis. Caulis elongatus, repens, hic illic fusco-radiculosus, dense ramosus, ramis patulis, usque ad $1 \mathrm{~cm}$. longis, dense pinnatim ramulosis, ramulis complanatis, usque ad $5 \mathrm{~mm}$. longis, cum foliis ca. $1,3 \mathrm{~mm}$. latis, dense foliosis, obtusis. Folia erectopatentia, tenera, hyalina, lateralia orato-oblonga, apiculata, limbata, limbo angustissimo, vix conspicuo, ex unica serie cellularum formato, usque ad apicem producto, marginibus erectis, integris vel subintegris, nervis binis, tenuibus, infra apicem evanidis, dorso laevibus, cellulis superioribus subrotundato-hexagonis, ca. 0,030 mm., basilaribus longioribus. Caetera ignota.

Hab. in Guadeloupe in Morne Gobelin ad truncos arborum: Duss n. 237 (in Herb. Berol.).

Obs. Species statura pergracili, caule bipimnatim ramoso, foliis angustissime limbatis, integris dignoscenda.

20. Papillaria martinicensis Broth. (n. sp.). Dioica; robusta, mollis, pallide viridis, nitidiuscula. Caulis elongatus, pendulus, laxiuscule foliosus, dense ramosus, ramis patnlis, vix ultra $5 \mathrm{~mm}$. longis, densiuscule foliosis, obtusis. Folia ramea sicea suberecta, plicata, humida erecto-patentia, concava, e basi breviter decurrente, cordata ovato-oblonga, in acumen piliforme subito contracta, marginibus erectis vel basi uno latere inflexis, indistincte denticulatis, nerro tenui, ultra medium evanido, cellulis elongatis angustissimis, minutissime papillosis, alaribus paucis, viridibus, subquarlratis. Caetera ignota.

Hab. in Martinique in Montagne Pelée ad arbores: Duss n. 302 (in Herb. Berol.).

Obs. Speciés foliorum forma cum P. lalifolic (Lindlb.) comparanda, sed statura multo minore, ramis haud julaceis, foliis minus concavis longe diversa. 


\title{
VII. Burmanniaceae.
}

\author{
Exposuit \\ Ignatius Urban.
}

Die drei Gattungen Gymmosiphon, Dictyostegia und Apteria, welchen sich im Jahre 1898 noch Dipterosiphon Huber als entferntere Verwandte anschloss, werden von den nenesten Autoren (Bexthas in Benth. ef Hook. Gen. III p. 456, ExGLer in Engl.-Prantl Nat. Pfl.-fam. II. 6 p. 48) in folgender Weise charakterisirt:

Gymmosiphon durch ein Perianth, dessen oberer Theil durch ringförmige Abspaltung nach der Anthese abgeworfen wird, ein Connectiv olme Anhängsel und fast kugelige Samen;

Dictyostegia durch ein nach der Anthese unversehrt bleibendes Perianth, ein Connectiv olne Anhängsel und linealische Samen;

Aptcria durch ein P'erianth mit drei Säckchen, an deren Basis die breitgeflügelten Staubfïden stehen, und verkehrt eiförmige Samen.

Diese Merkmale erweisen sich bei den beschriebenen $\Lambda$ rten nicht immer als zutreffend. So hat Gymmosiphon portoricensis ein Periantl, dessen oberer Theil sich fast niemals abgliedert, und ein Connectir mit ganz kurzen dorsalen Anhängseln, trotzdem die Art zweifellos zu dieser Gattung gehört, Dictyostegia umbellata Miers, die zweite der vom Autor der Cattung beschriebenen Arten, umgekehrt eiförmige Samen, Gymnosiphon trinitatis Johow Säckchen unter den Filamenten wie Apterio.

Es giebt nun ausser den genannten Merkmalen eine ganze Reihe anderer, welche entweder gänzlich übersehen oder wohl in der Besclreibung oder wenigstens in der Abbildung aufgeführt, aber für die Gattungsdiagnose nicht rerwendet worden sind.

Eine der merkwürdigsten Bildungen sind die drüsenähnlichen Körperchen (in folgendem kurzweg Drüsen oder Glandulae genannt), welche sich im Innern des Ovars bei allen von mir untersuchten Gymnosiphon-Arten (mit Ansuahme von (i. trinitatis) vorfinden. Sie treten immer zu sechs parweise an orler unter der Spitze jerler Placenta auf und 
sind fast immer von rundlich-convexer oder kugeliger Form (Fig. 6, 7, 10), sehr selten (G. cymosıs) eiförmig, nach innen etwas concar und an der Spitze ein wenig eingekrümmt. Meist sind sie der Leiste, welche die flache, mehr oder weniger breite Placenta mit der Wand des Ovariums verbindet, unmittelbar angewachsen, so dass sie zu zweien eng aneinander liegen und ron den beiden Flïgeln der Placenta, wenn diese so weit hinaufreichen, zur Hälfte verdeckt werden, selten sehr kurz und dicklich gestielt (G. nireus, suaveolens); bisweilen aber nehmen sie ihren Ursprung dicht neben der Spitze der Placenta nicht von dieser, sondern von der Innenseite der apicalen Wandung des Orars, so bei G. divaricatus, G. nuticus, G. (C'ymbocarpa) refractus (Fig. 10). Gewöhnlich sind sie mehrere Male grösser als die Orula, von intensiv gelber oder Orange-Färbung und schimmern an den schwachen Vorwölbungen rings um die obere Kante des Ovars mehr oder weniger durch. Wenn sie farblos und kleiner sind, lassen sie sich in dem Orar allerdings oft schwierig auffinden, so bei $G$. sucteolens, niveus, sphaerocarpus; man kann sie dann aber, da sie niemals abfallen, in der Frucht sehr leicht nachweisen. - Was die biologische Bedeutung dieser Drüsen betrifft, so könnte man denken, dass sie, wenn sie wirklich secerniren, iluren Saft durch ihre Lage im Innern des Ovars gegen unberufene Gäste schützen, dass aber besuchende Insekten mit kräftigerem Rüssel sehr leicht den dünnen, gewöhnlich nur aus einer Zellschicht bestehenden Scheitel des Ovars durchbohren und zu dem Honig gelangen können. Es fragt sich jedoch, ob diese kleinen, im dichtesten Urwalde auf rermoderndem Laub wachsenden bleichen Pflänzchen auf Insektenbesuch angewiesen sind. Denn in den wenigen Fällen, wo eine unversehrte Blüthe vorlag, und ebenso auch in den erwachsenen Knospen fand ich immer die Antheren den Narben eng anliegend; ja die Pollenschläuche verbanden beide so innig, dass sie kaum zu trennen waren, ohne zu zerreissen; dabei bilden alle Kapseln sehr reichlich Samen aus. - Diese Drïsen sind den Autoren nicht rollstïndig entgangen; so biklet sie Miers (in Trans. Linn. Soc. XVIII tab. $38.4 \mathrm{~m}$ ) ab, ohne ihrer im Texte Erwälnung zu thum; Bextham (in Hook. Journ. of Bot. and Kew Gard. Misc. VII p. 15) lält sie für die einzigen reif werdenden Samen bei der betreffenden Art, KARsTix (in Linnaea XXVIII p. 420) beschreibt sie ziemlich zutreffend als "Corpuscula duo, orulis magnis anatropis similia, cujusvis spermophori apicem terminant", ExgLer (Bot. Jahrb. XX p. 138 tab. V H, J) hält sie für eine Verdickung der Placenten. Bei Dictyostegia mubellata Miers finden sich unter der Spitze des Ovars und zwar ausserlialb sechs Drüsen, paarweise über den Placenten halbkugelig hervortretend und unter sich miteinander verwachsen (Fig. 16). - Gymuosiphon trinitutis Johow hat diese Drüsen, welche ron dem 


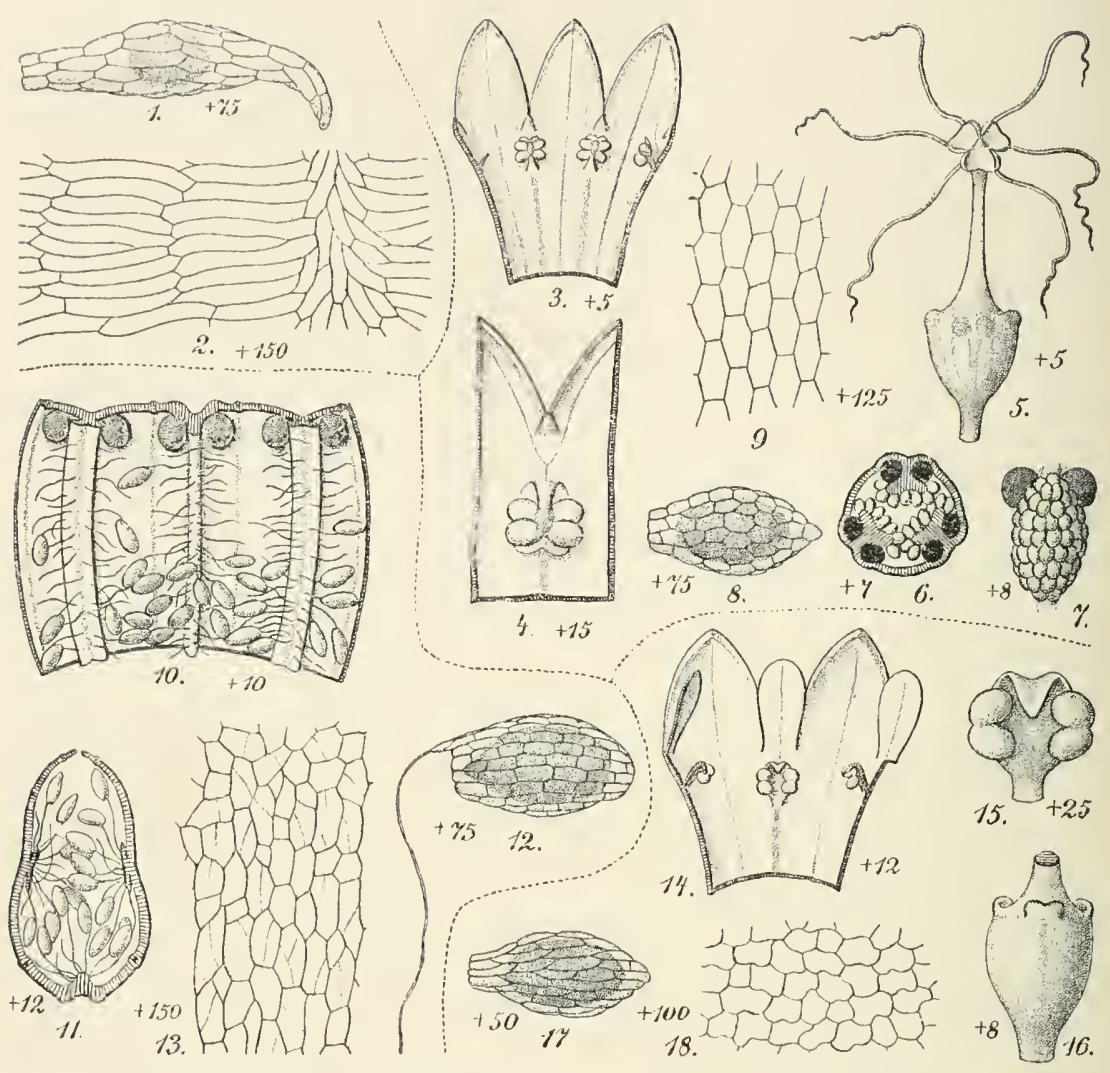

Fig. 1 - 2 Dichyostegia orobanchoides, 1. Samen, 2. Zellnetz des Pericarps. - Fig. 3-9 Gymnosiphon portoricensis, 3. Perianth ausgebreitet, 4. ein Theil desselben mit einem nach abwärts geschlagenen Stamen, 5. Gynaecenm, 6. Querschnitt durch den obersten Theil des Ovars, 7. Placenta mit den Drïsen nud Orulis, S. Samen, 9. 'Zcllnetz des Periearps. Fig. 10-13 Cymbocarpa refracta, 10. Frucht, welche sich gerade ïfnet, von der Dehiscenzkante lier ansgebreitet nach Wegnahme zahlreicher Samen, 11. đieselbe im Qnerschnitt (Pericarp zu dick gezeichnet), 12. Samen mit dem Funiculus, 13. Zellnetz der immeren Kapselwand. - Fig. 14-18 Miersiella umbellata, 14. Perianth ausgebreitet nach Wegnahme eines der insseren Segmente, 15. jüngeres Staubblatt, 16. Ovarium nit den Aussendrüisen, 17. Samen, 18. Zclhnetz des Pericarps. 

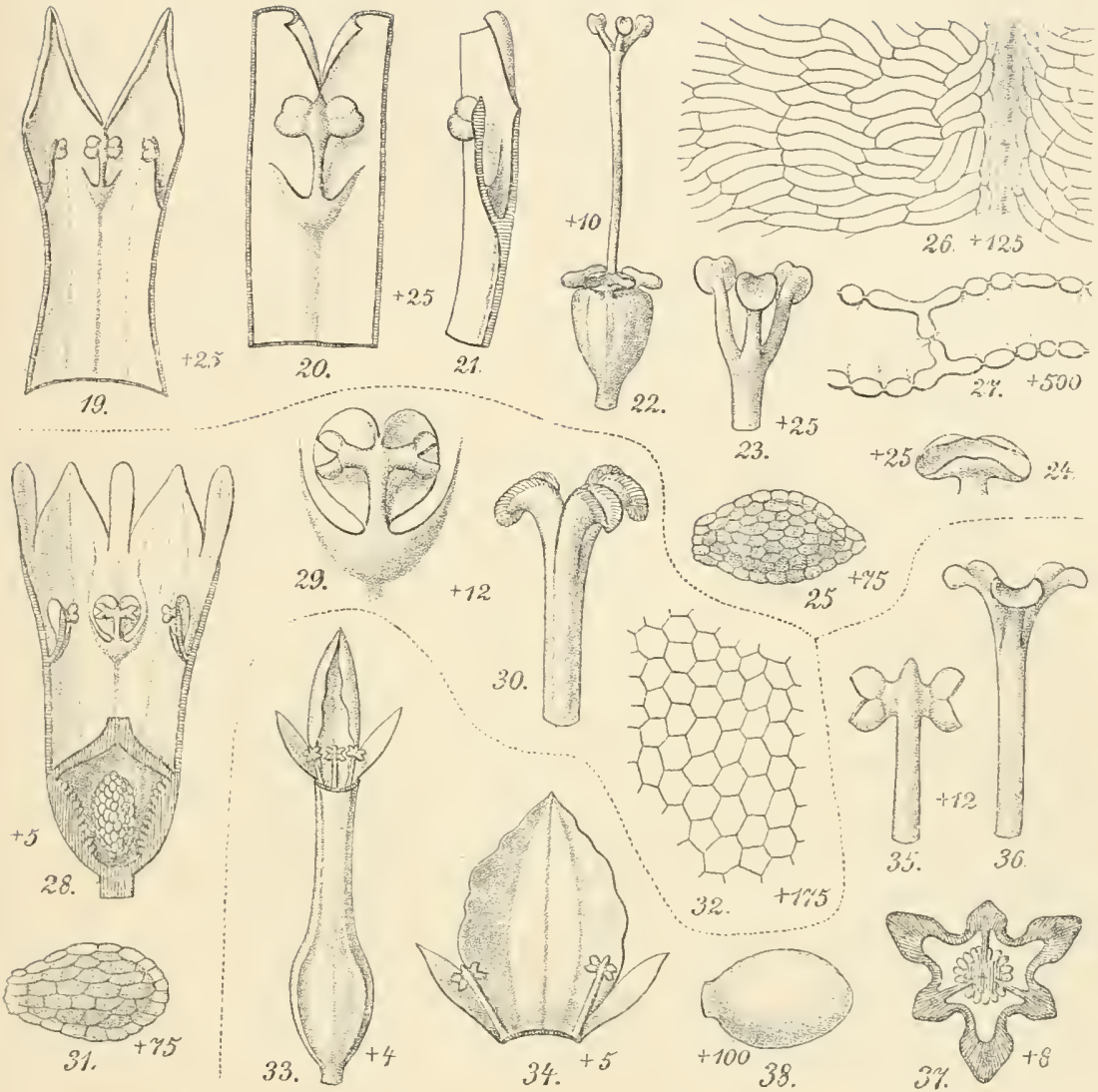

33.

30.

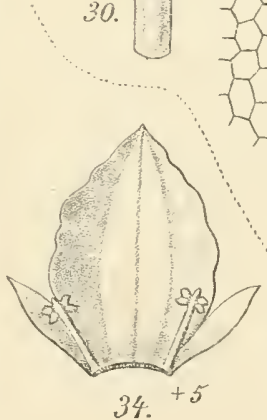

23.

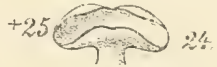

Fig. 19-27 Irarthella trinitatis, 19. Theil des Perianths ausgebreitet, 20. ein kleinerer Theil desselben, 21. desgleichen von der Seite, 22. Grnaeceum, 23. oberer Griffeltheil, 24. Doppeldrüse rom Scheitel des Orars, 25. Samen, 26. Zellnetz des Pericarps, 27. Zellen desselben mit rosenkranzartigen Verdickungen im Querschnitt. - Fig. 28 - 32 Apteria hymenanthera, 28. Blüthe nach Wegnahme eines äusseren Segments und des Griffels, ausgebreitet, 29. Staubblatt mit der Tasche, 30. Griffel, 31. Samen, 32. Zellnetz des Pericarps. - Fig. 33-38 Hexapterella gentianoides, 33. Blüthe nach dem Abfallen von zwei äusseren und einem inneren Segmente, 34. ein äusseres und zwei innere Segmente des Perianths ansgebreitet, 35. Staubblatt, 36. Griffel, 37. Querschnitt durch das Ovarium, 38. Ovulum. 
Autor cbenso wie die 'Täschchen unter den Filanıenten übersehen worlen sind, ebenfalls aussen am Scheitel des Ovars; sie sind aber paarweise kurz gestielt, schrïg nach oben und aussen ausgehölt und sehen aus wie verstäubte Antheren mit zusammenfliessenden Fäichern (Fig. 22, 24). - Bei allen übrigen Arten fehlen die Drïsenbildungen sowohl unter wie auf rem Scheitel des Orar's.

Bei den meisten Arten gehen die der Commisssur der äusseren Perianthsegmente angehörigen Nerren direkt theils in die Stamina, theils in die inneren Segmente oder wenn diese fehlell, nach einer Bifurcation als Seitennerven in die äusseren Segmente. - Bei allen Apteria-Arten tritt unter der Insertion der Filamente eine Trifurcation dieser Nerven ein (Fig. 28, 29). Der Mittelast verhält sich wie vorher; die beiden Seitenschenkel, welche bogenförmig in die äusseren Segmente als Seitennerven eintreten, senden ron der Basis an bis fast in die Höhe der Antheren ein Häutchen nacl innen und oben, welches ein sclumal halbmondförmiges Täschchen bildet. Aus der Mitte des freien Randes dieses Täschchens (nicht, wie die Autoren angeben, an dessen Basis) gehen die Filamente herror. Die letzteren, sowie das Mittelstück des Connectirs sind in eine umgekehrt eiförmige oder fast pentagone, an der Spitze ausgerandete, membranöse Platte verbreitert, auf deren oberer Innenseite die Seitenäste des Connectivs mit den Antleren lagern. - Bei Gymmosiphon trinitatis Johow (Fig. 19-21) ist die Bildung der Täschchen und die Anheftungsweise der Filamente eine ganz gleiche; nur setzen sich die Seitenäste der Nerven nicht über die Enden des Täschchens hinaus fort; auch fehlt an den Filamenten und am Connectiv die flügelartige Platte.

Bei den Apteria-Arten ist das Connectir in zwei ziemlich lorizontal stehende Schenkel wagebalkenartig gespalten (Fig. 28, 29). - Bei allen übrigen Arten ist es knopfförmig oder plättchenartig, mehr oder weniger verdickt, meist nit vorgezogener, bisweilen (Fig. 15) stark eingebogener Spitze. Sehr selten gehen von demselben noch auf dem Rücken zwei kleine Häutchen ab, welche die Antherenfächer ein wenig überragen (Fig. 4). Bei Dipterosiphon hat das Connectiv an der Spitze ein vorderes (ventrales) und zwei lintere (dorsale) Läppchen.

Bei allen Arten von Apteria und Dictyostegia (Fig. 14, 28) sind die inneren Segmente des Perianths vollständig entwickelt, nur schmaler als die üusseren (mit Ausnalnme von Apteria lilacina Miers, bei welcher die inneren etwas breiter sein sollen). Bei Gymmosiphon dagegen sind sie rudimentär (Fig. 3,4) oder felılen naclı Bкттам vollständig.

Durchans nicht linreichend bekannt war bisher das Aufspringen der Kapsel. Bei Dictyostegia reisst sie ron der Spitze nach der Basis zu mehr oder weniger tief fach-theilig auf, so dass die mit unregel- 
mässig gezähnten Rändern rersehenen Klappen die Placenta auf der Mitte tragen. - Bei Apteria springt sie seitlich durch drei Längsspalten an der Stelle auf, wo der Pückenkiel der Placenta aus dem Pericarp hervorgeht, also wand-theilig. Zu allerletzt fällt das Pericarp mit dem verwelkten Perianth ab, so dass nur die drei Placenten mit den verkïmmerten Orulis und einigen reifen Samen besetzt wie drei Hörner stehen bleiben. Ob A. lilacina Mier's, welche nach Beschreibung und Abbildung des Autors auch sonst erheblich ron den anderen Arten abweicht, eine an der Spitze aufspringende Kapsel hat, muss, da die Pflanze noch nicht wiedergefunden $z u$ sein scheint, am Original im British Museum noch einmal nachuntersucht werden, da die Misrs'schen Beobachtungen und Zeichnungen nicht immer zurerlässig sind. - Bei Gymmosiphon ist das Aufspringen ein verschiedenartiges. Bei den allermeisten Species reisst die ron der Perianthröhre gekrönte. ringsum gleichmässig ausgebildete Frucht seitlich durch drei Längsspalten an den Jerren zwischen je zwei Placenten, also fach-theilig, auf. Erst zu allerletzt und zwar nur selten fällt das Perianth ab; es bleiben dann die drei durch die Theile der Fruchtwand geflügelten Placenten übrig, mit welchen die Zwischennerven in der Gestalt ron Fäden abwechseln. Bei denjenigen amerikanischen Arten, welche BextHax unter dem Gattungsnamen Ptychomeria beschrieb (Hook. Journ. of Bot. and Kew Gard. Misc. VII p. 14), soll die Kapsel an der Spitze unregelmässig aufreissen. Ich habe von diesen keine reife Frucht untersuchen können. Die der Pt. mutica Benth. sehr nahestehende oder mit ihr identische Benitria Poeppigiana Karst. zeigt die rorhin beschriebene gewöhnliche Dehiscenz. Dagegen springt die Frucht von G. aphyllus, dem Typus der Gattung; zweifellos nur an der Spitze imnerhalb der persistirenden Perianthröhre auf und scheint ihren zart membranösen Scheitel fast ganz zu rerlieren; sonderbarer Weise wird auch in den Seitenwandungen der membranöse Theil zwischen den verdickten Netzleisten abgeworfen, so dass hier zahlreiche Oeffnungen entstehen, die aber nicht gross genug sind, um die Samen hindurchzulasssen. - Die Gattung Cymbocurpa Miers, welche mit Gymmosiphon das Vorkommen und die Stellung der Drüsen innerhalb des Ovars und das Abwerfen der oberen Perianthpartie theilt, wurde rom Autor durch eine, Capsula latere unico ad angulum superiorem tantum dehiscens" charakterisirt, ron Bexтныu (in Gen. Plant. III p. 4ว5) aber mit den Worten ,a genere nequaquam differt nisi capsula plus minus refracta interdumque nec semper inaequaliter maturescens" und ebenso von Exaler als Synonym zu (iymosiphon gezogen. Nach meiner Meinung ganz mit Unrecht (Fig. 10, 11). Denn in der That springt die mehr oder weniger horizontal gestellte Kapsel nur an der oberen Kante zwischen den beiden oberen Placenten seitlich loculicid 
auf und bleibt mit zurückgeschlagenen Rändern in der Forn eines kurzen Kiahnes bis zuletzt. Danit ist aber zugleich auch eine stark zygontorphe Ausbildung der Frucht verbunden; ob auch der Blüthe, homnte bei dem ausserordentlich spärlichen und nicht gnt conservirten Naterial an rolliommenen Blüthen nicht ermittelt werden. Höchst wahrscheinlich ist die Frucht von der Seite her stark zusammengedrückt; sicher ist, dass die obere Kante über die Basis hinaus etwas stärker vorspringt, während die untere Kante nach aussen schwach zweikielig ist. Ausserdem ragt die unterste Placenta in das Ovarium kielartig hinein, die seitlichen liegen der Innenwand des Ovariums zweiflügelig an. Zwischen der untersten und den seitlichen Placenten findet sich in der Kapselwand nur je ein feiner Nerr und zwar jener mehr genähert als diesen; an der oberen Kante dagegen, an der Stelle der späteren Deliscenz, trifft man mehrere getrennte Gefässbündel an. Endlich, was bisher gänzlich übersehen ist, sind die Samen voll Cymbocarpa mittelst eines verhältnissmässig langen, ihrer Länge ungefähr gleich kommenden, spinnwebeartig dünnen Funiculus an der Placenta befestigt, während er bei den übrigen verwandten Gattungen ausserordentlich kurz ist oder fehlt. - Von Dictyostegia umbellata Miers und Gymmosiphon trimitatis, welche, wie sich aus dieser Darstellung ergiebt, die Typen neuer Gattungen sind, ist leider das Aufspringen nicht bekannt. Zwar zeichnet Miers (l. c. tab. 37 fig. 2 l) für erstere eine Kapsel, welche sich an der Spitze mit geraden Rändern öffnet. Doch sagt er im Text (p. 542), dass die Pflanze, was at that time not sufficiently advanced to ascertain the dehiscence of the capsule".

Der anatomische Bau des Pericarps ist für die meisten der Gattungen so charakteristisch, dass man diese schon an einem Partikelchen desselben erkennen kanı. Bei Dictyostegia orobanchoides (Fig. 2) sind die Zellen ganz schnal und zwar horizontal in die Länge gezogen; die Stellen, wo bei den übrigen Gattungen die mit den Placenten abwechselnden Zwischennerven stehen, sind nur durch kürzere, schräg oder senkrecht gestellte Zellen markirt. - Bei Gymmosiphon trinitatis (Marthella) sind die Zellen ebenfalls der Quere nach ausgezogen, aber etwas kürzer: die Zwischennerven sind hier bereits vollkommen entwickelt (Fig. 26). - Bei INictyostegia umbellata (Miersiella) findet man mehr oder weniger hexaëdrische, der Quere nach nur unmerklich verlängerte Zellen (Fig. 18). — Apteria besitzt hexaëdrisch rundliche Zellen (Fig. 32). - Gymmosiphon und Cymbocarpa haben hexaëdrische, in verticaler Richtung etwas in die Länge gezogene Zellen (Fig. 9). Diese sind natürlich dann am besten zu sehen, wenn die Wandung des Pericarps sehr dünn oder einschichtig ist, z. B. bei G. divaricatus, muticus. Bei G. aphyllus Bl. und wie aus Beccan's Beschreibung (Malesia I p. 240) 
hervorgeht, auch bei den beiden anderen Arten aus dem Monsungebiete (r. borneensis und papuanus haben die Zellen dieselbe Form und Richtung wie bei den amerikanischen und afrikanischen Arten. Ausserdem ist aber diesem membranösen Pericarp ein Netz mit riel grösseren Maschen, welche etwa $S-10$ jener kleineren Zellen umfassen, und mit starken Wandungen rersehen aufgelagert. Bei der Fruchtreife rerschwinden die kleineren Zellen, so dass die Samen durch die Maschen dieses Netzes sichtbar werden.

Am besten war bisher der Bau der Samen bekannt. Der Nucleus hat immer eine ovale bis fast kugelige Gestalt. Bei Nictyostegic (mit Ausnahme ron V. umbellata) umhüllt die Testa denselben nur sehr locker und ist an beiden Enden über ihn um das mehrfache seiner Länge hinaus rorgezogen, so dass der Umriss des Samens lanzettlich linealisch wird und zwar nach der Anheftungsstelle zu mehr cylindrisch, nach der entgegengesetzten Seite hin acuminat und oft etwas eingebogen (Fig. 1). Bei D. umbellata Miers und den übrigen Gattungen liegt die Testa dem Nucleus mehr oder weniger eng an und ist an beiden Enden nicht oder nur wenig uiber denselben vorgezogen. so dass der Same die ungefähre Gestalt des Nucleus Lat, oft an der einen Seite mit einem stumpfen Spitzchen, (Fig. S. 12, 17, 25, 31).

Aus der richtigen Benutzung dieser Beobachtungen ergeben sich folgende

\section{Cliaracteres generum reformati.}

Dictyostegia Miers (p. p.). Inflorescentia semel cymose dirisa. dein in cincinnos laxifloros abiens. Perianthium totum persistens, segmentis interioribus evolutis. Stamina ad tubum medium inserta; filamenta subnulla, basi sacculo carentia, dorso non alata; connectirum inter loculos superne triangulari-productum, dorso laminula non instructum. Nervi ad insertionem staminum bifurcati, ramo altero in filamenta, altero in segmenta interiora abeunte. Orarium circumcirca aequaliter evolutum, nec apice extrinsecus, nec intus dorso summo placentarum glanduliferum. Capsula ab apice plus minus profunde loculicide dehiscens, ralvis medio placentiferis, margine irregulariter denticulatis; pericarpii cellulae angustissimae, transrersim ralde elongatae, nerris cum placentis crassis alternantibus vix indicatis. Semina lanceolato-linearia r. sublinearia; testa nucleo laxe accumbens, utrinque supra eum longe' producta, apice subulato, basi crassiuscule r. cylindraceofiliformi.

Gymmosiphon Bl. Inflorescentia semel cymose divisa, dein in cincinnos laxifloros abiens, raro subcapitato-contracta. Perianthium fere semper posterius sub fauce plus minus regulariter circumscissum. 
parte superiore decidua, segmentis interioribus nullis v. minutis v. parvis dentiformibns. Stamina ad $v$. sub fance inserta; filamenta brevissima r. subnulla, sacculo carentia, non alata; connectivum crassiusculum, non appendiculatum v. dorso supra loculos in lamellulas 2 membranaceas perbreves productum. Nervi tubi ad insertionem staminum bifurcati, ramo altero in filamenta abeunte, altero supra insertionem nunc iterum obsolete bifurcato, ramulis lis in segmenta corollae exteriora abeuntibus. Ovarium circumcirca aequaliter evolutum, apice extrinsecus eglandulosum, intus juxta v. post quamque placentam ad ejus apicem glandulis binis crassiusculis rotundatis r. globulosis V. ovatis sessilibus v. brevissime stipitatis, plerumque placentae adnatis, raro e latere verticis ovarii interiore prodeuntibus instructum. Capsula apice irregulaliter v. plerumque rimis 3 longitudinalibus loeulicide dehiscens, valvis medio placentiferis; pericarpii cellulae subquadratae v. breviter et longitrorsum liexangulares, nervis cum placentis alternantibus bene evolutis. Semina funiculis nullis subnullisve, globulosa, obovata, anguste oborata v. ovalia; testa accumbens, utrinque supra nucleum parum v. vix producta.

Sect. I. Eugynnosiphon Urb. Capsula apice tantum dehiscens. Pericarpium reti valido postremum perforato constructum. - Java, Borneo, Nora Guinea.

Sect. II. Ptychomeria Urb. Capsula rimis 3 longitudinalibus dehiscens (an semper?). Pericarpium reti carens, tenue v. tenuissimum. - Africa et America tropica.

Obs. Species examinatae: G. aphyllus Bl. (generis typus, e Java), G. comutus Benth. (e Brasilia sept.), G. cymosus Benth. (item), G. divaricatus Benth. (item), G. fimbriatus Urb. (Ptychomeria fimbriata Benth., item), G. Glarioiii Urb. ${ }^{1}, G$. muticus Urb. (Ptychomeria mutica Benth., item; ad hunc Benitzia Poeppigiana Karst. valde accedit r. idem est), G. pusillus Urb.2, G. squamatus Wright (ex Africa occid.; rerisimiliter continet species diversas), G. suaveolens Urb. (Benitria suaveolens Karst. e Venezuela), G. tenellus Urb.

1) G. Glaziovii Urb. (n. sp.p.) planta $5-7 \mathrm{~cm}$. alta, foliis caulinis $4-6$ late oratis $\mathrm{r}$. subrotundatis ca. $1 \mathrm{~mm}$. longis; inflorescentiis 1 - v. plerumque cymose 3 -floris, pedicellis fructiferis ca. $1 \mathrm{~mm}$. longis; perianthii tubo (quoad persistente) $5 \mathrm{~mm}$. longo, 0,8 mm. lato, segmentis?; stylo usque $2 \mathrm{~mm}$. exserto; capsula breriter globulosa, basi attenuata, $1,3 \mathrm{~mm}$. longa et crassa; seminibus luteis oboratis, vix $0,3 \mathrm{~mm}$. longis, 0,15-0,18 mm. crassis. - Hab. in Brasilia: Glazion n. 19908 (p. p.).

2) G. pusillus Urb. (n. sp.) planta $3-5 \mathrm{~cm}$. alta, foliis caulinis $4-7$ ovatis v. breviter ovatis ca. $1 \mathrm{~mm}$. longis; inflorescentiis cymose $3-5$-floris, pedicellis fructiferis 2-5 mm. longis; perianthii tubo (quoad persistente) ca. 1,5 mm. lougo, 0,7-0,8 mm. crasso, segmentis?; stylo parum exserto; capsula ovali-oblonga, $3 \mathrm{~mm}$. longa, 1,5 mu. crassa; seminibus flavis, obovatis v. anguste obovatis, $0,3 \mathrm{~mm}$. longis, 0,18-0,2 num. crassis. - Hab. in Brasilia: Glaziou n. 19908 (p. p.). 
(Ptychomeria tenella Benth., e Brasilia sept.), G. nsambaricus Engl. (ex Africa orient.) et species 5 antillanae insequentes. - Mihi non visi: G. bomeensis Becc. (Borneo), G. papuanus Becc. (Nova Guinea), G. congestus Wright (Africa tropica), G. capitatus Urb. (Ptychomeria capitata Benth., Brasilia sept.).

Cymbocarpa Miers. Inflorescentia semel cymose divisa, dein in cincimnos pauci- et laxifloros abiens r. uniflora. Perianthium postremo sub fauce circumscissum, parte superiore decidua, segmentis interioribus parvis v. minutis. Stamina ad faucem inserta; filamenta subnulla, sacculo carentia, non alata; connectivum latum non appendiculatum. Nerri tubi ad insertionem staminum bifurcati, ramo altero in stamina abeunte, altero ut videtur superne evanescente. Ovarium: zygomorphum, apice extrinsecus eglandulosum, intus juxta quamque placentam ad ejus apicem glandulis binis crassiusculis globulosis instructum. Capsula zygomorpha, verisimiliter a latere compressa, basi supera paullo protracta, latere supero rima solitaria longitudinali loculicide dehiscens; pericarpii cellulae longitrorsum subhexangulares, nervis cum placentis alternantibus 2 inferioribus (anticis) tenuibus, superiore in fasciculos singulos fibrovasales dissoluto. Semina funiculis elongatis tenuissime arachnoideosetaceis affixa, elliptica v. oblonga; testa accumbens, utrinque supra nucleum parum producta. - Species unica.

Miersiella Urb. (n. gen.). Inflorescentia semel cymose divisa, dein in cincinnos abiens, sed plus minus umbelliformi-abbreviata. Perianthium totum persistens, segmentis interioribus evolutis. Stamina sub fauce inserta; filamenta brevissima latiuscula, basi sacculo carentia, dorso non alata; connectivum dorso supra loculos paullulo laminiformi-productum, apice valde inflexo specie bilobum. Nervi ad insertionem staminum bifurcati, ramo altero in filamenta, altero in segmenta interiora abeunte. Orarium circumcirca aequaliter evolutum, sub apice extrinsecus glandulis 6 supra placentas binatim connatis depresso-calliformibus praeditum, intus sub apice placentarum eglandulosum. Capsula ? dehiscens; pericarpii cellulae subquadrato- r. breviter transversim rectangularihexagonae, nervis cum placentis angustis alternantibus bene erolutis. Semina (juniora) oborata v. obovato-oblonga, testa utrinque non producta. - Species unica. ${ }^{1}$

1) I. umbeilata Urb. Fig. nostrae 14-18. - Dictyostegia mmbellata Miers in Proc. Limn. Soc. I (1S10) p.61, Ann. of Tat. Hist. V p. 133 et in Trans. Lim. Soc. IVIII p. $5+1^{\circ}$ tab. 37 fig. 2; Warm. in Vidensk. Selsk. Fork. Kopenh. 1901 p. 1 S. f.5. - Hab, in Brasilia austro-orientali: Glaziou n. 18560, Sellow, Ule n.2704.

Obs. Descriptio et icones Miersianae bene quadrant praeter ovarii apicem 3 gibberosum (sine dubio male observatum), orula erronee more Dictyostegiae delineata et styli apices male exaratos (re vera simpliciter canaliculatos). Quibus rebus neglectis non dubito quin exemplaria laudata speciem Miersianam praebcant. 
Marthella Urb. (n. gen.). Inflorescentia semel cymose divisa, dein in cincinnos abiens, sed semper capituliformi-contracta. Perianthium persistens, segmentis interioribus nullis. Stamina ad faucem tubi e margine medio sacculi parvi abeuntia; filamenta bene evoluta, exalata; connectirum breve non appendiculatum, inter loculos superne apiculatum. Nervi sub insertione sacculi trifurcati, ramo intermedio in filamenta abeunte, 2 lateralibus sacculum suffulcientibus et supra eum vix productis. Ovarium circumcirca aequaliter evolutum, sub apice extrinsecus glandulis 6 supra placentas binatim inter sese connatis, extrinsecus concavis, brevissime stipitatis praeditum, intus sub apice placentarum eglandulosum. Capsula ? dehiscens; pericarpii cellulae anguste subrectangulares, transversim elongatae, nervis cum placentis satis angustis alternantibus parum evolutis. Semina ovali-globosa v. subglobosa; testa accumbens, utrinque non producta.

Ipteria Nutt. Inflorescentia ab initio cincinnosa, rarissime semel bifurcata. Perianthium totum persistens, segmentis interioribus evolutis. Stamina ad tubum medium e margine medio sacculi parri abeuntia; filamenta bene evoluta sicut connectivum dorso in laminulam obcordatam dilatata; connectivum in ramos 2 subhorizontales protractum. Nervi sub insertione sacculi trifurcati, ramo intermedio partim in filamenta, partim in segmenta interiora abeunte, ramis 2 lateralibus sacculum suffulcientibus et in segmenta exteriora arcuatim intrantibus. Orarium circumcirca aequaliter erolutum, nec apice extrinsecus, nec intus dorso summo placentarum glanduliforum. Capsula lateraliter longitrorsum secus placentas (septicide) dehiscens, valvis postremo cum perianthio emarcidn deciduis, placentis persistentibus; pericarpii cellulae minutae hexagonoorbiculares, nervis cum placentis latis alternantibus bene erolutis. Semina obovata v. obovato-oblonga; testa accumbens, utrinque non producta.

Dipterosiphon Huber. Inflorescentia semel cymose divisa, dein in cincinnos laxifloros abiens. Perianthium totum persistens, segmentis interioribus bene evolutis quam exteriora paullo angustioribus, sed aequilongis. Stamina sub fauce inserta; filamenta perbreria, sacculo carentia, non alata; connectivum apice antico (interiore) in lobulum forma varium excurrens, dorso praeterea lobulis duobus divergentibus instructum. Nerri tubi ad insertionem staminum bifurcati, ramo altero in stamina abeunte, altero paullo superius trifurcato, ramulo intermedio in segmenta interiora, lateralibus in latera segmentorum exteriorum excurrentibus. Ovarium lineari-oblongum, paullo compressum, anguste bialatum ideoque subzygomorphum, placentis ope lamellulae valde prominentis in cavitatem intrusis sed in centro sese non attingentibus, glandulis apice extrinsecus 
et intus sub apice deficientibus. Capsula . . Semina breviter obovata, funiculis brevissimis.

Species unica Brasiliae prov. Pará inhabitans (cf. Hulber in Bol. Mrus. Paraense II 1898 p. 502 et Bull. de l'Herb. Boiss. VII 1899 p. 124-128 tab. IV). - Vidi specimen a cl. Huber herbario Boissier-Barbey traditum.

\section{Claris generum antillanorum.}

A. Ovarium 1-loculare.

a. Semina lanceolato-linearia v. sublinearia.

Intlorescentia semel cymose dirisa, dein cincinnosa. Perianthinm 6-lobum persistens. Capsula ab apice loculicide dehiscens

T. Dictyostcgia Miers.

b. Semina subglobosa usque ovali-elliptica.

a. Periantlium sub fauce fere semper circumscissum, parte superiore decidua. Filanenta basi sacculo carentia. Orarium intus post v. juxta apicem placentarum glandulis 6 instructum. Perianthii segmenta interiora plus minus abortiva $v$. nulla.

Capsula circumcirea aequaliter evoluta, apice irregulariter v. fissuris 3 lateraliter loculicide dehiscens. Seminum funiculi nulli . . . . . . . II. Gymmosiphon Bl.

Capsula zygomorpla (a latere compressa), rima solitaria postice (suipra) longitrorsum dehiscens. Seminum funiculi tenuissimi elongati . . . III. Cymbocarpa Miets.

$\beta$. Perianthium totum persistens. Filamenta basi sacculo instructa. Orarium intus non glanduliferum.

Inflorescentia semel cymose divisa, dein cincinnosa, sed capituliformi-contracta. Perianthii segmenta interiora nulla Filamenta non alata. Orarium apice extrinsecus glandulis 6 binatim connatis instructum. Capsula?

IV. Marthella Urb.

Inflorescentia ab initio laxe cincinnosa. Perianthii segmenta interiora evoluta. Filamenta late alata. Ovarium apice nudum. Capsula septicide dehiscens

\section{T. Apteric Nutt.}

B. Orarium 3-loculare

VI. Burmamia L.

\section{Dictyostegia Miers.}

1. Dictyostegia orobanchoides Miers in Proc. Linn. Soc. I (1810) p. 61, in Amm. of Nat. ITist. I p. 133 et in Thans. Limn. Soc. XVIII (18t1) p. 539 tab. 37 fig. 1!; Senb. in Mart. Flor: Bras. III. I p. 58; Griseb.! Flor. p. 606; .Johom in Pringsh. Jahrb. TX (1889) 
p. 455 seq. tab. 19 fig. 4 (hab.), tab. 22 fig. 20 (semen); Engl.-Prantl. Nat. Pfl.-fam. II. 6 p. 49 fig. 39 D-G. - Fig. nostrae 1-2.

Apteria orobanchoides Hook. Ic. plant. III (1840) tab. 254.

Hab. in Trinidad in Savana de Aripo: Crueger n. 236; - praeterea in Guiana gallica: Sagot n. $116 \pm$ (p. p.), Brasilia austro-orientali: Glaziou n. 4886, 18559, Ule n. 332, 877, 4002.

Obs. Planta trinitensis et guianensis rix nisi corolla paullo breviore $1,5 \mathrm{~mm}$. longa et segmentis obtusioribus a typo hrasiliensi differt.

\section{Gymnosiphon Bl.}

\section{Conspectus specierum.}

A. Perianthium 2-3 mm. longum. Capsula globulosa.

a. Styli lobi non appendiculati. Semina pallide brunescentia

\section{G. sphecrocarpus Urb.}

b. Styli lobi in fila producti. Semina flava 3. G. parviflorus Urb.

B. Perianthium $3,5-5 \mathrm{~mm}$. longum. Capsula obovata, ovalis r. ovatooblonga.

a. Perianthii segmenta exteriora lobulis v. dentibus binis aucta.

$\alpha$. Segmenta exteriora märgine infero bilobulata, interiora ad sinum abeuntia. Capsula $3-4 \mathrm{~mm}$. longa. Semina brunea

4. G. nivens Urb.

ß. Segmenta exteriora sub apice bidentata, interiora sub sinu abeuntia. Capsula $2-2,5 \mathrm{~mm}$. longa. Semina pallicle flava, multo minora

5. G. Germaini Urb.

b. Perianthii segmenta exteriora integerrima.

Capsula obovata. Semina pallide flava 6. G. portoricensis Urb.

2. Gymmosiphon sphacrocarpus Urb. (n. sp.) inflorescentia usque $30 \mathrm{~mm}$. longa, laxa, 7-15-flora, prophyllis $1,3-1 \mathrm{~mm}$. longis, pedicellis primariis interdum usque $2,5 \mathrm{~mm}$., caeteris $1,5-0,5 \mathrm{~mm}$. longis; perianthii tubo ca. $2 \mathrm{~mm}$. longo, segmentis 3 exterioribus tubo $2-21 / 2$ plo brevioribus 3 -lobis, lobo intermedio breviter triangulari, lateralibus oblongo-lanceolatis v. ovato-oblongis, segmentis interioribus sub sinu abeuntibus minutis ovato-oblongis $\mathrm{r}$. oblongis; styli lobis transversim subovalibus, non appendiculatis; ovario breviter turbinato v. semiovali; capsulis globulosis, $1,5-1,8 \mathrm{~mm}$. longis; seminibus breviter v. globoso-obovatis, pallide brunescentibus, $0,15-0,2 \mathrm{~mm}$. longis, $0,12-0,15 \mathrm{~mm}$. latis.

Planta $6-10 \mathrm{~cm}$. alta. Caulis erectus, saepius tortuosus, simplex v. ramosus, inferne $0,3-0,7 \mathrm{~mm}$. crassus, in sicco flavo-albidus, internodiis $0,5-1 \mathrm{~cm}$. longis. Folia basalia lanceolato-linearia v. lineari-subulata, sursum curvata, caulina $6-12$, ovata r. late ovata ca. $1 \mathrm{~mm}$. longa obtusa, superiora magis remota, saepe gemmas in axillis gerentia. Inflorescentia semel cymose divisa, dein in cincinnos laxifloros abiens: pedicelli recti erecti. Perianthii tubus cylindraceus; segmenta 3 exteriora $0,7-1 \mathrm{~mm}$. 
longa, lobo intermedio breviter triangnlari obtusiusculo, lateralibus vix $r$. uon brevioribus, sed pluries angustioribus; interiora sub sinu exteriorum ad faucem abeuntia; pars perianthii superior postremo circumcirca soluta et decidua. Stamina tubo corollino smpra medium affixa; filamenta subnulla; antlerac anbitu subquadratae, connectivo crassiusculo supra loculos in apiculum subulatum brevissimum producto, transversim dehiscentes. Stylus $1.5 \mathrm{~mm}$. longus, ad apicem et basin paullo incrassatus; lobi subsessiles obsolete bilobulati, marginibus incurris, concavi. Orarium sub antlesi $0,7-1$ mun. lougum et superne crassum. intus sub apice post placentas latintsculas glandulis ter binis orbicularibus saepe difficile conspicuis, extrinsecus non manifestis instructum; orula unltiseriata oborata v. breviter obovata. Capsula basi vix r. non attenuata, 1,5-1,S mm. diametro, longitrorsum fissuris 3 dehiscens. Semina basi breviter acuminata $r$. apiculata, testa accumbente brinescente.

Hab. in Guadeloupe: l'Herminier, in sylvis superioribus BainsJaunes parum frequens ad arbores emortuas, m. Oct. fl. et fr.: Duss 1. 3942 .

Obs. Affinis est G. areuatus Urb. (e Guiana gallica ad Karouaur: Sagot 11. 1164 p. p.), qui inflorescentia pauciflora, ramis cincinnormm arcuatis, periantlui tubo persistente fere duplo longiore, capsulis sphaeroideis, seminibus dimidio majoribus bruneis differt.

3. Gymmosiphon parviflorus Urb. (n. sp.) inflorescentia $2 \mathrm{~cm}$. longa, laxa, ca. 7 -flora, prophyllis $1,5-1 \mathrm{~mm}$. longis, pedicellis $2-1 \mathrm{~mm}$. longis; perianthii tubo ca. $1,5 \mathrm{~mm}$. longo, segmentis 3 exterioribus lobulo lineari utrinque donatis, interioribus....; styli lobis fila bina emittentibus; orario obovato-globoso; capsulis globulosis r. oborato-globulosis 2 -2,5 mm. longis et crassis; seminibus oboratis, flavis, $0.25 \mathrm{~mm}$. longis, $0.15 \mathrm{~mm}$. crassis.

Planta 12 cns. alta (specimen unicum tantum risum). Caulis curvatoerectus, simplex, inferne $0,5 \mathrm{~mm}$. crassus, in sicco stramineus, internodiis $0,4-0,8 \mathrm{~cm}$. longis. Folia basalia oblongo-lanceolata acuminata $1-1,5 \mathrm{~mm}$. longa, canlina 14 orata v. late ovata, apice rotundata v. obtusa, pleraque gemmas in axillis gerentia. Inflorescentia semel cymose divisa, dein in cincinnos laxifloros abiens; prophylla ovata; pedicelli suberecti v. postrento patentes, recti v. vix arcuati. Perianthium (unicum in alabastro tantum examinatum) verisimiliter vix supra $2 \mathrm{~mm}$. longum; tubus subcylindraceus; lobi obtusi; pars superior demum circumcirca solnta et decidua, inferior persistens vix $1,5 \mathrm{~mm}$. longa. Stamina fauci perianthii affixa; antherarum loculi superne connectivo crassiusculo disjuncti, transrersim deliscentes. Stylus superne paullo attenuatus; lobi subsessiles. Orarium sub anthesi $1,7 \mathrm{~mm}$. longum, $1,4 \mathrm{~mm}$. crassum, intus sub apice post placentas glandulas ter binas rotundatas orulis parum majores, extrinsecus non conspicuas praebens; orula multiseriata, oborata r. subanguste oborata. Capsula basi vix r. parum protracta, longitrorsum deliscens. Semina apice olitusa v. rotundata, basi paullo supra micleum producta obtusa, testa accumbente.

Hab. in Cuba or. inter folia emortua prope Montererde, m. Aug. flor.: Wright. 
(O)s. Ab altera specie cubensi internodiis brevibus, longitudine pedicellorum, periantliii parte persistente perbrevi, forma capsularum, seminibus flaris minoribus statim dignoscendus.

4. (ymmosiphon nivens Urb. inflorescentia $20-50 \mathrm{~mm}$. longa, laxa, 7-13-flora, prophyllis $2-1,5 \mathrm{~mm}$. longis, pedicellis $3-4 \mathrm{~mm}$. longis: perianthii tubo $3 \mathrm{~mm}$. longo, segmentis 3 exterioribus tubo duplo brevioribus, margine infero lobulos 2 lanceolato-lineares gerentibus, interioribus parris ovatis ad sinum abeuntibus; styli lobis fila 2 setaceoattenuata enittentibus; ovario ovali-oblongo; capsulis ovalibus v. ovatooblongis, $3-4 \mathrm{~mm}$. longis: seminibus anguste obovatis, bruneis, $0,35-0,4 \mathrm{~mm}$. longis, $0,15-0,2 \mathrm{~mm}$. crassis.

Ptychomeria niven Griscb.! Cat. (1866) p. 257; Sanv. Cub. n. 2486 p. 166 .

Planta $10-20 \mathrm{~cm}$. alta, albida (ex $W_{R}$ ). Ca nlis ascendenti-erectus, simplex $v$. parce ramosus, inferue $0,5-0,8 \mathrm{~mm}$. crassus, in sicco stramineus, internodiis inferiorihus $1-2 \mathrm{~cm}$. longis. Folia caulina $5-10$, ovata v. late ovata $1-1,5 \mathrm{~mm}$. longa. Infloresceutia semel cymose divisa, dein in cincinnos laxifloros abiens; perlicelli postremo patentes v. subhorizontales, recti v. subarcuati. Perianthii tubus cylindricus; segmenta 3 exteriora $1,5-1,8 \mathrm{~mm}$. longa, lobo intermedio ovato $\mathrm{v}$. anguste ovato obtuso, interiora clavata (ex $W_{\mathrm{R}}$.); pars perianthii superior postremo circumcirca soluta et decidua. Stamina tubo perianthii supra medium affixa; filamenta subnulla; antherae ambitu subquadratae, connectivo lato, antice truncato. Stylus 2,3 mm. longus, ad basin ipsam incrassatus, caeterum aequicrassus; lobi lutei sessiles, antice leviter emarginati. Ovarium basi obtusum, sub anthesi $1,5 \mathrm{~mm}$. longum, superne $0,6-0,7 \mathrm{~mm}$. crassum, intus sub apice post placentis glandulis ter binis (nunc pancioribus) parvis quan orula paullo tantum majoribus non coloratis ideoque difficile conspicuis (in fructu manifestioribus breviter et crassiuscule stipitatis) instructum; ovula pauciseriata suborbicularia. Capsula basi parum v. vix acutata, $2 \mathrm{~mm}$. crassa, longitrorsum fissuris 3 dehiscens, postremo in crura 3 placentifera et fila 3 (nervos cum placentis alternos) disceclens. Semina basi appendice cylindracea iis duplo et ultra breviore obtusa praedita, testa accumbente.

Hab. in Cuba orient. inter folia emortua sylrarum ad Valparaiso: Wright n. 3285 .

()bs. Florem unicum tantum imperfecte obvium examinare potui.

5. Gymmosiphon Gernaini Urb. (n. sp.) inflorescentia $15-80 \mathrm{~mm}$. longa, laxa, 7-15-flora, prophyllis 1,5-1 mm. longis, pedicellis primariis $2-5 \mathrm{~mm}$, caeteris $4-1,5 \mathrm{~mm}$. longis; perianthii tubo $2,5-3 \mathrm{~mm}$. longo, segmentis 3 exterioribus tubo ca. dimiclio brevioribus, sub apice bidentatis, interioribus sub sinu abeuntibus minutis oratis r. oblongis: styli lobis fila 2 setaceo-attenuata usque $3 \mathrm{~mm}$. longa emittentibus; ovario turbinato; capsulis ovalibus r. oboratis $2-2,5 \mathrm{~mm}$. longis: seminibus obovatis $v$. anguste obovatis, pallide flavis, $0,2-0,25 \mathrm{~mm}$. longis, $0,1-0,12 \mathrm{~mm}$. crassis. 
Planta $10-20 \mathrm{~cm}$. alta. Caulis erectus, strictus v. curratus, simplex v. rarius ramum solitarium emittens, inferne $0,3-1 \mathrm{~mm}$. crassus, in sicco stramineus. Folia basalia ovata r. oblonga acuminata $1-1,5 \mathrm{~mm}$. longa. caulina $4-7$ ovata r. late ovata oltusa ca. $1 \mathrm{~mm}$. longa, internodiis $1,3-2 \mathrm{~cm}$. longis. Inflorescentia semel cymose divisa, dein in cincinnos laxifloros abiens; pedicelli recti v. subrecti, posterius patentes r. divaricati. Perianthii tubus subcylindricus; segmenta 3 exteriora $1,8-2 \mathrm{~mm}$. longa, ovata obtusa, superme ntroque latere lobulum dentiformem gerentia, interiora sub sinu ad faucem abeuntia; pars perianthii superior postremo circumcirca soluta et decidua. Stamina tubo perianthii in $2 / 3$ alt. affixa; filamenta subnulla; antherae ambitu subquadratae, comnectivo crassiusculo dorso olssolete biapiculato. Stylus $2-2,5 \mathrm{~mm}$. longus, ad basin sensim incrassatus; lobi lutei subsessiles, antice leriter emarginati. Orarium inferne sensim attenuatum, sub anthesi 1,5-2 mm. longum, superne 0,8-1,2 mm. crassum, intus sub apice post placentas glanchulis orbicularibus crassis extrinsecus bene conspicuis instructum; orula multiseriata oborata. Capsula basi plus minns attenuata, 1,5-1,S mm. crassa, longitrorsum fissuris 3 dehiscens. Semina basi apiculata $\mathrm{r}$. breviter acuminata, testa accumbente.

Hab. in Guadeloupe in sylris ad truncos emortuos, m. Oct. fl. et fr.: Germain (herb. l'Herminier).

Obs. A G. portoricensi Lrb. vix nisi perianthii segmentis bidentatis diversus, quoad e floribus non perfecte obviis apparet.

6. Grymosiphon portoricensis Urb. (n. sp.) inflorescentia usque $25 \mathrm{~mm}$. longa, laxa, 3-11-flora, prophyllis 1,5-1 mm. longis, pedicellis inferioribus 2 - $3 \mathrm{~mm}$, raro usque $5 \mathrm{~mm}$. longis; perianthii tubo fere $3 \mathrm{~mm}$. longo, segmentis 3 exterioribus tubo subaequilongis r. paullo brevioribus integerrimis, interioribus minutis: styli lobis breviter obtriangularibus, fila 2 setaceo-attenuata usque $4 \mathrm{~mm}$. longa emittentibus; ovario turbinato; capsulis obovatis, $3 \mathrm{~mm}$. longis; seminibus oralibus $\mathrm{r}$. oratis, pallide flaris, $0,2-0,3 \mathrm{~mm}$. longis, $0,1-0,15 \mathrm{~mm}$. crassis. Fig. nostrae $3-9$.

Planta $7-15 \mathrm{~cm}$. alta. Caulis e basi curvata erectus, simplex $\mathrm{r}$. raro ramum solitarium emittens, albidus (ex SiNT.), in viro teres, 0,3-0,5 mm. crassus, internodiis inferioribus $1-1,8 \mathrm{~cm}$. longis. Folia caulina $5-15$, orata 5 . late orata apice rotundata, ca. $1 \mathrm{~mm}$. longa, superiora valde remota, saepe gemmas in axillis gerentia. Inflorescentia semel cymose divisa, dein in cincinnos laxifloros abiens; prophylla ovata, apice rotundata r.obtusa; pedicelli recti patentes. Perianthinm album (ex Suxт.); tubus cylindraceus sub fauce paullo constrictus; segmenta 3 exteriora in aestivatione valvata, marginibus incurvis, anguste ovata r. oblonga, $2,5-3 \mathrm{~mm}$. longa, sub anthesi subplana; pars perianthii superior plerumque persistens marcescens, rarius circumcirca solutus et deciduus. Stamina tubo supero inserta; filamenta subnulla; antherae subsessiles, loculis connectivo crassiusculo globuloso dorso supra loculos in lamellulas 2 membranaceas producto clisjunctis. Stylus 2,3 mm. longus, crassiuscule filiformis, superne parum attenuatus; lobi sessiles, marginibus lateralibus incurvis, apicali leriter emarginato, extrinsecus ad latera sub apice fila bina emittentes, filis in alabastro sub 
apice segmentorum perianthii rarie curvatis v. involutis. Ovarium obtuse trigonum, sub anthesi $2 \mathrm{~mm}$. longum, superne 1,3 $\mathrm{mm}$. crassum, intus glandulas globulosas ovulis pluries crassiores aurantiacas, extrinsecus bene conspicuas, in apice utriusque lateris placentarum sitas et post eas affixas gerens; ovula multiseriata, elliptica v. ovalia. Capsula basi attenuata, superie $2 \mathrm{~mm}$. crassa, longitrorsum fissuris 3 deliscens. Semina apice brerissime v. vix acuminata, basi saepius obtuse apiculata, testa accumbente, utrinque brevissime supra moleum producta.

Hab. in Portorico prope Yabucoa in sylva primaeva ad Guajabota rara m. Sept. fl. et in monte Piedra azul ad Jácana m. Oct. fl., prope Aguada in terra humosa sylvae montis Piedra blanca, m. Dec. fl.: Sintenis n. 5170 (materiem alcoolicam quoque examinavi), 5259, 5707.

Obs. Habitu simillimus G. niveo, sed perianthii segmentis exterioribus integris, glandulis sub apice ovarii crassis bene conspicuis, seminum magnitudine et colore sine dubio specifice diversus.

\section{Cymbocarpa Miers.}

7. Cymbocarpa refracta Miers! in Proc. Lim. Soc. I (1840), Amm. of Nat. Hist. Y p. 13.3 p. 62 et in Trans. Limn. Soc. IVIII (1St1) p. $5 . t$ lab. 38 f. t!'; Senb. in Mart. Flor. bras. III. I p. 60; Karst.! in Limnaca XXIIII p. 423. - Fig. nostrae 10-13.

Ptychomeria tenella Ciriseb.! Cat. (1S66) p. 257; Sauv. Cub. n. 2485 p. 166 , - non Benth.

Gymmosiphon refractus Benth. in Benth. et Hook. Gen. III (1883) p. 458; Johow in Pringsh. Jahrb. XY tab. XIX fig. 3 (mala).

Planta $8-12 \mathrm{~cm}$. alta. Caulis erectus v. curvato-erectus, simplex, inferne $0,3-0,6 \mathrm{~mm}$. crassus, in siceo flavidus, internodiis inferioribus $0,6-1,5 \mathrm{~cm}$. longis. Folia basalia ovata vo ovato-oblonga acuminata, $1-1,5 \mathrm{~mm}$. longa, imbricata, canlina $6-15$ ovata $\mathrm{r}$. ovalia, apice acutata r. obtusa, $1-1,5 \mathrm{~mm}$. longa. Inflorescentia scmel cymose divisa, dein v. ab initio in cincinnos laxifloros abiens, $1-5$-, raro-7-flora; prophylla 2-1 mm. longa; pedicelli subuulli v. usque $1 \mathrm{~mm}$. longi; flores post anthesin subhorizontaliter positi. Perianthii tubus cylindraceus, $2,5-4 \mathrm{~mm}$. longus; segmenta 3 exteriora tubo dimidio v. duplo breviora, 1,5-2 mm. longa, ovata $v$. anguste ovata acuminata, margine infero v. medio lobulos 2 lancenlato-lineares saepins incurvos gerentia, interiora ad sinum abenntia, parva v. minuta, ovata v. orbicularia, omnia cum tubo supremo valde decidua. Stamina tubo perianthii ad fancem affixa; filamenta subnulla; antherae ambitu latinscule quadratae, connectivo latiusculo supra loculos non producto truncato v. obsoletissime apiculato, transversim dehiscentes. Stylus aequicrassus v. superne obsolete attenuatus, $3 \mathrm{~mm}$. longus; lobi (nou liene observati) sessiles fila 2 filiformi-setacea emittentes. Ovarium a latere bresiter v. ovato-rectangulare, basi subobliquum obtusum, sub anthesi $1,8-2 \mathrm{~mm}$. longum, $1-1,2 \mathrm{~mm}$. latum, glandulis intus sub apice obviis extrinsecus plerumque bene conspicuis; ovula multiseriata. Capsula rerisimiliter a latere compressa, ovata $\mathrm{v}$. breviter ovata, 2,5-3 $\mathrm{mm}$. longa, horizontaliter 
posita, laterc inferiore obsolcte bicarinata, latere supero tantum dehiscens, marginibus plus minus reflexis, caeterum in integro remanens; placenta infima (anterior) in cavitatem carinato-prominens, laterales planae parieti adpressae. Scmin a elliptica v. oblonga, flava, $0,3-0,4 \mathrm{~mm}$. longa, $0,12-0,15 \mathrm{~mm}$. crassa, apice saepius breviter et obtuse apiculata v. acuminata, basi supra nucleum paullo protracta subtruncata, funiculis semina longitudine aequantibus $\mathrm{v}$. supcrantibus.

Hab. in Cuba or. in monte Libanon, m. Sept. fl. et fr., prope villam Montererde: Wright n. 1470,3284 , - praeterea in Nora Granata prope Bogota: Karsten, Brasilia: Glaziou n. 18561, Miers n. 4653, Ule n. 4001.

Obs. I. Specimina cubensia a continentalibus vix nisi perianthii tubo paullo longiore et seminibus paullo crassioribus recedit.

Obs. II. Ptychomeria tenella Benth. (e Brasilia septentrionali) styli lobis inappendieulatis (ex BeNтн.), fructu erecto circumcirca aequaliter evoluto actinomorpho (dehiscentia non visa), seminibus ad placentas sessilibus discrepat et rerum Gymnosiphon praebct.

\section{Iarthella Urb. (n. gen.).}

Perianthium persistens; tubus elongatus exalatus; segmenta 3 exteriora in aestivatione induplicato-valvata integerrima, interiora omnino deficientia. Stamina 3 cum segmentis corollae alterna; filamenta fauce corollae e margine nedio sacculi parri abeuntia, bene evoluta, exalata; loculi ad latera comnectivi brevis crassiusculi inappendiculati affixi, breviter ovales, transversim dehiscentes. Nervi sub insertione sacculi trifurcati, ramo intermedio in filamenta abeunte, 2 lateralibus sacculum suffulcientibus et supra eum vix productis. Ovarium circumcirca aequaliter evolutum, 1 -loculare, intus sub apice placentarum eglandulosum; placentae 3 parietales applanatae; ovula pauciseriata elliptica; glandulae 3 extrinsecus sub vertice orarii supra placentas obriae, brevissime stipitatae, didymae, supra extrinsecus concavae (forma antlerarum loculis confluentibus effoetarum). Stylus perianthio inclusus, apice trifidus, ramis in limbum parvum marginibus incurvatis concarum non appendiculatum dilatatis. Capsula obovato-turbinata, longitrorsum 3-sulcata, dehiscentia?; pericarpium tenuissimum, luce permeante densissime et anguste reticulato, areolis trausversim multo longioribus, nervis cum placentis satis angustis alternantibus parum evolutis. Semina. minima, orali-globosa $r$. subglobosa, testa laxe appressa exappendiculata reticulata. - Planta trinitensis tenera. Caulis erectus simplex lilacinocoloratus. Folia omnia ad squamas parvas reducta. Inflorescentia semel cymose divisa, dein in cincinnos abiens, sed semper capituliformi-contracta; prophylla primaria foliis caulinis majora, caetera minuta v. deficientia; pedicelli brevissimi erecti. Perianthii lobi flarescentes. 
Obs. I. Genus nominatum in lonorem uxoris meae carissimae, Martun e gente Kunтz, quae stndia mea botanica consilio atque benevolentia adjuvat. Ad Gymmosiphon et Apteriam accedit, quorum jrior sacculo sub filamentis deficiente, glandulis 2 post apicen cujusris placentae in ovario ipso obviis, perianthii tubo infra apicem circumscisso, posterior filamentis et connectivo in laminam obcordatan dilatatis, perianthii lohis intcrioribus evolutis, ovulis multiseriatis, nterque glandulis in apice ovarii extus deficientibus discrepat.

Obs. II. Omnes flores longe deflorati corollam integram praebuerunt, unico cxcepto cujus tubus in $1 / 3$ alt. irregulariter (an casu?) partem supcriorem perdidit. Ex instituto botanico Bonnensi materiem alcoolicam accepi, quae studiis cli. Jorow inservivit.

8. Marthella trinitatis Urb. - Fig. nostrae $19-27$.

Burmannia capitata Johow! in Pringsh. Jahrb. XVI (1855) 1. 417 seq., tab. Ir] fig. 2, - non Mart.

Gymnosiphon trinitatis Johow! in Pringsh. Jahrb. I. (1889) p. 477 .

Planta 5-10 cm. alta. Rhizoma breve squamigerım, radiculas filiformes clongatas glabras emittens. Caulis erectus simplex lilacinus (e JoH.) rigidulus, inferne flexuosus, $0,4-0,6 \mathrm{~mm}$. crassus, superne nudus suhnudusve. Folia $6-10$ in quoque caule, intermedia ovata r. ovato-lanceolata acuminata $2-3 \mathrm{~mm}$. longa. Inflorescentia $3-7$-flora, axibus cincinnorum ca. $2 \mathrm{~mm}$. longis; prophylla primaria ovata acuminata $4-5 \mathrm{~mm}$. longa, caetera minima r. obsoleta; pedicelli $1-0,6 \mathrm{~mm}$. longi erecti. Perianthium $4 \mathrm{~mm}$. longum; tubus cylindraceus, medio paullo constrictus, $3 \mathrm{~mm}$. longus, superne fere $1 \mathrm{~mm}$. crassus; segmenta duplo breviora, ovata sensim acuminata flavescentia (ex Jor.), 1,5 mm. longa, sub anthesi quoque margine inflexa. Filamenta ca. $0,3 \mathrm{~mm}$. longa; antherarum loculi breviter ovales, transversim dehiscentes, connectivo brumeo inter loculos superne plus minus apiculato v. mucronato-producto. Stylus $3,5 \mathrm{~mm}$. longus, filiformis, ad apicem paullo incrassatus, apice trifidus, ramis in limbun parvum marginilus incurvatis concavum dilatatis. Ovarium ovale v. obovatum, sul, anthesi $1,5 \mathrm{~mm}$. longum $1 \mathrm{~mm}$. crassum. Capsula obovato-turbinata, $2 \mathrm{~mm}$. longa, superne 1,5 mm. crassa. Scmina ovali-globosa v. subglobosa, latere altero tantum obtuse et brevissime apiculata, $0,3 \mathrm{~mm}$. longa, brunea, cellulis testae parvis subrotundis.

Hab. in Trinidad supra ligna putrida et inter folia emortua in sylvis montium septentrionalium, m. Febr. 1883: Johow.

\section{Apteria Nutt.}

9. Ipteria Iymenanthera Miq. Stivp. Sur. (1550) p. 216 tab.65 Fig. A!; Walp. Am. III p. G0S. - Fig. nostrae 28-32.

Apteria setacea Hook. Ic. plant. II ser. vol. III (1841) tab. 660!; Griseb.! Flor. p. 606 et Cat. p. 257; Sauv. Cub.n.2454 p.166; Johow in Pringsh. Jahrb. XVI p. 417 seq. tab. 16 f.1 (habitus), tab.17 f.17-18 (anat.), tab. 18 f. 38 - 42 (embryol.); Engl.-Prantl Nat. Pfl. fam. II. 6 
p. 49 fig. 39 A! (non $B$ at C quae ad A. lilacinam Miers pertinent); Duss! Flor. Ant. frans. p. 587, - non Nintt.

Voyprice tenella Griseb.! Krar. (1557) p. 94, - non Guild.

Caulis $3-12 \mathrm{~cm}$. altus, $0,25-0,35 \mathrm{~mm}$. crassus, rubro-violacens. Pedicelli 2-8 mm. longi. Corolla pallide caerulea, intus maculis obscure caeruleis (ex Sint.), fauce albida (ex Duss), $5-7 \mathrm{~mm}$. longa; segmenta campanulato-connirentia (ex Sisт.), exteriora lireriter orata v. semiovalia, interiora latiuscule linearia, omnia obtusa r. obtusiuscula. Connectiri rami applanati, filamentis 3-plo breviores. Styli rami apice ampliato extrinsecus non appendiculati. Placentae latae crassiusculae applanatae. Capsula oborata. Semina oborato-oblonga brunea.

Hab. in Cuba: Wright n. 3283; Jamaica in savanis interioribus territorii Manchester: Purdie, Wilson (ex Hook. et Griseb.), ad Mabess River $18 \mathrm{~m}$. supra flurii ripam in sylvarum regetabilibus putrescentibus, m. Sept. fl.: Fawcett n. 8436 (perigonio extrinsecus albo, intus caeruleo); Portorico in srlva primaera prope Iabucoa ad Guarabota rara, m. Sept. flor., prope Lares ad Buenos Ayres, m. Jan. flor.: Sintenis n. 5171, 6070; Guadeloupe: Duchassaing, l'Herminier, ad ripas riruli des Trois-Rivières in radicibus Fici speciei, $340 \mathrm{~m}$. alt.: Duss 11. 2856, ad ripam riruli prope Bassin Girard du morne Gommier terrestris, $380 \mathrm{~m}$. alt., m. Febr. fl.: Duss n. 4061; Trinidad ad Aripo: Crueger ex Griseb.; - praeterea Guiana gall.: Sagot n. 362, batava: Hostmann n. 959; Brasilia pror. Rio de Janeiro in montibus prope Copocabana: Ule n. 4003.

Obs. A. selacea Nutt. et A. lilacina Miers a nostra specie habitu robustiore, caule altiore, pedicellis multo longioribus, corollis $10-12 \mathrm{~mm}$. longis recedunt, prior praeterea ex specimine floridano (Nash n. 1093) ramis styli apice extrinsecus appendiculatis, appendice ramis subaequilonga deflexa apice stigmatifera, posterior (e MIEns) segmentis corollae exterioribus lanceolatis acuminatis, interioribus oratis mucronulatis, connectivi ramis filamenta longitudine subaequantilsus, crassiuscule filiformibus, placentis angustis subteretibus et ? dehiscentia capsulae. Caeterum specimen originarium Nuttallianum, quod cl. Hooker cum planta jamaicensi congruere indicavit, iterum comparandum erit.

\section{Burmannia Linn.}

10. Burmamia hicolor Mart. floribus $1-5$ in cymam contractam collectis; perianthio cum ovario $8-15 \mathrm{~mm}$. longo, coeruleoriolaceo, laciniis nune luteis, nunc caeruleis, angulis solemniter membranaceo-alatis.

Burmannia bicolor Mart.! Nor. Gen. I (1824) p. 10 tab. 5 f. I!; Seuh.! in Mart. Flor. Iros. III. I p. 55; Miers in Trons. Limn. Soc. XTIII p. 535 tab. 35 f. 3!; Malme! in Bih. till Sienslia T'rt.-Akad. 
IIandl. XXII Afd. III n. 8 p. 21 Taf. I f.3! et in Bot. Not. 1898 p. 185.

Burmannia brachyphylla Willd. Msc. in Schult. f. Syst. VII. II (1830) p. LXXV et herb. n. 6341!

Tripterella bicolor Roem. et Schult. Syst. Mant. in vol. II addit. (1824) p. (109) 357.

Hab. in Venezuela!, Guiana!, Brasilia!

Var. $\beta$. subcoelestis Malme! in Bih. till Svenska Vet.-Akad. Handl. XXII Afd. III n. S (1896) p. 22 Taf. I f. 3 c!, caule $25-40 \mathrm{~cm}$. alto; foliis basalibus usque ad $15 \mathrm{~mm}$. longis, $4,5 \mathrm{~mm}$. latis; tubo perianthii cum ovario $11-13 \mathrm{~mm}$. longo, alis tubo paullulo tantum latioribus, sat anguste semiellipticis.

Burmannia quadriflora Willd. Msc. in Schult. f. Syst. VII. II (1830) p. LXXIV et herb. n. 6343!

Burmannia bicolor Griseb. Cat.(1S66) p. 257; Sauv. Cub.n. 2481 p. 165.

Hab. in Cuba: Wright n. 3282, — praeterea in Guiana!, Brasilia!

11. Burmamnia flava Mart. floribus $1-5$ in cymam contractam capituliformem collectis; perianthio cum ovario $6-8 \mathrm{~mm}$. longo, viridiflavo v. flavo, angulis solemniter membranaceo-alatis.

Burmannia flava Mart. Nov. Gen. I (182t) p. 11 tab. 5 f. III!; Serb.! in Mart. Flor. bras. III. I p. 56; Malme! in Bih. till Srenska Vet.-Akad. Handl. XXII Afd. III n. 8 p. 24.

Tripterella flava Roem. et Schult. Syst. Mant. in vol. II adilit. (1824) $p \cdot$ (109) 357.

Burmannia flavula C. Wr. in Saus. Cub. (1871),n. 2482 p. 165.

Hab. in $\mathrm{Cuba}$ en los pinares altos de Viñales in districtu Vuelta de Abajo: Wright n. 3749, - praeterea in Venezuela!, Brasilia!

12. Burmamnia capitata Mart. cyma pluri- r. multiflora contracta capituliformi; perianthio cum ovario $3-5 \mathrm{~mm}$. longo, albo, nunc (ex Chapy.) coeruleo-tincto v. (ex MaLme) laciniis'sordide luteis, angulis costa filiformi v. angustissime alato-prominente notatis.

Burmannia capitata Mart. Nov. Gen. I (1S24) p. 12; Seub.! in Mart. Flor. bras. III. I p. 56; Griseb.! Flor. p. 606 et Cat. p. 257; Sauv. Cub. n. 2483 p. 165; Chapm. Flor. South. U. St. p. 452 et III ed. p. 477: Johow in Pringsh. Jahrb. XX tab. XIX fig. 2 (hab.), XX fig. 10, XXI fig. 16, XXII fig. 18 (anat., embryol.); Malme! in Bih. till Srenslia Vet-Alad. Mandl. XXII Afd. III n. 8 p. 26 Taf. I fig. 4 ! 
Anonymos capitatus Walt. Flor. carol. (17S8) p. 69.

Vogelia capitata J. F. Gimel. Syst. (1791) p. 107; Poir. in Lam. Enc. TIII p. 115 .

Tripterella capitata Michx. Flor. bor. am. I (1803) p. 19 tab. 3; Roem. et Schult. Syst. I p. 366 et Mant. in rol. I addit. p. (23) 271.

Hab. in Cuba: Wright n. 3281, prope Cieneguita prov. Sta. Clara: Combs n. 688, in udis sarannarum prope Sumidero, m. Oct. f1.: Poeppig; Jamaica: Wullschlägel ex Griseb.; Trinidad in savannahs: Crueger, Bot. Gard. Herb. n. 1608, - praeterea in America sept. a Florida usque Carolinam, Guiana!, Brasilia!, Paraguay!

Genus novum Burmanniae affine hoc loco proponere liceat:

\section{Hexapterella Urb. (n. gen.).}

Perianthii tubus superne vix v. angustissime, inferne sensim magis 6 -alatus, persistens; segmenta 3 exteriora induplicato-valvata, 3 interiora pluries minora lanceolata, omnia posterius tempore inaequali abrupta et decidua. Stamina 3 in ore tubi ad basin segmentorum interiorum affixa, paullo exserta; filamenta bene evoluta, sed brevia; loculi globulosi, connectivo disjuncti, transversim deliscentes; connectivum crassinsculun ovatum v. oblongum, inter loculos superne liberum et conico-apiculatum, sed supra eos non productum nec appendiculatum. Ovarium 6-alatum, 3-loculare, placentis axilibus; ovula numerosissima multiseriata, breviter obovata; stylus apice exsertus, cruribus 3 brevibus apice concariusculis, margine paullo dilatato papillosis. Capsula... Semina... - Herba brasiliensis, erecta simplex tenerrima verisimiliter colorata. Folia minima squamiformia dissita. Inflorescentia cymosa, 2-3-flora, pedicellis brevibus.

Obs. Affinis Burmanniae L., quae perianthii tubo 3-angulato v. 3alato, segmentis persistentibns, antheris intra tubum sessilibus r. subsessilibus, connectivo supra loculos in cristam producto, stylo perianthio incluso, forma stigmatum valde ahiena, (an etiam dehiscentia capsulae?) abunde differt.

Species unica:

$\checkmark \quad$ IIexapterellii gentianoides Urb. - (Fig. nostrae 33-38).

Herba 8-10 cm. alta. Caulis arcuato-erectus, 0,3-0,5 mm. crassus, in sicco angulatus, internodiis $10-15 \mathrm{~mm}$. longis. Folia caulina inferiora orata acuta $1-1,5 \mathrm{~mm}$. Ionga, superiora lanceolato-linearia acuta v. acuminata, $2-3 \mathrm{~mm}$. longa. Prophylla ovata r. ovato-lanceolata, sensim acuminata, $2-3,5 \mathrm{~mm}$. longa; pedicelli erecti, primarii $1-1,5 \mathrm{~mm}$. secundarii usque $3 \mathrm{~mm}$. longi $\mathrm{v}$. supra prophylhm nulli. Perianthium $8,5 \mathrm{~mm}$. longum; tubus cylindraceus, sed inferne sensim dilatatus; segmenta 
exteriora sub anthesi late incurva, explanata late rhombeo-ovata, $4 \mathrm{~mm}$ longa, 2,5 mm. lata, acuta, tubo panllo breviora, 3 -nervia, interiora plana, anguste lanceolata acuminata, vix '2 $\mathrm{mm}$. longa, $0,5 \mathrm{~mm}$. lata. Filamenta $0,7 \mathrm{~mm}$. longa, 3 -angulata, angulo interiore paullo decurrente, post segmentorum delapsum persistentia; loculi connectivo a latere subcompresso lateraliter appositi. Stylus $5 \mathrm{~mm}$. longus; rami stigmatiferi $0,5 \mathrm{~mm}$. longi. Ovarium obovato-globosum, ca. $2 \mathrm{~mm}$. longum, et crassum, alis ca. $0,5 \mathrm{~mm}$. latis.

Hab. in Brasiliae civitate Pará ad Colares in sylvis inter folia dejecta, m. Majo 1832: Poeppig D. n. 3005 (herb. Boissier-Barbey). 


\section{Ficus Linn.}

Exposuit

Otto Warburg.

Clavis specierum.

Sect. Urostigma Gasp. (sub gen.). Receptacula polygama, si in foliorum axillis semper bina. Flores masculi monandri. — Folia haud scabrida, renis vulgo curvatis aut si strictis vulgo crebris, basalibus saepe divergentibus.

A. Receptacula $12-25 \mathrm{~mm}$. longa, folia vulgo magna. Ser. Megacarpae. a. Receptacula sessilia.

$\alpha$. Bracteae receptaculorum basales $1-3 \mathrm{~mm}$. longae.

Folia apice subacuta, receptacula puberula. - Cuba

1. F. membranacea Warb.

Folia apice rotundata, receptacula subvelutina. - Cuba

2. F. Combsii Warb.

$\beta$. Bracteae receptaculorum basales $4-6 \mathrm{~mm}$. longae.

Folia apice subacuta, receptacula sericeo-puberula. - Jamaica

3. F. Harrisii Warb.

Folia apice rotundata vel obtusa.

Receptacula cinereo-velutina. - Hispaniola

4. F. mitrophora Warb.

Receptacula glabra. - Trinidad

5. F. Hartii Warb.

b. Receptacula paullo pedunculata, fere glabra; bracteae receptaculorum hasales usque $12 \mathrm{~mm}$. latae. - Antillae minores

6. F. Urbaniana Warb.

B. Receptacula $3-12 \mathrm{~mm}$. longa.

a. Receptacula sessilia.

$\alpha$. Folia glabra, basi acuminata vel rotundata, nervi tenues.

Ser. Tenuiveniae.

Folia ovata apice subobtuse apiculata. - Florida, Bahama

7. F. aurea Nutt.

Folia elliptica vel oblonga apicc acute subacuminata. - Key,

Bah., Cuba, Jam., Hispan. 8. F. sapotifolia Kth. et Bché.

$\beta$. Folia subtus ferrugineo-pubescentia, apice rotundata, basi subcordata, nervi grossi.

Ser. Grossiveniae.

Cuba

9. F. Wrightii Warb. 
b. Receptacula pedunculata.

a. Ostiolum receptaculi immersum, annulo clevato circumdatum.

Ser. Foraminiferae.

Stipulae appresse aureo-pilosae; pedunculi $2-6 \mathrm{~mm}$. longi. Folia vulgo apice rotundata. - Portorico, Ant. min.

10. F. crassinervia Willd.

Stipulae minute puberulae ferc glabrae; pedunculi $7-10 \mathrm{~mm}$. longi. Folia vulgo apice acuminata. - Jamaica

\section{1. $F$. ochroleuca Griseb.}

ק. Ostiolum receptaculi prominens.

1. Folia parva $(2-10 \mathrm{~cm}$. longa) stricte venosa.

Ser. Strictiveniac.

- Folia venis tenuibus interjectis arcte parallele venosa.

Folia distincte apiculata; receptacula pisiformia. - Portorico . . . 12. F. Sintenisii Warb.

Folia haud apiculata; receptacula piperiformia. - Cuba

13. F. jacquinifolia A. Rich.

= Folia dense sed renis interjectis desinentibus haud arcte parallelo-renosa, haud vel vix apiculata; receptacula pisiformia. - Antillae min. 14. F. omphalophora Warb.

= Folia venis vix distinctis parce parallelo-venosa, haud vel vix apiculata; receptacula pisiformia. - Jamaica

15. F. Wilsoni Warb.

2. Folia mediocria (vulgo $8-15 \mathrm{~cm}$. longa) haud stricte venosa.

- Bracteae receptaculorum basales fimbriatae.

Ser. Mamilla tae.

Folia basi subcordata; bracteae receptaculorum basales glabrae. - Jamaica 16. F. Berteroi Warb.

Folia basi haud subcordata, bracteae minute puberulac. - Cuba, Hispaniola

17. F. Eggersii Warb.

= Bracteae receptaculorum basales haud fimbriatae.

Bracteae receptaculorum basales glabrae; ostiolum valde prominens. -- Jamaica

18. F. mamillifera Warb.

Bracteae receptaculorum basales minute puberulae; ostiolum paullo prominens. - Portorico

19. F. Stahlii Warb.

$\gamma$. Ostiolnm receptaculi haud vel vix prominens. Ser. Populneae. 1. Folia basi cordata et $3-5$-nervia.

Folia membranacea, vulgo anguste ovata, apicc acuminata. - Florida, Bahama, Cubá, Portorico, Ant. min.

20. F. populnea Willd.

Folia vulgo pergamacea, late usque rotundo-ovata, apice apiculata usque cuspidata. - Cuba

2. Folia basi haud cordata.

21. F. populoides Warb.

- Folia stricte et crasse venosa.

Ser. Umbonatae.

Folia obovata usque late elliptica, raro subapiculata. -

Trinidad . . 22. F. umbonigera Warb. 
Folia elliptica distincte apiculata. - Grenada

23. F. grenadensis Warb.

= Folia arcuate et tenuiter venosa.

Folia ovata vel oblonga. - Trinidad, Surinam

24. F. pertusa L. f.

Folia anguste lanceolata. - Trinidad

25. F. prinoides $\mathrm{H}$. et $\mathrm{B}$.

Sect. Pharmacosyce Miq. (sub gen.). Receptacula polygama, vulgo singula in axillis. Flores masculi diandri. - Folia rulgo scabrida, venis haud valde crebris vulgo fere strictis parallelis, basalibus haud divergentibus.

A. Folia subtus scabrida.

Ser. Scabridae.

a. Folia subtus pubescentia. - Hispaniola

b. Folia subtus haud pubescentia. - Trinidad

26. F. Picardae Warb.

27. F. radula Willd.

B. Folia subtus subscabrida.

a. Innovationes pubescentes. - Jamaica

Ser. Subscabridae.

b. Innovationes glabrae.

28. F. suffocans Griseb.

$\alpha$. Folia apice rotundata, receptaculo pruni magnitudine. - Cuba 29. F. subscabrida Warb.

$\beta$. Folia apice obtusa vel apiculata.

Folia haud parva, basi obtusa paucivenia. - Hispaniola

30. F. mbricosta Warb.

Folia parva, basi cuneata multirenia. - Trinidad

31. F. Finlayana Warb.

C. Folia subtus laevia.

Ser. Laeves.

a. Ramuli crassi; folia pergamacea elliptica vel oblonga, ca. 13-venia. - Antillae minores . . . . 32. F. Krugiana Warb.

b. Ramuli laud crassi; folia membranacea late elliptica, ca. 7-venia. - Cuba . . . . . 33. F. venusta Kth. et Bché.

\section{Sect. Urostigma.}

1. Ficus membranacea C. Wright. Frutex vel arbor, ramis crassis cicatricibus foliorum et receptaculorum nodosis; stipulis pubescentibus; foliis magnis pergamaceis glabris, ovatis, basi cordatis vel subcordatis, apice subacutis, basi breviter 5 -nerviis, haud longe petiolatis; receptaculis binis axillaribus sessilibus cerasiformibus paullo depressis minute puberulis, in sicco brunneo-maculatis, basi bracteis latis brevibus paullo pubescentibus suffultis; ostiolo parro vix prominente.

Ficus membranacea C. Wright in Sauv. Cuba (1871) p. 149 n. 2331.

Ficus crașsinervia Combs! (haud Willd.) Cub. (1597) p. 465.

Jagüey Cub. ex Wr., Jagüey macho Cub. ex Combs.

Arbor v. frutex. Rami ca. $8 \mathrm{~mm}$. lati cinerei; ramuli juniores $3 \mathrm{~mm}$. lati. Stipulae caducae lanceolatae, $1 \mathrm{~cm}$. longae, acutae, extus appresse sericeo-pubescentes. Petioli $4-6 \mathrm{~cm}$. longi, $3 \mathrm{~mm}$. lati, in sicco lutescentes; folia $12-16 \mathrm{~cm}$. longa, $7-10 \mathrm{~cm}$. lata, basi laud profunde 
cordata, lolis haud sese attingentibus, apice interdum paullo apiculata, supra in sicco nigrescentia, subtus fuscescentia, nervis basalibus lateralibus superioribus $1 / 4$ folii nondum attingentilus, venis praeterea ca. 8 subcurvatis ad marginem vix confluentibus, subtus prominentihus, in sicco flavidis, supra prominulis, in sicco suberubescentibus, nervis tertiariis transversis subtus tantum prominulis, reticulatione tenuissima subtus tantum et vix distincta. Receptacula $12 \mathrm{~mm}$. longa, $15 \mathrm{~mm}$. lata, bracteis basalibus $1-2 \mathrm{~mm}$. longis. Ostiolum $1 \mathrm{~mm}$. latum, squamis latis inclusum, annulo vix distincto circumdatum. Florum $q$ sepala ovata obtusa subnigra fuscomarginata.

Hab. in Cuba secus Rio Santa-Cruz, Balestena: Wright n. 3679, prope Cieneguita, secus fluvios in solo fertili vulgaris, m. Jun.: Combs n. 145 (foliis subpergamaceis haud membranaceis, in sicco nigricantibus subtus fuscescentibus differt).

Obs. Planta viva quaedam olim ab ()тто e Cuba in hortum botanicum Berolinensem translata probabiliter ad hane speciem pertinet; folia tantum exstantia differunt petiolo multo longiore. Folia alia ejusdem plantae in herbario Berolimensi erronee pro $F$. eximia Schott et pro $F \cdot 1$ seudo-nymphacifolia sumpta sunt. Folia iis $F$. syringifoliae similia, sed facile nervis paucis discernuntur.

2. Ficus ('ombsii Warb. (n. sp.) ramis crassis, cicatricibus foliorum vix elevatis; stipulis glabris pruinosis; foliis magnis crasse pergamaceis glabris ovatis usque oblongis, basi subcordatis, apice rotundatis, basi breviter 5-nerviis, petiolis haud longis pruinosis; receptaculis sessilibus, in juventute bracteis in calyptram connatis unitis et inclusis, cerasiformibus haud depressis, pilis minutis subvelutinis, in sicco sordide luteo-maculatis, basi bracteis brevibus glabris inter se connatis suffultis; ostiolo paullo impresșo, annulo subelevato circumdato.

Ficus crassinervia (affinis) Combs! (haud Willd.) Cub. (1897) p. 465 .

Arbor $6,6 \mathrm{~m}$. alta. Rami ca. $8 \mathrm{~mm}$. lati, brunneo-cinerei, in sicco sulcati. Stipulae caducae, ca. $8 \mathrm{~mm}$. longae, lanceolatae acutae. Petioli $11 / 2-3 \frac{1}{2} \mathrm{~cm}$. longi, $2-2^{1 / 2} \mathrm{~min}$. lati, subcomplanati, vix canaliculati; folia $13-18 \mathrm{~cm}$. longa, $7 \frac{1}{2}-11 \mathrm{~cm}$. lata, costa subtus alte prominente in basi glandulosa, nervis basalibus lateralibus superioribus patentibus vix $1 / 6$ folii attingentibus, venis praeterea ca. 7 crassioribus patentibus vix curvatis, ante marginem irregulariter arcuato-conjunctis, supra prominulis, subtus prominentibus, nervis tertiariis utrinque prominulis, reticulatione tenuissima subtus tantum distincta. Bracteae calyptram formantes breves, mox deciduae, extus subpubescentes. Receptacula $1 \frac{1}{2} \mathrm{~cm}$. longa et lata, verrucosa (ex Cours), bracteis basalibus scariosis $2-3 \mathrm{~mm}$. longis. Ostiolum $2 \mathrm{~mm}$. latum squamis latis clausum, annulo elevato $3 / 4 \mathrm{~mm}$. lato. Florum $q$ sepala obtusa nigro-fuscescentia pallide marginata.

Hab. in Cuba prope Calicita in litoralibus rara, m. Aug. 1895: Combs n. 500 . 
Obs. A F. membranacea differt foliis crassioribus apice rotundatis basi minus cordatis, petiolis brevioribus pruinosis, receptaculis haud depressis magis relutinis in jurentute a bracteis in calyptran connatis inclusis, ostiolo impresso; F. mitrophorae et $F$. Hartii magis affinis.

3. Ficus Harrisii Warb. (n. sp.) ramis crassis, cicatricibus foliorum et receptaculorum elevatis nodosis; stipulis pilosis; foliis magnis subpergamaceis glabris ovatis, basi cordatis, apice vulgo subacutis, basi breviter 5-7-nerviis, longe petiolatis; receptaculis binis axillaribus sessilibus cerasiformibus paullo depressis sericeo-puberulis, in sicco grosse brunneo-maculatis, usque ad medium bracteis latis circumdatis; ostiolo parvo haud prominente.

Arbor maxima. Rami $6-7 \mathrm{~mm}$. lati, in sicco cinerei, irregulariter sulcati. Stipulae caducae, $1 \cdot \mathrm{cm}$. longae, lanceolatae acutae, dense appresse sericeo-pilosae. Petioli $6-7 \mathrm{~cm}$. longi, $2 \mathrm{~mm}$. lati, in sicco sulcati, lutescentes; folia $17-22 \mathrm{~cm}$. longa, $11-13 \mathrm{~cm}$. lata, supra in sicco nigrescentia, subtus obscure viridia, apice vix apiculata, lobis basalibus hand sese attingentibus, nervis basalibus lateralibus superioribus $1 / 3$ folii nondum attingentibus, renis praeterea $7-9$ utrinque nervis basalibus parallelis subcurvatis, ante marginem arcuate conjunctis, subtus in sicco flaridis prominentibus, supra erubescentibus prominulis, nervis tertiariis transversis tenuibus supra vix distinctis subtus prominulis, reticulatione tenuissima subtus tantum vix distincta. Receptacula $13 \mathrm{~mm}$. longa, $15 \mathrm{~mm}$. lata. Ostiolum vix $1 \frac{1}{2} \mathrm{~mm}$. in diametro, squamis latis clausum, annulo vix prominente et distincto circumdatum. Bracteae in cupulam $5 \mathrm{~mm}$. altam connatae, extus pubescentes. Florum $Q$ sepala obtusa ovata, fusca rel subnigra, anguste pallide marginata.

Hab. in Jamaica, Blue mountains, m. Febr. 1894: W. Harris n. 5221.

Obs. Haec planta cum descriptione $F$. crassinerviae a Grisebach in Flor. Br. W. Ind. p. 150 data quadrat, sed minime cum F. crassinerria Willd., quoad typum in hb. Willd. asservatum. F. membranaceae Wr. valde affinis, sed bracteis receptaculorum multo majoribus diversa. Foliis F. eximiac e Brasilia similis, quae autem renis pluribus, stipulis majoribus glabris, receptaculis pedunculatis, ramulis laevibus caris instructa est.

4. Ficus mitrophor'i Warb. (n. sp.) ramis crassis, cicatricibus foliorum et receptaculorum elevatis; stipulis pilosis; foliis pergamaceis glabris oblongis, basi rotundatis, breviter cordatis vel subcordatis, apice rotundatis vel valde obtusis, basi brevissime $3-5$-nerviis, petiolis pro rata brevibus; receptaculis binis axillaribus, in jurentute bracteis in calyptram mitriformem connatis diu persistentibus omnino inclusis, sessilibus, cerasi-vel pruniformibus, vix depressis, extus cinereo-velutinis, basi bracteis mediocribus extus ferrugineo-pilosis inter se connatis suffultis; ostiolo subimmerso annulo circumdato.

Arbor $5-20 \mathrm{~m}$. alta, dense foliosa. Ramuli $7-8 \mathrm{~mm}$. lati, juniores ferrugineo-tomentosi، Stipulae deciduae, lanceolatae acutac, extus dense 
appresse albido-pilosae. Petioli $1 \frac{1}{2}-3 \mathrm{~cm}$. longi, $2-4 \mathrm{~mm}$. lati, in sicco sordide lutei vel fuscescentes, paullo complanati; folia $11-23 \mathrm{~cm}$. longa, 5-12 cm. lata, in sicco fuscescentia, subtus vix pallidiora, si cordata sinu clauso vel lobis sese tegentibus, nervis basalibus lateralibus patentibus brevissimis, venis praeterea $8-10$ patentibus vix curvatis, ante marginem vix arcuate connexis, supra prominulis, subtus prominentibus, nervis tertiariis utrinque prominulis, reticulatione tenerrima subtus tantum distincta. Receptacula globosa $1 \frac{1}{2}-21 / 2 \mathrm{~cm}$. longa et lata. Bracteae receptacula juniora includentes calyptriformes ovatae vel late lanceolatae, $11 / 2-3 \mathrm{~cm}$. longae, extus velutinae vel pubescentes; bracteae basales receptaculorum $4-5 \mathrm{~mm}$. longae. Ostioium $2 \frac{1}{2}-3 \mathrm{~mm}$. latum, squamis latis elevatis occlusum, annulo $3 / 4 \mathrm{~mm}$. late prominente. Florum $q$ sepala obtusa nigro-fuscescentia pallide marginata.

Hab. in Haiti: Ehrenberg n. 352, prope Gonaïves m. Majo: Prax, ad Bizothon prope Port-au-Prince, m. Jan.: Eggers n. 3357, ad Jérémie: Eggers n. 3403 (foliis junioribus subtus pubescentibus), prope Jérémie in montibus, m. Jan.: Picarda n. 1339; Sto. Domingo in Sierra de Jarabacoa ad Arroyo de la nuez $600 \mathrm{~m}$. alt., m. Majo: Eggers n. 2083, in sylvis prope Susúa, 50 m. alt., m. Jun.: Eggers n. 2581. - In Hort. Berol. e seminibus a cl. Eggers sub n. 2581 in Sto. Domingo lectis olim culta.

Obs. I. Affinis F. Combsii e Cuba, differt petiolis haud pruinosis, stipulis et ramis junioribus pilosis, receptaculis magis tomentellis, bracteis basalibus pubescentibus majoribus.

Obs. II. Ad hanc speciem fortasse Ficus maxima, folio citri subrotundo, fructu umbilicato Plum. Cat. (1703) p. 21 et ed. Burm. p. 123 t. 131 f. 2 referenda est, quae differt tamen receptaculis brevi-pedunculatis.

5. Ficus Hartii Warb. (n. sp.) ramis crassis glabris, cicatricibus foliorum vix prominentibu'; stipulis pilosis; foliis magnis crasse pergamaceis oblougis, basi rotundatis, breviter 5 -pli-nerviis, apice rotundatis raro valde obtusis, petiolis pro rata haud longis; receptaculis sessilibus, in juventute bracteis in calyptram connatis inclusis, adultis cerasiformibus depresso-globosis glabris, in sicco vix distincte maculatis, basi bracteis mediocribus inter se connatis suffultis; ostiolo paullo impresso annulo subelevato circumdato.

Rami ca. $7 \mathrm{~mm}$. lati, in sicco cinerei, juniores in sicco lutei sulcati. Stipulae caducac, $1 \mathrm{~cm}$. longae, lanccolatae, extus appresse sericeo-pilosae. Petioli $2-3^{1} / 2 \mathrm{~cm}$. longi, $2 \mathrm{~mm}$. lati, in sicco fusci supra complanati et canaliculati; folia $11-18 \mathrm{~cm}$. longa, $6-9 \mathrm{~cm}$. lata, in sicco utrinque fusca, subtus haud pallidiora, costa subtus alte prominente, in basi haud glandulosa, nervis basalibus lateralibus superioribus patentibus vix $1 / 6$ folii attingentibus, venis praeterea ca. 7 crassioribus patentibus vix curvatis, ante marginem arcuate confluentibus, supra prominulis, subtus prominentibus, nervis tertiariis utrinque prominulis, reticulatione grossa supra prominula tenuissima, subtus tantum distincta. Receptacula $13-15 \mathrm{~mm}$. lata, $11-13 \mathrm{~mm}$. longa, in sicco brunnea glabra. Bracteae calyptram formantes nondum $1 \mathrm{~cm}$. longae, late ovatae acutae fere glabrae; bracteae basales receptaculorum scariosae, 
paullo connatae, rotundatae, $4-5 \mathrm{~mm}$. longae. Ostiolum $3 \mathrm{~mm}$. latum, squamis latis clausum, annulo $3 / 4 \mathrm{~mm}$. lato vix elevato circumdatum. Florum $q$ sepala obtusa nigricantia fusco-marginata.

Hab. in Trinidad: D. W. Alexander n. 5043.

Obs. Differt a F. Combsii e Cuba bracteis basalibus majoribus, stipulis pilosis, calyptra glabra, petiolis haud pruinosis, a $F$. mitrophora ex Hispaniola innovationibus et bracteis glabris, calyptra parva glabra decidua, a F. Urbaniana ex Antillis minoribus receptaculis haud pedunculatis, bracteis basalibus minoribus.

6. Ficus Urbaniana Warb. (n. sp.) ramis crassis, cicatricibus foliorum et receptaculorum vix prominentibus; stipulis glabris; foliis magnis pergamaceis glabris late ovatis, obovatis vel oblongo-obovatis, apice rotundatis vel valde obtusis, basi obtusis vel subrotundatis, nervis basalibus interdum tantum exstantibus et tum brerissimis, petiolis crassis pro rata haud longis; receptaculis binis axillaribus brevissime pedunculatis cerasiformibus vix depressis, in juventute bracteis in calyptram connatis mox deciduis omnino inclusis, parte inferiore receptaculorum bracteis 2 paullo inter se connatis extus sericeo-puberulis magnis $1 / 3$ fere receptaculi circumdantibus suffultis; ostiolo vix impresso, annulo vix elevato circumdato.

Ficres crassinervia Egg.! (hand Willd.) St. Croix (1876) p. 147 et St. Croix and Virg. Isl. p. 95.

? Ficus americana hb. Suartz (haud Aubl.) e West St. Croix (1793) p. 312 .

? Urostigma Gardnerianum Miq. in Hook. Lond. Jomrn. Bot. VI (1847) p. 530 (quoad spec. ex Antigua).

Figuier grandes feuilles Guad. ex Duss.

Arbor mediocris v, elata. Rami $8 \mathrm{~mm}$. crassi, in sicco valde rugosi, nigro-cinerei, innovationibus in sicco fuscescentibus lenticellis albidis inspersis. Stipulae deciduae, late lanceolatae, in sicco fusccscentes. Petioli $3-4 \mathrm{~cm}$. longi, $21 / 2-3 \mathrm{~mm}$. lati, in sicco sordide lutei vel fusci; folia $14-22 \mathrm{~cm}$. longa, $7-14 \mathrm{~cm}$. lata, in sicco fuscescentia, subtus vix pallicliora, costa subtus ad basin glandulosa, venis utrinque $7-9$ obliquis ad marginem arcuate vix distincte confluentibus, supra prominulis, subtus prominentibus, nervis tertiariis supra vix distinctis subtus prominulis, reticnlatione tenuissima subtus tantum distincta. Receptacula $1 \frac{1}{2}-21 / 2 \mathrm{~cm}$. in diametro in sicco sordide lutea, minutc tomentella vel fere glabra, pallide vel fusco-maculata; perlunculis $0-3 \mathrm{~mm}$. longis, $4 \mathrm{~mm}$. latis. Bracteae calyptram formantes lanceolatae, $1 \mathrm{~cm}$. longae, acutac, cxtus vix distincte minute puberulae; bracteae basales usque $12 \mathrm{~mm}$. longae et latae, interdum apice fissae in discum usque $13 \mathrm{~mm}$. latum connatae. Florum $q$ sepala lanceolata fusca, margine pallirliora.

Hab. in St. Croix: West (lıb. Haun.), ad Bassin, m. Jun.: A. E. Ricksecker n. 414, ad Crequis m. Jul., ad Sweet Bottom m. Jan.: Eggers (hb. Haun.), prope Annaly m. Jan.: Borgesen (hb. Haun.); 
St. Martin m. Majo: Suringar; St. Eustache ad Boren m. Apr., ad Quill m. Majo: Suringar; Guadeloupe: Bertero (folium), Duchassaing, région moyenne et inférieure, alt. $40-400$ m.: Duss n. 2196; Martinique, Route des Trois Ilets à la Plaine alt. $180 \mathrm{~m}$., m. Aug.: Duss n. 1410, 1411, 4480, Hauteur du Lamentin: Hahn n. 819; St. Vincont: Smith n. 1797 (folio exstante unico fere orbiculari-orato, $21 \mathrm{~cm}$. longo $16 \mathrm{~cm}$. lato).

Obs. Affinis F. Combsii et F. mitrophorae, sed differt bracteis basalibus magnis et receptaculis vulgo paullo pedunculatis.

7. Ficus anrea Nutt. ramis, stipulis, foliis, receptaculis glabris; foliis subcoriaceis, ovatis, basi rotundatis vel subacuminatis, apice brerissime apiculatis subobtusis, basi subtrinerviis, venis tenuibus patentibus fere strictis; receptaculis sessilibus depresso-globosis pisiformibus, basi bracteis magnis latis circumdatis; ostiolo submagno, squamis subprominentibus occluso.

Ficus aurea Nutt. Sylva 11 (1S54) p. 4, II ed. I p. 154; Chapm. Flor. III ed. p. 438.

?Ficus trigonata Gardiner (haud L.) Baham. in Proc. Ac. Phil. (1889) p. 403.

Arbor parva $4 \mathrm{~m}$. alta. Ramuli ca. $4 \mathrm{~mm}$. lati, in sicco fusci, vix sulcati, demum lenticellis minutis albidis oblongis subelevatis inspersi. Stipulae lanceolatae acutae deciduae, $1-1 \frac{1}{2} \mathrm{~cm}$. longae, in sicco glauco- vel nigro-cinereae. Petioli $1 \frac{1}{2}-2 \mathrm{~cm}$. longi, $1 \frac{1}{2}-21 / 2 \mathrm{~mm}$. lati, complanati, supra canaliculati, in siceo cinerei; folia $8-15 \mathrm{~cm}$. longa, $41 / 2-81 / 2 \mathrm{~cm}$. lata, in sicco supra obscure fuscescentia, subtus pallidiora, costa subtus prominente in basi saepe glandulosa, reuis utrinque $6-10$ ante marginem subarcuate conjunctis, infimis subarcuatis vix magis ascendentibus, omnibus tenuibus supra insculptis subtus prominulis, nervis tertiariis vix distinctis, reticulatione tenerrima subtus tantum distincta. Receptacula in sicco fusca, $6-12 \mathrm{~mm}$. lata, $5-10 \mathrm{~mm}$. longa, basi bracteis $6-8 \mathrm{~mm}$. latis, $2-2 \frac{1}{2} \mathrm{~mm}$. longis suffulta. Ostiolum $2 \mathrm{~mm}$. latum. Flores $\sigma^{7}$ monandri, pauci prope ostiolum, anthera brevi, sepalis calyptriformibus nigris pallide marginatis. Florum $q$ sepala elliptica fusca pallicle marginata, squamis interfloralibus lanceolatis acutis anguste pallide marginatis.

Hab. in Florida austr., ad Indian River, Merritt's Island: Curtiss n. 2546; Bahama, New Providence m. Mart.: Eggers n. 4376 (foliorum nervis rubris). - Culta olim in Hort. Paris. sub nom. F. populnea (stipulis pro rata majoribus); in horb. Berol. sub nom. F. lentiginosa Vaht (foliis ut videtur ramorum juvenilium majoribus et petiolis multo longioribus usque $7 \mathrm{~cm}$. attingentibus).

8. Ficus sapotifolia Kth. et Bché. ramis foliis stipulis receptaculis glabris; foliis subcoriaceis, ellipticis usque oblongis, utrinque aequo modo subacuminatis acutis, subtus pallidioribus, costa subtu's in basi 
glandulosa, renis tenuibus obliquis fere strictis; receptaculis depressopisiformibus binis sessilibus axillaribus, bracteis basalibus magnis latis rotundatis suffultis; ostiolo magno, squamis prominentibus occluso.

Ficus sapotaefolia Kunth et Bouché! Ind. sem. hort. Berol. 1846 p. 17 n. 26.

Ficns'laevis Desf. Cat.ed. 3 (1829) p. 414 (nomen), - nec Blume Bijdr: (1825).

Ficus sororia Kumth et Bouché! Ind. sem. hort. Berol. 1846 p. 17 n. 27 .

Ficus aurantiaca, bulbosa, elegans nom. in Hort. Berol. 1846.

Ficus dimidiata Griseb.! Flor. (1859) p. 151, Pl. Wright p. 173 et Cat. p. 57; Sauv. Fl. Cub. n. 2334 p. 149; Hitche. Bah. p. 130; Combs! Cuba in Transact. St. Louis Ac. Sc. (1897) p. 465.

Jagüey $v$. Jagüey liembra $v$. Higon $r$. Higueron Cub. ex Egg. et $W r$.

Arbor $4-20 \mathrm{~m}$. alta. Ramuli in sicco fusci vel lutei, sulcati, mox fulro-cinerei glabri. Stipulae lanceolatae, $1-1 \frac{1}{2} \mathrm{~cm}$. longae acutae deciduae. Petioli $1-3^{1 / 2} \mathrm{~cm}$. longi, $1^{1 / 2}-2 \mathrm{~mm}$. lati, glabri, in sicco fusci rel nigrescentes, supra canaliculati; folia $6-13 \mathrm{~cm}$. longa, $21 / 2-5^{1} / 2 \mathrm{~cm}$. lata, costa haud valde crassa supra insculpta subtus prominula, renis $7-10$ majoribus saepe praesertim supra vix distinctis, ante marginem nerro subarcuato-conjunctis, interjectis tenuioribus subparallelis, inferioribus magis ascendentibus, nervis tertiariis haud conspicuis, reticulatione tenerrima subtus tantum distincta. Receptacula $6-8 \mathrm{~mm}$. lata, $4-6 \mathrm{~mm}$. longa, in sicco lutea. Ostiolum 2-3 $\mathrm{mm}$. in diametro, fuscescens. Bracteae basales ca. 3-4 mm. latae. Florum o sepala late lanceolata, vulgo acuta, fusca pallide marginata.

Hab. in Key West: Cabanis (differt foliis pro rata latioribus et majoribus); Bahama, New Providence ad Killarney m. Mart.: Eggers n. 4382, ad Nassau m. Jan.: Northrop n. 119 (differt foliis pro rata latioribus obtusioribus, venis minoribus crassioribus); $\mathrm{Cuba}$ : Wright n. 542, 1683, ad Rio Seco, m. Mart.: Eggers n. 4799, prope Potrero Redondo ad Romelie, m. Apr.: Eggers n. 5355 (fructib. purpureis), prope Cieneguita solo fertili secus rivulos, m. Jun.: Combs n. 147 (foliis pro rata latioribus et obtusis); Jamaica: Wullschlaegel n. $\overline{1378}$ (foliis pro rata obtusis); Gr. Cayman: Hitchcock (n. v.); Haiti, prope Gonaïres, m. Majo: Prax. - Cult. in hort. Berol. Febr. 1846, Sept. 1846, 1857, Nor. 1873, Sept. 1884, Febr. 1885; hort. Paris misit Oct. 1846 (differt in ramis junioribus foliis paullo longioribus, stipulis multo longioribus usque $5 \mathrm{~mm}$. longis).

9. Ficus Wrightii Warb. (n. sp.) stipulis longis glabris caducis; foliis parvis late oratis usque ellipticis, apice rotundatis, basi subcordatis, coriaceis, supra glabris laevibus, subtus grosse reticulatis ferru- 
gineo-pubescentibus; receptaculis sessilibus cerasiformibus ferrugineopuberulis, bracteis parvis suffultis; ostiolo magno impresso, annulo elevato circumdato.

Ficus elliptica Griseb. (hand H. B. K.) Pl. Wright. I (1860) p. 173 et Cat. Pl. Cub. p. 5 ; ; Saur. Fl. Cub. n. 2335 p. 149.

Jagüey moiho Cub. ex $W r$.

Rami 3-5 mm. lati, in sicco cinerei, laeves vel subrugosi. Stipulae lanceolatae glabrae $7 \mathrm{~mm}$. longae carlucae. Petioli $7-18 \mathrm{~mm}$. longi, $1-1 \frac{1}{2} \mathrm{~mm}$. lati, paullo squamulosi, vix puberuli, supra complanati et sulco lineari canaliculati; folia coriacea, $3-5 \mathrm{~cm}$. longa, $2-4 \mathrm{~cm}$. lata, utrinque in sicco fuscescentia, costa subtus crasse prominente, supra insculpta, venis utrinque 6 supra vix distinctis subimpressis, subtus valde prominentibus obliquis, ante marginem arcuate confluentibus, infimis basalibus ceteris parallelis, nervis tertiariis reticulum grossum formantibus subtus prominentibus supra haud conspicuis, reticulatione tenerrima subtus tantum distincta. Receptacula ca. $1 \mathrm{~cm}$. lata et longa. Ostiolum 21/2 mm. latum, quam receptaculum obscurius. Bracteae vix $1 \frac{1}{2} \mathrm{~mm}$. longae.

Hab. in Cuba: Wright. n. 1443.

Obs. A. Grisebach erronee pro $F$. elliptica H. B. K. habita, a qua specie Columbiana valde differt foliis supra haud scabridis neque in nervis pubescentibus venis minoribus, petiolis crassioribus, receptaculis majoribus etc. F. crassinerviae affinis esse videtur praesertim propter ostiolum impressum annulo circumdatum, sed differt receptaculis sessilibus, foliis et receptaculis pubescentibus, stipulis glabris, forma et nervatura foliorum.

10. Ficus crassincria Willd. ramulis vulgo haud crassis, in sicco angulosis laevibus; stipulis brevibus caducis appresse aureo-pilosis; foliis ovatis ellipticis usque oblongis mediocribus glabris pergamaceis, apice rotundatis obtusis rel subacutis, basi rotundatis rel subcordatis, nervis lateralibus basalibus brevibus a venis habitu et directione vulgo vix diversis rarius magis ascendentibus, petiolis pro rata breribus; receptaculis axillaribus binis globosis cerasi magnitudine vel minoribus glabris, basi bracteis $3-4$ parvis plus minus in discum extus ferrugineo-puberulum connatis suffultis; pedunculis brevibus pubescentibus; ostiolo immerso annulo valde prominente circumdato.

Ficus crassinevia Willd.! Sp. pl. IV 2 (1806) p. 1138 n. 25; Desf. Cat. hort. Paris, ed. 2 (1815) p. 209 et ed. 3 (1829) p.. 346 (nomen); Bello Apmut. p. 108 n. 696. - haud Spreng. Syst. III (1826) p. 778 (Jamaica), Griseb. Flor:p. 150 (quoad Jam. et Cuba), Pl. Wright. p. 174, Cat. p. 57; Sauv. Fl. Cub. (1871) n. 2329; Egg. Flor. St. Croix (1876) p. 147, Fl. St. Croix and Virg. 1sl. 1. 774; Mitchc. Bale. etc. (1893) p. 130 (Jamaica); Combs Cuba p. 465 n. 145 neque Urostigma crassinervium Miq. in Hook. Lond. Jonrn. Bot. VI (1847) 535 (Jamaica), Walp. Ann. I (1848) p. 675 (Jamaica). 
Ficus trigonata Egg.! (haud L.) Flor. St. Croix (1876) p. 147 et Flor. St. Croix and Virg. Isl. (1879) p. 95.

Hagü,ey $v$. Yagüey Port. ex Sint., Figuier Guad. ex Duss, Figuier grand feuilles St. Luc. ex Ram.

Arbor 8-20 m. alta. Ramuli $3-5 \mathrm{~mm}$. lati, in sicco cinereobrunnei. Stipulae $1 \mathrm{~cm}$. longae. Petioli $1-3^{1 / 2} \mathrm{~cm}$. longi, $1 \frac{1}{2} \mathrm{~mm}$. lati, saepe squamulosi; folia $5-17 \mathrm{~cm}$. longa, $3 \frac{1}{2}-10 \mathrm{~cm}$. lata, in sicco utrinque pallide fuscescentia, costa subtus in basi saepe glandulosa, renis utrinque ca. 8-11 tenuibus patentibus ad apicem tantum curvatis et ante marginem arcuate confluentibus, subtus prominentibus, supra lıand prominulis, parallelis tenuioribus saepe inspersis, nervis tertiariis subtus tantum prominulis et distinctis, reticulatione tenerrima subtus tantum distincta. Receptacula $9-15 \mathrm{~mm}$. in diametro, interdum paullo pyriformia, in vivo viridia, saepe e rubro brunneo-maculata verrucosa v. subverruculosa (ex Sint.), in sicco lutea paullo obscurius maculata. Pedunculi $2-6 \mathrm{~mm}$. longi, $1^{1 / 2} \mathrm{~mm}$. lati, bracteis $1^{1 / 2}-2 \mathrm{~mm}$. longis. Ostiolum $2 \mathrm{~mm}$. latum squamis glabris clausum, annulo $1 \mathrm{~mm}$ lato. Florum sepala obtusa rubra luteo-marginata.

Hab. in Portorico: Bertero, prope Guanica in sylva de la Boca apud Barina in rupibus m. Mart.: Sintenis n. 3905, prope Adjuntas in sylva montis Cienega m. April. et Majo: Sintenis n. 4163, 4373, prope Peñuelas in sylva montis Yagua m. Jun.: Sintenis n. 4455, prope Yabucoa in sylvis primaevis montis Piedra azul: Sintenis n. $5305^{\mathrm{b}}$ (specimen sterile e ramis junioribus, foliis multo majoribus consistens, sed stipulis aureo-pilosis facile cognoscenda), prope Naguabo ad hacienda Oriente m. Nor.: Sintenis n. 5531 (specimen foliis parvis latioribus basi magis cordatis crassioribus praeditum); St. Thomas: Oersted (hb. Haun.), Riedlé (ex hb. Mus. Paris), Ore Paulsen n. 215 (hb. Haun.), in sylvis ad Canaan, 200 m., m. Aug.: Eggers ed. Toepff. 11. 726; Guadeloupe: Bertero (folio'lato), ad Rivière noire haud procul a Camp-Jacob, fruct. maturi m. Dec. et Jan.: Duss n. 3759 (foliis magnis); Nartinique: Plée (ex hb. Mus. Paris); St. Lucia in Fonds St. Jaques, m. Mart.: Ramage (arbor primum parasitica demum locum arboris destructae occupans, receptacula rubro-maculata, folia valde varia inter oblonga elliptica, ovata et oborata, nervis basalibus in formis obovatis magis ascendentibus).

Obs. I. Specimen originarium Hb. Willdenowii e Jardin des plantes (Seidel) omnino cum speciminibus Indiae occidentalis quadrat etian stipulis aureo-pilosis. In hortis botanicis nunc haec species, quae facile stipularum pilis aureis dignoscenda est, adesse haud ridetur. Quod specimen in horto bot. Berol. e seminibus a Sintenis sub n. 4373 in Portorico lectis ortum et in mus. Berol. asservatum demonstrat, plantas valde juveniles jam stipulis aureopilosis instructas esse.

Obs. II. Haec species interdum in herbariis pro F. trigonata L. Amoen. acad. 8 p. 265 (=F. trigona L.f. Suppl. p. 441) sumpta est; sed omnino dubium est, quid sit haec planta surinamensis a DaLberg lecta. Descriptio Liswafi in supplemento haud valde quadrat cum nostra specie, quia calyx 
(= bractcac basales receptaculi) dicitur csse bifidus, umbilicus (id est ostiolum) triangularis, singulo angulo lacuna oblonga fisso, pedunculus brevissimus.

Obs. III. Ad hanc specicm fortasse Ficus folio citri obtuso, fructu sang. Plum. Cat. (1703) p. 21 et cd. Burm. p. 123 t. 132 f. 1 referenda est.

11. Ficus ochroleuca Griseb. ramulis tenuibus vel subcrassis, in sicco angulosis vel sulcatis; stipulis parris minute puberulis vel fere glabris caducis; foliis pergamaceis, glabris, in sicco praesertim supra cystolithis eleratis saepe albido-punctatis, elliptico-oblongis usque ellipticis, basi subacutis vel cuneato-obtusiusculis usque rotundatis vel subcordatis, apice acuminatis subacutis vel obtusiusculis, basi vix distincte trinerviis, venis validioribus paucis patentibus fere strictis, petiolis modicis; receptaculis binis axillaribus g!obosis glabris, cerasiformibus, basi bracteis 2 paullo connatis puberulis suffultis; pedunculis pro rata longis glabris vel subpuberulis; ostiolo profunde immerso, annulo paullo elerato circumdato.

Ficus ochroleuca Griseb.! Flor. (1859) p. 151.

Ficus Fadyeni Miq. in Amn. Mus. Bot. Lugd. Bat. III (1861) p. 219.

Urostigma crassinerium Miq. in Hool. Lond. Journ. Bot. VI (1847) p. 535; Walp. Amn. I p.675.

Ramuli $2-3 \mathrm{~mm}$. lati, in sicco flavido-cinerei, mox fulvi. Stipulae $4-7 \mathrm{~mm}$. longae lanceolatae acutae, in sicco nigrescentes. Petioli $1-1^{1 / 2} \mathrm{~cm}$. longi, $1 \mathrm{~mm}$. lati, in sicco flavido-fusci; folia $6-10 \mathrm{~cm}$. longa, $3-5 \mathrm{~cm}$. lata, in sicco utrinque subfuscescentia, subtus haud pallidiora, nervis basalibus brevissimis, venis utrinque $6-8$ tenuibus utrinque prominentibus, subtus cum costa in sicco flavidis, ante marginem arcuate confluentibus, interjectis subparallelis tenuioribus, nervis tertiariis utrinque prominulis, reticulatione haud tenui subtus tantum distincta. Receptacula in sicco flavida obscure maculata, $11-12 \mathrm{~mm}$. in diametro. Pedunculi $7-10 \mathrm{~mm}$. longi, $1 \frac{1}{2} \mathrm{~mm}$. lati, bracteis basalibus rotundatis $1 \frac{1}{2} \mathrm{~mm}$. longis, in sicco cum pedunculis fulvis. Ostioli foramen $2 \mathrm{~mm}$. latum, $1 \mathrm{~mm}$. profundum, in basi squamis latis convexe clausum. Florum $q$ sepala lanceolata acuta fusca pallide marginata.

Hab. in Jamaica: Mac Fadyen, Alexander, March (hb. Griseb.), in Blue Mountains, m. April., Jul., Oct.: Harris 11. 5120, 5261, 5385, ad Mabess m. Aug.: Harris n. 7704.

Obs. I. Planta ostiolo immerso affinis $F$. crassinerviae, differt foliis tenuioribus acutioribus angustioribus etc.; habitu magis ad Ficum pertusam accedit, sed differt praeter characteres minores foliorum etiam receptaculis majoribus et ostiolo impresso.

Obs. II. Planta in insula Bonaire a Suringar m. Febr. 1885 lecta, vulgo Maho appellata species probabiliter nova, $F$. ochroleucae valde affinis est, differt foliis minoribus tenuioribus laud punctatis basi magis rotundatis, apice brevius apiculatis. Receptacula haud adsunt, sed radices aereae.

12. Ficus Sintenisii Warb. (u. sp.) ramulis tenuibus, in sicco sulcatis; stipulis parvis glabris caducis; foliis pergamaceis glabris, late 
Firus.

ellipticis, basi subacutis subobtusis vel rotundatis, apice apiculatis acutis rel obtusis, renis multis arcte parallelis strictis, petiolis brevibus; receptaculis binis axillaribus pisiformibus glabris haud depressis, basi bracteis 2 connatis suffultis; ostiolo prominente haud annulato; pedunculis quam receptacula longioribus rel aequilongis glabris..

\section{Jagiies Port. ex Sint., Hignillo preto Port. ex Egg.}

Arbor 5-20 m. alta. Ramuli $1 \frac{1}{2}-2 \mathrm{~mm}$. lati, in sicco cinerei. Stipulae $5-8 \mathrm{~mm}$. longae, in sicco nigrescentes. Petioli $6-12 \mathrm{~mm}$. longi, $1 \mathrm{~mm}$. lati laeves, in sicco fusci; folia $3-7 \mathrm{~cm}$. longa, $1 \frac{1}{2}-3^{1} / 2 \mathrm{~cm}$. lata, in sicco paullo fuscescentia, subtus vix pallicliora, costa prope basin glandulosa, venis utrinque ca. 16 tenuibus patentibus hasalibus haud diversis, ante marginem nervo marginali vix arcuato conjunctis, interjectis parallelis vix tenuioribus utrinque prominulis, nervis tertiariis utrinque distinctis, reticulatione vix distincta. Receptacula saepe rubello- vel fusco-maculata $4-6 \mathrm{~mm}$. in dianetro, in vivo viridia, in sicco lutea. Pedunculi $4-7 \mathrm{~mm}$. longi, $1 / 2 \mathrm{~mm}$. lati, in sicco nigrescentes, bracteis $1-1 \frac{1}{2} \mathrm{~mm}$. longis inaequalibus. Ostiolum 11/2-2 mm. latum, prominens sed haud distincte a receptaculo separatum, squamis latis rotundatis clausum. Flores or monandri pauci prope ostiolum, sepalis fuscis obtusis late pallide marginatis.

Hab. in Portorico: Ledru (hb. Haun., pedunculis longioribus), Stahl (foliis minoribus), Heller 11. 915, in Sierra de Naguabo in monte Piedra pelada, m. April.: Sintenis n. 1250, in Sierra de Luquillo in silvis montis Jimenes, m. Jun.: Sintenis n. 1346, prope Aybonito in silva primaera ad Cuyón, m. Nov.: Sintenis n. 1992 (foliis minoribus), 2332, in Sierra de Yabucoa in silvis inter Valenciano arriba et Cerro gordo, m. Sept.: Sintenis n. 2553, prope Adjuntas in silva montis Cedro, m. April.: Sintenis 11. 4175 (foliis minoribus), Sierra de las Piedras in silva montis Francés, m. Nor.: Sintenis n. 5495, Sierra de Luquillo prope El Sobrante $700 \mathrm{~m}$. in silvis altis, 111. Majo: Eggers ed. Toepff. n. 1030.

13. Ficus jacquinifolia A. Rich. ramulis tenuibus, in sicco fere laevibus; stipulis parvis glabris caducis; foliis parris subcoriaceis glabris oblongis, oblongo-ovatis, ellipticis vel obovatis, apice rotundatis vel subacutis, basi obtusis vel subacutis, renis multis parallelis strictis, petiolis brevibus; receptaculis binis axillaribus, magnitudine et forma grani piperis nigri, glabris haud depressis, basi bracteis $2-3$ connatis suffultis; ostiolo prominente haud annulato; pedunculis quam receptacula brevioribus vel aequilongis.

Ficus jacqminiaefolia A. Fich. in La Sagra Cnbo XI (1850) p. 221 t. 72.

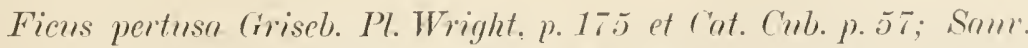
Fl. Cul. n. 2336 p. 150 ; Cardin. in Proc. Ac. Phil. 1889 p. 40 3. Hitche. Liahrum. p. 1:30: - hamel L. fil. 
Jagüeicillo $\varkappa$. Higueron $r$. Jagü ey hembra Cub. ex Wr.

Arbor $3.3 \mathrm{~m}$. alta, cortice tenacissimo (ex EGG.). Ramnli $11 / 2-2 \mathrm{~mm}$. lati, in sicco cinerei, apice squamulose ferruginei. Stipulae lanceolatae, $4-8 \mathrm{~mm}$. longae, in sicco nigrescentes. Petioli $3-5 \mathrm{~mm}$. longi, $2 / 3 \mathrm{~mm}$. lati laeves, in sicco fusci; folia $2-5 \mathrm{~cm}$. Ionga, $1-3 \mathrm{~cm}$. lata, in sicco viridia vel paullo fuscescentia, subtus vix pallidiora, costa prope basin vix glandulosa, venis $14-20$ tenuibus patentibus basalibus haud diversis, ante marginem nervo marginali vix arcuato conjunctis, interjectis parallelis rix tenuioribus utrinque prominulis, nervis tertiariis utrinque distinctis, reticulatione vix distincta. Receptacula $3-4 \mathrm{~mm}$. in diametro, in sicco pallide lutea. Pedunculi $2-4 \mathrm{~mm}$. longi, $1 / 2 \mathrm{~mm}$. lati, in sicco nigrescentes, bracteis $1 \mathrm{~mm}$. longis in sicco fuscis. Ostiolum $1 \mathrm{~mm}$. latum prominens, squamis latis rotundatis clausum. Florum $\underset{+}{\bigcirc}$ sepala nigra albido-marginata.

Hab. in Ballama Andros Island, ad Mastic Point, m. Jun.: Northrop n. 586, New Providence, in silvis montium Blue hills: Eggers n. 4482 (ramis sterilibus, foliis majoribus); Cuba: C. Wright n. 545, Ramon de la Sagra.

Obs. Haec species est $F$. Sintenisii Warb. valde affinis, differt foliis minoribus angustioribus et magis coriaceis, receptaculis minoribus et brevius pedunculatis, sepalis florum nigris.

14. Ficus omphalophor:a Warb. (n. sp.) ramulis tenuibus, in sicco angulosis vel profunde sulcatis; stipulis parvis glabris caducis; foliis pergamaceis usque coriaceis, glabris, oblongis, obovato-oblongis usque ellipticis, rarius oblanceolatis vel obovatis, apice obtusis vel rotundatis vel obsolete apiculatis, basi angustatis denum rotundatis, venis primariis haud valde crebris parallelis fere strictis, petiolis brevibus; receptaculis binis axillaribus pisiformibus, apice saepe paullo depressis, glabris, basi bracteis 2 rarius 3 paullo connatis suffultis, apice ostiolo conico-prominente distincte umbonatis; pedunculis baud crassis quam receptacula vulgo brevioribus.

Ficus pertusa Griseb.! (haud L.f.) Flor. (1859) p. 152 (p.p.); Manë Nomencl. Gradel. p. 103; Duss! Flor. Ant. frane. p. 155.

Ficus pallida Griseb.! (haud Tahl) Flor. (1859) p. 151 (quoad specim. Dominic.).

Urostigma pertusum Miq. in Hook. Lond. .Joum. Bot. VI (1847) p. 548 (p.p.); Walp. Am. I p. 680; Griseb.! Veg. Kar. n. 316 p. 46.

Arbor parva elegans raro mediocris, ramis patentibus vel fastigiatis secundum expositionem (ex Duss), nunc in St. Vincent 27-30 m. alta (ex EGG.). Ramuli $2-3 \mathrm{~mm}$. lati, in sicco cinerei rel juniores subfusci. Stipulae $1 / 2-1 \mathrm{~cm}$. longae, lanceolatae acutae, in sicco nigrescentes. Petioli $1 / 2-1 \mathrm{~cm}$. longi, $1-1^{1} / 2 \mathrm{~mm}$. lati, laeres, in sicco nigrescentes; folia $3 \frac{1}{2}-91 / 2$ cm. longa, $1 \frac{1}{2}-3 \frac{1}{2} \mathrm{~cm}$. lata, costa crassa subtus prope basin saepe glandulosa, venis utrinque ca. $13-15$ tenuibus ntrinque prominulis nervo marginali vix arcuato conjunctis, nervis basalibus a ceteris haud diversis, nervis tertiariis utrinque subprominulis, reticulatione subtus prae- 
sertim distincta. Receptacula $7 \mathrm{~mm}$. lata, $6 \mathrm{~mm}$. alta, in sicco lutea. Pedunculi $3-4 \mathrm{~mm}$. longi, $1 \mathrm{~mm}$. lati, bracteis rotundatis $1-1 \frac{1}{2} \mathrm{~mm}$. longis. Ostiolum $1 \frac{1}{2}-2 \mathrm{~mm}$. latum, $1 \mathrm{~mm}$. altum, squamis latis rotundatis clausum, in sicco fuscum. Florum $q$ sepala obtusa fusea pallide marginata.

Hab. in St. Eustache: Suringar (steril.): St. Kitts: Ryan (hb. Haun., steril.): Guadeloupe: Bertero, Duchassaing, in Natouba, Camp Jacob, Houel-Mont, alt. 400-700 m.: Duss n. 2195, Bois des Bains jaunes, receptaculis maturis m. Majo, Jun.: Duss n. 3428: Dominica: Imray n. 170 (sub nomine F. pallida Tahl ex hb. Griseb.), ad Rosehill 660 m. alt., m. Febr.: Eggers, in valle supra Point Michel, ca. 330 m. alt.. m. Dec.: Ramage (forma crassifolia, foliis coriaceis), ad Castle Bruce, m. Febr.: Ramage (receptacula pallide rubella); Martinique, in Jont Parnasse m. Oct.: Hahn n. 327, in silvis inferioribus: Duss n. 29, 615, 651, in eircuitu Gros Morne, m. Jul.: Duss n. 982, ị Trois Islets (plateau de la Plaine), m. Aug.: Duss n. 4483, ad Champflore, m. Aug.: Duss n. 4636: St. Vincent, in montibus St. Andrews: Eggers n. 6748, in silvis ad Soufrière ad $450 \mathrm{~m}$., m. Jan.: Eggers n. 6897, Smith s. n. (forma angustifolia, foliis oblanceolatis insignis), Smith n. 1732 (forma latifolia foliis oboratis); Grenada, in monte Fedon's Camp, m. Jun.: Broadway n. 960.

Ohs. I. Haec species est $F$. Sintenisii Warb. e Portorico valde affinis, foliis in superiore parte latioribus, haud ita crebro et distincte renosis, apice haud rel obsolete apiculatis et rulgo angustioribus diversa.

Obs. II. Ad lane speciem fortasse Ficus foliis Lauri, fructu minore Plum. Cat. (1703) p. 21 et ed. Burm. p. 124 t. 132 f. $2=$ Ficus americane Aubl. Guian. (1775) p. 952 (non Swartz) quoad synon. referenda est.

Obs. III. Ficus pallida Vahl e Columbia est (ex specim. origin.) planta valde diversa, quae magis ad $F$. ligustrinam, myrtifoliam, genuinam etc. accedit.

15. Ficus Wilsoni Warb. (n. sp.) ramulis tenuibus, in sicco subrugoso-sulcatis; stipulis glabris caducis; foliis crasse pergamaceis rel subcoriaceis, glabris, oblongis usque oborato-ellipticis, basi cuneato-subacutis, apice obtusis rel rotundatis rarius subapiculatis; renis paucis validioribus fere strictis, petiolis brevibus; receptaculis binis axillaribus pisiformibus haud depressis glabris, basi bracteis 2 connatis suffultis: ostiolo haud rel vix prominente haud annulato; pedunculis crassis receptaculis aequilongis vel brevioribus.

Ficus pedunculata Giriseb.! (haud Ait.) Flor. (1859) p. 151.

Ficus americana Su. (hand Aubl.) Prodr. (17-8S) p. $12 \mathrm{r}$ et Flor. Ind. occ. III. (1S06) p. 1569; Lun. Hort. .Jam. 1. p. 295: Roem. et Scimlt. Syst. Veg. I p. 504. 
Arbol $6-13$ m. alta (ex Erif.). Ramuli $2-3$ mm. lati cinerei, juniores rubello-squamulosi. Stipulac $1-2 \mathrm{em}$. longae lanceolatae acutae, in siceo nigrescentes. Petioli 5-10 $\mathrm{mm}$. longi, $1-1 \frac{1}{2} \mathrm{~mm}$. lati laeves, in sicro fusci; folia $4-8 \mathrm{~cm}$. longa, $1 \frac{1}{2}-3 \mathrm{~cm}$. lata, in sicco vulgo fuscescentia, costa crassa ad basim hand glandulosa, venis utrinque $6-10$ tenuibus vix subtus prominulis patentibus strictis nervo marginali rix arcuato conjunctis, interspersis parallelis tenuioribus vix distinctis, nervis tertiariis vix conspicuis, reticulatione hand distincta. Receptacula in sicco lutea 7-10 mm. in diametro. Pedunculi 4-6 mm. longi, $1 \mathrm{~mm}$. lati glabri, bracteis $1 \frac{1}{2} \mathrm{~mm}$. Inngis rotundatis glabris cum pedunculis in sicco fuscis. Ostiolum $1-1 \frac{1}{2} \mathrm{~mm}$. latum, in sicco fuscum. Florum $q$ sepala fusca vel nigro-fusca, in margine pallida.

Hab. in Jamaica: Wilson n. 347 (ex hb. Grisebach sub nom. $F$. pedunculata Ait.), prope Hope River, 350 m. alt., m. Jan: Eggers n. 3483, prope Bellevue, 1300 m. alt., m. Jan.: Eggers n. 3776, Port Royal Mts., m. Jul.: Harris n. 5264.

Obs. I. Species a $F$. Sintenisii foliorum forma angustiore et magis obovata praesertim autem venis pancis distinctis diversa.

Obs. II. A. Grisebach certe erronee ad F. pedunculatam Ait. (Hort. Kew. III p. 450) referta, quae habet tamen folia ovata oblonga cordata acuta, petiolos elongatos. - Quid sit haec $F$. pedumculata Ait., planta ex America patria speciali ignota olim in hortum Kewensem introducta, dubium remanet, sed fortasse ad formam $F$. popnlneae referendam esse existimo. - $F$. pedunculata Willd. (haud Ait.) Sp. pl. IV 2 p. 1138 (symonymis exclusis) e specimine orig. Herb. Willd. est F. gigantea H. B. K. leg. Humboldt u. 722 prope Caracas, species a $F$. Wilsoni ralde diversa, ad seriem $F$. populneae pertinens.

Obs. III. Fortasse nostra species est Ficus americana Swartz Prodr. p. 127 et Flor. III p. 1569 (hand Aublet), cujus descriptio cum nostra specie congruit et cujus plantae praesertim in Jamaica collectae sunt. Quid sit ipsa F. americana Aubl. e Guyana, dubium remanet, quia autor descriptionem propriam hand dedit, sed tantum descriptionem Burmanni (Americ. 124 t. 132 f. 2) et Pudmeri (Cat. p. 21) elgo plantae cujusdam ex Antillis (prol,abiliter $=F$. omphalophora Warb.) reddidit.

16. Fir.us Berteroi Warb. (11. sp.) ramulis haud crassis, in sicco sulcatis vel junioribus angulosis; stipulis haud valde longis caducis glabris; foliis membranaceis glabris, ovatis vel ellipticis, apice rotundatis vel obtusis, basi vulgo subcordatis, raro rotundatis, nervis basalibus $5-7$ brevibus, superioribus a venis directione et labitu vix diversis, petiolis pro rata brevibus; receptaculis axillaribus binis subdepresso-globosis quam cerasi minoribus glabris, basi bracteis $2-3$ paullo connatis glabris in margine minute fimbriatis suffultis; pedunculo crasso parvo vel minimo; ostiolo mamilliformi prominulo haud amnulo circumdato.

Ficus lamifolia Griseb. (non Lam.) Flor. (1859) p. 150 (quoad sperim. Jam.). 
? Ficus trigonata Griseb. (hand L.) Flor. (1859) p. 150: Hitche. Baham. etc. (1893) p. 130.

Ramuli 2-4 mm. longi, in siceo ex rubello-cinerei. Stipulae $1 \frac{1}{2}-2 \mathrm{~cm}$. longae lanceolatae acutae, in sicco rubrae. Petioli $2-3 \mathrm{~cm}$. longi, $1 \frac{1}{2} \mathrm{~mm}$. lati, laeves glabri, in sicco cinerei; folia $13-17 \mathrm{~cm}$. longa. 7-10 cm. lata, interdum in costae basi glandulosa, in sicco prope costam fuscescentia, venis utrinque praeter nervos basales $7-9$ supra vix prominulis subtus prominentibus, fuscis, patulis fere strictis, ad marginem arcuate connexis, nervis tertiaris subtus tantum prominulis, reticulatione tenerrima subtus tantum distincta. Receptacula usque $1 \mathrm{~cm}$. lata et $8 \mathrm{~mm}$. longa, in sicco lutea. Pedunculi $0-2 \mathrm{~mm}$. longi, $2 \mathrm{~mm}$. lati, bracteis basalibus 2-4 mm. longis. Ostiolum $2 \mathrm{~mm}$. latum, squamis glabris clausum. Florum sejala nigro-fusca obtusa pallide marginata.

Hab. in Jamaica: Bertero n. 2328.

Obs. I. Ex lıb. Serenger in lib. Berol. sub eodem numero adest folium e Jamaica enorme $36 \mathrm{~cm}$. longum, $21 \mathrm{~cm}$. latum, textura et nervatura inter F. Harrisii et Berteroi intermedium. - In hb. Mrequel in Utrecht asservato exstat folium a MAC F.DYEex in Jamaica lectum forma cum $F$. Berteroi yuadrans, sed textura firmiore et venis in sicco albicantibus; receptaculum sessile bracteis haud fimbriatis suffultum est.

Obs. II. Slodve Cat. (1696) p. 189 et Hist. Jam. II (1725) p. 140: Ficus Indica folio oblongo obtuso fructu minore pallide huteo sphaerico ad hane speciem fortasse pertinet.

Obs. III. F. mbrinervia Link Enum. H. Berol. II. 448, olim in horto Berol. cnlta, quae dicitur in Brasilia habitare, et $F$. oblongata Link Enum. H. Berol. II. 449, olim in lorto Berol. culta, quae certe erronee in Promontorio bonae spei halitare dicitur, ex habitu et structura foliorum in hb. Berol. asservatorum valde ad $F$. Berteroi accedunt.

17. Ficus Eogersii Warb. (n. sp.) ramulis haud crassis, laevibus, in sicco sulcatis; stipulis caducis glabris; foliis subpergamaceis glabris, ellipticis vel late ellipticis, basi et apice rotundatis raro subobtusis, nervis basalibus a venis hand diversis, petiolis brevibus; receptaculis binis axillaribus glabris quam cerasi minoribus, basi bracteis haud parvis obtusis vel rotundatis minutissime puberulis et fimbriatis basi paullo connatis suffultis; pedunculo brevi crasso minute puberulo; ostiolo mamilliformi valde prominente.

Ficus trigona A. Rich. (hand L.) in La Sagra Cuba XI (1850) p. 221; Sauv. Cuba n. 2330 p. 149 (p. p.).

Ficus trigonata (iriseb.! (hand L.) Pl. Wright. (1S60) p. 172 et Cat. I'l. Cub. p. 5 \%.

Jagüey Gub.ex Egg., Hije Sto. Dom. ex Egg.

Ramnli 4-5 mm. lati, in siceo luteo-vel fusen-cinerei. Stipulae lanceolatae, $6-20 \mathrm{~mm}$. longae. Petioli $1-2 \mathrm{~cm}$. longi, $1 \frac{1}{2}-2 \mathrm{~mm}$. lati laeves glabri, in sicco cinerei vel fusci; folia $7-18 \mathrm{~cm}$. longa, $5-12 \mathrm{~cm}$. lata, in sicco utrinque pallide viridia, subtus hand pallidiora, costa crassa subtus in basi glandulosa, venis utrinque ca. $6-10$ utrim pue praeter basales 
patentibus strictis ante marginem areuate conjunctis, supra prominulis subtus prominentibus in siceo lntcis, nervis tertiariis utrinque prominulis, reticulatione grossa snbtus vel utrinque prominula, reticulatione tenerrima haud distincta. Receptacula ca. $1 \mathrm{~cm}$. longa et lata, in sicco luteo-fusca haud maculata. Pedunculi $2-3 \mathrm{~mm}$. longi et lati, squamosi ct apicc verrucosi, bracteis basalibus ca. $3-4 \mathrm{~mm}$. longis in sicco fuscis. Ostiolum $3 \mathrm{~mm}$. in diametro, squamis latis rotundatis in sicco nigrescentibus clausum. Florum sepala nigro-fusca, fusco-marginata.

Hab. in Cuba: Wright n. 1444 (ex hb. Griseb. sub F. trigonata), ad Monte Toro 400 m. alt. m. Majo: Eggers n. 5427; Sto. Domingo: Prenleloup 11. 553, in silvis prope Mata Redonda juxta flumen Muñoz 200 m. alt., m. Jun.: Eggers n. 2488.

Obs. Species valde affinis $F$. Berteroi, differt foliis hand subcordatis, reticulatione tenerrima haud distincta, pedunculis majoribus bracteis minute puberulis.

18. Fivus mamillifera Warb. (n. sp.) ramulis haud crassis, in sicco profunde sulcatis; stipulis brevibus caducis glabris; foliis pergamaceis glabris, late vel ovato-ellipticis usque fere rotundis, vulgo utrinque rotundatis, interdum basi subcordatis et apice subobtusis, nervis basalibus brevibus a venis haud diversis, petiolis brevibus; receptaculis axillaribus binis globosis vel depresso-globosis, quam cerasi vulgo minoribus glabris, basi bracteis pro rata magnis maxima parte in discum connatis glabris circumclatis; perlunculo parvo glabro; ostiolo mamilliformi valde prominente, haud annulo circumdato.

Ramuli $2-4 \mathrm{~mm}$. lati, in sicco cinerei. Stipulae lanceolatae acutae, 8 - $12 \mathrm{~mm}$. longae. Petioli $8-28 \mathrm{~mm}$. longi, $1 \frac{1}{2} / 2 \mathrm{~mm}$. lati, omnino laeves et glabri; folia 7-12 cm. longa, $4-8 \mathrm{~cm}$. lata, in sicco utrinque fusca, subtus vix pallidiora, costa subtus in basi interdum glandulosa, venis utrinque praeter basales 5 - $S$ patentibus strictis, antc marginen arcuato-connexis, subtus prominentibus, supra vix prominulis, tenuioribus parallelis saepe inspersis, nervis tertiariis subtus tantum prominulis, reticnlatione tenerrima subtus tantum distincta. Receptacula $8-10 \mathrm{~mm}$. longa, $10 \mathrm{~mm}$. lata, in sicco fusca maculis obscurioribus inspersa. Pedunculi $1-3 \mathrm{~mm}$. longi, $1 \frac{1}{2}-2 \mathrm{~mm}$. lati, bracteis basalibus $3-4 \mathrm{~mm}$. longis rotundatis, in sicco nigrescentibus, haud fimbriatis. Ostiolum $2 \mathrm{~mm}$. in diametro, $1 \frac{1}{2}-2 \mathrm{~mm}$. altum, squamis nigrescentibus clansum. Florum sepala nigricantia, pallide marginata.

Hab. in Jamaica in Blue Mountains, m. Majo, Sept., Oct.: Harris n. $5206,5348,5396$.

Obs. Haec species $F$. Stahlii Warb. e Portorico valde affinis, differt foliis vulgo latioribus, venis minoribus, reticulatione subtus distincta, bracteis basalibus majoribus glaberrimis, ostiolo altius prominente.

19. Ficus Stahlii Warb. (n. sp.) ramulis haud valde crassis, in sicco hand angulosis, sed sulcatis; stipnlis hand valde longis caducis glabris; foliis pergamaceis glabris, vulgo late ellipticis usque oratis vel oblongis, vulgo utrinque rotundatis, nervis basalibus a venis vix diversis 
brevibus, petiolis vulgo brevibus; receptaculis axillaribus binis forma et magnitudine cerasi parvi glabris, basi bracteis $3-4$ parvis plus minus connatis rotundatis ninute albido-puberulis suffultis; pedunculo parvo glabro; ostiolo manilliformi paullo prominente, haud annulo circumdato. Hagüey $v$. Jagüey Port. ex Sint.

Frutex $3 \mathrm{~m}$. v. arbor usque $15 \mathrm{~m}$. alta. Ramuli $4-5 \mathrm{~mm}$. lati, in sicco Inteoli vel cinerei. Stipulae lanceolatae acutae $12-18 \mathrm{~mm}$. longae. Peticli $1-2 \frac{1}{2} \mathrm{~cm}$. longi, $1 \frac{1}{2}-2 \mathrm{~km}$. lati, omnino laeves et glabri; folia $8-17 \mathrm{~cm}$. longa, $5-8 \mathrm{~cm}$. lata, in sicco utrinque fusea, subtus vix pallidiora, costa subtus in basi saepe glandulosa, venis utrinque praeter basales 8-10 patulis fere strictis, ante marginem arcuate connexis, subtus prominentibus supra vix prominulis, tenuioribus parallelis saepe inspersis, nervis tertiariis et reticulatione grossa utrinque prominulis, reticulatione tenerrima haud distincta. Receptacula ca. $1 \mathrm{~cm}$. longa et lata, in vivo viridia (ex Sint.), in sicco fusca, maculis parvis obseurioribus inspersa. Pedunculi $3-4 \mathrm{~mm}$. longi, $2-3 \mathrm{~mm}$. lati, bracteis 2-4 $\mathrm{mm}$. longis. Ostiolum 3-4 mm. in diametro, squamis glabris clausum. Florim $q$ sepala fusca, pallide marginata.

Hab. in Portorico prope Bayamon in silvis, m. Jajo: Stahl n. 485, prope Hatillo ad Guayanés, in. Febr.: Sintenis n. 6283, prope Manatí in montibus calcariis ad Rio arriba saliente, m. April.: Sintenis 11. 6697, prope Utuado in scopulosis ad Los Angeles, m. Jan.: Sintenis n. 6030 (ramis sterilibus, foliis pro parte enormibus usque $28 \mathrm{~cm}$. longis, $16 \mathrm{~cm}$. latis, longe petiolatis).

Obs. Haec species ex liabitu valde ad $F$. crassinerviam Willd. accedit, stipulis glabris, nervatura foliorum tenerrima haud distincta pedunculis glabris receptaculis minoribus et praecipue ostiolo prominulo haud impresso neque anmulo circumdato differt.

20. Ficus populnea Willd. ramulis tenuibus rel modice crassis, in sicco vulgo sulcatis glabris; stipulis parris glabris caducis; foliis membranaceis usque pergamaceis glabris, supra cystolithis in sicco fere semper elevatis saepe albido-punctatis, forma et magnitudine valde variabilibus, vulgo ovatis rarius ellipticis, basi cordatis, rotundatis truncatis vel obtusis, apice obtusis vel subacutis vel breviter saepe oblique acuminatis rarius cuspidatis, basi vulgo $3-5$-nerviis, venis primariis laad crebris subarcuatis, petiolis modicis rel longiusculis; receptaculis binis axillaribus globosis vel depresso-globosis vel subpyriformibus, pisi usque cerasi magnitudine, basi bracteis 2 parvis paullo connatis suffultis glabris; ostiolo haud vel paullo prominulo vel convexo haud annulato; pedunculis quan receptacula brevioribus, aequilongis vel longioribus glabris.

Ficus populnea Willd.! Sp. pl. IV (1806) p. 1141; Roem. et Schult. Mantissa p. 330; Spreng. Syst. III p. 780 (Portorico); Desf. Cat. hort. Paris. ed. 3 p. 412; A. Rich.! in La Sugra C'uba XI p. 220; Griseb. 
Flor. 1) 151 (Antigua: Vichols., Wullschl.) et Cat. Cub. p. 57 (Wr.); Hemsl. Biol. (entr. Au. III p. 147 (Inul. Oce.); Kew Bull.! n. 811893 1. 276 (St. Vincent: Smith n. 447, 924, Bequia: Smith n. 54, 55, Mustique: Smith n. 122).

Urostigna populneum Miq. in Hook. Joum. Bot. VI (1817) 1. 537 (Jam.. Antig.); Walp. Anu. I p. 675.

? Ficus populifolia Desf. (nomen, hand Vahl) Cat. hort. Paris. ed. I (1804) 7.269.

Ficus laevigata Vahl! Emum. II (1805) p. 183; West St. Croix (1793) p. 313 (nomen); Spreng. Syst. III p. 777 (Carib.); Roem. et Sch. Syst. Veg. I p. 500 (Ind. oce.); Griseb.! Flor. p. $151 \mathrm{et} \mathrm{Pl.} \mathrm{Wright.} \mathrm{p.} 172$ (Wr. 544, 1684) et Catal. p. 57 (Wr.511, 1684): Sauv. Fl. Cub. p. 149 11. 2332 (Wr. 514, 1681); Egg.! St. Croix p. 147 et Fl. St. Croix and Virg. Isl. p. 776 (St. Croix); Hitchc. Baham. p. 130 (Bahamas, Grand Caymani).

Urostigma laerigalum Miq.! in Kook. Lond. Journ. of Bot. VI (15.77) p. 539 (Ind. occ.); Walp. Amn. I p. 676, 38; Liebm.! Urticac. mexicanue, in Vidensk. Selsk. Skrift. Afl. II p. 324 (St. Croix, St. Thomas).

Ficus lentiginosa Vahl! Enum. II (1805) p. 183; Roem. et Sch. Syst. Vey. I p. 500 (Montservat: Ryan); Spreng. Syst. III p. 779 (Carib.); Giriseb.! Flor. p. 151 (Moutservat, Dominica, Guadeloupe), nec Pl. Wright. 1. 172 nec Catal. p. 57; Maré Nomencl. in Bull. de la Soc. de Fronce XXX p. 103 (Guadeloupe); Egg.! Filor. St. Croix and Virg. Isl. n. 777 (St.Thomas); Duss! Flou. Ant. fraur. p. 154 (Guadeloupe u. 2197, Martinique n. 1407).

Urostigma lentiginosum Licbm!! Urticac. mexic. in Vidensk. Selsk. Slivift. Afd. II (1851) p. 323 (Moutservat: Riyan).

Ficus sancti-erncis Miq.! in Amm. Mus. Lugd. Bat. III (1867) p. 299 и. 95.

Urostiyma Sanctae Crucis Liebm.! in Tidensk. Selsk. Skrift. Afd. II (1851) p. 328 (St. Croix: Oersted).

Ficus peduneulata Vahl! Enmm. II (1805) p. 183 (prob. haud Ait.); spreng. Syst. III (1826) p. 778 (Carib.); Griseb. Flor. p. 151 (St. Croix); Egg.! St. Croix p. 117 et St. Croix and Virg. Isl. u. 779; Chapm. Fl. South. U.-St. p. 415 (S. Florida).

Urostignua pedumenlatum Miq. in Hook. Loud. Journ. Bol. VI (1847) p. 540 (Americ.); Liebm.! in Vidensk. Selsk. Skrift. Afd. II (1851) p. 325 (St. Croix: West).

Urostigma lanrifolium (rriseb. (non Miq.) Veg. Kurib. n. 314 p. 46.

Ficrs Schumacheri Bello! (haud Griseb.) Apunt. Fl. Portor. II (1883) p. 108. 
Ficus.

Ficus portoricensis Urb.! Symb. I (1900) p. 472.

Ficus thomaen Miq.! in Amm. Mus. Luyd. Bat. III (1867) 11. 299 sp. 96 .

Ficus brevifolia Nutt. Sylva II (1854) p. 3, rel. 2 I p. 153.

? Ficus citrifolia Lam. Eucycl. II (1786) p. 494 (excl. syn. Mill. et Plum.).

? Ficus foliis Lauri, finctu minore Plum. Cat. (1703) 1. 21 et ed. Burm. p. 124 t. 132 f. 2.

Ramuli $2-3 \mathrm{~mm}$. lati, in sicco cinerei vel fusci. Stipulae $1 / 2-1 \mathrm{~cm}$. longae, lanceolatae acutac, in sicen fuscae usque nigrescentes. Petioli glabri, $1 \frac{1}{2}-4 \mathrm{~cm}$. longi, $1 / 2-1 \mathrm{~mm}$. lati, in sicco fuscescentes; folia $3-18 \mathrm{~cm}$. longa, $1 \frac{1}{2}-10 \mathrm{~cm}$. lata, in sicco vulgo viridia, subtus pallidiora, interdum fuscescentia, nervis basalibus brevibus $1 / 3$ folii raro superantibus, venis utrinque praeterea $6-8$ patentibus haud crassis ante marginem subarcuate connexis, utrinque prominulis, interspersis parallelis tenuioribus brevioribusque, nervis tertiariis vix prominulis, reticulatione tenerrima subtus praecipue distincta. Receptacula $6-10 \mathrm{~mm}$. in diametro flavida nsque lutea, interdum valde distincte grosse obscuro-maculata. Pedunculi $3-20 \mathrm{~mm}$. longi, $1 / 2-1 \mathrm{~mm}$. lati, bracteis 1-12 mm. longis vulgo ol,tusis in sicco fuscis. Ostiolum $1-1 \frac{1}{2} \mathrm{~mm}$. latum, squamis glabris fuscis rotundatis vel obtusis clausum. Florum or monandrium et $q$ sepala late lanceolata vulgo obtusa fusca rel e nigro fuscescentia pallide marginata.

Var. a. brevifolia (Nutt.) Warb. foliis pro rata parvis et longiuscule peliolatis, basi rotundatis obtusis vel truncatis vel rarius subcordatis distincte trinerviis, costa petiolo venis in sicco flavidis; receptaculis quam cerasi vulgo minoribus in sicco pallidis ad ostiolum fuscis: pedunculis receptaculis aequilongis vel paullo tantum minoribus rel longioribus.

Subvar. $\alpha$. floridiua Warb. pedunculis et bracteis basalibus receptaculorum subpruinosis.

Ficus brevifolia Nutt. Sylva II (1854) p. 3, en. 2 I p. 153.

Hab. in Florida australi, in Meig's Key in rupibus corallinis: Curtiss n. 2548.

Subvar. $\beta$. cubana Warb. pedunculis et bracteis haud pruinosis. Jagüey Cub. ex Valeñuela.

Hab. in Cuba, in silvis partis occidentalis ad Tuelta Abajo: Valenzuela (spec. origin. pro A. Rich. Fl. Cub. XI p. 220), loco non indicato: Wright n. 544, 1684 (ex hb. Griseb. sub $F$. lacviyata), prope Cienfuëgos ad. Faro Villa Nueva, m. Sept.: Combs n. 599 (forma majuscula foliis submajoribus subacuminatis, receptaculis cerasi magnitudine).

Var. b. bahamensis Warb. foliis plo rata parvis et longiuscule petiolatis, basi rotundatis, truncatis vel subcordatis, trinerviis, sed nervis 
basalibus haud valde directione a venis ceteris diversis, costa et venis in sicco luteis; receptaculis quam cerasi vulgo minoribus in sicco haud pallidis; pedunculis quam receptacula vulgo subminoribus.

Hab. in Bahama insulis New-Providence in pinetis, m. Mart.: Egger's n. 4380 (frutex procumbens), prope Nassau m. Jan.: Northrop n. 46, Hog Island in silvestribus m. Mart.: Eggers 11. 4496 (arbor 9 m. alta), Fortune Island m. Febr.: Eggers n. 3800 (arbor 13 m. alta).

Var. c. Iacvigata (Vahl) Warb. foliis in ramis receptacula gerentibus vulgo parvis vel modice longis, ellipticis rarius oblongis vel ovatis, apice obtusis usque subacutis, raro acuminatis vel apiculatis, basi vulgo obtusis, rotundatis vel truncatis, rarius subcordatis, vulgo longiuscule petiolatis, trinerviis sed nervis basalibus directione vix a ceteris venis divergentibus; receptaculis vulgo globosis, rarius depresso-globosis vel subpyriformibus, pisiformibus vel majoribus, sed cerasis minoribus; pedunculis receptaculis aequilongis vel subbrevioribus.

Subvar. $\alpha$. portoricensis (Urb.) Warb. receptaculis junioribus subpyriformibus pisiformibus, ostiolo paullo prominente, maturis majoribus usque fere cerasiformibus globosis; pedunculis vulgo minute puberulis, quam receptacula vulgo paullo minoribus; foliis vulgo ellipticis fere duplo longioribus quam latis.

Ficus portoricensis Urb.! Symb. Ant. I (1900) p. 472.

Hab. in Portorico inter Peñelas et Adjuntas, alt. 700 m., m. Aug.: Stahl n. 1144, prope Fajardo in silvis montanis m. April.: Sintenis n. $1243^{\mathrm{b}}$, prope Guanica in silva montana ad Cobana, m. Febr.: Sintenis n. 3855 (frutex $3-5 \mathrm{~m}$. altus, receptaculis albis, fulro-maculatis), prope Guanica in silva inter Barina et la Boca, m. Mart.: Sintenis 11.3904 (arbor $10 \mathrm{~m}$. alta, receptaculis viridibus fulvo-maculatis), eodem loco m. Mart.: Sintenis n. 3906 (arbor vasta cum radicibus aëreis $20 \mathrm{~m}$. longis), prope Guayanilla in fruticetis littoralibus ad Peñon, m. Jul.: Sintenis n. 4900 (arbor $15 \mathrm{~m}$. alta), prope Yabucoa ad Puerto de la vaca, m. Sept.: Sintenis n. 5037 (arbor 10 m. alta, receptaculis albis, maturis nigris), prope Manatí in litoralibus: Sintenis n. 6714 (frutex), prope Fajardo ad litora, m. Febr:: Heller n. 4600 , loco non indicato: Heller n. 1016.

Obs. Probabiliter specimen sterile in Herb. Willd. sub n. 19313 asservatum, e Portorico a Miques ad $F$. thomaeam refertum hue pertinet.

Subvar. $\beta$. thomalea (Miq.) Warb. receptaculis pisiformibus vel majoribus subpyriformibus, ostiolo paullo prominente; pedunculis vulgo minute puberulis quam receptacula vulgo longioribus vel aequilongis; foliis vulgo late ovatis vix $1 \frac{1}{2}$-plo longioribus quam latis.

Ficus laeviguta I'ahl! Einum. II (1805) p. 183. 
Ficus.

Ficus thomaen Miq.! in Anm. Mus. bot. Lugd.- Bot. III (1867) p. 299 n. 966.

Hab. in St. Thomas: Riedlé (a. 1798, ex hb. Mus. Paris.), Ehrenberg n. 236 (spec. origin. F. thomoeae Miq.), H. Krebs (m. April., Jul.), Eggers ed. Toepff. n. 725: St. Croix: West (hb. Haun., spec. origin. F. laevigatce V Vhl), Isert (a. 1787, hb. Haun.), Benzon (hb. Haun.), ad Anualy m. Jan.: Börgesen (hb. Haun.), Parasol Bukke, m. Dec., Alm. North Side, m. Jan.: Eggers (sub nom. $F$. pedunculate Ait.), ad Crequis m. Sept. et Nov., Shoys m. April.: Eggers (hb. Haun.), East end roadside m. Jul., ad Bassin m. Febr.: Ricksecker n. 190, 466.

Subvar. \% Sancti-Joannis Warb. receptaculis pisi magnitudinis vel submajoribus subpyriformibus; ostiolo subimpresso vel paullo prominente, pedunculis fere glabris quam receptacula brevioribus; foliis vulgo late ovatis vix $11 / 2$-plo longioribus quam latis, apice vix acutis.

Hab. in St. Jan ad Klein Camel Bay m. Dec.: Eggers n. 3094 (arbor $13 \mathrm{~m}$. alta), ad Küstenberg. 300 m., m. Dec.: Eggers n. 3260 (arbor $6 \mathrm{~m}$. alta, hb. Haun.).

Subrar. $\delta$. Sancti-Eustachii Warb. receptaculis pisis majoriburs valde depressis, ostiolo saepe subimpresso; pedunculis subpuberulis subcrassis quan receptacula brevioribus; foliis pro varietate magnis acuminatis, late oratis basi rotundatis vel subcordatis.

Hab. in St. Eustacle ad Klif, Fairplay, m. Majo: Suringar; St. Martin m. Majo: Suringar.

Subvar. $\varepsilon$. Sanctae Crucis Warb. receptaculis pisi magnitudinis sed depressis, ostiolo nec prominente neque impresso: pedunculis receptaculis aequilongis puberulis; foliis parvis ellipticis acutis, 2-21/2plo longioribus quam latis, basi obtusis vel rotundatis.

Urostigma Sanctoe Crucis Liebm.! in Vidensk. Selsk. Skrift. Afa. II (1851) p. 328.

Ficus sancti-crucis Miq.! in Ann. Inus. Lngd.- Bat. III (1869) p. 299 и. 95 .

Hab. in St. Croix: Oersted.

Subvar. ‘. pedunculata (Vahl) Warb. receptaculis pisi parri magnitudinis subpyriformibus, ostiolo laud prominente; pedunculis receptaculis aequilongis puberulis; foliis oblongis pro varietate longis apiculatis, 21/2-4-plo longioribus quam latis, basi rotundatis rel subcordatis.

Ficus pedunculata Vahl! (1prob. hand Ait.) Emmm. II (1805) p. 183.

Hab. in St. Croix: Dr. West. 
Subvar. $\eta$. IIspaniolar Warb. receptaculis pisi magnitudinis globosis, ostiolo subprominente; pedunculis receptaculis aequilongis subpuberulis; foliis parvis ellipticis apice vulgo subacutis, haud apiculatis neque acuminatis, basi rotumdatis vel subcordatis, vix 2-plo longioribus quam latis.

Hab. in Sto. Domingo: Bertero; Haiti: Madem. Roquefeuille (ex hb. Paris.), Poiteau, Flanes du Morne l'Hôpital 400-500 nı., m. Nov.: Picarda 11. 1169 (arbor alta, ramis extensis), ad Anse à Veau m. Jul.: Picarda 11. 1287 (arbor alta).

Var. d. lentixinosa (Valıl) Warb. foliis etiam in ramis receptacula gerentibus vulgo magnis (12 cm. superantibus), vulgo ovatis, rarius ellipticis, apice vulgo acuminatis vel apiculatis subacutis vel obtusis, basi truncatis vel subcordatis rarius rotundatis vel cordatis raro obtusis, vulgo breviter vel modice petiolatis, in basi vulgo 5 -nerviis, nervis inferioribus brevibus fere marginalibus, superioribus a venis ceteris vix diversis; receptaculis vulgo globosis magnitudine pisi vel cerasi, ostiolo haud prominente; pedunculo quam receptaculum breviore.

Subrar. $\alpha$. typica Warb. foliis ramorum receptacula gerentium pro rata maguis, basi truncatis vel subcordatis, apice apiculatis usque cuspidatis; receptaculis magnitudine pisi subdepressis in sicco luteis brunneo-maculatis.

Ficus lentiginosa Tahl! Symb. II (1865) p. 183.

Hab. in Montserrat: Ryan.

Subvar. $\beta$. subcorlata Warb. foliis ramulorum receptacula gerentium pro rarietate haud magnis, vulgo subcordatis vel truncatis, apice breviter acuminatis rarius cuspidatis, in sicco vulgo fuscis, petiolis vulgo brevibus haud crassis; ramulis vulgo fulvis; receptaculis pisi usque cerasi magnitudine, junioribus in sicco flavidis brunneomaculatis, ostiolo haud prominente.

Ficus Schumacheri Bello! (hiud Giriseb.) Ap. II (1S83) p. 108. Jagiiey v. Jiguerillo Port. ex Krug, Lecliesillo ex Sint.

Hab. in Portorico: Riedlé (a. 1798, ex hb. Mus. Paris.), prope Mayagiiez: Krug n. 987, 985, 989, 992, Sierra de Luquillo ad La Pendula, $500 \mathrm{~m}$. in silvis altis, m. Majo: Eggers ed. Toepff. n. 841, prope Maricao in silvis montanis, m. Nov.: Sintenis n. 255, prope Cabo rojo circa Puerto real m. Jan.: Sintenis n. 255 b prope Fajardo in silvis montanis, m. April.: Sintenis n. 1243 (arbor $15-20 \mathrm{~m}$. alta), prope Cayey in monte Torito $857 \mathrm{~m}$. alt., n1. Oct.: Sintenis n. 2045 (arbor $15 \mathrm{~m}$. alta, receptaculis viridibus, rubello-maculatis), Sierra de Yabucoa in silva primaeva montis Cerro Gordo w. Sept.: Sintenis 1. $2607^{\text {b }}$ (arbor 15 m. alta), prope Adjuntas in silva montis La Vega, 
m. Majo: Sintenis n. 4411 (arbor $15-20 \mathrm{~m}$. alta, receptaculis viridibus, fulvo-maculatis, maturis more Fici rubris; e seminibus hujus plantae in horto botan. Berol. cultis, 9/12 1887, planta parva basi bulbiformiter incrassata foliis adultis aequalibus sed minoribus instructa in hb. Berol. asservata, et in horto Berol. arbuscula satis magna exstat), prope Barinas m. Febr:: Sintenis n. 4582 ${ }^{\mathrm{h}}$, prope Lares in fruticetis ad Piletas m. Jan.: Sintenis n. 6089 (arbor $10 \mathrm{~m}$. alta, receptaculum viride, fulvo-maculatum), prope Lares ad Buenos Aires m. Jan.: Sintenis n. 6090 (receptaculum luteo-viride, fulvo-maculatum), sine loco speciali: Heller n. 868 .

Subrar. $\gamma$ olıliquicuspis Warb. foliis ramorum receptacula gerentium pro varietate modicis rel magnis, basi rotundatis vel obtusis, apice breviter oblique subcuspidatis, nervorum reticulatione subtus haud valde distincta; receptaculis pisi magnitudine subglobosis, ostiolo haud proninente.

Hab. in Portorico: Bertero; Guadeloupe: Bertero (foliis majoribus): Martinique: Plée.

Subrar. $\delta$. sululepressa Warb. foliis ramorum receptacula gerentium pro varietate parvis, basi truncato-rotundatis, apice vix apiculatis rel acuminatis, subtus nervorum reticulatione distincta: receptaculis pisi magnitudine subdepressis, ostiolo convexo.

Figuier maudit Guad. ex Duchass.

Hab. in Guadeloupe: Duchassaing.

Subral. $\varepsilon$. sulpyriformis Warb. foliis ramorum receptacula gerentium pro varietate magnis, basi cordatis, apice acuminatis acutis, subtus nervorum reticulatione distincta; receptaculis piso majoribus depresso-pyriformibus, in sicco luteis maculatis, interdum longissime pedunculatis, ostiolo prominente.

Hab. in Guadeloupe: Bertero.

Subrar. G. cerasicalpa Warb. foliis ramorum receptacula gerentium pro rarietate modicis, basi truncatis vel subcordatis, apice subapiculatis, nervorum reticulatione subtus haud valde distincta; receptaculis cerasi magnitudine rix depresso-globosis, in sicco vulgo flavidis, ostiolo haud prominente.

Hab. in Guadeloupe, lic et illic in silvis montanis et in sarannis regionis inferioris 40-400 m.: Duss n. 2197 (arbor altitudinis mediocris).

Subvar. $\eta$. reticulosa Warb. foliis ramorum receptacula gerentium pro rarietate parvis, hasi truncato-rotundatis, apice acuminatis rel paullo apiculatis, subtus nervorum reticulatione distincta: recep- 
taculis pisi magnitudine globosis in sicco luteis, ustiolo paullo prominente.

Figuier maudit Mart. ex Plée.

Hab. in Martinique: Plée.

Subvar. S. subcuspidata Warb. foliis ramorum receptacula gerentium pro varietate modicis, basi rotundatis vel truncatis, apice breviter cuspidatis rarius apiculatis, nervorum reticulatione subtus hand valde distiucta; receptaculis cerasi parvi magnitudine, ostiolo paullo prominente.

Hab. in Dominica: Duss, in La Plaine in litoris rupibus, m. Jan.: Ramage: Martiuique in regione inferiore: Duss (arbor parva).

Subvar. . crassipetiolata Warb. foliis ramorum receptacula gerentium pro varietate parris crassis, basi rotundatis vel subcordatis, apice vix acuminatis saepe obtusis, reticulatione nervorum subtus haud distincta, petiolis pro rata longis et crassis; receptaculis pisi magnitudine vel paullo majoribus, saepe paullo complanatis, ostiolo haud prominente.

Hab. in Martinique, Hauteur de Diamant, m. Mart.: Hahn 11. 624, Fort de France à la redoute: Halın n. 716, Collines du Fort boulet: Hahn n. 1466, in regione inferiore: Duss n. 28 (arbor parva).

Subvar. \%. flavicosta Warb. foliis ramorum receptacula gerentium pro varietate modicis vel magnis, basi truncatis usque subcordatis, costa et renis in sicco flavidis, nervorum reticulatione subtus haud valde distincta; receptaculis quam cerasi minoribus in sicco flaridis, ostiolo haud prominente fusco.

Hab. in St. Tincent in montibus St. Andrews, alt. $660 \mathrm{~m}$., m. Dec.: Eggers n. 6697 (arbor 15 m. alta), in silvis m. Jan.: Smith n. 924 .

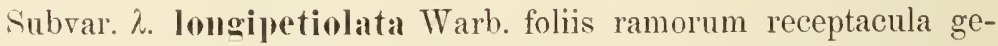
rentium pro varietate magnis sed angustis, basi truncatis vel subcordatis, apice subacutis vel subacuminatis, reticulatione nerrorum subtus distincta; petiolis pro lata longis et crassis; receptaculis cerasi magnitudine, globosis, ostiolo haud prominente.

Hab. in Barbados: Rob. Schomburgk n. 19.

Subvar. $\mu$. diversifolia Warb. foliis ramorum receptacula gerentium magnitudine variabilibus, basi rotundatis vel subcordatis, apice acuminatis vel apiculatis, reticulatione nervorum subtus distincta: receptaculis pisi usque cerasi magnitudine, subdepresso-globosis, ostiolo subprominente.

Hab. in Grenada, in rupibus supra mare, m. Dec.: Broadway n. 1413 (arbor parva). 


\section{$I I I-I 903$}

Ficus.

Formae ex hortis tantum notae:

Forma eupopulnea Warb. = Ficus populuea Willd. (specimen typicum, originarium in hb. Willd. n. 19294) = Ficus populifolir Desf. nom. (hand Tahl) Cat. hort. Paris. ed. I (1804) p. 209 (specimen e signatura in lib. Willd. e Jardin des plantes missum, a Seidel collectum).

Forma citrifolia Warb. $=$ F. citrifolia Lam. Encycl. II (1is6) p. 494 (excl. synon. Will. et Plum.). Folium unicum sub nomine F. citrifolia in herbario Willdenow n. 19318 asserratum cum descriptione Lamarckii satis quadrans probabiliter e Jardin des plantes missum, ad F. populneam Willd. rar. Ientiginosam (Vahl) Warb. pertinere existimo, subrarietatibus subtus distincte reticulato-renosis (subvar. subdepressa e Guadeloupe vel reticulosa e Martinique) probabiliter submittendum. Sed incertum remanet, an Lamarckii specimen cum Willdenowii quadret.

Forma botryapioides Warb. = F. botryapioides Kth. et Bché.! Ind. Sem. hort. bot. Berol. 1846 p. 15 11. 16 (= F. laerigata Link! Enum. II. p. 449, nec Vahl) in Hort. Berol. 1846 (probab. erronee e Mexico signata) est forma $F$. populueae var. laerigatae; anno 1902 in hort. bot. deerat.

Forma planicostata Warb. = F. planicostata Kth. et Bché.! Ind. Sem. hort. bot. Berol. 1846 p. 16 n. 19 forma foliis apice suboblique cuspidatis basi obtusis.

21. Ficus populoides $\mathbf{W}$ arb). (n. sp.) ramulis teretibus haud crassis, in siceo vix sulcatis glabris; stipulis parris glabris caducis; folis pergamaceis glabris, supra cystolithis fere semper elevatis punctatis, oratis usque rotundo-oratis usque suborbicularibus, basi cordatis rel subcordatis rarius truncatis vel obtusis, apice apiculatis usque subcuspidatis, basi $5-7$-nerviis, venis primariis haud crebris crassis cum tenuioribus alternantibus fere strictis patentibus ante marginem arcuato-conjunctis, petiolis longiusculis; receptaculis binis axillaribus globosis raro subpyriformibus pisiformibus vel ceraso paullo minoribus, basi bracteis 2 parris fere omnino connatis suffultis, glabris; ostiolo haud vel vix prominente; pedunculis quam receptacula multo brevioribus glabris.

Ficus lentiginosa Griseb. (hand Tahl) Pl. Wr. (1860) p. 172 et Cat. p. 57; Saux. Cub. n. 2233 p. 149: Combs! Cuba p. 465.

Ramuli $2-3 \mathrm{~mm}$. lati, in sicco flavidi usque lutei, demum interdum fulvi. Stipulae $5-10 \mathrm{~mm}$. longae oratae acutae, in sicco fuscae vel nigrescentes paullo pruinosae. Petioli glabri $1-2 \mathrm{~mm}$. lati, $3-7 \mathrm{~cm}$. longi, in sicco fuscescentes; folia $3 \frac{1}{2}-18 \mathrm{~cm}$. longa, $21 / 2-10 \mathrm{~cm}$. lata, in sicco viridia vel fusca, renis $9-12$ utrinque in sicco saepe rubellis utrinque prominentibus, nervis basalibus superioribus venis parallelis inferioribus recurris brevioribus, nervis tertiariis parallelis fere strictis, reticulatione subtus praesertim distincta. Receptacula glabra, 7-11 mm. in diametro, in sicco flavida saepe maculata. Pedunculi $1-3 \mathrm{~mm}$. longi, $1 \mathrm{~mm}$. lati, 
in sicco obscure fusci, bracteis basalibus $11 / 2-2 \mathrm{~mm}$. altis rotundatis fuscis. Ostiol $11 \mathrm{~m} \mathrm{1/2}-2 \mathrm{~mm}$. latum, squamis glabris brumneis rotundatis clausum. Florum or monandrium et $\bigcirc$ sepala late lanceolata vel oblonga obtusa uigrofusca et fusco-marginata.

Var. $\alpha$. elonata Warb. foliis vulgo $1 / 2$-plo longioribus quam latis; receptaculis globosis, in sicco flavidis vix maculatis, ostiolo haud prominente.

Jagüey Cub. ex Egg.

Hab. in Cuba ad Rio Purial, $200 \mathrm{~m}$. in sylvis m. Majo: Eggers n. 5435 (arbor excelsa), Read.

Var. $\beta$. maculosa Warb. foliis paullo longioribus quam latis, receptaculis parvis, in sicco maculose cinereis subpyriformibus, ostiolo saepe subpruinoso subconvexo.

Hab. in Cuba: Wright n. 1686 (sub nom. F. lentiginosa Vahl), in distr. Cienfuëgos prope Cieneguita m. Jan.: Combs n. 366.

Var. $\gamma$. dilatata Warb. foliis vix longioribus quam latis; receptaculis globosis, in sicco flavidis. vix maculatis; ostiolo haud prominente.

Hab. in Haitj: C. Ehrenberg n. 247, ad fontes aquarum prope Port-au-Prince in montibus silvaticis, m. Jun.: Jaeger n. 189, 201; St. Domingo in silvis ad ripam Yasica inter Batey et Jamao m. Jun.: Eggers n. 2619 (arbor 15 m. alta).

Ad liane speciem, var. cubensis, probabiliter pertinent:

Forma syrinsifolia Warb. = Ficus syringifolia Kumth et Bonche! in Ind. sem. hort. Berol. 1846 p. $15 \mathrm{n} .13=$ Urostigma syringaefolium Liebm. in Vidensk. Selsk. Skrift. Afd. II (1851) p. 323, cujus semina misit Moritz, ut Kuмтн et Bouché affirmant, e Caracas, sed fortasse Caracas portus tantum erat, quia nunquam specimen simile in Venezuela collectum est, dum specimina olim in horto Berolinensi culta omnino cum planta cubensi quadrant.

Forma umlurition Warb. $=F$. umbrifera Kunth et Bouché! in Ind. sem. hort. Berol. (1846) p. 18 n. 33, olim in hort. Berol. culta, etiam ad hanc speciem pertinere mihi videtur, e signatura probabiliter ab Otto e Cuba missa.

Ficus awi-awi Bl. Bijdr. p. 446 e specimine Hort. Berol. in hb. Berol. ita determinata nihil est nisi Ficus mbrifera Kith. et Bché., sed specimen typicum Blumei non vidi.

Obs. Ficus populoides differt a $F$. populnea foliis crassioribus latioribus, et vulgo majoribus, pedunculis brevioribus, bracteis magis comnatis, sed arcte affinis est.

22. Ficus umbonicera Warb. (n. sp.) ramulis crassis laevibus in sicco sulcatis; stipulis caducis glabris; foliis pergamaceis glabris, obovatis usque late ellipticis, apice rotundatis rel rarius subapiculatis, basi 
obtusis vel subrotundatis, nerris basalibus brevibus quam renae magis ascendentibus, renis multis fere strictis subcrassis, petiolis subbrevibus subcrassis; receptaculis axillaribus binis glabris globosis pisiformibus, basi bracteis 2-3 parris obtusis rel rotundatis glabris basi paullo connatis suffultis; pedunculis quam receptacula brevioribus glabris; ostiolo lato umbonato vix prominente.

Ramuli 4-6 mm. lati, in sicco albido-cinerei. Petioli. $1^{1 / 2}$ ad $3 \mathrm{~cm}$. longi, $2 \mathrm{~mm}$. lati, in sicco sulcati subnigrescentes laeves; folia $9-15 \mathrm{~cm}$. longa, $4^{1} / 2-9 \mathrm{~cm}$. lata, in sicco utrinque pallide fuscescentia, subtus haud pallidiora, costa crassa subtus in basi subglandulosa, renis utrinque ca. 12 patulis ante marginem arcuato-confluentibus, interspersis parallelis minoribus, supra vix prominulis, nervis tertiariis subtus tantum prominulis, reticulatione etiam subtus vix distincta. Receptacula ca. $7 \mathrm{~mm}$. in diametro, in sicco lutea haud maculata. Pedunculi 2-5 mm. longi, $1 \mathrm{~mm}$. lati, bracteis basalibus $2 \mathrm{~mm}$. longis, in sicco fuscis, haud fimbriatis. Ostiolum $3-4 \mathrm{~mm}$. in diametro, squamis latis rotundatis in sicco cinereis clansum. Florum sepala nigro-fusca pallide marginata.

Hab. in Trinidad inter Latrea et Irais in littor. maris, m. Jun.: Hart n. 2808.

Obs. Forma et nervatione foliorum $F$. Martini Miq. e Surinam similis, quae tamen foliis coriaceis in sicco rubris receptaculis minoribus tenuiter pedunculatis ostiolo parvo perlunculis minute puberulis instructa est.

23. Ficus grenadensis Warb. (n. sp.) ramulis haud crassis, in sicco laevibus sulcatis; stipulis brevibus glabris caducis; foliis pergamaceis glabris, vulgo ellipticis rarius oblongis rel oborato-ellipticis, apice distincte apiculatis, basi obtusis usque subacutis, nervis basalibus ascendentibus fere marginalibus in nervum marginalem transeuntibus, venis multis strictis, subcrassis, petiolis breribus crassis; receptaculis axillaribus pisiformibus, basi bracteis 2 glabris parvis rotundatis basi inter se connatis patentibus instructis; pedunculis quan receptacula 2-3-plo brerioribus tenuibus slabris; ostiolo lato umbonato paullo prominente.

Ramuli 3-4 mm. lati, in sicco rubro-brunnei. Stipulae lanceolatae acutae, $8-10 \mathrm{~mm}$. longae, in sicco nigrescentes. Petioli $1-1 \frac{1}{2} \mathrm{~cm}$. longi, $2 \mathrm{~mm}$. lati, glabri, in sicco brunnei; folia $8-11 \mathrm{~cm}$. longa, $3-6 \mathrm{~cm}$. lata, in sicco supra pallida, subtus pallide fusca, costa crassa supra basin glandulosa, venis utrinque $12-15$ patentilus ante marginem nerro vix arcuato conjunctis, interspersis tenuioribus subtus prominulis supra rix distinctis, nervis tertiariis supra haud subtus vix prominulis, reticnlatione subtus tantum et vix distincta. Receptacula $6-7 \mathrm{~mm}$. longa et lata, in viro rulra (ex $\mathrm{E}_{\mathrm{G} G .}$ ), in sicco lutea. Pedunculi 2-3 mm. longi, $1 \mathrm{~mm}$. crassi, in sicco rubri, bracteis $1-1 \frac{1}{2} \mathrm{~mm}$. longis. Ostiolum $2 \mathrm{~mm}$. latum, squamis in sicco rubris latis rotundatis glabris clansum. Florum $q$ sepala obtusa e nigro rulura, pallide marginata. 
Hab. in Grenada prope Plaisance in regione inferiore montis St. Catherine 600 alt. m. Dec.: Eggers n. 6138.

Obs. Haec species valde affinis est $F$. umbonigerae e Trinidad, differt foliis minoribus angustioribus distinctius apiculatis ad basin magis acutis, receptaculis paullo minoribus et brevius pedunculatis.

24. Ficus pertusi L. fil. ramulis tenuibus in sicco angulosis glabris; stipulis parvis glabris caducis; foliis membranaceis glabris, ovatis, oblongis vel lanceolato-oblongis, basi rotundatis, apice apiculatis usque mucronatis, basi $3-5$-nerviis, venis primariis haud crebris fere strictis, petiolis haud longis; receptaculis binis axillaribus pisiformibus globosis laaud depressis, basi bracteis 2 parvis paullo connatis suffultis; ostiolo disciformi haud elevato; pedunculis quam receptacula brevioribus glabris.

Ficus pertusa. L. f. Suppl. (1781) p. 442.

Ficus perforata L. (haud Miq.) Amoen. acad. VIII (1775) Pl. suin. p. 265 (momen).

Irostignu Rolanderi Liebm.! in Vidensk. Selsk. Skrift. Afd. II (1851) p. 45.

Ficus Rolanderi Miq.! (erronee F. Rolandri) in Am. Mus. Lugd. Bat. III (1867) p. 298 n. 85.

Ficus surimamensis Miq.! l. c. III (1867) p. 219.

Ficus Schumacheri Griseb.! Flor. (1859) p. 151.

Ramuli $2-3 \mathrm{~mm}$. lati, in sicco fusco-cinerei. Stipulae $1 / 2-1 \mathrm{~cm}$. longae, lanceolatac acutac, in sicco nigrescentes. Petioli glabri $1-2 \mathrm{~cm}$. longi, $2 / 3-1 \mathrm{~mm}$. lati, in siceo fusci; folia $6-13 \mathrm{~cm}$. longa, $2-4 \mathrm{~cm}$. lata, in sicco fusca, subtus hand pallidiora, nervis basalibus vulgo $1 / 4$ folii haud superantibus, venis utrinque ca. $7-8$ patentibus tenuibus, ad marginem subarcuato-connexis, utrinque prominulis, interspersis parallelis tenuioribus vix distinctis, nervis tertiariis vix conspicuis, reticulatione haud conspicua. Receptacula $6-7 \mathrm{~mm}$. in diametro, in sicco lata haud distincte maculata. Pedunculi $3-4 \mathrm{~mm}$. longi, $2 / 3 \mathrm{~mm}$. lati, in sicco fusci, bracteis $1-1 \frac{1}{2} \mathrm{~mm}$. longis patentibus rotundatis in sicco fuscis. Ostio$1 \mathrm{~m} 1 \frac{1}{2}-2 \mathrm{~mm}$. latum, vix convexum, squamis rotundatis in sicco fuscis clansum. Florum $q$ sepala lanceolata fusca pallide marginata.

Hab. in Trinidad: Crüger, Herb. Trinid. n. 2802, in Aripo Savanna m. Jan.: D. W. Alexander n. 5686 ; praeterea Surinam in sylvis prope plantat. Quarta: Kegel n. 186 (arbor $15 \mathrm{~m}$. alt.), ad Boven Surinam: Focke n. 1304, sine loco speciali: Rolander (in hb. Schumacher et Tahl in lib. Haun. sub nom. Urostigma Rolanderi Liebm., asservata olim sub nom. F. trigona), sine loco speciali: Dalberg (vidi specimen a Thunberg missum in hb. Haun. asservatum).

Obs. I. Typus a Dalbergio lectus foliis paullo latioribus et basi rotundatis instructus, omnibus aliis characteribus autem cum F. Rolanderi et 
Ficus.

surinamensi quadrat; typus $F$. Rolanderi foliis longius et minus abrupte cuspidatis differt a typo $F$. surimamensis; sed propter variabilitatem foliorum generis Ficus ne varietates quidem in his characteribus statnere licet.

Obs. II. Ficus guianensis Ham. Prodr. Ind. oce. (1825) p. 62 e descr. emendata in Desr. Ann. Sc. nat. II sér. XVIII (1S42) p. 312 differt pedunculis pubescentibus receptaculis minoribus (diam. grani Piperis) et puberulis foliis crassis.

25. Ficus prinoides Humb. et Bonpl. ramulis tenuibus, in siceo sulcatis, innovationibus pilis minutis puberulis; stipulis parvis glabris caducis; foliis pergamaceis glabris, anguste lanceolatis, apice sensim angustatis demum obtusis, basi obtusis vel rotundatis, venis primariis haud valde crebris parallelis strictis, interjectis parallelis tenuibus indistinctis, petiolis brevibus; receptaculis binis axillaribus piperiformibus depresso-globosis, in sicco flavidis fulvo-maculatis, basi bracteis 2 paullo connatis suffultis; ostiolo plano minute impresso, haud annulo circumdato; pedunculis quam receptacula 2-3-plo brevioribus.

Ficus pinoides H. et B.! ex Willd. Spec. IV (1S06) p. 1149.

Urostigma Schmmacheri Liebm.!' in Tidensk. Selsk. Skrift. Afd. II (1851) p. 328.

Ficus geniua Griseb.! (haud Ruir et Pav.) Flor. (1859) p. 710.

Ramuli $1 \frac{1}{2}-2 \frac{1}{2} \mathrm{~mm}$. lati, in sicco ex rubro cinerei. Stipnlae $3-5 \mathrm{~mm}$. longae acutae in sicco nigrescentes. Petioli $7-10 \mathrm{~mm}$. longi, $1 \mathrm{~mm}$. lati, in sicco lntei laeves; folia $4-9 \mathrm{~cm}$. longa, $1-2 \mathrm{~cm}$. lata, in sicco utrinque viridia, costa in sicco lutea, subtus prope basim purpureoglanduloso-maculata, renis vix distinctis ca. 8 utrinque subvalidioribus, multis parallelis tenuioribus interjectis, nervo marginali vix distincto, reticulatione et nervis tertiariis haud ommino conspicuis. Receptacula $5 \mathrm{~mm}$. lata, 3-4 mm. longa. Peduneuli $2 \mathrm{~mm}$. longi, $2 / 3 \mathrm{~mm}$. lati, bracteis basalibus glabris latis $1 \mathrm{~mm}$. longis rotundatis in sicen fuscis. Ostiol um $11 \%$ mm. latum, squamis latis glabris in sicco fuscis clausum. Flores or pauci monandri sepalis ovatis rotundatis ex nigro fuscis marginatis; flores q sepalis obtusis obscure fuscis pallide marginatis, stigmate valde dilatato.

Hab. in 'Trinidad: Thomson (hb. Schumacher in hb. Haun.), Crüger n. $10 \mathrm{I}$ (ex hb. Griseb.), ad St. Clair Bridge: Hart n. 5781 ; praeterea Columbia: Hartweg 11. 1355, prope Merida: Bonpland 11. 1696.

Obs. I. Haec spccies nulli speciei Antillarum affinis est, sed compluribus speciebus Guyanae, Venezuelae, Columbiae, praesertim F. ligustionae Kunth et Bouché e Venezuela et Gnyana, cujus receptacula haud nota sunt, quacm quoad folia et ramos optime quadrat. Probabiliter etiam F. myrtifolia Link ex hortis ad candem affinitatem pertinet; specimen e Venezuela, quod cum hac quoad folia et ramos satis quadrat, receptaculis maculatis. ostiolo plano, pedunculo brevi optime cum $F$. pinoules quadrat.

Obs. II. F. Schumacheri Bello (haud Griseb.) Apunt. kl. Puerto-Rico II (1883) p. 108 e specin. Krugii n. 987 est $F$. populuea Willd. var. lentigiuosa (Vahl) subvar. subcordata Warh. 


\section{Sect. Phimmancosyce.}

26. Ficus Pi(andac Warb. (n. sp.) ramulis teretibus haud suleatis, innovationibus incano-pilosis mox glabris; stipulis parvis carlucis glabris; foliis subcoriaceis ellipticis usque nblongis, supra subscabridis, subtus scabridis et pubescentibus, basi obtusis vel subrotundatis, apice apiculatis vel rotundatis, basi breviter trinerviis, venis haud multis subarcuatis, petiolis brevibus crassis paullo pubescentibus.

Ramuli $3-5 \mathrm{~mm}$. lati, in sicco fulvi. Stipulae lanceolatae acutae $1 \mathrm{~mm}$. longae, in sicco nigrescentes. Petioli $1-2 \mathrm{~cm}$. longi, $2 \mathrm{~mm}$. lati, in sicco pallidi epidermide soluta paullo lepidoti, pilis albidis pubescentes; folia $10-16 \mathrm{~cm}$. longa, $4-7 \mathrm{~cm}$. lata, in siceo utrinque viridia, nervis basalibus brevibus ascenclentibus, venis utrinque ca. $10-11$, subtus pallidis prominentibus, ad marginem confluentibus, interspersis parallelis tenuioribus, nervis tertiariis sultus tantum distinctis, reticulatione etiam subtus haud distincta.

Hab. in Haiti prope Pétionville: Picarda n. 983 (arbor superba).

Obs. Certe species est sectionis Pharmacosyce, ab omnibus speciebus hujus sectionis ex India occidentali differt foliis subtus pubescentibus, ad F. pssudoradula Miq. e Mexico valde accedit, differt foliis angustioribus.

27. Ficus radula Willd. ramis teretibus, in siceo haud sulcatis, innovationibus scabridis mox glabris; stipulis parris caducis glabris; foliis pergamaceis, late usque oblonge ellipticis, basi subacutis, apice apiculatis vel breviter acuminatis subacutis, supra glabris vix paullo scabridis, subtus valde scabridis, basi breviter 3 -nerviis, venis patentibus haud multis, petiolis brevibus; receptaculis solitariis axillaribus cerasiformibus brerissime stipitatis globosis extus scabridis; ostiolo hand prominente, pedunculis tenuibus scabridis quam receptacula vix minoribus.

Fieus radula Willd.! Spee. pl. IV 2 (1806) 1144; Griseb. Flor. p. 710 (haud Cat. Pl. ('ub. nec La Sagra nee Sauv. Cub. p. 149).

Pharmacosycea Raduk Liebm.! in Tidensk. Selsk. Slirift. Afd. II (1851) p. 330 .

Ramuli $2 \mathrm{~mm}$. lati, in siceo fusci. Stipulae $8-10 \mathrm{~mm}$. longae, lanceolatae acutae. Petioli $1-3 \mathrm{~cm}$. lougi, 1-2 mm. lati, in siceo fusci glabri; folia $9-17 \mathrm{~cm}$. longa, $5-7 \mathrm{~cm}$. lata, nervis basalibus ascendentibus brevibus, venis sultus prominentibus, in sicco pallidis subcurvatis, apice arcuato-confluentibus, utrinque ca. 10 majoribus, interspersis tenuioribus parallelis, nervis tertiariis supra vix distinctis subtus promiuulis, reticulatione supra hand subtus vix distincta. Receptacula ca. $1 \frac{1}{2} \mathrm{~cm}$. in diametro nigrescentia, stipite vix $1 \mathrm{~mm}$. longo. Pedunculi $1 \frac{1}{2} \mathrm{~cm}$. longi, $1 \mathrm{~mm}$. lati, in sicco nigrescentes, ad apicem minute bracteati. Florum $q$ sepala multa linearia saepe acuta sed haud ciliolata neque in tubo acnleata ut in figura Miquelii in Hook. Lond. Journ. falso designata est.

Hab. in Trinidad: Hart n. 5401 (an culta tantum?), e reliquiis Crueger. n. 2806; praeterea surinam hb. Willd. n. 19322 (sub nom. 
F. anthelmintica); Venezuela: Suringar, in silvis Orinoco et Rio negro: Humboldt et Bonpland (hb. Willd. n. 19300): Columbia ad Puerto Cabello: Karsten; cult. in Hort. Bogor.: Hillebrand.

Ous. Differt a ceteris speciebns sectionis foliis subtus scabridis, receptaculis cerasi magnitudine scabriclis nigrescentibus, pedunculis tennibus scabridis nigrescentibus receptacula fere aequantibus. Specimina hrasiliensia in Flora brasiliensi huc relata a Gardner et Schott collecta probabiliter ad species alias pertinent.

28. Ficus suffocans Griseb. ramulis teretibus in sicco haud sulcatis vix lineatis glabris, innovationibus minute pilosis mox glabris; stipulis caducis parvis glabris; foliis pergamaceis vel subcoriaceis, utrinque cystolithis subelevatim punctatis, ellipticis v. oblongis, interdum paullo obliquis, basi rotundatis obtusis vel subacutis, apice obtusis vel obtuse subapiculatis, supra glabris, subtus paullo scabridis, basi breviter $3-5$ nervis, venis paucis subarcuatis, petiolis brevibus subcrassis; receptaculis globosis pruniformibus breviter pedunculatis glabris; ostiolo haud prominente.

Ficus suffocans Griseb. Flor. (1859) p. 150.

Ficus laurifolia Griseb.! (hand Lam.) Flor. (1859) 1). 150 (quoad specim. Jamaic.)

Arbor $12-15 \mathrm{~m}$. alta, divaricata. Ramuli $2-3 \mathrm{~mm}$. lati, in siceo argentei. Stipulae $8-15 \mathrm{~mm}$. longae lanceolatae acutae, in sicco fuscae vel pallidae. Petioli $1 / 2-3 \mathrm{~cm}$. longi, $1 \frac{1}{2}-2 \mathrm{~mm}$. lati, in sicco pallide fusci, in initio laminae fulvo-glandulosi; folia $9-20 \mathrm{~cm}$. longa, $3^{1} / 2-8 \mathrm{~cm}$. lata, in sicco utrinque viridia, nervis basalibus superioribus ascendentibus, venis utrinque $7-9$ subtus valde prominentibus ante marginem arcuate confluentibus in sicco luteis, alternatim interspersis multo tenuioribus, nervis tertiariis utrinque subprominulis, reticulatione subtus vix distincta. Receptacula in sicco $1 \frac{1}{2}-2 \frac{1}{2} \mathrm{~cm}$. in vivo $3 \mathrm{~cm}$. in diametro, in sicco nigrescentia. Pedunculus $7 \mathrm{~mm}$. longus, $3 \mathrm{~mm}$. latus glaber, supra medium bracteis vix $1 \mathrm{~mm}$. Iongis latis obtusis instructus. Flores or diandri et $q$ inixti; florum $\bigcirc$ sepala multa anguste linearia apice obtusa; florum ${ }^{x}$ sepala panca latiora.

Hab. in Jamaica: Wilson n. 349, in Blue Mountains m. Jun.: Harris n. 5177, ad Ferry River m. Aug.: Harris 11. 8259.

29. Ficus subscabrida Warb. (n. sp.) ramulis fere teretibus in sicco vix sulcatis glabris, innorationibus glabris; stipulis caducis glabris; foliis pergamaceis late usque oblonge ellipticis, basi obtusis vel rotundatis raro subtruncatis, apice rotundatis, supra glabris subtus paullo scabridis, basi breviter 3-5-nerviis, venis paucis subarcuatis, petiolis brevibus subcrassis; receptaculis globosis interdum stipitatis pruniformibus, breviter pedunculatis, glabris; ustiolo liaul prominente. 
Ficus suffocans Griseb.! Plant. Wr. I (1560) p. 172 et Cat. p.57 (nee Flora p. 150); Sam. Cub.n. 2328 p. 149; Combs! Cuba p. 465. Jagüey hembra cub. ex Wr.

Ramuli $3 \mathrm{~mm}$. lati, in siceo frsci. Stipulae $1 / 2-2 \mathrm{~cm}$. longae acutae, in sicen palliclae. Petioli $1-2 \mathrm{~cm}$. longi, $1 \frac{1}{2}-2 \mathrm{~mm}$. lati, in sicco epidermide sqnamulose soluta lepidoti; folia in sicco viridia $8-12 \mathrm{~cm}$. longa, $4-6 \mathrm{~cm}$. lata, nervis hasalibus superioribus ascendentibus, venis utrinque 7-10 patentibus, ad marginem arcuate conjunctis, subtus prominentibus, in siceo pallidis, alternatim interspersis minoribus multo tenuioribus, nervis tertiariis supra hand distinctis subtus vix prominulis, reticulatione haud distincta. Receptacula in sieco livida, $21 / 2 \mathrm{~cm}$. in diametro. Pedunculi $8-10 \mathrm{~mm}$. longi, $2 \mathrm{~mm}$. lati, paullo infra apicem bracteis 2 parvis $1 \frac{1}{2} \mathrm{~mm}$. longis circumdati. Flores or diandri et $Q$ mixti; florum $q$ sepala linearia vel lanceolata, subacuta vel obtusa; florum $o^{x}$ sepala pauca oblonga obtusa, omnia in siceo fusca.

Hab. in Cuba: Wright n. 543 (sub F. suffocans hb. Banks ex hb. Griseb.), prope Cieneguita m. Jun.: Combs n. 146.

Obs. I. Differt a $F$. suffocans foliis apice rotundatis, innovationibus glabris, receptaculis longius pedunculatis.

Obs. II. Haec species prob. est F. radula A. Rich. in La Sagra Cuba XI. (1850) p. 222 , Griseb. Cat. p. 57 (Rich.), Sauv. Fl. Cub. p. 149.

30. Ficus rubricosta Warb. (n. sp.) ramis teretibus, in sicco hand sulcatis, innovationibus glabris; stipulis caducis glabris; foliis pergamaceis vel membranaceis, late ellipticis usque oblongis, basi obtusis vel subacutis, apice subapiculatis vel obtusis, supra glabris, subtus subscabridis, basi breviter 3-nerviis, costa supra in sicco rubra vulgo purpurea, subtus lutea, venis haud multis patentibus, subtus in sicco rubris purpurascentibus, petiolis brevibus glabris: receptaculis solitariis axillaribus coryliformibus globosis fere laevibus; ostiolo haud prominente, pedunculo parvo.

\section{Hamo Doming. ex Egg.}

A rbor $13 \mathrm{~m}$. alta. Ramuli $2-3 \mathrm{~mm}$. lati, in sicco fulvi. Stipulae $1-1 \frac{1}{2} \mathrm{~cm}$. longae lanceolatae acutae. Petioli $1-2 \mathrm{~cm}$. longi, $1-1 \frac{1}{2} \mathrm{~mm}$. lati, in sicco fusci, epidermide sqamulose soluta lepidoti; folia $8-15 \mathrm{~cm}$. longa, $3-6 \mathrm{~cm}$. lata, nervis basalibus ascendentibus brevibus, venis utrinque ca. 7 subeurvatis ad marginem arenate confluentibus, subtus prominentibus, interspersis multo tenuioribus subparallelis, nervis tertiariis utrinque distincte prominulis, reticulatione vix distincta. Receptacula in siceo nigrescentia, in siceo $15-17 \mathrm{~mm}$., in vivo $25 \mathrm{~mm}$. in diametro hand dulcia (ex Egr.) Pedunculi ca. ${ }^{1 / 2} \mathrm{~cm}$. longi, $1 \mathrm{~mm}$. lati, in siceo fulvi fere glabri paullo squamulosi, apice bracteis ninimis vix $1 \mathrm{~mm}$. longis instructi. Flornm $q$ sepala multa linearia subacuta, in sicco fulva; florum $0^{7}$ sepala latiora.

Hab. in Haiti: C. Ehrenberg; Sto. Domingo prope Batey juxta thumen Yasica m. Jun.: Eggers n. 2625. 
Ficus.

Obs. Species F. subscabridae et $F$. suffocanti affinis, sed foliorum forma et receptaculis minoribus et tenuiter pedunculatis diversa. Foliis forma F. obtusiusculae Miq. e Brasilia similis, sed differt scabritate et receptaculis multo majoribus.

31. Ficus Finlayana Warb. (n. sp.) folio (unico exstante) obelliptico $8 \mathrm{~cm}$. longo, $3 \mathrm{~cm}$. lato, basi cuneato acuto, apice apiculato subacuto, coriaceo, in sicco utrinque pallide viridi, basi vix distincte trinervio, nervis lateralibus in nervum marginalem transeuntibus, venis utrinque ca. 16 majoribus strictis ad marginem vix arcuato-connexis tenuibus, supra distinctis subtus prominentibus, nervis tertiariis et reticulatione utrinque haud distinctis, petiolo $1 \mathrm{~cm}$. longo, $1 \mathrm{~mm}$. lato glabro in sicco livido; receptaculo (unico exstante) globoso cerasi magnitudine, $1 \frac{1}{2} \mathrm{~cm}$. in diametro, in siceo nigrescente; ostiolo haud prominente; pedunculo haud exstante, sed e forma regulari certe adest.

Hab. probab. in Trinidad (e schedula prob. erronee St. Thomas): Finlay (ex hb. Mus. Par.)

32. Ficus Kru@iana Warb. (n. sp.) ramulis crassis teretibus, in sicco haud sulcatis, innovationibus glabris; stipulis magnis caducis glabris; foliis pergamaceis, utrinque glabris hand scabridis, ellipticis usque oblongo-ellipticis, basi rotundatis rarius obtusis, apice obtusis, subacutis vel late acuminatis acutis, utrinque glabris, basi sub-5-plinerviis, venis patentibus haud multis, petiolis saepe haud brevibus; receptaculis solitariis axillaribus globosis coryli magnitudine, extus hand scabridis; ostiolo haud prominente; pedunculis quam receptacula vix minoribus.

Ficus laurifolia Duss! (haud Lam.) Fl. Ant. franc. (1897) p. 153.

Fije Domin. ex Ram., Figuier maudit Mart. ex Duss, Cocoyer rivière Mart. ex Hahn.

Arbor elata vel gigantea. Ramuli $4-5 \mathrm{~mm}$. lati, in sicco fusci usque fulvi. Stipulae usque $7 \mathrm{~cm}$. longae, lanceolatae, acutae, in sicco virides. Petioli $1 \frac{1}{2}-3 \frac{1}{2} \mathrm{~cm}$. longi, $2-3 \mathrm{~cm}$. lati, glabri, in sicco lividi; folia $10-30 \mathrm{~cm}$. longa, $4 \frac{1}{2}-13 \mathrm{~cm}$. lata, in sicco vulgo viridia, nervis basalibus 2 brevibus patentibus, suprabasalibus 2 ascendentibus, renis utrinque ca. 13 majnribus vix curvatis, ad marginem arcuate connexis, utrinque prominulis, subtus in sicco flavidis, tenuibus interspersis multo tennioribus parallelis, nervis tertiariis supra tantum prominulis, reticulatione subtus tantum distincta. Receptacula in sicco fere $2 \mathrm{~cm}$. in diametro, nigrescentia, in vivo viridi-lutea, $2 \frac{1}{2} \mathrm{~cm}$. diametro (ex EGG.). Pedunculi $10-14 \mathrm{~mm}$. longi, $1 \frac{1}{2} \mathrm{~mm}$. lati, in sicco lividi, apice bracteis latis patentibus obtusis $2-2 \frac{1}{2} \mathrm{~mm}$. longis instructi. Florum sepala in sicco fusca, florum $q$ linearia.

Hab. in Guadeloupe in omnibus silvis magnis, 400-900 m. alt.: Duss n. 2194; Dominica ad Laion flats, m. Jun.: Ramage: Martinique ad rivulorum margines: Isert (a. 1787, hb. Haun.), Hahn u. 326 
(m. Dec.), in silvis haud lara: Duss n. 1412; St. Vincent in silvis montis St. Andrews m. Dec.: Egger's n. 6670, in silvis subcomnunis $150-660$ m. alt. : Snith n. 747.

33. Ficous venusta Kth. et Bché. ramulis haud crassis teretibus in siceo subsulcatis, innovationibus glabris; stipulis interdum magnis caducis glabris; foliis membranaceis utrinque glabris laud scabridis, late ellipticis, basi rotundatis, apice subapiculatis fere acutis, basi 3- v. sub5 -plinerviis, venis haud multis patentibus, petiolis saepe haud brevibus; receptaculis ...

Ficus remusta Kth. et Bché.! Ind. sem. hort. Berol. 1846 p. 16 n. 17; Griseb. Cat. p. 57; A. Rich. in Sagra Cub. p. 221.

Trostigma venustum Miq.! in Hook. Lond. Journ. Bot. VI (1847) p. 538; Walp. Amn. I p. 676.

Ramuli $2-3 \mathrm{~mm}$. lati, in sicco fusci. Stipulae $1 \frac{1}{2}-4 \mathrm{~cm}$. longae, lanceolatae acutae, in sicco fuscescentes. Petioli $2-5 \mathrm{~cm}$. longi, $1-1 \frac{1}{2} \mathrm{~mm}$. lati, in sicco obscuri; folia $8-23 \mathrm{~mm}$. longa, $4-10 \mathrm{~cm}$. lata, in sicco viridia, costa in sicco utrinque purpurea, nervis basalibus krevibus patentibus, suprabasalibus oblique ascendentibus, venis utrinque ca. 7 fere strictis, ante marginem vix arcuate conjunctis, interspersis tenuioribus subparallelis utrinque vix prominulis, nervis tertiariis supra vix subtus haud prominulis, reticulatione subtus valde distincta.

Hab. in Cuba: Otto (nis. sem. in hort. Berol., ubi culta).

Obs. Species $F$. Krugianae valde affinis, differt foliis tenuioribus, latioribus, venis minoribus.

Species generis Ficus in India occidentali cultae.

34. Ficus carica L. Sp. pl. (1753) p. 1059; Lun. Hort. Jam. I p. 293; Mruye. Barb. 1\%.406; Eggers! St. Croix p. 147 et St. Croix and Virg. Isl. p. 95; Duss Fl. Ant. franc. p. 155.

Fig-tree Hughes Nat. Hist. Barbad. (1750) p. 187.

St. Croix: Eggers n. 570 (sterile, in hb. Haun.); Guadeloupe et Martinique ex. Duss; Barbados ex Mayc.

35. Ficus tinctoria Forst. f. Prodr. (1786) p. 76 ; Lun. Hort. Jam. I p. 296; Tuss. Flor. Ant. II p. 54 t. 14 receptaculis cerasiformibus fulvis sessilibus axillaribus vel ex axillis defoliatis nascentibus nota.

Ex Lun. in Jamaicae hortum Eastensem per navem "Providence" importata, ex Tussac e mari australi (Tahiti etc.) in Jamaicam et Sto. Doningo introducta, a Tussac in horto botanico Jamaicensi et in Hort. Paquetii in Sto. Domingo observata.

Obs. In Flor. Br. W. Ind. (1859) a Grisebach erronee ad F. lentiginosam Vahl referta. 
Picus.

36. Ficus nitida Thunb. Diss. Ficus (1786) p. 10; Mayc. Barbad. 1). 406 .

Ficus pertusa Willd.! (hand L. f.) Spec. pl. IV. 2 (1806) p. 1144; A. Rich. iu Sagra Cuba XI p. 221.

Ficus sp. Combs! Cuba in Trans. St. Louis Ac. Sc. (1897) p. 465.

Laurel de India Port. ex Sint. et Krug; Evergreen of Barbados Trinid. ex Crueg.

Ex Asia merid. introducta, nune in fere omnibus insulis Indiae occidentalis culta vel subspont., e. gr. Cuba prov. Santa Clara in distr. Cienfuëgos prope Cieneguita m. Aug.: Combs n. 314 (arbor $40-50$ m. alta); Portorico prope Bayamon m. Nart.: Sintenis II. 1116 (arbor 15-20 m. alta, nunquam floribus instructa esse dicitur), prope Arroyo ad vias cult.: Sintenis n. 2197, prope Mayagüez m. Jun.: Anna Philippi, Krug n. 990 (arbor magnifica $15-20$ m. alta); St. Lucia prope Castries in litoralibus: Duss n. 1406; Barbados prope St. Johns Churelı m. Jan.: Eggers n. 7365 (arbor $18 \mathrm{~m}$. alta); Trinidad: Crüger n. 94 (m. Mart. fr.).

Obs. In herbariis vulgo sub nom. $F$. pertusae.

37. Ficus Benjanimea L. Mantissa (1767) p. 129.

Ex Malesia introducta in Hort. Trinidad: Hart n. 3430.

38. Ficus elastica Roxb. Hort.beng. (1814) p. 65; Mayc. Barbad. p. 408; Egg. St. Croix p. 147 et St. Croix and Virg. Isl. p. 95; Gardiner Baham. p. 409; Duss! Fl. Ant. frane. p. 155.

Ex Assam vel Malesia, nunc in multis insulis Indiae occidentalis culta, e. gr. in Bahamas ex Gard.; St. Thomas, St. Croix ex Egg.; Guadeloupe: Duss n. 3271; Martinique: Duss n. 1413; Barbados ex Maycock.

39. Fieus triangularis Warb.! in Engl. Jahrb. XX (1894) p. 170.

Ex Africa occidentali introducta in hort. bot. Basse Terre in Guadeloupe: Duss n. 4038 (arbor adhuc parva ramis prinum fastigiatis demum horizontalibus postremo pendulis; floret n. Mart. et April.).

40. Ficus cunia Buch. Ham. e Roxb. Hoit. beng. (181t) p. 66 .

Ex India orientali introducta in hort. Trinidad: Hart n. 2986.

41. Firns Canoni N. E. Br. in Gard. Chron. 1888 I p. 9.

Ficus metallica Hort. e Duss!' Fl. Ant. frauc. (1897) I p. 155.

Ex insulis Societatis introducta in hortos Europaeos (auctore Bull), in Martinique culta: Duss.

Firms indiea L. e Sandmack Fl. Jam. (1759) in Am. Ac. V p. 384 quid sit, dubium remanet.

Ficus indica fructu et foliis minoribus Plum. Mss. 7 n. 109 a Lamarck in Encycl. II (1786) p. 49.4 pro F. indica L., a Roemer et 
Schult. in Syst. Veg. I (1817) p. 505 pro F. cotoneaefolia Vahl sumpta est, quae sunt in Asia meridionali indigenae. An potius F. mitida Thunb. sit?

Species nomine tantum notae, oblivione dignae.

Ficus caribaea Jacq. Obs. Bot. II. 30 e descriptione cum nulla specie Indiae occidentalis quadrat, an planta brasiliensis?

Ficus ('atesbaei Steud. Nom. I (1840) p. 635 (F. citrifolia Mill.) Ind. oce.

Ficus Hookeri Sweet e Steud. Nom. I (1840) p. 636 (F. nitida Hook., non Thumb.) Ind. occ.

Ficus undulata Desf. e Steud. Nom. I (1840) p. 638. Antill.

Species generis Ficus e Flora Indiae occidentalis excludendae.

Ficius Iaurifolia Lam. Encycl. méth. II (1786) p. 495 n. 9 (quoad specim. Hort. reg.).

Ficns martinicensis Willd.! Sp. plant. IV 2 (1806) p. 1137 и. 21.

Ficns rhododendrifolia Kunth ct Bonché! Ind. sem. Hort. Berol. (1S46) p. 16 и. 21.

Ficus neriifolia Hort. berol.! olim (1846).

Ficus Kunthii Miq. Ann. Mus. Lugd. Bat.III (1867) p. 298 n. 50.

? Ficus virens Ait. Hort. Kew. ed. III (1784) p. 351.

Urostigma laurifolium Miq. in Hook. Lond. Journ. of Bot. VI (1847) p. 539.

Urostigma Kunthii Miq. in Mart. Fl. brasil. IV 1 (1853) p. 96.

F. laurifolia verosimiliter non est planta ex Antillis. Specimen originar. LAMARCKII secundum folium e museo Paris. missum cum $F$. martinicensi Herbarii Willdenowiani et cum $F$. rhododendrifolia et neriifolia Hort. berol. valde quadrat, e Mrquel etiam cum specimine Molliano brasiliensi ex Herbario Martii.

WARMing sub n. 1917 specimen in Lagoa Santa (Minas) in Brasilia legit, quod forma et nervatura foliorum satis cum $F$. laurifolia Iam. quadrat, sed textura et colore foliorum differt; quia haec folia sunt arboris reteris, specimina hortorum antem plantarum jurenilium, attamen ea ad eandem speciem pertinere possibile est, sed certe affirmare haud andeo.

Quid sit F. marimicensis Mayc. Barbad. (1830) p. 406, speciminibus originariis deficientibus dubium remanet.

Quid sit F. laurifolia Lam. e Griseb. Flor. Lnd. (1859) p. 150 e Jamaica (March) et Dominica (Imr.) sine plantis originariis statuere non possum.

Specimen jamaicense SloaneI in Hist. Jam. II p. 140 t. 223 sub nomine $F$. intica maxima depictum et a Lamanckio cum $F$. laurifolia Lam. 
unitum (t. Lmn. I p. $294=F$. virens Ait.) ex icone nervatura folii valde a specimine horti Parisiensis discrepat et prob. F. suffocans est.

Ficus catappifolia Kunth et Bouclé! Ind. sem. Berol. 1846 p. 14.

Urostigma catappifolium Kiq.! in Hook. Lond. Journ. Bot. VI (1847) p. 533; Walp. Amn. I (1849) p. 674 e Martinique in hortos europaeos introducta esse dicitur, sed valde dubium est; suspicor speciem esse brasiliensem.

Ficus scandens Lam. probabiliter est $F$. pumila L. f. microphylla ex Asia orientali.

Species haud ad genus Eicus pertinentes.

Ficus Imaculata L. Spec. II. ed. 1515 condita in F. castanecuefolia fructu globoso maculato Plum. Cat. (1703) p. 21 et ed. Burm. p. 122 t. 131 f. 1; Spreng. Syst. III p. 784; Roem. et Schult. Syst. Veg. I p. 515; Willd. Sp. pl. IV. 2 p. 1152 e Sto. Domingo propter foliorum serraturam in America in genere Ficus unicam et propter racemos terminales haud ad hoc genus pertinere videtur; sed quid?

Ficus jamaicensis Miq.! in Ann. Mus. Ingd. Bat. III (1867) p. 300; Pharmacosycea jamaicensis Liebm.! in Vidensk. Selsk. Skrift. Afd. II (1851) p. 331; Griseb. Flor. p. 150 est Omphalea triandran L.

Urostigma scandens Liebm.! in Vidensk. Selsk. Skrift. Afd. II (1851) p. 329 etiam ex India occidentali nota est (in hb. Schumacheri); sed haec planta non est Ficus, sed Maregravia sp., ut etiam specimina Liebuanai e Mexico. 


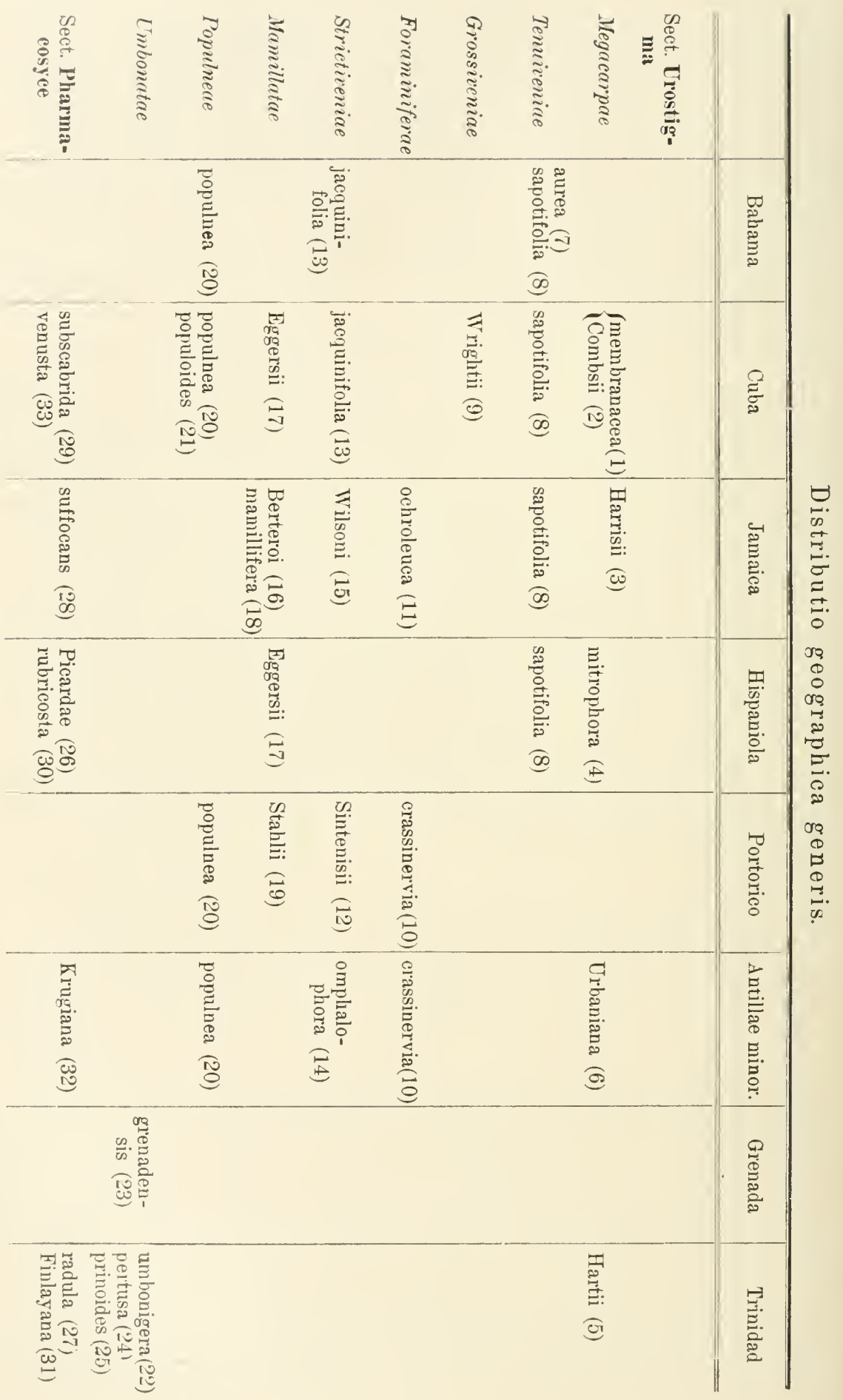




\title{
IX. Cruciferae.
}

\author{
Exposuit \\ Oтто E. Schulz.
}

Clavis generum.

A. Fructus indehiscens vel in articulos secedens.

I. Fructus minutus, $1,35 \mathrm{~mm}$. longus, $2,25 \mathrm{~mm}$. latus, didymus

II. Coronopus Gaertn.

II. Fructus multo major; oblongus.

a. Fructus manifeste in articulos binos transversim secedens. Semina articuli superioris erecta. Planta carnosa

V. Cakile Juss.

b. Fructus multilocularis, non vel vix articulatus. Omnia semina pendula. Planta non carnosa VIII. Raphanus L.

B. Fructus valvis dehiscens.

I. Valrae convexae, desilientes, plerumque manifeste nervosae.

a. Septum siliculae angustissimum.

1. Siliculae triangulari-obcordatae. Valvae reticulato-nerrosae. Ovarium 24-28-ovnlatum . XI. Capsella Medic.

2. Siliculae ellipticae, orbiculari-compressae $v$. fere globosae. Valvae laeves. Ovarium 2-20-orulatum.

a. Planta perenuis. Petala patula, $5-6 \mathrm{~mm}$. longa. Ovarium 9-20-ovulatum. Siliculae fere globosae

III. Cochlearia L.

b. Planta annua. Petala erecta, $1-2 \mathrm{~mm}$. longa. Orarium 2 -ovulatum. Siliculae compressae

\section{Lepidium L.}

b. Septum, siliculae vel siliquae latum.

1. Semina, saltem ovula, biseriata. Valvae vel valvulae membranaceae. Ovarium 20-160-ovulatum

IX. Nasturtium R. Br.

2. Semina uniseriata. Valvae firmulae. Ovarium 4-24ovulatum. 
a. Siliquae subuliformes, rhachidi adpressae. Semina oblonga, notorrhiza . . . . TV. Sisymbrimm L.

b. Siliquae lanceolatae vel late lineares, patulae. Semina globosa: cotyledones conduplicatae.

1. Siliquae evidenter 1 -nerves, in rostrum lineare attenuatae. Ovarium 12-24-ovulatum

VII. Brassica L.

2. Siliquae manifeste 3-5-nerves, in rostrum conicum vel ensiforme attenuatae. Ovarium 4-12-ovulatum

VI. Sinapis L.

II. Valvae planae, a basi ad apicem sese revolventes, enerves

X. Cardamine L.

\section{Lepidium L.}

Conspectus specierum.

Petala sepalis aequilonga. Stamina 2. Pedicelli fructiferi horizontales 1. L. virginicum L. Petala sepalis duplo longiora. Stamina 6. Pedicelli fructiferi erecti 2. L. sativum L.

1. Lepidium viloginicum L. Folia inferiora obovata, ad basin in petiolum cuneato-angustata, ima ad basin saepe profunde incisa vel pinnatifida, sub anthesi plerumque desiccata, sequentia utrinque ca. 10 serrata, media obverse lanceolata, in petiolum brevem cuneato-angustata, utrinque ad apicem remote et grosse ca. 4-serrata, ad basin integra, superiora vix minora, linearia, minute serrata rel integra. Racemus sub anthesi densissimus, deinde ralde elongatus, laxiusculus, $40-80$-florus. Pedicelli floriferi $2,5-3 \mathrm{~mm}$, fructiferi $4-5 \mathrm{~mm}$. longi. Flores ca. $1 \mathrm{~mm}$. Iongi. Petala 4 sepalis vix longiora, anguste obovato-cuneata, alba. Stamina 2 petalis aequilonga. Pistillum orbiculare, apice emarginatum; ovarium 2-ovulatum; stigma sessile. Siliculae pedicellis 士 horizontalibus insidentes, $3-3,5 \mathrm{~mm}$. longae, 2,75-3 $\mathrm{mm}$. latae, valde compressae, $0,5 \mathrm{~mm}$. crassae, fere orbiculatae. Semina 2, fere semper pleurorrhiza; cotyledones ovatae.

Lepidium virginicum L. Spec. I ed. II (1753) p. 645; DC. Syst. Nat. II p. 538 et Prodr. I p. 205; A. Rich. in. Sagra Cuba X p. 25; Griseb. Flor. p. 14; Bello Ap. I p. 236 n. 22; Stahl! Est. II p. 37; Chapm. Flor. II. ed. p. 30: Robins. in Gray Syn. Flor. I, 1 p. 126; Duss! Flor: Ant. franc. p. 9.

Lepidium Iberis Descourt. Fl. Méd. Ant. I (1821) p. 193 tab. 41, - non $L$.

Nasturtium virginicum O. Kuntse Revis. I (1891) p. 35. 
Iberis humilior armua Virginiana Sloane Cat. (1696) p. 80 et Hist. I p. 195 tab. 123 fig. 3.

Sabe-leccion Cub. ex Sugra; Mastnerzo Portor. ex Krug et Sint.; Cresson de savanne Mart. ex Duss.

Radix annua, raro biennis. Caulis $25-60$, plerumque ca. $30 \mathrm{~cm}$. altus, erectus, a basi longi-ramosus, dense 20--30-folius, puberulus. Folia inferiora $3-9 \mathrm{~cm}$., media $2-4 \mathrm{~cm}$. longa, inferiora utrinque sparse et longinscule pilosa. Sepala oblonga, dorso pilosula. Stamina 2, rarissime $3-4$; antherae $0,2 \mathrm{~mm}$. longae. Siliculae apice emarginatae, dilute virides, laeves; stigma sessile. Semina $2 \mathrm{~mm}$. longa, $1 \mathrm{~mm}$. lata, $0,35 \mathrm{~mm}$. crassa, orata, anguste alata, dilute fulva, pleurorrhiza, rarissime notorrhiza. Cotyledones manifeste petiolatae.

Hab. in ruderatis, cultis, pratis, ad vias, circa domos in ins. Baham. New Providence prope Nassau: Eggers n. 4271; Cuba: Ramon de la Sagra; Jamaica prope Kingston in montibus: O. Hansen, prope Gordontown $333 \mathrm{~m}$. alt.: Eggers n. 3617, J. Ball, prope Resource $1200 \mathrm{~m}$. alt.: W. Harris n. 6914; Haiti prope Gonaïves ad Jorne Piton Ciel 900 m. alt.: W. Buclı n. 772, prope Pétionville: Picarda n. 1114, prope Fessard: E. Christ n. 1732; Portorico prope Caguas: O. Kuntze n. 270, prope Maricao circa haciendam Piñan ad Montoso: P. Sintenis n. 172, prope Guanica ad Punta de los Pescadores: idem n. $3503^{\mathrm{b}}$, prope Lares: idem n. 5824, prope Barceloneta juxta flumen Azul ad Florida: idem n. 6678, prope Bayanon: Stahl n. 218, 738; St. Thomas: Ehrenberg n. 203, Eggers ed. Toepff. n. 358; St. Croix ad King's hill: Ricksecker n. 312 et 357; Antigua ex Griseb.; Guadeloupe: Duchassaing, Steinheil, Duss n. 2298; Martinique: Hahn n. 778; St. Vincent 167 m. alt.: Smith 11. 670; Barbados in Joes River Wood: Eggers n. 7279, prope Hastings: Waby n. 100; Tobago ex Griseb. - America septentrionalis a Canada ad Texas; in Europam etc. introd. - Floret totum per annum.

Var. $\beta$. pimnatisectum O. E. Schulz. Folia inferiora pinnatisecta; lobus terminalis obovatus, inaequaliter profunde serrato-incisus vel lobulatus, laterales oblongi, praecipue latere superiore serrati; superiora profunde serrato-incisa.

Hab. in Portorico prope Mayagüez: L. Krug n. 29 et tab. 262.

Obs. L. apetalum Willd. (ex Asia et Amer. sept.) huic proximum, quod in Indiam occid. postero tempore fortasse introducetur, caule a basi breviramoso, foliis canlinis mediis utrinque densius ca. 6-, praesertim ad basin profunde, serrato-incisis, racemo 40 - 60 - floro, pedicellis floriferis $1,5-2 \mathrm{~mm}$., fructiferis $2,5-3 \mathrm{~mm}$. longis, erecto-patentibus, floribus minoribus, $0,75 \mathrm{~mm}$. longis, apetalis, sepalis dorso longiuscule pilosis, silicnlis minus compressis, seminibus notorrhizis secernendum est; L. muderale L. (ex Enrop., quasi spont. in Amer. sept.) basi multicauli, caule humiliore, foliis inferioribus pinnati- 
fidis, superioribus manifeste minoribus, integris, racemo $80-100$-floro, pedicellis florifcris 1,5 , fructiferis $3 \mathrm{~mm}$. longis, erecto-patentibus, floribus $0,75 \mathrm{~mm}$. longis, apetalis, seminibis notorrhizis a specie nostra diversum.

2. Lepidium sativum L. Folia inferiora breviter petiolata, pinnata, 3-4-juga: foliola circuitu oborata, terminale trifidum, lateralia lobis (utrinque 1 -2) 1 -3-serratis pinnatifida, omnia petiolulata; media brevius petiolata, 2 -juga: foliola oblonga, obtusiuscula, ad basin cuneatoangustata, sessilia, integra vel hic illic 1 -serrata; superiora sessilia, trifida vel linearia, 土 integra. Racemus sub anthesi minutus, congestus, postea valde elongatus, laxiusculus, 20-45-florus. Pedicelli floriferi $1-1,5 \mathrm{~mm}$., fructiferi $2-3 \mathrm{~mm}$. longi. Flores $1,5-2 \mathrm{~mm}$. longi. Petala alba rel dilute violacea, obovata, apice truncata, in unguiculum linearem aequilongum contracta. Stamina 6, interiora $1,8 \mathrm{~mm}$, exteriora $1,5 \mathrm{~mm}$. longa; antherae purpureae. Ovarium late ovale, anguste alatum, apice emarginatum, 2-ovulatum; stylus $0,5 \mathrm{~mm}$. longus; stigma stylo vix latius. Siliculae pedicellis brevibus, erectis, crassiusculis insidentes, rhachidi adpressae, brevi-ellipticae, compressae, $6 \mathrm{~mm}$. longae, $4-5 \mathrm{~mm}$. latae, 1,3 $\mathrm{mm}$. crassae, praesertim ad apicem late alatae. Semina 2, notorrhiza; cotyledones trisectae, lobo medio oblongo, apice obtuso, lateralibus linearibus majore.

Lepidium sativum I. Spec. I edit. II (1753) p. 644; DC. Syst. Nat. II p. 533 et Prodr. I 1. 204; Macf. Jam. I p. 29; Griseb. Flor. p. 14; Robins. in Gray Syn. Flor. 1, 1 p. 126.

Lepidium Iberis Descourt. Fl. Méd. Ant. I (1821) p. 197 tab. 42, - non $L$.

Nasturtium sativum O. Kuntse Revis. I (1891) p. 35.

Radix annua. Caulis $15-60 \mathrm{~cm}$. altus, ramosus, $6-12$-folius, teres, glaber, pruinosus, glancus, saepe basi violaceus. Folia inferiora $3-6 \mathrm{~cm}$., superiora $3-4 \mathrm{~cm}$. longa, nmnia glaberrima, sed basi petioli pilosula. Pedicelli floriferi suberecti, filiformes. Sepala $1 \mathrm{~mm}$. longa, ovata, membranacea, dorco pilosula. Antherae $0,3 \mathrm{~mm}$. Iongae. Siliculae apice emarginatae, pallide virides vel flavidae, laeves; stylus $0,5 \mathrm{~mm}$. longus; stigma $0,2 \mathrm{~mm}$. latum, stylo vix latius. Semina majuscula, fere $3 \mathrm{~mm}$. longa, 1,1 $\mathrm{mm}$. lata, 0,9 mm. crassa, oblonga, minutissime tuberculata, fulra, vix alata; funiculus $0,75 \mathrm{~mm}$. longus, filiformis. Cotyledones brevissime petiolatae.

Hab. in Jamaica quasi spontanea: ex Macfadyen. - Patria Asia occidentalis. Saepe in hortis colitur.

\section{Coronopus Gaertn.}

3. Coronopus didymus (L.) Smith. Planta multicaulis. Caules prostrati vel accumbentes. Folja caulina pinnatifida, manifeste petiolata: lobi lineares vel anguste oblongi, ad basin cuneato-angustati, sessiles 
rel sublecurrentes, terminalis integer, laterales utrinque $3-4$ saepe 1 - 3-partiti. Racemus sub anthesi brevissimus, vix conspicuus, sessilis, dein mox elongatus, fructifer $2-3 \mathrm{~cm}$. longus, 25-30-florus. Pedicelli floriferi $0,75-1 \mathrm{~mm}$. longi, erecti, fructiferi $1.5-2 \mathrm{~mm}$. longi. Flores minimi, 0,5 mm. longi, inconspicui, congesti. Petala 4 squaniformia, $0,3 \mathrm{~mm}$. longa, oblonga. Stamina bina, 0,4 mm. longa. Pistillum orbiculare, apice emarginatum; orarium 2-orulatum; stigma in emarginatura sessile. Siliculae pedicellis subhorizontalibus insidentes, didymae, 1,35 mm. longae, 2,25 mm. latae, utrinque emarginatae; valvulae clausae, reticulato-nervosae, griseae. Semina in quoque loculo singula, notorrhiza; cotyledones lineares.

C'oronopns didymus .J. E. Smith Fl. IBit. II (1804) p. 691.

Lepidinm didymum L. Mant. Pl. (1767) p. 92.

Senebiera pimmatifida DC. in. Mém. Soc. Hist. Not. Par. (1799) 1. 144 et Syst. Nat. II p. 523 et Prodr. I p. 203; Mocfad. Fl. Jam. I 1. 28; Griseb. Flar. p. 14; Eichl. in Wart. Fl. Bras. IIII, 1 1. 308; Chapm. F7. South. Umit. Stat. II edit. 1. 30; Robirs. in Gray Synopt. Fl. I, 1 p. 130; Duss! Flor. Ant. franc. p. 10.

Radix annua vel biennis. Caules e collo numerosi, $15-20 \mathrm{~cm}$. longi, longi-ramosi, dense ca. 15-foliati, subvillosi. Folia ima longe petiolata, pinnata, 5-7-juga: foliolum terminale lineare, integrum, lateralia sensim latiora et incisa, ima breviter petiolulata, ambitn oborata, utrinque lobulis ca. $5 \pm$ profunde inciso-lobulata; caulina media ca. 2 cm. longa: lobi ca. $5 \mathrm{~mm}$. longi; omnia pilosula vel glabra, ad basin petioli longiuscule pilosa. Racemi oppositifolii. Sepala $0,5 \mathrm{~mm}$. longa, late oblonga, uninervia, dorso parce longiuscule pilosa. Petala ex anctoribus interinm deficientia. Stamina ex auctoribus interdum 4, rarius 6. Pedicelli fructiferi filiformes. Stigma in emarginatura siliculae sessile. Semina 1,25 mm. longa, 0,75 $\mathrm{mm}$. lata, $0,4 \mathrm{~mm}$. crassa, oblonga, sed subcurvata, vix tuberculata, dilute fulva; funiculus nullus.

Hab. in Bermuda: J. Rein n. 2; Jamaica ex Macfad. 1. c.; Antigua: Wullschägel; Martinique au pied des murs du Morne Rouge et du Presbytère 500 m. alt., m. Aug. fl. et fr.: Duss n. 1786, 4041. - Amer. cont., in Europam, Africam, Australiam introd.

\section{Cochlearia L.}

4. Cochlearia armoracia L. Radix crassissima, longa, multiceps. Folia radicalia maxima, longe petiolata, oblonga, basi interdum subcorlata, apice obtusiuscula, dense minute sinuato-crenata; caulina multo minora, inferiora breviter petiolata, lobis linearibus obtusis \pm pectinatopinnatifida, superiora sessilia, simplicia, oblonga rel linearia, remote serrato-dentata, summa integra. Racemus sub anthesi corymbosus, dein elongatus, $30-50$-florus. Pedicelli floriferi $5-8 \mathrm{~mm}$. longi, fructiferi 
non elongati. Flores 5-6 mm. longi. Petala alba, obovato-cuncata, patula, exteriora majora. Stamina brevia, interiora $2 \mathrm{~mm}$, exteriora $1,5 \mathrm{~mm}$. longa. Ovarium ellipticum, ad basin subattenuatum, apice in stylum brevissimum, crassum contractum, 9-20-ovulatum; stigma majusculum, bilobum, longiuscule dense papillosum, stylo latius. Siliculae perlicellis erecto-patentibus insirlentes, hrevi-ellipticae vel fere globosae, 3-4 mm. longae, 2,5-3 mm. latae of crassae, fere semper steriles; stigma $0,5 \mathrm{~mm}$. latum, stylo brevissimo latius; valvulae viridulo-griseae, enerves. Semina matura mili non visa.

Cochlearia Armoracia L. Spec. I edit. II (1753) p. 648; DC. Syyst. Nat. II p. 360 et Piorlr. I p. 173: Macfad. Fl. Jam. I p. 26.

Nesturtimm Armoracin Fies F'. Serm. (1835) p. 6.5; Robins. in Gray Symopt. Fl. 1, 1 1. 146.

Cardamine Amoracia O. Kuntie lieris. I (1S91) p. 26.

Radix perennis, cylindrica, allirla, acerrima. Caulis $60-120 \mathrm{~cm}$. altus, erectus, ramosis, fistulosus, sulcatus, glaber, ut tota planta. Folia radicalia renosa, $30-50 \mathrm{~cm}$, caulina media $8-10 \mathrm{~cm}$. longa. Pedicelli floriferi erecto-patentes. Sepala $2 \mathrm{~mm}$. longa, ovata, obtusa, non saccata, flavido-viridia, margine late hyalina. Antherae $1 \mathrm{~mm}$. longae, oblongae. Glandulae parum conspicuae.

Hab. quasi spontan. in Jamaica: ex Macfad. 1. c. - Patria Furopa media.

\section{Sisymlorium L.}

5. Sisymbrium officiuale (L.) Seop. Planta annua. Caulis praesertim superne ramis rectangule patentibus ramosus. Folia inferiora rmoncinato-pinnatifida, breviter petiolata: lobus terminalis caeteris multo major, circuitu triangularis, \pm in segmenta 3 inaequaliter grosse dentata partitus, laterales $4-6$ magnitudine descrescentes, oblongi, grosse dentati; superiora minora, brevissime petiolata: lobus terminalis hastatus, denticulatus, laterales 2 lineares, integri, rel deficientes. Racemus sub anthesi brevissimus, congestus, dein valde elongatus, $15-20 \mathrm{~cm}$. longus, 20 - 40 -florus. Pedicelli floriferi $0,5-1 \mathrm{~mm}$. longi, filiformes, fructiferi vix elongati, $1-2 \mathrm{~mm}$. longi, crassi. Flores $2,5-3 \mathrm{~mm}$. Iongi. Petala flava, oblongo-cuneata, apice rotundata. Stamina interiora 2, exteriora 1,5-1,8 mm. longa. Pistillum cylindricum, vix stylosum, dense pilosum; ovariun 16-20-ovulatum; stigma stylo crasso aequilatum. Siliquae pedicellis brevissimis erectis insidentes, rhachidi adpressae, mimutae, $10-14 \mathrm{~mm}$. longae, basi $1-1,5 \mathrm{~mm}$. latae, teretes, in stylum brevissimum subuliformi-attenuatae (mucronatae), breviter villosae; stigna $0,3 \mathrm{~mm}$. latum, stylo vix latius, subbilobum; valvae valde convexae, longitudinaliter 3 -nerves, viridulae. Semina minutissime tuberculata, oblique notorliza; cotyledomes ollipticae. 
Sisymbrimm officinale Scop. Fl. Cormiol. II edit. II (1772) p. 26; DC. Syst. Not. II p. 45.9 ot Prodr. I p. 191; Macforl. Fl. Jam. I p. 27; (irivel. Flor. p. 13; Eichl. in Mort. Fl. Liras. XIII, 1 p. 303; Chapm. F. Sonth. Tnit. Stot. II alit. p. 28; liobins. in cirny synopt. Flor. I, 1 1. 137.

Erysimmm officinole L. Spec. I cdit. II (1753) p. 660.

Caulis $30-60 \mathrm{~cm}$. altus, $8-12$-folius, pilis recurratis disperse pilosus, pruinosus, firmus. Folia inferiora $4-20$, plerumque $6-8 \mathrm{~cm}$., superiora $3-7 \mathrm{~cm}$. longa; omnia \pm pilosa. Sepala $1,5-2 \mathrm{~mm}$. longa, oblonga, non saccata, 3 -nervia, dorso pilosula. Petala ca. 3 -nervia. Antherae $0,5 \mathrm{~mm}$. longae. Semina uniseriata, $1 \mathrm{~mm}$. longa, $0,5 \mathrm{~mm}$. lata, $0,4 \mathrm{~mm}$. crassa, rectangula, saepe subcurrata, fnlva; funiculus $0,3 \mathrm{~mm}$. longus, filiformis.

Hab. quasi spontan. in Jamaica: ex Macfad. 1. c. - Patria Europa tota.

Var. p. liocarpum DC. Siliquae glaberrimae.

Sisymbrimm officinale Scop. B. leiocarpmm. Dr. Syst. Nat. II (1521) p. 460 el Prodi. I p. 191.

Hab. quasi spontan. in Haiti in montibus Furey: Picarda n. 1527. - Ubique cum specie typica.

\section{Cakile Juss.}

Yor einigen Jahren hat Ch. F. MrLuspadgh (Plantae Utowanae in Field Columb. Mus. Publ. 50 Bot. Ser. Vol. II, 2. 1900. p. 123-33) sowohl die in Nord- und Mittelamerika heimischen, als auch die dorthin aus Europa eingeschleppten Calile-Formen einer monographischen Bearbeitung unterzogen und im ganzen zehn Arten und zwei Bastarde festgestellt, welche ron ihm ausführlich beschrieben und mit Abbildungen ihrer Früchte und Samen versehen wurden. Im westindischen Gebiete kommen nach dem Autor drei Arten vor. Da die Colile-Formen von jeher betreffs ihrer Bewerthung den Systematikern grosse Schwierigkeiten bereitet haben, schien es zweckmässig zu sein, die ganze Gattung auf ihre Formenkreise hin genau zu untersuchen. Leider sah ich im Berliner Bot. Museum nur ein reichhaltiges Material aus Europa, Ifrika, Asien und Westindien. Dennoch konnte mit Erfolg aus der in der alten Welt stattfindenden Formbildung, sowie an der Hand der MILLSP'sugh'schen Abhandlung auf die analogen Terhältnisse der ron mir nicht gesehenen amerikanischen Varietïten geschlossen werden.

An C. maritima Scop. wurden folgende Tariationen beobachtet, welche meistentheils indiriduell auftreten und nur dic Aufstellung ron Einheiten niederen Ranges (Rassen, Tarietäten, Formen), keineswegs aber ron Arten rechtfertigen: 
1. Grösse. Die Ptlanze erreicht gewöhmlich eine Höhe ron 15 bis $30 \mathrm{~cm}$; hin und wieder finden sich auch Zwergfornen mit kleineren Frichten.

2. Blattform. In der Regel ist das Blatt einfach gefiedert oder tief fiederspaltig; seine Fiedern sind lineal, ganzrandig orler etwas gezälmelt. Bisweilen erscheinen letztere aber auch tief fiedertheilig. Es kommt ferner der Fall vor, dass die Lappen breiter werden und eine seichte Kerbung aufweisen. Andere Formen zeigen mehr oder weniger lang gestielte oder sitzende Blätter von einfacher, länglicher Gestalt, welche gelappt, geschweift-gezähnt oder völlig ganzandig sind. - Bereits C. Baumin hat eine Pflanze mit fiedertheiligen Blättern cultivirt und aus ihren Samen eine Form mit einfachen Blättern erlualten. Auch LinNé war die Veränderlichkeit der Blattform, welche man nicht selten an einem Exemplare beobachten kann, bekannt.

3. Blüthenstiel. Bisweilen werden die Blüthenstiele so sehr verkürzt, dass Blüthen und Früchte an der Spindel zu sitzen scheinen.

4. Blumenblatt. Die Blumenblätter sind an der Spitze abgerundet, gestutzt oder seicht ausgerandet. Ihre Farbe ist violett, rosa, seltener weiss.

5. Frucht. Die Frucht besteht aus zwei Gliedern. Das untere besitzt eine kreiselförmige Gestalt; an seinem oberen Ende ist es dachförmig gestaltet, d. l. mit einer meisselartigen Schneide versehen und nach beiden Seiten abgeschrägt. Diese Schrägung läuft auf jeder Seite in einen zuriickgebogenen Zahn aus, welcher in der Regel $1 \mathrm{~mm}$. lang ist, in seltenen Fällen auch eine Länge von $2 \mathrm{~mm}$. erreicht oder ganz verschwindet. Letzteres tritt besonder's damn ein, wenn das untere Glied verkümmert. Wird das untere Glied zu einem blossen Stiele reducirt, so echält die Frucht ein fremdartiges Aussehen. Das obere Glied erscheint eiförmig mit abgerundetem Grunde. Diese Verkümmerung tritt sehr häufig in einer Traube neben normal ausgebildeten unteren Gliedern auf. Manchmal vollzieht sich der soeben erwähnte Vorgang an allen Früchten. Die Pflanze ruft in diesem Falle den Eindruck einer neuen Art hervor ( $C$. monosperma Lange!). - Das obere Glied bricht sehr leicht vom unteren ab. Seine Zuspitzung schwankt in der Breite zwischen 0,5 und 2,5 $\mathrm{nm}$. - Die Frucht erscheint in ibrer Gesammtheit scharf vierkantig; zwischen den Kielen laufen ein bis zwei schwächere Längsnerven, welche etwas anastomosiren. Mitunter werden die Kanten stumpf und die Nerven undeutlich. Die schwammigen Wände der Fächer können sich bedeutend verstärken. Dadurch nähern sich die Glieder der kugeligen Gestalt.

6. Same. Jedes Fach enthält gewöhnlich einen Samen, welcher im unteren Längt, im oberen aufwärts gewendet ist. Nach BrRTorovi 
kommen im oberen Fache auch zwei Samenkörner vor. In den meisten Fällen liegt die Radicula der Spalte an, welche durch die beiden Keimblätter gebildet wird. Einmal wurde indessen an einem Samen des oberen Gliedes die notorrhize Lage constatirt.

Im allgemeinen erweisen sich die Form des Gelenkes, das Verhältnis der Länge und Breite des oberen Gliedes zum unteren, die Richtung der Fruchtstiele und der Wuchs der Pflanze constant.

C. lanceolata (Willd.) O. E. Schulz subsp. A. edentula (Bigel.) O. E. Schulz wird von der vorigen Art, mit welcher sie nahe verwandt ist, sofort dadurch unterchieden, dass die Gliederung der Frucht durch eine ebene Fläche stattfindet. Die zalmartigen Höcker fehlen, dagegen ist die Frucht an Gelenk häufig ein wenig eingeschnürt. Fernerhin liegen die Früchte der Spindel an oder stehen schräg aufwärts von ihr ab. Die Blätter sind im allgemeinen einfacher gestaltet, die Blüthen erreichen eine geringere Grösse, und die Früchte spitzen sich mehr zu. Im übrigen zeigt diese Art dieselben Veränderungen wie die vorige. Als neues Moment verdient hervorgehoben zu werden, dass die Petala oft rudimentär auftreten oder gänzlich abortiren. Hierauf machte zuerst Тн. Меенах (1893) aufmerksam.

C. laneeolata (Willd.) O. E. Schulz subsp. B. domingensis (Tuss.). O. E. Schulz. Diese Pflanze nähert sich in Bau der Früchte der Unterart $A$. edentula (Bigel.) O. E. Schulz und ist durch Übergänge (proles geniculata Robinson) mit ihr verbunden. Das obere dolelıförmige Glied ist zwei-bis viermal länger, aber nicht breiter als das untere. Beide sind melır oder weniger stielrund, oft sogar in der Längsrichtung sclıwach gefurcht. Die Früchte enthalten häufig im unteren, selten auch im oberen Gliede je zwei Samenkörner. - Sehr variabel erweist sich in den Samen die Orientirung der Radicula zu den Cotyledonen. Ich habe folgende Fälle constatirt:

1. ein Same im unteren Glied: pleurorrhiz; ein Same im oberen Glied: pleurorrhiz (bäufig!),

2. ein Same im unteren Glied: pleurorrhiz; ein Same im oberen Glied: notorrhiz (selten),

3. zwei Samen im unteren Glied: beide notorrhiz; ein Same im oberen Glied: pleurorrhiz (selten),

4. zwei Samen im unteren Glied: beide schief notorrhiz; zwei Samen im oberen Glied: beide schief notorrhiz (selten).

Schliesslich möchte ich nicht unerwähnt lassen, dass ich die beiden Samen des unteren Gliedes in lıängender Lage autraf. Ihre Nabelstränge waren an seinem oberen Ende neben einander befestigt. Der eine war $0,5 \mathrm{~mm}$. lang, der andere dagregen besass eine Länge ron $3 \mathrm{~mm}$. und lief an der Seite des oberen Samens entlang. Die beiden Samen des 
oberen Gliedes standen auf kurzen, 0,5 mm. langen, übereinander angehefteteu Nabelsträngen aufrecht. A. P. de Candolue und Mus spaugh teilen nur die Beobachtung mit, dass sich im unteren Gliede zwei samen ausbilden könmen. Nach ihnen soll der obere Same hängen, der untere aber aufgerichtet sein.

Die in Australien rorkommenden Cakile-Formen ähneln nach dem geringen, wenig instructiven Material, welclies ich von dort gesehen habe, sehr der amerikanischen C. Ianceolata (Willd.) O. E. Schulz subsp. A. edentulu (Bigel.) O. E. Schulz. Sie mnterscheiden sich aber von ihr durch eine tiefe Einschnürung ihrer Früchte an den Gelenken und durch häufige Ausbildung von zwei Samenkörnern im unteren Gliede.

\section{Conspectus specierum.}

A. Geniculum fructus marginatum, utrinque obliquum, bicorniculatum

C. marilima Scop.

B. Geniculum fructus non marginatum, horizontale, planum, non corniculatum, saepe subconstrictum . : . . 6. C. lanceolata 9. E. Schulz

Cakile maritima Scop. Caulis $15-30 \mathrm{~cm}$. longus, procumbens vel adscendens, ramis reflexis diffusus. Folia manifeste ( $=1 / 2$ fol.) petiolata, profunde pinnatifica: lobi lineares, obtusi, parce denticulati rel integri, laterales utrinque 2-3. Racemus sub anthesi brevis, corymbosus, dein elongatus, sed densiusculus, $8-30$-, raro-50-florus. Pedicelli floriferi 1 - $2 \mathrm{~mm}$. longi, erecto-patentes, tennes, fructiferi $3-5 \mathrm{~mm}$. longi, crassi. Flores $4-6 \mathrm{~mm}$., rapo-- $11 \mathrm{~nm}$. (f. grandiflora) longi. Petala violacea vel rosea, raro alba (f. lactea), anguste obovato-cuneata. Stamina interiora 4 mm., exteriora $3 \mathrm{~mm}$. longa. Pistillum cylindricum; ovarium 2-ovulatum; stigma subbilobum, ovario aequilatum. Fructus lomentacei, fungosi, ad pedicellos horizontales horizontaliter patuli, $10-22 \mathrm{~mm}$. longi, $4-6 \mathrm{~mm}$. lati, tetragoni, in quoque latere nervis 1-2 longitudinalibus tenuibus hine illine anastomosantibus instructi; articulus inferior turbinatus, apice utrinque obliquus et appendice ca. $1 \mathrm{~mm}$. longa, refracta praeditus (ergo fructus ad articulationem hastatus), interdum \pm abortivus; superior inferiore $1 \frac{1}{2}-2-p l o$ longior et paulo latior, anguste oratus, supra basin cavam marginatam contractus, in stylum ancipitem, apice obtuso $1-1,5 \mathrm{~mm}$. latum attenuatıs; stigma stylo multo angustius. Semen articuli inferioris pendulum, superioris erectum, utrumque pleurorrhizum. Cotyledones lineares.

Calive maritima Scop. Fl. Carniol. II cdit. II (1772) 1. 35.

Bunins caliile L. Spec. I edit. II (1753) p. 670.

Calizle Serrpionis Gaertn. Frnet. Sem. II (1791) p. 287.

Cakile pimatifida Stokes biot. Mat. Medic. III (1S12) p. 181. 
Cakile ballica Jordan Diagn. Esp. Sont. I (1861) 1. 345 (nomen. mudum).

('alicile calile Karsten Deutsch. H7. (1883) 1. 663.

Tota planta carnosa. Radix annua vel biennis, perpendiculariter descendens, longi-ramosa, alba. Caulis $6-9$-folins, glaberrimus, basi saepe violacens. Folia $3-9 \mathrm{~cm}$. longa: lohus terminalis $10-16 \mathrm{~mm}$. longus, $1-3 \mathrm{~mm}$. latus: omnia glabra. Sepala $3-4 \mathrm{~mm}$. longa, erecto-patentia, oblonga, obtusa, interiora subsacuata, ca. 5-nerria, margine anguste hyalina, glabra, interdum dorso pilosula, tlavida. Petala ajice rotundata vel leviter emarginata. Antherae $1 \mathrm{~mm}$. longae, oblongae. Glandulae medianae conicae et laterales semiorticulares bene conspicuae. Fructus firmi, nitiduli, flavidi. Semina ca. $4 \mathrm{~mm}$. longa, 1,75 $\mathrm{mm}$. lata, $1 \mathrm{~mm}$. crassa, oblonga, serl subcurvata, minute rugulosa, fulva; funiculus fere mullus.

Hab. in arenosis, glareosis, saxosis maritimis, in Europa a Scania ad Rossiam meridionalem, Asia occidentali ad Persiam meridionalem, Africa septentrionali. - Flor. Majo - Octob.

Variat:

B. proles edentula (Jord.) O. E. Schulz. Appendices apice articuli inferioris breves, ca. $0,5 \mathrm{~mm}$. longae. Fructus angustiores, $2,5-4 \mathrm{~mm}$. lati.

Calicle edentula Jordun Diann. Esp. Nour. I (1961) p. 3.1.

Hab. praesertim in regione mediterranea.

C. proles litoralis (Jord.) O. E. Schulz. Appendices ca. 22,5 mm. longae, valde deflexae.

Calive litoralis Jordan l. c. 1. 34.5.

Hab. hic illic in regione mediterranea.

II. Var. Honosperma (Lange) O. E. Schulz. Articulus inferior omnium fructumm abortivus, stipitiformis, superior ovatus, basi rotundatus, apice \pm acutus. Folia saepe simplicia.

Calile monosperma Lange Descript. et Icon. I'l. Nor. Fl. Hisp. Fusc. I (1S64) 1.5 tab. 7.

Hab. ab ins. Helgoland ad Lusitaniam.

III. var. oxycarpa O. E. Schulz. Omnes fructus apice acuti $0,5 \mathrm{~mm}$. lati.

Hab. a Dalmatia ad litora maris nigri orientalis.

IV. rar. amblycarpa O. E. Schulz. Omnes fructus apice obtusissimi, 2,5 $\mathrm{mm}$. lati.

Hab. in Borussia orientali, Italia.

V. var. hispanica (Jord.) O. E. Schulz. Fructus tumidi, $18 \mathrm{~mm}$. longi, $9 \mathrm{~mm}$. lati et crassi, valde fungosi; articulus inferior apice vix narginatus, superior basi latissime alatus, fere globosus, non attenuatus. 
Calive hispanica Jordan l. e. p. 345.

Hab. in Hispania et Lusitania.

b. var. sessiliflora O. E. Schulz. Pedicelli brevissimi, floriferi $0,5 \mathrm{~mm}$., fructiferi $1 \mathrm{~mm}$. longi.

Hab. in Graecia.

2. var. latifolia Desf. Folia simplicia, anguste obovata vel oblonga, ad basin cuneato-angustata, \pm longe petiolata rel subsessilia, utrinque \pm profunde $5-6$-sinuato-dentata.

Cakile mavitima Scop. val. A. latifolia Desf. Fl. Atlant. II (1795) $p .77$.

Calite aegyptiaca Willd. Spec. Plant. III, 1 (1500) 1). 477.

Cakile latifolia Poir. Encyel. in Lam. Bot. Suppl. II (1S11) p. 88.

Cakile simuatifolia Stokes Bot. Mat. Medic. III (1812) p. 4 S5.

Cakile maritima Scop. rar. $\beta$. simatifolia DC. Syst. Nat. II (1S21) 7.429. fig. 3.

Bunias oralis Viviani Fl. Libye. Specim. (1821) p. 35 tab. 16

Cakile cyrenaice Spre. Syst. II (1825) p. S52.

Cakile crenata Jordan l. c. p. 346.

Calile Barhini Jordan l. e. 1. 347.

Hab. ubique eum specie typica.

3. var. integrifolia Boiss. Omnia folia oblonga rel linearia, integerrima vel vix denticulata.

Cakile maritima Scop. var. $\beta$. integrifolia Boiss. Fl. Orient. I (1867) 10.365.

Hab. ubique, sed raro cum specie typica.

4. var bipinuta O. E. Schulz. Omnia folia lobis lateralibus rursus in lobulos ca. 5 lineares dissectis bipinnata.

Hab. ad mare balticum prope Pillau, in Turcia, Graecia.

b. f. pygmaea 0 . E. Schulz. Caulis simplex, humilis, $5-6 \mathrm{~cm}$. longus. Fructus minores, $10 \mathrm{~mm}$. longi, $3 \mathrm{~mm}$. lati. Hab. in Aegypto, probabiliter etiam alibi.

c. f. pandataria Temaciano. Planta saepe caespitosa vel ramulosa. Folia crassiora et minora.

Calile maritima Scop. var. pandataria Terr. in Annal.

Acad. Aspir. Natrual. 3. Ser. I (1884) p. 5.

Hab. prope Neapolim in ins. Ventotene.

\section{Cakile lanceolata (Willd.) O. E. Schulz.}

Subsp. A. edentula (Bigel.) O. E. Schulz. Differt a C. maritima: Caulis \pm erectus, rami erecto-patentes vel adscendentes. Folia simplicia, anguste oborata rel oblonga, ad basin in petiolum brevem cuneato-angustata, utrinque \pm profunde ca. 4-dentata, ad basin integra. Fructus pedicellis erecto-patentibus insidentes, suberecti, paulo minores; articulus inferior vix turbinatus, fere cylindricus, non acriter 
tetragonus, teretiusculus, apice planus, non appendiculatus; superior inferiore $1 \frac{1}{2}$-plo longior, ovatus, tetragonus, manifeste nervosus, in stylum brevem, \pm acutum, apice $0,5-1,5 \mathrm{~mm}$. latum attenuatus. Semen articuli superioris interdum notorrhizum.

Cakile edentula Hook. Fl. Bor.-Amer. I (1840) p. 59; Millsp. I'l. Utou: in Field Colmmb. Mns. II, 2 p. 129.

Bnnias edentula Bigelou Fl. Bost. I edit. (1S1-t) p. 157.

Colite americana Nitt.! Gener. North Amer. Pl. II (181S) p. 62; Millspangh l. c. p. 127.

Cakile cubensis Millspangh l. c. p. 131, - non Kunth.

Area geogr.: America orientalis ab ins. New Foundland ad Venezuelam, California; Islandia; A ustralia?

Subsp. B. dominerensis (Tuss.) O. E. Schulz. Recedit a subspecie A: Caulis erectus, 20-50 cm. altus. Folia utrinque \pm profunde 6-10-dentata, ad basin integra. Racemus fructifer laxus. Pedicelli fructiferi paulo breviores. Flores $6-8 \mathrm{~mm}$. longi. Petala ohorata, apice leviter emarginata, ad basin subito in unguiculum 4-plo breviorem angustata. Ovarium 2-4-ovulatum. Fructus pedicellis erecto-patentibus insidentes, suberecti, majusculi, $18-33 \mathrm{~mm}$. longi, angusti, $4 \mathrm{~mm}$. lati, \pm teretes, \pm sulcati, interdum 4 -spermi; articulus inferior cylindricus; superior inferiore 2-4-plo longior, non latior, pugioniformis, apice $1-1,5 \mathrm{~mm}$. latus. Semina saepe \pm notorrhiza.

Raphanus lauceolatns Willd.! Spec. Plant. 1II, 1 (1S01) p. 562; Macfad. Fl. Jam. I p. 32.

Cakile domingensis Tuss. Fl. Ant. I (1SOS) p. 119.

Cakile aegyptiaca Thss. l. c. tab. 17, - non Willd.

Cakile aequalis L'Ilérit. apmed DC. Syst. Nat. II (1S21) p. 430 et Prodr. I p. 185; Griseb. Filor. p. 11 et Cat. p. 6; Stahl! Est. II 11. 37; Duss! Fl. Ant. fians. p. 10.

Cakile anericana Nutt. $\beta$. cubensis DC. l. c. p. 429.

Calile cubensis H. B. K. Nov. Geu. et Sipec. V (1821) p. 58.

Bunias cakile Desconrt. Fl. Méd. Ant. I (1821) p. 199 tab. 43, - non $L$.

Cakile americana Spr. Syst. II (1825) p. S52, - nou Nutt.

Cakile maritima 1. Rich. in Sagra Cub. X (1845) p. 24; Bello Ap. I p. 236 ,n. 20; Krug Ic. t. 260, - non Scop.

Ernca derodecima sire maritima Italica etc. Sloane Cat. (1696) p. 81 et Hist. I p. 195.

IIostacilla del mar Port. ex Stahl.

Hab. in ins. Bah amens. New Providence prope Adelaïde: Eggers n. 4329, Turk Islands ex Griseb.; Jamaica ex Griseb.; Sto. Domingo: 
Prenleloup n. 6; Portorico: Heller n. 256, prope Mayagiez: Krug 11. 27, prope Guanica ad salinas: Sintenis n. 3503, prope Manatí idem n. 6940, prope Salinas de Cabo-Rojo: idem n. 591, ibidem ad Los Morillos: idem n. $591^{\text {b}}$, prope Bayamon ad Cataño: idem n. 591c, 1265 , ibidem: Stahl n.655; St. Thomas: Ehrenberg n. 196, ad Soldier Bay: Eggers s. n. et ed. Toepffer n. 212; St. Croix prope New Fort et ad Judith's Fancy: Ricksecker n. 68, 304; St. Barthélemy: A. v. Goös (hb. holm.); Antigua: Nicholls; Désirade: Duss n. 3659; Marie Galante ex Duss; Martinique: hb. berol.; St. V incent ex Griseb.; Barbados prope Hastings: Waby n. :31. - Columbia prope Cartagrena in ins. Tierra Bomba: Billberg. - Floret totum per annum.

11. proles geniculata (Robiuson) O. E. Schulz. Articulus superior $1 \frac{1}{2}-2$-plo longior quam inferior, caeterum $=$ subsp. B. domingensis (Tuss.) O. E. Schulz.

Cakile maritima Scop. iar. genienlata Robinson in Crray symopt. Flor. I (1895) p. 132.

Cakile monitima Seop. ear. aequalis Chopm. Fl. South. Imit. stat. II ed. (1S87) 1. 31.

Calile maritima Scop. car. conbensis Chapm. l. c. p. Go6.

Cakile fusiformis Grecne in Pittomia III (1S98) 1. 340.

Cakile geniculate Millspongh 1. e. p. 126.

Cakile alacranensis z acqmelis Millspangh l. c. p. 130?

Hab. in Cuba: Ramon de la Sagra, ad Cabo Corientes: Ch. F. Milspaugh n. 1465. - Praeterea in Florida, Texas.

Obs. Nonnullae formae huius prolis ad subspeciem A, aliae at subspericm B accedunt.

b. var. Ilillspaumhii O. E. Schulz. Articulus inferior 2-spermus, superiori aequilongus.

Coliile geniculato $\times$ edentula Mill.rpangh l. e. p. 127.

Hab. in Staten Island prope Sow York.

c. var. alaconacusis (Millsp.) 0. E. Schulz. Fructus turgidissimi, fungosi, $16-20 \mathrm{~mm}$. longi, $11 \mathrm{~mm}$. lati; articulus supelior brevi-ovatus vel fere globosus, acutus.

Cakile alacranensis Millspangh, l. c. 1) 130.

Calile Chopmanii Millspangh l. e.

Hab. in Florida et ins. Alacran.

2. var. apetala O. E. Schulz. Petala rudimentaria vel nulla. Hab. in Staten Island prope New York: v. Ralvenan.

b. var. pimmatilida O. E. Schulz. Folia \pm profunde pinnatifida, ut in C. maritima typical.

Hab. ubique, sed non frequenter cum specie. 
c. var. integrifolia (). E. Schulz. Folia angusta, oblonga rel linearia, integerrima.

ic. . 261 .

Cakile aequalis Bello Ip. I (1881) 1. 23.36 n. 21; Ling

Hab. in locis numerosis.

2. f. pygmaea O. E. Schutz. Planta humillima, 22 $-8 \mathrm{~cm}$. longa. Fructus ca. $10 \mathrm{~mm}$. longi.

Hah, in Islandia: Wender.

\section{Sillapis L.}

Conspectus specierum.

Folia lyrato pinnatifida. Pedicelli fructiferi $8-10 \mathrm{~mm}$. longi. Orarium 4-6-ovulatum. Siliquae 3-4 mm. latae. 7. S. allo I.

Folia ovata, dentata. Pedicelli fructiferi $3-4 \mathrm{~mm}$. longi. Ovarium $9-12-$ ovulatum. Siliquae $2-2,5 \mathrm{~mm}$. latae . . 8. S. arensis L.

7. Sinapis alba I. Planta annua. Folia lyrato-pinnatifida, breriter petiolata; lobus terminalis ovatus, reliquis multo major, laterales magnitudine descrescentes, oblongi, omnes inaequaliter obtusiuscule sinuato-dentati. Racemus sub anthesi laxiusculus, deinde elongatus, laxus, $30-50$-florus. Pedicelli floriferi $5-7 \mathrm{~mm}$., fructiferi $8-10 \mathrm{~mm}$. longi. Flores $6-8 \mathrm{~mm}$. longi. Sepala horizontaliter patentia. Petala flara; lamina breviter obovata vel fere orbicularis, patula, subito in unguiculum anguste linearem paulo breriorem angustata. Stamina interiora 4-5 mm., exteriora 2,5-3 $\mathrm{mm}$. longa. Pistillum subuliforme, pilis inferne longiusculis, superne brecibus adpresse pilosum; orarium 4-6-ovulatum, in stylum aequilongum, $2 \mathrm{~mm}$. longum sensim attenuatum; stigma stylo sublatius. Siliquae pedicellis \pm horizontalibus insidentes, erectae rel erecto-patentes, $20-25 \mathrm{~mm}$. longae, $3-4 \mathrm{~mm}$. latae, cylindricae, in rostrum $10-15 \mathrm{~mm}$. longum, ensiforme, longitudinaliter 5-nerve, riride, parce pilosum attenuatae; stigma subbilobum, $0,5 \mathrm{~mm}$. latum, stylu sublatius; valsae convexae, torulosae, hispidae, 3-nerves, flavae. Semina fere globosa, minutissime tuberculata: cotyledones conduplicatae.

Sinapis alba L. Spec. I edit. II (1753) p. 668; DC. Syst. Nat. II p. 620 et Prodr. I p. 220; C'hapm. Fl. South. Unit. Stat. III edit. p. 29. Brassica alba lioiss. Voy. Espagne II (1839-45) p. 39; Robins. in Gray Synopt. Flor. I, 1 p. 134.

Caul is $30-60 \mathrm{~cm}$. altus, erectus, ramosus, $8-10$-folius, acutangulus, firmus, pilis recurvatis hispidus. Folia $3-5 \mathrm{~cm}$. longa, glabra vel disperse adpresse pilosa. Pedicelli floriferi filiformes, erecto-patentes, fructiferi crassiores. Sepala $3,5-4 \mathrm{~mm}$. longa, oblonga, basi non saccata, glabra. Antherac $1,5 \mathrm{~mm}$. longae, late oblongae. Glandulae bene conspicuae. Semina 1,5 mm. longa, $1 \mathrm{~mm}$. lata et crassa, pallide bruneola; 
funiculus $1-1,5 \mathrm{~mm}$. longus, dilatatus. Cotylerlones brevissime petiolatae, reniformes.

Introducta in Portorico prope Dorado in pratis litoralibus $m$. Mlaj. fr.: Sintenis n. 7020. - Patria Europa australis. Saepe colitur.

8. Simapis arrensis L. Planta annua. Folia ovata vel late oblonga, inferiora in petiolum brevem cuneato-angustata, superiora 士 sessilia, inaequaliter sinuato-dentata, inferiora saepe basi pinnatifida. Racemus sub anthesi corymbosus, postea valde elongatus, 20-35florus. Pedicelli floriferi $3-4 \mathrm{~mm}$. longi, fructiferi non elongati. Flores $9-10 \mathrm{~mm}$. longi. Sepala horizontaliter patula. Petala aurea; lamina breviter obovata, apice truncata vel leviter emarginata, ad basin in unguiculum paulo breviorem, angustissimum angustata. Stamina interiora $6-7 \mathrm{~mm}$, exteriora $4 \mathrm{~mm}$. longa. Pistillum anguste cylindricum, glabrum; ovarium 9-12-ovulatum, in stylum tenuem, aequilongum, $3,5 \mathrm{~mm}$. longum attenuatum; stigma stylo manifeste latius. Siliquae pedicellis brevibus crassis erecto-patentibus insidentes, erecto-patulae vel suberectae, $25-35 \mathrm{~mm}$. longae, $2-2,5 \mathrm{~mm}$. latae, teretes, in rostrum $10-12 \mathrm{~mm}$. longum paulatim attenuatae; stigma $0,75 \mathrm{~mm}$. latum, stylo evidenter latius; valvae torulosae, nervis 3 crassis vix anastomosantibus manifeste 3 -nerres, viridulae. Semina globosa, sublaevia; cotyledones conduplicatae.

Sinapis arvensis L. Spec. I edit. II (1753) p. 668; DC. Syst. Nat. II p. 615 et Prodr. I p. 219; Egg. Flor. St. Croix and Virg. Isl. p. 24. Brassica sinapistrum Boiss. Voy. Espagne II (1839-45) p. 39; Robins. in Gray Symopt. Flor. I, 1 p. 133.

Brassica arensis O. Kuntre Revis. I (1891) p. 19.

Caulis $20-60 \mathrm{~cm}$. altus, erectus, simplex vel longe ramosus, ca. 8 -foliatus, obtusangulus, firmus, pilis rigidulis reversis hispidus. Folia $6-12 \mathrm{~cm}$., raro-30 cm. longa, disperse pilosa, in axillis rubro-maculata. Pcdicelli floriferi tenues. Sepala $4 \mathrm{~mm}$. longa, angustc oblonga. Antherac $1,5 \mathrm{~mm}$. longae, anguste oblongae. Glandulae bene conspicuae. Semina 1,5 mm. diam., nigricantia; funiculus $0,5 \mathrm{~mm}$. longus, dilatatus. Cotyledones sessiles, reniformes.

Quasi spontan. in St. Croix prope Anguilla: ex Eggers. - Patria Europa, Asia occidentalis.

\section{Brassica L.}

Conspectus specierum.
A. Folia canlina scmiamplcxicaulia
9. B. Rapa L.

B. Folia caulina sessilia, non amplexicaulia.

I. Folia caulina supcriora linearia, integra 10. B. integrifolia O. E. Schulz

II. Folia caulina superiora oblonga, profunde serrato-incisa

11. B. Urbaniana O. E. Schulz 
9. Brassica rapa $L_{\text {. }}$ Folia caulina inferiora lyrata, longiuscule petiolata, sed basi dilatata semiamplexicaulia, riridia: lobus terminalis maximus obovatus, apice rotundatus, sinuato-dentatus, laterales $2-3$ multo minores, triangulares; superiora obverse lanceolata vel linearia, acutiuscula, sessilia, basi cordata semiamplexicaulia, repando-dentata vel integra, glauca. Racemus sub anthesi densiusculus, floribus imis alabastra superantibus, dein elongatus, laxus, 25-50-florus. Pedicelli floriferi $10 \mathrm{~mm}$., fructiferi $15 \mathrm{~mm}$. longi. Flores $6-8 \mathrm{~mm}$. longi. Petala flava, obovata, apice rotundata, in unguiculum fere aequilongum sensim cuneato-angustata. Stamina interiora $6 \mathrm{~mm}$., exteriora $4 \mathrm{~mm}$. longa. Pistillum cylindricum; ovarium 24-ovulatum, in stylum 1,5 mm. longum contractum; stigma capituliforme, stylo sublatius. Siliquae pedicellis fere horizontalibus, crassiusculis insidentes, erecto-patentes, late lineares, $50-54 \mathrm{~mm}$. longae, $3,5 \mathrm{~mm}$. latae, in stylum $15-17 \mathrm{~mm}$. longum subuliformem longitudinaliter 3 -nerrem viridem attenuatae; stigma $0,5 \mathrm{~mm}$. latum, stylo sublatius; ralvae conrexae, flaridae, longitudinaliter 3-nerves, nerro medio crasso, lateralibus tenuioribus, anastomosantibus. Semina minutissime tuberculata. Cotyledones conduplicatae.

Brassica rapa L. Spec. I edit. II (1753) p. 666; DC. Syst. Nat. II p. 590 et Prodr. I p. 214.

Brassica campestris L. l.c.; Robins. in Gray Synopt. Flor. I, I p. 133.

Radix annua rel biennis. Caulis $50-90 \mathrm{~cm}$. altus, ramosus, ca. 8 -folius, \pm disperse setulosus, pruinosus, acutangulus. Folia inferiora $10-12 \mathrm{~cm}$., superiora $6-10 \mathrm{~cm}$. longa, omnia \pm subtus in nerris disperse setulosa. Pedicelli saepe setigeri, floriferi erecto-patentes. Sepala $4 \mathrm{~mm}$. longa, oblonga, glabra, denique patentia. Antherae $1,5 \mathrm{~mm}$. longae, oblongae. Pistillum glabrum. Siliquae torulosae. Semina $1 \mathrm{~mm}$. longa et lata, $0,5 \mathrm{~mm}$. crassa, obscure fulva; funiculus $1 \mathrm{~mm}$. longus, angriste alatus. Cotyledones obverse reniformes.

Introducta in Haiti: Picarda n. 93. - Patria dubia, probabiliter regio mediterranea. Planta frequenter colitur.

10. Brassica integrifolia (West) O. E. Schulz. Folia caulina inferiora late oborata, in petiolum cuneato-angustata, utrinque inaequaliter grosse $12-15$-dentata, saepe basi lobulis parce dentatis decurrentibus instructa; media oblonga, obtusiuscula, utrinque minute ca. 8-dentata; superiora linearia, obtusiuscula, in petiolum brevem, sed bene conspicuum angustata, integerrima. Racemus sub anthesi laxiusculus, postea laxus, $30-40$-florus. Pedicelli floriferi $6-8 \mathrm{~mm}$. longi, fructiferi rix elongati. Flores $6-9 \mathrm{~mm}$. longi. Petala dilute flava; lamina late obovata vel fere orbicularis, in unguiculum linearem, fere aequilongum subito angustata. Stamina interiora 5,5-6,5 $\mathrm{mm}$., exteriora 
4-5 mm. longa. Pistillum cylindricum; ovarium 12 - 18-ovulatum, in stylum tenuem, aequilongum, ca. $2 \mathrm{~mm}$. longum attenuatim; stigma capituliforme, stylo latius. Siliquae pedicellis erecto-patentibus insidentes, suberectae vel eresto-patulae, lineares, torulosae, $30-35 \mathrm{~mm}$. longae, $1,5-2 \mathrm{~mm}$. latae, in stylum tenuem, $3-6 \mathrm{~mm}$. longum subabrupte attenuatae; stigma $0,33 \mathrm{~mm}$. latum, stylo paulo latius; valvae convexae, longitudinaliter 3-nerves, nervo medio crasso, lateralibus tenuioribus, serpentino-flexuosis, hinc illine anastomosantibus, flavidogriseae. Semina vix tuberculata. Cotyledones conduplicatae.

Sinapis integrifolia H. West Bidl. St. Croix (1793) p. 2.96; Willd.! Mort. Berol. (1816) tab. 15; DC. Syst. Nat. II p. 612 et Prodr. I p. 218. Sinapis lanceolate I) (: Syst. Nat. II (1821) p. 611 et Prode. I p. 218.

Raphames lanceolatus DC. Syst. Nat. II (1S21) P. G11; Macfad. Fl. Jam. I p. 31, - non Willd.

Simmpis nigra Descomt. Fl. Méd. Ant. TT (182S) 1. 207 tab. 4.30, - 11011 L.

Mrassica Willdenowii Inoiss. in Ammal. Sciene. Tht. 2. sér. IVII (1842) $1 \% .88$.

Simapis massicata Girsel. Flor. (1859) p. 1t; Egg. St. Cioix and Tirg. 1sl. 1. 24; Bello 1p. 1 11. 235 11. 18; Stahl! Fist. II 1. 184, -. noul $L$.

Brassicn lanceolnta Lange! Fl. Danien XLT (1861) tal. 2658 et in Bot. Tidsslir. XVII 1. 170; Sall. C'ul. 11. 43 \%. 3.

Simupis juncere Eichl. in Mart. Fl. Bras. XIII, 1 (1865) 1) 306 , - $11012 \mathrm{~L}_{\mathrm{s}}$.

Brassica arrensis O. Kunt:e var. B. jumeen O. Kuntse lieris. I (1S:)1) 1). 19.

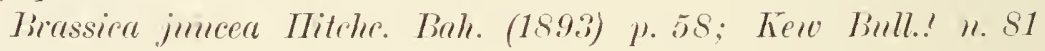
p. $236,-110 n$ Coss.

simapi fol. suluotmulis servatis sloume Cat. (1696i) 1. 79 et Hist. I p. 193 t. 123 f. 2 !

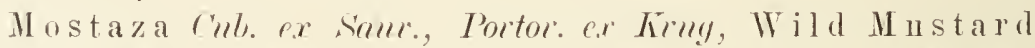
St. Thom., Isarbal., Trinid., st. Tine. ex rariis, Mo u t a rde Martin. ex. Dilss.

Tota planta glanca. Radix amnua. Canlis $30-80 \mathrm{~cm}$. altus, a medio longe ramosus, ra. 8-folins, glaher vel basi pilis parcissimis obsitus. Folia canlina inferiora $8-28 \mathrm{~cm}$., superiora $4-8 \mathrm{~cm}$. longa, omnia albovenosa, glabra. Pedicelli floriferi erecto-patentes, filiformes. Sepala $4-5 \mathrm{~mm}$. longa, ollonga, ea. 3-nervia, margine rix hyalina. Antherae 1,8 mm. longae, anguste oblongae. Semina $1,3 \mathrm{~mm}$. longa, $1 \mathrm{~mm}$. lata, 0,75 mm. crassa, brevi-elliptica, obscure brunea; funienlus $1 \mathrm{~mm}$. longns, anguste alatus. Cotyledones obrerse reniformes. 
Quasi spontanea in ruderatis, campis, incultis, ad vias, interdum culta: Jamaica: ex Macfad. l. c.; Portorico prope Mayagïez: Krug n. 24, prope Coamo circa San Ildefonso: Sintenis n. 3320, prope Adjuntas ad ripam fluminis La Cidra: idem n. 4008, prope Manatí in litoralibus: idem n. 6696, prope Maricao ad cementerio: idem n. 29s, prope Bayamon culta: Stahl n. 749 ; St. Thomas et St. Jan: ex Eggers; St. Croix: Ricksecker n. 128, 336; Guadeloupe: Duchassaing, Bertero n. 43, Duss n. 2299; Martinique: Duss n. 1785; St. Vincent 500 m. alt.: Smith n. 137, prope Calliaqua: Eggers n. 7012; Bequia: Eggers n. 7070 ; Barbados prope St. Andrews: E. H. L. Krause n. 48, in Joës River Wood ad radices montis Hacketts Cliff: Eggers n. 7266; Trinidad in Dibi Valley: Broadway n. 4776. - Patria Asia australis et orientalis. - Flor. Aug.-April.

Obs. I. Sinapis juncea L. Spec. I ed. II p. 668 species duas continet: altera quoad iconem PADLI Hermanxi laudatam (Paradisus Batarus 1698 p. 230 tab. 94): Sinapi indicum maximum lactucae folio certe ad plantam supra descriptam pertinet, altera ex notis in Horto Tpsal. a Lidxaco ipso indicatis: „Folia inferiora obverse ovata, lacera, subtus scabra, fere rapiformia, superiora lanceolata, integerrima, indivisa, utrinque glabra " est species alia, quae in Rossia meridionali et Asia centrali habitat $=$ Brassica juncea (L.) Cosson Appendix Fl. Juvenalis I in Bull. Soc. Bot. Fr. VI (1859) 1. $609=$ Sinapis juncea L. Spec. I edit. II (1753) p. 668 (excl. ic. P. Herm. tab. 94). Ulterior differt a Brassica integrifolia O. E. Schnlz caule et foliis inferioribus basi sultusque disperse setulosis, foliis inferioribus basi lohis 2-4 magnitudine decrescentibus profunde pinnatifidis, siliquis longioribus, $32-56 \mathrm{~mm}$. longis, $2-2,5 \mathrm{~mm}$. latis, in styhum $8-9,5 \mathrm{~mm}$. longum sensim attenuatis.

Obs. II. Sinapis brassicata L. Syst. Nat. XII edit. III (1768) p. 231 a Brassica integrifolia 0. E. Schulz et Brassica juncea Cosson foliis summis amplexicaulibus longe recedit.

11. Brassiea Irbaniana O. E. Schulz. Recedit a B. integrifolin O. E. Schulz notis sequentibus: Caulis humilior, $35-60 \mathrm{~cm}$. altus. simplex vel parce ramosus, ca. 5 -foliatus. Folia caulina inferiora obovata, utrinque inaequaliter profunde ca. $6-8$-inciso-dentata, ad basin cuneatam lobis majoribus dentatis fere pinnatifida, subtus manifeste setulosa, 6-12 cm. longa, superiora evidenter petiolata, anguste ovata vel oblonga, utrinque dentibus ca. 3 saepe rursus denticulatis profunde serrato-dentata, $4-6 \mathrm{~cm}$. longa. Racemus ca. 20 -florus. Petala obscurius flava (ex. Lixwako alba!?), in siceo albescentia, obovata, ar hasin panlatim cuneato-angustata. Antherae $1,5 \mathrm{~mm}$. longae. Ovarium 12-16nvulatum. Siliquae maturae mili non visae.

Sinapis chinensis L. Mant. Ilant. I (176i5) 1. 95; DC. Syst. Nat. II p.613 et Prodr. I 1. 219, - "non Bretssian chimensis L. Amoen. Ac. IT (1759) p. 280 (spec. adhue dubia). 
Mostaza Cub. ex. ligg.

Quasi spontanea in Cuba prope Jagüey m. April. fl.: Eggers n.5141; Haiti prope Morne Bellance, 800 m. alt. m. Jul. fl.: Buch n. 661. Patria Clinia (ex I.).

Obs. Specimina Indiae occidentalis cum icone Petri Arnumi a Linnaeo citata (Animadv. Bot. Specim. I 1759 tab. 10) bene congr'unut.

\section{Raphanus L.}

12. Raphanus sativus L. Radix annua vel biennis. Folia inferiora lyrata, breviter petiolata; lobus terminalis obovatus vel orbicnlatus, inaequaliter minute dentatus, laterales pauci $(2-3)$, multo minores, triangulares; superiora minora, simplicia, anguste orata vel lanceolata, acuta, ad basin cuneato-angustata, utrinque manifeste vel grosse dentata. Racemus sub anthesi laxiusculus, postea valde elongatus, laxissimus, 12-20-florus. Pedicelli floriferi $5-6 \mathrm{~mm}$. longi, fructiferi vix elongati, $8 \mathrm{~mm}$. longi, crassi. Flores majusculi, $9-15 \mathrm{~mm}$. longi. Petala alba vel violacea, obscurius venosa; Jamina obovata, apice truncata vel leviter emarginata, patula, in unguiculum linearem, aequilongum contracta. Stamina interiora $8-10 \mathrm{~mm}$, exteriora $6-8 \mathrm{~mm}$. longa. Pistillum cylindricum, brevissime pilosum; ovarium 4-8-ovulatum, in stylum $2 \mathrm{~mm}$. Jongum attenuatum; stigma subbilobum, stylo sublatius. Siliquae pedicellis brevibus, erecto-patentibus insidentes, suberectae, magnae, $36 \mathrm{~mm}$. longae, 6,5 mm. latae, tumidae, fungosae, non dehiscentes, cylindricae, conice attenuatae, longitudinaliter nerrosae, dilute bruneae, disperse breviter adpresse pilosae; stigma $0,5 \mathrm{~mm}$. latum, stylo aequilatum. Semina valde compressa, foveato-punctata. Cotyledones conduplicatae, inaequales.

Raphanus sativus L. Spec. Plant. I edit. II (1753) p. 669; DC. Syst. Nat. II p. 663 et Prodr. I p. 228; Robins. in Gray Synopt. Flor. I, 1 p. 133.

Caulis $30-50 \mathrm{~cm}$. altus, ramosus, ca. 6 -folius, disperse pilis recurvatis obsitus. Folia inferiora $6-10 \mathrm{~cm}$., superiora $3-6,5 \mathrm{~cm}$. longa, omnia disperse pilosa. Pedicelli floriferi erecto-patentes. Sepala $5-7 \mathrm{~mm}$. longa, erecta, oblonga, basi vix siccata, dorso setulosa. Antherae 1,5 mm. longae, oblongae. Glandulae minutae. Semina $3,5 \mathrm{~mm}$. longa, $3 \mathrm{~mm}$. lata, $0,75 \mathrm{~mm}$. crassa, fere orbicularia, obscure fulva; funiculus $1-1,5 \mathrm{~mm}$. longus, dilatatus. Cotyledones obrerse reniformes.

Quasi spontaneus in St. Thomas ad habitationes et in ruderatis m. August. flor et subfr.: Eggers ed. 'Toepff. n. 980. - Patria Asia. In lortis vulgatissima. 


\section{Nasturtium R. Br.}

Conspectus specierum.

A. Petala sepalis duplo longiora. Pedicelli fructiferi $7-14 \mathrm{~mm}$. longi

13. $N$. fontanum Aschers.

B. Petala sepalis paulo longiora vel aequilonga vel breviora, interdum nulla. Pedicelli fructiferi $1,5-8 \mathrm{~mm}$. longi.

I. Fructus slobosi vel breviter elliptici, 2-5 mm. longi. Petala bene conspicua.

a. Folia caulina pinnata; foliola linearia, integra. Siliculae pedicello $2-3$-plo breviores. Semina cancellata

14. N. pyrenaicum R. Br.

b. Folia caulina simplicia, oblonga, grosse dentata. Siliculae pedicello

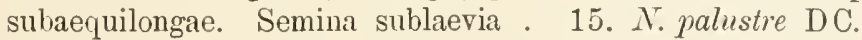

II. Fructus lineares, $4-25 \mathrm{~mm}$. longi. Petala vix conspicua vel deficientia.

a. Siliquae 4-10 $\mathrm{mm}$. longae, erecto-patentes. Folia pinnata. Petala minutissima . . . . . . . 16. N. brevipes Griseb.

b. Siliquae $25 \mathrm{~mm}$. longae, horizontales. Folia simplicia, ad basin lyrato-pinnatifida. Petala nulla . 17. N.heterophyllum Blume.

13. Nasturtium fontanum (Lam.) Aschers. Planta perennis. Caulis decumbens, ex axillis radicans, superne adscendens. Folia pinnata, $1-3-$ juga; inferiora longe petiolata: foliolum terminale orbiculatum, parce repandum, manifeste petiolulatum, lateralia proxima duplo minora, sensim magnitudine decrescentia, inaequilatera, sessilia; superiora brevius petiolata, saepe basi foliolis minutis auriculata: foliola brevi-ovata, caeterum similia. Racemus sub anthesi congestus, dein elongatus, laxus, $30-50$-florus. Pedicelli floriferi $3-4 \mathrm{~mm}$., fructiferi $7-14 \mathrm{~mm}$. longi. Flores 3,5-4 mm. Jongi. Petala alba, obovato-cuneata, patula. Stamina 6 , interiora $3 \mathrm{~mm}$, exteriora 2,5 mm. longa. Pistillum cylindricum; ovarium 32 -ovulatum; stigma subsessile, ovario aequilatum. Siliquae pedicellis horizontalibus vel deflexis insidentes, horizontales, subcurvatae, late lineares, $15-18 \mathrm{~mm}$. longae, $1,5 \mathrm{~mm}$. latae, in stylum $0,5-1 \mathrm{~mm}$. longum subito contractae; valrae griseo-virides. Semina numerosa, cancellata, pleurorrhiza.

Nasturtimm fontamm Aschers. Fl. Prov. Brandenb. (1864) p. 32. Cardamine fontana Lam. Encycl. II (1786) p. 185.

Sisymbrimm Nasturtimm L. Spec. I. edit. II (1753) p. 657.

Nasturtinm officinale R. Br. in Ait. Hort. Kew. 2. edit. IT (1812) p. 110; DC. Syst. Nat. II p.188 et Prodr. I p. 13\%; Macfad. Fl. Jam. I p. 24; Griseb. Flor. p. 13 et Cat. p. 5; Eichl. in Mart. Fl. Bras. XIII, 1 p. 29s; Egg. Fl. St. Croix and Firg. Isl. p. 24; Stahl Est. II p. 36; Chapm. Fl. South. Unit. Stat. 2. edit. p. 25; Robins. in Gray Synopt. Flor. I, 1 p. 146: Duss Flor. Ant. franc. p. 10. 
Nesturtium roridulum Bello! Ap. I (1S81) p. 236 u. 19; Krug Ic. t. 259.

Curdamine Nasturtium O. Kuntre Retis. I (1891) p. 22.

Nasturtium aquaticum vulgare Sloane Cat. (1696) p. 59 et Hist. I p. 193.

Berros Portor. ex Krng el Sint.; Water-cress St. Thom. et St. Croix ex Egg.; Cresson de fontaine Mart. ex Duss.

Caulis $20-40 \mathrm{~cm}$. longus, a basi ramosus, dense ca. 15 -folius, fistulosus, glaber. Folia ima rarius simplicia, inferiora $5,5-10 \mathrm{~cm}$. longa: foliolum terminale $12-34 \mathrm{~mm}$. diam., superiora $4-8 \mathrm{~cm}$. longa: foliolum terminale $14-35 \mathrm{~mm}$. longum, $6-25 \mathrm{~mm}$. latum; omnia glabra. Pedicelli floriferi suberecti. Sepala $2 \mathrm{~mm}$. longa, oblonga, ca. 3 -nervia, viridia, dorso pilosula. Antherae $0,5 \mathrm{~mm}$. longae. Ovula alata. Stigua siliquarum 0,33 mm. latmm, stylo aequilatum. Semin a $0,75 \mathrm{~mm}$. longa, $0,5 \mathrm{~mm}$. lata et crassa, brevi-elliptica, angustissime v. vix conspicue alata, fulva.

Hab. in Cuba: Wright n. 7, in fluvio San Juan: Rugel n. 234, in distr. Cienfuëgos prope Cieneguita: Combs n. 156; Jamaica: ex Macfadyen 1. c.; Portorico prope Mayagiiez: Krug n. 25, prope Adjuntas ad ripam fluminis circa haciendam Rosario ad Guillarte: Sintenis 11. 4606, in humidis montis Cienega ad La Lucia: idem n. 4116, prope Cayey ad flumen circa montem Cedro: idem n. 2185; St. Thomas et St. Croix (inquil.): ex Eggers; Dominica: ex DC.; Martinique (inquil.): ex Duss; St. Vincent prope Kingstown etc. 333 m. alt.: Smith n. 1590. Fere totus orbis terrarum.

Obs. Pleraque Antillarum specimina ad formam microphyllam Reichenb. (Icon. Fl. German. I p. 15 tab. 50 fig. 4360) spectant.

14. Nasturtium pyrenaicum (L.) R. Br. Planta perennis. Radix descendens, multiceps. Caulis erectus. Folia rosulata ima longe petiolata, simplicia, obovata, apice rotundata, ad basin in petiolum cuneatoangustata, integra vel utrinque, praesertim ad basin, \pm profunde $4-5-$ crenata, sequentia breviter petiolata, pinnata, $2-8$-juga: foliolum terminale breviter obovatum vel fere orbiculatum, apice rotundatum, ad basin cuneatum, integrum, rarius utrinque ca. 4 -crenulatum, sessile, cum lateralibus proximis \pm confluens, lateralia sensim magnitudine decrescentia, \pm alteria, oborata vel oblonga, crenulata vel integra, basi lata sessilia, ima minutissima; folia caulina liversa, sessilia, 4-8-juga, basi auriculis linearibus amplexicaulibus praedita: omnia foliola anguste linearia, integra, rarius hic illic 1-2-deutata. Racemus sub anthesi densus, corymbosus, dein elongatus, laxiusculus, 25-35-florus. Pedicelli floriferi $3,5-6 \mathrm{~mm}$., fructiferi $6-9 \mathrm{~mm}$. longi. Flores $2,2-2,5 \mathrm{~mm}$. longi. Petala dilute flava, oblonga, apice rotundata, ad basin cuneatoangustata, erecto-patentia. Stamina 6 , interiora ca. $2,5 \mathrm{~mm}$. longa, petalis 
aequilonga, exteriora paulo breviora, 2 mm. Longa. Ovarium ovatum, 8-12-ovulatum, in stylum $0,75 \mathrm{~mm}$. longum, filiformem subito attenuatum; stigma subbilobum, stylo aequilatum. Siliculae pedicellis erectopatentibus vel fere horizontalibus insidentes, ovales, $3-4 \mathrm{~mm}$. longae, 1,2 - 1,5 nım. latae, ca. $1 \mathrm{~mm}$. crassae, stylo $1-1,5 \mathrm{~mm}$. longo, filiformi apiculatae; valvae convexae, flavido-virides vel rubellae. Semina cancellata, pleurorrhiza.

Nasturtium pyrenaicum R. Br. in Ait. Hort. Kew. 2. edit. IV (1S12) p. 110; DC. Syst. Nat. II p. 196 et Prodr. I p. 138.

Sisymbrim pyrenaicum L. Syst. Not. 10. edit. (1759) p. 1132.

Brachylobus domingensis Desv.! Jomrn. Bot. III (1814) p. 183.

Sisymbrim domingense Poiret! in Lam. Encycl. Suppl. V (1818) p. 161 .

Nastmrtium pyrenaicum R. Br. var. 3. DC.! Syst. Nat. II (1821) 1). 196 .

Cardamine pyrenaica O. Truntie Rev. I (1891) p. 26.

Radix longe perpendiculariter descendens. Caulis $15-30 \mathrm{~cm}$. altus, superne ramosus, dense $8-15$-folius, ad basin brevissime pilosus. Folia rosulata $2,5-4,5 \mathrm{~cm}$. longa: foliolum terminale $6-8 \mathrm{~mm}$. diam.; caulina media $2-4,5 \mathrm{~cm}$. longa: foliolum terminale $8-21 \mathrm{~mm}$. longum, $0,75-1 \mathrm{~mm}$. latum; onnia disperse pilosa, ad auriculas ciliata. Pedicelli erecto-patentes. Sepala 1,5-1,8 mm. longa, oblonga, 3-nervia, pallide viridia, glabra. Antherae $0,3 \mathrm{~mm}$. longae. Valvulae vix conspicue nerrosae; stigma minutissimun, 0,2 nm. latum, stylo vix latins. Semina minuta, 0,75-1 mm. longa et lata, $0,4 \mathrm{~mm}$. crassa, orbicularia, non alata, obscure purpurea vel nigricantia. Europa.

Hab. in. Sto. Domingo: Desportes (hb. Juss. n. 11026 A). - Patria

Obs. Hanc speciem ex Gallia casu in Hispaniolam esse introductam haud dubito.

15. Nasturtium palustre (Leyss.) DC. Syst. Nat. II (1821) p. 191 et Prodr. I p. 137; Chapm. Fl. South. Unit. Stat. 2. edit. p. 25.

Sisymbrium palustre Leyss. Fl. Hal. 1. edit. (1761) p. 166.

Cardamine palustris O. Kuntre Revis. I (1S91) p. 21.

Area geogr.: Europa, Asia et America septentrionales.

Subsp. hispidum (Desv.) Fisch. et Mey. Caulis erectus, \pm hirsutus. Folia inferiora anguste obovata vel obverse lanceolata, apice obtusiuscula, superne inaequaliter dentata, ad basin cuneatam pinnatifida, evidenter petiolata, sed basi petioli raginato-dilatata; superiora minora, angustiora, oblonga, ad basin grosse dentata, auriculis obtusis curvatis semiamplexicaulia; omnia utrinque sparse pilosa. Racemus sub anthesi brevissimus, dein valde elongatus, laxiusculus, ca. 80 -florus. Pedicelli floriferi 1,5 mm., 
fructiferi 2,5-3 mm. longi. Flores $1,5 \mathrm{~mm}$. longi. Petala albida?, sepalis aequilonga, oborato-cuneata, apice truncata. Stamina 6 , interiora petalis aequilonga, exteriora vix breviora. Pistillum latum; ovarium ovale, 20 - 40-ovulatum, in stylum brevissimum subito contractum; stigma stylo vix latius. Siliculae pedicellis erecto-patentibus insidentes, globosae vel breviter ellipticae, $2-2,5 \mathrm{~mm}$. diam.; stylus $0,5 \mathrm{~mm}$. longus; stigma stylo aequilatum; valvae griseo-virides. Semina minutissima, vix conspicue reticulato-nervosa, pleurorrhiza.

Nasturtium hispidum. DC. Syst. Nat. II (1821) p. 201.

Brachylobus hispidus Desv. Joum. Bot. III (1S14) p. 183.

Nasturtium terrestre (With.) R. Br. var. hispidum Fisch. et Mey. in Ind. Sem. Hort. Petrop. III (1837) p. 41; Robins. in Gray Synopt. Flor. 1,1 p. 148.

Radix annua vel biennis. Caulis $20-40 \mathrm{~cm}$. altus, superne breviter ramosus, dense $10-15$-folius, superne acutangulus. Folia infcriora saepe approximata, inferiora $8-10 \mathrm{~cm}$., superiora $3-4 \mathrm{~cm}$. longa. Pedicelli floriferi erecto-jatentes. Sepala ovata, obtusa, ca. 5-nervia, dorso pilosula, viridia. Semina $0,5 \mathrm{~mm}$. longa, $0,4 \mathrm{~mm}$. lata, $0,33 \mathrm{~mm}$. crassa, fere orlicularia, dilute fulva.

Hab. in Haiti prope Petite rivière de l'Artibonite m. April. flor. et fruct.: Picarda n. 1575 .

Var. $\beta$. glabrum O. E. Schulz. Tota planta fere glabra. Folia majora, inferiora ca. $25 \mathrm{~cm}$. longa, suprema linearia et integra. Pedicelli longiores. Petala sepalis paulo longiora. Siliculae $5 \mathrm{~mm}$. longae, 2, $5 \mathrm{~mm}$. latae.

Nasturtium palustre Griseb. Cat. (1866) p. 6.

Hab. in Cuba: Wright n. 1862.

Obs. Nasturtium pahustre (Leyss.) DC. typicum caule foliisque glabris, petalis brevioribus, fructibus longioribus, oblongis gaudet.

16. Nasturtium brevipes (DC.) Griseb. Planta annua. Caulis a basi ramosus. Folia profunde, plerumque interrupte pinnatifida; inferiora manifeste petiolata: lobus terminalis obovatus, 3 -crenatus vel 3 -crenato-lobulatus, laterales utrinque ca. 8 alterni, magnitudine decrescentes, late oblongi, praesertim latere inferiore ca. 3 -sinuato-crenati vel profundiuscule crenato-lobulati; superiora breviter petiolata, minora, utrinque lobis lateralibus ca. 4 praedita, caeterum similia. Racemus sub anthesi brevissimus, vix conspicuus, postea valde elongatus, 15-22florus. Pedicelli brevissimi, floriferi $0,5 \mathrm{~mm}$., fructiferi $1,5 \mathrm{~mm}$., raro imi-4 $\mathrm{mm}$. longi. Flores minimi, 1,5 $\mathrm{mm}$. longi, interdum apetali. Petala 2 sepalis triplo breviora, $0,5 \mathrm{~mm}$. longa, oblongo-cuneata, albida. Stamina 4, raro 5, $1 \mathrm{~mm}$. longa. Pistillum late cylindricum; orarium 72-160- 
ovulatum, in stylum brevissimum subito contractum; stigma stylo latius. Siliquae pedicellis brevissimis insidentes, erecto-patentes, imae interdum fere horizontales, $7-10 \mathrm{~mm}$. longae, 1,5-2 mm. latae, late cylindricae, obtusae; stigma sessile, $0,5 \mathrm{~mm}$. latum, albidum; valvae griseo-virides. Semina numerosa, reticulato-foreolata, pleuror'hiza.

Nasturtium brevipes Griseb.! Pl. Wright. I (1860) p. 15 tet Cat. p. 6.

Nasturtium palustre DC. var. $\varepsilon$ ? brevipes DC. Syst. Nat. II (1821) p. 192 ct Prodr. I 1. 137.

Nasturtium portoricense Spreng. Syst. II (1825) p. 882.

Cardamine palustris O. Kuntre a. brevipes O. Kuntre Revis. I (1891) p. 24.

Nasturtium tanacetifolinm (Walt.) Hook. et Arn. var. insulamm Rolins. in Gray Synopt. Flor. I, 1 (1895) p. 149.

Caulis $15-30 \mathrm{~cm}$. longus, diffusus, $2-5$-folius, glaber vel basi parce adpresse pilosus. Folia omnia glabra, 5,5-12 cm. longa. Racemus fructifer ca. $8-12 \mathrm{~cm}$. longus. Pedicelli floriferi erecti. Sepala $1,5 \mathrm{~mm}$. longa, late oblonga, obtusa, viridia, ca. 3 -nervia, vix pilosula. Antherae $0,3 \mathrm{~mm}$. longae. Glandulae deficientes. Valrae interdum rubellae, subtiliter reticulato-nervosae. Semina $0,5 \mathrm{~mm}$. longa, $0,33 \mathrm{~mm}$. lata, $0,25 \mathrm{~mm}$. crassa, late oblonga, dilute fulva; funiculus $0,3 \mathrm{~mm}$. longus, filiformis.

Hab. praesertim ad fossas in Cuba: Poeppig; Sto. Domingo: Prenleloup n. 7; Portorico prope Bayamon: Stahl n. 848 , prope Barceloneta juxta flumen Azul ad Florida: Sintenis n. 6711, prope Cabo-Rojo circa haciendam Carmelita: idem n. 699, prope Añasco in litoralibus: idem 11. 5625, prope Adjuntas circa haciendam Guillarte et ad Utuado versus: idem n. 4033, 4033 b. - Flor. Dec.-Maj.

Var. $\beta$. pumilum O. E. Schulz. Caulis $5-15 \mathrm{~cm}$. altus, aphyllus vel 1-2-foliatus. Folia inferiora rosulata, $4 \mathrm{~cm}$. longa. Racemus pauci(ca. 12-) florus. Ovarium ca. 56-ovulatum. Siliquae minores, saepe $4-5 \mathrm{~mm}$. longae.

Hab. in Cuba: Wright n. 1562, in Yumury valle: Rugel n. 235.

Obs. I. Nasturtium palustre (Leyss.) DC. caule crasso elato, foliis numerosis semiamplexicaulibus, pedicellis longioribus, petalis 4 , staminibus 6 , ovulis pancioribus (ca. 32) etc. longe recedit. Sed nonnullae species ralde affines terram continentem americanam incolentes ( $N$. obtusum Nutt. etc.) forma foliorum, pedicellis longioribus, staminibus 6 a specie nostra aegerrime sunt distinguendae.

Obs. II. Cl. Robisson 1. c. speciem nostram sub nomine var. insularum immerito cum Nasturtio tanacetifolio (Walt.) Hook. et Am. comnexit.

17. Nasturtium heterophyllum Blume. Planta annua. Caulis humilis. Folia inferiora longe petiolata, breviter ovata, apice rotumdata, ad basin subcuneata, utrinque ca. 8-repando-dentata, superiora 
brerius petiolata, saepe majuscula, anguste ovata, acutiuscula, denticulata, ad basin pinnatifida, summum sessile, angustum. Racemus sub anthesi brevis, densus, dein elongatus, laxus, 10-15-florus. Pedicelli floriferi $1-1,5 \mathrm{~mm}$. longi, fructiferi breves, $3 \mathrm{~mm}$. longi. Flores $1,8 \mathrm{~mm}$. longi, apetali. Stamina 6 , interiora $1,5 \mathrm{~mm}$. longa, exteriora vix breviora. Pistillum lineare; ovarium 64-ovulatum, in stylum brevissimum vix attenuatum; stigma stylo aequilatum. Siliquae pedicellis horizontalibus insidentes, horizontales, anguste lineares, strictae, teretes, $25 \mathrm{~mm}$. longae, $0,75 \mathrm{~mm}$. latae; stylus $0,5 \mathrm{~mm}$. longus; stigma manifestum, stylo subaequilatum; valvae virides. Semina minuta, numerosa, subtiliter tuberculata, pleurorrhiza.

Nasturtium heterophyllum Blume! Bijdr. Fl. Nederl. Ind. II St. (1825) p. 50.

Radix majuscula, ramosa. Caulis $2,5-15 \mathrm{~cm}$. longus, erectus vel adscendens, a basi patenter ramosus, $3-4$-foliatus, valde flexuosus, glaber. Folia glabra, inferiora $5-6,5 \mathrm{~cm}$. longa, lamina $30: 22 \mathrm{~mm}$., superiora $3,5-4,5 \mathrm{~cm}$. longa, lamina $30-40: 18-20 \mathrm{~mm}$. Pedicelli floriferi erecto-patentes. Sepala erecta, anguste oblonga, ca. 3 -nervia, viridia, glabra. Antherae oblongae, $0,5 \mathrm{~mm}$. longae. Semina $0,75 \mathrm{~mm}$. longa, $0,5 \mathrm{~mm}$. lata, 0,2 $\mathrm{mm}$. crassa, rectangula, obscure brunea, anguste alata.

Hab. in Trinidad: Bot. Gard. Herb. n. 853. - Brit. Guiana prope Georgetown: Jenman n. 5866. Regiones tropicae Asiae et Americae.

\section{Cardamine L.}

Conspectus specierum.
A. Folia trifoliolata .
18. C. africana L.
B. Folia pinnata.

I. Petala $6,5-8 \mathrm{~mm}$. longa, plerumque violacea

19. C. Jamesonii Hook.

II. Petala 1,5-4 mm. longa, alba, interdum nulla.

a. Folia caulina basi non auriculata.

1. Canlis vix flexuosus, basi petioli ciliatus, caeterum plerumque glaber. Folia caulina rosulatis minora. Stamina fere semper 4. Siliquae rhachidi \pm accumbentes, infimae flores superiores superantes . . . . . . . . 20. C. hirsuta L.

2. Caulis flexuosus, \pm hirsutus. Folia caulina superiora inferioribus majora. Stamina 6. Siliquae erecto-patentes, infimae flores superiores non superantes . 21. C. flexuosa With.

b. Folia caulina basi auriculata . . . 22. C. impatiens L.

18. Cardamine africana L. Folia majuscula, omnia longe petiolata, trifoliolata; foliolum terminale ovatum, acuminatum, basi rotundatum, utrinque 4-8-crenato-serratum, manifeste petiolulatum, lateralia similia, paulo minora, basi inaequilatera, brevius petiolulata. Racemus 
sub anthesi brevissimus, dein elongatus, $6-15$-florus. Pedicelli floriferi $0,5-1,5 \mathrm{~mm}$. longi, fructiferi valde elongati, $3-12 \mathrm{~mm}$., plerumque $6 \mathrm{~mm}$. longi. Flores minuti, $3-4 \mathrm{~mm}$. longi. Petala alba, oblongocuneata, apice rotundata. Stamina interiora $3 \mathrm{~mm}$, exteriora $2,5 \mathrm{~mm}$. longa. Pistillum cylindricum; orarium $S-16$-ovulatum, in stylum crassum, ca. $0,5 \mathrm{~mm}$. longum subattenuatum; stigma stylo paulo latius. Siliquae congestae, perlicellis erecto-patentibus, crassis insidentes, suberectae, lineares, 25-43 $\mathrm{mm}$. longae, fere $2 \mathrm{~mm}$. latae, in stylum plerumque $1 \mathrm{~mm}$. longum, crassum attenuatae; ralvae viridulo-bruneae; stigma conspicuum. Semina pleurorrhiza, laevia.

Cardamine africana L. Spec. 1. edit. II (1753) p. 655; DC. Syst. Vat. II p. 252 et Prodr. I p. 150.

Radix flexuosa, longe ramosa. Caulis per multos annos successite ex axillis foliorum inferiorum se renovans, $10-40 \mathrm{~cm}$. longus, e basi decumbente et radicante adscendens, $3-6$-foliatus, superne plerumique longe nudus, glaber. Folia ca. $9 \mathrm{~cm}$. longa, disperse pilosa; foliolum terminale $4-5 \mathrm{~cm}$. longuu. Sepala $2,5-3 \mathrm{~mm}$. longa, oblonga, erecta. Antherae $0,5 \mathrm{~mm}$. longae, oblongiusculae. Semina $2 \mathrm{~mm}$. longa, $1,5 \mathrm{~mm}$. lata, $0,5 \mathrm{~mm}$. crassa, subrectangulo-oblonga, angustissime alata, \pm dilute fulra; funiculus 0,75 $\mathrm{mm}$. longus, anguste alatus.

Hab. in Sto. Domingo: R. Schomburgk n. 148*. - Praeterea in montibus altissimis regionum tropicarum ab Africa per Indiam orientalem et Javam ad Andes et Brasiliam.

19. Cardamine Jamesonii Hook. Folia caulina inferiora longiuscule petiolata, 2-3-juga: foliolum terminale suborbiculare, basi subcordatum, utrinque inaequaliter et grosse 2-4-crenato-lobulatum, longe petiolulatum, lateralia similia, inaequilatera, manifeste petiolulata; superiora brevius petiolata, 1 -juga: foliola late ovata vel oblongo-ovata. Racemus florifer laxus, dein laxissimus, 8-15-tlorus. Pedicelli floriferi $6-8 \mathrm{~mm}$. longi, fructiferi vix elongati. Flores $6,5-8 \mathrm{~mm}$. Jongi. Petala rosea vel violacea, raro alba, late obovata, apice subtruncata, ad basin breviter cuneato-angustata. Stamina interiora $5-6 \mathrm{~mm}$, exteriora $4,5-5 \mathrm{~mm}$. longa. Orarium 16-ovulatum, in stylum $1-2 \mathrm{~mm}$. longum attenuatum; stigma stylo paulo latius. Siliquae pedicellis erecto-patentibus insidentes, suberectae, lineares, 42-50 $\mathrm{mm}$. longae, 1,5 $\mathrm{mm}$. latae, in stylum 3-5 $\mathrm{mm}$. longum, apice incrassatum attenuatae; valvae viridulo-bruneae; stigma stylo sublatius. Semina pleurorrhiza, laeria.

Cardamisue Jamesonii Hook.! in Lond. Journ. Bot. VI (1817) p. 293.

Caulis ex axillis foliorum inferiorum se renorans, $45-60 \mathrm{~cm}$. longus, adscendenti-erectus, basi radicans, simplex vel longe ramosus, remote $4-9$ folius, glaber, acutangulus. Folia inferiora $5-7,5 \mathrm{~cm}$. longa: foliolum terminale $16: 15 \mathrm{~mm}$. diam., superiora $4,5-5 \mathrm{~cm}$. longa: foliolum terminale 
$18-20: 8,5-9 \mathrm{~mm}$. diam.; omnia parce ciliata vel glabra. Sepala $3,5-4 \mathrm{~mm}$. longa, ovata, ca. 5-nervia, margine hyalina. Antherae $1 \mathrm{~mm}$. longae, oblongae. Semina $1,75 \mathrm{~mm}$. longa, $1,1 \mathrm{~mm}$. lata, $0,5 \mathrm{~mm}$. crassa, oblonga, brunea; funiculus $1 \mathrm{~mm}$. longus, filiformis.

Hab. in Haiti ad fontes: Poiteau (hb. Delessert), in sylvis montis Morne Tranchant $1800 \mathrm{~m}$. alt., m. August. fl. et fr.: Picarda n. 789. Venezuela, Columbia, Ecuador, Bolivia.

20. Cardamine lirsuta L. Folia rosulata numerosa et caulina inferiora longiuscule petiolata, 1-3-juga: foliolum terminale reniforme, 3 -5-crenatum, manifeste petiolulatum, lateralia oblique breviter ovata vel orbiculata, ad basin subcuneata, in petiolulum angustata, obscure 3-crenata vel integra; caulina superiora multo minora, brevius petiolata 2-3-juga: omnia foliola angustiora vel linearia, ad basin in petiolulum cuneato-angustata, ca. 3-crenata. Racemus sub anthesi densus, corymbosus, dein elongatus, laxus, $12-20$-florus. Pedicelli floriferi 1,5-2 mm., fructiferi $5-8 \mathrm{~mm}$. longi. Flores $2,5-3 \mathrm{~mm}$. longi. Petala alba, anguste oborato-cuneata, apice obtusa. Stamina plerumque 4, $2 \mathrm{~mm}$. longa. Ovarium 24-36-ovulatum; stylus vix conspicuus; stigma manifestum, ovario aequilatum. Siliquae pedicellis suberectis, apice incrassatis insidentes, erectae, rhachidi \pm accumbentes, infimae flores superiores superantes, lineares, $18-25 \mathrm{~mm}$., plerumque ca. $20 \mathrm{~mm}$. longae, ca. $1 \mathrm{~mm}$. latae, in stylum $0,3-0,5 \mathrm{~mm}$., rarius $-1 \mathrm{~mm}$. longum, crassiusculum subattenuatae; valvae viridulo-flavae, interdum violaceae; stignra $0,33 \mathrm{~mm}$. latum, stylo fere aequilatum. Semina pleurorrhiza, laevia.

Cardamine hirsuta L. Spec. Plant. I. edit. II (1753) p. 655; DC. Syst. Nat. II p. 259 et Prodi. I p. 152; Griseb. Flor. p. 13; Chapm. Fl. South. Unit. Stat. II. edit. p. 26 (pro parte); Robins. in Gray Synopt. Flor. I, 1 p. 158.

Cardamine syliatica Macfad. Fl. Jam. I (1837) p. 25, - non Liul.

Annua saepe inulticaulis. Caules adscendentes, $10-20 \mathrm{~cm}$. longi, plerumque a basi ramosi, remote $2-6$-foliati, plerumque glabri. Folia rosulata $6-8 \mathrm{~cm}$. longa: foliolum terminale $6-10: 8-15 \mathrm{~mm}$. diam., caulina ca. 2,5 cm. longa: foliolum terminale $6-10: 2-4 \mathrm{~mm}$. diam.; omnia praesertim basi petioli pilis perpaucis longiusculis pilosa. Sepala $1,5 \mathrm{~mm}$. longa, oblonga, dorso parce pilosa. Antherae ca. 0,4 mm. longae. Semina $1 \mathrm{~mm}$. longa, $0,75 \mathrm{~mm}$. lata, 0,2 $\mathrm{mm}$. crassa, subquadrata, obscure brunea, angustissime alata; funiculus $0,5 \mathrm{~mm}$. longus, filiformis.

Hab. in Jamaica ad Quashi Hill $1667 \mathrm{~m}$. alt., m. Januar. fl. et fr.: Eggers n. 3761. - Tota Europa (Rossia excepta), Asia ab Anatolia ad Javam, Africa borealis et media, America boreali-orientalis, Mexico.

21. Cardanine flexuosa With. Arr. Brit. 1\%. 3. edit. III (1796) p. 578 .

Area geogr.: Europa, Jароиia. 
Subsp. penusylvanica (Mühl.) O. E. Schulz. Folia rosulata pauca, sub anthesi saepe desiccata, inferiora longiuscule petiolata, $3-5$-juga: foliolum terminale orbiculare, breviter petiolulatum, obseure 5 -crenatum, lateralia ovata, inaequilatera, sessilia, integra; superiora majora, brevius petiolata, 4-5-juga: foliolum terminale obovatum vel oblongum, ad basin cuneato-angustatum, sessile, apice obtusum, 3-5-lobatum, lateralia oblonga, \pm decurrentia, 1 -dentata. Racemus sub anthesi laxiusculus, dein elongatus, laxus, ca. 20 -florus. Pedicelli floriferi $3-4 \mathrm{~mm}$, fructiferi $7-10 \mathrm{~mm}$. longi. Flores $2-3 \mathrm{~mm}$. longi. Petala alba, anguste oborato-cuneata. Stamina semper 6, interiora 1,8-2,5 mm., exteriora $1,5-2 \mathrm{~mm}$. longa. Ovarium 20-32-0vulatum, vix stylosum; stigma ovario aequilatum. Siliquae pedicellis fere horizontaliter patentibus insidentes, erectae vel erecto-patulae, imae flores superiores non superantes, lineares, ca. $20 \mathrm{~mm}$. longae, $1 \mathrm{~mm}$. latae, in stylum ca. $1 \mathrm{~mm}$. longum attenuatae; valrae stramineae, saepe violaceae; stigma stylo sublatius. Semina pleurorrhiza, laevia.

Cardamine pennsylranica Mïhl.! apud Willd. Spec. Plant. III (1801) p. 486; DC. Syst. Nat. II p. 258 et Prodr. I p. 151; Chapm. Fl. South. Unit. Stat. II. edit. p. 26 (pro parte); Robins. in Gray Symopt. Flor. I, 1 p. 158.

\section{Cresson de savanne Doming. ex Poitean.}

Planta unicaulis, plerumque annua, rarius liennis vel perennis. Caulis $10-40 \mathrm{~cm}$. altus, erectus, ramosus, dense $4-10$-folius, flexuosus, praecipue basi breviter hirsutus, hasi violaceus. Folia membranacea, inferiora $5-7 \mathrm{~cm}$. longa: foliolum terminale $10-12 \mathrm{~mm}$. diam., superiora $7-9 \mathrm{~cm}$. longa: foliolum terminale $25-30: 10-15 \mathrm{~mm}$. diam.; omnia \pm disperse pilosa. Sepala 1,5-1,75 mm. longa, late oblonga, ca. 3-nervia. Antherae $0,33 \mathrm{~mm}$. longae. Semina eis C. hirsutae aequalia.

Hab. in Haiti: Poiteau (hb. Ventenat in hb. Delessert). - America septentr.

22. Cardamine impatiens L. Folia rosulata 2-4-juga, sub anthesi desiccata; caulina 6-9-juga, inferiora longe petiolata, basi petioli breriter auriculata: foliolum terminale breviter ovatum rel suborbiculare, profunde 3-5-inciso-lobulatum, longiuscule petiolulatum, lateralia rix minora, similia, manifeste petiolulata; caulina media et superiora breviter petiolata, auriculis linearibus, acuminatis, ciliatis evidenter auriculata: foliolum terminale anguste ovato- vel lanceolatocuneatum, \pm acutum, 5-lobulatum, lateralia obliqua, similia, 3-5crenato-lobulata, ima saepe minuta, integra, omnia breviter petiolulata. Racemus sub anthesi densissimus, dein elongatus, sed proportionaliter brevis, plerumque ca. 30 -florus. Pedicelli floriferi ca. $2,5 \mathrm{~mm}$., fructiferi $6-10 \mathrm{~mm}$. longi. Flores ca. $2,5 \mathrm{~mm}$. longi, saepe apetali (f. ape- 
tala (ilibert). Petala alba, oblongo-cuneata. Stamina interiora plerumque petalis longiora, 2,75 mm., exteriora 2,5 mm. longa. Orarium 10 - 24-ovulatum, in stylum vix conspicuum subattenuatum; stigma stylo sublatius. Siliquae pedicellis sublorizontalibus insidentes, suberectae, saepe ex statione secundae, lineares, ca. $22 \mathrm{~mm}$. longae, $1 \mathrm{~mm}$. latae, in stylum $0,75 \mathrm{~mm}$. longum attenuatae; valvae stramineae vel purpureae; stigma minutum. Semina pleurorrhiza, laevia.

Cardamine impatiens L. Spec. 1. edit. II (1753) p. 655; DC. Syst. Nat. II p. 261 et Prodr. I p. 152.

Radix biennis, ochroleuca. Caulis $25-50 \mathrm{~cm}$. altus, erectus, simplex rel a basi breviter ramosus, 6-15-foliatus, flexuosus, acutangulus, basi purpureus, glaber. Folia inferiora $4-6 \mathrm{~cm}$. longa: foliolum terminale $6-10 \mathrm{~mm}$. diam., superiora $7-10 \mathrm{~cm}$. longa: foliolum terminale $16-25$ : 10-14 mm. diam.; omnia parce ciliata. Sepala $1,5 \mathrm{~mm}$. longa, allida, oblonga, apice acutiuscula. Antherae viridulae, $0,5 \mathrm{~mm}$. longae. Semina $1,3 \mathrm{~mm}$. longa, fere $1 \mathrm{~mm}$. lata, $0,25 \mathrm{~mm}$. crassa, oblongo-elliptica, angustissime, praecipue basi, alata, fulva; funiculus $0,3 \mathrm{~mm}$. longus, filiformis.

In Haiti in Plaine dicta, m. Maj. fl.: Buch n. 229, verisimiliter temporibus Gallorum ex Europa introducta. - Patria Europa, fere tota Asia septentrionalis et centralis.

\section{Capsella Medic.}

23. Capsella loursa pastoris (L.) Medic. Planta annua. Caulis praesertim basi pilis stellatis hispidus. Folia inferiora breviter petiolata, \pm profunde pinnatifida, rarius simplicia: lobus terminalis ovatus, acutus, laterales sensim minores, oblongi, omnes denticulati; media et superiora minora, oblonga, acuminata, \pm denticulata, basi dilatata auriculis curvatis sagittata; omnia pilis stellatis \pm obsita. Racenus sub anthesi densus, corymbosus, dein valde elongatus, $40-80$-florus. Pedicelli floriferi $3-4 \mathrm{~mm}$, fructiferi $6-15 \mathrm{~mm}$. longi. Flores $2 \mathrm{~mm}$. longi. Petala alba, obovata, in unguiculum linearem dimidio breriorem cuneato-angustata. Stamina 6 , interiora $2 \mathrm{~mm}$, exteriora $1,5 \mathrm{~mm}$. longa. Pistillum fere orbiculatum, apice truncato stylo $0,3 \mathrm{~mm}$. longo, crassiusculo instructum; ovarium 24-2S-ovulatum; stigma stylo aequilatum. Siliculae pedicellis fere horizontalibus, tenuiusculis insidentes, triangulariobcordatae, valde compressae, $6-7 \mathrm{~mm}$. longae, antice $5 \mathrm{~mm}$. latae; septum angustissimum; valvulae reticulato-nervosae, virides, saepe rubellae; stylus brevissimus, $0,5 \mathrm{~mm}$. longus; stigma $0,25 \mathrm{~mm}$. latum, stylo aequilatum. Semina numerosa, linearia, notorrhiza. Cotyledones lineares.

Capsella bursa pastoris Medic. Pflanzengatt. I (1792) p. 85; DC. Syst. Nat. II p. 383 et Prodr. I p. 177; Griseb. Flor. p. 14; Eichl. in 
IIart. Fl. Bras. XIII, 1 p. 307; Chapm. Fl. South. Tuit. Stat. II. edit. p. 30; Robins. in Gray Synopt. Flor. I, 1 p. 131.

Thlaspi Bursa pastoris L. Spee. 1. edlit. II (1753) p. 647.

Bursa pastoris Wigg. ex O. Kuntze Revis. I (1891) p. 20.

Caulis $15-50 \mathrm{~cm}$. altus, ramosus vel subsimplex, 4-6-foliatus, pruinosus. Folia inferiora $4-8 \mathrm{~cm}$. longa, ima saepe rosulata, patula, superiora $2-4 \mathrm{~cm}$. Innga, erecta. Pedicelli floriferi erecto-patentes, filiformes. Sepala $1,5 \mathrm{~mm}$. longa, late oblonga, glahra, saepe rubella. Petala interdum apice leviter emarginata. Antherae $0,33 \mathrm{~mm}$. longae, ellipticae. Semina $1 \mathrm{~mm}$. longa, $0,33 \mathrm{~mm}$. lata et crassa, fulva, minutissime tuberculata; funiculus $0,5 \mathrm{~mm}$. longus, filiformis.

Hab. in Jamaica in plantationibus montium quasi spontanea: ex Griseb. 1. c. - Patria Europa, unde verisimiliter in orbem totum migravit. 


\title{
$X$. Selaginellae novae.
}

\author{
Exposuit \\ G. Hingonyus.
}

Selaginella tobagensis Hieron. (n. sp.). Heterophyllum e turma S. jungermannioidis (Gaud.) Spring, caulibus ubique radicantibus dichotomis, usque ad ca. $2 \mathrm{dm}$. longis, expansis; ramis pinnatim ramosis; ramulis inferioribus pinnatim ramulosis, superioribus dichotomis vel furcatis, supremis saepius simplicibus; rlizophoris tenuibus, filiformibus, compressis, vix usque ad $5 \mathrm{~cm}$. longis, ca. $1 / 6 \mathrm{~mm}$. crassis, stramineis, nitentibus, apice radices fibrillosas breves vix ultra $5 \mathrm{~mm}$. longas gerentibus; plano caulium et ramorum primariorum ca. $6 \mathrm{~mm}$. lato, ramulorum ultimorum ca. $4 \mathrm{~mm}$. lato; foliis ubique heteromorphis, subglauco-viridibus; foliis lateralibus inaequilateris, e basi superiore pallescente producta rotundata et inferiore truncata oblique ovatis, obtusis vel obtusiusculis, margine superiore ubique, marginis inferioris basi et ad apicem versus piloso-denticulatis (pilis dentiformibus basalibus maximis usque ad $0,07 \mathrm{~mm}$. longis), in epidermide lateris aligularis fibras scleroticas optime sub lente perspicuas gerentibus; foliis lateralibus maximis ca. $31 / 2 \mathrm{~mm}$. longis, $2 \mathrm{~mm}$. supra basin latis; foliis axillaribus aequilateris, e basi utrinque subcordata pallescente oratis, obtusiusculis rel subacutiusculis, margine ubique piloso-denticulatis, ceterum lateralibus ceteris similibus; foliis intermediis subaequilateris e basi exteriore obsolete auriculata subcuneata et interiore rotundata ovatis, in cuspidem ca. $1 / 3$ lamiuae aequantem aristiformem acuminatis, margine ubique pilosodenticulatis (pilis dentiformibus vix ultra $0,05 \mathrm{~mm}$. longis) et parte superiore vitta e cellulis scleroticis formata marginatis; foliis intermediis maximis ca. $2 \mathrm{~mm}$. longis, $1 \mathrm{~mm}$. latis; floribus (spicis) apice ramulorum ultimorum usque ad $5 \mathrm{~mm}$. longorum terminalibus, solitariis, $2-6 \mathrm{~mm}$. longis, ca. $1 \frac{1}{2}-2 \mathrm{~mm}$. crassis, subplatystichis; sporophyllis (bracteis) manifeste lieteromorphis, subaequilongis; dorsalibus inaequilateris (semifacie in lumen inclinata parum latiore viridi, semifacio altera pallescente), suboblique ovato-cymbiformibus in cuspidem brevem acuminatis dorso carinatis, margine basi integra excepta sparse piloso-denticulatis, parto 
superiore vitta angustissima cellulis scleroticis formata marginatis, in epidermide lateris aligularis semifaciei pallenscentis fibras scleroticas gerentibus; ventralibus aequilateris, pallescetibus, in epidermide lateris aligularis ubique fibras scleroticas gerentibus, ceterum dorsalibus similibus; sporophyllis maximis ca. $4 \mathrm{~mm}$. longis, $1 \frac{3}{4} \mathrm{~mm}$. supra basin latis; macrosporangiis in axillis sporophyllorum ventralium, microsporangiis in axillis sporophyllorum dorsalium sitis; macrosporis sulphureis, ca. $0,3 \mathrm{~mm}$. crassis, latere rotundato irregulariter rugulosis, inter costas commissurales tuberculo centrali (interdum subevanido) ornatis; microsporis croceis, ca. $0,02 \mathrm{~mm}$. crassis, levibus.

Hab. in Tobago, in silvis primaevis montis Morne d'or, alt. s. m. ca. 500 m., ad Cremorne River versus, 11. November 1889: Eggers n. 5815.

Obs. Species S. Seemanni Bak. proxime affinis est, differt foliis lateralibus et intermediis latioribus fibras scleroticas optime perspicuas in epidermide lateris aligularis gerentibus, macrosporis sulphureis (nee ut in illa lutescentialbidis).

$\checkmark$ Selaginella Hartii Hieron. (n.sp.). Heterophyllum e turma S. flabellatae (L.) Spring, caulibus e basi radicante (rhizomate) stolonifera erectis, usque ad $3 \mathrm{dm}$. altis; stolonibus usque ad 1/2 mm. crassis, compresso-teretibus squamis subtetrastichis parum leteromorphis oratis (alteris acuminatis, alteris breviter cuspidatis) lata basi sessilibus parum inaequilateris margine minute piloso-denticulatis obtectis; parte inferiore caulium erectorum simplici $1-2 \mathrm{dm}$. longa, $1-1 \frac{1}{2} \mathrm{~mm}$. crassa, compresso-tereti, bracteis praesertin apicem versus heteromorphis subtetrastichis vel apicem caulis versus subplatystichis (alteris lateralibus late et oblique rotundato-ovatis valde inaequilateris acuminatis, alteris intermediis ovatis minus inaequilateris breviter cuspidatis) et hic foliis partis caulium flabelliformis similibus obtectis; parte superiore caulium flabellatim expansa ambitu ovata pinnatim ramosa, ramis inferioribus pinnatim ramulosis, superioribus dichotomis vel furcatis supremis simplicibus; axis primarii et ramorum primi ordinis plano usque ad $9 \mathrm{~mm}$. lato (foliis lateralibus inclusis), ramulornm ultimorum plano $3-5 \mathrm{~mm}$. lato; foliis lateralibus axis et ramorum primi ordinis parum inaequilateris, subfalcato-orato-oblongis, breviter acuminatis, margine superiore toto et ad apicem versus margine inferiore minute piloso-denticulatis (pilis dentiformibus maximis ca. $0,03 \mathrm{~mm}$. longis); foliis lateralibus ramulorum subaequilateris subrectis, ceterum similibus; foliis axillaribus omnibus rectis, aequilateris, obtusiusculis, ceterum lateralibus ceteris similibus; foliis lateralibus axis primarii maximis ca. $5 \mathrm{~mm}$. longis, $21 / 4 \mathrm{~mm}$. supra basin latis; foliis intermediis e basi exteriore cordata et basi interiore rotundata falcato-ovatis parum inaequilateris in cuspidem aristiformem vix $1 / 4$ laminae aequantem 
acuminatis, margine basi excepta nbique minutissime piloso-denticulatis; foliis intermediis maximis ca. $2^{1 / 4} \mathrm{~mm}$. longis, $1^{1 / 4}$ supra basin latis; floribus (spicis) in ramulis ultimis $1 / 2-1 \frac{1}{2} \mathrm{~cm}$. longis terminalibus, solitariis, subtetragonis, usque ad $\delta \mathrm{mm}$. longis, $11 \frac{1}{2} \mathrm{~mm}$. crassis; sporophyllis (bracteis) parum heteromorphis; 'dorsalibus parum inaequilateris (semifacie in lumen inclinata paulo latiore et obscurius viridi), ovato-cymbiformibus, acutis, dorso carinatis, margine basi excepta minutissime piloso-denticulatis; ventralibus aequilateris pallide viridibus in cuspidem brevem acuminatis, ceterum similibus; maximis c. $1 \frac{1}{4} \mathrm{~mm}$. longis, $3 / 4 \mathrm{~mm}$. latis; macrosporangiis in axillis sporophyllorum ventralium, microsporangiis in axillis sporophyllorum dorsalium sitis; macrosporis lutescenti-albidis, latere rotundato irregulariter rugulosis, inter costas commissurales plicatulas crenulatas pro conditione altas levibus, c. $0,18 \mathrm{~mm}$. crassis; microsporis pallide aurantiacis, latere rotundato gibbis coni-vel subcapituliformibus sparse ornatis ca. $0,02 \mathrm{~mm}$. crassis.

Hab. in Trinidad prope Tocucle: Crueger in Herb. Horti bot. Trinidad n. 181, loco accuratius nom indicato: Herb. Horti bot. Trinidad n. $180,1172$.

Obs. Specimina a cl. Bakero nomine S. flabellatae determinata sunt. Species a $S$. flabellata Spring differt foliis lateralibus latioribus brevius acuminatis margine superiore minute piloso-denticulatis, foliis intermediis latioribus, floribus brevioribus etc.; magis affinis est S. Wendlandii Hieron., a qua differt statura multo minore, foliis lateralibus brevius acuminatis in epidermide lateris alignlaris fibras scleroticas non gerentibus minus crassis et minus obscure viridibus, foliis intermediis majoribus latioribus basi exteriore cordata nec manifeste auriculata, fibras scleroticas in epidermide lateris aligularis non gerentibus, floribus brevioribus etc.

Selaginella Krugii Hieron. (n. sp.) Heterophyllum e turma S. flexuosae Spring, caulibus decumbentibus fere usque ad apicem radicantibus et rhizophoros saepe $10-12 \mathrm{~cm}$. longos usque ad $1 / 2 \mathrm{~mm}$. crassos subteretes vel parum compressos stramineos nitentes apice repetito dichotomos gerentibus, compresso-teretibus, usque ad $1 \mathrm{~mm}$. crassis, stramineis, nitentibus, parte inferiore parce, parte superiore crebre pinnatim ramosis; ramis partis inferioris brevibus vix ultra $2 \frac{1}{2} \mathrm{~cm}$. longis; ranis partis superioris longioribus, plerumque ultra $3 \mathrm{~cm}$. raro usque ad $10 \mathrm{~cm}$. longis et inde saepius rhizophoros gerentibus; omnibus pinnatim ramulosis; ramulis furcatis vel dichotomis rarius pinnatim ramulosis; plano axis primarii ca. $5-6 \mathrm{~mm}$. lato (foliis lateralibus inclusis), ramulorum ultimorum 2-3 $\mathrm{mm}$. lato; foliis ubiqne heteromorphis, clare vel subobscure lutescenti-viridibus, supra opacis, subtus subnitentibus; foliis lateralibus in caulibus remotis (distantia inter folia lateralia ejusdem lateris caulis usque ca. $3 \mathrm{~mm}$. longa), in ranis ramulisque magis approximatis, supremis marginibus sese attingenibus vel subimbricatis; 
foliis lateralibus caulium inaequilateris, e basi inferiore subcuneata et superiore truncato-rotundata vel subcordata late protracta oblique ovatis, acutiusculis vel obtusiusculis, margine superiore vitta angustissima (basi latiore sed vix ultra $0,02 \mathrm{~mm}$. lata) cellulis scleroticis formata prueditis, et usque ultra medium laminae pilis (basi laminae longioribus sed vix ultra $0,08 \mathrm{~mm}$. longis mox decrescentibus) ornatis fibras scleroticas minutas parum conspicuas dispersas in epidermide lateris aligularis gerentibus, apicem versus utroque margine minutissime piloso-denticulatis; foliis maximis caulium ca. $3 \frac{1}{2} \mathrm{~mm}$. longis, vix $2 \mathrm{~mm}$. supra basin latis; foliis lateralibus ramulorum angustioribus minus inaequilateris, oblique ovato-oblongis minoribus (minimis ca. $2 \mathrm{~mm}$. longis $3 / 4 \mathrm{~mm}$. supra basin latis), ceterum similibus; foliis axillaribus e basi utraque rotundata ovatis acutiusculis, utrinque vitta angustissima marginatis et piloso-denticulatis ceterum foliis lateralibus ceteris similibus; foliis intermediis omnibus ovatis, basi exauriculatis, cuspidatis (cuspide 3/4 laminae vel laminam totam aequante), margine utroque vitta angustissima cellulis scleroticis formata et ciliis usque ad $0,1 \mathrm{~mm}$. longis crebris ornatis, dorso parte superiore infra cuspidem manifeste carinatis; foliis intermediis maximis caulium ca. $3^{1 / 4} \mathrm{~mm}$. longis (cuspide inclusa) $1 \frac{1}{6} \mathrm{~mm}$. infra medium latis; floribus (spicis) $2-6 \mathrm{~mm}$. longis $1 \frac{1}{2}-2 \mathrm{~nm}$. crassis in ramulis brevibus solitariis vel binis; sporophyllis (bracteis) manifeste heteromorplis, ovato-cymbiformibus in apicem breviter cuspidatum acuminatis, margine utroque vitta angustissima cellulis scleroticis formata praeditis et utrinque piloso-denticulatis (pilis incurvis vix ultra $0,07 \mathrm{~mm}$. longis); sporophyllis dorsalibus inaequilateris (semifacie ad lucem majore et latiore obscurius viridi), majoribus (ca. $31 / 2 \mathrm{~mm}$. longis $3 / 4$ mm. basi latis); ventralibus aequilateris, pallide viridibus, minoribus; macrosporangiis in axillis sporophyllorum ventralium sitis; microsporangiis in axillis sporophyllorum dorsalium; macrosporis usque ad $0,3 \mathrm{~mm}$. crassis sublutescenti-albidis, latere rotundato irregulariter verrucoso-rugulosis, inter costas parce verrucosis; microsporis croceis, ca. 0,02 mm. crassis, latere rotundato gibbis capituliformibus sparsis ornatis.

Hab. in Portorico in Sierra de Luquillo: ? Blauner (hb. Shuttleworth n. 320), Eggers ed. Toepff. n. 898 et hb. pr. n. 1192, Heller n. 4616, Sintenis n. 1548, P. Wilson n. 92 et 134; in Sierra de Naguabo: Sintenis n. 1045 (p.p.), 5427; loco non indicato: Heller n. 1091.

Obs. Species S. portoricensi Al. Br. affinis, differt caulibus decumbentibus longioribus usque fere ad apicem radicantibus, foliis latcralibus minus acutis cellulas scleroticas multo minores parum conspicuas in epidermide lateris aligularis gerentibus, intermediis plerumque longius cuspidatis, floribus tenuioribus, sporophyllis minoribus, macrosporis sublutescenti-albidis etc. 


\section{INDEX}

\section{NOMINUM LATINORUM.}

Acidoton microphyllus Urb. 302.

Acrocarpidium cordifolium Miq. 228. exile Miq. 225.

Guildingianum Miq. 249.

hispidulum Miq. 223.

majus Miq. 247.

nummularifolium Miq. 229.

forma pilosior Miq. 230.

pulicare Miq. 249.

repens Miq. 249.

rotundifolium Miq. 264.

scandens Miq. 249.

tenellum Miq. 224.

urocarpum Miq. 247.

Aegiphila elata Sw. 367.

nervosa Urb. 366.

plicata Urb. 365.

Swartziana Urb. 364.

uniflora Urb. 365.

Anastraphia bahamensis Urb. 415.

Northropiana Greenm. 416, 417. var. Combsii Urb. 417.

oligantha Urb. 417.

paurifloscula Hitche. 416, 417.

paucifloscula C. Wright 417.

Picardae Urb. 414.

Anonymos capitutus Walt. 451.

Anthacanthus acicularis Nees 382.

Apteria Nutt. 440, 448.

hymenanthera Miq. 448.

lilacina Micrs 449.

orobanchoides Hook. 442.

setacea Hook. 448.

setacea Nutt. 449.
Ardisia coriacea Sw. 330 . coriacea Sw. 331. guadelupensis Duchass. 330. Harrisiana Mez 331. tinifolia Sw. 331.

Aristolochia stenophylla Urb. 281.

Artanthe Miq. 159.

adunca Griseb. 186.

adunca Miq. 184.

aequalis Miq. 203.

aspera Miq. 187.

aurita Miq. 200.

Bredemeyeri Griseb. 198.

caracasana Miq. 173.

catalpaefolia Miq. 172, 173.

caudata Miq. 172.

celtidifolia Miq. 184.

concinna Miq. 204.

conteans Griseb. 183.

corylifolia Miq. 198.

decurrens Miq. 178.

geniculata Griseb. 176, 207.

geniculata Miq. 179, 180.

hexagyna Miq. 214.

hirsuta Mir. 187.

Jacquemontiana Miq. 182.

jamaicensis Griseb. 193.

lanceata Miq. 186.

Lessertiana Miq. 180.

linguaefolia Miq. 186.

Luschuthiana Miq. 179, 180. macrophylla Griseb. 179. mucropleylla Miq. 195.

Martiana Griseb. 203. 
Artanthe Martinicae Miq. 201.

Olfersiana Miq. 187.

rugosa Griseb. 182.

scabra Miq. 187.

var. fol. minor. Miq. 191.

Schackii Miq. 183.

Seemanniana Niq. 200.

staminea Miq. 176.

Swartriana Griseb. 175.

Suartziana Miq. 177.

trichostachya Miq. 182.

tuberculata Miq. 17S.

ulmifolin Miq. 198.

Velloriana Miq. 184.

vermecosa Griseb. 179.

Wydleriann Miq. 182.

xestophylla Miq. 179.

xylopioides Miq. 179, 180.

xylosteoides Griseb. 205.

Aster frutescens stoech. vitr. fol. Plum. 414.

Baccharis cotinifolia Lrb. 406.

dioina Griseb. 406.

dioica Vahl 406.

myrsinites Griseh. 391.

ptarmicifolia Griseb. 406.

speciosa P. DC. 407.

Tahlii DC. 406.

Banara Vanderbiltii Urb. 320.

Barbula hymenostylioides Brotlı. 423.

Batatas macrorhizos G. Don 352. termata G. Don 355.

Beetle Codi Rheede 214.

Benitria Poeppigiana Karst. 438.

snareolens Karst. 438.

Bisgoeppertia gracilis 0. Ktze. 332.

Prenleloupii Lrb. 331.

volubilis O. Ktze. 332.

Bonania adenodon Bentlı. 310 .

cubana A. Rich. 311.

microphrlla Urb. 311.

Borreria porlocephala Stahl 388.

Brachylobus domingensis Desv. 515. hispidus Dest. 516.

Brassica L. 50 S. albo Boiss. 507.

campestris L. 509.

arvensis 0. Ktze. 508.

var. juncea O. Ktze. 510.

integrifolia O. E. Scliulz 509.

Urban, Symb. ant. IIJ.
Brassica juncea Coss. 511.

juncea Hitclic. 510.

lanceolata Lange 510 .

rapa L. 509.

sinapistrmm Boiss. 508.

Urbaniana O. E. Schulz 511.

IVilldenowii Boiss. 510.

Biossaea cocciner L. 330.

Brunfelsia Fawcettii Urb. 371.

Harrisii Urb. 373.

jamaicensis Griseb. 374.

maliformis Crb. 372.

undulata Sw. 374.

Burmannia Linn. 449.

bicolor Griseb. 450.

bicolor Nart. 449.

var. subcoelestis Malme 450 .

brachyphylla Willd. $\$ 50$.

capitata Jolnow 448.

capitata Mart. 450.

flava Mart. 450.

flarula C. Wr. 450.

quadriflora Willd. 450.

Bursa pastori.s Wigg. 523.

Bunias cakile Descourt. 505.

calite L. 502.

edentula Bigel. 505.

oralis Viv. 504.

Cakile Juss. 499.

aeg!ptiaca Tuss. 505.

aegyptiaca Willd. 504.

aequalis Bello 507.

aequalis l'Hér. 505.

alacranensis Millsp. 506.

alacranensis $>$ aequalis Millsp. 506.

americana Nutt. 505.

var. cubensis DC. 505.

americana Spr. 505.

baltica Jord. 503.

Baulini Jord. 504.

calile Karst. 503.

Chapmanii Millsp. 506.

crenata Jord. 504.

cubensis H. B. K. 505.

cubensis Millsp. 505.

cyrenaica Spr. 504.

domingensis Tuss. 505.

edentula Hook. 505.

edentula .Tord. 503.

fusiformis Grcene 506. 
Cakile geniculata Millsp. 506 . geniculata $\times$ edentula Millsp. 506. hispanira Jord. 504.

lanceolata O. E. Schulz 504. subsp. domingensis 0 . E. Schulz 505.

subsp. edentula O. E. Schulz 504 .

prol. geniculata O. E. Schulz 506.

var. alacranensis 0. E. Schulz 506.

var. apetala 0 . E. Schulz 506.

var. integrifolia O. E. Schulz 507.

var. Millspanghii O. E. Schulz 506.

var. pinnatifida O. E. Seluulz 506.

form. pygmaea 0. E.Schulz 507 . litoralis Jord. 503.

latifolia Poir. 504.

maritima A. Rich. 505.

maritima Scop. 502.

prol. edentula O.E. Sclulz 503. prol. litoralis O. E. Schulz 503. var. acqualis Chapm. 506. var. amblycarpa O. E. Schulz 503.

var. bipinnata O. E. Schnlz 504 . var. cubensis Chapm. 506. var. geniculata Robins. 506 . var. hrispanica O.E. Schulz 503. var. integrifolia Boiss. 504 . var. latifolia Desf. 504. var. monosperma O. E. Schulz 503.

var. oxycarpa O. E. Schulz 503. var. pandataria Terr. 504. var. sessiliflora O. E. Schulz 504.

var. simuatifolia DC. 504.

form. pandataria O. E. Schulz 504.

form. pygmaea O.E. Schulz 504 . monosperma Lange 503. pimnatifida Stokes 502. Serapionis Gaertn. 502. simuatifolia Stokes 504.

Culabura alba P'nk. 363.
Callianira Miq. 159.

Calymperes guadalupense Broth. 423. Capsella Medic. 522. bursa pastoris Medic. 522.

Cardamine L. 518. africana L. 518. armoracia 0. Ktzc. 498. flexuosa With. 520.

var. pennsylvanica O. F. Schulz, 521.

fontana Lam. 513.

hirsuta L. 520.

Jamesonii Hook. 519.

impatiens L. 521.

nasturtium O. Ktze. 514.

palustris O. Ktze. 515.

var. brevipes 0 . Ktze. 517. pennsylvanica Mülıl. 521. pyrenaica O. Ktze. 515.

Carpunya C. DC. 163.

Carpunya Presl 159.

Casearia bahamensis Urb. 322. guianensis Trb. 322. orlorata Macf. 321. ramiflora Valll 322. var. spinosa Griscb. 321.

Caulobryon Klotzsch 159.

Ceanothus ferreus P. DC. 314.

Cestrum inclusum Urb. 370.

Chaenocephalus rupestris Trb. 412.

Chaenotheca Urb. 284. domingensis Trb. 285. neopeltandra Urb. 285.

Cliaptalia albicans Northr. 419. dentata Cass. 419.

Eggersii Urb. 418. media Urb. 419. membranacea Urb. 418. nutans Hemsl. 419. obovata C. Wright 420 . pumila Urb. 420. stenocephala Urb. 420 .

Chavica Engl. 159.

Chavica Miq. 159. auriculata Miq. 213. Betle Miq. 213. Labillardieri Miq. 213. maritima Miq. 213. officinarnm Miq. 212. vetrofracta Miq. 213. 
C'helonanthus frigidus Trb. 334.

Chione coriacea Urb. 380.

C'issus acida I. rar. macilentr J. E. Planch. 318. macilenta Urb. 318. Picardae ( $\mathrm{rl}$ ). 317.

Clerodendron Picardae Crb. 367.

Caccobryon C. DC. 163.

Coccobryon Klotzsch 159.

Cochlcaria L. 497. armoracia L. 497.

Condalia ferrea Griseb. 314.

Concolvnlus alatus Ham. 343. bahiensis Spreng. 351. corcincus heptophyllos rad. crass. Plum. 352.

criospermus Desr. 351. fol. lan. in tres lac. diviso Sloane 344.

fol. pedato-palmatis Plum. 344 . frondosns Willd. 340. Gaberi Chapm. 341. havancusis Grisel. 340. harancnsis Jacq. 342. jamaicensis Jacq. 340. var. major A. Rich. 340 . jamaicensis Spr. 344. jamaie. tiilob. fol. tom. Pluk. 34t. macrocarpus L. 343. macrorkhinus T. 352. micranthus Griseh. 340. micianthus R. et Sch. 339. min. scand., flor. plur. al. P. Br. 339. operculatus Gomez 3.14. parviflorus Desr. 339. Plumicrii Spreng. 339. polycarpus H. B. K. 339. polyphyllus fl. et fi: nuip. mux. Plum. 344. rnber. Vahl 345. vulerarius H. B. K. 340. sermdens fol. trilobis quamlonne cordatis $\mathrm{P}$. Br. 344. seipyllifolius II. B. K. 341. termatus Spreng. 355. tomentosus I. 344. Valenzmelamus A. Rich. 341. revticillatus. I. 339.

Comyer domingensis Willd. 114.
Comiza lurcus Poir. 414. Cordia areolata Crb. 362 . asperrima P.. DC. 360 . bullatu Griseb. 363. ealcicola Lrh. 359. rhomachifolir Rees 363. elliptica Griseb. 357. elliptica Sw. 357. exarata Trb. $35 \mathrm{~S}$. Fawcettii Trb. 357. haitiensis Urb. 357. lima Roem. et Schult. 361. var. subinflata Trb. 362. mivabiliflora A. DC. 363. var. chomectrifolie A. DC. 363. mimabiloides Rocm. et Schult. 363. nitida Vahl var. angustata Urb. 357.

Picardae Urb. 360. vadula P. DC. 362. radula Spreng. 361. retimlatn Tahl $35 \%$. serrata Gürke 363. stivigosa Spreng. 363. villose Spreng. 358.

Cordiopsis minabiliflorn P. DC. 363. mimbiloides Desr. 363.

Coronopus Gaertn. 496. didymus Smith 496.

Croton angustatus Urb. 296. angustifolius Desr. 292. astroites Ait. 292. bahamensis Desv. 292. brachytrichus Urb. 299. Casenilln L. 298. var. $\alpha$. Griseb. 296. cascailloilles, Geisel. 298. guadeloupensis Desr. 292. litoralis $\mathrm{Trb}$. 294.

var. Rùgelianus Urh. 294. lucidns I. 292. martinicensis $\mathrm{Yrb}$. 295. megaladenus Trb. 298. microcarpus Desr. 292. microstachrus Desr. 291. Picarlae Urb. 297. Poitaei Urb. 300. polytomus Trb. 293. Priorianus ('rh. 295. rosmm inifolius var. Grisel. 295. 
Croton subglaber Urb. 301.

waltherioides Jrb. 292.

Cruciferae 493.

Cubeba Miq. 159.

Cuphea urens Koeline 329.

Cymbocarpa Miers 439, 446.

refracta Niers 446.

Daltonia Dussii Broth. 426.

Diasperus neopeltandrus O. Ktze. 285.

Dicranella Martinicae Brotl. 421.

Dictyostegia Miers 437, 441. orobanchoides Miers 441.

umbellata Niers 439.

Diodia rigida Cham. et Sclıleclst. var. angustissima Urb. 387.

Dipterosiplion Huber 440.

Encliea C. DC. 160.

Enckea Kunth 159.

Amalago Griseb. 202.

var. $\alpha$. Griseb. 168, 169.

var. hivtella Griseb. 169.

var. variifolia Griseb. 170.

articulata Griseb. 207.

blattarum Kunth 206.

ceanothifolia Kuntlı 166.

discolor Kunth 169.

glancescens Kunth 169.

orthostuchya Kunth 166 .

plantaginea Kunth 166.

reticulata Griseb. 201.

reticulata Miq. 171.

Sieberi Griseb. 166.

Sieberi Miq. 167.

smilacifolia Griseb. 171.

subpanduriformis Miq. 170.

Swartrii Griseb. 202.

unguiculata Kunth 169.

Enckea Miq. 159.

Erigeron araneosus Urb. 404.

domingensis Urb. 403.

jamaicensis Duss 404.

polycladus Urb. 403.

Erithalis revoluta Urb. 379.

Enter marit. Ital. Sloane 505.

Erysimum officinale L. 499.

Eugymmosiphon Urb. 438.

Eupatorium bahamense Urb.*) 391.
Eupatorium Bemmii Polakowsky 407. rotinifolium Willd. 406. cubense P. DC. 397. cubense A. Ricli. 398. cynanchifolium DC. 400. cynanchifolium Griseb. 400.

var. Griseb. 401. cynanchifolium Sauv. 401. deltoiderm Poepp. 397. dictyoneurum Urb. 402. Gundlachii Urb. 399. Hartii Urb. 395. Jaegerianum Urb. 394. illitum Urb. 401. integrifolium Gard., Br., Doll. 392. maestrense Trb. 397. medullosum Urb. 393. mononeurum Urb. 392. Poeppigii Spreug. 397. polystictum Urb. 400. semicrenatum Urb. 398. triradiatum Urb. 396.

Eupiper C. DC. 164.

Eusavia Trb. 284.

Excaecaria albicans Griseb. 312. biglandulosa var. aucupen ia Müll. Arg. 310.

var. hippomane Miill. Ar'g. 306. eglandulosa Mïll. Arg. 310 . laurocerasus var. elliption Miill. Arg. 308.

var. genmina Müll. Arg. 307. var. laurifolia Müll. Arg. 308. lencogyna Müill. Arg. 310. leucosperma Müll. Arg. 310. Sagraei Müll. Arg. 311. suberosa Müll. Arg. 306. venulosa C. Wr. 312.

spec. Duss 303.

Exogonium eriospermm Choisy 351. Exostema acumiuatum Urb. 378. salicifolinm Griseb. 379.

Ficus Linn. 453. americana Aull. 467, 468. americana Sw. $467,468$. americana lib. Swartz. 459. aurantiaca Hort. Berol. 461.

*) = Eupatorium bahamense Northr. in Mem. Torr. Bot. Club XII (Dec. 1902) p. 60 tab. 19 . 
Ficus aurea Nutt. 460 . ali-rui Bl. 480 .

Benjaminea L. 489.

Berteroi Warb. 468.

botiyaprioides Kith. et Behé. 479.

brevifolin Nutt. 473.

bulbose Hort. Berol. 461.

Canoni N. E. Br. 489.

caribaea Jacq. 490.

eariea I. 488.

castrunearfolia fi. glob. mar. P'lum.

491.

catappifolia Kth. et Behé. 491.

Cateslaei Stend. 490.

citrifolir Lam. 473, 479.

Combsii Warb. 456.

rassincrvia Combs 455, 456 .

mssincria Griseb. 459.

crassinervia Willd. 462.

cunia Bueh. Ham. 489.

limidiate Griseb. 461.

Eggersii Warb. 469.

clastica Roxb. 489.

cleyans Hort. Berol. 461.

slliptice Griseb. 462.

Farlyeni Miq. 464.

Finlayana Warb. 487.

fol. citri obt. frurt. smu. Plum. 464.

fol. Lami finet. min. Plum. 467,

473.

gemina Griseb. 483.

gigantea H. B. K. 468.

grenadensis Warb. 481.

Harrisii Warb. 457.

Hartii Warb. 458.

Hookeri Sweet 490.

jacquinifolia A. Rieh. 465.

jumaicensis Miq. 491.

indiene L. 489.

Indira fol. obl. obt. fiuetu mimone

pallide luteo sphare. Sloane 469.

inclira fre et fol. sninm: P'lmu. 489.

indira maxima Sloane 490.

Krugiana Warb. 487.

Kunthii Miq. 490.

lacvigate Link 479.

laevignta Valıl 472, 474.

laeris Desf. 461.

Irmifolia Duss 487.

laurifolia Griseb. 468, 485, 490.
Fieus lamifolia Lam. 490.

lentiginosn Grisel). 479.

lentigimose Vahl 472, 476.

maenlata I. 491.

manillifera Warh. 470.

matinicensis Naye. 490.

matinicensis Willd. 490.

membranacea C. Wright 455 .

mitrophom Warb. 457.

max. fol. ritri subrot. fir mmbil.

Plum. 458.

neriifolia Hort. Berol. 490.

nitida Thunb. 489.

oblongata Link 469.

oehrolenea Griseb. 464.

omphalophora Warb. 466.

pallida Griseb. 466.

perlmnculata Ait. 468 .

pedumemlete Griseb. 467.

pedmenlate Vahl 472, 475.

perlunculata Willd. $46 \mathrm{~s}$.

preforate L. 482.

pertusa Griseb. 465, 466.

pertusa L. fil. 482.

pertuse Willd. 489.

Pieardae Warb. 484.

planicostata Kith. et Behé. 479.

populifolia Desf. 472, 479.

populnca Willd. 471, 479.

forma botryajioides Warb. 479.

forma citrifolia Warb. 479.

forma eupopulnea Warb. 479.

forma planicostata Warb. 479 .

var. Lahamensis Warb. 473.

var. brevifolia Warb. 473.

subvar. cubana Warb. 473.

subvar. floridana Warb. 473.

var. laevigata Warb. 474.

subvar. Hispaniolae Warb. 476.

subvar. peduneulata Warb. 475.

subvar. portoricensis Warb. 474.

subrar. Sanetae Cruc is Warb. 475.

subrar. Saneti - Eustaelin Warb. 475.

sulwar. Saneti-.loannis Warb. 475. 
Ficus populnea Willel. subvar. thomaea $\mathrm{W}$ arb. 474.

var. lentiginosa Warb. 476. subvar. cerasicarpa Warb. 477.

subvar. crassipetiolata Warb. 478.

subvar. diversifolia Warb. 478 .

subvar. flavicosta Warb. 478. subvar. longipetiolata Warb. 478.

subvar. obliquicuspis Warb. 477.

subvar.reticulosa Warb. 477. subvar. subcordata Warb. 476.

subvar. subcuspidata Warb. 478.

subvar. subdepressa Warb. 477.

subvar. subpyriformis Warb. 477.

subvar. typica Warb. 476. populoides Warb. 479.

forma syringifolia Warb. 480 . forma umbrifera Warb. 480. var. cubensis 480 .

var. dilatata Warb. 480. var. elongata Warb. 480.

var. maculosa Warb. 480. portoricensis Urb. $473,474$. prinoides H. et B. 483. pumila L. form. microphylla 491. radula A. Rich. 486. radula Willd. 484. rhododendrifolia Kth. et Bché. 490. Rolanderi Mii. 482. rulnicosta Warb. 486. rubrinervia Link 469. sancti-crucis Miq. 472, 475. sapotifolia Kith. et Bché. 460 . scandens Lam. 491.

Schumacheri Bello 472, 176. Schmecheri Griseb. 482.

Sintenisii Warb. 464. sororia Kunth et Bchó. 461 . Stahlii Warb. 470. subscabrida Warb. 485. suffocans Griseb. 185.
Hicus suffoctus Griseb. 486. surinamensis Miq. 482. syringifolia Kunth et Bché. 180. thomaen Miq. 473, 475. tinctoria Forst. f. 488. triangularis Warb. 489. trigone A. Rich. 469. trigomata Egg. 463. trigomata Gardiner 460. trigonata Griseb. 469. umbonigera Warb. 4SO. umbrifara Kth. et Bché. 480. undulata Desf. 490.

Urbaniana $\mathrm{W}$ arb. 459.

venusta Kth. et Bché. 488. virens dit. 490.

Wilsoni Warb. 467. Wrightii Warb. 461.

Fissidens rochensis Brotl. 421.

Gaultheria anastomosans Griseb. 330. coccinea Urb. 330. cordifolia Raeusch. 330. domingensis Urb. 329.

Gnaphalium domingense Bello 409. Eggersii Urb. 410. portoricense Urb. 409.

Gundlachia domingensis A. Gray 40i, 406.

var. colymbosa Urb. 406. var. genuina Urb. 405. var. Lindeniana Urb. 405.

Gymnanthes albicans Urb. 312. recurva Urb. 312.

Gymnosiphon Bl. 437, 442. aphyllus Bl. 438 . arcuatus Urb. 443. borneelsis Becc. 439. capitatus Urb. 439. congestus Wright 439. cornutus Benth. 438. crmosus Benth. 438. divaricatus Benth. 438 . fimbriatus Urb. 438. Germaini I'rb. 444. Glaziovii Urb. 438. muticus Urb. $43 \mathrm{~s}$. nivens Ir.b. 444. papuanus Beec. 439. parviflor'ss Url. 443. portoricensis Urb. 445. 
Gymnosiphon pusillus $\mathrm{U}^{\top} \mathrm{rh} .438$. refractus Benth. 446 .

splacrocarpus Urb. 442. squamatus Wright 438 . suaveolens Urb. 438. tenellus Urb. 438. trinitatis Johow 448. usambaricus Engl. 439.

Hecleria Engl. 159.

Heclerin Kunth 159.

peltate Kunth 208. smetata Kunth 208. sidaefolia Kunth 210. speciosa Kunth 208. umbellata Kiunth 210.

Helia frigida O. Ktze. 334.

IIelirhyysum aborese. ilicis coeriyl. fol. Plum. 417.

Ietcrosavia Urb. 284.

Hexapterella Urb. 451. gentianoides Urb. 451.

Himpomane glandulose L. 306, 309. higlumdulosa L. 306, 309.

Hoolieria Antillarum Broth. 427. densifolia Broth. 428. limlatula Broth. 429 . subglareosa Broth. $42 \mathrm{~S}$.

Hyòplila guadalupensis Broth. 424 . mollis Broth. 424.

Jaborandi sp. quarta arb. Piso 182. Jacquemontia havanensis Urb. 342. jamaicensis Hall. f. 340 . micranthe G. Don 339. meraria Hall. f. 341. serpyllifolia Urb. 341. verticillata Urb. 339. var. stenophylla Urb. 340.

Iberis humilior amma Viry. Sloane 495.

Ipomoea altissima Mart. 343.

Buchii Urb. 356. carolina L. 352.

ritiolate Stahl 345 .

digitata L. 348.

eriosperma Bertero 351.

criosperma Urb. 351.

flavo-purpurca Urb. 345. fol. cordato-obl, sin. flor rertic. Plum. 340.

Furcyensis Urb. 351.
Ipomoca Grisebachii Urb. 353. havanensis Chois. 342. heptaphylla Griseb. 352. Horsfalliae W. Hook. 352. var. alba Hort. 355. Horsfalliae Mast. 354. jamaicensis Don 344. leuconeura Urb. 350. lineolata Urb. 355. macrorrlina Griseb. 354. macrorrhiza R. et Sch. 352.

forma Griseb. 355.

val. Thomsoniana IIast. 355. var. ternata Mast. 355. microdactyla Griseb. $34 \mathrm{~S}$. nematoloba Urb. 349. opereulata Mart. 344. pellata Poit. 349. pendula Choisy 353. polyeerpa G. Don 339. pterodes Choisy 343. mulchella W. Hook. 353. punctate C. Wright 345. repanda Jacq. 351. rubra Millsp. 345.

var. albo-flavida Urb. 345.

var. palustris Urb. 345 .

rubrocincta Urb. 347. ruderaria G. Don 340. serpyllifolia G. Don 341. setiferr Poir. 345. ternata Jacq. 354. Thomesoniane Mast. 355. tomentosa Urb. 344. trinitensis Urb. $3+6$. revticillata Linn. 339. viridiflora Urb. 348.

Walpersiana Duchass. 345. Iroucana guianensis Aubl. 322. Isotachis tenax Steph. 277. Jungermannia Dussiana Steph. 276. Kirugiodendron Urb. 313.

ferreum Urb. 314.

Laurifolia ren. fol. ler: serv. Sloane 306.

Leiunthus longifolius var. yracilis Bello 332.

silenifolius Griscb. 334.

T.cpidium L. 494. apetalum Willd. 495 . 
Lepidium rlirlymum L. 497.

Iberis Descourt. 494, 496.

luderale L. 495.

sativum L. 496.

virginicum L. 494.

var. pinnatisectum $\mathrm{O}$. E. Schulz 495 .

Lepidopilum calomicron Broth. 426. integrifolium Broth. 427.

Leria albiernss P. DC. 419.

media Griseb. 419.

mtans P. DC. 419.

pumila P. DC. 420.

stenocephala Griseb. 420.

Limm seandens fl.dil.pmip. Sloane 341.

Lisianthus aemminatus DesI. 334.

domingensis Urb. 333.

frigidus Sw. 334.

glandulosus A. Rich. 334.

gracilis Perk. 332.

grandiflorns Wikstr. 334.

laxiflorus Urb. 332.

silenifolius Urb. 334.

Lithocadium limm O. Kitze. 361. servatum O. Kitze. 363.

Lonchocarpus Ehrenbergii Uph. 283. neurophyllus Trb. 282.

Macromitrium Dussii Broth. 424.

Malngo Cod Rheede 215.

Macropiper Engl. 159.

Macropiper Miq. 159.

Mancanilla lauri fol. obl. Plum. 309.

Narcgravia spec. 491.

Narthella Urb. $440,447$. trinitatis Urb. 448.

Melanthera Buchii Urb. 411.

Metzgeria Dussiana Steph. 275.

Mirropiper Langsdorffii Miq. 266.

Niersiella Urb. 439

umbellata Urb. 439.

Mildea Griseb. 216.

elrgans Griseb. 217.

hydrocotylifolia Griseb. 217.

Mitracarpus Christii Urb. 388.

frigidus K. Schum. 387.

var. portoricensis Urb. 387.

polycladus Urb. 389.

Mnldera Miq. 159:

Murumia orbicnlato Pers. 326.

Nasturtium R. Br. 513.
Nasturtium aquat. vuly. Sloame 514. armoracia L. 498.

brevipes Griseb. 516.

var. pumilum O. E. Schul\% 517.

fontanum Aschers. 513.

heterophyllum Bl. 517.

hispirlum DC. 516.

officinale $\mathrm{R}$. Br. 512.

palustre DC. 515.

var. brevipes DC. 517.

subsp. hispidum F. et II. 515.

var. glabrum O. E. Schnlz 516 .

palustre Griseb. 516 .

portoricense Spr. 517.

pyrenaicum R. Br. 514.

var. $\beta$. DC. 515.

roridulum Bello 514 .

satimum O. Ktze. 496.

tanacetifolium Hook. et Ain. var. insularum Robins. 517.

tervestre $\mathrm{R}$. Br. var. hispidum $\mathrm{F}$. et M. 516 .

virginicum O. Ktze. 494.

Nematanthera Engl. 159.

Neobuchia Urb. 319.

Paulinac Urb. 319.

Odontolejcunea subbifida Steph. 277.

Omphalea triandra I. 491.

Operculina alata Urb. 343.

altissima Meissn. 343.

convolvrlus Silva Hanso 344.

leptoptera Urb. 342.

macrocarpa Urb. 343.

pterodes Meissn. 343.

triquetra Hall. f. 343.

ventricosa Peter 343.

Ottomia Kunth 159.

punctata Grisch. 202.

sphaerocarpa Griseb. 174.

var. articulata Griseb. 175.

Vahlii Kunth 174.

Ottomia Miq. 159.

Papillaria martinicensis Broth. 429.

Passiflora anadenia Irb. 323.

bicrura Urb. 323.

coriacea A. Rich. 327.

cubensis Urb. 326.

dasyadenia Urb. 328.

luciensis $\left(l^{\top}\right.$ b. 324.

Muruenjir Griseb. 327. 
Passiflora murucuia M. Mast. 326. normalis L. 324. oblongata Griseb. 327. orbiculata Cav. 325.

Peltobryon Miq. 159.

Peperomia R. et P. 218. acuminata Dahlst. 210, 243. acuminata C. DC. 242. acuminata Griseb. 239. acuminata Miq. 239. alate Hensch. 242. alata R. et Pav. 241. var. angustifolia C. DC. 242. var. pterocanlis C. DC. 242. alpina A. Dietr. 257. alpina Griseb. 272. alpina Kew Bull. 257. alpina Mart. et Gal. 260. amplexicaulis A. Dietr. 258.

forma grandifolia Miq. 257. var. longifolia C.DC. $258,259$. amplexifolia A. Dietr. 258. angulate Dahlst. 265 . Antillarum C. DC. 234. Balbisii Dahlst. 268. Belangeri C. DC. 234. blanda var. Langsdorffii Hensch. 266.

blattarum A. Dietr. 206. brachyphylla A. Dietr. 235. brachyphylla Miq. 236. bracteiflora C. DC. 273. var. stigmatifera C. DC. 274. Broadwayi C. DC. 240. Casimiri Heurck et Müll. Arg. 231. caulibarbis Mir. 235.

var. Jimenesma C. DC. 236. ciliata Kunth 266. rircinnata Link 264. rircularis Hensch. 264. clusiifolia Hook. 257. Cogniauxii Urb. 227. roncimna A. Dietr. 244. cordifolia A. Dietr. 228. cubana C. DC. $239,241$. cubensis C. DC. 252. chueata Miq. 249. cuneifolia A. Dietr. 258. cuspidata Dahlst. 250. cyclophylla Hemsl. 265.
Peperomia demisse Dalilst. 227. dendrophila Griseb. 241, 242. forma parvifolia fol. obtus. Griseb. 234. diaphanoides Dahlst. 240. var. vincentensis Dahlst. 240. discolor C. DC. 261. dissitiflora C. DC. 233. distachya A. Dietr. 251. var. cubensis C. DC. 252. distachya Griseb. 252. forma Griseb. 250, 252. distachya Miq. 253. dominicana C. DC. 270. Dussii C. DC. 231. Eggersii C. DC. 225. emarginella C. DC. 225. cmarginata R. et Pav. 254. exilis Griseb. 225. filiformis A. Dietr. 261. fimbriata Niq. 265. var. pilosior Miq. 265. galioides Kunth 261. glabella A. Dietr. 235. var. brachyphylla C. DC. 236 . var. Eustatiana C. DC. 236. var. Jimenesana C. DC. 236. var. nigropumetata Duss 243. forma parifolia 0. Ktze. 236. glabella Griseb. 243. Grisebachii C. DC. 259. guadalupensis C. DC. 239. var. pubescens C. DC. 234.

Hahnii C. DC. 233.

Hamiltoniana Miq. 237.

var. emarginulata C. DC. 238. Harrisii C. DC. 243. hederacea Miq. 248. hemionitidifolia Ham. 254.

Herminieri C. DC. 273.

var. stigmatifera C. DC. 273. hernandifolia A. Dietr. 246. hirta C. DC. '232. hirtella Griseb. 233. hirtella Miq. 232. hispidula A. Dietr. 223. var. Suctrimena Dahlst. 223. humilis A. Dietr. 266. ionophylla Griseb. 248. Langsdorffii Miq. 266. 
Peperomia Langselorffii var. dissimilis

Dahlst. 266.

lineatipila Rich. 235.

lumaria Han. 216.

lumaris A. Dietr. 216.

macrostachya Griseb. 254.

maculosa W. Hook. 245.

magnoliaefolia A. Dietr. 254.

var. microphylla Dahlst. 256.

var. parvifolia C. DC. 256.

major C. DC. 247.

melanostigma Sauv. 243.

var. glabrior C. DC. 243.

metapalcoensis C. DC. 227.

minima C. DC. 225.

Miqueliana Griseb. 227.

monsterifolia Griseb. 246.

Myosurus A. Dietr. 249.

myrioearpa Miq. 253.

myrtifolia Dilhlst. 239.

myrtifolia A. Dietr. 237.

Myrtillus Miq. 269.

nematostachya Link 253.

nemorosa C. DC. 243.

nemorosa Kew Bull. 241.

nigropmetata Miq. 243.

nummmlarifolia Kiunth 229.

var. pubescens C. DC. 230.

obovata C. DC. 269.

olstusifolia A. Dietr. 254, 257.

var. clusiifolia C. DC. 258.

var. cuncata Dahlst. 250.

var. cumeata Griseb. 234.

obtusifolia A. Dietr. 257.

obiersa A. Dietr. 269.

obversa Griseb. 259.

oralifolia Hook. 267.

papillosa Dahlst. 260.

Parkeriana Miq. 253.

pellucida Griseb. 238.

pellucida Kunth 244.

peltate A. Dietr. 209.

pereskiifolia Kunth 272.

pernambueensis Miq. 245.

petiolaris C. DC. 238.

polystaehya Hook. 271.

Ponthieni Miq. 247.

portoricensis Ulb. 226.

producta Griseb. 251.

producta Sauv. 250.
Peperomia prminosa Kunth 208. psendoamplexicantis C. DC. 255. psendomajor C. DC. 248.

psendo-pereskiffolia C. DC. 272. pterocaulis Miq. 242.

pulchella A. Dietr. 263.

melicaris Opiz 249.

quadrangularis A. Dietr. 265. quadrifolia Kunth 260.

quitensis Miq. 266.

reflexa A. Dietr. 263.

form. americana Miq. 264.

form. peruviana Mii. 269.

var. enervulosa C. DC. 264.

var. valantoides C. DC. 264.

reniformis A. Dietr. 216.

reniformis Hook. 249.

repens Kunth 248.

rhombea R. et Pav. 268.

rhomboides Dahlst. 270.

rotundifolia Kunth 228.

forma orata Dahılst. 230.

var, pilosior C. DC. 230.

var. ovata Dahlst. 230.

rubella Hook. 262.

mbricaulis A. Dietr. 273.

Rupertiana C. DC. 238.

scandens R. et P. 248.

scutata A. Dietr. 209.

septemmervis R. et Par. 271.

septuplinervia C. DC. 246.

serpens Griseb. 216, 230.

sillaefolia A. Dietr. 210.

simplex Ham. 259.

Sintenisii C. DC. 240.

Smithiana C. DC. 235.

spathoplyylla Dahlst. 227.

var. monteverdensis C. DC. 228.

*patulata Ham. 228.

speciosa Kunth 202.

stellata A. Dietr. 270.

var. Narehii C. DC. 270.

surveolens Ham. 261.

sulvotunda A. Dietr. 255.

subrotundifolia C. DC. 230.

subvillosa Heurek et Müll. Arğ. 231.

Seartiana Griseb. 259.

Swartziana Miq. 262.

talinifolia Kunth 252. 
Peperomia talinifolia Link 258.

tenella A. Dietr. 224.

var. glabra C. DC. 224.

tenerrima Schlecht. form. robustior

Dahlst. 259.

tetraphylla Hook. et Arn. 263.

tithymaloides A. Dietr. 255.

trifolia C. DC. 268.

trifolia Dahlst. 269.

form. pilosior Dahlst. 267.

trifolia A. Dietr. 267.

trincrvis var. brachyphylla C. DC. $235,236$.

truncigaudens C. DC. 237.

umbellata Kunth 210.

urocarpa Fisch. et Ney. 247.

ralantoides Miq. 264.

Vanheurckii C. DC. 238.

Vellowiana Miq. 242.

relutina Urb. 232.

verticillata A. Dietr. 262.

vincentiana Miq. 226.

Wrightiana C. DC. 252.

yabucoana Urb. et C. DC. 232.

Pharbitis tomentosa Choisy 344.

Pharmacosyce Miq. 455.

Phamacosycca jamaicensis Liebm.491. Radula Liebm. 484.

Pharmacnm longum vulgare Rumph. 212.

Philonotis evanescens Broth. 425. var. acutifolia Broth. 425. subsphaericarpa Broth. 425.

Phyllanthus acacioides Urb. 287.

bahamensis Urb. 289.

barbadensis Urb. 287.

Buchii Urb. 288.

isolepis Urb. 290.

neopeltandrus Griseb. 285.

mutans Griseb. 286.

pachystylus Urb. 286.

Picardaea Urb. 376.

haitiensis Urb. 377.

Piper Engl. 159.

Piper Jinn. 159.

acuminatrm Linn. 242.

acuminatum West 239.

aduncum Limn. 184.

aemmlum Endl. 263.

acquale Kew Bull. 204.
Piper aequale Vahl 203.

var. Dussii C. DC. 204.

var. lasiocarpum C. DC. 204.

var. ovalifolium C. DC. 204.

alare Ham. 172.

alatrm. Vahl 241.

alpinnm Sw. 257.

Amalayo L. 212.

Amalago L. 167.

Amalago Rheede 212.

amplexicaule Sw. 259.

amplexifolinm Link $25 \mathrm{~S}$.

Andersonii C. DC. 194.

ongustifolium Sauv. 186.

angustifolium R. et Pav. var. rordulatum C. DC. 185.

var. Ossanum C. DC. 185.

angustilimbum C. DC. 201.

anisatrum Kunth 172.

articulatum A. Rich. 207.

auritum Kunth 199.

Balbisianum C. DC. 205.

Berteroanum C. DC. 169.

Betle L. 213.

blattarum Syreng. 206.

var. magnifolium C. DC. 206.

brachyphyllum Spreng. 236.

broctcatum Thomp. 248.

Broadwayi C. DC. 191.

bullatum Vahl 187.

callosum Opiz 212.

candatum Vahl 172.

caracasanum Bredem. 173.

cotalpaefolinm Kunth 172.

ccanothifolinm Kunth 165.

celtidifolinm Ham. 168.

celtidifolium Kunth 184.

Chaba Hook. 212.

Christyi C. DC. 215.

ciliatum R. et Sch. 266.

circinatum Schult. 264.

citrifolium Lam. 181.

citrifolium Duss 184.

clnsiifolimm Jacq. 257.

colonum Presl 215.

concinnum C. DC. 204.

var. trinitense C. DC. 204.

concinnmm Haw. 244.

confusum C. DC. 186.

var. prendanum C. DC. 186. 
Piper ronfusum Kew Bull. 199. corlifolium Sw. 228. cormifolium Spreng. 205. corylifolium Kunth 198. mibensc C. DC. 202. cuncifolium Jacq. $25 \mathrm{~s}$. cuspidatum Ham. 192. decumanum AubI. 171. diambrum C. DC. 212. dilatatum Kew Bull. 199. dilatatum L. Cl. Rich. 197. var. Vincentianum C. DC. 198. discolor Schlecht. 169.

discolor Sw. 167. sistnchyon I. 251. dominicanum C. DC. 205. dubium A. Dietr. 169.

Durhassaingii C. DC. 171.

Dussii C. DC. 190.

var. scabridum C. DC. 191.

Eggersii C. DC. 200.

emarginellum Sw. 225.

exserens C. DC. 175.

Fadyeni C. DC. 191.

fallax Vahl 214.

filiforme Sw. 262.

fol. cord. crule proc. I. 244.

foliis quaternis Plum. 260.

frut diffus. ram. flex. gen. P. Br.

167.

gnlioides R. et Sch. 261.

geniculatum C. DC. 180.

var. $\alpha$. C. DC. 180 .

var. $\alpha, \gamma$. C. DC. 179.

var. $\beta$. C. DC. 180 .

var. $\delta$. C. DC. 180 .

var. jamaicensc C. DC. 193.

var. rigidmm C. DC. 176.

var. stamineum C. DC. 176.

geniculatum Sauv. 176.

geniculatum Sw. 178.

yoniculatum Sw. 179.

glabelhum Sw. 235.

glauescens Jacq. 169.

gradelupense C. DC. 201.

guavanum C. DC. 190.

Finildingirmum Spr. 249.

Harrisii C. DC. 189.

Hartii C. DC. 164.

hebecarpum C. DC. 183.
Piper herbaceum Roem. et Sch. 249. hermondifolimm Vahl 247. hirsutum Sauv. $18 S$.

hivisutum Sw. 187.

var. jamaicense C. DC. 187.

var. magnifolium C. DC. 188. hispridulum Sw. 223.

hispidum Sw. 187.

var. albescens DC. 188 .

var. magnifolium C. DC. 188. var. plurinerve C. DC. 188.

Hohenackeri C. DC. 165.

humile Poir. 254.

hommile Vahl 266.

Jacquemontiomum Kunth 182.

jamaicense C. DC. 192.

forma magnifolia 193.

forma ovalifolia 193.

incurvum Sieber 201.

lancifolinm Ham. 186 .

lapathifolium C. DC. 179.

lntifolium Lam. 210.

Ledebourii C. DC. 182.

var. jamaicense C. DC. 182. leptostachyum A. Rich. 202.

Lindenianum C. DC. 202. lingnaefolium Ham. 186.

lomg. arb. altius Sloane 167.

long. anb. fol. latiss. Sloane 179.

long. fol. nerv. Sloane 184.

long. humil. fruct. e summitate crulis prod. Sloane 255.

long. min. luerb. scand. Sloane 229. longum Bl. 212.

longum Piso 212.

lomymm Rumph. 212.

macrophyllum Kunth 194.

macrophyllum Sw. 178, 179.

mamom'um Kunth 177.

maculosum. L. 246.

magnoliaefolium Haw. 257.

magnoliaefolium Jacr. 254.

malamiris L. 213.

mananthum C. Wright 170 .

marginatum C. DC. 173.

marginatum Haw. 257.

marginatum Jacq. 171.

var. anisatum C. DC. 172.

var. catalpifolium C. DC. 172, 173. 
Piper maryinutum var. catalpaefolium C. DC. 172 .

var. firmum C. DC. 173. maritimum Bl. 212.

Ifritimum C. DC. 203. martinicense C. DC. 195. var. Montis-pilati C. DC. 196. medium Jacq. 165. melamivis Hill 212. microphyllum C. DC. 190. Milleri R. et Sch. 254. molliromm C. DC. 189. mornicola C. DC. 194.

var. longifolium C. DC. 194. Hurrayanum C. DC. 193. myrtifolium Vahl 237. nigrum L. 214.

nitidum Sw. 178. nodulosum Link 179. nummularifolium Sw. 229. mitans Opiz 177. obocatum Balb. 268. obovatum Vahl 269. obtusifolium Jacq. 271. obtusifolium Lam. 257. obtusifolium L. 254. obtusum C. DC. 206. obrersum Vahl 269. officinarum C. DC. 212. orthostachyum Kunth 165. Otophyllum C. DC. 196. ovale C. DC. 175. ovatum Vahl 174. penduretum C. DC. 170. papantlense C. DC. 211. pelluridum L. 244. peltatum L. 208.

var. hirtellum C. DC. 210. peltutum R. et Par. 210. pereskiaefolirm Jacr. 273. Picardae C. DC. 207. plantagineum Lam. 167. polystarlyyon Ait. 271. pruinosum Willd. 208. pssudoblattarmm C. DC. 202. pulclecllum Ait. 262. punctatum R. et Par. 203. pusillum Bl. 263. pyrifolium Opiz 169. quadrangulare Thomps. 265.
Piper quadrifolium L. 260. quadrifolium Vell. 264. Readii C. DC. 197. reflexum L. fil. 263. rniforme Willd. 216. repens Poir. 249. retienlatum Duss 191. reticulatum L. 170. retienlatum Sw. 172. reticulatum Vell. 165. retrofractum Vahl 212. rlomberm. Vahl 269. Richardianum C. DC. 169. rigidum C. DC. 175.

var. Verdeanum C. DC. 176. rotundifolium Hill 247. rotundifolium L. 229. rotundum nigrum Pluk. 215. mbellum Haw. 262. mbricaule Nees 273. rugosum Vahl 181. Sagreanum Saur. 207. Sngranum C. DC. 207. sammoides Ham. 166. scabrum Lam. 184. scalvum. Sw. 187. scandens Sw. 235. scandens: Vahl 248. Schackii C. DC. 183. Schlerhtendalii Steud. 169. scutatum Willd. 208. Seitzii C. DC. 181. septemnerve Vahl 271. serpens Sw. 248. siduefolium Lk. et Otto 210. Sirbrri C. DC. 167. Siebri Kew Bull. 166. smilarifolim C. DC. 171. speriosum Willd. 208. sphaerocarpum C. Wr. 174.

var. tenuifolium C. DC. 175. spluerostarlingem C. DC. 174. spurium Link 215. stamineum C. DC. 176. var. longifolium C. DC. 177. stellatum Sw. 270. sulpanduriforme C. DC. 170. subpeltatum var. sidnefolinem C. DC. 210.

suaveolens Cat. Hort. Par. 261. 
Piper subrectinerve C. I)C. 180.

Swartzianum C. DC. 177.

Swertzianum Sauv. 175, 176.

Swartzii C. DC. 202.

tenellum Sw. 224.

terminale Funth $16 \mathrm{~S}$.

tetraphyllum Forst. 263.

Tigeriamum C. DC. 165.

titlymmaloides Vahl 254.

tobagoanum C. DC. 199.

var. humilior C. DC. 199.

trifolinu L. 267.

Trinitatis C. DC. 197.

tuberculatum Jacq. 177.

umbellatum L. 210.

unguiculatım R. et P. 168.

verrucosum Sw. 178, 180.

verruesum Willd. 198.

verticillatum L. 262.

Wrightii C. DC. 189.

Wullschlaegelii C. DC. 168.

Wydleriamum C. DC. 182.

Piper L. 218.

Piperaceae 159.

Pittonia arb. chamaedrif. maj. et min.

Plum. 363.

Plagiochila amplexicaulis Steph. 276.

Dussiana Steph. 277.

Pluchea Eggersii Urb. 407.

Plumieria biglandulosa Urb. 337.

domingensis Urb. 338.

gibbosa Urb. 338.

Marchii Urb. 334.

Paulinae Urb. 336.

stenopetala Urb. 335.

Potomorphe C. DC. 164.

Potomorphe Miq. 159.

peltata Miq. 209.

scutata Miq. 209.

sidaefolia Miq. 211.

speciosa Miq. 209.

umbellata Miq. 210.

Psendocestrum Urb. 371.

Psychotria brevistipula Urb. 386 .

Buchii Urb. 385.

coriacea Spreng. 380.

cyclophylla Urh. 383.

dolichocarpa Urb. 382.

exserta DC. 380.

mornirola Urb. $3 S 4$.
Psychotria stenocarpa Urb. 382.

Inychomeria Urb. 438. capitata Benth. 439.

fimbriata Benth. $43 \mathrm{~S}$.

muliea Benth. 438.

nivea Griseb. 444.

tenella Benth. 439.

tenella Griseb. 446.

Pycnolejeunia Dussiana Steph. 278.

Quamoelit purpur. solanifol. min. Plum. 339.

Rajania Sintenisii Uline 281.

Raphanus L. 512.

lamecolatus DC. 510.

lemeeolatus Willd. 505.

sativus L. 512.

Reynosia Northropiana Urb. 315.

Rhammidium forreum Sarg. 314.

Rhammus ferreus Vahl 314.

Rhyncholepis Miq. 159.

Riccia Dussiana Steph. 275. subplana. Steph. 275.

Ricinoides aelacagni folio Plum. 298. Rondeletia Christii Urb. 377.

Sachsia bahamensis Urb. 408.

Salvia brachyphylla Urb. 368.

Buchii Urb. 369.

Sapium adenodon Griseb. 310. aucuparium Bello 307.

alleuparium Jacq. 310.

var. hippomane Griseb. 306. aucuparium Hemsl. 307.

aucuparium Mazé 309. aueuparium Willd. 306.

biglandulosum var. Meyeriamm

Müll. Arg. 306.

caribaeum Urb. 308.

crythrospermum Müll. Arg. 312.

glrmdulosum Morong. 306, 309.

hippomane G. F. WV. Mey. 305.

jamaicense Sw. $30 \mathrm{~S}$.

laurifolium Griseb. 308.

laurocerasus Desf. 307.

var. genuinum Müll. Arg. 307.

lencogynum C. Wright 310.

leucospermum Griseb. 310.

suberosum. Müll. Arg. 306.

Sarcomphalıs crenatus Urb. 316.

ferreus Weberh. 314.

Saumms alins humil. P'sum. 243. 
Sumerus arbor. fol. ampl. word. non umbil. Plum. 211.

arbor. fol. ampl. rot. umb. Plum. 209.

arbor. fi. adunco Plum. 184. botryitis major Plum. 171.

erectus minor fol orb. rert. $\mathrm{P} . \mathrm{Br}$. 263.

fol. lanceolato-oratis Linn. 167 . fint. fol. plantag. Plum. 172.

heder. crul. maenl. major Plum. 246.

heder. canl. macul. minor Plum. 251.

heder. triphyllus Plum. 267.

humilis fol. carn. subrot. Plum. 255.

minor mocumb. Plum. 244. repens fol. orbie. Plum. 229.

Savia Willd. 284. chusiifolia Griseb. 284. erythroxyloiles Griscb. 284. laurifolia Griseb. $2 S 4$. sessiliflora Willd. 284.

Schilleria Kunth 159. aurita Kunth 200. caudata Kunth 172. corylifolia Kunth 19S. macropleylle Kunth 195. marginate Kunth 172. ulmifolia Kunth $19 \mathrm{~S}$.

Schizonepliros Griff. 159.

Scolosanthus densiflorus Lrb. 381.

Srgraerms. Millsp. 3S2.

Scutia ferrea Brongn. 314.

Sebastiania albicans C. ITr. 312. Grisebachiana Müll. Arg. 312. var. albirans Mïll. Arg. 312. var. virens Müll. Arg. 312. hexaptera Urb. 303. Picardae Urh. 304.

Selaginella Hartii Hieron. 525. Krugii Hieron. 526. tobagensis Hieron. 524.

Senebiera pinnatifida DC. 497.

Seneeio conyzoides P. DC. 414. lucens Urb. 413.

Pieardae Krr. et Url. 414.

Sinapis L. 507.

alba $\mathrm{L}$. 507.
Sinapis arrensis I. 508.

brassicate Griseb. 510.

cleinensis L. 511 .

fol. subrot. serr. Sloane 510.

integrifolia West 510 .

juncea Eiehl. 510.

juncer L. 511.

lanceolreta DC. 510.

nigre Descourt. 510.

Sirii folium Rumph. 214.

Sisymbrium I. $49 \mathrm{~S}$.

domingense Poir. 515.

nasturtium L. 513.

offieinale Scop. 499.

var. liocarpum DC. 499.

palustre Lejss. 515.

pyrenaicum L. 515.

Solidago domingensis Griseb. 406.

domingensis Hitehe. 406.

domingensis Spreng. 405.

Lindeniana A. Rich. 406.

Spermacoce frigida Willd. 387.

Splanerostachys Miq. 159.

Splachnobryum elatum Brotlı. 423.

Steffersia C. DC. 160.

Steffensia Kunth 159.

adunce Kunth 184.

cerecesana Fiunth 173.

celtidifolia Kimth 184.

genieulate Kunth 179.

livisnta Kunth 187.

Jacquemontiana Kunth 182.

Luselmathiana Kunth 179.

secubre Kunth 187.

tuberculata Kunth 177.

xylopioides Kunth 179.

Stillingia eglandulosa A. Rieh. 311.

hippomane Baill. 306.

lamifolia A. Rich. 30 S.

laurorerasus Baill. 307.

Symbryon Griseb. 274.

Syrrhopodon Dussii Broth. 422.

martinicensis Broth. 422.

Taxilcjemnea Urbani Steph. 278.

Tecoma acrophylla Urb. 37t.

Buehii Urb. 375.

Tetrorchidium rubrivenium Poepls. ct Endl. 303.

Thlaspi burse pastoris L. 523 .

Tinantia caribaea Irlo. 280. 
Tillummelus arbor ame mali merl. fol. amepl. Pluk. 306.

Tournefortia servata Linn. 363.

Ti ipterella bicolor Roem. et Schult. 450 . copitata Michx. 451.

flava Roem. et Schult. 450 .

Tussilago albicaus Sw. 419.

dentrita Linn. 419.

nntans Linn. 419.

pumila Sw. 420.

Uiostignia Gasp. 453.

entappifolium Miq. 491.

cressinervium Miq. 464.

Gardneriannm Miq. 459.

Kunthii Miq. 490.

laevigatum Miq. 472.

lanrifolimm Griseb. 472.

laurifolium Miq. 490.

lentiginosnm Liebm. 472.

pedunculatum Miq. 472.

pertusum. Miq. 466.

populueum Miq. 472.

Rolanderi Liebm. 482.

Sunctae Crucis Liebm. 472, 475.

scandens Liebm. 491.

Schumacheri Liebm. 483.

syringaefolinn Liebm. 480.
Liosligma irmstmm Miq. 4S8.

Varonia lnellata Linn. 363. geniculata Pers. 363.

lima Desv. 361.

mirabiloides Jacq. 363.

scaberrima Bert. 361, 362.

Verhuellia Miq. 216.

cordifolia C. DC. 217.

elegans C. DC. 217.

elegans Miq. 216.

hydrocotylifolia C. Wr. 217.

lunaria C. DC. 216.

pellucida Schmitz 217.

reniformis C. DC. 216.

serpens Miq. 249.

sp. incert. Miq. 216.

Vernonia acuminata Less. 391. arborescens Sw. var. Lessingionu Stahl 391.

borinquensis Urb. 390. var. Stahlii Urb. 391.

Voyelia capitata J. F. Gmel. 451.

Voyria tenella Griseb. 449.

Wedelia longipes Urb. 411.

Zippelia Niq. 159.

Zisypluse cmarginatus Siv. 314. 


\section{INDEX}

\section{NOMINUM VERNACULORUM.}

Anisete Doming. 187.

Anizillo Doming. 172.

Basquina Port. 211.

Basquiña cerralla Port. 209.

Batatilla Port. 353.

Berros Port. 514.

Biajama Doming. 282.

Black Iron wood Florid. 314.

Bois anisette Mart. 209.

Bois Caiman Hait. 283.

Bois de fer blanc Guad. 314.

Bois de soie Gnad. 309.

Bois Guillaume Désir. 406.

Bois Guillaume Nart. 407.

Bois-la-glu Mart. 309.

Bombon capitaine Hait. 363 .

Bombon chat Hait. 363.

Botoncillo Port. 409.

Campanilla Port. 332.

Cocliléaria Guad. 244.

Coclaria Port. 244.

Cocoyer rivière Jart. 487.

Corkwood Sab. 209.

Cresson de fontaine Mart. 514.

Cresson de saranne Mart. 495.

Cresson de savanne Doming. 521.

Dent de Chien blanc Hait. 363.

Edden-wood St. Thom. 314.

Espejuelo Port. 314.

Evergreen of Barbados Trinid.489.

Fig-tree Barb. 4Ss.

Figuier Guad. 463.

Figuier grandes feuilles Guad. $459,463$.

Figuier maudit Nart. 478, 487.
Fije Doming. 487.

Frangipani Hait. 336, 337.

Frangipani épineux Hait. 33 ๖.

Frangipanier Hait. 336.

Gironflé Mart. 229.

Glutier Mart. 309.

Grand mouron Guad. 267.

Gueule-de-loup-montagne Guad. 334.

Hagüey Port. 463, 471.

Hamo Doming. 486.

Herbe à coureze Mart. 244.

Higon Cub. 461.

Higuerou Cub. 461, 466.

Higuillo de limon Port. 166.

Higuillo oloroso Port. 172, 184. 187, 206.

Higuillo preto Port. 465.

Hije Doming. 469.

Hincha-hueros Port. 308.

Jagüeicillo Cub. 466.

Jagüey Cub. 455, 461，469，473.

Jagiiey Port. 465, 471, 476.

Jagü ey hembra Cub. 161, 466, 486.

Jagüey macho Cub. 455 .

Jagüey moilıo Cub. 462.

Jiguerillo Port. 476.

$J$ mbee Candlebush Tobag. 199.

La-gli Domin. 309.

La gluic St. Luc. 309.

Laurel de India Port. 489.

Lechesillo Port. 308, 476.

Liane rouge à tomnelles Mart. et Guad. 353.

Linio Doming. 380. 
Lis-montagne Guad. 334.

Malimbé Mart. 166, 191, 198, 203.

IIanzanillo Port. 308.

Mastuerzo Port. 495.

Matico Mart. 187.

Milk tree Barb. 306.

Mostacilla del mar Port. 505.

Mostaza Cub. 510, 512.

Mouron Guad. et Mart. 229, 243, 267.

Mouron grand fenille Guad, et Hart. 243.

Mouron rouge Guad. 268.

Moutarde Mart. 510.

Palo de hierro Doming. 314.

Petit bois-de-fer Guad. 314.

Petit mouron Guad. 229.

Platanillo de monte Cub. 186.

Poison-tree Hugh. 306.

Poivre à épis làches Descourt. 167.

Poivrier à Ombelles Descourt. 211.

Poivrier aromatique Descourt. 215.

Poivrier à feuilles obtuses Desc. 255.
Poivrier à feuilles transparentes Descourt. 244.

Poivrier à fruit crochu Descourt. 184.

Poivrier en bouclier Descourt. 209.

Poivrier tacheté Descourt. 246.

Quemadora Port. 308.

Quene de lézard Guad. et Mart. $166,191$.

Quene de rat Guad. 191.

Qneue de rat Mart. 166.

Sabe-leccion Cub. 495.

Sereno Port. 406.

Tabeiba Port. 308.

Thé du pays Hait. 298.

Vinagre Port. 249.

Water-cress ins. Dan. 514.

Wild Mnstard Ant. 510 .

Tagiiey Port. 463.

Yerba de Guavá Port. 226.

Yerba de medio real Port. 229.

Yerba linda Port. 230. 







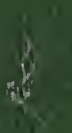

